\title{
Selective C-H Activation: Ruthenaelectro-Catalysis and Carborane Cage Activation
}

\author{
Dissertation \\ for the award of the degree \\ "Doctor rerum naturalium" (Dr.rer.nat.) \\ of the Georg-August-Universität Göttingen \\ within the doctoral program of chemistry \\ of the Georg-August-Universität School of Science (GAUSS)
}

Submitted by

Long Yang

From Ganzhou (China)

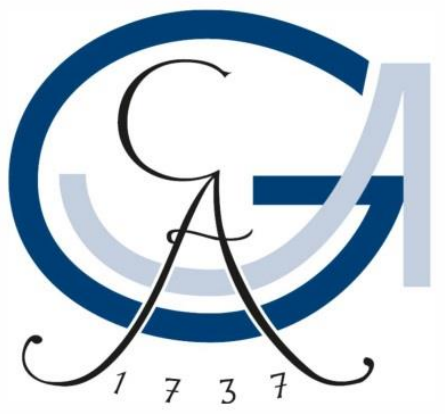

Göttingen, 2021 



\section{Thesis Committee}

Prof. Dr. Lutz Ackermann, Institute of Organic and Biomolecular Chemistry

Prof. Dr. Shoubhik Das, ORSY Division, Department of Chemistry, Universiteit Antwerpen, Antwerpen, Belgium.

\section{Members of the Examination Board}

Reviewer: Prof. Dr. Lutz Ackermann, Institute of Organic and Biomolecular Chemistry, Göttingen

Second Reviewer: Prof. Dr. Shoubhik Das, ORSY Division, Department of Chemistry, Universiteit Antwerpen, Antwerpen, Belgium.

\section{Further members of the Examination Board}

Prof. Dr. Dietmar Stalke, Institute of Inorganic Chemistry, Göttingen

Jun.-Prof. Dr. Johannes C. L. Walker, Institute of Organic and Biomolecular Chemistry, Göttingen

Dr. Michael John, Institute of Organic and Biomolecular Chemistry, Göttingen

Dr. Daniel Janßen-Müller, Institute of Organic and Biomolecular Chemistry, Göttingen

Date of the Oral Examination: 30.09 .2021 



\section{Contents}

1. Introduction 1

1.1 Transition Metal-Catalyzed C-H Functionalization .................................................. 1

1.2 General Modes for Metal-Mediated C-H Activation Processes .....................................

1.3 General Strategies for Selective C-H Functionalizations ......................................... 4

1.4 Ruthenium-Catalyzed Selective C-H Activation.................................................... 5

1.4.1 Ruthenium-Catalyzed ortho-Selective C-H Activation ..................................... 5

1.4.2 Ruthenium-Catalyzed meta-Selective C-H Activation ........................................ 12

1.4.3 Ruthenium-Catalyzed para-Selective C-H Activation ...................................... 14

1.5 Transition Metal-Catalyzed Electrochemical C-H Activation ....................................... 15

1.5.1 Palladaelectro-Oxidative $\mathrm{C}-\mathrm{H}$ Activation ....................................................... 15

1.5.2 Rhodaelectro-Oxidative C-H Activation ........................................................... 17

1.5.3 Ruthenaelectro-Oxidative C-H Activation ...................................................... 19

1.5.4 Iridaelectro-Oxidative C-H Activation ......................................................... 21

1.5.5 Cobaltaelectro-Oxidative C-H Activation ....................................................... 22

1.5.6 Nickellaelectro-Oxidative C-H Activation ........................................................ 24

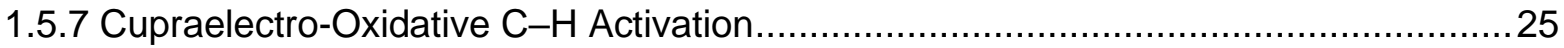

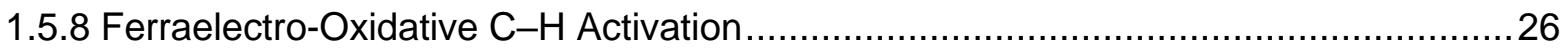

1.5.9 Manganaelectro-Oxidative C-H Activation .....................................................27

1.6 Transition Metal Catalyzed B-H Cage Activation of 0 -Carborane ..................................27

1.6.1 Transition Metal-Catalyzed Cage B(3,6)-H Functionalization .................................29

1.6.2 Transition Metal-Catalyzed Cage B(4,5,7,11)-H Functionalization ........................... 31

1.6.3 Transition Metal-Catalyzed Cage B(8,9,10,12)-H Functionalization .........................39

1.7 Electrochemical Functionalization of Carboranes ................................................... 40

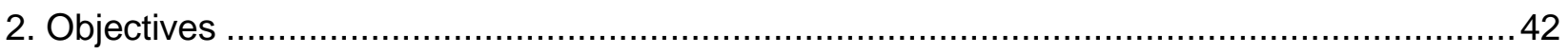

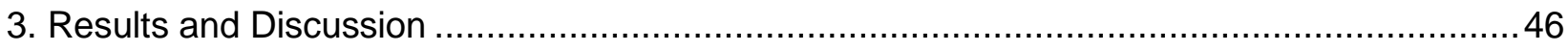

3.1 Ruthenium(IV) Intermediates in $\mathrm{C}-\mathrm{H}$ Annulation by Weak $\mathrm{O}$-Coordination ........................46

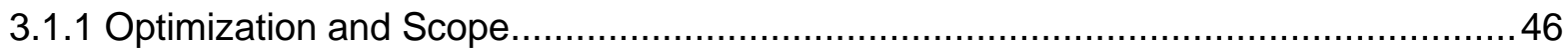

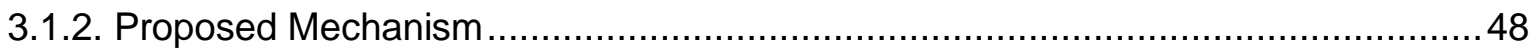

3.2 Twofold $\mathrm{C}-\mathrm{H} / \mathrm{N}-\mathrm{H}$ Annulations towards $\mathrm{m}$-Extended Polyaromatics ................................50

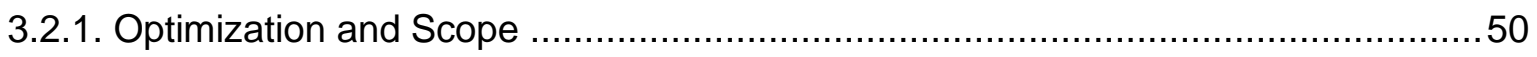

3.2.2. UV-Vis Absorption and Fluorescence Spectroscopy ...................................52 
3.3 Ruthenaelectro(II/III/I)-Catalyzed Alkyne Annulations .....................................................53

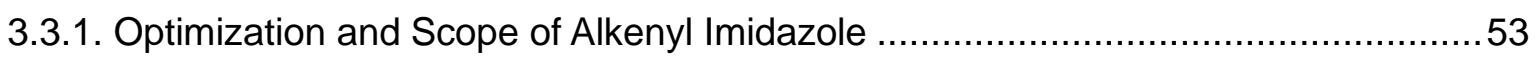

3.3.2. Optimization and Scope of of benzimidazoles ……........................................56

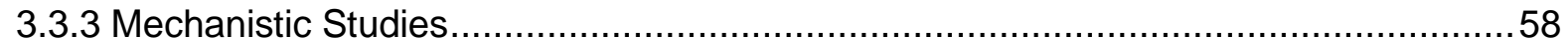

3.3.3.1 H/D Exchange and Competition Experiments …….......................................58

3.3.3.2 Isolation and Characterization of Ruthenium(II) Intermediate ...........................59

3.3.3.3 Cyclic Voltammetry Studies of Ruthenium(II) Intermediate ...............................60

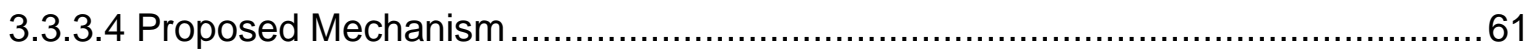

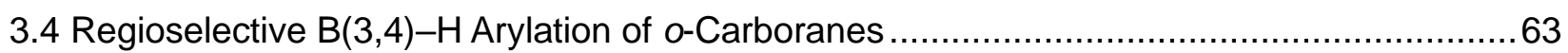

3.4.1. Optimization and Scope of $B(3,4)-H$ Arylation of $o$-Carboranes...........................63

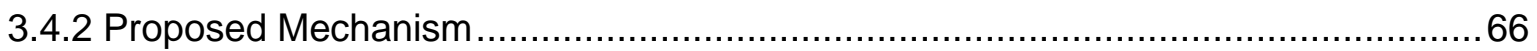

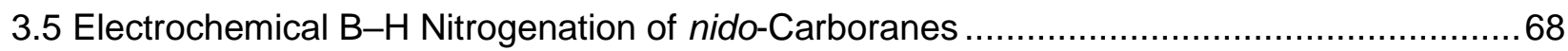

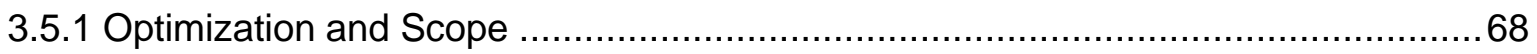

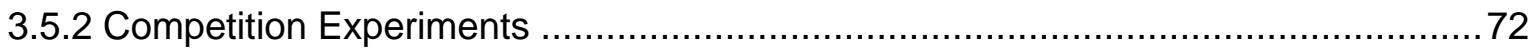

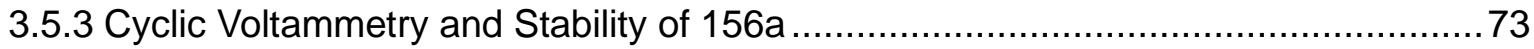

3.5.4 Spectroscopic Data of BODIPY-Labelled nido-Carborane ……...........................74

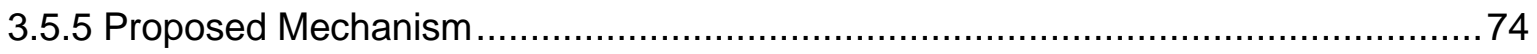

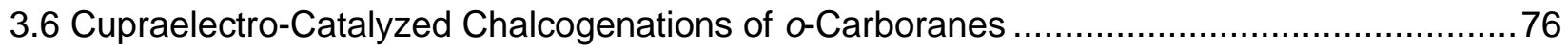

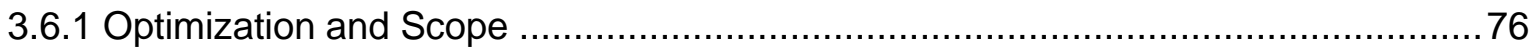

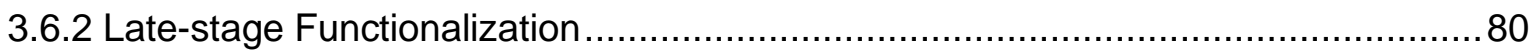

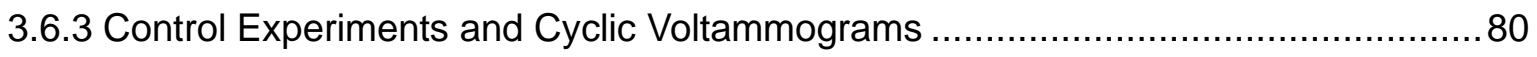

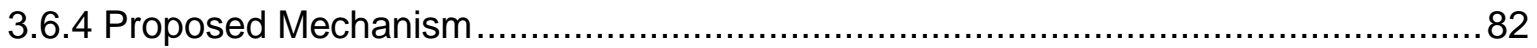

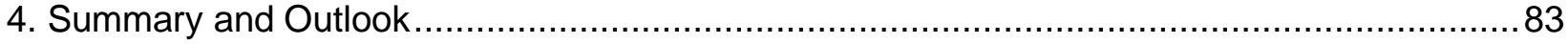

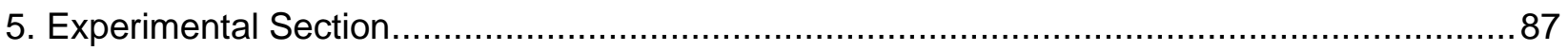

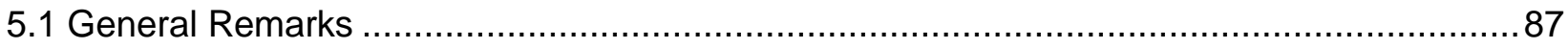

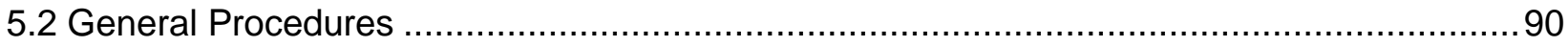

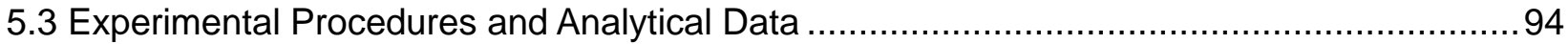

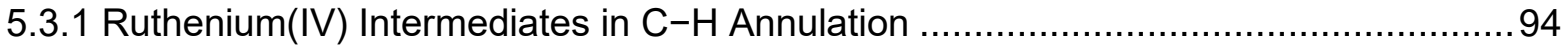

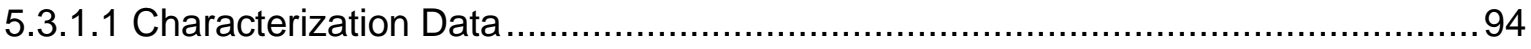

5.3.2 Twofold $\mathrm{C}-\mathrm{H} / \mathrm{N}-\mathrm{H}$ Annulations towards $\pi$-Extended Polyaromatics ....................... 103

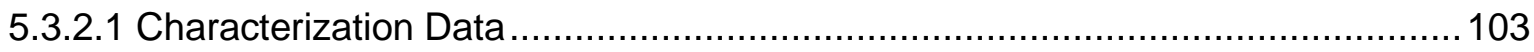

5.3.2.2 Investigation of Rotameric Species........................................................... 108

5.3.3 Ruthenaelectro(II/III//)-Catalyzed Alkyne Annulations ........................................111

5.3.3.1 Characterization Data ............................................................................ 111 


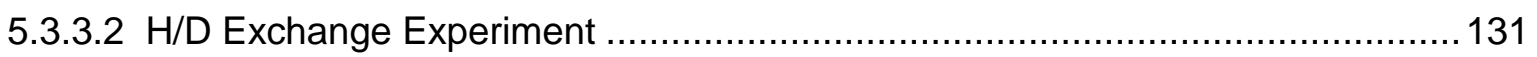

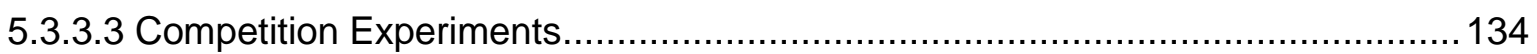

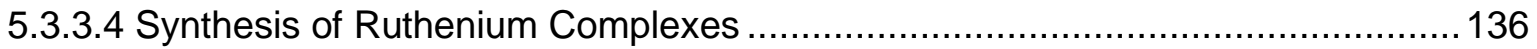

5.3.3.5 Ruthenium Complexes Catalyzed C-H/N-H Activation .................................138

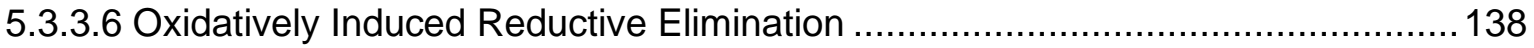

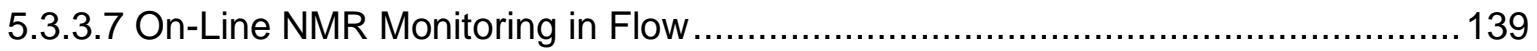

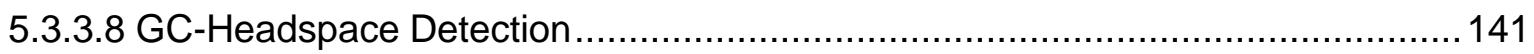

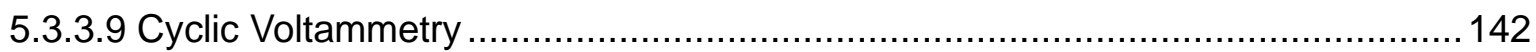

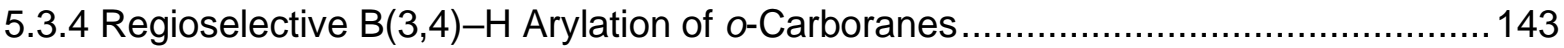

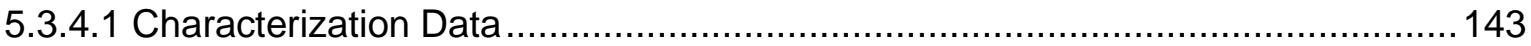

5.3.5 Electrochemical B-H Nitrogenation of nido-Carboranes ....................................... 153

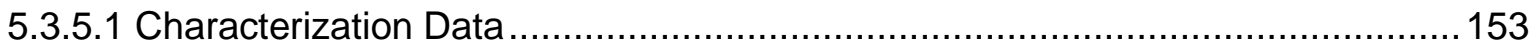

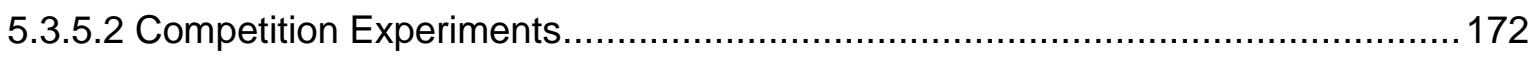

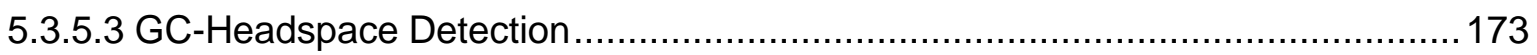

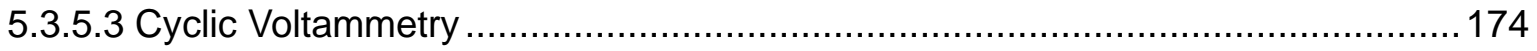

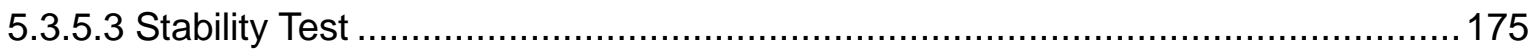

5.3.6 Cupraelectro-Catalyzed Chalcogenations of $o$-Carboranes ..................................179

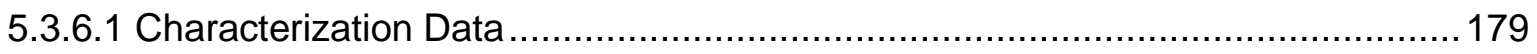

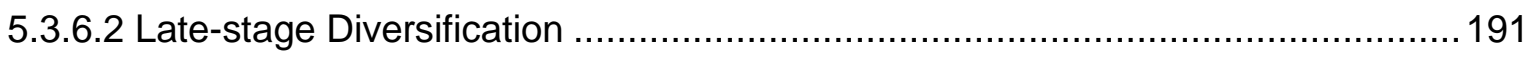

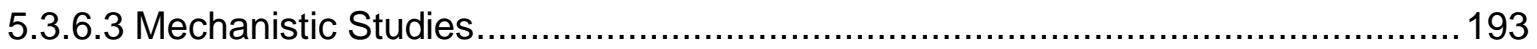

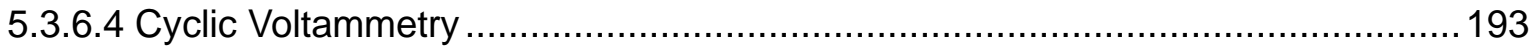

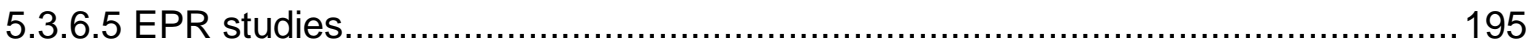

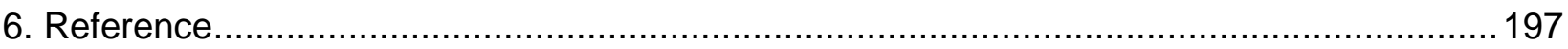

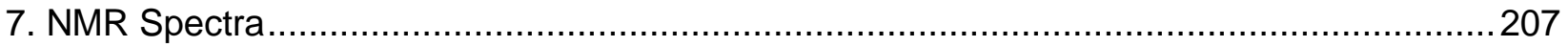

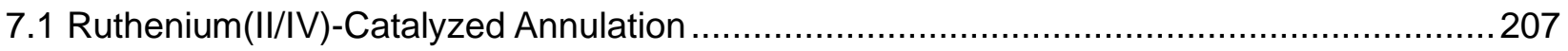

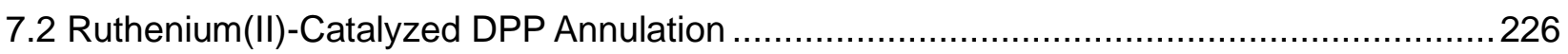

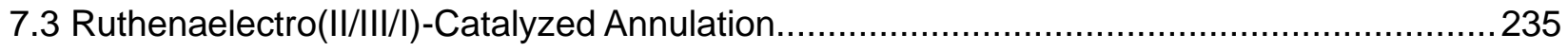

7.4 Palladium(II)-Catalyzed B(3,4)-Arylation of 0 -Carboranes ............................................2. 280

7.5 Electrochemical B-H Nitrogenation of nido-Carboranes ................................................ 310

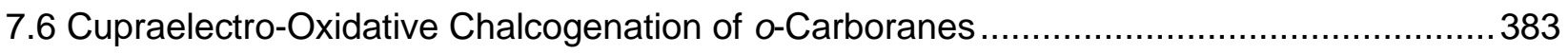

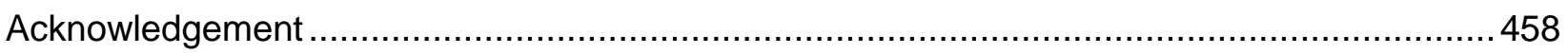

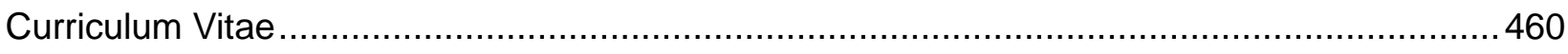





\section{List of Abbreviations}

\begin{tabular}{|c|c|}
\hline$A c$ & acetyl \\
\hline acac & acetyl acetonate \\
\hline Ad & Adamantane \\
\hline Alk & alkyl \\
\hline AMLA & ambiphilic metal-ligand activation \\
\hline aq. & aqueous \\
\hline $\operatorname{Ar}$ & aryl \\
\hline atm & atmospheric pressure \\
\hline BDMAE & bis(2-dimethylaminoethyl)ether \\
\hline BHT & butylated hydroxytoluene \\
\hline BIES & base-assisted internal electrophilic substitution \\
\hline $\mathrm{Bn}$ & benzyl \\
\hline Boc & tert-butyloxycarbonyl \\
\hline bpy & 2,2'-bipyridyl \\
\hline$B Q$ & 1,4-benzoquinone \\
\hline $\mathrm{Bu}$ & butyl \\
\hline $\mathrm{Bz}$ & benzoyl \\
\hline calc. & calculated \\
\hline cat. & catalytic \\
\hline CCE & constant current electrode \\
\hline CMD & concerted-metalation-deprotonation \\
\hline cod & 1,5-cyclooctadiene \\
\hline conv. & conversion \\
\hline $\mathrm{Cp}$ & cyclopentadienyl \\
\hline$C p^{*}$ & 1,2,3,4,5-pentamethylcyclopenta-1,3-dienyl \\
\hline Cy & cyclohexyl \\
\hline$\delta$ & chemical shift \\
\hline$d$ & doublet \\
\hline DBU & 1,8-diazabicyclo[5.4.0]undec-7-ene \\
\hline DCE & 1,2-dichloroethane \\
\hline DCIB & dichloro-iso-butane \\
\hline dcype & 1,2-bis-(dicyclohexylphosphino)ethane \\
\hline dd & doublet of doublet \\
\hline DFT & density functional theory \\
\hline$D G$ & directing group \\
\hline DME & dimethoxyethane \\
\hline DMA & $N, N$-dimethylacetamide \\
\hline DMAP & 4-dimethylaminopyridine \\
\hline DMF & $N, N$-dimethylformamide \\
\hline DMPU & 1,3-dimethyltetrahydropyrimidin-2(1H)-one \\
\hline
\end{tabular}




\begin{tabular}{|c|c|}
\hline $\begin{array}{l}\text { dppbz } \\
\text { dt }\end{array}$ & $\begin{array}{l}\text { 1,2-bis(diphenylphosphino)benzene } \\
\text { doublet of triplet }\end{array}$ \\
\hline El & electron ionization \\
\hline equiv & equivalent \\
\hline ES & electrophilic substitution \\
\hline ESI & electrospray ionization \\
\hline Et & ethyl \\
\hline Fc & Ferrocene \\
\hline$F G$ & functional group \\
\hline g & gram \\
\hline GC & gas chromatography \\
\hline GVL & $\gamma$-valerolactone \\
\hline $\mathrm{h}$ & hour \\
\hline Hal & halogen \\
\hline Het & heteroatom \\
\hline Hept & heptyl \\
\hline Hex & hexyl \\
\hline HFIP & 1,1,1,3,3,3-hexafluoro-2-propanol \\
\hline HPLC & high performance liquid chromatography \\
\hline HR-MS & high resolution mass spectrometry \\
\hline $\mathrm{Hz}$ & Hertz \\
\hline$i$ & iso \\
\hline $\mathrm{IPr} \cdot \mathrm{HCl}$ & 1,3-bis-(2,6-diisopropylphenyl) imidazolinium chloride \\
\hline IR & infrared spectroscopy \\
\hline IES & internal electrophilic substitution \\
\hline$J$ & coupling constant \\
\hline KIE & kinetic isotope effect \\
\hline $\mathrm{L}$ & ligand \\
\hline$m$ & meta \\
\hline $\mathrm{m}$ & multiplet \\
\hline M & molar \\
\hline$[\mathrm{M}]^{+}$ & molecular ion peak \\
\hline $\mathrm{Me}$ & methyl \\
\hline Mes & mesityl \\
\hline $\mathrm{mg}$ & milligram \\
\hline $\mathrm{MHz}$ & megahertz \\
\hline $\min$ & minute \\
\hline $\mathrm{mL}$ & milliliter \\
\hline $\mathrm{mmol}$ & millimole \\
\hline M.p. & melting point \\
\hline$M Q$ & 6-methylquinoline \\
\hline Ms & Mesyl \\
\hline MS & mass spectrometry \\
\hline
\end{tabular}




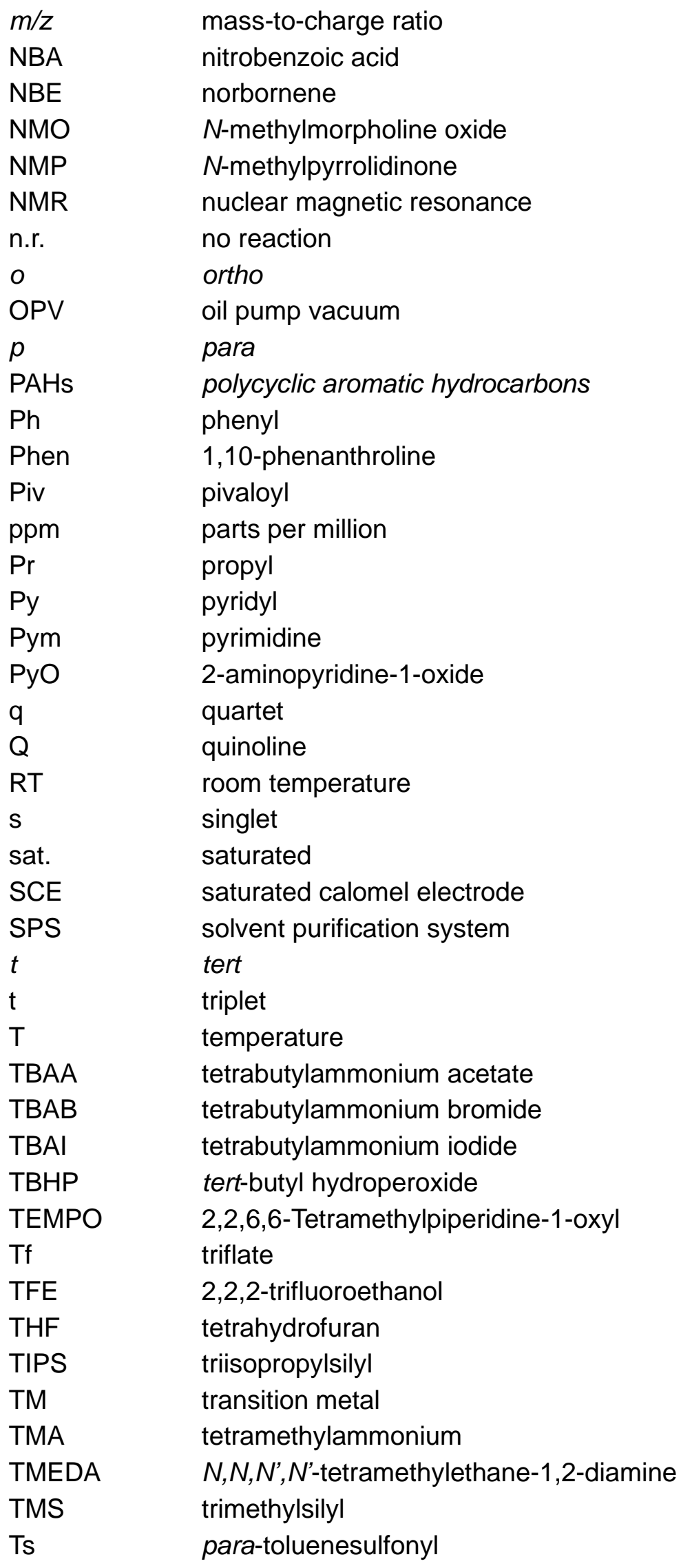





\section{Introduction}

Synthetic organic chemistry mainly focuses on the cleavage and formation of bonds in a practical and selective fashion, where the formation of carbon-carbon $(\mathrm{C}-\mathrm{C})^{[1]}$ and $\mathrm{C}-$ Heteroatom $(\mathrm{C}-\mathrm{Het})^{[2]}$ bonds constitutes one of the most important subjects. During the last century, great progress has been made in organic synthesis, with considerable applications to pharmaceutical industry, materials chemistry, and crop-protection filed, among others. ${ }^{[3]}$ However, the environmental issues associated with organic synthesis are inevitable in terms of chemical waste and toxic reagents. Therefore, significant attention has been paid to the development of sustainable strategies for molecular assembly in terms of both the economic and environmental benefits. ${ }^{[4]}$ In 1988, Anastas and Warner introduced the twelve principles of green chemistry as guidelines for minimizing the environmental footprint of chemical syntheses. ${ }^{[5]}$ According to these guidelines, the application of catalysis to organic chemistry is essential to increase the economic benefits and reduce waste formation by avoiding stoichiometric amounts of metal-based catalysts, oxidants or reductants.

\subsection{Transition Metal-Catalyzed C-H Functionalization}

Since the early contributions using stoichiometric or catalytic amounts of copper in the coupling reactions by Glaser ${ }^{[6]}$ and Ullmann ${ }^{[7]}$ in the late of $19^{\text {th }}$ century, significant progress has been witnessed in transition-metal-catalyzed cross-coupling reactions between a (hetero)aryl halide and an organometallic reagent for the construction of $\mathrm{C}-\mathrm{C}$ bonds, such as the Suzuki-Miyaura coupling, ${ }^{[8]}$ the Stille coupling, ${ }^{[9]}$ the Hiyama coupling, ${ }^{[10]}$ the Kumada-Corriu coupling, ${ }^{[11]}$ and the Negishi coupling ${ }^{[12]}$ reactions (Scheme 1.1). Additionally, transition-metal-catalyzed crosscoupling reactions, such as the Buchwald-Hartwig amination, ${ }^{[13]}$ the Ullmann-Goldberg, ${ }^{[14]}$ and the Chan-Evans-Lam-coupling, ${ }^{[15]}$ were successfully explored for $\mathrm{C}-\mathrm{Het}$ bond formations. These important contributions were recognized with the award of the 2010 Nobel Prize in Chemistry to Heck, Negishi and Suzuki "for palladium-catalyzed cross-couplings in organic synthesis". ${ }^{[16]}$ 


$$
\begin{aligned}
\mathrm{R}-\mathrm{X}+\mathrm{R}^{\prime}-\mathrm{M} & \stackrel{\text { cat. } \mathrm{Pd}(0)}{\mathrm{R}-\mathrm{R}^{\prime}} \\
\mathrm{M} & =\mathrm{B}(\mathrm{OH})_{2}: \text { Suzuki-Miyaura } \\
\mathrm{M} & =\mathrm{SnR}_{3}: \text { Stille } \\
\mathrm{M} & =\mathrm{MgX}: \text { Kumada-Corriu (cat. Ni(0)) } \\
\mathrm{M} & =\mathrm{ZnX}: \text { Negishi } \\
\mathrm{M} & =\mathrm{SiR}_{3}: \text { Hiyama }
\end{aligned}
$$

Scheme 1.1. Transition metal-catalyzed cross-coupling reactions.

Although traditional cross-coupling reactions represent one of the most reliable methods to access (hetero)-aryl-(hetero)aryl moieties, this method requires two fully prefunctionalized starting materials, namely organic (pseudo)halides and organometallic reagents e.g. Grignard reagents, organostannanes, organozinc and organolithium compounds, which are typically sensitive to air and moisture, and require multistep synthetic procedures, ${ }^{[17]}$ and generate stoichiometric amounts of salt waste. In contrast, transition metal-catalyzed $\mathrm{C}-\mathrm{H}$ functionalizations ${ }^{[18]}$ provide an opportunity to overcome these limitations to some extent. ${ }^{[19]}$ In particular, cross dehydrogenative couplings (CDC) between two aromatic $\mathrm{C}-\mathrm{H}$ bonds represent one of the most straightforward and sustainable concepts to forge bi(hetero)aryl structures $\left(\mathrm{C}-\mathrm{H} / \mathrm{C}-\mathrm{H}\right.$ type) with molecular hydrogen as the sole byproduct (Scheme 1.2.). ${ }^{20]}$

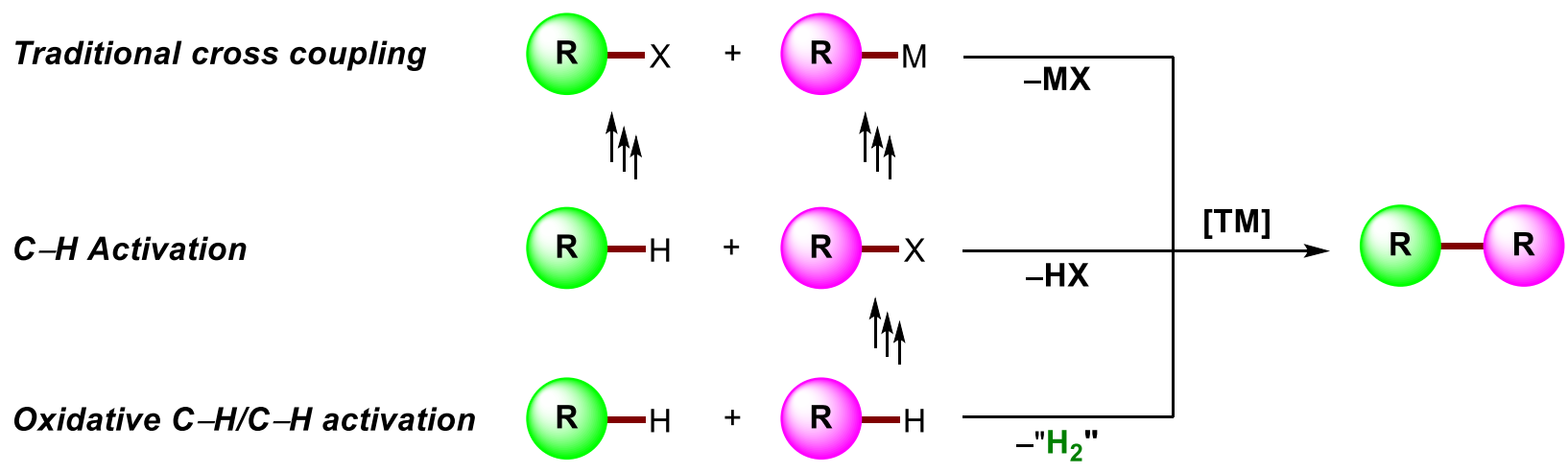

Scheme 1.2. Traditional cross-coupling reactions versus $\mathrm{C}-\mathrm{H}$ activation.

\subsection{General Modes for Metal-Mediated C-H Activation Processes}

In general terms, the transition-metal-facilitated cleavage of $\mathrm{C}-\mathrm{H}$ bond is the common key step in $\mathrm{C}-\mathrm{H}$ functionalization strategies. Computational chemistry has made a particularly strong contribution to the understanding of the range of possible mechanisms for the $\mathrm{C}-\mathrm{H}$ scission. ${ }^{[21]}$ 
Excluding radical $\mathrm{C}-\mathrm{H}$ activation or radical cross-coupling reactions, ${ }^{[22]}$ five different pathways can be classified depending on the electronic properties and the nature of the metal (Scheme 1.3). Electron-rich complexes of late transition metals are prone to cleave the inert $\mathrm{C}-\mathrm{H}$ bonds by oxidative addition, while this mode of action is unfavorable for early transition metals (Scheme 1.3a). ${ }^{[23]}$ Most late transition metals in higher oxidation states often act as a Lewis acid to cleave $\mathrm{C}-\mathrm{H}$ bond by an electrophilic substitution mode (Scheme 1.3b). ${ }^{[24]}$ The $\sigma$-bond metathesis is observed for early transition metals which cannot undergo oxidative addition (Scheme 1.3c). ${ }^{[25]}$ Metals containing an unsaturated $\mathrm{M}=\mathrm{X}$ bond tend to undergo $\mathrm{C}-\mathrm{H}$ activation via 1,2-addition (Scheme 1.3d). ${ }^{[26]}$ Furthermore, a base-assisted $\mathrm{C}-\mathrm{H}$ activation event ${ }^{[21 b, 27]}$ is proposed by the combination of electrophilic attack of the metal with deprotonation by carboxylate or carbonate ligands (Scheme 1.3e).

\section{a) Oxidative addition}

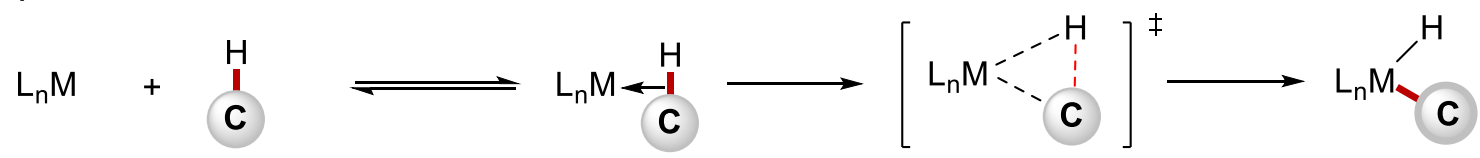

b) Electrophilic substitution

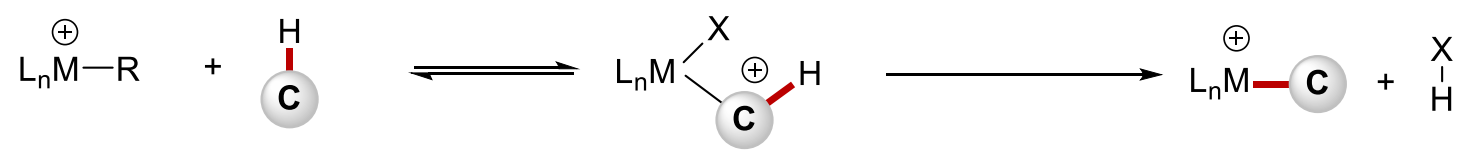

c) $\sigma$-Bond metathesis

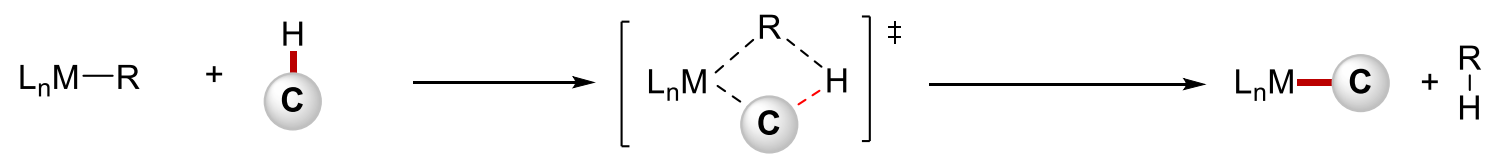

d) 1,2-Addition

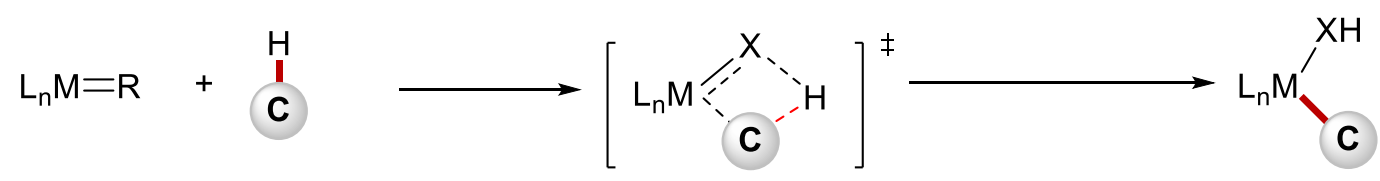

e) Base-assisted metalation

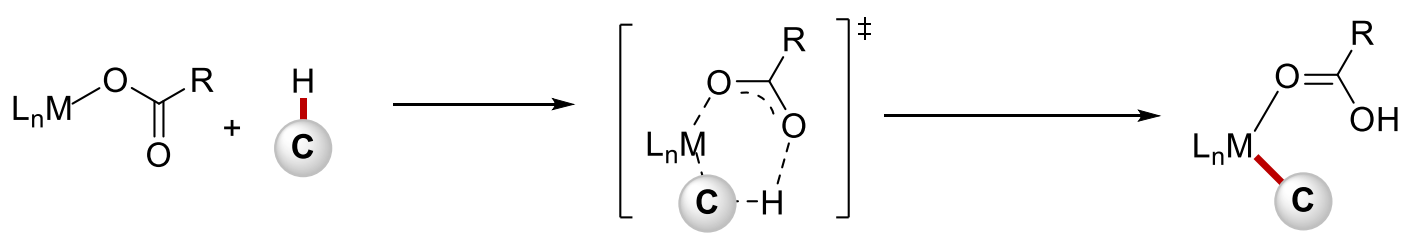

Scheme 1.3. Mechanistic pathways for $\mathrm{C}-\mathrm{H}$ activation. 
Meanwhile, the base-assisted mechanism was further investigated in detail to unveil the important role of an internal base for the $\mathrm{C}-\mathrm{H}$ cleavage processes, and this base-assisted mechanism could be further categorized by concerted metalation-deprotonation (CMD), ${ }^{[28]}$ ambiphilic metal-ligand activation $(A M L A)^{[29]}$ and base-assisted internal electrophilic substitution (BIES). ${ }^{[30]}$ (Scheme 1.4). Both CMD and AMLA mechanisms involving metalation and deprotonation steps proceed through a six-membered transition state and are favorable for electron-deficient substrates with high kinetic $\mathrm{C}-\mathrm{H}$ acidity. In sharp contrast the BIES mechanism was preferential observed for electron-rich arenes with acetate or carboxylate ligands and proceeds via an electrophilic substitution-type pathway. ${ }^{[30-31]}$

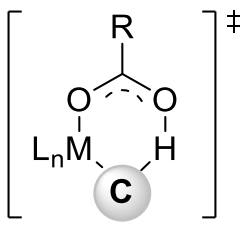

CMDIAMLA

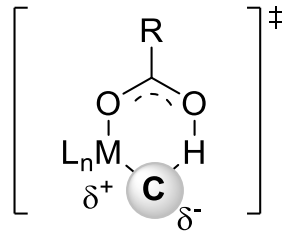

BIES

Scheme 1.4. Distinct transition state models for base-assisted $\mathrm{C}-\mathrm{H}$ metalation.

\subsection{General Strategies for Selective C-H Functionalizations}

Since $\mathrm{C}-\mathrm{H}$ bonds are ubiquitous in organic molecules and exhibit similar bond dissociation energies $\left(113.5 \mathrm{kcal} / \mathrm{mol}\right.$ for $\mathrm{C}\left(\mathrm{sp}^{2}\right)-\mathrm{H}$ bonds in benzene), ${ }^{[32]}$ the site-selective activation of several $\mathrm{C}-\mathrm{H}$ bonds in a molecule is a major challenge. To overcome this problem, different approaches have been introduced (Scheme 1.5). One of the methods to differentiate the $\mathrm{C}-\mathrm{H}$ bonds in heterocycles is by the inherent reactivity in their kinetic acidities and bond dissociation energies (Scheme 1.5a). ${ }^{[33]}$ Another strategy is the introduction of a bulky substituent on the substrate, resulting in a steric control by preventing access to the adjacent $\mathrm{C}-\mathrm{H}$ bonds (Scheme 1.5b). Nevertheless, both steric bias and electronic bias have intrinsically limited applications in molecular synthesis owing to the requirement for particular substrates. A more extensively used approach is the installation of Lewis-basic directing groups to precoordinate the transition metal center, thus activating the proximal $\mathrm{C}-\mathrm{H}$ bond and further facilitating the key $\mathrm{C}-\mathrm{H}$ activation step selectively (Scheme 1.5c). ${ }^{[34]}$ In addition, transient directing groups that can be reversibly installed in situ and removed in the catalytic $\mathrm{C}-\mathrm{H}$ cleavage possess have been developed in recent years and have great potential to decrease the number of tedious synthetic steps (Scheme 1.5e). ${ }^{[35]}$ Moreover, ruthenium-catalyzed $\sigma$-activation by strongly influencing the electronic properties of the aromatic ring (Scheme 1.5d), ${ }^{[36]}$ and exploiting carboxylic acids as 
traceless directing groups (Scheme 1.5f) ${ }^{[37]}$ are the alternative strategies for the remote metaselective $\mathrm{C}-\mathrm{H}$ activation. In contrast, the palladium/norbornene (NBE) cooperative Catellani-type reaciton has emerged as a powerful approach to achieve site-selective $\mathrm{C}-\mathrm{H}$ activation (Scheme 1.5g). ${ }^{[38]}$ Here, the ortho selective $\mathrm{C}-\mathrm{H}$ activation occurs in the presence of $\mathrm{Pd} / \mathrm{NBE}$ to generate a palladium-norbornene species, which can further activate the adjacent $\mathrm{C}-\mathrm{H}$ bond to finally achieve the remote selective meta-C-H bond functionalizations.

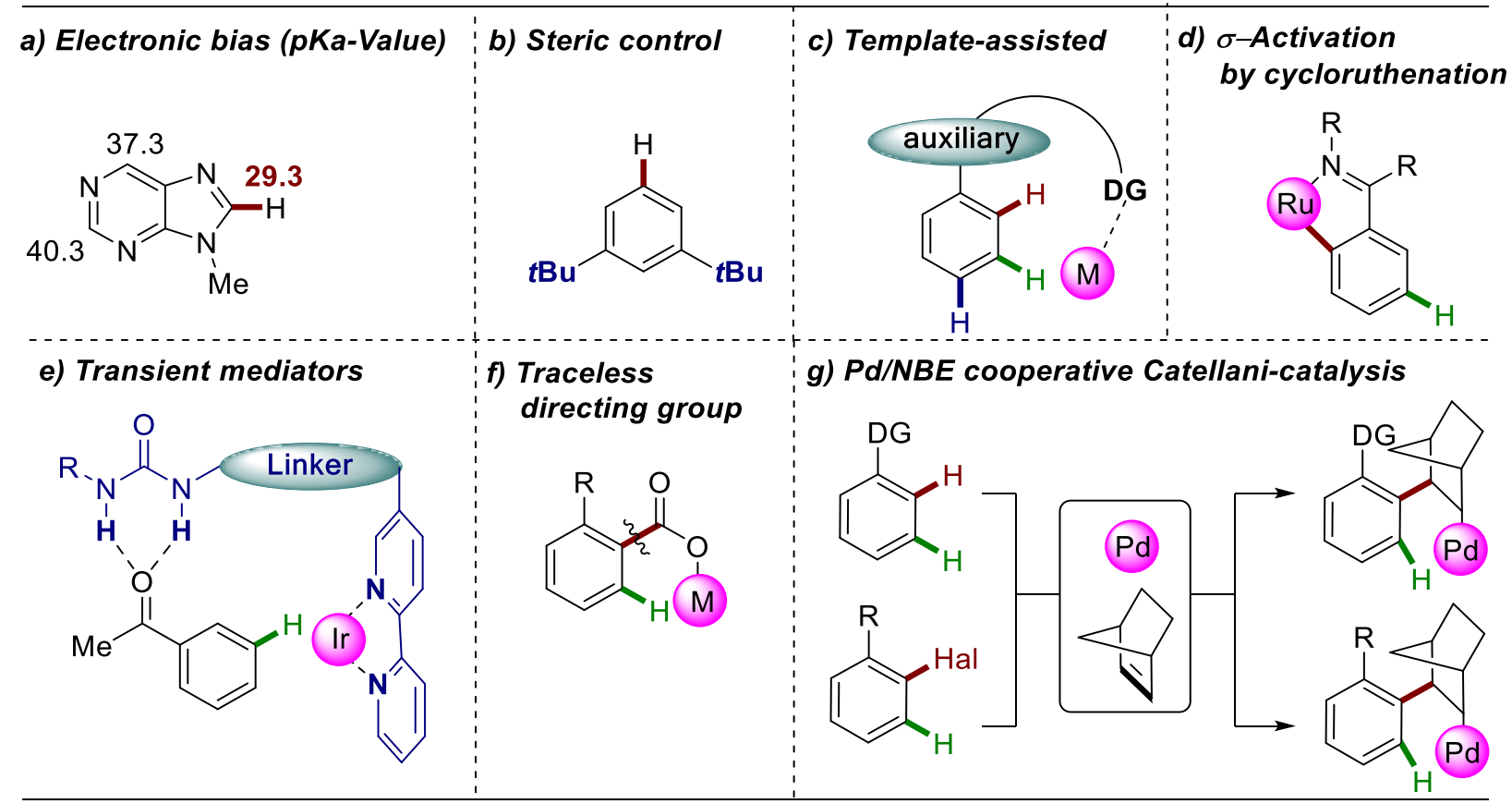

Scheme 1.5. Different strategies for selective $\mathrm{C}-\mathrm{H}$ functionalizations.

\subsection{Ruthenium-Catalyzed Selective C-H Activation}

While tremendous contributions have been made in the field of palladium or rhodium complexescatalyzed $\mathrm{C}-\mathrm{H}$ bond activation to promote $\mathrm{C}-\mathrm{C}$ bond formation, the application of cost-effective ruthenium catalysts is now useful and highly desirable for the efficient catalytic conversion of $\mathrm{C}-\mathrm{H}$ bonds. ${ }^{[35 \mathrm{a}]}$

\subsubsection{Ruthenium-Catalyzed ortho-Selective C-H Activation}

As early as 1965, Chatt and Davidson presented the ruthenium-mediated $\mathrm{C}-\mathrm{H}$ activation, in which the ruthenium(II)-phosphine complex $\left[\mathrm{RuCl}_{2}\left(\mathrm{Me}_{2} \mathrm{PCH}_{2} \mathrm{CH}_{2} \mathrm{PMe}_{2}\right)_{2}\right] \mathbf{1}$ was employed to achieve the $\mathrm{C}-\mathrm{H}$ bond cleavage of sodium arene 2 in THF for the generation of hydrideruthenium(II) complex 3 (Scheme 1.6). ${ }^{[39]}$ 


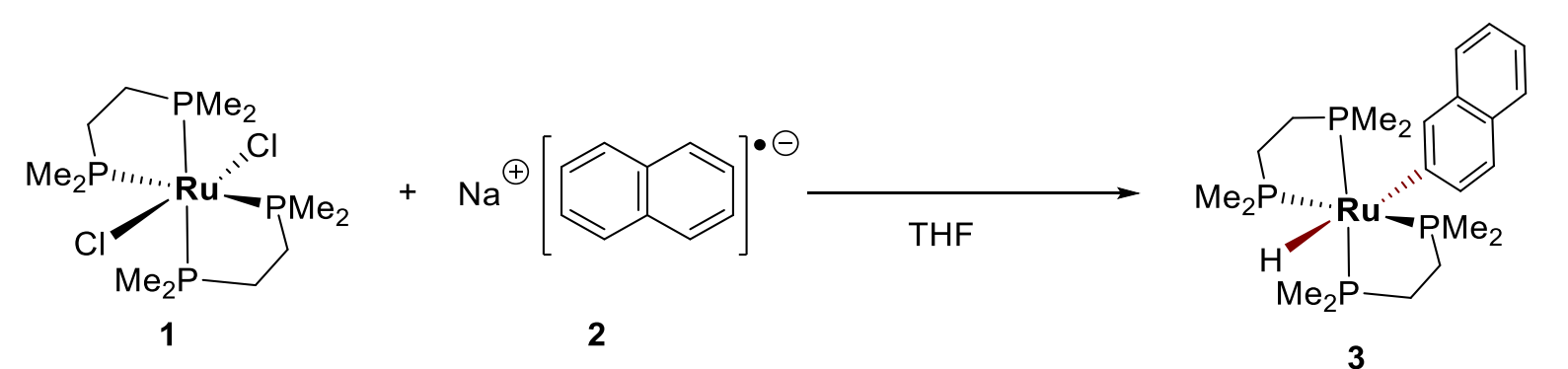

Scheme 1.6. Ruthenium-mediated $\mathrm{C}-\mathrm{H}$ activation.

In 1986, the first ortho-metalated ruthenium complex 7 catalyzed regioselective $\mathrm{C}-\mathrm{H}$ ethylation was reported by Lewis and Smith, thus inspiring further developments in $\mathrm{C}-\mathrm{H}$ activation by ruthenium catalystsis. A proposed mechanism for the insertion reaction involves phosphite substitution by ethylene, insertion of ethylene for $\mathrm{C}-\mathrm{C}$ bond formation into the $\mathrm{Ru}-\mathrm{C}$ bond, and finally reductive elimination to give an ethyl group (Scheme 1.7). ${ }^{[40]}$
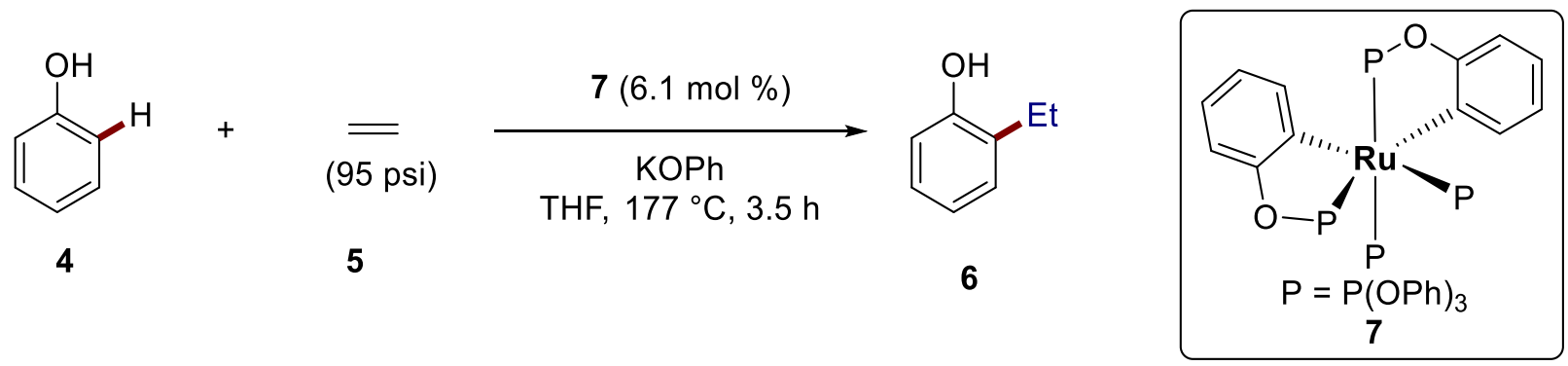

Scheme 1.7. Ruthenium-catalyzed C-H alkylation.

In 1993, a subsequent report in transition-metal-catalyzed C-H bond activation was achieved by the Murai-Chatani-Kakiuchi (Scheme 1.8). ${ }^{[41]}$ This was the first example of chelation-assisted catalytic alkylation of aromatic ketones $\mathbf{8}$ in the presence of a ruthenium( 0$)$ catalyst. This reaction proceeded by an initial insertion of ruthenium( 0 ) into a $\mathrm{C}-\mathrm{H}$ bond for the generation of active $\mathrm{C}-\mathrm{Ru}-\mathrm{H}$ species, and subsequent reaction of this metal complex with unsaturated substrates to provide the desired product 11. Importantly, the use of chelation assistance to form the cyclometalated ruthenium-hydride $\mathbf{1 0}$ proved crucial for the $\mathrm{C}-\mathrm{H}$ cleavage. 


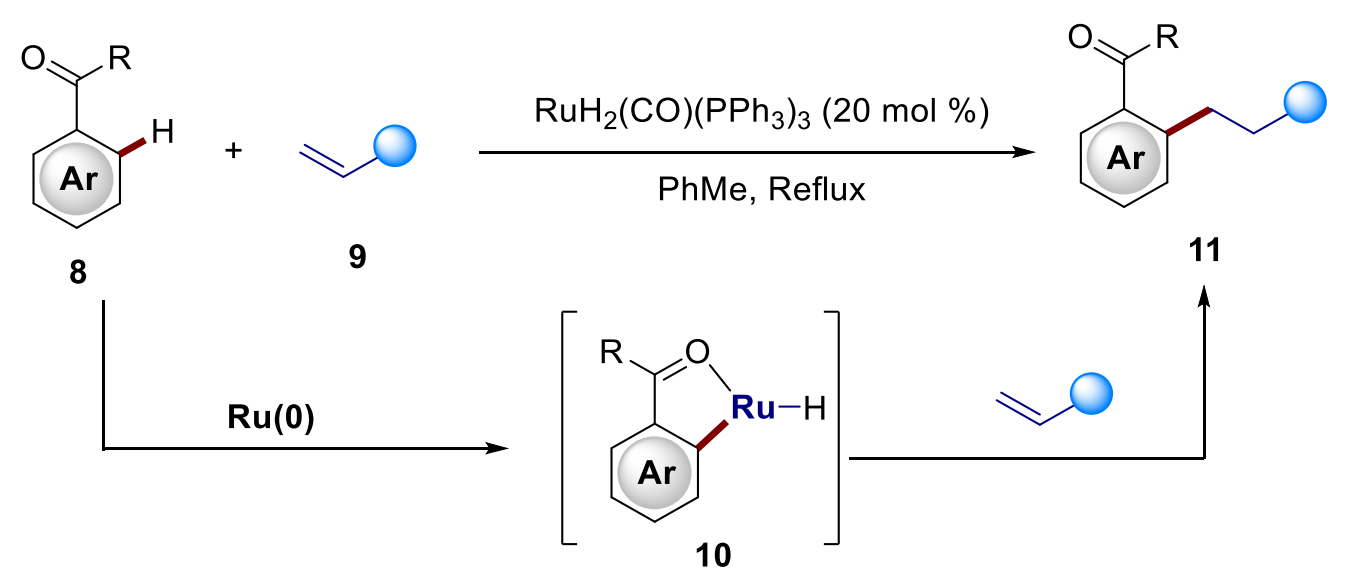

Scheme 1.8. Ruthenium-catalyzed $\mathrm{C}-\mathrm{H}$ alkylation of aromatic ketones.

In 2001, Milstein and coworkers introduced a novel ruthenium-catalyzed oxidative coupling of olefin 13 with arene 12 to furnish aryl alkene 14, where either dioxygen or the alkene 13 can play a role of an oxidant, eventually leading to reasonable turnover numbers (Scheme 1.9). ${ }^{[42]}$

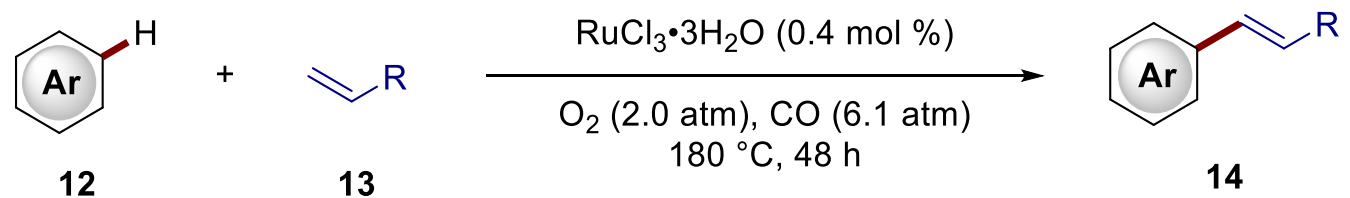

Scheme 1.9. Ruthenium-catalyzed oxidative coupling

In the same year, the first ortho-selective $\mathrm{C}-\mathrm{H}$ mono- or di-arylations of the aromatic ring in 2arylpyridines, 2-aryloxazolines and 2-arylimidazolines 15 with organic halides 16 in the presence of a ruthenium(II)-phosphine complex as the catalyst were reported by Oi and Inoue (Scheme 1.10). ${ }^{[43]}$ However, this protocol was later shown not to be reproducible. Thus, low-level impurities of $y$-butyrolactone were found in the NMP solvent, which could hydrolyze under the basic conditions to generate a carboxylate. ${ }^{[44]}$

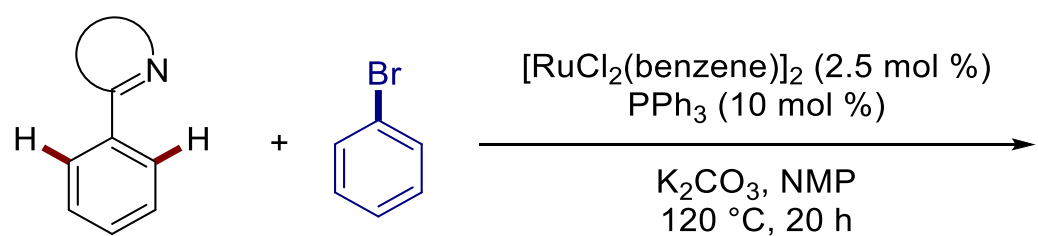

15
16

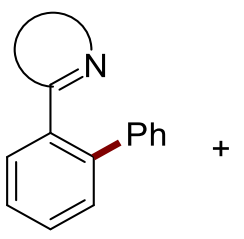

17<smiles>c1ccc(-c2cccc(-c3ccccc3)c2C2=NCCCC2)cc1</smiles>

18

Scheme 1.10. Ruthenium-catalyzed ortho-selective $\mathrm{C}-\mathrm{H}$ arylation.

In 2005, the first generally applicable method for the direct arylation of functionalized arenes using ruthenium(II) catalysts was reported by Ackermann ${ }^{[45]}$ by the introduction of phosphine oxide $\mathrm{R}_{2} \mathrm{P}(\mathrm{O}) \mathrm{H}$ additives that were shown to activate the ruthenium(II) catalyst more efficiently than tertiary phosphine ligand ${ }^{[44]}$ (Scheme 1.11). In this case, the air-stable adamantyl- 
substituted secondary phosphine oxide (SPO) $(1-\mathrm{Ad})_{2} \mathrm{P}(\mathrm{O}) \mathrm{H}$ was used as the preligand, leading to the effective arylation with the less reactive, but readily available aryl chlorides 19 . As to this working mode of the SPO-based ruthenium(II) catalyst, a base-assisted metalation was proposed to be the decisive feature via transition state $\mathbf{A}$ (Scheme 1.12). Later, the same group embarked on exploration of other bifunctional ligands, such as carboxylates, for direct arylations that were expected to give rise to transition state B. ${ }^{[46]}$
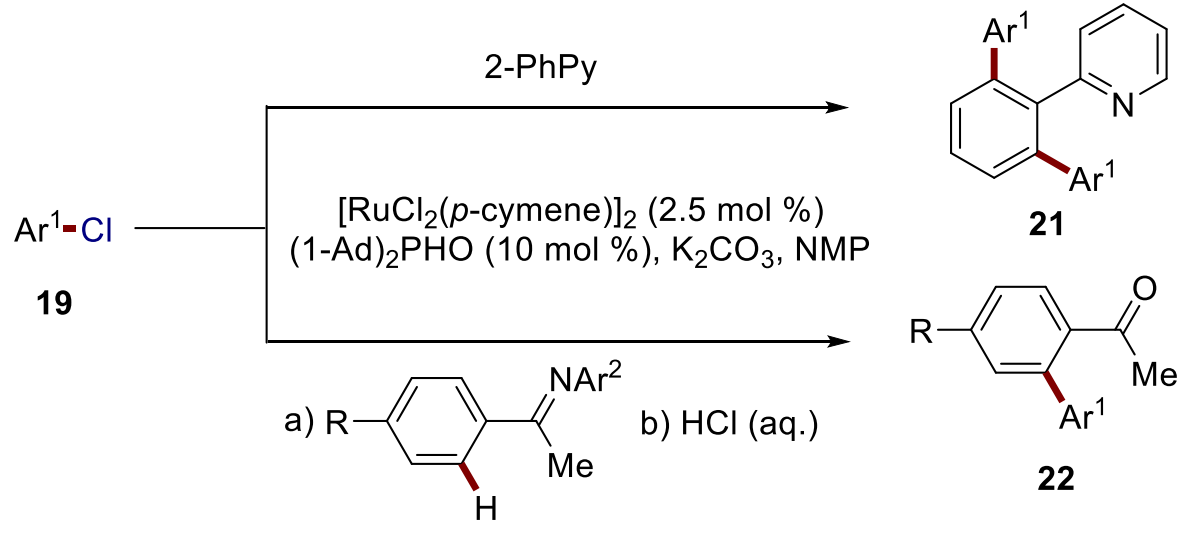

21

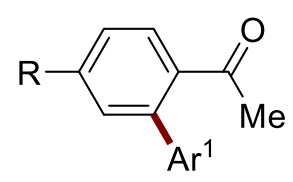

22

20

Scheme 1.11. Ruthenium-catalyzed ortho-selective $\mathrm{C}-\mathrm{H}$ arylation using phosphine oxide as preligand.

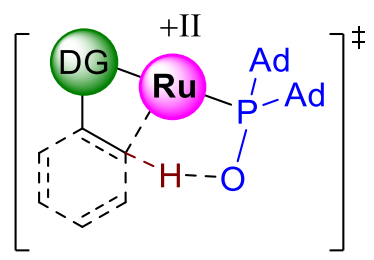

A

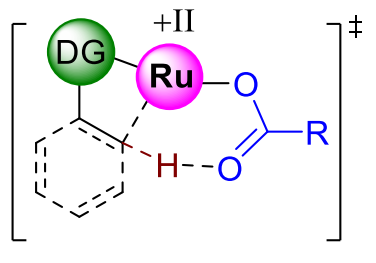

B

Scheme 1.12. Proposed transition states for base-assisted ruthenations.

In 2008, the Ackermann group demonstrated the first case of carboxylate-assisted ruthenium(II)catalyzed $\mathrm{C}-\mathrm{H}$ activation, even in apolar solvent, involving the possible generation of a sixmembered ruthenium-carboxylate species (Scheme 1.13a). ${ }^{[47]}$ Subsequently, this most powerful strategy also enabled site- and chemo-selective $\mathrm{C}-\mathrm{H}$ alkylations $25,{ }^{[48]} \mathrm{C}-\mathrm{H}$ oxygenations $26,{ }^{[49]}$ $\mathrm{C}-\mathrm{H}$ halogenations 27, ${ }^{[50]}$ or $\mathrm{C}-\mathrm{H}$ cyanations 28 (Scheme 1.13b). ${ }^{[51]}$ 
a) Carboxylate-assisted ruthenium(II)-catalyzed $\mathrm{C}-\mathrm{H}$ arylation

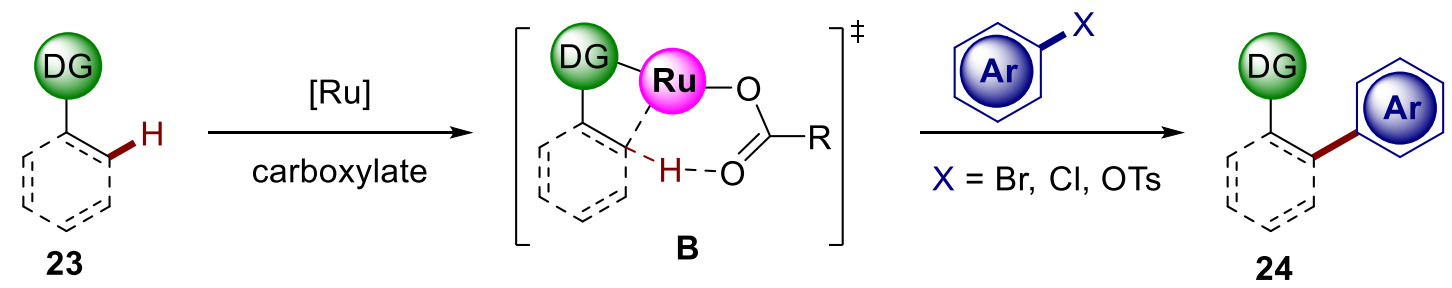

b) Carboxylate-assisted ruthenium(II)-catalyzed $\mathrm{C}-\mathrm{H}$ alkylation, hydroxylation, halogenation and cyanation
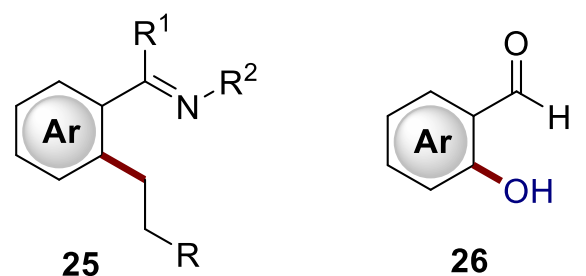<smiles>[R20]C(=O)c1ccccc1[Hg]</smiles>

27<smiles>[R2]NC(=O)c1ccccc1C#N</smiles>

28

Scheme 1.13. Ruthenium-catalyzed $\mathrm{C}-\mathrm{H}$ arylation, alkylation, hydroxylation, halogenation and cyanation under carboxylate assistance.

The robust nature of the ruthenium(II)-catalyzed C-H activation was not limited to direct arylation chemistry. Indeed, this general concept of carboxylate-assisted ruthenium-catalyst was found to be broadly applicable for various heterocyclic molecular synthesis in terms of oxidative annulations for $\mathrm{C}-\mathrm{H} / \mathrm{N}-\mathrm{H}^{[52]}$ and $\mathrm{C}-\mathrm{H} / \mathrm{O}-\mathrm{H}$ bond ${ }^{[53]}$ activations in the presence of copper(II) oxidants (Scheme 1.14). ${ }^{[54]}$ 


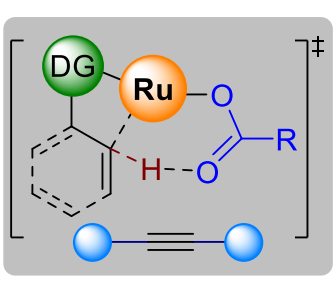

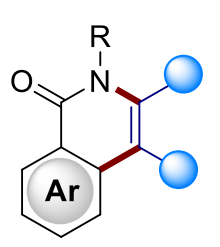

a) Ackermann, 2011

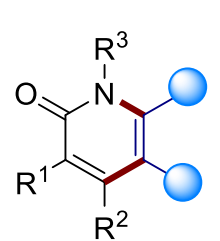

b) Ackermann, 2011<smiles>[R]c1nn2c([O-])c(O)c3ccccc3c2c1[R]</smiles>

g) Ackermann, 2012 Jeganmohan, 2012

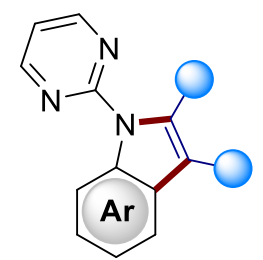

c) Ackermann, 2012

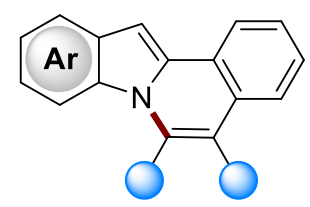

d) Ackermann, 2012<smiles>[R]c1c(O)c([O-])n([R])c1[R]</smiles>

e) Ackermann, 2012

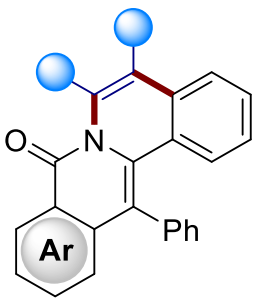

f) Wang, 2012

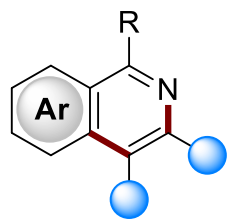

I) Urriolabeitia, 2013<smiles>[R]c1cccc2c1C(O)=C(O)Oc1ccccc1-2</smiles>

h) Ackermann, 2012<smiles>[R]c1c(O)c(O)n(-c2ncccn2)c1[R]</smiles>

i) Ackermann, 2013<smiles>O=c1oc(O)c(O)c2ccccc12</smiles>

j) Ackermann 2012/2013

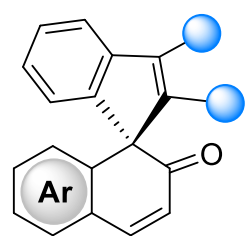

k) Luan, 2013<smiles>[R]C1([R])OC([O-])=C(O)c2ccccc21</smiles>

m) Ackermann, 2014

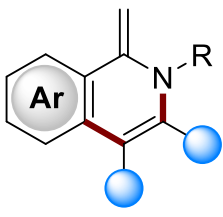

n) Ackermann, 2014

Scheme 1.14. Ruthenium-catalyzed oxidative $\mathrm{C}-\mathrm{H} / \mathrm{X}-\mathrm{H}$ annulations with alkynes.

Furthermore, carboxylate assisted ruthenium-catalyzed selective oxidative $\mathrm{C}\left(\mathrm{sp}^{2}\right)-\mathrm{H}$ olefinations of heteroarenes were accomplished to generate the desired aryl alkenes (Scheme 1. 15). Different directing groups were explored for these transformations by the Ackermann group, among others, such as, carboxylic acids, ${ }^{[5]}$ oxazoles/triazoles, ${ }^{[56]}$ ketones/aldehydes, ${ }^{[57]}$ esters, ${ }^{[58]}$ carbamates, ${ }^{[59]}$ 2-pyridyloxys, ${ }^{[60]}$ sulfonic acids, ${ }^{[30 b]} \mathrm{N}$-dimethylcarbamoyls ${ }^{[61]}$ and amides. ${ }^{[62]}$ 

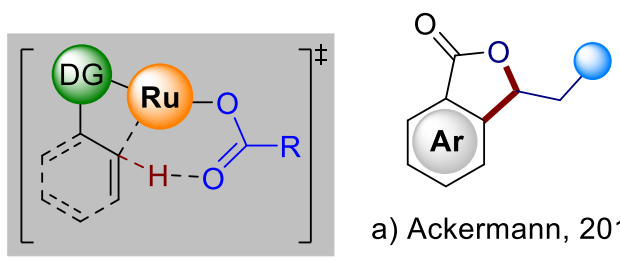

a) Ackermann, 2011<smiles>[R2]NC(=O)Oc1ccccc1/C=C/O</smiles>

e) Ackermann, 2012 Jeganmohan, 2013

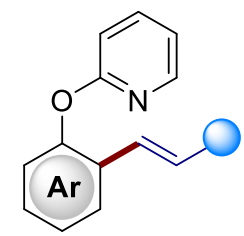

f) Ackermann, 2013<smiles>O=C(O)c1[Y]c2ccccc2c1/C=C/O</smiles>

b) Miura, 2011<smiles>O=S(=O)(O)c1ccccc1C=CO</smiles>

g) Ackermann, 2014<smiles>O/C=C/c1ccccc1C1=NCCN1</smiles>

c) Dixneu, 2011 Miura, 2012 Ackermann, 2015

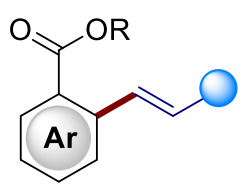

d) Ackermann, 2012 Jeganmohan, 2012<smiles>[R]/C(C=CO)=C(\[R])C(=O)C([R])[R]</smiles>

i) Ackermann, 2011 Miura, 2011 Loh, $\quad 2012$

Scheme 1.15. Ruthenium-catalyzed oxidative annulation and olefinations with olefines.

Most of these reactions used copper acetate, which acted not only as the oxidant, but also served as the essential source of acetate for the carboxylate-assisted ruthenation manifold. In order to avoid using the copper salt as an oxidant, an alternative strategy was viable through the use of substrates bearing $\mathrm{N}-\mathrm{O}$ bonds as "internal oxidants" for the syntheses of isoquinolones, isoquinolines ${ }^{[63]}$ olefination or alkyl annulation ${ }^{[64]}$ and benzofuran derivatives (Scheme 1.16). ${ }^{[65]}$

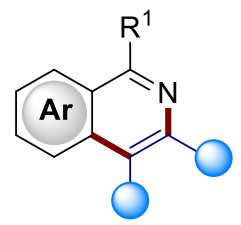

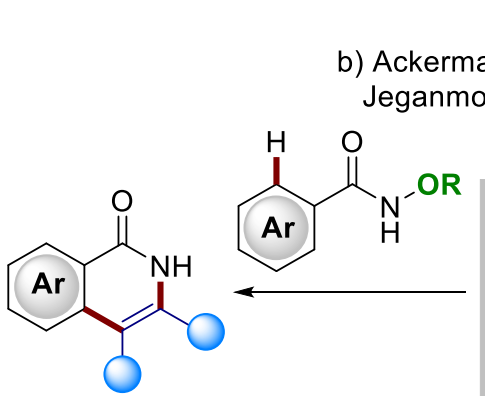

a) Wang, 2011

Ackermann, 2011/2014

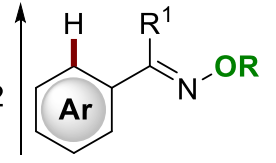

, 2012
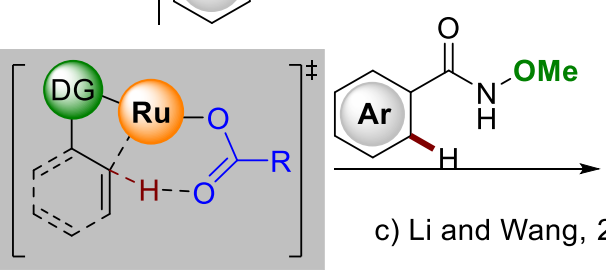

c) Li and Wang, 2012

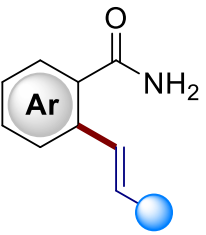

or

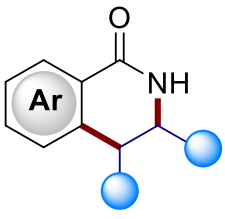

Scheme 1.16. Ruthenium-catalyzed redox-neutral annulation and olefinations with olefines. 


\subsubsection{Ruthenium-Catalyzed meta-Selective $\mathrm{C}-\mathrm{H}$ Activation}

meta-Selective $\mathrm{C}-\mathrm{H}$ functionalizations can be elegantly achieved via $\sigma$-activation through cyclometallation. ${ }^{[36,66]}$ This strategy usually installs a directing group at the ortho-position to produce a significant electronic bias at the arene ring, thus allowing for subsequent functionalizations to take place at the para position with respect to the $\mathrm{Ru}-\mathrm{C}$ bond, leading to an overall meta-selective functionalization.

In 1994, Roper reported the ortho/para-selective stoichiometric nitration of ruthenium aryl complexes 29 via $\sigma$-activation strategy (Scheme 1.17a). ${ }^{[67]}$ Later, van Koten reported the first chelation-assisted oxidative para $\mathrm{C}-\mathrm{H} / \mathrm{C}-\mathrm{H}$ functionalization of a ruthenium-arene complex $\mathbf{3 4}$, furnishing the binuclear complex $\mathbf{3 5}$ as well as small amounts of chlorinated ruthenium complex 36. (Scheme 1.17b). ${ }^{[68]}$ These results presumably clarified that the site-selectivity of $\mathrm{C}-\mathrm{H}$ activation could be controlled by the formation of $\mathrm{C}-\mathrm{Ru}$ bond via the electronic influence on the arene ring.

a)

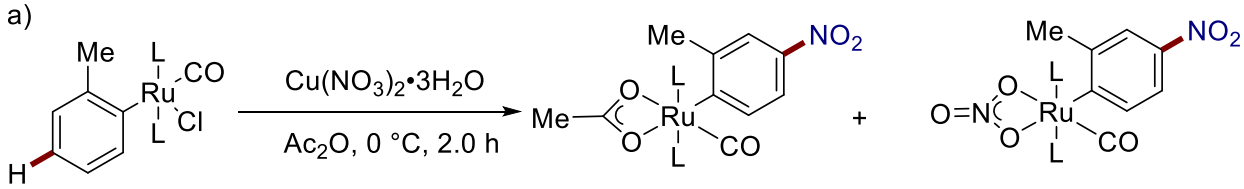

29

$\mathrm{L}=\mathrm{PPh}_{3}$

30: $41 \%$

31: $<7 \%$

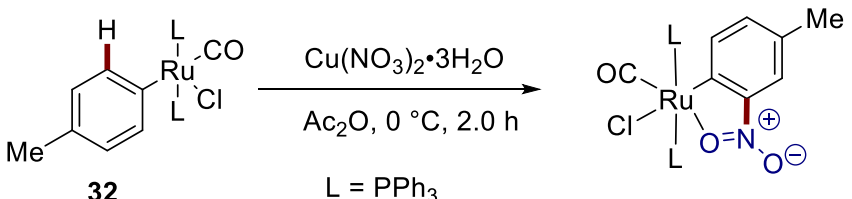

32

$\mathrm{L}=\mathrm{PPh}_{3}$

33: $31 \%$

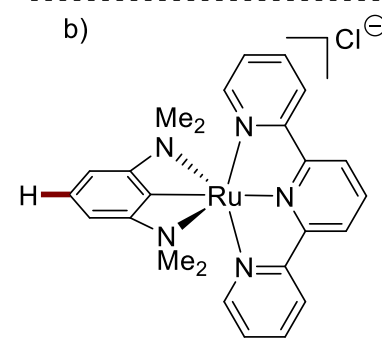

34

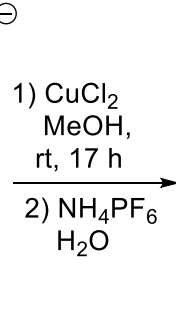

$\mathrm{H}_{2} \mathrm{O}$

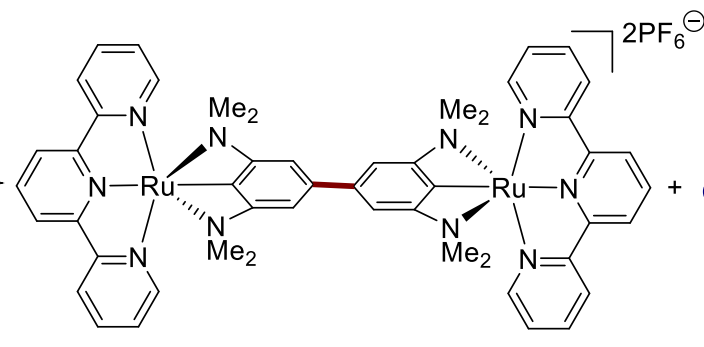

35: $60 \%$

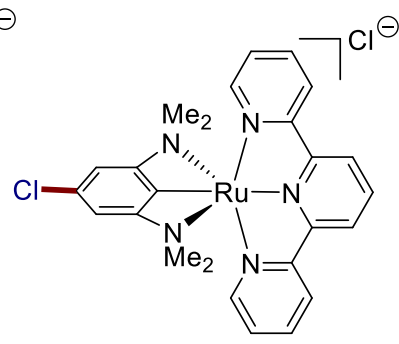

$36:<10 \%$

Scheme 1.17. $\mathrm{C}-\mathrm{H}$ activation of cyclometalated ruthenium complexes.

In 1998, the group of Coudret achieved the electrophilic $\mathrm{C}-\mathrm{H}$ meta-bromination of phenylpyridine-ruthenium complex 37 with $\mathrm{N}$-bromosuccinimide (NBS) in excellent yield and regioselectivity (Scheme 1.18a). ${ }^{[6]}$ Afterwards, Roper and Wright disclosed the electrophilic meta-selective $\mathrm{C}-\mathrm{H}$ bromination of phenylpyridine-ruthenium complex 39 with $\mathrm{PyHBr}_{3}$ as the 
halogenating reagent and iron powder as catalyst (Scheme 1.18b). ${ }^{[70]}$ These observations suggested that the site-selective electrophilic transformation could be controllable by the electronic directing effect of the metal centers.
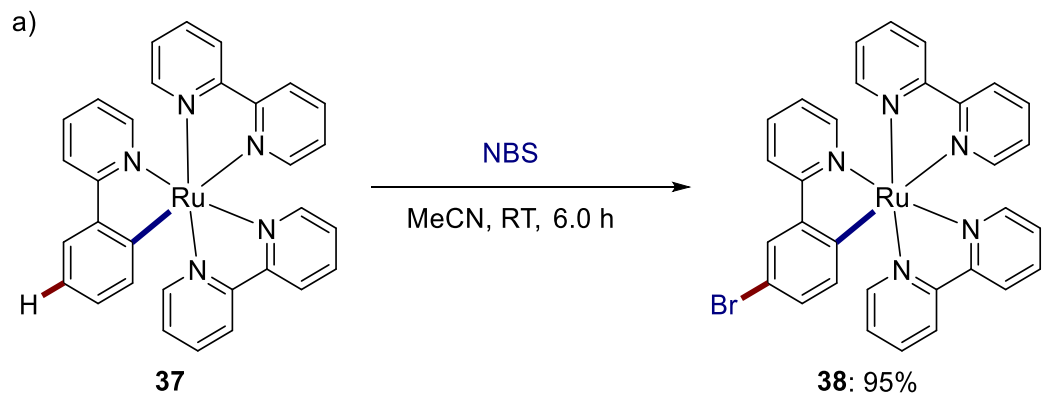

b)

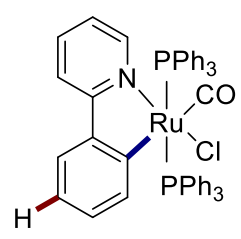

39

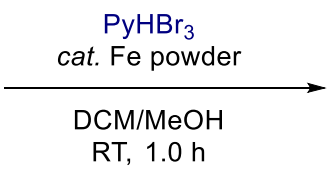

$\mathrm{RT}, 1.0 \mathrm{~h}$

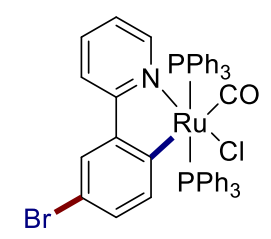

40: $69 \%$

Scheme 1.18. Remote $\mathrm{C}-\mathrm{H}$ bromination of cycloruthenium complexes.

The first observation for the ruthenium-catalyzed meta-selective $\mathrm{C}-\mathrm{H}$ functionalization was reported by the Ackermann group in 2011 (Scheme 1.19). ${ }^{[71]}$ While chelation assisted rutheniumcatalyzed ortho-selective $\mathrm{C}-\mathrm{H}$ alkylations of the phenylpyridine was the major product, an unprecedented meta-alkylated arene $\mathbf{4 3}$ was also observed, albeit in rather low yield.

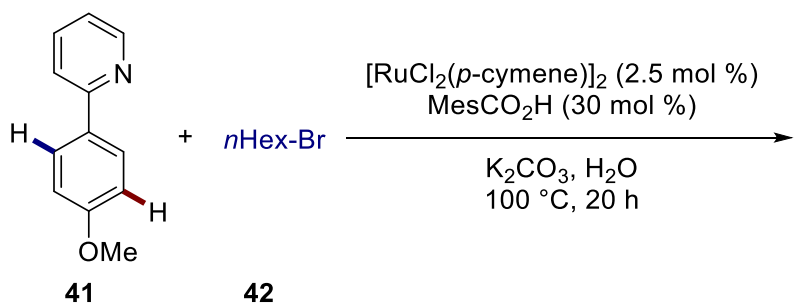

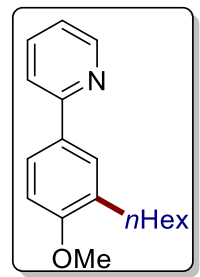

43: $7 \%$

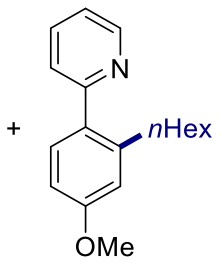

44: $45 \%$

Scheme 1.19. The first ruthenium-catalyzed meta-C-H alkylation.

Inspired by this initial result of ruthenium-catalyzed meta-selective $\mathrm{C}-\mathrm{H}$ alkylation, Ackermann ${ }^{[72]}$ and other groups ${ }^{[73]}$ independently disclosed this method for remote meta-C-H alkylations using secondary and tertiary alkyl bromides through an ortho-ruthenation strategy (Scheme 1.20). The catalytic remote alkylations were applicable to pyridines, pyrimidines, azoles and imines as directing groups, leading to the formation of meta-alkylated arenes with excellent levels of position-selectivity. Detailed mechanistic studies of this remote functionalization were supportive of a radical mechanism, involving a reversible $\mathrm{C}-\mathrm{H}$ ruthenation and a subsequent site-selective alkylation, which was rationalized by the strong electronic effect of the $\mathrm{Ru}-\mathrm{C}\left(\mathrm{sp}^{2}\right)$ bond. ${ }^{\text {[2b-d] }}$ Recently, a breakthrough in meta-C-H alkylations under photoredox conditions, using a 
polymer-based hybrid ruthenium catalyst and in a decarboxylative manner were demonstrated by the Ackermann group. ${ }^{[74]}$ Furthermore, ruthenium-catalyzed carboxylate-assisted meta-C-H

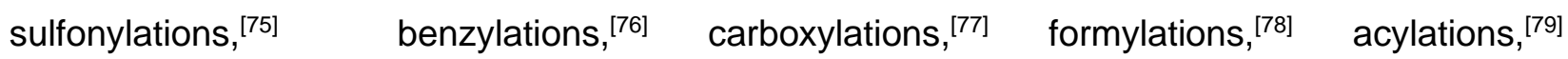
halogenations $^{[80]}$ and nitrations ${ }^{[81]}$ were developed, respectively, illustrating the key importance of carboxylate-assisted $\mathrm{C}-\mathrm{H}$ activation with ruthenium(II) complexes in the molecular modifications (Scheme 1.20). ${ }^{[35 a]}$

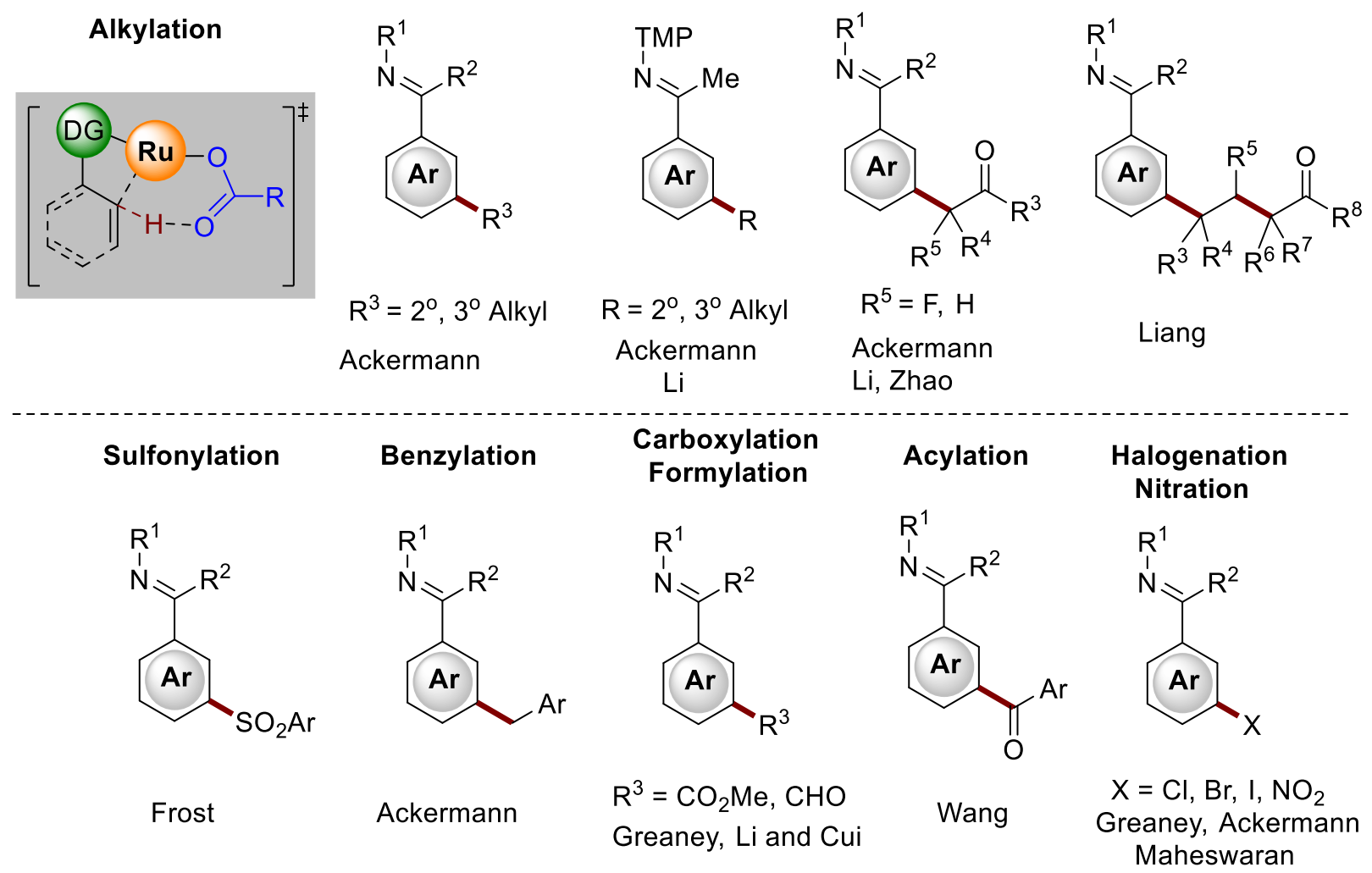

Scheme 1.20. Ruthenium-catalyzed selective meta-C-H activation in the presence of nitrogen-containing directing groups.

\subsubsection{Ruthenium-Catalyzed para-Selective C-H Activation}

In contrast to the significant progress in meta-selective $\mathrm{C}-\mathrm{H}$ functionalizations, challenging $\mathrm{C}-\mathrm{H}$ functionalizations at para position remain underdeveloped. ${ }^{[82]}$ In 2017, Frost reported rutheniumcatalyzed para-selective $\mathrm{C}-\mathrm{H}$ alkylations with $\alpha$-bromo esters 46 (Scheme 1.21). ${ }^{[83]}$ Mechanistic studies by experiments and DFT calculations suggested a four-membered ruthenacycle 45 a as the key intermediate for the transformations. Afterwards, ruthenium-catalyzed para-selective C$\mathrm{H}$ fluoroalkylation of anilides and ketoximes with $\alpha$-bromo esters $\mathbf{4 6}$ were also demonstrated by the Zhao and Ackermann groups. ${ }^{[84]}$ 


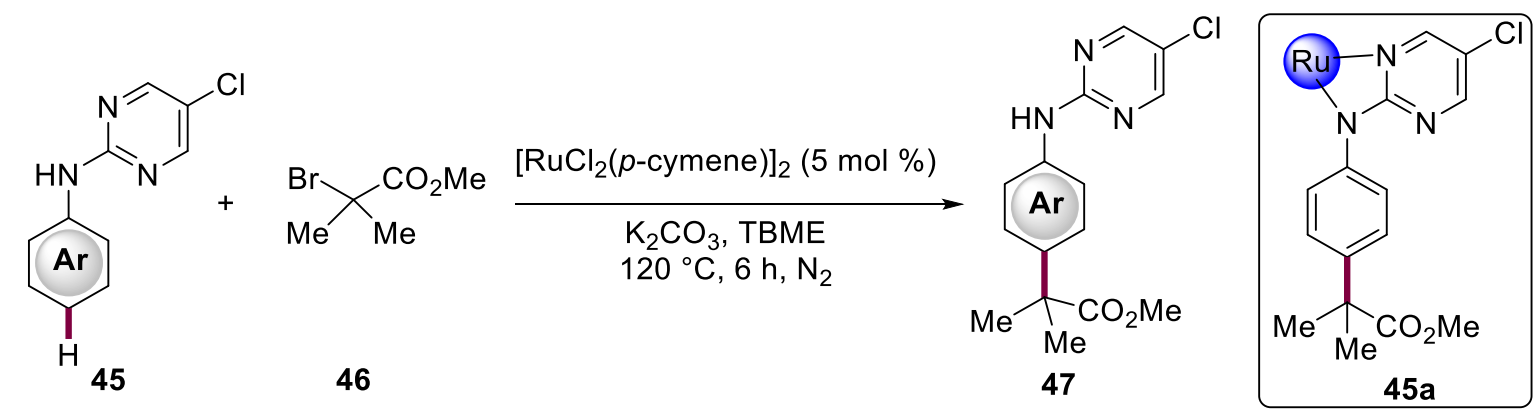

Scheme 1.21. Ruthenium-catalyzed selective para-C-H alkylation.

\subsection{Transition Metal-Catalyzed Electrochemical C-H Activation}

Since early contributions from Volta, ${ }^{[85]}$ Kolbe, ${ }^{[86]}$ and Faraday, ${ }^{[87]}$ electrosynthesis with inexpensive and waste-free electricity as a viable redox equivalent has recently experienced a renaissance, ${ }^{[88]}$ holding huge potential to accomplish excellent levels of oxidant and resource economy. ${ }^{[89]}$ In contrast to classical metal-free electrosynthesis, metalla-electrocatalysis sets the stage for transition-metal-catalyzed site-selective $\mathrm{C}-\mathrm{H}$ activations, ${ }^{[90]}$ forming $\mathrm{C}-\mathrm{C}$ or $\mathrm{C}-\mathrm{Het}$ bonds without stoichiometric chemical oxidants.

\subsubsection{Palladaelectro-Oxidative C-H Activation}

A pioneering contribution in palladaelectro-oxidative $\mathrm{C}-\mathrm{H}$ olefinations $\mathbf{5 0}$ was reported by the Amatore and Jutand group in 2007 (Scheme 1.22). ${ }^{[91]}$ This modified Fujiwara-Moritani-type reaction ${ }^{[92]}$ employed catalytic amounts of benzoquinone as the redox mediator and electricity as a terminal redox equivalent to replace stoichiometric silver(I) and copper(II) salts as oxidants, albeit with a limited scope.

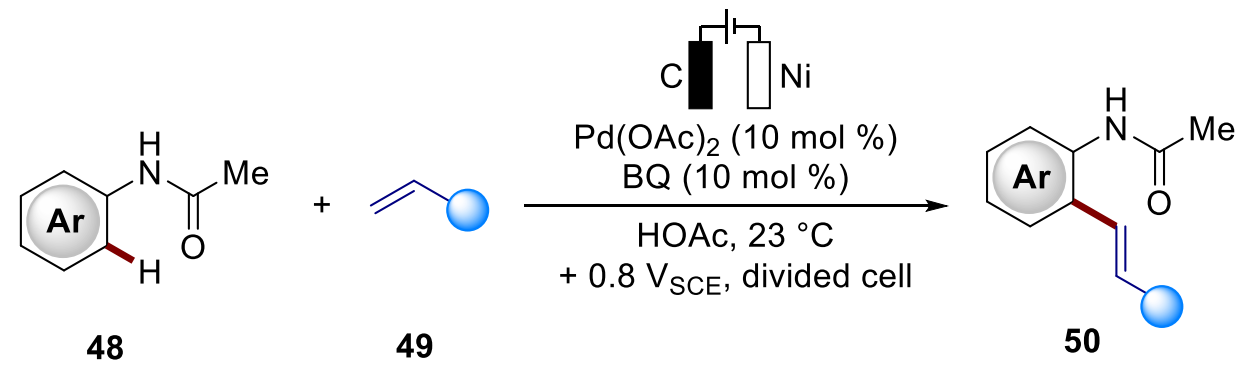

Scheme 1.22. Pallada-electrochemical C-H olefination.

Subsequently, Kakiuchi exploited palladium-catalyzed electrochemical $\mathrm{C}-\mathrm{H}$ halogenation of 2phenyl pyridine with hydrogen halides or iodine as the halogenation reagents (Scheme 1.23). ${ }^{[93]}$ Then, this protocol was further expanded to achieve ortho-selective chlorination using bidentate directing groups. ${ }^{[94]}$ The versatility of pyridine as a chelating group was not only explored for $\mathrm{C}-\mathrm{H}$ 
halogenation of arenes by palladaelectro-catalysis, but also for electrocatalytic homocoupling of arenes via intermolecular $\mathrm{C}-\mathrm{H}$ arylation. ${ }^{[95]}$

In 2017, a further contribution was made in electrochemical palladium-catalyzed $\mathrm{C}\left(\mathrm{sp}^{3}\right)-\mathrm{H}$ oxygenation by Mei (Scheme 1.23). ${ }^{[96]}$ This protocol offered a broad scope of synthetically useful oxime derivatives under rather mild reaction conditions. ${ }^{[97]}$ In subsequent efforts, the efficient palladium-catalyzed oxidative ortho- $\mathrm{C}\left(\mathrm{sp}^{2}\right)-\mathrm{H}$ methylation and benzoylation of oximes were reported by the Mei group using methyltrifluoroborates and benzoyl acetic acids as coupling partners, respectively. ${ }^{[98]}$ Also, palladium-catalyzed anodic ortho- $\mathrm{C}\left(\mathrm{sp}^{2}\right)-\mathrm{H}$ acetoxylation, ${ }^{\text {[99] }}$ halogenation ${ }^{[100]}$ and alkylation ${ }^{[101]}$ were also achieved by the same group.

Another example of palladium-catalyzed electrooxidative $\mathrm{C}\left(\mathrm{sp}^{3}\right)-\mathrm{H}$ acetoxylation of 8methylquinoline with tetramethylammonium acetate (TMAOAc, a stronger nucleophile) was introduced by the Sanford group (Scheme 1.23). ${ }^{[102]}$ In addition, a pyridine-directed palladiumcatalyzed electrochemical $\mathrm{C}\left(\mathrm{sp}^{2}\right)-\mathrm{H}$ bond phosphonation was also reported by Budnikova. ${ }^{[03]}$ Moreover, in 2020, the Lei group developed a palladium-catalyzed electro-oxidative intramolecular $\mathrm{C}-\mathrm{H} / \mathrm{N}-\mathrm{H}$ annulation reaction without an additive, offering a variety of pyrido[1,2a]benzimidazoles. ${ }^{[104]}$

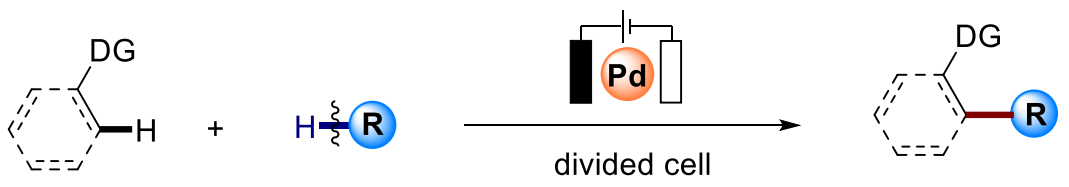

51

52

53

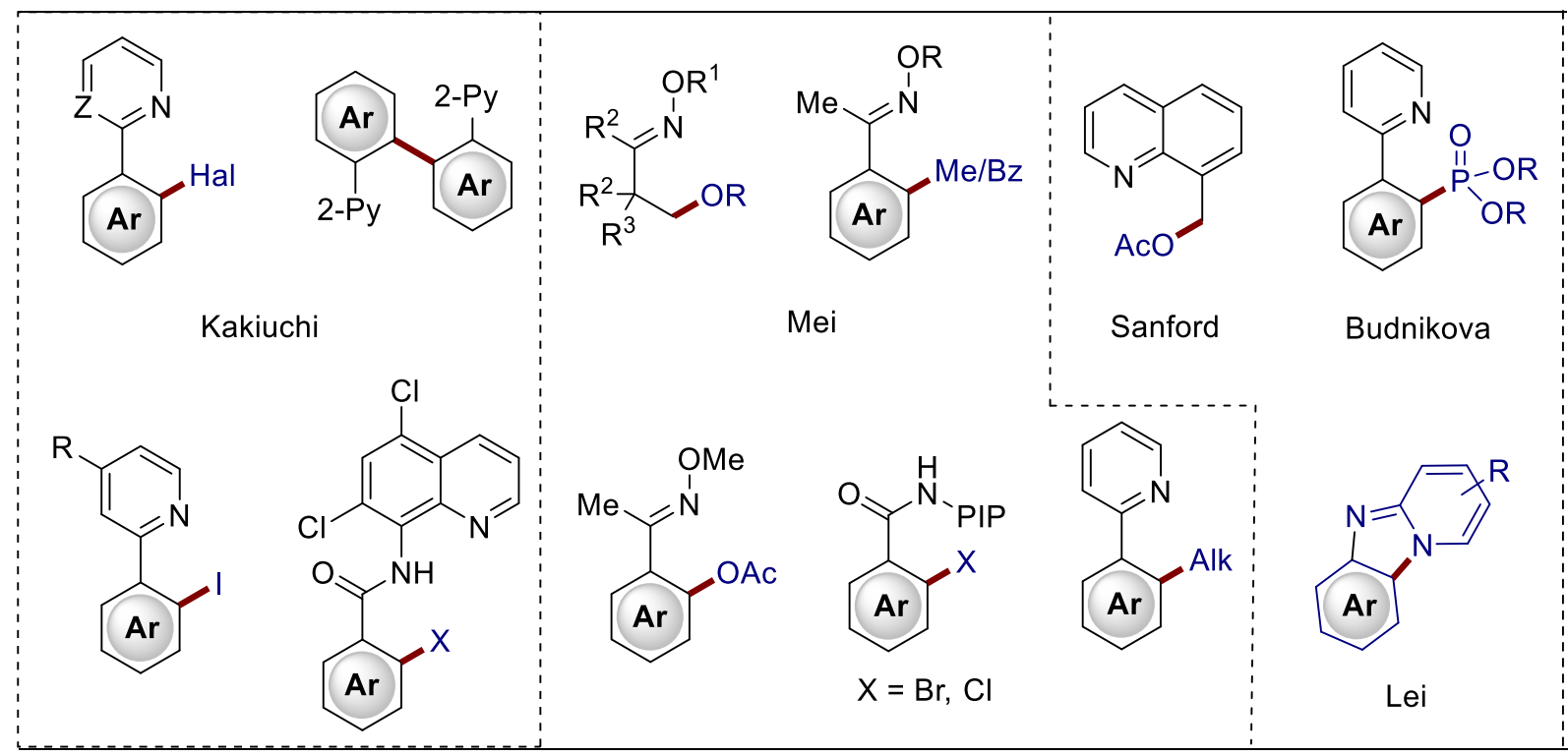

Scheme 1.23. Pallada-electrooxidative $\mathrm{C}-\mathrm{H}$ activation.

In 2020, the first asymmetric pallada-electrocatalyzed C-H olefination was achieved by the Ackermann group through the synergistic cooperation with a chiral transient directing group for 
the construction of various axially chiral biaryls 55a-55c. Pleasingly the reaction proceeded under undivided cell setup. Further conversion of the thus-obtained products $\mathbf{5 5}$ gave expedient access to enantioenriched BINOLs, dicarboxylic acids and helicenes (Scheme 1.24). ${ }^{[05]}$

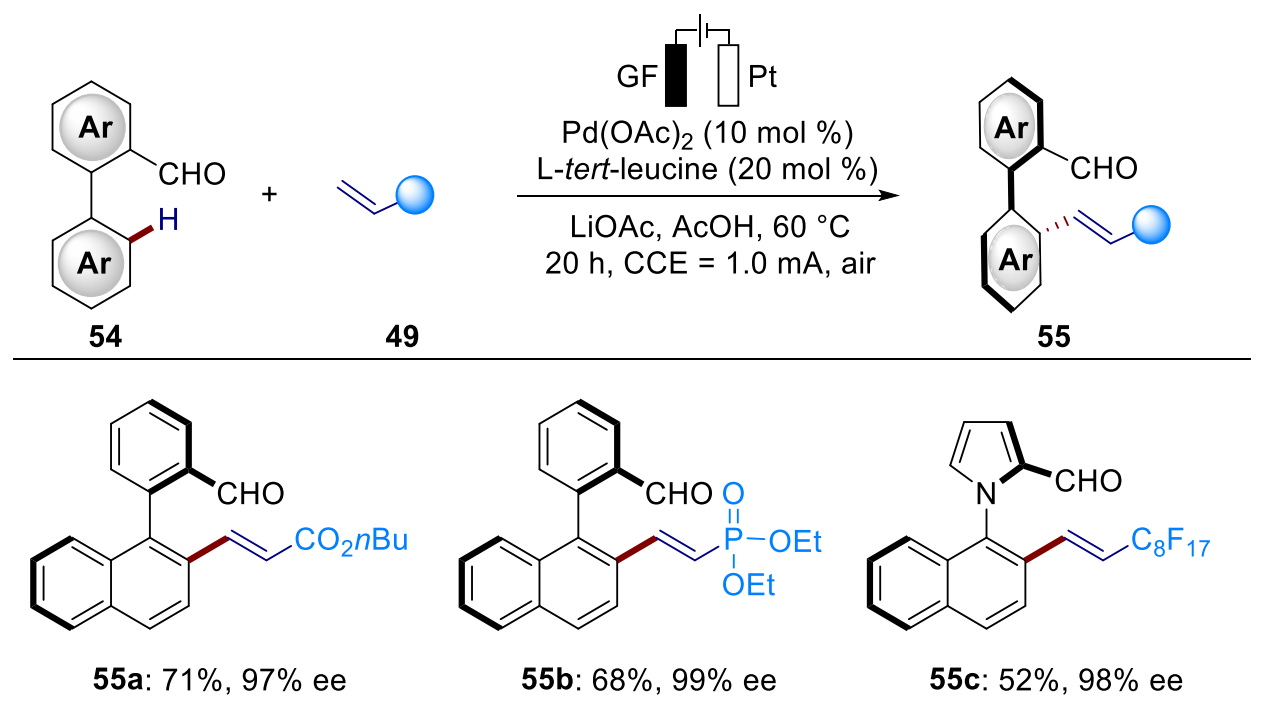

Scheme 1.24. First examples for asymmetric pallada-electrooxidative $\mathrm{C}-\mathrm{H}$ activation.

\subsubsection{Rhodaelectro-Oxidative C-H Activation}

Rhodaelectro-oxidative $\mathrm{C}-\mathrm{H}$ activations have been well documented by Ackermann (Scheme 1.25). In 2018, they reported the first electrochemical cross-dehydrogenative alkene annulation under rhodium catalysis with benzoic acids, amides and indoles 56A (Scheme 1.25a). ${ }^{[106]}$ The olefinations of challenging electron-poor benzamides 56B were established in a fully dehydrogenative fashion using rhodaelectro-catalysis by the same group in 2020, featuring a broad substrate scope (Scheme 1.25b). ${ }^{[107]}$ In 2019, the first electrochemical C-C activation was accomplished by expedient oxidative rhodium(III) catalysis. This organometallic $\mathrm{C}-\mathrm{C}$ activation manifold proceeded with ample scope and excellent levels of chemo- and position-selectivities, providing unique access to challenging densely substituted arenes $57 \mathrm{C}$, which are not viable by any $\mathrm{C}-\mathrm{H}$ activation methods (Scheme 1.25c). ${ }^{[108]}$

Subsequently, the Ackermann group achieved rhodaelectro-catalyzed cascade $\mathrm{C}-\mathrm{H}$ annulation for the synthesis of novel non-planar polycyclic aromatic hydrocarbons (PAHs) 57F from simple arylboronic acids 56F (Scheme 1.25f). ${ }^{[109]}$ Later, nitrogen-doped polycyclic aromatic hydrocarbons (aza-PAHs) 57H were obtained via a rhodium-catalyzed electrochemical cascade $\mathrm{C}-\mathrm{H}$ annulations of amidoximes $56 \mathrm{H}$ with alkynes (Scheme 1.25h). ${ }^{[110]}$ In addition, a flowrhodaelectro-catalyzed $\mathrm{C}-\mathrm{H}$ alkyne annulation was firstly established by the same group. Two key rhodacycles were synthesized and detailed mechanistic studies suggest an oxidativelyinduced reductive elimination pathway on rhodium(III) in an electrocatalytic regime (Scheme 
$1.25 \mathrm{~g}){ }^{[111]}$ Recently, an efficient electrooxidative rhodium-catalyzed alkyne annulation via C$\mathrm{H} / \mathrm{O}-\mathrm{H}$ activations was realized using electricity as the sole oxidant, featuring ample substrate scope and high site-selectivities (Scheme 1.25i,j). ${ }^{[112]}$
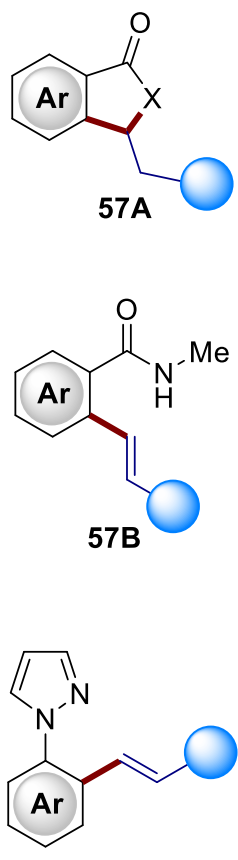

$57 \mathrm{C}$

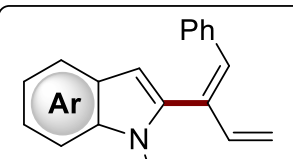

57D 2-pym
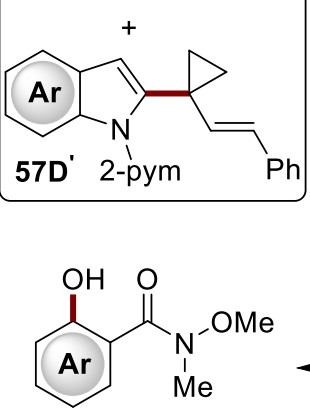

57E

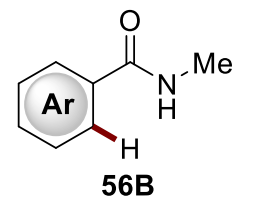

b) Ackermann, 2020

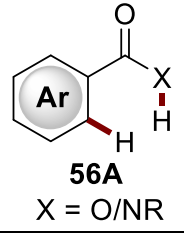

a) Ackermann, 2018

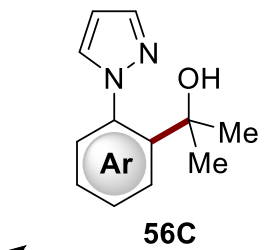

c) Ackermann, 2019

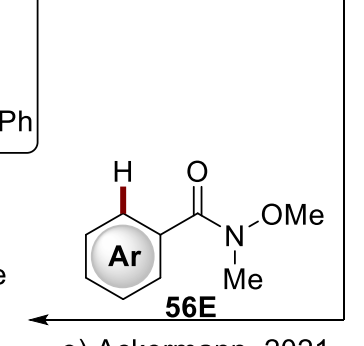

e) Ackermann, 2021

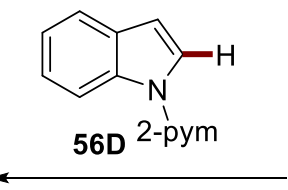

d) Ackermann, 2021

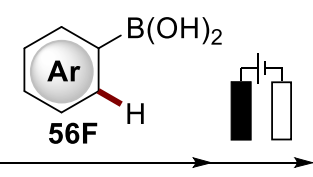

f) Ackermann 2019

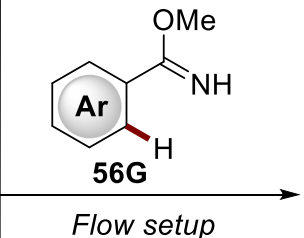

Flow setup

g) Ackermann, 2019

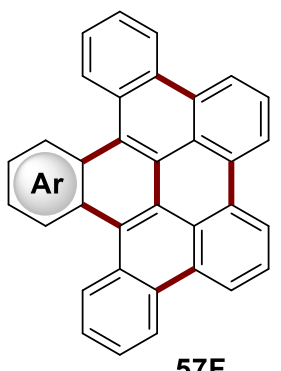

$57 \mathrm{~F}$

Rh

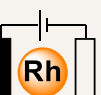

h) Ackermann, 2020

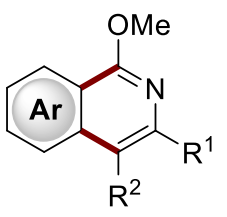

$57 G$

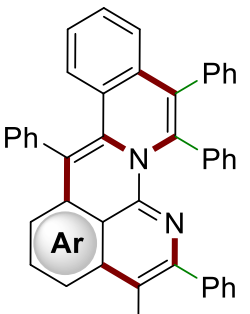

57H $\mathrm{Ph}$

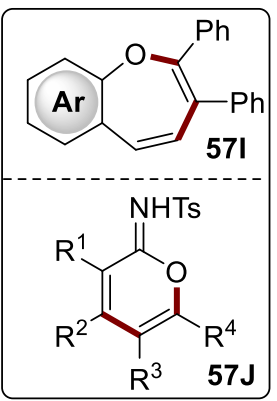

j) Mei, 2021

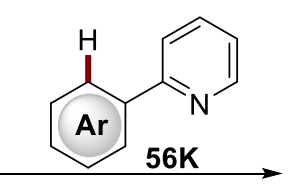

k) Xu, 2019

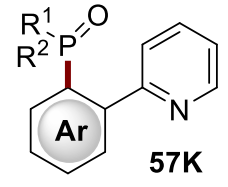

Scheme 1.25. Rhoda-electrooxidative $\mathrm{C}-\mathrm{H}$ activations.

In 2021, the Ackermann group demonstrated a rhodaelectro-catalyzed $\mathrm{C}-\mathrm{H}$ activation of indole 56D with alkylidenecyclopropanes (ACPs) for the chemo-selective assembly of cyclopropanes or dienes. This unique strategy allowed for the control of selectivity within different mechanistic pathways by either $\beta-\mathrm{H}$ or $\beta-\mathrm{C}$ elimination (Scheme 1.25d). ${ }^{[113]}$ Moreover, electrocatalyzed arene $\mathrm{C}-\mathrm{H}$ oxygenation using bimetallic rhodium complex by weakly $\mathrm{O}$-coordinating amides and 
ketones 56E were reported by Ackermann (Scheme 1.25e). ${ }^{[14]}$ On a different note, a rhodiumcatalyzed electrochemical phosphorylation of 2-phenylpyridine $56 \mathrm{~K}$ was also reported by $\mathrm{Xu}$ and coworkers (Scheme 1.25k). ${ }^{[15]}$

\subsubsection{Ruthenaelectro-Oxidative C-H Activation}

In 2018, Xu and Ackermann ${ }^{[16]}$ (Scheme 1.26a-b) independently reported ruthenaelectrooxidative $\mathrm{C}-\mathrm{H}$ alkyne annulations with aniline derivatives 58A and weakly $\mathrm{O}$-coordinating benzoic acid 58B, leading to the cost-effective preparation of indole derivatives 59A and isocoumarins 59B, respectively. Subsequently, naphthol, aromatic carbamates 58C, benzylic alcohols 58D, acetophenones 58E and benzoylamides 58F proved to be viable substrates for ruthenium-catalyzed dehydrogenative $\mathrm{C}-\mathrm{H} / \mathrm{Het}-\mathrm{H}$ alkyne annulations (Scheme 1.26c-f). ${ }^{[17]}$

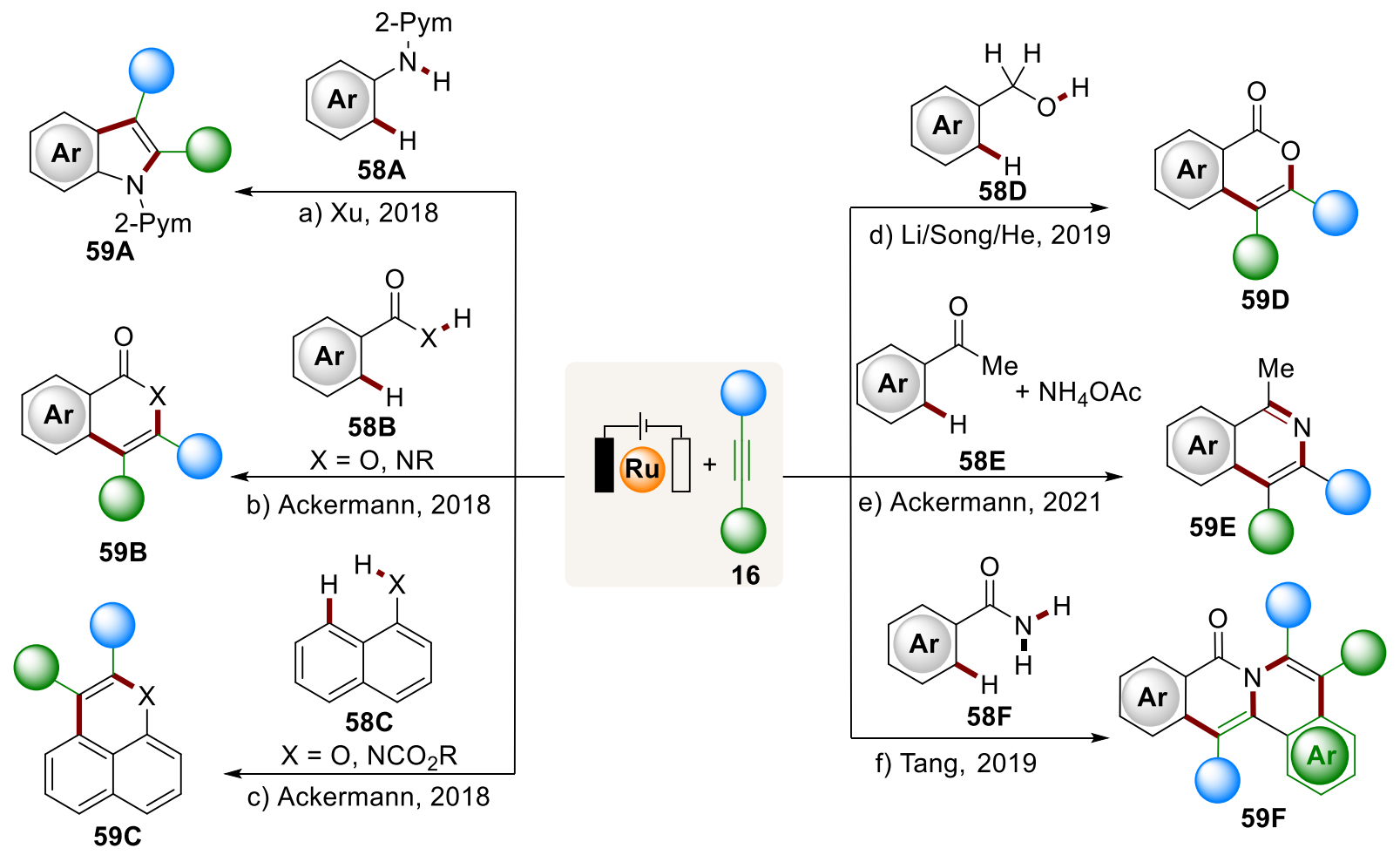

Scheme 1.26. Ruthena-electrooxidative $\mathrm{C}-\mathrm{H} / \mathrm{X}-\mathrm{H}$ annulation. $(\mathrm{X}=\mathrm{N}, \mathrm{O})$.

In 2020, Ackermann developed a novel electrochemical co-catalytic system for the $\mathrm{C}-\mathrm{H}$ oxygenation of synthetically useful amides and ketones 60 , employing dual catalysis with electrogenerated hypervalent iodine(III) and ruthenium(II) complexes. Thus, catalytic amounts of iodoarenes and ruthenium(II) catalyst allowed for versatile $\mathrm{C}-\mathrm{H}$ oxygenations with ample scope and high functional group tolerance 61a-61f (Scheme 1.27). ${ }^{[118]}$ 


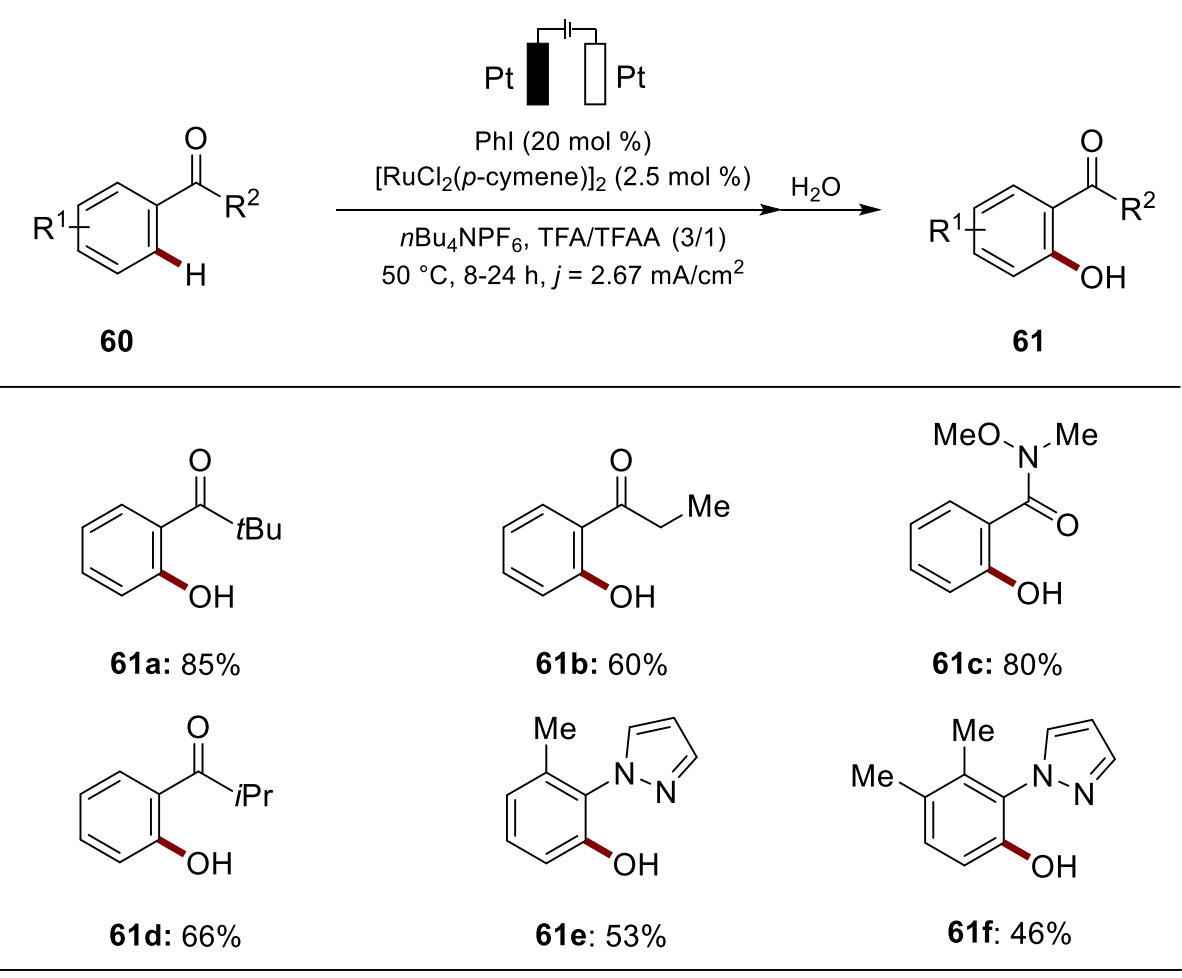

Scheme 1.27. Ruthenaelectro-catalyzed $\mathrm{C}-\mathrm{H}$ activation of ketones amides and pyrazoles.

Based on the detailed mechanistic studies, a plausible catalytic cycle was proposed for the ioda/ruthena-electrocatalyzed $\mathrm{C}-\mathrm{H}$ oxygenation (Scheme 1.28). The catalytic cycle is initiated by $\mathrm{C}-\mathrm{H}$ activation on the amide with the ruthenium(II) catalyst. Then, the anodically generated iodine(III) reagent oxidizes the ruthenium(II) intermediate II, delivering ruthenium(IV) intermediate III, which then undergoes rapid reductive elimination and subsequent hydrolysis to furnish hydroxylation product $\mathbf{6 1}$ and regenerate the active catalyst $\mathbf{I}$. 


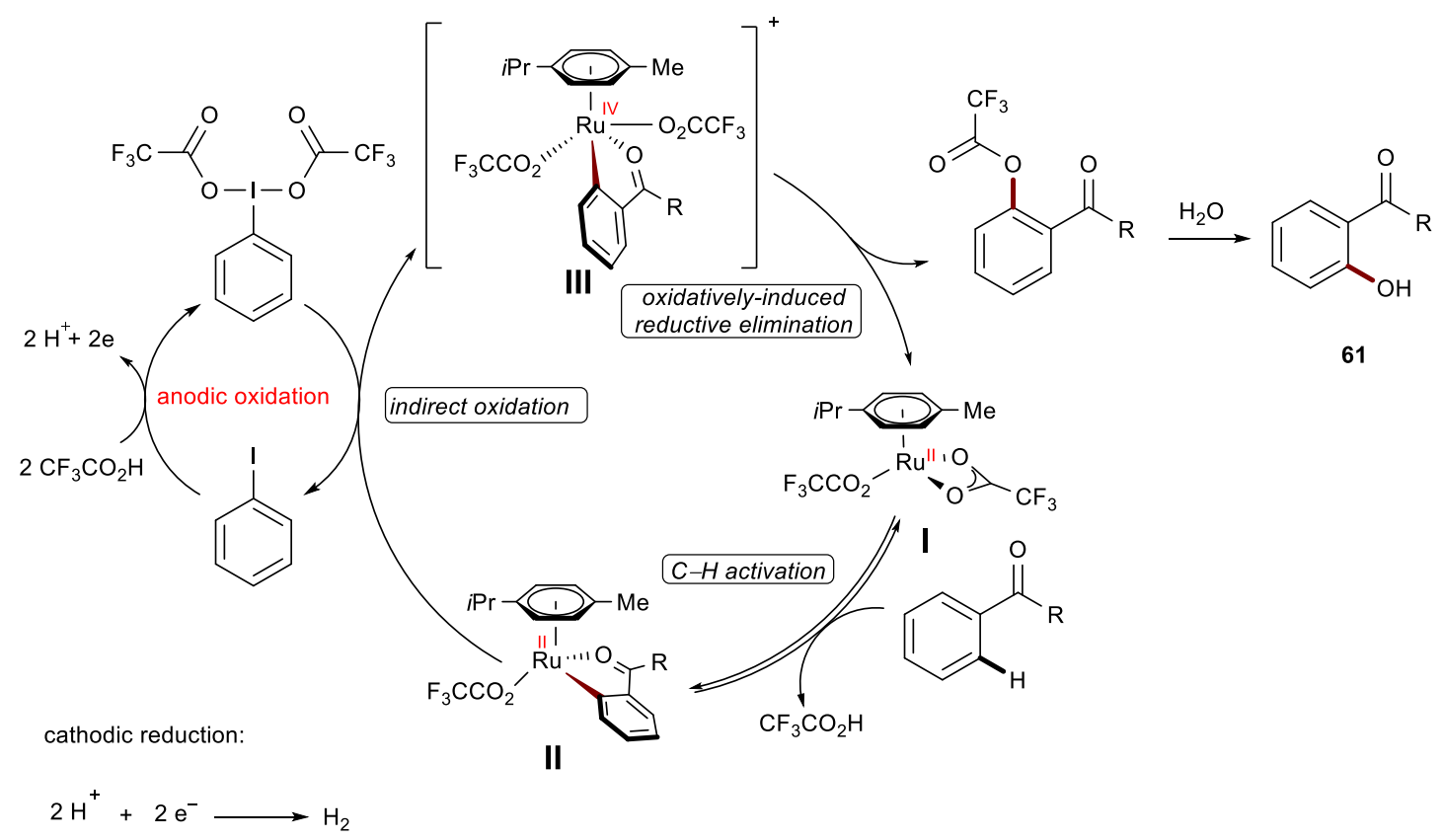

Scheme 1.28. Proposed catalytic cycle for the ruthenaelectro-catalyzed C-H oxygenation.

\subsubsection{Iridaelectro-Oxidative C-H Activation}

Besides ruthenium and rhodium catalysts, $5 d$ transition metal iridium complexes have also been proven as effective cataltsts in $\mathrm{C}-\mathrm{H}$ functionalizations. ${ }^{[119]}$ While the oxidative reaction in this research arena was largely dominated by chemical oxidants, Ackermann made a pioneering contribution to the electrooxidative iridium-catalyzed $\mathrm{C}-\mathrm{H}$ activation with weak O-coordinating benzoic acids 62A (Scheme 1.29a). ${ }^{[120]}$ These $\mathrm{C}-\mathrm{H}$ transformations using $p$-benzoquinone (BQ) as redox mediator presented a high functional-group tolerance, delivering a series of 5membered heterocycles 63A. Very recently, the Mei and Guo groups independently reported this type of electrochemical annulation with alkynes by iridium catalysis (Scheme 1.29d). ${ }^{[121]}$ In 2019, Mei reported the irida-electrochemical vinylic $\mathrm{C}-\mathrm{H}$ alkyne annulation of acrylic acids 62B with alkynes, affording $\alpha$-pyrones 63B with good to excellent yields. In this case, preliminary mechanistic studies show that the anodic oxidation was crucial for releasing the product 63B and regeneration of the active iridium(III) catalyst (Scheme 1.29b). ${ }^{[122]}$

In 2020, the Shi and Xie groups developed an electrochemical approach in promoting directed $\mathrm{C}-\mathrm{H}$ alkynylation with terminal alkyne 65 via iridium catalysis. Detailed mechanistic studies in terms of isolation of key iridium(III) intermediates and control experiments suggested an oxidatively-induced reductive elimination, giving the desired aromatic alkynes $63 \mathrm{C}$ in good yields without the addition of external oxidants (Scheme 1.29c). ${ }^{[123]}$ 
a) Ackermann, 2018<smiles>O=C(O[OH2+])c1ccccc1</smiles>

62A

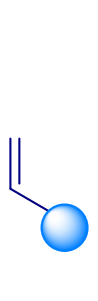

49
$\mathrm{RVC} \overbrace{}^{\circ} \mathrm{Pt}$

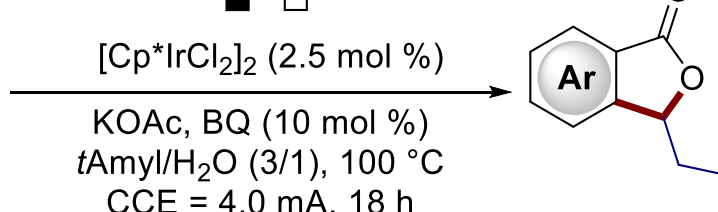

63A

$\mathrm{CE}=4.0 \mathrm{~mA}, 18 \mathrm{~h}$

undivided cell

b) Mei, 2019

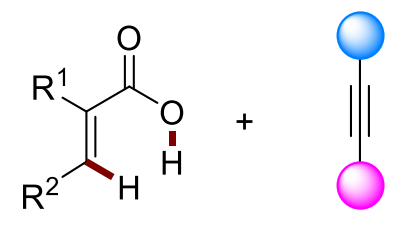

$\mathrm{Pt}$

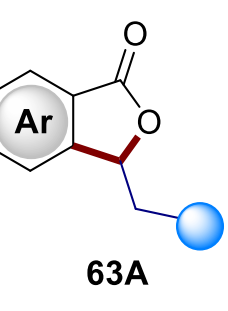

64
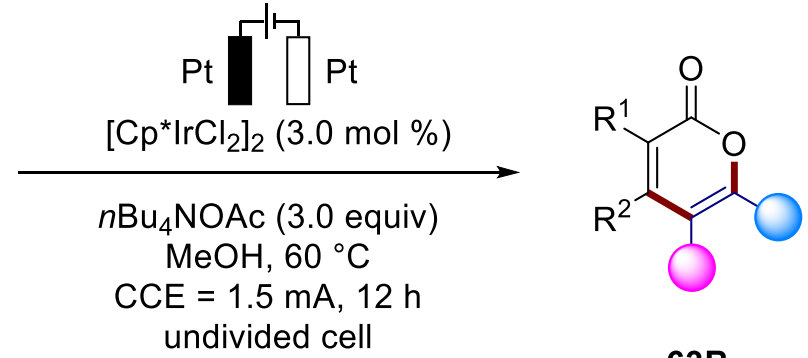

undivided cell

c) Xie/Shi, 2020<smiles>[R1]N=C([R])c1ccccc1</smiles>

62C

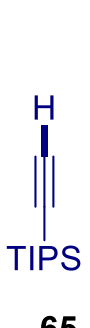

65

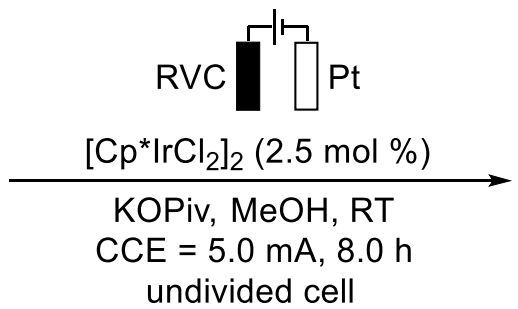

undivided cell

d) Mei/Guo, 2021<smiles>O=C(O[OH2+])c1ccccc1</smiles>

$62 A$

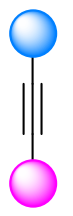

64

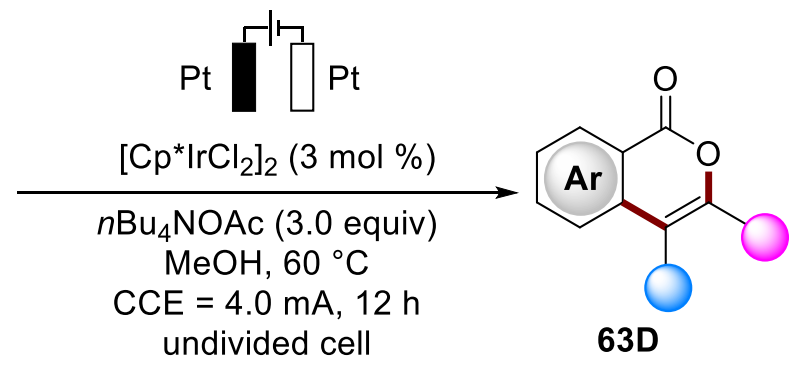

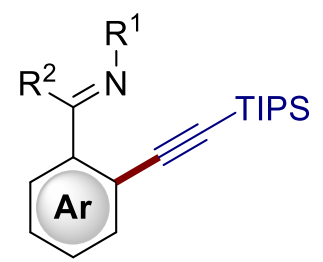

$63 \mathrm{C}$

Scheme 1.29. Irida-electrooxidative $\mathrm{C}-\mathrm{H} / \mathrm{O}-\mathrm{H}$ annulation.

\subsubsection{Cobaltaelectro-Oxidative C-H Activation}

The merger of $\mathrm{C}-\mathrm{H}$ activation and electrochemistry set the stage to establish new reactivities with high levels of resource economy. Despite indisputable advances in electrocatalytic organometallic $\mathrm{C}-\mathrm{H}$ activations with the precious $4 \mathrm{~d}$ and $5 \mathrm{~d}$ transition metals, the development of less toxic, cost-effective and the sustainable nature of Earth-abundant $3 \mathrm{~d}$ metals in the electrosynthesis is a more environmentally-benign and economically-attractive alternative.

In 2017, the Ackermann group reported the first $3 \mathrm{~d}$ metallaelectro-catalysis for $\mathrm{C}-\mathrm{H}$ activation 
with cobalt catalysts. This proof of concept study realized the direct $\mathrm{C}-\mathrm{H}$ oxygenation of aryl and alkenyl amides 66 with inexpensive and Earth-abundant $\mathrm{Co}(\mathrm{OAc})_{2} \cdot 4 \mathrm{H}_{2} \mathrm{O}$ as the catalyst (Scheme 1.30). ${ }^{[124]}$ Based on detailed experimental studies, including the full characterization of key cyclometalated intermediates of cobaltaelectro-catalyzed $\mathrm{C}-\mathrm{H}$ activation, Ackermann proposed a plausible reaction pathway by involving a Co(III/IV/II) manifold. ${ }^{[125]}$

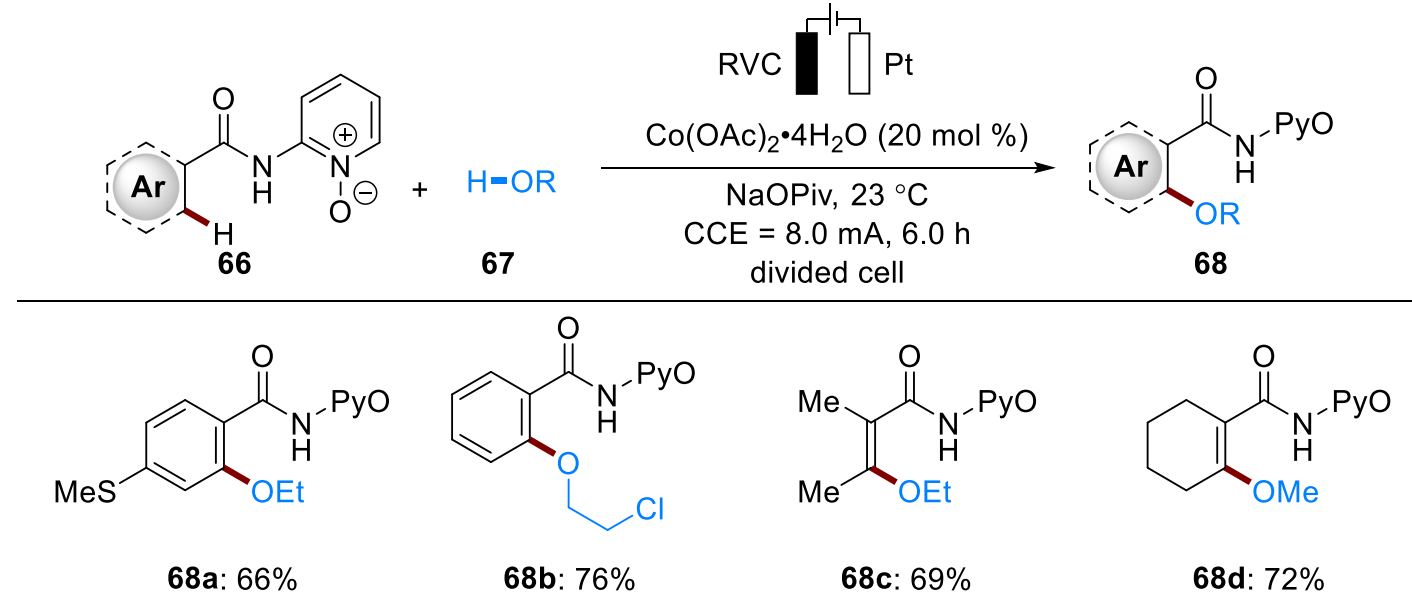

Scheme 1.30. Cobalta-electrooxidative aryl and vinylic $\mathrm{C}-\mathrm{H}$ oxygenation.

The cobaltaelectro-catalyzed $\mathrm{C}-\mathrm{H}$ activation was not limited to $\mathrm{C}-\mathrm{O}$ bond formations. Thus, Ackermann and Lei established an intermolecular $\mathrm{C}-\mathrm{H}$ amination protocol under mild reaction conditions with different directing groups ( $\mathrm{N}, \mathrm{O}$ - or $\mathrm{N}, \mathrm{N}$-coordinating auxiliaries) for the $\mathrm{C}-\mathrm{Het}$ formation (Scheme 1.31a,b). ${ }^{[126]}$ Thereafter, Ackermann described a cobalt-catalyzed C-O bond formation for the electrochemically promoted $\mathrm{C}-\mathrm{H}$ acyloxylations (Scheme 1.31e). ${ }^{[127]}$ Moreover, cobalta-electrocatalysis was extremely effective for the $\mathrm{C}-\mathrm{H} / \mathrm{N}-\mathrm{H}$ annulation of arene and olefin derivatives with alkynes, ${ }^{[128]}$ alkenes, ${ }^{[129]}$ allenes, ${ }^{[130]}$ carbon monoxide or isocyanides ${ }^{[131]}$ to generate biorelevant heterocycles (Scheme 1.31c,d,f-j). More recently, the robust and versatile cobalt catalysis also enabled the electrochemical $\mathrm{C}-\mathrm{H}$ allylation with non-actived alkenes in the biomass-derived solvent $\gamma$-valerolactone, generating allylated benzamides with high levels of functional group tolerance and regioselectivity (Scheme 1.31k). ${ }^{[132]}$ 


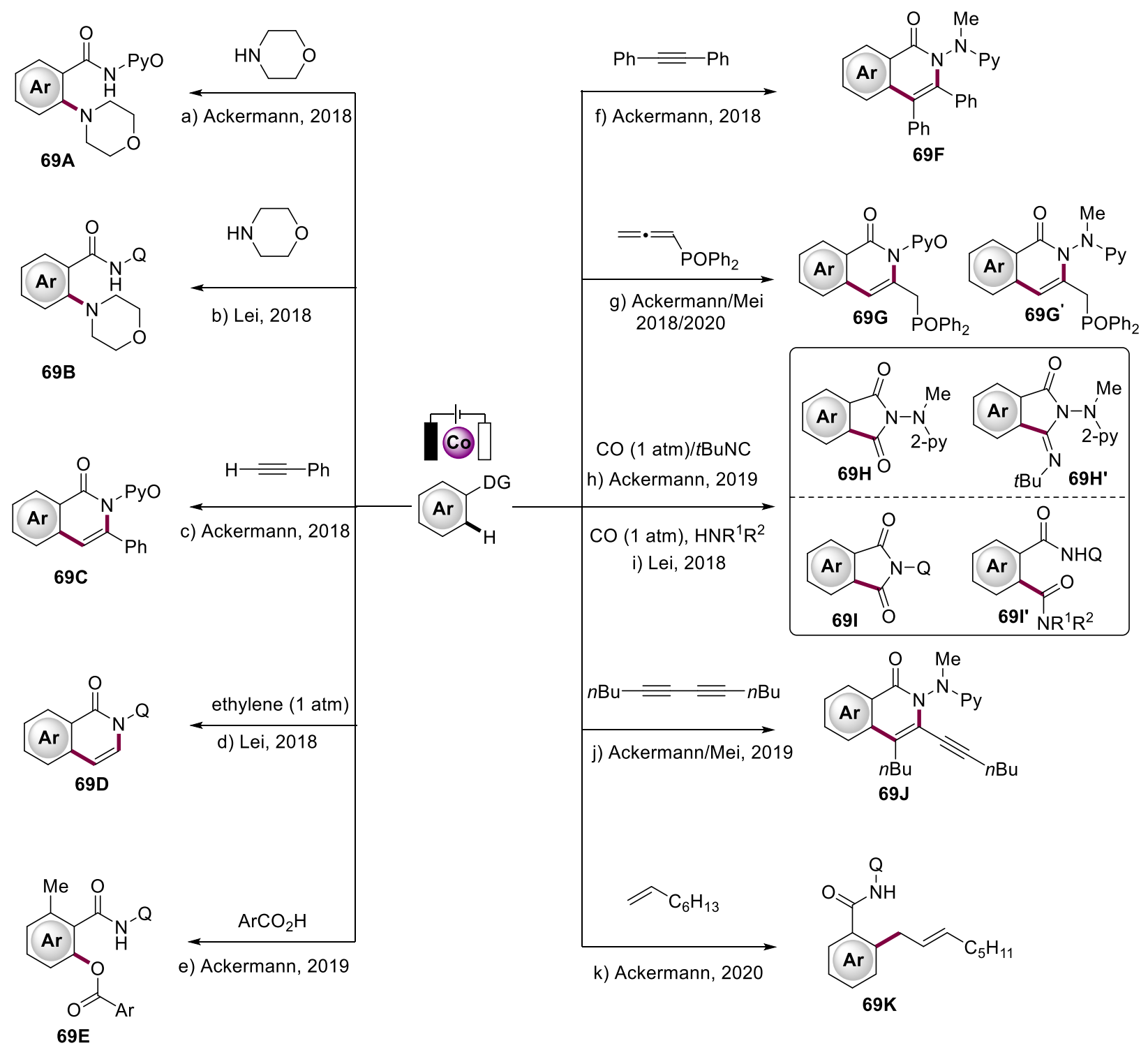

Scheme 1.31. Cobalta-electrooxidative $\mathrm{C}-\mathrm{H}$ activation.

\subsubsection{Nickellaelectro-Oxidative C-H Activation}

Regarding its Earth-abundance, economical reliability and reactivities, nickel is often considered to be an potential alternative to expensive palladium catalysts. For this reason, a plethora of $\mathrm{C}-$ $\mathrm{H}$ activations have been achieved by utilizing nickel catalysis. ${ }^{[133]}$ Despite this indisputable progress, nickella-electrochemical $\mathrm{C}-\mathrm{H}$ activation remained elusive until recently.

In 2018, the Ackermann group reported the first example of nickella-electrooxidative $\mathrm{C}-\mathrm{H}$ aminations with ample scope and high levels of chemo- and position-selectivity (Scheme 1.32a). ${ }^{[134]}$ In contrast to previous metal-catalyzed electrochemical $\mathrm{C}-\mathrm{H}$ activations, this nickel 
electrosynthesis proved particularly potent in the $\mathrm{C}-\mathrm{H}$ amination 72A of electron-deficient arenes 70A. Afterwards, the same group developed nickella-electrocatalyzed alkoxylations ${ }^{[135]} \mathbf{7 2 B}$ with challenging secondary alcohols 71B and phosphorylations 72C (Scheme 1.32b,c). ${ }^{[136]}$ Detailed mechanistic studies provided strong support for a nickel(III/IV/II) manifold for these transformations.

a) Ackermann, 2018

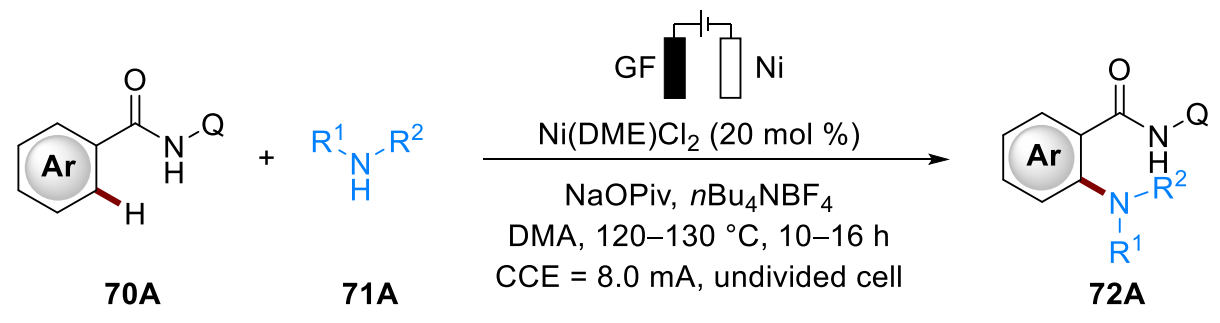

b) Ackermann, 2020

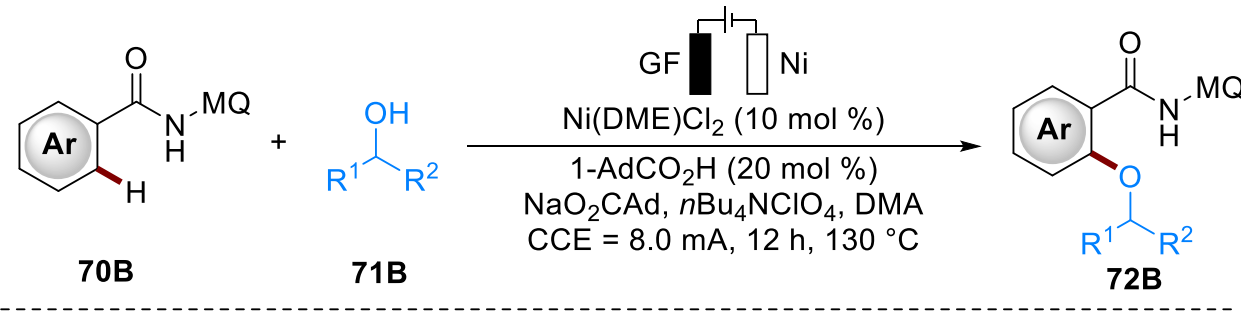

c) Ackermann, 2021

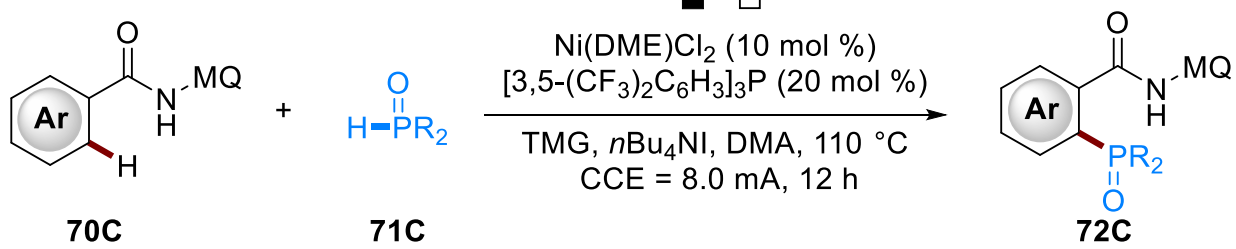

Scheme 1.32. Nickella-electrooxidative $\mathrm{C}-\mathrm{H}$ aminations.

\subsubsection{Cupraelectro-Oxidative C-H Activation}

Recently, the Mei group successfully highlighted the efficiency of copper catalysis ${ }^{[137]}$ in electrochemical $\mathrm{C}-\mathrm{H}$ functionalizations (Scheme 1.33a). ${ }^{[138]}$ Here, they employed catalytic amounts of $\mathrm{Cu}(\mathrm{OTf})_{2}$ and $n-\mathrm{Bu}_{4} \mathrm{NI}$ as the redox mediator to facilitate the ortho-selective $\mathrm{C}-\mathrm{H}$ amination of aryl amines 73A bearing the picolinamide (PA) directing group. The detailed experimental studies suggested a single electron transfer (SET) and a high valent copper(III) species to be involved in the reaction mechanism. In a subsequent report, a redox mediator-free condition was applied by Nicholls for the cupraelectro-oxidative $\mathrm{C}-\mathrm{H}$ amination of benzamides 
73B with $A Q$ as a directing group (Scheme 1.33b). ${ }^{[139]}$ The synthetic utility of this protocol was well explored for various amines containing active pharmaceutical ingredients.

The copper electrocatalysis was not restricted to $\mathrm{C}-\mathrm{H}$ aminations. Indeed, the Ackermann group revealed a first example of cupraelectro-catalyzed $\mathrm{C}-\mathrm{H} / \mathrm{N}-\mathrm{H}$ alkyne annulation with electricity as the terminal oxidant to provide the bioactive five-membered isoindolones $74 \mathrm{C}$ in both a dehydrogenative and decarboxylative manner (Scheme 1.33c). ${ }^{[140]}$

a) Mei, 2018

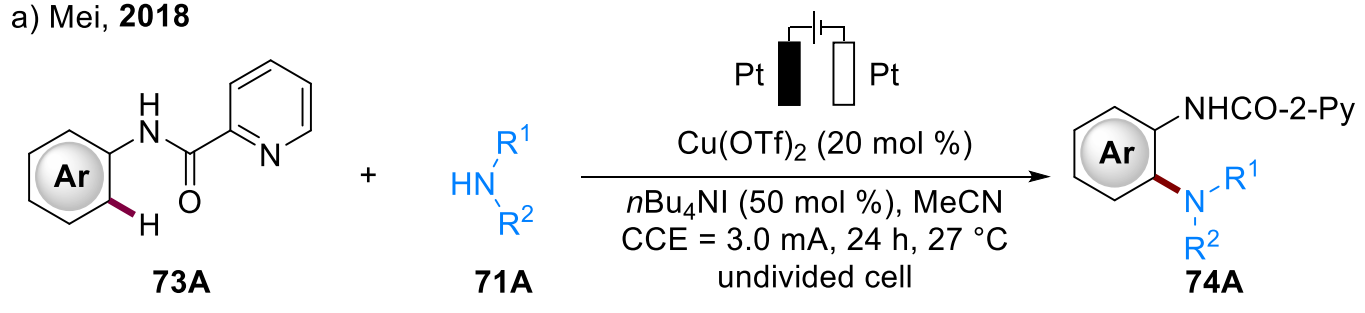

b) Nicholls, 2019

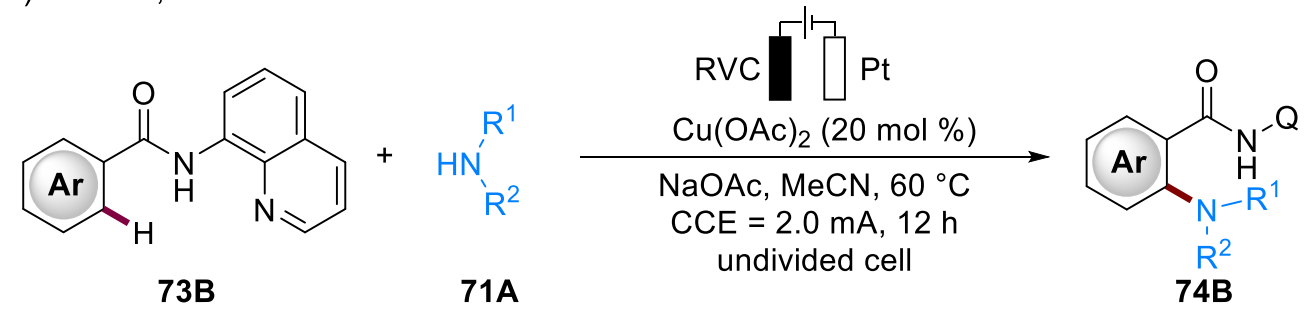

c) Ackermann, 2019

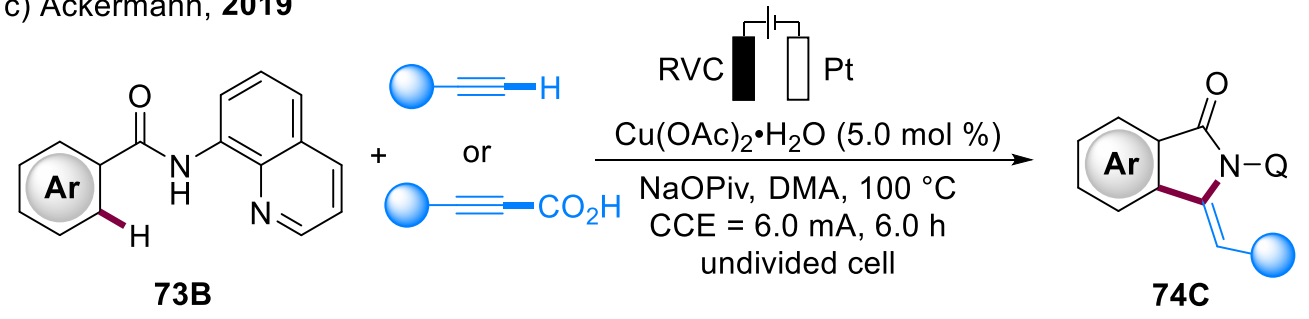

Scheme 1.33. Cupraelectro-oxidative $\mathrm{C}-\mathrm{H}$ activation.

\subsubsection{Ferraelectro-Oxidative C-H Activation}

Due to growing interest in chemical utilization of less toxic, natural Earth-abundance and costeffective metal catalysts, iron catalysis has become a rapidly increasing research area for sustainable molecular syntheses via $\mathrm{C}-\mathrm{H}$ activation. ${ }^{[141]}$ Despite indisputable advances, the ironcatalyzed oxidative $\mathrm{C}-\mathrm{H}$ transformations strongly relied on superstoichiometric amounts of costintensive 1,2-dichloroisobutane (DCIB) as the sacrificial oxidant, thereby generating stoichiometric amounts of waste. To overcome this major restriction, the Ackermann group 
disclosed the unprecedented ferraelectrocatalytic strategy for oxidative $\mathrm{C}-\mathrm{H}$ arylation with Grignard reagent 76 for the synthesis of biaryls 77 (Scheme 1.34). ${ }^{1142]}$ Furthermore, detailed mechanistic studies in terms of experiments and DFT calculations suggested an electrooxidative iron(II/III/I) manifold. [142-143]

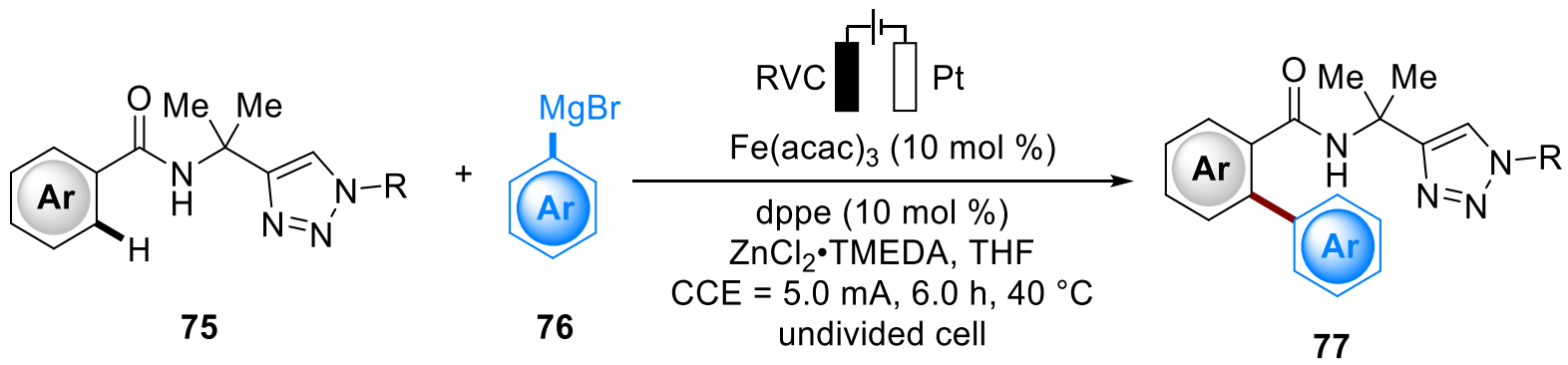

Scheme 1.34. Ferra-electrooxidative $\mathrm{C}-\mathrm{H}$ activation.

\subsubsection{Manganaelectro-Oxidative C-H Activation}

The sustainable electrochemical organometallic $\mathrm{C}-\mathrm{H}$ activation was further investigated in the presence of non-toxic and readily accessible manganese catalysts. As a proof of concept, Ackermann showcased the potential of $\mathrm{MnCl}_{2}$ in combination with electrocatalysis for the transformative $\mathrm{C}-\mathrm{H}$ arylation of picolinic acids in the assistance of zinc salt (Scheme 1.35). ${ }^{[142]}$

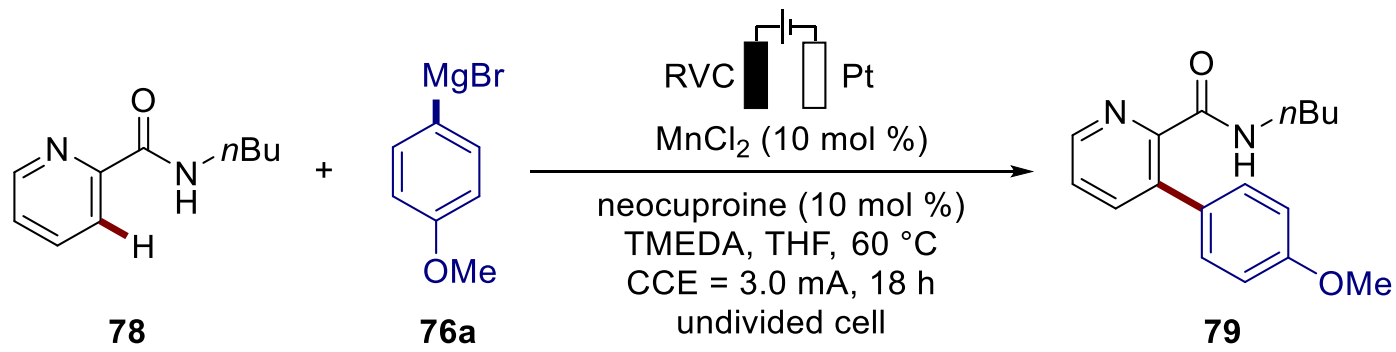

Scheme 1.35. Manganaelectro-oxidative $\mathrm{C}-\mathrm{H}$ arylation.

\subsection{Transition Metal Catalyzed B-H Cage Activation of o-Carborane}

Carboranes, polyhedral boron-carbon molecular clusters, have one or more of the $\mathrm{BH}$ vertices replaced by $\mathrm{CH}$ units (Scheme 1.36). ${ }^{[144]}$ Among them, icosohedral 1,2-dicarba-closododecaborane $\left(0-\mathrm{C}_{2} \mathrm{~B}_{10} \mathrm{H}_{12}\right)$, which was first reported in $1963,{ }^{[145]}$ has attracted significant attention because of its high symmetry, remarkable stability and subsequent commercial availability. This cluster comprises ten boron atoms and two neighboring carbon atoms, and each atom is hexacoordinated, featuring 26 delocalized electrons over the entire structure of the cluster. $^{[146]}$ Over the past decades, 0 -carboranes have been extensively studied and have found 
wide applications as useful functional building blocks in supramolecular design or nanomaterials, ${ }^{[147]}$ in medicine as boron neutron capture therapy (BNCT) agents or pharmacophores, ${ }^{[148]}$ in organometallic/coordination chemistry ${ }^{[149]}$ and more. Owing to the strongly electron-withdrawing character of the o-carborane unit toward carbon substituents, the $\mathrm{C}-\mathrm{H}$ bonds are weakly acidic in this cage $\left(\mathrm{p} K_{\mathrm{a}}=22.0\right)^{[150]}$ and can be deprotonated with strong bases, such as alkyllithium or Grignard reagents. Thus, a larger number of carbon-substituted $o-$ carboranes have been prepared by the reaction of negatively charged carbon atoms with electrophilic reagents (alkylhalides, carbonyl derivatives, and chlorosilanes). In sharp contrast, selective functionalization of chemically very similar ten $\mathrm{B}-\mathrm{H}$ vertices in $\mathrm{o}$-carboranes is very challenging and less explored. ${ }^{[151]}$

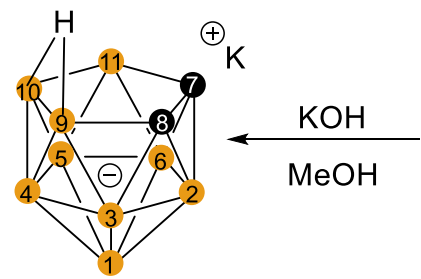

nido-carborane

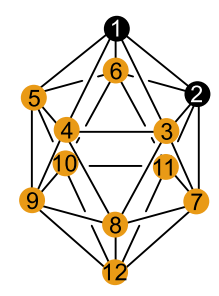

o-carborane

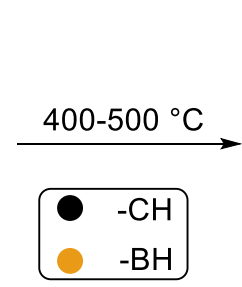

$m$-carborane

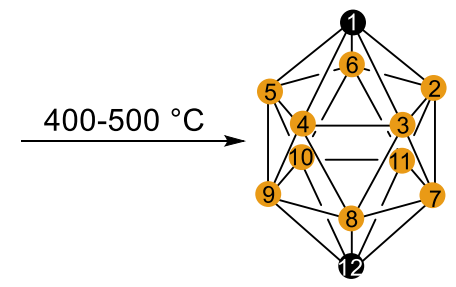

p-carborane

Scheme 1.36. Molecular nido-carborane and geometry of $o-, m$-, $p$-dicarba-closo-dodecarboranes, IUPAC numbering of the cage atoms and their chemical transformations.

Generally, according to differences in electronegativity and the distance between boron and carbon atoms, the $10 \mathrm{~B}-\mathrm{H}$ bonds of $\mathrm{o}$-carboranes have different electron density, leading to the electrophilic substitution reactions of carborane derivatives with the reaction rate $\mathrm{B}(9,12)-\mathrm{H}>$ $\mathrm{B}(8,10)-\mathrm{H}>\mathrm{B}(4,5,7,11)-\mathrm{H}>\mathrm{B}(3,6)-\mathrm{H}$, which also corresponds to the calculated charge distribution on the cage. ${ }^{[152]}$ As charge differences are very small, achieving high regioselectivity in these substitution reactions is usually problematic.

A general strategy for transition metal-catalyzed selective cage $\mathrm{B}-\mathrm{H}$ functionalization of $\mathrm{o}$ carboranes involves three principles: ${ }^{[153]}$ (1) electron-rich transition metal catalysts preferably functionalize the most electron-deficient $\mathrm{B}(3,6)-\mathrm{H}$ bonds, which are bonded to both cage carbons; (2) electrophilic transition metal catalysts would be appropriate for the functionalization of electron-rich $\mathrm{B}(8,9,10,12)-\mathrm{H}$ bonds (not bonded to any cage carbons); and (3) employing directing group with electrophilic transition metal catalysts is essential for $\mathrm{B}(4,5,7,11)-\mathrm{H}$ functionalization proximal to only one cage carbon (Scheme 1.37). 
a) $\mathrm{B}(3,6)-\mathrm{H}$

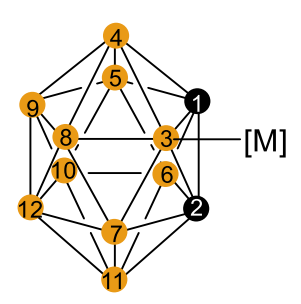

oxidative addition b) $\mathrm{B}(4,5,7,11)-\mathrm{H}$

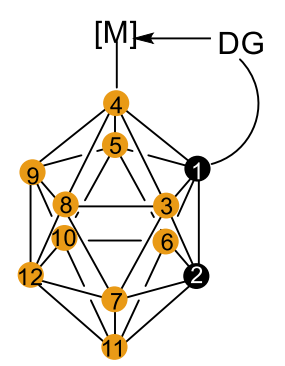

Directing-Group-assisted electrophilic substitution c) $\mathrm{B}(8,9,10,12)-\mathrm{H}$

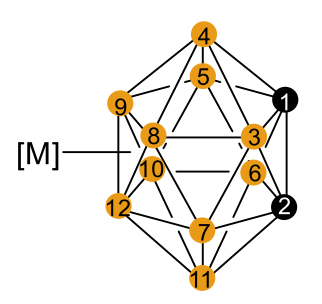

electrophilic substitution

Scheme 1.37. General strategy for catalytic selective cage B-H functionalization.

\subsubsection{Transition Metal-Catalyzed Cage B(3,6)-H Functionalization}

In 1977 , a transition metal-catalyzed cage $\mathrm{B}(3,6)-\mathrm{H}$ deuteration of 0 -carborane $\mathbf{8 0}$ with $\mathrm{D}_{2}$ was described by Hawthorne. ${ }^{[154]}$ In 1988 , Sneddon developed $\left[\mathrm{Cp}^{*} \mid \mathrm{rCl}_{2}\right]_{2} /$ Proton Sponge catalyst system for the selective cage $\mathrm{B}(3)-\mathrm{H}$ propenylation of o-carborane with propyne 81 (Scheme 1.38). ${ }^{[155]}$ A plausible catalytic cycle is proposed in Scheme 1.38, which commences with a reduction of complex $\left[\mathrm{Cp}^{*} \mid \mathrm{rCl}_{2}\right]_{2}$ to the active iridium(I) species under the reaction conditions. Subsequently, oxidative addition of the most electron-deficient cage $\mathrm{B}(3)-\mathrm{H}$ with the iridium(l) species generates the $\mathrm{B}(3)-\mathrm{Ir}$ intermediate $\mathrm{I}$. Thereafter, propyne $\mathbf{8 1}$ insertion followed by reductive elimination affords the desired product $\mathbf{8 2}$ and regenerates the active iridium(I) catalyst. Although only propyne was examined with low reaction efficacy, this example indicated the feasibility of transition metal-catalyzed selective cage B-H functionalization of $o$-carboranes. 


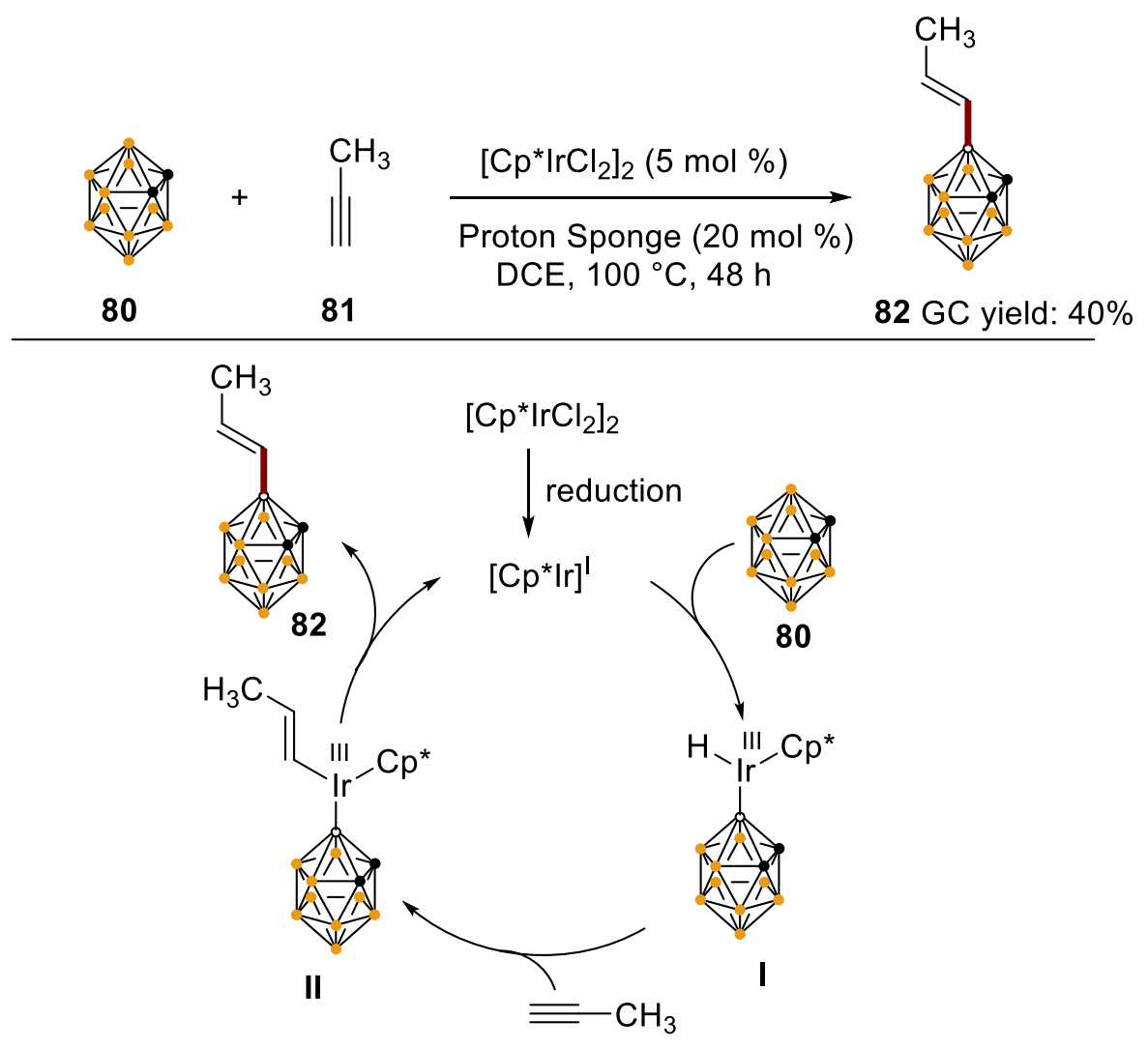

Proton Sponge: 1,8-bis(dimethylamino)naphthalene

Scheme 1.38. Irridium-catalyzed cage B(3)-propenylation of 0 -carborane.

In 2017, the Xie group disclosed an efficient iridium-catalyzed selective cage $B(3,6)$-diborylation of 0 -carboranes with $\mathrm{B}_{2} \mathrm{pin}_{2}$ as coupling partner in THF at $110{ }^{\circ} \mathrm{C}$ for $5 \mathrm{~h}$, affording $\mathrm{B}(3,6)$ diborylated $\mathrm{o}$-carboranes $\mathbf{8 3} \mathbf{A}^{\prime}$ in high yields (Scheme 1.39a).. ${ }^{[156]}$ Later, a pyridyl-assisted rhodium-catalyzed selective B(3)-acyloxylation of o-carboranes and a palladium-catalyzed intramolecular $\mathrm{B}-\mathrm{H} / \mathrm{O}-\mathrm{H}$ dehydrogenative coupling reaction were reported by $\mathrm{Yan}^{[157]}$ and $\mathrm{Xie}^{[158]}$ respectively (Scheme 1.39b,c). In addition, $\mathrm{Pd} / \mathrm{NHC}(\mathrm{NHC}=\mathrm{N}$-heterocyclic carbene) catalyzed cage $\mathrm{B}(3,6)$-arylation of $O$-carboranes was achieved by Cao (Scheme 1.39d). ${ }^{[159]}$ Concurrently, another phosphine-directed rhodium-catalyzed $\mathrm{B}(3,6)$-diarylation of 1-PAr-o-carboranes with aryl bromides was reported by Chi, ${ }^{[160]}$ offering a series of $\mathrm{B}(3,6)$-diarylated o-carboranes 83D (Scheme 1.39d). Inspired by the Sneddon's work, ${ }^{[155]}$ Xie recently described iridium-catalyzed cage $\mathrm{B}(3,6)$-alkenylation of $o$-carboranes (Scheme 1.39e). ${ }^{[161]} \mathrm{A}$ plausible mechanism involving a $\operatorname{Ir}(\mathrm{III} / \mathrm{V} / \mathrm{III})$ pathway is proposed for this cage $\mathrm{B}(3,6)$-alkenylation. Thereafter, the same group revealed a palladium-catalyzed B(3)-oxidative annulation of 1-hydroxy-o-carborane with internal alkynes, leading to facile synthesis of a class of 0 -carborane-fused oxaboroles $83 \mathrm{~F}$ in moderate yields (Scheme 1.39f). ${ }^{[162]}$ 


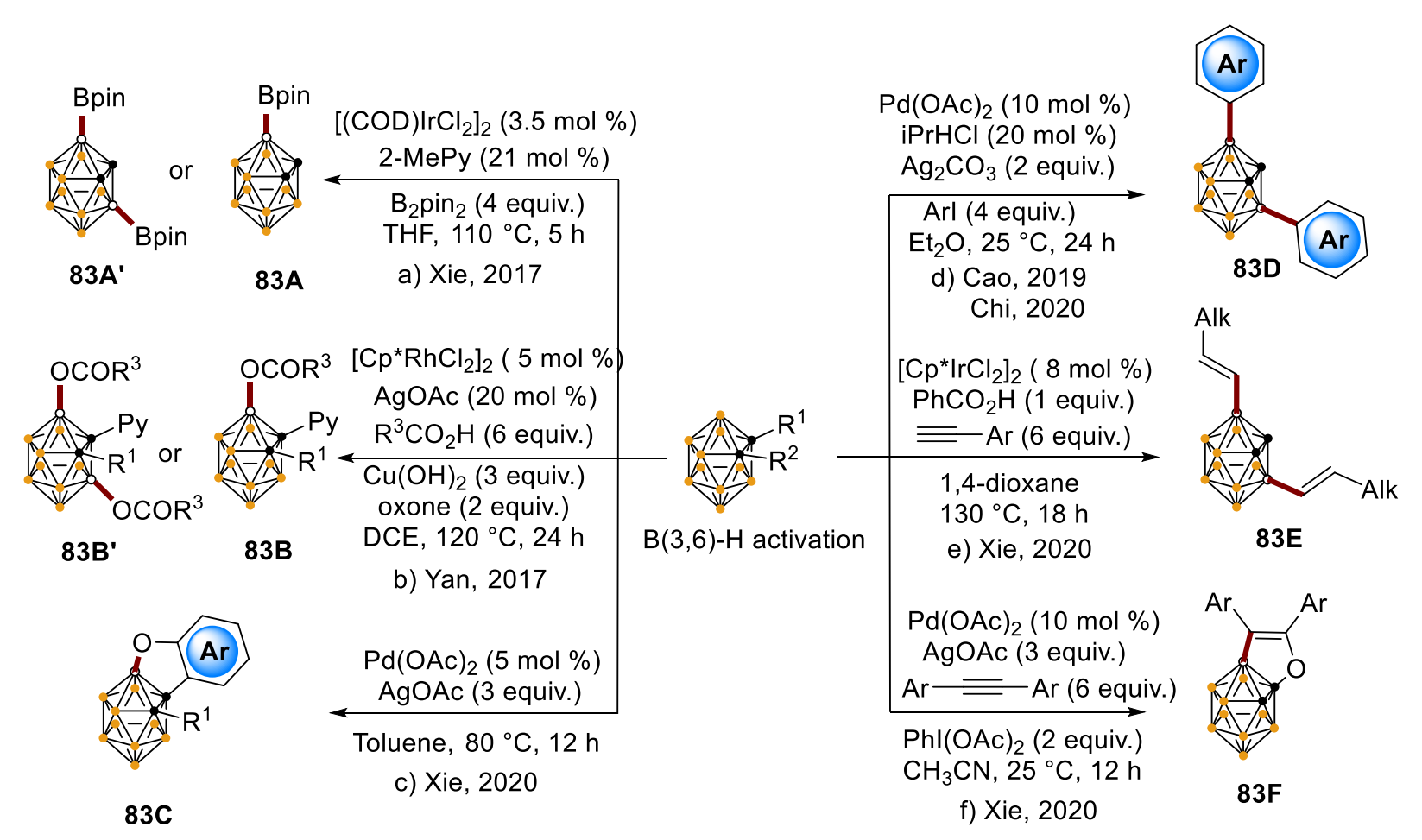

Scheme 1.39. Cage $\mathrm{B}(3,6)-\mathrm{H}$ functionalization of $o$-carboranes.

\subsubsection{Transition Metal-Catalyzed Cage $B(4,5,7,11)-H$ Functionalization}

A general strategy to realize the cage $\mathrm{B}(4,5,7,11)-\mathrm{H}$ functionalization is introduction of the directing group on one of the cage carbon vertices.

In 2014, Xie disclosed an irridium-catalyzed B(4)-alkenylation of o-carboranes by employing a carboxylic acid as the traceless directing group at the cage carbon vertex, generating a range of $\mathrm{B}(4)$-alkenylated 0 -carboranes 85 in high yield with excellent regioselectivity. ${ }^{[163]}$ A plausible catalytic cycle is proposed involving a cage $\mathrm{B}(4)-\mathrm{H}$ activation, followed by alkyne insertion, protonation and decarboxylation give the final products 85 (Scheme 1.40a). Later, the same group extended this research to $\mathrm{B}(4,5)$-dialkenylation through palladium catalysis (Scheme 1.40b). ${ }^{[164]}$ Applying a similar methodology, the Lu group synthesized a series of $B(4)$ - and $\mathrm{B}(4,5)$-substituted 0 -carboranes (87A and 87A') containing $\alpha, \beta$-unsaturated carbonyls in moderate to good yields by employing $\operatorname{Pd}\left(\right.$ TFA) as the catalyst (Scheme 1.40c). ${ }^{[165]}$ 
a) Cage $\mathrm{B}(4,5)-\mathrm{H}$ alkenylation (Xie, 2014)

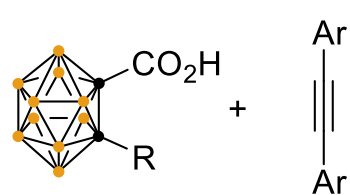

84

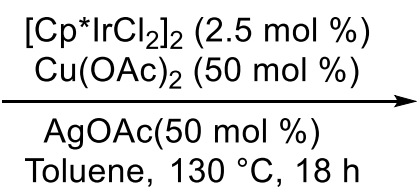

Toluene, $130{ }^{\circ} \mathrm{C}, 18 \mathrm{~h}$

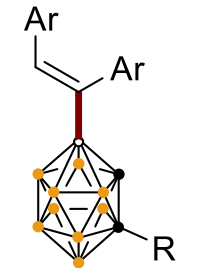

85

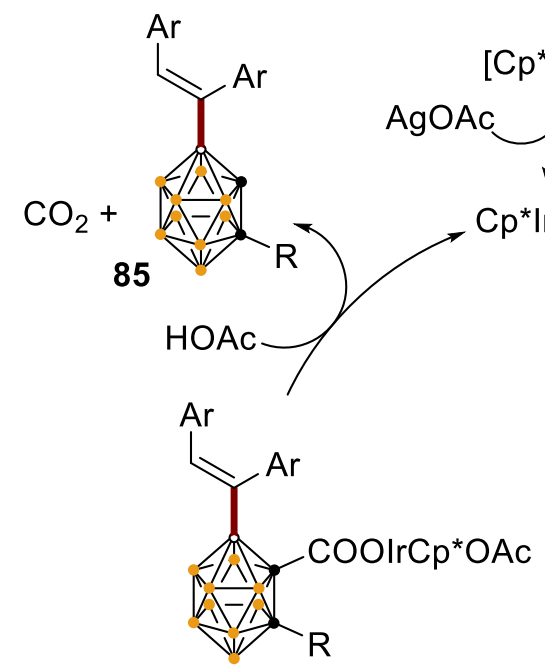

III

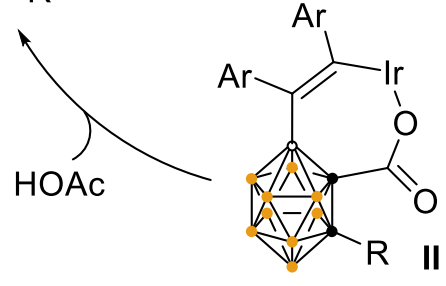
$\searrow_{\text {HOAc }} 84$

b) Cage $\mathrm{B}(4,5)-\mathrm{H}$ dialkenylation (Xie, 2015)
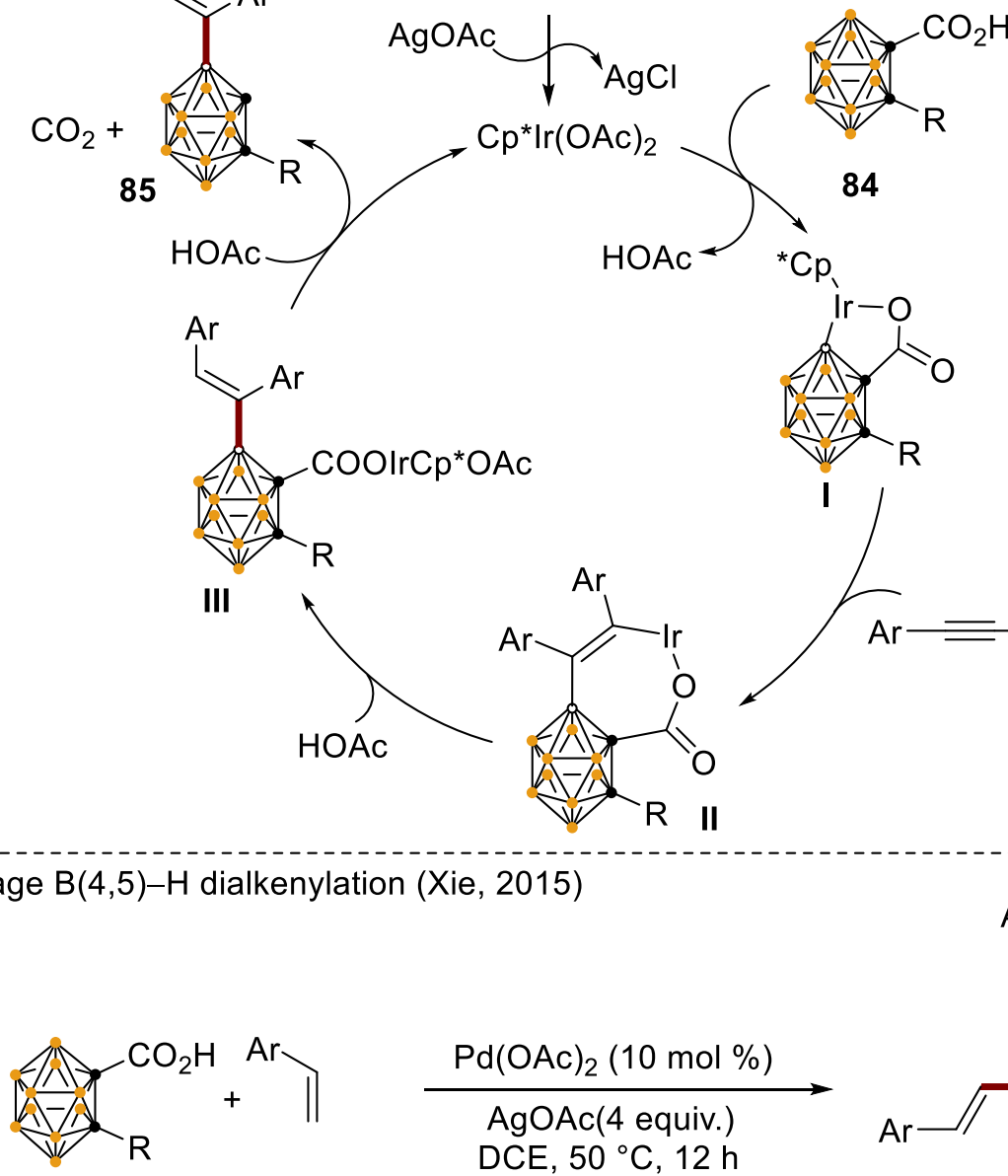

84

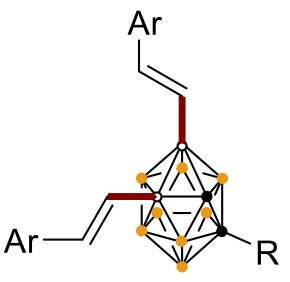

c) Cage $\mathrm{B}(4,5)-\mathrm{H}$ alkenylation ( $\mathrm{Lu}, 2020)$

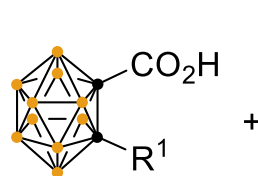

84<smiles>[R]C(=O)C=C</smiles>

$\underset{\operatorname{Pd}(\mathrm{TFA})_{2}(10 \mathrm{~mol} \%)}{\operatorname{AgOAc}(4 \text { equiv. })}$ DCE, $70^{\circ} \mathrm{C}, 18 \mathrm{~h}$

86

$86-1-1$


annulation of 1-hydroxyl-o-carboranes 88 with internal alkynes 64 and CO (Scheme 1.41a). ${ }^{[166]}$ This protocol provided a new class of C,B-substituted carborano-coumarin derivatives 89 with potential applications to pharmaceuticals in moderate to good yields. Although most selective cage $\mathrm{B}-\mathrm{H}$ functionalizations of $\mathrm{o}$-carboranes were catalyzed by noble transition metal catalysts, Xie established the unprecedented copper-catalyzed regioselective cage B-H alkyne annulation of carboranyl amides $\mathbf{9 0}$ with internal alkynes in the presence of a bidentate directing group at the cage carbon position, affording previously inaccessible C,B-substituted o-carborane-fusedpyridone derivatives 91 (Scheme 1.41b). ${ }^{[167]}$ Likewise, terminal alkynes led to dehydrogenative $\mathrm{B}-\mathrm{H} / \mathrm{C}-\mathrm{H}$ alkynation. The copper(I) complex 92 was isolated, which underwent protonation with concentrated hydrochloric acid to afford the B(4)-alkynylated compounds 93.

a) Cage B(4)-H carbonylative annulation (Xie, 2020)
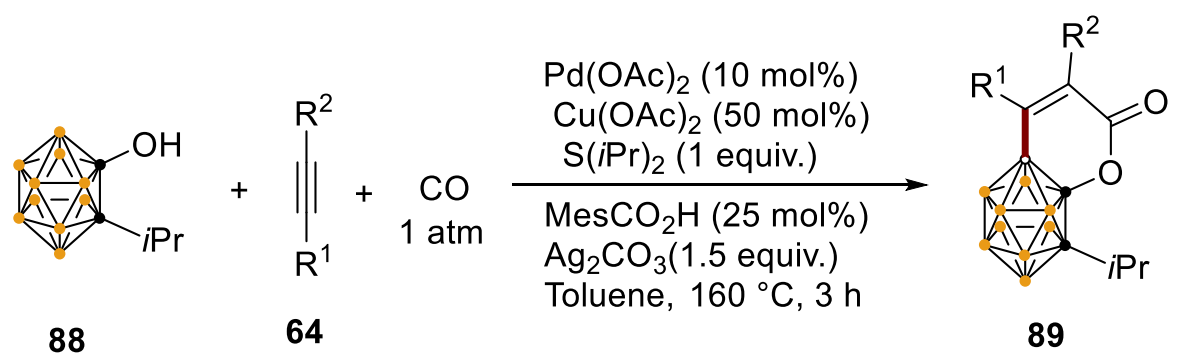

89

b) Cage B(4)-H alkyne annulation (Xie, 2019)
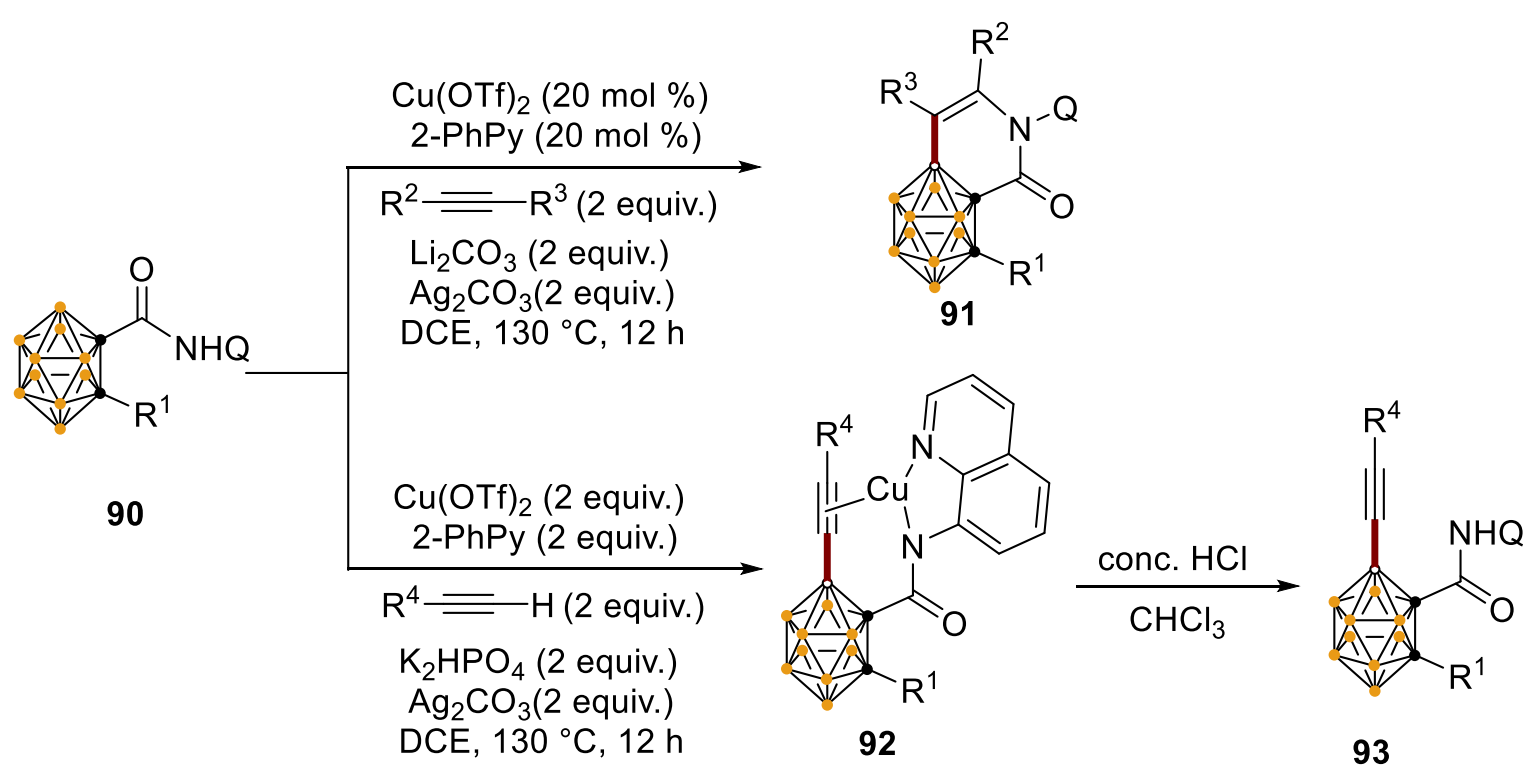

Scheme 1.41. Cage B(4)-H annulation of 0 -carboranes

In 2016, palladium-catalyzed cage $\mathrm{B}(4,5)$-diarylation was accomplished by the treatment of carboranyl carboxylic acids $\mathbf{8 4}$ with aryl iodides (Scheme 1.42a). ${ }^{[168]}$ Moreover, using glycine or 
glyoxylic acid as a transient directing group for palladium-catalyzed $\mathrm{B}(4)$-arylation or $\mathrm{B}(4,5)$ diarylation of carboranyl aldehydes 95 or methylamines 97 was also reported by Yan (Scheme $1.42 b) .{ }^{[169]}$ Meantime, with the assistance of an acyl amino directing group at the cage $B(9)$ position 99, palladium-catalyzed regioselective $\mathrm{B}(4)$-arylation of o-carboranes with aryl boronic acids was achieved by Cao in 2018 (Scheme 1.42c). ${ }^{[170]}$ Importantly, a proof-of-principle study of palladium-catalyzed enantioselective intramolecular $\mathrm{B}-\mathrm{H}$ arylation of $\mathrm{O}$-carboranes 101 was first introduced by Xie in the presence of chiral phosphine ligand L1 (Scheme 1.42d). ${ }^{[171]}$

a) Cage $\mathrm{B}(4,5)-\mathrm{H}$ diarylation (Xie, 2016)

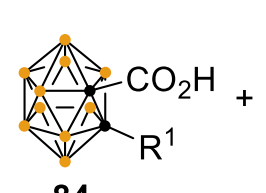

Arl
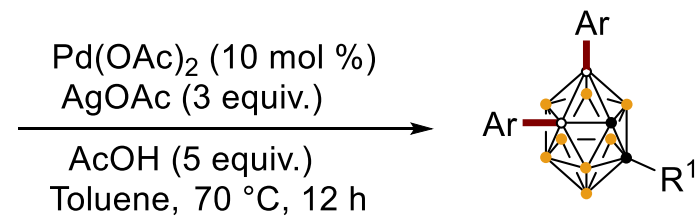

84

94

b) Cage $B(4,5)-H$ arylation by transient DG (Yan, 2017/2018)

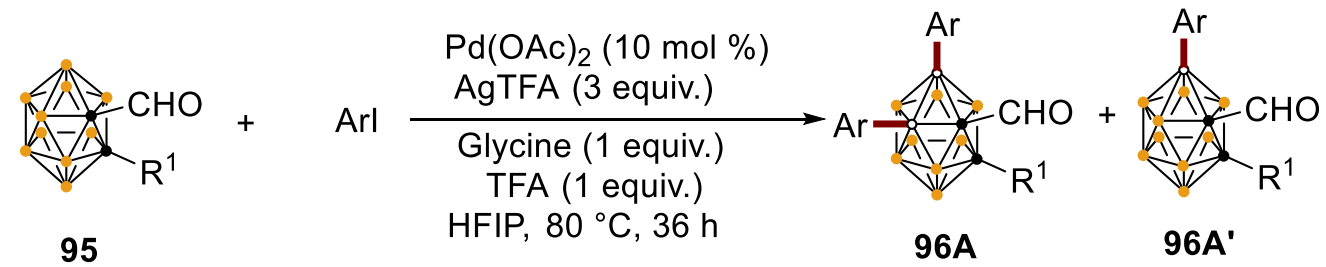

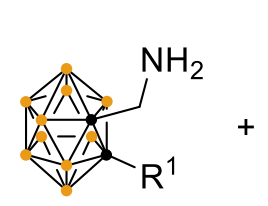

97

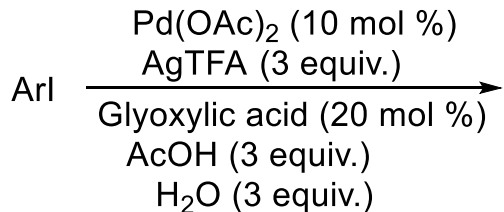

$\mathrm{H}_{2} \mathrm{O}$ (3 equiv.)

HFIP, $80^{\circ} \mathrm{C}, 12 \mathrm{~h}$

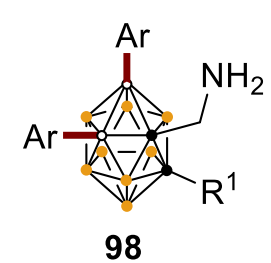

c) Cage $\mathrm{B}(4)-\mathrm{H}$ arylation (Cao, 2018)<smiles>[R]C(=O)NC12C3C4C5C3C1C5C42</smiles>

99
$\mathrm{Pd}(\mathrm{MeCN})_{4}\left(\mathrm{BF}_{4}\right)_{2}(10 \mathrm{~mol} \%)$ $\mathrm{Cu}(\mathrm{OAc})_{2}$ (2 equiv.)

$\mathrm{CyCO}_{2} \mathrm{H}$ (1 equiv.)

$\mathrm{THF}, 40^{\circ} \mathrm{C}, 24 \mathrm{~h}$

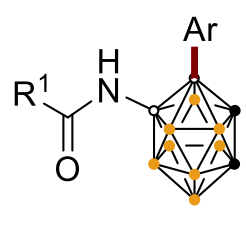

100 
d) Cage $\mathrm{B}(4)-\mathrm{H}$ enantioselective arylation (Xie, 2018)

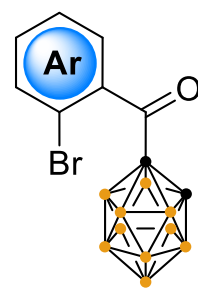

101

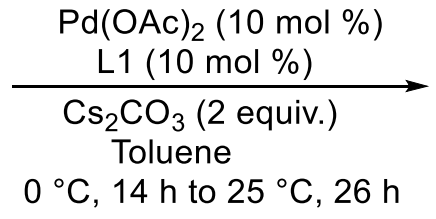

$0{ }^{\circ} \mathrm{C}, 14 \mathrm{~h}$ to $25^{\circ} \mathrm{C}, 26 \mathrm{~h}$

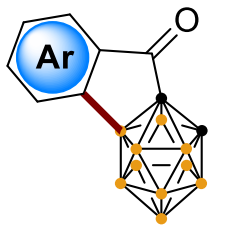

102

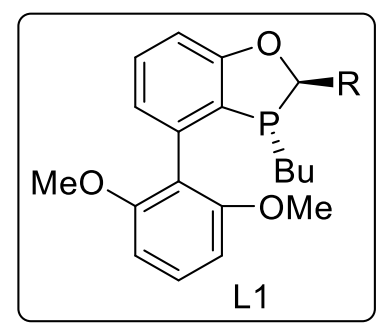

\section{$\mathrm{L} 1$}

Scheme 1.42. Cage $\mathrm{B}(4,5)-\mathrm{H}$ arylation of $\mathrm{o}$-carboranes

In the aforementioned aryl coupling reactions, aryl iodides were employed. In 2017, another protocol with atom- and step-economical cross-dehydrogenative coupling of carboranyl carboxylic acids 84 with thiophenes was developed in the presence of an iridium catalyst, affording B(4)-thienylated o-carboranes 104 in moderate to high yields (Scheme 1.43a). ${ }^{[172]}$ Afterwards, this dehydrogenative coupling reaction of 0 -carboranes was extended to (hetero)aryls using a double directing groups strategy. In the presence of iridium(III) catalyst, carboranyl carboxylic acids $\mathbf{8 4}$ reacted with (hetero)arenes 105 to provide the corresponding $\mathrm{B}(4)-\mathrm{C}\left(\mathrm{sp}^{2}\right)$ coupling products 106 in high yields (Scheme 1.43b). ${ }^{[173]}$

a) Cage $\mathrm{B}(4)-\mathrm{H} / \mathrm{C}-\mathrm{H}$ dehydrogenative arylation (Xie, 2017)

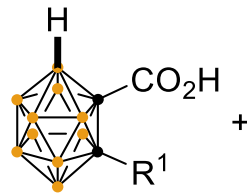

84

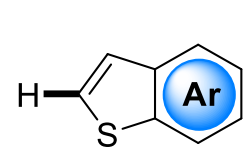

103
$[\mathrm{Cp} * \mathrm{rCl}]_{2}(5 \mathrm{~mol} \%)$ $\mathrm{AgNTf}_{2}(10 \mathrm{~mol} \%)$

$\mathrm{AgOAc}(10 \mathrm{~mol} \%)$ $\mathrm{Li}_{2} \mathrm{CO}_{3}$ (2 equiv.) $\mathrm{Cu}(\mathrm{OAc})_{2}$ (3 equiv.) Toluene, $130{ }^{\circ} \mathrm{C}, 24 \mathrm{~h}$

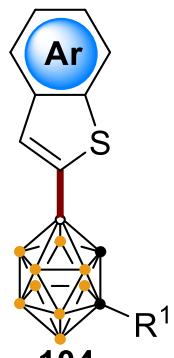

104

b) Cage $\mathrm{B}(4)-\mathrm{H} / \mathrm{C}-\mathrm{H}$ dehydrogenative arylation (Xie, 2020)

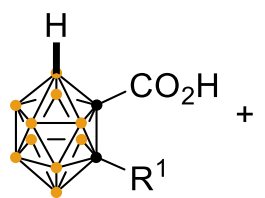

84

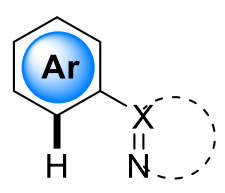

105
$\left[\mathrm{Cp}^{*} \mathrm{IrCl}\right]_{2}(5 \mathrm{~mol} \%)$

$\underset{\operatorname{AgOTf}(10 \mathrm{~mol} \%)}{\operatorname{AgOAc}(10 \mathrm{~mol} \%)}$

$\mathrm{Cu}(\mathrm{OAc})_{2}$ (3 equiv.)

Toluene, $130{ }^{\circ} \mathrm{C}, 12 \mathrm{~h}$

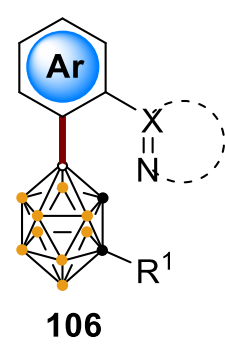

Scheme 1.43. Cage $\mathrm{B}(4)-\mathrm{H} / \mathrm{C}-\mathrm{H}$ dehydrogenative arylation of $\mathrm{o}$-carboranes

In 2016, two protocols for palladium-catalyzed regioselective cage $\mathrm{B}(4)$-alkynylation of $o$ carboranes were established by treatment of carboranyl carboxylic acids $\mathbf{8 4}$ with 1 equivalent of alkynyl bromides or 2 equivalent of terminal alkynes in the presence of palladium catalyst, giving the $\mathrm{B}(4)$-alkynylated o-carborane derivatives 107 in moderate to good yields (Scheme 1.44a). ${ }^{[174]}$ 
A carboxylic acid directed rhodium-catalyzed B(4,5)-dialkylation of o-carboranes with allylic alcohols was described by Lu (Scheme 1.44b). ${ }^{[175]}$ This method was well compatible with various aryl-or alkyl-substituted allyl alcohols to provide the corresponding $\beta$-aryl or -alkyl ketone products 109 in high efficiency. In contrast, B(9)-acyl amino group directed palladium-catalyzed $\mathrm{B}(4)$-methylation of $o$-carboranes with methyl iodide as coupling partner was also described for $\mathrm{B}(4)$-alkylation of $\mathrm{o}$-carboranes 111(Scheme 1.44b). ${ }^{[176]}$ Furthermore, a carboranyl carboxylic acid-directed rhodium-catalyzed $\mathrm{B}(4)$-hydroxylation with $\mathrm{O}_{2}$ gas was disclosed by Xie, leading to a sequence of 4-OH-o-carboranes 112 in high yields with excellent regioselectivity (Scheme $1.44 \mathrm{c}){ }^{[177]}$

a) Cage B(4)-alkynylation (Xie, 2016)

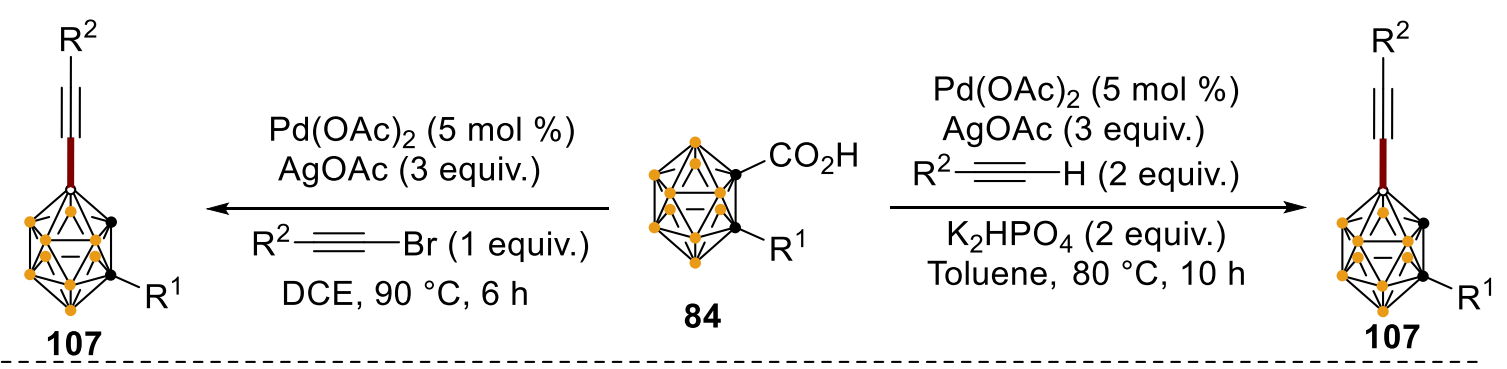

b) Cage B(4,5)-alkylation (Lu/Cao, 2019)

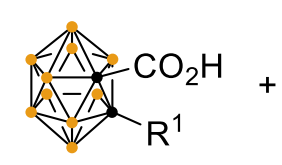

84

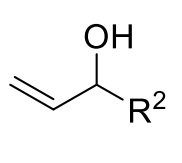

108

\section{$\left[\mathrm{Cp}^{*} \mathrm{RhCl}_{2}\right]_{2}(5 \mathrm{~mol} \%)$}

AgOAc (4 equiv.)

1,4-dioxane, $70^{\circ} \mathrm{C}, 18 \mathrm{~h}$

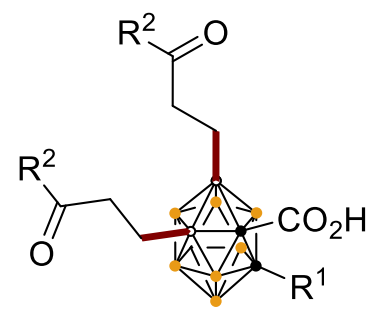

109

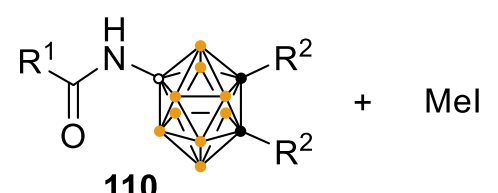

$\mathrm{Pd}(\mathrm{MeCN})_{4}(\mathrm{Cl})_{2}(10 \mathrm{~mol} \%)$

AgOAc (3 equiv.)

Toluene, $25^{\circ} \mathrm{C}, 12 \mathrm{~h}$ 110

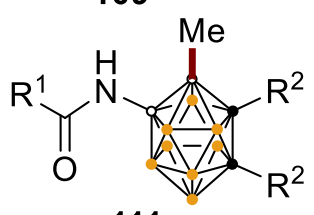

111

c) Cage B(4,5)-oxygenation (Xie, 2016)

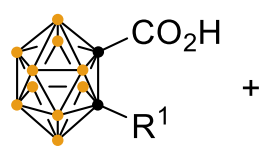

84
$\left[\mathrm{Cp}^{*} \mathrm{RhCl}_{2}\right]_{2}(2.5 \mathrm{~mol} \%)$ KOAc (2 equiv.)

Toluene, $95^{\circ} \mathrm{C}, 36 \mathrm{~h}$

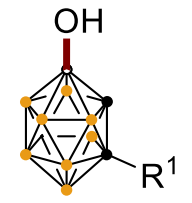

112

Scheme 1.44. Cage B(4,5)-alkynlation, alkylation, oxygenation of $o$-carboranes

In 2016, palladium- and ruthenium-catalyzed B(4)-amination of carboranyl carboxylic acids 84 with O-benzoyl hydroxylamines and sulfonyl azides were realized, respectively, by Xie. This B-N 
coupling reaction led to a series of tertiary carboranyl amines 114 and secondary carboranyl amines 113 with high functional group tolerance (Scheme 1.45a). ${ }^{[178]}$ Later, Yan reported an iridium-catalyzed B(4)-amination of carboranyl carboxylic acids $\mathbf{8 4}$ with organic azides and Lee disclosed a similar B(4)-amination by employing dioxazolones as the coupling partner and rhodium as the catalyst (Scheme $1.45 b) .{ }^{[179]}$

a) Cage B(4)-amination (Xie, 2016)

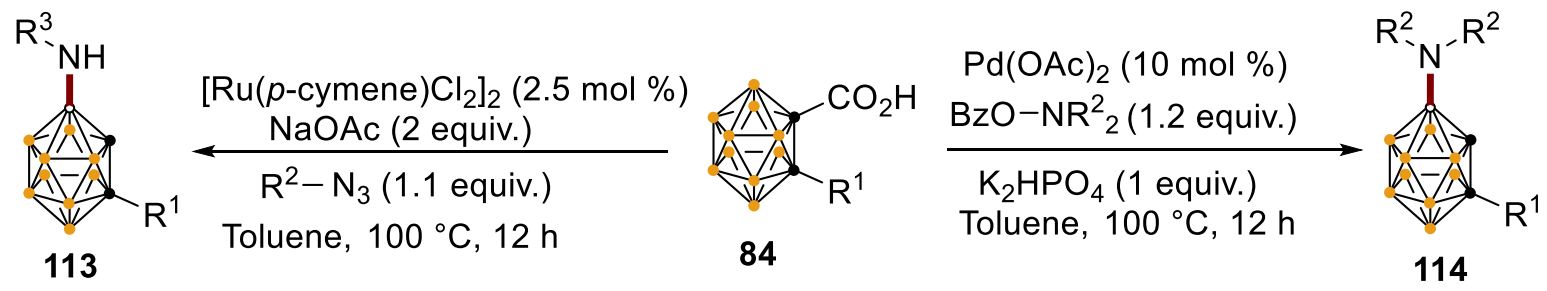

b) Cage B(4)-amination (Yan, 2016 / Lee, 2019)

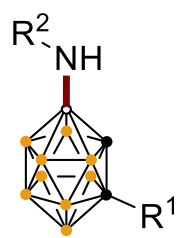

113

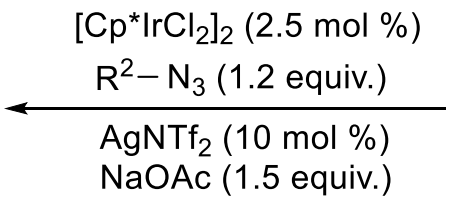

DCE, $85^{\circ} \mathrm{C}, 10 \mathrm{~h}$

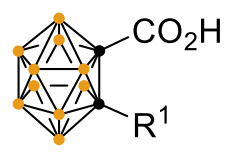

84

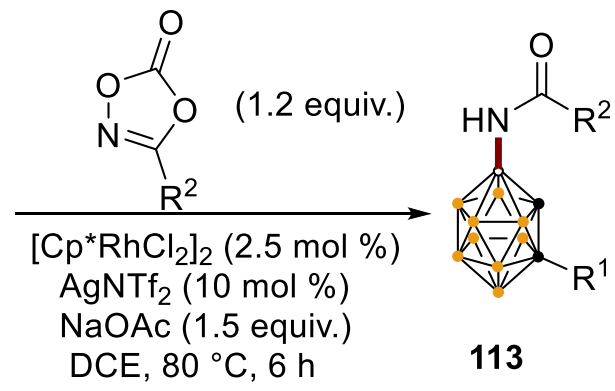

Scheme 1.45. Cage B(4,5)-amination of $o$-carboranes

Recently, Transition metal catalyzed B(4)-halogenation 116, $B(4,5)$-diiodination $115,{ }^{[180]} \mathrm{B}(4)$ homocoupling $(\mathbf{1 1 8 , 1 1 9})^{[181]}$ and $\mathrm{B}(4,5)$-disulfenylation $121^{[182]}$ of $O$-carboranes were reported by the Xie and Cao group, respectively. These protocols have a wide variety of functional group tolerance, offering a series of functionalized carboranes (Scheme 1.46).

a) Cage $B(4,5)$-halogenation (Xie, 2017)

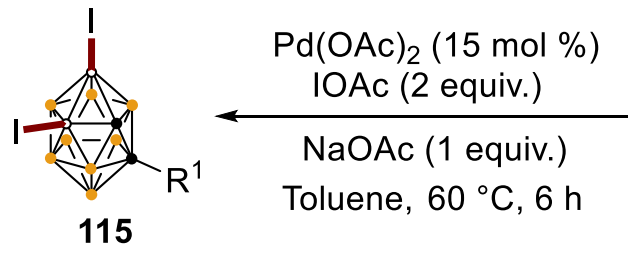

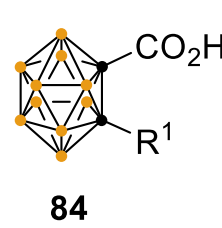

84
$\left[\mathrm{Cp} * \mathrm{ICl}_{2}\right]_{2}(2.5 \mathrm{~mol} \%)$ halogenating source

$\mathrm{AgNTf}_{2}(10 \mathrm{~mol} \%)$ $\mathrm{NaOAc}(1$ equiv.) DCE, $100^{\circ} \mathrm{C}, 12 \mathrm{~h}$

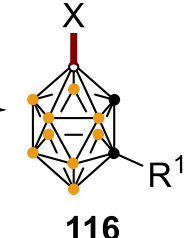

116 
b) Cage B(4)-homocoupling (Cao, 2019)
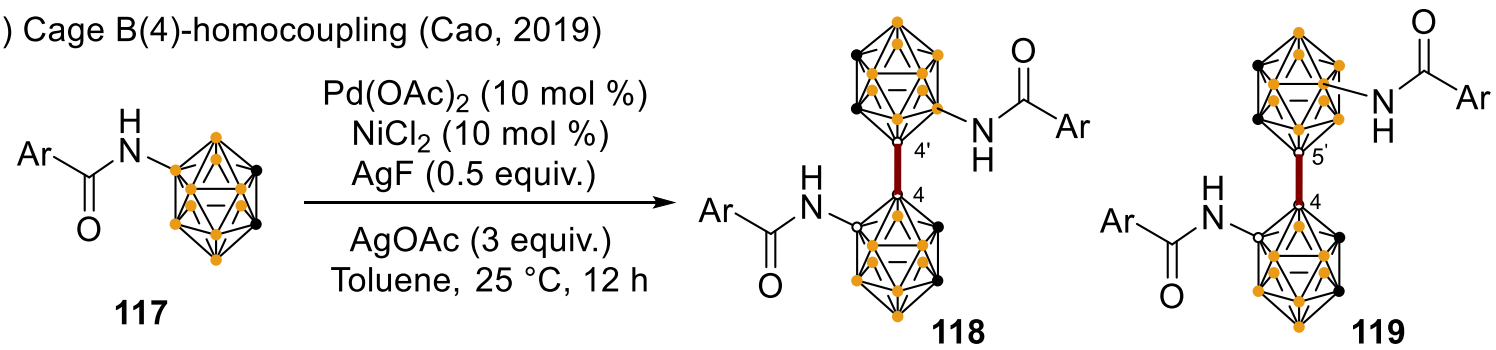

c) Cage B(4,5)-disulfenylation (Xie, 2020)<smiles>[R]C12C3C4C1C1C2C3C41C(=O)O</smiles><smiles></smiles>

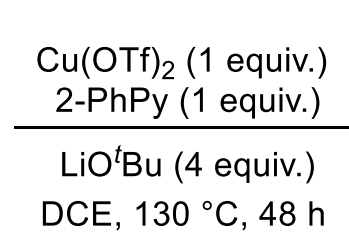

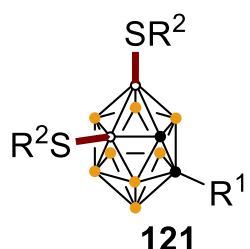

Scheme 1.46. Cage B(4,5)-halogenation, homocoupling and disulfenylation of $o$-carboranes

With respect to step-economy and bond-forming efficiency, synthetic methods merging multiple reaction steps into a simple one-pot process have attracted massive research interests. Thereby, a rhodium-catalyzed $\mathrm{B}(4)-\mathrm{H} / \mathrm{C}-\mathrm{H}$ cascade cyclization of carboranyl $\mathrm{N}$-arylimines 122 with vinyl ketones 49 was developed (Scheme 1.47a). ${ }^{[183]}$ Very recently, a proof-of-concept investigation of cascade cross-dehydrogenative coupling featuring two $\mathrm{B}-\mathrm{H}$, one $\mathrm{C}-\mathrm{H}$ and one $\mathrm{N}-\mathrm{H}$ bonds activation was also disclosed. Subsequently, the Xie group extended their studies to include the cascade cross-dehydrogenative coupling of carboranyl carboxylic acids $\mathbf{8 4}$ with benzoic acids 56A (Scheme 1.47b). ${ }^{[184]}$ More recently, Lee reported an iridium-catalyzed cyclative indenylation of carboranyl carboxylic acids 84 with propargyl alcohols 64, leading to previously unavailable $\mathrm{B}(4)$-indenylated 0 -carboranes 126 in high yields (Scheme 1.47c). ${ }^{[185]}$

a) $\mathrm{B}(4)-\mathrm{H}$ and $\mathrm{C}-\mathrm{H}$ cascade cyclization (Xie, 2018)
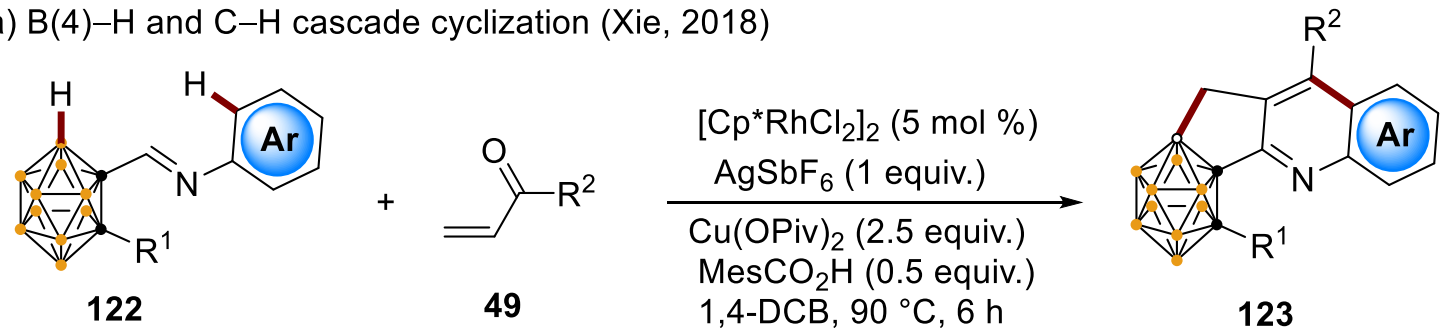

b) B(4,5)-dehydrogenatiive coupling (Xie, 2019/2020)

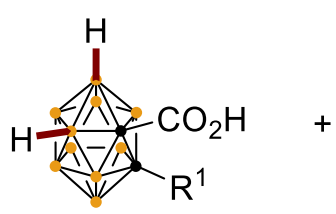

84<smiles>NC(=O)c1ccccc1</smiles>

$58 \mathrm{~F}$

$\left[\mathrm{Cp}^{*} \mathrm{IrCl}_{2}\right]_{2}(5 \mathrm{~mol} \%)$

$\underset{\mathrm{AgOAc}}{ }(10 \mathrm{~mol} \%)$
$\mathrm{Li}_{2} \mathrm{CO}_{3}(2$ equiv. $)$
$\mathrm{Cu}(\mathrm{OPiv})_{2}$ (5 equiv.)

Toluene, $140{ }^{\circ} \mathrm{C}, 15 \mathrm{~h}$

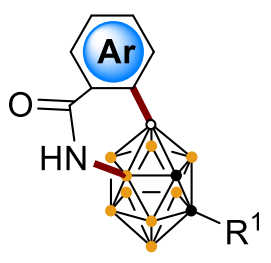

124 

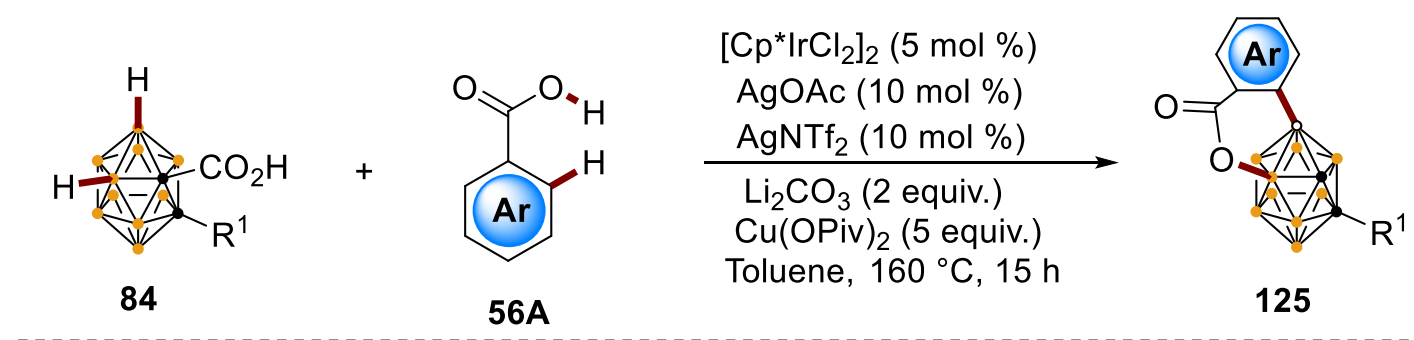

125

c) B(4)-indenylayion (Lee, 2020)

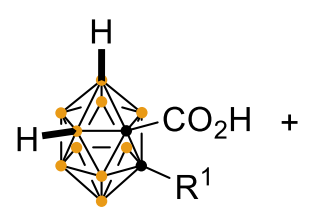

84
1) $\left[\mathrm{Cp}^{*} \mathrm{IrCl}_{2}\right]_{2}(4 \mathrm{~mol} \%)$ $\mathrm{AgSbF}_{6}(16 \mathrm{~mol} \%)$

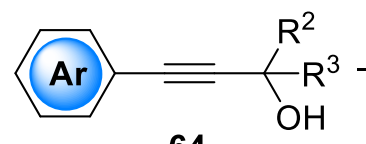

64 $\mathrm{NaOAc}$ (1 equiv.) TFE, $60{ }^{\circ} \mathrm{C}, 12 \mathrm{~h}$

2) Toluene, $130{ }^{\circ} \mathrm{C}, 3 \mathrm{~h}$

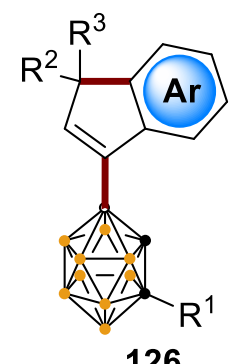

126

Scheme 1.47. Cage B $(4,5)$-cascade reaction of $o$-carboranes

\subsubsection{Transition Metal-Catalyzed Cage $B(8,9,10,12)-H$ Functionalization}

Owing to the small differences in electron density at the vertices $\mathrm{B}(8,9,10,12)-\mathrm{H}$, palladiumcatalyzed tetrafluorination $1 \mathbf{1 2}^{[186]}$ and tetraacetoxylation $137^{[187]}$ of $o$-carboranes were described by Xie and Cao, respectively (Scheme 1.48a,d). Since then, B(8/9)-chlorination 131, ${ }^{[188]}$ alkenylation $\mathbf{1 3 2},{ }^{[189]}$ and -arylation $\mathbf{1 3 3 ^ { [ 1 9 0 ] }}$ were efficiently achieved with the palladium as the catalyst by the Cao group (Scheme 1.48b). A breakthrough on regioselective $\mathrm{B}(8)$-arylation of $O$ carboranes 134 was disclosed under the assistance of an acyl amino group at B(3) position (Scheme 1.48c). ${ }^{[191]}$ 
a) Cage $B(8,9,10,12)$-tetraflurination (Xie, 2013)

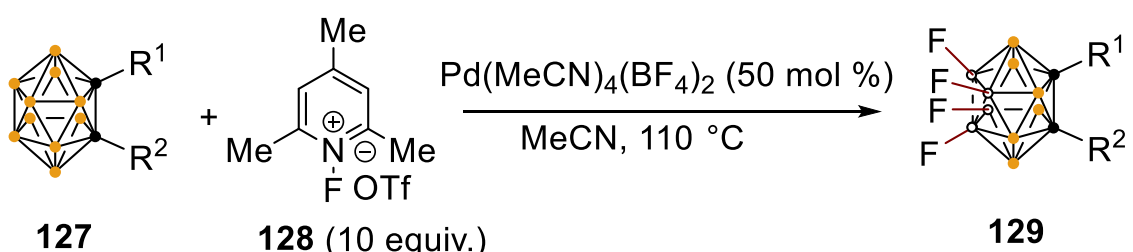

b) Cage B(8/9)-chlorination, alkenylation and arylation (Cao, 2017, 2015,2015)

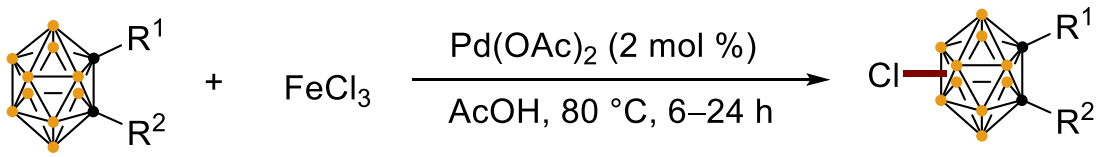

127

130

131
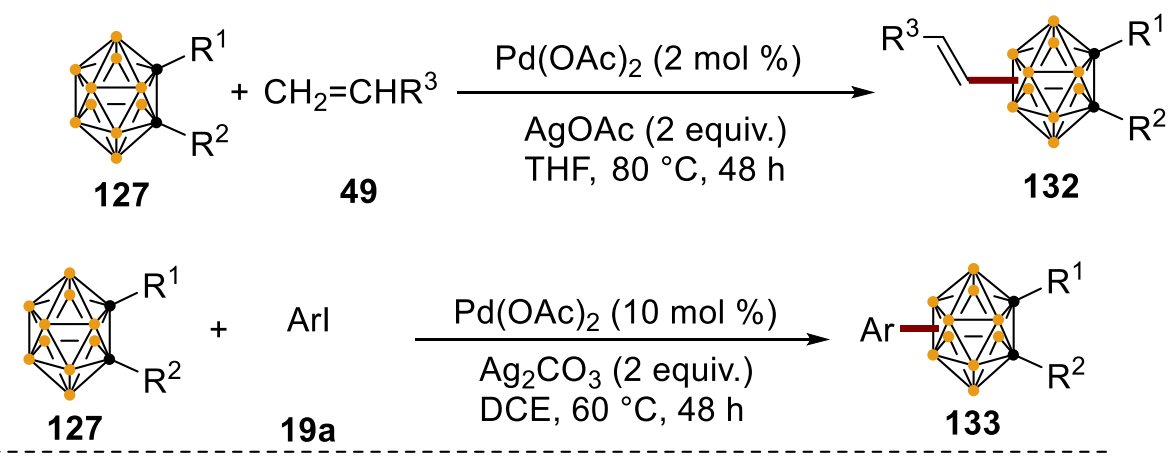

c) Cage B(8)-arylation (Xie, 2019)

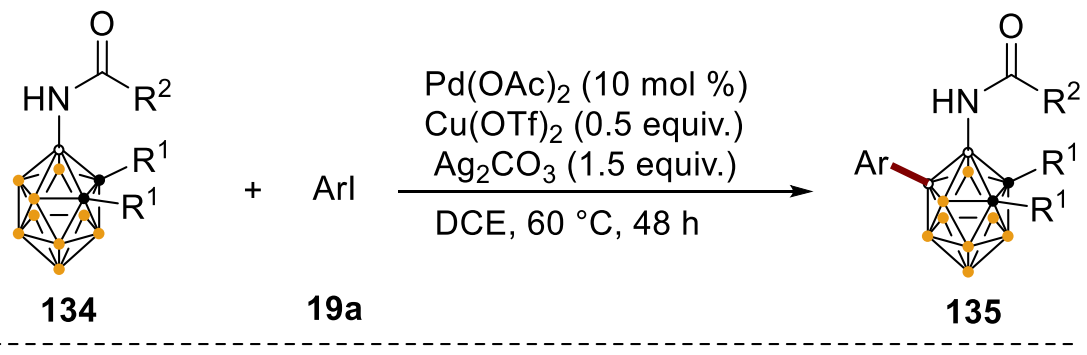

d) Cage $B(8,9,10,12)$-tetraacetoxylation (Cao, 2016/2018)
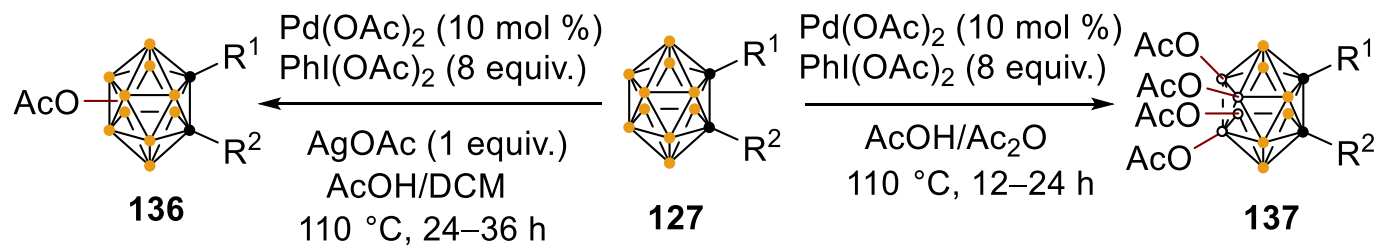

Scheme 1.48. Cage $B(8,9,10,12)$-halogenation, alkenylation, arylation and tetraacetoxylation of $o$-carboranes

\subsection{Electrochemical Functionalization of Carboranes}

While significant progress have been realized by the merger of electrocatalysis with organometallic $\mathrm{C}-\mathrm{H}$ activation, ${ }^{[192]}$ electrochemical functionalization of carborane continues to be scarce. As early as 2005, Shirokii and Potkin group described the metal-free electrochemical thiocyanation of nido-carboranes $138 .{ }^{[193]}$ Recently, the Xie group reported a copper-catalyzed 
electrochemical B-H oxygenation of o-carboranes 90 using a divided cell setup at room temperature. This reaction does not require any additional chemical oxidants and generates $\mathrm{H}_{2}$ and lithium salt as by-products. The control experiments indicate that a high valent copper(III) species is likely involved in the electrochemical process (Scheme 1.49). ${ }^{[194]}$

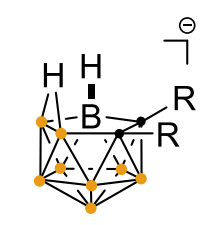

138

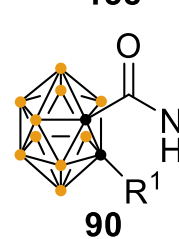

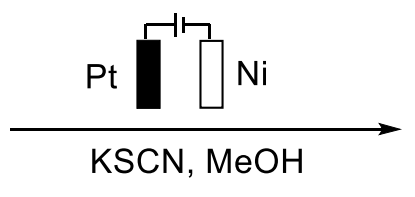

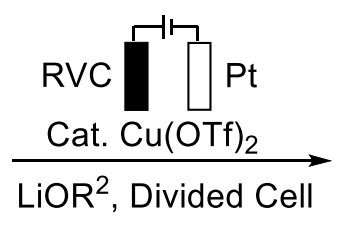

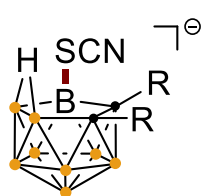

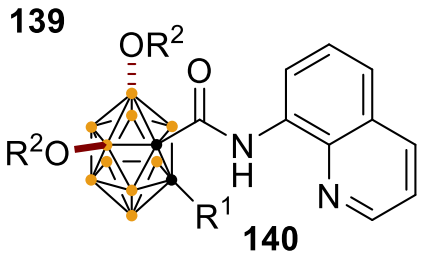

(Shirokii \& Potkin)

(Xie)

Scheme 1.49. Electrochemical functionalization of carboranes 


\section{Objectives}

During the last decades, transition metal-catalyzed $\mathrm{C}-\mathrm{H}$ functionalization ${ }^{[18]}$ has emerged as a powerful tool for the construction of $\mathrm{C}-\mathrm{C}$ and $\mathrm{C}-\mathrm{Het}$ bonds due to the excellent levels of atom${ }^{[195]}$ and step-economy. ${ }^{[196]} \mathrm{C}-\mathrm{H}$ bonds are ubiquitous in organic compounds, thus, chemo- and position-selective functionalizations of $\mathrm{C}-\mathrm{H}$ bonds are challenging and extremely important. In contrast to other $4 \mathrm{~d}$ transition metal catalysts, such as palladium and rhodium, cost-effective ruthenium catalysts ${ }^{[197]}$ are highly desirable for selective $\mathrm{C}-\mathrm{H}$ activations.

The mechanistic understanding of the fundamental aspects on $\mathrm{C}-\mathrm{H}$ activation ${ }^{[198]}$ is vital to the development of synthetically useful $\mathrm{C}-\mathrm{H}$ functionalization methods. ${ }^{[21 \mathrm{~b}]}$ In recent years, ruthenium(II)-catalyzed C-H activation ${ }^{[198 c, 199]}$ has emerged as a transformative tool in molecular synthesis, with key applications to drug discovery ${ }^{[200]}$ and agrochemistry. ${ }^{[201]}$ In stark contrast to recent findings on rhodium $(\mathrm{V})^{[202]}$ and iridium(V)-catalyzed ${ }^{[119 c, 203]} \mathrm{C}-\mathrm{H}$ activation, detailed mechanistic insights into the importance of ruthenium(IV) intermediates in $\mathrm{C}-\mathrm{H}$ activation processes continues to be limited. ${ }^{[204]}$ In this context, a ruthenium(II/IV) manifold enabled $\mathrm{C}-\mathrm{H}$ activation via weak O-coordination should be explored (Scheme 2.1).

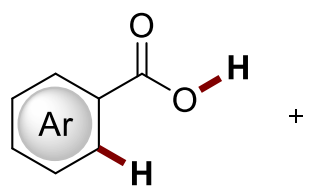

62<smiles>[R]C(=O)C=S(C)(C)=O</smiles>

141

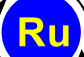

ruthenium(II/IV) manifold

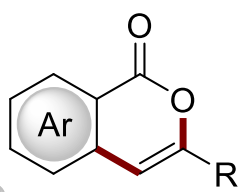

142

Scheme 2.1. Ruthenium (II/IV))-catalyzed $\mathrm{C}-\mathrm{H}$ activation by weak $\mathrm{O}$-coordination

Diketopyrrolopyrroles (DPPs) ${ }^{[205]} \mathbf{1 4 3}$ - relevant small molecules and conjugated semiconducting polymers - have attracted the attention of researchers from different areas, including optoelectronic materials ${ }^{[206]}$ and bioimaging probes. ${ }^{[207]}$ In comparison to the numerous efforts devoted to the modification of the DPP periphery via $\mathrm{C}-\mathrm{H}$ functionalization or direct arylation polymerization (DArP), ${ }^{[208]}$ their de novo assembly leading to $\pi$-extended structures continuous to be underdeveloped. Thus, ruthenium-catalyzed twofold $\mathrm{C}-\mathrm{H} / \mathrm{N}-\mathrm{H}$ activation for sustainable alkyne annulations towards $\pi$-extended polyaromatics should be investigated (Scheme 2.2). 


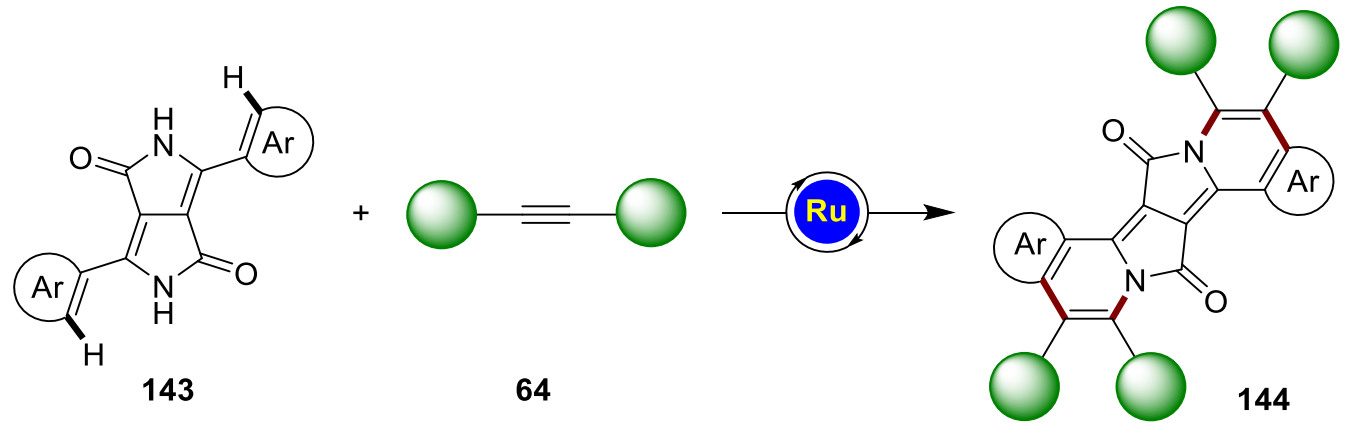

Scheme 2.2. Ruthenium (II/IV)-catalyzed double $\mathrm{C}-\mathrm{H} / \mathrm{N}-\mathrm{H}$ annulation for diketopyrrolopyroles (DPPs) 144.

Recently, the elegant merger of metalla-electrocatalyzed oxidative $\mathrm{C}-\mathrm{H}$ functionalization without expensive and toxic metal oxidants holds the unique power for the resource-economical and environmentally-benign molecular construction. ${ }^{[90,}{ }^{209]}$ Despite considerable progress, ${ }^{[122,}$ 140, 210] the development of new catalytic manifolds is still hampered by a lack of mechanistic understanding. This holds especially true for ruthenaelectrocatalysis, which continues to be underdeveloped. ${ }^{[116-118]}$ Therefore, another main objective of the thesis is the $\mathrm{C}-\mathrm{H}$ activation by ruthenaelectro-catalysis (Scheme 2.3).
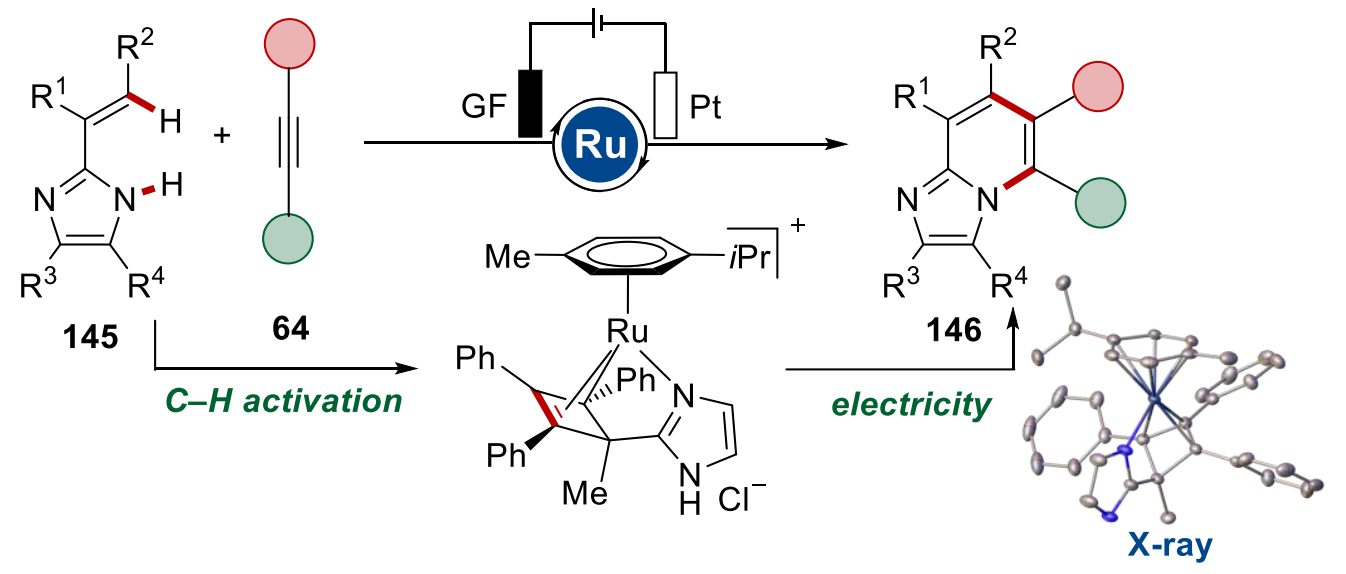

Scheme 2.3. Ruthenaelectro(II/III/I)-catalyzed alkyne annulations. 
In recent years, transition metal-catalyzed cage B-H activation for the regioselective boron functionalization of 0 -carboranes has emerged as a powerful tool for molecular syntheses. ${ }^{[151]}$ However, the electron density of the $10 \mathrm{~B}-\mathrm{H}$ bonds in o-carboranes are not equal, which results in selectivity issues. Despite indisputable progress, efficient approaches for complementary siteselective functionalizations of 0 -carboranes are hence in high demand. Therefore, we wish to develop an efficient approach for the regioselective $\mathrm{B}(3,4)-\mathrm{H}$ arylations of $\mathrm{O}$-carboranes (Scheme 2.4).

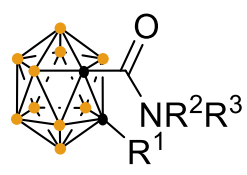

149

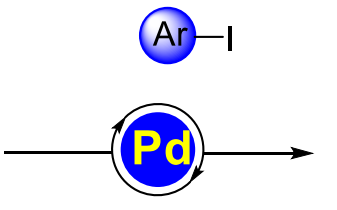

$B(3,4)-H$ activation

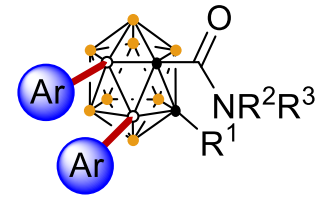

150 $\mathrm{B}(3,4)$-diarylation or

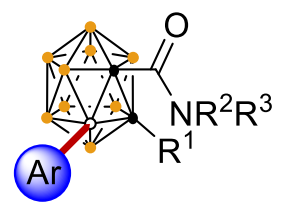

153

$\mathrm{B}(3)$-monoarylation

Scheme 2.4. Palladium-catalyzed B(3,4)-arylations.

Moreover, nitrogen-containing carboranes have received increasing attention in recent years, because they possess major potential in drug discovery ${ }^{[211]}$ as well as molecule catalysis. ${ }^{[212]}$ In contrast to transition metal-catalyzed regioselective B-H functionalization of closo-carborane, B$\mathrm{H}$ functionalization of nido-carborane $\left(7,8-\mathrm{C}_{2} \mathrm{~B}_{9} \mathrm{H}_{12}{ }^{-}\right)$remains in its infancy. ${ }^{[213]}$ One major challenge is represented by the negatively charged cluster, which inhibits the $\mathrm{B}-\mathrm{H}$ bond from undergoing nucleophilic substitutions. While significant recent impetus was gained by the merger of electrocatalysis with organometallic $\mathrm{C}-\mathrm{H}$ activation, ${ }^{[90,209]}$ electrochemical regioselective cage B-H functionalization continues to be scarce, ${ }^{[193-194,214]}$ Thus, the merger of electrocatalysis with B-H functionalization of nido-carborane $\left(7,8-\mathrm{C}_{2} \mathrm{~B}_{9} \mathrm{H}_{12}{ }^{-}\right)$should be studied (Scheme 2.5).

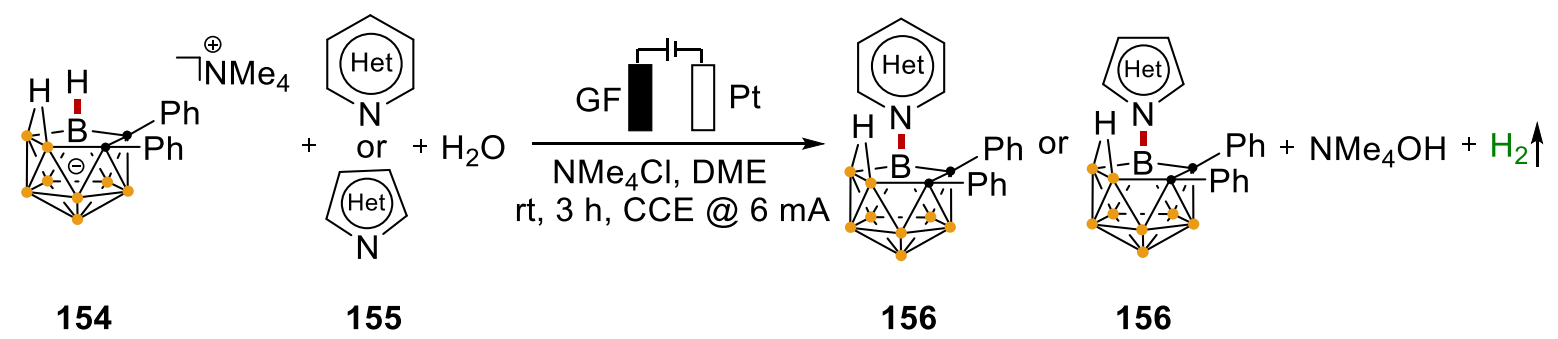

Scheme 2.5. Electrooxidative cage B-H nitrogenation of nido-carboranes 154.

While $\mathrm{C}-\mathrm{S}$ bonds are important structural motifs in various biologically active molecules and functional materials, ${ }^{[215]}$ strategies for the assembly of chalcogen-substituted carboranes are relatively rare. ${ }^{[149 a, 182]} \mathrm{A}$ major challenge is hence represented by the strong coordination abilities 
of thiols to most transition metals, which often leads to catalyst deactivation. ${ }^{[216]}$ Furthermore, oxidative cage $\mathrm{B} / \mathrm{C}-\mathrm{H}$ functionalizations largely call for noble transition metal catalysts ${ }^{[170,217]}$ and stoichiometric amounts of expensive chemical oxidants, such as silver(I) salts. ${ }^{[176,183,191]}$ Thus, we explored the copper-catalyzed electrochemical cage $\mathrm{C}-\mathrm{H}$ chalcogenations of $\mathrm{o}$-carboranes in a dehydrogenative manner, assembling a variety of C-sulfenylated and C-selenylated 0 carboranes (Scheme 2.6).

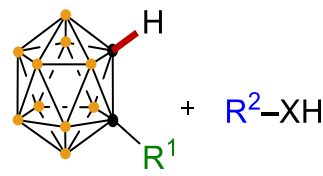

160

161

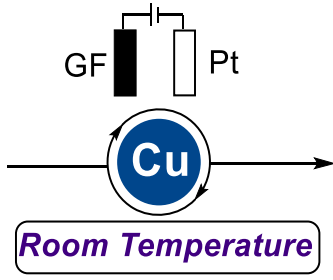

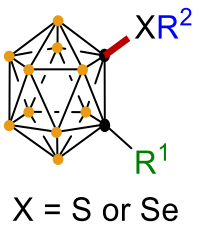

162

Scheme 2.6. Cupraelectro-oxidative cage $\mathrm{C}-\mathrm{H}$ chalcogenantion o-carboranes 160. 


\section{Results and Discussion}

\subsection{Ruthenium(IV) Intermediates in $\mathrm{C}-\mathrm{H}$ Annulation by Weak $\mathrm{O}$ - Coordination}

The mechanistic understanding of the $\mathrm{C}-\mathrm{H}$ activation is crucial to develop new type of reactions (vide supra). In this regard, we developed the annulations of sulfoxonium ylides 141 with benzoic acids 62 to provide an expedient access to diversely decorated isocoumarins with ample scope.

\subsubsection{Optimization and Scope}

Optimization studies on the ruthenium(II)-catalyzed $\mathrm{C}-\mathrm{H}$ annulation were done by Dr. Yu-Feng Liang as shown in Table 3.1.1. ${ }^{[218]}$ We commenced our studies by probing the envisioned redoxneutral $\mathrm{C}-\mathrm{H} / \mathrm{O}-\mathrm{H}$ functionalization of weakly $\mathrm{O}$-coordinating benzoic acid 62 with sulfoxonium ylide 141 using $\left[\operatorname{RuCl}_{2}(p \text {-cymene })\right]_{2}$ as the catalyst. A base additive was found essential for the desired $\mathrm{C}-\mathrm{H}$ annulation, with $\mathrm{NEt}_{3}$ identified as being optimal (entries 1-5). Interestingly, different ruthenium precursors could be employed, highlighting the importance of carboxylate assistance (entries 6-8). In contrast, frequently used rhodium, iridium and cobalt complexes fell short in delivering the desired product 142 (entries 9-12).

Table 3.1.1. Optimization of reaction conditions. ${ }^{[a]}$

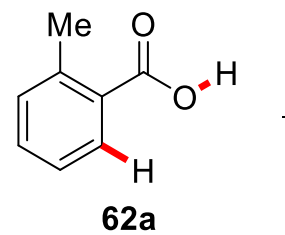

$62 a$<smiles>CS(C)(=O)=CC(=O)c1ccccc1</smiles>

$141 \mathrm{a}$

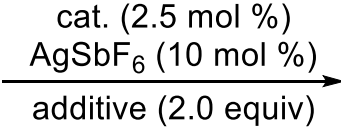

DCE, $100^{\circ} \mathrm{C}, 16 \mathrm{~h}$

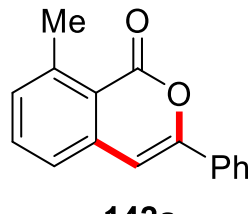

$142 a$

\begin{tabular}{cccc}
\hline Entry & Cat. & Additive & Yield of 3aa $[\%]^{[\mathrm{b}]}$ \\
\hline 1 & {$\left[\mathrm{RuCl}_{2}(p \text {-cymene })\right]_{2}$} & - & --- \\
2 & {$\left[\mathrm{RuCl}_{2}(p \text {-cymene })\right]_{2}$} & $\mathrm{NaOAc}$ & 30 \\
3 & {$\left[\mathrm{RuCl}_{2}(p \text {-cymene })\right]_{2}$} & $\mathrm{Na}_{2} \mathrm{CO}_{3}$ & 51 \\
4 & {$\left[\mathrm{RuCl}_{2}(p \text {-cymene })\right]_{2}$} & $\mathrm{KOtBu}$ & 23 \\
$\mathbf{5}$ & {$\left[\mathrm{RuCl}_{2}(p \text {-cymene })\right]_{2}$} & $\mathrm{NEt}_{3}$ & 76 \\
6 & {$\left[\mathrm{RuCl}_{2}(p \text {-cymene })\right]_{2}$} & $\mathrm{NEt}_{3}$ & $33^{[\mathrm{c}]}$ \\
7 & $\mathrm{Ru}(\mathrm{OAc})_{2}(p$-cymene $)$ & $\mathrm{NEt}_{3}$ & $65^{[\mathrm{c}, \mathrm{d}]}$ \\
\hline
\end{tabular}




\begin{tabular}{|c|c|c|c|}
\hline 8 & $\mathrm{Ru}\left(\mathrm{O}_{2} \mathrm{CMes}\right)_{2}(p$-cymene $)$ & $\mathrm{NEt}_{3}$ & $63^{[c, d]}$ \\
\hline 9 & - & $\mathrm{NEt}_{3}$ & --- \\
\hline 10 & {$\left[\mathrm{Cp}^{*} \mathrm{RhCl}_{2}\right]_{2}$} & $\mathrm{NEt}_{3}$ & 13 \\
\hline 11 & {$\left[\mathrm{Cp}^{*} \mid \mathrm{ICl}_{2}\right]_{2}$} & $\mathrm{NEt}_{3}$ & $<3$ \\
\hline 12 & $\mathrm{Cp}^{*} \mathrm{Co}(\mathrm{CO}) \mathrm{I}_{2}$ & $\mathrm{NEt}_{3}$ & --- \\
\hline
\end{tabular}

Utilizing the optimized conditions, we next evaluated the versatility of the redox-neutral annulation (Scheme 3.1.1a). Thus, benzoic acids 62 featuring ortho-substituents smoothly reacted with sulfoxonium ylides 141 . Moreover, mono-C-H functionalization products $\mathbf{1 4 2}$ were selectively obtained, when employing $\mathrm{Zn}(\mathrm{OAc})_{2}$ as the Lewis-acid additive. Interestingly, the

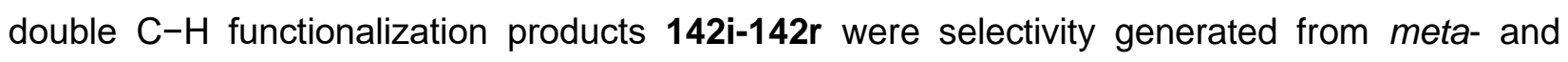
para-substituted benzoic acids 62 by the judicious choice of the stoichiometry. Thereby, the versatile ruthenium catalysis manifold proved amenable to both electron-rich as well as electrondeficient arenes 62 (Scheme 3.1.1a). Valuable electrophilic functional groups were fully tolerated. Likewise, aryl-substituted sulfoxonium ylides bearing electron-donating or electron-withdrawing groups delivered the desired products (142m-142r). 

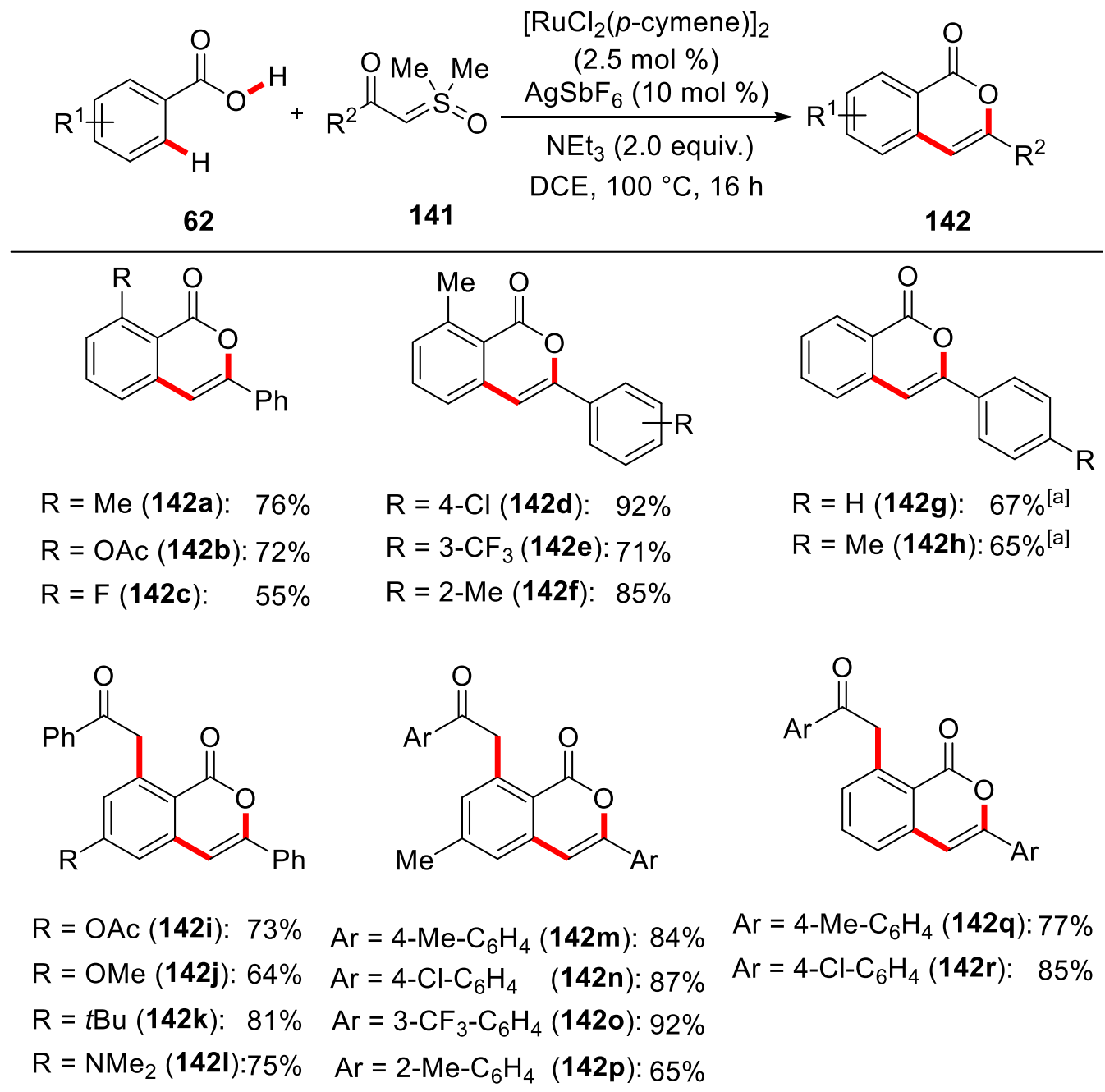

Scheme 3.1.1. Ruthenium-catalyzed C-H/O-H annulation with sulfoxonium ylides 141. [a] $\mathrm{Zn}(\mathrm{OAc}) 2$ (50 mol \%).

\subsubsection{Proposed Mechanism}

Based on experimental mechanistic studies, a plausible catalytic cycle was proposed in Scheme 3.1.2. The cyclometalated intermediate $B$ is coordinated by the sulfoxonium ylide $\mathbf{1 4 1}$, leading to ruthenium(II) species $\mathbf{C}$. This intermediate $\mathbf{C}$ is transformed into key ruthenium(IV) species $\mathbf{D}$ by $\alpha$-elimination of DMSO. Insertion with the ruthenium(IV) species generats six-membered ruthenacycle E. Finally, proto-demetalation affords the acyclic compound, which undergoes a cyclization to get product 142. 


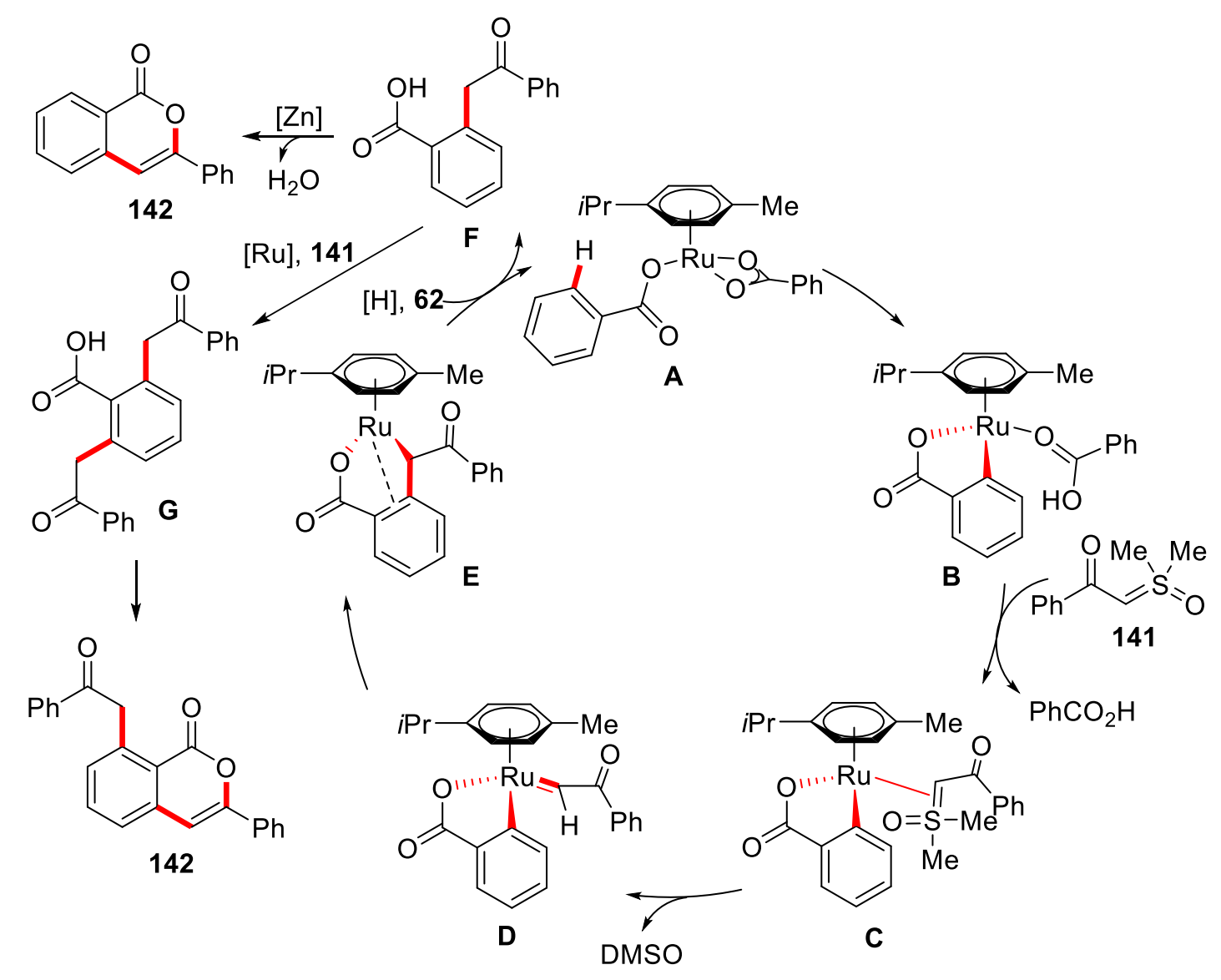

Scheme 3.1.2. Proposed catalytic cycle through a ruthenium(II/IV) manifold. 


\subsection{Twofold $\mathrm{C}-\mathrm{H} / \mathrm{N}-\mathrm{H}$ Annulations towards m-Extended Polyaromatics}

The widespread applications of substituted diketopyrrolopyrroles (DPPs) call for the development of efficient methods for their modular assembly. Herein, we developed a novel and efficient $\pi$-expansion-strategy of DPPs core in a mild and sustainable fashion, employing versatile ruthenium catalysis in the process of a $\mathrm{C}-\mathrm{H}$ activation of DPPs. ${ }^{[219]}$

\subsubsection{Optimization and Scope}

Optimization studies on the ruthenium(II)-catalyzed $\mathrm{C}-\mathrm{H}$ allylations were done by Dr. Elżbieta Gońka. ${ }^{[19]}$ After testing various bases and solvents, the catalytic reaction conditions comprised of $\left[\mathrm{RuCl}_{2}(p \text {-cymene) }]_{2}(10 \mathrm{~mol} \%), \mathrm{KOAc}\right.$ (1.0 equiv), CuOAc (4.0 equiv) in o-xylene at $100{ }^{\circ} \mathrm{C}$ for $16 \mathrm{~h}$ was identified as optimal. With the optimized catalytic conditions in hand, we tested the versality of the ruthenium(II)-catalyzed double $\mathrm{C}-\mathrm{H} / \mathrm{N}-\mathrm{H}$ annulation of DPP 143 with different diaryl alkynes 64 (Scheme 3.2.1). Thereby, m-extended PAHs were accessed from electron-rich as well as electron-deficient alkynes in an efficient manner, including sensitive tetrabromo/chloro DPPs 144e-144f, which should prove instrumental for further modifications and applications of the DPPs 144. The double ruthenium-catalyzed $\mathrm{C}-\mathrm{H} / \mathrm{N}-\mathrm{H}$ annulation was not restricted to aromatic alkynes. Indeed, the reaction also proceeded well with alkyl alkynes, delivering the corresponding products $144 \mathrm{~g}$ and $144 \mathrm{~h}$ efficiently. 


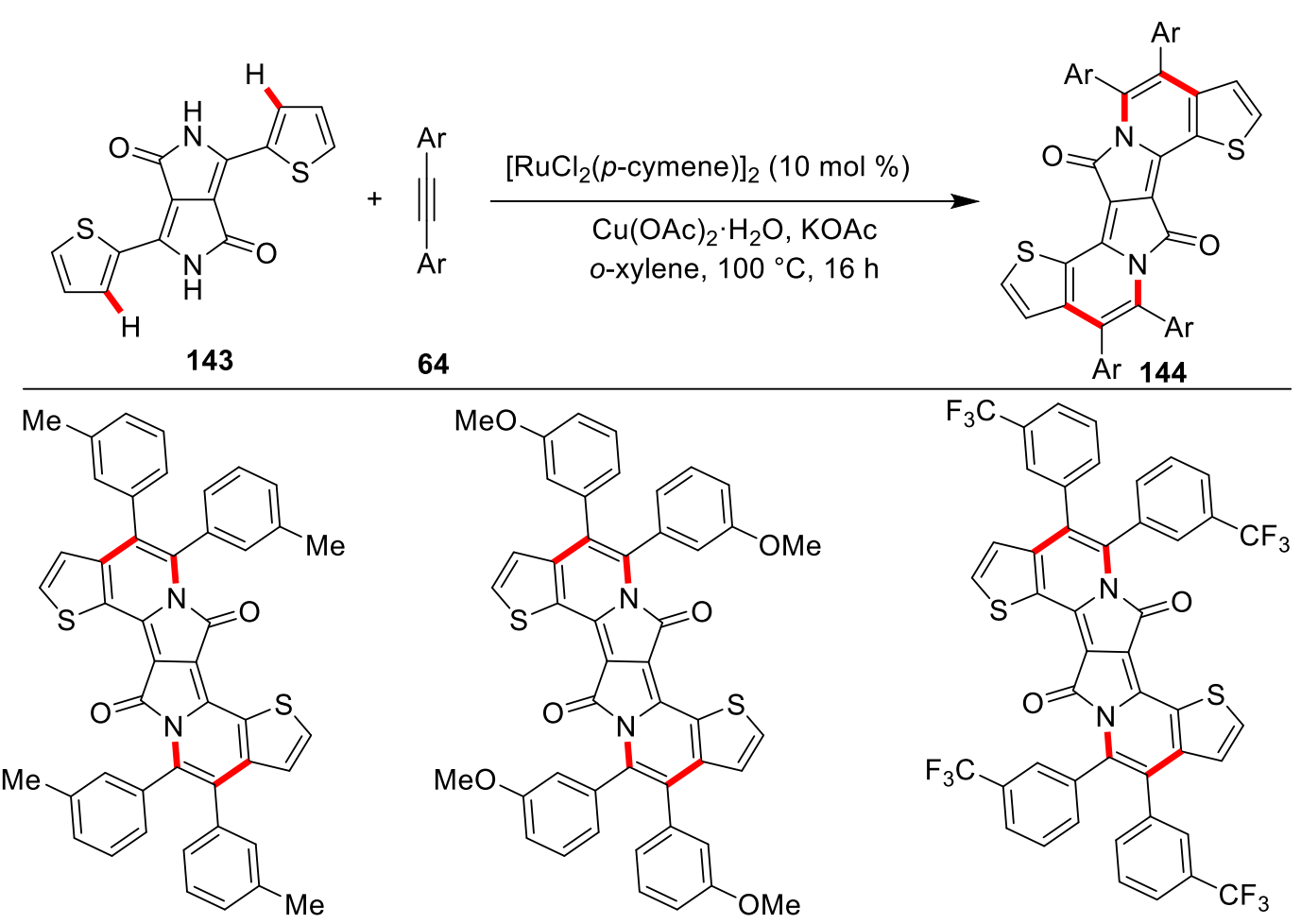

144a: $71 \%$

144b: $52 \%$

144c: $50 \%$<smiles></smiles><smiles></smiles>

144e: $51 \%$<smiles></smiles>

144f: $53 \%$<smiles></smiles>

144g: $58 \%$

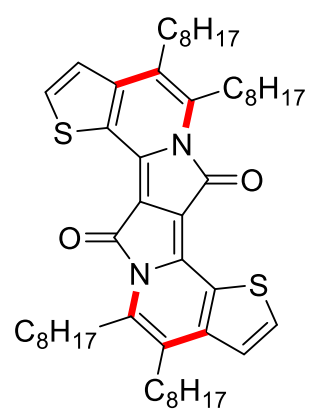

144h: $56 \%$

Scheme 3.2.1. Ruthenium-catalyzed double $\mathrm{C}-\mathrm{H} / \mathrm{N}-\mathrm{H}$ annulation with aryl alkynes. 


\subsubsection{UV-Vis Absorption and Fluorescence Spectroscopy}

The optical properties of the thus-obtained novel compounds $144 \mathrm{a}-\mathbf{1 4 4 h}$ were studied by UVVis absorption and fluorescence spectroscopy (Table 3.2.2). The unprecedented DPPs exhibited very intense absorption in the UV and visible region, with absorption maxima between 600 $640 \mathrm{~nm}$, which results in intense blue to purple color. The absorption maximum in all synthesized derivatives is bathochromically shifted in comparison with the previously synthesized, unsubstituted compounds, ${ }^{[220]}$ whereas both Stoke shift and absorption coefficient are similar.

Table 3.2.2. Spectroscopic data of m-extended diketopyrrolopyrroles 144a-144h.

\begin{tabular}{lllll}
\hline Compound & \multicolumn{1}{c}{$\lambda_{\text {max }}^{a b s}$} & $\lambda_{\max }^{e m}$ & Stokes shift $\left[\mathrm{cm}^{-1}\right]$ & $\varepsilon_{\max }\left[\mathrm{M}^{-1} \mathrm{~cm}^{-1}\right]$ \\
\hline 144a & 635 & 645 & 244 & 52083 \\
144b & 635 & 646 & 268 & 71946 \\
144c & 632 & 641 & 222 & 66051 \\
$\mathbf{1 4 4 d}$ & 631 & 640 & 223 & 47269 \\
$\mathbf{1 4 4 e}$ & 633 & 644 & 270 & 76626 \\
$\mathbf{1 4 4 f}$ & 633 & 643 & 246 & 76107 \\
$\mathbf{1 4 4 g}$ & 630 & 639 & 223 & 71598 \\
$\mathbf{1 4 4 h}$ & 631 & 642 & 272 & 84835 \\
\hline
\end{tabular}




\subsection{Ruthenaelectro(II/III/I)-Catalyzed Alkyne Annulations}

In this section, a ruthenium-catalyzed electrochemical dehydrogenative annulation reaction of imidazoles with alkynes was developed, allowing for the synthesis of various bridgehead $\mathrm{N}$-fused [5,6]-bicyclic heteroarenes through regioselective electrochemical $\mathrm{C}-\mathrm{H} / \mathrm{N}-\mathrm{H}$ annulation without chemical oxidants. Novel aza-ruthena-bicyclo-[3.2.0]-heptadienes were fully characterized and identified as the key intermediates for this transformation. Experimental and DFT mechanistic studies were suggestive of an oxidatively-induced reductive elimination pathway within a ruthenium(II/III) regime. ${ }^{[221]}$

\subsubsection{Optimization and Scope of Alkenyl Imidazole}

The study was commenced by probing various reaction conditions for the envisioned rutheniumcatalyzed electrooxidative $\mathrm{C}-\mathrm{H} / \mathrm{N}-\mathrm{H}$ annulation of alkenyl imidazole 145 with alkyne 64 in an operationally simple undivided cell setup equipped with a GF (graphite felt) anode and a Pt cathode (Table 3.3.1). After considerable preliminary experimentations, we observed that the desired product 146a was obtained by catalytic amounts of $\left[\mathrm{RuCl}_{2} \text { (p-cymene) }\right]_{2}$, along with $\mathrm{KPF}_{6}$ as the optimal catalytic additive, and DMF as the best solvent (entries 1-5). The yield was found to be reduced when sodium salts were used, such as $\mathrm{NaCl}$ and $\mathrm{NaPF}_{6}$ (entries 6-7). Gratifyingly, reducing the reaction time to $8 \mathrm{~h}$ led to the same yield of product 146a (entry 8 ). The reaction with a Pt anode resulted in a sharp drop in yield (entry 10). The addition of the redox mediator of $B Q$ did not improve the performance of the ruthenium catalyst (entries 11-12). Control experiments verified the essential role of the electricity, the additive, and the ruthenium catalyst (entries 13 -15). A set of otherwise typical transition metal catalysts were also probed but gave none or significantly reduced amounts of product $146 a$ (entries 16-20).

Table 3.3.1. Optimization of ruthenaelectro-catalyzed annulation. ${ }^{[a]}$

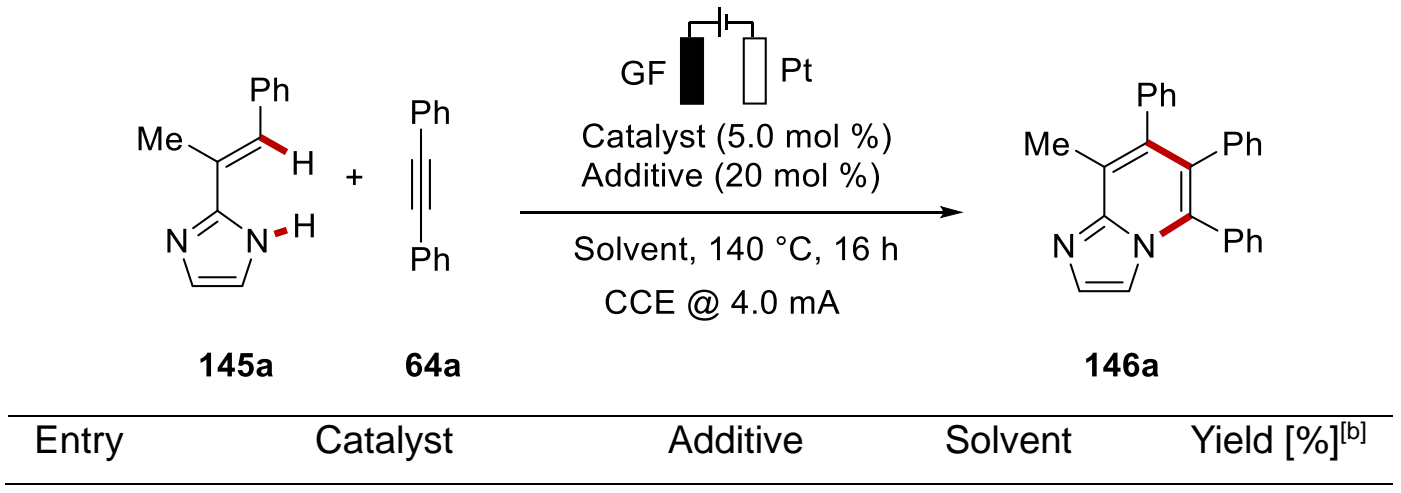




\begin{tabular}{|c|c|c|c|c|}
\hline 1 & {$\left[\mathrm{RuCl}_{2}(p \text {-cymene })\right]_{2}$} & $\mathrm{KPF}_{6}$ & $\mathrm{MeOH}$ & $10 \%[c]$ \\
\hline 2 & {$\left[\mathrm{RuCl}_{2}(p \text {-cymene })\right]_{2}$} & $\mathrm{KPF}_{6}$ & $t-\mathrm{AmOH} / \mathrm{H}_{2} \mathrm{O}$ & $12 \%[d]$ \\
\hline 3 & {$\left[\mathrm{RuCl}_{2}(p \text {-cymene })\right]_{2}$} & $\mathrm{KPF}_{6}$ & DMA & $33 \%$ \\
\hline 4 & {$\left[\mathrm{RuCl}_{2}(p \text {-cymene })\right]_{2}$} & $\mathrm{KPF}_{6}$ & NMP & $10 \%$ \\
\hline 5 & {$\left[\mathrm{RuCl}_{2}(p \text {-cymene })\right]_{2}$} & $\mathrm{KPF}_{6}$ & DMF & $75 \%$ \\
\hline 6 & {$\left[\mathrm{RuCl}_{2}(p \text {-cymene })\right]_{2}$} & $\mathrm{NaCl}$ & DMF & $50 \%$ \\
\hline 7 & {$\left[\mathrm{RuCl}_{2}(p \text {-cymene })\right]_{2}$} & $\mathrm{NaPF}_{6}$ & DMF & $66 \%$ \\
\hline 8 & {$\left[\mathrm{RuCl}_{2}(p \text {-cymene })\right]_{2}$} & $\mathrm{KPF}_{6}$ & DMF & $75 \%[e]$ \\
\hline 9 & {$\left[\mathrm{RuCl}_{2}(p \text {-cymene })\right]_{2}$} & $\mathrm{KPF}_{6}$ & DMF & $56 \%{ }^{[f]}$ \\
\hline 10 & {$\left[\mathrm{RuCl}_{2}(p \text {-cymene })\right]_{2}$} & $\mathrm{KPF}_{6}$ & DMF & $46 \%[g]$ \\
\hline 11 & {$\left[\mathrm{RuCl}_{2}(p \text {-cymene })\right]_{2}$} & $\mathrm{KPF}_{6}$ & DMF & $33 \%[h]$ \\
\hline 12 & {$\left[\mathrm{RuCl}_{2}(p \text {-cymene })\right]_{2}$} & $\mathrm{KPF}_{6}$ & DMF & $28 \%\left[{ }^{[i]}\right.$ \\
\hline 13 & {$\left[\mathrm{RuCl}_{2}(p \text {-cymene })\right]_{2}$} & $\mathrm{KPF}_{6}$ & DMF & $10 \%\left[{ }^{[j]}\right.$ \\
\hline 14 & {$\left[\mathrm{RuCl}_{2}(p \text {-cymene })\right]_{2}$} & --- & DMF & $50 \%$ \\
\hline 15 & --- & $\mathrm{KPF}_{6}$ & DMF & --- \\
\hline 16 & $\mathrm{Ru}(p$-cymene $)(\mathrm{OAc})_{2}$ & $\mathrm{KPF}_{6}$ & DMF & $53 \%$ \\
\hline 17 & $\mathrm{Co}(\mathrm{OAc})_{2} \cdot 4 \mathrm{H}_{2} \mathrm{O}$ & $\mathrm{KPF}_{6}$ & DMF & --- \\
\hline 18 & {$\left[\mathrm{Cp}^{*} \mathrm{RhCl}_{2}\right]_{2}$} & $\mathrm{KPF}_{6}$ & DMF & $36 \%$ \\
\hline 19 & {$\left[\mathrm{Cp}^{*} \mid \mathrm{ICl}_{2}\right]_{2}$} & $\mathrm{KPF}_{6}$ & DMF & $10 \%$ \\
\hline 20 & $\mathrm{Pd}(\mathrm{OAc})_{2}$ & $\mathrm{KPF}_{6}$ & DMF & --- \\
\hline
\end{tabular}

[a] Reaction conditions: undivided cell, $145(0.40 \mathrm{mmol}), 64(0.80 \mathrm{mmol})$, catalyst $(5.0 \mathrm{~mol} \%)$, additive $(20 \mathrm{~mol} \%)$, solvent $(4.0 \mathrm{~mL}), 140^{\circ} \mathrm{C}, 16 \mathrm{~h}$, constant current at $4.0 \mathrm{~mA}$, GF anode, Pt-plate cathode. [b] Yields of isolated products. [c] $60^{\circ} \mathrm{C}$. [d] $t-\mathrm{AmOH} / \mathrm{H}_{2} \mathrm{O}=1 / 1,100{ }^{\circ} \mathrm{C}$. [e] $8.0 \mathrm{~h}$. [f] $5.0 \mathrm{~h}$. [g] Pt-plate as anode. [h] BQ (10 mol \%). [i] BQ (10 mol \%), $100^{\circ} \mathrm{C}$. [i] no electricity. DMF $=N, N$-Dimethylformamide, $B Q=1,4$-Benzoquinone.

With the optimal reaction conditions in hand, we explored the versatility of the electrochemical annulations with diversely decorated alkynes 64 (Scheme 3.1.1). Electron-rich as well as electron-poor aromatic moieties at the alkynes 64 were amenable to the ruthenaelectrocatalyzed $\mathrm{C}-\mathrm{H}$ functionalizations. Thereby, a variety of synthetically useful electrophilic functional groups, such as chloro (146f), cyano (146g) and bromo (146I) substituents, were fully tolerated, which should prove invaluable for late-stage manipulations. We next turned our attention to diversified alkenyl imidazoles 145. Imidazoles bearing a range of substituents at different sites on the alkene or the imidazole were effectively transferable to deliver products 146m-146q. In addition, benzimidazole substrates with a $\beta$-methyl group and without a $\beta$ substituent on the alkene were effective for $\mathrm{C}-\mathrm{H} / \mathrm{N}-\mathrm{H}$ activation $146 \mathrm{r}-146 s$. Notably, thiophenyl 
substituted benzimidazole also was a competent substrate, giving the corresponding annulation product 146t with high efficacy.

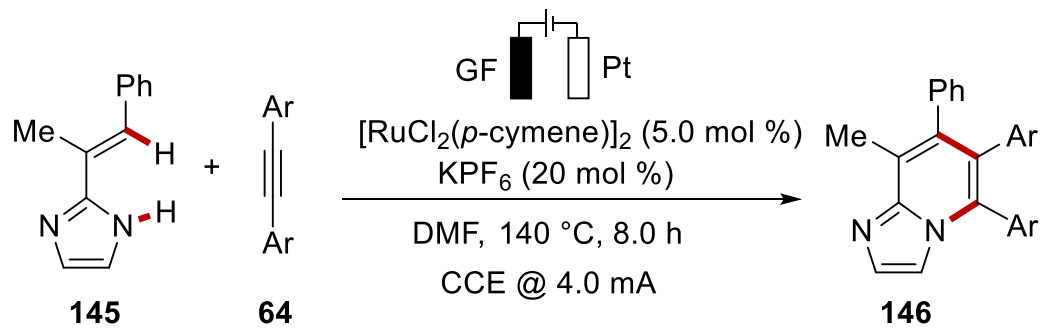<smiles>Cc1c(-c2ccccc2)c(-c2ccccc2)c(-c2ccccc2)n2ccnc12</smiles>

146a: $75 \%$<smiles>Cc1c(-c2ccccc2)c(-c2cccc(C#N)c2)c(-c2ccccc2)n2ccnc12</smiles>

146g: $67 \%$<smiles>Cc1cc(-c2ccccc2)c(-c2ccccc2)n2ccnc12</smiles>

146m: $55 \%$<smiles>Cc1nc2c(C)cc(-c3ccccc3)c(-c3ccccc3)n2c1[N+](=O)[O-]</smiles>

146q: $40 \%$<smiles>[R]c1cccc(-c2c(-c3cccc([R])c3)c(-c3ccccc3)n3ccnc3c2C)c1</smiles>

$$
R=M e \quad(146 b): 75 \%
$$
$\mathrm{R}=\mathrm{OMe}(\mathbf{1 4 6 c}): 76 \%$<smiles>[R]c1ccc(-c2c(C)c(C)c3nccn3c2-c2ccc([R])cc2)cc1</smiles>

$\mathrm{R}=\mathrm{Me} \quad$ (146h): $69 \%$ $\mathrm{R}=\mathrm{OMe}(\mathbf{1 4 6 i}): 71 \%$<smiles>Cc1c(-c2ccccc2)c(-c2ccccc2)n2ccnc2c1C</smiles>

146n: $53 \%$<smiles>Cc1cc2nc3c(C)c(C)c(-c4ccccc4)c(-c4ccccc4)n3c2cc1C</smiles>

146r: $50 \%$<smiles>Cc1c(-c2ccccc2)c(-c2cccc(C(F)(F)F)c2)c(-c2cccc(C(F)(F)F)c2)n2ccnc12</smiles>

146d: $73 \%$<smiles>Cc1c(-c2ccccc2)c(-c2ccc(C(F)(F)F)cc2)c(-c2ccc(C(F)(F)F)cc2)n2ccnc12</smiles>

146j: $69 \%$<smiles>Cc1cn2c(-c3ccccc3)c(-c3ccccc3)cc(C)c2n1</smiles>

1460: $50 \%$

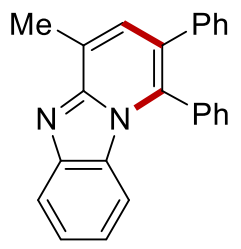

146s: $51 \%$<smiles>[R]c1cccc(-c2c(-c3cccc([R])c3)c(-c3ccccc3)n3ccnc3c2C)c1</smiles>

$R=F \quad(146 e): 63 \%$

$\mathrm{R}=\mathrm{Cl} \quad(\mathbf{1 4 6 f}): 70 \%$
$R=F \quad(146 k): 52 \%$

$\mathrm{R}=\mathrm{Br}(146 \mathrm{I}): 68 \%$<smiles>Cc1cc(-c2ccccc2)c(-c2ccccc2)n2cc(-c3ccccc3)nc12</smiles>

146p: $51 \%$<smiles></smiles>

146t: $72 \%$

Scheme 3.3.1. Scope of the electrochemical $\mathrm{C}-\mathrm{H} / \mathrm{N}-\mathrm{H}$ activation with alkynes 64 . (146c, 146h, 146i and $146 \mathrm{l}$ did by Msc. Ralf Steinbock) 


\subsubsection{Optimization and Scope of of benzimidazoles}

Next, we investigated the electrooxidative annulation of benzimidazoles 147 with alkyne 64, as shown in Table 3.3.2. After considerable optimizations of ruthenium complexes, bases and solvents, a catalytic system containing $\left[\mathrm{Ru}(p\right.$-cymene $\left.) \mathrm{Cl}_{2}\right](5 \mathrm{~mol} \%), \mathrm{KOAc}$ (2.0 equiv) in a mixture of solvents of $t-\mathrm{AmOH}$ and $\mathrm{H}_{2} \mathrm{O}$ at $100{ }^{\circ} \mathrm{C}$ for $4 \mathrm{~h}$ was identified as the ideas reaction condition (entry 5). Control experiments highlighted the essential role of the ruthenium catalyst and electricity (entries 6-12).

Table 3.3.2: Optimization of Electrochemical annulation with benzimidazole 147. . $^{\text {[a] }}$

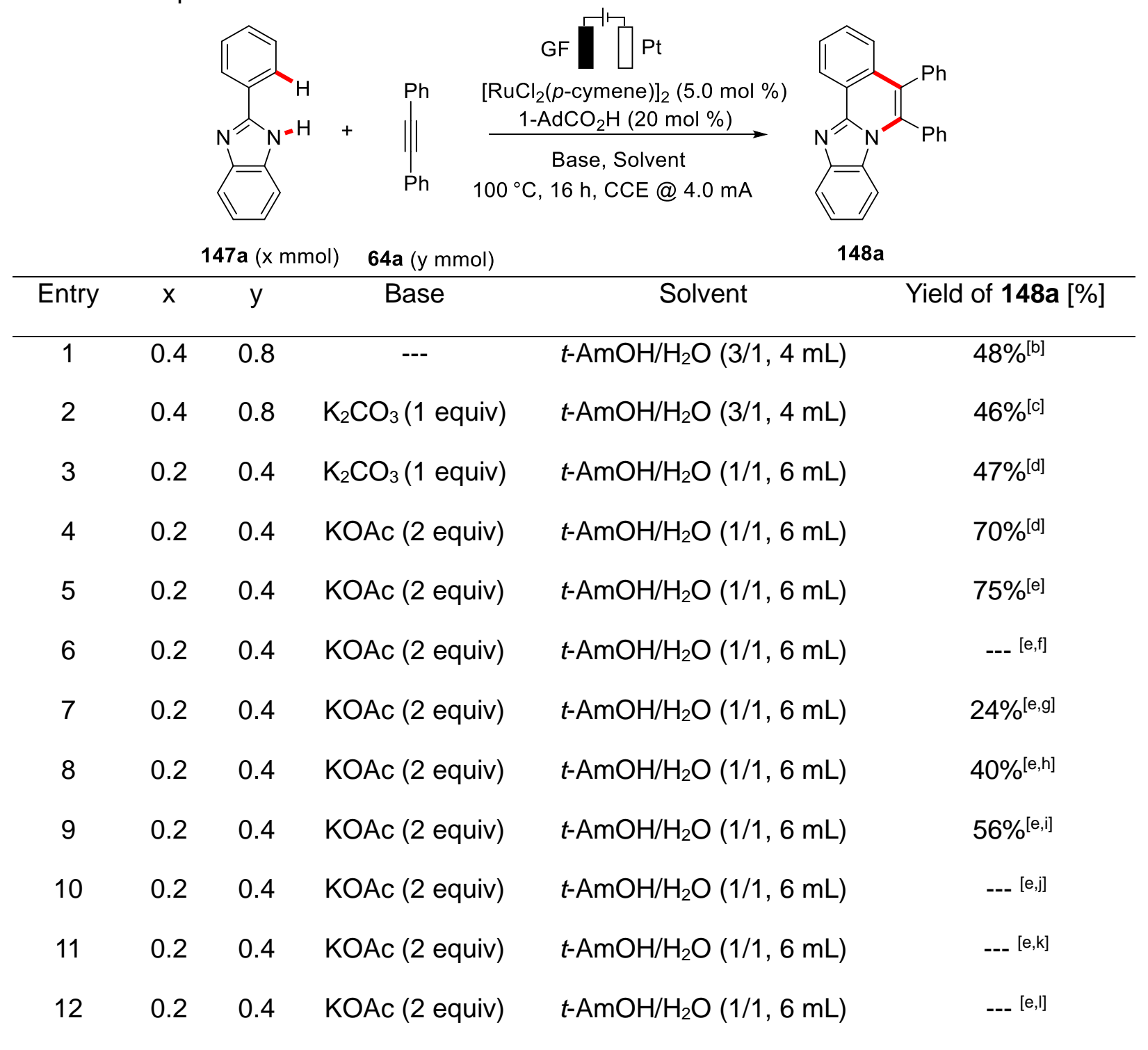


[a] Reaction conditions: Undivided cell, 147 (x mmol), 64 (y mmol), $\left[\operatorname{RuCl}_{2}(p \text {-cymene })\right]_{2}(5.0 \mathrm{~mol} \%), 100{ }^{\circ} \mathrm{C}, 16 \mathrm{~h}$ under $\mathrm{N}_{2}$, constant current at $4.0 \mathrm{~mA}$, GF anode, Pt-plate cathode, isolated yields. ${ }^{[b]} \mathrm{KPF}_{6}\left(20 \mathrm{~mol} \%\right.$ ) as additive. ${ }^{[c]} 10 \mathrm{~h}$. ${ }^{[\mathrm{d}]}$ 8 h. [e] $8 \mathrm{~mA}, 4$ h. ${ }^{[f]}$ no catalyst. [g] no current. [h] Pt instead of GF. [i] [ $\left.\mathrm{Cp}^{*} \mathrm{RhCl}_{2}\right]_{2}(5.0 \mathrm{~mol} \%)$ as catalyst. [] $\mathrm{Pd}(\mathrm{OAc})_{2}$ $(10 \mathrm{~mol} \%)$ as catalyst. ${ }^{[\mathrm{k}]} \mathrm{Co}(\mathrm{OAc}) 2 \cdot 4 \mathrm{H}_{2} \mathrm{O}(10 \mathrm{~mol} \%)$ as catalyst. ${ }^{[]}\left[\mathrm{Cp}^{*} \mid \mathrm{rCl}\right]_{2}(5.0 \mathrm{~mol} \%)$ as catalyst.

With the best conditions in hand, we next investigated the generality of the metallaelectrocataylsis by the assembly of the benzimidazoisoquinoline skeleton 148 through annulation of alkynes 64 with 2-arylimidazoles 147 (Scheme 3.3.2). Substitutions at the 2-aryl group and the benzimidazole gave the desired benzimidazoisoquinolines (148b-148q). Likewise, 2-naphthylbenzimidazole and 2-phenylnaphthoimidazole also afforded the corresponding products (148j,148k). The unsymmetrical 1-phenyl-1-propyne gave the product $148 \mathrm{n}$ with a high level of regioselectivity. Importantly, chloro, bromo, ester, amide and enolizable ketone substituents were thereby fully tolerated to deliver products $\mathbf{1 4 8 f - 1 4 8 g , ~ 1 4 8 0 - 1 4 8 q}$.
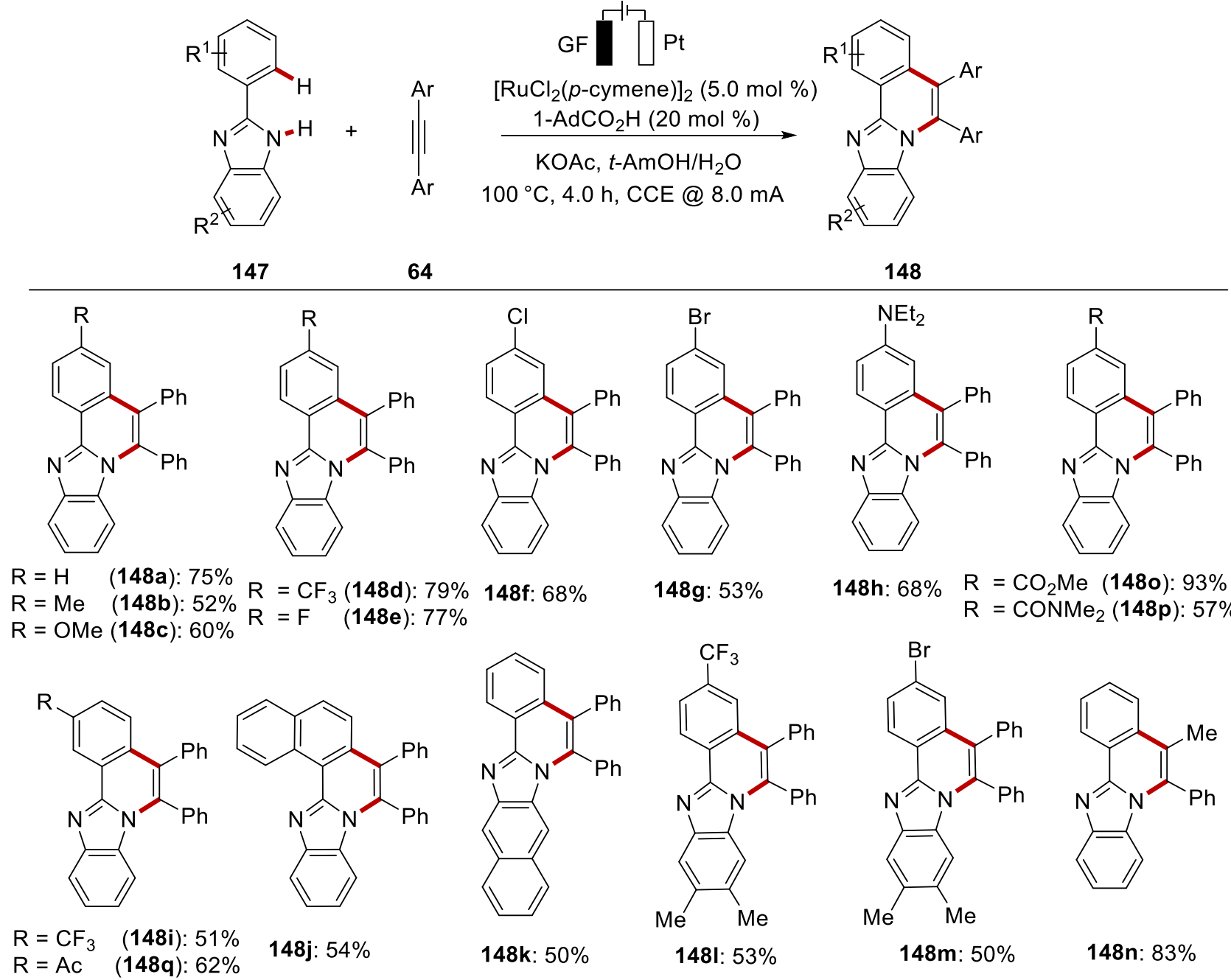

Scheme 3.3.2. Electrochemical $\mathrm{C}-\mathrm{H} / \mathrm{N}-\mathrm{H}$ activation with alkynes 64 . (148d, 148f, 148h and $\mathbf{1 4 8 \mathrm { n }}$ did by Msc. Ralf Steinbock) 


\subsubsection{Mechanistic Studies}

\subsubsection{H/D Exchange and Competition Experiments}

The optimized reaction was conducted in the presence of the cosolvent $C_{3} \mathrm{OD}$ and $\mathrm{D}_{2} \mathrm{O}$. A H/D scrambling was observed in the reisolated substrate 145a and the product 146a, which suggested a reversible $\mathrm{C}-\mathrm{H}$ cleavage, occurring by an organometallic $\mathrm{C}-\mathrm{Ru}$ bond formation (Scheme 3.3.3.1a). Intermolecular competition experiments showed a slight preference for electron-poor alkynes 64 and electron-rich arenes 147 (Scheme 3.3.3.1b).

a) $H / D$ exchange experiments
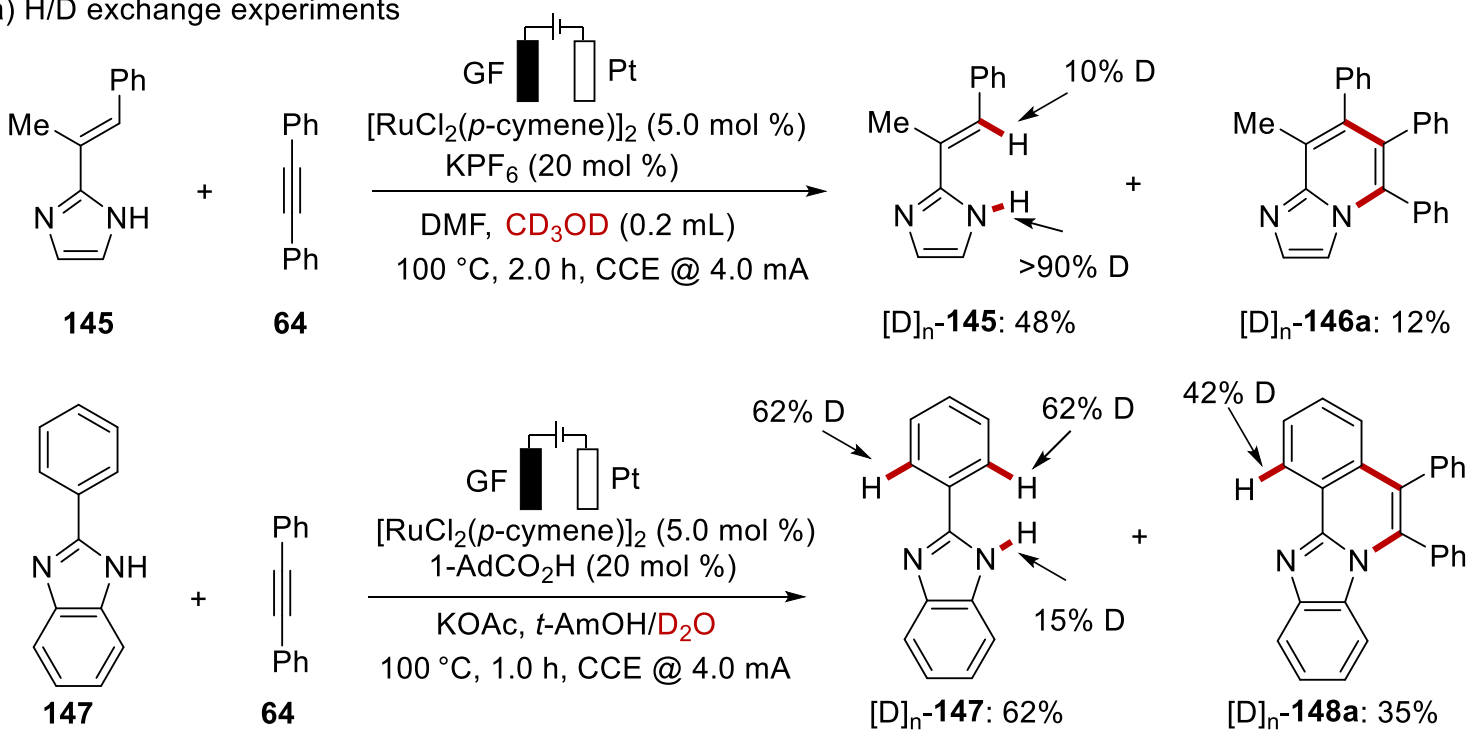

b) competition experiments<smiles>[R]c1cccc(C#Cc2cccc([R])c2)c1</smiles>

145 64b: $R=M e$

64d: $R=\mathrm{CF}_{3}$

$[D]_{n}-147: 62 \%$

[D] $-148 a: 35 \%$
$\left[\mathrm{RuCl}_{2}(p \text {-cymene })\right]_{2}(5.0 \mathrm{~mol} \%)$ $\mathrm{KPF}_{6}(20 \mathrm{~mol} \%)$

DMF, $140{ }^{\circ} \mathrm{C}, 8.0 \mathrm{~h}$ CCE @ 4.0 mA

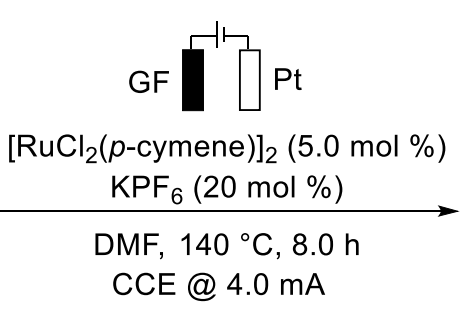

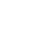
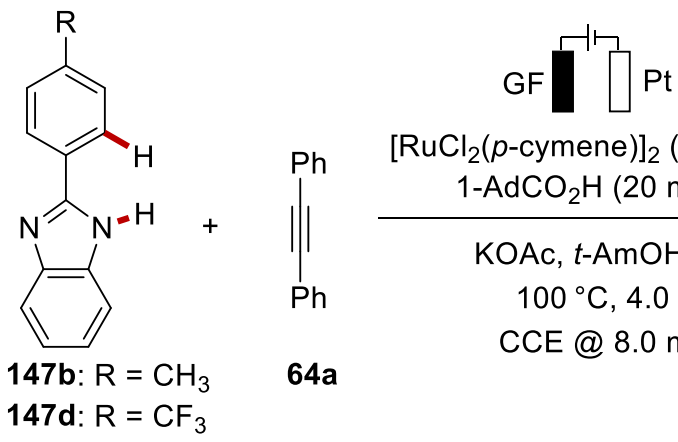

$\left[\mathrm{RuCl}_{2}(p \text {-cymene })\right]_{2}(5.0 \mathrm{~mol} \%)$ $1-\mathrm{AdCO}_{2} \mathrm{H}(20 \mathrm{~mol} \%)$

$\mathrm{KOAc}, t-\mathrm{AmOH} / \mathrm{H}_{2} \mathrm{O}$

$100^{\circ} \mathrm{C}, 4.0 \mathrm{~h}$

CCE @ 8.0 mA<smiles>Cc1cccc(-c2c(-c3ccccc3)c(C)c3nccn3c2-c2ccccc2)c1</smiles>

146b: $24 \% \pm 3 \%$

146d: $28 \% \pm 3 \%$<smiles>Cc1c(-c2ccccc2)c(-c2cccc(C(F)(F)F)c2)c(-c2cccc(C(F)(F)F)c2)n2ccnc12</smiles><smiles>FC(F)(F)c1ccc2c(c1)c(-c1ccccc1)c(-c1ccccc1)n1c3ccccc3nc21</smiles>

148d: $34 \% \pm 2 \%$

Scheme 3.3.3.1. Mechanistic studies. (Competition experiments did by Msc. Ralf Steinbock) 


\subsubsection{Isolation and Characterization of Ruthenium(II) Intermediate}

Next, we probed the isolation of intermediates by stoichiometric experimentation. Thus, we first selectively prepared the ruthenacycle Ru-II (Scheme 3.3.3.2a). Second, the ruthenacycle Ru-II delivered the unprecedented aza-ruthena(II)-bicyclo-[3.2.0]-heptadienes Ru-IVa and Ru-IVb upon stoichiometric reaction with the alkynes 64. Ru-IVa and Ru-IVb were unambiguously characterized by X-ray diffraction analysis. Notably, the metallacyles Ru-II and Ru-IV proved also to be competent under catalytic reaction conditions (Scheme 3.3.3.2b). It is noteworthy that the aza-ruthena(II)-bicyclo-[3.2.0]-heptadiene Ru-IVa was stable, but gave the product 146a under electrolysis, being suggestive of an oxidation-induced reductive elimination within a ruthenium(II/III) manifold (Scheme 3.3.3.2c).

(a) ruthenium complex synthesis

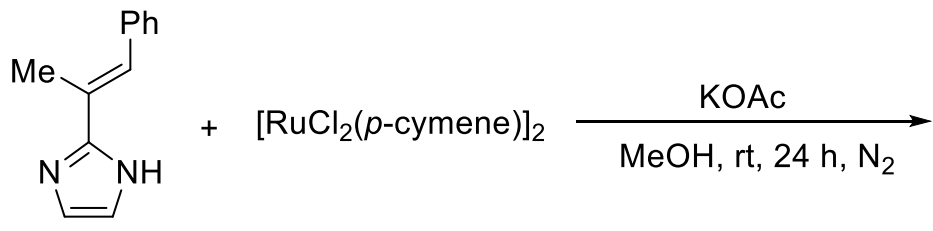

145

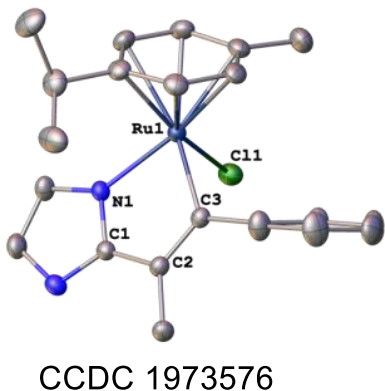

Ru-II $70 \%$

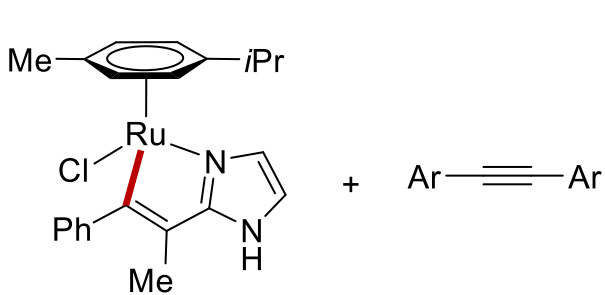

Ru-II

64

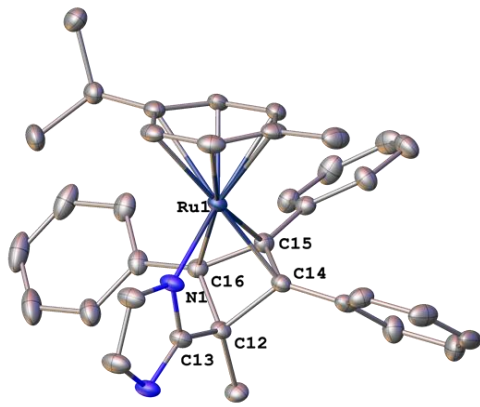

CCDC 1976887

$\mathrm{Ar}=\mathrm{C}_{6} \mathrm{H}_{5}(\mathbf{R u}-\mathrm{IVa}): 53 \%$
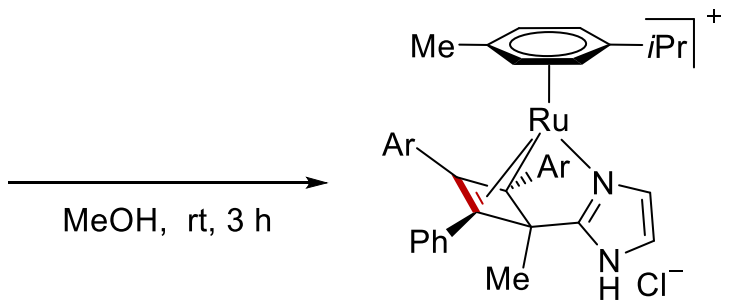

Ru-IV

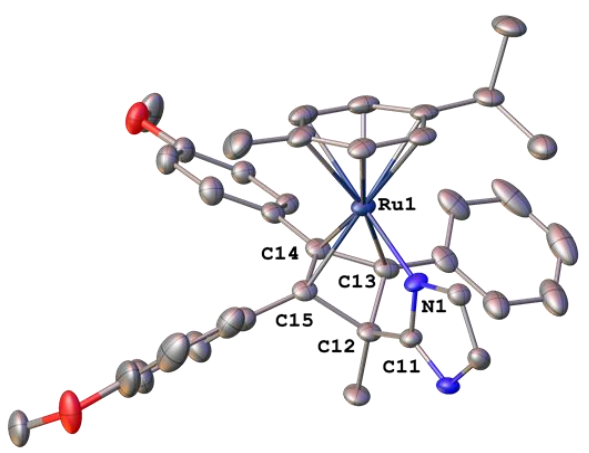

CCDC 1976885

$\mathrm{Ar}=4-\mathrm{MeOC}_{6} \mathrm{H}_{4}$ (Ru-IVb): $67 \%$ 
(b) catalytic reactivity of $\mathbf{R u}-\mathbf{I I}$ and $\mathbf{R} \mathbf{u}-\mathbf{I V a}$<smiles>C/C(=C\c1ccccc1)c1ncc[nH]1</smiles>

145a

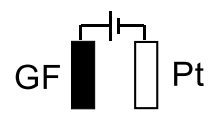<smiles>C#CPc1ccccc1</smiles>

$64 a$

Ru-II or Ru-IVa (10 $\mathrm{mol} \%)$<smiles>O=C(O)COC(=O)CO</smiles>

CCE @ $4.0 \mathrm{~mA}$<smiles>CC(C)(C)c1cnc2c(Cl)c(-c3ccccc3)c(-c3ccccc3)c(-c3ccccc3)n12</smiles>

$146 a$

with Ru-II : $74 \%$ with Ru-IVa : $61 \%$

(c) oxidatively induced reductive elimination

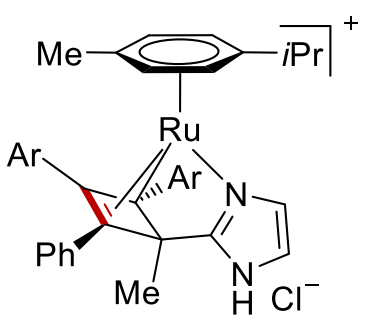

Ru-IVa

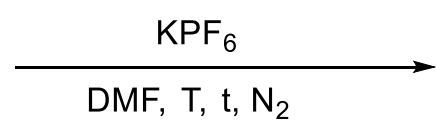<smiles>Cc1c(-c2ccccc2)c(-c2ccccc2)c(-c2ccccc2)n2ccnc12</smiles>

\begin{tabular}{cccccc}
\hline Entry & $\mathrm{t} / \mathrm{min}$ & $\mathrm{T} /{ }^{\circ} \mathrm{C}$ & Current & $\mathbf{R u}-\mathrm{IVa}$ & $\mathbf{1 4 6 a}$ \\
\hline 1 & 10 & $\mathrm{rt}$ & --- & $100 \%$ & --- \\
2 & 10 & $\mathrm{rt}$ & $4.0 \mathrm{~mA}$ & $67 \%$ & $17 \%$ \\
3 & 10 & 80 & --- & $100 \%$ & --- \\
4 & 10 & 80 & $4.0 \mathrm{~mA}$ & $57 \%$ & $24 \%$ \\
5 & 60 & 80 & --- & $77 \%$ & --- \\
6 & 60 & 80 & $4.0 \mathrm{~mA}$ & --- & $53 \%$ \\
\hline
\end{tabular}

Scheme 3.3.3.2. Isolation and characterization of ruthenium(II) complexes. (a) ruthenium complex synthesis; (b) catalytic reactivity of ruthenium complex; (c) oxidatively-induced reductive elimination.

\subsubsection{Cyclic Voltammetry Studies of Ruthenium(II) Intermediate}

Furthermore, we probed the electrochemical $\mathrm{C}-\mathrm{H}$ activation by means of cyclovoltammetric analysis of the well-defined ruthenacycles along with Msc. Alexej Scheremetjew in the Ackermann group (Scheme 3.3.3.3). Thus, we observed at ambient temperature an irreversible oxidation of the ruthenium(II) complex Ru-II at $E_{p}=0.60 \mathrm{~V} v$ s. SCE. The aza-ruthena(II)-bicyclo[3.2.0]-heptadiene Ru-IVa featured a considerably higher oxidation wave at $E_{p}=1.20 \mathrm{~V} v$ s. SCE, both of which could be rationalized by an oxidation-induced reductive elimination within a ruthenium(II/III) regime. 


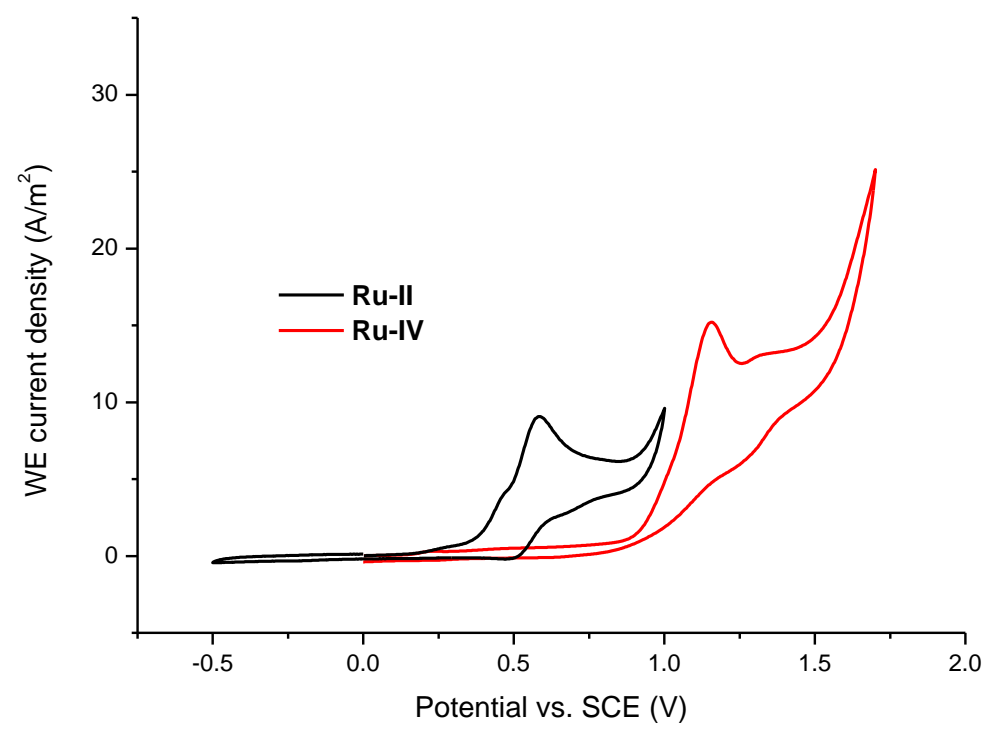

Scheme 3.3.3.3. Cyclic voltammetry in DMF with $100 \mathrm{~mm} \mathrm{KPF}_{6}$ under $\mathrm{N}_{2}$ at $100 \mathrm{mV} / \mathrm{s}$ of Ru-II (5 mM) and Ru-V (5 $\mathrm{mM})$. CV was performed by Msc. Alexej Scheremetjew.

\subsubsection{Proposed Mechanism}

Finally, based on our mechanistic studies, we proposed a plausible catalytic cycle to commence by a fast organometallic $\mathrm{C}-\mathrm{H}$ activation (Scheme 3.3.3.4). Thereby, ruthena(II)cycle Ru-II is generated. Thereafter, alkyne 64 coordination and migratory insertion furnish the aza-ruthenabicyclo-[3.2.0]-heptadiene Ru-IV, which undergoes anodic oxidation to deliver the ruthenium(III) complex Ru-V. Subsequent pericyclic ring opening yields ruthenium(III) complex Ru-VI. Oxidation-induced reductive elimination forms ruthenium(I) complex Ru-VII, which is anodically reoxidized to release the product and regenerate ruthenium(II) catalyst. 


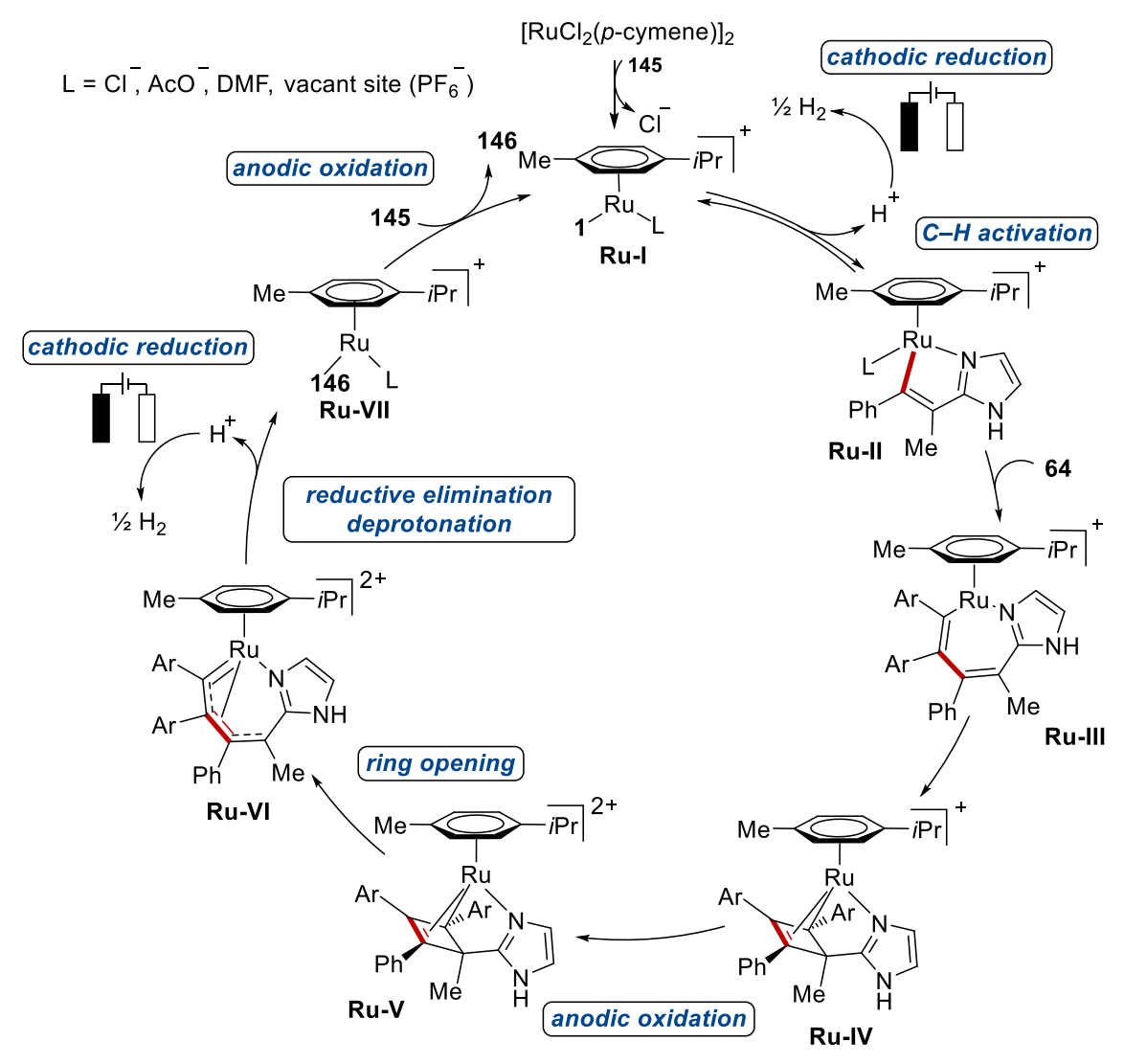

Scheme 3.3.3.4. Proposed mechanism of ruthenium(II/III/I)-catalyzed alkyne annulations. 


\subsection{Regioselective $\mathrm{B}(3,4)-\mathrm{H}$ Arylation of $o$-Carboranes}

Significant progress has been achieved in the regioselective functionalization of 0 -carboranes (vide supra). Despite indisputable advances, ${ }^{[151]}$ efficient approaches for complementary siteselective functionalizations of 0 -carboranes are hence in high demand. Thus, metal-catalyzed position-selective $\mathrm{B}(3,4)-\mathrm{H}$ functionalizations of $\mathrm{o}$-carboranes has thus far not been reported. In this chapter, a palladium-catalyzed regioselective di- or mono-arylation of 0 -carboranes was achieved by weakly coordinating amides at room temperature. ${ }^{[222]}$ Thereby, a series of $\mathrm{B}(3,4)$ diarylated and $\mathrm{B}(3)$-monoarylated 0 -carboranes anchored with valuable functional groups were accessed for the first time. This strategy provided an efficient approach for the selective activation of $\mathrm{B}(3,4)-\mathrm{H}$ bonds for functionalizations of $o$-carboranes.

\subsubsection{Optimization and Scope of $B(3,4)-H$ Arylation of $o$-Carboranes}

Optimization studies on the palladium-catalyzed $\mathrm{B}(3,4)-\mathrm{H}$ arylation were initially performed by $\mathrm{Dr}$. Yu-Feng Liang ${ }^{[22]}$ and after testing various additives and solvents, catalytic reaction conditions comprised of $\mathrm{Pd}(\mathrm{OAc})_{2}$ (10 mol \%), $\operatorname{AgTFA}$ (2.0 equiv) and TFA (1.0 equiv.) in HFIP at room temperature for $16 \mathrm{~h}$ were identified as optimal for the uncommon $\mathrm{B}(3,4)$-di-arylated product 150. While replacing AgTFA with $\mathrm{Ag}_{2} \mathrm{CO}_{3}$ resulted in the formation of $\mathrm{B}(3)-\mathrm{H}$ mono-arylation product 153 as the major product. With the optimized reaction conditions in hand, Dr. Yu-Feng Liang probed the scope of the $\mathrm{B}-\mathrm{H}$ di-arylation of $\mathrm{o}$-carboranes 149 with different aryl iodides 19a (Scheme 3.4.1.1). The versatility of the room temperature $\mathrm{B}(3,4)-\mathrm{H}$ di-arylation was demonstrated by tolerating valuable functional groups, including bromo (150c), chloro (150d, 150f), and enolizable ketone (150e) substituents. 


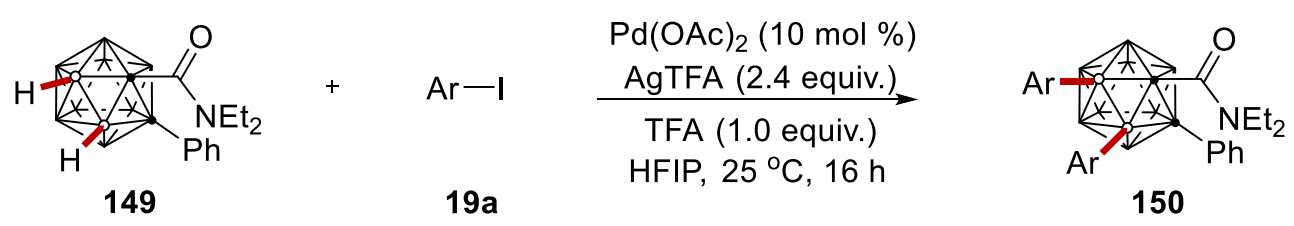

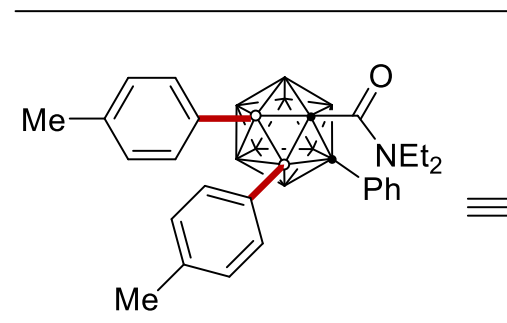

150a: $71 \%$

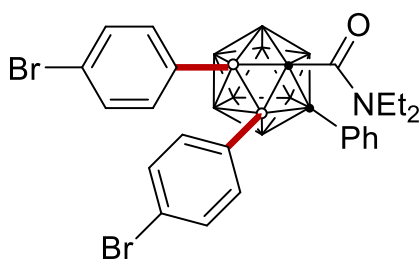

150c: $61 \%$<smiles>CCNC(=O)c1c(-c2ccc(C(C)=O)cc2)cc2c(c1-c1ccc(C(C)=O)cc1)-c1ccccc1-2</smiles>

150e: $58 \%$

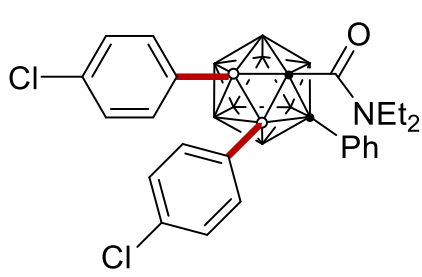

150d: $68 \%$

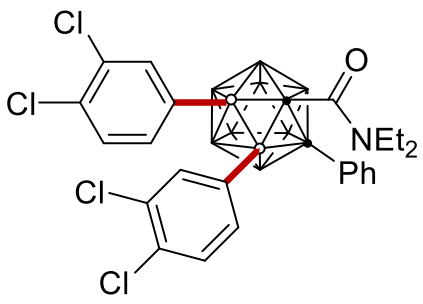

150f: $64 \%$

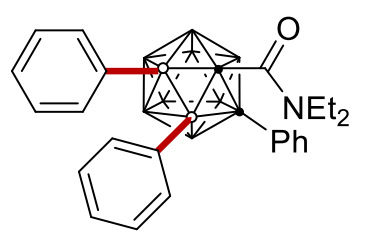

150b: $68 \%$

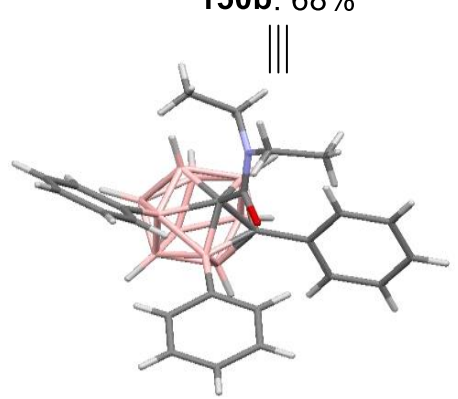

CCDC 1983600 $150 \mathrm{~b}$

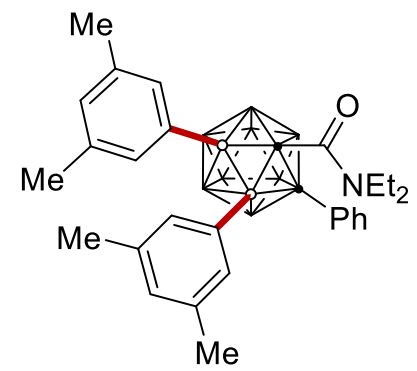

150g: $63 \%$

Scheme 3.4.1.1. Palladium-catalyzed B(3,4)-diarylation carried out by Dr. Yu-Feng Liang.

Next, we explored the effect exerted by the $N$-substituent at the amide moiety (Scheme 3.4.1.2). Tertiary amides 151 proved to be suitable substrates with optimal conditions. The effect of varying the cage carbon substituents $R^{1}$ on the reaction was also probed, and both aryl and alkyl substituents gave the $\mathrm{B}-\mathrm{H}$ arylation products $152 \mathrm{a}-\mathbf{1 5 2 \mathrm { g }}$. 

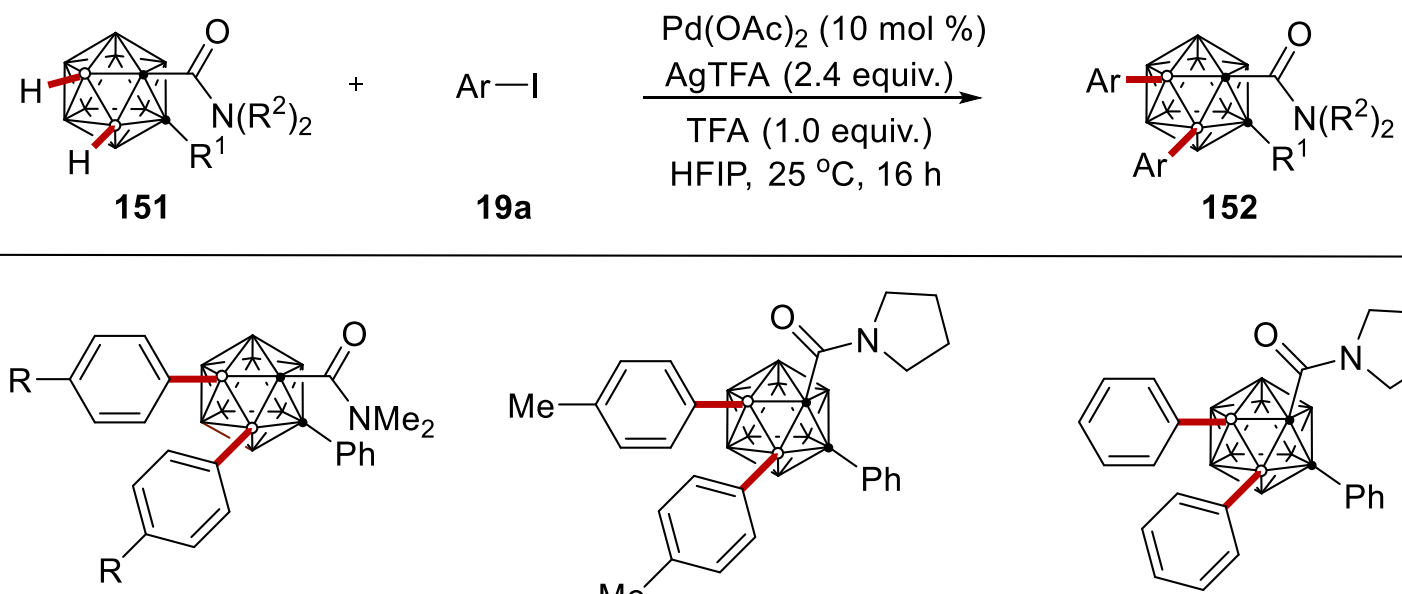

$R=M e(152 a): 51 \%$

$R=H \quad$ (152b): $53 \%$

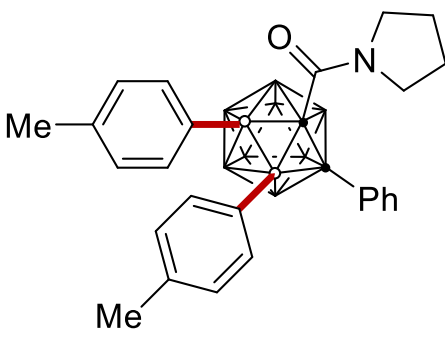

152c: $60 \%$ [a]

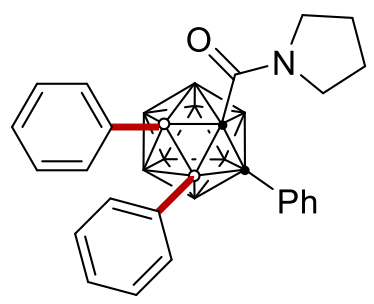

152d: $53 \%$

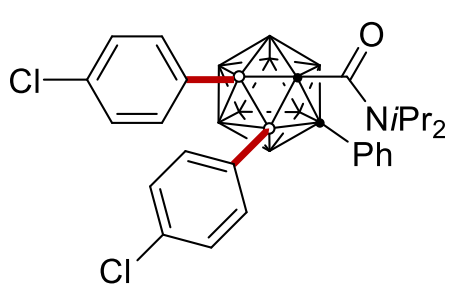

152e: $54 \%$

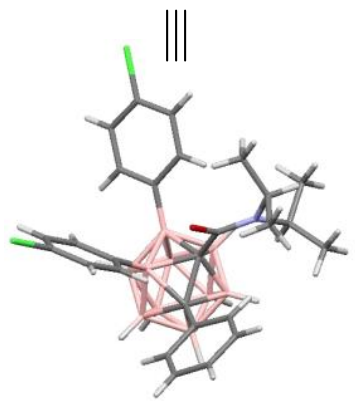

CCDC 1983612

$152 e$

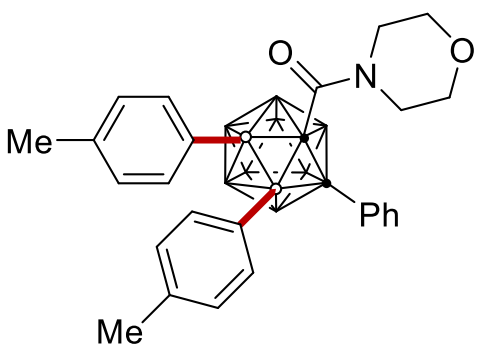

152f: $52 \%$

$\|$

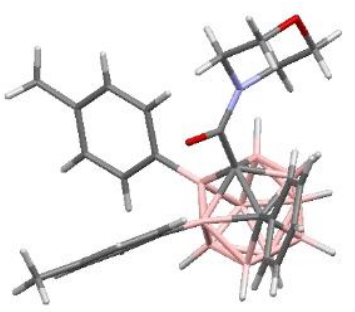

CCDC 1983607

$152 f$

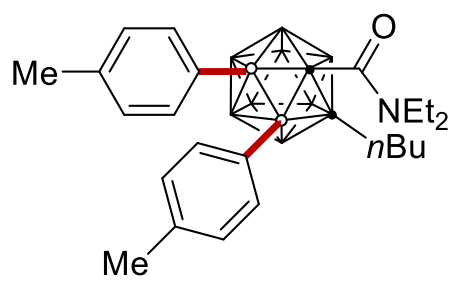

152g: $47 \%$
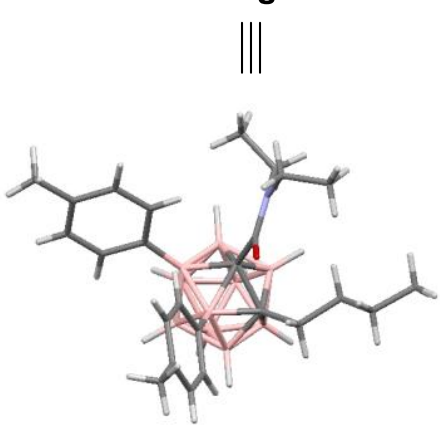

CCDC 1983615

$152 \mathrm{~g}$

Scheme 3.4.1.2. Palladium-catalyzed B(3,4)-diarylation with different o-carboranes. (152c did by Becky Bongsuiru Jei)

Thereafter, the robustness of the palladium-catalyzed $\mathrm{B}-\mathrm{H}$ functionalization was subsequently investigated by Dr. Yu-Feng Liang and Becky Bongsuiru Jei for the challenging catalytic B-H monoarylation of o-carboranes (Scheme 3.4.1.3). The $\mathrm{B}(3)-\mathrm{H}$ monoarylation proceeded smoothly with valuable functional groups, featuring aldehyde (153d) bromo (153c) and nitro (153b) substituents, which allow for invaluable further late-stage manipulation. 


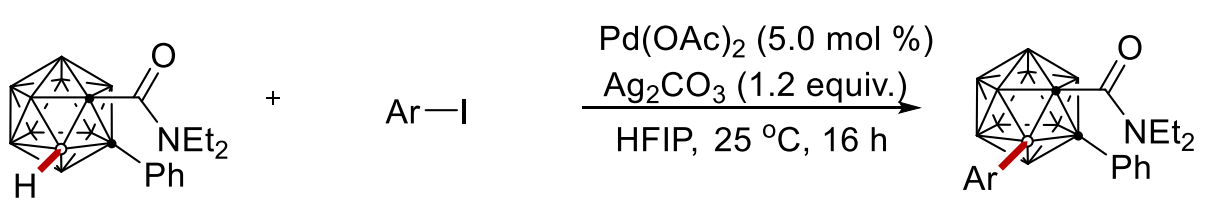

149

$19 a$

153

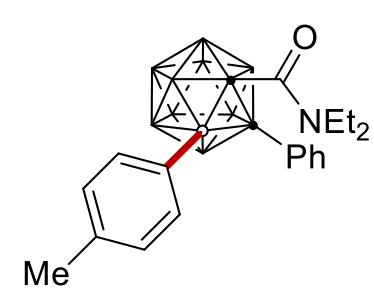

153a: $55 \%$

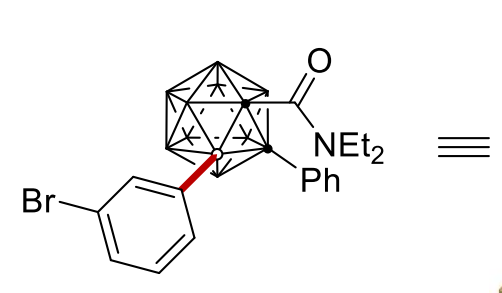

153c: $50 \%$

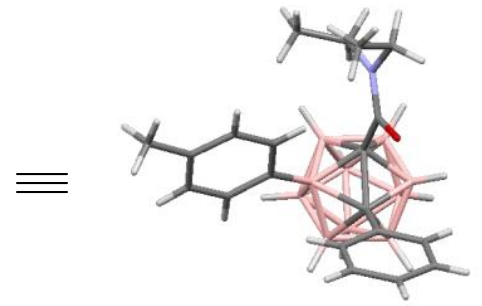

CCDC 1893313

153a

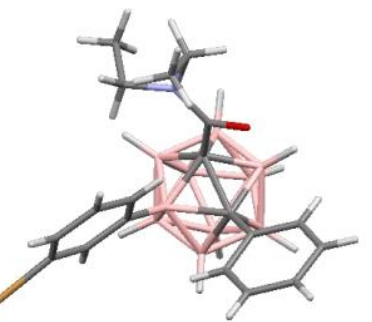

CCDC 1983611 $153 \mathrm{c}$

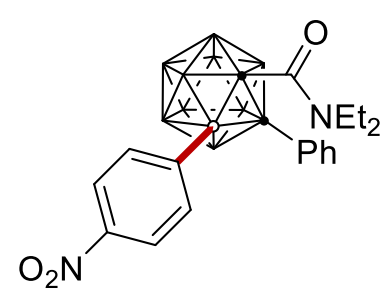

153b: $61 \%$

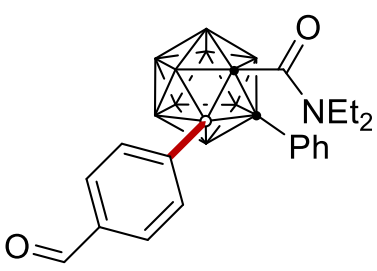

153d: $51 \%$

Scheme 3.4.1.3. Palladium-catalyzed B(3)-arylation. (153a, 153b and 153d did by Dr. Yu-Feng Liang. 153c did by Becky Bongsuiru Jei)

\subsubsection{Proposed Mechanism}

A plausible reaction mechanism is proposed to commence by an organometallic $B(3)-H$ activation of $\mathbf{1 4 9}$ by weak assistance of the amide group and AgTFA to form cationic intermediate I (Scheme 3.4.2). Oxidative addition with Arl 19a affords proposed palladium(IV) cationic intermediate II, followed by reductive elimination to give the B(3)-mono-arylation product 153. Subsequent $B(4)$-arylation occurs assisted by the weakly-coordinating amide to generate the $B(3,4)$-di-arylation product 150 . Due to the innate reactivity of the $B(4)-H$ bond in 153 , which is inherently higher than that of the $\mathrm{B}(6)-\mathrm{H}$ bond, the $\mathrm{B}(3,6)$-di-arylation product is not formed. 


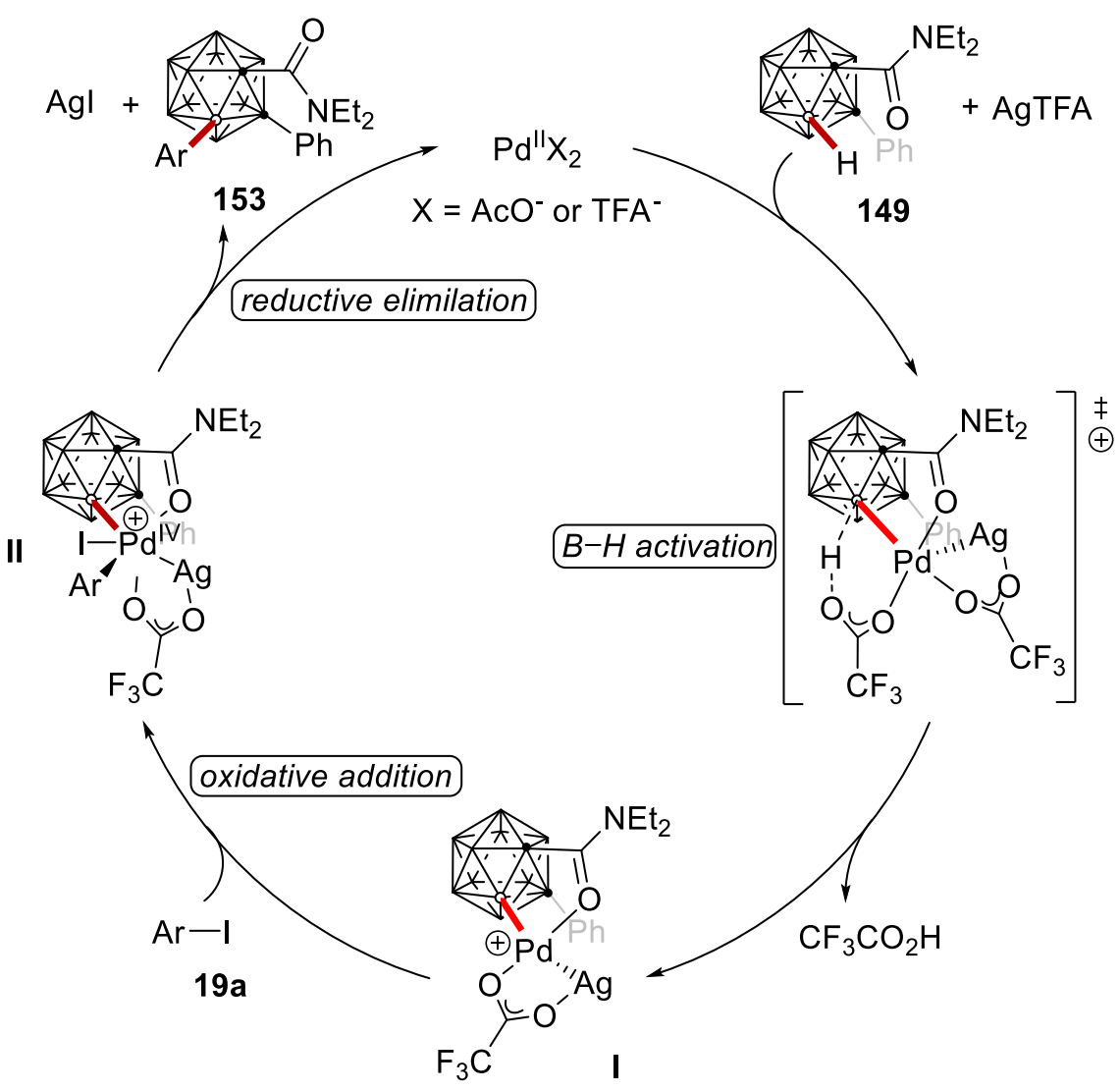

Scheme 3.4.2. Proposed mechanism for palladium-catalyzed B(3,4)-arylation. 


\subsection{Electrochemical B-H Nitrogenation of nido-Carboranes}

While the use of electricity as a redox reagent to facilitate chemical reactions has been recognized as an increasingly viable and environmentally-friendly strategy, ${ }^{[00,209]}$ the merger of electrosynthesis with cage $\mathrm{B}-\mathrm{H}$ functionalization of carboranes continues to be scarce. In this context, we have developed a strategy for unprecedented electrochemical regioselective cage B-H nitrogenation of nido-carborane in a dehydrogenative manner, assembling a variety of $N$ heterocycle-, amino acid- and BODIPY-labeled nido-carboranes. ${ }^{[223]}$

\subsubsection{Optimization and Scope}

The study was started by probing various reaction conditions for the envisioned electrochemicalcatalyzed B-N coupling of nido-carborane 154 with pyridine 155 at room temperature in an operationally simple undivided cell setup equipped with a GF (Graphite Felt) anode and a Ptplate cathode (Table 3.5.1). After considerable preliminary experimentation, we were delighted to observe that the desired B-pyridine nido-carborane product 156 was obtained in $60 \%$ yield in $\mathrm{DME} / \mathrm{H}_{2} \mathrm{O}$ as the reaction medium (entries 1-4). Further electrolyte optimization indicated that $\mathrm{NMe}_{4} \mathrm{Cl}$ was best (entries 5-7). Increasing the amount of $\mathrm{H}_{2} \mathrm{O}$ to $1.0 \mathrm{~mL}$ led to a significant decrease in the yield (entries 8-9), while reducing it to $0.2 \mathrm{~mL}$ increased the catalytic efficiency to $83 \%$ isolated yield of product 156 (entry 10). Control experiments confirmed the essential role of the $\mathrm{H}_{2} \mathrm{O}$, the electricity, the $\mathrm{NMe}_{4} \mathrm{Cl}$ additive and the GF as the anode material (entries 11-16).

Table 3.5.1: Optimization of the reaction conditions. ${ }^{[a]}$

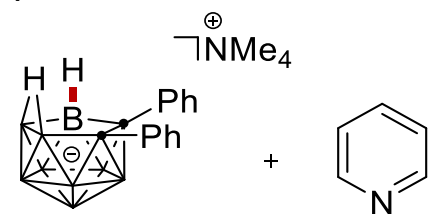

$154 a$

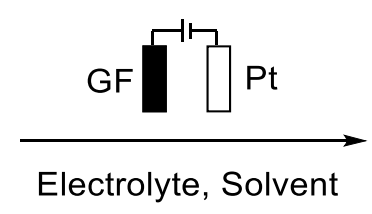

rt, 3.0 h, CCE @ 6.0 mA

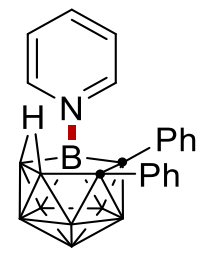

$156 a$

\begin{tabular}{|c|c|c|c|}
\hline Entry & Electrolyte & Solvent & Yield [\%] $]^{[b]}$ \\
\hline 1 & --- & $\mathrm{MeOH} / \mathrm{H}_{2} \mathrm{O}$ & $8 \%[c]$ \\
\hline 2 & --- & $\mathrm{THF} / \mathrm{H}_{2} \mathrm{O}$ & $36 \%[c]$ \\
\hline 3 & --- & $\mathrm{CH}_{3} \mathrm{CN} / \mathrm{H}_{2} \mathrm{O}$ & $40 \%[c]$ \\
\hline 4 & --- & $\mathrm{DME} / \mathrm{H}_{2} \mathrm{O}$ & $60 \%[c]$ \\
\hline 5 & $n \mathrm{BuNPF}_{6}$ & $\mathrm{DME} / \mathrm{H}_{2} \mathrm{O}$ & $20 \%[c]$ \\
\hline
\end{tabular}




\begin{tabular}{|c|c|c|c|}
\hline 6 & $n \mathrm{BuNBF}_{4}$ & $\mathrm{DME} / \mathrm{H}_{2} \mathrm{O}$ & $63 \%[c]$ \\
\hline 7 & $\mathrm{NMe}_{4} \mathrm{Cl}$ & $\mathrm{DME} / \mathrm{H}_{2} \mathrm{O}$ & $65 \%[c]$ \\
\hline 8 & $\mathrm{NMe}_{4} \mathrm{Cl}$ & $\mathrm{DME} / \mathrm{H}_{2} \mathrm{O}$ & $32 \%[d]$ \\
\hline 9 & $\mathrm{NMe}_{4} \mathrm{Cl}$ & $\mathrm{DME} / \mathrm{H}_{2} \mathrm{O}$ & $50 \%\left[{ }^{[e]}\right.$ \\
\hline 10 & $\mathrm{NMe}_{4} \mathrm{Cl}$ & $\mathrm{DME} / \mathrm{H}_{2} \mathrm{O}$ & $87 \%(83 \%)^{[f]}$ \\
\hline 11 & $\mathrm{NMe}_{4} \mathrm{Cl}$ & DME & $10 \%$ \\
\hline 12 & $\mathrm{NMe}_{4} \mathrm{Cl}$ & $\mathrm{DME} / \mathrm{H}_{2} \mathrm{O}$ & ---[g] \\
\hline 13 & --- & $\mathrm{DME} / \mathrm{H}_{2} \mathrm{O}$ & $67 \%$ \\
\hline 14 & $\mathrm{KCl}$ & $\mathrm{DME} / \mathrm{H}_{2} \mathrm{O}$ & $75 \%$ \\
\hline 15 & $\mathrm{NaCl}$ & $\mathrm{DME} / \mathrm{H}_{2} \mathrm{O}$ & $70 \%$ \\
\hline 16 & $\mathrm{NMe}_{4} \mathrm{Cl}$ & $\mathrm{DME} / \mathrm{H}_{2} \mathrm{O}$ & $73 \% \%^{[h]}$ \\
\hline
\end{tabular}

[a] Reaction conditions: 154 (0.10 mmol), 155 (0.30 mmol), electrolyte (2 equiv.), DME (4.0 mL), $\mathrm{H}_{2} \mathrm{O}(0.2 \mathrm{~mL}), 25^{\circ} \mathrm{C}$, $3 \mathrm{~h}$. [b] Yield was determined by ${ }^{1} \mathrm{H}$ NMR with $\mathrm{CH}_{2} \mathrm{Br}_{2}$ as the standard. [c] $\mathrm{H}_{2} \mathrm{O}(0.5 \mathrm{~mL})$. [d] $\mathrm{H}_{2} \mathrm{O}(1.0 \mathrm{~mL})$. [e] DME $(5.0 \mathrm{~mL}), \mathrm{H}_{2} \mathrm{O}(1.0 \mathrm{~mL})$. [f] Isolated yields in parenthesis. [g] No electricity. [h] Pt-plate as anode. DME = 1,2Dimethoxyethane, THF = Tetrahydrofuran.

With the optimized reaction conditions in hand, we probed its versatility for the $\mathrm{B}-\mathrm{N}$ coupling of nido-carboranes 154 with different $N$-heterocyclic substrates 155 (Scheme 3.5.1.1). Electron-rich as well as electron-deficient groups on the pyridine 155 were amenable to the electrocatalyzed $\mathrm{B}-\mathrm{H}$ oxidation coupling, providing the corresponding products in good to excellent yields (156a$156 \mathrm{~m})$. Thereby, a variety of synthetically useful functional groups, such as ester (156h), amide (156i), chloro (156j) and bromo (156k), were fully tolerated, which could prove instrumental for further late-stage manipulations. In addition, various isoquinolines (155n-155q) and even the carbazole-substituted pyridine (155r), afforded the corresponding electro-oxidative B-N coupling product in good to excellent yields (156n-156r). Notably, the free $\mathrm{NH}_{2}$-amino group (155d, 155I) was also tolerated under the mild electro-oxidative conditions, although the amine-substituted and Boc-protected amino isoquinoline products (156p-156q) were isolated in somewhat lower yields. Interestingly, the Steglich catalyst 4-dimethylaminopyridine (DMAP) was also a competent pyridine derivative in the electrochemical reaction, providing the DMAP decorated nido-carborane product $(\mathbf{1 5 6 m})$ with good efficacy.

The robustness of the electrooxidative $\mathrm{B}-\mathrm{N}$ formation at room temperature was next evaluated by other $N$-heterocyclic substrates, such as imidazole with $N=11.47$ in MeCN according to the Mayr's scale, ${ }^{[22]} \mathrm{N}$-substituted derivatives of imidazoles, thiazole and azaindoles, giving the corresponding B-N products in good to excellent yields (156s-156aa). In addition, dialkyl 
substituted nido-carboranes at the $\mathrm{C}$ (cage) site also proceed well under these electrochemical conditions, providing the corresponding B-N coupling products in good yields (156bb-156cc). Thus, the oxidant- and catalyst-free electrochemical oxidative $\mathrm{B}-\mathrm{N}$ coupling provides a new route to a convenient and versatile synthesis of $\mathrm{N}$-heterocycle-substituted nido-carboranes.

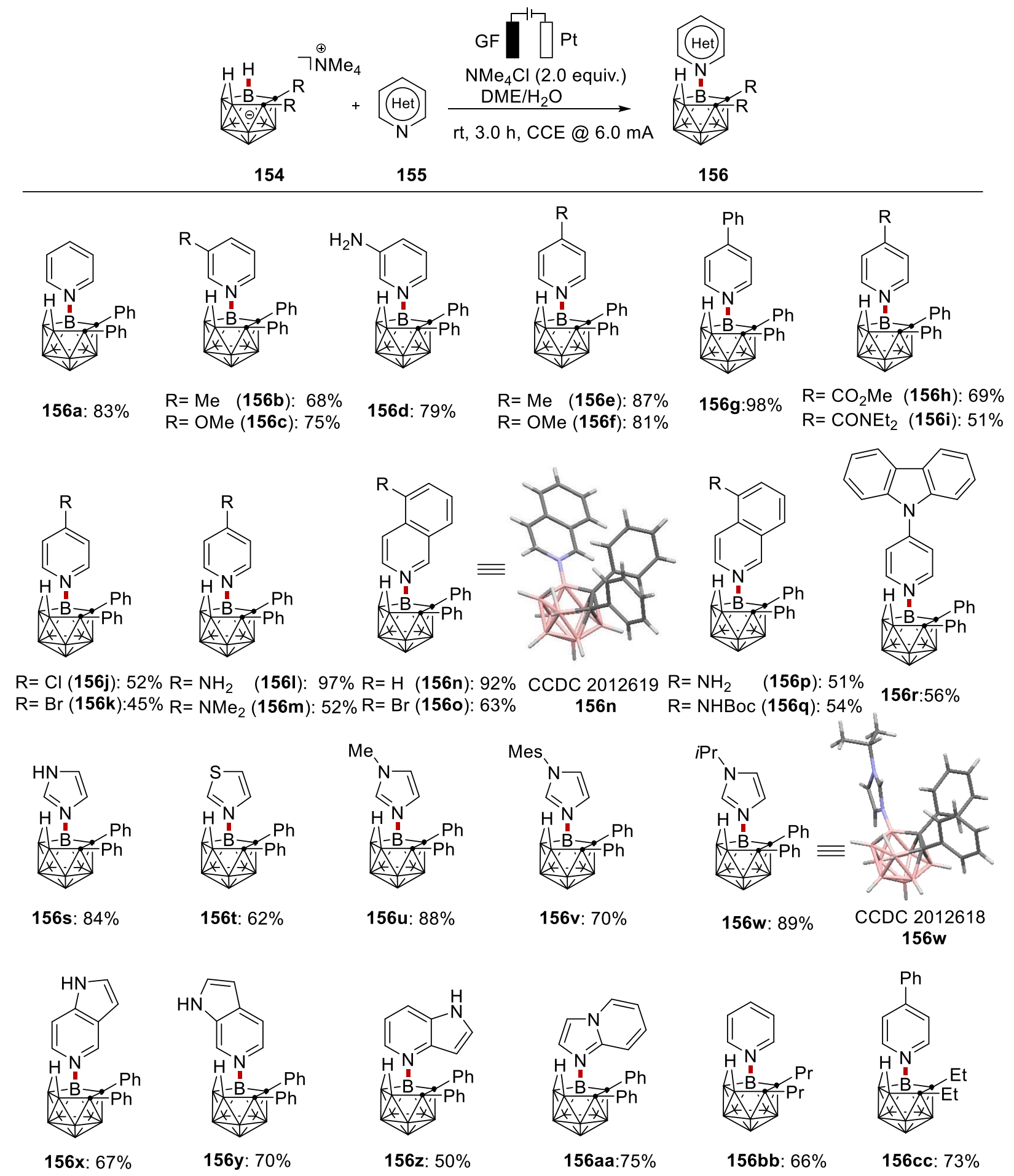

Scheme 3.5.1.1. Electrooxidative B-H nitrogenation of nido-carborane with $N$-heterocycles. (156b-156g, 156i-156k, 156q, 156s, 156t and 156x-156aa did by Becky Bongsuiru Jei) 
Encouraged by the unique efficiency of the electrocatalyzed metal-free $\mathrm{B}-\mathrm{N}$ oxidative coupling with various $\mathrm{N}$-heterocyclic substrates, we became intrigued to explore the late-stage amino acid and BODIPY diversification of structurally complex nido-carboranes (Scheme 3.5.1.2). Both amino acid- and BODIPY-labeled pyridine proved to be suitable substrates (157a-157e).
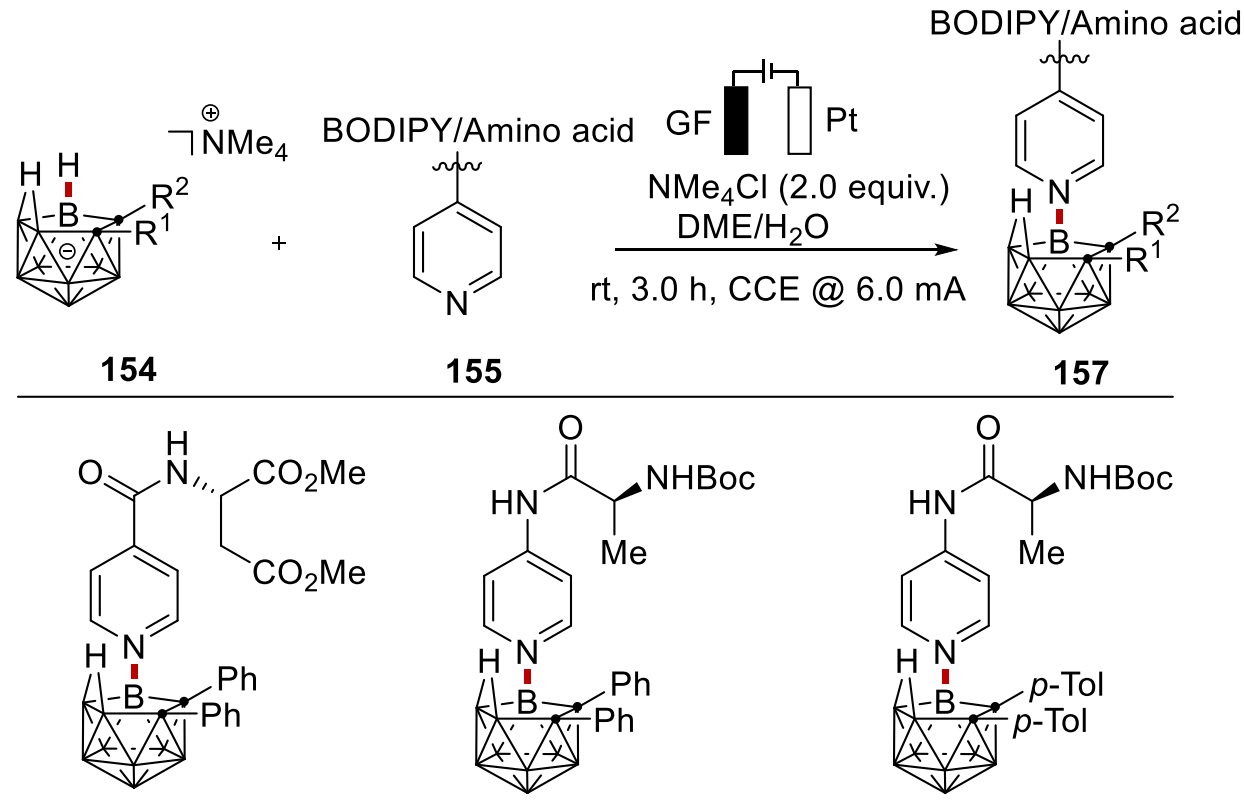

157a: $84 \%$

157b: $80 \%$

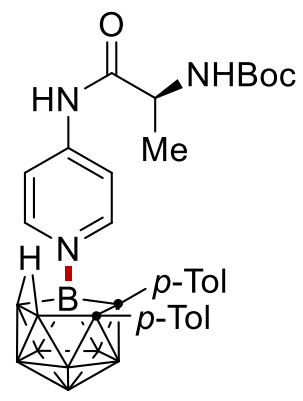

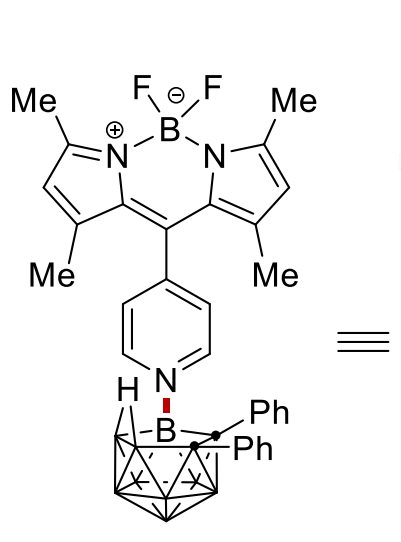

157d: $71 \%$

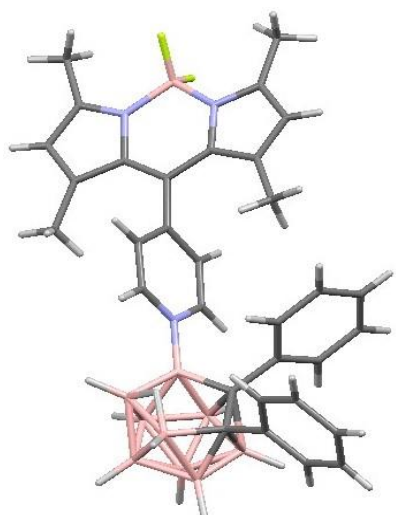

CCDC 2012620

$157 d$

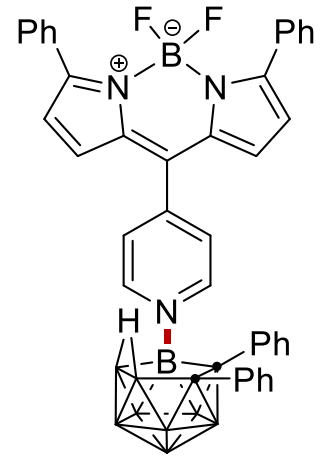

157e: $50 \%$

Scheme 3.5.1.2. Electrooxidative B-H nitrogenation of nido-carborane with amino acids and BODIPY pyridines. (157c did by Becky Bongsuiru Jei) 
The strategy was not restricted to intermolecular transformations. Actually, the intramolecular B-N couplings of nido-carborane 158 was likewise accomplished (Scheme 3.5.1.3), and either aryl or alkyl substituents at the cage-carbon site afforded comparable results (159a, 159b).

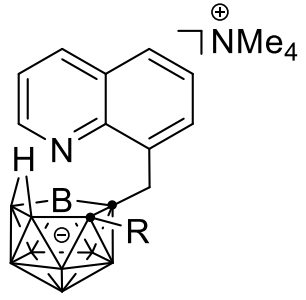

158

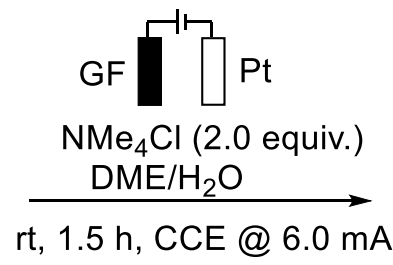

rt, 1.5 h, CCE @6.0 mA

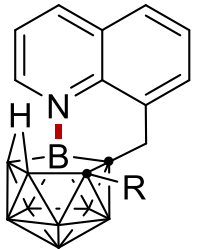

159

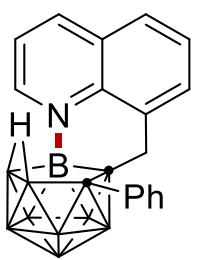

159a: $83 \%^{\mathrm{a}}$

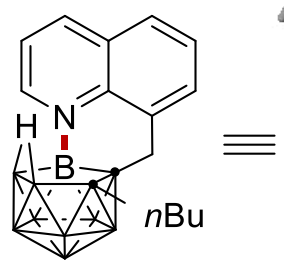

159b: $88 \%^{\mathrm{a}}$

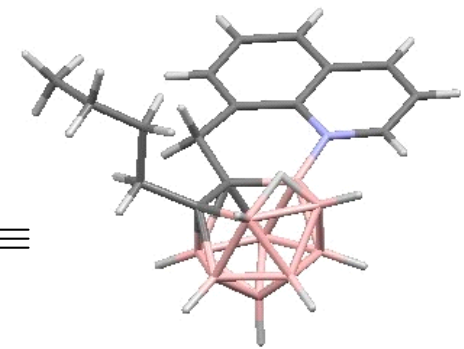

CCDC 2013117

Scheme 3.5.1.3. Electrooxidative intramolecular B-N annulation.

\subsubsection{Competition Experiments}

The high efficacy of the electrocatalyzed B-H activation for the synthesis of $\mathrm{N}$-heterocyclic nidocarboranes motivated us to delineate its mode of action. Thus, an intermolecular competition experiment between pyridine and imidazole revealed a slight preference for pyridine, likely due to the higher nucleophilicity of pyridine when compared to imidazole (pyridine: $N=11.05$ in $\mathrm{H}_{2} \mathrm{O}$, imidazole: $N=9.63$ in $\mathrm{H}_{2} \mathrm{O}$ ) ${ }^{[224]}$ (Scheme 3.5.2).

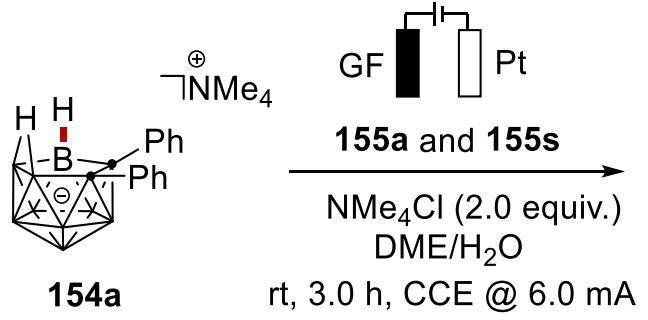

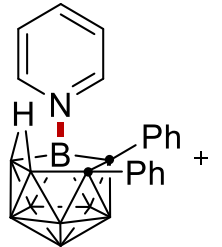

156a: $33 \%$

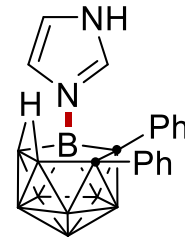

156s: $30 \%$

Scheme 3.5.2. Competition experiments. 


\subsubsection{Cyclic Voltammetry and Stability of $156 a$}

Furthermore, we probed the electrochemical B-H activation by means of cyclovoltammetric analysis of the nido-carborane along with Msc. Alexej Scheremetjew in the Ackermann group (Scheme 3.5.3). Thus, we observed an irreversible oxidation of the nido-carborane at $E_{\mathrm{p} / 2}=0.56$ $\mathrm{V} v s . \mathrm{Ag} / \mathrm{Ag}^{+}$at ambient temperature, which is indicative of a direct oxidation of the nidocarborane under electrochemical condition. Furthermore, the calculated half-wave oxidation potential of 154a using DFT computation by Dr. Rositha Kuniyil at the B97D3/def2-QZVP+ $\mathrm{CPCM}(\mathrm{DME}) / / \mathrm{B} 97 \mathrm{D} 3 /$ def2-TZVP level of theory is in good agreement with the one observed in our CV studies (exp: $E_{\mathrm{p} / 2}=0.87 \mathrm{~V}$ vs. SCE, calc: $E_{1 / 2}=0.86 \mathrm{~V} v$ s. SCE). Then, we also analyzed the thermal and chemical stability of 156a. We found that compound 156a $\left(0.4 \mathrm{~mL}\right.$ DMSO- $\left.\mathrm{d}_{6}\right)$ was quite stable when being heated to $120{ }^{\circ} \mathrm{C}$ for $10 \mathrm{~h}$ with only minor decomposition. In addition, the solution of $156 \mathrm{a}\left(0.4 \mathrm{~mL} \mathrm{CD}{ }_{3} \mathrm{CN}\right)$ was treated with $0.1 \mathrm{~mL} \mathrm{H}_{2} \mathrm{O}, \mathrm{HCl}$, or $\mathrm{NaOH}$, respectively. To this end, the ${ }^{11} \mathrm{~B}$ NMR experiments demonstrate that 156a has an excellent stability in a neutral environment, however, it is not stable in strongly acidic or alkaline environments.

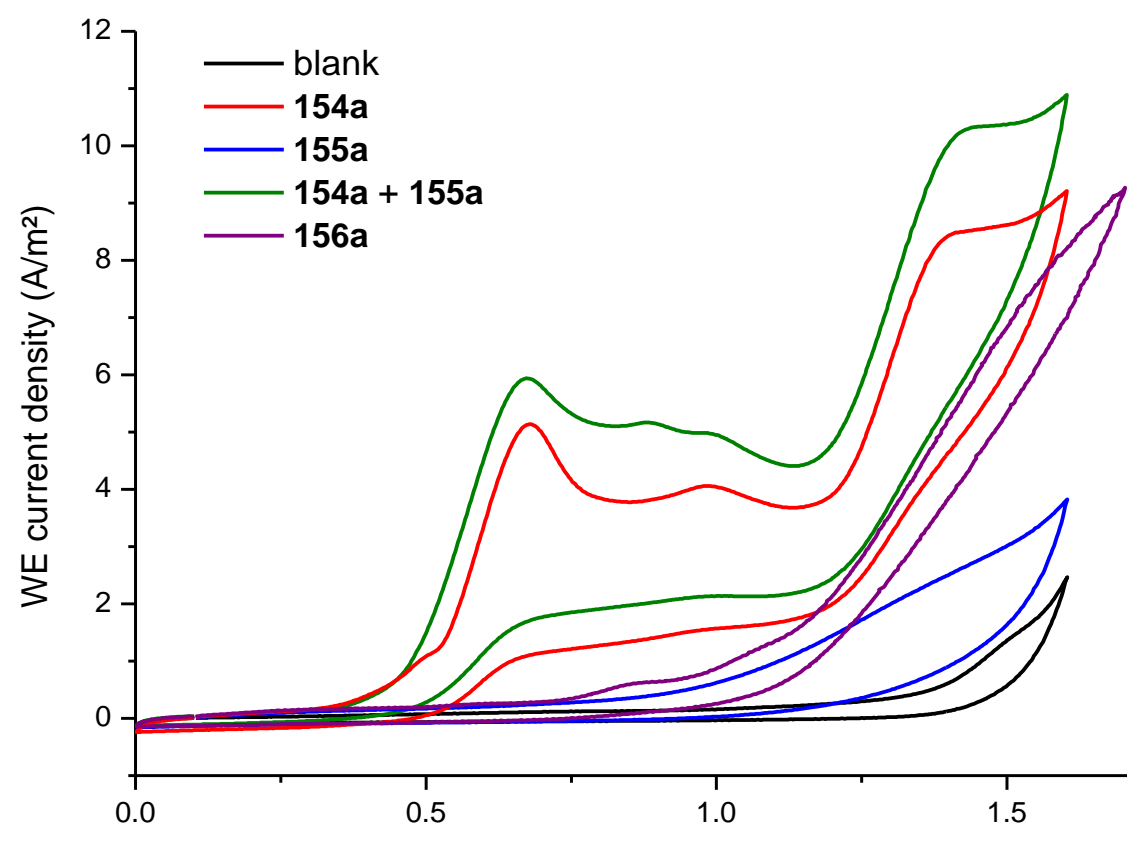

Potential vs. $\mathrm{Ag} / \mathrm{Ag}^{+}(\mathrm{V})$

Scheme 3.5.3. Cyclic voltammograms at $100 \mathrm{mV} / \mathrm{s}, n \mathrm{Bu}_{4} \mathrm{NPF}_{6}(0.1 \mathrm{M}$ in DME), concentration of substrates $1.0 \mathrm{mM}$. $\mathrm{CV}$ was performed by Msc. Alexej Scheremetjew. 


\subsubsection{Spectroscopic Data of BODIPY-Labelled nido-Carborane}

The optical properties of the thus-obtained novel BODIPY-labeled nido-carborane $157 \mathbf{d}$ and 157e were studied in detail by UV-Vis absorption and fluorescence spectroscopy in various solvents (Table 3.5.4). The unprecedented BODIPY-labeled nido-carboranes exhibited very intense absorption in the UV and visible region, with an absorption maximum between 507$582 \mathrm{~nm}$ and high Stokes shift, resulting in an intense red to purple color. This could be rationalized by the possible donor-acceptor-donor structure of the compounds $157 \mathrm{~d}$ and $157 \mathrm{e}$, as the nido-carborane core is an electron acceptor. These spectroscopic data indicated the unique potential applications of the BODIPY-labeled nido-carborane compounds in pharmaceuticals, luminescent materials and bioimaging.

Table 3.5.4. Spectroscopic data of BODIPY-labelled nido-carboranes 157d and 157e.

\begin{tabular}{cccccc}
\hline Compound & Solvent & ${ }^{\operatorname{Max}} \lambda_{\text {abs }}[\mathrm{nm}]$ & ${ }^{\operatorname{Max}} \lambda_{\text {em }}[\mathrm{nm}]$ & Stokes shift $\left[\mathrm{cm}^{-1}\right]$ & $\mathcal{E}_{\text {max }}\left[\mathrm{M}^{-1} \mathrm{~cm}^{-1}\right]$ \\
\hline \multirow{6}{*}{ 157d } & $\mathrm{DCM}$ & 512 & 569 & 1956 & 68812 \\
& $\mathrm{CHCl}_{3}$ & 513 & 567 & 1856 & 69790 \\
& Actone & 507 & 559 & 1834 & 73746 \\
& $\mathrm{DMF}$ & 509 & 561 & 1821 & 69557 \\
& $\mathrm{THF}$ & 509 & 562 & 1852 & 72549 \\
\hline \multirow{6}{*}{ 157e } & $\mathrm{DCM}$ & 577 & 634 & 1558 & 63459 \\
& $\mathrm{CHCl}_{3}$ & 582 & 640 & 1557 & 60882 \\
& $\mathrm{Actone}$ & 570 & 623 & 1492 & 65681 \\
& $\mathrm{DMF}$ & 574 & 602 & 810 & 58557 \\
& $\mathrm{THF}$ & 575 & 630 & 1518 & 67718 \\
\hline
\end{tabular}

\subsubsection{Proposed Mechanism}

Based on CV analysis and literature reports, ${ }^{[225]}$ a plausible reaction mechanism is proposed in Scheme 3.5.5, which commences with an anodic single electron-transfer (SET) process from nido-carborane ainon to form intermediate $\mathbf{I}$, followed by the oxidation to generate intermediate II. Subsequently, deprotonation of the bridge proton results in the formation of cage-open carborane intermediate III. Finally, the pyridine undergoes nucleophilic attack on the electron 
deficient $\mathrm{B}(9 / 11)-\mathrm{H}$ site of the intermediate III with consecutive transfer of $H$ to the $B(10)$ and $\mathrm{B}(11)$ forming a new bridge proton. In addition, molecular $\mathrm{H}_{2}$ is generated as the by-product through cathodic proton reduction, which was confirmed by head-space GC analysis.

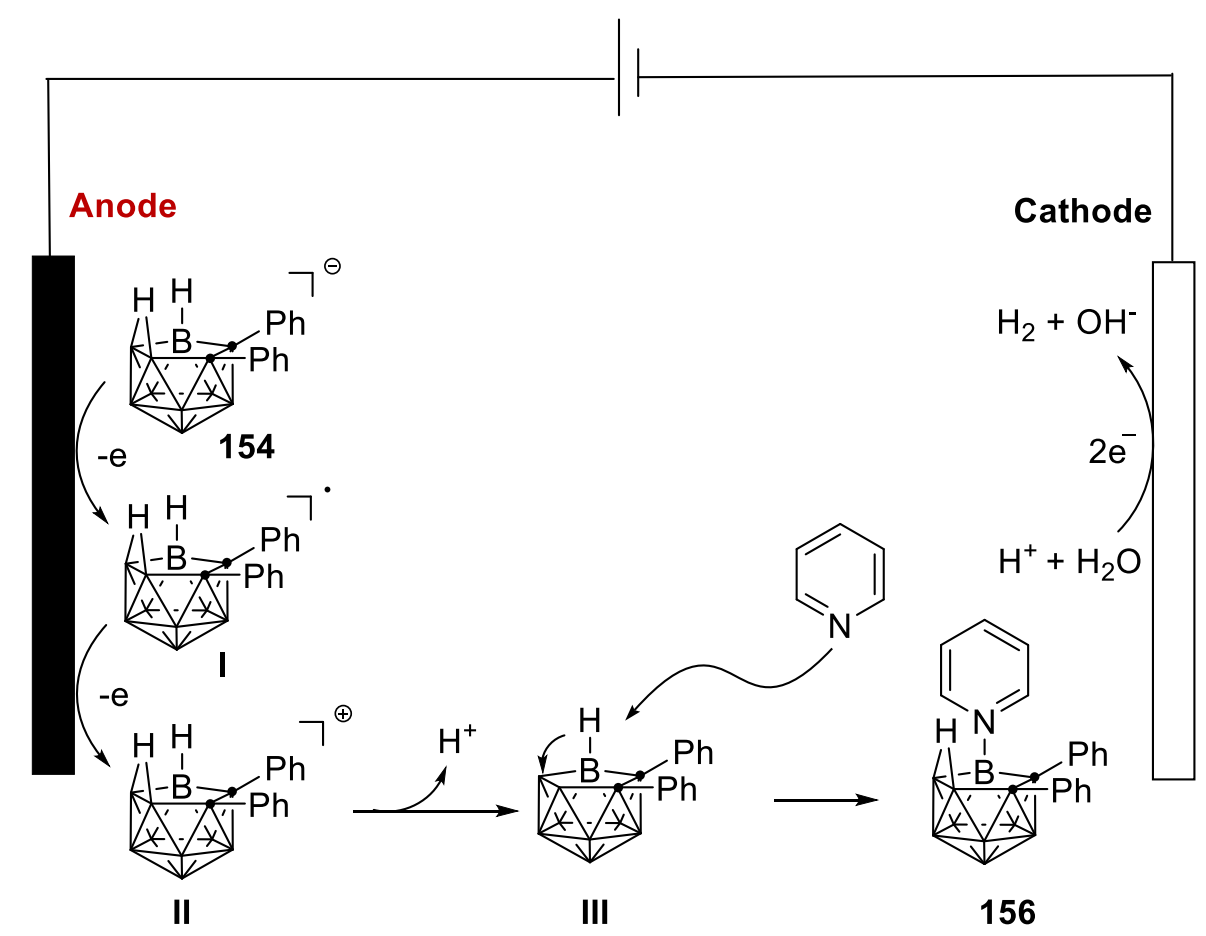

Scheme 3.5.5. Proposed reaction mechanism. 


\subsection{Cupraelectro-Catalyzed Chalcogenations of $o$-Carboranes}

In this section, we will disclose copper-catalyzed electrochemical direct chalcogenations of 0 carboranes at room temperature. Thereby, a series of cage C-sulfenylated and C-selenylated $o$ carboranes anchored with valuable functional groups were accessed with high levels of positionand chemo-selectivity control. The cupraelectrocatalysis provided efficient approaches to activate otherwise inert cage $\mathrm{C}-\mathrm{H}$ bonds for the late-stage diversification of $\mathrm{o}$-carboranes.

\subsubsection{Optimization and Scope}

We commenced our studies by probing various reaction conditions for the envisioned coppercatalyzed cage $\mathrm{C}-\mathrm{H}$ thiolation of $\mathrm{o}$-carborane in an operationally simple undivided cell setup equipped with a GF (graphite felt) anode and a Pt cathode (Table 3.6.1). After extensive experimentation, we observed that the thiolation of substrate $\mathbf{1 6 0}$ proceeded efficiently with catalytic amounts of CuOAc and 2-phenylpyridine in the presence of LiOtBu as the base, $n$ $\mathrm{Bu}_{4} \mathrm{NI}$ as the electrolyte at room temperature under a constant current of $2 \mathrm{~mA}$ (entry 1). The yield was reduced when other copper sources or additives were used (entries 2-5). Surprisingly, $n-\mathrm{Bu}_{4} \mathrm{NPF}_{6}$ as the electrolyte failed to facilitate the carborane modification, indicating that $n$ $\mathrm{Bu}_{4} \mathrm{NI}$ operates not only as electrolyte, but also as a redox mediator (entry 6). Altering the stoichiometry of the electrolyte or using $\mathrm{KI}$ did not improve the performance (entries 7,8). Product formation was not observed, when the reaction was conducted with DCE as the solvent, while $\mathrm{CH}_{3} \mathrm{CN}$ resulted in a drop of the catalytic performance (entries 9,10). Control experiments confirmed the essential role of the electricity and the catalyst (entries 11,12 ), while a sequential procedure was found to be beneficial (entries 13-15).

Table 3.6.1: Optimization of the reaction conditions. ${ }^{[a]}$

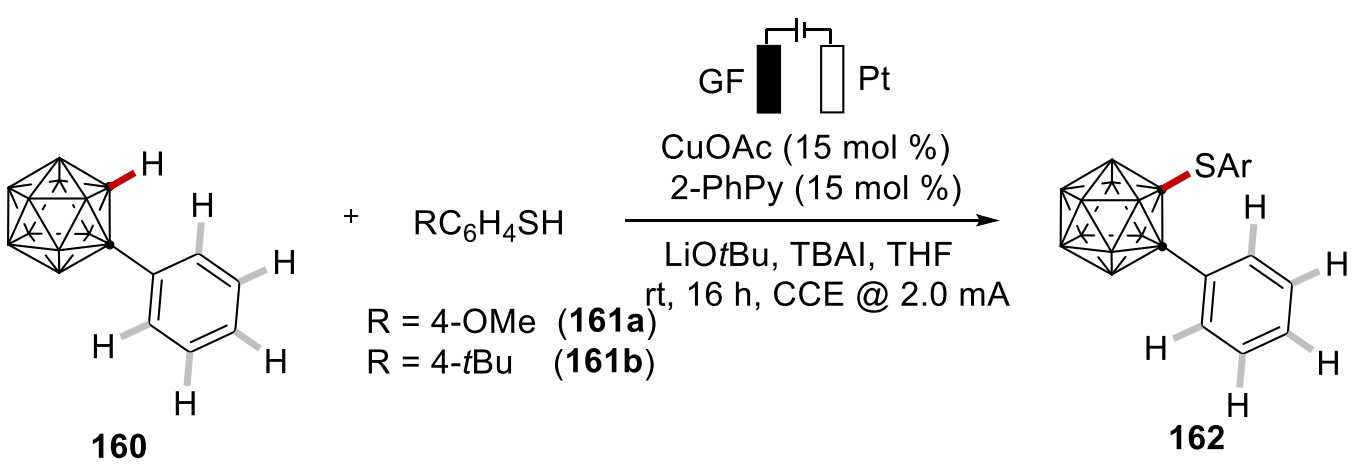




\begin{tabular}{|c|c|c|}
\hline Entry & Deviation from standard conditions & Yield [\%] ${ }^{[b]}$ \\
\hline 1 & none & $90 \%(85 \%)^{[c]}$ \\
\hline 2 & $\mathrm{Cu}(\mathrm{OAc})_{2}$ instead of $\mathrm{CuOAc}$ & $51 \%$ \\
\hline 3 & Cul instead of $\mathrm{CuOAc}$ & $43 \%$ \\
\hline 4 & 2,6-Lutidine instead of 2-PhPy & $71 \%$ \\
\hline 5 & 1,10-Phen instead of 2-PhPy & $16 \%$ \\
\hline 6 & TBAPF $_{6}$ instead of TBAI & --- \\
\hline 7 & TBAI (3 equiv.) & $49 \%$ \\
\hline 8 & $\mathrm{KI}$ (1 equiv) as additive & $67 \%$ \\
\hline 9 & DCE instead of THF & --- \\
\hline 10 & $\mathrm{CH}_{3} \mathrm{CN}$ instead of THF & $49 \%$ \\
\hline 11 & No electricity & $14 \%[\mathrm{~d}]$ \\
\hline 12 & No [Cu] & --- \\
\hline 13 & Procedure B (161b) & $66 \%(62 \%)^{[e, d]}$ \\
\hline 14 & Procedure B: second step without electricity (161b) & $--_{-[}[]$ \\
\hline 15 & Procedure B (161a) & $92 \%[\mathrm{e}]$ \\
\hline
\end{tabular}

[a] Reaction conditions: Procedure A: 160a $(0.10 \mathrm{mmol}), 161 \mathrm{a}(0.3 \mathrm{mmol})$, CuOAc (15 mol \%), 2-PhPy (15 mol \%), LiOtBu (0.2 mmol), TBAI (2.0 equiv.), solvent $(3.0 \mathrm{~mL})$, platinum cathode $(10 \mathrm{~mm} \times 15 \mathrm{~mm} \times 0.25 \mathrm{~mm})$, graphite felt (GF) anode (10 mm $\times 15 \mathrm{~mm} \times 6 \mathrm{~mm}), 2 \mathrm{~mA}$, under air, rt, $16 \mathrm{~h}$. [b] Yield was determined by ${ }^{1} \mathrm{H} \mathrm{NMR}$ with $\mathrm{CH}_{2} \mathrm{Br}_{2}$ as the internal standard. [c] Isolated yields in parenthesis. [d] $\mathrm{KI}$ (1.0 equiv) as additive. [e] Procedure B: 161a (0.3 mmol), LiOtBu (0.2 mmol), TBAI (2.0 equiv), solvent (3.0 mL), $2 \mathrm{~mA}$, rt, $3 \mathrm{~h}$, then adding 160a $(0.10 \mathrm{mmol})$, 2-PhPy (15 mol \%), CuOAc (15 mol \%), 2 mA, rt, 16 h. [f] 161b (0.3 mmol), LiOtBu (0.2 mmol), KI (1.0 equiv.), TBAl (2.0 equiv.), solvent (3.0 mL), $2 \mathrm{~mA}$, rt, $3 \mathrm{~h}$, then adding 160a (0.10 mmol), 2-PhPy (15 mol \%), CuOAc (15 mol \%), rt, $16 \mathrm{~h}$.

With the optimized reaction conditions in hand, we explored the versatility of the cage $\mathrm{C}-\mathrm{H}$ thiolation of $o$-carborane 160a with different thiols 161 (Scheme 3.6.1.1). Electron-rich as well as electron-deficient substituents on the arenes were found to be suitable for the electrocatalyzed $\mathrm{C}-\mathrm{H}$ activation, providing the corresponding thiolation products $162 \mathrm{a}-162 \mathrm{O}$ in good to excellent yields. Thereby, a variety of synthetically useful functional groups, such as fluoro (162e and $162 \mathrm{~m}$ ), chloro (162f, 162k, and $162 \mathrm{n}$ ) and bromo (162g and 162l), were fully tolerated, which should prove instrumental for further late-stage manipulations. Various disubstituted aromatic and heterocyclic thiols afforded the corresponding cage $C-S$ modified products 162p-162s. Notably, aliphatic thiols efficiently underwent the electrochemical transformation to provide the corresponding cage alkylthiolated products $162 \mathrm{t}-162 \mathrm{u}$. 


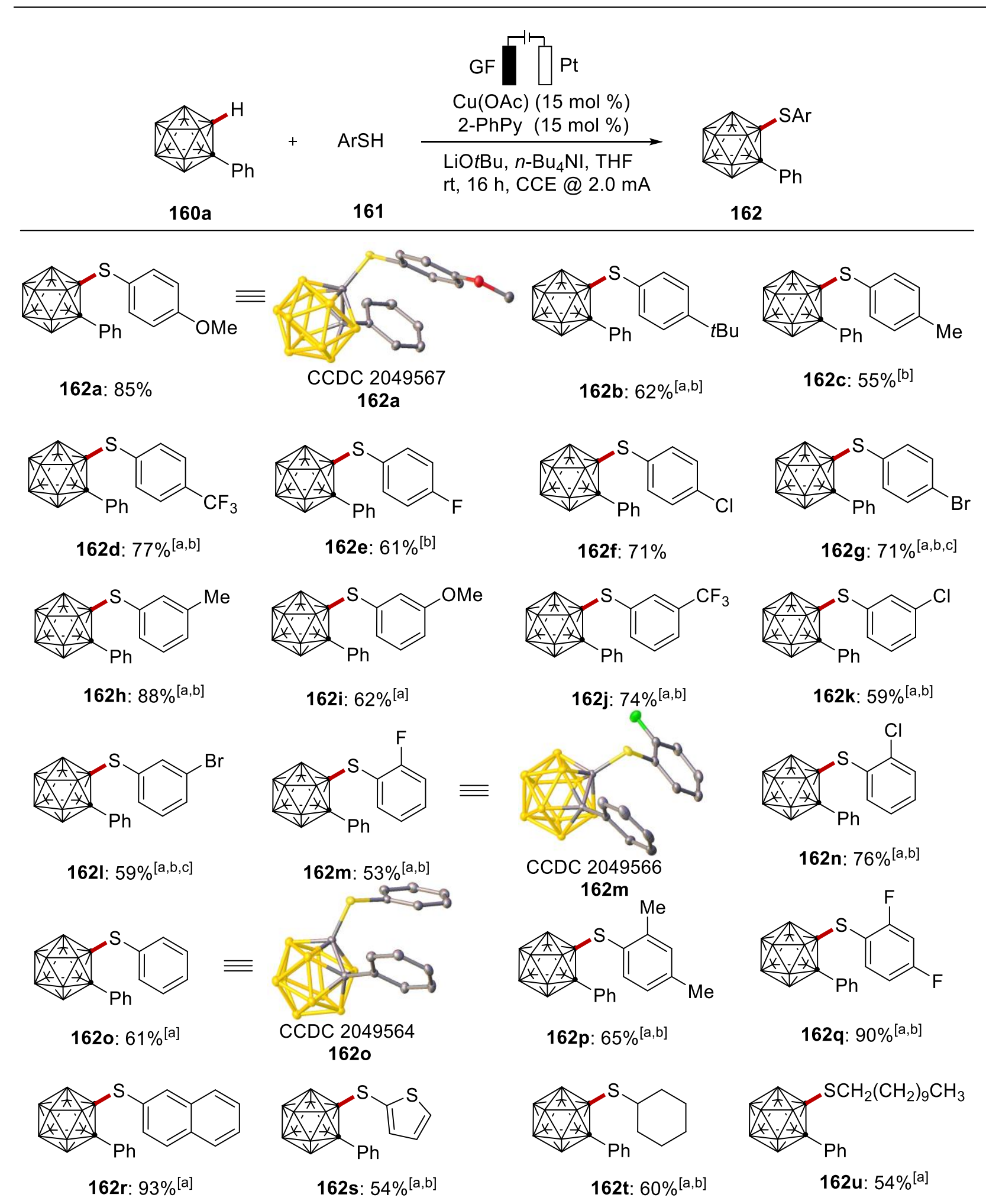

Scheme 3.6.1.1. Electrochemical $\mathrm{C}-\mathrm{H}$ thiolation of $o$-carborane. ${ }^{[a]}$ Procedure B. ${ }^{[b]} \mathrm{KI}$ (1 equiv.). ${ }^{[c]} \mathrm{Cul}$ as the catalyst. (162c-162d, 162g-162h, 162j-162I, 162n, 162p-162r, 162t did by Becky Bongsuiru Jei) 
Encouraged by the efficiency of the cupraelectro-oxidative cage $\mathrm{C}-\mathrm{H}$ thiolation, we became intrigued to explore the chalcogenantion of differently-decorated o-carboranes 160 (Scheme 3.6.1.2). Electronically diverse o-carboranes 160 served as competent coupling partners, giving the corresponding thiolation products (163a-163e) with high levels of efficacy in a positionselective manner. The strategy was not restricted to phenyl-substituted 0 -carboranes. Indeed, substrates bearing benzyl and even alkyl groups also performed well to deliver the desired products $163 \mathrm{f}-\mathbf{1 6 3 i}$. It is noteworthy that the $\mathrm{C}-\mathrm{H}$ activation approach was also compatible with selenols to give the o-carborane $\mathbf{1 6 3 j}$.

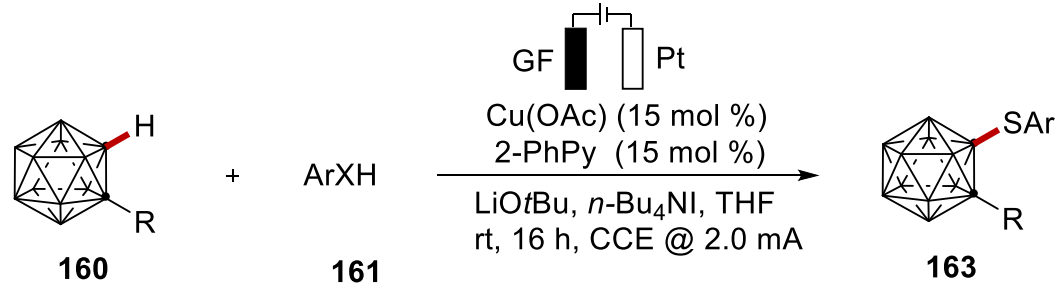

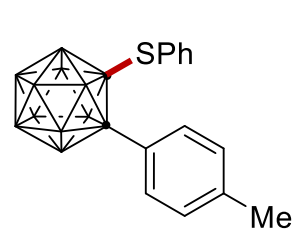

163a: $94 \%{ }^{[a]}$

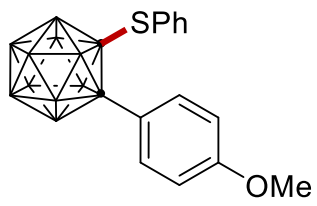

163d: $70 \%{ }^{[\mathrm{a}]}$

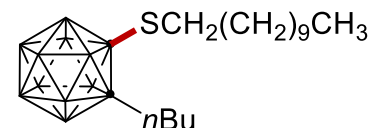

163h: $54 \%[$ [a]

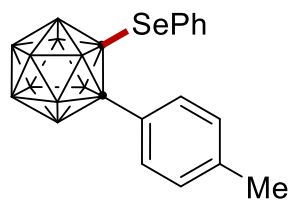

163k: $77 \%{ }^{[a]}$

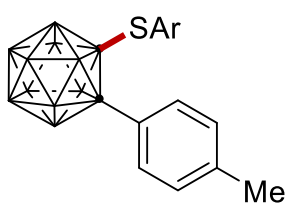

$\mathrm{Ar}=4-\mathrm{Bu} \mathrm{Ph}$

163b: $62 \%{ }^{[a]}$

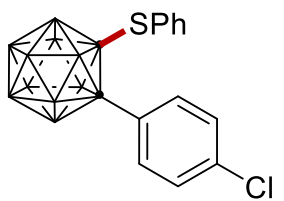

163e: $78 \%{ }^{[a, b]}$

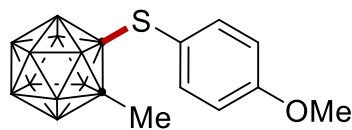

163i: $68 \%{ }^{[a]}$

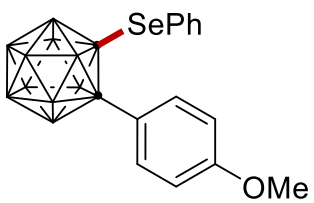

163I: $52 \%$ [a]

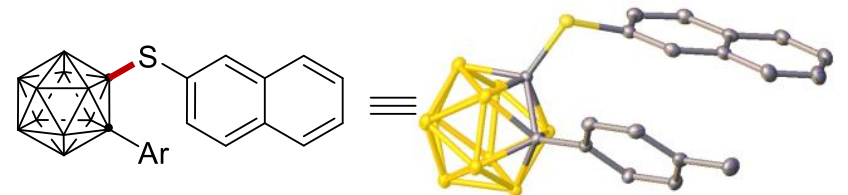

$\mathrm{Ar}=4-\mathrm{MePh}$

163c: $62 \%{ }^{[\mathrm{a}]}$

CCDC 2065339

$163 \mathrm{c}$
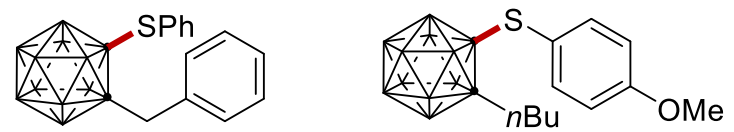

163f: $64 \%^{[a]}$

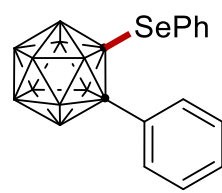

163j: $59 \%{ }^{[a]}$

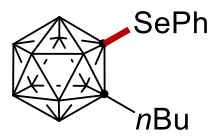

163m: $65 \%{ }^{[\mathrm{a}]}$

Scheme 3.6.1.2. Electrochemical C-H chalcogenation of o-carboranes. ${ }^{\text {[a] }}$ Procedure B. ${ }^{[b]} \mathrm{KI}$ (1 equiv.). (163a, 163c, 163d and 163e did by Becky Bongsuiru Jei) 


\subsubsection{Late-stage Functionalization}

Next, late-stage functionalization of the thus obtained carborane $162 \mathrm{~g}$ was studied. Sonogashira-Hagihara coupling of carborane $\mathbf{1 6 2 \mathrm { g }}$ with trimethylsilylacetylene gave the alkynylated derivative 164a (Scheme 3.6.2). Buchwald-Hartwig amination of carborane $\mathbf{1 6 2} \mathbf{g}$ with carbazole selectivity resulted in the formation of amine $164 \mathrm{~b}$, which offers a new route to cage C-substituted carborane-based host materials for possible applications to phosphorescent organic light-emitting diodes. ${ }^{[226]}$
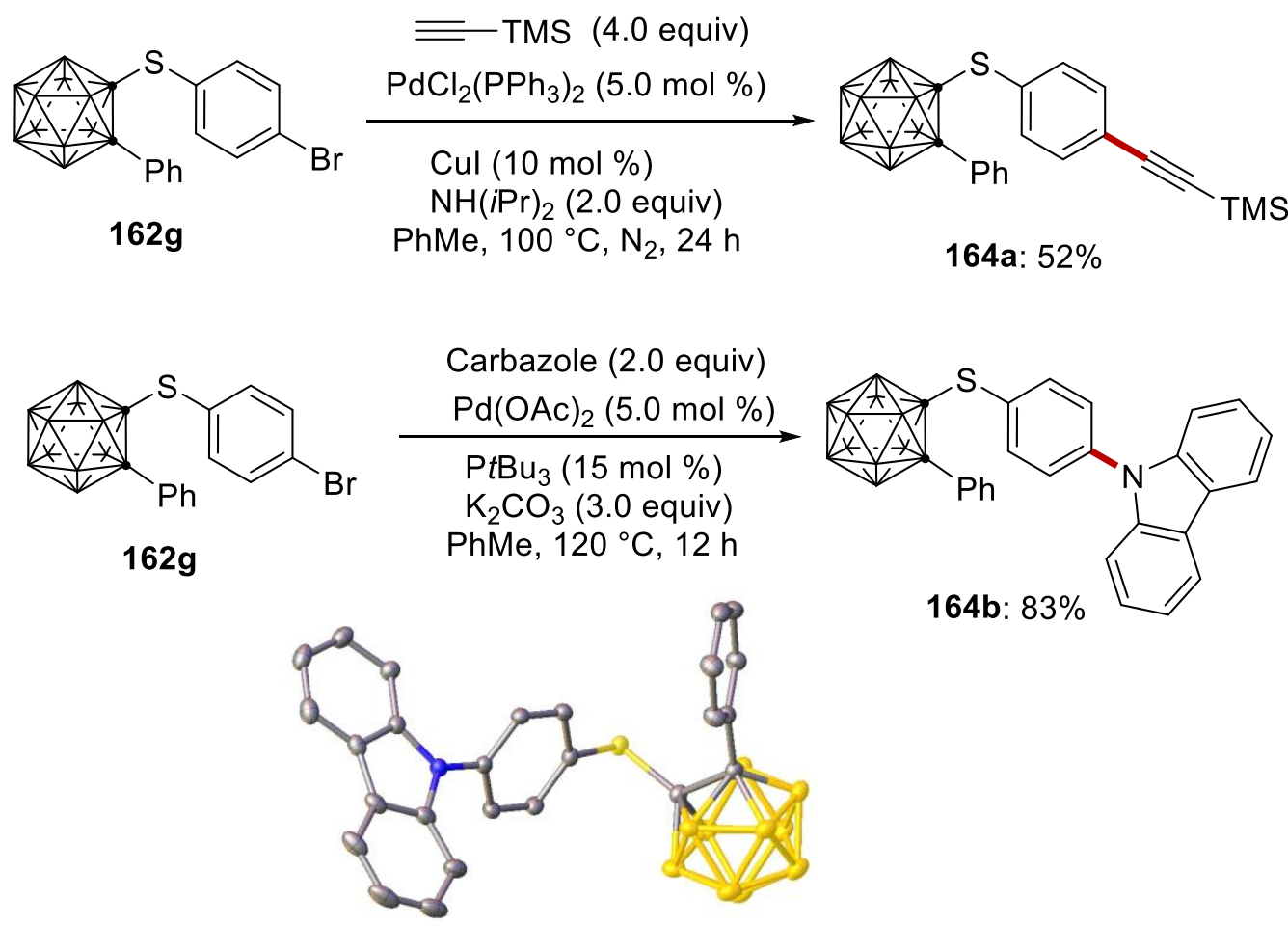

CCDC 2063919

$164 b$

Scheme 3.6.2. Late-stage diversification.

\subsubsection{Control Experiments and Cyclic Voltammograms}

The high efficacy of the cupraelectro-catalyzed cage $\mathrm{C}-\mathrm{H}$ chalcogenation motivated us to delineate the mode of action. To this end, control experiments were performed (Scheme 3.6.3a). First, electrocatalysis in the presence of TEMPO or $\mathrm{Ph}_{2} \mathrm{C}=\mathrm{CH}_{2}$ gave the desired product 162a. Second, the cupraelectrocatalysis occurred efficiently in the dark. Third, detailed 
cyclovoltammetric analysis of the thiol and iodide mediator by Msc. Alexej Scheremetjew (Scheme 3.6.3b) showed an irreversible oxidation of the thiol anion at $E_{p}=-0.62 \mathrm{Vvs}$. $\mathrm{Ag} / \mathrm{Ag}^{+}$ and two oxidation events for the iodide at $E_{p}=0.12 \mathrm{~V} v s . A g / \mathrm{Ag}^{+}$and $E_{p}=0.44 \mathrm{Vvs}$. $\mathrm{Ag} / \mathrm{Ag}^{+}$, which is in agreement with the literature reported iodide oxidation potential ${ }^{[227]}$ and suggestive of the preferential oxidation of the iodide as redox mediator. Moreover, the use of $n-\mathrm{Bu}_{4} \mathrm{NI}$ as a redox mediator to achieve copper-catalyzed electrochemical $\mathrm{C}-\mathrm{H}$ amination of arenes was also documented. ${ }^{[138]}$

a) Control experiments

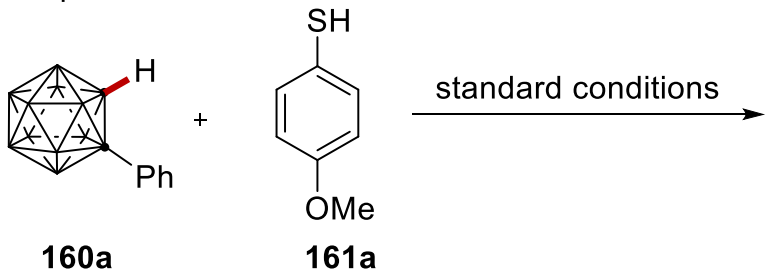

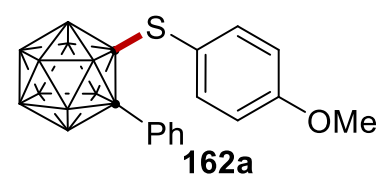

TEMPO: $75 \%$

$\mathrm{Ph}_{2} \mathrm{C}=\mathrm{CH}_{2}: 72 \%$

In the dark: $81 \%$ b) Cyclic votammograms
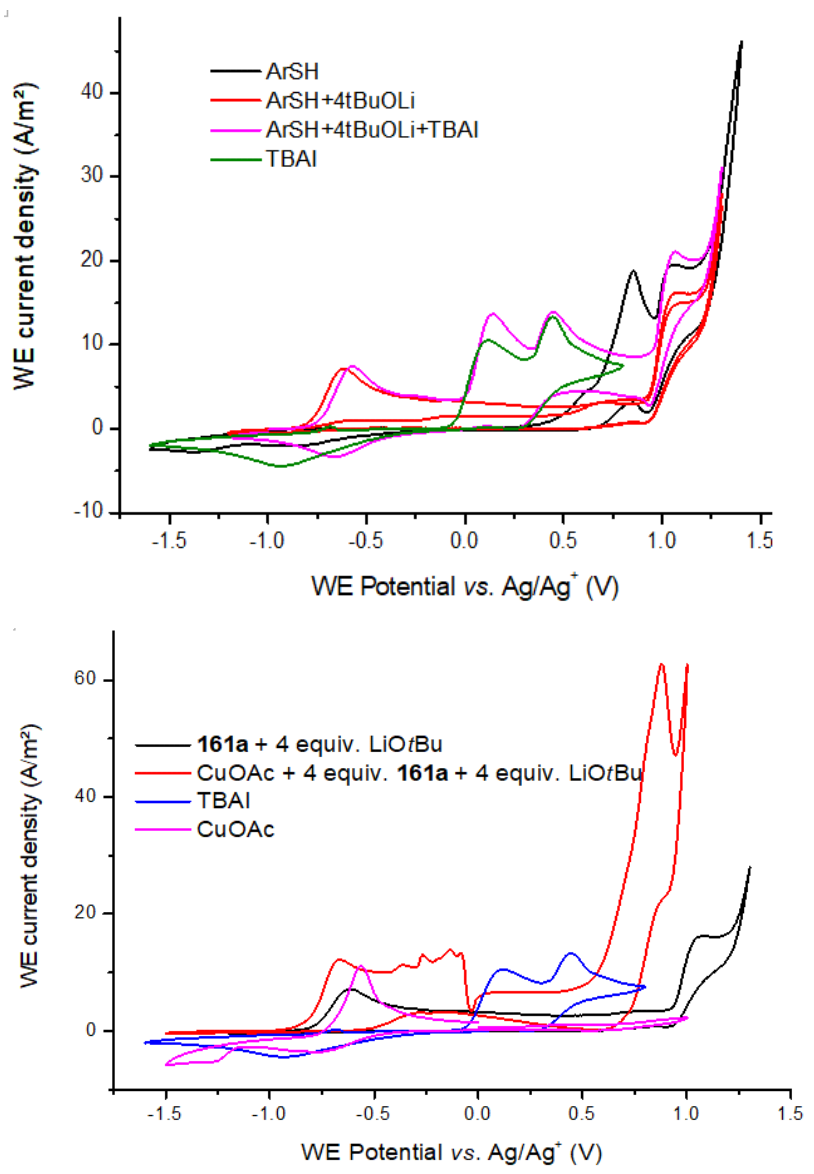
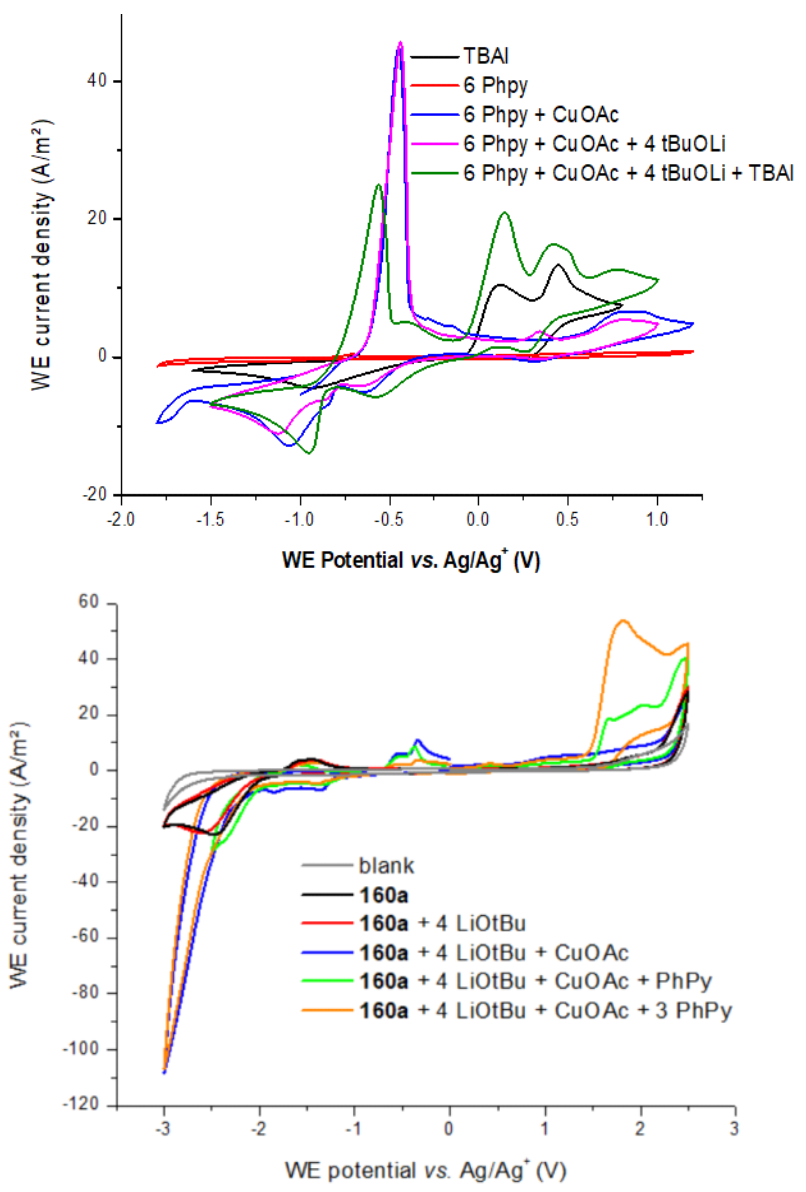

Scheme 3.6.3. Control experiments and cyclic voltammograms. CV studies did by Msc. Alexej Scheremetjew. 


\subsubsection{Proposed Mechanism}

Based on the findings, a plausible reaction mechanism is proposed in Scheme 3.6.4, which commences with an anodic single electron-transfer (SET) oxidation of the thiol anion $\mathbf{E}$ to form the sulfur-centered radical F. Subsequently, the copper(I) species A reacts with the sulfur radical $F$ to deliver copper(II) complex B, which next reacts with o-carborane 160a in the presence of $\mathrm{LiO}$ tBu to generate a copper(II)-o-carborane complex $\mathbf{C}$. Thereafter, the complex $\mathbf{C}$ is oxidized by the anodically generated redox mediator $I_{2}$ to furnish the copper(III) species $\mathbf{D}$, which subsequently undergoes reductive elimination, affording the final product and regenerating the catalytically active complex A. Alternatively, the direct oxidation of copper(II) complex C by electricity to generate copper(III) species $\mathbf{D}$ can not be excluded at this stage.

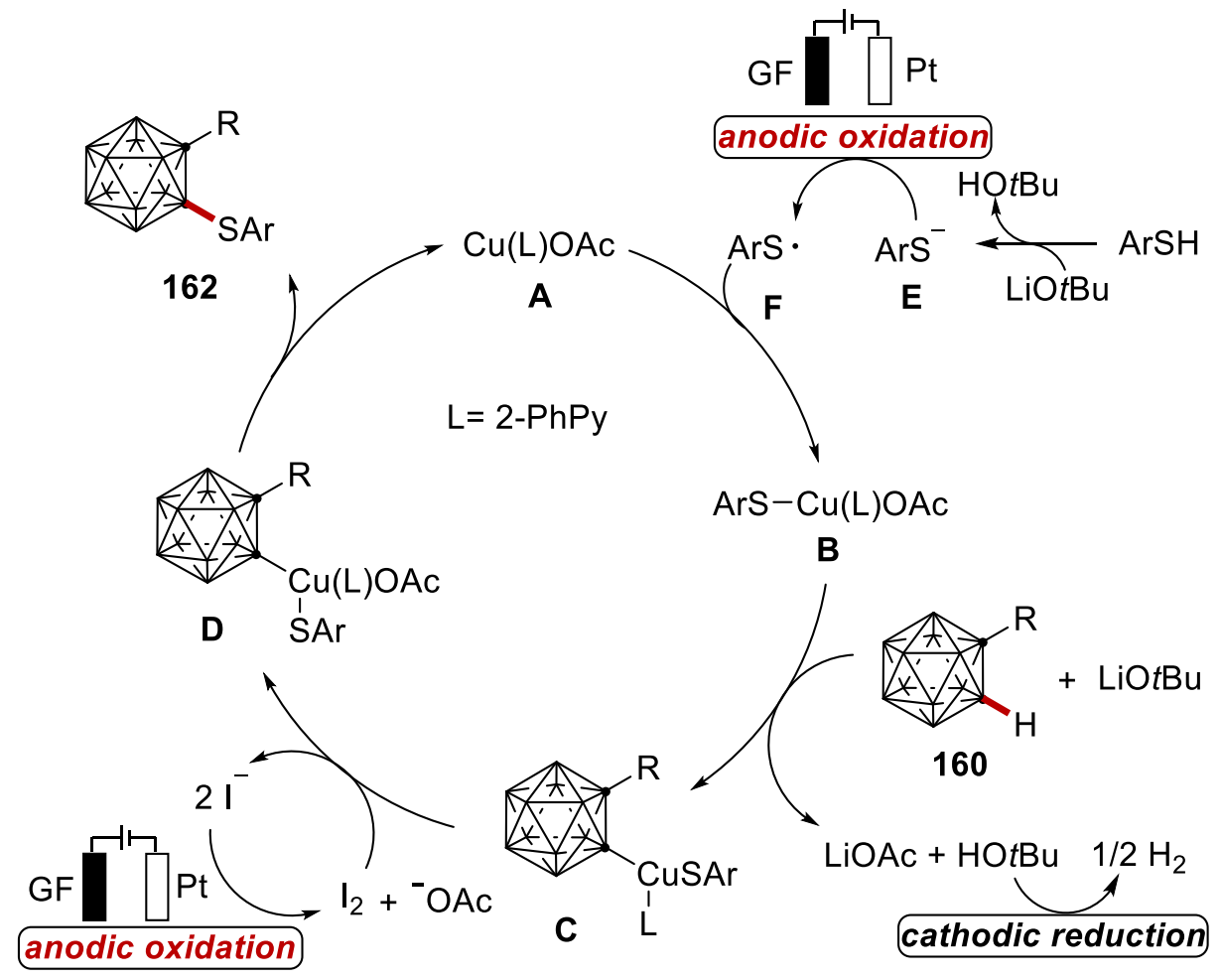

Scheme 3.6.4. Proposed reaction mechanism. 


\section{Summary and Outlook}

The development of highly step- and atom-economical $\mathrm{C}-\mathrm{H}$, and $\mathrm{B}-\mathrm{H}$ activations by inexpensive and Earth-abundant metals has emerged as an increasingly powerful tool in molecular syntheses. The selective functionalization of otherwise inert $\mathrm{C}-\mathrm{H}$ bonds remains a big challenge due to the ubiquitous $\mathrm{C}-\mathrm{H}$ bonds in organic compounds. Despite remarkable advances in the field, most of the reported approaches largely relied on precious metal catalysts, harsh reaction conditions and the necessity of stoichiometric amounts of chemical oxidants, compromising the overall sustainability of the strategy. In this thesis, new methods have been developed for sustainable selective $\mathrm{C}-\mathrm{H}$ activation and cage $\mathrm{B}-\mathrm{H} / \mathrm{C}-\mathrm{H}$ activation of carboranes by costeffective ruthenium, ruthenaelectro-catalysis and cupraelectro-catalysis.

In the first part, we have unraveled ruthenium(IV) complexes as key intermediates in redoxneutral $\mathrm{C}-\mathrm{H} / \mathrm{O}-\mathrm{H}$ activation of benzoic acid with easily-accessible sulfoxonium ylides by weak $O$-coordiantion. Base on the experimental and computational studies, a ruthenium(II/IV) catalysis manifold was proposed for the synthesis of various isocomarin derivatives (Scheme 4.1a). Furthermore, a new strategy towards the synthesis of m-extended DPPs was presented that employed sustainable, inexpensive, and widely applicable ruthenium catalysis. This method allowed for the rapid synthesis of new DPP derivatives, featuring various substituents on the ethylene bridge (Scheme 4.1b).

a) Ruthenium-catalyzed $\mathrm{C}-\mathrm{H} / \mathrm{O}-\mathrm{H}$ annulation

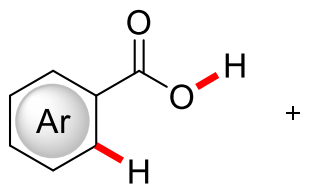

62

- Ruthenium(II/IV) manifold

- Weakly coordinating acids

141<smiles>[R]C(=O)C=S(C)(C)=O</smiles>

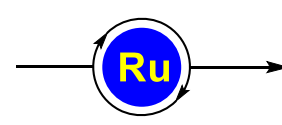

Ru outperforms $R h$ and Ir

Experimental and DFT studies

b) Ruthenium-catalyzed $\mathrm{C}-\mathrm{H} / \mathrm{N}-\mathrm{H}$ annulation<smiles>O=C1NC(c2ccccc2)=C2C(=O)NC(c3ccccc3)=C12</smiles>

143

Double $\mathrm{C}-\mathrm{H} / \mathrm{N}-\mathrm{H}$ annulation on DPP core Active dyes with high absorption coefficient

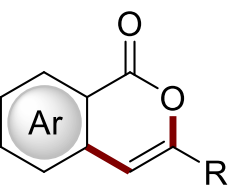

142

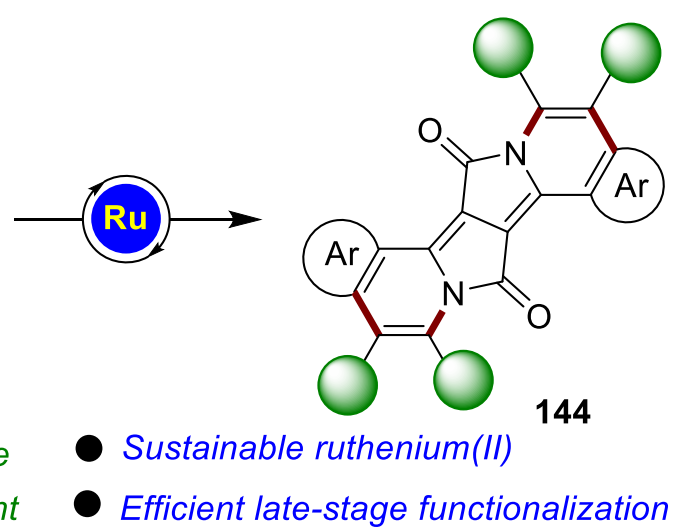

Scheme 4.1. Ruthenium-catalyzed annulations. 
In contrast to the chemical oxidative $\mathrm{C}-\mathrm{H}$ functionalizations, electrocatalytic $\mathrm{C}-\mathrm{H}$ activations employ electricity as the redox reagent to replace toxic and expensive chemical oxidants, which has been recognized as an increasingly viable, environmentally-friendly strategy and closely related to the trend of atom- and step-economy.

In the second part, we have reported on the electrocatalytic organometallic $\mathrm{C}-\mathrm{H} / \mathrm{N}-\mathrm{H}$ functionalization of imidazoles (Scheme 4.2). Novel aza-ruthena-bicyclo-[3.2.0]-heptadienes were isolated and identified as the key intermediates, setting the stage for alkyne annulations from synthetically meaningful alkenyl and aryl imidazoles with ample scope. The $\mathrm{C}-\mathrm{H}$ activation employed electricity as the only oxidant and generated molecular hydrogen as the sole byproduct. Mechanistic studies by experiment and DFT provided strong support for an oxidationinduced reductive elimination of aza-ruthena-bicyclo-[3.2.0]-heptadienes by environmentallybenign electricity. These findings should prove instrumental for the mechanistic understanding and design of ruthenium(II)-catalyzed oxidative $\mathrm{C}-\mathrm{H}$ activations.

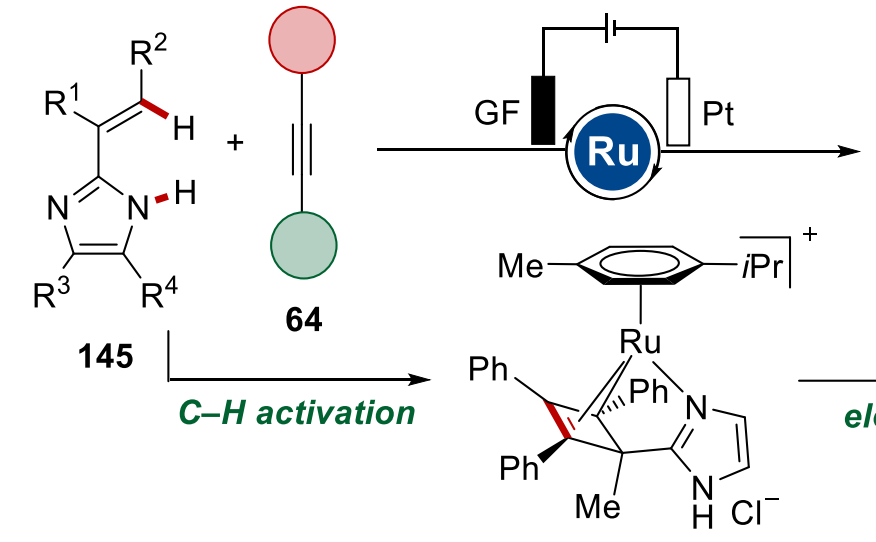

RuIV
- Aza-ruthena-bicyclo-[3.2.0]-heptadiene

Oxidation-induced reductive elimination
- Electricity as green oxidant

- Novel mechanism: Ru(II/IIIII)

Scheme 4.2. Ruthenaelectro(II/III/I)-catalyzed alkyne annulations.

In the third part, we described the cage $\mathrm{B}-\mathrm{H} / \mathrm{C}-\mathrm{H}$ functionalizations of carboranes.

First, a palladium-catalyzed direct arylations at cage $B(3,4)$ positions in o-carboranes has been achieved at room temperature with the aid of weakly-coordinating, synthetically useful amides (Scheme 4.3). Thus, palladium-catalyzed B-H activations enabled the assembly of a variety of arylated $o$-carboranes. This method featured high position-selectivity, high tolerance of functional groups, and mild reaction conditions, thereby offering a platform for the design and synthesis of boron-substituted $o$-carboranes. Our findings offered a facile strategy for selective activations of 
$\mathrm{B}(3,4)-\mathrm{H}$ bonds, which will be instrumental for future design of optoelectronics nanomaterials, and boron neutron capture therapy agents.

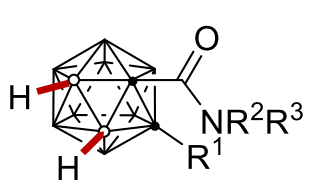

149
$B(3,4)-H$ Activation

\section{Pd}

\section{Room Temperature}

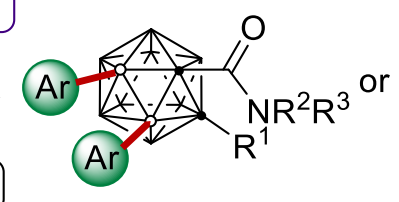

$\mathrm{B}(3,4)$-diarylation

150 or 152

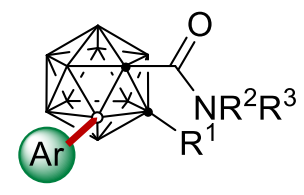

$\mathrm{B}(3)$-monoarylation

153
- Organometallic B-H Activation

- Unprecedented DFT studies

\section{Di/Mono Selectivity}

- Selective B-H Arylation

Scheme 4.3. Palladium(II)-catalyzed $\mathrm{B}(3,4)-\mathrm{H}$ arylation of $\mathrm{o}$-carboranes.

Second, metal-free electrocatalyzed direct B-N oxidative couplings of nido-carborane with $\mathrm{N}$ heterocyclic compound have been achieved at room temperature with molecular hydrogen as the sole by-product (Scheme 4.4). This method featured mild reaction conditions and high tolerance of functional groups leading to various amino acid- and BODIPY-labeled nidocarboranes, thereby offering a new platform for the design and synthesis of $\mathrm{N}$-substituted nidocarborane by environmentally-benign electricity. A plausible mechanism was established by cyclic voltammetry studies and computation. The thus-obtained BODIPY-labeled nido-carborane displayed enhanced spectroscopic features.
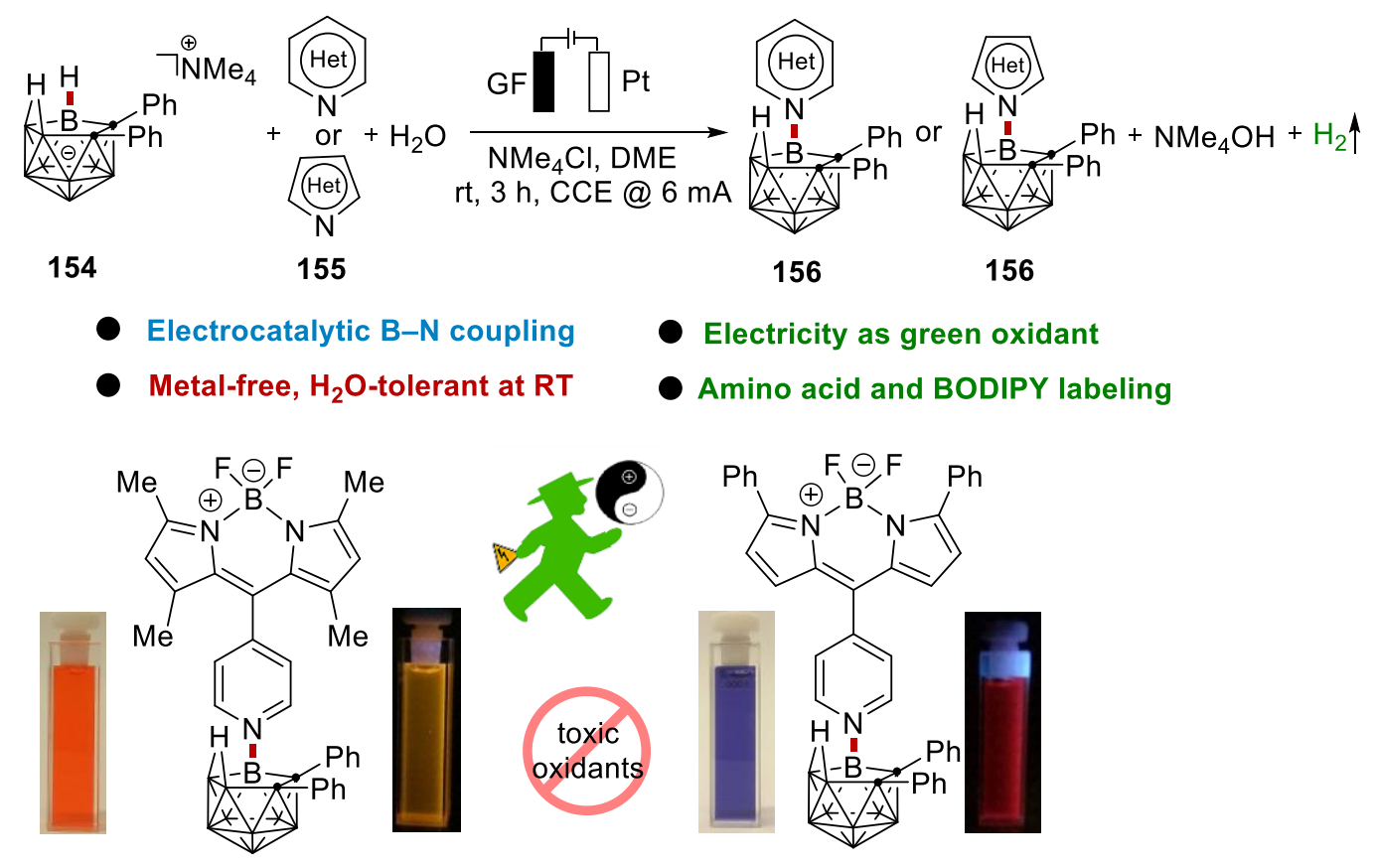

Scheme 4.4. Electrocatalzed B-H nitrogenation of nido-carboranes. 
Last, an efficient and operationally-benign electrocatalytic organometallic cage $\mathrm{C}-\mathrm{H}$ chalcogenation of o-carboranes with thionols and selenols has been achieved at room temperature. This strategy featured mild reaction conditions and high tolerance of functional groups, leading to the facile assembly of a series of $o$-carboranes, thereby offering a new platform for the design of cage $\mathrm{C}-\mathrm{S} / \mathrm{Se}$ substituted $\mathrm{o}$-carboranes by environmentally-sound electricity. A plausible mechanism was established by control experiments and detailed cyclic voltammetry studies. Our findings should prove instrumental for the further development of decorated carboranes and boron clusters by molecular electrocatalysis.

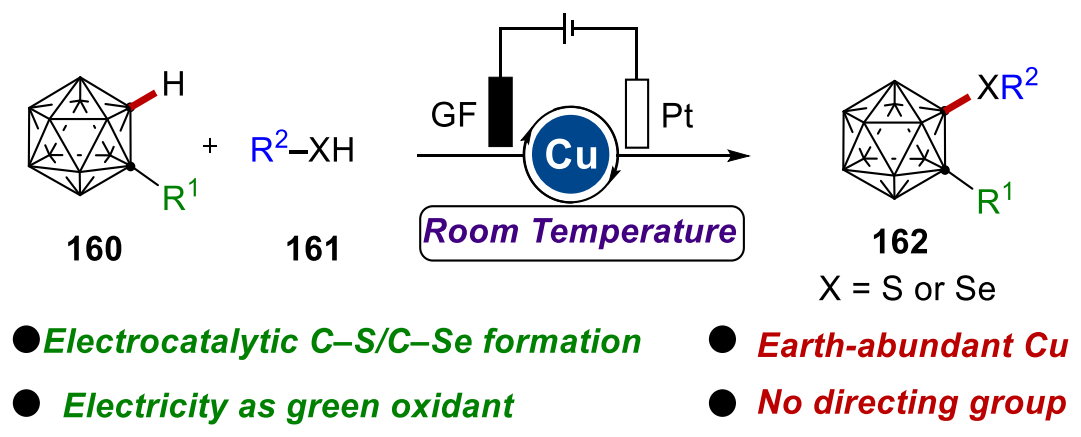

Scheme 4.5. Cupraelectro-catalzed C-H chalcogenation of o-carboranes 160. 


\section{Experimental Section}

\subsection{General Remarks}

Catalytic reactions under an atmosphere of air were conducted in the sealed tubes or Schlenk tubes. Unless otherwise noted, other reactions were performed under $\mathrm{N}_{2}$ atmosphere using predried glassware and standard Schlenk techniques.

If not otherwise noted, yields refer to isolated compounds, estimated to be $>95 \%$ pure as determined by ${ }^{1} \mathrm{H}$ NMR.

\section{Vacuum}

The following pressures were measured on the used vacuum pump and were not corrected: membrane pump vacuum (MPV): 0.5 mbar, oil pump vacuum (OPV): 0.1 mbar.

\section{Melting Points (M.p.)}

Melting points were measured using a Stuart ${ }^{\circledR}$ Melting Point Apparatus SMP3 from BARLOWORLD SCIENTIFIC. The reported values are uncorrected.

\section{Chromatography}

Analytical thin layer chromatography (TLC) was performed on $0.25 \mathrm{~mm}$ silica gel 60F-plates (MACHEREY-NAGEL) with $254 \mathrm{~nm}$ fluorescent indicator from MERCK. Plates were visualized under UV-light. Chromatographic purification of products was accomplished by flash column chromatography on MERCK silica gel, grade $60(0.040-0.063 \mathrm{~mm}$ and $0.063-0.200 \mathrm{~mm})$.

\section{Gas Chromatography (GC)}

The conversions of the reactions were monitored by applying coupled gas chromatography/mass spectrometry using G1760C GCDplus with mass detector HP 5971, 5890 Series // with mass detector HP 5972 from HEWLETT-PACKARD and 7890A GC-System with mass detector 5975C (Triplex-Axis-Detector) from AGILENT TECHNOLOGIES equipped with HP-5MS columns $(30 \mathrm{~m} \times 0.25 \mathrm{~mm} \times 0.25 \mathrm{~m})$.

\section{Gel Permeation Chromatography (GPC)}

GPC purifications were performed on a JAI system (JAI-LC-9260 II NEXT) equipped with two sequential columns (JAIGEL-2HR, gradient rate: 5.000; JAIGEL-2.5HR, gradient rate: 20.000; internal diameter $=20 \mathrm{~mm}$; length $=600 \mathrm{~mm}$; Flush rate $=10.0 \mathrm{~mL} / \mathrm{min}$ and chloroform (HPLCquality with $0.6 \%$ ethanol as stabilizer) was used as the eluent. 
Infrared spectra were recorded with a BRUKER Alpha-P ATR FT-IR spectrometer. Liquid samples were measured as a film, solid samples neat. The analysis of the spectra was carried out using the software from BRUKER OPUS 6 . The absorption was given in wave numbers $\left(\mathrm{cm}^{-1}\right)$ and the spectra were recorded in the range of $4000-400 \mathrm{~cm}^{-1}$.

\section{Mass Spectrometry}

Electron-ionization (EI) mass spectra were recorded on a Jeol AccuTOF instrument at $70 \mathrm{eV}$. Electrospray-ionization (ESI) mass spectra were obtained on Bruker micrOTOF and maXis instruments. All systems were equipped with time-of-flight (TOF) analyzers. The ratios of mass to charge $(\mathrm{m} / \mathrm{z})$ were reported and the intensity relative to the base peak $(I=100)$ is given in parenthesis.

\section{Nuclear Magnetic Resonance Spectroscopy (NMR)}

Nuclear magnetic resonance (NMR) spectra were recorded on VARIAN Inova 500, 600, VARIAN Mercury 300, VX 300, VARIAN Avance 300, VARIAN VNMRS 300 and BRUKER Avance III 300, 400 and $H D 500$ spectrometers. All chemical shifts were given as $\delta$-values in ppm relative to the residual proton peak of the deuterated solvent or its carbon atom, respectively. ${ }^{1} \mathrm{H}$ and ${ }^{13} \mathrm{C} N M R$ spectra were referenced using the residual proton or solvent carbon peak (see table), respectively. ${ }^{13} \mathrm{C}$ and ${ }^{19} \mathrm{~F}$ NMR were measured as proton-decoupled spectra.

\begin{tabular}{lll} 
& ${ }^{1} \mathrm{H}$ NMR & ${ }^{13} \mathrm{C} \mathrm{NMR}$ \\
\hline $\mathrm{CDCl}_{3}$ & 7.26 & 77.16 \\
{$[\mathrm{D}]_{6}$-DMSO } & 2.50 & 39.52
\end{tabular}

The observed resonance-multiplicities were described by the following abbreviations: $s$ (singlet), $d$ (doublet), $t$ (triplet), $q$ (quartet), hept (heptet), $m$ (multiplet) or analogous representations. The coupling constants $J$ were reported in Hertz $(\mathrm{Hz})$. Analysis of the recorded spectra was carried out with MestReNova 10 software.

\section{EPR Spectroscopy}

EPR spectra were measured on a Bruker ELEXSYS E500 spectrometer, equipped with the digital temperature control system ER 4131VT using nitrogen as coolant. All spectra were measured at room temperature or at temperatures around $150 \mathrm{~K}$, and were recorded at about 9.4 $\mathrm{GHz}$ microwave frequency, $100 \mathrm{kHz}$ field modulation frequency, and around $10 \mathrm{~mW}$ microwave power.

\section{Electrochemistry}

Platinum electrodes $(10 \mathrm{~mm} \times 15 \mathrm{~mm} \times 0.25 \mathrm{~mm}, 99.9 \%$; obtained from ChemPur $\AA$ Karlsruhe, 
Germany) and graphite felt (GF) electrodes (10 mm $\times 15 \mathrm{~mm} \times 6 \mathrm{~mm}$, SIGRACELL ${ }^{\circledR}$ GFA 6 EA, obtained from SGL Carbon, Wiesbaden, Germany) were connected using stainless steel adapters. Electrolysis was conducted using an AXIOMET AX-3003P potentiostat in constant current mode. For reactions performed with the standardized electrochemistry kit, ElectraSyn 2.0 from Ika, the commercialized electrodes and $10 \mathrm{~mL}$ undivided cells were used, if not stated otherwise. For reactions in flow an Ismatec REGLO Digital MS-2/12 (ISM 596) peristaltic pump was employed. CV studies were performed using a Metrohm Autolab PGSTAT204 workstation and Nova 2.0 software. Divided cells separated by a P4-glassfrit were obtained from Glasgerätebau Ochs Laborfachhandel e. K. (Bovenden, Germany).

\section{Solvents}

All solvents for reactions involving moisture-sensitive reagents were dried, distilled and stored under inert atmosphere $\left(\mathrm{N}_{2}\right)$ according to the following standard procedures.

Purified by solvent purification system (SPS-800, M. Braun): $\mathrm{CH}_{2} \mathrm{Cl}_{2}$, toluene, tetrahydrofuran, dimethylformamide, diethylether, 1,2-dichloroethane, $N$-methyl-2-pyrrolidone (NMP), $N, N$ dimethylacetamide (DMA), dimethylsulfoxide (DMSO) and $y$-valerolactone (GVL) was dried over $\mathrm{CaH}_{2}$ for $8 \mathrm{~h}$, degassed and distilled under reduced pressure. 1,2-dimethoxyethane (DME) was dried over sodium and freshly distilled under $\mathrm{N}_{2}$. 1,1,1,3,3,3-hexafluoropropan-2-ol (HFIP) was distilled from $3 \AA$ molecular sieves. 2,2,2-trifluoroethanol (TFE) was stirred over $\mathrm{CaSO}_{4}$ and distilled under reduced pressure. Water was degassed by repeated Freeze-Pump-Thaw degassing procedure. 1,4-dioxane and di-n-butyl-ether $\left(n \mathrm{Bu}_{2} \mathrm{O}\right)$ were distilled from sodium benzophenone ketyl.

\section{Reagents}

Chemicals obtained from commercial sources with purity above $95 \%$ were used without further purification. The following compounds were known and were synthesized according to previously described methods.

Sulfoxonium ylides $141^{[228]}, \mathbf{1 4 3 ^ { [ 2 2 9 ] } ,} \mathbf{6 4}^{[230]}, \mathbf{1 4 5 ^ { [ 2 3 1 ] }}, \mathbf{1 4 7 ^ { [ 2 3 2 ] } ,} \mathbf{1 4 9}^{[233]}, \mathbf{1 5 4 ^ { [ 2 2 5 ] } \text { and } \mathbf { 1 6 0 }}$

The following compounds were synthesized and provided by the persons listed below:

Karsten Rauch: $\left.\left[\mathrm{RuCl}_{2}(p \text {-cymene })\right]_{2}, \quad\left[\mathrm{Cp}^{*} \mathrm{RhCl}_{2}\right]_{2}, \quad\left[\mathrm{Cp}^{*} \mid \mathrm{rCl}\right]_{2}\right]_{2}, \quad\left[\mathrm{Ru}\left(\mathrm{O}_{2} \mathrm{CMes}\right)_{2}(p\right.$-cymene $\left.)\right]$, $\left[\mathrm{Ru}(\mathrm{OAc})_{2}(p\right.$-cymene).

\section{Cooperation clarification:}

In the project of ruthenaelectro-catalytic $\mathrm{C}-\mathrm{H} / \mathrm{N}-\mathrm{H}$ annulation, Ralf Steinbock carried out some experiments for the scope (146c, 146h, 146i, 146I, 148d, 148f, 148h, 148n), competition 
experiments and GC-Headspace analysis. CV studies were performed by Alexej Scheremetjew. DFT calculations were performed Dr. Rositha Kuniyil. On-line NMR monitoring in flow was performed by Dr. Lars H. Finger. Dr. Antonis M. Messinis helped to get the crystal of ruthenium intermediates.

In the project of metal-free electrocatalytic B-H nitrogenation of nido-carboranes, Becky Bongsuiru Jei carried out some experiments for the scope (156b, 156c, 156d, 156e, 156f, 156g, 156i, 156j, 156k, 156q, 156s, 156t, 156x, 156y, 156z, 156aa, 157c). Alexej Scheremetjew carried out GC-Headspace analysis and CV studies. DFT calculations were performed by Dr. Rositha Kuniyil.

In the project of cupraelectro-catalytic $\mathrm{C}-\mathrm{H}$ chalcogenation of o-carboranes, Becky Bongsuiru Jei carried out some experiments for the scope (162c, 162d, 162g, 162h, 162j, 162k, 162l, 162n, 162p, 162q, 162r, 162t, 163a, 163c, 163d, 163e). Alexej Scheremetjew carried out CV studies. Binbin Yuan carried out DFT studies. Dr. A. Claudia Stückl carried out EPR measurements and analyzed all EPR data. Dr. Christopher Golz analyzed all the X-ray data in the thesis.

\subsection{General Procedures}

\section{General Procedure A: Ruthenium(II)-Catalyzed C-H/O-H Annulation of ortho-Substituted Benzoic Acids}

Benzoic acid 62 (0.25 mmol), sulfoxonium ylide 141 (0.38 mmol), $\left[\mathrm{RuCl}_{2}(p \text {-cymene) }]_{2}\right.$ (3.8 $\mathrm{mg}$, $2.5 \mathrm{~mol} \%), \mathrm{AgSbF}_{6}(8.6 \mathrm{mg}, 10 \mathrm{~mol} \%), \mathrm{NEt}_{3}(51 \mathrm{mg}, 2.0$ equiv), and DCE $(2.0 \mathrm{~mL})$ were placed in a $25 \mathrm{~mL}$ Schlenk flask under $\mathrm{N}_{2}$ atmosphere. The mixture was stirred at $100{ }^{\circ} \mathrm{C}$ for $16 \mathrm{~h}$. At ambient temperature, the reaction mixture was transferred into a separatory funnel with EtOAc $(20 \mathrm{~mL})$ and washed with brine $(5.0 \mathrm{~mL})$. The mixture was extracted with EtOAc $(3 \times 20 \mathrm{~mL})$ and the combined organic layer was dried over $\mathrm{Na}_{2} \mathrm{SO}_{4}$, concentrated under reduced pressure and purified by column chromatography on silica gel using a mixture of $n$-hexane and EtOAc to afford the desired product 142 .

\section{General Procedure B: Ruthenium(II)-Catalyzed mono-C-H Activation of meta- and para- substituted Benzoic Acids}

Benzoic acid 62 (0.75 mmol), sulfoxonium ylide 141 (0.083 mmol), $\left[\mathrm{RuCl}_{2}(p \text {-cymene) }]_{2}\right.$ (3.8 $\mathrm{mg}$, $2.5 \mathrm{~mol}_{0}$ ), AgSbF 6 (8.6 mg, $10 \mathrm{~mol} \%$ ), $\mathrm{Zn}(\mathrm{OAc})_{2}$ (23 mg, $50 \mathrm{~mol} \%$ ), NEt 3 (76 mg, 3.0 equiv), and DCE $(2.0 \mathrm{~mL})$ were placed in a $25 \mathrm{~mL}$ Schlenk flask under $\mathrm{N}_{2}$ atmosphere. The mixture was stirred at $100^{\circ} \mathrm{C}$ for $2 \mathrm{~h}$. Then, sulfoxonium ylide $141(0.083 \mathrm{mmol})$ dissolved in DCE $(0.5 \mathrm{~mL})$ was added. And $2 \mathrm{~h}$ later, another portion of sulfoxonium ylide $141(0.083 \mathrm{mmol})$ dissolved in 
DCE $(0.5 \mathrm{~mL})$ was added. The resulting mixture was then stirred for $12 \mathrm{~h}$. At ambient temperature, the reaction mixture was transferred into a separatory funnel with EtOAc $(20 \mathrm{~mL})$ and washed with brine $(5.0 \mathrm{~mL})$. The mixture was extracted with EtOAc $(3 \times 20 \mathrm{~mL})$ and the combined organic layer was dried over $\mathrm{Na}_{2} \mathrm{SO}_{4}$, concentrated under reduced pressure and purified by column chromatography on silica gel using a mixture of $n$-hexane and EtOAc to afford the desired product 142.

\section{General Procedure C: Ruthenium(II)-Catalyzed double C-H Activation of meta- and para- substituted Benzoic Acids}

Benzoic acid $62(0.25 \mathrm{mmol})$, sulfoxonium ylide $141(0.75 \mathrm{mmol})$, $\left[\mathrm{RuCl}_{2}(p \text {-cymene })\right]_{2}(7.7 \mathrm{mg}$, $5.0 \mathrm{~mol} \%), \mathrm{AgSbF}_{6}$ (17.2 mg, $\left.20 \mathrm{~mol} \%\right), \mathrm{NEt}_{3}(51 \mathrm{mg}, 2.0$ equiv), and DCE (2.0 mL) were placed in a $25 \mathrm{~mL}$ Schlenk flask under $\mathrm{N}_{2}$ atmosphere. The mixture was stirred at $100{ }^{\circ} \mathrm{C}$ for $16 \mathrm{~h}$. At ambient temperature, the reaction mixture was transferred into a round bottom flask with EtOAc $(20 \mathrm{~mL})$ and washed with brine $(5.0 \mathrm{~mL})$. The mixture was extracted with EtOAc $(3 \times 20$ $\mathrm{mL}$ ) and the combined organic layer was dried over $\mathrm{Na}_{2} \mathrm{SO}_{4}$, concentrated under reduced pressure and purified by column chromatography on silica gel using a mixture of $n$-hexane and EtOAc to afford the desired product 142.

\section{General Procedure D: Ruthenium(II)-Catalyzed Double C-H/N-H Annulation}

To the pre-oven dried $25 \mathrm{~mL}$ Schlenk flask diketopyrrolopyrrole $143(0.25 \mathrm{mmol}, 1.0$ equiv), alkyne 64 (1.00 mmol, 4.0 equiv), $\left[\mathrm{RuCl}_{2}(p \text {-cymene) }]_{2}(10 \mathrm{~mol} \%), \mathrm{Cu}(\mathrm{OAc})_{2} \cdot \mathrm{H}_{2} \mathrm{O}(1.00 \mathrm{mmol}\right.$, 4.0 equiv), KOAc ( $0.25 \mathrm{mmol}, 1.0$ equiv) were added. The Schlenk tube was evaporated and refilled with $\mathrm{N}_{2}$ and o-xylene $(2 \mathrm{~mL})$ was added. The reaction was stirred at $100{ }^{\circ} \mathrm{C}$ for $16 \mathrm{~h}$ under a $\mathrm{N}_{2}$ atmosphere. At ambient temperature, the reaction mixture was transferred to the separation funnel with the $\mathrm{CH}_{2} \mathrm{Cl}_{2}$ and washed with the $\mathrm{NH}_{4} \mathrm{Cl}(\mathrm{aq})$ solution and dried over $\mathrm{Na}_{2} \mathrm{SO}_{4}$. The solvent was removed under vacuo and the remaining residue was washed with $n$ hexane. The precipitate was separated by the centrifuge, dissolved in $\mathrm{CH}_{2} \mathrm{Cl}_{2}$ and filtrated through filtration paper giving the desired product.

\section{General Procedure E: Ruthenium(II)-Catalyzed Double Double C-H/N-H Annulation}

To the pre-oven dried $25 \mathrm{~mL}$ Schlenk flask diketopyrrolopyrrole $143(0.25 \mathrm{mmol}, 1.0$ equiv), alkyne 64 (1.00 mmol, 4.0 equiv), $\left[\mathrm{RuCl}_{2}(p \text {-cymene) }]_{2}(10 \mathrm{~mol} \%), \mathrm{Cu}(\mathrm{OAc})_{2} \cdot \mathrm{H}_{2} \mathrm{O}(1.00 \mathrm{mmol}\right.$, 4.0 equiv), KOAc ( $0.25 \mathrm{mmol}, 1.0$ equiv) were added. The Schlenk tube was evaporated and refilled with $\mathrm{N}_{2}$ and o-xylene $(2 \mathrm{~mL})$ was added. The reaction was stirred at $100{ }^{\circ} \mathrm{C}$ for $16 \mathrm{~h}$ 
under a $\mathrm{N}_{2}$ atmosphere. At ambient temperature, the reaction mixture was transferred to the separation funnel with $\mathrm{CH}_{2} \mathrm{Cl}_{2}$ and washed with the $\mathrm{NH}_{4} \mathrm{Cl}(\mathrm{aq})$ solution and dried over $\mathrm{Na}_{2} \mathrm{SO}_{4}$. The solvent was removed under vacuo and the remaining residue was purified by column chromatography on silica gel ( $n$-hxane: $\mathrm{CH}_{2} \mathrm{Cl}_{2}$ ) giving the desired product.

\section{General Procedure F: Electrochemical C-H/N-H Activation with Alkenyl Imidazoles}

The electrocatalysis was carried out in an undivided cell under $\mathrm{N}_{2}$, with a graphite felt (GF) anode $(10 \mathrm{~mm} \times 15 \mathrm{~mm} \times 6 \mathrm{~mm})$ and a platinum cathode $(10 \mathrm{~mm} \times 15 \mathrm{~mm} \times 0.25 \mathrm{~mm})$. Alkenyl imidazoles 145 ( $0.4 \mathrm{mmol}, 1.0$ equiv), alkyne 64 ( $0.8 \mathrm{mmol}, 2.0$ equiv), $\mathrm{KPF}_{6}(14.7 \mathrm{mg}, 20 \mathrm{~mol} \%)$ and $\left[\operatorname{RuCl}_{2}(p \text {-cymene })\right]_{2}(12.5 \mathrm{mg}, 5.0 \mathrm{~mol} \%)$ were dissolved in DMF $(4.0 \mathrm{~mL})$. Electrocatalysis was performed at $140{ }^{\circ} \mathrm{C}$ with a constant current of $4.0 \mathrm{~mA}$ maintained for $8 \mathrm{~h}$. The GF anode was washed with EtOAc $(3 \times 10 \mathrm{~mL})$ in an ultrasonic bath. Evaporation of the solvent and subsequent purification by column chromatography on silica gel afforded the corresponding products 146 .

\section{General Procedure G: Electrochemical C-H/N-H Activation of 2-Phenylbenzimidazoles}

The electrocatalysis was carried out in an undivided cell under $\mathrm{N}_{2}$, with a graphite felt GF anode $(10 \mathrm{~mm} \times 15 \mathrm{~mm} \times 6 \mathrm{~mm})$ and a platinum cathode $(10 \mathrm{~mm} \times 15 \mathrm{~mm} \times 0.25 \mathrm{~mm}) .2-$ Phenylbenzimidazoles 147 (0.2 mmol, 1.0 equiv), alkyne 64 (0.4 mmol, 2.0 equiv), KOAc (0.4 mmol, 2.0 equiv), $1-\mathrm{AdCO}_{2} \mathrm{H}(7.2 \mathrm{mg}, 20 \mathrm{~mol} \%)$ and $\left[\mathrm{RuCl}_{2}(p \text {-cymene })\right]_{2}(6.2 \mathrm{mg}, 5.0 \mathrm{~mol} \%)$ were dissolved in $t-A m O H / H_{2} \mathrm{O}(1 / 1,6.0 \mathrm{~mL})$. Electrocatalysis was performed at $100{ }^{\circ} \mathrm{C}$ with a constant current of $8.0 \mathrm{~mA}$ maintained for $4 \mathrm{~h}$. The GF anode was washed with EtOAc $(3 \times 10 \mathrm{~mL})$ in an ultrasonic bath. Evaporation of the solvent and subsequent purification by column chromatography on silica gel afforded the corresponding products 148.

\section{General Procedure H: Palladium-Catalyzed B(3,4)-H Diarylation}

o-Carborane 149a (1-CONEt $\left.2-2-\mathrm{Ph}-\mathrm{o}-\mathrm{C}_{2} \mathrm{~B}_{10} \mathrm{H}_{10}\right)(0.20 \mathrm{mmol})$, 4-iodotoluene 19a $(0.48 \mathrm{mmol})$, $\mathrm{Pd}(\mathrm{OAc})_{2}(10 \mathrm{~mol} \%)$, AgTFA $(0.48 \mathrm{mmol})$, TFA $(0.20 \mathrm{mmol})$ and HFIP $(0.50 \mathrm{~mL})$ were placed in a $25 \mathrm{~mL}$ Schlenk tube under $\mathrm{N}_{2}$ atmosphere. The mixture was stirred at $25^{\circ} \mathrm{C}$ for $16 \mathrm{~h}$. Then, the reaction solution was concentrated to dryness in vacuum and purified by column chromatography on silica gel using a mixture of $n$-hexane and EtOAc (20/1 in v/v) and Gel Permeation Chromatography (GPC) to afford the desired product 150a.

\section{General Procedure I: Palladium-Catalyzed B(3)-H Arylation of 0 -Carboranes}

$o$-Carborane 149a (1-CONEt $\left.2-2-\mathrm{Ph}-0-\mathrm{C}_{2} \mathrm{~B}_{10} \mathrm{H}_{10}\right)(0.20 \mathrm{mmol})$, 4-iodotoluene 19a $(0.08 \mathrm{mmol})$, 
$\mathrm{Pd}(\mathrm{OAc})_{2}(10 \mathrm{~mol} \%), \mathrm{Ag}_{2} \mathrm{CO}_{3}(0.24 \mathrm{mmol})$ and HFIP $(0.50 \mathrm{~mL})$ were placed in a $25 \mathrm{~mL}$ Schlenk tube under $\mathrm{N}_{2}$ atmosphere. The mixture was stirred at $25^{\circ} \mathrm{C}$ for $4 \mathrm{~h}$. Then, 4-iodotoluene 19a $(0.08 \mathrm{mmol})$ was added. And $4 \mathrm{~h}$ later, another portion of 4-iodotoluene $19 \mathrm{a}(0.08 \mathrm{mmol})$ was added. The resulting mixture was then stirred for $8 \mathrm{~h}$. Then, the reaction solution was concentrated to dryness in vacuum and purified by column chromatography on silica gel using a mixture of $n$-hexane and EtOAc (20/1 in v/v) and Gel Permeation Chromatography (GPC) to afford the desired product 153a.

\section{General Procedure J: Electrochemical-Catalyzed B-H Nitrogenation of nido-Carboranes}

The electrocatalysis was carried out in an undivided cell under air, with a graphite felt (GF) anode $(10 \mathrm{~mm} \times 15 \mathrm{~mm} \times 6 \mathrm{~mm})$ and a platinum cathode $(10 \mathrm{~mm} \times 15 \mathrm{~mm} \times 0.25 \mathrm{~mm})$. nidoCarborane $154 \mathrm{a}$ ( $0.10 \mathrm{mmol}, 1.0$ equiv), pyridine $155 \mathrm{a}$ ( $0.30 \mathrm{mmol}, 3.0$ equiv), and $\mathrm{NMe}_{4} \mathrm{Cl}(0.20$ mmol, 2.0 equiv) were dissolved in $\operatorname{DME}(4.0 \mathrm{~mL})$ and $\mathrm{H}_{2} \mathrm{O}(0.2 \mathrm{~mL})$. Electrocatalysis was performed at room temperature with a constant current of $6.0 \mathrm{~mA}$ maintained for $3 \mathrm{~h}$. The GF anode was washed with $\mathrm{CH}_{2} \mathrm{Cl}_{2}(3 \times 10 \mathrm{~mL})$. Evaporation of the solvent and subsequent purification by column chromatography on silica gel with $\mathrm{CH}_{2} \mathrm{Cl}_{2} / n$-hexane (1/1) afforded the corresponding products $156 \mathrm{a}$.

\section{General Procedure K: Cupraelectro-Catalyzed C-H Chalcogenation of $o$-Carboranes}

The electrocatalysis was carried out in an undivided cell under air, with a graphite felt (GF) anode $(10 \mathrm{~mm} \times 15 \mathrm{~mm} \times 6 \mathrm{~mm})$ and a platinum cathode $(10 \mathrm{~mm} \times 15 \mathrm{~mm} \times 0.25 \mathrm{~mm})$. Carborane 160 (0.10 mmol, 1.0 equiv), thiol 161 (0.30 mmol, 3.0 equiv), CuOAc (15 mol \%), 2PhPy (15 mol \%), LiOtBu ( $0.2 \mathrm{mmol}, 2.0$ equiv) and TBAI ( $0.2 \mathrm{mmol}, 2.0$ equiv) were dissolved in THF (3.0 mL). Electrocatalysis was performed at room temperature with a constant current of $2.0 \mathrm{~mA}$ maintained for $16 \mathrm{~h}$. The GF anode was washed with ethyl acetate $(3 \times 10 \mathrm{~mL})$. Evaporation of the solvent and subsequent purification by column chromatography on silica gel with $n$-hexane or gel permeation chromatography (GPC) afford the corresponding products 162 .

\section{General Procedure L: Cupraelectro-Catalyzed C-H Chalcogenation of $o$-Carboranes}

The electrocatalysis was carried out in an undivided cell under air, with a graphite felt (GF) anode $(10 \mathrm{~mm} \times 15 \mathrm{~mm} \times 6 \mathrm{~mm})$ and a platinum cathode $(10 \mathrm{~mm} \times 15 \mathrm{~mm} \times 0.25 \mathrm{~mm})$. Thiol 161 (0.30 mmol, 3.0 equiv), LiOtBu ( $0.2 \mathrm{mmol}, 2.0$ equiv) and TBAl ( $0.2 \mathrm{mmol}, 2.0$ equiv) were dissolved in THF (3.0 mL). Electrocatalysis was performed at room temperature with a constant current of $2.0 \mathrm{~mA}$ maintained for $3 \mathrm{~h}$. Then, o-carborane 160 ( $0.10 \mathrm{mmol}, 1.0$ equiv), CuOAc (15 $\mathrm{mol} \%)$ and 2-PhPy (15 mol \%) were added to the reaction mixture and electrocatalysis was 
performed at room temperature with a constant current of $2.0 \mathrm{~mA}$ maintained for another $16 \mathrm{~h}$. The GF anode was washed with ethyl acetate $(3 \times 10 \mathrm{~mL})$. Evaporation of the solvent and subsequent purification by column chromatography on silica gel with $n$-hexane or gel permeation chromatography (GPC) afford the corresponding products 162.

\subsection{Experimental Procedures and Analytical Data}

\subsubsection{Ruthenium(IV) Intermediates in C-H Annulation}

\subsubsection{Characterization Data}<smiles>Cc1cccc2cc(-c3ccccc3)oc(=O)c12</smiles>

\section{Methyl-3-phenyl-1H-isochromen-1-one (142a).}

The representative procedure A was followed using 2-methylbenzoic acid (62a) (34 mg, 0.25 $\mathrm{mmol}$ ) and 2-[dimethyl(oxo)- $\lambda^{6}$-sulfaneylidene]-1-phenylethan-1-one (141a) $(74 \mathrm{mg}, 0.38 \mathrm{mmol})$. Isolation by column chromatography ( $n$-hexane/EtOAc: $10 / 1$ ) yielded $142 \mathrm{a}(45 \mathrm{mg}, 76 \%)$ as a colorless solid. M.p. $=133^{\circ} \mathrm{C} .{ }^{1} \mathrm{H}$ NMR $\left(300 \mathrm{MHz}, \mathrm{CDCl}_{3}\right): \delta=7.94-7.84(\mathrm{~m}, 2 \mathrm{H}), 7.60-7.52(\mathrm{~m}$, 1H), 7.52-7.41 (m, 3H), 7.35-7.26 (m, 2H), $6.89(\mathrm{~s}, 1 \mathrm{H}), 2.87(\mathrm{~s}, 3 \mathrm{H}) .{ }^{13} \mathrm{C} \mathrm{NMR}\left(75 \mathrm{MHz}, \mathrm{CDCl}_{3}\right)$ : $\delta=161.7\left(\mathrm{C}_{\mathrm{q}}\right), 153.1\left(\mathrm{C}_{\mathrm{q}}\right), 143.6\left(\mathrm{C}_{\mathrm{q}}\right), 139.0\left(\mathrm{C}_{\mathrm{q}}\right), 134.0(\mathrm{CH}), 131.9\left(\mathrm{C}_{\mathrm{q}}\right), 131.0(\mathrm{CH}), 129.8$ $(\mathrm{CH}), 128.8(\mathrm{CH}), 125.1(\mathrm{CH}), 124.2(\mathrm{CH}), 119.0\left(\mathrm{C}_{\mathrm{q}}\right), 102.3(\mathrm{CH}), 23.2\left(\mathrm{CH}_{3}\right)$. IR (ATR): 3061, 1712, 1592, 1471, 1227, 1074, 796, $691 \mathrm{~cm}^{-1}$. MS (ESI) $\mathrm{m} / \mathrm{z}$ (relative intensity): 259 (60) $[\mathrm{M}+\mathrm{Na}]^{+}, 237(100)[\mathrm{M}+\mathrm{H}]^{+}$. HR-MS (ESI): $\mathrm{m} / z$ calcd. for $\mathrm{C}_{16} \mathrm{H}_{12} \mathrm{O}_{2}[\mathrm{M}+\mathrm{H}]^{+}: 237.0910$, found: 237.0905 .<smiles>CC(=O)Oc1cccc2cc(-c3ccccc3)oc(=O)c12</smiles>

\section{1-Oxo-3-phenyl-1H-isochromen-8-yl acetate (142b).}

The representative procedure $\mathbf{A}$ was followed using 2-acetoxybenzoic acid (62b) (45 mg, 0.25 $\mathrm{mmol}$ ) and 2-[dimethyl(oxo)- $\lambda^{6}$-sulfaneylidene]-1-phenylethan-1-one (141a) $(74 \mathrm{mg}, 0.38 \mathrm{mmol}$ ). Isolation by column chromatography ( $n$-hexane/EtOAc: $10 / 1)$ yielded $142 b(50 \mathrm{mg}, 72 \%)$ as a 
colorless solid. M.p. $=137^{\circ} \mathrm{C} .{ }^{1} \mathrm{H}$ NMR $\left(300 \mathrm{MHz}, \mathrm{CDCl}_{3}\right): \delta=7.90-7.83(\mathrm{~m}, 2 \mathrm{H}), 7.78-7.68(\mathrm{~m}$, 1H), 7.51-7.44 (m, 3H), 7.39 (d, J = 7.9 Hz, 1H), $7.14(\mathrm{~d}, J=7.8 \mathrm{~Hz}, 1 \mathrm{H}), 6.95(\mathrm{~s}, 1 \mathrm{H}), 2.48(\mathrm{~s}$, 3H). ${ }^{13} \mathrm{C}$ NMR $\left(75 \mathrm{MHz}, \mathrm{CDCl}_{3}\right): \delta=169.7\left(\mathrm{C}_{\mathrm{q}}\right), 158.8\left(\mathrm{C}_{\mathrm{q}}\right), 154.2\left(\mathrm{C}_{\mathrm{q}}\right), 152.0\left(\mathrm{C}_{\mathrm{q}}\right), 140.0\left(\mathrm{C}_{\mathrm{q}}\right)$, $135.6(\mathrm{CH}), 131.6\left(\mathrm{C}_{\mathrm{q}}\right), 130.2(\mathrm{CH}), 128.9(\mathrm{CH}), 125.3(\mathrm{CH}), 124.1(\mathrm{CH}), 122.4(\mathrm{CH}), 113.3\left(\mathrm{C}_{\mathrm{q}}\right)$, $101.6(\mathrm{CH}), 21.2\left(\mathrm{CH}_{3}\right)$. IR (ATR): 3068, 1770, 1731, 1609, 1564, 1189, 1079, $689 \mathrm{~cm}^{-1}$. MS (ESI) $\mathrm{m} / \mathrm{z}$ (relative intensity): $303(100)[\mathrm{M}+\mathrm{Na}]^{+}, 281(20)[\mathrm{M}+\mathrm{H}]^{+}$. HR-MS $(E S I): m / z$ calcd. for $\mathrm{C}_{17} \mathrm{H}_{12} \mathrm{O}_{4}[\mathrm{M}+\mathrm{H}]^{+}: 281.0806$, found: 281.0802. The analytical data correspond with those reported in the literature. ${ }^{[234]}$<smiles>O=c1oc(-c2ccccc2)cc2cccc(F)c12</smiles>

\section{8-Fluoro-3-phenyl-1H-isochromen-1-one (142c).}

The representative procedure A was followed using 2-fluorobenzoic acid (62c) (35 mg, 0.25 $\mathrm{mmol}$ ) and 2-[dimethyl(oxo)- $\lambda^{6}$-sulfaneylidene]-1-phenylethan-1-one (141a) $(74 \mathrm{mg}, 0.38 \mathrm{mmol}$ ). Isolation by column chromatography ( $n$-hexane/EtOAc: $10 / 1)$ yielded $142 \mathrm{c}(33 \mathrm{mg}, 55 \%)$ as a colorless solid. M.p. $=121^{\circ} \mathrm{C} .{ }^{1} \mathrm{H}$ NMR $\left(300 \mathrm{MHz}, \mathrm{CDCl}_{3}\right): \delta=7.94-7.84(\mathrm{~m}, 2 \mathrm{H}), 7.71-7.67(\mathrm{~m}$, 1H), 7.53-7.44 (m, 3H), $7.30(\mathrm{~d}, J=7.6 \mathrm{~Hz}, 1 \mathrm{H}), 7.22-7.11(\mathrm{~m}, 1 \mathrm{H}), 6.94(\mathrm{~s}, 1 \mathrm{H}) .{ }^{13} \mathrm{C}$ NMR $(75$ $\left.\mathrm{MHz}, \mathrm{CDCl}_{3}\right): \delta=163.0\left(\mathrm{~d},{ }^{1} \mathrm{~J}=265.1 \mathrm{~Hz}, \mathrm{C}_{\mathrm{q}}\right), 157.8\left(\mathrm{C}_{\mathrm{q}}\right), 154.6\left(\mathrm{C}_{\mathrm{q}}\right), 140.1\left(\mathrm{C}_{\mathrm{q}}\right), 136.3\left(\mathrm{~d},{ }^{3} \mathrm{~J}=\right.$ $10.1 \mathrm{~Hz}, \mathrm{CH}), 131.5\left(\mathrm{C}_{\mathrm{q}}\right), 130.3(\mathrm{CH}), 128.9(\mathrm{CH}), 125.4(\mathrm{CH}), 121.8\left(\mathrm{~d},{ }^{4} \mathrm{~J}=4.4 \mathrm{~Hz}, \mathrm{CH}\right), 115.2$ $\left(\mathrm{d},{ }^{2} \mathrm{~J}=21.2 \mathrm{~Hz}, \mathrm{CH}\right), 109.3\left(\mathrm{C}_{\mathrm{q}}\right), 101.1(\mathrm{CH}) .{ }^{19} \mathrm{~F}$ NMR $\left(282 \mathrm{MHz}, \mathrm{CDCl}_{3}\right): \delta=-107.2$. IR (ATR): 3105, 1725, 1640, 1475, 1228, 1079, 803, $684 \mathrm{~cm}^{-1}$. MS (ESI) $\mathrm{m} / \mathrm{z}$ (relative intensity): 263 (100) $[\mathrm{M}+\mathrm{Na}]^{+}, 241(70)[\mathrm{M}+\mathrm{H}]^{+}$. HR-MS (ESI): $\mathrm{m} / z$ calcd. for $\mathrm{C}_{15} \mathrm{H}_{9} \mathrm{FO}_{2}[\mathrm{M}+\mathrm{H}]^{+}: 241.0659$, found: 241.0655 .<smiles>O=c1oc(-c2ccc(Cl)cc2)cc2cccc([N+](=O)[O-])c12</smiles>

3-(4-Chlorophenyl)-8-methyl-1H-isochromen-1-one (142d).

The representative procedure $\mathbf{A}$ was followed using 2-methylbenzoic acid (62a) (34 mg, 0.25 $\mathrm{mmol}$ ) and 1-(4-chlorophenyl)-2-[dimethyl(oxo)- $\lambda^{6}$-sulfaneylidene]ethan-1-one (141b) (87 mg, $0.38 \mathrm{mmol}$ ). Isolation by column chromatography ( $n$-hexane/EtOAc: $10 / 1)$ yielded $142 \mathbf{d}(62 \mathrm{mg}$, 
92\%) as a colorless solid. M.p. $=156{ }^{\circ} \mathrm{C} .{ }^{1} \mathbf{H}$ NMR $\left(300 \mathrm{MHz}, \mathrm{CDCl}_{3}\right): \delta=7.78(\mathrm{~d}, \mathrm{~J}=8.7 \mathrm{~Hz}$, 2H), 7.58-7.51 (m, 1H), $7.78(\mathrm{~d}, J=8.7 \mathrm{~Hz}, 2 \mathrm{H}), 7.33-7.25(\mathrm{~m}, 2 \mathrm{H}), 6.84(\mathrm{~s}, 1 \mathrm{H}), 2.84(\mathrm{~s}, 3 \mathrm{H})$. ${ }^{13} \mathrm{C}$ NMR $\left(75 \mathrm{MHz}, \mathrm{CDCl}_{3}\right): \delta=161.3\left(\mathrm{C}_{\mathrm{q}}\right), 152.0\left(\mathrm{C}_{\mathrm{q}}\right), 143.6\left(\mathrm{C}_{\mathrm{q}}\right), 138.8\left(\mathrm{C}_{\mathrm{q}}\right), 135.8\left(\mathrm{C}_{\mathrm{q}}\right), 134.1$ $(\mathrm{CH}), 131.3(\mathrm{CH}), 130.4\left(\mathrm{C}_{\mathrm{q}}\right), 129.0(\mathrm{CH}), 126.3(\mathrm{CH}), 124.3(\mathrm{CH}), 118.9\left(\mathrm{C}_{\mathrm{q}}\right), 102.5(\mathrm{CH}), 23.2$ $\left(\mathrm{CH}_{3}\right)$. IR (ATR): 3097, 1714, 1493, 1095, 1074, 1014, 825, $687 \mathrm{~cm}^{-1}$. MS (ESI) $\mathrm{m} / \mathrm{z}$ (relative intensity): $293(60)[\mathrm{M}+\mathrm{Na}]^{+}, 271(100)[\mathrm{M}+\mathrm{H}]^{+}$. HR-MS (ESI): m/z calcd. for $\mathrm{C}_{16} \mathrm{H}_{11} \mathrm{ClO}_{2}[\mathrm{M}+\mathrm{H}]^{+}$: 271.0520, found: 271.0516 .<smiles>Cc1cccc2cc(-c3cccc(C(F)(F)F)c3)oc(=O)c12</smiles>

\section{8-Methyl-3-[3-(trifluoromethyl)phenyl]-1H-isochromen-1-one (142e).}

The representative procedure $\mathbf{A}$ was followed using 2-methylbenzoic acid (62a) (34 mg, 0.25 $\mathrm{mmol}$ ) and 2-[dimethyl(oxo)- $\lambda^{6}$-sulfaneylidene]-1-[3-(trifluoromethyl)phenyl]ethan-1-one (141c) (99 mg, $0.38 \mathrm{mmol}$ ). Isolation by column chromatography ( $n$-hexane/EtOAc: 10/1) yielded 142e (54 mg, 71\%) as a colorless solid. M.p. $=159{ }^{\circ} \mathrm{C} .{ }^{1} \mathbf{H}$ NMR $\left(300 \mathrm{MHz}, \mathrm{CDCl}_{3}\right): \delta=8.12(\mathrm{~s}, 1 \mathrm{H})$, $8.06(\mathrm{~d}, J=7.8 \mathrm{~Hz}, 1 \mathrm{H}), 7.68(\mathrm{~d}, J=7.8 \mathrm{~Hz}, 1 \mathrm{H}), 7.64-7.56(\mathrm{~m}, 2 \mathrm{H}), 7.39-7.30(\mathrm{~m}, 2 \mathrm{H}), 6.96(\mathrm{~s}$, $1 \mathrm{H}), 2.87(\mathrm{~s}, 3 \mathrm{H}) .{ }^{13} \mathrm{C}$ NMR $\left(75 \mathrm{MHz}, \mathrm{CDCl}_{3}\right): \delta=161.1\left(\mathrm{C}_{\mathrm{q}}\right), 151.5\left(\mathrm{C}_{\mathrm{q}}\right), 143.8\left(\mathrm{C}_{\mathrm{q}}\right), 138.5\left(\mathrm{C}_{\mathrm{q}}\right)$, $134.2(\mathrm{CH}), 132.8\left(\mathrm{C}_{\mathrm{q}}\right), 131.6(\mathrm{CH}), 130.9\left(\mathrm{q},{ }^{2} \mathrm{~J}=32.9 \mathrm{~Hz}, \mathrm{C}_{\mathrm{q}}\right), 129.4(\mathrm{CH}), 128.2(\mathrm{CH}), 126.3(\mathrm{q}$, $\left.{ }^{3} J=3.9 \mathrm{~Hz}, \mathrm{CH}\right), 124.4(\mathrm{CH}), 123.9\left(\mathrm{q},{ }^{1} \mathrm{~J}=270.9 \mathrm{~Hz}, \mathrm{C}_{\mathrm{q}}\right), 121.9\left(\mathrm{q},{ }^{3} \mathrm{~J}=3.9 \mathrm{~Hz}, \mathrm{CH}\right), 119.2\left(\mathrm{C}_{\mathrm{q}}\right)$, $103.4(\mathrm{CH}), 23.2\left(\mathrm{CH}_{3}\right) .{ }^{19} \mathrm{~F}$ NMR $\left(282 \mathrm{MHz}_{\mathrm{CDCl}}\right): \delta=-62.7$. IR (ATR): 2932, 1721, 1333, 1309, 1222, 1166, 1113, $1073 \mathrm{~cm}^{-1}$. MS (ESI) $\mathrm{m} / \mathrm{z}$ (relative intensity): 327 (70) [M+Na] $]^{+}, 305(100)$ $[\mathrm{M}+\mathrm{H}]^{+}$. HR-MS $(\mathrm{ESI}): \mathrm{m} / \mathrm{z}$ calcd. for $\mathrm{C}_{17} \mathrm{H}_{11} \mathrm{~F}_{3} \mathrm{O}_{2}[\mathrm{M}+\mathrm{H}]^{+}:$305.0784, found: 305.0777 .<smiles>Cc1ccccc1-c1cc2cccc(C)c2c(=O)o1</smiles>

8-Methyl-3-(o-tolyl)-1H-isochromen-1-one (142f).

The representative procedure $\mathbf{A}$ was followed using 2-methylbenzoic acid (62a) (34 $\mathrm{mg}, 0.25$ $\mathrm{mmol}$ ) and 2-[dimethyl(oxo)- $\lambda^{6}$-sulfaneylidene]-1-(o-tolyl)ethan-1-one (141d) (79 mg, $0.38 \mathrm{mmol}$ ). 
Isolation by column chromatography ( $n$-hexane/EtOAc: $10 / 1)$ yielded $\mathbf{1 4 2 f}(51 \mathrm{mg}, 85 \%)$ as a colorless solid. M.p. $=14{ }^{\circ} \mathrm{C} .{ }^{1} \mathbf{H}$ NMR $\left(300 \mathrm{MHz}, \mathrm{CDCl}_{3}\right): \delta=7.63-7.50(\mathrm{~m}, 2 \mathrm{H}), 7.37-7.25(\mathrm{~m}$, $5 \mathrm{H}), 6.56(\mathrm{~s}, 1 \mathrm{H}), 2.89(\mathrm{~s}, 3 \mathrm{H}), 2.54(\mathrm{~s}, 3 \mathrm{H}) .{ }^{13} \mathrm{C} \mathrm{NMR}\left(75 \mathrm{MHz}, \mathrm{CDCl}_{3}\right): \delta=162.0\left(\mathrm{C}_{\mathrm{q}}\right), 155.2$ $\left(\mathrm{C}_{\mathrm{q}}\right), 143.5\left(\mathrm{C}_{\mathrm{q}}\right), 139.1\left(\mathrm{C}_{\mathrm{q}}\right), 136.8\left(\mathrm{C}_{\mathrm{q}}\right), 134.0(\mathrm{CH}), 132.8\left(\mathrm{C}_{\mathrm{q}}\right), 131.1(\mathrm{CH}), 131.1(\mathrm{CH}), 129.7$ $(\mathrm{CH}), 129.1(\mathrm{CH}), 126.0(\mathrm{CH}), 124.1(\mathrm{CH}), 118.8\left(\mathrm{C}_{\mathrm{q}}\right), 106.4(\mathrm{CH}), 23.3\left(\mathrm{CH}_{3}\right), 20.8\left(\mathrm{CH}_{3}\right)$. IR (ATR): 2926, 1710, 1646, 1593, 1573, 1490, 1223, $723 \mathrm{~cm}^{-1}$. MS (ESI) $\mathrm{m} / \mathrm{z}$ (relative intensity): $273(90)[\mathrm{M}+\mathrm{Na}]^{+}, 251(100)[\mathrm{M}+\mathrm{H}]^{+}$. HR-MS (ESI): m/z calcd. for $\mathrm{C}_{17} \mathrm{H}_{14} \mathrm{O}_{2}[\mathrm{M}+\mathrm{H}]^{+}: 251.1067$, found: 251.1062 .<smiles>O=c1oc(-c2ccccc2)cc2ccccc12</smiles>

\section{3-Phenyl-1H-isochromen-1-one (142g).}

The representative procedure $B$ was followed using benzoic acid (62d) $(92 \mathrm{mg}, 0.75 \mathrm{mmol})$ and 2-[dimethyl(oxo)- $\lambda^{6}$-sulfaneylidene]- 1-phenylethan-1-one (141a) $(49 \mathrm{mg}, 0.25 \mathrm{mmol}$ ). Isolation

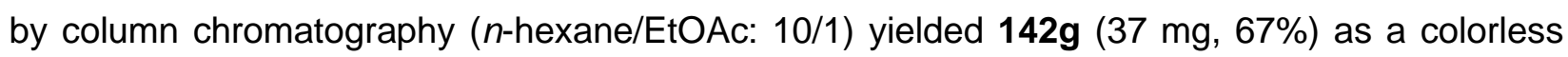
solid. M.p. $=90^{\circ} \mathrm{C} .{ }^{1} \mathrm{H}$ NMR $\left(300 \mathrm{MHz}, \mathrm{CDCl}_{3}\right): \delta=8.31(\mathrm{~d}, J=8.0 \mathrm{~Hz}, 1 \mathrm{H}), 7.88(\mathrm{dd}, J=7.8$, $1.8 \mathrm{~Hz}, 2 \mathrm{H}), 7.76-7.67(\mathrm{~m}, 1 \mathrm{H}), 7.53-7.42(\mathrm{~m}, 5 \mathrm{H}), 6.95(\mathrm{~s}, 1 \mathrm{H}) .{ }^{13} \mathrm{C} \mathrm{NMR}\left(75 \mathrm{MHz}, \mathrm{CDCl}_{3}\right): \delta=$ $162.3\left(\mathrm{C}_{\mathrm{q}}\right), 153.6\left(\mathrm{C}_{\mathrm{q}}\right), 137.5\left(\mathrm{C}_{\mathrm{q}}\right), 134.9(\mathrm{CH}), 132.0\left(\mathrm{C}_{\mathrm{q}}\right), 130.0(\mathrm{CH}), 129.6(\mathrm{CH}), 128.8(\mathrm{CH})$, $128.2(\mathrm{CH}), 126.0(\mathrm{CH}), 125.2(\mathrm{CH}), 120.5\left(\mathrm{C}_{\mathrm{q}}\right), 101.8(\mathrm{CH})$. IR (ATR): 3062, 1720, 1636, 1607, 1483, 1234, 1107, 767, $690 \mathrm{~cm}^{-1}$. MS (ESI) m/z (relative intensity): $245(50)[\mathrm{M}+\mathrm{Na}]^{+}, 223(100)$ $[\mathrm{M}+\mathrm{H}]^{+}$. HR-MS (ESI): $\mathrm{m} / z$ calcd. for $\mathrm{C}_{15} \mathrm{H}_{10} \mathrm{O}_{2}[\mathrm{M}+\mathrm{H}]^{+}: 223.0754$, found: 223.0758 . The analytical data correspond with those reported in the literature. ${ }^{[235]}$

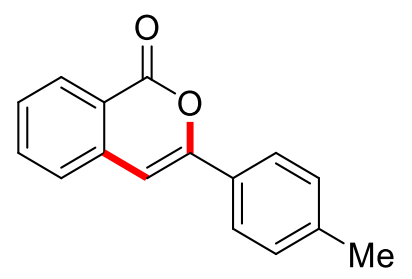

\section{3-(p-Tolyl)-1 H-isochromen-1-one (142h).}

The representative procedure $B$ was followed using benzoic acid (62d) $(92 \mathrm{mg}, 0.75 \mathrm{mmol})$ and 2-[dimethyl(oxo)- $\lambda^{6}$-sulfaneylidene]-1-( $p$-tolyl)ethan-1-one (141e) $(53 \mathrm{mg}, 0.25 \mathrm{mmol}$ ). Isolation by column chromatography ( $n$-hexane/EtOAc: $10 / 1$ ) yielded $142 \mathrm{~h}(38 \mathrm{mg}, 65 \%)$ as a colorless solid. M.p. $=114{ }^{\circ} \mathrm{C} .{ }^{1} \mathrm{H}$ NMR $\left(300 \mathrm{MHz}, \mathrm{CDCl}_{3}\right): \delta=8.32(\mathrm{~d}, J=8.5 \mathrm{~Hz}, 1 \mathrm{H}), 7.79(\mathrm{~d}, J=8.2 \mathrm{~Hz}$, 2H), 7.76-7.69 (m, 1H), 7.53-7.46 (m, 2H), 7.31-7.26 (m, 2H), $6.92(\mathrm{~s}, 1 \mathrm{H}), 2.42(\mathrm{~s}, 3 \mathrm{H}) .{ }^{13} \mathrm{C}$ 
NMR $\left(75 \mathrm{MHz}, \mathrm{CDCl}_{3}\right): \delta=162.4\left(\mathrm{C}_{\mathrm{q}}\right), 153.9\left(\mathrm{C}_{\mathrm{q}}\right), 140.3\left(\mathrm{C}_{\mathrm{q}}\right), 137.7\left(\mathrm{C}_{\mathrm{q}}\right), 134.8(\mathrm{CH}), 129.6$ $(\mathrm{CH}), 129.5(\mathrm{CH}), 129.2\left(\mathrm{C}_{\mathrm{q}}\right), 127.9(\mathrm{CH}), 125.9(\mathrm{CH}), 125.2(\mathrm{CH}), 120.4\left(\mathrm{C}_{\mathrm{q}}\right), 101.1(\mathrm{CH}), 21.4$ $\left(\mathrm{CH}_{3}\right)$. IR (ATR): 2918, 1731, 1630, 1066, 1008, 816, 752, $688 \mathrm{~cm}^{-1}$. MS (ESI) $\mathrm{m} / z$ (relative intensity): 259 (90) $[\mathrm{M}+\mathrm{Na}]^{+}, 237(100)[\mathrm{M}+\mathrm{H}]^{+}$. HR-MS (ESI): $\mathrm{m} / z$ calcd. for $\mathrm{C}_{16} \mathrm{H}_{12} \mathrm{O}_{2}[\mathrm{M}+\mathrm{H}]^{+}$: 237.0910, found: 237.0905. The analytical data correspond with those reported in the literature. ${ }^{[236]}$<smiles>CC(=O)Oc1cc(CC(=O)c2ccccc2)c2c(=O)oc(-c3ccccc3)cc2c1</smiles>

1-Oxo-8-(2-oxo-2-phenylethyl)-3-phenyl-1 H-isochromen-6-yl acetate (142i).

The representative procedure $\mathbf{C}$ was followed using 4-acetoxybenzoic acid (62e) (45 mg, 0.25 $\mathrm{mmol}$ ) and 2-[dimethyl(oxo)- $\lambda^{6}$-sulfaneylidene]-1-phenylethan-1-one (141a) $(147 \mathrm{mg}, 0.75 \mathrm{mmol}$ ). Isolation by column chromatography ( $n$-hexane/EtOAc: $10 / 1)$ yielded $142 \mathbf{i}(73 \mathrm{mg}, 73 \%$ ) as a colorless solid. M.p. $=195^{\circ} \mathrm{C} .{ }^{1} \mathbf{H}$ NMR $\left(300 \mathrm{MHz}, \mathrm{CDCl}_{3}\right): \delta=8.17-8.08(\mathrm{~m}, 2 \mathrm{H}), 7.88-7.80(\mathrm{~m}$, 2H), 7.66-7.59 (m, 1H), 7.57-7.50 (m, 2H), 7.48-7.42 (m, 3H), $7.28(\mathrm{~s}, 1 \mathrm{H}), 7.09(\mathrm{~d}, J=2.2 \mathrm{~Hz}$, 1H), $6.92(\mathrm{~s}, 1 \mathrm{H}), 4.91(\mathrm{~s}, 2 \mathrm{H}), 2.36(\mathrm{~s}, 3 \mathrm{H}) .{ }^{13} \mathrm{C}$ NMR $\left(75 \mathrm{MHz}, \mathrm{CDCl}_{3}\right): \delta=196.7\left(\mathrm{C}_{\mathrm{q}}\right), 168.5$ $\left(\mathrm{C}_{\mathrm{q}}\right), 161.1\left(\mathrm{C}_{\mathrm{q}}\right), 154.7\left(\mathrm{C}_{\mathrm{q}}\right), 154.1\left(\mathrm{C}_{\mathrm{q}}\right), 142.0\left(\mathrm{C}_{\mathrm{q}}\right), 141.1\left(\mathrm{C}_{\mathrm{q}}\right), 137.2\left(\mathrm{C}_{\mathrm{q}}\right), 133.1(\mathrm{CH}), 131.5\left(\mathrm{C}_{\mathrm{q}}\right)$, $130.2(\mathrm{CH}), 128.9(\mathrm{CH}), 128.6(\mathrm{CH}), 128.3(\mathrm{CH}), 125.6(\mathrm{CH}), 125.3(\mathrm{CH}), 117.6(\mathrm{CH}), 116.6\left(\mathrm{C}_{q}\right)$, $102.0(\mathrm{CH}), 45.6\left(\mathrm{CH}_{2}\right), 21.3\left(\mathrm{CH}_{3}\right)$. IR (ATR): 2000, 1643, 1603, 1575, 1061, 1003, 910, 530 $\mathrm{cm}^{-1}$. MS (ESI) $\mathrm{m} / \mathrm{z}$ (relative intensity): 421 (95) [M+Na] $]^{+}, 399(100)[\mathrm{M}+\mathrm{H}]^{+}$. HR-MS (ESI): $\mathrm{m} / \mathrm{z}$ calcd. for $\mathrm{C}_{25} \mathrm{H}_{18} \mathrm{O}_{5}[\mathrm{M}+\mathrm{H}]^{+}: 399.1227$, found: 399.1218 .<smiles>COc1cc(CC(=O)c2ccccc2)c2c(=O)oc(-c3ccccc3)cc2c1</smiles>

\section{6-Methoxy-8-(2-oxo-2-phenylethyl)-3-phenyl-1H-isochromen-1-one (142j).}

The representative procedure $\mathbf{C}$ was followed using 4-methoxybenzoic acid (62f) (38 $\mathrm{mg}, 0.25$ $\mathrm{mmol}$ ) and 2-[dimethyl(oxo)- $\lambda^{6}$-sulfaneylidene]-1-phenylethan-1-one (141a) (147 mg, $\left.0.75 \mathrm{mmol}\right)$. Isolation by column chromatography ( $n$-hexane/EtOAc: $10 / 1$ ) yielded $142 \mathrm{j}(59 \mathrm{mg}, 64 \%)$ as a colorless solid. M.p. $=188^{\circ} \mathrm{C} .{ }^{1} \mathrm{H}$ NMR $\left(300 \mathrm{MHz}, \mathrm{CDCl}_{3}\right): \delta=8.17-8.08(\mathrm{~m}, 2 \mathrm{H}), 7.88-7.79(\mathrm{~m}$, 
2H), 7.64-7.57 (m, 1H), 7.57-7.49 (m, 2H), 7.49-7.40 (m, 3H), 6.94-6.82 (m, 3H), 4.86 (s, 2H), $3.93(\mathrm{~s}, 3 \mathrm{H}) .{ }^{13} \mathrm{C}$ NMR $\left(75 \mathrm{MHz}, \mathrm{CDCl}_{3}\right): \delta=197.1\left(\mathrm{C}_{\mathrm{q}}\right), 163.7\left(\mathrm{C}_{\mathrm{q}}\right), 161.4\left(\mathrm{C}_{\mathrm{q}}\right), 153.8\left(\mathrm{C}_{\mathrm{q}}\right), 141.9$ $\left(\mathrm{C}_{\mathrm{q}}\right), 141.7\left(\mathrm{C}_{\mathrm{q}}\right), 137.4\left(\mathrm{C}_{\mathrm{q}}\right), 132.9(\mathrm{CH}), 131.8\left(\mathrm{C}_{\mathrm{q}}\right), 129.9(\mathrm{CH}), 128.8(\mathrm{CH}), 128.6(\mathrm{CH}), 128.3$ (CH), $125.2(\mathrm{CH}), 120.6(\mathrm{CH}), 112.3\left(\mathrm{C}_{\mathrm{q}}\right), 107.5(\mathrm{CH}), 102.4(\mathrm{CH}), 55.6\left(\mathrm{CH}_{3}\right), 45.7\left(\mathrm{CH}_{2}\right)$. IR (ATR): 3059, 1711, 1599, 1468, 1212, 1160, 735, $628 \mathrm{~cm}^{-1}$. MS (ESI) $\mathrm{m} / \mathrm{z}$ (relative intensity): 393 (50) $[\mathrm{M}+\mathrm{Na}]^{+}, 371(100)[\mathrm{M}+\mathrm{H}]^{+}$. HR-MS (ESI): $\mathrm{m} / z$ calcd. for $\mathrm{C}_{24} \mathrm{H}_{18} \mathrm{O}_{4}[\mathrm{M}+\mathrm{H}]^{+}: 371.1278$, found: 371.1276 .<smiles>CC(C)(C)c1cc(CC(=O)c2ccccc2)c2c(=O)oc(-c3ccccc3)cc2c1</smiles>

6-(tert-Butyl)-8-(2-oxo-2-phenylethyl)-3-phenyl-1H-isochromen-1-one (142k).

The representative procedure $\mathbf{C}$ was followed using 4-(tert-butyl)benzoic acid $(\mathbf{6 2 g})(45 \mathrm{mg}, 0.25$ $\mathrm{mmol}$ ) and 2-[dimethyl(oxo)- $\lambda^{6}$-sulfaneylidene]-1-phenylethan-1-one (141a) $(147 \mathrm{mg}, 0.75 \mathrm{mmol}$ ). Isolation by column chromatography ( $n$-hexane/EtOAc: $10 / 1)$ yielded $142 \mathbf{k}(80 \mathrm{mg}, 81 \%)$ as a colorless solid. M.p. $=198^{\circ} \mathrm{C} .{ }^{1} \mathbf{H}$ NMR $\left(300 \mathrm{MHz}, \mathrm{CDCl}_{3}\right): \delta=8.20-8.12(\mathrm{~m}, 2 \mathrm{H}), 7.90-7.83(\mathrm{~m}$, 2H), 7.65-7.58 (m, 1H), 7.57-7.50 (m, 2H), 7.49-7.40 (m, 4H), $7.36(\mathrm{~d}, J=1.9 \mathrm{~Hz}, 1 \mathrm{H}), 6.99(\mathrm{~s}$, $1 \mathrm{H}), 4.93(\mathrm{~s}, 2 \mathrm{H}), 1.43(\mathrm{~s}, 9 \mathrm{H}) .{ }^{13} \mathrm{C}$ NMR $\left(75 \mathrm{MHz}, \mathrm{CDCl}_{3}\right): \delta=197.3\left(\mathrm{C}_{\mathrm{q}}\right), 161.8\left(\mathrm{C}_{\mathrm{q}}\right), 158.0\left(\mathrm{C}_{\mathrm{q}}\right)$, $153.2\left(\mathrm{C}_{q}\right), 139.3\left(\mathrm{C}_{\mathrm{q}}\right), 139.1\left(\mathrm{C}_{\mathrm{q}}\right), 137.5\left(\mathrm{C}_{\mathrm{q}}\right), 132.9(\mathrm{CH}), 132.0\left(\mathrm{C}_{\mathrm{q}}\right), 130.2(\mathrm{CH}), 129.8(\mathrm{CH})$, $128.8(\mathrm{CH}), 128.6(\mathrm{CH}), 128.3(\mathrm{CH}), 125.1(\mathrm{CH}), 122.3(\mathrm{CH}), 116.8\left(\mathrm{C}_{\mathrm{q}}\right), 102.9(\mathrm{CH}), 45.9\left(\mathrm{CH}_{2}\right)$, $35.2\left(\mathrm{C}_{\mathrm{q}}\right), 31.0\left(\mathrm{CH}_{3}\right)$. IR (ATR): 2965, 1716, 1688, 1600, 1496, 1212, 756, $688 \mathrm{~cm}^{-1}$. MS (ESI) $\mathrm{m} / \mathrm{z}$ (relative intensity): $419(30)[\mathrm{M}+\mathrm{Na}]^{+}, 397(100)[\mathrm{M}+\mathrm{H}]^{+}$. HR-MS $(\mathrm{ESI}): \mathrm{m} / \mathrm{z}$ calcd. for $\mathrm{C}_{27} \mathrm{H}_{24} \mathrm{O}_{3}[\mathrm{M}+\mathrm{H}]^{+}: 397.1798$, found: 397.1800 .<smiles>CNc1cc(CC(=O)c2ccccc2)c2c(=O)oc(-c3ccccc3)cc2c1</smiles>

\section{6-(Dimethylamino)-8-(2-oxo-2-phenylethyl)-3-phenyl-1H-isochromen-1-one (142I).}

The representative procedure $\mathbf{C}$ was followed using 4-(dimethylamino)benzoic acid (62h) $(41 \mathrm{mg}$, $0.25 \mathrm{mmol}$ ) and 2-[dimethyl(oxo)- $\lambda^{6}$-sulfaneylidene]-1-phenylethan-1-one (141a) (147 mg, 0.75 
mmol). Isolation by column chromatography ( $n$-hexane/EtOAc: $10 / 1)$ yielded $142 \mathrm{l}(72 \mathrm{mg}, 75 \%)$ as a colorless solid. M.p. $=189^{\circ} \mathrm{C} .{ }^{1} \mathbf{H}$ NMR $\left(300 \mathrm{MHz}, \mathrm{CDCl}_{3}\right): \delta=8.17-8.12(\mathrm{~m}, 2 \mathrm{H}), 7.83(\mathrm{dd}$, $J=7.9,1.7 \mathrm{~Hz}, 2 \mathrm{H}), 7.62-7.57(\mathrm{~m}, 1 \mathrm{H}), 7.54-7.48(\mathrm{~m}, 2 \mathrm{H}), 7.46-7.38(\mathrm{~m}, 3 \mathrm{H}), 6.83(\mathrm{~s}, 1 \mathrm{H})$, $6.61(\mathrm{~d}, J=2.5 \mathrm{~Hz}, 1 \mathrm{H}), 6.49(\mathrm{~d}, J=2.5 \mathrm{~Hz}, 1 \mathrm{H}), 4.83(\mathrm{~s}, 2 \mathrm{H}), 3.08(\mathrm{~s}, 6 \mathrm{H}) .{ }^{13} \mathrm{C}$ NMR $(75 \mathrm{MHz}$, $\left.\mathrm{CDCl}_{3}\right): \delta=197.7\left(\mathrm{C}_{\mathrm{q}}\right), 162.0\left(\mathrm{C}_{\mathrm{q}}\right), 153.4\left(\mathrm{C}_{\mathrm{q}}\right), 153.0\left(\mathrm{C}_{\mathrm{q}}\right), 141.0\left(\mathrm{C}_{\mathrm{q}}\right), 140.9\left(\mathrm{C}_{\mathrm{q}}\right), 137.6\left(\mathrm{C}_{\mathrm{q}}\right)$, $132.7(\mathrm{CH}), 132.3\left(\mathrm{C}_{\mathrm{q}}\right), 129.5(\mathrm{CH}), 128.6(\mathrm{CH}), 128.5(\mathrm{CH}), 128.3(\mathrm{CH}), 125.1(\mathrm{CH}), 116.7(\mathrm{CH})$, $107.2\left(\mathrm{C}_{\mathrm{q}}\right), 105.4(\mathrm{CH}), 102.8(\mathrm{CH}), 46.1\left(\mathrm{CH}_{2}\right), 39.9\left(\mathrm{CH}_{3}\right)$. IR $(\mathrm{ATR}):$ 3051, 1694, 1597, 1494, 1448, 1388, 1335, $559 \mathrm{~cm}^{-1}$. MS (ESI) $\mathrm{m} / z$ (relative intensity): $406(40)[\mathrm{M}+\mathrm{Na}]^{+}, 384(100)$ $[\mathrm{M}+\mathrm{H}]^{+}$. HR-MS (ESI): $\mathrm{m} / z$ calcd. for $\mathrm{C}_{25} \mathrm{H}_{21} \mathrm{NO}_{3}[\mathrm{M}+\mathrm{H}]^{+}:$384.1594, found: 384.1588 .<smiles>Cc1ccc(C(=O)Cc2cc(C)cc3cc(-c4ccc(C)cc4)oc(=O)c23)cc1</smiles>

6-Methyl-8-[2-oxo-2-(p-tolyl)ethyl]-3-(p-tolyl)-1H-isochromen-1-one (142m).

The representative procedure $\mathbf{C}$ was followed using 4-methylbenzoic acid (62i) (34 mg, 0.25 mmol) and 2-[dimethyl(oxo)- $\lambda^{6}$-sulfaneylidene]-1-( $p$-tolyl)ethan-1-one (141f) (158 mg, 0.75 $\mathrm{mmol}$ ). Isolation by column chromatography ( $n$-hexane/EtOAc: $10 / 1$ ) yielded $142 \mathrm{~m}(80 \mathrm{mg}, 84 \%)$ as a colorless solid. M.p. $=201{ }^{\circ} \mathrm{C} .{ }^{1} \mathbf{H}$ NMR $\left(300 \mathrm{MHz}, \mathrm{CDCl}_{3}\right): \delta=8.04(\mathrm{~d}, J=8.2 \mathrm{~Hz}, 2 \mathrm{H})$, $7.73(\mathrm{~d}, J=8.3 \mathrm{~Hz}, 2 \mathrm{H}), 7.32(\mathrm{~d}, J=8.0 \mathrm{~Hz}, 2 \mathrm{H}), 7.28-7.20(\mathrm{~m}, 3 \mathrm{H}), 7.11(\mathrm{~s}, 1 \mathrm{H}), 6.84(\mathrm{~s}, 1 \mathrm{H})$, $4.84(\mathrm{~s}, 2 \mathrm{H}), 2.45(\mathrm{~s}, 3 \mathrm{H}), 2.43(\mathrm{~s}, 3 \mathrm{H}), 2.40(\mathrm{~s}, 3 \mathrm{H}) .{ }^{13} \mathrm{C} \mathrm{NMR}\left(75 \mathrm{MHz}, \mathrm{CDCl}_{3}\right): \delta=197.0\left(\mathrm{C}_{\mathrm{q}}\right)$, $161.8\left(\mathrm{C}_{\mathrm{q}}\right), 153.5\left(\mathrm{C}_{\mathrm{q}}\right), 145.1\left(\mathrm{C}_{\mathrm{q}}\right), 143.6\left(\mathrm{C}_{\mathrm{q}}\right), 140.0\left(\mathrm{C}_{\mathrm{q}}\right), 139.7\left(\mathrm{C}_{\mathrm{q}}\right), 139.5\left(\mathrm{C}_{\mathrm{q}}\right), 135.0\left(\mathrm{C}_{\mathrm{q}}\right)$, $133.4(\mathrm{CH}), 129.5(\mathrm{CH}), 129.3(\mathrm{CH}), 129.2\left(\mathrm{C}_{\mathrm{q}}\right), 128.4(\mathrm{CH}), 125.6(\mathrm{CH}), 125.0(\mathrm{CH}), 116.5\left(\mathrm{C}_{\mathrm{q}}\right)$, $101.6(\mathrm{CH}), 45.3\left(\mathrm{CH}_{2}\right), 21.7\left(\mathrm{CH}_{3}\right), 21.6\left(\mathrm{CH}_{3}\right), 21.3\left(\mathrm{CH}_{3}\right)$. IR (ATR): 2919, 1716, 1686, 1567, 1408, 1333, 1272, 765, $690 \mathrm{~cm}^{-1}$. MS (ESI) $\mathrm{m} / z$ (relative intensity): 405 (20) [M+Na] $]^{+}, 383$ (100) $[\mathrm{M}+\mathrm{H}]^{+}$. HR-MS (ESI): $\mathrm{m} / z$ calcd. for $\mathrm{C}_{26} \mathrm{H}_{22} \mathrm{O}_{3}[\mathrm{M}+\mathrm{H}]^{+}: 383.1642$, found: 383.1645 .<smiles>Cc1cc(CC(=O)c2ccc(Cl)cc2)c2c(=O)oc(-c3ccc(Cl)cc3)cc2c1</smiles>

3-(4-Chlorophenyl)-8-[2-(4-chlorophenyl)-2-oxoethyl]-6-methyl-1H-isochromen-1-one 100 
(142n). The representative procedure $\mathbf{C}$ was followed using 4-methylbenzoic acid (62i) (34 mg, $0.25 \mathrm{mmol}$ ) and 1-(4-chlorophenyl)-2-[dimethyl(oxo)- $\lambda^{6}$-sulfaneylidene]ethan-1-one (141g) (173 $\mathrm{mg}, 0.75 \mathrm{mmol}$ ). Isolation by column chromatography ( $n$-hexane/EtOAc: 10/1) yielded 142n (92 mg, $87 \%)$ as a colorless solid. M.p. $=21{ }^{\circ} \mathrm{C} .{ }^{1} \mathrm{H}$ NMR $\left(300 \mathrm{MHz}, \mathrm{CDCl}_{3}\right): \delta=8.07(\mathrm{~d}, \mathrm{~J}=8.7 \mathrm{~Hz}$, 2H), $7.76(\mathrm{~d}, J=8.7 \mathrm{~Hz}, 2 \mathrm{H}), 7.50(\mathrm{~d}, J=8.7 \mathrm{~Hz}, 2 \mathrm{H}), 7.42(\mathrm{~d}, J=8.7 \mathrm{~Hz}, 2 \mathrm{H}), 7.26(\mathrm{~s}, 1 \mathrm{H}), 7.15$ $(\mathrm{s}, 1 \mathrm{H}), 6.88(\mathrm{~s}, 1 \mathrm{H}), 4.81(\mathrm{~s}, 2 \mathrm{H}), 2.48(\mathrm{~s}, 3 \mathrm{H}) .{ }^{13} \mathrm{C}$ NMR $\left(75 \mathrm{MHz}, \mathrm{CDCl}_{3}\right): \delta=196.2\left(\mathrm{C}_{\mathrm{q}}\right), 161.5$ $\left(\mathrm{C}_{\mathrm{q}}\right), 152.3\left(\mathrm{C}_{\mathrm{q}}\right), 145.5\left(\mathrm{C}_{\mathrm{q}}\right), 139.3\left(\mathrm{C}_{\mathrm{q}}\right), 139.2\left(\mathrm{C}_{\mathrm{q}}\right), 139.1\left(\mathrm{C}_{\mathrm{q}}\right), 135.9\left(\mathrm{C}_{\mathrm{q}}\right), 135.7\left(\mathrm{C}_{\mathrm{q}}\right), 133.9(\mathrm{CH})$, $130.3\left(\mathrm{C}_{\mathrm{q}}\right), 129.7(\mathrm{CH}), 129.1(\mathrm{CH}), 128.9(\mathrm{CH}), 126.4(\mathrm{CH}), 126.0(\mathrm{CH}), 116.6\left(\mathrm{C}_{\mathrm{q}}\right), 102.5(\mathrm{CH})$, $45.4\left(\mathrm{CH}_{2}\right), 21.8\left(\mathrm{CH}_{3}\right)$. IR (ATR): 2916, 1717, 1690, 1589, 1568, 1400, 1168, $966 \mathrm{~cm}^{-1}$. MS (ESI) $\mathrm{m} / \mathrm{z}$ (relative intensity): $445(70)[\mathrm{M}+\mathrm{Na}]^{+}, 423(100)[\mathrm{M}+\mathrm{H}]^{+}$. HR-MS (ESI): $\mathrm{m} / \mathrm{z}$ calcd. for $\mathrm{C}_{24} \mathrm{H}_{16} \mathrm{Cl}_{2} \mathrm{O}_{3}[\mathrm{M}+\mathrm{H}]^{+}:$423.0549, found: 423.0545 .

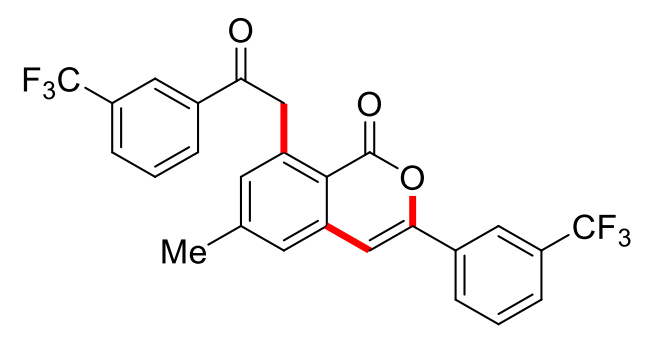

\section{6-Methyl-8-(2-oxo-2-[3-(trifluoromethyl)phenyl]ethyl)-3-[3-(trifluoromethyl)phenyl]-1 H-}

isochromen-1-one (1420). The representative procedure $C$ was followed using 4methylbenzoic acid (62i) (34 mg, $0.25 \mathrm{mmol}$ ) and 2-[dimethyl(oxo)- $\lambda^{6}$-sulfaneylidene]-1-[3(trifluoromethyl)phenyl]ethan-1-one (141h) (198 $\mathrm{mg}, 0.75 \mathrm{mmol}$ ). Isolation by column chromatography ( $n$-hexane/EtOAc: $10 / 1)$ yielded $\mathbf{1 4 2 0}(113 \mathrm{mg}, 92 \%)$ as a colorless solid. M.p. $=220^{\circ} \mathrm{C} .{ }^{1} \mathrm{H}$ NMR $\left(300 \mathrm{MHz}, \mathrm{CDCl}_{3}\right): \delta=8.38(\mathrm{~s}, 1 \mathrm{H}), 8.33(\mathrm{~d}, J=7.8 \mathrm{~Hz}, 1 \mathrm{H}), 8.08(\mathrm{~s}, 1 \mathrm{H})$, $8.01(\mathrm{~d}, J=7.8 \mathrm{~Hz}, 1 \mathrm{H}), 7.88(\mathrm{~d}, J=7.8 \mathrm{~Hz}, 1 \mathrm{H}), 7.73-7.65(\mathrm{~m}, 2 \mathrm{H}), 7.63-7.54(\mathrm{~m}, 1 \mathrm{H}), 7.31$ (s, $1 \mathrm{H}), 7.19(\mathrm{~s}, 1 \mathrm{H}), 7.00(\mathrm{~s}, 1 \mathrm{H}), 4.85(\mathrm{~s}, 2 \mathrm{H}), 2.50(\mathrm{~s}, 3 \mathrm{H}) .{ }^{13} \mathrm{C}$ NMR $\left(75 \mathrm{MHz}, \mathrm{CDCl}_{3}\right): \delta=195.9$ $\left(\mathrm{C}_{\mathrm{q}}\right), 161.4\left(\mathrm{C}_{\mathrm{q}}\right), 151.7\left(\mathrm{C}_{\mathrm{q}}\right), 145.8\left(\mathrm{C}_{\mathrm{q}}\right), 139.0\left(\mathrm{C}_{\mathrm{q}}\right), 138.8\left(\mathrm{C}_{\mathrm{q}}\right), 137.8\left(\mathrm{C}_{\mathrm{q}}\right), 134.2(\mathrm{CH}), 132.6\left(\mathrm{C}_{\mathrm{q}}\right)$, $131.4(\mathrm{CH}), 130.4\left(\mathrm{q},{ }^{1} J=268.2 \mathrm{~Hz}, \mathrm{C}_{\mathrm{q}}\right), 129.7\left(\mathrm{q},{ }^{3} \mathrm{~J}=3.6 \mathrm{~Hz}, \mathrm{CH}\right), 129.4(\mathrm{CH}), 129.3(\mathrm{CH})$, $128.1(\mathrm{CH}), 127.4\left(\mathrm{q},{ }^{1} \mathrm{~J}=270.1 \mathrm{~Hz}, \mathrm{C}_{\mathrm{q}}\right), 126.3\left(\mathrm{q},{ }^{3} \mathrm{~J}=3.8 \mathrm{~Hz}, \mathrm{CH}\right), 126.2(\mathrm{CH}), 125.6\left(\mathrm{q},{ }^{2} \mathrm{~J}=\right.$ $\left.27.3 \mathrm{~Hz}, \mathrm{C}_{\mathrm{q}}\right), 125.0\left(\mathrm{q},{ }^{3} \mathrm{~J}=3.8 \mathrm{~Hz}, \mathrm{CH}\right), 124.0$ (q, $\left.{ }^{2} J=26.4 \mathrm{~Hz}, \mathrm{C}_{\mathrm{q}}\right), 121.9$ (q, $\left.{ }^{3} J=3.8 \mathrm{~Hz}, \mathrm{CH}\right)$, 116.7 $\left(\mathrm{C}_{\mathrm{q}}\right), 103.3(\mathrm{CH}), 45.5\left(\mathrm{CH}_{2}\right), 21.7\left(\mathrm{CH}_{3}\right) .{ }^{19} \mathrm{~F} \mathrm{NMR}\left(282 \mathrm{MHz}, \mathrm{CDCl}_{3}\right): \delta=-62.7,-62.8 . \mathrm{IR}$ (ATR): 3082, 1718, 1643, 1611, 1321, 1166, 1125, $695 \mathrm{~cm}^{-1}$. MS (ESI) $\mathrm{m} / z$ (relative intensity): $513(70)[\mathrm{M}+\mathrm{Na}]^{+}, 491(100)[\mathrm{M}+\mathrm{H}]^{+}$. HR-MS (ESI): $\mathrm{m} / z$ calcd. for $\mathrm{C}_{26} \mathrm{H}_{16} \mathrm{~F}_{6} \mathrm{O}_{3}[\mathrm{M}+\mathrm{H}]^{+}:$: 491.1076, found: 491.1079 . 


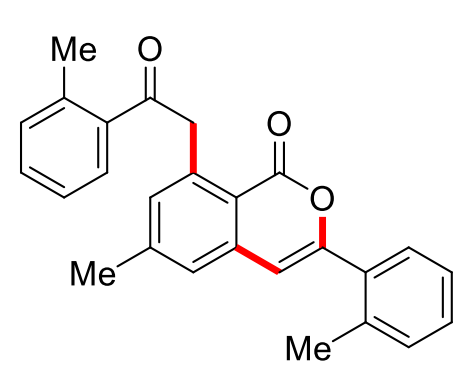

\section{6-Methyl-8-[2-oxo-2-(o-tolyl)ethyl]-3-(o-tolyl)-1H-isochromen-1-one (142p).}

The representative procedure $\mathbf{C}$ was followed using 4-methylbenzoic acid (62i) (34 mg, 0.25 $\mathrm{mmol}$ ) and 2-[dimethyl(oxo)- $\lambda^{6}$-sulfaneylidene]-1-(o-tolyl)ethan-1-one (141i) $(158 \mathrm{mg}, 0.75 \mathrm{mmol}$ ). Isolation by column chromatography ( $n$-hexane/EtOAc: $10 / 1)$ yielded $142 \mathrm{p}(62 \mathrm{mg}, 65 \%)$ as a colorless solid. M.p. $=196{ }^{\circ} \mathrm{C} .{ }^{1} \mathrm{H}$ NMR $\left(300 \mathrm{MHz}, \mathrm{CDCl}_{3}\right): \delta=8.02(\mathrm{dd}, J=7.6,1.2 \mathrm{~Hz}, 1 \mathrm{H})$, 7.57-7.50 (m, 1H), 7.45-7.39 (m, 1H), 7.38-7.25 (m, 6H), $7.18(\mathrm{~s}, 1 \mathrm{H}), 6.58(\mathrm{~s}, 1 \mathrm{H}), 4.82(\mathrm{~s}, 2 \mathrm{H})$, $2.55(\mathrm{~s}, 3 \mathrm{H}), 2.52(\mathrm{~s}, 3 \mathrm{H}), 2.51(\mathrm{~s}, 3 \mathrm{H}) .{ }^{13} \mathrm{C}$ NMR $\left(75 \mathrm{MHz}, \mathrm{CDCl}_{3}\right): \delta=201.0\left(\mathrm{C}_{\mathrm{q}}\right), 162.0\left(\mathrm{C}_{\mathrm{q}}\right)$, $155.3\left(\mathrm{C}_{\mathrm{q}}\right), 145.3\left(\mathrm{C}_{\mathrm{q}}\right), 139.5\left(\mathrm{C}_{\mathrm{q}}\right), 139.3\left(\mathrm{C}_{\mathrm{q}}\right), 138.5\left(\mathrm{C}_{\mathrm{q}}\right), 138.1\left(\mathrm{C}_{\mathrm{q}}\right), 136.7\left(\mathrm{C}_{\mathrm{q}}\right), 133.8(\mathrm{CH})$, $132.7\left(\mathrm{C}_{\mathrm{q}}\right), 131.9(\mathrm{CH}), 131.2(\mathrm{CH}), 131.1(\mathrm{CH}), 129.7(\mathrm{CH}), 129.1(\mathrm{CH}), 128.7(\mathrm{CH}), 126.0(\mathrm{CH})$, $125.7(\mathrm{CH}), 125.6(\mathrm{CH}), 116.5\left(\mathrm{C}_{\mathrm{q}}\right), 106.5(\mathrm{CH}), 48.5\left(\mathrm{CH}_{2}\right), 21.8\left(\mathrm{CH}_{3}\right), 21.2\left(\mathrm{CH}_{3}\right), 20.8\left(\mathrm{CH}_{3}\right)$. IR (ATR): 2963, 1716, 1645, 1458, 1326, 1047, 994, $727 \mathrm{~cm}^{-1}$. MS (ESI) $\mathrm{m} / \mathrm{z}$ (relative intensity): 405 (60) $[\mathrm{M}+\mathrm{Na}]^{+}, 383(100)[\mathrm{M}+\mathrm{H}]^{+}$. HR-MS (ESI): $\mathrm{m} / \mathrm{z}$ calcd. for $\mathrm{C}_{26} \mathrm{H}_{22} \mathrm{O}_{3}[\mathrm{M}+\mathrm{H}]^{+}: 383.1642$, found: 383.1646 .

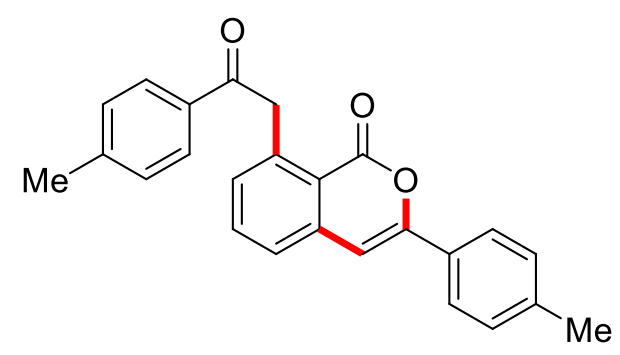

\section{6-[2-Oxo-2-(p-tolyl)ethyl]-3-(p-tolyl)-1 1 -isochromen-1-one (142q).}

The representative procedure $\mathbf{C}$ was followed using benzoic acid $(\mathbf{6 2 d})(31 \mathrm{mg}, 0.25 \mathrm{mmol})$ and 2-[dimethyl(oxo)- $\lambda^{6}$-sulfaneylidene]-1-( $p$-tolyl)ethan-1-one (141f) (158 $\mathrm{mg}, 0.75 \mathrm{mmol}$ ). Isolation by column chromatography ( $n$-hexane/EtOAc: $10 / 1)$ yielded $142 q(71 \mathrm{mg}, 77 \%)$ as a colorless solid. M.p. $=205^{\circ} \mathrm{C} .{ }^{1} \mathrm{H}$ NMR $\left(300 \mathrm{MHz}, \mathrm{CDCl}_{3}\right): \delta=8.04(\mathrm{~d}, J=8.2 \mathrm{~Hz}, 2 \mathrm{H}), 7.75(\mathrm{~d}, J=8.2 \mathrm{~Hz}$, 2H), 7.68-7.64 (m, 1H), $7.45(\mathrm{~d}, J=7.9 \mathrm{~Hz}, 1 \mathrm{H}), 7.36-7.28(\mathrm{~m}, 3 \mathrm{H}), 7.26(\mathrm{~d}, J=8.2 \mathrm{~Hz}, 2 \mathrm{H})$, $6.93(\mathrm{~s}, 1 \mathrm{H}), 4.90(\mathrm{~s}, 2 \mathrm{H}), 2.46(\mathrm{~s}, 3 \mathrm{H}), 2.41(\mathrm{~s}, 3 \mathrm{H}) .{ }^{13} \mathrm{C} \mathrm{NMR}\left(75 \mathrm{MHz}, \mathrm{CDCl}_{3}\right): \delta=196.9\left(\mathrm{C}_{\mathrm{q}}\right)$, $161.8\left(\mathrm{C}_{\mathrm{q}}\right), 153.5\left(\mathrm{C}_{\mathrm{q}}\right), 143.6\left(\mathrm{C}_{\mathrm{q}}\right), 140.2\left(\mathrm{C}_{\mathrm{q}}\right), 139.7\left(\mathrm{C}_{\mathrm{q}}\right), 139.6\left(\mathrm{C}_{\mathrm{q}}\right), 134.9\left(\mathrm{C}_{\mathrm{q}}\right), 134.2(\mathrm{CH})$, $131.9(\mathrm{CH}), 129.5(\mathrm{CH}), 129.3(\mathrm{CH}), 129.1\left(\mathrm{C}_{\mathrm{q}}\right), 128.4(\mathrm{CH}), 125.6(\mathrm{CH}), 125.1(\mathrm{CH}), 119.0\left(\mathrm{C}_{\mathrm{q}}\right)$, $101.6(\mathrm{CH}), 45.5\left(\mathrm{CH}_{2}\right), 21.7\left(\mathrm{CH}_{3}\right), 21.4\left(\mathrm{CH}_{3}\right)$. IR (ATR): 2920, 1719, 1676, 1572, 1337, 1223, 
1000, $768 \mathrm{~cm}^{-1}$. MS (ESI) $\mathrm{m} / \mathrm{z}$ (relative intensity): $391(80)[\mathrm{M}+\mathrm{Na}]^{+}, 369(100)[\mathrm{M}+\mathrm{H}]^{+}$. HR-MS (ESI): $\mathrm{m} / z$ calcd. for $\mathrm{C}_{25} \mathrm{H}_{20} \mathrm{O}_{3}[\mathrm{M}+\mathrm{H}]^{+}: 369.1485$, found: 369.1484 .<smiles>O=C(Cc1cccc2cc(-c3ccc(Cl)cc3)oc(=O)c12)c1ccc(Cl)cc1</smiles>

1-(4-Chlorophenyl)-8-(2-(4-chlorophenyl)-2-oxoethyl)-1H-isochromen-1-one (142r).

The representative procedure $\mathbf{C}$ was followed using benzoic acid $(\mathbf{6 2 d})(31 \mathrm{mg}, 0.25 \mathrm{mmol})$ and 1-(4-chlorophenyl)-2-[dimethyl(oxo)- $\lambda^{6}$-sulfaneylidene]ethan-1-one (141g) $(174 \mathrm{mg}, 0.75 \mathrm{mmol})$. Isolation by column chromatography ( $n$-hexane/EtOAc: $10 / 1$ ) yielded $142 \mathrm{r}(87 \mathrm{mg}, 85 \%)$ as a colorless solid. M.p. $=218^{\circ} \mathrm{C} .{ }^{1} \mathrm{H}$ NMR $\left(300 \mathrm{MHz}, \mathrm{CDCl}_{3}\right): \delta=8.07(\mathrm{~d}, J=8.9 \mathrm{~Hz}, 2 \mathrm{H}), 7.77(\mathrm{~d}$, $J=8.9 \mathrm{~Hz}, 2 \mathrm{H}), 7.72-7.65(\mathrm{~m}, 1 \mathrm{H}), 7.53-7.39(\mathrm{~m}, 5 \mathrm{H}), 7.35-7.31(\mathrm{~m}, 1 \mathrm{H}), 6.95(\mathrm{~s}, 1 \mathrm{H}), 4.86(\mathrm{~s}$, 2H). ${ }^{13} \mathrm{C}$ NMR $\left(75 \mathrm{MHz}, \mathrm{CDCl}_{3}\right): \delta=196.0\left(\mathrm{C}_{\mathrm{q}}\right), 161.5\left(\mathrm{C}_{\mathrm{q}}\right), 152.3\left(\mathrm{C}_{\mathrm{q}}\right), 139.4\left(\mathrm{C}_{\mathrm{q}}\right), 139.3\left(\mathrm{C}_{\mathrm{q}}\right)$, $139.2\left(\mathrm{C}_{\mathrm{q}}\right), 136.0\left(\mathrm{C}_{\mathrm{q}}\right), 135.7\left(\mathrm{C}_{\mathrm{q}}\right), 134.5(\mathrm{CH}), 132.4(\mathrm{CH}), 130.2\left(\mathrm{C}_{\mathrm{q}}\right), 129.7(\mathrm{CH}), 129.1(\mathrm{CH})$, $128.9(\mathrm{CH}), 126.4(\mathrm{CH}), 126.0(\mathrm{CH}), 119.0\left(\mathrm{C}_{\mathrm{q}}\right), 102.6(\mathrm{CH}), 45.6\left(\mathrm{CH}_{2}\right)$. IR (ATR): 2921, 1730, 1686, 1590, 1492, 1072, 997, $687 \mathrm{~cm}^{-1}$. MS (ESI) $\mathrm{m} / \mathrm{z}$ (relative intensity): $431(100)[\mathrm{M}+\mathrm{Na}]^{+}$, 409 (20) [M+H] ${ }^{+}$. HR-MS (ESI): $\mathrm{m} / z$ calcd. for $\mathrm{C}_{23} \mathrm{H}_{14} \mathrm{Cl}_{2} \mathrm{O}_{3}[\mathrm{M}+\mathrm{H}]^{+}: 409.0393$, found: 409.0389 .

\subsubsection{Twofold $\mathrm{C}-\mathrm{H} / \mathrm{N}-\mathrm{H}$ Annulations towards $\pi$-Extended Polyaromatics}

\subsubsection{Characterization Data}

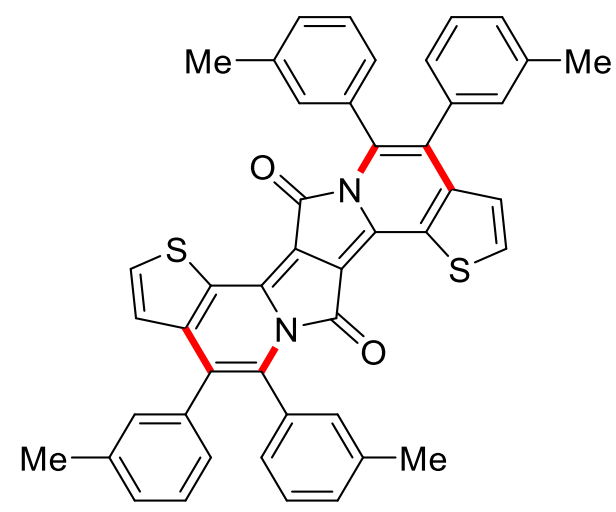

4,5,11,12-tetra-m-tolyl-7H,14H-thieno[3',2':7,8]indolizino[2,1-a]thieno[3,2-g]indolizine-7,14dione (144a):

The general procedure D was followed using 3,6-di(thiophen-2-yl)-2,5-dihydropyrrolo[3,4- 
c]pyrrole-1,4-dione 143a $(0.2 \mathrm{mmol}, 60 \mathrm{mg})$ and 1,2-di-m-tolylethyne $64 \mathrm{a}(0.8 \mathrm{mmol}, 165 \mathrm{mg})$. yielding $144 a$ (100 $\mathrm{mg}, 71 \%$ ) as the purple crystals. $\mathbf{M}$. p. = over the limit of the detection. ${ }^{1} \mathbf{H}$ NMR $\left(300 \mathrm{MHz}, \mathrm{CDCl}_{3}\right) \delta=7.60(\mathrm{~d}, J=5.2 \mathrm{~Hz}, 2 \mathrm{H}), 7.20-6.80(\mathrm{~m}, 18 \mathrm{H}), 2.35-2.15(\mathrm{~m}, 12 \mathrm{H})$. ${ }^{13} \mathrm{C} \mathrm{NMR}\left(126 \mathrm{MHz}, \mathrm{CDCl}_{3}\right) \delta=156.5\left(\mathrm{C}_{\mathrm{q}}\right), 143.6\left(\mathrm{C}_{\mathrm{q}}\right), 138.0\left(\mathrm{C}_{\mathrm{q}}\right), 137.4\left(\mathrm{C}_{\mathrm{q}}\right), 137.3\left(\mathrm{C}_{\mathrm{q}}\right), 136.7$ $\left(\mathrm{C}_{\mathrm{q}}\right), 136.4\left(\mathrm{C}_{\mathrm{q}}\right), 136.3\left(\mathrm{C}_{\mathrm{q}}\right), 135.7\left(\mathrm{C}_{\mathrm{q}}\right), 133.1(\mathrm{CH}), 132.5\left(\mathrm{C}_{\mathrm{q}}\right), 132.4\left(\mathrm{C}_{\mathrm{q}}\right), 131.3(\mathrm{CH}), 131.2$ $(\mathrm{CH}), 131.0(\mathrm{CH}), 130.9(\mathrm{CH}), 128.7(\mathrm{CH}), 128.7(\mathrm{CH}), 128.0\left(\mathrm{C}_{\mathrm{q}}\right), 127.8(\mathrm{CH}), 127.7(\mathrm{CH})$, $127.6(\mathrm{CH}), 127.6(\mathrm{CH}), 127.5(\mathrm{CH}), 127.4(\mathrm{CH}), 127.3(\mathrm{CH}), 126.8(\mathrm{CH}), 126.7(\mathrm{CH}), 124.8$ $(\mathrm{CH}), 123.8\left(\mathrm{C}_{\mathrm{q}}\right), 96.6\left(\mathrm{C}_{\mathrm{q}}\right), 21.4\left(\mathrm{CH}_{3}\right), 21.3\left(\mathrm{CH}_{3}\right), 21.3\left(\mathrm{CH}_{3}\right)$. IR (ATR): 3089, 1687, 1628, $1502,1347,1095,1033,788,757,692,490 \mathrm{~cm}^{-1}$. (The lack of symmetry is caused by the presence of rotameric species at the room temperature). HR-MS (ESI) $\mathrm{m} / \mathrm{z}$ calc. for $\mathrm{C}_{46} \mathrm{H}_{33} \mathrm{~N}_{2} \mathrm{O}_{2} \mathrm{~S}_{2}[\mathrm{M}+\mathrm{H}]^{+}:$709.1978, found: 709.1985.

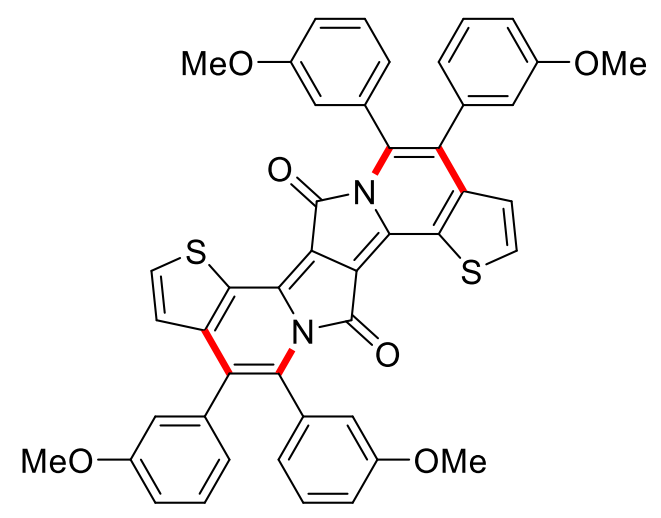

\section{4,5,11,12-tetrakis(3-methoxyphenyl)-7H,14H-thieno[3',2':7,8]indolizino[2,1-a]thieno[3,2- g]indolizine-7,14-dione (144b).}

The general procedure D was followed using 3,6-di(thiophen-2-yl)-2,5-dihydropyrrolo[3,4c]pyrrole-1,4-dione 143a (0.2 mmol, $60 \mathrm{mg}$ ) and 1,2-bis(3-methoxyphenyl)ethyne $64 \mathrm{~b}(0.8 \mathrm{mmol}$, $191 \mathrm{mg})$. yielding $144 \mathrm{~b}(80 \mathrm{mg}, 52 \%)$ as the purple crystals. M. p. $=346{ }^{\circ} \mathrm{C} .{ }^{1} \mathbf{H}$ NMR $(400 \mathrm{MHz}$, $\left.\mathrm{CDCl}_{3}\right) \delta=7.57(\mathrm{~d}, J=5.2 \mathrm{~Hz}, 2 \mathrm{H}), 7.22-7.07(\mathrm{~m}, 4 \mathrm{H}), 6.98-6.93(\mathrm{~m}, 1 \mathrm{H}), 6.89-6.83(\mathrm{~m}, 3 \mathrm{H})$, 6.83-6.60 (m, 9H), $6.51(\mathrm{~s}, 1 \mathrm{H}), 3.70-3.59(\mathrm{~m}, 12 \mathrm{H}) .{ }^{13} \mathrm{C} \mathrm{NMR}\left(101 \mathrm{MHz}, \mathrm{CDCl}_{3}\right) \delta=159.1\left(\mathrm{C}_{\mathrm{q}}\right)$, $159.1\left(\mathrm{C}_{\mathrm{q}}\right), 158.5\left(\mathrm{C}_{\mathrm{q}}\right), 158.4\left(\mathrm{C}_{\mathrm{q}}\right), 156.3\left(\mathrm{C}_{\mathrm{q}}\right), 143.3\left(\mathrm{C}_{\mathrm{q}}\right), 137.5\left(\mathrm{C}_{\mathrm{q}}\right), 137.0\left(\mathrm{C}_{\mathrm{q}}\right), 137.0\left(\mathrm{C}_{\mathrm{q}}\right)$, $136.7\left(\mathrm{C}_{\mathrm{q}}\right), 133.7(\mathrm{CH}), 133.3(\mathrm{CH}), 129.0(\mathrm{CH}), 128.9(\mathrm{CH}), 128.2(\mathrm{CH}), 128.2(\mathrm{CH}), 128.0(\mathrm{CH})$, $124.8(\mathrm{CH}), 123.5\left(\mathrm{C}_{\mathrm{q}}\right), 123.1(\mathrm{CH}), 123.0(\mathrm{CH}), 122.9(\mathrm{CH}), 115.9(\mathrm{CH}), 115.9(\mathrm{CH}), 115.8(\mathrm{CH})$, $115.7(\mathrm{CH}), 115.7(\mathrm{CH}), 114.0(\mathrm{CH}), 113.9(\mathrm{CH}), 113.5(\mathrm{CH}), 113.4(\mathrm{CH}), 113.2(\mathrm{CH}), 113.2(\mathrm{CH})$, 96.6 $\left(\mathrm{C}_{\mathrm{q}}\right), 55.2\left(\mathrm{CH}_{3}\right), 55.1\left(\mathrm{CH}_{3}\right), 55.1\left(\mathrm{CH}_{3}\right), 55.1\left(\mathrm{CH}_{3}\right)$. (The lack of symmetry is caused by the presence of rotameric species at the room temperature). IR (ATR): 3090, 1685, 1632, 1575, 1475, 1284, 778, 756, $488 \mathrm{~cm}^{-1}$. HR-MS (ESI) m/z calc. for $\mathrm{C}_{46} \mathrm{H}_{33} \mathrm{~N}_{2} \mathrm{O}_{6} \mathrm{~S}_{2}{ }^{+}[\mathrm{M}+\mathrm{H}]^{+}:$773.1775, found: 773.1766 . 
<smiles></smiles>

4,5,11,12-tetrakis(3-(trifluoromethyl)phenyl)-7H,14H-thieno[3',2':7,8]indolizino[2,1a]thieno[3,2-g]indolizine-7,14-dione (144c).

The general procedure D was followed using 3,6-di(thiophen-2-yl)-2,5-dihydropyrrolo[3,4c]pyrrole-1,4-dione 143a $(0.2 \mathrm{mmol}, 60 \mathrm{mg})$ and 1,2-bis(3-methoxyphenyl)ethyne $64 \mathrm{c}(0.8 \mathrm{mmol}$, $251 \mathrm{mg}$ ). yielding 144c (92 mg, 50\%) as the purple crystals. M. $\mathbf{p} .=$ over the limit of the detection. ${ }^{1} \mathrm{H}$ NMR $\left(400 \mathrm{MHz}, \mathrm{CDCl}_{3}\right) \delta=7.75-7.68(\mathrm{~m}, 1 \mathrm{H}), 7.65-7.33(\mathrm{~m}, 7 \mathrm{H}), 7.26-7.15$ $(\mathrm{m}, 1 \mathrm{H}), 6.91-6.80(\mathrm{~m}, 1 \mathrm{H}) .{ }^{13} \mathrm{C}$ NMR $\left(126 \mathrm{MHz}, \mathrm{CDCl}_{3}\right) \delta=156.2\left(\mathrm{C}_{\mathrm{q}}\right), 142.7\left(\mathrm{C}_{\mathrm{q}}\right), 142.6\left(\mathrm{C}_{\mathrm{q}}\right)$, $136.7\left(\mathrm{C}_{\mathrm{q}}\right), 136.5\left(\mathrm{C}_{\mathrm{q}}\right), 135.9\left(\mathrm{C}_{\mathrm{q}}\right), 135.9\left(\mathrm{C}_{\mathrm{q}}\right), 134.3(\mathrm{CH}), 134.3(\mathrm{CH}), 133.8(\mathrm{CH}), 133.5(\mathrm{CH})$, $133.4(\mathrm{CH}), 133.4(\mathrm{CH}), 133.4(\mathrm{CH}), 133.3(\mathrm{CH}), 133.3(\mathrm{CH}), 133.3(\mathrm{CH}), 132.8\left(\mathrm{C}_{\mathrm{q}}\right), 132.7\left(\mathrm{C}_{\mathrm{q}}\right)$, $128.8(\mathrm{CH}), 128.7\left(\mathrm{C}_{\mathrm{q}}\right), 127.7(\mathrm{CH}), 127.5(\mathrm{CH}), 127.3(\mathrm{CH}), 127.0(\mathrm{CH}), 125.1(\mathrm{CH}), 125.0(\mathrm{CH})$, $124.8\left(\mathrm{C}_{\mathrm{q}}\right), 124.8\left(\mathrm{C}_{\mathrm{q}}\right), 124.8\left(\mathrm{C}_{\mathrm{q}}\right), 124.8\left(\mathrm{C}_{\mathrm{q}}\right), 124.7\left(\mathrm{C}_{\mathrm{q}}\right), 124.4\left(\mathrm{C}_{\mathrm{q}}\right), 124.4(\mathrm{CH}), 124.4(\mathrm{CH})$, $124.3(\mathrm{CH}), 122.9\left(\mathrm{C}_{\mathrm{q}}\right), 122.8\left(\mathrm{C}_{\mathrm{q}}\right), 122.7\left(\mathrm{C}_{\mathrm{q}}\right), 122.6\left(\mathrm{C}_{\mathrm{q}}\right), 122.6\left(\mathrm{C}_{\mathrm{q}}\right), 122.5\left(\mathrm{C}_{\mathrm{q}}\right), 96.8\left(\mathrm{C}_{\mathrm{q}}\right) .{ }^{19} \mathrm{~F}$ NMR $\left(471 \mathrm{MHz}, \mathrm{CDCl}_{3}\right): \delta=-62.79,-62.93,-62.97,-63.08$. (The lack of symmetry is caused by the presence of rotameric species at the room temperature). IR (ATR): 2927, 2851, 1706, 1632, 1326, 1164, 1070, 803, 699, $664 \mathrm{~cm}^{-1}$. HR-MS (ESI) m/z calc. for $\mathrm{C}_{46} \mathrm{H}_{21} \mathrm{~F}_{12} \mathrm{~N}_{2} \mathrm{O}_{2} \mathrm{~S}_{2}{ }^{+}[\mathrm{M}+\mathrm{H}]^{+}$: 925.0847, found: 925.0839 .

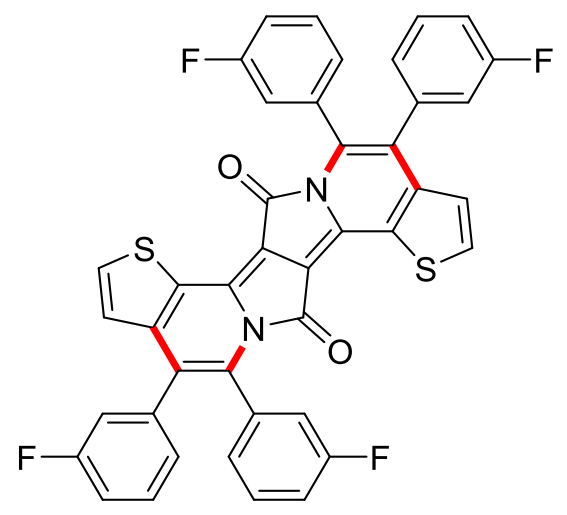

4,5,11,12-tetrakis(3-fluorophenyl)-7H,14H-thieno[3',2':7,8]indolizino[2,1-a]thieno[3,2- 


\section{g]indolizine-7,14-dione (144d).}

The general procedure D was followed using 3,6-di(thiophen-2-yl)-2,5-dihydropyrrolo[3,4c]pyrrole-1,4-dione 143a $(0.2 \mathrm{mmol}, 60 \mathrm{mg})$ and 1,2-bis(3-methoxyphenyl)ethyne $64 \mathrm{~d}(0.8 \mathrm{mmol}$, $171 \mathrm{mg}$ ). yielding 144d (90 mg, 62\%) as the purple crystals. M. p. = over the limit of the detection. ${ }^{1} \mathrm{H}$ NMR $\left(500 \mathrm{MHz}, \mathrm{CDCl}_{3}\right) \delta=7.62(\mathrm{~d}, J=5.2 \mathrm{~Hz}, 2 \mathrm{H}), 7.24-7.14(\mathrm{~m}, 4 \mathrm{H}), 7.06(\mathrm{~d}, J$ $=7.6 \mathrm{~Hz}, 2 \mathrm{H}), 7.03-6.74(\mathrm{~m}, 12 \mathrm{H}) .{ }^{13} \mathrm{C}$ NMR $\left(126 \mathrm{MHz}, \mathrm{CDCl}_{3}\right) \delta=162.4\left(\mathrm{~d},{ }^{1} \mathrm{~J}_{\mathrm{C}-\mathrm{F}}=247 \mathrm{~Hz}, \mathrm{C}_{\mathrm{q}}\right)$, $161.8\left(\mathrm{~d},{ }^{1} \mathrm{~J}_{\mathrm{C}-\mathrm{F}}=247 \mathrm{~Hz}, \mathrm{C}_{\mathrm{q}}\right), 156.2\left(\mathrm{C}_{\mathrm{q}}\right), 142.9\left(\mathrm{C}_{\mathrm{q}}\right), 137.3\left(\mathrm{~d},{ }^{4} \mathrm{~J}_{\mathrm{C}-\mathrm{F}}=7.9 \mathrm{~Hz}, \mathrm{C}_{\mathrm{q}}\right), 136.6\left(\mathrm{C}_{\mathrm{q}}\right)$, $136.4\left(\mathrm{C}_{\mathrm{q}}\right), 134.1$ (d, $\left.{ }^{3} \mathrm{~J}_{\mathrm{C}-\mathrm{F}}=8.5 \mathrm{~Hz}, \mathrm{C}_{\mathrm{q}}\right), 133.9(\mathrm{CH}), 129.8\left(\mathrm{~d},{ }^{3} \mathrm{~J}_{\mathrm{C}-\mathrm{F}}=9 \mathrm{~Hz}, \mathrm{CH}\right), 129.7$ (d, ${ }^{3} \mathrm{~J}_{\mathrm{C}-\mathrm{F}}=$ $9 \mathrm{~Hz}, \mathrm{CH}), 129.0\left(\mathrm{~d},{ }^{3} \mathrm{~J}_{\mathrm{C}-\mathrm{F}}=8.5 \mathrm{~Hz}, \mathrm{CH}\right), 128.8\left(\mathrm{~d},{ }^{4} \mathrm{~J}_{\mathrm{C}-\mathrm{F}}=8.3 \mathrm{~Hz}, \mathrm{CH}\right), 128.4\left(\mathrm{C}_{\mathrm{q}}\right), 126.2\left(\mathrm{~d},{ }^{2} \mathrm{~J}_{\mathrm{C}-\mathrm{F}}\right.$ $=19.5 \mathrm{~Hz}, \mathrm{CH}), 124.5(\mathrm{CH}), 122.6\left(\mathrm{C}_{\mathrm{q}}\right), 117.4\left(\mathrm{~d},{ }^{2} \mathrm{~J}_{\mathrm{C}-\mathrm{F}}=20 \mathrm{~Hz}, \mathrm{CH}\right), 115.4\left(\mathrm{~d},{ }^{2} \mathrm{~J}_{\mathrm{C}-\mathrm{F}}=21 \mathrm{~Hz}, \mathrm{CH}\right)$, $114.6\left(\mathrm{~d},{ }^{2} \mathrm{~J}_{\mathrm{C}-\mathrm{F}}=21 \mathrm{~Hz}, \mathrm{CH}\right), 96.7\left(\mathrm{C}_{\mathrm{q}}\right) .{ }^{19} \mathrm{~F}$ NMR $\left(471 \mathrm{MHz}, \mathrm{CDCl}_{3}\right): \delta=-112.58,-112.85,-113.30$, -113.56. (The lack of symmetry is caused by the presence of rotameric species at the room temperature). IR (ATR): 1702, 1610, 1582, 1479, 1431, 1146, 758, 695, $489 \mathrm{~cm}^{-1}$. HR-MS (ESI) $\mathrm{m} / \mathrm{z}$ calc. for $\mathrm{C}_{42} \mathrm{H}_{21} \mathrm{~F}_{4} \mathrm{~N}_{2} \mathrm{O}_{2} \mathrm{~S}_{2}{ }^{+}[\mathrm{M}+\mathrm{H}]^{+}:$725.0975, found: 725.0961 .

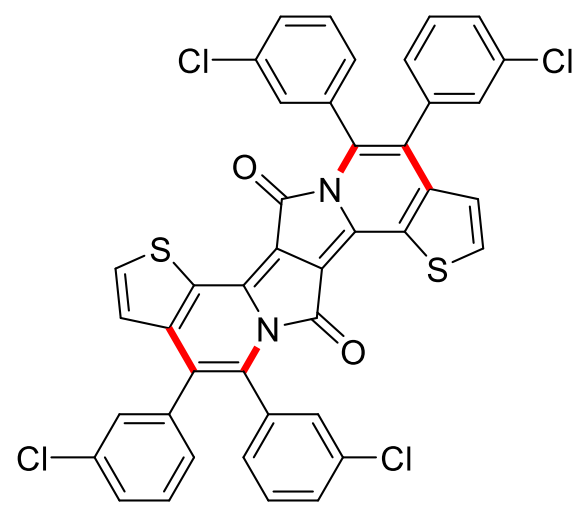

\section{4,5,11,12-tetrakis(3-chlorophenyl)-7H,14H-thieno[3',2':7,8]indolizino[2,1-a]thieno[3,2-} g]indolizine-7,14-dione (144e).

The general procedure D was followed using 3,6-bis(5-octylthiophen-2-yl)-2,5dihydropyrrolo[3,4-c]pyrrole-1,4-dione 143a $(0.2 \mathrm{mmol}, 60 \mathrm{mg})$ and 1,2-bis(3chlorophenyl)ethyne $64 \mathrm{e}(0.8 \mathrm{mmol}, 198 \mathrm{mg})$. yielding $144 \mathrm{e}(81 \mathrm{mg}, 51 \%)$ as the purple crystals M. p. $=$ over the limit of the detection. ${ }^{1} \mathbf{H}$ NMR $\left(400 \mathrm{MHz}, \mathrm{CDCl}_{3}\right) \delta=7.68(\mathrm{~d}, \mathrm{~J}=5.1 \mathrm{~Hz}, 2 \mathrm{H})$, $7.28-7.15(\mathrm{~m}, 13 \mathrm{H}), 7.11(\mathrm{~s}, 1 \mathrm{H}), 7.02(\mathrm{~s}, 1 \mathrm{H}), 6.96(\mathrm{~d}, \mathrm{~J}=7.7 \mathrm{~Hz}, 1 \mathrm{H}), 6.91-6.83(\mathrm{~m}, 2 \mathrm{H}) .{ }^{13} \mathrm{C}$ NMR $\left(101 \mathrm{MHz}, \mathrm{CDCl}_{3}\right) 156.2\left(\mathrm{C}_{\mathrm{q}}\right), 142.9\left(\mathrm{C}_{\mathrm{q}}\right), 137.0\left(\mathrm{C}_{\mathrm{q}}\right), 136.7\left(\mathrm{C}_{\mathrm{q}}\right), 136.4\left(\mathrm{C}_{\mathrm{q}}\right), 134.2\left(\mathrm{C}_{\mathrm{q}}\right)$, $134.1\left(\mathrm{C}_{\mathrm{q}}\right), 134.0(\mathrm{CH}), 133.9\left(\mathrm{C}_{\mathrm{q}}\right), 133.5\left(\mathrm{C}_{\mathrm{q}}\right), 133.3\left(\mathrm{C}_{\mathrm{q}}\right), 130.5(\mathrm{CH}), 130.4(\mathrm{CH}), 130.2(\mathrm{CH})$, $129.6(\mathrm{CH}), 129.5(\mathrm{CH}), 128.8(\mathrm{CH}), 128.7(\mathrm{CH}), 128.6(\mathrm{CH}), 128.5(\mathrm{CH}), 127.9(\mathrm{CH}), 124.5$ $(\mathrm{CH}), 122.6\left(\mathrm{C}_{\mathrm{q}}\right), 96.7\left(\mathrm{C}_{\mathrm{q}}\right)$. (The lack of symmetry is caused by the presence of rotameric species at the room temperature). IR (ATR): 1698, 1635, 1565, 1472, 1095, 1029, 789, 751, 
$707,486 \mathrm{~cm}^{-1}$. HR-MS (ESI) m/z calc. for $\mathrm{C}_{42} \mathrm{H}_{21} \mathrm{Cl}_{4} \mathrm{~N}_{2} \mathrm{O}_{2} \mathrm{~S}_{2}{ }^{+}[\mathrm{M}+\mathrm{H}]^{+}:$788.9793, found: 788.9787 .<smiles>O=c1c2c(-c3cccc(Br)c3)c3sccc3c(-c3cccc(Br)c3)c(-c3cccc(Br)c3)n-2c(=O)c2c1sc1c(-c3cccc(Br)c3)c(-c3cccc(Br)c3)c3ccsc3c12</smiles>

4,5,11,12-tetrakis(3-bromophenyl)-7H,14H-thieno[3',2': 7,8]indolizino[2,1-a]thieno[3,2g]indolizine-7,14-dione (144f)

The general procedure D was followed using 3,6-bis(5-octylthiophen-2-yl)-2,5dihydropyrrolo[3,4-c]pyrrole-1,4-dione 143a $(0.2 \mathrm{mmol}, 60 \mathrm{mg})$ and 1,2-bis(3bromophenyl)ethyne $64 \mathrm{f}(0.8 \mathrm{mmol}, 269 \mathrm{mg})$. yielding $144 \mathrm{f}(103 \mathrm{mg}, 53 \%)$ as the purple crystals. M. p. $=$ over the limit of the detection. ${ }^{1} \mathrm{H}$ NMR $\left(300 \mathrm{MHz}, \mathrm{CDCl}_{3}\right) \delta=7.68(\mathrm{~d}, J=5.2 \mathrm{~Hz}, 2 \mathrm{H})$, $7.47-7.37(\mathrm{~m}, 6 \mathrm{H}), 7.34(\mathrm{~s}, 1 \mathrm{H}), 7.27-7.05(\mathrm{~m}, 8 \mathrm{H}), 6.99(\mathrm{~d}, J=7.9 \mathrm{~Hz}, 1 \mathrm{H}), 6.87(\mathrm{~d}, J=5.4$ $\mathrm{Hz}, 2 \mathrm{H}) .{ }^{13} \mathrm{C}$ NMR $\left(126 \mathrm{MHz}, \mathrm{CDCl}_{3}\right) \delta=156.2\left(\mathrm{C}_{\mathrm{q}}\right), 142.8\left(\mathrm{C}_{\mathrm{q}}\right), 137.2\left(\mathrm{C}_{\mathrm{q}}\right), 137.1\left(\mathrm{C}_{\mathrm{q}}\right), 136.6$ $\left(\mathrm{C}_{\mathrm{q}}\right), 136.3\left(\mathrm{C}_{\mathrm{q}}\right), 134.0(\mathrm{CH}), 133.5(\mathrm{CH}), 133.3(\mathrm{CH}), 133.0(\mathrm{CH}), 132.9(\mathrm{CH}), 131.4(\mathrm{CH}), 130.8$ $(\mathrm{CH}), 129.8(\mathrm{CH}), 129.7(\mathrm{CH}), 129.2(\mathrm{CH}), 129.1(\mathrm{CH}), 128.9(\mathrm{CH}), 128.7(\mathrm{CH}), 128.5\left(\mathrm{C}_{\mathrm{q}}\right)$, 124.5, $122.6\left(\mathrm{C}_{q}\right), 122.2\left(\mathrm{C}_{q}\right), 122.1\left(\mathrm{C}_{\mathrm{q}}\right), 121.5\left(\mathrm{C}_{\mathrm{q}}\right), 121.4\left(\mathrm{C}_{\mathrm{q}}\right), 96.7\left(\mathrm{C}_{\mathrm{q}}\right)$. (The lack of symmetry is caused by the presence of rotameric species at the room temperature). IR (ATR): 1697, 1635, 1559, 1470, 1347, 1094, 787, 746, 682, $482 \mathrm{~cm}^{-1}$. HR-MS (ESI) m/z calc. for $\mathrm{C}_{42} \mathrm{H}_{21} \mathrm{Br}_{4} \mathrm{~N}_{2} \mathrm{O}_{2} \mathrm{~S}_{2}{ }^{+}[\mathrm{M}+\mathrm{H}]^{+}:$964.7772, found: 964.7712.

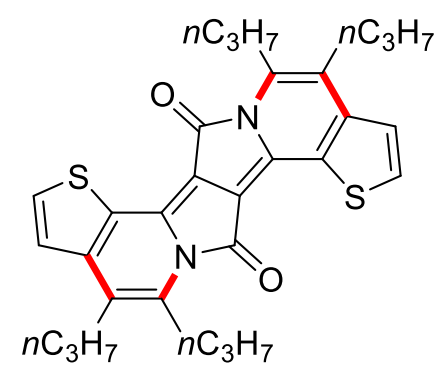

\section{4,5,11,12-tetra-n-propyl-7H,14H-thieno[3',2' :7,8]indolizino[2,1-a]thieno[3,2-g]indolizine-}

\section{7,14-dione (144g).}

The general procedure D was followed using 3,6-di(thiophen-2-yl)-2,5-dihydropyrrolo[3,4c]pyrrole-1,4-dione 143a $(0.2 \mathrm{mmol}, 60 \mathrm{mg})$ and oct-4-yne $64 \mathrm{~g}(0.8 \mathrm{mmol}, 88 \mathrm{mg})$. yielding $\mathbf{1 4 4 \mathrm { g }}$ 
(60 mg, 58\%) as the purple crystals. M. p. $=333^{\circ} \mathrm{C} .{ }^{1} \mathbf{H}$ NMR $\left(300 \mathrm{MHz}, \mathrm{CDCl}_{3}\right) \delta=7.74(\mathrm{~d}, \mathrm{~J}=$ $5.3 \mathrm{~Hz}, 2 \mathrm{H}), 7.27(\mathrm{~d}, 2 \mathrm{H}), 3.48-3.39(\mathrm{~m}, 4 \mathrm{H}), 2.80-2.71(\mathrm{~m}, 4 \mathrm{H}), 1.86-1.76(\mathrm{~m}, 4 \mathrm{H}), 1.72-1.62(\mathrm{~m}$, $4 \mathrm{H}), 1.14(\mathrm{t}, J=6.6 \mathrm{~Hz}, 6 \mathrm{H}), 1.09(\mathrm{t}, J=6.6 \mathrm{~Hz}, 6 \mathrm{H}) .{ }^{13} \mathrm{C}$ NMR $\left(126 \mathrm{MHz}, \mathrm{CDCl}_{3}\right) \delta=157.5\left(\mathrm{C}_{\mathrm{q}}\right)$, $143.5\left(\mathrm{C}_{\mathrm{q}}\right), 141.1\left(\mathrm{C}_{\mathrm{q}}\right), 137.2\left(\mathrm{C}_{\mathrm{q}}\right), 133.1(\mathrm{CH}), 127.4\left(\mathrm{C}_{\mathrm{q}}\right), 122.8(\mathrm{CH}), 120.2\left(\mathrm{C}_{\mathrm{q}}\right), 96.1\left(\mathrm{C}_{\mathrm{q}}\right), 30.9$ $\left(\mathrm{CH}_{2}\right)$, $30.6\left(\mathrm{CH}_{2}\right), 28.2\left(\mathrm{CH}_{2}\right), 24.1\left(\mathrm{CH}_{2}\right), 23.7\left(\mathrm{CH}_{2}\right), 14.4\left(\mathrm{CH}_{3}\right), 14.3\left(\mathrm{CH}_{3}\right)$. IR (ATR): 3074, 2963, 2951, 2928, 2867, 1683, 1640, 1546, 1028, 768, 698, $467 \mathrm{~cm}^{-1}$. HR-MS (ESI) m/z calc. for $\mathrm{C}_{30} \mathrm{H}_{33} \mathrm{~N}_{2} \mathrm{O}_{2} \mathrm{~S}_{2}[\mathrm{M}+\mathrm{H}]^{+}:$517.1978, found: 517.1974.

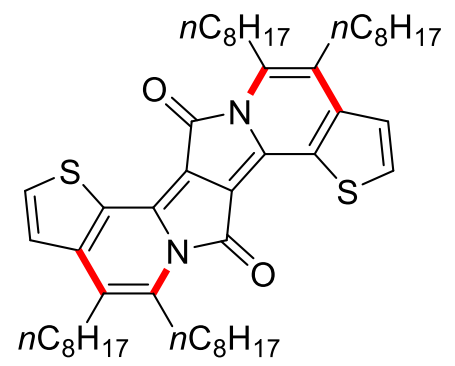

\section{4,5,11,12-tetrakis(3-n-octylphenyl)-7H,14H-thieno[3',2':7,8] indolizino[2,1-a]thieno[3,2- g]indolizine-7,14-dione (144h).}

The general procedure D was followed using 3,6-di(thiophen-2-yl)-2,5-dihydropyrrolo[3,4c]pyrrole-1,4-dione 143a (0.2 mmol, $60 \mathrm{mg})$ and octadec-9-yne 64h $(0.8 \mathrm{mmol}, 200 \mathrm{mg})$. yielding 144h $(89 \mathrm{mg}, 56 \%)$ as the purple crystals. M. p. $=287^{\circ} \mathrm{C} .{ }^{1} \mathbf{H}$ NMR $\left(400 \mathrm{MHz}, \mathrm{CDCl}_{3}\right) \delta=7.73$ (d, $J=5.2 \mathrm{~Hz}, 2 \mathrm{H}$ ), 7.27 (d, $J=5.5 \mathrm{~Hz}, 2 \mathrm{H}$ ), 3.44 (t, $J=8.0 \mathrm{~Hz}, 4 \mathrm{H}$ ), 2.75 (t, $J=8.1 \mathrm{~Hz}, 4 \mathrm{H}$ ), $1.81-1.71(\mathrm{~m}, 4 \mathrm{H}), 1.68-1.59(\mathrm{~m}, 4 \mathrm{H}), 1.53-1.28(\mathrm{~m}, 40 \mathrm{H}), 0.95-0.88(\mathrm{~m}, 12 \mathrm{H}) .{ }^{13} \mathrm{C}$ NMR $\left(101 \mathrm{MHz}, \mathrm{CDCl}_{3}\right) \delta=157.5\left(\mathrm{C}_{\mathrm{q}}\right), 143.6\left(\mathrm{C}_{\mathrm{q}}\right), 141.3\left(\mathrm{C}_{\mathrm{q}}\right), 137.1\left(\mathrm{C}_{\mathrm{q}}\right), 133.1(\mathrm{CH}), 127.4\left(\mathrm{C}_{\mathrm{q}}\right)$, $122.7(\mathrm{CH}), 120.3\left(\mathrm{C}_{\mathrm{q}}\right), 96.1\left(\mathrm{C}_{\mathrm{q}}\right), 31.9\left(\mathrm{CH}_{2}\right), 31.9\left(\mathrm{CH}_{2}\right), 30.8\left(\mathrm{CH}_{2}\right), 30.5\left(\mathrm{CH}_{2}\right), 29.9\left(\mathrm{CH}_{2}\right)$, $29.8\left(\mathrm{CH}_{2}\right), 29.5\left(\mathrm{CH}_{2}\right), 29.4\left(\mathrm{CH}_{2}\right), 29.3\left(\mathrm{CH}_{2}\right), 28.6\left(\mathrm{CH}_{2}\right), 26.3\left(\mathrm{CH}_{2}\right), 22.7\left(\mathrm{CH}_{2}\right), 22.7\left(\mathrm{CH}_{2}\right)$, $14.1\left(\mathrm{CH}_{3}\right), 14.1\left(\mathrm{CH}_{3}\right)$. IR (ATR): 2954, 2918, 2848, 1676, 1538, 1505, 1349, 1017, 772, 700 $\mathrm{cm}^{-1}$. HR-MS (ESI) m/z calc. for $\mathrm{C}_{50} \mathrm{H}_{73} \mathrm{~N}_{2} \mathrm{O}_{2} \mathrm{~S}_{2}[\mathrm{M}+\mathrm{H}]^{+}:$797.5108, found: 797.5091 .

\subsubsection{Investigation of Rotameric Species}

Due to the lack of the symmetry on the ${ }^{1} \mathrm{H}$ NMR spectra for compounds 144a-144f, we have investigated the possibility of the presence of the rotameric species at the room temperature. In order to do that, we have measured ${ }^{1} \mathrm{H}$ NMR spectra for compound 144a in different temperatures using 1,1,2,2-tetrachloroethane- $\mathrm{d}_{2}$ as a solvent. In comparison to the ${ }^{1} \mathrm{H}$ NMR spectrum measured at $298 \mathrm{~K}$, where four signals for all methyl groups can be easily distinguished, at higher temperatures $(323 \mathrm{~K}$ and $338 \mathrm{~K})$ only two signals are visible. Our 
observation clearly shows that the lack of symmetry, observed on spectra at room temperature of meta-substituted derivatives, is caused by the presence of rotameric species.

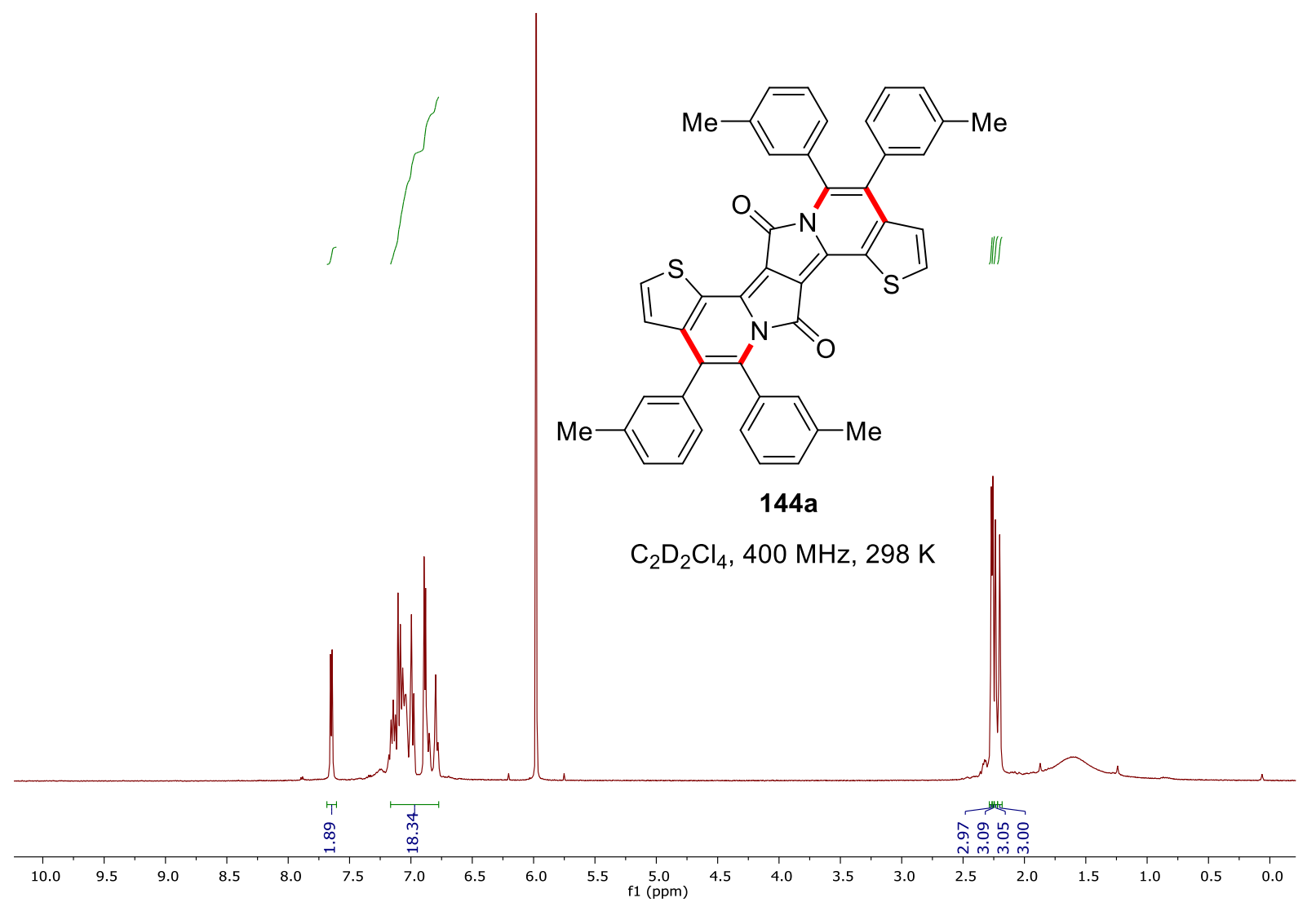




\section{Experimental Section}
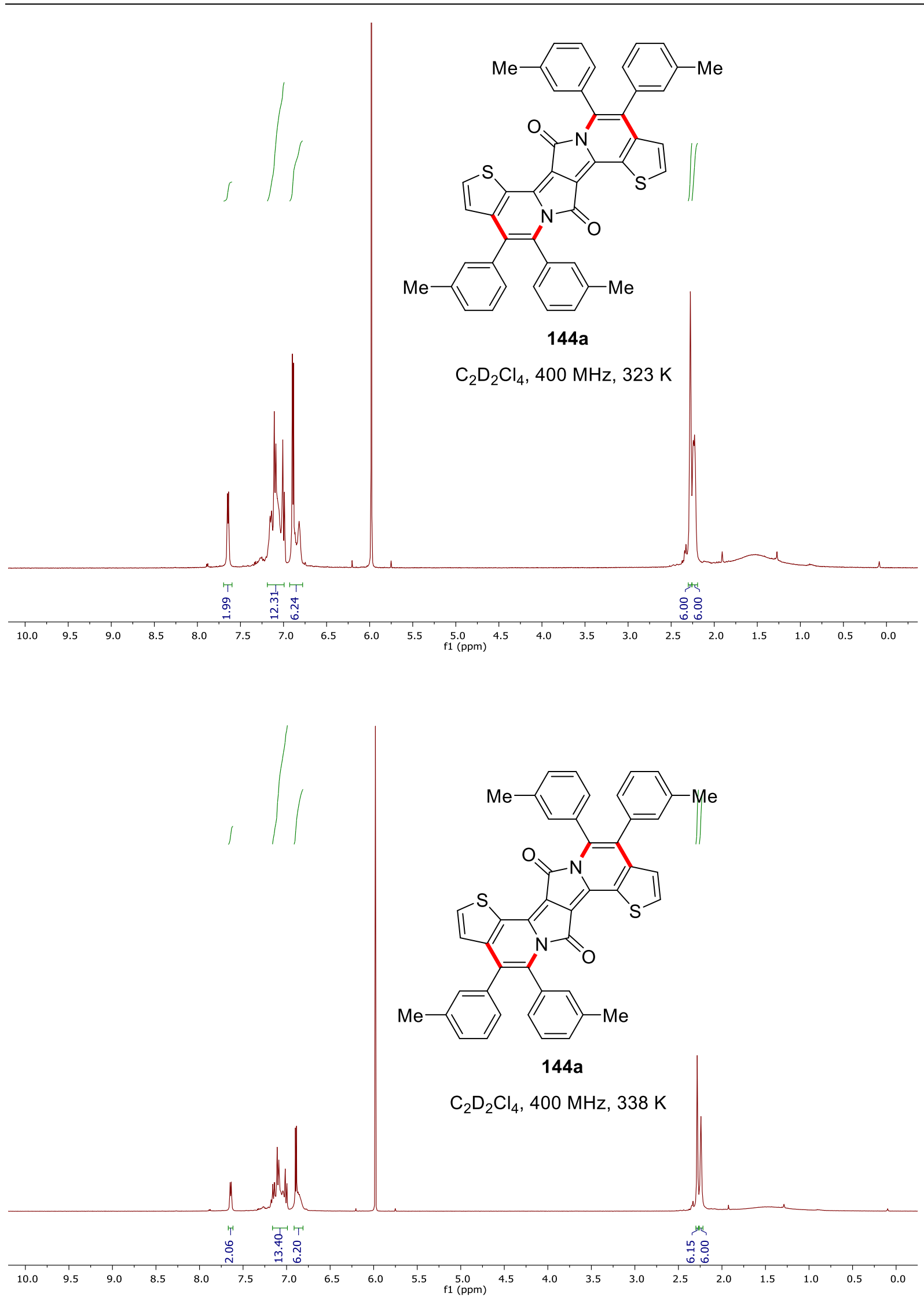


\subsubsection{Ruthenaelectro(II/III/I)-Catalyzed Alkyne Annulations}

\subsubsection{Characterization Data}<smiles>Cc1c(-c2ccccc2)c(-c2ccccc2)c(-c2ccccc2)n2ccnc12</smiles>

\section{8-Methyl-5,6,7-triphenylimidazo[1,2-a]pyridine (146a)}

The general procedure $\mathbf{F}$ was followed using 145a (74 mg, $0.4 \mathrm{mmol}$ ) and 64a (142 $\mathrm{mg}, 0.8$ $\mathrm{mmol})$ at $140{ }^{\circ} \mathrm{C}$ for $8 \mathrm{~h}$. Purification by column chromatography on silica gel $(n$-hexane/EtOAc $=$ 5:1) yielded 146a (108 mg, 75\%) as a white solid. M.p.: $242{ }^{\circ} \mathrm{C} .{ }^{1} \mathbf{H}$ NMR $\left(300 \mathrm{MHz}, \mathrm{CDCl}_{3}\right): \delta=$ $7.64(\mathrm{~d}, J=1.2 \mathrm{~Hz}, 1 \mathrm{H}), 7.34-7.27(\mathrm{~m}, 6 \mathrm{H}), 7.23-7.13(\mathrm{~m}, 3 \mathrm{H}), 7.07-7.02(\mathrm{~m}, 2 \mathrm{H}), 6.95-$ $6.88(\mathrm{~m}, 3 \mathrm{H}), 6.86-6.79(\mathrm{~m}, 2 \mathrm{H}), 2.53(\mathrm{~s}, 3 \mathrm{H}) .{ }^{13} \mathrm{C}$ NMR $\left(101 \mathrm{MHz}, \mathrm{CDCl}_{3}\right): \delta=145.8\left(\mathrm{C}_{\mathrm{q}}\right)$, $138.6\left(\mathrm{C}_{\mathrm{q}}\right), 137.8\left(\mathrm{C}_{\mathrm{q}}\right), 137.3\left(\mathrm{C}_{\mathrm{q}}\right), 133.9\left(\mathrm{C}_{\mathrm{q}}\right), 133.3\left(\mathrm{C}_{\mathrm{q}}\right), 133.1(\mathrm{CH}), 131.5(\mathrm{CH}), 130.2(\mathrm{CH})$, $130.2(\mathrm{CH}), 128.7(\mathrm{CH}), 127.6$ (overlapped, $\mathrm{CH}), 127.0(\mathrm{CH}), 126.7\left(\mathrm{C}_{\mathrm{q}}\right), 126.6(\mathrm{CH}), 126.1(\mathrm{CH})$, $123.8\left(\mathrm{C}_{\mathrm{q}}\right), 112.2(\mathrm{CH}), 15.2\left(\mathrm{CH}_{3}\right)$. IR (ATR): 2922, 1495, 1474, 1443, 1285, 1141, 752, 700, $515 \mathrm{~cm}^{-1}$. MS (ESI) m/z (relative intensity): 361 (100) $[\mathrm{M}+\mathrm{H}]^{+}$. HR-MS (ESI) $\mathrm{m} / \mathrm{z}$ calc. for $\mathrm{C}_{26} \mathrm{H}_{21} \mathrm{~N}_{2}[\mathrm{M}+\mathrm{H}]^{+}:$361.1699, found: 361.1706. The analytical data corresponds with those reported in the literature. ${ }^{[231]}$<smiles>Cc1cccc(-c2c(-c3cccc(C)c3)c(-c3ccccc3)n3ccnc3c2C)c1</smiles>

\section{9-Methyl-7-phenyl-5,6-di-m-tolylimidazo[1,2-a]pyridine (146b)}

The general procedure $\mathbf{F}$ was followed using $145 \mathrm{a}(74 \mathrm{mg}, 0.4 \mathrm{mmol})$ and $64 \mathrm{~b}$ (165 $\mathrm{mg}, 0.8$ $\mathrm{mmol})$ at $140{ }^{\circ} \mathrm{C}$ for $8 \mathrm{~h}$. Purification by column chromatography on silica gel $(n$-hexane/EtOAc $=$ 5:1) yielded 146b (117 mg, 75\%) as a white solid. M.p.: $183^{\circ} \mathrm{C} .{ }^{1} \mathbf{H}$ NMR $\left(400 \mathrm{MHz} \mathrm{CDCl}_{3}\right): \delta=$ $7.63(\mathrm{~s}, 1 \mathrm{H}), 7.29(\mathrm{~s}, 1 \mathrm{H}), 7.22-6.96(\mathrm{~m}, 9 \mathrm{H}), 6.79(\mathrm{t}, J=7.6 \mathrm{~Hz}, 1 \mathrm{H}), 6.71(\mathrm{~d}, J=7.6 \mathrm{~Hz}, 1 \mathrm{H})$, $6.62(\mathrm{~d}, J=8.5 \mathrm{~Hz}, 2 \mathrm{H}), 2.52(\mathrm{t}, J=1.4 \mathrm{~Hz}, 3 \mathrm{H}), 2.29(\mathrm{~s}, 3 \mathrm{H}), 2.03(\mathrm{~s}, 3 \mathrm{H}) .{ }^{13} \mathrm{C} \mathrm{NMR}(101 \mathrm{MHz}$, $\left.\mathrm{CDCl}_{3}\right): \delta=145.7\left(\mathrm{C}_{\mathrm{q}}\right), 138.8\left(\mathrm{C}_{\mathrm{q}}\right), 138.2\left(\mathrm{C}_{\mathrm{q}}\right), 138.0\left(\mathrm{C}_{\mathrm{q}}\right), 137.1\left(\mathrm{C}_{\mathrm{q}}\right), 136.3\left(\mathrm{C}_{\mathrm{q}}\right), 133.9\left(\mathrm{C}_{\mathrm{q}}\right)$, $133.4\left(\mathrm{C}_{\mathrm{q}}\right), 132.9(\mathrm{CH}), 132.4(\mathrm{CH}), 130.7(\mathrm{CH}), 130.2(\mathrm{CH}), 129.3(\mathrm{CH}), 128.6(\mathrm{CH}), 128.4(\mathrm{CH})$, 
$127.5(\mathrm{CH}), 127.2(\mathrm{CH}), 126.7(\mathrm{CH}), 126.7(\mathrm{CH}), 126.5(\mathrm{CH}), 123.5\left(\mathrm{C}_{\mathrm{q}}\right.$, overlapped), $112.3(\mathrm{CH})$, $21.3\left(\mathrm{CH}_{3}\right), 21.1\left(\mathrm{CH}_{3}\right), 15.2\left(\mathrm{CH}_{3}\right)$. IR (ATR): 2920, 1583, 1475, 1287, 1141, 775, 701, $530 \mathrm{~cm}^{-1}$. MS (ESI) m/z (relative intensity): $389(100)[M+H]^{+}$. HR-MS (ESI) $\mathrm{m} / \mathrm{z}$ calc. for $\mathrm{C}_{28} \mathrm{H}_{25} \mathrm{~N}_{2}[\mathrm{M}+\mathrm{H}]^{+}$: 389.2012, found: 389.2014 .<smiles>COc1cccc(-c2c(-c3ccccc3)c(C)c3nccn3c2-c2cccc(OC)c2)c1</smiles>

\section{5,6-Bis(3-methoxyphenyl)-8-methyl-7-phenylimidazo[1,2-a]pyridine (146c)}

The general procedure $F$ was followed using $145 \mathrm{a}(74 \mathrm{mg}, 0.4 \mathrm{mmol})$ and $64 \mathrm{c}$ (190 $\mathrm{mg}, 0.8$ $\mathrm{mmol})$ at $140{ }^{\circ} \mathrm{C}$ for $8 \mathrm{~h}$. Purification by column chromatography on silica gel $(n$-hexane/EtOAc $=$ 5:1) yielded 146c (127 mg, 76\%) as a white solid. M.p.: $262{ }^{\circ} \mathrm{C} .{ }^{1} \mathbf{H} \mathbf{~ N M R}\left(300 \mathrm{MHz}, \mathrm{CDCl}_{3}\right): \delta=$ $7.61(\mathrm{~d}, J=1.3 \mathrm{~Hz}, 1 \mathrm{H}), 7.35-7.32(\mathrm{~m}, 1 \mathrm{H}), 7.25-7.12(\mathrm{~m}, 4 \mathrm{H}), 7.10-6.96(\mathrm{~m}, 2 \mathrm{H}), 6.91(\mathrm{~d}, J$ $=7.6 \mathrm{~Hz}, 1 \mathrm{H}), 6.85-6.76(\mathrm{~m}, 3 \mathrm{H}), 6.51-6.29(\mathrm{~m}, 3 \mathrm{H}), 3.66(\mathrm{~s}, 3 \mathrm{H}), 3.48(\mathrm{~s}, 3 \mathrm{H}), 2.50(\mathrm{~s}, 3 \mathrm{H})$. ${ }^{13} \mathrm{C}$ NMR $\left(101 \mathrm{MHz}, \mathrm{CDCl}_{3}\right): \delta=159.8\left(\mathrm{C}_{\mathrm{q}}\right), 158.5\left(\mathrm{C}_{\mathrm{q}}\right), 145.8\left(\mathrm{C}_{\mathrm{q}}\right), 138.7\left(\mathrm{C}_{\mathrm{q}}\right), 138.7\left(\mathrm{C}_{\mathrm{q}}\right), 137.8$ $\left(\mathrm{C}_{q}\right), 135.2\left(\mathrm{C}_{\mathrm{q}}\right), 133.2\left(\mathrm{C}_{\mathrm{q}}\right), 133.2(\mathrm{CH}), 130.2(\mathrm{CH}), 129.8(\mathrm{CH}), 128.1(\mathrm{CH}), 127.7(\mathrm{CH}), 126.8$ $(\mathrm{CH}), 126.5\left(\mathrm{C}_{\mathrm{q}}\right), 124.3(\mathrm{CH}), 124.0\left(\mathrm{C}_{\mathrm{q}}\right), 122.5(\mathrm{CH}), 117.0(\mathrm{CH}), 115.6(\mathrm{CH}), 114.8(\mathrm{CH}), 112.5$ (CH), $112.4(\mathrm{CH}), 55.3\left(\mathrm{CH}_{3}\right), 55.2\left(\mathrm{CH}_{3}\right), 15.3\left(\mathrm{CH}_{3}\right)$. IR (ATR): 1599, 1474, 1473, 1430, 1316, 1287, 1244, 1045, $762 \mathrm{~cm}^{-1}$. MS (ESI) m/z (relative intensity): 421 (100) [M+H] $]^{+}, 185$ (10). HRMS (ESI) m/z calc. For $\mathrm{C}_{28} \mathrm{H}_{25} \mathrm{~N}_{2} \mathrm{O}_{2}[\mathrm{M}+\mathrm{H}]^{+}: 421.1916$ found: 421.1911 .<smiles>Cc1c(-c2ccccc2)c(-c2cccc(C(F)(F)F)c2)c(-c2cccc(C(F)(F)F)c2)n2ccnc12</smiles>

\section{8-Methyl-7-phenyl-5,6-bis[3-(trifluoromethyl)phenyl]imidazo[1,2-a]pyridine (146d)}

The general procedure $\mathbf{F}$ was followed using $145 \mathrm{a}(74 \mathrm{mg}, 0.4 \mathrm{mmol})$ and $64 \mathrm{~d}(251 \mathrm{mg}, 0.8$ $\mathrm{mmol}$ ) at $140^{\circ} \mathrm{C}$ for $8 \mathrm{~h}$. Purification by column chromatography on silica gel ( $n$-hexane/EtOAc $=$ 5:1) yielded $146 \mathrm{~d}(145 \mathrm{mg}, 73 \%)$ as a white solid. M.p.: $183^{\circ} \mathrm{C} .{ }^{1} \mathrm{H}$ NMR $\left(400 \mathrm{MHz}, \mathrm{CDCl}_{3}\right): \delta=$ 
$7.70(\mathrm{~s}, 1 \mathrm{H}), 7.60(\mathrm{t}, J=4.7 \mathrm{~Hz}, 1 \mathrm{H}), 7.57-7.46(\mathrm{~m}, 3 \mathrm{H}), 7.27-7.11(\mathrm{~m}, 5 \mathrm{H}), 7.11-6.90(\mathrm{~m}$, $5 \mathrm{H}), 2.55(\mathrm{~s}, 3 \mathrm{H}) .{ }^{13} \mathrm{C}$ NMR $\left(101 \mathrm{MHz}, \mathrm{CDCl}_{3}\right): \delta=145.8\left(\mathrm{C}_{\mathrm{q}}\right), 137.8$ (overlapped, $\left.\mathrm{C}_{\mathrm{q}}\right), 137.2\left(\mathrm{C}_{\mathrm{q}}\right)$, $134.5(\mathrm{CH}), 134.2\left(\mathrm{C}_{\mathrm{q}}\right), 133.8(\mathrm{CH}), 133.3(\mathrm{CH}), 131.8\left(\mathrm{C}_{\mathrm{q}}\right), 131.5\left(\mathrm{q},{ }^{2} \mathrm{~J}_{\mathrm{C}-\mathrm{F}}=18 \mathrm{~Hz}, \mathrm{C}_{\mathrm{q}}\right), 131.2(\mathrm{q}$, $\left.{ }^{2} \mathrm{~J}_{\mathrm{C}-\mathrm{F}}=18 \mathrm{~Hz}, \mathrm{C}_{\mathrm{q}}\right), 130.0(\mathrm{CH}), 129.5(\mathrm{CH}), 128.4\left(\mathrm{q},{ }^{3} \mathrm{~J}_{\mathrm{C}-\mathrm{F}}=3 \mathrm{~Hz}, \mathrm{CH}\right), 127.9(\mathrm{CH}), 127.8(\mathrm{CH})$, $127.3\left(\mathrm{q},{ }^{3} \mathrm{~J}_{\mathrm{C}-\mathrm{F}}=3 \mathrm{~Hz}, \mathrm{CH}\right), 127.1(\mathrm{CH}), 126.0\left(\mathrm{C}_{\mathrm{q}}\right), 125.8\left(\mathrm{q},{ }^{3} \mathrm{~J}_{\mathrm{C}-\mathrm{F}}=3 \mathrm{~Hz}, \mathrm{CH}\right), 125.2\left(\mathrm{C}_{\mathrm{q}}\right), 123.6$ (q, $\left.{ }^{1} J_{C-F}=272 \mathrm{~Hz}, C_{q}\right), 123.5\left(q,{ }^{1} J_{C-F}=272 \mathrm{~Hz}, C_{q}\right), 123.2$ (q, $\left.{ }^{3} J_{C-F}=5 \mathrm{~Hz}, \mathrm{CH}\right), 112.0(\mathrm{CH}), 15.2$ $\left(\mathrm{CH}_{3}\right) \cdot{ }^{19} \mathrm{~F}$ NMR (376 MHz, $\left.\mathrm{CDCl}_{3}\right): \delta=-63.3$ (s), -63.4 (s). IR (ATR): 1343, 1314, 1297, 1163, 1117, 1076, 780, 705, $668 \mathrm{~cm}^{-1}$. MS (ESI) m/z (relative intensity): 497 (100) $[\mathrm{M}+\mathrm{H}]^{+}, 519$ (10) $[\mathrm{M}+\mathrm{Na}]^{+}$. HR-MS (ESI) m/z calc. for $\mathrm{C}_{28} \mathrm{H}_{19} \mathrm{~N}_{2} \mathrm{~F}_{6}[\mathrm{M}+\mathrm{H}]^{+}:$497.1447, found: 497.1449 .<smiles>Cc1c(-c2ccccc2)c(-c2cccc(F)c2)c(-c2cccc(F)c2)n2ccnc12</smiles>

\section{5,6-Bis(3-fluorophenyl)-8-methyl-7-phenylimidazo[1,2-a]pyridine (146e)}

The general procedure $\mathbf{F}$ was followed using $145 \mathrm{a}(74 \mathrm{mg}, 0.4 \mathrm{mmol})$ and $64 \mathrm{e}(171 \mathrm{mg}, 0.8$ $\mathrm{mmol})$ at $140{ }^{\circ} \mathrm{C}$ for $8 \mathrm{~h}$. Purification by column chromatography on silica gel $(n$-hexane/EtOAc $=$ 5:1) yielded 146e (100 mg, 63\%) as a white solid. M.p.: $182{ }^{\circ} \mathrm{C} .{ }^{1} \mathbf{H}$ NMR $\left(300 \mathrm{MHz}, \mathrm{CDCl}_{3}\right): \delta=$ $7.67(\mathrm{~s}, 1 \mathrm{H}), 7.44-7.28(\mathrm{~m}, 2 \mathrm{H}), 7.26-7.15(\mathrm{~m}, 3 \mathrm{H}), 7.11-6.98(\mathrm{~m}, 5 \mathrm{H}), 6.90$ (t, J = $7.2 \mathrm{~Hz}$, $1 \mathrm{H}), 6.70-6.59(\mathrm{~m}, 2 \mathrm{H}), 6.55(\mathrm{dd}, J=9.5,2.4 \mathrm{~Hz}, 1 \mathrm{H}), 2.52(\mathrm{~s}, 3 \mathrm{H}) .{ }^{13} \mathrm{C}$ NMR $(101 \mathrm{MHz}$, $\left.\mathrm{CDCl}_{3}\right): \delta=162.7\left(\mathrm{~d},{ }^{1} J_{\mathrm{C}-\mathrm{F}}=248 \mathrm{~Hz}, \mathrm{C}_{\mathrm{q}}\right), 161.7\left(\mathrm{~d},{ }^{1} \mathrm{~J}_{\mathrm{C}-\mathrm{F}}=246 \mathrm{~Hz}, \mathrm{C}_{\mathrm{q}}\right), 145.7\left(\mathrm{C}_{\mathrm{q}}\right), 139.2\left(\mathrm{~d},{ }^{3} J_{\mathrm{C}-\mathrm{F}}\right.$ $\left.=8 \mathrm{~Hz}, \mathrm{C}_{\mathrm{q}}\right), 138.0\left(\mathrm{C}_{\mathrm{q}}\right), 137.3\left(\mathrm{C}_{\mathrm{q}}\right), 135.5\left(\mathrm{~d},{ }^{3} \mathrm{~J}_{\mathrm{C}-\mathrm{F}}=8 \mathrm{~Hz}, \mathrm{C}_{\mathrm{q}}\right), 133.5(\mathrm{CH}), 131.8\left(\mathrm{C}_{\mathrm{q}}\right), 130.6(\mathrm{~d}$, $\left.{ }^{3} J_{\mathrm{C}-\mathrm{F}}=7 \mathrm{~Hz}, \mathrm{CH}\right), 130.0(\mathrm{CH}), 128.7\left(\mathrm{~d},{ }^{3} \mathrm{~J}_{\mathrm{C}-\mathrm{F}}=7 \mathrm{~Hz}, \mathrm{CH}\right), 127.8(\mathrm{CH}), 127.2\left(\mathrm{~d},{ }^{4} \mathrm{~J}_{\mathrm{C}-\mathrm{F}}=3 \mathrm{~Hz}, \mathrm{CH}\right)$, $127.0(\mathrm{CH}), 125.9\left(\mathrm{~d},{ }^{4} \mathrm{~J}_{\mathrm{C}-\mathrm{F}}=3 \mathrm{~Hz}, \mathrm{CH}\right), 125.7\left(\mathrm{C}_{\mathrm{q}}\right), 124.7\left(\mathrm{C}_{\mathrm{q})}, 118.2\left(\mathrm{~d},{ }^{2} \mathrm{~J}_{\mathrm{C}-\mathrm{F}}=21 \mathrm{~Hz}, \mathrm{CH}\right), 117.1\right.$ $\left(\mathrm{d},{ }^{2} \mathrm{~J}_{\mathrm{C}-\mathrm{F}}=22 \mathrm{~Hz}, \mathrm{CH}\right), 116.1\left(\mathrm{~d},{ }^{2} \mathrm{~J}_{\mathrm{C}-\mathrm{F}}=22 \mathrm{~Hz}, \mathrm{CH}\right), 113.4\left(\mathrm{~d},{ }^{2} \mathrm{~J}_{\mathrm{C}-\mathrm{F}}=21 \mathrm{~Hz}, \mathrm{CH}\right), 112.1(\mathrm{CH}), 15.2$ $\left(\mathrm{CH}_{3}\right) .{ }^{19} \mathrm{~F}$ NMR $\left(376 \mathrm{MHz}, \mathrm{CDCl}_{3}\right): \delta=-111.7$ (s), -114.3 (s). IR (ATR): 3029, 1611, 1579, 1472 , 1430, 1227, 931, 765, $695 \mathrm{~cm}^{-1}$. MS (ESI) m/z (relative intensity): 397 (100) $[\mathrm{M}+\mathrm{H}]^{+}, 419$ (10) $[\mathrm{M}+\mathrm{Na}]^{+}$. HR-MS (ESI) m/z calc. for $\mathrm{C}_{26} \mathrm{H}_{19} \mathrm{~N}_{2} \mathrm{~F}_{2}[\mathrm{M}+\mathrm{H}]^{+}:$397.1511, found: 397.1512. 
<smiles>Cc1c(-c2ccccc2)c(-c2cccc(Cl)c2)c(-c2cccc(Cl)c2)n2ccnc12</smiles>

\section{5,6-Bis(3-chlorophenyl)-8-methyl-7-phenylimidazo[1,2-a]pyridine (146f)}

The general procedure $\mathbf{F}$ was followed using $145 \mathrm{a}(74 \mathrm{mg}, 0.4 \mathrm{mmol})$ and $64 \mathrm{f}$ (198 $\mathrm{mg}, 0.8$ $\mathrm{mmol}$ ) at $140{ }^{\circ} \mathrm{C}$ for $8 \mathrm{~h}$. Purification by column chromatography on silica gel $(n$-hexane/EtOAc $=$ 5:1) yielded $146 f(120 \mathrm{mg}, 70 \%)$ as a white solid. M.p.: $198^{\circ} \mathrm{C} .{ }^{1} \mathbf{H} \mathbf{N M R}\left(400 \mathrm{MHz}, \mathrm{CDCl}_{3}\right): \delta=$ $7.67(\mathrm{~s}, 1 \mathrm{H}), 7.39-7.28(\mathrm{~m}, 4 \mathrm{H}), 7.26-7.12(\mathrm{~m}, 4 \mathrm{H}), 7.08-6.98(\mathrm{~m}, 2 \mathrm{H}), 6.96-6.81(\mathrm{~m}, 3 \mathrm{H})$, $6.73(\mathrm{t}, J=6.8 \mathrm{~Hz}, 1 \mathrm{H}), 2.52(\mathrm{~s}, 3 \mathrm{H}) .{ }^{13} \mathrm{C} \operatorname{NMR}\left(101 \mathrm{MHz}, \mathrm{CDCl}_{3}\right): \delta=145.7\left(\mathrm{C}_{\mathrm{q}}\right), 138.8\left(\mathrm{C}_{\mathrm{q}}\right)$, $138.0\left(\mathrm{C}_{\mathrm{q}}\right), 137.4\left(\mathrm{C}_{\mathrm{q}}\right), 135.2\left(\mathrm{C}_{\mathrm{q}}\right), 134.7\left(\mathrm{C}_{\mathrm{q}}\right), 133.5(\mathrm{CH}), 133.0\left(\mathrm{C}_{\mathrm{q}}\right), 131.8\left(\mathrm{C}_{\mathrm{q}}\right), 131.4(\mathrm{CH})$, $130.3(\mathrm{CH}), 130.1(\mathrm{CH}), 130.0(\mathrm{CH}), 129.6(\mathrm{CH}), 129.3(\mathrm{CH}), 128.5(\mathrm{CH}), 128.4(\mathrm{CH})$, $127.9(\mathrm{CH}), 127.0(\mathrm{CH}), 126.7(\mathrm{CH}), 125.7\left(\mathrm{C}_{\mathrm{q}}\right), 124.8\left(\mathrm{C}_{\mathrm{q}}\right), 112.1(\mathrm{CH}), 15.2\left(\mathrm{CH}_{3}\right)$. IR (ATR): 3046, 1592, 1564, 1463, 1289, 1145, 770, 697, $533 \mathrm{~cm}^{-1}$. MS (ESI) m/z (relative intensity): 429 (100) $[\mathrm{M}+\mathrm{H}]^{+}$. HR-MS (ESI) m/z calc. for $\mathrm{C}_{26} \mathrm{H}_{19} \mathrm{~N}_{2}{ }^{35} \mathrm{Cl}_{2}[\mathrm{M}+\mathrm{H}]^{+}: 429.0920$, found: 429.0921 .<smiles>Cc1c(-c2ccccc2)c(-c2cccc(C#N)c2)c(-c2cccc(C#N)c2)n2ccnc12</smiles>

\section{3,3'-(8-Methyl-7-phenylimidazo[1,2-a]pyridine-5,6-diyl)dibenzonitrile (146g)}

The general procedure $\mathbf{F}$ was followed using $145 \mathrm{a}(74 \mathrm{mg}, 0.4 \mathrm{mmol})$ and $64 \mathrm{~g}$ (183 $\mathrm{mg}, 0.8$ $\mathrm{mmol})$ at $140{ }^{\circ} \mathrm{C}$ for $8 \mathrm{~h}$. Purification by column chromatography on silica gel ( $n$-hexane/EtOAc $=$ 5:1) yielded $146 \mathrm{~g}(110 \mathrm{mg}, 67 \%)$ as a white solid. M.p.: $240{ }^{\circ} \mathrm{C} .{ }^{1} \mathbf{H}$ NMR $\left(400 \mathrm{MHz} \mathrm{CDCl}_{3}\right): \delta=$ $7.70(\mathrm{~s}, 1 \mathrm{H}), 7.70-7.65(\mathrm{~m}, 1 \mathrm{H}), 7.63-7.49(\mathrm{~m}, 3 \mathrm{H}), 7.31-7.24(\mathrm{~m}, 2 \mathrm{H}), 7.23-7.17(\mathrm{~m}, 3 \mathrm{H})$, $7.14-7.05(\mathrm{~m}, 3 \mathrm{H}), 7.05-6.92(\mathrm{~m}, 2 \mathrm{H}), 2.53(\mathrm{~s}, 3 \mathrm{H}) .{ }^{13} \mathrm{C}$ NMR $\left(101 \mathrm{MHz}, \mathrm{CDCl}_{3}\right): \delta=145.8$ $\left(\mathrm{C}_{\mathrm{q}}\right), 138.3\left(\mathrm{C}_{\mathrm{q}}\right), 137.5\left(\mathrm{C}_{\mathrm{q}}\right), 137.0\left(\mathrm{C}_{\mathrm{q}}\right), 135.6(\mathrm{CH}), 134.8(\mathrm{CH}), 134.6\left(\mathrm{C}_{\mathrm{q}}\right), 134.4(\mathrm{CH}), 134.2$ $(\mathrm{CH}), 133.6(\mathrm{CH}), 132.8(\mathrm{CH}), 130.9\left(\mathrm{C}_{q}\right), 130.4(\mathrm{CH}), 130.1(\mathrm{CH}), 130.0(\mathrm{CH}), 128.3(\mathrm{CH})$, $128.1(\mathrm{CH}), 127.4(\mathrm{CH}), 126.0\left(\mathrm{C}_{\mathrm{q}}\right), 125.4\left(\mathrm{C}_{\mathrm{q}}\right), 118.0\left(\mathrm{C}_{\mathrm{q}}\right), 117.4\left(\mathrm{C}_{\mathrm{q}}\right), 113.9\left(\mathrm{C}_{\mathrm{q}}\right), 111.9\left(\mathrm{C}_{\mathrm{q}}\right)$, $111.8(\mathrm{CH}), 15.1\left(\mathrm{CH}_{3}\right)$. IR (ATR): 3029, 2230, 1473, 1291, 1143, 811, 781, $695 \mathrm{~cm}^{-1}$. MS (ESI) 
m/z (relative intensity): $411(100)[\mathrm{M}+\mathrm{H}]^{+}, 433(10)[\mathrm{M}+\mathrm{Na}]^{+}$. HR-MS (ESI) m/z calc. for $\mathrm{C}_{28} \mathrm{H}_{19} \mathrm{~N}_{4}$ $[\mathrm{M}+\mathrm{H}]^{+}:$:11.1604, found: 411.1604 .<smiles>Cc1ccc(-c2c(-c3ccccc3)c(C)c3nccn3c2-c2ccccc2)cc1</smiles>

\section{8-Methyl-7-phenyl-5,6-di-p-tolylimidazo[1,2-a]pyridine (146h)}

The general procedure $\mathbf{F}$ was followed using $145 \mathrm{a}(74 \mathrm{mg}, 0.4 \mathrm{mmol})$ and $64 \mathrm{~h}$ (165 $\mathrm{mg}, 0.8$ $\mathrm{mmol}$ ) at $140{ }^{\circ} \mathrm{C}$ for $8 \mathrm{~h}$. Purification by column chromatography on silica gel $(n$-hexane/EtOAc $=$ 5:1) yielded 146h (107 mg, 69\%) as a white solid. M.p.: $259^{\circ} \mathrm{C} .{ }^{1} \mathbf{H} \mathbf{N M R}\left(300 \mathrm{MHz}, \mathrm{CDCl}_{3}\right): \delta=$ $7.63(\mathrm{~d}, J=1.1 \mathrm{~Hz}, 1 \mathrm{H}), 7.31-7.29(\mathrm{~m}, 1 \mathrm{H}), 7.24-7.11(\mathrm{~m}, 7 \mathrm{H}), 7.05-7.00(\mathrm{~m}, 2 \mathrm{H}), 6.75-$ $6.66(\mathrm{~m}, 4 \mathrm{H}), 2.52(\mathrm{~s}, 3 \mathrm{H}), 2.35(\mathrm{~s}, 3 \mathrm{H}), 2.13(\mathrm{~s}, 3 \mathrm{H}) .{ }^{13} \mathrm{C} \mathrm{NMR}\left(101 \mathrm{MHz}, \mathrm{CDCl}_{3}\right): \delta=145.9\left(\mathrm{C}_{\mathrm{q}}\right)$, $130.0\left(\mathrm{C}_{\mathrm{q}}\right), 138.5\left(\mathrm{C}_{\mathrm{q}}\right), 138.3\left(\mathrm{C}_{\mathrm{q}}\right), 135.4\left(\mathrm{C}_{\mathrm{q}}\right), 134.3\left(\mathrm{C}_{\mathrm{q}}\right), 133.4\left(\mathrm{C}_{\mathrm{q}}\right), 132.8(\mathrm{CH}), 131.3(\mathrm{CH})$, $131.1\left(\mathrm{C}_{\mathrm{q}}\right), 130.3(\mathrm{CH}), 130.1(\mathrm{CH}), 129.5(\mathrm{CH}), 127.9(\mathrm{CH}), 127.7(\mathrm{CH}), 127.1\left(\mathrm{C}_{\mathrm{q}}\right), 126.6(\mathrm{CH})$, $123.6\left(\mathrm{C}_{\mathrm{q}}\right), 112.4(\mathrm{CH}), 21.5\left(\mathrm{CH}_{3}\right), 21.2\left(\mathrm{CH}_{3}\right), 15.3\left(\mathrm{CH}_{3}\right)$. IR (ATR): 1600, 1513, 1483, 1442, 1287, 1144, 817, 731, $702 \mathrm{~cm}^{-1}$. MS (ESI) m/z (relative intensity): $389(100)[\mathrm{M}+\mathrm{H}]^{+}$. HR-MS (ESI) m/z calc. for $\mathrm{C}_{28} \mathrm{H}_{25} \mathrm{~N}_{2}[\mathrm{M}+\mathrm{H}]^{+}:$389.2018, found: 389.2012.<smiles>COc1ccc(-c2c(-c3ccccc3)c(C)c3nccn3c2-c2ccccc2)cc1</smiles>

\section{5,6-Bis(4-methoxyphenyl)-8-methyl-7-phenylimidazo[1,2-a]pyridine (146i)}

The general procedure $\mathbf{F}$ was followed using $145 \mathrm{a}(74 \mathrm{mg}, 0.4 \mathrm{mmol})$ and $64 \mathbf{i}$ (165 $\mathrm{mg}, 0.8$ $\mathrm{mmol})$ at $140{ }^{\circ} \mathrm{C}$ for $8 \mathrm{~h}$. Purification by column chromatography on silica gel $(n$-hexane/EtOAc $=$ 5:1) yielded 146i (119 mg, 71\%) as a white solid. M.p.: $197^{\circ} \mathrm{C} .{ }^{1} \mathbf{H} \mathbf{N M R}\left(400 \mathrm{MHz}, \mathrm{CDCl}_{3}\right): \delta=$ $7.62(\mathrm{~d}, J=1.3 \mathrm{~Hz}, 1 \mathrm{H}), 7.31(\mathrm{~d}, J=1.3 \mathrm{~Hz}, 1 \mathrm{H}), 7.23-7.13(\mathrm{~m}, 5 \mathrm{H}), 7.05-7.00(\mathrm{~m}, 2 \mathrm{H}), 6.85$ $(\mathrm{d}, J=8.7 \mathrm{~Hz}, 2 \mathrm{H}), 6.71(\mathrm{~d}, J=8.7 \mathrm{~Hz}, 2 \mathrm{H}), 6.47(\mathrm{~d}, J=8.7 \mathrm{~Hz}, 2 \mathrm{H}), 3.80(\mathrm{~s}, 3 \mathrm{H}), 3.64(\mathrm{~s}, 3 \mathrm{H})$, $2.50(\mathrm{~s}, 3 \mathrm{H}) .{ }^{13} \mathrm{C}$ NMR $\left(101 \mathrm{MHz}, \mathrm{CDCl}_{3}\right): \delta=159.4\left(\mathrm{C}_{\mathrm{q}}\right), 157.5\left(\mathrm{C}_{\mathrm{q}}\right), 145.8\left(\mathrm{C}_{\mathrm{q}}\right), 138.9\left(\mathrm{C}_{\mathrm{q}}\right)$, $138.2\left(\mathrm{C}_{\mathrm{q}}\right), 133.3\left(\mathrm{C}_{\mathrm{q}}\right), 132.9(\mathrm{CH}), 132.5(\mathrm{CH}), 131.4(\mathrm{CH}), 130.2(\mathrm{CH}), 129.8\left(\mathrm{C}_{\mathrm{q}}\right), 127.6(\mathrm{CH})$, $126.5(\mathrm{CH}), 126.4$ (overlapped, $\left.\mathrm{C}_{\mathrm{q}}\right), 123.5\left(\mathrm{C}_{\mathrm{q}}\right), 114.1(\mathrm{CH}), 112.5(\mathrm{CH}), 112.1(\mathrm{CH}), 55.2\left(\mathrm{CH}_{3}\right)$, $54.9\left(\mathrm{CH}_{3}\right), 15.2\left(\mathrm{CH}_{3}\right)$. IR (ATR): 3022, 2959, 2835, 1605, 1511, 1478, 1288, 1240, $701 \mathrm{~cm}^{-1}$. 
MS (ESI) m/z (relative intensity): 421 (100) $[\mathrm{M}+\mathrm{H}]^{+}, 185$ (10). HR-MS (ESI) m/z calc. for $\mathrm{C}_{28} \mathrm{H}_{25} \mathrm{~N}_{2} \mathrm{O}_{2}[\mathrm{M}+\mathrm{H}]^{+}: 421.1911$, found: 421.1912.<smiles>Cc1c(-c2ccccc2)c(-c2ccc(C(F)(F)F)cc2)c(-c2ccc(C(F)(F)F)cc2)n2ccnc12</smiles>

\section{8-Methyl-7-phenyl-5,6-bis[4-(trifluoromethyl)phenyl]imidazo[1,2-a]pyridine (146j)}

The general procedure $\mathbf{F}$ was followed using $145 \mathrm{a}(74 \mathrm{mg}, 0.4 \mathrm{mmol})$ and $64 \mathrm{j}(251 \mathrm{mg}, 0.8$ $\mathrm{mmol})$ at $140^{\circ} \mathrm{C}$ for $8 \mathrm{~h}$. Purification by column chromatography on silica gel $(n$-hexane/EtOAc $=$ 5:1) yielded 146j (137 mg, 69\%) as a white solid. M.p.: $266{ }^{\circ} \mathrm{C} .{ }^{1} \mathbf{H} \mathbf{~ N M R}\left(300 \mathrm{MHz}, \mathrm{CDCl}_{3}\right): \delta=$ $7.68(\mathrm{~d}, J=1.1 \mathrm{~Hz}, 1 \mathrm{H}), 7.63(\mathrm{~d}, J=8.0 \mathrm{~Hz}, 2 \mathrm{H}), 7.42(\mathrm{~d}, J=8.0 \mathrm{~Hz}, 2 \mathrm{H}), 7.25-7.17(\mathrm{~m}, 6 \mathrm{H})$, $7.04-6.98(\mathrm{~m}, 2 \mathrm{H}), 6.95(\mathrm{~d}, J=8.0 \mathrm{~Hz}, 2 \mathrm{H}), 2.54(\mathrm{~s}, 3 \mathrm{H}) .{ }^{13} \mathrm{C} \mathrm{NMR}\left(101 \mathrm{MHz}, \mathrm{CDCl}_{3}\right): \delta=$ $145.8\left(\mathrm{C}_{\mathrm{q}}\right), 140.8\left(\mathrm{C}_{\mathrm{q}}\right), 137.7\left(\mathrm{C}_{\mathrm{q}}\right), 137.2\left(\mathrm{C}_{\mathrm{q}}\right), 137.1\left(\mathrm{C}_{\mathrm{q}}\right), 133.7(\mathrm{CH}), 131.7\left(\mathrm{C}_{\mathrm{q}}\right), 131.7(\mathrm{CH})$, $131.2\left(\mathrm{q},{ }^{2} \mathrm{~J}_{\mathrm{C}-\mathrm{F}}=33 \mathrm{~Hz}, \mathrm{C}_{\mathrm{q}}\right.$ ), $130.7(\mathrm{CH}), 130.0(\mathrm{CH}), 128.6$ (q, $\left.{ }^{2} \mathrm{~J}_{\mathrm{C}-\mathrm{F}}=33 \mathrm{~Hz}, \mathrm{C}_{\mathrm{q}}\right), 127.9(\mathrm{CH})$, $127.1(\mathrm{CH}), 126.0$ (q, $\left.{ }^{3} \mathrm{~J}_{\mathrm{C}-\mathrm{F}}=4 \mathrm{~Hz}, \mathrm{CH}\right), 125.8\left(\mathrm{C}_{\mathrm{q}}\right), 125.2\left(\mathrm{C}_{\mathrm{q}}\right), 124.2\left(\mathrm{q},{ }^{3} \mathrm{~J}_{\mathrm{C}-\mathrm{F}}=4 \mathrm{~Hz}, \mathrm{CH}\right)$, $123.8\left(\mathrm{q},{ }^{1} \mathrm{~J}_{\mathrm{C}-\mathrm{F}}=273 \mathrm{~Hz}, \mathrm{C}_{\mathrm{q}}\right), 123.5\left(\mathrm{q},{ }^{1} \mathrm{~J}_{\mathrm{C}-\mathrm{F}}=273 \mathrm{~Hz}, \mathrm{C}_{\mathrm{q}}\right), 112.0(\mathrm{CH}), 15.2\left(\mathrm{CH}_{3}\right) .{ }^{19} \mathrm{~F}$ NMR $(282$ $\mathrm{MHz}, \mathrm{CDCl}_{3}$ ): $\delta=-62.7$ (s), -62.9 (s). IR (ATR): 1615, 1323, 1157, 1109, 1065, 1019, 850, 704 $\mathrm{cm}^{-1}$. MS (ESI) m/z (relative intensity): $497(100)[\mathrm{M}+\mathrm{H}]^{+}, 519(10)[\mathrm{M}+\mathrm{Na}]^{+}$. HR-MS (ESI) m/z calc. for $\mathrm{C}_{28} \mathrm{H}_{19} \mathrm{~N}_{2} \mathrm{~F}_{6}[\mathrm{M}+\mathrm{H}]^{+}: 497.1447$, found: 497.1449 .<smiles>Cc1c(-c2ccc(F)cc2)c(-c2ccc(F)cc2)c(-c2ccccc2)n2ccnc12</smiles>

\section{5,6-Bis(4-fluorophenyl)-8-methyl-7-phenylimidazo[1,2-a]pyridine (146k)}

The general procedure A was followed using $145 \mathrm{a}(74 \mathrm{mg}, 0.4 \mathrm{mmol})$ and $64 \mathrm{k}(171 \mathrm{mg}, 0.8$ $\mathrm{mmol}$ ) at $140^{\circ} \mathrm{C}$ for $8 \mathrm{~h}$. Purification by column chromatography on silica gel ( $n$-hexane/EtOAc $=$ 5:1) yielded 146k (82 mg, 52\%) as a white solid. M.p.: $249{ }^{\circ} \mathrm{C} .{ }^{1} \mathbf{H ~ N M R}\left(400 \mathrm{MHz}, \mathrm{CDCl}_{3}\right): \delta=$ $7.66(\mathrm{~d}, J=1.2 \mathrm{~Hz}, 1 \mathrm{H}), 7.29-7.26(\mathrm{~m}, 2 \mathrm{H}), 7.25-7.14(\mathrm{~m}, 4 \mathrm{H}), 7.07-6.99(\mathrm{~m}, 4 \mathrm{H}), 6.79-$ $6.74(\mathrm{~m}, 2 \mathrm{H}), 6.68-6.60(\mathrm{~m}, 2 \mathrm{H}), 2.52(\mathrm{~s}, 3 \mathrm{H}) .{ }^{13} \mathrm{C} \mathrm{NMR}\left(101 \mathrm{MHz}, \mathrm{CDCl}_{3}\right): \delta=162.5\left(\mathrm{~d},{ }^{1} \mathrm{~J}_{\mathrm{C}-\mathrm{F}}=\right.$ $250 \mathrm{~Hz}, \mathrm{C}_{\mathrm{q}}$ ), 161.1 (d, $\left.{ }^{1} \mathrm{~J}_{\mathrm{C}-\mathrm{F}}=250 \mathrm{~Hz}, \mathrm{C}_{\mathrm{q}}\right), 145.7\left(\mathrm{C}_{\mathrm{q}}\right), 138.3\left(\mathrm{C}_{\mathrm{q}}\right), 137.8\left(\mathrm{C}_{\mathrm{q}}\right), 133.2(\mathrm{CH}), 133.1$ $\left(\mathrm{d},{ }^{4} \mathrm{~J}_{\mathrm{C}-\mathrm{F}}=3 \mathrm{~Hz}, \mathrm{C}_{\mathrm{q}}\right), 132.9\left(\mathrm{~d},{ }^{3} \mathrm{~J}_{\mathrm{C}-\mathrm{F}}=8 \mathrm{~Hz}, \mathrm{CH}\right), 132.4\left(\mathrm{C}_{\mathrm{q}}\right), 132.0\left(\mathrm{~d},{ }^{3} \mathrm{~J}_{\mathrm{C}-\mathrm{F}}=8 \mathrm{~Hz}, \mathrm{CH}\right), 130.1$ 
$(\mathrm{CH}), 129.7\left(\mathrm{~d},{ }^{4} \mathrm{~J}_{\mathrm{C}-\mathrm{F}}=4 \mathrm{~Hz}, \mathrm{C}_{\mathrm{q}}\right), 127.8(\mathrm{CH}), 126.8(\mathrm{CH}), 126.1\left(\mathrm{C}_{\mathrm{q}}\right), 124.3\left(\mathrm{C}_{\mathrm{q}}\right), 116.1\left(\mathrm{~d},{ }^{2} \mathrm{~J}_{\mathrm{C}-\mathrm{F}}=\right.$ $22 \mathrm{~Hz}, \mathrm{CH}), 114.2\left(\mathrm{~d},{ }^{2} \mathrm{~J} \mathrm{C}-\mathrm{F}=22 \mathrm{~Hz}, \mathrm{CH}\right), 112.0(\mathrm{CH}), 15.2\left(\mathrm{CH}_{3}\right) \cdot{ }^{19} \mathrm{~F} \mathrm{NMR}\left(377 \mathrm{MHz}, \mathrm{CDCl}_{3}\right): \delta$ $=-111.3(\mathrm{~s}),-115.6(\mathrm{~s})$. IR (ATR): 3025, 1601, 1508, 1481, 1288, 1216, 1143, 782, $700 \mathrm{~cm}^{-1}$. MS (ESI) m/z (relative intensity): $397(100)[\mathrm{M}+\mathrm{H}]^{+}, 419$ (10) [M+Na] ${ }^{+}$. HR-MS (ESI) m/z calc. for $\mathrm{C}_{26} \mathrm{H}_{19} \mathrm{~N}_{2} \mathrm{~F}_{2}[\mathrm{M}+\mathrm{H}]^{+}:$397.1511, found: 397.1511.<smiles>Cc1c(-c2ccccc2)c(-c2ccc(Br)cc2)c(-c2ccccc2)n2ccnc12</smiles>

\section{5,6-Bis(4-bromophenyl)-8-methyl-7-phenylimidazo[1,2-a]pyridine (146I)}

The general procedure $\mathbf{F}$ was followed using $145 \mathrm{a}(74 \mathrm{mg}, 0.4 \mathrm{mmol})$ and $64 \mathrm{l}(269 \mathrm{mg}, 0.8$ $\mathrm{mmol}$ ) at $140^{\circ} \mathrm{C}$ for $8 \mathrm{~h}$. Purification by column chromatography on silica gel $(n$-hexane/EtOAc $=$ 5:1) yielded $146 \mathrm{I}(141 \mathrm{mg}, 68 \%)$ as a white solid. M.p.: $276{ }^{\circ} \mathrm{C} .{ }^{1} \mathrm{H}$ NMR $\left(300 \mathrm{MHz}, \mathrm{CDCl}_{3}\right): \delta=$ $7.65(\mathrm{~d}, J=1.2 \mathrm{~Hz}, 1 \mathrm{H}), 7.50(\mathrm{~d}, J=8.4 \mathrm{~Hz}, 2 \mathrm{H}), 7.27-7.17(\mathrm{~m}, 4 \mathrm{H}), 7.17-7.12(\mathrm{~m}, 2 \mathrm{H}), 7.11$ - $7.05(\mathrm{~m}, 2 \mathrm{H}), 7.03-6.97(\mathrm{~m}, 2 \mathrm{H}), 6.68(\mathrm{~d}, J=8.4 \mathrm{~Hz}, 2 \mathrm{H}), 2.50(\mathrm{~s}, 3 \mathrm{H}) .{ }^{13} \mathrm{C}$ NMR $(75 \mathrm{MHz}$, $\left.\mathrm{CDCl}_{3}\right): \delta=145.7\left(\mathrm{C}_{\mathrm{q}}\right), 138.1\left(\mathrm{C}_{\mathrm{q}}\right), 137.4\left(\mathrm{C}_{\mathrm{q}}\right), 136.1\left(\mathrm{C}_{\mathrm{q}}\right), 133.4(\mathrm{CH}), 132.9(\mathrm{CH}), 132.5\left(\mathrm{C}_{\mathrm{q}}\right)$, $132.3(\mathrm{CH}), 132.0\left(\mathrm{C}_{\mathrm{q}}\right), 131.7(\mathrm{CH}), 130.5(\mathrm{CH}), 130.1(\mathrm{CH}), 127.9(\mathrm{CH}), 127.0(\mathrm{CH}), 125.7\left(\mathrm{C}_{\mathrm{q}}\right)$, $124.6\left(\mathrm{C}_{\mathrm{q}}\right), 123.3\left(\mathrm{C}_{\mathrm{q}}\right), 120.7\left(\mathrm{C}_{\mathrm{q}}\right), 112.0(\mathrm{CH}), 15.2\left(\mathrm{CH}_{3}\right)$. IR (ATR): 2149, 1977, 1948, 1474, 1070, 1011, 822, 732, $700 \mathrm{~cm}^{-1}$. MS (ESI) m/z (relative intensity): $516(100)[\mathrm{M}+\mathrm{H}]^{+}, 441$ (10). HR-MS (ESI) m/z calc. for $\mathrm{C}_{26} \mathrm{H}_{19} \mathrm{~N}_{2}{ }^{79} \mathrm{Br}_{2}[\mathrm{M}+\mathrm{H}]^{+}: 516.9910$, found: 516.9913 .<smiles>Cc1cc(-c2ccccc2)c(-c2ccccc2)n2ccnc12</smiles>

\section{8-Methyl-5,6-diphenylimidazo[1,2-a]pyridine (146m)}

The general procedure $\mathbf{F}$ was followed using $145 \mathrm{~b}(43 \mathrm{mg}, 0.4 \mathrm{mmol})$ and $64 \mathrm{a}$ (143 $\mathrm{mg}, 0.8$ $\mathrm{mmol}$ ) at $140^{\circ} \mathrm{C}$ for $8 \mathrm{~h}$. Purification by column chromatography on silica gel ( $n$-hexane/EtOAc $=$ 5:1) yielded $146 \mathrm{~m}(63 \mathrm{mg}, 55 \%)$ as a white solid. M.p.: $135^{\circ} \mathrm{C} .{ }^{1} \mathrm{H} \mathrm{NMR}\left(300 \mathrm{MHz}, \mathrm{CDCl}_{3}\right): \delta=$ $7.59(\mathrm{~d}, J=1.3 \mathrm{~Hz}, 1 \mathrm{H}), 7.41-7.36(\mathrm{~m}, 3 \mathrm{H}), 7.35(\mathrm{~d}, J=1.3 \mathrm{~Hz}, 1 \mathrm{H}), 7.34-7.29(\mathrm{~m}, 2 \mathrm{H}), 7.23$ - $7.17(\mathrm{~m}, 4 \mathrm{H}), 7.17-7.12(\mathrm{~m}, 2 \mathrm{H}), 2.72(\mathrm{~s}, 3 \mathrm{H}) .{ }^{13} \mathrm{C} \mathrm{NMR}\left(75 \mathrm{MHz}, \mathrm{CDCl}_{3}\right): \delta=145.7\left(\mathrm{C}_{\mathrm{q}}\right)$, $138.6\left(\mathrm{C}_{\mathrm{q}}\right), 133.6\left(\mathrm{C}_{\mathrm{q}}\right), 133.0\left(\mathrm{C}_{\mathrm{q}}\right), 132.9(\mathrm{CH}), 130.3(\mathrm{CH}), 129.9(\mathrm{CH}), 129.0(\mathrm{CH}), 128.9(\mathrm{CH})$, $128.0(\mathrm{CH}), 126.9(\mathrm{CH}), 126.8(\mathrm{CH}), 126.1\left(\mathrm{C}_{\mathrm{q}}\right), 125.6\left(\mathrm{C}_{\mathrm{q}}\right), 112.2(\mathrm{CH}), 17.0\left(\mathrm{CH}_{3}\right)$. IR (ATR): 2918, 1477, 1442, 1307, 1265, 1146, 763, $696 \mathrm{~cm}^{-1}$. MS (ESI) m/z (relative intensity): 285 (100) 
$[\mathrm{M}+\mathrm{H}]^{+}$. HR-MS (ESI) $\mathrm{m} / \mathrm{z}$ calc. for $\mathrm{C}_{20} \mathrm{H}_{17} \mathrm{~N}_{2}[\mathrm{M}+\mathrm{H}]^{+}:$285.1386, found: 285.1388 . The analytical data corresponds with those reported in the literature. ${ }^{[231]}$<smiles></smiles>

\section{7,8-Dimethyl-5,6-diphenylimidazo[1,2-a]pyridine (146n)}

The general procedure $\mathbf{F}$ was followed using $145 \mathrm{c}(49 \mathrm{mg}, 0.4 \mathrm{mmol})$ and $64 \mathrm{a}(143 \mathrm{mg}, 0.8$ $\mathrm{mmol}$ ) at $140^{\circ} \mathrm{C}$ for $8 \mathrm{~h}$. Purification by column chromatography on silica gel ( $n$-hexane/EtOAc $=$ 5:1) yielded 146n (63 mg, 53\%) as a white solid. M.p.: $196{ }^{\circ} \mathrm{C} .{ }^{1} \mathrm{H} \mathrm{NMR}\left(300 \mathrm{MHz}, \mathrm{CDCl}_{3}\right): \delta=$ $7.57-7.49(\mathrm{~m}, 1 \mathrm{H}), 7.33-7.27(\mathrm{~m}, 3 \mathrm{H}), 7.25-7.16(\mathrm{~m}, 5 \mathrm{H}), 7.15--7.12(\mathrm{~m}, 1 \mathrm{H}), 7.10-7.02$ (m, 2H), $2.70(\mathrm{~s}, 3 \mathrm{H}), 2.10(\mathrm{~s}, 3 \mathrm{H}) .{ }^{13} \mathrm{C}$ NMR $\left(75 \mathrm{MHz}, \mathrm{CDCl}_{3}\right): \delta=146.1\left(\mathrm{C}_{\mathrm{q}}\right), 137.9\left(\mathrm{C}_{\mathrm{q}}\right), 133.9$ $\left(\mathrm{C}_{\mathrm{q}}\right), 133.1\left(\mathrm{C}_{\mathrm{q}}\right), 132.4(\mathrm{CH}), 131.6\left(\mathrm{C}_{\mathrm{q}}\right), 130.7(\mathrm{CH}), 130.0(\mathrm{CH}), 128.6(\mathrm{CH}), 128.5(\mathrm{CH}), 127.8$ $(\mathrm{CH}), 127.6\left(\mathrm{C}_{\mathrm{q}}\right), 126.8(\mathrm{CH}), 123.2\left(\mathrm{C}_{\mathrm{q}}\right), 111.7(\mathrm{CH}), 17.1\left(\mathrm{CH}_{3}\right), 13.9\left(\mathrm{CH}_{3}\right)$. IR (ATR): 1979, 1474, 1442, 1306, 869, 755, $695 \mathrm{~cm}^{-1}$. MS (ESI) m/z (relative intensity): 299 (100) [M+H] $]^{+}$. HRMS (ESI) $\mathrm{m} / \mathrm{z}$ calc. for $\mathrm{C}_{21} \mathrm{H}_{19} \mathrm{~N}_{2}[\mathrm{M}+\mathrm{H}]^{+}:$299.1543, found: 299.1544 .

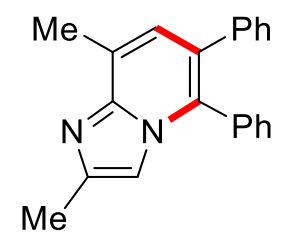

\section{2,8-Dimethyl-5,6-diphenylimidazo[1,2-a]pyridine (1460)}

The general procedure $\mathbf{F}$ was followed using $145 \mathrm{~d}$ (49 $\mathrm{mg}, 0.4 \mathrm{mmol}$ ) and $64 \mathrm{a}$ (143 mg, 0.8 $\mathrm{mmol}$ ) at $140^{\circ} \mathrm{C}$ for $8 \mathrm{~h}$. Purification by column chromatography on silica gel ( $n$-hexane/EtOAc $=$ 5:1) yielded $1460(60 \mathrm{mg}, 50 \%)$ as a white solid. M.p.: $189^{\circ} \mathrm{C} .{ }^{1} \mathrm{H}$ NMR $\left(400 \mathrm{MHz}, \mathrm{CDCl}_{3}\right): \delta=$ $7.42-7.36(\mathrm{~m}, 3 \mathrm{H}), 7.32-7.28(\mathrm{~m}, 2 \mathrm{H}), 7.23-7.17(\mathrm{~m}, 3 \mathrm{H}), 7.16-7.12(\mathrm{~m}, 3 \mathrm{H}), 7.10(\mathrm{~s}, 1 \mathrm{H})$, $2.70(\mathrm{~s}, 3 \mathrm{H}), 2.45(\mathrm{~s}, 3 \mathrm{H}) .{ }^{13} \mathrm{C}$ NMR $\left(101 \mathrm{MHz}, \mathrm{CDCl}_{3}\right): \delta=145.3\left(\mathrm{C}_{\mathrm{q}}\right), 142.6\left(\mathrm{C}_{\mathrm{q}}\right), 138.8\left(\mathrm{C}_{\mathrm{q}}\right)$, $133.8\left(\mathrm{C}_{\mathrm{q}}\right), 132.5\left(\mathrm{C}_{\mathrm{q}}\right), 130.3(\mathrm{CH}), 129.9(\mathrm{CH}), 128.9(\mathrm{CH}), 128.9(\mathrm{CH}), 127.9(\mathrm{CH}), 126.7(\mathrm{CH})$, $126.6(\mathrm{CH}), 125.1\left(\mathrm{C}_{\mathrm{q}}\right), 125.0\left(\mathrm{C}_{\mathrm{q}}\right), 109.4(\mathrm{CH}), 17.1\left(\mathrm{CH}_{3}\right), 14.5\left(\mathrm{CH}_{3}\right)$. IR (ATR): 2017, 1989, 1476, 1437, 1320, 1180, 768, $699 \mathrm{~cm}^{-1}$. MS (ESI) m/z (relative intensity): 299 (100) [M+H] ${ }^{+}$. HRMS (ESI) m/z calc. for $\mathrm{C}_{21} \mathrm{H}_{19} \mathrm{~N}_{2}[\mathrm{M}+\mathrm{H}]^{+}:$299.1543, found: 299.1543 . 


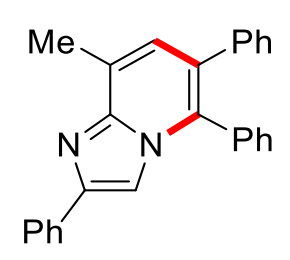

\section{8-Methyl-2,5,6-triphenylimidazo[1,2-a]pyridine (146p)}

The general procedure $\mathbf{F}$ was followed using $145 \mathrm{e}(74 \mathrm{mg}, 0.4 \mathrm{mmol})$ and $64 \mathrm{a}$ (143 $\mathrm{mg}, 0.8$ $\mathrm{mmol})$ at $140^{\circ} \mathrm{C}$ for $8 \mathrm{~h}$. Purification by column chromatography on silica gel $(n$-hexane/EtOAc $=$ 5:1) yielded 146p (74 mg, 51\%) as a white solid. M.p.: $20{ }^{\circ} \mathrm{C} .{ }^{1} \mathrm{H}$ NMR $\left(300 \mathrm{MHz}, \mathrm{CDCl}_{3}\right): \delta=$ $7.98-7.90(\mathrm{~m}, 2 \mathrm{H}), 7.63(\mathrm{~s}, 1 \mathrm{H}), 7.45-7.41(\mathrm{~m}, 4 \mathrm{H}), 7.41-7.28(\mathrm{~m}, 4 \mathrm{H}), 7.24-7.13(\mathrm{~m}, 6 \mathrm{H})$, $2.79(\mathrm{~s}, 3 \mathrm{H}) .{ }^{13} \mathrm{C}$ NMR $\left(75 \mathrm{MHz}, \mathrm{CDCl}_{3}\right): \delta=146.0\left(\mathrm{C}_{\mathrm{q}}\right), 145.3\left(\mathrm{C}_{\mathrm{q}}\right), 138.7\left(\mathrm{C}_{\mathrm{q}}\right), 134.2\left(\mathrm{C}_{\mathrm{q}}\right), 133.7$ $\left(\mathrm{C}_{\mathrm{q}}\right), 132.8\left(\mathrm{C}_{\mathrm{q}}\right), 130.4(\mathrm{CH}), 129.9(\mathrm{CH}), 129.0$ (overlapped, $\left.\mathrm{CH}\right), 128.6(\mathrm{CH}), 128.0(\mathrm{CH}), 127.7$ $(\mathrm{CH}), 127.2(\mathrm{CH}), 126.8(\mathrm{CH}), 126.2(\mathrm{CH}), 126.1\left(\mathrm{C}_{\mathrm{q}}\right), 125.6\left(\mathrm{C}_{\mathrm{q}}\right), 108.0(\mathrm{CH}), 17.1\left(\mathrm{CH}_{3}\right)$. IR (ATR): 1979, 1950, 1475, 724, 695, 583, $509 \mathrm{~cm}^{-1}$. MS (ESI) m/z (relative intensity): 361 (100) $[\mathrm{M}+\mathrm{H}]^{+}$. HR-MS (ESI) $\mathrm{m} / \mathrm{z}$ calc. for $\mathrm{C}_{26} \mathrm{H}_{21} \mathrm{~N}_{2}[\mathrm{M}+\mathrm{H}]^{+}: 361.1699$, found: 361.1699 .<smiles>Cc1nc2c(C)cc(-c3ccccc3)c(-c3ccccc3)n2c1C</smiles>

\section{2,3,8-Trimethyl-5,6-diphenylimidazo[1,2-a]pyridine (146q)}

The general procedure $\mathbf{F}$ was followed using $145 \mathrm{f}(55 \mathrm{mg}, 0.4 \mathrm{mmol})$ and $64 \mathrm{a}(143 \mathrm{mg}, 0.8$ $\mathrm{mmol}$ ) at $140^{\circ} \mathrm{C}$ for $8 \mathrm{~h}$. Purification by column chromatography on silica gel ( $n$-hexane/EtOAc $=$ 5:1) yielded $146 q(50 \mathrm{mg}, 40 \%)$ as a white solid. M.p.: $185{ }^{\circ} \mathrm{C} .{ }^{1} \mathbf{H} \mathbf{~ N M R}\left(400 \mathrm{MHz}, \mathrm{CDCl}_{3}\right): \delta=$ $7.38-7.24(\mathrm{~m}, 5 \mathrm{H}), 7.19-7.13(\mathrm{~m}, 3 \mathrm{H}), 7.11-7.06(\mathrm{~m}, 2 \mathrm{H}), 6.99(\mathrm{~s}, 1 \mathrm{H}), 2.68(\mathrm{~s}, 3 \mathrm{H}), 2.40(\mathrm{~s}$, 3H), $1.66(\mathrm{~s}, 3 \mathrm{H}) .{ }^{13} \mathrm{C}$ NMR $\left(101 \mathrm{MHz}, \mathrm{CDCl}_{3}\right): \delta=144.6\left(\mathrm{C}_{\mathrm{q}}\right), 140.5\left(\mathrm{C}_{\mathrm{q}}\right), 139.3\left(\mathrm{C}_{\mathrm{q}}\right), 133.7\left(\mathrm{C}_{\mathrm{q}}\right)$, $133.5\left(\mathrm{C}_{\mathrm{q}}\right), 131.9(\mathrm{CH}), 130.0(\mathrm{CH}), 128.5(\mathrm{CH}), 127.6(\mathrm{CH}), 127.3(\mathrm{CH}), 126.4(\mathrm{CH}), 126.3\left(\mathrm{C}_{\mathrm{q}}\right)$, $125.4(\mathrm{CH}), 125.1\left(\mathrm{C}_{\mathrm{q}}\right), 118.6\left(\mathrm{C}_{\mathrm{q}}\right), 17.2\left(\mathrm{CH}_{3}\right), 13.7\left(\mathrm{CH}_{3}\right), 12.0\left(\mathrm{CH}_{3}\right)$. IR (ATR): 2148, 2085, 1978, 1438, 1251, 710, 697, $642 \mathrm{~cm}^{-1}$. MS (ESI) m/z (relative intensity): $313(100)[\mathrm{M}+\mathrm{H}]^{+}$. HRMS (ESI) m/z calc. for $\mathrm{C}_{22} \mathrm{H}_{21} \mathrm{~N}_{2}[\mathrm{M}+\mathrm{H}]^{+}: 313.1699$, found: 313.1704 . 


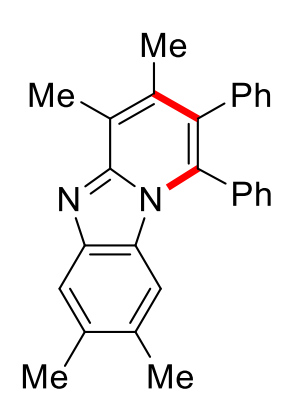

\section{3,4,7,8-Tetramethyl-1,2-diphenylbenzo[4,5]imidazo[1,2-a]pyridine (146r)}

The general procedure $\mathbf{F}$ was followed using $145 \mathrm{~g}(80 \mathrm{mg}, 0.4 \mathrm{mmol})$ and $64 \mathrm{a}(143 \mathrm{mg}, 0.8$ $\mathrm{mmol}$ ) at $140^{\circ} \mathrm{C}$ for $8 \mathrm{~h}$. Purification by column chromatography on silica gel $(n$-hexane/EtOAc $=$ 5:1) yielded 146r $(75 \mathrm{mg}, 50 \%)$ as a white solid. M.p.: $256{ }^{\circ} \mathrm{C} .{ }^{1} \mathrm{H} \mathrm{NMR}\left(300 \mathrm{MHz}, \mathrm{CDCl}_{3}\right): \delta=$ $7.70(\mathrm{~s}, 1 \mathrm{H}), 7.42-7.33(\mathrm{~m}, 3 \mathrm{H}), 7.27-7.16(\mathrm{~m}, 5 \mathrm{H}), 7.13-7.08(\mathrm{~m}, 2 \mathrm{H}), 5.75(\mathrm{~s}, 1 \mathrm{H}), 2.78(\mathrm{~s}$, 3H), $2.36(\mathrm{~s}, 3 \mathrm{H}), 2.13(\mathrm{~s}, 3 \mathrm{H}), 2.06(\mathrm{~s}, 3 \mathrm{H}) .{ }^{13} \mathrm{C} \mathrm{NMR}\left(101 \mathrm{MHz}, \mathrm{CDCl}_{3}\right): \delta=149.3\left(\mathrm{C}_{\mathrm{q}}\right), 143.8$ $\left(\mathrm{C}_{\mathrm{q}}\right), 137.6\left(\mathrm{C}_{\mathrm{q}}\right), 135.6\left(\mathrm{C}_{\mathrm{q}}\right), 135.5\left(\mathrm{C}_{\mathrm{q}}\right), 134.2\left(\mathrm{C}_{\mathrm{q}}\right), 133.8$ (overlapped, $\left.\mathrm{C}_{\mathrm{q}}\right), 130.9(\mathrm{CH}), 130.4$ $(\mathrm{CH}), 128.8(\mathrm{CH}), 128.8\left(\mathrm{C}_{\mathrm{q}}\right), 128.6(\mathrm{CH}), 127.8(\mathrm{CH}), 126.8(\mathrm{CH}), 126.2\left(\mathrm{C}_{\mathrm{q}}\right), 122.7\left(\mathrm{C}_{\mathrm{q}}\right), 119.1$ $(\mathrm{CH}), 114.6(\mathrm{CH}), 20.7\left(\mathrm{CH}_{3}\right), 20.5\left(\mathrm{CH}_{3}\right), 17.7\left(\mathrm{CH}_{3}\right), 14.4\left(\mathrm{CH}_{3}\right)$. IR (ATR): 2152, 2086, 2045, 1464, 856, 726, $697 \mathrm{~cm}^{-1}$. MS (ESI) m/z (relative intensity): 377 (100) [M+H] $]^{+}$. HR-MS (ESI) m/z calc. for $\mathrm{C}_{27} \mathrm{H}_{25} \mathrm{~N}_{2}[\mathrm{M}+\mathrm{H}]^{+}: 377.2012$, found: 377.2014 .<smiles>Cc1cc(-c2ccccc2)c(-c2ccccc2)n2c1nc1ccccc12</smiles>

\section{4-Methyl-1,2-diphenylbenzo[4,5]imidazo[1,2-a]pyridine (146s)}

The general procedure $\mathbf{F}$ was followed using $145 \mathrm{~h}(63 \mathrm{mg}, 0.4 \mathrm{mmol}$ ) and $64 \mathrm{a}(143 \mathrm{mg}, 0.8$ $\mathrm{mmol})$ at $140{ }^{\circ} \mathrm{C}$ for $8 \mathrm{~h}$. Purification by column chromatography on silica gel $(n$-hexane/EtOAc $=$ 5:1) yielded 146s (68 $\mathrm{mg}, 51 \%)$ as a white solid. M.p.: $232{ }^{\circ} \mathrm{C} .{ }^{1} \mathrm{H}$ NMR $\left(300 \mathrm{MHz}, \mathrm{CDCl}_{3}\right): \delta=$ $7.98(\mathrm{~d}, J=8.0 \mathrm{~Hz}, 1 \mathrm{H}), 7.53-7.34(\mathrm{~m}, 7 \mathrm{H}), 7.26-7.15(\mathrm{~m}, 5 \mathrm{H}), 6.91(\mathrm{t}, J=7.8 \mathrm{~Hz}, 1 \mathrm{H}), 6.20$ $(\mathrm{d}, J=8.5 \mathrm{~Hz}, 1 \mathrm{H}), 2.82(\mathrm{~s}, 3 \mathrm{H}) .{ }^{13} \mathrm{C}$ NMR $\left(75 \mathrm{MHz}, \mathrm{CDCl}_{3}\right): \delta=149.3\left(\mathrm{C}_{\mathrm{q}}\right), 145.0\left(\mathrm{C}_{\mathrm{q}}\right), 138.2$ $\left(\mathrm{C}_{q}\right), 135.9\left(\mathrm{C}_{\mathrm{q}}\right), 133.3\left(\mathrm{C}_{\mathrm{q}}\right), 131.1(\mathrm{CH}), 130.7(\mathrm{CH}), 130.4\left(\mathrm{C}_{\mathrm{q}}\right), 130.0(\mathrm{CH}), 129.5(\mathrm{CH}), 129.0$ $(\mathrm{CH}), 127.9(\mathrm{CH}), 126.7(\mathrm{CH}), 126.1\left(\mathrm{C}_{\mathrm{q}}\right), 124.8(\mathrm{CH}), 124.5\left(\mathrm{C}_{\mathrm{q}}\right), 120.3(\mathrm{CH}), 119.7(\mathrm{CH}), 114.9$ (CH), $17.6\left(\mathrm{CH}_{3}\right)$. IR (ATR): 2149, 2096, 1476, 1448, 1382, 1361, 730, $699 \mathrm{~cm}^{-1}$. MS (ESI) m/z (relative intensity): $335(100)[\mathrm{M}+\mathrm{H}]^{+}, 357(10)[\mathrm{M}+\mathrm{Na}]^{+}$. HR-MS (ESI) m/z calc. for $\mathrm{C}_{24} \mathrm{H}_{19} \mathrm{~N}_{2}$ $[\mathrm{M}+\mathrm{H}]^{+}:$335.1543, found: 335.1541 . 


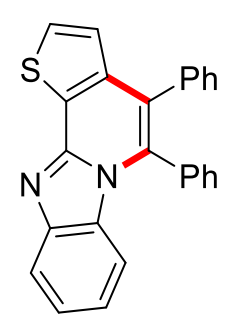

\section{4,5-Diphenylbenzo[4,5]imidazo[1,2-a]thieno[2,3-c]pyridine (146t)}

The general procedure $\mathbf{F}$ was followed using $145 \mathbf{i}(80 \mathrm{mg}, 0.4 \mathrm{mmol})$ and $64 \mathrm{a}(143 \mathrm{mg}, 0.8$ $\mathrm{mmol}$ ) at $140^{\circ} \mathrm{C}$ for $8 \mathrm{~h}$. Purification by column chromatography on silica gel $(n$-hexane/EtOAc $=$ 5:1) yielded 146t (108 mg, 72\%) as a white solid. M.p.: $255^{\circ} \mathrm{C}$. ${ }^{1} \mathbf{H} \mathbf{N M R}\left(300 \mathrm{MHz}, \mathrm{CDCl}_{3}\right): \delta=$ $7.97(\mathrm{dt}, J=8.2,1.0 \mathrm{~Hz}, 1 \mathrm{H}), 7.63(\mathrm{~d}, J=5.2 \mathrm{~Hz}, 1 \mathrm{H}), 7.50-7.34(\mathrm{~m}, 6 \mathrm{H}), 7.31-7.23(\mathrm{~m}, 5 \mathrm{H})$, $7.07(\mathrm{~d}, J=5.2 \mathrm{~Hz}, 1 \mathrm{H}), 6.93$ (ddd, $J=8.5,7.1,1.2 \mathrm{~Hz}, 1 \mathrm{H}$ ), 6.10 (dt, $J=8.5,0.9 \mathrm{~Hz}, 1 \mathrm{H}$ ). ${ }^{13} \mathrm{C}$ $\operatorname{NMR}\left(75 \mathrm{MHz}, \mathrm{CDCl}_{3}\right): \delta=145.2\left(\mathrm{C}_{\mathrm{q}}\right), 144.9\left(\mathrm{C}_{\mathrm{q}}\right), 140.3\left(\mathrm{C}_{\mathrm{q}}\right), 136.1\left(\mathrm{C}_{\mathrm{q}}\right), 135.0\left(\mathrm{C}_{\mathrm{q}}\right), 133.2\left(\mathrm{C}_{\mathrm{q}}\right)$, $130.8(\mathrm{CH}), 130.8(\mathrm{CH}), 130.7\left(\mathrm{C}_{\mathrm{q}}\right), 129.4(\mathrm{CH}), 129.2(\mathrm{CH}), 128.9(\mathrm{CH}), 128.0(\mathrm{CH}), 127.3(\mathrm{CH})$, $125.7\left(\mathrm{C}_{\mathrm{q}}\right), 125.3(\mathrm{CH}), 124.5(\mathrm{CH}), 121.5\left(\mathrm{C}_{\mathrm{q}}\right), 120.7(\mathrm{CH}), 119.4(\mathrm{CH}), 114.4(\mathrm{CH})$. IR (ATR): 2010, 1979, 1950, 1629, 1483, 1410, 733, $695 \mathrm{~cm}^{-1}$. MS (ESI) m/z (relative intensity): 377 (100) $[\mathrm{M}+\mathrm{H}]^{+}, 399(10)[\mathrm{M}+\mathrm{Na}]^{+}$. HR-MS (ESI) $\mathrm{m} / \mathrm{z}$ calc. for $\mathrm{C}_{25} \mathrm{H}_{17} \mathrm{~N}_{2} \mathrm{~S}[\mathrm{M}+\mathrm{H}]^{+}: 377.1107$, found: 377.1109. The analytical data correspond with those reported in the literature. ${ }^{[237]}$<smiles></smiles>

\section{5,6-Diphenylbenzo[4,5]imidazo[2,1-a]isoquinoline (148a)}

The general procedure $\mathbf{G}$ was followed using $147 \mathrm{a}(39 \mathrm{mg}, 0.2 \mathrm{mmol})$ and $64 \mathrm{a}(72 \mathrm{mg}, 0.4 \mathrm{mmol})$ at $100{ }^{\circ} \mathrm{C}$ for $4 \mathrm{~h}$. Purification by column chromatography on silica gel ( $n$-hexane/EtOAc $=5: 1$ ) yielded 148a (56 mg, $75 \%)$ as a white solid. M.p.: $275^{\circ} \mathrm{C}$. ${ }^{1} \mathbf{H ~ N M R ~}\left(300 \mathrm{MHz}, \mathrm{CDCl}_{3}\right): \delta=9.02$ (d, $J=8.3 \mathrm{~Hz}, 1 \mathrm{H}), 8.02(\mathrm{~d}, J=8.1 \mathrm{~Hz}, 1 \mathrm{H}), 7.71(\mathrm{t}, J=7.5 \mathrm{~Hz}, 1 \mathrm{H}), 7.59(\mathrm{t}, J=7.7 \mathrm{~Hz}, 1 \mathrm{H})$, $7.47-7.34(\mathrm{~m}, 7 \mathrm{H}), 7.33-7.23(\mathrm{~m}, 5 \mathrm{H}), 6.96(\mathrm{t}, J=7.8 \mathrm{~Hz}, 1 \mathrm{H}), 6.04(\mathrm{~d}, J=8.5 \mathrm{~Hz}, 1 \mathrm{H}) .{ }^{13} \mathrm{C}$ $\operatorname{NMR}\left(101 \mathrm{MHz}, \mathrm{CDCl}_{3}\right): \delta=147.8\left(\mathrm{C}_{\mathrm{q}}\right), 144.3\left(\mathrm{C}_{\mathrm{q}}\right), 135.7\left(\mathrm{C}_{\mathrm{q}}\right), 135.1\left(\mathrm{C}_{\mathrm{q}}\right), 133.7\left(\mathrm{C}_{\mathrm{q}}\right), 132.7\left(\mathrm{C}_{\mathrm{q}}\right)$, $131.5(\mathrm{CH}), 131.2\left(\mathrm{C}_{\mathrm{q}}\right), 130.6(\mathrm{CH}), 129.9(\mathrm{CH}), 129.2(\mathrm{CH}), 128.7(\mathrm{CH}), 128.0(\mathrm{CH}), 127.8(\mathrm{CH})$, $127.3(\mathrm{CH}), 126.4(\mathrm{CH}), 125.1(\mathrm{CH}), 124.1(\mathrm{CH}), 123.5\left(\mathrm{C}_{\mathrm{q}}\right), 122.9\left(\mathrm{C}_{\mathrm{q}}\right), 121.2(\mathrm{CH}), 119.6(\mathrm{CH})$, 114.1 (CH). IR (ATR): 2142, 2021, 1522, 1487, 1443, 1330, 744, $700 \mathrm{~cm}^{-1}$. MS (ESI) m/z (relative intensity): $371(100)[\mathrm{M}+\mathrm{H}]^{+}$. HR-MS (ESI) m/z calc. for $\mathrm{C}_{27} \mathrm{H}_{19} \mathrm{~N}_{2}[\mathrm{M}+\mathrm{H}]^{+}: 371.1543$, 
found: 371.1547. The analytical data correspond with those reported in the literature. ${ }^{[238]}$<smiles>Cc1ccc2c(c1)c(-c1ccccc1)c(-c1ccccc1)n1c3ccccc3nc21</smiles>

\section{3-Methyl-5,6-diphenylbenzo[4,5]imidazo[2,1-a]isoquinoline (148b)}

The general procedure $\mathbf{G}$ was followed using $147 \mathrm{~b}$ (42 $\mathrm{mg}, 0.2 \mathrm{mmol}$ ) and 64a (72 $\mathrm{mg}, 0.4 \mathrm{mmol})$ at $100{ }^{\circ} \mathrm{C}$ for $4 \mathrm{~h}$. Purification by column chromatography on silica gel ( $n$-hexane/EtOAc $=5: 1$ ) yielded 148b (40 mg, 52\%) as a white solid. M.p.: $264{ }^{\circ} \mathrm{C} .{ }^{1} \mathbf{H}$ NMR $\left(300 \mathrm{MHz} \mathrm{CDCl}_{3}\right): \delta=8.90$ $(\mathrm{d}, J=8.2 \mathrm{~Hz}, 1 \mathrm{H}), 7.99(\mathrm{~d}, J=8.5 \mathrm{~Hz}, 1 \mathrm{H}), 7.55$ (dd, $J=8.2,1.6 \mathrm{~Hz}, 1 \mathrm{H}), 7.45-7.33(\mathrm{~m}, 6 \mathrm{H})$, $7.33-7.28(\mathrm{~m}, 3 \mathrm{H}), 7.26-7.21(\mathrm{~m}, 2 \mathrm{H}), 7.13(\mathrm{~s}, 1 \mathrm{H}), 6.93(\mathrm{td}, J=8.4,1.1 \mathrm{~Hz}, 1 \mathrm{H}), 6.01(\mathrm{dd}, J$ $=8.5,0.9 \mathrm{~Hz}, 1 \mathrm{H}), 2.45(\mathrm{~s}, 3 \mathrm{H}) \cdot{ }^{13} \mathrm{C}$ NMR $\left(75 \mathrm{MHz}, \mathrm{CDCl}_{3}\right): \delta=148.0\left(\mathrm{C}_{\mathrm{q}}\right), 144.3\left(\mathrm{C}_{\mathrm{q}}\right), 140.3$ $\left(\mathrm{C}_{\mathrm{q}}\right), 135.8\left(\mathrm{C}_{\mathrm{q}}\right), 135.1\left(\mathrm{C}_{\mathrm{q}}\right), 133.8\left(\mathrm{C}_{\mathrm{q}}\right), 132.8\left(\mathrm{C}_{\mathrm{q}}\right), 131.5(\mathrm{CH}), 131.2\left(\mathrm{C}_{\mathrm{q}}\right), 130.7(\mathrm{CH}), 129.3$ $(\mathrm{CH}), 129.1(\mathrm{CH}), 128.7(\mathrm{CH}), 128.0(\mathrm{CH}), 127.2(\mathrm{CH}), 126.1(\mathrm{CH}), 125.0(\mathrm{CH}), 124.0(\mathrm{CH})$, $123.4\left(\mathrm{C}_{\mathrm{q}}\right), 121.0(\mathrm{CH}), 120.7\left(\mathrm{C}_{\mathrm{q}}\right), 119.4(\mathrm{CH}), 114.1(\mathrm{CH}), 22.0\left(\mathrm{CH}_{3}\right)$. IR (ATR): 2046, 1625, 1524, 1486, 1444, 1326, 1257, 819, $779 \mathrm{~cm}^{-1}$. MS (ESI) m/z (relative intensity): 385 (100) $[\mathrm{M}+\mathrm{H}]^{+}$. HR-MS (ESI) $\mathrm{m} / \mathrm{z}$ calc. for $\mathrm{C}_{28} \mathrm{H}_{21} \mathrm{~N}_{2}[\mathrm{M}+\mathrm{H}]^{+}:$385.1699, found: 385.1699. The analytical data correspond with those reported in the literature. ${ }^{[237]}$<smiles>COc1ccc2c(c1)c(-c1ccccc1)c(-c1ccccc1)n1c3ccccc3nc21</smiles>

\section{3-Methoxy-5,6-diphenylbenzo[4,5]imidazo[2,1-a]isoquinoline (148c)}

The general procedure $\mathbf{G}$ was followed using $147 \mathrm{c}(45 \mathrm{mg}, 0.2 \mathrm{mmol})$ and $64 \mathrm{a}$ (72 $\mathrm{mg}, 0.4 \mathrm{mmol})$ at $100{ }^{\circ} \mathrm{C}$ for $4 \mathrm{~h}$. Purification by column chromatography on silica gel ( $n$-hexane/EtOAc $=5: 1$ ) yielded $148 \mathrm{C}$ (48 mg, 60\%) as a white solid. M.p.: $235^{\circ} \mathrm{C} .{ }^{1} \mathbf{H}$ NMR $\left(400 \mathrm{MHz}, \mathrm{CDCl}_{3}\right): \delta=8.93$ $(\mathrm{d}, J=8.8 \mathrm{~Hz}, 1 \mathrm{H}), 7.97(\mathrm{~d}, J=8.1 \mathrm{~Hz}, 1 \mathrm{H}), 7.45-7.34(\mathrm{~m}, 6 \mathrm{H}), 7.34-7.26(\mathrm{~m}, 4 \mathrm{H}), 7.25-$ $7.22(\mathrm{~m}, 2 \mathrm{H}), 6.92(\mathrm{t}, J=7.7 \mathrm{~Hz}, 1 \mathrm{H}), 6.76(\mathrm{~d}, J=2.5 \mathrm{~Hz}, 1 \mathrm{H}), 6.00(\mathrm{~d}, J=8.5 \mathrm{~Hz}, 1 \mathrm{H}), 3.77$ (s, 
3H). ${ }^{13} \mathrm{C}$ NMR $\left(101 \mathrm{MHz}, \mathrm{CDCl}_{3}\right): \delta=161.0\left(\mathrm{C}_{\mathrm{q}}\right), 148.0\left(\mathrm{C}_{\mathrm{q}}\right), 144.4\left(\mathrm{C}_{\mathrm{q}}\right), 135.7\left(\mathrm{C}_{\mathrm{q}}\right), 135.6\left(\mathrm{C}_{\mathrm{q}}\right)$, $134.6\left(\mathrm{C}_{\mathrm{q}}\right), 133.8\left(\mathrm{C}_{\mathrm{q}}\right), 131.4(\mathrm{CH}), 131.2\left(\mathrm{C}_{\mathrm{q}}\right), 130.6(\mathrm{CH}), 129.2(\mathrm{CH}), 128.7(\mathrm{CH}), 128.1(\mathrm{CH})$, $127.3(\mathrm{CH}), 127.0(\mathrm{CH}), 124.0(\mathrm{CH}), 123.2\left(\mathrm{C}_{\mathrm{q}}\right), 120.8(\mathrm{CH}), 119.2(\mathrm{CH}), 116.8\left(\mathrm{C}_{\mathrm{q}}\right), 116.4(\mathrm{CH})$, $114.0(\mathrm{CH}), 108.8(\mathrm{CH}), 55.3\left(\mathrm{CH}_{3}\right)$. IR (ATR): 2138, 1609, 1464, 1444, 1221, 725, 696, 567 $\mathrm{cm}^{-1}$. MS (ESI) m/z (relative intensity): 401 (100) [M+H] $]^{+}$. HR-MS (ESI) m/z calc. for $\mathrm{C}_{28} \mathrm{H}_{21} \mathrm{~N}_{2} \mathrm{O}$ $[\mathrm{M}+\mathrm{H}]^{+}: 401.1648$, found: 401.1649 . The analytical data correspond with those reported in the literature. ${ }^{[238]}$<smiles>FC(F)(F)c1ccc2c(c1)c(-c1ccccc1)c(-c1ccccc1)n1c3ccccc3nc21</smiles>

\section{5,6-Diphenyl-3-(trifluoromethyl)benzo[4,5]imidazo[2,1-a]isoquinoline (148d)}

The general procedure $\mathbf{G}$ was followed using $147 \mathrm{~d}(52 \mathrm{mg}, 0.2 \mathrm{mmol})$ and $64 \mathrm{a}(72 \mathrm{mg}, 0.4 \mathrm{mmol})$ at $100{ }^{\circ} \mathrm{C}$ for $4 \mathrm{~h}$. Purification by column chromatography on silica gel ( $n$-hexane/EtOAc $=5: 1$ ) yielded 148d (69 mg, 79\%) as a white solid. M.p.: $240{ }^{\circ} \mathrm{C} .{ }^{1} \mathrm{H}$ NMR $\left(300 \mathrm{MHz}, \mathrm{CDCl}_{3}\right): \delta=9.13$ (d, $J=8.4 \mathrm{~Hz}, 1 \mathrm{H}$ ), 8.04 (dt, $J=8.2,1.0 \mathrm{~Hz}, 1 \mathrm{H}), 7.92$ (ddd, $J=8.4,1.8,0.6 \mathrm{~Hz}, 1 \mathrm{H}$ ), 7.63 (dt, $J$ $=1.7,0.8 \mathrm{~Hz}, 1 \mathrm{H}), 7.50-7.40(\mathrm{~m}, 4 \mathrm{H}), 7.39-7.30(\mathrm{~m}, 5 \mathrm{H}), 7.26-7.20(\mathrm{~m}, 2 \mathrm{H}), 7.01$ (ddd, $J=$ 8.5, 7.2, $1.2 \mathrm{~Hz}, 1 \mathrm{H}), 6.05(\mathrm{dt}, J=8.5,0.9 \mathrm{~Hz}, 1 \mathrm{H}) .{ }^{13} \mathrm{C} \mathrm{NMR}\left(101 \mathrm{MHz}, \mathrm{CDCl}_{3}\right): \delta=146.8\left(\mathrm{C}_{\mathrm{q}}\right)$, $144.4\left(\mathrm{C}_{\mathrm{q}}\right), 136.7\left(\mathrm{C}_{\mathrm{q}}\right), 134.8\left(\mathrm{C}_{\mathrm{q}}\right), 133.4\left(\mathrm{C}_{\mathrm{q}}\right), 132.6\left(\mathrm{C}_{\mathrm{q}}\right), 131.6\left(\mathrm{q},{ }^{2} \mathrm{~J}_{\mathrm{C}-\mathrm{F}}=32 \mathrm{~Hz}, \mathrm{C}_{\mathrm{q}}\right), 131.5(\mathrm{CH})$, $131.3\left(\mathrm{C}_{\mathrm{q}}\right), 130.6(\mathrm{CH}), 129.7(\mathrm{CH}), 129.0(\mathrm{CH}), 128.5(\mathrm{CH}), 127.9(\mathrm{CH}), 126.1(\mathrm{CH}), 125.4\left(\mathrm{C}_{\mathrm{q}}\right)$, $124.7(\mathrm{CH}), 124.1$ (q, $\left.{ }^{1} \mathrm{~J}_{\mathrm{C}-\mathrm{F}}=273 \mathrm{~Hz}, \mathrm{C}_{\mathrm{q}}\right), 124.0\left(\mathrm{q},{ }^{3} \mathrm{~J}_{\mathrm{C}-\mathrm{F}}=3 \mathrm{~Hz}, \mathrm{CH}\right), 123.6$ (q, $\left.{ }^{3} \mathrm{~J}_{\mathrm{C}-\mathrm{F}}=4 \mathrm{~Hz}, \mathrm{CH}\right)$, $123.3\left(\mathrm{C}_{\mathrm{q}}\right), 122.1(\mathrm{CH}), 120.1(\mathrm{CH}), 114.5(\mathrm{CH}) .{ }^{19} \mathrm{~F}$ NMR $\left(377 \mathrm{MHz}, \mathrm{CDCl}_{3}\right): \delta=-62.5(\mathrm{~s})$. IR (ATR): 1450, 1432, 1416, 1321, 1167, 1122, 1065, 1017, 850, $744 \mathrm{~cm}^{-1}$. MS (ESI) m/z (relative intensity): $439(100)[\mathrm{M}+\mathrm{H}]^{+}$. HR-MS (ESI) $\mathrm{m} / \mathrm{z}$ calc. for $\mathrm{C}_{28} \mathrm{H}_{18} \mathrm{~F}_{3} \mathrm{~N}_{2}[\mathrm{M}+\mathrm{H}]^{+}: 439.1422$ found: 439.1417. The analytical data correspond with those reported in the literature. ${ }^{[238]}$ 
<smiles>Fc1ccc2c(c1)c(-c1ccccc1)c(-c1ccccc1)n1c3ccccc3nc21</smiles>

\section{3-Fluoro-5,6-diphenylbenzo[4,5]imidazo[2,1-a]isoquinoline (148e)}

The general procedure $\mathbf{G}$ was followed using $147 \mathrm{e}(42 \mathrm{mg}, 0.2 \mathrm{mmol})$ and $64 \mathrm{a}(72 \mathrm{mg}, 0.4 \mathrm{mmol})$ at $100{ }^{\circ} \mathrm{C}$ for $4 \mathrm{~h}$. Purification by column chromatography on silica gel ( $n$-hexane/EtOAc $\left.=5: 1\right)$ yielded 148e (60 mg, 77\%) as a white solid. M.p.: $251^{\circ} \mathrm{C} .{ }^{1} \mathbf{H}$ NMR $\left(300 \mathrm{MHz}, \mathrm{CDCl}_{3}\right): \delta=9.00$ (dd, $J=8.9,5.7 \mathrm{~Hz}, 1 \mathrm{H}), 7.99(\mathrm{dt}, J=8.2,0.9 \mathrm{~Hz}, 1 \mathrm{H}), 7.50-7.28(\mathrm{~m}, 10 \mathrm{H}), 7.26-7.19(\mathrm{~m}, 2 \mathrm{H})$, $7.01(\mathrm{dd}, J=10.4,2.5 \mathrm{~Hz}, 1 \mathrm{H}), 6.95(\mathrm{t}, J=8.4 \mathrm{~Hz}, 1 \mathrm{H}), 6.02(\mathrm{dt}, J=8.5,0.9 \mathrm{~Hz}, 1 \mathrm{H}) .{ }^{13} \mathrm{C} \mathrm{NMR}$ $\left(75 \mathrm{MHz}, \mathrm{CDCl}_{3}\right): \delta=163.7\left(\mathrm{~d},{ }^{1} \mathrm{~J}_{\mathrm{C}-\mathrm{F}}=248 \mathrm{~Hz}, \mathrm{C}_{\mathrm{q}}\right), 147.3\left(\mathrm{C}_{\mathrm{q}}\right), 144.3\left(\mathrm{C}_{\mathrm{q}}\right), 136.3\left(\mathrm{C}_{\mathrm{q}}\right), 135.1\left(\mathrm{C}_{\mathrm{q}}\right)$, $134.8\left(\mathrm{~d},{ }^{3} J_{\mathrm{C}-\mathrm{F}}=9.1 \mathrm{~Hz}, \mathrm{C}_{\mathrm{q}}\right), 133.4\left(\mathrm{C}_{\mathrm{q}}\right), 131.4(\mathrm{CH}), 131.1\left(\mathrm{C}_{\mathrm{q}}\right), 130.5(\mathrm{CH}), 129.4(\mathrm{CH}), 128.8$ $(\mathrm{CH}), 128.2(\mathrm{CH}), 127.7\left(\mathrm{~d},{ }^{3} \mathrm{~J}_{\mathrm{C}-\mathrm{F}}=9.3 \mathrm{~Hz}, \mathrm{CH}\right), 127.6(\mathrm{CH}), 124.3(\mathrm{CH}), 122.9\left(\mathrm{~d},{ }^{4} \mathrm{~J}_{\mathrm{C}-\mathrm{F}}=3.4 \mathrm{~Hz}\right.$, $\left.\mathrm{C}_{\mathrm{q}}\right), 121.3(\mathrm{CH}), 119.5(\mathrm{CH}), 119.5\left(\mathrm{C}_{\mathrm{q}}\right), 116.4\left(\mathrm{~d},{ }^{2} \mathrm{~J}_{\mathrm{C}-\mathrm{F}}=24 \mathrm{~Hz}, \mathrm{CH}\right), 114.1(\mathrm{CH}), 111.7\left(\mathrm{~d},{ }^{2} \mathrm{~J}_{\mathrm{C}-\mathrm{F}}=\right.$ $23 \mathrm{~Hz}, \mathrm{CH}) .{ }^{19} \mathrm{~F}$ NMR (282 MHz, $\left.\mathrm{CDCl}_{3}\right): \delta=-108.3$ (s). IR (ATR): 2140, 2014, 1467, 1444, 1324, 1267, 1201, $730 \mathrm{~cm}^{-1}$. MS (ESI) m/z (relative intensity): 389 (100) [M+H] ${ }^{+}$. HR-MS (ESI) m/z calc. for $\mathrm{C}_{27} \mathrm{H}_{18} \mathrm{~N}_{2} \mathrm{~F}[\mathrm{M}+\mathrm{H}]^{+}:$389.1449, found: 389.1447 . The characterization data correspond with those reported in the literature. ${ }^{[237]}$<smiles>Clc1ccc2c(-c3ccccc3)c(-c3ccccc3)n3c4ccccc4nc3c2c1</smiles>

\section{3-Chloro-5,6-diphenylbenzo[4,5]imidazo[2,1-a]isoquinoline (148f)}

The general procedure $\mathbf{G}$ was followed using $147 \mathrm{f}(46 \mathrm{mg}, 0.2 \mathrm{mmol})$ and $64 \mathrm{a}$ (72 $\mathrm{mg}, 0.4 \mathrm{mmol})$ at $100{ }^{\circ} \mathrm{C}$ for $4 \mathrm{~h}$. Purification by column chromatography on silica gel ( $n$-hexane/EtOAc $=5: 1$ ) yielded $148 \mathrm{f}$ (55 mg, 68\%) as a white solid. M.p.: $295{ }^{\circ} \mathrm{C} .{ }^{1} \mathbf{H}$ NMR $\left(400 \mathrm{MHz}, \mathrm{CDCl}_{3}\right): \delta=8.94$ $(\mathrm{d}, J=8.6 \mathrm{~Hz}, 1 \mathrm{H}), 8.00(\mathrm{~d}, J=8.2 \mathrm{~Hz}, 1 \mathrm{H}), 7.67(\mathrm{~d}, J=8.6 \mathrm{~Hz}, 1 \mathrm{H}), 7.49-7.38(\mathrm{~m}, 4 \mathrm{H}), 7.38-$ $7.29(\mathrm{~m}, 6 \mathrm{H}), 7.26-7.18(\mathrm{~m}, 2 \mathrm{H}), 6.97(\mathrm{t}, J=7.8 \mathrm{~Hz}, 1 \mathrm{H}), 6.02(\mathrm{~d}, J=8.5 \mathrm{~Hz}, 1 \mathrm{H}) .{ }^{13} \mathrm{C} \mathrm{NMR}$ $\left(101 \mathrm{MHz}, \mathrm{CDCl}_{3}\right): \delta=147.1\left(\mathrm{C}_{\mathrm{q}}\right), 144.3\left(\mathrm{C}_{\mathrm{q}}\right), 136.4\left(\mathrm{C}_{\mathrm{q}}\right), 136.2\left(\mathrm{C}_{\mathrm{q}}\right), 134.9\left(\mathrm{C}_{\mathrm{q}}\right), 133.9\left(\mathrm{C}_{\mathrm{q}}\right)$, 
$133.4\left(\mathrm{C}_{q}\right), 131.4(\mathrm{CH}), 131.1\left(\mathrm{C}_{\mathrm{q}}\right), 130.4(\mathrm{CH}), 129.4(\mathrm{CH}), 128.8(\mathrm{CH}), 128.3(\mathrm{CH}), 128.2(\mathrm{CH})$, $127.6(\mathrm{CH}), 126.7(\mathrm{CH}), 125.7(\mathrm{CH}), 124.4(\mathrm{CH}), 122.6\left(\mathrm{C}_{\mathrm{q}}\right), 121.5(\mathrm{CH}), 121.3\left(\mathrm{C}_{\mathrm{q}}\right), 119.6(\mathrm{CH})$, 114.2 (CH). IR (ATR): 2141, 2046, 2022, 1920, 1444, 733, $710 \mathrm{~cm}^{-1}$. MS (ESI) m/z (relative intensity): 405 (100) [M+H] $]^{+}, 371$ (10). HR-MS (ESI) m/z calc. for $\mathrm{C}_{27} \mathrm{H}_{18} \mathrm{~N}_{2}{ }^{35} \mathrm{Cl}[\mathrm{M}+\mathrm{H}]^{+}:$405.1153, found: 405.1156 . The analytical data correspond with those reported in the literature. ${ }^{[237]}$<smiles>Brc1ccc2c(c1)c(-c1ccccc1)c(-c1ccccc1)n1c3ccccc3nc21</smiles>

\section{3-Bromo-5,6-diphenylbenzo[4,5]imidazo[2,1-a]isoquinoline (148g)}

The general procedure $\mathbf{G}$ was followed using $\mathbf{1 4 7 g}(55 \mathrm{mg}, 0.2 \mathrm{mmol})$ and $64 \mathrm{a}(72 \mathrm{mg}, 0.4 \mathrm{mmol})$ at $100{ }^{\circ} \mathrm{C}$ for $4 \mathrm{~h}$. Purification by column chromatography on silica gel ( $n$-hexane/EtOAc $\left.=5: 1\right)$ yielded $\mathbf{1 4 8 g}$ (48 mg, 53\%) as a white solid. M.p.: $297{ }^{\circ} \mathrm{C} .{ }^{1} \mathbf{H}$ NMR $\left(400 \mathrm{MHz}, \mathrm{CDCl}_{3}\right): \delta=8.87$ (d, $J=8.5 \mathrm{~Hz}, 1 \mathrm{H}$ ), 7.99 (dd, $J=8.2,1.0 \mathrm{~Hz}, 1 \mathrm{H}), 7.81$ (d, $J=8.7 \mathrm{~Hz}, 1 \mathrm{H}), 7.49(\mathrm{~s}, 1 \mathrm{H}), 7.46-$ $7.38(\mathrm{~m}, 4 \mathrm{H}), 7.37-7.29(\mathrm{~m}, 5 \mathrm{H}), 7.24-7.19(\mathrm{~m}, 2 \mathrm{H}), 6.97$ (t, $J=8.4 \mathrm{~Hz}, 1 \mathrm{H}), 6.02$ (dd, J = 8.6, $0.9 \mathrm{~Hz}, 1 \mathrm{H}) .{ }^{13} \mathrm{C}$ NMR $\left(101 \mathrm{MHz}, \mathrm{CDCl}_{3}\right): \delta=147.2\left(\mathrm{C}_{\mathrm{q}}\right), 144.3\left(\mathrm{C}_{\mathrm{q}}\right), 136.4\left(\mathrm{C}_{\mathrm{q}}\right), 134.9\left(\mathrm{C}_{\mathrm{q}}\right)$, $134.1\left(\mathrm{C}_{\mathrm{q}}\right), 133.4\left(\mathrm{C}_{\mathrm{q}}\right), 131.4(\mathrm{CH}), 131.1\left(\mathrm{C}_{\mathrm{q}}\right), 131.0(\mathrm{CH}), 130.5(\mathrm{CH}), 129.4(\mathrm{CH}), 128.8(\mathrm{CH})$, $128.8(\mathrm{CH}), 128.2(\mathrm{CH}), 127.6(\mathrm{CH}), 126.7(\mathrm{CH}), 124.6\left(\mathrm{C}_{\mathrm{q}}\right), 124.4(\mathrm{CH}), 122.5\left(\mathrm{C}_{\mathrm{q}}\right), 121.6\left(\mathrm{C}_{\mathrm{q}}\right)$, $121.6(\mathrm{CH}), 119.7(\mathrm{CH}), 114.2(\mathrm{CH})$. IR (ATR): 3049, 1599, 1486, 1443, 1417, 1324, 732, 702 $\mathrm{cm}^{-1}$. MS (ESI) m/z (relative intensity): 449 (100) [M+H] $]^{+}, 631$ (30). HR-MS (ESI) m/z calc. for $\mathrm{C}_{27} \mathrm{H}_{18} \mathrm{~N}_{2}{ }^{79} \mathrm{Br}[\mathrm{M}+\mathrm{H}]^{+}:$449.0648, found: 449.0647 . The analytical data correspond with those reported in the literature. ${ }^{[237]}$<smiles>CCN(CC)c1ccc2c(c1)c(-c1ccccc1)c(-c1ccccc1)n1c3ccccc3nc21</smiles>

\section{$\mathrm{N}, \mathrm{N}$-Diethyl-5,6-diphenylbenzo[4,5]imidazo[2,1-a]isoquinolin-3-amine (148h)}

The general procedure $\mathbf{G}$ was followed using $147 \mathrm{~h}(53 \mathrm{mg}, 0.2 \mathrm{mmol})$ and $64 \mathrm{a}(72 \mathrm{mg}, 0.4 \mathrm{mmol})$ 
at $100{ }^{\circ} \mathrm{C}$ for $4 \mathrm{~h}$. Purification by column chromatography on silica gel $(n$-hexane/EtOAc $=5: 1$ ) yielded $148 \mathrm{~h}(60 \mathrm{mg}, 68 \%)$ as a white solid. M.p.: $260{ }^{\circ} \mathrm{C}$. ${ }^{1} \mathrm{H}$ NMR $\left(400 \mathrm{MHz}, \mathrm{CDCl}_{3}\right): \delta=8.78$ (d, $J=9.0 \mathrm{~Hz}, 1 \mathrm{H}), 7.91(\mathrm{~d}, J=8.1 \mathrm{~Hz}, 1 \mathrm{H}), 7.43-7.34(\mathrm{~m}, 5 \mathrm{H}), 7.33-7.28(\mathrm{~m}, 3 \mathrm{H}), 7.26-$ $7.22(\mathrm{~m}, 3 \mathrm{H}), 7.10(\mathrm{dd}, J=9.1,2.6 \mathrm{~Hz}, 1 \mathrm{H}), 6.86(\mathrm{t}, J=7.3 \mathrm{~Hz}, 1 \mathrm{H}), 6.35(\mathrm{~d}, J=2.6 \mathrm{~Hz}, 1 \mathrm{H})$, $5.95(\mathrm{~d}, J=8.4 \mathrm{~Hz}, 1 \mathrm{H}), 3.32(\mathrm{q}, J=7.1 \mathrm{~Hz}, 4 \mathrm{H}), 1.10$ (t, $J=7.0 \mathrm{~Hz}, 6 \mathrm{H}) .{ }^{13} \mathrm{C}$ NMR $(101 \mathrm{MHz}$, $\left.\mathrm{CDCl}_{3}\right): \delta=148.8\left(\mathrm{C}_{\mathrm{q}}\right), 148.8\left(\mathrm{C}_{\mathrm{q}}\right), 144.7\left(\mathrm{C}_{\mathrm{q}}\right), 136.3\left(\mathrm{C}_{\mathrm{q}}\right), 135.0\left(\mathrm{C}_{\mathrm{q}}\right), 134.8\left(\mathrm{C}_{\mathrm{q}}\right), 134.2\left(\mathrm{C}_{\mathrm{q}}\right)$, $131.5(\mathrm{CH}), 131.3\left(\mathrm{C}_{\mathrm{q}}\right), 130.7(\mathrm{CH}), 129.0(\mathrm{CH}), 128.6(\mathrm{CH}), 127.8(\mathrm{CH}), 127.0(\mathrm{CH}), 126.6(\mathrm{CH})$, $123.6(\mathrm{CH}), 123.4\left(\mathrm{C}_{\mathrm{q}}\right), 120.0(\mathrm{CH}), 118.7(\mathrm{CH}), 113.7(\mathrm{CH}), 113.4(\mathrm{CH}), 111.9\left(\mathrm{C}_{\mathrm{q}}\right), 106.2(\mathrm{CH})$, $44.6\left(\mathrm{CH}_{2}\right), 12.4\left(\mathrm{CH}_{3}\right)$. IR (ATR): 3051, 2972, 1626, 1604, 1484, 1442, 1253, 1073, $700 \mathrm{~cm}^{-1}$. MS (ESI) m/z (relative intensity): $442(100)[M+H]^{+}$. HR-MS (ESI) $\mathrm{m} / \mathbf{z}$ calc. for $\mathrm{C}_{31} \mathrm{H}_{28} \mathrm{~N}_{3}[\mathrm{M}+\mathrm{H}]^{+}$: 442.2278, found: 442.2279. The analytical data correspond with those reported in the literature. ${ }^{[237]}$

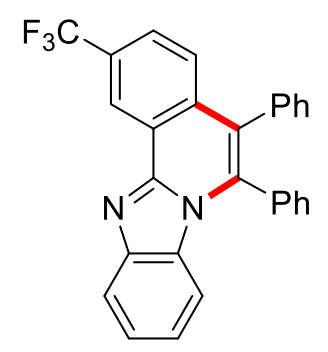

\section{5,6-Diphenyl-2-(trifluoromethyl)benzo[4,5]imidazo[2,1-a]isoquinoline (148i)}

The general procedure $\mathbf{G}$ was followed using $147 \mathbf{i}(52 \mathrm{mg}, 0.2 \mathrm{mmol})$ and $64 \mathrm{a}(72 \mathrm{mg}, 0.4 \mathrm{mmol})$ at $100{ }^{\circ} \mathrm{C}$ for $4 \mathrm{~h}$. Purification by column chromatography on silica gel $(n$-hexane/EtOAc $=5: 1)$ yielded 148i (45 mg, 51\%) as a white solid. M.p.: $285^{\circ} \mathrm{C} .{ }^{1} \mathbf{H} \mathbf{~ N M R}\left(400 \mathrm{MHz}, \mathrm{CDCl}_{3}\right): \delta=9.32$ $(\mathrm{d}, J=2.0 \mathrm{~Hz}, 1 \mathrm{H}), 8.03$ (d, $J=8.2 \mathrm{~Hz}, 1 \mathrm{H}), 7.77$ (dd, $J=8.6,1.8 \mathrm{~Hz}, 1 \mathrm{H}), 7.50-7.37(\mathrm{~m}, 7 \mathrm{H})$, $7.36-7.29(\mathrm{~m}, 3 \mathrm{H}), 7.26-7.22(\mathrm{~m}, 2 \mathrm{H}), 6.99$ (ddd, $J=8.4,7.2,1.3 \mathrm{~Hz}, 1 \mathrm{H}), 6.05$ (d, J = 8.5 Hz, 1H). ${ }^{13} \mathrm{C}$ NMR $\left(101 \mathrm{MHz}, \mathrm{CDCl}_{3}\right): \delta=146.9\left(\mathrm{C}_{\mathrm{q}}\right), 144.2\left(\mathrm{C}_{\mathrm{q}}\right), 137.2\left(\mathrm{C}_{\mathrm{q}}\right), 135.0\left(\mathrm{C}_{\mathrm{q}}\right), 134.8\left(\mathrm{C}_{\mathrm{q}}\right)$, $133.2\left(\mathrm{C}_{\mathrm{q}}\right), 131.4(\mathrm{CH}), 131.1\left(\mathrm{C}_{\mathrm{q}}\right), 130.4(\mathrm{CH}), 129.6\left(\mathrm{q},{ }^{2} \mathrm{~J}_{\mathrm{C}-\mathrm{F}}=33 \mathrm{~Hz}, \mathrm{C}_{\mathrm{q}}\right), 129.5(\mathrm{CH}), 128.9$ $(\mathrm{CH}), 128.3(\mathrm{CH}), 127.6(\mathrm{CH}), 127.2(\mathrm{CH}), 125.8\left(\mathrm{q},{ }^{3} \mathrm{~J}-\mathrm{F}=3.4 \mathrm{~Hz}, \mathrm{CH}\right), 124.6(\mathrm{CH}), 124.0(\mathrm{q}$, $\left.{ }^{1} \mathrm{~J}_{\mathrm{C}-\mathrm{F}}=272 \mathrm{~Hz}, \mathrm{C}_{\mathrm{q}}\right), 122.8\left(\mathrm{C}_{\mathrm{q}}\right), 122.8\left(\mathrm{C}_{\mathrm{q}}\right), 122.6\left(\mathrm{q},{ }^{3} \mathrm{~J}_{\mathrm{C}-\mathrm{F}}=4.1 \mathrm{~Hz}, \mathrm{CH}\right), 121.9(\mathrm{CH}), 119.8(\mathrm{CH})$, $114.3(\mathrm{CH}) .{ }^{19} \mathrm{~F}$ NMR $\left(377 \mathrm{MHz}, \mathrm{CDCl}_{3}\right): \delta=-62.16$ (s). IR (ATR): 2270, 2149, 1977, 1948, 1474 , 1070, 1011, 732, $700 \mathrm{~cm}^{-1}$. MS (ESI) m/z (relative intensity): 439 (100) [M+H] $]^{+}$. HR-MS (ESI) $\mathrm{m} / \mathrm{z}$ calc. for $\mathrm{C}_{28} \mathrm{H}_{18} \mathrm{~N}_{2} \mathrm{~F}_{3}[\mathrm{M}+\mathrm{H}]^{+}: 439.1417$, found: 439.1417 . The analytical data correspond with those reported in the literature. ${ }^{[237]}$ 
<smiles>c1ccc(-c2c(-c3ccccc3)n3c4ccccc4nc3c3c2ccc2ccccc23)cc1</smiles>

\section{7,8-Diphenylbenzo[h]benzo[4,5]imidazo[2,1-a]isoquinoline (148j)}

The general procedure $\mathbf{G}$ was followed using 147j (49 mg, $0.2 \mathrm{mmol}$ ) and 64a (72 mg, $0.4 \mathrm{mmol})$ at $100{ }^{\circ} \mathrm{C}$ for $4 \mathrm{~h}$. Purification by column chromatography on silica gel ( $n$-hexane/EtOAc $=5: 1$ ) yielded 148j (45 mg, 54\%) as a white solid. M.p.: $236{ }^{\circ} \mathrm{C} .{ }^{1} \mathbf{H} \mathbf{N M R}\left(400 \mathrm{MHz}, \mathrm{CDCl}_{3}\right): \delta=11.17$ $(\mathrm{d}, J=8.5 \mathrm{~Hz}, 1 \mathrm{H}), 8.16(\mathrm{t}, J=8.1 \mathrm{~Hz}, 1 \mathrm{H}), 8.06-7.94(\mathrm{~m}, 3 \mathrm{H}), 7.76(\mathrm{t}, J=7.6 \mathrm{~Hz}, 1 \mathrm{H}), 7.51-$ $7.38(\mathrm{~m}, 7 \mathrm{H}), 7.37-7.29(\mathrm{~m}, 5 \mathrm{H}), 6.99(\mathrm{t}, J=7.8 \mathrm{~Hz}, 1 \mathrm{H}), 6.12(\mathrm{~d}, J=8.4 \mathrm{~Hz}, 1 \mathrm{H}) .{ }^{13} \mathrm{C} \mathrm{NMR}$ $\left(101 \mathrm{MHz}, \mathrm{CDCl}_{3}\right): \delta=147.9\left(\mathrm{C}_{\mathrm{q}}\right), 144.7\left(\mathrm{C}_{\mathrm{q}}\right), 136.4\left(\mathrm{C}_{\mathrm{q}}\right), 136.1\left(\mathrm{C}_{\mathrm{q}}\right), 134.0\left(\mathrm{C}_{\mathrm{q}}\right), 132.6$ (overlapped, $\mathrm{C}_{\mathrm{q}}$ ), $132.4\left(\mathrm{C}_{\mathrm{q}}\right), 131.7(\mathrm{CH}), 130.8(\mathrm{CH}), 130.6$ (overlapped, $\left.\mathrm{CH}\right), 130.2\left(\mathrm{C}_{\mathrm{q}}\right), 129.9$ $\left(\mathrm{C}_{\mathrm{q}}\right), 129.2(\mathrm{CH}), 128.8(\mathrm{CH}), 128.3(\mathrm{CH}), 128.2(\mathrm{CH}), 128.1(\mathrm{CH}), 127.3(\mathrm{CH}), 126.8(\mathrm{CH})$, $124.3(\mathrm{CH}), 124.0(\mathrm{CH}), 121.1(\mathrm{CH}), 119.9(\mathrm{CH}), 118.1\left(\mathrm{C}_{\mathrm{q}}\right), 114.4(\mathrm{CH})$. IR (ATR): 2905, 1745, 1590, 1481, 1447, 1377, 1175, 825, $730 \mathrm{~cm}^{-1}$. MS (ESI) m/z (relative intensity): 421 (100) $[\mathrm{M}+\mathrm{H}]^{+}$. HR-MS (ESI) $\mathrm{m} / \mathrm{z}$ calc. for $\mathrm{C}_{31} \mathrm{H}_{21} \mathrm{~N}_{2}[\mathrm{M}+\mathrm{H}]^{+}:$421.1699, found: 421.1699. The analytical data correspond with those reported in the literature. ${ }^{[237]}$

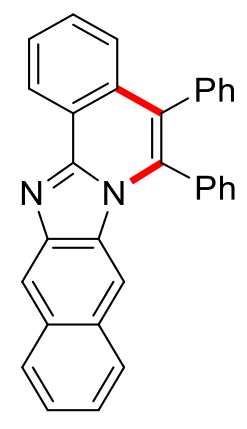

\section{5,6-Diphenylnaphtho[2',3':4,5]imidazo[2,1-a]isoquinoline (148k)}

The general procedure $\mathbf{G}$ was followed using $147 \mathrm{k}(49 \mathrm{mg}, 0.2 \mathrm{mmol})$ and $64 \mathrm{a}$ (72 $\mathrm{mg}, 0.4 \mathrm{mmol})$ at $100{ }^{\circ} \mathrm{C}$ for $4 \mathrm{~h}$. Purification by column chromatography on silica gel ( $n$-hexane/EtOAc $=5: 1$ ) yielded 148k (42 mg, 50\%) as a white solid. M.p.: $287^{\circ} \mathrm{C} .{ }^{1} \mathbf{H} \mathbf{N M R}\left(300 \mathrm{MHz}, \mathrm{CDCl}_{3}\right): \delta=9.18$ $(\mathrm{d}, J=7.9 \mathrm{~Hz}, 1 \mathrm{H}), 8.49$ (s, $1 \mathrm{H}), 8.03(\mathrm{~d}, J=8.4 \mathrm{~Hz}, 1 \mathrm{H}), 7.77(\mathrm{t}, J=7.5 \mathrm{~Hz}, 1 \mathrm{H}), 7.68(\mathrm{t}, J=7.7$ $\mathrm{Hz}, 1 \mathrm{H}), 7.59-7.38(\mathrm{~m}, 8 \mathrm{H}), 7.37-7.26(\mathrm{~m}, 6 \mathrm{H}), 6.40(\mathrm{~s}, 1 \mathrm{H}) \cdot{ }^{13} \mathrm{C}$ NMR $\left(75 \mathrm{MHz}, \mathrm{CDCl}_{3}\right): \delta=$ $135.5\left(\mathrm{C}_{\mathrm{q}}\right), 135.2$ (overlapped, $\left.\mathrm{C}_{\mathrm{q}}\right), 133.8\left(\mathrm{C}_{\mathrm{q}}\right), 133.4\left(\mathrm{C}_{\mathrm{q}}\right), 131.5(\mathrm{CH}), 131.4(\mathrm{CH}), 131.3\left(\mathrm{C}_{\mathrm{q}}\right)$, 131.2 (overlapped, $\mathrm{C}_{\mathrm{q}}$ ), $130.7(\mathrm{CH}), 129.5(\mathrm{CH}), 129.0$ (overlapped, $\mathrm{C}_{\mathrm{q}}$ ), $128.9(\mathrm{CH}), 128.4(\mathrm{CH})$, $128.2(\mathrm{CH}), 128.2(\mathrm{CH}), 127.8(\mathrm{CH}), 127.5(\mathrm{CH}), 126.5(\mathrm{CH}), 126.1(\mathrm{CH}), 124.8(\mathrm{CH}), 124.0$ $(\mathrm{CH}), 121.6\left(\mathrm{C}_{q}\right), 115.0(\mathrm{CH}), 111.8(\mathrm{CH})$. IR (ATR): 2196, 1528, 1487, 1439, 1254, 859, 769, 
729, $696 \mathrm{~cm}^{-1}$. MS (ESI) m/z (relative intensity): 421 (100) [M+H] $]^{+}, 381$ (10). HR-MS (ESI) m/z calc. for $\mathrm{C}_{31} \mathrm{H}_{21} \mathrm{~N}_{2}[\mathrm{M}+\mathrm{H}]^{+}:$: 21.1699 , found: 421.1700 .<smiles>Cc1cc2nc3c4ccc(C(F)(F)F)cc4c(-c4ccccc4)c(-c4ccccc4)n3c2cc1C</smiles>

\section{9,10-Dimethyl-5,6-diphenyl-3-(trifluoromethyl)benzo[4,5]imidazo[2,1-a]isoquinoline (148I)}

The general procedure $\mathbf{G}$ was followed using $147 \mathrm{I}(58 \mathrm{mg}, 0.2 \mathrm{mmol}$ ) and $64 \mathrm{a}(72 \mathrm{mg}, 0.4 \mathrm{mmol})$ at $100{ }^{\circ} \mathrm{C}$ for $4 \mathrm{~h}$. Purification by column chromatography on silica gel ( $n$-hexane/EtOAc $=5: 1$ ) yielded $\mathbf{1 4 8 I}(49 \mathrm{mg}, 53 \%)$ as a white solid. M.p.: $309^{\circ} \mathrm{C} .{ }^{1} \mathbf{H} \mathbf{~ N M R}\left(400 \mathrm{MHz}, \mathrm{CDCl}_{3}\right): \delta=9.06$ (d, $J=8.4 \mathrm{~Hz}, 1 \mathrm{H}), 7.88(\mathrm{dd}, J=8.5,1.8 \mathrm{~Hz}, 1 \mathrm{H}), 7.76(\mathrm{~s}, 1 \mathrm{H}), 7.63-7.61(\mathrm{~m}, 1 \mathrm{H}), 7.50-7.42$ (m, 3H), $7.40-7.30(\mathrm{~m}, 5 \mathrm{H}), 7.27-7.23(\mathrm{~m}, 2 \mathrm{H}), 5.73(\mathrm{~s}, 1 \mathrm{H}), 2.38(\mathrm{~s}, 3 \mathrm{H}), 2.09(\mathrm{~s}, 3 \mathrm{H}) .{ }^{13} \mathrm{C}$ $\operatorname{NMR}\left(101 \mathrm{MHz}, \mathrm{CDCl}_{3}\right): \delta=145.9\left(\mathrm{C}_{\mathrm{q}}\right), 142.9\left(\mathrm{C}_{\mathrm{q}}\right), 136.5\left(\mathrm{C}_{\mathrm{q}}\right), 134.8\left(\mathrm{C}_{\mathrm{q}}\right), 133.8\left(\mathrm{C}_{\mathrm{q}}\right), 133.5\left(\mathrm{C}_{\mathrm{q}}\right)$, $132.1\left(\mathrm{C}_{\mathrm{q}}\right), 131.4(\mathrm{CH}), 131.1\left(\mathrm{C}_{\mathrm{q}}\right), 130.9\left(\mathrm{q},{ }^{2} \mathrm{~J}_{\mathrm{C}-\mathrm{F}}=32 \mathrm{~Hz}, \mathrm{C}_{\mathrm{q}}\right), 130.5(\mathrm{CH}), 129.5\left(\mathrm{C}_{\mathrm{q}}\right)$, $129.2(\mathrm{CH}), 128.7(\mathrm{CH}), 128.2(\mathrm{CH}), 127.6(\mathrm{CH}), 125.6(\mathrm{CH}), 125.2\left(\mathrm{C}_{\mathrm{q}}\right), 124.0\left(\mathrm{q},{ }^{1} \mathrm{~J}_{\mathrm{C}-\mathrm{F}}=272 \mathrm{~Hz}\right.$, $\left.\mathrm{C}_{\mathrm{q}}\right), 123.5$ (q, $\left.{ }^{3} \mathrm{JC}_{\mathrm{F}}=3 \mathrm{~Hz}, \mathrm{CH}\right), 123.3$ (q, ${ }^{3} \mathrm{~J}_{\mathrm{C}-\mathrm{F}}=4 \mathrm{~Hz}, \mathrm{CH}$ ), $122.5\left(\mathrm{C}_{\mathrm{q}}\right), 119.6(\mathrm{CH}), 114.3(\mathrm{CH})$, $20.7\left(\mathrm{CH}_{3}\right), 20.4\left(\mathrm{CH}_{3}\right) .{ }^{19} \mathrm{~F}$ NMR (377 MHz, $\left.\mathrm{CDCl}_{3}\right): \delta=-62.3$ (s). IR (ATR): 2920, 1487, 1458, 1357, 1313, 1151, 1125, $698 \mathrm{~cm}^{-1}$. MS (ESI) m/z (relative intensity): 467 (100) [M+H] $]^{+}$HR-MS (ESI) $\mathrm{m} / \mathrm{z}$ calc. for $\mathrm{C}_{30} \mathrm{H}_{22} \mathrm{~N}_{2} \mathrm{~F}_{3}[\mathrm{M}+\mathrm{H}]^{+}: 467.1730$, found: 467.1732 .<smiles>Cc1cc2nc3c4ccc(Br)cc4c(-c4ccccc4)c(-c4ccccc4)n3c2cc1C</smiles>

\section{3-Bromo-9,10-dimethyl-5,6-diphenylbenzo[4,5]imidazo[2,1-a]isoquinoline (148m)}

The general procedure $\mathrm{G}$ was followed using $147 \mathrm{~m}(60 \mathrm{mg}, 0.2 \mathrm{mmol})$ and $64 \mathrm{a}(72 \mathrm{mg}, 0.4$ $\mathrm{mmol})$ at $100{ }^{\circ} \mathrm{C}$ for $4 \mathrm{~h}$. Purification by column chromatography on silica gel $(n$-hexane/EtOAc $=$ 
5:1) yielded $148 \mathrm{~m} \mathrm{(48} \mathrm{mg,} 50 \%)$ as a white solid. M.p.: $307^{\circ} \mathrm{C} .{ }^{1} \mathrm{H}$ NMR $\left(400 \mathrm{MHz}, \mathrm{CDCl}_{3}\right): \delta=$ $8.80(\mathrm{~d}, J=8.6 \mathrm{~Hz}, 1 \mathrm{H}), 7.76(\mathrm{dd}, J=8.6,1.9 \mathrm{~Hz}, 1 \mathrm{H}), 7.73(\mathrm{~s}, 1 \mathrm{H}), 7.48-7.39(\mathrm{~m}, 4 \mathrm{H}), 7.36-$ $7.28(\mathrm{~m}, 5 \mathrm{H}), 7.25-7.21(\mathrm{~m}, 2 \mathrm{H}), 5.69(\mathrm{~s}, 1 \mathrm{H}), 2.37(\mathrm{~s}, 3 \mathrm{H}), 2.08(\mathrm{~s}, 3 \mathrm{H}) .{ }^{13} \mathrm{C}$ NMR $(101 \mathrm{MHz}$, $\left.\mathrm{CDCl}_{3}\right): \delta=146.5\left(\mathrm{C}_{\mathrm{q}}\right), 142.9\left(\mathrm{C}_{\mathrm{q}}\right), 136.3\left(\mathrm{C}_{\mathrm{q}}\right), 135.1\left(\mathrm{C}_{\mathrm{q}}\right), 133.9\left(\mathrm{C}_{\mathrm{q}}\right), 133.6\left(\mathrm{C}_{\mathrm{q}}\right), 133.6\left(\mathrm{C}_{\mathrm{q}}\right)$, $131.5(\mathrm{CH}), 130.8(\mathrm{CH}), 130.6\left(\mathrm{C}_{\mathrm{q}}\right), 130.5(\mathrm{CH}), 129.5\left(\mathrm{C}_{\mathrm{q}}\right), 129.2(\mathrm{CH}), 128.7(\mathrm{CH}), 128.7(\mathrm{CH})$, $128.2(\mathrm{CH}), 127.5(\mathrm{CH}), 126.5(\mathrm{CH}), 124.1\left(\mathrm{C}_{\mathrm{q}}\right), 121.9\left(\mathrm{C}_{\mathrm{q}}\right), 121.7\left(\mathrm{C}_{\mathrm{q}}\right), 119.4(\mathrm{CH}), 114.3(\mathrm{CH})$, $20.8\left(\mathrm{CH}_{3}\right), 20.4\left(\mathrm{CH}_{3}\right)$. IR (ATR): 1598, 1522, 1444, 1416, 1072, 872, 703, $661 \mathrm{~cm}^{-1}$. MS (ESI) m/z (relative intensity): 477 (100) [M+H] $]^{+}, 659$ (20). HR-MS (ESI) m/z calc. for $\mathrm{C}_{29} \mathrm{H}_{22} \mathrm{~N}_{2}{ }^{79} \mathrm{Br}$ $[\mathrm{M}+\mathrm{H}]^{+}:$: 77.0961 , found: 477.0957 .<smiles>Cc1c(-c2ccccc2)n2c3ccccc3nc2c2ccccc12</smiles>

\section{5-Methyl-6-phenylbenzo[4,5]imidazo[2,1-a]isoquinoline (148n)}

The general procedure $\mathrm{G}$ was followed using $147 \mathrm{a}(39 \mathrm{mg}, 0.2 \mathrm{mmol})$ and $64 \mathrm{~m}(46 \mathrm{mg}, 0.4$ $\mathrm{mmol})$ at $100{ }^{\circ} \mathrm{C}$ for $4 \mathrm{~h}$. Purification by column chromatography on silica gel ( $n$-hexane/EtOAc $=$ $5: 1)$ yielded $148 \mathrm{n}(51 \mathrm{mg}, 83 \%)$ as a white solid. M.p.: $238{ }^{\circ} \mathrm{C} .{ }^{1} \mathrm{H}$ NMR $\left(300 \mathrm{MHz}, \mathrm{CDCl}_{3}\right): \delta=$ $8.99(\mathrm{dd}, J=7.6,1.4 \mathrm{~Hz}, 1 \mathrm{H}), 8.00-7.93(\mathrm{~m}, 2 \mathrm{H}), 7.82-7.72(\mathrm{~m}, 2 \mathrm{H}), 7.73-7.65(\mathrm{~m}, 3 \mathrm{H})$, $7.54-7.49(\mathrm{~m}, 2 \mathrm{H}), 7.39-7.34(\mathrm{~m}, 1 \mathrm{H}), 6.93(\mathrm{ddd}, J=8.4,7.2,1.2 \mathrm{~Hz}, 1 \mathrm{H}), 5.96(\mathrm{~d}, J=8.5 \mathrm{~Hz}$, $1 \mathrm{H}), 2.34(\mathrm{~s}, 3 \mathrm{H}) .{ }^{13} \mathrm{C}$ NMR $\left(101 \mathrm{MHz}, \mathrm{CDCl}_{3}\right): \delta=147.7\left(\mathrm{C}_{\mathrm{q}}\right), 144.1\left(\mathrm{C}_{\mathrm{q}}\right), 134.7\left(\mathrm{C}_{\mathrm{q}}\right), 134.4\left(\mathrm{C}_{\mathrm{q}}\right)$, $132.5\left(\mathrm{C}_{\mathrm{q}}\right), 131.3\left(\mathrm{C}_{\mathrm{q}}\right), 130.4(\mathrm{CH}), 130.2(\mathrm{CH}), 129.9(\mathrm{CH}), 129.7(\mathrm{CH}), 127.8(\mathrm{CH}), 125.5(\mathrm{CH})$, $124.2(\mathrm{CH}), 124.0(\mathrm{CH}), 123.3\left(\mathrm{C}_{\mathrm{q}}\right), 121.2(\mathrm{CH}), 119.6(\mathrm{CH}), 115.6\left(\mathrm{C}_{\mathrm{q}}\right), 114.0(\mathrm{CH}), 14.6\left(\mathrm{CH}_{3}\right)$. IR (ATR): 1524, 1448, 1376, 1253, 907, 906, 730, 701, $650 \mathrm{~cm}^{-1}$. MS (ESI) m/z (relative intensity): 309 (100) $[\mathrm{M}+\mathrm{H}]^{+}$. HR-MS (ESI) $\mathrm{m} / \mathrm{z}$ calc. for $\mathrm{C}_{22} \mathrm{H}_{17} \mathrm{~N}_{2}[\mathrm{M}+\mathrm{H}]^{+}: 309.1392$ found: 309.1386. The analytical data correspond with those reported in the literature. ${ }^{[238]}$<smiles>CC(=O)c1ccc2c(c1)c(-c1ccccc1)c(-c1ccccc1)n1c3ccccc3nc21</smiles> 


\section{Methyl 5,6-diphenylbenzo[4,5]imidazo[2,1-a]isoquinoline-3-carboxylate (1480)}

The general procedure $\mathbf{G}$ was followed using $147 \mathrm{n}(51 \mathrm{mg}, 0.2 \mathrm{mmol})$ and $64 \mathrm{a}(72 \mathrm{mg}, 0.4 \mathrm{mmol})$ at $100{ }^{\circ} \mathrm{C}$ for $4 \mathrm{~h}$. Purification by column chromatography on silica gel ( $n$-hexane/EtOAc $=5: 1$ ) yielded 1480 (80 mg, 93\%) as a white solid. M.p.: $265^{\circ} \mathrm{C}$. ${ }^{1} \mathbf{H}$ NMR $\left(400 \mathrm{MHz}, \mathrm{CDCl}_{3}\right): \delta=9.07$ (d, $J=8.4 \mathrm{~Hz}, 1 \mathrm{H}$ ), 8.33 (dd, $J=8.4,1.6 \mathrm{~Hz}, 1 \mathrm{H}$ ), $8.09(\mathrm{~s}, 1 \mathrm{H}), 8.03(\mathrm{~d}, J=8.4 \mathrm{~Hz}, 1 \mathrm{H}$ ), $7.49-$ $7.40(\mathrm{~m}, 4 \mathrm{H}), 7.40-7.26(\mathrm{~m}, 6 \mathrm{H}), 7.26-7.24(\mathrm{~m}, 1 \mathrm{H}), 7.00(\mathrm{t}, J=8.4 \mathrm{~Hz}, 1 \mathrm{H}), 6.05(\mathrm{~d}, J=8.5$ $\mathrm{Hz}, 1 \mathrm{H}), 3.92(\mathrm{~s}, 3 \mathrm{H}) .{ }^{13} \mathrm{C}$ NMR $\left(101 \mathrm{MHz}, \mathrm{CDCl}_{3}\right): \delta=166.7\left(\mathrm{C}_{\mathrm{q}}\right), 146.9\left(\mathrm{C}_{\mathrm{q}}\right), 144.4\left(\mathrm{C}_{\mathrm{q}}\right), 136.0$ $\left(\mathrm{C}_{\mathrm{q}}\right), 134.9\left(\mathrm{C}_{\mathrm{q}}\right), 133.5\left(\mathrm{C}_{\mathrm{q}}\right), 132.3\left(\mathrm{C}_{\mathrm{q}}\right), 131.5(\mathrm{CH}), 131.2\left(\mathrm{C}_{\mathrm{q}}\right), 131.1\left(\mathrm{C}_{\mathrm{q}}\right), 130.6(\mathrm{CH}), 129.4$ $(\mathrm{CH}), 128.8(\mathrm{CH}), 128.2$ (overlapped, $\mathrm{CH}$ ), $127.9(\mathrm{CH}), 127.6(\mathrm{CH}), 126.0\left(\mathrm{C}_{\mathrm{q}}\right), 125.3(\mathrm{CH})$, $124.5(\mathrm{CH}), 123.6\left(\mathrm{C}_{\mathrm{q}}\right), 121.9(\mathrm{CH}), 119.9(\mathrm{CH}), 114.3(\mathrm{CH}), 52.4\left(\mathrm{CH}_{3}\right)$. IR (ATR): 2920, 1722, 1446, 1266, 738, 709, 500, 467, $449 \mathrm{~cm}^{-1}$. MS (ESI) m/z (relative intensity): 429 (100) [M+H] . HR-MS (ESI) m/z calc. for $\mathrm{C}_{29} \mathrm{H}_{21} \mathrm{~N}_{2} \mathrm{O}_{2}[\mathrm{M}+\mathrm{H}]^{+}: 429.1598$ found: 429.1602.<smiles>CC(=O)c1ccc2c(c1)c(-c1ccccc1)c(-c1ccccc1)n1c3ccccc3nc21</smiles>

\section{$\mathrm{N}, \mathrm{N}$-Dimethyl-5,6-diphenylbenzo[4,5]imidazo[2,1-a]isoquinoline-3-carboxamide (148p)}

The general procedure $\mathbf{G}$ was followed using $64 \mathrm{o}(53 \mathrm{mg}, 0.2 \mathrm{mmol})$ and $64 \mathrm{a}(72 \mathrm{mg}, 0.4 \mathrm{mmol})$ at $100{ }^{\circ} \mathrm{C}$ for $4 \mathrm{~h}$. Purification by column chromatography on silica gel $(n$-hexane/EtOAc $=1: 1)$ yielded 148p (50 mg, $57 \%$ ) as a white solid. M.p.: $310^{\circ} \mathrm{C}$. ${ }^{1} \mathbf{H} \mathbf{~ N M R ~}\left(400 \mathrm{MHz}, \mathrm{CDCl}_{3}\right): \delta=9.04$ (d, $J=8.2 \mathrm{~Hz}, 1 \mathrm{H}), 8.02(\mathrm{~d}, J=8.2 \mathrm{~Hz}, 1 \mathrm{H}), 7.74(\mathrm{dd}, J=8.2,1.6 \mathrm{~Hz}, 1 \mathrm{H}), 7.47-7.34(\mathrm{~m}, 7 \mathrm{H})$, $7.33-7.22(\mathrm{~m}, 5 \mathrm{H}), 6.98(\mathrm{t}, J=7.9 \mathrm{~Hz}, 1 \mathrm{H}), 6.04(\mathrm{~d}, J=8.5 \mathrm{~Hz}, 1 \mathrm{H}), 3.11(\mathrm{~s}, 3 \mathrm{H}), 2.95(\mathrm{~s}, 3 \mathrm{H})$. ${ }^{13} \mathrm{C}$ NMR $\left(101 \mathrm{MHz}, \mathrm{CDCl}_{3}\right): \delta=170.8\left(\mathrm{C}_{q}\right), 147.2\left(\mathrm{C}_{q}\right), 144.3\left(\mathrm{C}_{q}\right), 137.6\left(\mathrm{C}_{q}\right), 136.0\left(\mathrm{C}_{q}\right), 135.1$ $\left(\mathrm{C}_{\mathrm{q}}\right), 133.5\left(\mathrm{C}_{\mathrm{q}}\right), 132.5\left(\mathrm{C}_{\mathrm{q}}\right), 131.5(\mathrm{CH}), 131.2\left(\mathrm{C}_{\mathrm{q}}\right), 130.5(\mathrm{CH}), 129.4(\mathrm{CH}), 128.8(\mathrm{CH}), 128.2$ $(\mathrm{CH}), 127.5(\mathrm{CH}), 126.2(\mathrm{CH}), 125.3(\mathrm{CH}), 125.1(\mathrm{CH}), 124.4(\mathrm{CH}), 123.5\left(\mathrm{C}_{q}\right), 123.3\left(\mathrm{C}_{q}\right), 121.6$ (CH), $119.8(\mathrm{CH}), 114.2(\mathrm{CH}), 39.5\left(\mathrm{CH}_{3}\right), 35.3\left(\mathrm{CH}_{3}\right)$. IR (ATR): 1624, 1485, 1442, 1391, 1071, 839, 744, $722 \mathrm{~cm}^{-1}$. MS (ESI) m/z (relative intensity): 442 (100) [M+H] . HR-MS (ESI) m/z calc. for $\mathrm{C}_{30} \mathrm{H}_{24} \mathrm{~N}_{3} \mathrm{O}[\mathrm{M}+\mathrm{H}]^{+}: 442.1914$ found: 442.1915 . 
<smiles>CC(=O)c1ccc2c(-c3ccccc3)c(-c3ccccc3)n3c4ccccc4nc3c2c1</smiles>

\section{1-[5,6-Diphenylbenzo[4,5]imidazo[2,1-a]isoquinolin-2-yl]ethan-1-one (148q)}

The general procedure $\mathbf{G}$ was followed using $147 \mathrm{p}(47 \mathrm{mg}, 0.2 \mathrm{mmol})$ and $64 \mathrm{a}(72 \mathrm{mg}, 0.4 \mathrm{mmol})$ at $100{ }^{\circ} \mathrm{C}$ for $4 \mathrm{~h}$. Purification by column chromatography on silica gel ( $n$-hexane/EtOAc $\left.=5: 1\right)$ yielded $148 \mathrm{q}(51 \mathrm{mg}, 62 \%)$ as a white solid. M.p.: $275{ }^{\circ} \mathrm{C}$. ${ }^{1} \mathbf{H} \mathbf{N M R}\left(400 \mathrm{MHz}, \mathrm{CDCl}_{3}\right): \delta=9.55$ (d, $J=1.9 \mathrm{~Hz}, 1 \mathrm{H}), 8.19$ (dd, $J=8.6,1.9 \mathrm{~Hz}, 1 \mathrm{H}), 8.04(\mathrm{~d}, J=8.2 \mathrm{~Hz}, 1 \mathrm{H}), 7.51-7.40(\mathrm{~m}, 5 \mathrm{H})$, $7.40-7.35(\mathrm{~m}, 2 \mathrm{H}), 7.35-7.28(\mathrm{~m}, 3 \mathrm{H}), 7.25-7.20(\mathrm{~m}, 2 \mathrm{H}), 6.99(\mathrm{t}, J=8.5 \mathrm{~Hz}, 1 \mathrm{H}), 6.05(\mathrm{~d}, J$ $=8.5 \mathrm{~Hz}, 1 \mathrm{H}), 2.87(\mathrm{~s}, 3 \mathrm{H}) \cdot{ }^{13} \mathrm{C}$ NMR $\left(101 \mathrm{MHz}, \mathrm{CDCl}_{3}\right): \delta=197.5\left(\mathrm{C}_{\mathrm{q}}\right), 147.4\left(\mathrm{C}_{\mathrm{q}}\right), 144.2\left(\mathrm{C}_{\mathrm{q}}\right)$, $137.4\left(\mathrm{C}_{\mathrm{q}}\right), 135.8\left(\mathrm{C}_{\mathrm{q}}\right), 135.8\left(\mathrm{C}_{\mathrm{q}}\right), 135.1\left(\mathrm{C}_{\mathrm{q}}\right), 133.3\left(\mathrm{C}_{\mathrm{q}}\right), 131.4(\mathrm{CH}), 131.1\left(\mathrm{C}_{\mathrm{q}}\right), 130.3(\mathrm{CH})$, $129.5(\mathrm{CH}), 128.9(\mathrm{CH}), 128.3(\mathrm{CH}), 128.2(\mathrm{CH}), 127.6(\mathrm{CH}), 126.9(\mathrm{CH}), 126.2(\mathrm{CH}), 124.6$ $(\mathrm{CH}), 123.2\left(\mathrm{C}_{\mathrm{q}}\right), 122.6\left(\mathrm{C}_{\mathrm{q}}\right), 121.7(\mathrm{CH}), 119.7(\mathrm{CH}), 114.3(\mathrm{CH}), 27.0\left(\mathrm{CH}_{3}\right)$. IR (ATR): 1683, 1608, 1421, 1257, 916, 825, $700 \mathrm{~cm}^{-1}$. MS (ESI) m/z (relative intensity): $413(100)[\mathrm{M}+\mathrm{H}]^{+}$. HRMS (ESI) m/z calc. for $\mathrm{C}_{29} \mathrm{H}_{21} \mathrm{~N}_{2} \mathrm{O}[\mathrm{M}+\mathrm{H}]^{+}: 413.1648$ found: 413.1651 .

\subsubsection{H/D Exchange Experiment}<smiles></smiles>

$145 a$

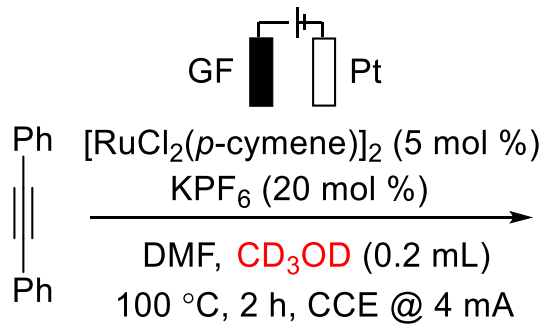

$64 a$

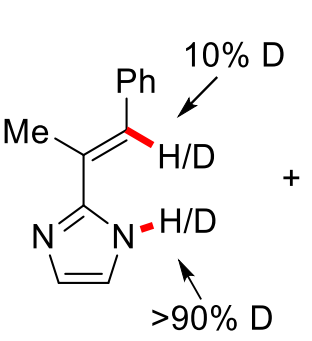

$[D]_{n}-145 a: 48 \%$<smiles>Cc1c(-c2ccccc2)c(-c2ccccc2)c(-c2ccccc2)n2ccnc12</smiles>

$[D]_{n}-146 a: 12 \%$

In an undivided cell equipped with a GF anode $(10 \mathrm{~mm} \times 15 \mathrm{~mm} \times 6 \mathrm{~mm})$ and a platinum cathode $(10 \mathrm{~mm} \times 15 \mathrm{~mm} \times 0.25 \mathrm{~mm}), 145 \mathrm{a}(74 \mathrm{mg}, 0.4 \mathrm{mmol})$, alkyne 64a (142.4 mg, 0.8 $\mathrm{mmol}), \mathrm{KPF}_{6}(15 \mathrm{mg}, 20.0 \mathrm{~mol} \%)$ and $\left[\mathrm{RuCl}_{2}(p \text {-cymene })\right]_{2}(12.5 \mathrm{mg}, 5.0 \mathrm{~mol} \%)$ were dissolved in DMF $(4 \mathrm{~mL})$ and $\mathrm{CD}_{3} \mathrm{OD}(0.2 \mathrm{~mL})$ under $\mathrm{N}_{2}$. Electrocatalysis was performed at $100{ }^{\circ} \mathrm{C}$ with a constant current of $4.0 \mathrm{~mA}$ maintained for $2 \mathrm{~h}$. After the reaction, the GF anode was washed with EtOAc $(3 \times 10 \mathrm{~mL})$ in an ultrasonic bath. The combined organic phases were added to the reaction mixture. Evaporation of the solvent and subsequent column chromatography ( $n$ hexane/EtOAc $=10: 1 \rightarrow 5: 1)$ yielded $[D]_{n}-145 a(35 \mathrm{mg}, 48 \%)$ as a white solid and $[D]_{n}-146 a(17$ 
$\mathrm{mg}, 12 \%)$ as a white solid. The D-incorporation was estimated by ${ }^{1} \mathrm{H}$ NMR spectroscopy.
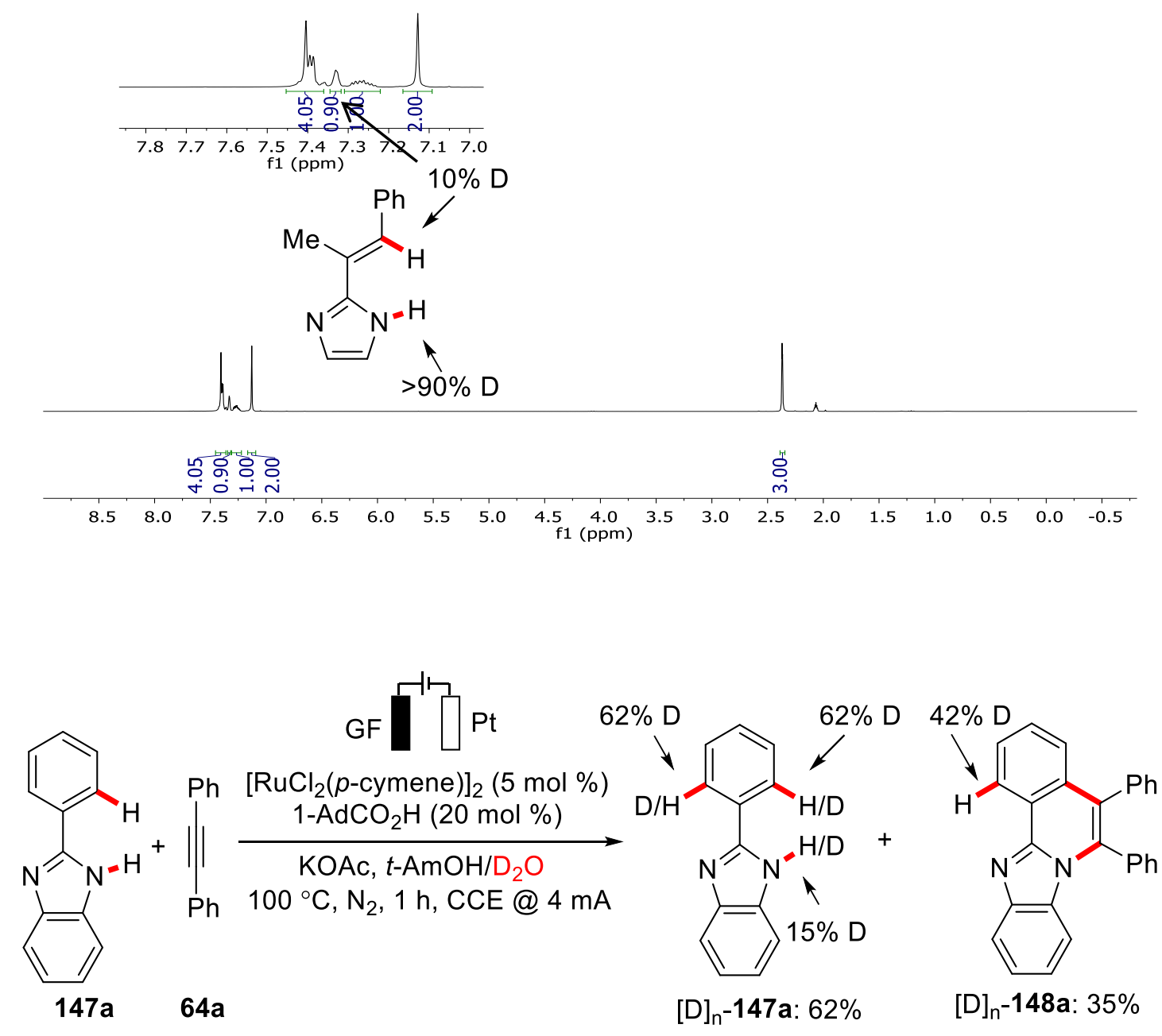

In an undivided cell equipped with a GF anode $(10 \mathrm{~mm} \times 15 \mathrm{~mm} \times 6 \mathrm{~mm})$ and a platinum cathode $(10 \mathrm{~mm} \times 15 \mathrm{~mm} \times 0.25 \mathrm{~mm}), 147 \mathrm{a}(39 \mathrm{mg}, 0.2 \mathrm{mmol})$, alkyne $64 \mathrm{a}(71 \mathrm{mg}, 0.4 \mathrm{mmol})$, $1-\mathrm{AdCO}_{2} \mathrm{H}(7.2 \mathrm{mg}, 20.0 \mathrm{~mol} \%)$ and $\left[\mathrm{RuCl}_{2}(p \text {-cymene })\right]_{2}(6.2 \mathrm{mg}, 5.0 \mathrm{~mol} \%)$ were dissolved in $t$-AmOH $(3 \mathrm{~mL})$ and $\mathrm{D}_{2} \mathrm{O}(3 \mathrm{~mL})$ under $\mathrm{N}_{2}$. Electrocatalysis was performed at $100{ }^{\circ} \mathrm{C}$ with a constant current of $4.0 \mathrm{~mA}$ maintained for $1 \mathrm{~h}$. The GF anode was washed with ethyl acetate $(3 \times 10 \mathrm{~mL})$ in an ultrasonic bath. Evaporation of the solvent and subsequent column chromatography ( $n$-hexane/EtOAc $=10: 1 \rightarrow 5: 1)$ yielded $[\mathrm{D}]_{\mathrm{n}}-147 \mathrm{a}(24 \mathrm{mg}, 62 \%)$ as a white solid and $[\mathrm{D}]_{\mathrm{n}}-148 \mathrm{a}(26 \mathrm{mg}, 35 \%)$ as a white solid. The D-incorporation was estimated by ${ }^{1} \mathrm{H}$ NMR spectroscopy. 

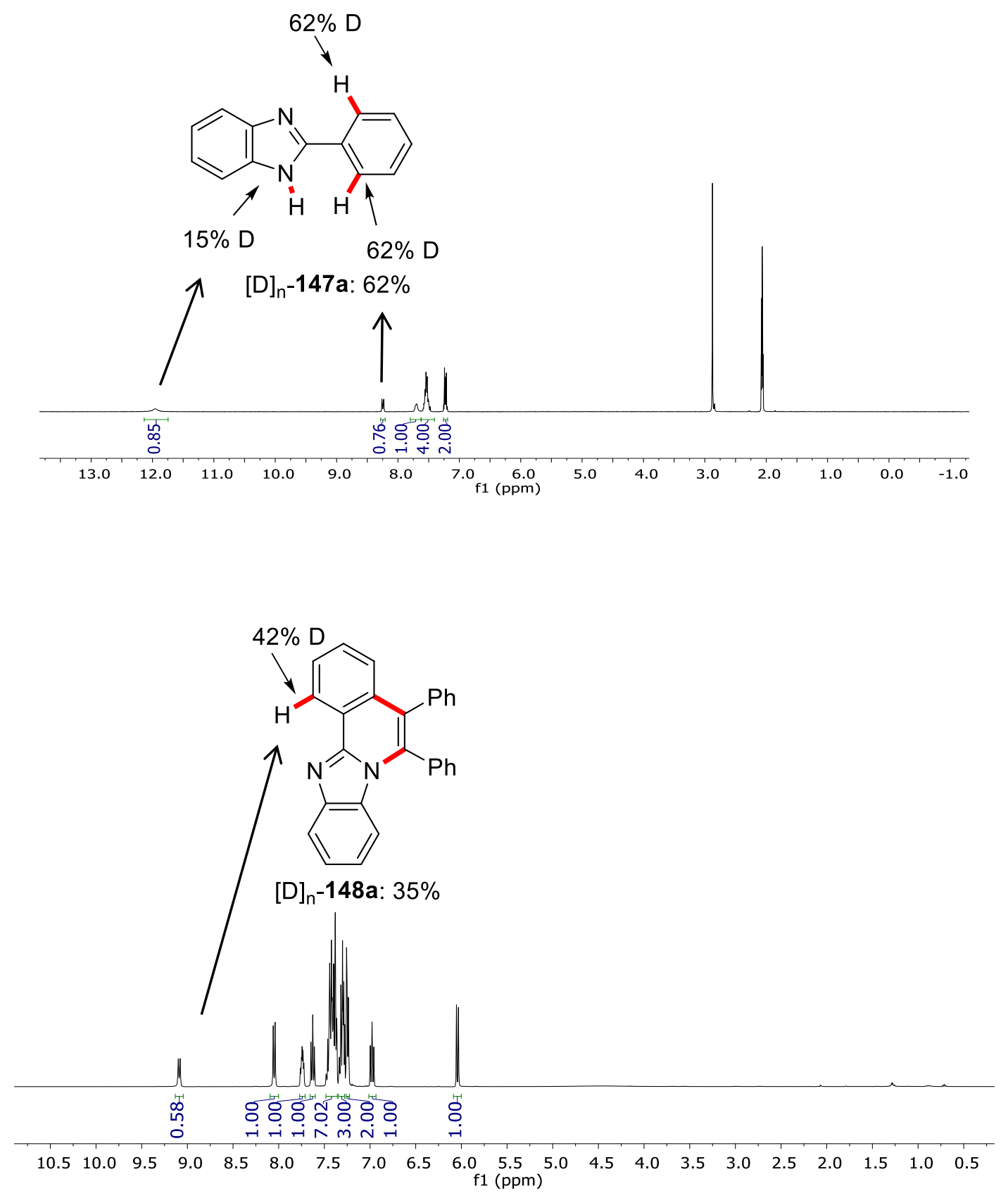


\subsubsection{Competition Experiments}

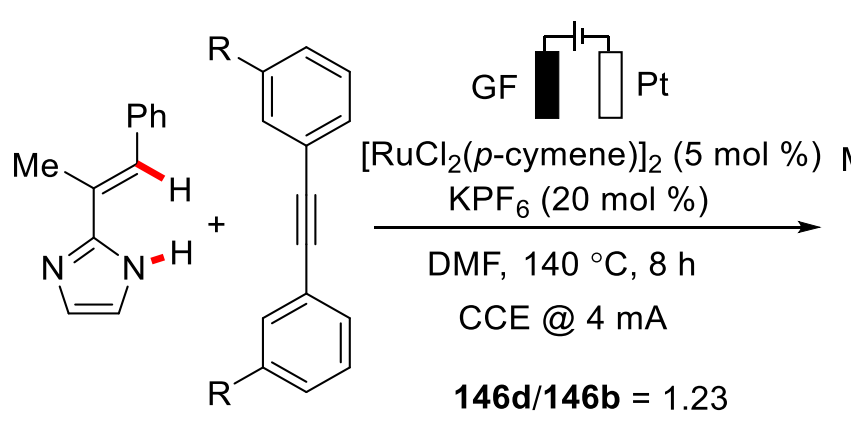

$145 a$

64b: $\mathrm{R}=\mathrm{CH}_{3}$

64d: $\mathrm{R}=\mathrm{CF}_{3}$<smiles>Cc1cccc(-c2c(-c3cccc(C)c3)c(-c3ccccc3)n3ccnc3c2C)c1</smiles>

146b: $22 \%$<smiles>Cc1c(-c2ccccc2)c(-c2cccc(C(F)(F)F)c2)c(-c2cccc(C(F)(F)F)c2)n2ccnc12</smiles>

146d: $27 \%$

The general procedure $\mathbf{F}$ was followed using $145 \mathrm{a}(74 \mathrm{mg}, 0.40 \mathrm{mmol})$, alkyne $64 \mathrm{~b}$ (82 $\mathrm{mg}, 0.40$ $\mathrm{mmol}$ ) and $64 \mathrm{~d}(125 \mathrm{mg}, 0.40 \mathrm{mmol})$. Then, the crude reaction mixture was filtered through a short pad of Celite. The conversion to $146 \mathrm{~b}(22 \%)$ and $146 \mathrm{~d}(27 \%)$ were determined by crude ${ }^{1} \mathrm{H}$ NMR spectroscopy with $\mathrm{CH}_{2} \mathrm{Br}_{2}$ as the internal standard. Then, repeated this reaction another two times got 146b (27\%), 146d (31\%) and 146b (22\%), 146d (26\%), respectively.

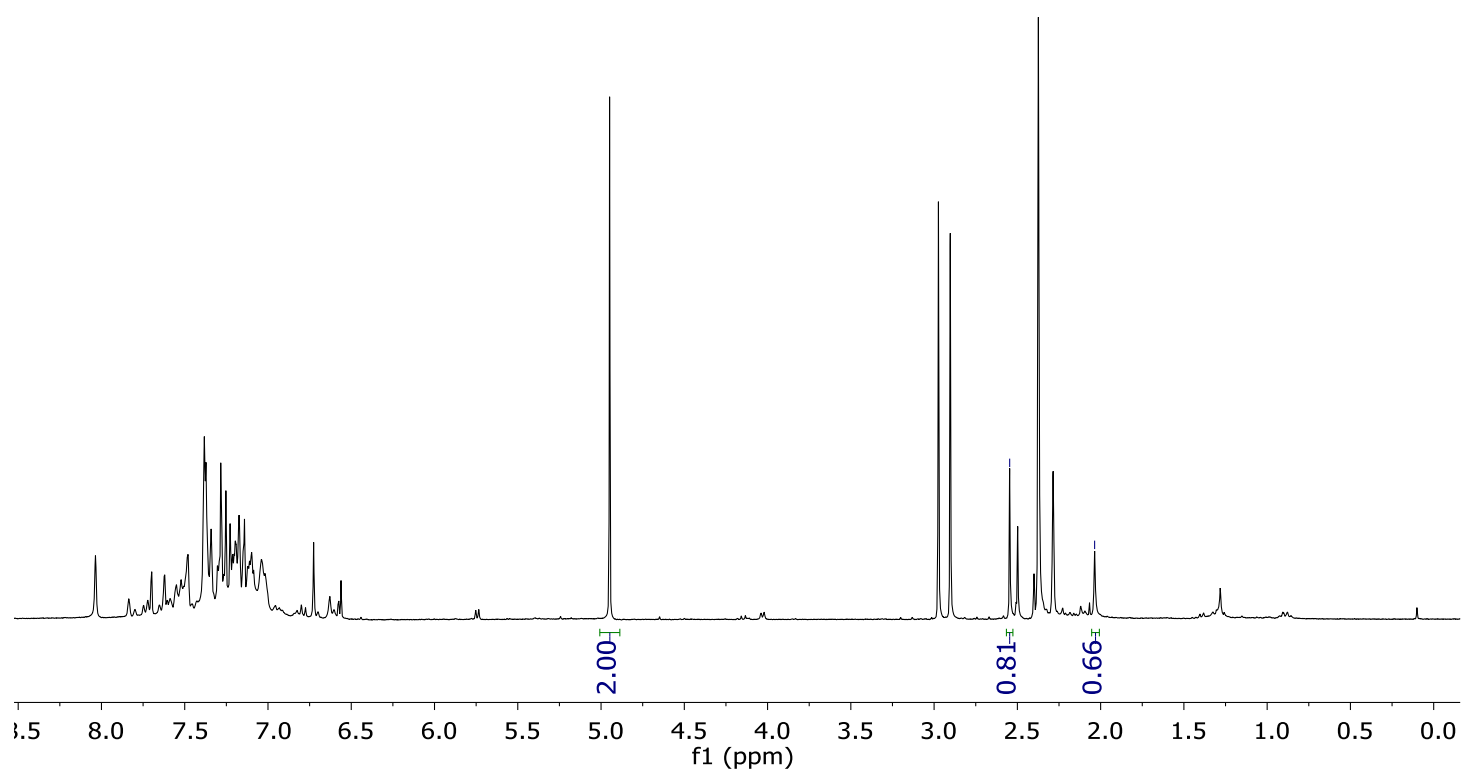


<smiles>[R]c1ccc(-c2nc3ccccc3[nH]2)cc1</smiles>

147b: $R=M e$ 147d: $\mathrm{R}=\mathrm{CF}_{3}$

$64 a$

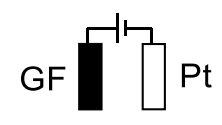

$\left[\mathrm{RuCl}_{2}(p \text {-cymene })\right]_{2}(5 \mathrm{~mol} \%)$ $1-\mathrm{AdCO}_{2} \mathrm{H}(20 \mathrm{~mol} \%)$

$\mathrm{KOAc}, t-\mathrm{AmOH} / \mathrm{H}_{2} \mathrm{O}$ $100{ }^{\circ} \mathrm{C}, 4 \mathrm{~h}, \mathrm{CCE} @ 8 \mathrm{~mA}$

$$
148 b / 148 d=1.15
$$<smiles>Cc1ccc2c3nc4ccccc4n(c(-c4ccccc4)c(-c4ccccc4)c2c1)-c1cc(C(F)(F)F)ccc1-3</smiles>

148b: $39 \%$

148d: $34 \%$

The general procedure $G$ was followed using $147 \mathrm{~b}(42 \mathrm{mg}, 0.20 \mathrm{mmol}), 147 \mathrm{~d}(52 \mathrm{mg}$, $0.20 \mathrm{mmol}$ ) and alkyne $64 \mathrm{a}(36 \mathrm{mg}, 0.20 \mathrm{mmol})$. Then, the crude reaction mixture was filtered through a short pad of Celite. The conversions to $148 \mathrm{~b}$ and $148 \mathrm{~d}$ were determined by crude ${ }^{1} \mathrm{H}$ NMR spectroscopy with $\mathrm{CH}_{2} \mathrm{Br}_{2}$ as the internal standard. Then, repeated this reaction another two times got $148 b(42 \%), 148 d(33 \%)$ and $148 b(42 \%), 148 d(35 \%)$, respectively.
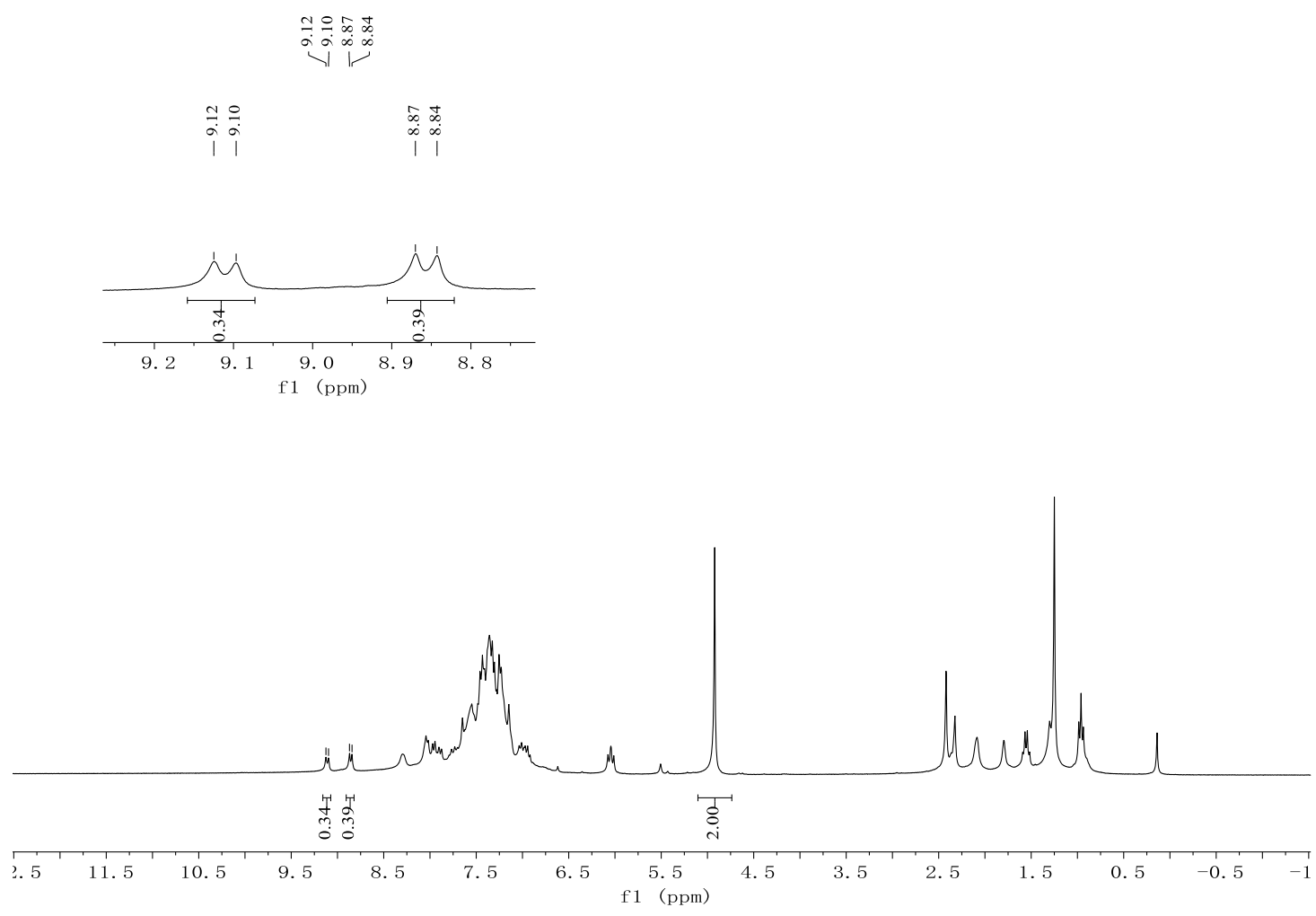


\subsubsection{Synthesis of Ruthenium Complexes}

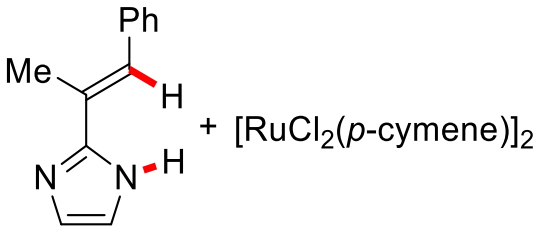

$145 a$

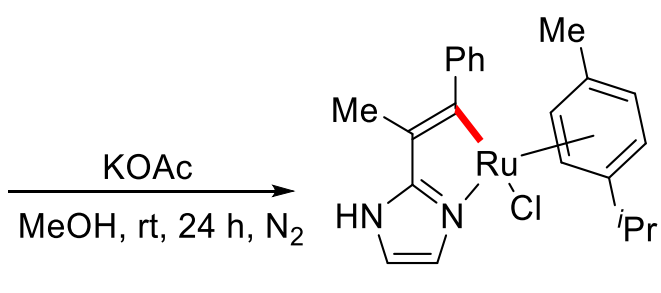

Ru-II $70 \%$

A $15 \mathrm{~mL}$ Schlenk tube was charged with $145 \mathrm{a}(18.4 \mathrm{mg}, 0.10 \mathrm{mmol}),\left[\mathrm{RuCl}_{2}(p \text {-cymene) }]_{2}(31.2\right.$ $\mathrm{mg}, 0.05 \mathrm{mmol}), \mathrm{KOAc}(20 \mathrm{mg}, 0.20 \mathrm{mmol})$, and $\mathrm{MeOH}(2.0 \mathrm{~mL})$. The mixture was stirred at ambient temperature for $24 \mathrm{~h}$, and then $\mathrm{MeOH}$ was removed in vacuo. After column chromatography on silica gel $\left(\mathrm{CH}_{2} \mathrm{Cl}_{2} / \mathrm{MeOH}=50: 1\right)$ and crystallization $\left(\mathrm{CH}_{2} \mathrm{Cl}_{2}\right.$ and $n$-pentane), Ru-II was isolated as a red solid (32 mg, 70\%). ${ }^{1} \mathbf{H}$ NMR (400 MHz, $\left.\mathrm{CDCl}_{3}\right): \delta=10.24(\mathrm{~s}, 1 \mathrm{H})$, $7.37-7.29(\mathrm{~m}, 4 \mathrm{H}), 7.17(\mathrm{t}, J=6.6 \mathrm{~Hz}, 1 \mathrm{H}), 7.06(\mathrm{~s}, 1 \mathrm{H}), 6.44(\mathrm{~s}, 1 \mathrm{H}), 5.29-5.24(\mathrm{~m}, 2 \mathrm{H}), 4.87$ (d, $J=5.5 \mathrm{~Hz}, 1 \mathrm{H}), 4.29(\mathrm{~d}, J=5.5 \mathrm{~Hz}, 1 \mathrm{H}), 2.20(\mathrm{p}, J=6.9 \mathrm{~Hz}, 1 \mathrm{H}), 1.93(\mathrm{~s}, 3 \mathrm{H}), 1.55(\mathrm{~s}, 3 \mathrm{H})$, $0.96(\mathrm{~d}, J=7.0 \mathrm{~Hz}, 3 \mathrm{H}), 0.79(\mathrm{~d}, J=6.9 \mathrm{~Hz}, 3 \mathrm{H}) .{ }^{13} \mathrm{C} \mathrm{NMR}\left(101 \mathrm{MHz}, \mathrm{CDCl}_{3}\right): \delta=187.0\left(\mathrm{C}_{\mathrm{q}}\right)$, $157.4\left(\mathrm{C}_{\mathrm{q}}\right), 153.2\left(\mathrm{C}_{\mathrm{q}}\right), 128.1(\mathrm{CH}), 127.4(\mathrm{CH}), 125.7(\mathrm{CH}), 124.3(\mathrm{CH}), 121.2\left(\mathrm{C}_{\mathrm{q}}\right), 115.5(\mathrm{CH})$, $96.7\left(\mathrm{C}_{\mathrm{q}}\right), 95.9\left(\mathrm{C}_{\mathrm{q}}\right), 89.0(\mathrm{CH}), 87.6(\mathrm{CH}), 84.3(\mathrm{CH}), 83.0(\mathrm{CH}), 30.8(\mathrm{CH}), 23.2\left(\mathrm{CH}_{3}\right), 20.9$ $\left(\mathrm{CH}_{3}\right), 18.6\left(\mathrm{CH}_{3}\right), 13.3\left(\mathrm{CH}_{3}\right)$. IR (ATR): 3078, 3050, 1626, 1600, 1484, 1442, 1253,760, 704 $\mathrm{cm}^{-1}$. MS (ESI) m/z (relative intensity): 419 (100) [M-Cl] ${ }^{+}$. HR-MS (ESI) m/z calcd for $\mathrm{C}_{22} \mathrm{H}_{25} \mathrm{~N}_{2} \mathrm{Ru}$ [M-Cl] : 419.1062, found: 419.1064 .

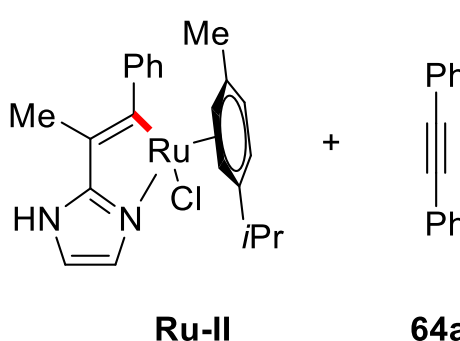

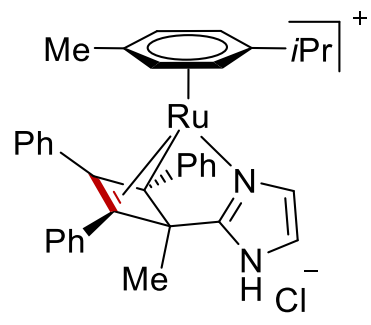

Ru-IVa

$53 \%$

A $15 \mathrm{~mL}$ Schlenk tube was charged with Ru-II (13.6 mg, $0.03 \mathrm{mmol}), 64 \mathbf{a}(5.9 \mathrm{mg}, 0.033 \mathrm{mmol}$ ) and $\mathrm{MeOH}(2.0 \mathrm{~mL})$. The mixture was stirred at ambient temperature for $3 \mathrm{~h}$, and then $\mathrm{MeOH}$ was removed in vacuo. After column chromatography on silica gel $\left(\mathrm{CH}_{2} \mathrm{Cl}_{2} / \mathrm{MeOH}=50: 1\right)$, RuIVa was isolated as a yellow solid (10 mg, 53\%), which could be crystallized in $\mathrm{MeOH}$ and $\mathrm{Et}_{2} \mathrm{O}$. ${ }^{1} \mathrm{H}$ NMR $\left(400 \mathrm{MHz}, \mathrm{CDCl}_{3}\right): \delta=14.31(\mathrm{~s}, 1 \mathrm{H}), 7.69-7.61(\mathrm{~m}, 2 \mathrm{H}), 7.50-7.40(\mathrm{~m}, 3 \mathrm{H}), 7.32-$ $7.26(\mathrm{~m}, 6 \mathrm{H}), 7.10-7.02(\mathrm{~m}, 6 \mathrm{H}), 5.14(\mathrm{~d}, J=5.7 \mathrm{~Hz}, 2 \mathrm{H}), 4.90(\mathrm{~d}, J=6.2 \mathrm{~Hz}, 2 \mathrm{H}), 2.38-2.28$ 
(m, 1H), $1.92(\mathrm{~s}, 3 \mathrm{H}), 1.64(\mathrm{~s}, 3 \mathrm{H}), 0.86(\mathrm{~d}, J=6.9 \mathrm{~Hz}, 6 \mathrm{H}) .{ }^{13} \mathrm{C}$ NMR $\left(101 \mathrm{MHz}, \mathrm{CDCl}_{3}\right)$ : $\delta=157.1\left(\mathrm{C}_{\mathrm{q}}\right), 134.5$ (overlapped, $\mathrm{C}_{\mathrm{q}}$ ), $134.1\left(\mathrm{C}_{\mathrm{q}}\right), 129.3(\mathrm{CH}), 128.9$ (overlapped, $\mathrm{CH}$ ), 128.6 (overlapped, $\mathrm{CH}$ ), 127.6 (overlapped, $\mathrm{CH}$ ), 127.0 (overlapped, $\mathrm{CH}$ ), $126.6(\mathrm{CH}), 118.4(\mathrm{CH})$, $117.1\left(\mathrm{C}_{\mathrm{q}}\right), 108.6\left(\mathrm{C}_{\mathrm{q}}\right), 106.7\left(\mathrm{C}_{\mathrm{q}}\right), 96.1$ (overlapped, $\left.\mathrm{C}_{\mathrm{q}}\right), 87.8$ (overlapped, $\mathrm{CH}$ ), 86.4 (overlapped, $\mathrm{CH}$ ), $61.8\left(\mathrm{C}_{\mathrm{q}}\right), 30.3(\mathrm{CH}), 22.4$ (overlapped, $\left.\mathrm{CH}_{3}\right), 20.8\left(\mathrm{CH}_{3}\right), 17.7\left(\mathrm{CH}_{3}\right)$. IR (ATR): 2958, 2148, 1706, 1494, 1293, 1208, 726, $693 \mathrm{~cm}^{-1}$. MS (ESI) m/z (relative intensity): 597 (100) [M-Cl] + . HR-MS (ESI) m/z calcd for $\mathrm{C}_{36} \mathrm{H}_{35} \mathrm{~N}_{2} \mathrm{Ru}$ [M-Cl] $]^{+}$597.1848, found: 597.1842 .

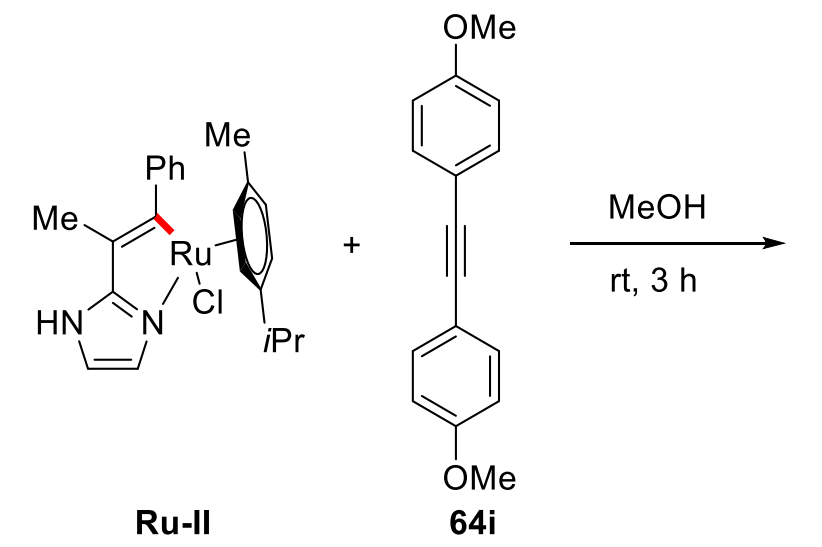

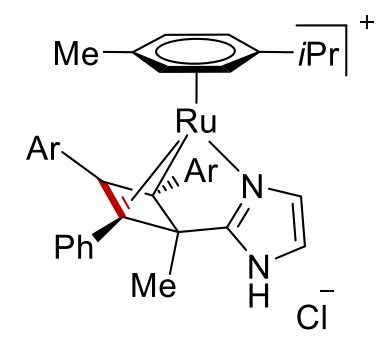

Ru-IVb, $\mathrm{Ar}=4-\mathrm{OMeC}_{6} \mathrm{H}_{4}$ $67 \%$

A $15 \mathrm{~mL}$ Schlenk tube was charged with Ru-II (13.6 mg, $0.03 \mathrm{mmol}), 64 \mathbf{i}(7.9 \mathrm{mg}, 0.033 \mathrm{mmol})$ and $\mathrm{MeOH}(2 \mathrm{~mL})$. The mixture was stirred at ambient temperature for $3 \mathrm{~h}$, and then $\mathrm{MeOH}$ was removed in vacuo. After column chromatography on silica gel $\left(\mathrm{CH}_{2} \mathrm{Cl}_{2} / \mathrm{MeOH}=50: 1\right)$, Ru-IVb was isolated as yellow solid (14 mg, $67 \%$ ), which could be crystallized in $\mathrm{MeOH}$ and diethyl ether. ${ }^{1} \mathrm{H}$ NMR $\left(400 \mathrm{MHz}, \mathrm{CDCl}_{3}\right): \delta=14.38(\mathrm{~s}, 1 \mathrm{H}), 7.60(\mathrm{~d}, J=8.5 \mathrm{~Hz}, 2 \mathrm{H}), 7.29(\mathrm{~d}, J=0.9 \mathrm{~Hz}, 3 \mathrm{H})$, $7.13-7.06(\mathrm{~m}, 3 \mathrm{H}), 7.05-6.99(\mathrm{~m}, 3 \mathrm{H}), 6.97(\mathrm{~d}, J=8.6 \mathrm{~Hz}, 2 \mathrm{H}), 6.82(\mathrm{~d}, J=8.4 \mathrm{~Hz}, 2 \mathrm{H}), 5.06$ (dd, $J=18.7,5.9 \mathrm{~Hz}, 2 \mathrm{H}$ ), 4.81 (d, $J=39.5 \mathrm{~Hz}, 2 \mathrm{H}$ ), $3.90(\mathrm{~s}, 3 \mathrm{H}), 3.82(\mathrm{~s}, 3 \mathrm{H}), 2.42-2.32(\mathrm{~m}$, 1H), $1.94(\mathrm{~s}, 3 \mathrm{H}), 1.62(\mathrm{~s}, 3 \mathrm{H}), 0.91(\mathrm{~d}, J=6.8 \mathrm{~Hz}, 3 \mathrm{H}), 0.86(\mathrm{~d}, J=6.8 \mathrm{~Hz}, 3 \mathrm{H}) .{ }^{13} \mathrm{C}$ NMR $(101$ $\left.\mathrm{MHz}, \mathrm{CDCl}_{3}\right): \delta=160.0\left(\mathrm{C}_{\mathrm{q}}\right), 159.0\left(\mathrm{C}_{\mathrm{q}}\right), 157.2\left(\mathrm{C}_{\mathrm{q}}\right), 134.9\left(\mathrm{C}_{\mathrm{q}}\right), 130.0(\mathrm{CH}), 128.9(\mathrm{CH})$, $128.6(\mathrm{CH}), 127.4(\mathrm{CH}), 126.9(\mathrm{CH}), 126.6\left(\mathrm{C}_{\mathrm{q}}\right), 126.3(\mathrm{CH}), 126.0\left(\mathrm{C}_{\mathrm{q}}\right), 118.4(\mathrm{CH}), 116.6\left(\mathrm{C}_{\mathrm{q}}\right)$, $114.4(\mathrm{CH}), 113.9(\mathrm{CH}), 108.2\left(\mathrm{C}_{\mathrm{q}}\right), 107.3\left(\mathrm{C}_{\mathrm{q}}\right), 96.4\left(\mathrm{C}_{\mathrm{q}}\right), 95.5\left(\mathrm{C}_{\mathrm{q}}\right)$, $87.3(\mathrm{CH}), 87.1(\mathrm{CH}), 86.1$ $(\mathrm{CH}), 85.7(\mathrm{CH}), 61.7\left(\mathrm{C}_{\mathrm{q}}\right), 55.4\left(\mathrm{CH}_{3}\right), 55.4\left(\mathrm{CH}_{3}\right), 30.3(\mathrm{CH}), 22.7\left(\mathrm{CH}_{3}\right), 22.3\left(\mathrm{CH}_{3}\right), 20.9\left(\mathrm{CH}_{3}\right)$, $17.9\left(\mathrm{CH}_{3}\right)$. IR (ATR): 2959, 1604, 1499, 1439, 1288, 1245, 1173, 1022, $832 \mathrm{~cm}^{-1}$. MS (ESI) m/z (relative intensity): $657(100)$ [M-Cl] $]^{+}$HR-MS (ESI) m/z calcd for $\mathrm{C}_{38} \mathrm{H}_{39} \mathrm{~N}_{2} \mathrm{RuO}_{2}[\mathrm{M}-\mathrm{Cl}]^{+}$: 657.2060, found: 657.2062 . 


\subsubsection{Ruthenium Complexes Catalyzed C-H/N-H Activation}<smiles>[H][Y15]1cc2nc(C(C)=Cc3ccccc3)c1[nH]2</smiles>

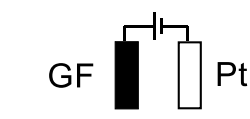

Ru-Il or Ru-IVa (10 mol \%)
$\underset{\mathrm{KPF}_{6}(20 \mathrm{~mol} \%)}{\mathrm{DMF}, 140{ }^{\circ} \mathrm{C}, 8 \mathrm{~h}}$
$\mathrm{CCE} @ 4 \mathrm{~mA}$

In an undivided cell with GF anode $(10 \mathrm{~mm} \times 10 \mathrm{~mm} \times 6 \mathrm{~mm})$ and a platinum cathode $(20 \mathrm{~mm} \times$ $10 \mathrm{~mm} \times 0.25 \mathrm{~mm}$ ), alkenyl imidazole $145 \mathrm{a}(0.4 \mathrm{mmol}, 1.0$ equiv), alkyne 64a $(0.8 \mathrm{mmol}, 2.0$ equiv), $\mathrm{KPF}_{6}(14.7 \mathrm{mg}, 20 \mathrm{~mol} \%$ ) and Ru-II (18 mg, $10.0 \mathrm{~mol} \%)$ were dissolved in DMF (4.0 mL) under $\mathrm{N}_{2}$. Electrocatalysis was performed at $140{ }^{\circ} \mathrm{C}$ with a constant current of $4.0 \mathrm{~mA}$ maintained for $8 \mathrm{~h}$. The GF anode was washed with EtOAc $(3 \times 10 \mathrm{~mL})$ in an ultrasonic bath. The combined organic phases were added to the reaction mixture. Evaporation of the solvent and subsequent column chromatography on silica gel afforded the corresponding product $146 a$ ( $74 \%$ based on 145a). The analogous procedure with Ru-IVa (25 mg, 10.0 mol \%) yielded 146a (61\% based on 145a).

\subsubsection{Oxidatively Induced Reductive Elimination}

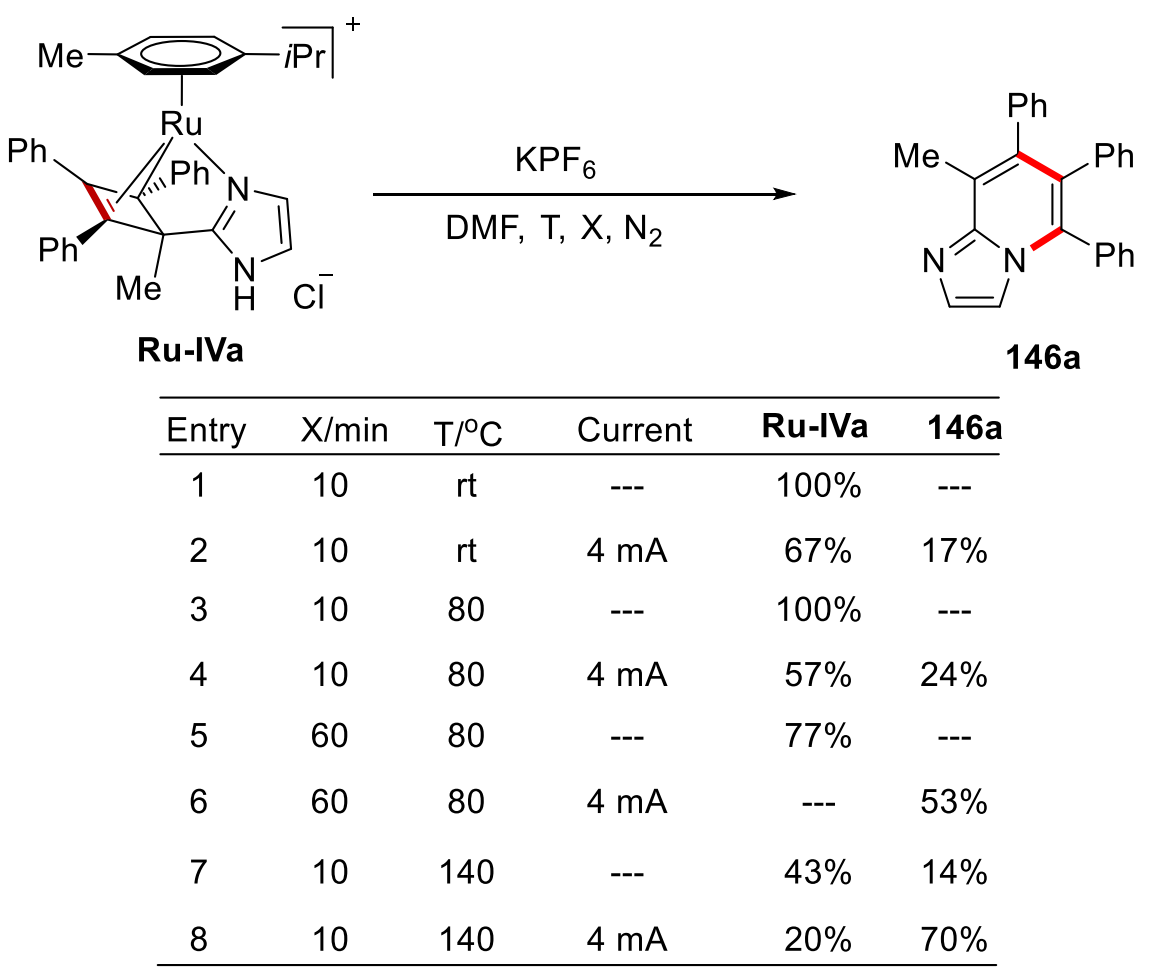


A $15 \mathrm{~mL}$ Schlenk tube was charged with Ru-IVa $(9.5 \mathrm{mg}, 0.015 \mathrm{mmol})$ and $\mathrm{KPF}_{6}(14.7 \mathrm{mg}, 0.08$ $\mathrm{mmol})$. The tube was evacuated and filled with $\mathrm{N}_{2}$ three times. Then, DMF $(4 \mathrm{~mL})$ was added and the mixture was electrolyzed at a constant current of $4 \mathrm{~mA}$ for $10 \mathrm{~min}$ or $60 \mathrm{~min}$ at ambient temperature or $80^{\circ} \mathrm{C}$ or $140{ }^{\circ} \mathrm{C}$ (GF anode, $(10 \mathrm{~mm} \times 15 \mathrm{~mm} \times 6 \mathrm{~mm}$ ) and a platinum cathode $(10 \mathrm{~mm} \times 15 \mathrm{~mm} \times 0.25 \mathrm{~mm}$ ). The solvent was removed in vacuo and trimethoxybenzene (5.05 $\mathrm{mg}, 0.03 \mathrm{mmol})$ was added as standard. Then, the residue was dissolved in $\mathrm{CDCl}_{3}(0.8 \mathrm{~mL})$ and subjected to ${ }^{1} \mathrm{H}$ NMR spectroscopy.

\subsubsection{On-Line NMR Monitoring in Flow}

On-line monitoring in flow was performed by Dr. Lars $\mathrm{H}$. Finger. The ${ }^{19} \mathrm{~F}$ NMR spectroscopy experiments in flow were performed on a Magritek Spinsolve 60 ULTRA (from Magritek GmbH, Germany) with the reaction monitoring kit supplied by the manufacturer. For pumping the solution to the spectrometer, an Ismatec REGLO Digital MS-2/12 (ISM 596) peristaltic pump was employed. The flow rate was $0.4 \mathrm{~mL} / \mathrm{min}$.

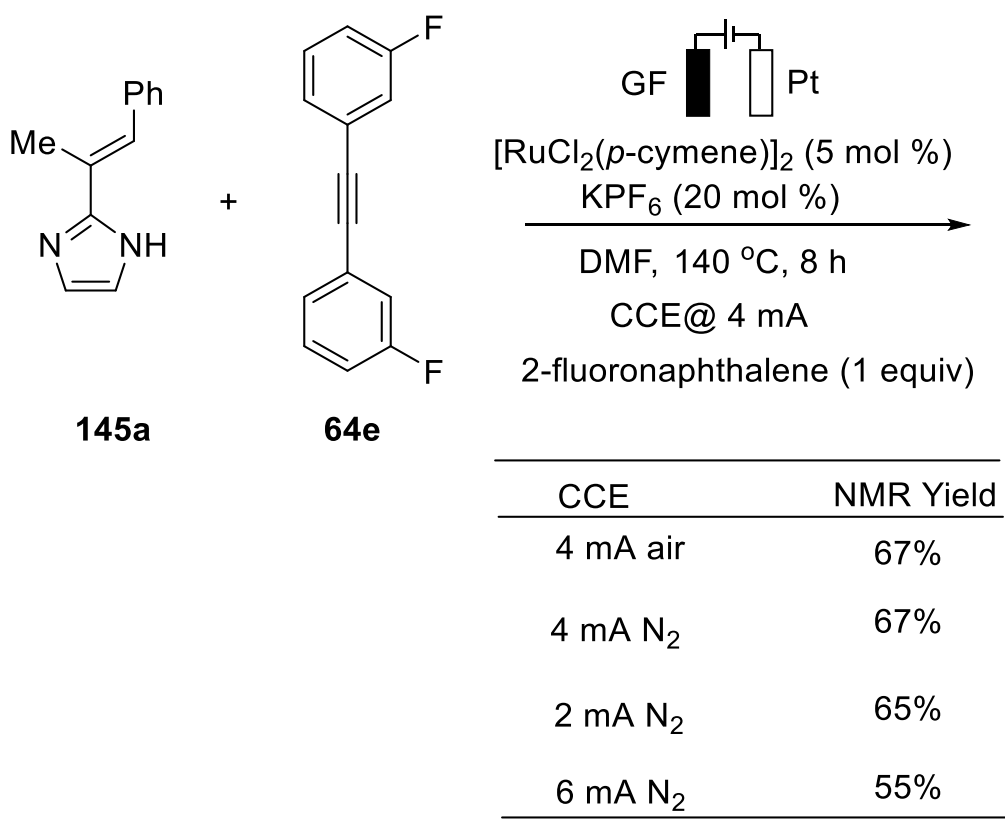

A $15 \mathrm{~mL}$ Schlenk tube was charged with $145 \mathrm{a}(110.4 \mathrm{mg}, 0.60 \mathrm{mmol}, 1.0$ equiv), $64 \mathrm{e}$ (256.8 $\mathrm{mg}$, $1.2 \mathrm{mmol}, 2.0$ equiv), $\mathrm{KPF}_{6}(22.1 \mathrm{mg}, 0.12 \mathrm{mmol}), 2$-fluoronaphthalene $(65.8 \mu \mathrm{L}, 0.6 \mathrm{mmol})$, $\left[\operatorname{RuCl}_{2}(p \text {-cymene })\right]_{2}(18.7 \mathrm{mg}, 5.0 \mathrm{~mol} \%)$ and DMF $(6 \mathrm{~mL})$. The solution was pumped to the NMR spectrometer by a peristaltic pump with a flow speed of $0.4 \mathrm{~mL} / \mathrm{min}$. The electrocatalysis was performed at $140^{\circ} \mathrm{C}$ with a constant current of $4.0 \mathrm{~mA}$ maintained for $8 \mathrm{~h}$. After evaporation of the solvent, the reaction yield of $146 \mathrm{e}$ was determined by ${ }^{1} \mathrm{H} \mathrm{NMR}$ with $\mathrm{CH}_{2} \mathrm{Br}_{2}$ as internal 
standard.

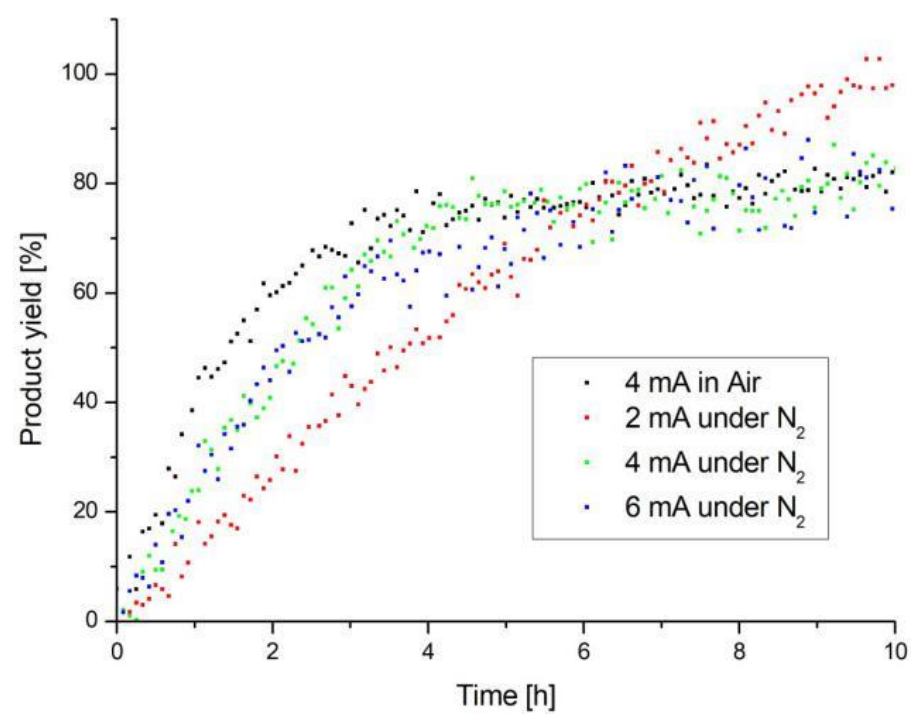

Scheme 5.3.3.7a Reaction profile determined by ${ }^{19} \mathrm{~F}$ NMR spectroscopic monitoring in flow.

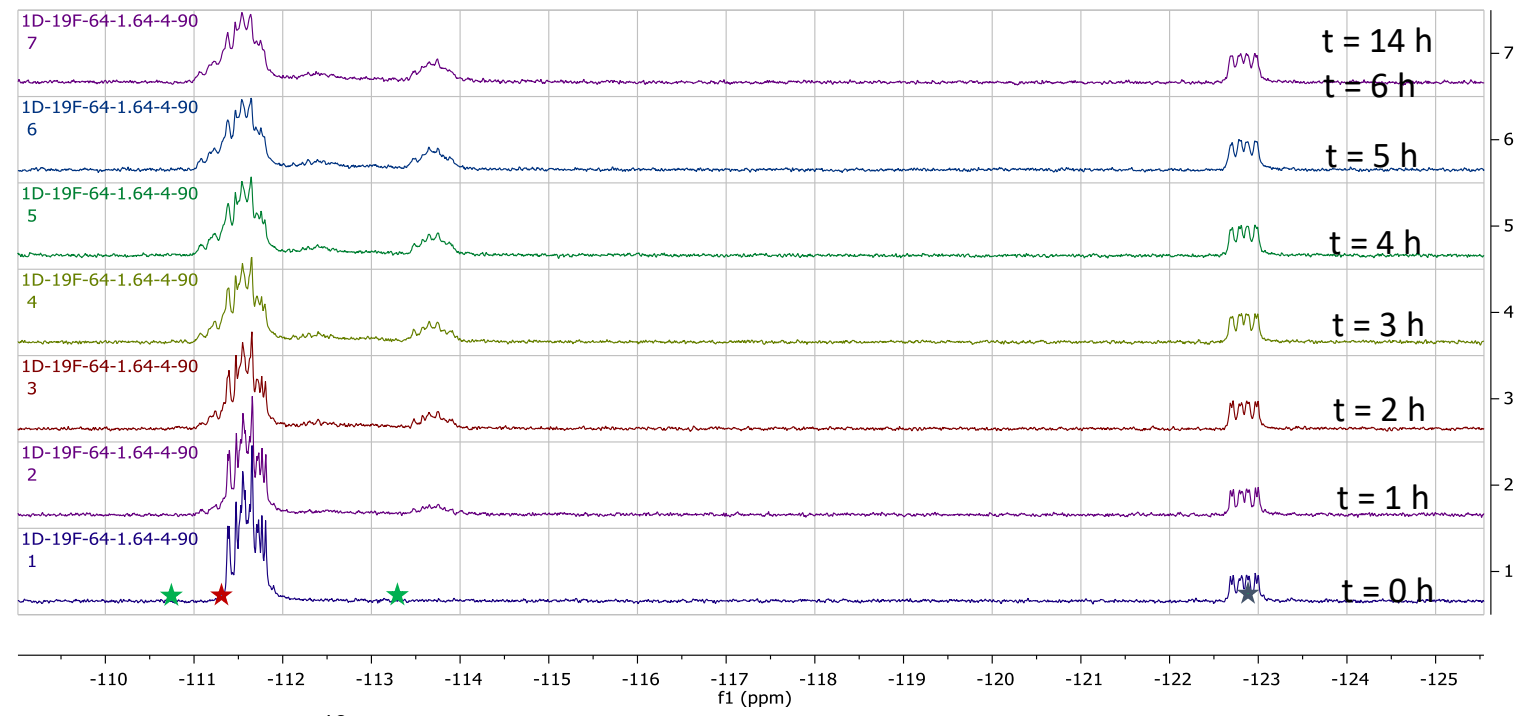

Scheme 5.3.3.7b ${ }^{19} \mathrm{~F}$ NMR spectra recorded in flow from the reaction mixture at $4 \mathrm{~mA}$ in air at selected times ( $\star$ : Product 146e, $\star$ : Starting material 64e, $\star$ : Internal standard (2fluoronaphthalene)). 


\subsubsection{GC-Headspace Detection}<smiles>c1ccc(-c2nc3ccccc3[nH]2)cc1</smiles>

$147 a$

$\left[\operatorname{RuCl}_{2}(p \text {-cymene })\right]_{2}(5.0 \mathrm{~mol} \%)$ $1-\mathrm{AdCO}_{2} \mathrm{H}(20 \mathrm{~mol} \%)$

$\mathrm{KOAc}, t-\mathrm{AmOH} / \mathrm{H}_{2} \mathrm{O}$ $100^{\circ} \mathrm{C}, 4$ h, CCE @ 8 mA<smiles>c1ccc(-c2c(-c3ccccc3)n3c4ccccc4nc3c3ccccc23)cc1</smiles>

$148 a$

$76 \%$

In an undivided cell equipped with a GF anode $(10 \mathrm{~mm} \times 15 \mathrm{~mm} \times 6 \mathrm{~mm})$ and a platinum cathode (10 mm $\times 15 \mathrm{~mm} \times 0.25 \mathrm{~mm}), 147 \mathrm{a}(39 \mathrm{mg}, 0.2 \mathrm{mmol})$, alkyne $64 \mathrm{a}(71 \mathrm{mg}, 0.4 \mathrm{mmol}$ ), $\mathrm{KOAc}(39 \mathrm{mg}, 0.4 \mathrm{mmol}), 1-\mathrm{AdCO}_{2} \mathrm{H}\left(7.2 \mathrm{mg}, 20.0 \mathrm{~mol} \%\right.$ ) and $\left[\mathrm{RuCl}_{2}(p \text {-cymene) }]_{2}(6.2 \mathrm{mg}, 5.0\right.$ mol \%) were dissolved in $t-\mathrm{AmOH}(3 \mathrm{~mL})$ and $\mathrm{H}_{2} \mathrm{O}(3 \mathrm{~mL})$ under $\mathrm{N}_{2}$. Electrocatalysis was performed at $100^{\circ} \mathrm{C}$ with a constant current of $8.0 \mathrm{~mA}$ maintained for $4 \mathrm{~h}$. After the reaction, 1.0 $\mathrm{mL}$ of the headspace volume was removed for $\mathrm{GC}$ analysis. The graphite felt anode was washed with EtOAc $(3 \times 20 \mathrm{~mL})$ in an ultrasonic bath. The yield of $148 \mathrm{a}(76 \%)$ was determined by ${ }^{1} \mathrm{H}$ NMR spectroscopy.

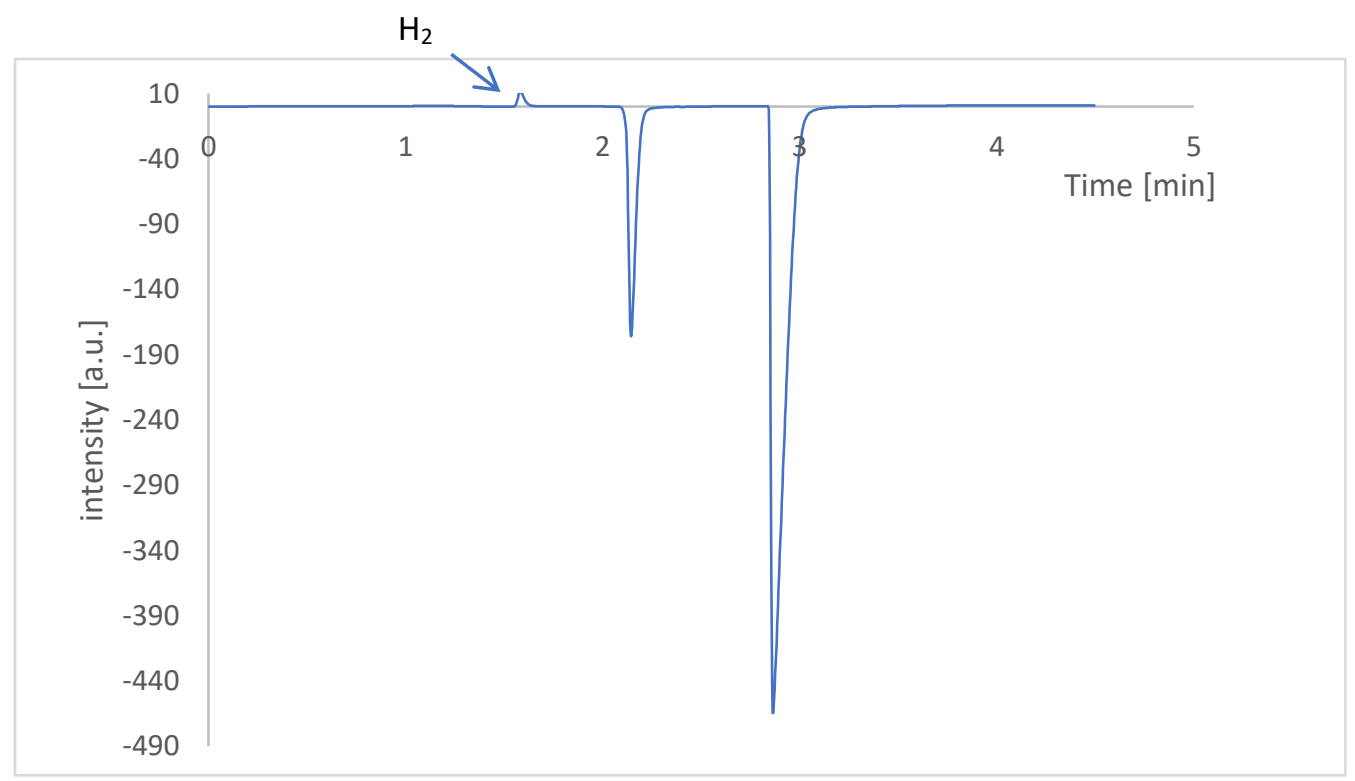




\subsubsection{Cyclic Voltammetry}

CV measurements were conducted with a Metrohm Autolab PGSTAT204 potentiostat and Nova 2.1 software. For all experiments, a glassy carbon working electrode (disk, diameter: $3 \mathrm{~mm}$ ), a platinum wire counter electrode and a saturated calomel reference electrode (SCE) were employed. The voltammograms were recorded at room temperature in DMF at a substrate concentration of $5 \mathrm{mmol} / \mathrm{L}$ and with $0.1 \mathrm{~mol}^{\prime} \mathrm{L} \mathrm{KPF}_{6}$ as supporting electrolyte. All solutions were saturated with $\mathrm{N}_{2}$ prior to the measurement and an overpressure of $\mathrm{N}_{2}$ was maintained throughout the experiment. The scan rate is $100 \mathrm{mV} / \mathrm{s}$. Deviations from the general experimental setup were indicated in the respective figures and descriptions.

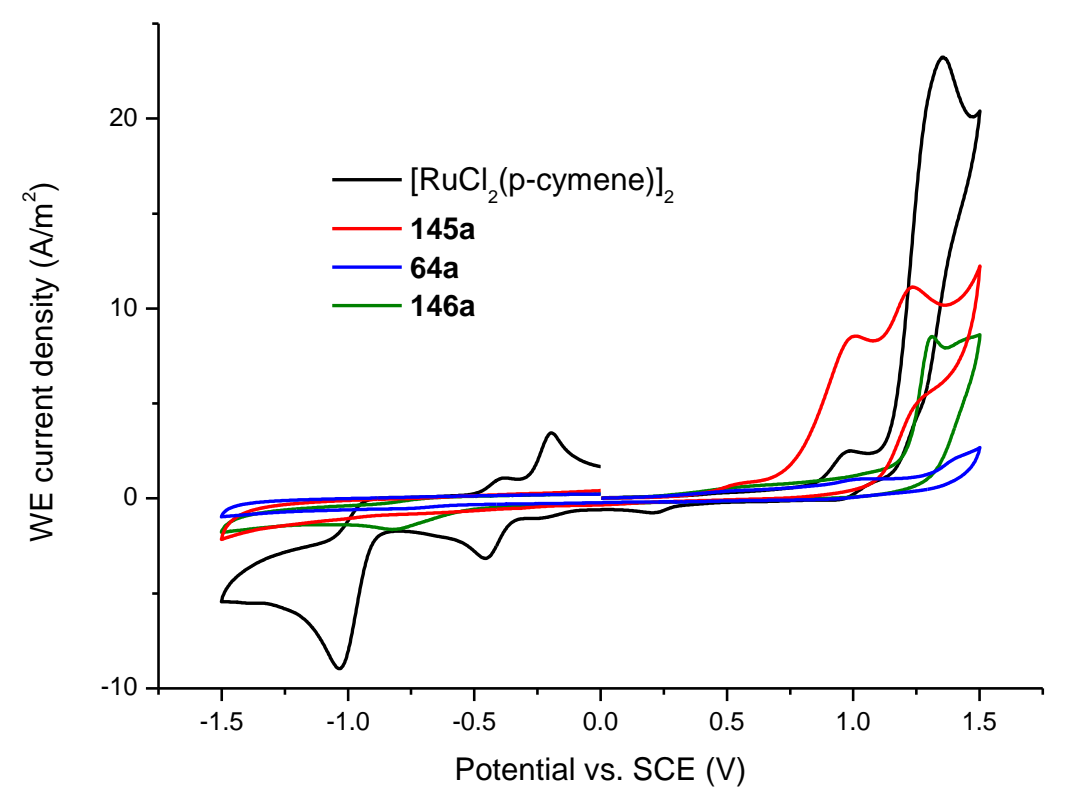

Cyclic voltammograms of $\left[\mathrm{RuCl}_{2}(p \text {-cymene) }]_{2}\right.$ (2.5 mM; black line), 145a (red line), 64a (blue line), 146a (green line) at rt. CV performed by Alexej Scheremetjew. 


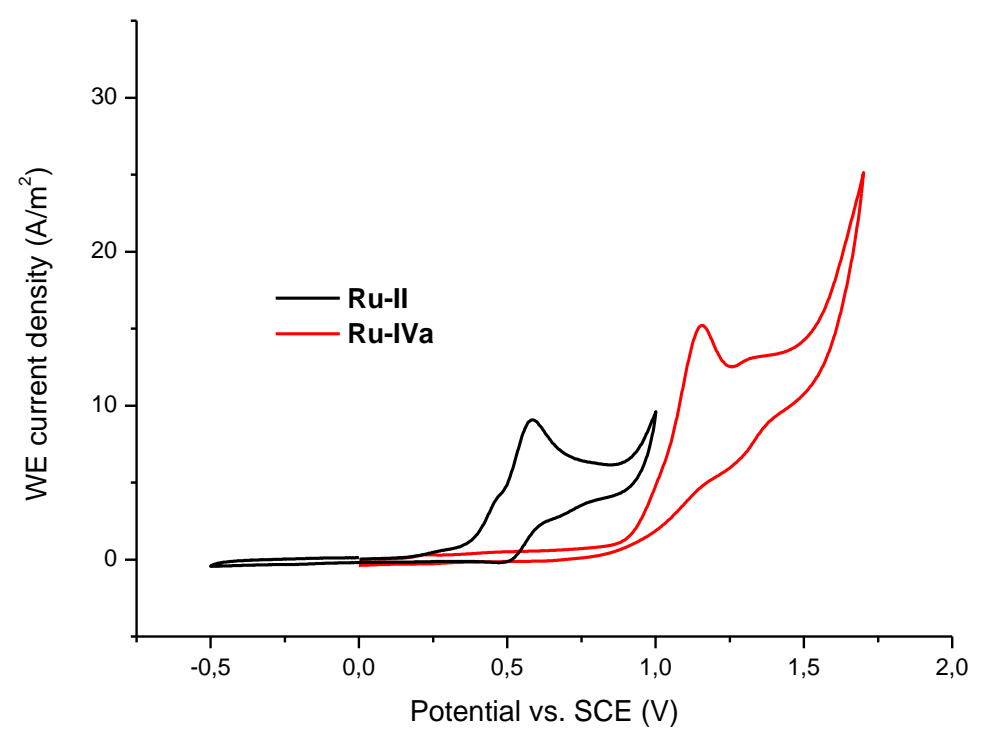

Cyclic voltammograms of Ru-II (black line), Ru-IVa (red line) in DMF under $\mathrm{N}_{2}$ at rt, $100 \mathrm{mM}$ $\mathrm{KPF}_{6}$ at $100 \mathrm{mV} / \mathrm{s}$.

\subsubsection{Regioselective $\mathrm{B}(3,4)-\mathrm{H}$ Arylation of $\mathrm{o}$-Carboranes}

\subsubsection{Characterization Data}

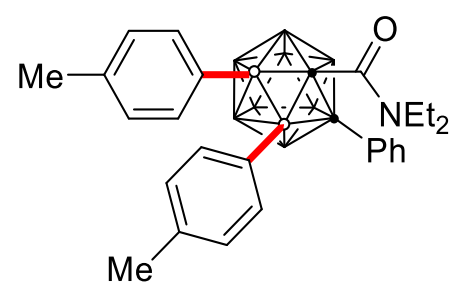

150a. The representative procedure $\mathrm{H}$ was followed using o-carborane $149 \mathrm{a}$ (1-CONEt $2-2-\mathrm{Ph}-\mathrm{O}$ $\left.\mathrm{C}_{2} \mathrm{~B}_{10} \mathrm{H}_{10}\right)(64 \mathrm{mg}, 0.20 \mathrm{mmol}$ ) and 4-iodotoluene 19a (105 mg, $0.48 \mathrm{mmol})$. Isolation by column chromatography ( $n$-hexane/EtOAc: 20/1) yielded 150a (71 mg, 71\%) as a colorless solid. M.p. $=$ 171-172 ${ }^{\circ} \mathrm{C}$. ${ }^{1} \mathrm{H}$ NMR $\left(500 \mathrm{MHz}, \mathrm{CDCl}_{3}\right): \delta=7.45(\mathrm{~d}, J=8.5 \mathrm{~Hz}, 2 \mathrm{H}), 7.39-7.32(\mathrm{~m}, 3 \mathrm{H}), 7.22$ (dd, $J=8.5,7.3 \mathrm{~Hz}, 2 \mathrm{H}), 7.17(\mathrm{~d}, J=8.0 \mathrm{~Hz}, 2 \mathrm{H}), 6.94-6.90(\mathrm{~m}, 4 \mathrm{H}), 3.49-3.44(\mathrm{~m}, 2 \mathrm{H}), 3.26-$ $3.22(\mathrm{~m}, 2 \mathrm{H}), 2.28(\mathrm{~s}, 3 \mathrm{H}), 2.24(\mathrm{~s}, 3 \mathrm{H}), 1.00(\mathrm{t}, J=7.0 \mathrm{~Hz}, 6 \mathrm{H}) .{ }^{13} \mathrm{C} \mathrm{NMR}\left(125 \mathrm{MHz}, \mathrm{CDCl}_{3}\right): \delta=$ $156.6\left(\mathrm{C}_{\mathrm{q}}\right), 138.1\left(\mathrm{C}_{\mathrm{q}}\right), 137.7\left(\mathrm{C}_{\mathrm{q}}\right), 136.5(\mathrm{CH}), 133.9(\mathrm{CH}), 133.3\left(\mathrm{C}_{\mathrm{q}}\right), 130.0(\mathrm{CH}), 129.3(\mathrm{CH})$, $128.1(\mathrm{CH}), 127.6(\mathrm{CH}), 127.5(\mathrm{CH}), 85.5\left(\mathrm{C}_{\mathrm{q}}\right), 79.3\left(\mathrm{C}_{\mathrm{q}}\right), 43.7\left(\mathrm{CH}_{2}\right), 21.2\left(\mathrm{CH}_{3}\right), 21.1\left(\mathrm{CH}_{3}\right)$, $12.9\left(\mathrm{CH}_{3}\right) .{ }^{11} \mathrm{~B}$ NMR $\left(160 \mathrm{MHz}, \mathrm{CDCl}_{3}\right): \delta=0.65(2 \mathrm{~B}),-1.38(1 \mathrm{~B}),-3.61(1 \mathrm{~B}),-6.20(1 \mathrm{~B}),-10.54$ (5B). IR (ATR): 2978, 2566, 1653, 1608, 1415, 1264, 1191, $772 \mathrm{~cm}^{-1}$. MS (ESI) $\mathrm{m} / \mathrm{z}$ (relative intensity): 522 (100) $\quad[\mathrm{M}+\mathrm{Na}]^{+}, \quad 500 \quad(40) \quad[\mathrm{M}+\mathrm{H}]^{+}$. HR-MS (ESI): $\mathrm{m} / \mathrm{z}$ calcd. for 
$\mathrm{C}_{27} \mathrm{H}_{38}{ }^{10} \mathrm{~B}_{2}{ }^{11} \mathrm{~B}_{8} \mathrm{NO}[\mathrm{M}+\mathrm{H}]^{+}: 500.3964$, found: 500.3951.

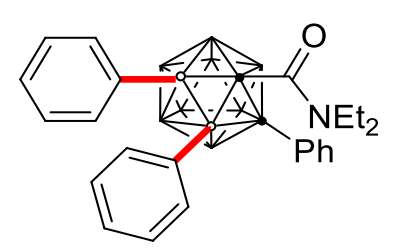

150b. The representative procedure $H$ was followed using o-carborane 149a (1-CONEt 2 -2-Ph-o$\left.\mathrm{C}_{2} \mathrm{~B}_{10} \mathrm{H}_{10}\right)(64 \mathrm{mg}, 0.20 \mathrm{mmol})$ and iodobenzene $19 \mathrm{~b}(98 \mathrm{mg}, 0.48 \mathrm{mmol})$. Isolation by column chromatography ( $n$-hexane/EtOAc: $20 / 1)$ yielded $150 \mathrm{~b}(64 \mathrm{mg}, 68 \%$ ) as a colorless solid. M.p. $=$ 197-198 ${ }^{\circ} \mathrm{C} .{ }^{1} \mathrm{H}$ NMR $\left(400 \mathrm{MHz}, \mathrm{CDCl}_{3}\right): \delta=7.53-7.42(\mathrm{~m}, 4 \mathrm{H}), 7.37-7.32(\mathrm{~m}, 1 \mathrm{H}), 7.29-7.15$ (m, 6H), 7.14-7.04 (m, 4H), 3.50-3.41 (m, 2H), 3.26-3.20 (m, 2H), $0.99(\mathrm{t}, J=7.0 \mathrm{~Hz}, 6 \mathrm{H}) .{ }^{13} \mathrm{C}$ NMR $\left(100 \mathrm{MHz}, \mathrm{CDCl}_{3}\right): \delta=156.6\left(\mathrm{C}_{\mathrm{q}}\right), 136.6(\mathrm{CH}), 134.0(\mathrm{CH}), 133.2\left(\mathrm{C}_{\mathrm{q}}\right), 130.1(\mathrm{CH}), 129.4$ $(\mathrm{CH}), 128.4(\mathrm{CH}), 128.0(\mathrm{CH}), 127.6(\mathrm{CH}), 127.2(\mathrm{CH}), 126.6(\mathrm{CH}), 86.0\left(\mathrm{C}_{q}\right), 79.7\left(\mathrm{C}_{q}\right), 43.8$ $\left(\mathrm{CH}_{2}\right), 12.9\left(\mathrm{CH}_{3}\right) .{ }^{11} \mathrm{~B}$ NMR $\left(128 \mathrm{MHz}, \mathrm{CDCl}_{3}\right): \delta=0.34(2 \mathrm{~B}),-1.31(1 \mathrm{~B}),-3.28(1 \mathrm{~B}),-5.82(1 \mathrm{~B}),-$ 10.20 (5B). IR (ATR): 2973, 2567, 1647, 1430, 1266, 1208, $696 \mathrm{~cm}^{-1}$. MS (ESI) $\mathrm{m} / \mathrm{z}$ (relative intensity): 494 (100) $[\mathrm{M}+\mathrm{Na}]^{+}, \quad 472 \quad(40) \quad[\mathrm{M}+\mathrm{H}]^{+}$. HR-MS (ESI): $\mathrm{m} / \mathrm{z}$ calcd. for $\mathrm{C}_{25} \mathrm{H}_{34}{ }^{10} \mathrm{~B}_{2}{ }^{11} \mathrm{~B}_{8} \mathrm{NO}[\mathrm{M}+\mathrm{H}]^{+}:$: 42.3650, found: 472.3631 .

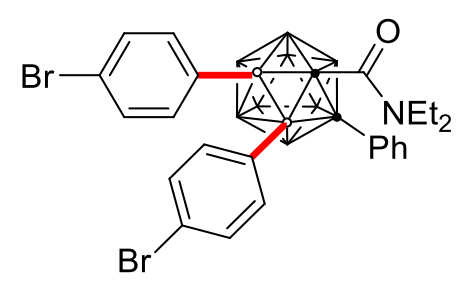

150c. The representative procedure $\mathrm{H}$ was followed using o-carborane $149 \mathrm{a}$ (1-CONEt $2-2-\mathrm{Ph}-\mathrm{O}$ $\left.\mathrm{C}_{2} \mathrm{~B}_{10} \mathrm{H}_{10}\right)(64 \mathrm{mg}, 0.20 \mathrm{mmol}$ ) and 1-bromo-4-iodobenzene 19c (136 mg, $0.48 \mathrm{mmol})$. Isolation by column chromatography ( $n$-hexane/EtOAc: $20 / 1)$ yielded $150 \mathrm{c}(76 \mathrm{mg}, 61 \%)$ as a colorless solid. M.p. $=205-206{ }^{\circ} \mathrm{C} .{ }^{1} \mathrm{H}$ NMR $\left(300 \mathrm{MHz}, \mathrm{CDCl}_{3}\right): \delta=7.50-7.39(\mathrm{~m}, 3 \mathrm{H}), 7.32-7.27(\mathrm{~m}, 5 \mathrm{H})$, 7.25-7.22 (m, 3H), 7.21-7.14 (m, 2H), 3.60-3.42 (m, 4H), $1.05(\mathrm{t}, J=6.9 \mathrm{~Hz}, 6 \mathrm{H}) .{ }^{13} \mathrm{C}$ NMR $(75$ $\left.\mathrm{MHz}, \mathrm{CDCl}_{3}\right): \delta=156.2\left(\mathrm{C}_{\mathrm{q}}\right), 138.0(\mathrm{CH}), 135.6(\mathrm{CH}), 132.0\left(\mathrm{C}_{\mathrm{q}}\right), 130.5(\mathrm{CH}), 129.8(\mathrm{CH}), 129.7$ $(\mathrm{CH}), 129.6(\mathrm{CH}), 127.9(\mathrm{CH}), 123.6\left(\mathrm{C}_{\mathrm{q}}\right), 123.2\left(\mathrm{C}_{\mathrm{q}}\right), 84.6\left(\mathrm{C}_{\mathrm{q}}\right), 78.5\left(\mathrm{C}_{\mathrm{q}}\right), 44.0\left(\mathrm{CH}_{2}\right), 13.1\left(\mathrm{CH}_{3}\right)$. ${ }^{11} \mathrm{~B}$ NMR (96 MHz, $\mathrm{CDCl}_{3}$ ): $\delta=0.22$ (3B), -3.11 (1B), -6.02 (1B), -9.94 (5B). IR (ATR): 2573, 1647, 1578, 1487, 1381, 1205,1010,693 $\mathrm{cm}^{-1}$. MS (ESI) $\mathrm{m} / \mathrm{z}$ (relative intensity): 652 (100) $[\mathrm{M}+\mathrm{Na}]^{+}, 630$ (10) $[\mathrm{M}+\mathrm{H}]^{+}$. HR-MS (ESI): $\mathrm{m} / \mathrm{z}$ calcd. for $\mathrm{C}_{25} \mathrm{H}_{31}{ }^{11} \mathrm{~B}_{10}{ }^{79} \mathrm{Br}_{2} \mathrm{NONa}[\mathrm{M}+\mathrm{Na}]^{+}$: 652.1657, found: 652.1642 . 


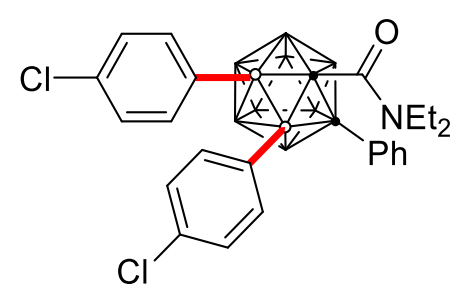

$150 \mathrm{~d}$. The representative procedure $H$ was followed using o-carborane $149 \mathrm{a}$ (1-CONEt $2-2-\mathrm{Ph}-\mathrm{O}-$ $\left.\mathrm{C}_{2} \mathrm{~B}_{10} \mathrm{H}_{10}\right)(64 \mathrm{mg}, 0.20 \mathrm{mmol})$ and 1-chloro-4-iodobenzene $19 \mathrm{~d}(115 \mathrm{mg}, 0.48 \mathrm{mmol})$. Isolation by column chromatography ( $n$-hexane/EtOAc: $20 / 1$ ) yielded $150 \mathrm{~d}$ (73 $\mathrm{mg}, 68 \%$ ) as a colorless solid. M.p. $=185-186^{\circ} \mathrm{C} .{ }^{1} \mathbf{H}$ NMR $\left(300 \mathrm{MHz}, \mathrm{CDCl}_{3}\right): \delta=7.48-7.40(\mathrm{~m}, 3 \mathrm{H}), 7.35-7.22(\mathrm{~m}, 6 \mathrm{H})$, 7.17-7.08 (m, 4H), 3.54-3.40 (m, 4H), $1.06(\mathrm{t}, J=7.0 \mathrm{~Hz}, 6 \mathrm{H}) .{ }^{13} \mathrm{C}$ NMR $\left(75 \mathrm{MHz}, \mathrm{CDCl}_{3}\right): \delta=$ $156.2\left(\mathrm{C}_{\mathrm{q}}\right), 137.8(\mathrm{CH}), 135.3(\mathrm{CH}), 135.0\left(\mathrm{C}_{\mathrm{q}}\right), 134.7\left(\mathrm{C}_{\mathrm{q}}\right), 132.1\left(\mathrm{C}_{\mathrm{q}}\right), 129.9(\mathrm{CH}), 129.6(\mathrm{CH})$, $128.0(\mathrm{CH}), 127.5(\mathrm{CH}), 126.9(\mathrm{CH}), 84.9\left(\mathrm{C}_{\mathrm{q}}\right), 78.9\left(\mathrm{C}_{\mathrm{q}}\right), 44.2\left(\mathrm{CH}_{2}\right), 12.9\left(\mathrm{CH}_{3}\right) .{ }^{11}$ B NMR $(96$ $\mathrm{MHz}, \mathrm{CDCl}_{3}$ ): $\delta=0.49$ (3B), -3.10 (1B), -6.38 (1B), -10.40 (5B). IR (ATR): 2571, 1648, 1584, 1489, 1268, 1205, 1092, $730 \mathrm{~cm}^{-1}$. MS (ESI) $\mathrm{m} / z$ (relative intensity): 564 (100) [M+Na] ${ }^{+}, 542$ (10) $[\mathrm{M}+\mathrm{H}]^{+}$. HR-MS (ESI): $\mathrm{m} / z$ calcd. for $\mathrm{C}_{25} \mathrm{H}_{31}{ }^{11} \mathrm{~B}_{10}{ }^{35} \mathrm{Cl}_{2} \mathrm{NONa}[\mathrm{M}+\mathrm{Na}]^{+}: 564.2649$, found: 564.2640 .

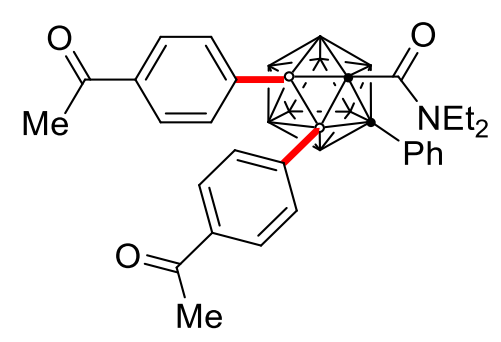

150e. The representative procedure $\mathrm{H}$ was followed using o-carborane $149 \mathrm{a}$ (1-CONEt $2-2-\mathrm{Ph}-\mathrm{O}$ $\left.\mathrm{C}_{2} \mathrm{~B}_{10} \mathrm{H}_{10}\right)(64 \mathrm{mg}, 0.20 \mathrm{mmol})$ and 1-(4-iodophenyl)ethanone $19 \mathrm{e}(118 \mathrm{mg}, 0.48 \mathrm{mmol})$. Isolation by column chromatography ( $n$-hexane/EtOAc: $20 / 1)$ yielded $150 \mathrm{e}$ (64 mg, 58\%) as a colorless solid. M.p. $=244-245{ }^{\circ} \mathrm{C} .{ }^{1} \mathrm{H}$ NMR $\left(300 \mathrm{MHz}, \mathrm{CDCl}_{3}\right): \delta=7.74(\mathrm{~d}, J=8.3 \mathrm{~Hz}, 2 \mathrm{H}), 7.66(\mathrm{~d}, J=$ $8.3 \mathrm{~Hz}, 2 \mathrm{H}), 7.51-7.39(\mathrm{~m}, 7 \mathrm{H}), 7.34-7.27(\mathrm{~m}, 2 \mathrm{H}), 3.60-3.45(\mathrm{~m}, 4 \mathrm{H}), 2.56(\mathrm{~s}, 3 \mathrm{H}), 2.55(\mathrm{~s}, 3 \mathrm{H})$, $1.09(\mathrm{t}, J=6.9 \mathrm{~Hz}, 6 \mathrm{H}) .{ }^{13} \mathrm{C} \mathrm{NMR}\left(75 \mathrm{MHz}, \mathrm{CDCl}_{3}\right): \delta=198.3\left(\mathrm{C}_{\mathrm{q}}\right), 198.1\left(\mathrm{C}_{\mathrm{q}}\right), 156.0\left(\mathrm{C}_{\mathrm{q}}\right), 136.6$ $\left(\mathrm{C}_{\mathrm{q}}\right), 136.5(\mathrm{CH}), 136.4\left(\mathrm{C}_{\mathrm{q}}\right), 134.2(\mathrm{CH}), 131.8\left(\mathrm{C}_{\mathrm{q}}\right), 130.1(\mathrm{CH}), 129.7(\mathrm{CH}), 128.0(\mathrm{CH}), 127.0$ $(\mathrm{CH}), 126.0(\mathrm{CH}), 84.9\left(\mathrm{C}_{\mathrm{q}}\right), 78.5\left(\mathrm{C}_{\mathrm{q}}\right), 43.9\left(\mathrm{CH}_{2}\right), 26.7\left(\mathrm{CH}_{3}\right), 26.5\left(\mathrm{CH}_{3}\right), 13.0\left(\mathrm{CH}_{3}\right) .{ }^{11} \mathbf{B}$ NMR $\left(96 \mathrm{MHz}, \mathrm{CDCl}_{3}\right): \delta=0.58$ (3B), -2.61 (1B), -5.98 (1B), -9.67 (5B). IR (ATR): 2572, 1679, 1642, $1357,1266,1200,730,590 \mathrm{~cm}^{-1}$. MS (ESI) $\mathrm{m} / \mathrm{z}$ (relative intensity): $578(100)[\mathrm{M}+\mathrm{Na}]^{+}, 556(10)$ 
$[\mathrm{M}+\mathrm{H}]^{+}$. HR-MS (ESI): $\mathrm{m} / z$ calcd. for $\mathrm{C}_{29} \mathrm{H}_{37^{10}} \mathrm{~B}_{2}{ }^{11} \mathrm{~B}_{8} \mathrm{NO}_{3} \mathrm{Na}[\mathrm{M}+\mathrm{Na}]^{+}: 578.3683$, found: 578.3676 .

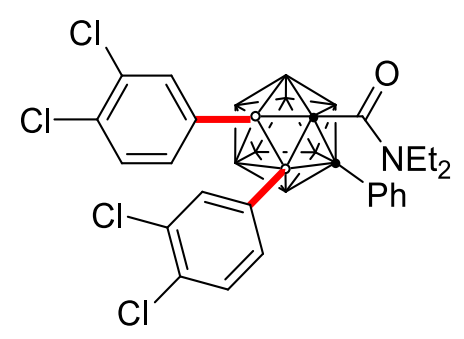

150f. The representative procedure $\mathbf{H}$ was followed using o-carborane $149 \mathrm{a}$ (1-CONEt $2-2-\mathrm{Ph}-\mathrm{O}$ $\left.\mathrm{C}_{2} \mathrm{~B}_{10} \mathrm{H}_{10}\right)(64 \mathrm{mg}, 0.20 \mathrm{mmol})$ and 1,2-dichloro-4-iodobenzene $19 \mathrm{f}(131 \mathrm{mg}, 0.48 \mathrm{mmol})$. Isolation by column chromatography ( $n$-hexane/EtOAc: $20 / 1$ ) yielded $150 \mathrm{f}(78 \mathrm{mg}, 64 \%)$ as a colorless solid. M.p. $=208-209{ }^{\circ} \mathrm{C} .{ }^{1} \mathbf{H}$ NMR $\left(300 \mathrm{MHz}, \mathrm{CDCl}_{3}\right): \delta=7.48-7.40(\mathrm{~m}, 4 \mathrm{H}), 7.36-$ $7.26(\mathrm{~m}, 4 \mathrm{H}), 7.22-7.11(\mathrm{~m}, 3 \mathrm{H}), 3.60-3.45(\mathrm{~m}, 4 \mathrm{H}), 1.13(\mathrm{t}, J=6.9 \mathrm{~Hz}, 6 \mathrm{H}) .{ }^{13} \mathrm{C}$ NMR $(75 \mathrm{MHz}$, $\left.\mathrm{CDCl}_{3}\right): \delta=155.8\left(\mathrm{C}_{\mathrm{q}}\right), 138.1(\mathrm{CH}), 135.6(\mathrm{CH}), 135.4(\mathrm{CH}), 133.2(\mathrm{CH}), 133.0\left(\mathrm{C}_{\mathrm{q}}\right), 132.9\left(\mathrm{C}_{\mathrm{q}}\right)$, $132.0\left(\mathrm{C}_{\mathrm{q}}\right), 131.5\left(\mathrm{C}_{\mathrm{q}}\right), 130.9\left(\mathrm{C}_{\mathrm{q}}\right), 130.2(\mathrm{CH}), 129.7(\mathrm{CH}), 129.5(\mathrm{CH}), 128.7(\mathrm{CH}), 128.2(\mathrm{CH})$, $85.0\left(\mathrm{C}_{\mathrm{q}}\right), 78.2\left(\mathrm{C}_{\mathrm{q}}\right), 44.2\left(\mathrm{CH}_{2}\right), 13.0\left(\mathrm{CH}_{3}\right) .{ }^{11} \mathrm{~B}$ NMR $\left(96 \mathrm{MHz}, \mathrm{CDCl}_{3}\right): \delta=0.76(3 \mathrm{~B}),-3.10(1 \mathrm{~B})$, -6.49 (1B), -10.24 (5B). IR (ATR): 2578, 1646, 1473, 1424, 1203, 1028, $695 \mathrm{~cm}^{-1}$. MS (ESI) $\mathrm{m} / \mathrm{z}$ (relative intensity): 632 (100) $[\mathrm{M}+\mathrm{Na}]^{+}, 610(10)[\mathrm{M}+\mathrm{H}]^{+}$. HR-MS (ESI): $\mathrm{m} / \mathrm{z}$ calcd. for $\mathrm{C}_{25} \mathrm{H}_{29}{ }^{11} \mathrm{~B}_{10}{ }^{35} \mathrm{Cl}_{4} \mathrm{NONa}[\mathrm{M}+\mathrm{Na}]^{+}: 632.1879$, found: 632.1867.

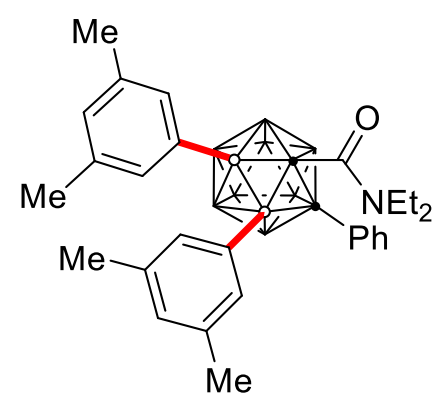

$150 \mathrm{~g}$. The representative procedure $\mathrm{H}$ was followed using o-carborane $149 \mathrm{a}$ (1-CONEt $2-2-\mathrm{Ph}-\mathrm{O}-$ $\left.\mathrm{C}_{2} \mathrm{~B}_{10} \mathrm{H}_{10}\right)$ (64 mg, $0.20 \mathrm{mmol}$ ) and 1-iodo-3,5-dimethylbenzene $19 \mathrm{~g}$ (112 $\mathrm{mg}, 0.48 \mathrm{mmol}$ ). Isolation by column chromatography ( $n$-hexane/EtOAc: $20 / 1)$ yielded $150 \mathrm{~g}(66 \mathrm{mg}, 63 \%)$ as a colorless solid. M.p. $=203-205^{\circ} \mathrm{C} .{ }^{1} \mathrm{H}$ NMR $\left(300 \mathrm{MHz}, \mathrm{CDCl}_{3}\right): \delta=7.52(\mathrm{~d}, J=7.4 \mathrm{~Hz}, 2 \mathrm{H})$, 7.40-7.32 (m, 1H), 7.29-7.18 (m, 4H), 7.00-6.90 (m, 3H), $6.87(\mathrm{~s}, 1 \mathrm{H}), 3.62(\mathrm{q}, J=7.0 \mathrm{~Hz}, 2 \mathrm{H})$, 3.09 (q, $J=7.0 \mathrm{~Hz}, 2 \mathrm{H}), 2.19(\mathrm{~s}, 6 \mathrm{H}), 2.16(\mathrm{~s}, 6 \mathrm{H}), 1.08$ (t, $J=7.0 \mathrm{~Hz}, 6 \mathrm{H}) .{ }^{13} \mathrm{C}$ NMR $(75 \mathrm{MHz}$, 
$\left.\mathrm{CDCl}_{3}\right): \delta=156.8\left(\mathrm{C}_{\mathrm{q}}\right), 136.2\left(\mathrm{C}_{\mathrm{q}}\right), 135.6\left(\mathrm{C}_{\mathrm{q}}\right), 134.3(\mathrm{CH}), 134.3\left(\mathrm{C}_{\mathrm{q}}\right), 131.8(\mathrm{CH}), 130.4(\mathrm{CH})$, $130.2(\mathrm{CH}), 129.7(\mathrm{CH}), 129.3(\mathrm{CH}), 127.5(\mathrm{CH}), 87.6\left(\mathrm{C}_{\mathrm{q}}\right), 80.3\left(\mathrm{C}_{\mathrm{q}}\right), 43.5\left(\mathrm{CH}_{2}\right), 21.4\left(\mathrm{CH}_{3}\right)$, $21.2\left(\mathrm{CH}_{3}\right), 12.7\left(\mathrm{CH}_{3}\right) .{ }^{11} \mathrm{~B}$ NMR $\left(96 \mathrm{MHz}, \mathrm{CDCl}_{3}\right): \delta=0.69(2 \mathrm{~B}),-1.17(1 \mathrm{~B}),-3.10(1 \mathrm{~B}),-5.90$ (1B), -10.05 (5B). IR (ATR): 2916, 2557, 1646, 1420, 1264, 1183, 855, $689 \mathrm{~cm}^{-1}$. MS (ESI) m/z (relative intensity): $550(100)[\mathrm{M}+\mathrm{Na}]^{+}, 528(10)[\mathrm{M}+\mathrm{H}]^{+}$. HR-MS (ESI): $\mathrm{m} / \mathrm{z}$ calcd. for $\mathrm{C}_{29} \mathrm{H}_{41}{ }^{10} \mathrm{~B}_{2}{ }^{11} \mathrm{~B}_{8} \mathrm{NONa}[\mathrm{M}+\mathrm{Na}]^{+}: 550.4097$, found: 550.4096 .

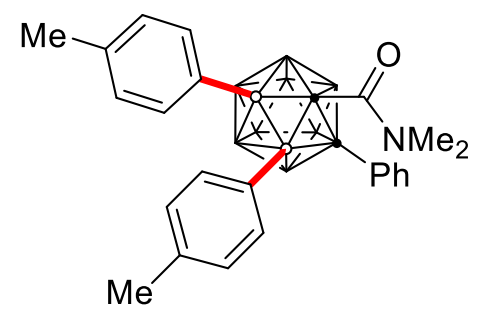

152a. The representative procedure $\mathbf{H}$ was followed using o-carborane $151 \mathrm{a}$ (1-CONMe$-2-\mathrm{Ph}$ $\left.0-\mathrm{C}_{2} \mathrm{~B}_{10} \mathrm{H}_{10}\right)$ (58 mg, $0.20 \mathrm{mmol}$ ) and 4-iodotoluene $19 \mathrm{a}(105 \mathrm{mg}, 0.48 \mathrm{mmol})$. Isolation by column chromatography ( $n$-hexane/EtOAc: $20 / 1$ ) yielded $152 \mathrm{a}(48 \mathrm{mg}, 51 \%)$ as a colorless solid. M.p. $=158-159^{\circ} \mathrm{C} .{ }^{1} \mathrm{H}$ NMR $\left(400 \mathrm{MHz}, \mathrm{CDCl}_{3}\right): \delta=7.45(\mathrm{~d}, J=7.4 \mathrm{~Hz}, 2 \mathrm{H}), 7.40-7.36(\mathrm{~m}, 1 \mathrm{H})$, 7.34-7.23 (m, 4H), 7.20 (d, J = 7.9 Hz, 2H), 6.99-6.90 (m, 4H), $3.04(\mathrm{~s}, 6 \mathrm{H}), 2.31$ (s, 3H), 2.29 (s, 3H). ${ }^{13} \mathrm{C}$ NMR $\left(100 \mathrm{MHz}, \mathrm{CDCl}_{3}\right): \delta=157.7\left(\mathrm{C}_{\mathrm{q}}\right), 138.3\left(\mathrm{C}_{\mathrm{q}}\right), 137.9\left(\mathrm{C}_{\mathrm{q}}\right), 136.3(\mathrm{CH}), 133.9$ $(\mathrm{CH}), 133.1\left(\mathrm{C}_{\mathrm{q}}\right), 130.0(\mathrm{CH}), 129.5(\mathrm{CH}), 128.4(\mathrm{CH}), 127.8(\mathrm{CH}), 127.6(\mathrm{CH}), 85.9\left(\mathrm{C}_{\mathrm{q}}\right), 78.6$ $\left(\mathrm{C}_{\mathrm{q}}\right), 40.8\left(\mathrm{CH}_{3}\right), 21.3\left(\mathrm{CH}_{3}\right), 21.2\left(\mathrm{CH}_{3}\right) .{ }^{11} \mathrm{~B}$ NMR $\left(128 \mathrm{MHz}, \mathrm{CDCl}_{3}\right): \delta=0.7(2 \mathrm{~B}),-1.3(1 \mathrm{~B}),-$ 3.2 (1B), -6.4 (1B), -10.6 (5B). IR (ATR): 2921, 2570, 1644, 1393, 1195, 743, $693 \mathrm{~cm}^{-1}$. MS (ESI) $\mathrm{m} / \mathrm{z}$ (relative intensity): $473(100)[\mathrm{M}+\mathrm{H}]^{+}$. HR-MS (ESI): $\mathrm{m} / \mathrm{z}$ calcd. for $\mathrm{C}_{25} \mathrm{H}_{34}{ }^{10} \mathrm{~B}_{1}{ }^{11} \mathrm{~B} 9 \mathrm{NO}[\mathrm{M}+\mathrm{H}]^{+}$: 473.3607, found: 473.3606 .

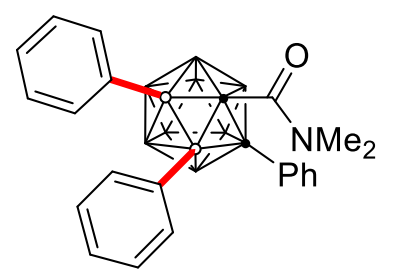

152b. The representative procedure $\mathrm{H}$ was followed using o-carborane 151a (1-CONMe$-2-\mathrm{Ph}$ $\left.0-\mathrm{C}_{2} \mathrm{~B}_{10} \mathrm{H}_{10}\right)(58 \mathrm{mg}, 0.20 \mathrm{mmol}$ ) and iodobenzene $19 \mathrm{~b}(98 \mathrm{mg}, 0.48 \mathrm{mmol})$. Isolation by column chromatography ( $n$-hexane/EtOAc: $20 / 1)$ yielded 152b (47 mg, 53\%) as a colorless solid. M.p. $=$ 
99-100 ${ }^{\circ} \mathrm{C} .{ }^{1} \mathrm{H}$ NMR $\left(400 \mathrm{MHz}, \mathrm{CDCl}_{3}\right): \delta=7.47-7.41(\mathrm{~m}, 4 \mathrm{H}), 7.40-7.35(\mathrm{~m}, 1 \mathrm{H}), 7.32-7.29(\mathrm{~m}$, $2 \mathrm{H}), 7.28-7.20(\mathrm{~m}, 4 \mathrm{H}), 7.18-7.10(\mathrm{~m}, 4 \mathrm{H}), 3.03(\mathrm{~s}, 6 \mathrm{H}) .{ }^{13} \mathrm{C} \mathrm{NMR}\left(100 \mathrm{MHz}, \mathrm{CDCl}_{3}\right): \delta=157.7$ $\left(\mathrm{C}_{\mathrm{q}}\right), 136.4(\mathrm{CH}), 133.9(\mathrm{CH}), 133.0\left(\mathrm{C}_{\mathrm{q}}\right), 130.0(\mathrm{CH}), 129.6(\mathrm{CH}), 128.6(\mathrm{CH}), 128.2(\mathrm{CH}), 127.9$ $(\mathrm{CH}), 127.5(\mathrm{CH}), 126.8(\mathrm{CH}), 86.4\left(\mathrm{C}_{\mathrm{q}}\right), 79.0\left(\mathrm{C}_{\mathrm{q}}\right), 40.8\left(\mathrm{CH}_{3}\right) .{ }^{11} \mathrm{~B}$ NMR $\left(128 \mathrm{MHz}, \mathrm{CDCl}_{3}\right): \delta=$ 0.57 (2B), -1.13 (1B), -3.10 (1B), -6.27 (1B), -10.23 (5B). IR (ATR): 3053, 2581, 1654, 1493, 1373, 1167, $744 \mathrm{~cm}^{-1}$. MS (ESI) $\mathrm{m} / \mathrm{z}$ (relative intensity): $444(100)[\mathrm{M}+\mathrm{H}]^{+}, 466(10)[\mathrm{M}+\mathrm{Na}]^{+}$. HR-MS (ESI): $m / z$ calcd. for $\mathrm{C}_{23} \mathrm{H}_{30}{ }^{10} \mathrm{~B}_{2}{ }^{11} \mathrm{~B}_{8} \mathrm{NO}[\mathrm{M}+\mathrm{H}]^{+}: 444.3336$, found: 444.3328 .

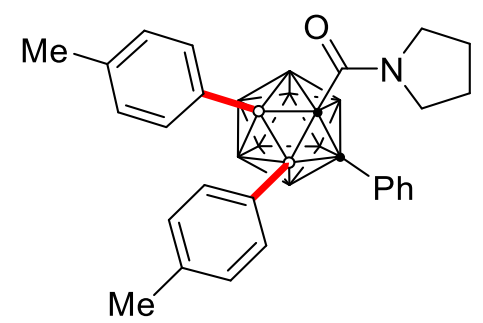

152c. The representative procedure $\mathbf{H}$ was followed using o-carborane $151 \mathrm{~b}\left(1-\mathrm{CON}\left(\mathrm{CH}_{2}\right)_{4}-2-\right.$ Ph-o- $\mathrm{C}_{2} \mathrm{~B}_{10} \mathrm{H}_{10}$ ) (63 mg, $0.20 \mathrm{mmol}$ ) and 4-iodotoluene 19a (105 mg, $0.48 \mathrm{mmol}$ ). Isolation by column chromatography ( $n$-hexane/EtOAc: $20 / 1)$ yielded 152c (59 mg, 60\%) as a pink solid. M.p. $=228-230^{\circ} \mathrm{C} .{ }^{1} \mathbf{H}$ NMR $\left(400 \mathrm{MHz}, \mathrm{CDCl}_{3}\right): \delta=7.44-7.38(\mathrm{~m}, 2 \mathrm{H}), 7.36-7.28(\mathrm{~m}, 3 \mathrm{H}), 7.22-7.16$ $(\mathrm{m}, 2 \mathrm{H}), 7.16-7.10(\mathrm{~m}, 2 \mathrm{H}), 6.96-6.87(\mathrm{~m}, 4 \mathrm{H}), 3.65-3.28(\mathrm{~m}, 4 \mathrm{H}), 2.25(\mathrm{~s}, 3 \mathrm{H}), 2.23(\mathrm{~s}, 3 \mathrm{H})$, 1.80-1.63 (m, 4H). ${ }^{13} \mathrm{C}$ NMR (100 MHz, $\left.\mathrm{CDCl}_{3}\right): \delta=155.7\left(\mathrm{C}_{\mathrm{q}}\right), 138.1\left(\mathrm{C}_{\mathrm{q}}\right), 137.7\left(\mathrm{C}_{\mathrm{q}}\right), 136.6$ $(\mathrm{CH}), 133.6(\mathrm{CH}), 132.9\left(\mathrm{C}_{\mathrm{q}}\right), 129.9(\mathrm{CH}), 129.4(\mathrm{CH}), 128.3(\mathrm{CH}), 127.7(\mathrm{CH}), 127.5(\mathrm{CH}), 85.0$ $\left(\mathrm{C}_{\mathrm{q}}\right), 78.7\left(\mathrm{C}_{\mathrm{q}}\right), 50.5$ (overlapped, $\left.\mathrm{CH}_{2}\right), 21.2\left(\mathrm{CH}_{3}\right), 21.2\left(\mathrm{CH}_{3}\right) .{ }^{11} \mathrm{~B}$ NMR $\left(128 \mathrm{MHz}, \mathrm{CDCl}_{3}\right): \delta=$ 0.57 (2B), -1.61 (1B), -3.32 (1B), -6.45 (1B), -10.78 (5B). IR (ATR): 2975, 2878, 2570, 1639, 1446, 1225, 865, 753, $690 \mathrm{~cm}^{-1}$. MS (ESI) $\mathrm{m} / z$ (relative intensity): $498(20)[\mathrm{M}+\mathrm{H}]^{+}, 520(100)$ $[\mathrm{M}+\mathrm{Na}]^{+}$. HR-MS (ESI) $\mathrm{m} / z$ calcd for $\mathrm{C}_{27} \mathrm{H}_{35}{ }^{10} \mathrm{~B}_{2}{ }^{11} \mathrm{~B}_{8} \mathrm{NONa}[\mathrm{M}+\mathrm{Na}]^{+} 520.3627$, found 520.3623 .

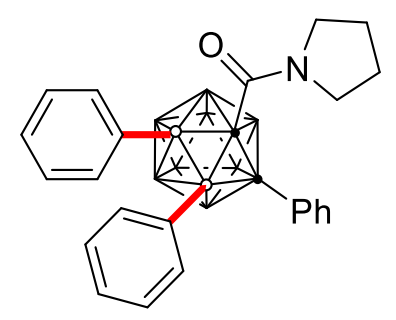

152d. The representative procedure $\mathbf{H}$ was followed using o-carborane 151b (1-CON $\left(\mathrm{CH}_{2}\right)_{4}-2$ $\left.\mathrm{Ph}-\mathrm{O}-\mathrm{C}_{2} \mathrm{~B}_{10} \mathrm{H}_{10}\right)(63 \mathrm{mg}, 0.20 \mathrm{mmol}$ ) and iodobenzene $19 \mathrm{~b}(98 \mathrm{mg}, 0.48 \mathrm{mmol}$ ). Isolation by 
column chromatography ( $n$-hexane/EtOAc: $20 / 1)$ yielded 152d (50 mg, 53\%) as a colorless solid. M.p. $=176-177^{\circ} \mathrm{C} .{ }^{1} \mathbf{H}$ NMR $\left(500 \mathrm{MHz}, \mathrm{CDCl}_{3}\right): \delta=7.51-7.44(\mathrm{~m}, 2 \mathrm{H}), 7.43-7.38(\mathrm{~m}, 2 \mathrm{H})$, 7.35-7.30 (m, 1H), 7.25-7.24 (m, 1H), 7.24-7.16 (m, 5H), 7.13-7.04 (m, 4H), 3.63-3.41 (m, 4H), 1.83-1.61 (m, 4H). ${ }^{13} \mathrm{C}$ NMR (125 MHz, $\left.\mathrm{CDCl}_{3}\right): \delta=155.7\left(\mathrm{C}_{\mathrm{q}}\right), 136.7(\mathrm{CH}), 133.6(\mathrm{CH}), 132.8$ $\left(\mathrm{C}_{\mathrm{q}}\right), 129.9(\mathrm{CH}), 129.5(\mathrm{CH}), 128.4(\mathrm{CH}), 128.1(\mathrm{CH}), 127.7(\mathrm{CH}), 127.4(\mathrm{CH}), 126.6(\mathrm{CH}), 85.5$ $\left(\mathrm{C}_{\mathrm{q}}\right), 79.1\left(\mathrm{C}_{\mathrm{q}}\right), 50.5$ (overlapped, $\mathrm{CH}_{2}$ ). ${ }^{11} \mathrm{~B}$ NMR $\left(96 \mathrm{MHz}, \mathrm{CDCl}_{3}\right): \delta=0.48(2 \mathrm{~B}),-1.36(1 \mathrm{~B})$, 3.15 (1B), -6.18 (1B), -10.26 (5B). IR (ATR): 2921, 2570, 1643, 1389, 1195, 861, 743, $692 \mathrm{~cm}^{-1}$. MS (ESI) $\mathrm{m} / \mathrm{z}$ (relative intensity): $471(100)[\mathrm{M}+\mathrm{H}]^{+}, 493$ (10) $[\mathrm{M}+\mathrm{Na}]^{+}$. HR-MS (ESI): $\mathrm{m} / z$ calcd. for $\mathrm{C}_{25} \mathrm{H}_{32}{ }^{10} \mathrm{~B}_{1}{ }^{11} \mathrm{~B} 9 \mathrm{NO}[\mathrm{M}+\mathrm{H}]^{+}: 471.3450$, found: 471.3448 .

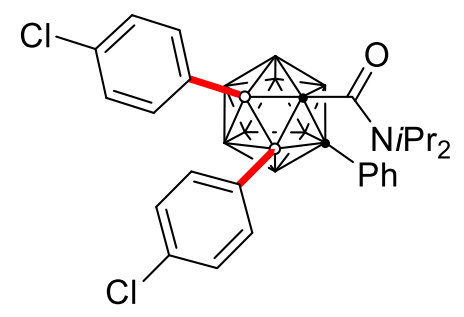

152e. The representative procedure $\mathrm{H}$ was followed using o-carborane 151c (1-CON'Pr $\mathrm{P}_{2}-2-\mathrm{Ph}-\mathrm{O}-$ $\mathrm{C}_{2} \mathrm{~B}_{10} \mathrm{H}_{10}$ ) (70 mg, $0.20 \mathrm{mmol}$ ) and 1-chloro-4-iodobenzene 19d (114 mg, $0.48 \mathrm{mmol}$ ). Isolation by column chromatography ( $n$-hexane/EtOAc: $20 / 1$ ) yielded $152 \mathrm{e}(61 \mathrm{mg}, 54 \%$ ) as a colorless solid. M.p. $=232-233^{\circ} \mathrm{C} .{ }^{1} \mathrm{H}$ NMR $\left(400 \mathrm{MHz}, \mathrm{CDCl}_{3}\right): \delta=7.52(\mathrm{~d}, J=7.4 \mathrm{~Hz}, 2 \mathrm{H}), 7.45-7.41$ (m, $1 \mathrm{H}), 7.35(\mathrm{~d}, J=8.4 \mathrm{~Hz}, 2 \mathrm{H}), 7.32-7.27(\mathrm{~m}, 2 \mathrm{H}), 7.19(\mathrm{~d}, J=8.6 \mathrm{~Hz}, 2 \mathrm{H}), 7.14(\mathrm{~d}, J=8.4 \mathrm{~Hz}$, $2 \mathrm{H}), 7.07(\mathrm{~d}, J=8.4 \mathrm{~Hz}, 2 \mathrm{H}), 5.24-5.18(\mathrm{~m}, 1 \mathrm{H}), 3.44-3.39(\mathrm{~m}, 1 \mathrm{H}), 1.29(\mathrm{~d}, J=6.7 \mathrm{~Hz}, 6 \mathrm{H})$, $1.04(\mathrm{~d}, J=6.7 \mathrm{~Hz}, 6 \mathrm{H}) \cdot{ }^{13} \mathrm{C}$ NMR $\left(100 \mathrm{MHz}, \mathrm{CDCl}_{3}\right): \delta=154.5\left(\mathrm{C}_{\mathrm{q}}\right), 137.9(\mathrm{CH}), 136.1(\mathrm{CH})$, $134.7\left(\mathrm{C}_{\mathrm{q}}\right), 134.5\left(\mathrm{C}_{\mathrm{q}}\right), 132.0\left(\mathrm{C}_{\mathrm{q}}\right), 129.9(\mathrm{CH}), 129.5(\mathrm{CH}), 128.0(\mathrm{CH}), 127.5(\mathrm{CH}), 126.5(\mathrm{CH})$, $83.9\left(\mathrm{C}_{\mathrm{q}}\right), 79.1\left(\mathrm{C}_{\mathrm{q}}\right), 50.3(\mathrm{CH}), 49.4(\mathrm{CH}), 20.5\left(\mathrm{CH}_{3}\right), 20.3\left(\mathrm{CH}_{3}\right), 19.7\left(\mathrm{CH}_{3}\right), 19.6\left(\mathrm{CH}_{3}\right) .{ }^{11} \mathbf{B}$ NMR (128 MHz, $\left.\mathrm{CDCl}_{3}\right): \delta=1.47$ (1B), -1.05 (2B), -3.30 (1B), -6.75 (1B), -10.90 (5B). IR (ATR): 2968, 2620, 2585, 1657, 1586, 1491, 1369, 1296, $691 \mathrm{~cm}^{-1}$. MS (ESI) $\mathrm{m} / \mathrm{z}$ (relative intensity): 569 (100) $[\mathrm{M}+\mathrm{H}]^{+}, 591$ (10) $[\mathrm{M}+\mathrm{Na}]^{+}$. HR-MS (ESI): $\mathrm{m} / \mathrm{z}$ calcd. for $\mathrm{C}_{27} \mathrm{H}_{36}{ }^{10} \mathrm{~B}_{1}{ }^{11} \mathrm{~B}_{9}{ }^{35} \mathrm{Cl}_{2} \mathrm{NO}[\mathrm{M}+\mathrm{H}]^{+}$: 569.3141, found: 569.3142 . 


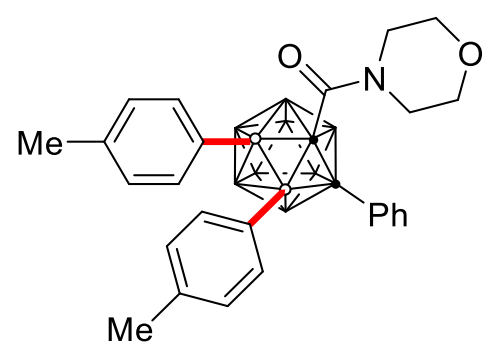

152f. The representative procedure $\mathbf{H}$ was followed using o-carborane $151 \mathbf{d}$ (1- $\mathrm{CON}\left(\mathrm{CH}_{2}\right)_{4} \mathrm{O}-2-$ $\left.\mathrm{Ph}-\mathrm{o}-\mathrm{C}_{2} \mathrm{~B}_{10} \mathrm{H}_{10}\right)(67 \mathrm{mg}, 0.20 \mathrm{mmol})$ and 4-iodotoluene 19a $(105 \mathrm{mg}, 0.48 \mathrm{mmol})$. Isolation by column chromatography ( $n$-hexane/EtOAc: $20 / 1$ ) yielded $152 \mathrm{f}(54 \mathrm{mg}, 52 \%)$ as a colorless solid. M.p. $=258-259^{\circ} \mathrm{C} .{ }^{1} \mathbf{H}$ NMR $\left(400 \mathrm{MHz}, \mathrm{CDCl}_{3}\right): \delta=7.49-7.41(\mathrm{~m}, 2 \mathrm{H}), 7.40-7.32(\mathrm{~m}, 3 \mathrm{H})$, 7.28-7.21 (m, 2H), 7.21-7.14 (m, 2H), 7.01 (d, J = 7.9 Hz, 2H), $6.96(\mathrm{~d}, J=7.8 \mathrm{~Hz}, 2 \mathrm{H}), 3.73-$ $3.58(\mathrm{~m}, 4 \mathrm{H}), 3.48-3.32(\mathrm{~m}, 4 \mathrm{H}), 2.34(\mathrm{~s}, 3 \mathrm{H}), 2.28(\mathrm{~s}, 3 \mathrm{H}) .{ }^{13} \mathrm{C} \mathrm{NMR}\left(100 \mathrm{MHz}, \mathrm{CDCl}_{3}\right): \delta=$ $157.6\left(\mathrm{C}_{\mathrm{q}}\right), 138.7\left(\mathrm{C}_{\mathrm{q}}\right), 138.2\left(\mathrm{C}_{\mathrm{q}}\right), 136.2(\mathrm{CH}), 134.2(\mathrm{CH}), 133.4\left(\mathrm{C}_{\mathrm{q}}\right), 130.1(\mathrm{CH}), 129.6(\mathrm{CH})$, $128.5(\mathrm{CH}), 128.0(\mathrm{CH}), 127.8(\mathrm{CH}), 86.7\left(\mathrm{C}_{\mathrm{q}}\right), 78.6\left(\mathrm{C}_{\mathrm{q}}\right), 66.5\left(\mathrm{CH}_{2}\right), 47.9\left(\mathrm{CH}_{2}\right), 21.3\left(\mathrm{CH}_{3}\right)$, $21.2\left(\mathrm{CH}_{3}\right) .{ }^{11} \mathrm{~B}$ NMR $\left(128 \mathrm{MHz}, \mathrm{CDCl}_{3}\right): \delta=0.67(2 \mathrm{~B}),-0.88(1 \mathrm{~B}),-3.11(1 \mathrm{~B}),-6.12(1 \mathrm{~B}),-10.53$ (5B). IR (ATR): 2843, 2549, 1660, 1447, 1411, 1264, 1225, $771 \mathrm{~cm}^{-1}$. MS (ESI) $\mathrm{m} / z$ (relative intensity): $514 \quad(70) \quad[\mathrm{M}+\mathrm{H}]^{+}, \quad 536 \quad(100) \quad[\mathrm{M}+\mathrm{Nad}]^{+}$. HR-MS $\quad(\mathrm{ESI}): \quad \mathrm{m} / \mathrm{z}$ calcd. for $\mathrm{C}_{27} \mathrm{H}_{35}{ }^{10} \mathrm{~B}_{2}{ }^{11} \mathrm{~B}_{8} \mathrm{NO}_{2} \mathrm{Na}[\mathrm{M}+\mathrm{Na}]^{+}:$536.3576, found: 536.3557 .

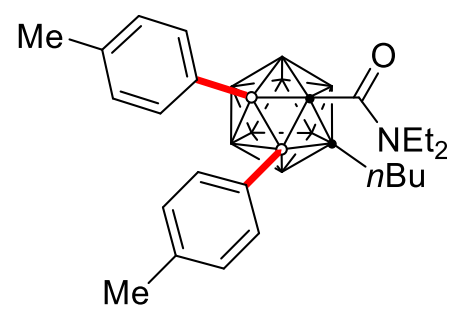

152g. The representative procedure $\mathbf{H}$ was followed using 0 -carborane $151 \mathrm{e}\left(1-\mathrm{CONEt}_{2}-2-{ }^{n} \mathrm{Bu}-\right.$ $\left.0-\mathrm{C}_{2} \mathrm{~B}_{10} \mathrm{H}_{10}\right)(60 \mathrm{mg}, 0.20 \mathrm{mmol})$ and 4-iodotoluene 19a $(105 \mathrm{mg}, 0.48 \mathrm{mmol})$. Isolation by column chromatography ( $n$-hexane/EtOAc: $20 / 1$ ) yielded $\mathbf{1 5 2 g ~}(45 \mathrm{mg}, 47 \%)$ as a colorless solid. M.p. $=88-89^{\circ} \mathrm{C} .{ }^{1} \mathrm{H}$ NMR $\left(400 \mathrm{MHz}, \mathrm{CDCl}_{3}\right): \delta=7.39(\mathrm{~d}, J=7.9 \mathrm{~Hz}, 2 \mathrm{H}), 7.17(\mathrm{~d}, J=7.8 \mathrm{~Hz}$, 2H), $7.12(\mathrm{~d}, J=7.9 \mathrm{~Hz}, 2 \mathrm{H}), 6.99(\mathrm{~d}, J=7.8 \mathrm{~Hz}, 2 \mathrm{H}), 4.15-3.66(\mathrm{~m}, 2 \mathrm{H}), 3.66-3.46(\mathrm{~m}, 2 \mathrm{H})$, 2.56-2.46 (m, 1H), $2.38(\mathrm{~s}, 3 \mathrm{H}), 2.30(\mathrm{~s}, 3 \mathrm{H}), 2.29-2.18(\mathrm{~m}, 1 \mathrm{H}), 1.66-1.56(\mathrm{~m}, 1 \mathrm{H}), 1.54-1.42$ $(\mathrm{m}, 1 \mathrm{H}), 1.35-1.19(\mathrm{~m}, 8 \mathrm{H}), 0.91(\mathrm{t}, J=7.3 \mathrm{~Hz}, 3 \mathrm{H}) .{ }^{13} \mathrm{C} \mathrm{NMR}\left(100 \mathrm{MHz}, \mathrm{CDCl}_{3}\right): \delta=156.3\left(\mathrm{C}_{\mathrm{q}}\right)$, $137.9\left(\mathrm{C}_{\mathrm{q}}\right), 137.8\left(\mathrm{C}_{\mathrm{q}}\right), 134.8(\mathrm{CH}), 133.3(\mathrm{CH}), 128.6(\mathrm{CH}), 127.7(\mathrm{CH}), 83.6\left(\mathrm{C}_{\mathrm{q}}\right), 73.6\left(\mathrm{C}_{\mathrm{q}}\right)$, $44.2\left(\mathrm{CH}_{2}\right), 34.5\left(\mathrm{CH}_{2}\right), 32.0\left(\mathrm{CH}_{2}\right), 22.4\left(\mathrm{CH}_{2}\right), 21.4\left(\mathrm{CH}_{3}\right), 21.3\left(\mathrm{CH}_{3}\right), 13.8\left(\mathrm{CH}_{3}\right), 13.1\left(\mathrm{CH}_{3}\right)$. ${ }^{11} \mathrm{~B}$ NMR $\left(128 \mathrm{MHz}, \mathrm{CDCl}_{3}\right): \delta=2.34(2 \mathrm{~B}),-1.13(2 \mathrm{~B}),-2.77(1 \mathrm{~B}),-7.74(1 \mathrm{~B}),-10.36(2 \mathrm{~B}),-12.42$ (1B), -13.91 (1B). IR (ATR): 2951, 2867, 2568, 1647, 1419, 1265, $809 \mathrm{~cm}^{-1}$. MS (ESI) $\mathrm{m} / \mathrm{z}$ 
(relative intensity): 480 (100) $[\mathrm{M}+\mathrm{H}]^{+}, 502$ (20) $[\mathrm{M}+\mathrm{Na}]^{+}$. HR-MS (ESI): $\mathrm{m} / \mathrm{z}$ calcd. for $\mathrm{C}_{25} \mathrm{H}_{42}{ }^{10} \mathrm{~B}_{2}{ }^{11} \mathrm{~B}_{8} \mathrm{NO}[\mathrm{M}+\mathrm{H}]^{+}:$: 480.4276, found: 480.4272 .

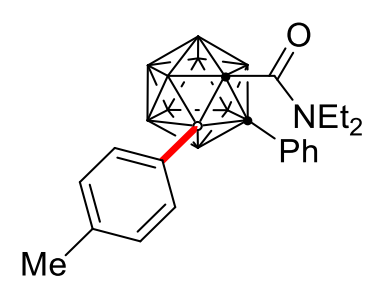

153a. The representative procedure I was followed using o-carborane 149a (1-CONEt $2-2-\mathrm{Ph}-\mathrm{O}$ $\left.\mathrm{C}_{2} \mathrm{~B}_{10} \mathrm{H}_{10}\right)(64 \mathrm{mg}, 0.20 \mathrm{mmol})$ and 4-iodotoluene 19a (53 mg, $\left.0.24 \mathrm{mmol}\right)$. Isolation by column chromatography ( $n$-hexane/EtOAc: $20 / 1)$ yielded 153a (45 mg, 55\%) as a colorless solid. M.p. $=$ 180-181 ${ }^{\circ} \mathrm{C} .{ }^{1} \mathrm{H}$ NMR $\left(400 \mathrm{MHz}, \mathrm{CDCl}_{3}\right): \delta=7.45-7.39(\mathrm{~m}, 4 \mathrm{H}), 7.28-7.22(\mathrm{~m}, 1 \mathrm{H}), 7.16-7.05$ (m, 4H), 3.55-3.35 (m, 4H), $2.34(\mathrm{~s}, 3 \mathrm{H}), 1.00(\mathrm{t}, J=7.1 \mathrm{~Hz}, 6 \mathrm{H}) .{ }^{13} \mathrm{C} \mathrm{NMR}\left(100 \mathrm{MHz}, \mathrm{CDCl}_{3}\right): \delta$ $=158.3\left(\mathrm{C}_{\mathrm{q}}\right), 139.1\left(\mathrm{C}_{\mathrm{q}}\right), 134.6(\mathrm{CH}), 134.0\left(\mathrm{C}_{\mathrm{q}}\right), 131.9(\mathrm{CH}), 129.2(\mathrm{CH}), 128.5(\mathrm{CH}), 127.0$ $(\mathrm{CH}), 89.5\left(\mathrm{C}_{\mathrm{q}}\right), 82.4\left(\mathrm{C}_{\mathrm{q}}\right), 43.6\left(\mathrm{CH}_{2}\right), 21.3\left(\mathrm{CH}_{3}\right), 12.2\left(\mathrm{CH}_{3}\right) .{ }^{11} \mathrm{~B}$ NMR $\left(128 \mathrm{MHz}, \mathrm{CDCl}_{3}\right): \delta=-$ 1.0 (1B), -2.26 (1B), -3.69 (1B), -7.91 (3B), -10.32 (4B). IR (ATR): 2635, 2563, 1648, 1476, 1418, 1269, 1208, 1080, $689 \mathrm{~cm}^{-1}$. MS (ESI) $\mathrm{m} / z$ (relative intensity): $432(100)[\mathrm{M}+\mathrm{Na}]^{+}, 410$ (10) $[\mathrm{M}+\mathrm{H}]^{+}$. HR-MS (ESI): $\mathrm{m} / z$ calcd. for $\mathrm{C}_{20} \mathrm{H}_{31}{ }^{10} \mathrm{~B}_{2}{ }^{11} \mathrm{~B}_{8} \mathrm{NONa}[\mathrm{M}+\mathrm{Na}]^{+}: 432.3311$, found: 432.3304 .

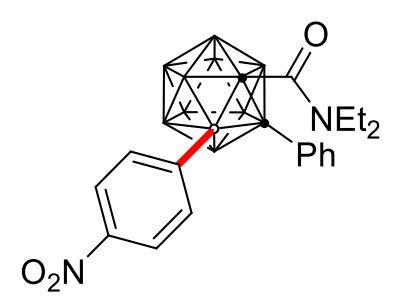

153b. The representative procedure I was followed using o-carborane 149a (1-CONEt $2-2-\mathrm{Ph}-\mathrm{O}-$ $\left.\mathrm{C}_{2} \mathrm{~B}_{10} \mathrm{H}_{10}\right)(64 \mathrm{mg}, 0.20 \mathrm{mmol})$ and 1-iodo-4-nitrobenzene $19 \mathrm{~h}(60 \mathrm{mg}, 0.24 \mathrm{mmol})$. Isolation by column chromatography ( $n$-hexane/EtOAc: $20 / 1)$ yielded $153 \mathrm{~b}(54 \mathrm{mg}, 61 \%)$ as a colorless solid. M.p. $=147-148^{\circ} \mathrm{C} .{ }^{1} \mathrm{H}$ NMR $\left(300 \mathrm{MHz}, \mathrm{CDCl}_{3}\right): \delta=8.14(\mathrm{~d}, J=8.7 \mathrm{~Hz}, 2 \mathrm{H}), 7.78(\mathrm{~d}, J=8.7 \mathrm{~Hz}$, 2H), 7.41-7.30 (m, 3H), 7.22-7.16 (m, 2H), 3.43-3.32 (m, 4H), $1.03(\mathrm{t}, J=7.0 \mathrm{~Hz}, 6 \mathrm{H}) .{ }^{13} \mathrm{C}$ NMR $\left(75 \mathrm{MHz}, \mathrm{CDCl}_{3}\right): \delta=158.0\left(\mathrm{C}_{\mathrm{q}}\right), 148.3\left(\mathrm{C}_{\mathrm{q}}\right), 135.5(\mathrm{CH}), 133.5\left(\mathrm{C}_{\mathrm{q}}\right), 131.4(\mathrm{CH}), 129.8(\mathrm{CH})$, $127.6(\mathrm{CH}), 122.3(\mathrm{CH}), 90.8\left(\mathrm{C}_{\mathrm{q}}\right), 83.0\left(\mathrm{C}_{\mathrm{q}}\right), 43.7\left(\mathrm{CH}_{2}\right), 14.0\left(\mathrm{CH}_{3}\right) .{ }^{11} \mathrm{~B}$ NMR $\left(96 \mathrm{MHz}, \mathrm{CDCl}_{3}\right)$ : $\delta=-0.10$ (2B), -3.09 (2B), -7.61 (3B), -8.98 (2B), -10.71 (1B). IR (ATR): 2980, 2561, 1647, 1513, $1346,1265,1208,843,687 \mathrm{~cm}^{-1}$. MS (ESI) $\mathrm{m} / \mathrm{z}$ (relative intensity): $463(100)[\mathrm{M}+\mathrm{Na}]^{+}, 441$ (10) 
$[\mathrm{M}+\mathrm{H}]^{+}$. HR-MS (ESI): $m / z$ calcd. for $\mathrm{C}_{19} \mathrm{H}_{28}{ }^{10} \mathrm{~B}_{2}{ }^{11} \mathrm{~B}_{8} \mathrm{~N}_{2} \mathrm{O}_{3} \mathrm{Na}[\mathrm{M}+\mathrm{Na}]^{+}: 463.3005$, found: 463.2995.

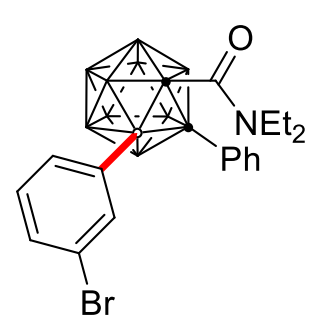

153c. The representative procedure I was followed using o-carborane 149a (1-CONEt $2-2-\mathrm{Ph}-\mathrm{O}$ $\left.\mathrm{C}_{2} \mathrm{~B}_{10} \mathrm{H}_{10}\right)(64 \mathrm{mg}, 0.20 \mathrm{mmol})$ and 1-iodo-3-bromobenzene $19 \mathrm{i}(60 \mathrm{mg}, 0.24 \mathrm{mmol})$. Isolation by column chromatography ( $n$-hexane/EtOAc: $20 / 1)$ yielded $153 \mathrm{c}(47.3 \mathrm{mg}, 50 \%)$ as a colorless solid. M.p. $=168-169^{\circ} \mathrm{C} .{ }^{1} \mathrm{H}$ NMR $\left(400 \mathrm{MHz}, \mathrm{CDCl}_{3}\right): \delta=7.66-7.61(\mathrm{~m}, 1 \mathrm{H}), 7.52-7.45(\mathrm{~m}, 2 \mathrm{H})$, 7.40-7.35 (m, 2H), 7.31-7.23 (m, 1H), 7.17-7.09 (m, 3H), 3.36-3.10 (m, 4H), $1.01(\mathrm{t}, J=7.2 \mathrm{~Hz}$, $6 \mathrm{H}) .{ }^{13} \mathrm{C}$ NMR $\left(100 \mathrm{MHz}, \mathrm{CDCl}_{3}\right): \delta=158.0\left(\mathrm{C}_{\mathrm{q}}\right), 137.1(\mathrm{CH}), 133.8\left(\mathrm{C}_{\mathrm{q}}\right), 133.2(\mathrm{CH}), 132.3(\mathrm{CH})$, $131.8(\mathrm{CH}), 129.5(\mathrm{CH}), 129.4(\mathrm{CH}), 127.3(\mathrm{CH}), 122.5\left(\mathrm{C}_{\mathrm{q}}\right), 90.5\left(\mathrm{C}_{\mathrm{q}}\right), 82.8\left(\mathrm{C}_{\mathrm{q}}\right), 44.1\left(\mathrm{CH}_{2}\right)$, 43.7 $\left(\mathrm{CH}_{2}\right), 14.0\left(\mathrm{CH}_{3}\right), 12.2\left(\mathrm{CH}_{3}\right) .{ }^{11} \mathrm{~B}$ NMR $\left(128 \mathrm{MHz}, \mathrm{CDCl}_{3}\right): \delta=-0.49(2 \mathrm{~B}),-3.35(2 \mathrm{~B}),-7.81$ (3B), -9.66 (3B). IR (ATR): 2976, 2575, 1645, 1420, 1266, 1156, 770, $689 \mathrm{~cm}^{-1}$. MS (ESI) $\mathrm{m} / \mathrm{z}$ (relative intensity): 497 (100) $\left[\mathrm{M}+\mathrm{Na}^{+}, 475(20)[\mathrm{M}+\mathrm{H}]^{+}\right.$. HR-MS (ESI) $\mathrm{m} / z$ calcd for $\mathrm{C}_{19} \mathrm{H}_{28}{ }^{10} \mathrm{~B}_{1}{ }^{11} \mathrm{~B}_{9}{ }^{79} \mathrm{BrNONa}[\mathrm{M}+\mathrm{Na}]^{+}:$497.2220, found 497.2229.

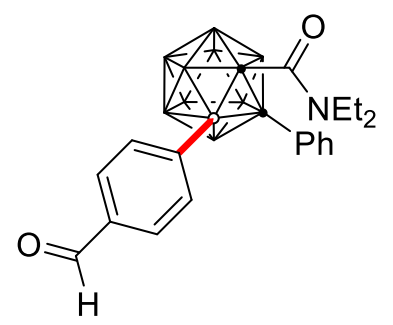

153d. The representative procedure I was followed using o-carborane 149a (1-CONEt $2-2-\mathrm{Ph}-\mathrm{O}$ $\left.\mathrm{C}_{2} \mathrm{~B}_{10} \mathrm{H}_{10}\right)(64 \mathrm{mg}, 0.20 \mathrm{mmol}$ ) and 4-iodobenzaldehyde 19j (56 mg, $0.24 \mathrm{mmol})$. Isolation by column chromatography ( $n$-hexane/EtOAc: $20 / 1$ ) yielded $153 \mathrm{~d}(43 \mathrm{mg}, 51 \%)$ as a colorless solid. M.p. $=211-212{ }^{\circ} \mathrm{C} .{ }^{1} \mathrm{H}$ NMR $\left(300 \mathrm{MHz}, \mathrm{CDCl}_{3}\right): \delta=10.07(\mathrm{~s}, 1 \mathrm{H}), 7.88-7.70(\mathrm{~m}, 4 \mathrm{H}), 7.44-7.37$ (m, 2H), 7.35-7.29 (m, 1H), 7.20-7.11 (m, 2H), 3.43-3.30 (m, 4H), $1.03(\mathrm{t}, J=7.0 \mathrm{~Hz}, 6 \mathrm{H}) .{ }^{13} \mathrm{C}$ NMR $\left(75 \mathrm{MHz}, \mathrm{CDCl}_{3}\right): \delta=192.3(\mathrm{CH}), 158.0\left(\mathrm{C}_{\mathrm{q}}\right), 136.3\left(\mathrm{C}_{\mathrm{q}}\right), 135.3(\mathrm{CH}), 133.7\left(\mathrm{C}_{\mathrm{q}}\right), 131.8$ $(\mathrm{CH}), 129.7(\mathrm{CH}), 128.5(\mathrm{CH}), 127.2(\mathrm{CH}), 90.8\left(\mathrm{C}_{\mathrm{q}}\right), 83.0\left(\mathrm{C}_{\mathrm{q}}\right), 43.7\left(\mathrm{CH}_{2}\right), 13.2\left(\mathrm{CH}_{3}\right) .{ }^{11} \mathrm{~B}$ NMR (96 MHz, $\mathrm{CDCl}_{3}$ ): $\delta=-0.28$ (2B), -3.35 (2B), -7.51 (3B), -9.39 (2B), -11.02 (1B). IR (ATR): 2980, 
2560, 1719, 1650, 1627, 1420, 1266, 1181, 761, $688 \mathrm{~cm}^{-1}$. MS (ESI) $\mathrm{m} / \mathrm{z}$ (relative intensity): 424 (100) $[\mathrm{M}+\mathrm{H}]^{+}$. HR-MS (ESI): $\mathrm{m} / z$ calcd. for $\mathrm{C}_{20} \mathrm{H}_{30}{ }^{10} \mathrm{~B}_{2}{ }^{11} \mathrm{~B}_{8} \mathrm{NO}_{2}[\mathrm{M}+\mathrm{H}]^{+}: 424.3284$, found: 424.3266.

\subsubsection{Electrochemical B-H Nitrogenation of nido-Carboranes}

\subsubsection{Characterization Data}

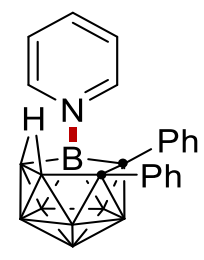

156a. The representative procedure $\mathbf{J}$ was followed using nido-carborane $154 a$ (36.0 $\mathrm{mg}, 0.10$ $\mathrm{mmol}$ ) and pyridine $155 \mathrm{a}(24.0 \mathrm{mg}, 0.30 \mathrm{mmol})$. Isolation by column chromatography ( $n$ hexane $\left./ \mathrm{CH}_{2} \mathrm{Cl}_{2}: 1 / 1\right)$ yielded $156 \mathrm{a}(30.0 \mathrm{mg}, 83 \%)$ as a colorless solid. M.p. $=280-282{ }^{\circ} \mathrm{C}$. ${ }^{1} \mathrm{H} \mathrm{NMR}\left(300 \mathrm{MHz}, \mathrm{CD}_{2} \mathrm{Cl}_{2}\right): \delta=8.75(\mathrm{~d}, J=5.2 \mathrm{~Hz}, 2 \mathrm{H}), 8.07$ (tt, $\left.J=7.7,1.5 \mathrm{~Hz}, 1 \mathrm{H}\right), 7.56-$ $7.48(\mathrm{~m}, 2 \mathrm{H}), 7.35-7.28(\mathrm{~m}, 2 \mathrm{H}), 7.08-6.96(\mathrm{~m}, 3 \mathrm{H}), 6.94-6.82(\mathrm{~m}, 5 \mathrm{H}),-1.97(\mathrm{~s}, 1 \mathrm{H}) .{ }^{13} \mathrm{C}$ NMR $\left(101 \mathrm{MHz}, \mathrm{CD}_{2} \mathrm{Cl}_{2}\right): \delta=147.7(\mathrm{CH}), 142.4(\mathrm{CH}), 138.7\left(\mathrm{C}_{\mathrm{q}}\right), 136.2\left(\mathrm{C}_{\mathrm{q}}\right), 132.1(\mathrm{CH}), 131.1$ $(\mathrm{CH}), 127.5(\mathrm{CH}), 127.1(\mathrm{CH}), 126.6(\mathrm{CH}), 126.3(\mathrm{CH}), 125.8(\mathrm{CH}) .{ }^{11} \mathrm{~B}$ NMR $\left(96 \mathrm{MHz}, \mathrm{CD}_{2} \mathrm{Cl}_{2}\right)$ : $\delta=4.92$ (1B), -3.89 (1B), -11.50 (1B), -15.73 (2B), -20.65 (1B), -26.08 (1B), -30.97 (1B), -35.87 (1B). IR (ATR): 2558, 2536, 2510, 1486, 1456, 1445, 1171, 764, $698 \mathrm{~cm}^{-1}$. MS (ESI) $\mathrm{m} / \mathrm{z}$ (relative intensity): $387(100)\left[\mathrm{M}+\mathrm{Na}^{+}, 365(20)[\mathrm{M}+\mathrm{H}]^{+}\right.$. HR-MS (ESI): $\mathrm{m} / \mathrm{z}$ calcd. for $\mathrm{C}_{19} \mathrm{H}_{24}{ }^{10} \mathrm{~B}_{1}{ }^{11} \mathrm{~B}_{8} \mathrm{~N}[\mathrm{M}+\mathrm{Na}]^{+}: 387.2688$, found: 387.2680 . The analytical data corresponds with those reported in the literature. ${ }^{[225]}$

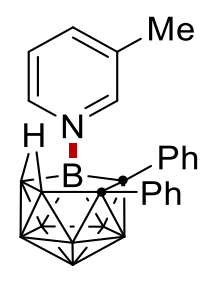

156b. The representative procedure $\mathbf{J}$ was followed using nido-carborane $154 \mathbf{a}$ (36.0 $\mathrm{mg}, 0.10$ $\mathrm{mmol}$ ) and 3-methylpyridine $155 \mathrm{~b}(27.9 \mathrm{mg}, 0.30 \mathrm{mmol})$. Isolation by column chromatography ( $n$-hexane $\left./ \mathrm{CH}_{2} \mathrm{Cl}_{2}: 1 / 1\right)$ yielded $156 \mathbf{b}(26.0 \mathrm{mg}, 68 \%)$ as a white solid. M.p. $=280-283{ }^{\circ} \mathrm{C} .{ }^{1} \mathbf{H}$ NMR $\left(500 \mathrm{MHz}, \mathrm{CDCl}_{3}\right): \delta=8.54(\mathrm{~d}, J=6.1 \mathrm{~Hz}, 1 \mathrm{H}), 8.45(\mathrm{~s}, 1 \mathrm{H}), 7.76(\mathrm{~d}, J=7.7 \mathrm{~Hz}, 1 \mathrm{H})$, $7.32(\mathrm{dd}, J=7.9,5.9 \mathrm{~Hz}, 1 \mathrm{H}), 7.28-7.24(\mathrm{~m}, 2 \mathrm{H}), 7.00-6.87(\mathrm{~m}, 3 \mathrm{H}), 6.86-6.77(\mathrm{~m}, 5 \mathrm{H})$, 
$2.27(\mathrm{~s}, 3 \mathrm{H}),-2.08(\mathrm{~s}, 1 \mathrm{H}) .{ }^{13} \mathrm{C}$ NMR $\left(126 \mathrm{MHz}, \mathrm{CDCl}_{3}\right): \delta=147.5(\mathrm{CH}), 144.9(\mathrm{CH}), 142.4(\mathrm{CH})$, $138.5\left(\mathrm{C}_{\mathrm{q}}\right), 136.4\left(\mathrm{C}_{\mathrm{q}}\right), 136.4\left(\mathrm{C}_{\mathrm{q}}\right), 132.1(\mathrm{CH}), 131.1(\mathrm{CH}), 127.4(\mathrm{CH}), 127.1(\mathrm{CH}), 126.6(\mathrm{CH})$, $126.2(\mathrm{CH}), 124.9(\mathrm{CH}), 18.5\left(\mathrm{CH}_{3}\right) .{ }^{11} \mathrm{~B}$ NMR $\left(128 \mathrm{MHz}, \mathrm{CDCl}_{3}\right): \delta=4.46(1 \mathrm{~B}),-4.56(1 \mathrm{~B}),-$ 11.28 (1B), -15.95 (2B), -21.01 (1B), -26.04 (1B), -30.94 (1B), -35.69 (1B). IR (ATR): 3059, 1487, 1443, 1201, 1155, 1056, 907, 734, $696 \mathrm{~cm}^{-1}$. MS (ESI) $\mathrm{m} / \mathrm{z}$ (relative intensity): 401 (90) [M+Na] ${ }^{+}$, 379 (20) $[\mathrm{M}+\mathrm{H}]^{+}$. HR-MS (ESI): $\mathrm{m} / z$ calcd. for $\mathrm{C}_{20} \mathrm{H}_{26}{ }^{10} \mathrm{~B}_{1}{ }^{11} \mathrm{~B}_{8} \mathrm{~N}[\mathrm{M}+\mathrm{Na}]^{+}: 401.2845$, found: 401.2850. The analytical data corresponds with those reported in the literature. ${ }^{[225]}$

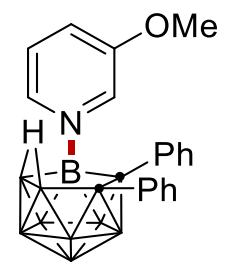

156c. The representative procedure $\mathbf{J}$ was followed using nido-carborane $154 a$ (36.0 $\mathrm{mg}, 0.10$ $\mathrm{mmol}$ ) and 3-methoxypyridine $155 \mathrm{c}(32.0 \mathrm{mg}, 0.30 \mathrm{mmol})$. Isolation by column chromatography ( $n$-hexane/ $\mathrm{CH}_{2} \mathrm{Cl}_{2}: 1 / 1$ ) yielded $156 \mathrm{c}(30.0 \mathrm{mg}, 75 \%)$ as a yellow solid. M.p. $=220-223{ }^{\circ} \mathrm{C}$. ${ }^{1} \mathrm{H}$ NMR $\left(500 \mathrm{MHz}, \mathrm{CD}_{2} \mathrm{Cl}_{2}\right): \delta=8.47(\mathrm{~d}, J=5.8 \mathrm{~Hz}, 1 \mathrm{H}), 8.13(\mathrm{~d}, J=2.7 \mathrm{~Hz}, 1 \mathrm{H}), 7.51$ (ddd, $J=$ 8.7, 2.7, $1.1 \mathrm{~Hz}, 1 \mathrm{H}), 7.40(\mathrm{dd}, J=8.7,5.8 \mathrm{~Hz}, 1 \mathrm{H}), 7.28-7.25(\mathrm{~m}, 2 \mathrm{H}), 6.99-6.93(\mathrm{~m}, 3 \mathrm{H})$, $6.91-6.83(\mathrm{~m}, 5 \mathrm{H}), 3.65(\mathrm{~s}, 3 \mathrm{H}),-2.01(\mathrm{~s}, 1 \mathrm{H}) .{ }^{13} \mathrm{C} \mathrm{NMR}\left(126 \mathrm{MHz}, \mathrm{CD}_{2} \mathrm{Cl}_{2}\right): \delta=157.1\left(\mathrm{C}_{\mathrm{q}}\right)$, $140.8(\mathrm{CH}), 139.0\left(\mathrm{C}_{\mathrm{q}}\right), 136.7\left(\mathrm{C}_{\mathrm{q}}\right), 134.7(\mathrm{CH}), 132.4(\mathrm{CH}), 131.5(\mathrm{CH}), 128.2(\mathrm{CH}), 127.8(\mathrm{CH})$, $127.4(\mathrm{CH}), 127.0(\mathrm{CH}), 126.6(\mathrm{CH}), 126.3(\mathrm{CH}), 56.8\left(\mathrm{CH}_{3}\right) .{ }^{11} \mathrm{~B}$ NMR $\left(128 \mathrm{MHz}, \mathrm{CD}_{2} \mathrm{Cl}_{2}\right): \delta=$ 4.82 (1B), - 4.05 (1B), -11.74 (1B), -15.83 (2B), -20.58 (1B), -26.13 (1B), -31.13 (1B), -35.90 (1B). IR (ATR): 2526, 1572, 1487, 1443, 1298, 1259, 1056, 881, $693 \mathrm{~cm}^{-1}$ MS (ESI) $\mathrm{m} / z$ (relative intensity): 417 (100) $[\mathrm{M}+\mathrm{Na}]^{+}, 395(20)[\mathrm{M}+\mathrm{H}]^{+}$. HR-MS (ESI): $\mathrm{m} / z$ calcd. for $\mathrm{C}_{20} \mathrm{H}_{26}{ }^{10} \mathrm{~B}_{1}{ }^{11} \mathrm{~B}_{8} \mathrm{NO}$ $[\mathrm{M}+\mathrm{Na}]^{+}:$417.2794, found: 417.2796 . The analytical data corresponds with those reported in the literature. ${ }^{[225]}$

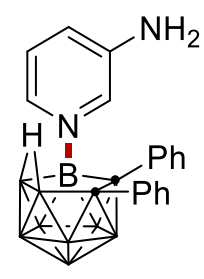

156d. The representative procedure $\mathbf{J}$ was followed using nido-carborane 154a (36.0 $\mathrm{mg}, 0.10$ $\mathrm{mmol}$ ) and pyridin-3-amine 155d $(28.2 \mathrm{mg}, 0.30 \mathrm{mmol})$. Isolation by column chromatography ( $n$ hexane $/ \mathrm{CH}_{2} \mathrm{Cl}_{2}:$ 1/1) yielded $156 \mathrm{~d}(30.0 \mathrm{mg}, 79 \%)$ as a yellow solid. M.p. $=250-253{ }^{\circ} \mathrm{C}$. ${ }^{1} \mathrm{H}$ NMR $\left(500 \mathrm{MHz}, \mathrm{CD}_{2} \mathrm{Cl}_{2}\right): \delta=8.07(\mathrm{~d}, J=2.4 \mathrm{~Hz}, 1 \mathrm{H}), 8.04(\mathrm{~d}, J=5.1 \mathrm{~Hz}, 1 \mathrm{H}), 7.29-7.24$ 
(m, 2H), $7.20-7.14(\mathrm{~m}, 2 \mathrm{H}), 6.99-6.92(\mathrm{~m}, 3 \mathrm{H}), 6.88-6.82(\mathrm{~m}, 5 \mathrm{H}), 4.13(\mathrm{~s}, 2 \mathrm{H}),-2.00(\mathrm{~s}, 1 \mathrm{H})$. ${ }^{13} \mathrm{C}$ NMR $\left(126 \mathrm{MHz}, \mathrm{CD}_{2} \mathrm{Cl}_{2}\right): \delta=145.0\left(\mathrm{C}_{\mathrm{q}}\right), 139.1\left(\mathrm{C}_{\mathrm{q}}\right), 137.8(\mathrm{CH}), 136.8\left(\mathrm{C}_{\mathrm{q}}\right), 134.2(\mathrm{CH})$, $132.4(\mathrm{CH}), 131.3(\mathrm{CH}), 127.5(\mathrm{CH}), 127.3$ (overlapped, $\mathrm{CH}), 126.8(\mathrm{CH}), 126.5(\mathrm{CH}), 126.0$ $(\mathrm{CH}) .{ }^{11} \mathrm{~B}$ NMR (128 MHz, $\left.\mathrm{CD}_{2} \mathrm{Cl}_{2}\right): \delta=4.99(1 \mathrm{~B}),-4.38(1 \mathrm{~B}),-12.03(1 \mathrm{~B}),-15.78(2 \mathrm{~B}),-21.02$ (1B), -26.20 (1B), -31.14 (1B), -36.05 (1B). IR (ATR): 3480, 3388, 2539, 1623, 1583, 1442, 1164, $697 \mathrm{~cm}^{-1}$. MS (ESI) $\mathrm{m} / \mathrm{z}$ (relative intensity): $402(100)[\mathrm{M}+\mathrm{Na}]^{+}, 380(50)[\mathrm{M}+\mathrm{H}]^{+}$. HR-MS (ESI): $\mathrm{m} / \mathrm{z}$ calcd. for $\mathrm{C}_{19} \mathrm{H}_{25}{ }^{10} \mathrm{~B}_{1}{ }^{11} \mathrm{~B}_{8} \mathrm{~N}_{2}[\mathrm{M}+\mathrm{Na}]^{+}$: 402.2797, found: 402.2796. The analytical data corresponds with those reported in the literature. ${ }^{[225]}$

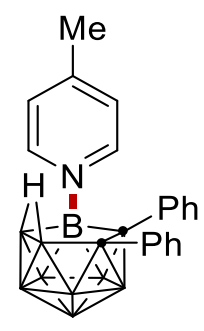

156e. The representative procedure $\mathbf{J}$ was followed using nido-carborane 154a $(36.0 \mathrm{mg}, 0.10$ $\mathrm{mmol})$ and 4-methylpyridine $155 \mathrm{e}(27.9 \mathrm{mg}, 0.30 \mathrm{mmol})$. Isolation by column chromatography $(n-$ hexane $\left./ \mathrm{CH}_{2} \mathrm{Cl}_{2}: 1 / 1\right)$ yielded $156 \mathrm{e}(33.0 \mathrm{mg}, 87 \%)$ as a white solid. M.p. $=247-250{ }^{\circ} \mathrm{C}$. ${ }^{1} \mathrm{H}$ NMR $\left(500 \mathrm{MHz}, \mathrm{CDCl}_{3}\right): \delta=8.52(\mathrm{~d}, J=6.6 \mathrm{~Hz}, 2 \mathrm{H}), 7.26-7.24(\mathrm{~m}, 1 \mathrm{H}), 7.24-7.23(\mathrm{~m}$, $1 \mathrm{H}), 7.21(\mathrm{~d}, J=7.5 \mathrm{~Hz}, 2 \mathrm{H}), 6.95-6.88(\mathrm{~m}, 3 \mathrm{H}), 6.85-6.77(\mathrm{~m}, 5 \mathrm{H}), 2.45(\mathrm{~s}, 3 \mathrm{H}),-2.06(\mathrm{~s}$, $1 \mathrm{H}) .{ }^{13} \mathrm{C}$ NMR $\left(126 \mathrm{MHz}, \mathrm{CDCl}_{3}\right): \delta=155.4\left(\mathrm{C}_{\mathrm{q}}\right), 146.9(\mathrm{CH}), 138.5\left(\mathrm{C}_{\mathrm{q}}\right), 136.5\left(\mathrm{C}_{\mathrm{q}}\right), 132.1(\mathrm{CH})$, $131.1(\mathrm{CH}), 127.1(\mathrm{CH}), 127.1(\mathrm{CH}), 126.6(\mathrm{CH}), 126.2$ (overlapped, $\mathrm{CH}), 21.7\left(\mathrm{CH}_{3}\right) .{ }^{11} \mathbf{B}$ NMR $\left(128 \mathrm{MHz}, \mathrm{CDCl}_{3}\right): \delta=4.43(1 \mathrm{~B}),-3.98(1 \mathrm{~B}),-11.46(1 \mathrm{~B}),-15.82(2 \mathrm{~B}),-20.70(1 \mathrm{~B}),-26.00(1 \mathrm{~B}),-$ 30.91 (1B), -35.77 (1B). IR (ATR): 3058, 2540, 2159, 1495, 1444, 761, $697 \mathrm{~cm}^{-1}$. MS (ESI) $\mathrm{m} / \mathrm{z}$ (relative intensity): 401 (100) $[\mathrm{M}+\mathrm{Na}]^{+}, 479$ (20) $[\mathrm{M}+\mathrm{H}]^{+}$. HR-MS (ESI): $\mathrm{m} / \mathrm{z}$ calcd. for $\mathrm{C}_{20} \mathrm{H}_{26}{ }^{10} \mathrm{~B}_{1}{ }^{11} \mathrm{~B}_{8} \mathrm{~N}$ [M+Na] $]^{+}: 401.2845$, found: 401.2842. The analytical data corresponds with those reported in the literature. ${ }^{[225]}$

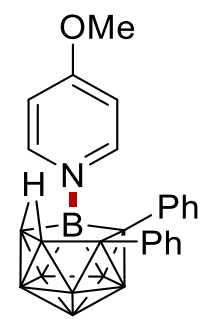

156f. The representative procedure $\mathbf{J}$ was followed using nido-carborane $154 a(36.0 \mathrm{mg}, 0.10$ 
$\mathrm{mmol}$ ) and 4-methoxypyridine $155 \mathrm{f}(32.7 \mathrm{mg}, 0.30 \mathrm{mmol})$. Isolation by column chromatography ( $n$-hexane $\left./ \mathrm{CH}_{2} \mathrm{Cl}_{2}: 1 / 1\right)$ yielded $156 \mathrm{f}\left(32.0 \mathrm{mg}, 81 \%\right.$ ) as a white solid. M.p. $=314-31{ }^{\circ} \mathrm{C}$. ${ }^{1} \mathrm{H}$ NMR $\left(500 \mathrm{MHz}, \mathrm{CD}_{2} \mathrm{Cl}_{2}\right): \delta=8.49(\mathrm{~d}, J=7.5 \mathrm{~Hz}, 2 \mathrm{H}), 7.27(\mathrm{~d}, J=6.6 \mathrm{~Hz}, 2 \mathrm{H}), 7.00-6.93$ $(\mathrm{m}, 3 \mathrm{H}), 6.89-6.82(\mathrm{~m}, 7 \mathrm{H}), 3.92(\mathrm{~s}, 3 \mathrm{H}),-2.02(\mathrm{~s}, 1 \mathrm{H}) .{ }^{13} \mathrm{C} \mathrm{NMR}\left(126 \mathrm{MHz}, \mathrm{CD}_{2} \mathrm{Cl}_{2}\right): \delta=169.8$ $\left(\mathrm{C}_{\mathrm{q}}\right), 149.5(\mathrm{CH}), 139.1\left(\mathrm{C}_{\mathrm{q}}\right), 136.8\left(\mathrm{C}_{\mathrm{q}}\right), 132.4(\mathrm{CH}), 131.4(\mathrm{CH}), 127.6(\mathrm{CH}), 127.3(\mathrm{CH}), 126.8$ $(\mathrm{CH}), 126.5(\mathrm{CH}), 111.5(\mathrm{CH}), 57.3\left(\mathrm{CH}_{3}\right) .{ }^{11} \mathrm{~B}$ NMR $\left(128 \mathrm{MHz}, \mathrm{CD}_{2} \mathrm{Cl}_{2}\right): \delta=4.80(1 \mathrm{~B}),-3.95(1 \mathrm{~B})$, -11.52(1B), -15.65 (2B), -20.30 (1B), -25.96 (1B), -30.82 (1B), -35.66 (1B). IR (ATR): 2570, 2525, 1631, 1516, 1319, 1162, 1005, $847 \mathrm{~cm}^{-1}$ MS (ESI) $\mathrm{m} / z$ (relative intensity): 417 (100) [M+Na] $395(20)[\mathrm{M}+\mathrm{H}]^{+}$. HR-MS (ESI): $\mathrm{m} / z$ calcd. for $\mathrm{C}_{20} \mathrm{H}_{26}{ }^{10} \mathrm{~B}_{1}{ }^{11} \mathrm{~B}_{8} \mathrm{NO}[\mathrm{M}+\mathrm{Na}]^{+}: 417.2794$, found: 417.2794. The analytical data corresponds with those reported in the literature. ${ }^{[225]}$

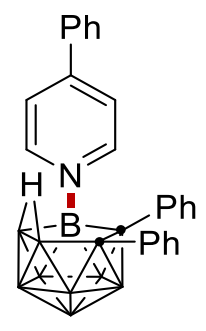

$\mathbf{1 5 6 g}$. The representative procedure $\mathbf{J}$ was followed using nido-carborane 154a (36.0 $\mathrm{mg}, 0.10$ $\mathrm{mmol}$ ) and 4-phenylpyridine $155 \mathrm{~g}(46.5 \mathrm{mg}, 0.30 \mathrm{mmol})$. Isolation by column chromatography ( $n$-hexane/ $\mathrm{CH}_{2} \mathrm{Cl}_{2}: 1 / 1$ ) yielded $\mathbf{1 5 6 g}\left(43.2 \mathrm{mg}, 98 \%\right.$ ) as a yellow solid. M.p. $=242-245{ }^{\circ} \mathrm{C}$. ${ }^{1} \mathrm{H}$ NMR $\left(500 \mathrm{MHz}, \mathrm{CD}_{2} \mathrm{Cl}_{2}\right): \delta=8.67(\mathrm{~d}, J=7.0 \mathrm{~Hz}, 2 \mathrm{H}), 7.68-7.65(\mathrm{~m}, 4 \mathrm{H}), 7.58-7.53(\mathrm{~m}$, $3 \mathrm{H}), 7.31-7.27(\mathrm{~m}, 2 \mathrm{H}), 7.01-6.95(\mathrm{~m}, 3 \mathrm{H}), 6.93-6.89(\mathrm{~m}, 2 \mathrm{H}), 6.87-6.83(\mathrm{~m}, 3 \mathrm{H}),-1.91(\mathrm{~s}$, 1H). ${ }^{13} \mathrm{C}$ NMR $\left(126 \mathrm{MHz}, \mathrm{CD}_{2} \mathrm{Cl}_{2}\right): \delta=154.4\left(\mathrm{C}_{\mathrm{q}}\right), 147.8(\mathrm{CH}), 139.1\left(\mathrm{C}_{\mathrm{q}}\right), 136.6\left(\mathrm{C}_{\mathrm{q}}\right), 134.6\left(\mathrm{C}_{\mathrm{q}}\right)$, $132.4(\mathrm{CH}), 131.9(\mathrm{CH}), 131.5(\mathrm{CH}), 129.9(\mathrm{CH}), 127.8(\mathrm{CH}), 127.7(\mathrm{CH}), 127.4(\mathrm{CH})$, $126.9(\mathrm{CH}), 126.6(\mathrm{CH}), 123.1(\mathrm{CH}) .{ }^{11} \mathrm{~B}$ NMR $\left(128 \mathrm{MHz}, \mathrm{CDCl}_{3}\right): \delta=6.28(1 \mathrm{~B}),-0.08(1 \mathrm{~B}),-7.92$ (1B), -10.65 (2B), -16.32 (1B), -20.79 (1B), -26.45 (1B), -31.72 (1B). IR (ATR): 2532, 1626, 1486, 1431, 1219, 1172, 1013, 763, $698 \mathrm{~cm}^{-1}$. MS (ESI) $\mathrm{m} / z$ (relative intensity): $463(100)[\mathrm{M}+\mathrm{Na}]^{+}, 441$ (50) $[\mathrm{M}+\mathrm{H}]^{+}$. HR-MS (ESI): $\mathrm{m} / z$ calcd. for $\mathrm{C}_{25} \mathrm{H}_{28}{ }^{10} \mathrm{~B}_{1}{ }^{11} \mathrm{~B}_{8} \mathrm{~N}$ [M+Na] $]^{+}: 463.3005$, found: 463.2997. The analytical data corresponds with those reported in the literature. ${ }^{[225]}$

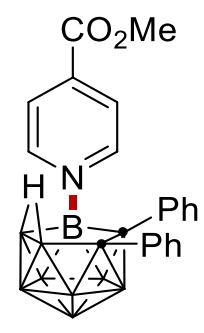


156h. The representative procedure $\mathbf{J}$ was followed using nido-carborane $154 \mathrm{a}$ (36.0 $\mathrm{mg}, 0.10$ $\mathrm{mmol}$ ) and methyl isonicotinate $155 \mathrm{~h}(41.0 \mathrm{mg}, 0.30 \mathrm{mmol})$. Isolation by column chromatography (n-hexane/ $\mathrm{CH}_{2} \mathrm{Cl}_{2}: 1 / 1$ ) yielded $156 \mathrm{~h}(29.0 \mathrm{mg}, 69 \%)$ as a colorless solid. M.p. $=242-246{ }^{\circ} \mathrm{C}$. ${ }^{1} \mathrm{H}$ NMR $\left(300 \mathrm{MHz}, \mathrm{CD}_{2} \mathrm{Cl}_{2}\right): \delta=8.84(\mathrm{~d}, J=6.9 \mathrm{~Hz}, 2 \mathrm{H}), 8.00(\mathrm{~d}, J=7.0 \mathrm{~Hz}, 2 \mathrm{H}), 7.34-7.28$ $(\mathrm{m}, 2 \mathrm{H}), 7.06-6.97(\mathrm{~m}, 3 \mathrm{H}), 6.94-6.87(\mathrm{~m}, 5 \mathrm{H}), 4.00(\mathrm{~s}, 3 \mathrm{H}),-1.89(\mathrm{~s}, 1 \mathrm{H}) .{ }^{13} \mathrm{C} \mathrm{NMR}(101 \mathrm{MHz}$, $\left.\mathrm{CD}_{2} \mathrm{Cl}_{2}\right): \delta=162.5\left(\mathrm{C}_{\mathrm{q}}\right), 148.4(\mathrm{CH}), 142.2\left(\mathrm{C}_{\mathrm{q}}\right), 138.6\left(\mathrm{C}_{\mathrm{q}}\right), 135.9\left(\mathrm{C}_{\mathrm{q}}\right), 132.1(\mathrm{CH}), 131.2(\mathrm{CH})$, $127.7(\mathrm{CH}), 127.1(\mathrm{CH}), 126.9(\mathrm{CH}), 126.4(\mathrm{CH}), 125.2(\mathrm{CH}), 53.7\left(\mathrm{CH}_{3}\right) .{ }^{11} \mathrm{~B}$ NMR (128 MHz, $\left.\mathrm{CD}_{2} \mathrm{Cl}_{2}\right): \delta=4.45(1 \mathrm{~B}),-3.67(1 \mathrm{~B}),-11.05(1 \mathrm{~B}),-15.83(2 \mathrm{~B}),-20.08(1 \mathrm{~B}),-26.03(1 \mathrm{~B}),-30.77(1 \mathrm{~B})$, -35.42 (1B). IR (ATR): 2529, 1743, 1440, 1427, 1289, 1112, 767, $690 \mathrm{~cm}^{-1}$. MS (ESI) m/z (relative intensity): $445(100)\left[\mathrm{M}+\mathrm{Na}^{+}, 423(20)[\mathrm{M}+\mathrm{H}]^{+}\right.$. HR-MS (ESI): $\mathrm{m} / \mathrm{z}$ calcd. for $\mathrm{C}_{21} \mathrm{H}_{26}{ }^{10} \mathrm{~B}_{1}{ }^{11} \mathrm{~B}_{8} \mathrm{NO}_{2}[\mathrm{M}+\mathrm{H}]^{+}: 423.2925$, found: 423.2897. The analytical data corresponds with those reported in the literature. ${ }^{[225]}$

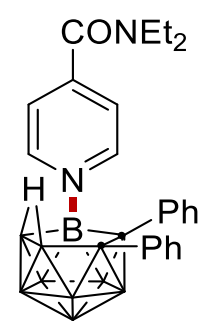

156i. The representative procedure $\mathbf{J}$ was followed using nido-carborane $154 \mathbf{a}(36.0 \mathrm{mg}, 0.10$ $\mathrm{mmol}$ ) and $N, N$-diethylisonicotinamide $155 \mathrm{i}(53.4 \mathrm{mg}, 0.30 \mathrm{mmol})$. Isolation by column chromatography $\left(\mathrm{CH}_{2} \mathrm{Cl}_{2}\right)$ yielded $156 \mathbf{i}(24.0 \mathrm{mg}, 51 \%)$ as a yellow solid. M.p. $=251-254{ }^{\circ} \mathrm{C}$. ${ }^{1} \mathrm{H}$ NMR $\left(400 \mathrm{MHz}, \mathrm{CD}_{2} \mathrm{Cl}_{2}\right): \delta=8.72(\mathrm{~d}, J=6.8 \mathrm{~Hz}, 2 \mathrm{H}), 7.41-7.34(\mathrm{~m}, 2 \mathrm{H}), 7.31-7.23(\mathrm{~m}$, $2 \mathrm{H}), 7.00-6.91(\mathrm{~m}, 3 \mathrm{H}), 6.89-6.80(\mathrm{~m}, 5 \mathrm{H}), 3.47(\mathrm{q}, J=7.1 \mathrm{~Hz}, 2 \mathrm{H}), 2.99(\mathrm{q}, J=7.1 \mathrm{~Hz}, 2 \mathrm{H})$, 1.19 (t, $J=7.2 \mathrm{~Hz}, 3 \mathrm{H}), 1.02(\mathrm{t}, J=7.1 \mathrm{~Hz}, 3 \mathrm{H}),-2.00(\mathrm{~s}, 1 \mathrm{H}) .{ }^{13} \mathrm{C}$ NMR $\left(101 \mathrm{MHz}, \mathrm{CD}_{2} \mathrm{Cl}_{2}\right): \delta=$ $165.4\left(\mathrm{C}_{\mathrm{q}}\right), 150.9\left(\mathrm{C}_{\mathrm{q}}\right), 148.4(\mathrm{CH}), 138.9\left(\mathrm{C}_{\mathrm{q}}\right), 136.4\left(\mathrm{C}_{\mathrm{q}}\right), 132.4(\mathrm{CH}), 131.5(\mathrm{CH}), 127.9(\mathrm{CH})$, 127.4 (CH), $127.1(\mathrm{CH}), 126.7(\mathrm{CH}), 123.3(\mathrm{CH}), 43.4\left(\mathrm{CH}_{2}\right), 39.9\left(\mathrm{CH}_{2}\right), 14.2\left(\mathrm{CH}_{3}\right), 12.7\left(\mathrm{CH}_{3}\right)$. ${ }^{11} \mathrm{~B}$ NMR $\left(128 \mathrm{MHz}, \mathrm{CD}_{2} \mathrm{Cl}_{2}\right): \delta=4.59(1 \mathrm{~B}),-3.84(1 \mathrm{~B}),-11.22(1 \mathrm{~B}),-15.78(2 \mathrm{~B}),-20.43(1 \mathrm{~B}),-$ 26.04 (1B), -30.87 (1B), -35.68 (1B). IR (ATR): 2530, 2223, 2177, 2035, 1991, 1628, 1053, 696 $\mathrm{cm}^{-1}$. MS (ESI) $\mathrm{m} / z$ (relative intensity): 486 (50) [M+Na] ${ }^{+}, 464(100)[\mathrm{M}+\mathrm{H}]^{+}$. HR-MS (ESI): $\mathrm{m} / \mathrm{z}$ calcd. for $\mathrm{C}_{24} \mathrm{H}_{33}{ }^{10} \mathrm{~B}_{1}{ }^{11} \mathrm{~B}_{8} \mathrm{~N}_{2} \mathrm{O}[\mathrm{M}+\mathrm{Na}]^{+}: 486.3375$, found: 486.3392 . 


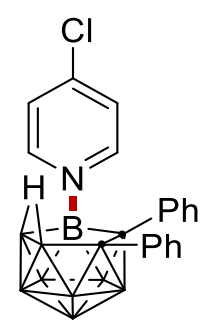

156j. The representative procedure $\mathbf{J}$ was followed using nido-carborane 154a $(36.0 \mathrm{mg}, 0.10$ $\mathrm{mmol}$ ) and 4-chloropyridine hydrochloride $155 \mathrm{j}(45.0 \mathrm{mg}, 0.30 \mathrm{mmol})$. Isolation by column chromatography ( $n$-hexane/ $\left.\mathrm{CH}_{2} \mathrm{Cl}_{2}: 3 / 1\right)$ yielded 156j $(20.0 \mathrm{mg}, 53 \%)$ as a yellow solid. $\mathbf{M} . \mathbf{p}$. = $232-234{ }^{\circ} \mathrm{C} .{ }^{1} \mathrm{H}$ NMR $\left(300 \mathrm{MHz}, \mathrm{CDCl}_{3}\right): \delta=8.62(\mathrm{~d}, J=7.0 \mathrm{~Hz}, 2 \mathrm{H}), 7.44(\mathrm{~d}, J=7.1 \mathrm{~Hz}, 2 \mathrm{H})$, $7.31-7.29(\mathrm{~m}, 1 \mathrm{H}), 7.28-7.26(\mathrm{~m}, 1 \mathrm{H}), 7.02-6.94(\mathrm{~m}, 3 \mathrm{H}), 6.91-6.85(\mathrm{~m}, 5 \mathrm{H}),-2.09(\mathrm{~s}, 1 \mathrm{H})$. ${ }^{13} \mathrm{C}$ NMR $\left(101 \mathrm{MHz}, \mathrm{CDCl}_{3}\right): \delta=151.3\left(\mathrm{C}_{\mathrm{q}}\right), 148.1(\mathrm{CH}), 138.4\left(\mathrm{C}_{\mathrm{q}}\right), 136.1\left(\mathrm{C}_{\mathrm{q}}\right), 132.04(\mathrm{CH})$, $131.2(\mathrm{CH}), 127.7(\mathrm{CH}), 127.2(\mathrm{CH}), 126.9(\mathrm{CH}), 126.4(\mathrm{CH}), 126.1(\mathrm{CH}) .{ }^{11} \mathrm{~B}$ NMR (128 MHz, $\left.\mathrm{CDCl}_{3}\right): \delta=4.15$ (1B), -3.56 (1B), -10.88 (1B), -15.95 (2B), -20.21 (1B), -25.97 (1B), -30.85 (1B), -35.56 (1B). IR (ATR): 3112, 2538, 1615, 1487, 1433, 1115, 1055, $696 \mathrm{~cm}^{-1}$. MS (ESI) $\mathrm{m} / \mathrm{z}$ (relative intensity): 421 (100) $[\mathrm{M}+\mathrm{Na}]^{+}, 399$ (20) $[\mathrm{M}+\mathrm{H}]^{+}$. HR-MS (ESI): $\mathrm{m} / z$ calcd. for $\mathrm{C}_{19} \mathrm{H}_{23}{ }^{10} \mathrm{~B}_{1}{ }^{11} \mathrm{~B}_{8}{ }^{35} \mathrm{CIN}$ [M+Na] $]^{+}: 421.2303$, found: 421.2298. The analytical data corresponds with those reported in the literature. ${ }^{[225]}$

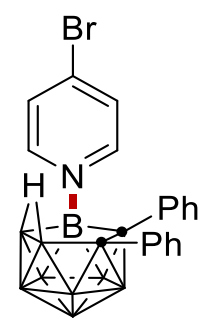

156k. The representative procedure $\mathbf{J}$ was followed using nido-carborane 154a $(36.0 \mathrm{mg}, 0.10$ $\mathrm{mmol}$ ) and 4-bromopyridine hydrochloride 155k (58.2 $\mathrm{mg}, 0.30 \mathrm{mmol})$. Isolation by column chromatography (n-hexane/ $\left.\mathrm{CH}_{2} \mathrm{Cl}_{2}: 3 / 1\right)$ yielded 156k $(21.0 \mathrm{mg}, 45 \%)$ as a yellow solid. $\mathbf{M} . \mathbf{p}$. = $233-236{ }^{\circ} \mathrm{C} .{ }^{1} \mathrm{H}$ NMR $\left(500 \mathrm{MHz}, \mathrm{CD}_{2} \mathrm{Cl}_{2}\right): \delta=8.46(\mathrm{~d}, J=7.0 \mathrm{~Hz}, 2 \mathrm{H}), 7.65-7.61(\mathrm{~m}, 2 \mathrm{H})$, $7.28-7.24(\mathrm{~m}, 2 \mathrm{H}), 7.02-6.92(\mathrm{~m}, 4 \mathrm{H}), 6.88-6.86(\mathrm{~m}, 4 \mathrm{H}),-2.05(\mathrm{~s}, 1 \mathrm{H}) .{ }^{13} \mathrm{C}$ NMR $(126 \mathrm{MHz}$, $\left.\mathrm{CD}_{2} \mathrm{Cl}_{2}\right): \delta=147.9(\mathrm{CH}), 141.1\left(\mathrm{C}_{\mathrm{q}}\right), 138.9\left(\mathrm{C}_{\mathrm{q}}\right), 136.2\left(\mathrm{C}_{\mathrm{q}}\right), 132.4(\mathrm{CH}), 131.5(\mathrm{CH}), 129.7(\mathrm{CH})$, $128.0(\mathrm{CH}), 127.4(\mathrm{CH}), 127.2(\mathrm{CH}), 126.7(\mathrm{CH}) .{ }^{1} \mathrm{~B}$ NMR $\left(128 \mathrm{MHz}, \mathrm{CD}_{2} \mathrm{Cl}_{2}\right): \delta=4.35(1 \mathrm{~B})$, 3.85 (1B), -11.36 (1B), -15.88 (2B), -20.30 (1B), -26.02 (1B), -30.90 (1B), -35.68 (1B). IR (ATR): 2923, 2852, 2149, 2030, 1974, 1723, 1459, $697 \mathrm{~cm}^{-1}$. MS (ESI) $\mathrm{m} / \mathrm{z}$ (relative intensity): 465 (100) $[\mathrm{M}+\mathrm{Na}]^{+}$. HR-MS (ESI) $\mathrm{m} / z$ calcd for $\mathrm{C}_{19} \mathrm{H}_{23}{ }^{10} \mathrm{~B}^{11} \mathrm{~B}_{8}{ }^{79} \mathrm{BrN}[\mathrm{M}+\mathrm{Na}]^{+} 465.1808$, found 465.1807. The analytical data corresponds with those reported in the literature. ${ }^{[225]}$ 


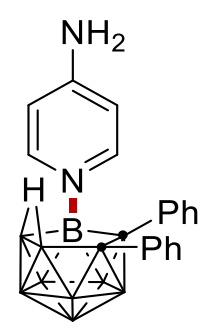

156l. The representative procedure $\mathbf{J}$ was followed using nido-carborane $154 a(36.0 \mathrm{mg}, 0.10$ $\mathrm{mmol}$ ) and pyridin-4-amine $155 \mathrm{I}(28.0 \mathrm{mg}, 0.30 \mathrm{mmol})$. Isolation by column chromatography ( $n$ hexane/ $\left.\mathrm{CH}_{2} \mathrm{Cl}_{2}: 1 / 1\right)$ yielded $156 \mathrm{I}(37.0 \mathrm{mg}, 97 \%)$ as a colorless solid. M.p. $=293-296{ }^{\circ} \mathrm{C}$. ${ }^{1} \mathrm{H}$ NMR $\left(400 \mathrm{MHz}\right.$, Acetone- $\left.d_{6}\right): \delta=8.32-8.23(\mathrm{~m}, 2 \mathrm{H}), 7.35-7.26(\mathrm{~m}, 2 \mathrm{H}), 7.10(\mathrm{~s}, 2 \mathrm{H}), 7.02$ - $6.88(\mathrm{~m}, 5 \mathrm{H}), 6.85-6.75(\mathrm{~m}, 3 \mathrm{H}), 6.72-6.64(\mathrm{~m}, 2 \mathrm{H}),-1.84(\mathrm{~s}, 1 \mathrm{H}) .{ }^{13} \mathrm{C}$ NMR $(101 \mathrm{MHz}$, Acetone- $\left.d_{6}\right): \delta=158.0\left(\mathrm{C}_{\mathrm{q}}\right), 147.7(\mathrm{CH}), 139.4\left(\mathrm{C}_{\mathrm{q}}\right), 137.4\left(\mathrm{C}_{\mathrm{q}}\right), 132.2(\mathrm{CH}), 131.2(\mathrm{CH}), 126.8$ $(\mathrm{CH}), 126.0(\mathrm{CH}), 125.9(\mathrm{CH}), 108.7(\mathrm{CH}), 108.6(\mathrm{CH}) .{ }^{11} \mathrm{~B}$ NMR $\left(96 \mathrm{MHz}\right.$, Acetone- $\left.d_{6}\right): \delta=5.24$ (1B), -5.39 (1B), -13.34 (1B), -15.81 (2B), -22.06 (1B), -26.12 (1B), -31.54 (1B), -36.82 (1B). IR (ATR): 3475, 3375, 2538, 1644, 1527, 1182, 831, $694 \mathrm{~cm}^{-1}$. MS (ESI) $\mathrm{m} / z$ (relative intensity): $402(100)[\mathrm{M}+\mathrm{Na}]^{+}, 380(30)[\mathrm{M}+\mathrm{H}]^{+}$. HR-MS (ESI): $\mathrm{m} / z$ calcd. for $\mathrm{C}_{19} \mathrm{H}_{25}{ }^{10} \mathrm{~B}_{1}{ }^{11} \mathrm{~B}_{8} \mathrm{~N}[\mathrm{M}+\mathrm{Na}]^{+}$: 402.2797, found: 402.2792. The analytical data corresponds with those reported in the literature. ${ }^{[225]}$

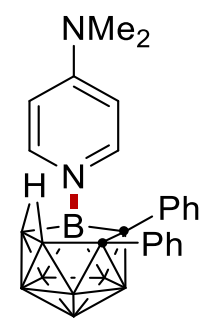

$156 \mathrm{~m}$. The representative procedure $\mathbf{J}$ was followed using nido-carborane $154 \mathrm{a}$ (36.0 $\mathrm{mg}, 0.10$ $\mathrm{mmol}$ ) and $\mathrm{N}, \mathrm{N}$-dimethylpyridin-4-amine $155 \mathrm{~m}(37.0 \mathrm{mg}, 0.30 \mathrm{mmol})$. Isolation by column chromatography ( $n$-hexane/ $\mathrm{CH}_{2} \mathrm{Cl}_{2}: 1 / 1$ ) yielded $156 \mathrm{~m}(21.0 \mathrm{mg}, 52 \%$ ) as a colorless solid. M.p. $=336-338^{\circ} \mathrm{C} .{ }^{1} \mathrm{H}$ NMR $\left(300 \mathrm{MHz}\right.$, DMSO- $\left.d_{6}\right): \delta=8.29(\mathrm{~d}, J=7.1 \mathrm{~Hz}, 2 \mathrm{H}), 7.30(\mathrm{~d}, J=6.4 \mathrm{~Hz}$, 2H), $7.02-6.90(\mathrm{~m}, 5 \mathrm{H}), 6.83-6.75(\mathrm{~m}, 3 \mathrm{H}), 6.70(\mathrm{~d}, J=7.4 \mathrm{~Hz}, 2 \mathrm{H}), 3.05(\mathrm{~s}, 6 \mathrm{H}),-1.56(\mathrm{~s}$, 1H). ${ }^{13} \mathrm{C}$ NMR (101 MHz, DMSO- $\left.d_{6}\right): \delta=155.7\left(\mathrm{C}_{\mathrm{q}}\right), 147.0(\mathrm{CH}), 139.4\left(\mathrm{C}_{\mathrm{q}}\right), 137.3\left(\mathrm{C}_{\mathrm{q}}\right), 132.5$ $(\mathrm{CH}), 131.4(\mathrm{CH}), 127.3(\mathrm{CH}), 127.2(\mathrm{CH}), 126.6(\mathrm{CH}), 126.5(\mathrm{CH}), 106.9(\mathrm{CH}), 39.8\left(\mathrm{CH}_{3}\right) .{ }^{11} \mathrm{~B}$ NMR (128 MHz, DMSO- $\left.d_{6}\right): \delta=5.14$ (1B), -6.22 (1B), -15.59 (3B), -21.95 (1B), -26.05 (1B), 31.52 (1B), -37.12 (1B). IR (ATR): 2554, 2528, 2502, 1643, 1565, 1441, 1166, 820, $696 \mathrm{~cm}^{-1}$. MS (ESI) $\mathrm{m} / z$ (relative intensity): $430(100)[\mathrm{M}+\mathrm{Na}]^{+}, 408(30)[\mathrm{M}+\mathrm{H}]^{+}$. HR-MS (ESI): $\mathrm{m} / z$ calcd. 
for $\mathrm{C}_{21} \mathrm{H}_{29}{ }^{10} \mathrm{~B}_{1}{ }^{11} \mathrm{~B}_{8} \mathrm{~N}_{2}[\mathrm{M}+\mathrm{Na}]^{+}: 430.3111$, found: 430.3110 .

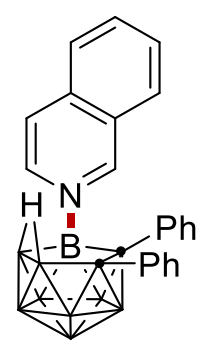

156n. The representative procedure $\mathbf{J}$ was followed using nido-carborane $154 a$ (36.0 $\mathrm{mg}, 0.10$ $\mathrm{mmol})$ and isoquinoline $155 \mathrm{n}(39.0 \mathrm{mg}, 0.30 \mathrm{mmol})$. Isolation by column chromatography ( $n-$ hexane $\left./ \mathrm{CH}_{2} \mathrm{Cl}_{2}: 1 / 1\right)$ yielded $156 \mathrm{n}(38.0 \mathrm{mg}, 92 \%)$ as a yellow solid. M.p. $=280-282{ }^{\circ} \mathrm{C}$. ${ }^{1} \mathrm{H} \mathrm{NMR}\left(300 \mathrm{MHz}, \mathrm{CD}_{2} \mathrm{Cl}_{2}\right): \delta=9.35(\mathrm{~s}, 1 \mathrm{H}), 8.56(\mathrm{dd}, J=6.8,1.0 \mathrm{~Hz}, 1 \mathrm{H}), 8.03-7.96(\mathrm{~m}, 3 \mathrm{H})$, $7.87-7.81(\mathrm{~m}, 2 \mathrm{H}), 7.37-7.32(\mathrm{~m}, 2 \mathrm{H}), 7.06-6.99(\mathrm{~m}, 3 \mathrm{H}), 6.97-6.93(\mathrm{~m}, 2 \mathrm{H}), 6.85-6.78$ (m, 3H), -1.85 (s, 1H). ${ }^{13} \mathrm{C}$ NMR $\left(101 \mathrm{MHz}, \mathrm{CD}_{2} \mathrm{Cl}_{2}\right): \delta=151.9(\mathrm{CH}), 139.1\left(\mathrm{C}_{\mathrm{q}}\right), 139.0(\mathrm{CH})$, $136.9\left(\mathrm{C}_{\mathrm{q}}\right), 136.7\left(\mathrm{C}_{\mathrm{q}}\right), 135.9(\mathrm{CH}), 132.5(\mathrm{CH}), 131.5(\mathrm{CH}), 130.7(\mathrm{CH}), 129.8(\mathrm{CH}), 127.7(\mathrm{CH})$, $127.6\left(\mathrm{C}_{\mathrm{q}}\right), 127.4(\mathrm{CH}), 126.9(\mathrm{CH}), 126.9(\mathrm{CH}), 126.6(\mathrm{CH}), 123.6(\mathrm{CH}) .{ }^{11} \mathrm{~B}$ NMR $(128 \mathrm{MHz}$, $\mathrm{CD}_{2} \mathrm{Cl}_{2}$ ): $\delta=4.98(1 \mathrm{~B}),-4.07(1 \mathrm{~B}),-11.80(1 \mathrm{~B}),-15.78(2 \mathrm{~B}),-20.56(1 \mathrm{~B}),-26.09(1 \mathrm{~B}),-31.06(1 \mathrm{~B})$, -35.86 (1B). IR (ATR): 3376, 2544, 1644, 1598, 1494, 1443, 1179, $697 \mathrm{~cm}^{-1}$. MS (ESI) $\mathrm{m} / \mathrm{z}$ (relative intensity): $437(100)\left[\mathrm{M}+\mathrm{Na}^{+}, 415(30)[\mathrm{M}+\mathrm{H}]^{+}\right.$. HR-MS (ESI): $\mathrm{m} / \mathrm{z}$ calcd. for $\mathrm{C}_{23} \mathrm{H}_{26}{ }^{10} \mathrm{~B}_{1}{ }^{11} \mathrm{~B}_{8} \mathrm{~N}[\mathrm{M}+\mathrm{Na}]^{+}:$:37.2847, found: 437.2849 .

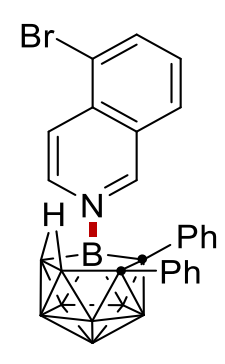

1560. The representative procedure $\mathbf{J}$ was followed using nido-carborane $154 a(36.0 \mathrm{mg}, 0.10$ $\mathrm{mmol}$ ) and 5-bromoisoquinoline $1550(62.0 \mathrm{mg}, 0.30 \mathrm{mmol})$. Isolation by column chromatography ( $n$-hexane/ $\mathrm{CH}_{2} \mathrm{Cl}_{2}: 1 / 1$ ) yielded $1560(31.0 \mathrm{mg}, 63 \%$ ) as a yellow solid. M.p. $=$ $280-283^{\circ} \mathrm{C} .{ }^{1} \mathrm{H}$ NMR $\left(400 \mathrm{MHz}, \mathrm{CD}_{2} \mathrm{Cl}_{2}\right): \delta=9.30-9.23(\mathrm{~m}, 1 \mathrm{H}), 8.70-8.59(\mathrm{~m}, 1 \mathrm{H}), 8.32-$ $8.21(\mathrm{~m}, 1 \mathrm{H}), 8.18-8.11(\mathrm{~m}, 1 \mathrm{H}), 7.95-7.88(\mathrm{~m}, 1 \mathrm{H}), 7.74-7.63(\mathrm{~m}, 1 \mathrm{H}), 7.37-7.28(\mathrm{~m}, 2 \mathrm{H})$, $7.04-6.97(\mathrm{~m}, 3 \mathrm{H}), 6.96-6.91(\mathrm{~m}, 2 \mathrm{H}), 6.87-6.79(\mathrm{~m}, 3 \mathrm{H}),-1.84(\mathrm{~s}, 1 \mathrm{H}) .{ }^{13} \mathrm{C}$ NMR $(101 \mathrm{MHz}$, $\left.\mathrm{CD}_{2} \mathrm{Cl}_{2}\right): \delta=151.5(\mathrm{CH}), 139.9(\mathrm{CH}), 139.0(\mathrm{CH}), 138.7\left(\mathrm{C}_{\mathrm{q}}\right), 136.2\left(\mathrm{C}_{\mathrm{q}}\right), 135.8\left(\mathrm{C}_{\mathrm{q}}\right), 132.1(\mathrm{CH})$, $131.3(\mathrm{CH}), 131.0(\mathrm{CH}), 129.3(\mathrm{CH}), 128.4\left(\mathrm{C}_{\mathrm{q}}\right), 127.6(\mathrm{CH}), 127.1(\mathrm{CH}), 126.8(\mathrm{CH}), 126.3(\mathrm{CH})$, $122.7(\mathrm{CH}), 121.5\left(\mathrm{C}_{\mathrm{q}}\right) .{ }^{11} \mathrm{~B}$ NMR $\left(96 \mathrm{MHz}, \mathrm{CD}_{2} \mathrm{Cl}_{2}\right): \delta=4.90(1 \mathrm{~B}),-3.78(1 \mathrm{~B}),-11.27(1 \mathrm{~B}),-$ 
15.75 (2B), -20.22 (1B), -26.03 (1B), -31.02 (1B), -35.73 (1B). IR (ATR): 2923, 2543, 1637, 1595, 1490, 1443, 1215, 748, $698 \mathrm{~cm}^{-1}$. MS (ESI) $\mathrm{m} / \mathrm{z}$ (relative intensity): $516(100)[\mathrm{M}+\mathrm{Na}]^{+}, 494$ (30)

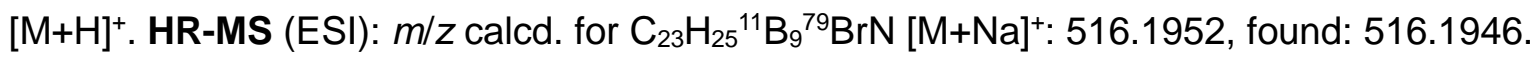

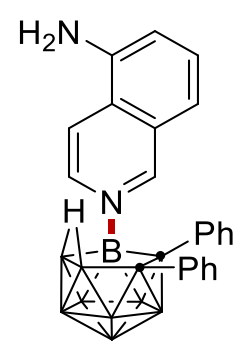

156p. The representative procedure $\mathbf{J}$ was followed using nido-carborane 154a (36.0 mg, 0.10 $\mathrm{mmol}$ ) and isoquinolin-5-amine $155 \mathrm{p}(43.0 \mathrm{mg}, 0.30 \mathrm{mmol})$. Isolation by column chromatography ( $n$-hexane/ $\left.\mathrm{CH}_{2} \mathrm{Cl}_{2}: 1 / 1\right)$ yielded $156 \mathrm{p}\left(22.0 \mathrm{mg}, 51 \%\right.$ ) as a yellow solid. M.p. $=291-293{ }^{\circ} \mathrm{C}$. ${ }^{1} \mathrm{H}$ NMR $\left(400 \mathrm{MHz}, \mathrm{CD}_{2} \mathrm{Cl}_{2}\right): \delta=9.24(\mathrm{~s}, 1 \mathrm{H}), 8.48-8.40(\mathrm{~m}, 1 \mathrm{H}), 7.74-7.68(\mathrm{~m}, 1 \mathrm{H}), 7.64-$ $7.57(\mathrm{~m}, 1 \mathrm{H}), 7.40-7.31(\mathrm{~m}, 3 \mathrm{H}), 7.23-7.18(\mathrm{~m}, 1 \mathrm{H}), 7.04-6.93(\mathrm{~m}, 5 \mathrm{H}), 6.86-6.77(\mathrm{~m}, 3 \mathrm{H})$, $4.45(\mathrm{~s}, 2 \mathrm{H}),-1.84(\mathrm{~s}, 1 \mathrm{H}) .{ }^{13} \mathrm{C}$ NMR $\left(101 \mathrm{MHz}, \mathrm{CD}_{2} \mathrm{Cl}_{2}\right): \delta=151.9(\mathrm{CH}), 142.1\left(\mathrm{C}_{\mathrm{q}}\right), 138.8\left(\mathrm{C}_{\mathrm{q}}\right)$, $137.0(\mathrm{CH}), 136.4\left(\mathrm{C}_{\mathrm{q}}\right), 132.2(\mathrm{CH}), 131.2(\mathrm{CH}), 131.2(\mathrm{CH}), 128.2\left(\mathrm{C}_{\mathrm{q}}\right), 127.4(\mathrm{CH}), 127.1(\mathrm{CH})$, 126.6 $(\mathrm{CH}), 126.3(\mathrm{CH}), 125.7\left(\mathrm{C}_{\mathrm{q}}\right), 119.3(\mathrm{CH}), 117.7(\mathrm{CH}), 117.4(\mathrm{CH}) .{ }^{11} \mathrm{~B}$ NMR $(96 \mathrm{MHz}$, $\mathrm{CD}_{2} \mathrm{Cl}_{2}$ ): $\delta=5.02(1 \mathrm{~B}),-4.05(1 \mathrm{~B}),-11.73(1 \mathrm{~B}),-15.70(2 \mathrm{~B}),-20.59(1 \mathrm{~B}),-26.07(1 \mathrm{~B}),-31.04(1 \mathrm{~B})$, -35.90 (1B). IR (ATR): 2529, 1627, 1596, 1494, 1399, 1385, 744, $693 \mathrm{~cm}^{-1}$. MS (ESI) $\mathrm{m} / \mathrm{z}$ (relative intensity): $452(100)[\mathrm{M}+\mathrm{Na}]^{+}, 430(20)[\mathrm{M}+\mathrm{H}]^{+}$. HR-MS (ESI): $\mathrm{m} / \mathrm{z}$ calcd. for $\mathrm{C}_{23} \mathrm{H}_{27}{ }^{10} \mathrm{~B}_{1}{ }^{11} \mathrm{~B}_{8} \mathrm{~N}_{2}[\mathrm{M}+\mathrm{Na}]^{+}:$452.2956, found: 452.2954 .

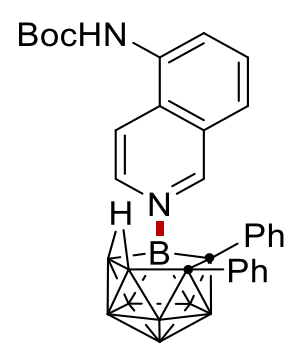

156q. The representative procedure $\mathbf{J}$ was followed using nido-carborane $154 a$ ( $36.0 \mathrm{mg}, 0.10$ $\mathrm{mmol}$ ) and tert-butyl isoquinolin-5-ylcarbamate $155 \mathrm{q}(53.4 \mathrm{mg}, 0.30 \mathrm{mmol})$. Isolation by column chromatography $\left(\mathrm{CH}_{2} \mathrm{Cl}_{2}\right)$ yielded $156 \mathbf{q}(25.1 \mathrm{mg}, 54 \%)$ as a yellow solid. M.p. $=198-201{ }^{\circ} \mathrm{C}$. ${ }^{1} \mathrm{H}$ NMR $\left(400 \mathrm{MHz}, \mathrm{CD}_{2} \mathrm{Cl}_{2}\right): \delta=9.27(\mathrm{~s}, 1 \mathrm{H}), 8.49(\mathrm{~d}, J=8.0 \mathrm{~Hz}, 1 \mathrm{H}), 8.32(\mathrm{~d}, J=7.7 \mathrm{~Hz}, 1 \mathrm{H})$, $7.81-7.73(\mathrm{~m}, 2 \mathrm{H}), 7.71-7.66(\mathrm{~m}, 1 \mathrm{H}), 7.32-7.27(\mathrm{~m}, 2 \mathrm{H}), 7.01-6.94(\mathrm{~m}, 3 \mathrm{H}), 6.93-6.86$ $(\mathrm{m}, 3 \mathrm{H}), 6.82-6.76(\mathrm{~m}, 3 \mathrm{H}), 1.52(\mathrm{~s}, 9 \mathrm{H}),-1.88(\mathrm{~s}, 1 \mathrm{H}) .{ }^{13} \mathrm{C}$ NMR $\left(101 \mathrm{MHz}, \mathrm{CD}_{2} \mathrm{Cl}_{2}\right): \delta=152.9$ $\left(\mathrm{C}_{q}\right), 152.1(\mathrm{CH}), 139.1\left(\mathrm{C}_{\mathrm{q}}\right), 138.5(\mathrm{CH}), 136.6\left(\mathrm{C}_{\mathrm{q}}\right), 133.8\left(\mathrm{C}_{\mathrm{q}}\right), 132.5(\mathrm{CH}), 131.6(\mathrm{CH}), 131.0$ 
$(\mathrm{CH}), 130.0\left(\mathrm{C}_{\mathrm{q}}\right), 128.2\left(\mathrm{C}_{\mathrm{q}}\right), 127.8(\mathrm{CH}), 127.4$ (overlapped, $\left.\mathrm{CH}\right), 127.0(\mathrm{CH}), 126.6(\mathrm{CH}), 125.6$ $(\mathrm{CH}), 117.7(\mathrm{CH}), 82.2\left(\mathrm{C}_{\mathrm{q}}\right), 28.2\left(\mathrm{CH}_{3}\right) .{ }^{11} \mathrm{~B}$ NMR (128 MHz, $\left.\mathrm{CD}_{2} \mathrm{Cl}_{2}\right): \delta=4.81(1 \mathrm{~B}),-3.96(1 \mathrm{~B}),-$ 11.51 (1B), -15.65 (2B), -20.31 (1B), -25.95 (1B), -30.82 (1B), -35.66 (1B). IR (ATR): 2540, 1682, 1521, 1491, 1444, 1252, 1151, $696 \mathrm{~cm}^{-1}$. MS (ESI) $\mathrm{m} / \mathrm{z}$ (relative intensity): 530 (50) [M+H] 552 (100) $[\mathrm{M}+\mathrm{Na}]^{+}$. HR-MS (ESI): $\mathrm{m} / z$ calcd. for $\mathrm{C}_{28} \mathrm{H}_{35}{ }^{10} \mathrm{~B}_{1}{ }^{11} \mathrm{~B}_{8} \mathrm{~N}_{2} \mathrm{O}_{2}[\mathrm{M}+\mathrm{Na}]^{+}: 552.3483$, found: 552.3478 .

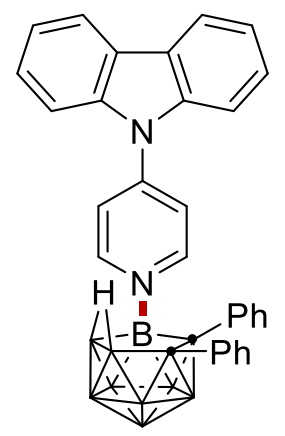

156r. The representative procedure $\mathbf{J}$ was followed using nido-carborane $154 a(36.0 \mathrm{mg}, 0.10$ mmol) and 9-(pyridin-4-yl)-9H-carbazole $155 \mathrm{r}(73.0 \mathrm{mg}, 0.30 \mathrm{mmol}$ ). Isolation by column chromatography ( $n$-hexane/ $\left.\mathrm{CH}_{2} \mathrm{Cl}_{2}: 1 / 1\right)$ yielded $156 \mathrm{r}(30.0 \mathrm{mg}, 56 \%)$ as a yellow solid. M.p. $=320-321^{\circ} \mathrm{C} .{ }^{1} \mathrm{H}$ NMR $\left(300 \mathrm{MHz}\right.$, DMSO- $\left.d_{6}\right): \delta=9.09(\mathrm{~d}, J=7.0 \mathrm{~Hz}, 2 \mathrm{H}), 8.28(\mathrm{~d}, J=$ $7.4 \mathrm{~Hz}, 2 \mathrm{H}), 8.12(\mathrm{~d}, J=7.1 \mathrm{~Hz}, 2 \mathrm{H}), 7.66-7.59(\mathrm{~m}, 2 \mathrm{H}), 7.52(\mathrm{t}, J=7.1 \mathrm{~Hz}, 2 \mathrm{H}), 7.46-7.40$ (m, 2H), $7.37(\mathrm{~d}, J=6.7 \mathrm{~Hz}, 2 \mathrm{H}), 7.09-6.94(\mathrm{~m}, 5 \mathrm{H}), 6.90-6.81(\mathrm{~m}, 3 \mathrm{H}),-1.42(\mathrm{~s}, 1 \mathrm{H})$. ${ }^{13} \mathrm{C}$ NMR $\left(101 \mathrm{MHz}\right.$, DMSO- $\left.d_{6}\right): \delta=150.7(\mathrm{CH}), 150.0\left(\mathrm{C}_{\mathrm{q}}\right), 139.1\left(\mathrm{C}_{\mathrm{q}}\right), 138.3\left(\mathrm{C}_{\mathrm{q}}\right), 136.6\left(\mathrm{C}_{\mathrm{q}}\right)$, $132.5(\mathrm{CH}), 131.5(\mathrm{CH}), 127.7(\mathrm{CH}), 127.5(\mathrm{CH}), 127.4(\mathrm{CH}), 126.9(\mathrm{CH}), 126.7(\mathrm{CH}), 125.1\left(\mathrm{C}_{\mathrm{q}}\right)$, $123.4(\mathrm{CH}), 121.5(\mathrm{CH}), 121.4(\mathrm{CH}), 111.1(\mathrm{CH}) .{ }^{11} \mathrm{~B}$ NMR (161 MHz, DMSO- $\left.d_{6}\right): \delta=19.79(1 \mathrm{~B})$, 5.14 (1B), -5.31 (1B), -15.72 (2B), -21.29 (1B), -26.27 (1B), -31.13 (1B), -36.92 (1B). IR (ATR): 2216, 2176, 2149, 1961, 1510, 1443, $749 \mathrm{~cm}^{-1}$. MS (ESI) $\mathrm{m} / z$ (relative intensity): 552 (100) $[\mathrm{M}+\mathrm{Na}]^{+}, 530(20)[\mathrm{M}+\mathrm{H}]^{+}$. HR-MS (ESI): $\mathrm{m} / \mathrm{z}$ calcd. for $\mathrm{C}_{31} \mathrm{H}_{31}{ }^{10} \mathrm{~B}_{1}{ }^{11} \mathrm{~B}_{8} \mathrm{~N}_{2}[\mathrm{M}+\mathrm{Na}]^{+}: 552.3274$, found: 552.3265 .

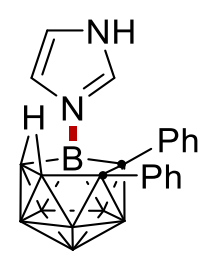

156s. The representative procedure $\mathbf{J}$ was followed using nido-carborane $154 a$ ( $36.0 \mathrm{mg}, 0.10$ $\mathrm{mmol}$ ) and imidazole $155 \mathrm{~s}(20.4 \mathrm{mg}, 0.30 \mathrm{mmol})$. Isolation by column chromatography $\left(\mathrm{CH}_{2} \mathrm{Cl}_{2}\right)$ yielded 156s (30.0 mg, $84 \%)$ as a white solid. M.p. $=283-285^{\circ} \mathrm{C} .{ }^{1} \mathrm{H}$ NMR $(500 \mathrm{MHz}$, Acetone- 
$\left.d_{6}\right): \delta=8.47(\mathrm{t}, J=1.4 \mathrm{~Hz}, 1 \mathrm{H}), 7.33(\mathrm{t}, J=1.6 \mathrm{~Hz}, 1 \mathrm{H}), 7.32-7.24(\mathrm{~m}, 3 \mathrm{H}), 7.04-6.98(\mathrm{~m}, 2 \mathrm{H})$, $6.97-6.91(\mathrm{~m}, 2 \mathrm{H}), 6.92-6.85(\mathrm{~m}, 1 \mathrm{H}), 6.86-6.77(\mathrm{~m}, 3 \mathrm{H}), 2.87(\mathrm{~s}, 1 \mathrm{H}),-1.81(\mathrm{~s}, 1 \mathrm{H}) .{ }^{13} \mathrm{C}$ NMR $\left(126 \mathrm{MHz}\right.$, Acetone- $\left.d_{6}\right): \delta=140.4\left(\mathrm{C}_{\mathrm{q}}\right), 138.4\left(\mathrm{C}_{\mathrm{q}}\right), 133.0(\mathrm{CH}), 132.1(\mathrm{CH}), 127.7(\mathrm{CH})$, 127.6 (overlapped, $\mathrm{CH}$ ), $127.3(\mathrm{CH}), 126.9(\mathrm{CH}), 126.7(\mathrm{CH}), 119.3(\mathrm{CH}) .{ }^{11} \mathrm{~B}$ NMR (128 MHz, Acetone $\left.d_{6}\right): \delta=6.28$ (1B), -0.05 (1B), -7.84 (1B), -10.55 (2B), -16.20 (1B), -20.71 (1B), -26.25 (1B), -31.58 (1B). IR (ATR): 3350, 3151, 2535, 1693, 1494, 1444, 1245, $1058 \mathrm{~cm}^{-1}$ MS (ESI) m/z (relative intensity): $376(100)[\mathrm{M}+\mathrm{Na}]^{+}, 354(20)[\mathrm{M}+\mathrm{H}]^{+}$. HR-MS (ESI): $\mathrm{m} / \mathrm{z}$ calcd. for $\mathrm{C}_{17} \mathrm{H}_{23}{ }^{10} \mathrm{~B}_{1}{ }^{11} \mathrm{~B}_{8} \mathrm{~N}_{2}[\mathrm{M}+\mathrm{Na}]^{+}: 376.2639$, found: 376.2637 . The analytical data corresponds with those reported in the literature. ${ }^{[225]}$

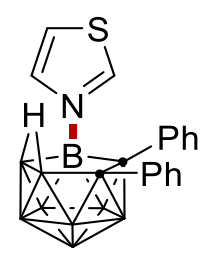

156t. The representative procedure $\mathbf{J}$ was followed using nido-carborane $154 a(36.0 \mathrm{mg}, 0.10$ $\mathrm{mmol}$ ) and thiazole $155 \mathrm{t}(25.5 \mathrm{mg}, 0.30 \mathrm{mmol})$. Isolation by column chromatography ( $n$ hexane/ $\left.\mathrm{CH}_{2} \mathrm{Cl}_{2}: 1 / 1\right)$ yielded $156 \mathrm{t}(23.0 \mathrm{mg}, 62 \%)$ as a white solid. M.p. $=278-280^{\circ} \mathrm{C} .{ }^{1} \mathbf{H}$ NMR (500 MHz, Acetone- $\left.d_{6}\right): \delta=9.62(\mathrm{dd}, J=2.4,1.2 \mathrm{~Hz}, 1 \mathrm{H}$ ), $8.19(\mathrm{dd}, J=3.6,1.2 \mathrm{~Hz}, 1 \mathrm{H}$ ), 8.01 (dd, $J=3.6,2.3 \mathrm{~Hz}, 1 \mathrm{H}), 7.33-7.28(\mathrm{~m}, 2 \mathrm{H}), 7.04-6.99(\mathrm{~m}, 2 \mathrm{H}), 6.96-6.87(\mathrm{~m}, 3 \mathrm{H}), 6.85-$ $6.80(\mathrm{~m}, 3 \mathrm{H}),-1.75(\mathrm{~s}, 1 \mathrm{H}) .{ }^{13} \mathrm{C}$ NMR $\left(126 \mathrm{MHz}\right.$, Acetone- $\left.d_{6}\right): \delta=160.8(\mathrm{CH}), 142.5\left(\mathrm{C}_{\mathrm{q}}\right)$, $139.9\left(\mathrm{C}_{\mathrm{q}}\right), 137.7(\mathrm{CH}), 132.9(\mathrm{CH}), 131.9(\mathrm{CH}), 127.9(\mathrm{CH}), 127.7(\mathrm{CH}), 127.3(\mathrm{CH}), 126.9(\mathrm{CH})$, $124.5(\mathrm{CH}) .{ }^{11 B}$ NMR (128 MHz, Acetone- $\left.d_{6}\right): \delta=2.16(1 \mathrm{~B}),-4.51(1 \mathrm{~B}),-11.95(1 \mathrm{~B}),-15.68(2 \mathrm{~B})$, -20.65 (1B), -25.91 (1B), -30.68 (1B), -36.28 (1B). IR (ATR): 3110, 2922, 2852, 1975, 1492, 1442, 1248, $688 \mathrm{~cm}^{-1}$. MS (ESI) $\mathrm{m} / z$ (relative intensity): $393(100)[\mathrm{M}+\mathrm{Na}]^{+}, 371(30)[\mathrm{M}+\mathrm{H}]^{+}$. HR-MS (ESI): $\mathrm{m} / z$ calcd. for $\mathrm{C}_{17} \mathrm{H}_{22}{ }^{10} \mathrm{~B}_{1}{ }^{11} \mathrm{~B}_{8} \mathrm{NS}[\mathrm{M}+\mathrm{Na}]^{+}: 393.2252$, found: 393.2252. The analytical data corresponds with those reported in the literature. ${ }^{[225]}$

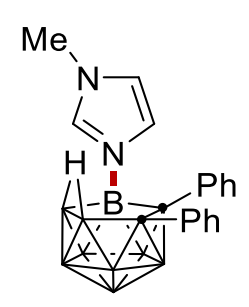

156u. The representative procedure $\mathbf{J}$ was followed using nido-carborane $154 a(36.0 \mathrm{mg}, 0.10$ $\mathrm{mmol}$ ) and 1-methyl-1H-imidazole $155 \mathrm{u}(25.0 \mathrm{mg}, 0.30 \mathrm{mmol})$. Isolation by column chromatography ( $n$-hexane/ $\left.\mathrm{CH}_{2} \mathrm{Cl}_{2}: 1 / 1\right)$ yielded $156 \mathrm{u}(32.0 \mathrm{mg}, 88 \%)$ as a colorless solid. M.p. 
$=270-272{ }^{\circ} \mathrm{C} .{ }^{1} \mathrm{H}$ NMR $\left(400 \mathrm{MHz}, \mathrm{CD}_{2} \mathrm{Cl}_{2}\right): \delta=7.74(\mathrm{~s}, 1 \mathrm{H}), 7.34-7.28(\mathrm{~m}, 2 \mathrm{H}), 7.04-6.90$ $(\mathrm{m}, 9 \mathrm{H}), 6.85(\mathrm{t}, J=1.8 \mathrm{~Hz}, 1 \mathrm{H}), 3.67(\mathrm{~s}, 3 \mathrm{H}),-1.98(\mathrm{~s}, 1 \mathrm{H}) .{ }^{13} \mathrm{C} \mathrm{NMR}\left(101 \mathrm{MHz}, \mathrm{CD}_{2} \mathrm{Cl}_{2}\right): \delta=$ $139.1\left(\mathrm{C}_{\mathrm{q}}\right), 137.3\left(\mathrm{C}_{\mathrm{q}}\right), 137.2(\mathrm{CH}), 132.2(\mathrm{CH}), 131.2(\mathrm{CH}), 127.2(\mathrm{CH}), 127.1(\mathrm{CH}), 127.0(\mathrm{CH})$, $126.4(\mathrm{CH}), 126.1(\mathrm{CH}), 121.6(\mathrm{CH}), 35.5\left(\mathrm{CH}_{3}\right) .{ }^{11} \mathrm{~B}$ NMR $\left(96 \mathrm{MHz}, \mathrm{CD}_{2} \mathrm{Cl}_{2}\right): \delta=0.89(1 \mathrm{~B}),-$ 4.66 (1B), -12.39 (1B), -15.64 (2B), -20.80 (1B), -25.99 (1B), -31.34 (1B), -36.47 (1B). IR (ATR): 3143, 2547, 2506, 1541, 1442, 1172, 829, 750, $689 \mathrm{~cm}^{-1}$. MS (ESI) $\mathrm{m} / z$ (relative intensity): 390 (100) $[\mathrm{M}+\mathrm{Na}]^{+}, 368(20)[\mathrm{M}+\mathrm{H}]^{+}$. HR-MS (ESI): $\mathrm{m} / z$ calcd. for $\mathrm{C}_{18} \mathrm{H}_{25}{ }^{10} \mathrm{~B}_{1}{ }^{11} \mathrm{~B}_{8} \mathrm{~N}_{2}[\mathrm{M}+\mathrm{Na}]^{+}$: 390.2796, found: 390.2795. The analytical data corresponds with those reported in the literature.[225]

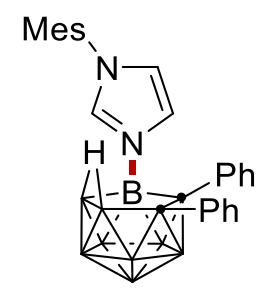

156v. The representative procedure $\mathbf{J}$ was followed using nido-carborane $154 \mathrm{a}$ ( $36.0 \mathrm{mg}, 0.10$ $\mathrm{mmol}$ ) and 1-mesityl-1 $\mathrm{H}$-imidazole $155 \mathrm{v}(56.0 \mathrm{mg}, 0.30 \mathrm{mmol})$. Isolation by column chromatography ( $n$-hexane/ $\left.\mathrm{CH}_{2} \mathrm{Cl}_{2}: 1 / 1\right)$ yielded $156 \mathrm{v}(33.0 \mathrm{mg}, 70 \%)$ as a colorless solid. M.p. $=237-239^{\circ} \mathrm{C} .{ }^{1} \mathbf{H}$ NMR $\left(300 \mathrm{MHz}, \mathrm{CD}_{2} \mathrm{Cl}_{2}\right): \delta=7.72(\mathrm{t}, J=1.5 \mathrm{~Hz}, 1 \mathrm{H}), 7.47(\mathrm{t}, J=1.6 \mathrm{~Hz}$, $1 \mathrm{H}), 7.36-7.30(\mathrm{~m}, 2 \mathrm{H}), 7.04-6.95(\mathrm{~m}, 7 \mathrm{H}), 6.93-6.87(\mathrm{~m}, 4 \mathrm{H}), 2.35(\mathrm{~s}, 3 \mathrm{H}), 1.94(\mathrm{~s}, 3 \mathrm{H})$, $1.60(\mathrm{~s}, 3 \mathrm{H}),-2.01(\mathrm{~s}, 1 \mathrm{H}) .{ }^{13} \mathrm{C}$ NMR $\left(101 \mathrm{MHz}, \mathrm{CD}_{2} \mathrm{Cl}_{2}\right): \delta=141.3\left(\mathrm{C}_{\mathrm{q}}\right), 139.3\left(\mathrm{C}_{\mathrm{q}}\right), 137.7\left(\mathrm{C}_{\mathrm{q}}\right)$, $137.4(\mathrm{CH}), 134.8\left(\mathrm{C}_{\mathrm{q}}\right), 134.7\left(\mathrm{C}_{\mathrm{q}}\right), 132.5(\mathrm{CH}), 131.4(\mathrm{CH}), 131.0\left(\mathrm{C}_{\mathrm{q}}\right), 129.7(\mathrm{CH}), 128.3(\mathrm{CH})$, 127.6 $(\mathrm{CH}), 127.3(\mathrm{CH}), 126.7(\mathrm{CH}), 126.4(\mathrm{CH}), 122.5(\mathrm{CH}), 21.1\left(\mathrm{CH}_{3}\right), 17.2\left(\mathrm{CH}_{3}\right), 17.0\left(\mathrm{CH}_{3}\right)$.

${ }^{11} \mathrm{~B}$ NMR $\left(128 \mathrm{MHz}, \mathrm{CD}_{2} \mathrm{Cl}_{2}\right): \delta=0.52(1 \mathrm{~B}),-4.70(1 \mathrm{~B}),-12.44(1 \mathrm{~B}),-15.97(2 \mathrm{~B}),-21.20(1 \mathrm{~B}),-$ 26.06 (1B), -31.28 (1B), -36.54 (1B). IR (ATR): 3475, 3375, 2534, 1644, 1527, 1181, 832, 695 $\mathrm{cm}^{-1}$. MS (ESI) $\mathrm{m} / \mathrm{z}$ (relative intensity): $494(100)[\mathrm{M}+\mathrm{Na}]^{+}, 472(30)[\mathrm{M}+\mathrm{H}]^{+}$. HR-MS (ESI): $\mathrm{m} / \mathrm{z}$ calcd. for $\mathrm{C}_{26} \mathrm{H}_{33^{10}} \mathrm{~B}_{1}{ }^{11} \mathrm{~B}_{8} \mathrm{~N}_{2}[\mathrm{M}+\mathrm{Na}]^{+}:$494.3427, found: 494.3417.

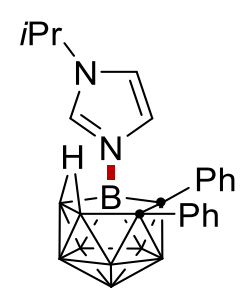

$156 \mathrm{w}$. The representative procedure $\mathbf{J}$ was followed using nido-carborane $154 a(36.0 \mathrm{mg}, 0.10$ $\mathrm{mmol}$ ) and 1-isopropyl-1H-imidazole $155 \mathrm{w}(33.0 \mathrm{mg}, 0.30 \mathrm{mmol})$. Isolation by column 
chromatography ( $n$-hexane/ $\mathrm{CH}_{2} \mathrm{Cl}_{2}: 1 / 1$ ) yielded $156 \mathbf{w}(35.0 \mathrm{mg}, 89 \%$ ) as a colorless solid. M.p. $=213-216{ }^{\circ} \mathrm{C} .{ }^{1} \mathrm{H}$ NMR $\left(300 \mathrm{MHz}, \mathrm{CD}_{2} \mathrm{Cl}_{2}\right): \delta=7.50(\mathrm{t}, J=1.6 \mathrm{~Hz}, 1 \mathrm{H}), 7.34-7.30(\mathrm{~m}, 2 \mathrm{H})$, 7.21 (t, $J=1.7 \mathrm{~Hz}, 1 \mathrm{H}$ ), $7.05-6.97(\mathrm{~m}, 3 \mathrm{H}), 6.96-6.91(\mathrm{~m}, 6 \mathrm{H}$ ), 4.24 (hept, $J=6.7 \mathrm{~Hz}, 1 \mathrm{H}$ ), $1.35(\mathrm{~d}, J=2.5 \mathrm{~Hz}, 3 \mathrm{H}), 1.33(\mathrm{~d}, J=2.5 \mathrm{~Hz}, 3 \mathrm{H}),-2.07(\mathrm{~s}, 1 \mathrm{H}) .{ }^{13} \mathrm{C} \mathbf{N M R}\left(101 \mathrm{MHz}, \mathrm{CD}_{2} \mathrm{Cl}_{2}\right): \delta=$ $139.4\left(\mathrm{C}_{\mathrm{q}}\right), 137.8\left(\mathrm{C}_{\mathrm{q}}\right), 134.8(\mathrm{CH}), 132.4(\mathrm{CH}), 131.5(\mathrm{CH}), 127.6(\mathrm{CH}), 127.5(\mathrm{CH}), 127.3(\mathrm{CH})$, $126.7(\mathrm{CH}), 126.4(\mathrm{CH}), 118.7(\mathrm{CH}), 52.4(\mathrm{CH}), 23.1\left(\mathrm{CH}_{3}\right), 22.9\left(\mathrm{CH}_{3}\right) .{ }^{11} \mathbf{B}$ NMR (128 MHz, $\left.\mathrm{CD}_{2} \mathrm{Cl}_{2}\right): \delta=0.72(1 \mathrm{~B}),-5.08(1 \mathrm{~B}),-12.70(1 \mathrm{~B}),-15.94(2 \mathrm{~B}),-21.04(1 \mathrm{~B}),-26.22(1 \mathrm{~B}),-31.68(1 \mathrm{~B})$, -36.64 (1B). IR (ATR): 3142, 2557, 2519, 1537, 1442, 1177, 838, 759, $657 \mathrm{~cm}^{-1}$. MS (ESI) $\mathrm{m} / \mathrm{z}$ (relative intensity): $418(100)[\mathrm{M}+\mathrm{Na}]^{+}, 396(30)[\mathrm{M}+\mathrm{H}]^{+}$. HR-MS $(\mathrm{ESI}): \mathrm{m} / \mathrm{z}$ calcd. for $\mathrm{C}_{20} \mathrm{H}_{29}{ }^{10} \mathrm{~B}_{1}{ }^{11} \mathrm{~B}_{8} \mathrm{~N}_{2}[\mathrm{M}+\mathrm{Na}]^{+}:$418.3111, found: 418.3114 .

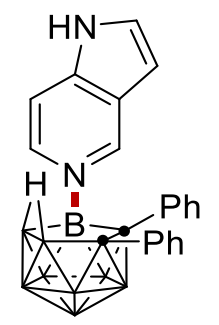

156x. The representative procedure $\mathbf{J}$ was followed using nido-carborane $154 a(36.0 \mathrm{mg}, 0.10$ $\mathrm{mmol}$ ) and $1 \mathrm{H}$-pyrrolo[3,2-c]pyridine $155 \mathrm{x}(35.4 \mathrm{mg}, 0.30 \mathrm{mmol})$. Isolation by column chromatography $\left(\mathrm{CH}_{2} \mathrm{Cl}_{2}\right)$ yielded $156 x(27.0 \mathrm{mg}, 67 \%)$ as a white solid. M.p. $=280-283^{\circ} \mathrm{C}$. ${ }^{1} \mathrm{H}$ NMR $\left(500 \mathrm{MHz}\right.$, Acetone- $\left.d_{6}\right): \delta=11.51(\mathrm{~s}, 1 \mathrm{H}), 9.40(\mathrm{~s}, 1 \mathrm{H}), 8.57(\mathrm{~d}, J=7.8 \mathrm{~Hz}, 1 \mathrm{H}), 7.75$ (dd, $J=3.4,1.9 \mathrm{~Hz}, 1 \mathrm{H}), 7.66(\mathrm{~d}, J=6.8 \mathrm{~Hz}, 1 \mathrm{H}), 7.35-7.30(\mathrm{~m}, 2 \mathrm{H}), 7.04-6.99(\mathrm{~m}, 2 \mathrm{H}), 6.97$ $-6.85(\mathrm{~m}, 4 \mathrm{H}), 6.75-6.60(\mathrm{~m}, 3 \mathrm{H}),-1.65(\mathrm{~s}, 1 \mathrm{H}) .{ }^{13} \mathrm{C} \mathrm{NMR}\left(126 \mathrm{MHz}\right.$, Acetone- $\left.d_{6}\right): \delta=144.2$ $(\mathrm{CH}), 141.7\left(\mathrm{C}_{\mathrm{q}}\right), 140.2\left(\mathrm{C}_{\mathrm{q}}\right), 139.9(\mathrm{CH}), 138.0\left(\mathrm{C}_{\mathrm{q}}\right), 133.0(\mathrm{CH}), 132.0(\mathrm{CH}), 131.9(\mathrm{CH}), 127.7$ $(\mathrm{CH}), 127.5(\mathrm{CH}), 126.8(\mathrm{CH}), 126.8(\mathrm{CH}), 125.6\left(\mathrm{C}_{\mathrm{q}}\right), 108.8(\mathrm{CH}), 104.6(\mathrm{CH}) .{ }^{11} \mathrm{~B}$ NMR $(128$ $\mathrm{MHz}$, Acetone- $\left.d_{6}\right): \delta=6.10(1 \mathrm{~B}),-4.91(1 \mathrm{~B}),-12.91(1 \mathrm{~B}),-15.57$ (2B), -21.64 (1B), -26.01 (1B), 30.95 (1B), -36.54 (1B). IR (ATR): 3386, 2923, 2536, 1631, 1493, 1357, 1225, $697 \mathrm{~cm}^{-1}$ MS (ESI) $\mathrm{m} / \mathrm{z}$ (relative intensity): $426(100)\left[\mathrm{M}+\mathrm{Na}^{+}, 404(30)[\mathrm{M}+\mathrm{H}]^{+}\right.$. HR-MS (ESI): $\mathrm{m} / \mathrm{z}$ calcd. for $\mathrm{C}_{21} \mathrm{H}_{25}{ }^{10} \mathrm{~B}_{1}{ }^{11} \mathrm{~B}_{8} \mathrm{~N}_{2}[\mathrm{M}+\mathrm{Na}]^{+}: 426.2798$, found: 426.2794 .

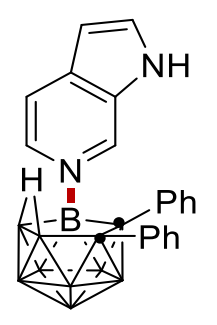


156y. The representative procedure $\mathbf{J}$ was followed using nido-carborane $154 \mathrm{a}$ (36.0 $\mathrm{mg}, 0.10$ $\mathrm{mmol}$ ) and $1 \mathrm{H}$-pyrrolo[2,3-c]pyridine $155 \mathrm{y}(35.4 \mathrm{mg}, 0.30 \mathrm{mmol})$. Isolation by column chromatography $\left(\mathrm{CH}_{2} \mathrm{Cl}_{2}\right)$ yielded 156y $(28.2 \mathrm{mg}, 70 \%)$ as a white solid. M.p. $=171-175{ }^{\circ} \mathrm{C}$. ${ }^{1} \mathrm{H}$ NMR $\left(500 \mathrm{MHz}\right.$, Acetone- $\left.d_{6}\right): \delta=11.55(\mathrm{~s}, 1 \mathrm{H}), 9.23(\mathrm{~s}, 1 \mathrm{H}), 8.53(\mathrm{~d}, J=6.6 \mathrm{~Hz}, 1 \mathrm{H}), 8.07(\mathrm{~d}$, $J=2.9 \mathrm{~Hz}, 1 \mathrm{H}$ ), $7.80(\mathrm{~d}, J=6.6 \mathrm{~Hz}, 1 \mathrm{H}), 7.31(\mathrm{~d}, J=7.2 \mathrm{~Hz}, 2 \mathrm{H}), 6.99(\mathrm{~d}, J=6.8 \mathrm{~Hz}, 2 \mathrm{H}), 6.93$ $(\mathrm{t}, J=7.4 \mathrm{~Hz}, 2 \mathrm{H}), 6.92-6.85(\mathrm{~m}, 1 \mathrm{H}), 6.79(\mathrm{~d}, J=2.9 \mathrm{~Hz}, 1 \mathrm{H}), 6.73-6.63(\mathrm{~m}, 3 \mathrm{H}),-1.64(\mathrm{~s}$, 1H). ${ }^{13} \mathrm{C}$ NMR (126 MHz, Acetone- $\left.d_{6}\right): \delta=140.1\left(\mathrm{C}_{\mathrm{q}}\right), 138.3(\mathrm{CH}), 137.9\left(\mathrm{C}_{\mathrm{q}}\right), 137.9(\mathrm{CH}), 136.4$ $\left(\mathrm{C}_{\mathrm{q}}\right), 134.8(\mathrm{CH}), 133.0(\mathrm{CH}), 132.6\left(\mathrm{C}_{\mathrm{q}}\right), 131.9(\mathrm{CH}), 127.7(\mathrm{CH}), 127.6(\mathrm{CH}), 126.9(\mathrm{CH}), 126.8$ $(\mathrm{CH}), 116.7(\mathrm{CH}), 103.6(\mathrm{CH}) .{ }^{11} \mathrm{~B}$ NMR $\left(128 \mathrm{MHz}\right.$, Acetone- $\left.d_{6}\right): \delta=6.24(1 \mathrm{~B}),-4.58(1 \mathrm{~B}),-12.66$ (1B), -15.43 (2B), -21.41 (1B), -25.92 (1B), -30.88 (1B), -36.41 (1B). IR (ATR): 2539, 1710, 1639, 1494, 1321, 1140, 836, $693 \mathrm{~cm}^{-1}$. MS (ESI) $\mathrm{m} / z$ (relative intensity): 426 (100) [M+Na] $]^{+}, 404$ (50) $[\mathrm{M}+\mathrm{H}]^{+}$. HR-MS (ESI): $\mathrm{m} / z$ calcd. for $\mathrm{C}_{21} \mathrm{H}_{25}{ }^{10} \mathrm{~B}_{1}{ }^{11} \mathrm{~B}_{8} \mathrm{~N}_{2}[\mathrm{M}+\mathrm{Na}]^{+}: 426.2798$, found: 426.2798 . The analytical data corresponds with those reported in the literature. ${ }^{[225]}$

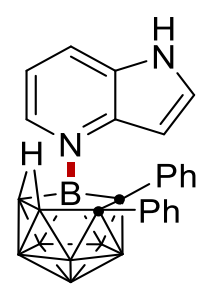

156z. The representative procedure $\mathbf{J}$ was followed using nido-carborane $154 a(36.0 \mathrm{mg}, 0.10$ mmol) and $1 \mathrm{H}$-pyrrolo[3,2-b]pyridine $155 \mathrm{z}(35.4 \mathrm{mg}, 0.30 \mathrm{mmol})$. Isolation by column chromatography $\left(\mathrm{CH}_{2} \mathrm{Cl}_{2}\right)$ yielded $156 \mathrm{z}(20.1 \mathrm{mg}, 50 \%)$ as a white solid. M.p. $=283-285^{\circ} \mathrm{C}$. ${ }^{1}$ H NMR $\left(500 \mathrm{MHz}\right.$, Acetone- $\left.d_{6}\right): \delta=11.57(\mathrm{~s}, 1 \mathrm{H}), 8.69(\mathrm{~d}, J=6.0 \mathrm{~Hz}, 1 \mathrm{H}), 8.30(\mathrm{~d}, J=8.1 \mathrm{~Hz}$, $1 \mathrm{H}), 8.22(\mathrm{~d}, J=3.3 \mathrm{~Hz}, 1 \mathrm{H}), 7.76(\mathrm{~d}, J=3.3 \mathrm{~Hz}, 1 \mathrm{H}), 7.38-7.29(\mathrm{~m}, 3 \mathrm{H}), 7.02-6.85(\mathrm{~m}, 5 \mathrm{H})$, $6.62-6.50(\mathrm{~m}, 3 \mathrm{H}),-1.67(\mathrm{~s}, 1 \mathrm{H}) .{ }^{13} \mathrm{C}$ NMR $\left(126 \mathrm{MHz}\right.$, Acetone- $\left.d_{6}\right): \delta=144.0\left(\mathrm{C}_{\mathrm{q}}\right), 142.6(\mathrm{CH})$, $140.0\left(\mathrm{C}_{\mathrm{q}}\right), 137.9\left(\mathrm{C}_{\mathrm{q}}\right), 135.3(\mathrm{CH}), 133.1(\mathrm{CH}), 132.7(\mathrm{CH}), 131.6\left(\mathrm{C}_{\mathrm{q}}\right), 127.8(\mathrm{CH}), 126.9(\mathrm{CH})$, $126.9(\mathrm{CH}), 126.7(\mathrm{CH}), 126.6(\mathrm{CH}), 116.9(\mathrm{CH}), 101.9(\mathrm{CH}) .{ }^{11} \mathrm{~B}$ NMR $\left(128 \mathrm{MHz}\right.$, Acetone- $\left.d_{6}\right): \delta$ $=4.40$ (1B), -4.77 (1B), -12.03 (1B), -15.09 (1B), -15.66 (1B), -22.01 (1B), -25.70 (1B), -29.83 (1B), -36.66 (1B). IR (ATR): 3386, 2540, 2199, 2021, 14958, 1425, 1367, 763, 698. cm-1. MS (ESI) $\mathrm{m} / z$ (relative intensity): 426 (100) [M+Na] ${ }^{+}, 404(30)[\mathrm{M}+\mathrm{H}]^{+}$. HR-MS (ESI): $\mathrm{m} / z$ calcd. for $\mathrm{C}_{21} \mathrm{H}_{25}{ }^{10} \mathrm{~B}_{1}{ }^{11} \mathrm{~B}_{8} \mathrm{~N}_{2}[\mathrm{M}+\mathrm{Na}]^{+}: 426.2798$, found: 426.2801 . 


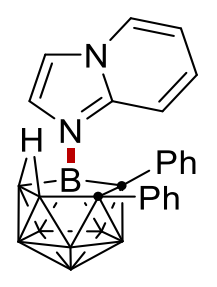

156aa. The representative procedure $\mathbf{J}$ was followed using nido-carborane $154 a$ (36.0 $\mathrm{mg}, 0.10$ mmol) and $H$-imidazo[1,2-a]pyridine 155aa $(35.4 \mathrm{mg}, 0.30 \mathrm{mmol})$. Isolation by column chromatography $\left(\mathrm{CH}_{2} \mathrm{Cl}_{2}\right)$ yielded 156aa $(30.0 \mathrm{mg}, 75 \%)$ as a white solid. M.p. $=265-268^{\circ} \mathrm{C}$. ${ }^{1} \mathrm{H}$ NMR $\left(500 \mathrm{MHz}, \mathrm{CD}_{2} \mathrm{Cl}_{2}\right): \delta=8.76(\mathrm{~d}, J=9.3 \mathrm{~Hz}, 1 \mathrm{H}), 8.16(\mathrm{dt}, J=6.7,1.2 \mathrm{~Hz}, 1 \mathrm{H}), 7.82$ (ddd, $J=9.3,7.0,1.3 \mathrm{~Hz}, 1 \mathrm{H}), 7.53(\mathrm{~d}, J=2.1 \mathrm{~Hz}, 1 \mathrm{H}), 7.39(\mathrm{~d}, J=1.3 \mathrm{~Hz}, 1 \mathrm{H}), 7.34-7.28(\mathrm{~m}$, 2H), $7.25(\mathrm{td}, J=6.9,1.1 \mathrm{~Hz}, 1 \mathrm{H}), 7.01-6.92(\mathrm{~m}, 3 \mathrm{H}), 6.83-6.76(\mathrm{~m}, 2 \mathrm{H}), 6.70-6.61(\mathrm{~m}, 3 \mathrm{H})$, $-1.87(\mathrm{~s}, 1 \mathrm{H}) .{ }^{13} \mathrm{C}$ NMR $\left(126 \mathrm{MHz}, \mathrm{CD}_{2} \mathrm{Cl}_{2}\right): \delta=143.8\left(\mathrm{C}_{\mathrm{q}}\right), 139.4\left(\mathrm{C}_{\mathrm{q}}\right), 137.8\left(\mathrm{C}_{\mathrm{q}}\right), 132.4(\mathrm{CH})$, $132.1(\mathrm{CH}), 130.9(\mathrm{CH}), 130.5(\mathrm{CH}), 127.9(\mathrm{CH}), 127.3(\mathrm{CH}), 127.0(\mathrm{CH}), 126.4(\mathrm{CH}), 126.2$ $(\mathrm{CH}), 116.9(\mathrm{CH}), 115.0(\mathrm{CH}), 113.1(\mathrm{CH}) .{ }^{11} \mathrm{~B}$ NMR $\left(128 \mathrm{MHz}, \mathrm{CD}_{2} \mathrm{Cl}_{2}\right): \delta=0.00(1 \mathrm{~B}),-4.98(1 \mathrm{~B})$, -11.82 (1B), -15.41 (1B), -16.03 (1B), -21.34 (1B), -25.59 (1B), -30.16 (1B), -36.53 (1B). IR (ATR): 3144, 2532, 1707, 1642, 1444, 1202, 752, $697 \mathrm{~cm}^{-1}$. MS (ESI) $\mathrm{m} / \mathrm{z}$ (relative intensity): 426 (100) $[\mathrm{M}+\mathrm{Na}]^{+}, 404(50)[\mathrm{M}+\mathrm{H}]^{+}$. HR-MS (ESI): $\mathrm{m} / \mathrm{z}$ calcd. for $\mathrm{C}_{21} \mathrm{H}_{25}{ }^{10} \mathrm{~B}_{1}{ }^{11} \mathrm{~B}_{8} \mathrm{~N}_{2}[\mathrm{M}+\mathrm{H}]^{+}:$426.2798, found: 426.2801 .

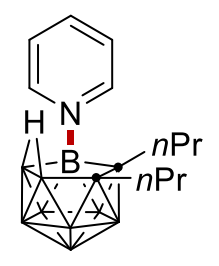

156bb. The representative procedure $\mathbf{J}$ was followed using nido-carborane $154 \mathbf{b}(29.1 \mathrm{mg}, 0.10$ $\mathrm{mmol}$ ) and pyridine $155 \mathrm{a}(24.0 \mathrm{mg}, 0.30 \mathrm{mmol})$. Isolation by column chromatography $(n-$ hexane $\left./ \mathrm{CH}_{2} \mathrm{Cl}_{2}: 1 / 1\right)$ yielded $156 \mathrm{bb}(19.5 \mathrm{mg}, 66 \%)$ as a yellow solid. M.p. $=199-200{ }^{\circ} \mathrm{C}$. ${ }^{1} \mathrm{H}$ NMR $\left(300 \mathrm{MHz}, \mathrm{CD}_{2} \mathrm{Cl}_{2}\right): \delta=9.09(\mathrm{~d}, J=4.9 \mathrm{~Hz}, 2 \mathrm{H}), 8.33(\mathrm{tt}, J=7.8,1.5 \mathrm{~Hz}, 1 \mathrm{H}), 7.85$ (dd, $J=7.7,6.6 \mathrm{~Hz}, 2 \mathrm{H}), 2.04-1.85(\mathrm{~m}, 6 \mathrm{H}), 1.01-0.86(\mathrm{~m}, 5 \mathrm{H}), 0.61(\mathrm{t}, J=7.3 \mathrm{~Hz}, 3 \mathrm{H}),-2.76(\mathrm{~s}$, 1H). ${ }^{13} \mathrm{C}$ NMR $\left(75 \mathrm{MHz}, \mathrm{CD}_{2} \mathrm{Cl}_{2}\right): \delta=148.9(\mathrm{CH}), 143.1(\mathrm{CH}), 126.5(\mathrm{CH}), 36.7\left(\mathrm{CH}_{2}\right), 33.4\left(\mathrm{CH}_{2}\right)$, $24.1\left(\mathrm{CH}_{2}\right), 22.9\left(\mathrm{CH}_{2}\right), 14.3\left(\mathrm{CH}_{3}\right), 14.1\left(\mathrm{CH}_{3}\right) .{ }^{11} \mathrm{~B} \mathrm{NMR}\left(96 \mathrm{MHz}, \mathrm{CD}_{2} \mathrm{Cl}_{2}\right): \delta=4.42(1 \mathrm{~B}),-5.99$ (1B), -12.19 (1B), -13.83 (1B), -17.06 (1B), -20.53 (1B), -27.25 (1B), -30.97 (1B), -37.54 (1B). IR (ATR): 2558, 2527, 2231, 2032, 1960, 1629, 572, $480 \mathrm{~cm}^{-1}$. MS (ESI) $\mathrm{m} / \mathrm{z}$ (relative intensity): 319 (100) [M+Na] $]^{+}, 297(50)[\mathrm{M}+\mathrm{H}]^{+}$. HR-MS (ESI): $m / z$ calcd. for $\mathrm{C}_{13} \mathrm{H}_{28}{ }^{10} \mathrm{~B}_{1}{ }^{11} \mathrm{~B}_{8} \mathrm{~N}[\mathrm{M}+\mathrm{Na}]^{+}:$319.2997, found: 319.2993 . 


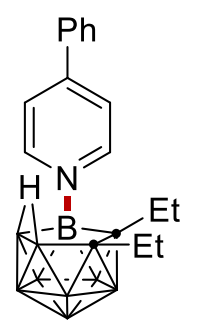

156cc. The representative procedure $\mathbf{J}$ was followed using nido-carborane $154 \mathrm{c}$ ( $26.3 \mathrm{mg}, 0.10$ $\mathrm{mmol}$ ) and 4-phenylpyridine $155 \mathrm{~g}(46.5 \mathrm{mg}, 0.30 \mathrm{mmol})$. Isolation by column chromatography ( $n$-hexane/ $\mathrm{CH}_{2} \mathrm{Cl}_{2}: 1 / 1$ ) yielded 156cc $\left(25.0 \mathrm{mg}, 73 \%\right.$ ) as a yellow solid. M.p. $=84-85{ }^{\circ} \mathrm{C}$. ${ }^{1} \mathrm{H}$ NMR $\left(300 \mathrm{MHz}, \mathrm{CD}_{2} \mathrm{Cl}_{2}\right): \delta=9.06(\mathrm{~d}, J=5.6 \mathrm{~Hz}, 2 \mathrm{H}), 8.02(\mathrm{~d}, J=5.6 \mathrm{~Hz}, 2 \mathrm{H}), 7.90-7.80$ (m, 2H), $7.71-7.62(\mathrm{~m}, 3 \mathrm{H}), 2.19-1.98(\mathrm{~m}, 2 \mathrm{H}), 1.92-1.80(\mathrm{~m}, 2 \mathrm{H}), 1.15(\mathrm{t}, J=7.5 \mathrm{~Hz}, 3 \mathrm{H})$, $0.65(\mathrm{t}, J=7.5 \mathrm{~Hz}, 3 \mathrm{H}),-2.72(\mathrm{~s}, 1 \mathrm{H}) .{ }^{13} \mathrm{C}$ NMR $\left(75 \mathrm{MHz}, \mathrm{CD}_{2} \mathrm{Cl}_{2}\right): \delta=155.0\left(\mathrm{C}_{\mathrm{q}}\right), 148.8(\mathrm{CH})$, $134.4\left(\mathrm{C}_{\mathrm{q}}\right), 131.8(\mathrm{CH}), 129.8(\mathrm{CH}), 127.6(\mathrm{CH}), 123.6(\mathrm{CH}), 27.1\left(\mathrm{CH}_{2}\right), 23.7\left(\mathrm{CH}_{2}\right), 14.9\left(\mathrm{CH}_{3}\right)$, $13.9\left(\mathrm{CH}_{3}\right) .{ }^{11} \mathrm{~B}$ NMR $\left(96 \mathrm{MHz}, \mathrm{CD}_{2} \mathrm{Cl}_{2}\right): \delta=4.3(1 \mathrm{~B}),-6.1(1 \mathrm{~B}),-12.5(1 \mathrm{~B}),-14.0(1 \mathrm{~B}),-17.2(1 \mathrm{~B})$, -20.7 (1B), -27.3 (1B), -31.1 (1B), -37.6 (1B). IR (ATR): 2527, 2032, 1994, 1961, 1629, 766, 692, $446 \mathrm{~cm}^{-1}$. MS (ESI) $\mathrm{m} / z$ (relative intensity): $367(100)[\mathrm{M}+\mathrm{Na}]^{+}, 345(50)[\mathrm{M}+\mathrm{H}]^{+}$. HR-MS (ESI): $\mathrm{m} / z$ calcd. for $\mathrm{C}_{17} \mathrm{H}_{28}{ }^{10} \mathrm{~B}_{1}{ }^{11} \mathrm{~B}_{8} \mathrm{~N}[\mathrm{M}+\mathrm{Na}]^{+}: 367.0000$, found: 367.2993 .

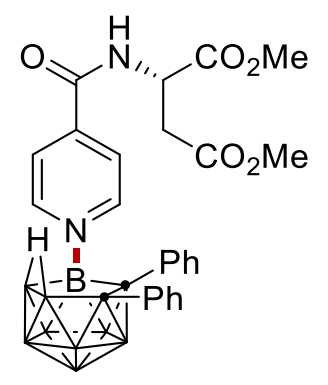

157a. The representative procedure $\mathbf{J}$ was followed using nido-carborane $154 a$ (36.0 $\mathrm{mg}, 0.10$ $\mathrm{mmol}$ ) and dimethyl isonicotinoyl- $L$-aspartate $155 \mathrm{bb}(80.0 \mathrm{mg}, 0.30 \mathrm{mmol})$. Isolation by column chromatography $\left(\mathrm{MeOH} / \mathrm{CH}_{2} \mathrm{Cl}_{2}: 1 / 100\right)$ yielded $157 \mathrm{a}(46.0 \mathrm{mg}, 84 \%)$ as a yellow solid. M.p. $=183-187^{\circ} \mathrm{C} .{ }^{1} \mathrm{H}$ NMR $\left(400 \mathrm{MHz}, \mathrm{CD}_{2} \mathrm{Cl}_{2}\right): \delta=8.83(\mathrm{~d}, J=6.7 \mathrm{~Hz}, 2 \mathrm{H}), 7.82(\mathrm{~d}, J=7.0$ $\mathrm{Hz}, 2 \mathrm{H}), 7.49-7.42(\mathrm{~m}, 1 \mathrm{H}), 7.32(\mathrm{~d}, J=6.5 \mathrm{~Hz}, 2 \mathrm{H}), 7.04-6.98(\mathrm{~m}, 3 \mathrm{H}), 6.96-6.89(\mathrm{~m}, 5 \mathrm{H})$, $5.03-4.96(\mathrm{~m}, 1 \mathrm{H}), 3.80(\mathrm{~s}, 3 \mathrm{H}), 3.72(\mathrm{~s}, 3 \mathrm{H}), 3.20-3.11(\mathrm{~m}, 1 \mathrm{H}), 3.02-2.94(\mathrm{~m}, 1 \mathrm{H}),-1.89(\mathrm{~s}$, 1H). ${ }^{13} \mathrm{C}$ NMR $\left(101 \mathrm{MHz}, \mathrm{CD}_{2} \mathrm{Cl}_{2}\right): \delta=171.4\left(\mathrm{C}_{\mathrm{q}}\right), 170.2\left(\mathrm{C}_{\mathrm{q}}\right), 161.8\left(\mathrm{C}_{\mathrm{q}}\right), 148.3(\mathrm{CH}), 145.7\left(\mathrm{C}_{\mathrm{q}}\right)$, $138.6\left(\mathrm{C}_{\mathrm{q}}\right), 135.8\left(\mathrm{C}_{\mathrm{q}}\right), 132.1(\mathrm{CH}), 131.2(\mathrm{CH}), 127.8(\mathrm{CH}), 127.1(\mathrm{CH}), 127.0(\mathrm{CH}), 126.4(\mathrm{CH})$, $123.5(\mathrm{CH}), 53.1\left(\mathrm{CH}_{3}\right), 52.2\left(\mathrm{CH}_{3}\right), 49.3(\mathrm{CH}), 35.4\left(\mathrm{CH}_{2}\right) .{ }^{11} \mathrm{~B}$ NMR $\left(96 \mathrm{MHz}, \mathrm{CD}_{2} \mathrm{Cl}_{2}\right): \delta=4.58$ (1B), -3.63 (1B), -11.19 (1B), -15.79 (2B), -20.13 (1B), -26.06 (1B), -30.87 (1B), -35.56 (1B). IR (ATR): $3335,2954,2541,1738,1708,1676,1434,1220,697 \mathrm{~cm}^{-1}$. MS (ESI) $\mathrm{m} / \mathrm{z}$ (relative 
intensity): 574 (100) $[\mathrm{M}+\mathrm{Na}]^{+}, \quad 552$ (20) $[\mathrm{M}+\mathrm{H}]^{+}$. HR-MS (ESI): $\mathrm{m} / \mathrm{z}$ calcd. for $\mathrm{C}_{26} \mathrm{H}_{33}{ }^{10} \mathrm{~B}_{1}{ }^{11} \mathrm{~B}_{8} \mathrm{~N}_{2} \mathrm{O}_{5}[\mathrm{M}+\mathrm{Na}]^{+}: 574.3174$, found: 574.3165 .

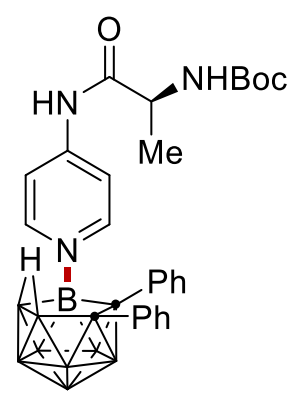

157b. The representative procedure $\mathbf{J}$ was followed using nido-carborane $154 \mathrm{a}(36.0 \mathrm{mg}$, $0.10 \mathrm{mmol}$ ) and tert-butyl (S)-(1-oxo-1-(pyridin-4-ylamino)propan-2-yl)carbamate $155 \mathrm{cc}$ ( $80.0 \mathrm{mg}, 0.30 \mathrm{mmol})$. Isolation by column chromatography $\left(\mathrm{MeOH} / \mathrm{CH}_{2} \mathrm{Cl}_{2}: 1 / 100\right)$ yielded $157 \mathrm{~b}$ (44.0 mg, 80\%) as a colorless solid. M.p. $=230-233^{\circ} \mathrm{C} .{ }^{1} \mathbf{H} \mathbf{~ N M R}\left(400 \mathrm{MHz}, \mathrm{CDCl}_{3}\right): \delta=10.00$ (s, $1 \mathrm{H}), 8.47(\mathrm{~d}, J=3.3 \mathrm{~Hz}, 2 \mathrm{H}), 7.51(\mathrm{t}, J=6.5 \mathrm{~Hz}, 2 \mathrm{H}), 7.33-7.28(\mathrm{~m}, 2 \mathrm{H}), 7.00-6.93(\mathrm{~m}$, $3 \mathrm{H}), 6.89-6.80(\mathrm{~m}, 5 \mathrm{H}), 4.98-4.84(\mathrm{~m}, 1 \mathrm{H}), 4.33-4.20(\mathrm{~m}, 1 \mathrm{H}), 1.48(\mathrm{~s}, 9 \mathrm{H}), 1.42(\mathrm{~d}, J=7.2$ $\mathrm{Hz}, 3 \mathrm{H}),-2.02(\mathrm{~s}, 1 \mathrm{H}) .{ }^{13} \mathrm{C}$ NMR $\left(101 \mathrm{MHz}, \mathrm{CDCl}_{3}\right): \delta=171.8\left(\mathrm{C}_{\mathrm{q}}\right), 157.2\left(\mathrm{C}_{\mathrm{q}}\right), 149.5\left(\mathrm{C}_{\mathrm{q}}\right), 148.3$ $(\mathrm{CH}), 138.6\left(\mathrm{C}_{\mathrm{q}}\right), 136.5\left(\mathrm{C}_{\mathrm{q}}\right), 132.1(\mathrm{CH}), 131.1(\mathrm{CH}), 127.4(\mathrm{CH}), 127.1(\mathrm{CH}), 126.6(\mathrm{CH})$, $126.2(\mathrm{CH}), 113.9(\mathrm{CH}), 82.2\left(\mathrm{C}_{\mathrm{q}}\right), 51.1(\mathrm{CH}), 28.2\left(\mathrm{CH}_{3}\right), 15.7\left(\mathrm{CH}_{3}\right) .{ }^{11} \mathrm{~B} \mathrm{NMR}\left(96 \mathrm{MHz}, \mathrm{CDCl}_{3}\right)$ : $\delta=5.18$ (1B), -3.87 (1B), -10.82 (1B), -15.36 (2B), -20.60 (1B), -26.03 (1B), -30.80 (1B), -35.93 (1B). IR (ATR): 3475, 3375, 2535, 1681, 1644, 1494, 1443, 1162, $695 \mathrm{~cm}^{-1}$. MS (ESI) $\mathrm{m} / \mathrm{z}$ (relative intensity): 573 (100) $[\mathrm{M}+\mathrm{Na}]^{+}, 551$ (50) $[\mathrm{M}+\mathrm{H}]^{+}$. HR-MS (ESI): $\mathrm{m} / z$ calcd. for $\mathrm{C}_{27} \mathrm{H}_{38}{ }^{10} \mathrm{~B}_{1}{ }^{11} \mathrm{~B}_{8} \mathrm{~N}_{3} \mathrm{O}_{3}[\mathrm{M}+\mathrm{Na}]^{+}:$573.3698, found: 573.3708 .

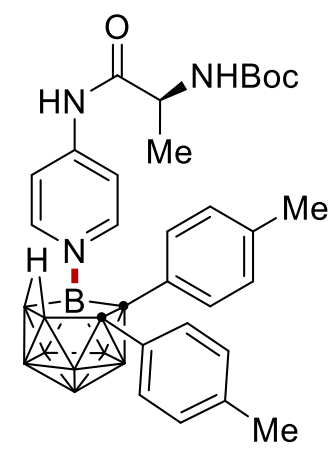

157c. The representative procedure $\mathbf{J}$ was followed using the toluene derivative of the nidocarborane 154d (38.8 mg, $0.10 \mathrm{mmol}$ ) and tert-butyl (S)-(1-oxo-1-(pyridin-4-ylamino)propan -2$\mathrm{yl})$ carbamate $155 \mathrm{dd}(80.0 \mathrm{mg}, 0.30 \mathrm{mmol})$. Isolation by column chromatography $\left(\mathrm{CH}_{2} \mathrm{Cl}_{2}\right)$ yielded $157 \mathrm{c}(32.0 \mathrm{mg}, 55 \%)$ as a white solid. $\mathbf{M . p .}=220-222{ }^{\circ} \mathrm{C} .{ }^{1} \mathbf{H} \mathbf{~ N M R}\left(300 \mathrm{MHz}, \mathrm{CD}_{2} \mathrm{Cl}_{2}\right)$ : 
$\delta=9.91(\mathrm{~s}, 1 \mathrm{H}), 8.48(\mathrm{~d}, J=7.3 \mathrm{~Hz}, 2 \mathrm{H}), 7.57(\mathrm{~d}, J=9.7 \mathrm{~Hz}, 2 \mathrm{H}), 7.19(\mathrm{~d}, J=8.1 \mathrm{~Hz}, 2 \mathrm{H}), 6.90$ - $6.76(\mathrm{~m}, 4 \mathrm{H}), 6.71(\mathrm{~d}, J=7.8 \mathrm{~Hz}, 2 \mathrm{H}), 5.01(\mathrm{~d}, J=6.5 \mathrm{~Hz}, 1 \mathrm{H}), 4.29(\mathrm{q}, J=7.0 \mathrm{~Hz}, 1 \mathrm{H}), 2.18$ (s, 3H), $2.10(\mathrm{~s}, 3 \mathrm{H}), 1.48(\mathrm{~s}, 9 \mathrm{H}), 1.42(\mathrm{~d}, J=7.1 \mathrm{~Hz}, 3 \mathrm{H}),-1.98(\mathrm{~s}, 1 \mathrm{H}) .{ }^{13} \mathrm{C}$ NMR $(101 \mathrm{MHz}$, $\left.\mathrm{CD}_{2} \mathrm{Cl}_{2}\right): \delta=171.9\left(\mathrm{C}_{\mathrm{q}}\right), 149.7\left(\mathrm{C}_{\mathrm{q}}\right), 148.3(\mathrm{CH}), 136.2\left(\mathrm{C}_{\mathrm{q}}\right), 136.2\left(\mathrm{C}_{\mathrm{q}}\right), 136.2\left(\mathrm{C}_{\mathrm{q}}\right), 135.8\left(\mathrm{C}_{\mathrm{q}}\right)$, $133.5\left(\mathrm{C}_{\mathrm{q}}\right), 132.0(\mathrm{CH}), 131.0(\mathrm{CH}), 128.1(\mathrm{CH}), 127.8(\mathrm{CH}), 113.8(\mathrm{CH}), 81.8\left(\mathrm{C}_{\mathrm{q}}\right), 29.7(\mathrm{CH})$, $27.9\left(\mathrm{CH}_{3}\right), 20.6\left(\mathrm{CH}_{3}\right), 20.6\left(\mathrm{CH}_{3}\right), 20.5\left(\mathrm{CH}_{3}\right) .{ }^{11} \mathrm{~B}$ NMR $\left(128 \mathrm{MHz}, \mathrm{CD}_{2} \mathrm{Cl}_{2}\right): \delta=6.10(1 \mathrm{~B}),-4.91$ (1B), -12.91 (1B), -15.57 (2B), -21.64 (1B), -26.01 (1B), -30.95 (1B), -36.54 (1B). IR (ATR): 3210, 2539, 1633, 1517, 1312, 1171, 845, $697 \mathrm{~cm}^{-1}$. MS (ESI) $\mathrm{m} / z$ (relative intensity): 596 (100) $\left[\mathrm{M}+\mathrm{NH}_{4}\right]^{+}$. HR-MS (ESI): $\mathrm{m} / z$ calcd. for $\mathrm{C}_{29} \mathrm{H}_{42}{ }^{10} \mathrm{~B}_{1}{ }^{11} \mathrm{~B}_{8} \mathrm{~N}_{3} \mathrm{O}_{3}\left[\mathrm{M}+\mathrm{NH}_{4}\right]^{+}: 596.4458$, found: 596.4449 .

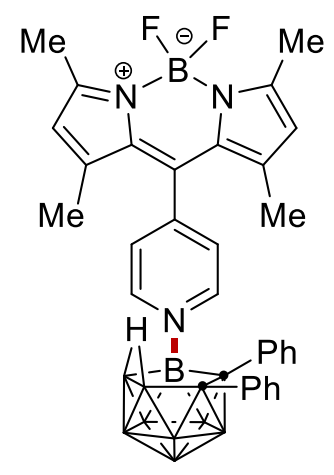

157d. The representative procedure $\mathbf{J}$ was followed using nido-carborane 154a $(36.0 \mathrm{mg}, 0.10$

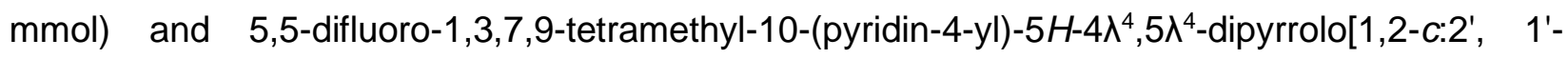
$f[1,3,2]$ diazaborinine 155ee $(98.0 \mathrm{mg}, 0.30 \mathrm{mmol})$. Isolation by column chromatography $\left(\mathrm{MeOH} / \mathrm{CH}_{2} \mathrm{Cl}_{2}: 1 / 100\right)$ yielded $157 \mathrm{~d}(43.0 \mathrm{mg}, 71 \%)$ as a red solid. M.p. $=318-319{ }^{\circ} \mathrm{C}$. ${ }^{1} \mathrm{H}$ NMR $\left(300 \mathrm{MHz}, \mathrm{CD}_{2} \mathrm{Cl}_{2}\right): \delta=8.94(\mathrm{~d}, J=6.8 \mathrm{~Hz}, 2 \mathrm{H}), 7.59(\mathrm{~d}, J=6.8 \mathrm{~Hz}, 2 \mathrm{H}), 7.37-7.30$ (m, 2H), $7.07-6.87(\mathrm{~m}, 8 \mathrm{H}), 6.09(\mathrm{~s}, 2 \mathrm{H}), 2.55(\mathrm{~s}, 6 \mathrm{H}), 1.25(\mathrm{~s}, 6 \mathrm{H}),-1.96(\mathrm{~s}, 1 \mathrm{H}) .{ }^{13} \mathrm{C}$ NMR $\left(101 \mathrm{MHz}, \mathrm{CD}_{2} \mathrm{Cl}_{2}\right): \delta=158.0\left(\mathrm{C}_{\mathrm{q}}\right), 150.7\left(\mathrm{C}_{\mathrm{q}}\right), 148.5(\mathrm{CH}), 142.1\left(\mathrm{C}_{\mathrm{q}}\right), 138.5\left(\mathrm{C}_{\mathrm{q}}\right), 136.0\left(\mathrm{C}_{\mathrm{q}}\right)$, $133.5\left(\mathrm{C}_{\mathrm{q}}\right), 132.1(\mathrm{CH}), 131.0(\mathrm{CH}), 129.4\left(\mathrm{C}_{\mathrm{q}}\right), 127.7(\mathrm{CH}), 127.2(\mathrm{CH}), 126.9(\mathrm{CH}), 126.4$ (overlapped, $\mathrm{CH}), 122.5(\mathrm{CH}), 15.1\left(\mathrm{CH}_{3}\right), 15.1\left(\mathrm{CH}_{3}\right), 14.5\left(\mathrm{CH}_{3}\right), 14.5\left(\mathrm{CH}_{3}\right) .{ }^{11} \mathrm{~B}$ NMR $(128$ $\mathrm{MHz}, \mathrm{CD}_{2} \mathrm{Cl}_{2}$ ): $\delta=4.61(1 \mathrm{~B}), 0.53\left(\mathrm{t}, J=31.9 \mathrm{~Hz}, \mathrm{BF}_{2}\right.$ ), -3.67 (1B), -10.68 (1B), -15.76 (2B), 20.49 (1B), -26.01 (1B), -30.72 (1B), -35.65 (1B). $\left.{ }^{19} \mathrm{~F} \mathrm{NMR} \mathrm{(377} \mathrm{MHz,} \mathrm{CD}_{2} \mathrm{Cl}_{2}\right): \delta=-146.29$ (dd, $J=64.0,32.5 \mathrm{~Hz}$ ). IR (ATR): 3478, 3376, 2541, 1644, 1518, 1443, 1197, 1161, $695 \mathrm{~cm}^{-1}$. MS (ESI) $\mathrm{m} / \mathrm{z}$ (relative intensity): $633 \quad(100) \quad[\mathrm{M}+\mathrm{Na}]^{+}$. HR-MS $(\mathrm{ESI}): \mathrm{m} / \mathrm{z}$ calcd. for $\mathrm{C}_{32} \mathrm{H}_{37}{ }^{10} \mathrm{~B}_{1}{ }^{11} \mathrm{~B}_{9} \mathrm{~F}_{2} \mathrm{~N}_{3}[\mathrm{M}+\mathrm{Na}]^{+}$: 633.3821, found: 633.3823 . 


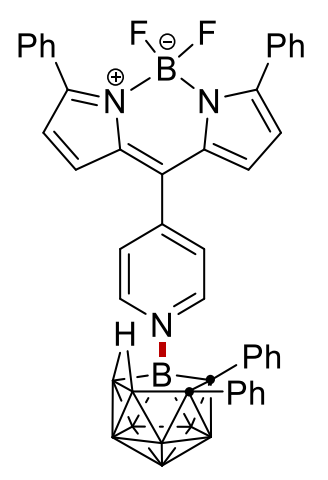

157e. The representative procedure $\mathbf{J}$ was followed using nido-carborane $154 \mathrm{a}(36.0 \mathrm{mg}, 0.10$ mmol) and 5,5-difluoro-3,7-diphenyl-10-(pyridin-4-yl)-5H-4 $\lambda^{4}, 5 \lambda^{4}$-dipyrrolo[1,2-c:2',1'-f][1,3, 2]diazaborinine $\mathbf{1 5 5 f f}(126.0 \mathrm{mg}, \quad 0.30 \mathrm{mmol})$. Isolation by column chromatography $\left(\mathrm{MeOH} / \mathrm{CH}_{2} \mathrm{Cl}_{2}: 1 / 100\right)$ yielded $157 e(35.0 \mathrm{mg}, 50 \%)$ as a purple solid. M.p. $=310-312{ }^{\circ} \mathrm{C}$. ${ }^{1} \mathrm{H}$ NMR $\left(300 \mathrm{MHz}, \mathrm{CD}_{2} \mathrm{Cl}_{2}\right): \delta=8.91(\mathrm{~d}, J=6.8 \mathrm{~Hz}, 2 \mathrm{H}), 7.92-7.85(\mathrm{~m}, 4 \mathrm{H}), 7.70(\mathrm{~d}, J=6.9$ $\mathrm{Hz}, 2 \mathrm{H}), 7.55-7.47(\mathrm{~m}, 6 \mathrm{H}), 7.40-7.33(\mathrm{~m}, 2 \mathrm{H}), 7.09-6.95(\mathrm{~m}, 8 \mathrm{H}), 6.78(\mathrm{~d}, J=4.3 \mathrm{~Hz}, 2 \mathrm{H})$, $6.62(\mathrm{~d}, J=4.4 \mathrm{~Hz}, 2 \mathrm{H}),-1.90(\mathrm{~s}, 1 \mathrm{H}) .{ }^{13} \mathrm{C}$ NMR $\left(101 \mathrm{MHz}, \mathrm{CD}_{2} \mathrm{Cl}_{2}\right): \delta=161.2\left(\mathrm{C}_{\mathrm{q}}\right), 148.5\left(\mathrm{C}_{\mathrm{q}}\right)$, $147.8(\mathrm{CH}), 138.6\left(\mathrm{C}_{\mathrm{q}}\right), 136.2\left(\mathrm{C}_{\mathrm{q}}\right), 135.4\left(\mathrm{C}_{\mathrm{q}}\right), 134.9\left(\mathrm{C}_{\mathrm{q}}\right), 132.1(\mathrm{CH}), 131.8\left(\mathrm{C}_{\mathrm{q}}\right), 131.2(\mathrm{CH})$, $130.3(\mathrm{CH}), 129.7(\mathrm{CH}), 129.5(\mathrm{CH}), 129.5(\mathrm{CH}), 129.4(\mathrm{CH}), 128.3(\mathrm{CH}), 127.7(\mathrm{CH})$, $127.2(\mathrm{CH}), 127.0(\mathrm{CH}), 126.9(\mathrm{CH}), 126.4(\mathrm{CH}), 122.6(\mathrm{CH}) .{ }^{11} \mathbf{B}$ NMR $\left(128 \mathrm{MHz}, \mathrm{CD}_{2} \mathrm{Cl}_{2}\right): \delta=$ 4.61 (1B), 1.24 ( (t, J=31.3 Hz, BF $)$, -3.79 (1B), -10.90 (1B), -16.09 (2B), -20.64 (1B), -26.21 (1B), -31.07 (1B), -35.67 (1B). ${ }^{19} F$ NMR (377 MHz, $\mathrm{CD}_{2} \mathrm{Cl}_{2}$ ): $\delta=-132.08$ (dd, J=63.1, $31.2 \mathrm{~Hz}$ ). IR (ATR): 2220, 2160, 2148, 1990, 1569, 1289, 1136, 1073, $699 \mathrm{~cm}^{-1}$. MS (ESI) $\mathrm{m} / z$ (relative

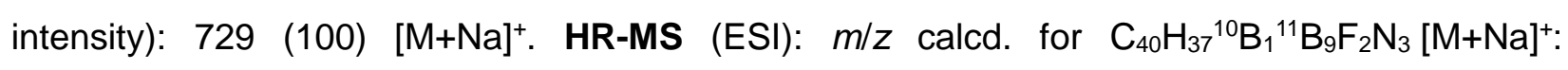
729.3822, found: 729.3833 .

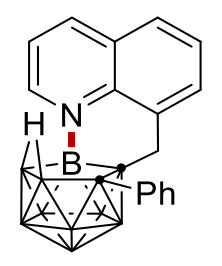

159a. The representative procedure $\mathbf{J}$ was followed using nido-carborane $158 \mathrm{a}$ (43.0 $\mathrm{mg}, 0.10$ $\mathrm{mmol})$. Isolation by column chromatography ( $\left.\mathrm{MeOH} / \mathrm{CH}_{2} \mathrm{Cl}_{2}: 1 / 100\right)$ yielded $159 \mathrm{a}(29.0 \mathrm{mg}, 83 \%)$ as a yellow solid. M.p. $=292-294^{\circ} \mathrm{C} .{ }^{1} \mathrm{H}$ NMR $\left(300 \mathrm{MHz}, \mathrm{CD}_{2} \mathrm{Cl}_{2}\right): \delta=9.30(\mathrm{~d}, J=5.4 \mathrm{~Hz}, 1 \mathrm{H})$, $8.63(\mathrm{dd}, J=8.4,1.6 \mathrm{~Hz}, 1 \mathrm{H}), 7.94(\mathrm{~d}, J=8.1 \mathrm{~Hz}, 1 \mathrm{H}), 7.79-7.67(\mathrm{~m}, 2 \mathrm{H}), 7.60-7.55(\mathrm{~m}, 1 \mathrm{H})$, $7.54-7.48(\mathrm{~m}, 2 \mathrm{H}), 7.38-7.26(\mathrm{~m}, 3 \mathrm{H}), 3.46(\mathrm{~d}, J=18.8 \mathrm{~Hz}, 1 \mathrm{H}), 3.10(\mathrm{~d}, J=18.8 \mathrm{~Hz}, 1 \mathrm{H})$, $1.86(\mathrm{~s}, 1 \mathrm{H}) .{ }^{13} \mathrm{C}$ NMR (101 MHz, $\left.\mathrm{CD}_{2} \mathrm{Cl}_{2}\right): \delta=145.5(\mathrm{CH}), 143.3(\mathrm{CH}), 138.9\left(\mathrm{C}_{\mathrm{q}}\right), 137.6\left(\mathrm{C}_{\mathrm{q}}\right)$, $134.5(\mathrm{CH}), 132.7\left(\mathrm{C}_{q}\right), 131.9(\mathrm{CH}), 129.6\left(\mathrm{C}_{q}\right), 128.9(\mathrm{CH}), 128.0(\mathrm{CH}), 127.6(\mathrm{CH}), 127.1(\mathrm{CH})$, 
$120.9(\mathrm{CH}), 33.9\left(\mathrm{CH}_{2}\right) .{ }^{11} \mathrm{~B}$ NMR $\left(96 \mathrm{MHz}, \mathrm{CD}_{2} \mathrm{Cl}_{2}\right): \delta=1.14(1 \mathrm{~B}),-4.04(1 \mathrm{~B}),-13.02(3 \mathrm{~B}),-$ 19.21 (1B), -27.64 (1B), -29.35 (1B), -34.55 (1B). IR (ATR): 2571, 2543, 2521, 1518, 1373, 829, 766, $695 \mathrm{~cm}^{-1}$. MS (ESI) $\mathrm{m} / z$ (relative intensity): $373(100)[\mathrm{M}+\mathrm{Na}]^{+}, 351(20)[\mathrm{M}+\mathrm{H}]^{+}$. HR-MS (ESI): $m / z$ calcd. for $\mathrm{C}_{18} \mathrm{H}_{22}{ }^{10} \mathrm{~B}_{1}{ }^{11} \mathrm{~B}_{8} \mathrm{~N}[\mathrm{M}+\mathrm{Na}]^{+}: 373.2531$, found: 373.2524 . The analytical data corresponds with those reported in the literature. ${ }^{[225]}$

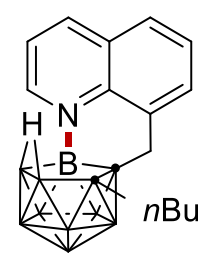

159b. The representative procedure $\mathbf{J}$ was followed using nido-carborane $158 \mathrm{~b}(41.0 \mathrm{mg}, 0.10$ $\mathrm{mmol})$. Isolation by column chromatography $\left(\mathrm{MeOH} / \mathrm{CH}_{2} \mathrm{Cl}_{2}: 1 / 100\right)$ yielded $159 \mathrm{~b}(29.0 \mathrm{mg}, 88 \%)$ as a yellow solid. M.p. $=235-237^{\circ} \mathrm{C} .{ }^{1} \mathrm{H}$ NMR $\left(300 \mathrm{MHz}, \mathrm{CD}_{2} \mathrm{Cl}_{2}\right): \delta=9.26(\mathrm{~d}, J=4.8 \mathrm{~Hz}, 1 \mathrm{H})$, $8.61(\mathrm{dd}, J=8.4,1.6 \mathrm{~Hz}, 1 \mathrm{H}), 8.01-7.93(\mathrm{~m}, 1 \mathrm{H}), 7.83-7.69(\mathrm{~m}, 3 \mathrm{H}), 3.88(\mathrm{~d}, J=18.4 \mathrm{~Hz}, 1 \mathrm{H})$, $3.64(\mathrm{~d}, J=18.4 \mathrm{~Hz}, 1 \mathrm{H}), 2.09-1.86(\mathrm{~m}, 2 \mathrm{H}), 1.73-1.47(\mathrm{~m}, 2 \mathrm{H}), 1.43-1.29(\mathrm{~m}, 2 \mathrm{H}), 0.95(\mathrm{t}$, $J=7.3 \mathrm{~Hz}, 3 \mathrm{H}),-2.44(\mathrm{~s}, 1 \mathrm{H}) .{ }^{13} \mathrm{C}$ NMR $\left(101 \mathrm{MHz}, \mathrm{CD}_{2} \mathrm{Cl}_{2}\right): \delta=145.3(\mathrm{CH}), 143.0(\mathrm{CH}), 137.7$ $\left(\mathrm{C}_{\mathrm{q}}\right), 134.5(\mathrm{CH}), 132.7\left(\mathrm{C}_{\mathrm{q}}\right), 129.6\left(\mathrm{C}_{\mathrm{q}}\right), 128.9(\mathrm{CH}), 127.6(\mathrm{CH}), 120.9(\mathrm{CH}), 34.1\left(\mathrm{CH}_{2}\right), 33.1$ $\left(\mathrm{CH}_{2}\right)$, $33.0\left(\mathrm{CH}_{2}\right), 23.1\left(\mathrm{CH}_{2}\right), 13.8\left(\mathrm{CH}_{3}\right) .{ }^{11} \mathrm{~B}$ NMR $\left(96 \mathrm{MHz}, \mathrm{CD}_{2} \mathrm{Cl}_{2}\right): \delta=0.54(1 \mathrm{~B}),-5.34(1 \mathrm{~B})$, -12.19 (1B), -15.65 (2B), -18.83 (1B), -27.89 (1B), -29.97 (1B), -35.37 (1B). IR (ATR): 2931, 2850, 2581, 2522, 1518, 1374, 1005, 826, $767 \mathrm{~cm}^{-1}$. MS (ESI) $\mathrm{m} / \mathrm{z}$ (relative intensity): 353 (100) $[\mathrm{M}+\mathrm{Na}]^{+}, 331$ (20) $[\mathrm{M}+\mathrm{H}]^{+}$. HR-MS (ESI): $\mathrm{m} / z$ calcd. for $\mathrm{C}_{16} \mathrm{H}_{26}{ }^{10} \mathrm{~B}_{1}{ }^{11} \mathrm{~B}_{8} \mathrm{~N}[\mathrm{M}+\mathrm{Na}]^{+}: 353.2843$, found: 353.2834 .

\subsubsection{Competition Experiments}

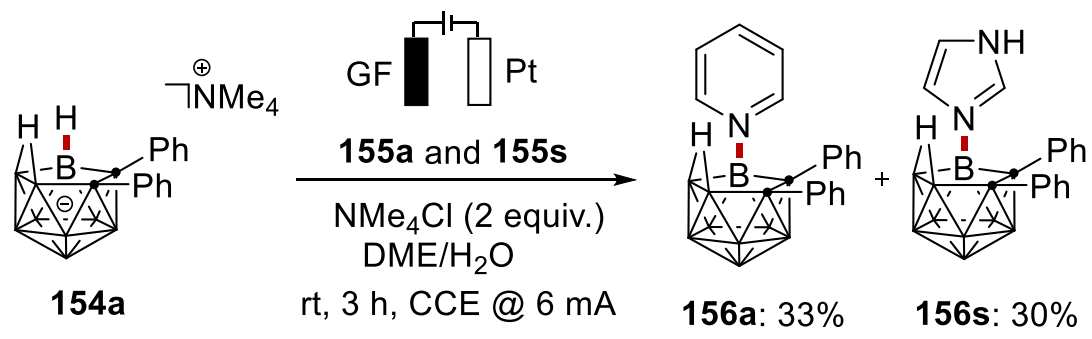

The general procedure $\mathbf{J}$ was followed using nido-carborane $154 \mathrm{a}$ (36 $\mathrm{mg}, 0.10 \mathrm{mmol}$ ), pyridine 155a (12 mg, $0.15 \mathrm{mmol}$ ) and imidazole $155 \mathrm{~s}$ (10 mg, $0.15 \mathrm{mmol}$ ). The conversions to 156a and 156s were determined by crude ${ }^{1} \mathrm{H}$ NMR spectroscopy with $\mathrm{CH}_{2} \mathrm{Br}_{2}$ as the internal standard. 


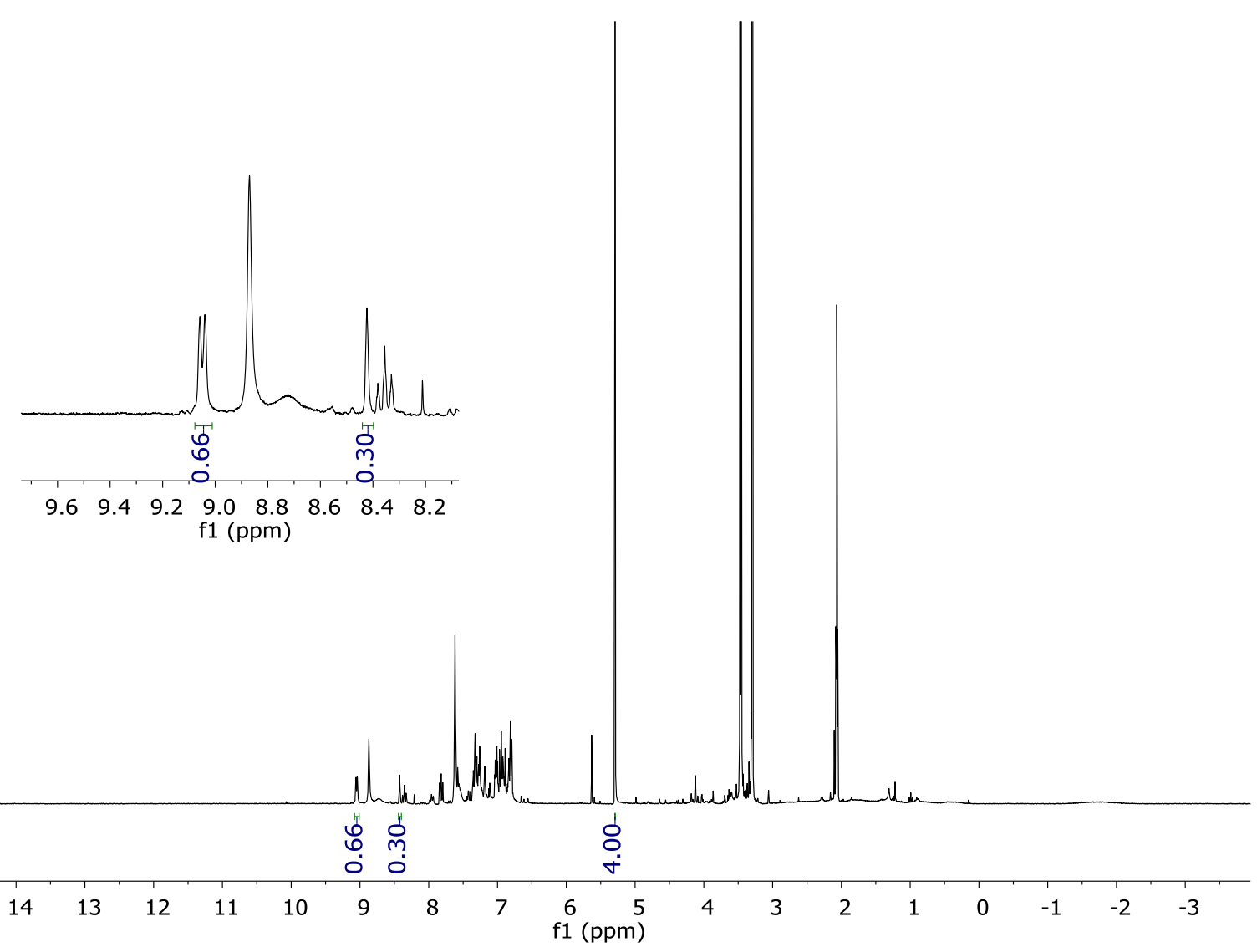

\subsubsection{GC-Headspace Detection}

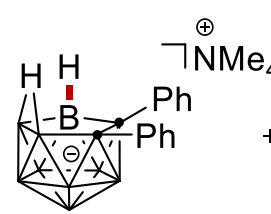

$154 a$

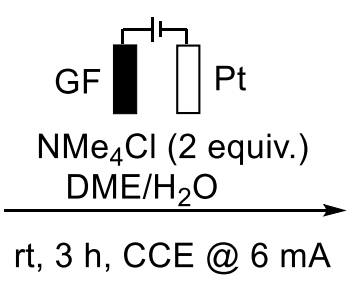

rt, 3 h, CCE @ 6 mA

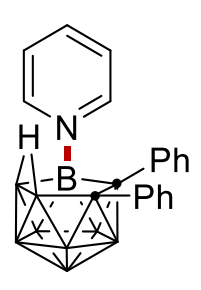

$156 a$

In an undivided cell equipped with a GF anode $(10 \mathrm{~mm} \times 15 \mathrm{~mm} \times 6 \mathrm{~mm})$ and a platinum cathode $(10 \mathrm{~mm} \times 15 \mathrm{~mm} \times 0.25 \mathrm{~mm})$, nido-Carborane $154 \mathrm{a}(0.1 \mathrm{mmol}, 1.0$ equiv), pyridine 155a (0.3 mmol, 3.0 equiv), and $\mathrm{NMe}_{4} \mathrm{Cl}(0.2 \mathrm{mmol}, 2.0$ equiv) were dissolved in DME (4.0 mL) and $\mathrm{H}_{2} \mathrm{O}(0.2 \mathrm{~mL})$. Electrocatalysis was performed at room temperature under a constant current of $6.0 \mathrm{~mA}$ maintained for $3 \mathrm{~h}$. After the reaction, $1.0 \mathrm{~mL}$ of the headspace volume was removed for $\mathrm{GC}$ analysis. The graphite felt anode was washed with $\mathrm{CH}_{2} \mathrm{Cl}_{2}(3 \times 10 \mathrm{~mL})$ in an ultrasonic bath. The yield of $156 \mathrm{a}(86 \%)$ was determined by ${ }^{1} \mathrm{H}$ NMR spectroscopy. 


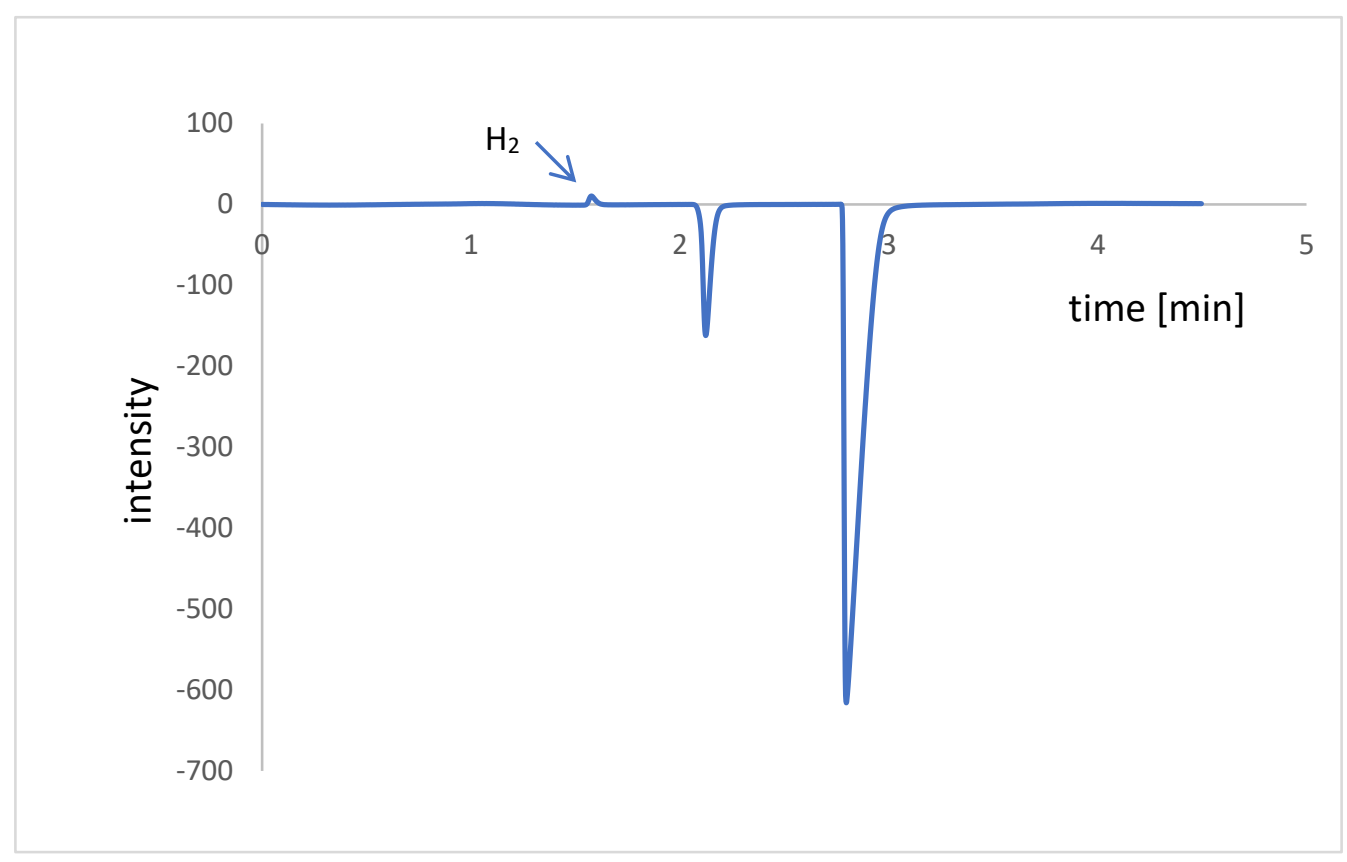

\subsubsection{Cyclic Voltammetry}

CV measurements were conducted with a Metrohm Autolab PGSTAT204 potentiostat and Nova 2.1 software. A glassy carbon working electrode (disk, diameter: $3 \mathrm{~mm}$ ), a coiled platinum wire counter electrode and a non-aqueous $\mathrm{Ag} / \mathrm{Ag}^{+}$reference electrode (ALS Japan) were employed. The voltammograms were recorded at room temperature in dry 1,2-dimethoxyethane (DME) at a substrate concentration of $1 \mathrm{mmol} / \mathrm{L}$ and with $100 \mathrm{mmol} / \mathrm{L} n-\mathrm{Bu}_{4} \mathrm{NPF}_{6}$ as supporting electrolyte. All solutions were degassed with DME-saturated $\mathrm{N}_{2}$ prior to measurement and an overpressure of protective gas was maintained throughout the experiment. The scan rate is $100 \mathrm{mV} / \mathrm{s}$. Deviations from the general experimental conditions are indicated in the respective figures and descriptions. The measured half-peak potential for the irreversible oxidation process of the nidocarborane standard substrate is: $+0.87 \mathrm{~V}$ vs. SCE in $\mathrm{DME} / \mathrm{H}_{2} \mathrm{O} 19: 1,+0.55 \mathrm{~V}$ vs. $\mathrm{Ag} / \mathrm{Ag}^{+}$in $\mathrm{DME} / \mathrm{H}_{2} \mathrm{O} 19: 1,+0.57 \mathrm{~V} v$ s. $\mathrm{Ag} / \mathrm{Ag}^{+}$in DME. 
1) Reagents
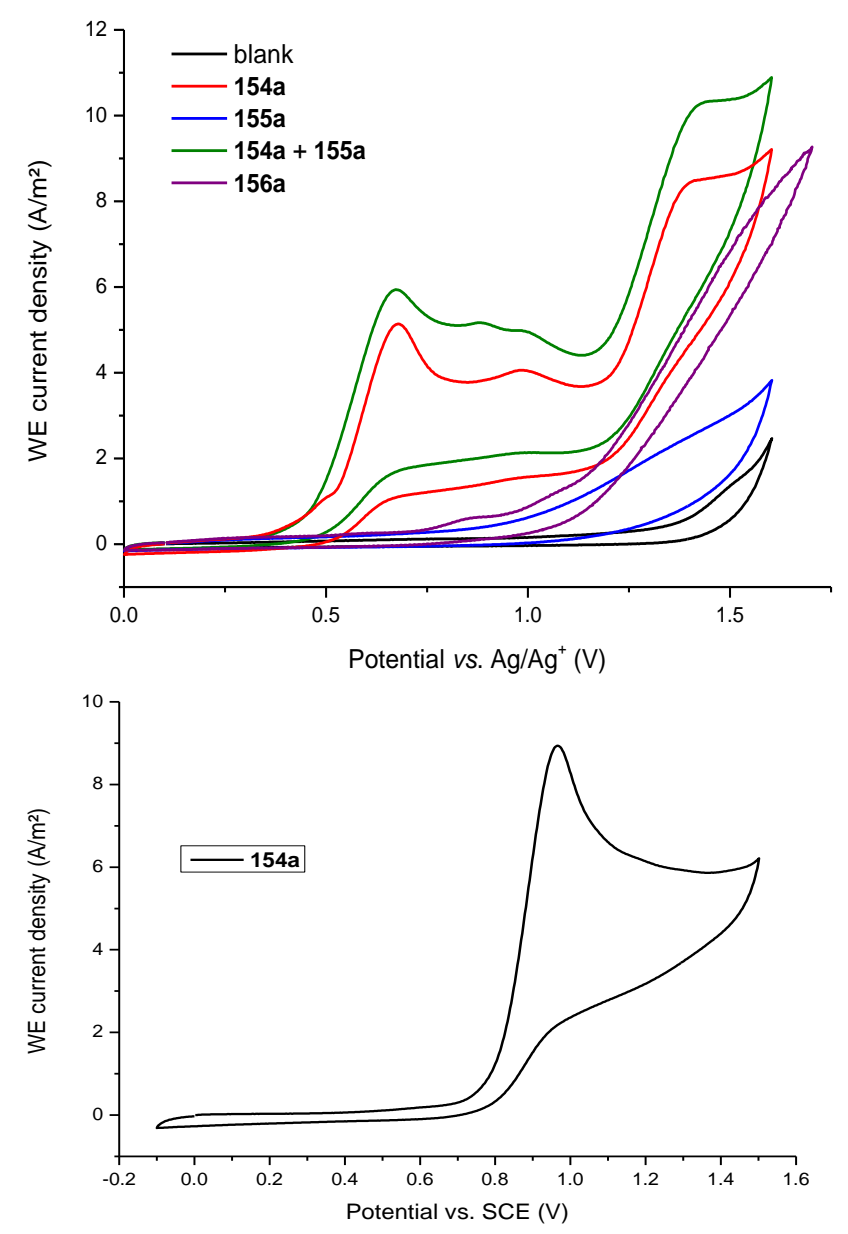

2) Effect of $\mathrm{H}_{2} \mathrm{O}$

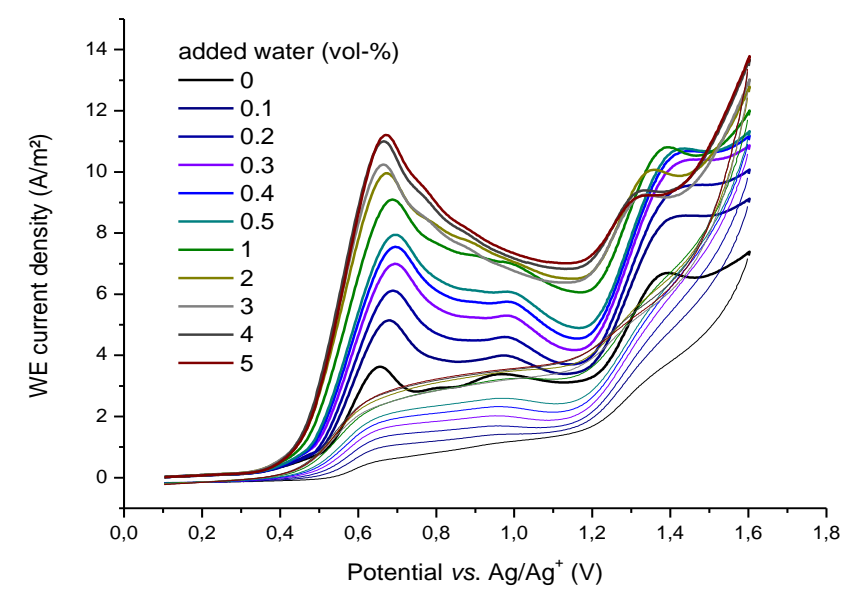

\subsubsection{Stability Test}

Thermal stability test: compound 156a was dissolved in an NMR tube (0.4 mL DMSO- $\left.d_{6}\right)$, then heated to $100{ }^{\circ} \mathrm{C}$ for $3 \mathrm{~h}, 120^{\circ} \mathrm{C}$ for $3 \mathrm{~h}$, and $120^{\circ} \mathrm{C}$ for $10 \mathrm{~h}$, respectively. The ${ }^{1} \mathrm{H}$ NMR and ${ }^{11} \mathrm{~B}$ 
NMR tracking experiments show that 156 a was quite stable at $100^{\circ} \mathrm{C}$ and $120^{\circ} \mathrm{C}$.

Chemical stability test: compound 156a was dissolved in an NMR tube $\left(0.4 \mathrm{~mL} \mathrm{CD}_{3} \mathrm{CN}\right)$, then $0.1 \mathrm{~mL} \mathrm{H} \mathrm{H}_{2} \mathrm{O}, \mathrm{HCl}(1 \mathrm{M})$ or $\mathrm{NaOH}(1 \mathrm{M})$ was added into the NMR tube, respectively. The ${ }^{11} \mathrm{~B}$ NMR tracking experiments show that 156a was stable in a neutral environment. However, 156a starts to decompose in a strong acidic or alkaline environment.

Note: although 156a was not stable in a strong acidic or alkaline environments, but during our experiments, we found these $\mathrm{B}-\mathrm{N}$ coupling compounds are very stable in the solid state or even in liquid solution at room temperature for a long time.

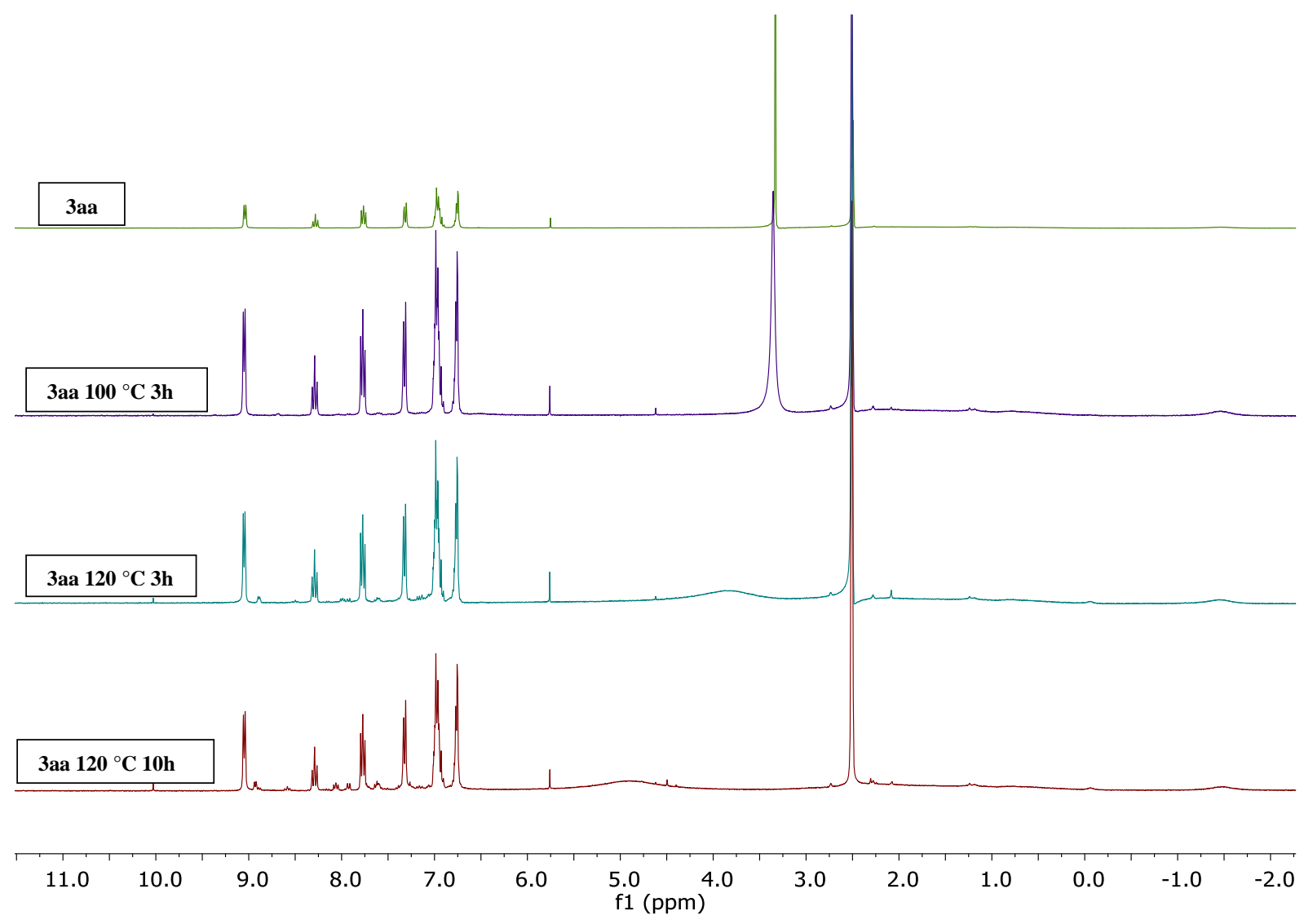

${ }^{1} \mathrm{H}$ NMR spectra of compound $156 a$ in DMSO- $\mathrm{d}_{6}$ at different temperature for stability test. 


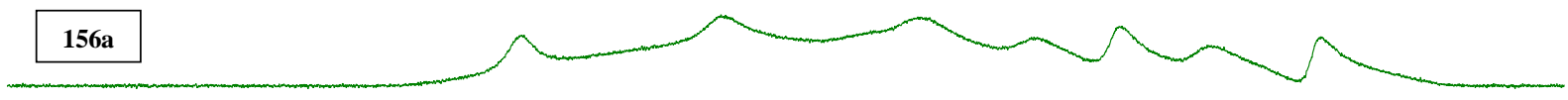

\section{$156 \mathrm{a} 100{ }^{\circ} \mathrm{C} 3 \mathrm{~h}$}
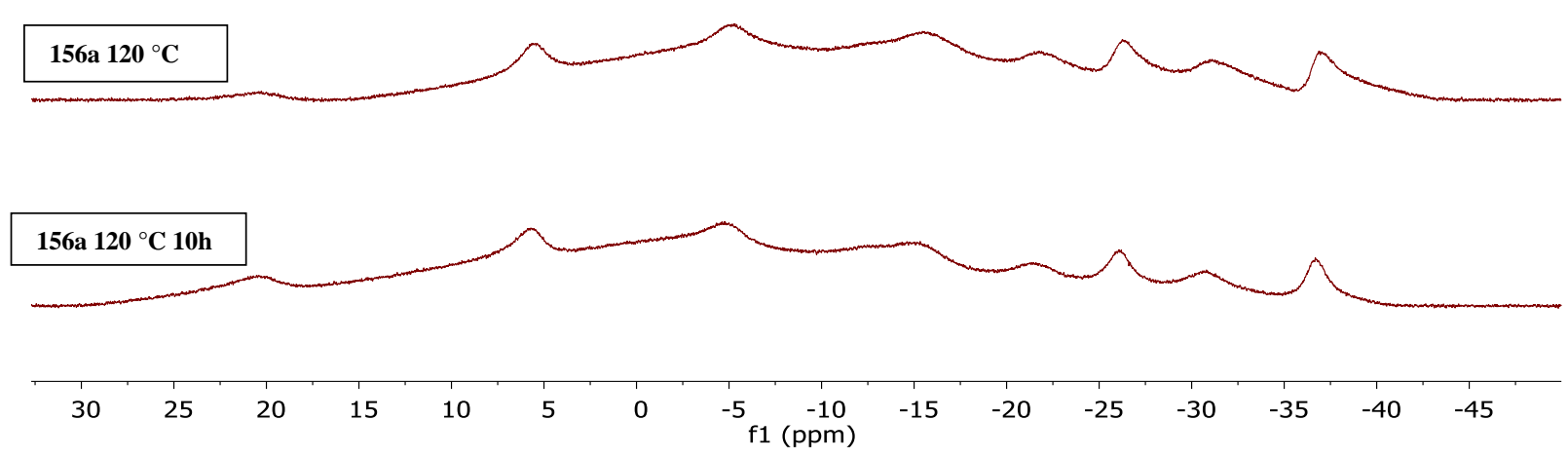

${ }^{11} \mathrm{~B}$ NMR spectra of compound $156 \mathrm{a}$ in DMSO-d 6 at different temperature for thermal stability test.
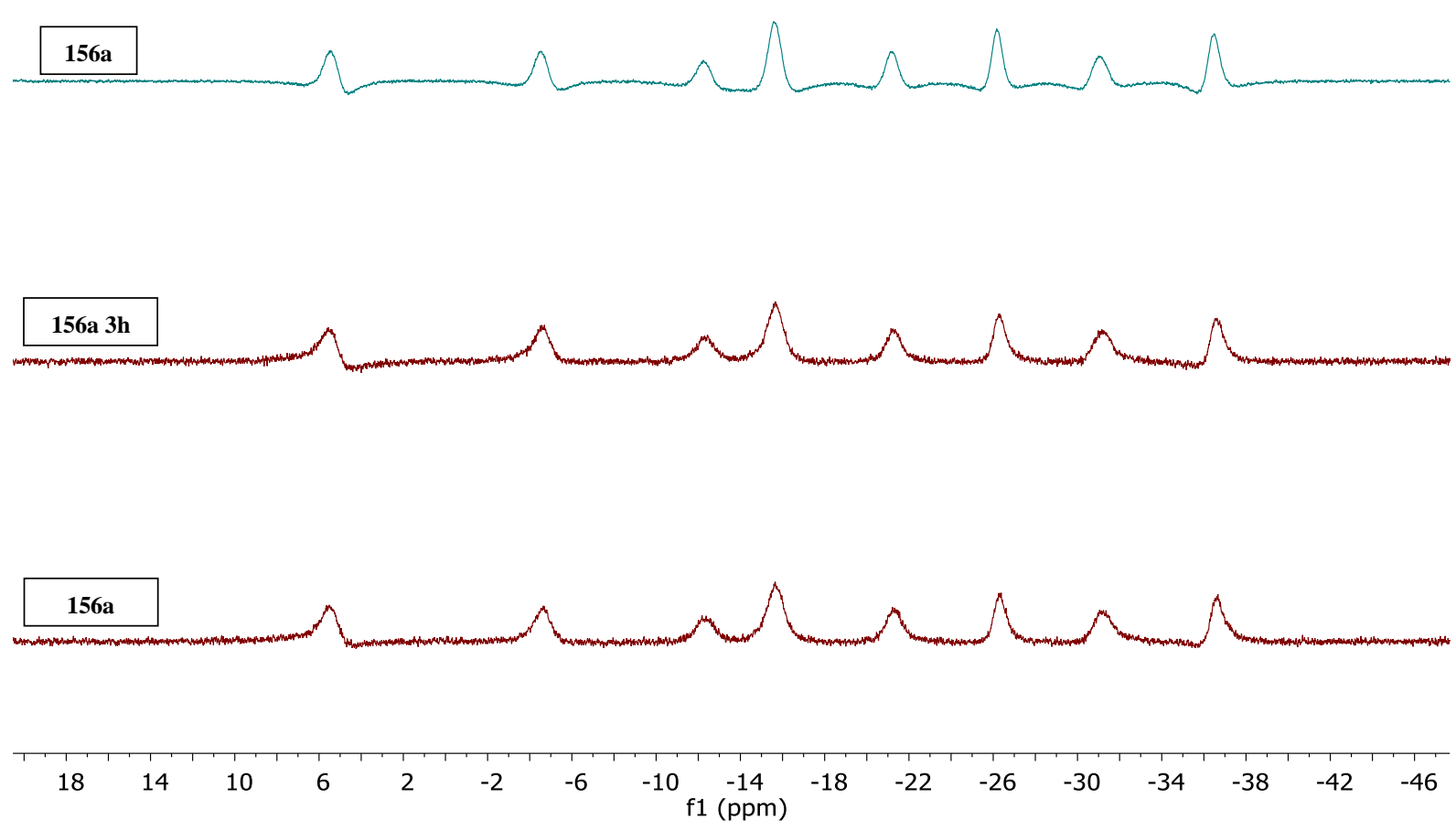

${ }^{11} \mathrm{~B}$ NMR spectra of compound $156 \mathrm{a}$ in $\mathrm{CD}_{3} \mathrm{CN}$ in $0.1 \mathrm{~mL} \mathrm{H} \mathrm{H}_{2} \mathrm{O}$ for chemical stability test. 


\section{Experimental Section}
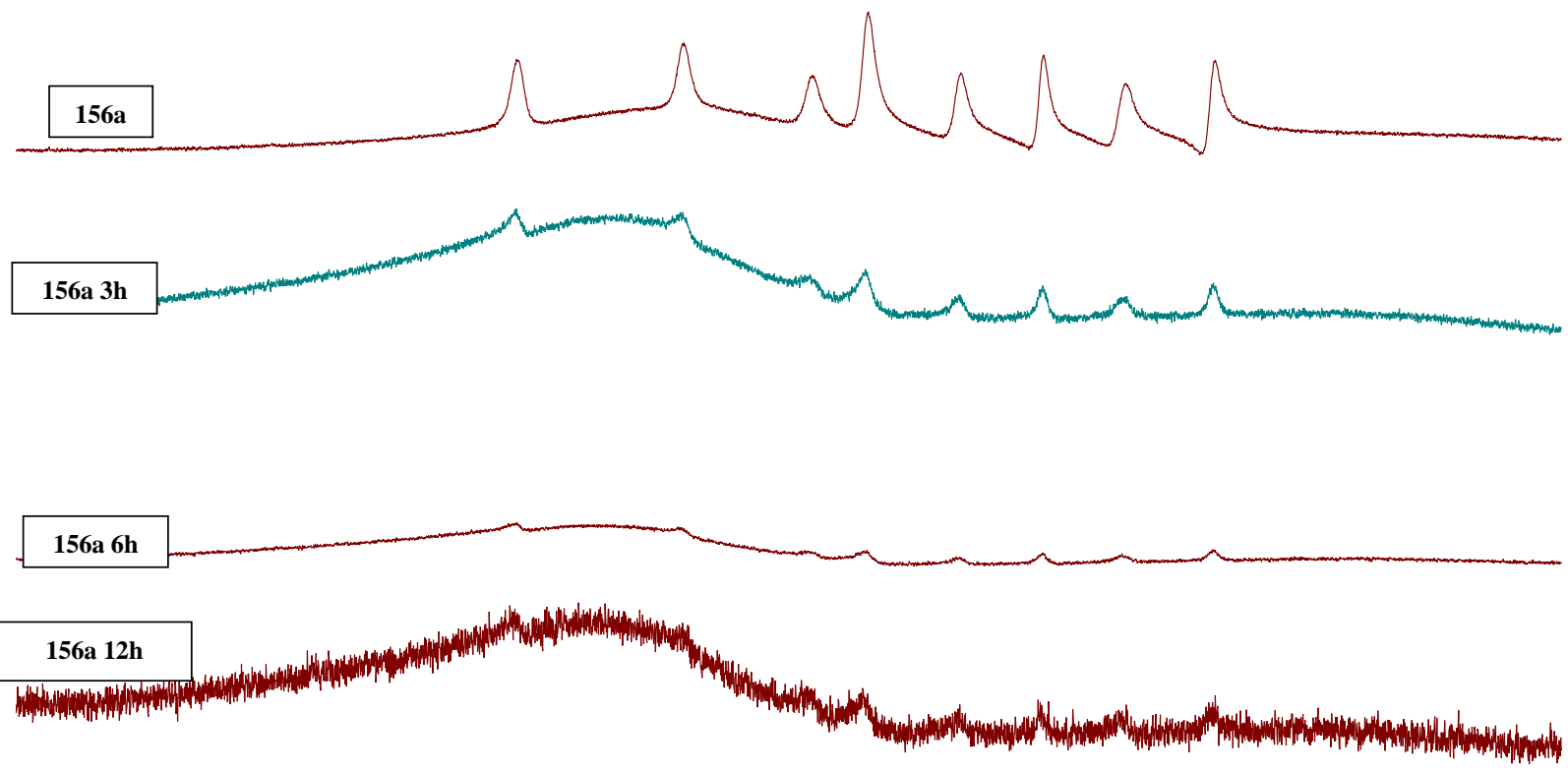

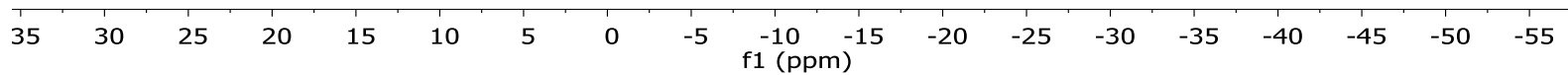

${ }^{11} \mathrm{~B}$ NMR spectra of compound $156 \mathrm{a}$ in $\mathrm{CD}_{3} \mathrm{CN}$ in $0.1 \mathrm{~mL} \mathrm{HCl}(1 \mathrm{M})$ for chemical stability test.

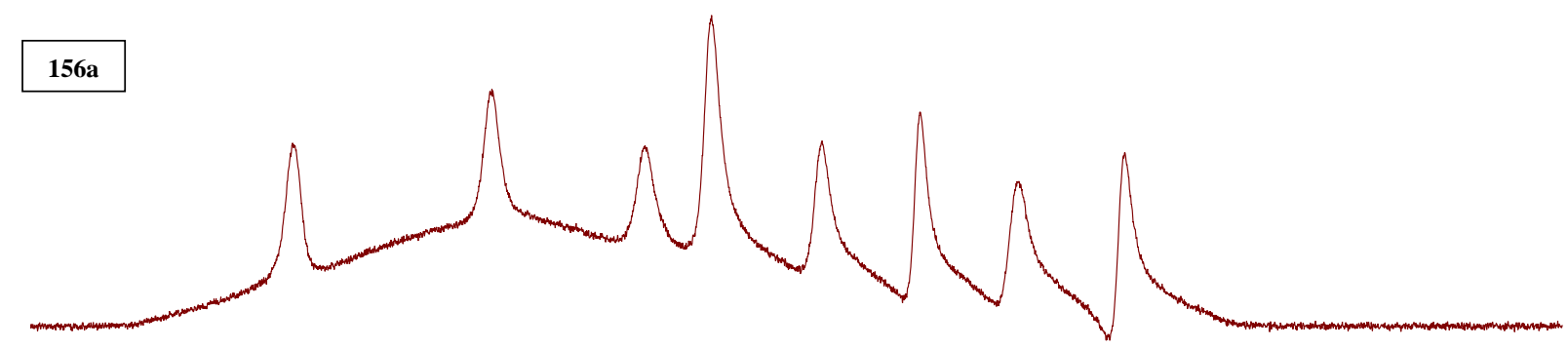

\section{3aa}

156a $3 h$

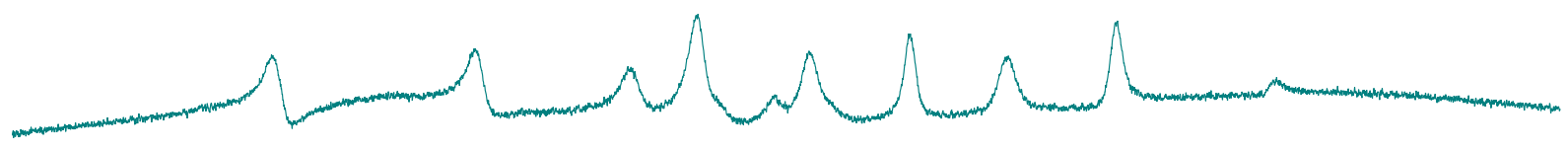

3aa $3 h$

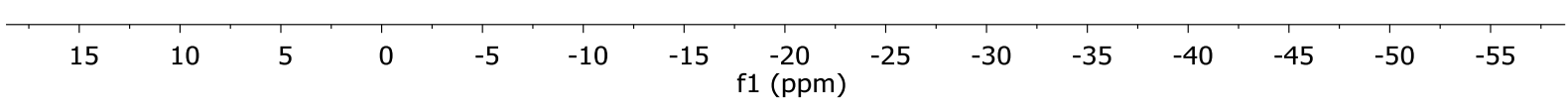

${ }^{11} \mathrm{~B}$ NMR spectra of compound $156 \mathrm{a}$ in $\mathrm{CD}_{3} \mathrm{CN}$ in $0.1 \mathrm{~mL} \mathrm{NaOH}(1 \mathrm{M})$ for chemical stability test. 


\subsubsection{Cupraelectro-Catalyzed Chalcogenations of $o$-Carboranes}

\subsubsection{Characterization Data}

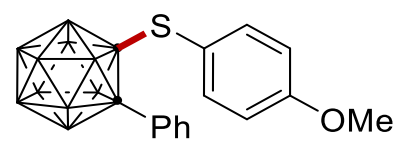

162a. The representative procedure $\mathrm{K}$ was followed using o-carborane $160 \mathrm{a}(22.0 \mathrm{mg}, 0.10$ $\mathrm{mmol})$ and 4-methoxybenzenethiol 161a (36.9 $\mu \mathrm{L}, 0.30 \mathrm{mmol})$. Isolation by column chromatography ( $n$-hexane) yielded $162 \mathrm{a}(30.5 \mathrm{mg}, 85 \%)$ as a colorless solid. M.p. $=141$ $143^{\circ} \mathrm{C} .{ }^{1} \mathrm{H}$ NMR $\left(400 \mathrm{MHz}, \mathrm{CDCl}_{3}\right): \delta=7.66(\mathrm{~d}, J=8.0 \mathrm{~Hz}, 2 \mathrm{H}), 7.57(\mathrm{t}, J=7.4 \mathrm{~Hz}, 1 \mathrm{H}), 7.48(\mathrm{t}$, $J=7.6 \mathrm{~Hz}, 2 \mathrm{H}), 6.86(\mathrm{~d}, J=8.7 \mathrm{~Hz}, 2 \mathrm{H}), 6.77(\mathrm{~d}, J=8.8 \mathrm{~Hz}, 2 \mathrm{H}), 3.83(\mathrm{~s}, 3 \mathrm{H}) .{ }^{13} \mathbf{C}$ NMR $\left(101 \mathrm{MHz}, \mathrm{CDCl}_{3}\right): \delta=161.8\left(\mathrm{C}_{\mathrm{q}}\right), 138.5(\mathrm{CH}), 132.2(\mathrm{CH}), 131.0\left(\mathrm{C}_{\mathrm{q}}\right), 130.8(\mathrm{CH}), 128.5(\mathrm{CH})$, $120.8\left(\mathrm{C}_{\mathrm{q}}\right), 114.5(\mathrm{CH}), 87.9$ (Cage C), 86.9 (Cage C), $55.4\left(\mathrm{CH}_{3}\right) .{ }^{11} \mathrm{~B}^{\mathrm{NMR}}\left(96 \mathrm{MHz}, \mathrm{CDCl}_{3}\right): \delta$ $=-2.78$ (2B), -9.14 (3B), -10.46 (3B), -11.59 (2B). IR (ATR): 2924, 2853, 2601, 2574, 2561, 1588, 1253, 1170, $1027 \mathrm{~cm}^{-1}$. MS (EI) $\mathrm{m} / \mathrm{z}: 358[\mathrm{M}]^{+}$. HR-MS (EI): $\mathrm{m} / \mathrm{z}$ calcd. for $\mathrm{C}_{15} \mathrm{H}_{22}{ }^{10} \mathrm{~B}_{2}{ }^{11} \mathrm{~B}_{8} \mathrm{OS}[\mathrm{M}]^{+}$: 358.2397, found: 358.2386.

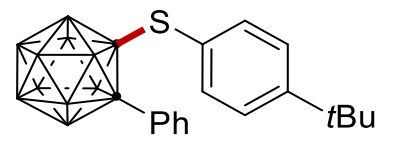

162b. The representative procedure $\mathbf{L}$ with $\mathrm{KI}(16.6 \mathrm{mg}, 0.10 \mathrm{mmol})$ was followed using $o_{-}$ carborane 160a (22.0 mg, $0.10 \mathrm{mmol})$ and 4-(tert-butyl)benzenethiol 161b $(49.9 \mu \mathrm{L}, 0.30 \mathrm{mmol})$. Isolation by column chromatography ( $n$-hexane) yielded $162 \mathrm{~b}(24.0 \mathrm{mg}, 62 \%)$ as a colorless solid. M.p. = $177-179^{\circ} \mathrm{C} .{ }^{1} \mathbf{H}$ NMR $\left(400 \mathrm{MHz}, \mathrm{CDCl}_{3}\right): \delta=7.69-7.64(\mathrm{~m}, 2 \mathrm{H}), 7.62-7.53(\mathrm{~m}$, $1 \mathrm{H}), 7.51-7.46(\mathrm{~m}, 2 \mathrm{H}), 7.30-7.26(\mathrm{~m}, 2 \mathrm{H}), 6.92-6.85(\mathrm{~m}, 2 \mathrm{H}), 1.33(\mathrm{~s}, 9 \mathrm{H}) .{ }^{13} \mathrm{C}$ NMR $(101$ $\left.\mathrm{MHz}, \mathrm{CDCl}_{3}\right): \delta=154.7\left(\mathrm{C}_{\mathrm{q}}\right), 136.5(\mathrm{CH}), 132.2(\mathrm{CH}), 131.0\left(\mathrm{C}_{\mathrm{q}}\right), 130.8(\mathrm{CH}), 128.5(\mathrm{CH}), 126.4$ $\left(\mathrm{C}_{\mathrm{q}}\right), 126.1(\mathrm{CH}), 88.1$ (Cage $\left.\mathrm{C}\right), 86.6$ (Cage C), $34.9\left(\mathrm{C}_{\mathrm{q}}\right), 31.1\left(\mathrm{CH}_{3}\right) .{ }^{11} \mathbf{B}$ NMR (96 MHz, $\left.\mathrm{CDCl}_{3}\right): \delta=-3.00$ (2B), -9.24 (3B), -10.43 (2B), -11.65 (3B). IR (ATR): 2966, 2924, 2866, 2577, 2564, 1446, 1073, $687 \mathrm{~cm}^{-1}$. MS (El) m/z: 384 [M] $]^{+}$HR-MS (El): $\mathrm{m} / z$ calcd. for $\mathrm{C}_{18} \mathrm{H}_{28}{ }^{10} \mathrm{~B}_{2}{ }^{11} \mathrm{~B}_{8} \mathrm{~S}[\mathrm{M}]^{+}:$384.2919, found: 384.2904.

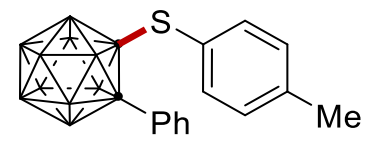

162c. The representative procedure $\mathrm{K}$ with $\mathrm{KI}(16.6 \mathrm{mg}, 0.10 \mathrm{mmol})$ was followed using $o_{-}$ carborane 160a (22.0 mg, $0.10 \mathrm{mmol})$ and 4-methylbenzenethiol 161c (37.2 mg, $0.30 \mathrm{mmol})$. Isolation by column chromatography ( $n$-hexane) yielded 162c (18.9 mg, 55\%) as a colorless 
solid. M.p. $=146-148{ }^{\circ} \mathrm{C} .{ }^{1} \mathrm{H}$ NMR $\left(400 \mathrm{MHz}, \mathrm{CDCl}_{3}\right): \delta=7.65-7.58(\mathrm{~m}, 1 \mathrm{H}), 7.55-7.49(\mathrm{~m}$, 2H), $7.47-7.39(\mathrm{~m}, 2 \mathrm{H}), 7.03(\mathrm{~d}, J=7.8 \mathrm{~Hz}, 2 \mathrm{H}), 6.79(\mathrm{~d}, J=8.2 \mathrm{~Hz}, 2 \mathrm{H}), 2.32(\mathrm{~s}, 3 \mathrm{H}) .{ }^{13} \mathrm{C}$ NMR $\left(101 \mathrm{MHz}, \mathrm{CDCl}_{3}\right): \delta=141.6\left(\mathrm{C}_{\mathrm{q}}\right), 136.7(\mathrm{CH}), 132.2(\mathrm{CH}), 130.9\left(\mathrm{C}_{\mathrm{q}}\right), 130.8(\mathrm{CH}), 129.8$ $(\mathrm{CH}), 128.5\left(\mathrm{C}_{\mathrm{q}}\right), 126.5(\mathrm{CH}), 88.0$ (Cage C), 86.5 (Cage $\mathrm{C}$ ), $21.37\left(\mathrm{CH}_{3}\right) .{ }^{11} \mathrm{~B}$ NMR (128 MHz, $\left.\mathrm{CDCl}_{3}\right): \delta=-2.59(1 \mathrm{~B}),-3.22(1 \mathrm{~B}),-8.51(2 \mathrm{~B}),-9.22(2 \mathrm{~B}),-10.42(2 \mathrm{~B}),-11.56$ (2B). IR (ATR): 2954, 2598, 2568, 1973, 1492, 1446, 1179, 1073, $885 \mathrm{~cm}^{-1}$. MS (EI) m/z: $342[\mathrm{M}]^{+}$. HR-MS (EI): $\mathrm{m} / \mathrm{z}$ calcd. for $\mathrm{C}_{15} \mathrm{H}_{22}{ }^{10} \mathrm{~B}_{2}{ }^{11} \mathrm{~B}_{8} \mathrm{~S}[\mathrm{M}]^{+}: 342.2448$, found: 342.2435 .

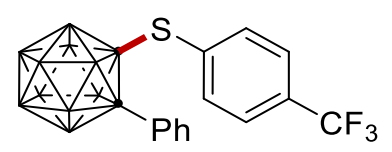

162d. The representative procedure $\mathbf{L}$ with $\mathrm{KI}(16.6 \mathrm{mg}, 0.10 \mathrm{mmol})$ was followed using 0 carborane 160a $(22.0 \mathrm{mg}, 0.10 \mathrm{mmol})$ and 4-(trifluoromethyl)benzenethiol 161d $(41.1 \mu \mathrm{L}, 0.30$ $\mathrm{mmol})$. Isolation by column chromatography ( $n$-hexane) yielded $162 \mathrm{~d}(30.6 \mathrm{mg}, 77 \%)$ as a colorless solid. M.p. $=84-86^{\circ} \mathrm{C} .{ }^{1} \mathrm{H}$ NMR $\left(400 \mathrm{MHz}, \mathrm{CDCl}_{3}\right): \delta=7.62-7.58(\mathrm{~m}, 2 \mathrm{H}), 7.57-$ $7.52(\mathrm{~m}, 1 \mathrm{H}), 7.51-7.47(\mathrm{~m}, 2 \mathrm{H}), 7.47-7.42(\mathrm{~m}, 2 \mathrm{H}), 7.05-7.00(\mathrm{~m}, 2 \mathrm{H}) .{ }^{13} \mathrm{C}$ NMR $(101 \mathrm{MHz}$, $\left.\mathrm{CDCl}_{3}\right): \delta=137.0(\mathrm{CH}), 133.8\left(\mathrm{C}_{\mathrm{q}}\right), 133.0\left(\mathrm{q},{ }^{2} \mathrm{~J}_{\mathrm{C}-\mathrm{F}}=33 \mathrm{~Hz}, \mathrm{C}_{\mathrm{q}}\right), 132.1(\mathrm{CH}), 131.0(\mathrm{CH}), 130.7$ $\left(\mathrm{C}_{\mathrm{q}}\right), 128.6(\mathrm{CH}), 125.9$ (q, ${ }^{3} \mathrm{~J}_{\mathrm{C}-\mathrm{F}}=3.7 \mathrm{~Hz}, \mathrm{CH}$ ), 123.4 (q, ${ }^{1} \mathrm{~J}_{\mathrm{C}-\mathrm{F}}=273 \mathrm{~Hz}, \mathrm{C}_{\mathrm{q}}$ ), 88.0 (Cage C), 84.7 (Cage C). ${ }^{11} \mathrm{~B}$ NMR (128 MHz, $\mathrm{CDCl}_{3}$ ): $\delta=-2.47$ (2B), -9.09 (4B), -10.22 (2B), -11.48 (2B). ${ }^{19} \mathrm{~F}$ NMR $\left(376 \mathrm{MHz}, \mathrm{CDCl}_{3}\right): \delta=-63.07$. IR (ATR): 2925, 2572, 1495, 1447, 1322, 1172, 1135 , 1062, $842 \mathrm{~cm}^{-1}$. MS (El) m/z: $396[\mathrm{M}]^{+}$. HR-MS (El): $\mathrm{m} / \mathrm{z}$ calcd. for $\mathrm{C}_{15} \mathrm{H}_{19}{ }^{10} \mathrm{~B}_{2}{ }^{11} \mathrm{~B}_{8} \mathrm{~F}_{3} \mathrm{~S}[\mathrm{M}]^{+}$: 396.2165, found: 396.2158 .

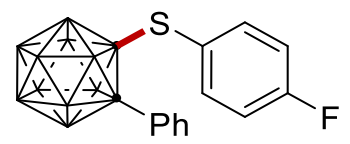

162e. The representative procedure $\mathrm{K}$ with $\mathrm{KI}(16.6 \mathrm{mg}, 0.10 \mathrm{mmol})$ was followed using 0 carborane 160a (22.0 mg, $0.10 \mathrm{mmol})$ and 4-fluorobenzenethiol 161e $(32.0 \mu \mathrm{L}, 0.30 \mathrm{mmol})$. Isolation by column chromatography ( $n$-hexane) yielded $162 \mathrm{e}(21.0 \mathrm{mg}, 61 \%)$ as a colorless solid. M.p. $=103-105{ }^{\circ} \mathrm{C} .{ }^{1} \mathrm{H}$ NMR $\left(400 \mathrm{MHz}, \mathrm{CDCl}_{3}\right): \delta=7.69-7.61(\mathrm{~m}, 2 \mathrm{H}), 7.61-7.54(\mathrm{~m}$, $1 \mathrm{H}), 7.51-7.44(\mathrm{~m}, 2 \mathrm{H}), 7.01-6.87(\mathrm{~m}, 4 \mathrm{H}) .{ }^{13} \mathrm{C} \mathrm{NMR}\left(101 \mathrm{MHz}, \mathrm{CDCl}_{3}\right): \delta=164.4\left(\mathrm{~d},{ }^{1} \mathrm{~J}_{\mathrm{C}-\mathrm{F}}=\right.$ $254 \mathrm{~Hz}, \mathrm{C}_{\mathrm{q}}$ ), 139.0 (d, $\left.{ }^{3} \mathrm{~J}_{\mathrm{C}-\mathrm{F}}=8.9 \mathrm{~Hz}, \mathrm{CH}\right), 132.1(\mathrm{CH}), 130.9(\mathrm{CH}), 130.8\left(\mathrm{C}_{\mathrm{q}}\right), 128.6(\mathrm{CH}), 125.3$ $\left(\mathrm{d},{ }^{4} \mathrm{~J}_{\mathrm{C}-\mathrm{F}}=3.6 \mathrm{~Hz}, \mathrm{C}_{\mathrm{q}}\right.$ ), 116.4 (d, ${ }^{2} \mathrm{~J}_{\mathrm{C}-\mathrm{F}}=22 \mathrm{~Hz}, \mathrm{CH}$ ), 87.8 (Cage C), 85.8 (Cage C). ${ }^{11} \mathrm{~B}$ NMR (96 $\left.\mathrm{MHz}, \mathrm{CDCl}_{3}\right): \delta=-2.67(2 \mathrm{~B}),-8.91(4 \mathrm{~B}),-10.32(2 \mathrm{~B}),-11.54(2 \mathrm{~B}) .{ }^{19} \mathrm{~F}$ NMR $\left(282 \mathrm{MHz}, \mathrm{CDCl}_{3}\right): \delta$ $=-107.68$. IR (ATR): 2609, 2572, 2561, 1585, 1486, 1233, 1155, 835, $687 \mathrm{~cm}^{-1}$. MS (EI) $\mathrm{m} / \mathrm{z}$ : $346[\mathrm{M}]^{+}$. HR-MS (EI): $\mathrm{m} / z$ calcd. for $\mathrm{C}_{14} \mathrm{H}_{19}{ }^{10} \mathrm{~B}_{2}{ }^{11} \mathrm{~B}_{8} \mathrm{FS}[\mathrm{M}]^{+}: 346.2197$, found: 346.2185 . 


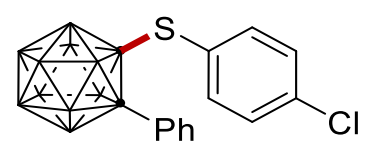

162f. The representative procedure $\mathrm{K}$ was followed using o-carborane $160 \mathrm{a}(22.0 \mathrm{mg}, 0.10$ $\mathrm{mmol}$ ) and 4-chlorobenzenethiol $161 \mathrm{f}(43.0 \mathrm{mg}, 0.30 \mathrm{mmol})$. Isolation by column chromatography ( $n$-hexane) yielded $\mathbf{1 6 2 f}(26.0 \mathrm{mg}, 71 \%)$ as a colorless solid. M.p. $=108-$ $110^{\circ} \mathrm{C} .{ }^{1} \mathrm{H}$ NMR $\left(400 \mathrm{MHz}, \mathrm{CDCl}_{3}\right): \delta=7.68-7.62(\mathrm{~m}, 2 \mathrm{H}), 7.61-7.54(\mathrm{~m}, 1 \mathrm{H}), 7.52-7.44(\mathrm{~m}$, 2H), $7.28-7.22(\mathrm{~m}, 2 \mathrm{H}), 6.90-6.81(\mathrm{~m}, 2 \mathrm{H}) .{ }^{13} \mathrm{C}$ NMR $\left(101 \mathrm{MHz}, \mathrm{CDCl}_{3}\right): \delta=138.0(\mathrm{CH})$, $137.9\left(\mathrm{C}_{\mathrm{q}}\right), 132.1(\mathrm{CH}), 131.0(\mathrm{CH}), 130.8\left(\mathrm{C}_{\mathrm{q}}\right), 129.4(\mathrm{CH}), 128.6(\mathrm{CH}), 128.1\left(\mathrm{C}_{\mathrm{q}}\right), 87.9$ (Cage C), 85.4 (Cage C). ${ }^{11} \mathrm{~B}$ NMR (96 MHz, $\mathrm{CDCl}_{3}$ ): $\delta=-2.60$ (2B), -8.90 (4B), -10.31 (2B), -11.54 (2B). IR (ATR): 2610, 2567, 1572, 1473, 1445, 1092, 1073, $746 \mathrm{~cm}^{-1}$. MS (EI) m/z: 362 [M] . HRMS (EI): $\mathrm{m} / \mathrm{z}$ calcd. for $\mathrm{C}_{14} \mathrm{H}_{19}{ }^{10} \mathrm{~B}_{2}{ }^{11} \mathrm{~B}_{8}{ }^{35} \mathrm{CIS}[\mathrm{M}]^{+}: 362.1904$, found: 362.1893 .

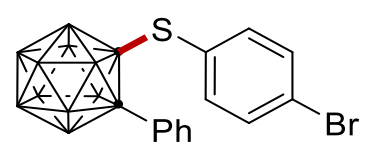

162g. The representative procedure $\mathrm{L}$ with $\mathrm{KI}(16.6 \mathrm{mg}, 0.10 \mathrm{mmol})$ and $\mathrm{Cul}(2.9 \mathrm{mg}, 15 \mathrm{~mol} \%)$ was followed using o-carborane $160 \mathrm{a}(22.0 \mathrm{mg}, 0.10 \mathrm{mmol})$ and 4-bromobenzenethiol $161 \mathrm{~g}$ $(56.1 \mathrm{mg}, 0.30 \mathrm{mmol})$. Isolation by column chromatography ( $n$-hexane) yielded $162 \mathrm{~g}(29.0 \mathrm{mg}$, $71 \%)$ as a colorless solid. M.p. $=126-128{ }^{\circ} \mathrm{C} .{ }^{1} \mathrm{H}$ NMR $\left(400 \mathrm{MHz}, \mathrm{CDCl}_{3}\right): \delta=7.62-7.58(\mathrm{~m}$, $2 \mathrm{H}), 7.56-7.50(\mathrm{~m}, 1 \mathrm{H}), 7.46-7.41(\mathrm{~m}, 2 \mathrm{H}), 7.39-7.34(\mathrm{~m}, 2 \mathrm{H}), 6.78-6.70(\mathrm{~m}, 2 \mathrm{H}) .{ }^{13} \mathrm{C}$ NMR $\left(101 \mathrm{MHz}, \mathrm{CDCl}_{3}\right): \delta=138.1(\mathrm{CH}), 132.4(\mathrm{CH}), 132.1(\mathrm{CH}), 130.9(\mathrm{CH}), 130.7\left(\mathrm{C}_{\mathrm{q}}\right), 128.6$ $\left(\mathrm{C}_{\mathrm{q}}\right), 128.5(\mathrm{CH}), 126.3\left(\mathrm{C}_{\mathrm{q}}\right), 87.9$ (Cage C), 85.2 (Cage C). ${ }^{11} \mathrm{~B}$ NMR $\left(128 \mathrm{MHz}, \mathrm{CDCl}_{3}\right): \delta=-$ 2.46 (2B), -9.13 (4B), -10.31 (2B), -11.52 (2B). IR (ATR): 2622, 2596, 1564, 1471, 1446, 1386, 1070, 1010, $810 \mathrm{~cm}^{-1}$. MS (EI) $\mathrm{m} / \mathrm{z}: 408[\mathrm{M}]^{+}$. HR-MS (EI): $\mathrm{m} / \mathrm{z}$ calcd. for $\mathrm{C}_{14} \mathrm{H}_{19}{ }^{11} \mathrm{~B}_{10} \mathrm{~S}^{79} \mathrm{Br}[\mathrm{M}]^{+}$: 408.1363, found: 408.1358 .

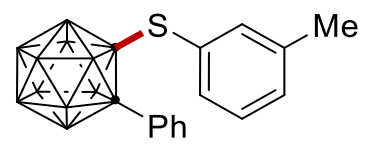

162h. The representative procedure $\mathrm{L}$ with $\mathrm{KI}(16.6 \mathrm{mg}, 0.10 \mathrm{mmol})$ was followed using ocarborane 160a (22.0 mg, $0.10 \mathrm{mmol}$ ) and 3-methylbenzenethiol 161h $(35.6 \mu \mathrm{L}, 0.30 \mathrm{mmol})$. Isolation by column chromatography ( $n$-hexane) yielded $162 \mathrm{~h}(30.3 \mathrm{mg}, 88 \%)$ as a colorless solid. M.p. $=58-60{ }^{\circ} \mathrm{C} .{ }^{1} \mathrm{H}$ NMR $\left(400 \mathrm{MHz}, \mathrm{CDCl}_{3}\right): \delta=7.63-7.59(\mathrm{~m}, 2 \mathrm{H}), 7.56-7.51(\mathrm{~m}$, $1 \mathrm{H}), 7.46-7.41(\mathrm{~m}, 2 \mathrm{H}), 7.20-7.16(\mathrm{~m}, 1 \mathrm{H}), 7.13(\mathrm{t}, J=7.6 \mathrm{~Hz}, 1 \mathrm{H}), 6.79(\mathrm{~d}, J=7.5 \mathrm{~Hz}, 1 \mathrm{H})$, 
$6.55(\mathrm{~s}, 1 \mathrm{H}), 2.22(\mathrm{~s}, 3 \mathrm{H}) .{ }^{13} \mathrm{C}$ NMR $\left(101 \mathrm{MHz}, \mathrm{CDCl}_{3}\right): \delta=138.9\left(\mathrm{C}_{\mathrm{q}}\right), 137.3(\mathrm{CH}), 133.6(\mathrm{CH})$, $132.2(\mathrm{CH}), 131.8(\mathrm{CH}), 130.8\left(\mathrm{C}_{\mathrm{q}}\right), 130.7(\mathrm{CH}), 129.4\left(\mathrm{C}_{\mathrm{q}}\right), 128.8(\mathrm{CH}), 128.4(\mathrm{CH}), 87.8($ Cage C), 86.2 (Cage C), $21.1\left(\mathrm{CH}_{3}\right) .{ }^{11} \mathrm{~B}$ NMR (128 MHz, $\left.\mathrm{CDCl}_{3}\right): \delta=-2.43(1 \mathrm{~B}),-3.16(1 \mathrm{~B}),-8.42(1 \mathrm{~B})$, -9.16 (2B), -10.45 (3B), -11.42 (2B). IR (ATR): 2922, 2564, 1591, 1494, 1474, 1446, 1377, 885, $780 \mathrm{~cm}^{-1}$. MS (EI) $\mathrm{m} / z: 342[\mathrm{M}]^{+}$. HR-MS (EI): $\mathrm{m} / z$ calcd. for $\mathrm{C}_{15} \mathrm{H}_{22}{ }^{10} \mathrm{~B}_{2}{ }^{11} \mathrm{~B}_{8} \mathrm{~S}[\mathrm{M}]^{+}: 342.2448$, found: 342.2434 .

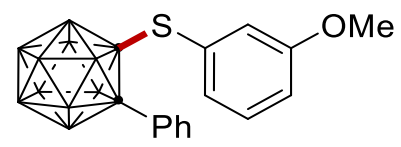

162i. The representative procedure $L$ was followed using o-carborane $160 \mathrm{a}(22.0 \mathrm{mg}, 0.10$ $\mathrm{mmol}$ ) and 3-methoxylbenzenethiol 161i $(37.2 \mu \mathrm{L}, 0.30 \mathrm{mmol})$. Isolation by column chromatography ( $n$-hexane) yielded $162 \mathbf{i}(22.2 \mathrm{mg}, 62 \%)$ as a colorless oil. ${ }^{1} \mathbf{H}$ NMR $(400 \mathrm{MHz}$, $\mathrm{CDCl}_{3}$ ): $\delta=7.66(\mathrm{~d}, J=8.0 \mathrm{~Hz}, 2 \mathrm{H}), 7.59-7.54(\mathrm{~m}, 1 \mathrm{H}), 7.51-7.44(\mathrm{~m}, 2 \mathrm{H}), 7.18(\mathrm{t}, J=8.0 \mathrm{~Hz}$, $1 \mathrm{H}), 6.97(\mathrm{dd}, J=8.4,2.5 \mathrm{~Hz}, 1 \mathrm{H}), 6.56(\mathrm{~d}, J=7.6 \mathrm{~Hz}, 1 \mathrm{H}), 6.50(\mathrm{~s}, 1 \mathrm{H}), 3.75(\mathrm{~s}, 3 \mathrm{H})$. ${ }^{13} \mathrm{C}$ NMR $\left(101 \mathrm{MHz}, \mathrm{CDCl}_{3}\right): \delta=159.5\left(\mathrm{C}_{\mathrm{q}}\right), 132.2(\mathrm{CH}), 131.0\left(\mathrm{C}_{\mathrm{q}}\right), 130.8(\mathrm{CH}), 130.6\left(\mathrm{C}_{\mathrm{q}}\right)$, $129.8(\mathrm{CH}), 129.0(\mathrm{CH}), 128.5(\mathrm{CH}), 121.5(\mathrm{CH}), 117.4(\mathrm{CH}), 88.1$ (Cage C), 86.1 (Cage C), $55.4\left(\mathrm{CH}_{3}\right) .{ }^{11} \mathrm{~B}$ NMR (96 MHz, $\left.\mathrm{CDCl}_{3}\right): \delta=-2.69(2 \mathrm{~B}),-9.12(4 \mathrm{~B}),-10.34(2 \mathrm{~B}),-11.44(2 \mathrm{~B})$. IR (ATR): 2961, 2934, 2597, 2564, 1589, 1479, 1249, 1231, 1040, $688 \mathrm{~cm}^{-1}$. MS (EI) m/z: 358 $[\mathrm{M}]^{+}$. HR-MS (EI): $\mathrm{m} / \mathrm{z}$ calcd. for $\mathrm{C}_{15} \mathrm{H}_{22}{ }^{10} \mathrm{~B}_{2}{ }^{11} \mathrm{~B}_{8} \mathrm{OS}[\mathrm{M}]^{+}: 358.2397$, found: 358.2385 .

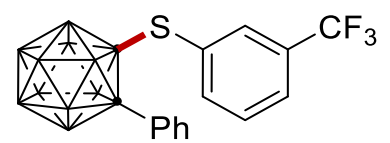

162j. The representative procedure $\mathrm{L}$ with $\mathrm{KI}(16.6 \mathrm{mg}, 0.10 \mathrm{mmol})$ was followed using $\mathrm{o}$ carborane 160a (22.0 mg, $0.10 \mathrm{mmol}$ ) and 3-(trifluoromethyl)benzenethiol 161j (40.8 $\mu \mathrm{L}, 0.30$ $\mathrm{mmol}$ ). Isolation by column chromatography ( $n$-hexane) yielded $162 \mathrm{j}(29.5 \mathrm{mg}, 74 \%)$ as a colorless oil. ${ }^{1} \mathrm{H}$ NMR $\left(400 \mathrm{MHz}, \mathrm{CDCl}_{3}\right): \delta=7.65(\mathrm{~d}, J=7.8 \mathrm{~Hz}, 1 \mathrm{H}), 7.61-7.52(\mathrm{~m}, 3 \mathrm{H}), 7.47$ $-7.40(\mathrm{~m}, 3 \mathrm{H}), 7.34-7.30(\mathrm{~m}, 1 \mathrm{H}), 6.93-6.87(\mathrm{~m}, 1 \mathrm{H}) .{ }^{13} \mathrm{C} \mathrm{NMR}\left(101 \mathrm{MHz}, \mathrm{CDCl}_{3}\right): \delta=$ $139.9(\mathrm{CH}), 133.5\left(\mathrm{q},{ }^{3} \mathrm{~J}_{\mathrm{C}-\mathrm{F}}=3.8 \mathrm{~Hz}, \mathrm{CH}\right), 132.0(\mathrm{CH}), 131.5\left(\mathrm{q},{ }^{2} \mathrm{~J}_{\mathrm{C}-\mathrm{F}}=33 \mathrm{~Hz}, \mathrm{C}_{\mathrm{q}}\right), 131.1(\mathrm{CH})$, $130.8\left(\mathrm{C}_{\mathrm{q}}\right), 130.5\left(\mathrm{C}_{\mathrm{q}}\right), 129(\mathrm{CH}), 128.7(\mathrm{CH}), 127.9\left(\mathrm{q},{ }^{3} \mathrm{~J}_{\mathrm{C}-\mathrm{F}}=3.7 \mathrm{~Hz}, \mathrm{CH}\right), 123.2\left(\mathrm{q},{ }^{1} \mathrm{~J}_{\mathrm{C}-\mathrm{F}}=273\right.$ $\mathrm{Hz}, \mathrm{C}_{\mathrm{q}}$ ), 88.0 (Cage C), 84.9 (Cage C). ${ }^{11} \mathrm{~B}$ NMR (128 MHz, CDCl 3 ): $\delta=-2.31$ (2B), -9.02 (4B), 10.25 (2B), -11.46 (2B). ${ }^{19} \mathrm{~F}$ NMR (376 MHz, $\mathrm{CDCl}_{3}$ ): $\delta=-62.78$. IR (ATR): 2755, 1580, 1420, 1320, 1272, 1165, 1122, 1071, $792 \mathrm{~cm}^{-1}$. MS (EI) m/z: 396 [M] $]^{+}$HR-MS (El): $\mathrm{m} / z$ calcd. for $\mathrm{C}_{15} \mathrm{H}_{19}{ }^{10} \mathrm{~B}_{2}{ }^{11} \mathrm{~B}_{8} \mathrm{~F}_{3} \mathrm{~S}[\mathrm{M}]^{+}:$396.2165, found: 396.2154 . 


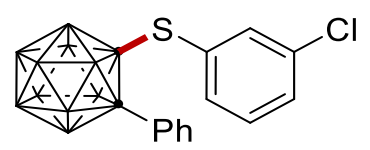

162k. The representative procedure $\mathbf{L}$ with $\mathrm{KI}(16.6 \mathrm{mg}, 0.10 \mathrm{mmol})$ was followed using ocarborane 160a $(22.0 \mathrm{mg}, 0.10 \mathrm{mmol})$ and 3-chlorobenzenethiol 161k (34.5 $\mu \mathrm{L}, 0.30 \mathrm{mmol})$. Isolation by column chromatography ( $n$-hexane) yielded $162 \mathrm{k}(21.4 \mathrm{mg}, 59 \%)$ as a colorless solid. M.p. $=60-62{ }^{\circ} \mathrm{C} .{ }^{1} \mathrm{H}$ NMR $\left(400 \mathrm{MHz}, \mathrm{CDCl}_{3}\right): \delta=7.63-7.52(\mathrm{~m}, 3 \mathrm{H}), 7.49-7.42(\mathrm{~m}$, 2H), 7.37 (ddd, $J=8.1,2.1,1.0 \mathrm{~Hz}, 1 \mathrm{H}$ ), $7.23-7.17(\mathrm{~m}, 1 \mathrm{H}$ ), 6.95 (ddd, $J=7.8,1.7,1.1 \mathrm{~Hz}, 1 \mathrm{H}$ ), 6.62 (ddd, $J=2.1,1.7,0.4 \mathrm{~Hz}, 1 \mathrm{H}) .{ }^{13} \mathrm{C}$ NMR $\left(101 \mathrm{MHz}, \mathrm{CDCl}_{3}\right): \delta=136.4(\mathrm{CH}), 134.7(\mathrm{CH})$, $134.4\left(\mathrm{C}_{\mathrm{q}}\right), 132.1(\mathrm{CH}), 131.3(\mathrm{CH}), 131.1\left(\mathrm{C}_{\mathrm{q}}\right), 131.0(\mathrm{CH}), 130.6\left(\mathrm{C}_{\mathrm{q}}\right), 130.1(\mathrm{CH}), 128.6(\mathrm{CH})$, 87.8 (Cage C), 85.1 (Cage C). ${ }^{11} \mathrm{~B}$ NMR (128 MHz, CDCl $)$ ): $\delta=-2.37$ (1B), -2.90 (1B), -9.11 (4B), -10.37 (2B), -11.46 (2B). IR (ATR): 2922, 2565, 1573, 1459, 1398, 1116, 1071, 864, $771 \mathrm{~cm}^{-1}$. MS (EI) $\mathrm{m} / z$ : $362[\mathrm{M}]^{+}$. HR-MS (El): $\mathrm{m} / z$ calcd. for $\mathrm{C}_{14} \mathrm{H}_{19}{ }^{10} \mathrm{~B}_{2}{ }^{11} \mathrm{~B}_{8} \mathrm{~S}^{35} \mathrm{Cl}[\mathrm{M}]^{+}: 362.1904$, found: 362.1893 .

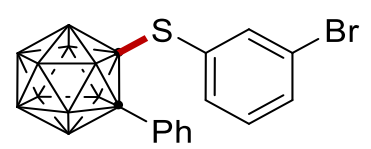

162l. The representative procedure $\mathbf{L}$ with $\mathrm{Kl}(16.6 \mathrm{mg}, 0.10 \mathrm{mmol})$ and Cul $(2.9 \mathrm{mg}, 15 \mathrm{~mol} \%)$ was followed using o-carborane $160 \mathrm{a}(22.0 \mathrm{mg}, 0.10 \mathrm{mmol})$ and 3-bromobenzenethiol $161 \mathrm{l}(31.0$ $\mu \mathrm{L}, 0.30 \mathrm{mmol}$ ). Isolation by column chromatography ( $n$-hexane) yielded $162 \mathrm{l}(24.1 \mathrm{mg}, 59 \%)$ as a colorless oil. ${ }^{1} \mathbf{H}$ NMR $\left(400 \mathrm{MHz}, \mathrm{CDCl}_{3}\right): \delta=7.62-7.57(\mathrm{~m}, 2 \mathrm{H}), 7.57-7.50(\mathrm{~m}, 2 \mathrm{H}), 7.49-$ $7.42(\mathrm{~m}, 2 \mathrm{H}), 7.15$ (t, $J=7.9 \mathrm{~Hz}, 1 \mathrm{H}$ ), 7.02 (ddd, $J=7.8,1.7,1.1 \mathrm{~Hz}, 1 \mathrm{H}), 6.75(\mathrm{t}, J=1.8 \mathrm{~Hz}$, 1H). ${ }^{13} \mathrm{C}$ NMR $\left(101 \mathrm{MHz}, \mathrm{CDCl}_{3}\right): \delta=139.2(\mathrm{CH}), 135.1(\mathrm{CH}), 134.2(\mathrm{CH}), 132.1(\mathrm{CH}), 131.4$ $\left(\mathrm{C}_{\mathrm{q}}\right), 131.0(\mathrm{CH}), 130.5\left(\mathrm{C}_{\mathrm{q}}\right), 130.4(\mathrm{CH}), 128.7(\mathrm{CH}), 122.4\left(\mathrm{C}_{\mathrm{q}}\right), 87.8$ (Cage C), 85.1 (Cage $\mathrm{C}$ ). 11B NMR (128 MHz, $\mathrm{CDCl}_{3}$ ): $\delta=-2.35$ (2B), -9.11 (4B), -10.37 (2B), -11.44 (2B). IR (ATR): 2918, 2589, 1559, 1455, 1394, 1066, 866, 770, $672 \mathrm{~cm}^{-1}$. MS (EI) m/z: 408 [M] $]^{+}$HR-MS (El): m/z calcd. for $\mathrm{C}_{14} \mathrm{H}_{19}{ }^{11} \mathrm{~B}_{10} \mathrm{~S}^{79} \mathrm{Br}[\mathrm{M}]^{+}: 408.1363$, found: 408.1360 .

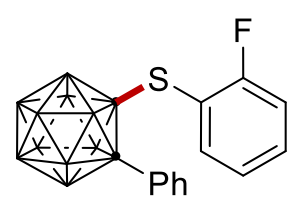

$162 \mathrm{~m}$. The representative procedure $\mathrm{L}$ with $\mathrm{KI}(16.6 \mathrm{mg}, 0.10 \mathrm{mmol}$ ) was followed using ocarborane $160 \mathrm{a}(22.0 \mathrm{mg}, 0.10 \mathrm{mmol})$ and 2-florobenzenethiol $161 \mathrm{~m}(32.0 \mu \mathrm{L}, 0.30 \mathrm{mmol})$. Isolation by column chromatography ( $n$-hexane) yielded $162 \mathrm{~m}(18.5 \mathrm{mg}, 53 \%)$ as a colorless solid. M.p. $=116-118{ }^{\circ} \mathrm{C} .{ }^{1} \mathrm{H}$ NMR $\left(400 \mathrm{MHz}, \mathrm{CDCl}_{3}\right): \delta=7.73-7.66(\mathrm{~m}, 2 \mathrm{H}), 7.61-7.54(\mathrm{~m}$, 
1H), $7.53-7.44(\mathrm{~m}, 3 \mathrm{H}), 7.17-7.03(\mathrm{~m}, 2 \mathrm{H}), 6.94-6.84(\mathrm{~m}, 1 \mathrm{H}) .{ }^{13} \mathrm{C}$ NMR $\left(101 \mathrm{MHz}, \mathrm{CDCl}_{3}\right)$ : $\delta=163.3\left(\mathrm{~d},{ }^{1} \mathrm{~J}_{\mathrm{C}-\mathrm{F}}=253 \mathrm{~Hz}, \mathrm{C}_{\mathrm{q}}\right), 139.4(\mathrm{CH}), 134.1\left(\mathrm{~d},{ }^{3} \mathrm{~J}_{\mathrm{C}-\mathrm{F}}=8.4 \mathrm{~Hz}, \mathrm{CH}\right), 132.1(\mathrm{CH})$, $130.9\left(\mathrm{C}_{\mathrm{q}}\right), 130.9(\mathrm{CH}), 128.5(\mathrm{CH}), 124.5\left(\mathrm{~d},{ }^{3} \mathrm{~J}_{\mathrm{C}-\mathrm{F}}=4.0 \mathrm{~Hz}, \mathrm{CH}\right), 117.0\left(\mathrm{~d},{ }^{2} \mathrm{~J}_{\mathrm{C}-\mathrm{F}}=18.2 \mathrm{~Hz}, \mathrm{C}_{\mathrm{q}}\right)$, $116.5\left(\mathrm{~d},{ }^{2} \mathrm{~J}_{\mathrm{C}-\mathrm{F}}=23.1 \mathrm{~Hz}, \mathrm{CH}\right.$ ), 88.7 (Cage C), 85.2 (Cage C). ${ }^{11} \mathrm{~B} \mathbf{N M R}\left(96 \mathrm{MHz}, \mathrm{CDCl}_{3}\right): \delta=-$ $2.87(2 \mathrm{~B}),-8.30(2 \mathrm{~B}),-9.21(1 \mathrm{~B}),-9.90(3 \mathrm{~B}),-11.53(2 \mathrm{~B}) .{ }^{19} \mathrm{~F}$ NMR $\left(282 \mathrm{MHz}, \mathrm{CDCl}_{3}\right): \delta=-$ 102.48. IR (ATR): 2598, 2557, 1470, 1261, 1223, 1067, 755, $689 \mathrm{~cm}^{-1}$. MS (EI) $\mathrm{m} / \mathrm{z}: 346[\mathrm{M}]^{+}$. HR-MS (EI): $\mathrm{m} / z$ calcd. for $\mathrm{C}_{14} \mathrm{H}_{19}{ }^{10} \mathrm{~B}_{2}{ }^{11} \mathrm{~B}_{8} \mathrm{FS}[\mathrm{M}]^{+}: 346.2197$, found: 346.2183 .

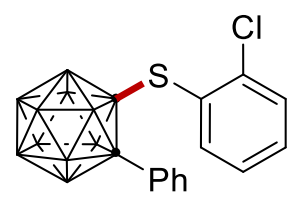

162n. The representative procedure $\mathrm{L}$ with $\mathrm{KI}(16.6 \mathrm{mg}, 0.10 \mathrm{mmol})$ was followed using 0 carborane 160a $(22.0 \mathrm{mg}, 0.10 \mathrm{mmol})$ and 2-chlorobenzenethiol $161 \mathrm{n}(33.6 \mu \mathrm{L}, 0.30 \mathrm{mmol})$. Isolation by column chromatography ( $n$-hexane) yielded $162 \mathrm{n}(27.5 \mathrm{mg}, 76 \%)$ as a colorless solid. M.p. $=146-148{ }^{\circ} \mathrm{C} .{ }^{1} \mathrm{H}$ NMR $\left(400 \mathrm{MHz}, \mathrm{CDCl}_{3}\right): \delta=7.72-7.64(\mathrm{~m}, 2 \mathrm{H}), 7.56-7.47(\mathrm{~m}$, $1 \mathrm{H}), 7.49-7.40(\mathrm{~m}, 3 \mathrm{H}), 7.40-7.31(\mathrm{~m}, 1 \mathrm{H}), 7.21-7.12(\mathrm{~m}, 1 \mathrm{H}), 7.02(\mathrm{~d}, J=7.8 \mathrm{~Hz}, 1 \mathrm{H}) .{ }^{13} \mathrm{C}$ NMR $\left(101 \mathrm{MHz}, \mathrm{CDCl}_{3}\right): \delta=141.1\left(\mathrm{C}_{\mathrm{q}}\right), 140.0(\mathrm{CH}), 132.7(\mathrm{CH}), 132.1(\mathrm{CH}), 131.1\left(\mathrm{C}_{\mathrm{q}}\right), 130.9$ $(\mathrm{CH}), 130.6(\mathrm{CH}), 128.9\left(\mathrm{C}_{\mathrm{q}}\right), 128.6(\mathrm{CH}), 127.1(\mathrm{CH}), 89.5$ (Cage C), 85.7 (Cage C). ${ }^{11} \mathrm{~B}$ NMR $\left(128 \mathrm{MHz}, \mathrm{CDCl}_{3}\right): \delta=-2.90(2 \mathrm{~B}),-8.40(2 \mathrm{~B}),-9.57$ (4B), -11.70 (2B). IR (ATR): 2500, 1945, $1447,1321,1259,1166,1134,1070,749 \mathrm{~cm}^{-1}$. MS (EI) $\mathrm{m} / \mathrm{z}: 362$ [M] $]^{+}$. HR-MS (El): $\mathrm{m} / \mathrm{z}$ calcd. for $\mathrm{C}_{14} \mathrm{H}_{19}{ }^{10} \mathrm{~B}_{2}{ }^{11} \mathrm{~B}_{8} \mathrm{~S}^{35} \mathrm{Cl}[\mathrm{M}]^{+}: 362.1904$, found: 362.1893 .

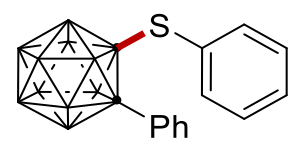

1620. The representative procedure $L$ was followed using o-carborane $160 \mathrm{a}(22.0 \mathrm{mg}, 0.10$ $\mathrm{mmol}$ ) and benzenethiol $1610(31.0 \mu \mathrm{L}, 0.30 \mathrm{mmol})$. Isolation by column chromatography ( $n$ hexane) yielded $1620(20.0 \mathrm{mg}, 61 \%)$ as a colorless solid. M.p. $=112-114{ }^{\circ} \mathrm{C} .{ }^{1} \mathbf{H}$ NMR $(300$ $\left.\mathrm{MHz}, \mathrm{CDCl}_{3}\right): \delta=7.66(\mathrm{~d}, J=7.6 \mathrm{~Hz}, 2 \mathrm{H}), 7.61-7.54(\mathrm{~m}, 1 \mathrm{H}), 7.51-7.40(\mathrm{~m}, 3 \mathrm{H}), 7.32-7.25$ $(\mathrm{m}, 2 \mathrm{H}), 6.96(\mathrm{~d}, J=7.7 \mathrm{~Hz}, 2 \mathrm{H}) .{ }^{13} \mathrm{C}$ NMR $\left(75 \mathrm{MHz}, \mathrm{CDCl}_{3}\right): \delta=136.8(\mathrm{CH}), 132.2(\mathrm{CH}), 131.1$ $(\mathrm{CH}), 130.9\left(\mathrm{C}_{\mathrm{q}}\right), 130.9(\mathrm{CH}), 129.8\left(\mathrm{C}_{\mathrm{q}}\right), 129.1(\mathrm{CH}), 128.5(\mathrm{CH}), 88.1$ (Cage C), 86.1 (Cage C). 11B NMR (96 MHz, $\mathrm{CDCl}_{3}$ ): $\delta=-2.78$ (2B), -9.14 (3B), -10.35 (3B), -11.50 (2B). IR (ATR): 2612, 2589, 2560, 1585, 1486, 1232, 1077, $686 \mathrm{~cm}^{-1}$. MS (EI) m/z: 328 [M] $]^{+}$HR-MS (EI): $\mathrm{m} / \mathrm{z}$ calcd. for $\mathrm{C}_{14} \mathrm{H}_{20}{ }^{10} \mathrm{~B}_{2}{ }^{11} \mathrm{~B}_{8} \mathrm{~S}[\mathrm{M}]^{+}:$: 328.2291, found: 328.2279. 


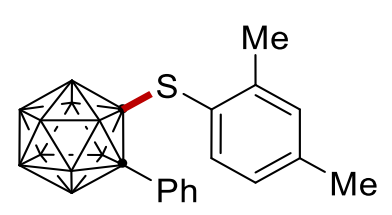

162p. The representative procedure $\mathrm{L}$ with $\mathrm{KI}(16.6 \mathrm{mg}, 0.10 \mathrm{mmol})$ was followed using 0 carborane 160a (22.0 mg, $0.10 \mathrm{mmol})$ and 2,4-dimethylbenzenethiol $161 \mathrm{p}(40.3 \mu \mathrm{L}, 0.30 \mathrm{mmol})$. Isolation by column chromatography ( $n$-hexane) yielded $162 \mathrm{p}(23.1 \mathrm{mg}, 65 \%)$ as a colorless solid. M.p. $=97-99{ }^{\circ} \mathrm{C} .{ }^{1} \mathrm{H}$ NMR $\left(400 \mathrm{MHz}, \mathrm{CDCl}_{3}\right): \delta=7.71-7.64(\mathrm{~m}, 2 \mathrm{H}), 7.55-7.47(\mathrm{~m}$, $1 \mathrm{H}), 7.49-7.40(\mathrm{~m}, 2 \mathrm{H}), 7.05-6.99(\mathrm{~m}, 1 \mathrm{H}), 6.91-6.84(\mathrm{~m}, 1 \mathrm{H}), 6.75(\mathrm{~d}, J=7.9 \mathrm{~Hz}, 1 \mathrm{H}), 2.29$ $(\mathrm{s}, 3 \mathrm{H}), 2.21(\mathrm{~s}, 3 \mathrm{H}) .{ }^{13} \mathrm{C}$ NMR $\left(101 \mathrm{MHz}, \mathrm{CDCl}_{3}\right): \delta=143.9\left(\mathrm{C}_{\mathrm{q}}\right), 141.9\left(\mathrm{C}_{\mathrm{q}}\right), 138.6(\mathrm{CH})$, $132.1(\mathrm{CH}), 131.7(\mathrm{CH}), 131.3\left(\mathrm{C}_{\mathrm{q})}, 130.7(\mathrm{CH}), 128.6(\mathrm{CH}), 127.3(\mathrm{CH}), 126.1\left(\mathrm{C}_{\mathrm{q}}\right), 89.5\right.$ (Cage C), 87.4 (Cage C), $21.3\left(\mathrm{CH}_{3}\right), 20.7\left(\mathrm{CH}_{3}\right) .{ }^{11} \mathrm{~B}$ NMR (128 MHz, $\left.\mathrm{CDCl}_{3}\right): \delta=-3.05(2 \mathrm{~B}),-8.58$ (2B), -9.80 (4B), -11.72 (2B). IR (ATR): 2919, 2851, 2586, 2569, 1600, 1446, 1232, 1074, 886 $\mathrm{cm}^{-1}$. MS (EI) $\mathrm{m} / z$ : $356[\mathrm{M}]^{+}$. HR-MS (EI): $\mathrm{m} / \mathrm{z}$ calcd. for $\mathrm{C}_{16} \mathrm{H}_{24}{ }^{10} \mathrm{~B}_{2}{ }^{11} \mathrm{~B}_{8} \mathrm{~S}[\mathrm{M}]^{+}: 356.2605$, found: 356.2593.

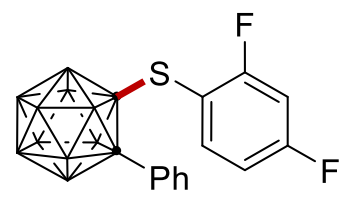

162q. The representative procedure $\mathbf{L}$ with $\mathrm{KI}(16.6 \mathrm{mg}, 0.10 \mathrm{mmol})$ was followed using ocarborane 160a (22.0 mg, $0.10 \mathrm{mmol})$ and 2,4-difluorobenzenethiol 161q $(33.1 \mu \mathrm{L}, 0.30 \mathrm{mmol})$. Isolation by column chromatography ( $n$-hexane) yielded $162 \mathrm{q}(32.8 \mathrm{mg}, 65 \%)$ as a colorless solid. M.p. $=109-111^{\circ} \mathrm{C} .{ }^{1} \mathrm{H}$ NMR $\left(400 \mathrm{MHz}, \mathrm{CDCl}_{3}\right): \delta=7.69-7.60(\mathrm{~m}, 2 \mathrm{H}), 7.56-7.48(\mathrm{~m}$, $1 \mathrm{H}), 7.48-7.39(\mathrm{~m}, 2 \mathrm{H}), 6.88-6.71(\mathrm{~m}, 3 \mathrm{H}) .{ }^{13} \mathrm{C} \mathrm{NMR}\left(101 \mathrm{MHz}, \mathrm{CDCl}_{3}\right): \delta=165.4\left(\mathrm{dd},{ }^{1} \mathrm{~J}_{\mathrm{C}-\mathrm{F}}=\right.$ $\left.257 \mathrm{~Hz},{ }^{3} \mathrm{~J}_{\mathrm{C}-\mathrm{F}}=10.8 \mathrm{~Hz}, \mathrm{C}_{\mathrm{q}}\right), 163.9$ (dd, ${ }^{1} \mathrm{~J}_{\mathrm{C}-\mathrm{F}}=256 \mathrm{~Hz},{ }^{3} \mathrm{~J}_{\mathrm{C}-\mathrm{F}}=13.4 \mathrm{~Hz}, \mathrm{C}_{\mathrm{q}}$ ), 140.6 (dd, ${ }^{3} \mathrm{~J}_{\mathrm{C}-\mathrm{F}}=$ 10.2, 10.2 Hz, CH), $132.1(\mathrm{CH}), 131.0(\mathrm{CH}), 130.9\left(\mathrm{C}_{\mathrm{q}}\right), 128.6(\mathrm{CH}), 112.9$ (dd, ${ }^{2} J_{\mathrm{C}-\mathrm{F}}=18.5 \mathrm{~Hz}$, $\left.{ }^{4} J_{\mathrm{C}-\mathrm{F}}=3.9 \mathrm{~Hz}, \mathrm{C}_{\mathrm{q}}\right), 112.2\left(\mathrm{dd},{ }^{2} \mathrm{~J}_{\mathrm{C}-\mathrm{F}}=22.0 \mathrm{~Hz},{ }^{4} \mathrm{~J}_{\mathrm{C}-\mathrm{F}}=3.9 \mathrm{~Hz}, \mathrm{CH}\right), 105.1\left(\mathrm{dd},{ }^{2} \mathrm{~J}_{\mathrm{C}-\mathrm{F}}=25.8,25.9\right.$ $\mathrm{Hz}, \mathrm{CH}$ ), 88.5 (Cage C), 84.9 (Cage C). ${ }^{11} \mathrm{~B}$ NMR (128 MHz, $\mathrm{CDCl}_{3}$ ): $\delta=-2.20$ (1B), -3.38 (1B), $7.71(2 \mathrm{~B}),-9.26(2 \mathrm{~B}),-10.50(2 \mathrm{~B}),-12.38(2 \mathrm{~B}) .{ }^{19} \mathrm{~F}$ NMR (282 MHz, $\left.\mathrm{CDCl}_{3}\right): \delta=-97.08(\mathrm{~d}, J=$ $11.5 \mathrm{~Hz}$ ), -101.85 (d, $J=11.5 \mathrm{~Hz}$ ). IR (ATR): 3059, 1487, 1443, 1201, 1155, 1056, 907, $734 \mathrm{~cm}^{-1}$. MS (EI) $m / z: 364$ [M] . HR-MS (EI): $m / z$ calcd. for $\mathrm{C}_{14} \mathrm{H}_{18}{ }^{10} \mathrm{~B}_{2}{ }^{11} \mathrm{~B}_{8} \mathrm{SF}_{2}[\mathrm{M}]^{+}: 364.2102$, found: 364.2098.

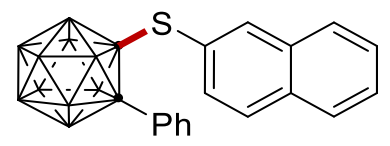


162r. The representative procedure $L$ was followed using o-carborane $160 \mathrm{a}(22.0 \mathrm{mg}, 0.10$ $\mathrm{mmol}$ ) and naphthalene-2-thiol $161 \mathrm{r}(43.2 \mathrm{mg}, 0.30 \mathrm{mmol})$. Isolation by column chromatography ( $n$-hexane) yielded $\mathbf{1 6 2 r}(35.2 \mathrm{mg}, 93 \%)$ as a colorless solid. M.p. $=129-131^{\circ} \mathrm{C} .{ }^{1} \mathbf{H}$ NMR $(400$ $\left.\mathrm{MHz}, \mathrm{CDCl}_{3}\right): \delta=7.83-7.79(\mathrm{~m}, 1 \mathrm{H}), 7.71(\mathrm{~d}, J=8.7 \mathrm{~Hz}, 1 \mathrm{H}), 7.64-7.44(\mathrm{~m}, 8 \mathrm{H}), 7.18-7.15$ (m, $1 \mathrm{H}), 7.08(\mathrm{dd}, J=8.5,1.8 \mathrm{~Hz}, 1 \mathrm{H}) .{ }^{13} \mathrm{C}$ NMR $\left(101 \mathrm{MHz}, \mathrm{CDCl}_{3}\right): \delta=137.6(\mathrm{CH}), 133.9\left(\mathrm{C}_{\mathrm{q}}\right)$, $132.8\left(\mathrm{C}_{\mathrm{q}}\right), 132.3(\mathrm{CH}), 132.1(\mathrm{CH}), 130.9\left(\mathrm{C}_{\mathrm{q}}\right), 130.8(\mathrm{CH}), 128.8(\mathrm{CH}), 128.5(\mathrm{CH}), 128.3(\mathrm{CH})$, $128.0(\mathrm{CH}), 127.7(\mathrm{CH}), 126.8(\mathrm{CH}), 126.8\left(\mathrm{C}_{\mathrm{q}}\right) 87.8$ (Cage C), 85.9 (Cage $\left.\mathrm{C}\right) .{ }^{11} \mathrm{~B}$ NMR (128 $\left.\mathrm{MHz}, \mathrm{CDCl}_{3}\right): \delta=-2.37(1 \mathrm{~B}),-3.12(1 \mathrm{~B}),-8.44(2 \mathrm{~B}),-9.14(2 \mathrm{~B}),-10.49$ (3B), -11.39 (1B). IR (ATR): 3057, 2594, 1581, 1494, 1446, 1072, 901, 859, 808, $743 \mathrm{~cm}^{-1}$. MS (EI) $\mathrm{m} / \mathrm{z}: 378[\mathrm{M}]^{+}$. HR-MS (EI): $m / z$ calcd. for $\mathrm{C}_{18} \mathrm{H}_{22}{ }^{10} \mathrm{~B}_{2}{ }^{11} \mathrm{~B}_{8} \mathrm{~S}[\mathrm{M}]^{+}: 378.2449$, found: 378.2436 .

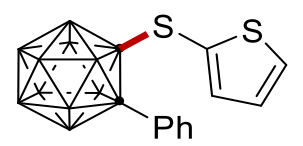

162s. The representative procedure $\mathrm{L}$ with $\mathrm{KI}(16.6 \mathrm{mg}, 0.10 \mathrm{mmol})$ was followed using $o$ carborane 160a (22.0 mg, $0.10 \mathrm{mmol})$ and benzenethiol 161s $(27.8 \mu \mathrm{L}, 0.30 \mathrm{mmol})$. Isolation by column chromatography ( $n$-hexane) yielded $162 \mathrm{~s}(18.0 \mathrm{mg}, 54 \%)$ as a colorless solid. M.p. $=83$ $-85^{\circ} \mathrm{C} .{ }^{1} \mathrm{H}$ NMR $\left(300 \mathrm{MHz}, \mathrm{CDCl}_{3}\right): \delta=7.68(\mathrm{~d}, J=7.6 \mathrm{~Hz}, 2 \mathrm{H}), 7.59-7.45(\mathrm{~m}, 4 \mathrm{H}), 6.97$ (dd, $J=5.3,3.6 \mathrm{~Hz}, 1 \mathrm{H}), 6.64(\mathrm{~d}, J=3.9 \mathrm{~Hz}, 1 \mathrm{H}) .{ }^{13} \mathrm{C} \mathrm{NMR}\left(75 \mathrm{MHz}, \mathrm{CDCl}_{3}\right): \delta=139.3(\mathrm{CH}), 134.1$ $(\mathrm{CH}), 132.1(\mathrm{CH}), 130.9(\mathrm{CH}), 130.6\left(\mathrm{C}_{\mathrm{q}}\right), 128.6(\mathrm{CH}), 127.7(\mathrm{CH}), 127.6\left(\mathrm{C}_{\mathrm{q}}\right), 87.4$ (Cage C), 85.6 (Cage C). ${ }^{11 B}$ NMR (96 MHz, $\mathrm{CDCl}_{3}$ ): $\delta=-2.70$ (2B), -9.16 (3B), -10.37 (3B), -11.72 (2B). IR (ATR): 2922, 2852, 2605, 2589, 2559, 1399, 1218, 852, $710 \mathrm{~cm}^{-1}$. MS (EI) m/z: 334 [M]+. HRMS (EI): $\mathrm{m} / z$ calcd. for $\mathrm{C}_{12} \mathrm{H}_{18}{ }^{10} \mathrm{~B}_{2}{ }^{11} \mathrm{~B}_{8} \mathrm{~S}_{2}[\mathrm{M}]^{+}: 334.1854$, found: 334.1845 .

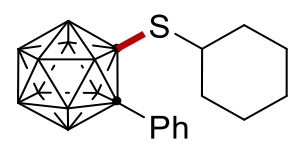

162t. The representative procedure $\mathrm{L}$ with $\mathrm{KI}(16.6 \mathrm{mg}, 0.10 \mathrm{mmol})$ was followed using ocarborane 160a (22.0 mg, $0.10 \mathrm{mmol})$ and cyclohexanethiol 161t $(35.5 \mu \mathrm{L}, 0.30 \mathrm{mmol})$. Isolation by column chromatography ( $n$-hexane) yielded $162 t(20.0 \mathrm{mg}, 60 \%)$ as a colorless oil. ${ }^{1} \mathbf{H}$ NMR $\left(400 \mathrm{MHz}, \mathrm{CDCl}_{3}\right): \delta=7.65-7.58(\mathrm{~m}, 2 \mathrm{H}), 7.47-7.41(\mathrm{~m}, 1 \mathrm{H}), 7.41-7.33(\mathrm{~m}, 2 \mathrm{H}), 2.76-2.68$ $(\mathrm{m}, 1 \mathrm{H}), 1.69-1.60(\mathrm{~m}, 2 \mathrm{H}), 1.51-1.40(\mathrm{~m}, 2 \mathrm{H}), 1.33-0.98(\mathrm{~m}, 6 \mathrm{H}) .{ }^{13} \mathrm{C}$ NMR $(101 \mathrm{MHz}$, $\left.\mathrm{CDCl}_{3}\right): \delta=131.8(\mathrm{CH}), 131.0\left(\mathrm{C}_{\mathrm{q}}\right), 130.6(\mathrm{CH}), 128.3(\mathrm{CH}), 88.6$ (Cage C), 87.0 (Cage C), 50.5 $(\mathrm{CH}), 33.9\left(\mathrm{CH}_{2}\right), 25.7\left(\mathrm{CH}_{2}\right), 25.0\left(\mathrm{CH}_{2}\right) .{ }^{11} \mathrm{~B}$ NMR $\left(128 \mathrm{MHz}, \mathrm{CDCl}_{3}\right): \delta=-2.81(2 \mathrm{~B}),-8.18(2 \mathrm{~B})$, -9.37 (2B), -10.21 (2B), -11.07 (2B). IR (ATR): 2932, 2852, 2557, 1494, 1447, 1321, 1261, 1075, $884 \mathrm{~cm}^{-1}$. MS (EI) m/z: $334[\mathrm{M}]^{+}$. HR-MS (EI): $\mathrm{m} / z$ calcd. for $\mathrm{C}_{14} \mathrm{H}_{26}{ }^{10} \mathrm{~B}_{2}{ }^{11} \mathrm{~B}_{8} \mathrm{~S}[\mathrm{M}]^{+}: 334.2760$, 
found: 334.2748 .

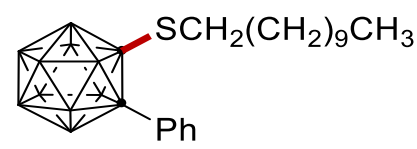

162u. The representative procedure $B$ was followed using o-carborane 160a $(22.0 \mathrm{mg}, 0.10$ $\mathrm{mmol})$ and 1-undecanethiol $161 \mathrm{u}(67.9 \mu \mathrm{L}, 0.30 \mathrm{mmol})$. Isolation by column chromatography ( $n$ hexane) yielded $162 \mathrm{u}(22.0 \mathrm{mg}, 54 \%)$ as a colorless oil. ${ }^{1} \mathrm{H} \mathrm{NMR}\left(300 \mathrm{MHz}, \mathrm{CDCl}_{3}\right): \delta=7.65(\mathrm{~d}$, $J=7.6 \mathrm{~Hz}, 2 \mathrm{H}), 7.52-7.46(\mathrm{~m}, 1 \mathrm{H}), 7.45-7.37(\mathrm{~m}, 2 \mathrm{H}), 2.65(\mathrm{t}, J=7.2 \mathrm{~Hz}, 2 \mathrm{H}), 1.37-1.12(\mathrm{~m}$, $18 \mathrm{H}), 0.95-0.88(\mathrm{~m}, 3 \mathrm{H}) .{ }^{13} \mathrm{C} \mathbf{N M R}\left(75 \mathrm{MHz}, \mathrm{CDCl}_{3}\right): \delta=131.6(\mathrm{CH}), 131.1\left(\mathrm{C}_{\mathrm{q}}\right), 130.7(\mathrm{CH})$, $128.5(\mathrm{CH}), 88.7$ (Cage C), 86.7 (Cage C), $36.9\left(\mathrm{CH}_{2}\right), 31.9\left(\mathrm{CH}_{2}\right), 29.6\left(\mathrm{CH}_{2}\right), 29.5\left(\mathrm{CH}_{2}\right), 29.3$ (2CH 2$), 28.8\left(\mathrm{CH}_{2}\right), 28.3\left(\mathrm{CH}_{2}\right), 28.0\left(\mathrm{CH}_{2}\right), 22.7\left(\mathrm{CH}_{2}\right), 14.1\left(\mathrm{CH}_{3}\right) .{ }^{11} \mathbf{B} \mathrm{NMR}\left(96 \mathrm{MHz}, \mathrm{CDCl}_{3}\right): \delta$ $=-2.96$ (2B), -8.35 (2B), -10.02 (5B), -11.34 (1B). IR (ATR): 2957, 2923, 2853, 2593, 1447, 1276, $766,750 \mathrm{~cm}^{-1}$. MS (EI) m/z: $406[\mathrm{M}]^{+}$. HR-MS (EI): $\mathrm{m} / z$ calcd. for $\mathrm{C}_{19} \mathrm{H}_{38}{ }^{10} \mathrm{~B}_{2}{ }^{11} \mathrm{~B}_{8} \mathrm{~S}[\mathrm{M}]^{+}: 406.3702$, found: 406.3694 .

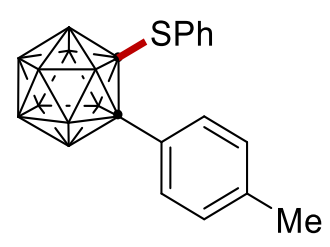

163a. The representative procedure $L$ was followed using o-carborane $160 \mathrm{~b}(23.4 \mathrm{mg}, 0.10$ $\mathrm{mmol})$ and benzenethiol $1610(30.8 \mu \mathrm{L}, 0.30 \mathrm{mmol})$. Isolation by column chromatography $(n-$ hexane) yielded 163a (32.2 mg, 94\%) as a colorless solid. M.p. $=114-116{ }^{\circ} \mathrm{C} .{ }^{1} \mathbf{H}$ NMR $(400$ $\left.\mathrm{MHz}, \mathrm{CDCl}_{3}\right): \delta=7.51-7.46(\mathrm{~m}, 2 \mathrm{H}), 7.42-7.37(\mathrm{~m}, 1 \mathrm{H}), 7.28-7.21(\mathrm{~m}, 4 \mathrm{H}), 7.01-6.96$ $(\mathrm{m}, 2 \mathrm{H}), 2.43(\mathrm{~s}, 3 \mathrm{H}) .{ }^{13} \mathrm{C}$ NMR $\left(101 \mathrm{MHz}, \mathrm{CDCl}_{3}\right): \delta=141.3\left(\mathrm{C}_{\mathrm{q}}\right), 137.0(\mathrm{CH}), 132.1(\mathrm{CH}), 131.1$ $(\mathrm{CH}), 129.9\left(\mathrm{C}_{\mathrm{q}}\right), 129.2(\mathrm{CH}), 129.1(\mathrm{CH}), 128.2\left(\mathrm{C}_{\mathrm{q}}\right), 88.6$ (Cage C), 86.3 (Cage C), $21.2\left(\mathrm{CH}_{3}\right)$. 11B NMR (128 MHz, $\mathrm{CDCl}_{3}$ ): $\delta=-2.90$ (2B), -9.10 (3B), -10.40 (3B), -11.55 (2B). IR (ATR): 2922, 2564, 1612, 1509, 1471, 1439, 1260, 1193, $888 \mathrm{~cm}^{-1}$. MS (EI) $\mathrm{m} / \mathrm{z}: 342[\mathrm{M}]^{+}$. HR-MS (El): $\mathrm{m} / \mathrm{z}$ calcd. for $\mathrm{C}_{15} \mathrm{H}_{22}{ }^{10} \mathrm{~B}_{2}{ }^{11} \mathrm{~B}_{8} \mathrm{~S}[\mathrm{M}]^{+}:$342.2448, found: 342.2436 . 


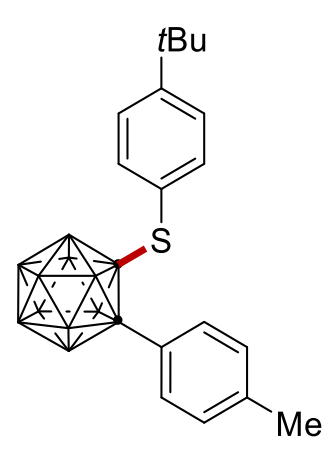

163b. The representative procedure $L$ was followed using o-carborane $160 \mathrm{~b}(23.0 \mathrm{mg}, 0.10$ $\mathrm{mmol}$ ) and 4-(tert-butyl)benzenethiol 161b $(49.9 \mu \mathrm{L}, 0.30 \mathrm{mmol})$. Isolation by column chromatography ( $n$-hexane) yielded 163b $(24.7 \mathrm{mg}, 62 \%)$ as a colorless solid. M.p. $=106-$ $108^{\circ} \mathrm{C} .{ }^{1} \mathrm{H}$ NMR $\left(400 \mathrm{MHz}, \mathrm{CDCl}_{3}\right): \delta=7.51$ (d, $\left.J=8.4 \mathrm{~Hz}, 2 \mathrm{H}\right), 7.27(\mathrm{~d}, J=6.0 \mathrm{~Hz}, 2 \mathrm{H}), 7.25(\mathrm{~d}$, $J=6.0 \mathrm{~Hz}, 2 \mathrm{H}), 6.93(\mathrm{~d}, J=8.4 \mathrm{~Hz}, 2 \mathrm{H}), 2.45(\mathrm{~s}, 3 \mathrm{H}), 1.30(\mathrm{~s}, 9 \mathrm{H}) .{ }^{13} \mathrm{C} \mathrm{NMR}\left(101 \mathrm{MHz}, \mathrm{CDCl}_{3}\right)$ : $\delta=154.6\left(\mathrm{C}_{\mathrm{q}}\right), 141.2\left(\mathrm{C}_{\mathrm{q}}\right), 136.6(\mathrm{CH}), 132.1(\mathrm{CH}), 129.2(\mathrm{CH}), 128.3\left(\mathrm{C}_{\mathrm{q}}\right), 126.5\left(\mathrm{C}_{\mathrm{q}}\right), 126.1$ $(\mathrm{CH}), 88.6$ (Cage C), 86.7 (Cage $\mathrm{C}$ ), $34.9\left(\mathrm{C}_{\mathrm{q}}\right), 31.1\left(\mathrm{CH}_{3}\right), 21.2\left(\mathrm{CH}_{3}\right) .{ }^{11} \mathrm{~B}$ NMR (96 MHz, $\mathrm{CDCl}_{3}$ ): $\delta=-3.14$ (2B), -9.15 (3B), -10.52 (3B), -11.76 (2B). IR (ATR): 2962, 2924, 2852, 2594, 2572, 1460, 1259, $765 \mathrm{~cm}^{-1}$. MS (El) $\mathrm{m} / \mathrm{z}: 398$ [M] $^{+}$. HR-MS (El): $\mathrm{m} / \mathrm{z}$ calcd. for $\mathrm{C}_{19} \mathrm{H}_{30}{ }^{10} \mathrm{~B}_{2}{ }^{11} \mathrm{~B}_{8} \mathrm{~S}[\mathrm{M}]^{+}:$398.3076, found: 398.3064 .

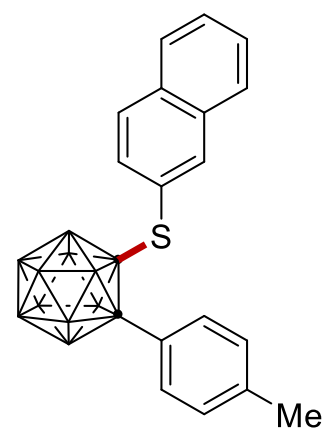

163c. The representative procedure $L$ was followed using o-carborane $160 \mathrm{~b}(23.4 \mathrm{mg}, 0.10$ $\mathrm{mmol}$ ) and naphthalene-2-thiol $161 \mathrm{r}(43.2 \mathrm{mg}, 0.30 \mathrm{mmol})$. Isolation by column chromatography ( $n$-hexane) yielded $163 \mathrm{c}(39.2 \mathrm{mg}, 62 \%)$ as a colorless solid. M.p. $=165-166^{\circ} \mathrm{C} .{ }^{1} \mathbf{H}$ NMR $(400$ $\left.\mathrm{MHz}, \mathrm{CDCl}_{3}\right): \delta=7.84-7.79(\mathrm{~m}, 1 \mathrm{H}), 7.72(\mathrm{dd}, J=8.5,0.6 \mathrm{~Hz}, 1 \mathrm{H}), 7.62-7.58(\mathrm{~m}, 1 \mathrm{H}), 7.57-$ $7.53(\mathrm{~m}, 1 \mathrm{H}), 7.53-7.47(\mathrm{~m}, 3 \mathrm{H}), 7.27-7.24(\mathrm{~m}, 2 \mathrm{H}), 7.22(\mathrm{dd}, J=1.8,0.9 \mathrm{~Hz}, 1 \mathrm{H}), 7.12(\mathrm{dd}, J$ $=8.5,1.8 \mathrm{~Hz}, 1 \mathrm{H}), 2.49(\mathrm{~s}, 3 \mathrm{H}) .{ }^{13} \mathrm{C}$ NMR $\left(101 \mathrm{MHz}, \mathrm{CDCl}_{3}\right): \delta=141.3\left(\mathrm{C}_{\mathrm{q}}\right), 137.6(\mathrm{CH}), 133.9$ $\left(\mathrm{C}_{\mathrm{q}}\right), 132.9\left(\mathrm{C}_{\mathrm{q}}\right), 132.2(\mathrm{CH}), 132.2(\mathrm{CH}), 129.2(\mathrm{CH}), 128.8(\mathrm{CH}), 128.2(\mathrm{CH}), 128.2\left(\mathrm{C}_{\mathrm{q}}\right), 128.0$ $(\mathrm{CH}), 127.7(\mathrm{CH}), 126.9\left(\mathrm{C}_{\mathrm{q}}\right), 126.8(\mathrm{CH}), 88.1$ (Cage C), 86.0 (Cage C), $21.3\left(\mathrm{CH}_{3}\right) .{ }^{11} \mathrm{~B}$ NMR (128 MHz, $\mathrm{CDCl}_{3}$ ): $\delta=-2.63$ (2B), -9.08 (4B), -10.53 (2B), -11.48 (2B). IR (ATR): 2591, 1276, $1259,816,766,748 \mathrm{~cm}^{-1}$. MS (EI) $\mathrm{m} / \mathrm{z}: 392[\mathrm{M}]^{+}$. HR-MS (EI): $\mathrm{m} / \mathrm{z}$ calcd. for $\mathrm{C}_{19} \mathrm{H}_{24}{ }^{10} \mathrm{~B}_{2}{ }^{11} \mathrm{~B}_{8} \mathrm{~S}[\mathrm{M}]^{+}$: 
392.2606, found: 392.2600 .

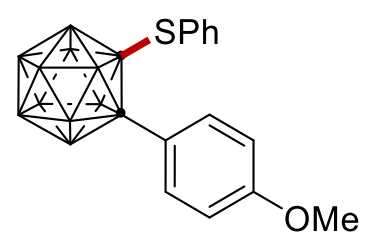

163d. The representative procedure $L$ was followed using o-carborane $160 \mathrm{c}(25.1 \mathrm{mg}, 0.10$ $\mathrm{mmol})$ and benzenethiol $1610(30.8 \mu \mathrm{L}, 0.30 \mathrm{mmol})$. Isolation by column chromatography ( $n-$ hexane) yielded 163d $(25.1 \mathrm{mg}, 70 \%)$ as a colorless oil. ${ }^{1} \mathbf{H} \mathbf{~ N M R}\left(400 \mathrm{MHz}, \mathrm{CDCl}_{3}\right): \delta=7.51$ (d, $J=9.0 \mathrm{~Hz}, 2 \mathrm{H}), 7.42-7.37(\mathrm{~m}, 1 \mathrm{H}), 7.28-7.22(\mathrm{~m}, 2 \mathrm{H}), 6.99(\mathrm{dd}, J=8.3,1.3 \mathrm{~Hz}, 2 \mathrm{H})$, $6.92(\mathrm{~d}, J=9.0 \mathrm{~Hz}, 2 \mathrm{H}), 3.88(\mathrm{~s}, 3 \mathrm{H}) .{ }^{13} \mathrm{C}$ NMR $\left(101 \mathrm{MHz}, \mathrm{CDCl}_{3}\right): \delta=161.6\left(\mathrm{C}_{\mathrm{q}}\right), 136.9(\mathrm{CH})$, $133.7(\mathrm{CH}), 131.1(\mathrm{CH}), 129.9\left(\mathrm{C}_{\mathrm{q}}\right), 129.1(\mathrm{CH}), 123.3\left(\mathrm{C}_{\mathrm{q}}\right), 113.7(\mathrm{CH}), 88.9($ Cage $\mathrm{C}), 86.7$ (Cage C), $55.5\left(\mathrm{CH}_{3}\right) .{ }^{11} \mathrm{~B}$ NMR (128 MHz, $\left.\mathrm{CDCl}_{3}\right): \delta=-3.01(2 \mathrm{~B}),-9.06(4 \mathrm{~B}),-10.52(2 \mathrm{~B}),-11.55$ (2B). IR (ATR): 2588, 1971, 1607, 1511, 1302, 1261, 1184, 835, $748 \mathrm{~cm}^{-1}$. MS (EI) $\mathrm{m} / \mathrm{z}: 358$ [M] ${ }^{+}$. HR-MS (EI): $m / z$ calcd. for $\mathrm{C}_{15} \mathrm{H}_{22}{ }^{10} \mathrm{~B}_{2}{ }^{11} \mathrm{~B}_{8} \mathrm{SO}[\mathrm{M}]^{+}: 358.2395$, found: 358.2391 .

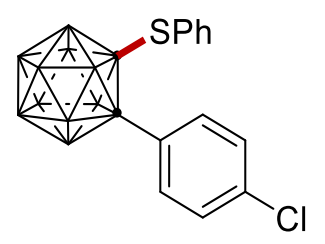

163e. The representative procedure $\mathrm{L}$ with $\mathrm{KI}(16.6 \mathrm{mg}, 0.10 \mathrm{mmol})$ was followed using ocarborane $160 \mathrm{~d}(25.4 \mathrm{mg}, 0.10 \mathrm{mmol})$ and benzenethiol $1610(30.8 \mu \mathrm{L}, 0.30 \mathrm{mmol})$. Isolation by column chromatography ( $n$-hexane) yielded $163 \mathrm{e}(28.2 \mathrm{mg}, 78 \%)$ as a colorless oil. ${ }^{1} \mathbf{H}$ NMR $\left(400 \mathrm{MHz}, \mathrm{CDCl}_{3}\right): \delta=7.55(\mathrm{~d}, J=8.6 \mathrm{~Hz}, 2 \mathrm{H}), 7.49-7.40(\mathrm{~m}, 3 \mathrm{H}), 7.29(\mathrm{t}, J=7.8 \mathrm{~Hz}, 2 \mathrm{H})$, $7.00(\mathrm{~d}, J=7.6 \mathrm{~Hz}, 2 \mathrm{H}) .{ }^{13} \mathrm{C}$ NMR $\left(101 \mathrm{MHz}, \mathrm{CDCl}_{3}\right): \delta=137.5\left(\mathrm{C}_{\mathrm{q}}\right), 136.8(\mathrm{CH}), 133.4(\mathrm{CH})$, $131.3(\mathrm{CH}), 129.7\left(\mathrm{C}_{q}\right), 129.6\left(\mathrm{C}_{q}\right), 129.2(\mathrm{CH}), 128.7(\mathrm{CH}), 87.1$ (Cage $\left.\mathrm{C}\right), 86.2$ (Cage $\left.\mathrm{C}\right)$. ${ }^{11} \mathrm{~B}$ NMR $\left(128 \mathrm{MHz}, \mathrm{CDCl}_{3}\right): \delta=-2.39(1 \mathrm{~B}),-3.00(1 \mathrm{~B}),-8.40(2 \mathrm{~B}),-9.20(1 \mathrm{~B}),-10.19(3 \mathrm{~B}),-$ 11.56 (2B). IR (ATR): 2924, 2593, 1593, 1492, 1401, 1100, 1070, 1016, $887 \mathrm{~cm}^{-1}$. MS (EI) m/z: $362[\mathrm{M}]^{+}$. HR-MS (EI): $\mathrm{m} / \mathrm{z}$ calcd. for $\mathrm{C}_{14} \mathrm{H}_{19}{ }^{10} \mathrm{~B}_{2}{ }^{11} \mathrm{~B}_{8} \mathrm{~S}^{35} \mathrm{Cl}[\mathrm{M}]^{+}: 362.1904$, found: 362.1894 .

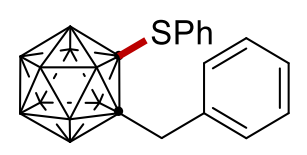

163f. The representative procedure $L$ was followed using o-carborane $160 \mathrm{e}(23.4 \mathrm{mg}, 0.10$ $\mathrm{mmol})$ and benzenethiol $1610(31.0 \mu \mathrm{L}, 0.30 \mathrm{mmol})$. Isolation by column chromatography $(n-$ hexane) yielded $163 f(22.0 \mathrm{mg}, 64 \%)$ as a colorless solid. M.p. $=119-121^{\circ} \mathrm{C} .{ }^{1} \mathbf{H}$ NMR $(300$ 
$\left.\mathrm{MHz}, \mathrm{CDCl}_{3}\right): \delta=7.70-7.66(\mathrm{~m}, 2 \mathrm{H}), 7.60-7.55(\mathrm{~m}, 1 \mathrm{H}), 7.53-7.46(\mathrm{~m}, 2 \mathrm{H}), 7.43-7.33$ $(\mathrm{m}, 3 \mathrm{H}), 7.29-7.25(\mathrm{~m}, 2 \mathrm{H}), 3.80(\mathrm{~s}, 2 \mathrm{H}) .{ }^{13} \mathrm{C}$ NMR $\left(75 \mathrm{MHz}, \mathrm{CDCl}_{3}\right): \delta=137.2(\mathrm{CH}), 135.6\left(\mathrm{C}_{\mathrm{q}}\right)$, $131.5(\mathrm{CH}), 130.4(\mathrm{CH}), 130.0\left(\mathrm{C}_{\mathrm{q}}\right), 129.6(\mathrm{CH}), 128.6(\mathrm{CH}), 128.0(\mathrm{CH}), 84.3$ (Cage C), 84.2 (Cage C), $40.9\left(\mathrm{CH}_{2}\right) .{ }^{11} \mathrm{~B}$ NMR (96 MHz, $\left.\mathrm{CDCl}_{3}\right): \delta=-3.85(2 \mathrm{~B}),-9.37(4 \mathrm{~B}),-10.84(4 \mathrm{~B})$. IR (ATR): 2923, 2852, 2577, 2560, 1493, 1470, 1439, 1419, $745 \mathrm{~cm}^{-1}$. MS (EI) $\mathrm{m} / \mathrm{z}: 342$ [M] $]^{+}$HRMS (El): $m / z$ calcd. for $\mathrm{C}_{15} \mathrm{H}_{22}{ }^{10} \mathrm{~B}_{2}{ }^{11} \mathrm{~B}_{8} \mathrm{~S}[\mathrm{M}]^{+}: 342.2448$, found: 342.2432 .

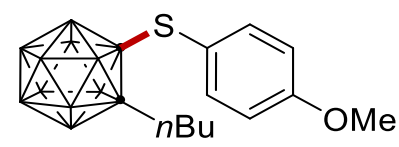

163g. The representative procedure $\mathrm{K}$ was followed using o-carborane $160 \mathrm{f}$ (20.0 $\mathrm{mg}, 0.10$ $\mathrm{mmol}$ ) and 4-methoxybenzenethiol 161a $(36.9 \mu \mathrm{L}, 0.30 \mathrm{mmol})$. Isolation by column chromatography ( $n$-hexane) yielded $\mathbf{1 6 3 g}(18.0 \mathrm{mg}, 53 \%)$ as a colorless oil. ${ }^{1} \mathbf{H}$ NMR (400 MHz, $\left.\mathrm{CDCl}_{3}\right): \delta=7.48(\mathrm{~d}, J=8.8 \mathrm{~Hz}, 2 \mathrm{H}), 6.94(\mathrm{~d}, J=8.7 \mathrm{~Hz}, 2 \mathrm{H}), 3.88(\mathrm{~s}, 3 \mathrm{H}), 2.52-2.47(\mathrm{~m}, 2 \mathrm{H})$, $1.59-1.53(\mathrm{~m}, 2 \mathrm{H}), 1.49-1.41(\mathrm{~m}, 2 \mathrm{H}), 1.01(\mathrm{t}, J=7.2 \mathrm{~Hz}, 3 \mathrm{H}) .{ }^{13} \mathrm{C} \mathrm{NMR}\left(101 \mathrm{MHz}, \mathrm{CDCl}_{3}\right): \delta$ $=162.0\left(\mathrm{C}_{\mathrm{q}}\right), 138.8(\mathrm{CH}), 120.9\left(\mathrm{C}_{\mathrm{q}}\right), 114.9(\mathrm{CH}), 84.7$ (Cage C), $84.6($ Cage $\mathrm{C}), 55.5\left(\mathrm{CH}_{3}\right), 35.0$ $\left(\mathrm{CH}_{2}\right), 31.8\left(\mathrm{CH}_{2}\right), 22.5\left(\mathrm{CH}_{2}\right), 13.8\left(\mathrm{CH}_{3}\right) .{ }^{11} \mathrm{~B}$ NMR $\left(96 \mathrm{MHz}, \mathrm{CDCl}_{3}\right): \delta=-4.27(2 \mathrm{~B}),-9.91(4 \mathrm{~B})$, -10.94 (4B). IR (ATR): 2959, 2930, 2564, 1591, 1493, 1254, 1172, $830 \mathrm{~cm}^{-1}$. MS (EI) m/z: 338 [M] $]^{+}$. HR-MS (EI): $\mathrm{m} / z$ calcd. for $\mathrm{C}_{13} \mathrm{H}_{26}{ }^{10} \mathrm{~B}_{2}{ }^{11} \mathrm{~B}_{8} \mathrm{OS}[\mathrm{M}]^{+}: 338.2709$, found: 338.2703 .

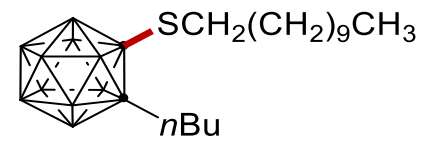

163h. The representative procedure $L$ was followed using o-carborane $160 \mathrm{f}$ (20.0 $\mathrm{mg}, 0.10$ $\mathrm{mmol})$ and 1 -undecanethiol $161 \mathrm{u}(67.9 \mu \mathrm{L}, 0.30 \mathrm{mmol})$. Isolation by column chromatography ( $n$ hexane) yielded $163 \mathrm{~h}(20.7 \mathrm{mg}, 54 \%)$ as a colorless oil. ${ }^{1} \mathrm{H}$ NMR $\left(300 \mathrm{MHz}, \mathrm{CDCl}_{3}\right): \delta=2.86(\mathrm{t}$, $J=7.2 \mathrm{~Hz}, 2 \mathrm{H}), 2.35-2.26(\mathrm{~m}, 2 \mathrm{H}), 1.67-1.59(\mathrm{~m}, 2 \mathrm{H}), 1.57-1.47(\mathrm{~m}, 2 \mathrm{H}), 1.45-1.21(\mathrm{~m}$, $18 \mathrm{H}), 1.01-0.85(\mathrm{~m}, 6 \mathrm{H}) .{ }^{13} \mathrm{C}$ NMR $\left(75 \mathrm{MHz}, \mathrm{CDCl}_{3}\right): \delta=85.0$ (Cage C), 83.9 (Cage C), 37.2 $\left(\mathrm{CH}_{2}\right)$, $34.6\left(\mathrm{CH}_{2}\right), 31.9\left(\mathrm{CH}_{2}\right), 31.8\left(\mathrm{CH}_{2}\right), 29.6\left(\mathrm{CH}_{2}\right), 29.5\left(\mathrm{CH}_{2}\right), 29.4\left(\mathrm{CH}_{2}\right), 29.3\left(\mathrm{CH}_{2}\right), 29.0$ $\left(\mathrm{CH}_{2}\right)$, $28.7\left(\mathrm{CH}_{2}\right), 28.2\left(\mathrm{CH}_{2}\right), 22.7\left(\mathrm{CH}_{2}\right), 22.4\left(\mathrm{CH}_{2}\right), 14.1\left(\mathrm{CH}_{3}\right), 13.7\left(\mathrm{CH}_{3}\right) .{ }^{11} \mathbf{B}$ NMR $(96 \mathrm{MHz}$, $\mathrm{CDCl}_{3}$ ): $\delta=-4.29$ (2B), -9.85 (4B), -10.95 (4B). IR (ATR): 2958, 2924, 2853, 2606, 2569, 1466, 1259, $748 \mathrm{~cm}^{-1}$. MS (EI) $\mathrm{m} / z: 386[\mathrm{M}]^{+}$. HR-MS (EI): $\mathrm{m} / z$ calcd. for $\mathrm{C}_{17} \mathrm{H}_{42}{ }^{10} \mathrm{~B}_{2}{ }^{11} \mathrm{~B}_{8} \mathrm{~S}[\mathrm{M}]^{+}$: 386.4014, found: 386.4008 . 


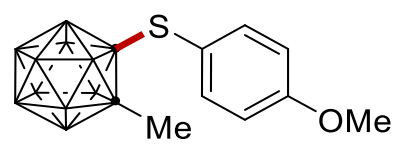

163i. The representative procedure $L$ was followed using o-carborane $160 \mathrm{~g}$ (15.8 $\mathrm{mg}, 0.10$ $\mathrm{mmol}$ ) and 4-methoxybenzenethiol 161a $(36.9 \mu \mathrm{L}, 0.30 \mathrm{mmol})$. Isolation by column chromatography ( $n$-hexane) yielded $163 \mathbf{i}(20.0 \mathrm{mg}, 68 \%)$ as a colorless solid. M.p. $=81-83^{\circ} \mathrm{C}$. ${ }^{1} \mathrm{H}$ NMR $\left(300 \mathrm{MHz}, \mathrm{CDCl}_{3}\right): \delta=7.49(\mathrm{~d}, J=8.9 \mathrm{~Hz}, 2 \mathrm{H}), 6.94(\mathrm{~d}, J=9.0 \mathrm{~Hz}, 2 \mathrm{H}), 3.87(\mathrm{~s}, 3 \mathrm{H})$, $2.24(\mathrm{~s}, 3 \mathrm{H}) .{ }^{13} \mathrm{C}$ NMR $\left(75 \mathrm{MHz}, \mathrm{CDCl}_{3}\right): \delta=162.0\left(\mathrm{C}_{\mathrm{q}}\right), 138.9(\mathrm{CH}), 121.0\left(\mathrm{C}_{\mathrm{q}}\right), 114.9(\mathrm{CH}), 82.7$ (Cage C), 79.3 (Cage C), $55.5\left(\mathrm{CH}_{3}\right), 23.6\left(\mathrm{CH}_{3}\right) .{ }^{11} \mathrm{~B}$ NMR $\left(96 \mathrm{MHz}, \mathrm{CDCl}_{3}\right): \delta=-3.86(1 \mathrm{~B})$, 4.97 (1B), -8.82 (2B), -9.90 (6B). IR (ATR): 2838, 2600, 2571, 2557, 1590, 1493, 1254, $828 \mathrm{~cm}^{-1}$. MS (EI) $\mathrm{m} / \mathrm{z}: 296[\mathrm{M}]^{+}$. HR-MS (EI): $\mathrm{m} / \mathrm{z}$ calcd. for $\mathrm{C}_{10} \mathrm{H}_{20}{ }^{10} \mathrm{~B}_{2}{ }^{11} \mathrm{~B}_{8} \mathrm{OS}[\mathrm{M}]^{+}: 296.2238$, found: 296.2230 .

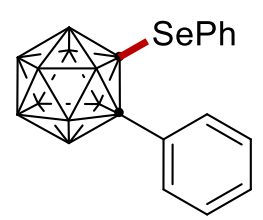

163j. The representative procedure $L$ was followed using o-carborane $160 \mathrm{a}(22.0 \mathrm{mg}, 0.10$ $\mathrm{mmol})$ and benzeneselenol $161 \mathrm{v}(31.9 \mu \mathrm{L}, 0.30 \mathrm{mmol})$. Isolation by column chromatography ( $n$ hexane) yielded 163j (22.0 mg, 59\%) as a colorless solid. M.p. $=112-114{ }^{\circ} \mathrm{C} .{ }^{1} \mathbf{H}$ NMR $(300$ $\left.\mathrm{MHz}, \mathrm{CDCl}_{3}\right): \delta=7.63-7.52(\mathrm{~m}, 3 \mathrm{H}), 7.45(\mathrm{t}, J=7.5 \mathrm{~Hz}, 3 \mathrm{H}), 7.29(\mathrm{t}, J=7.6 \mathrm{~Hz}, 2 \mathrm{H}), 7.16(\mathrm{~d}, J$ $=7.3 \mathrm{~Hz}, 2 \mathrm{H}) \cdot{ }^{13} \mathrm{C}$ NMR $\left(75 \mathrm{MHz}, \mathrm{CDCl}_{3}\right): \delta=137.6(\mathrm{CH}), 132.0(\mathrm{CH}), 131.7\left(\mathrm{C}_{\mathrm{q}}\right), 130.8(\mathrm{CH})$, $130.7(\mathrm{CH}), 129.2(\mathrm{CH}), 128.5(\mathrm{CH}), 127.1\left(\mathrm{C}_{\mathrm{q}}\right), 86.3$ (Cage C), 72.7 (Cage C). ${ }^{11 B}$ NMR (96 $\mathrm{MHz}, \mathrm{CDCl}_{3}$ ): $\delta=-2.44(2 \mathrm{~B}),-8.29$ (1B), -9.00 (1B), -9.78 (3B), -11.45 (3B). IR (ATR): 2630, 2609, 2572, 2561, 1585, 1486, 1233, $754 \mathrm{~cm}^{-1}$. MS (EI) $\mathrm{m} / \mathrm{z}: 376$ [M] $]^{+}$. HR-MS (El): $\mathrm{m} / \mathrm{z}$ calcd. for $\mathrm{C}_{14} \mathrm{H}_{20}{ }^{10} \mathrm{~B}_{2}{ }^{11} \mathrm{~B}_{8} \mathrm{Se}[\mathrm{M}]^{+}:$376.1729, found: 376.1726 .

\subsubsection{Late-stage Diversification}

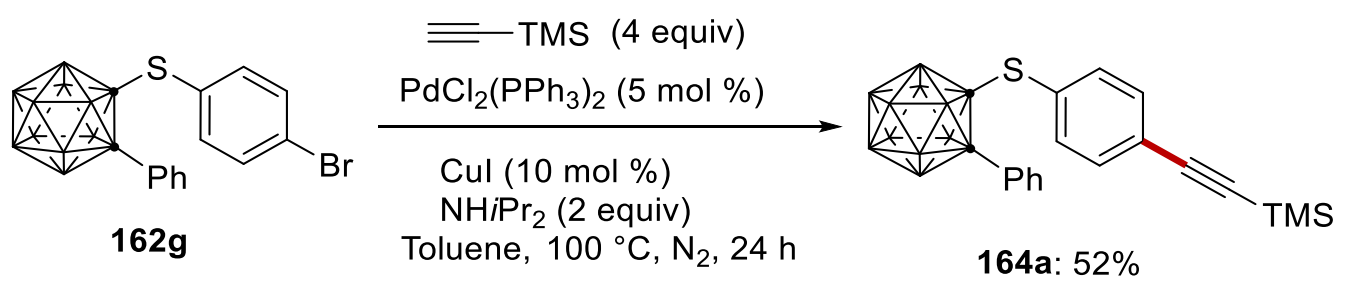

Compound $162 \mathrm{~g}(40.7 \mathrm{mg}, 0.10 \mathrm{mmol})$, trimethylsilylacetylene $(56.5 \mu \mathrm{L}, 0.40 \mathrm{mmol}$ ), $\mathrm{PdCl}_{2}\left(\mathrm{PPh}_{3}\right)_{2}(3.5 \mathrm{mg}, 0.005 \mathrm{mmol})$, Cul $(1.9 \mathrm{mg}, 0.01 \mathrm{mmol})$ and $\mathrm{NH}_{1} \operatorname{Pr}_{2}(28.2 \mu \mathrm{L}, 0.20 \mathrm{mmol})$ were combined together in toluene $(2.5 \mathrm{~mL})$. The resulting mixture was heated at $100{ }^{\circ} \mathrm{C}$ for $24 \mathrm{~h}$ 
under $\mathrm{N}_{2}$. Then, the reaction was quenched with with water $(10 \mathrm{~mL})$ and extracted with diethyl ether (10 mL $\times 3$ ). The organic layers were combined and concentrated to dryness in vacuo. The residue was subjected to flash column chromatography on silica gel using $n$-hexane as eluent to give the product 164a as a colorless oil (52\%). ${ }^{1} \mathrm{H}$ NMR $\left(300 \mathrm{MHz}, \mathrm{CDCl}_{3}\right): \delta=7.66-7.60(\mathrm{~m}$, 2H), $7.60-7.53(\mathrm{~m}, 1 \mathrm{H}), 7.47$ (t, $J=7.6 \mathrm{~Hz}, 2 \mathrm{H}), 7.34$ (d, $J=8.0 \mathrm{~Hz}, 2 \mathrm{H}), 6.86(\mathrm{~d}, J=8.0 \mathrm{~Hz}$, 2H), $0.28(\mathrm{~s}, 9 \mathrm{H}) .{ }^{13} \mathrm{C}$ NMR $\left(101 \mathrm{MHz}, \mathrm{CDCl}_{3}\right): \delta=136.6(\mathrm{CH}), 132.5(\mathrm{CH}), 132.3(\mathrm{CH}), 131.0$ $(\mathrm{CH}), 130.9\left(\mathrm{C}_{q}\right), 129.9\left(\mathrm{C}_{q}\right), 128.7(\mathrm{CH}), 126.3\left(\mathrm{C}_{q}\right), 103.6\left(\mathrm{C}_{q}\right), 98.0\left(\mathrm{C}_{q}\right), 88.1$ (Cage $\mathrm{C}$ ), 85.8 (Cage C), $0.0\left(\mathrm{CH}_{3}\right) .{ }^{11} \mathrm{~B}$ NMR $\left(96 \mathrm{MHz}, \mathrm{CDCl}_{3}\right)$ : $\delta=-2.65$ (2B), -8.99 (3B), -10.46 (5B). IR (ATR): 2958, 2923, 2594, 2575, 2158, 1480, 1250, 862, $841 \mathrm{~cm}^{-1}$. MS (EI) m/z: 424 [M]+. HR-MS (EI): $\mathrm{m} / \mathrm{z}$ calcd. for $\mathrm{C}_{19} \mathrm{H}_{28}{ }^{10} \mathrm{~B}_{2}{ }^{11} \mathrm{~B}_{8} \mathrm{SSi}[\mathrm{M}]+:$ : 424.2690 , found: 424.2678 .
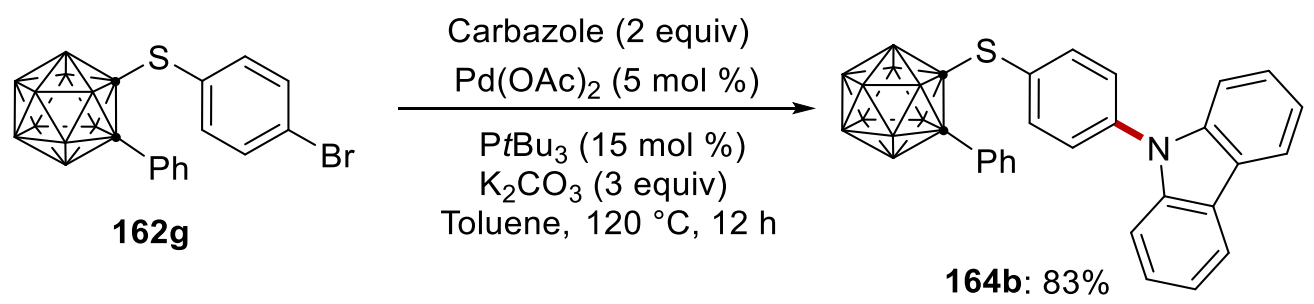

Compound $162 \mathrm{~g}$ ( $40.7 \mathrm{mg}, 0.10 \mathrm{mmol})$, carbazole $(33.4 \mathrm{mg}, 0.20 \mathrm{mmol}), \mathrm{Pd}(\mathrm{OAc})_{2}(1.1 \mathrm{mg}$, $0.005 \mathrm{mmol}), \mathrm{PtBu}_{3}(3.0 \mathrm{mg}, 0.015 \mathrm{mmol})$, and $\mathrm{K}_{2} \mathrm{CO}_{3}(41.4 \mathrm{mg}, 0.30 \mathrm{mmol})$ were combined together in toluene $(2.5 \mathrm{~mL})$. The resulting mixture was heated at $120^{\circ} \mathrm{C}$ for $12 \mathrm{~h}$. Then, the reaction was quenched with with water $(10 \mathrm{~mL})$ and extracted with diethyl ether $(10 \mathrm{~mL} \times 3)$. The organic layers were combined and concentrated to dryness in vacuo. The residue was subjected to flash column chromatography on silica gel using $n$-hexane and ethyl acetate (20/1) as eluent to give the product $164 \mathrm{~b}$ as a colorless solid (83\%). M.p. $=214-216{ }^{\circ} \mathrm{C} .{ }^{1} \mathbf{H}$ NMR $(300 \mathrm{MHz}$, $\left.\mathrm{CDCl}_{3}\right): \delta=8.14(\mathrm{~d}, J=7.8 \mathrm{~Hz}, 2 \mathrm{H}), 7.70(\mathrm{~d}, J=7.7 \mathrm{~Hz}, 2 \mathrm{H}), 7.58-7.53(\mathrm{~m}, 1 \mathrm{H}), 7.49(\mathrm{~d}, J=$ $8.5 \mathrm{~Hz}, 4 \mathrm{H}), 7.45-7.39(\mathrm{~m}, 4 \mathrm{H}), 7.32$ (ddd, $J=8.0,6.1,2.1 \mathrm{~Hz}, 2 \mathrm{H}), 7.14(\mathrm{~d}, J=8.4 \mathrm{~Hz}, 2 \mathrm{H}$ ). ${ }^{13} \mathrm{C}$ NMR $\left(101 \mathrm{MHz}, \mathrm{CDCl}_{3}\right): \delta=140.5\left(\mathrm{C}_{\mathrm{q}}\right), 140.1\left(\mathrm{C}_{\mathrm{q}}\right), 138.4(\mathrm{CH}), 132.2(\mathrm{CH}), 131.0(\mathrm{CH})$, $130.9\left(\mathrm{C}_{\mathrm{q}}\right), 128.6(\mathrm{CH}), 128.0\left(\mathrm{C}_{\mathrm{q}}\right), 127.0(\mathrm{CH}), 126.2(\mathrm{CH}), 123.8\left(\mathrm{C}_{\mathrm{q}}\right), 120.7(\mathrm{CH}), 120.5(\mathrm{CH})$, 109.6 (CH), 87.9 (Cage C), 85.7 (Cage C). ${ }^{11} \mathrm{~B}$ NMR (96 MHz, CDCl $)$ : $\delta=-2.51$ (2B), -9.09 (4B), -10.13 (4B). IR (ATR): 2921, 2851, 2595, 2565, 2555, 1586, 1446, 1223, $720 \mathrm{~cm}^{-1}$. MS (EI) m/z: 493 [M] $]^{+}$HR-MS (EI): $m / z$ calcd. for $\mathrm{C}_{26} \mathrm{H}_{27}{ }^{10} \mathrm{~B}_{2}{ }^{11} \mathrm{~B}_{8} \mathrm{NS}$ [M] $]^{+}: 493.2875$, found: 493.2861 . 


\subsubsection{Mechanistic Studies}

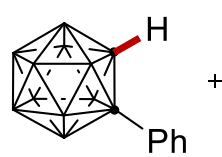

$160 a$<smiles>COc1ccc(S)cc1</smiles>

161a

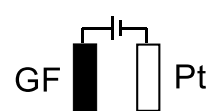

CuOAc $(15 \mathrm{~mol} \%)$

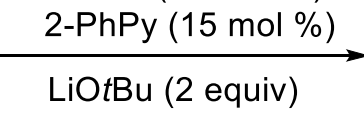

TBAI, THF (3 mL)

rt, 16 h, CCE @ 2 mA

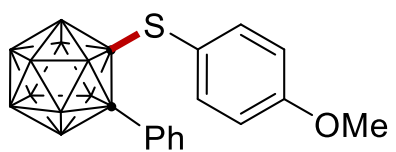

$162 a$

TEMPO or $\mathrm{Ph}_{2} \mathrm{CH}_{2}=\mathrm{CH}_{2}$ (1.0 equiv)

The general procedure $\mathrm{K}$ was followed using o-carborane 160a $(0.10 \mathrm{mmol}$, 1.0 equiv), 4methoxybenzenethiol 161a $(36.9 \mu \mathrm{L}, 0.30 \mathrm{mmol})$ and TEMPO or $\mathrm{Ph}_{2} \mathrm{CH}_{2}=\mathrm{CH}_{2}(0.1 \mathrm{mmol}, 1.0$ equiv). Electrocatalysis was performed at room temperature with a constant current of $2.0 \mathrm{~mA}$ maintained for $16 \mathrm{~h}$. The GF anode was washed with ethyl acetate $(3 \times 10 \mathrm{~mL})$. Evaporation of the solvent and subsequent purification by column chromatography on silica gel with $n$-hexane afforded the corresponding product 162a (TEMPO: 75\%, $\mathrm{Ph}_{2} \mathrm{CH}_{2}=\mathrm{CH}_{2}: 72 \%$ ).

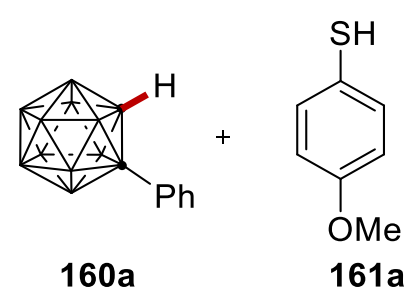

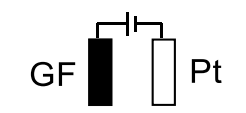

$$
\text { CuOAc }(15 \mathrm{~mol} \%)
$$

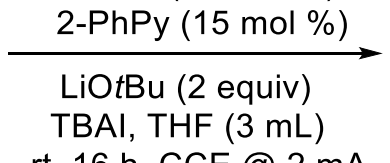

rt, 16 h, CCE @ 2 mA

In The Dark

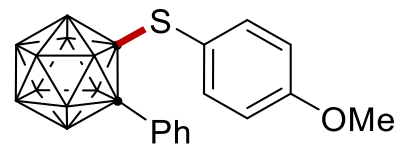

162a: $81 \%$

The general procedure $\mathbf{K}$ was followed using o-carborane $160 \mathrm{a}(0.10 \mathrm{mmol}$, 1.0 equiv), 4methoxybenzenethiol 161a $(36.9 \mu \mathrm{L}, 0.30 \mathrm{mmol})$. Electrocatalysis was performed in the dark at room temperature with a constant current of $2.0 \mathrm{~mA}$ maintained for $16 \mathrm{~h}$. The GF anode was washed with ethyl acetate $(3 \times 10 \mathrm{~mL})$. Evaporation of the solvent and subsequent purification by column chromatography on silica gel with $n$-hexane afforded the corresponding product $162 a$ (81\%).

\subsubsection{Cyclic Voltammetry}

CV measurements were conducted by Alexej Scheremetjew with a Metrohm Autolab PGSTAT204 potentiostat and Nova 2.1 software. A glassy carbon working electrode (disk, diameter: $3 \mathrm{~mm}$ ), a coiled platinum wire counter electrode and a non-aqueous $\mathrm{Ag} / \mathrm{Ag}^{+}$reference

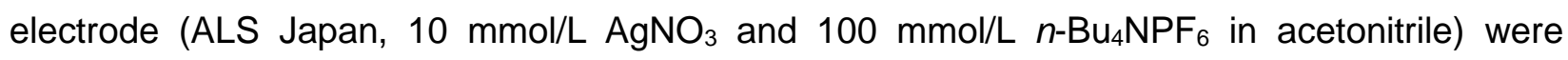


employed. The voltammograms were recorded at room temperature in dry acetonitrile at a substrate concentration of $5 \mathrm{mmol} / \mathrm{L}$ and with $100 \mathrm{mmol} / \mathrm{L} n-\mathrm{Bu}_{4} \mathrm{NPF}_{6}$ as supporting electrolyte. Prior to each measurement, the working electrode was thoroughly polished with $0.05 \mu \mathrm{m}$ alumina polishing powder and rinsed with water and methanol. All measured solutions were saturated with nitrogen gas and an overpressure of protective gas was maintained throughout the experiment. The nitrogen gas was previously saturated with solvent vapour by passing it through a gas washing bottle with acetonitrile. The scan rate is $100 \mathrm{mV} / \mathrm{s}$. Deviations from the general experimental conditions are indicated in the respective figures.
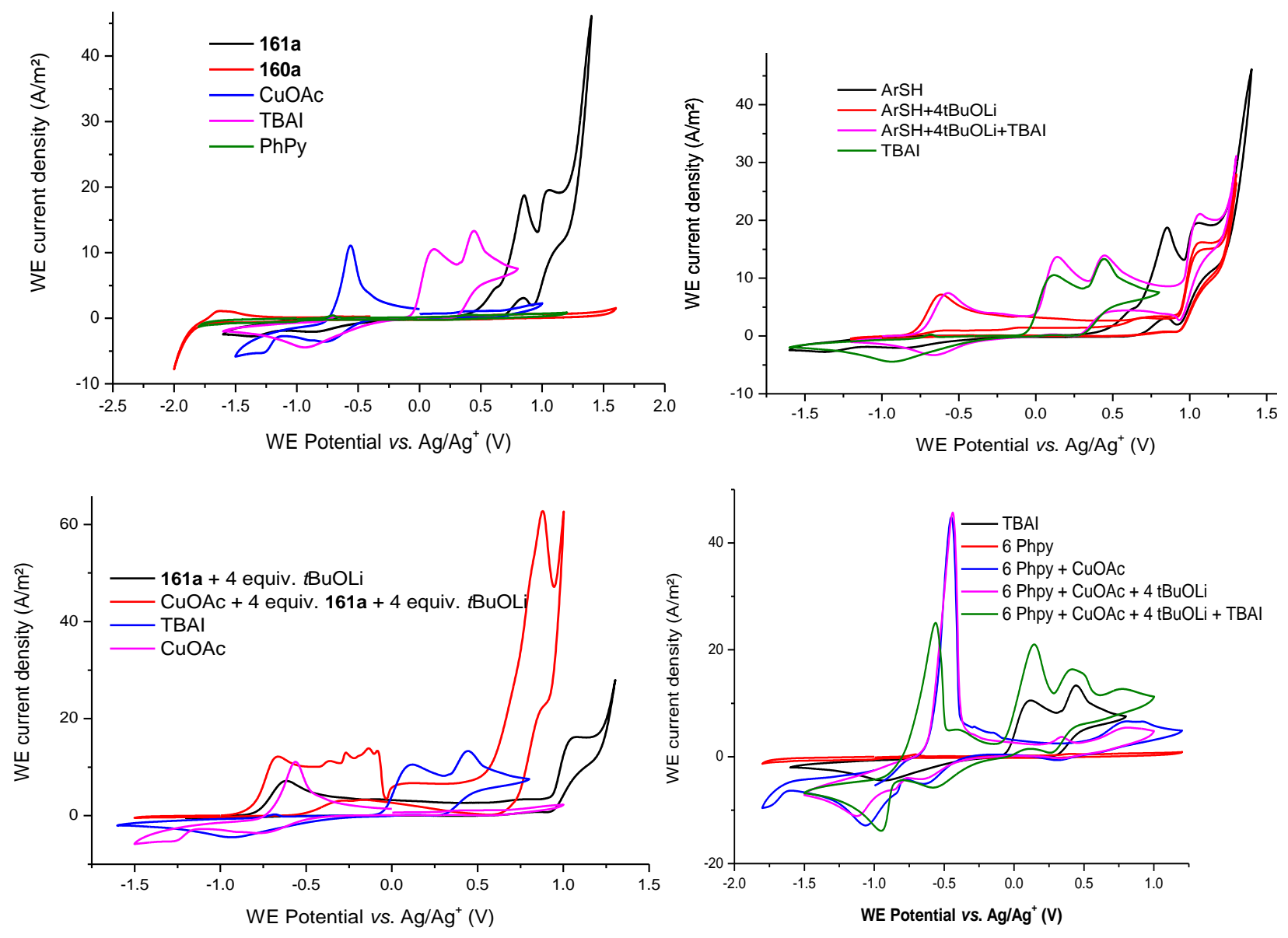


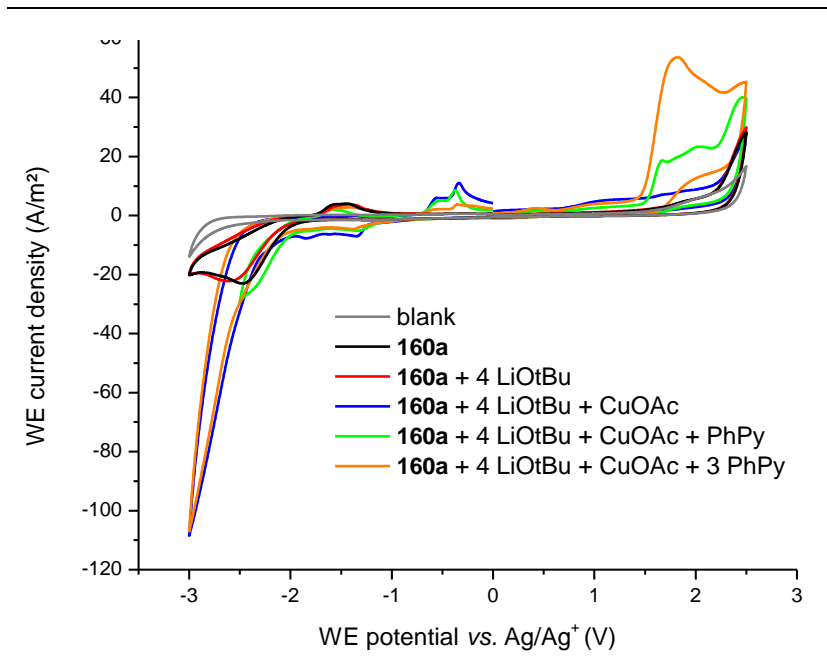

\subsubsection{EPR studies}

(EPR spectroscopy analysis did by Dr. A. Claudia Stcükl). The electrocatalysis was carried out in an undivided cell under air, with a graphite felt (GF) anode $(10 \mathrm{~mm} \times 15 \mathrm{~mm} \times 6 \mathrm{~mm})$ and a platinum cathode $(10 \mathrm{~mm} \times 15 \mathrm{~mm} \times 0.25 \mathrm{~mm})$. o-Carborane $160 \mathrm{a}(0.10 \mathrm{mmol}, 1.0$ equiv), 4 methoxybenzenethiol 161a (0.30 mmol, 3.0 equiv), CuOAc (15 mol \%), 2-PhPy (15 mol \%), LiOtBu (0.2 mmol, 2.0 equiv) and TBAI ( $0.2 \mathrm{mmol}, 2.0$ equiv) were dissolved in THF (3.0 mL). Electrocatalysis was performed at room temperature with a constant current of $2.0 \mathrm{~mA}$ maintained for $2 \mathrm{~h}$. Then PBN ( $\mathrm{N}$-tert-butyl-alpha-Phenylnitrone) (5 equiv.) (if noted) was added into the reaction system. After stirring 2 minutes, the mixture was immediately transferred into the EPR tube for EPR measurement.
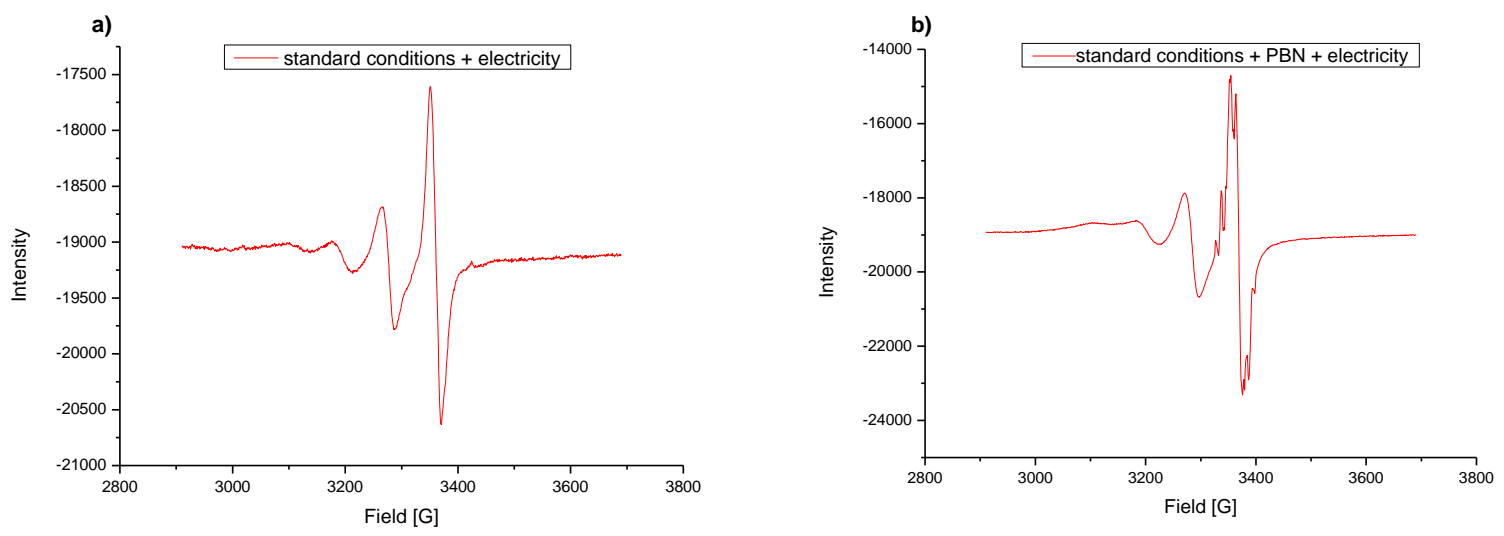

The electrocatalysis was carried out in an undivided cell under air, with a graphite felt (GF) anode $(10 \mathrm{~mm} \times 15 \mathrm{~mm} \times 6 \mathrm{~mm})$ and a platinum cathode $(10 \mathrm{~mm} \times 15 \mathrm{~mm} \times 0.25 \mathrm{~mm})$. 4methoxybenzenethiol $161 \mathrm{a}(0.30 \mathrm{mmol})$ and LiOtBu $(0.2 \mathrm{mmol})$ were dissolved in THF $(3.0 \mathrm{~mL})$. Electrocatalysis was performed at room temperature with a constant current of $2.0 \mathrm{~mA}$ maintained for $2 \mathrm{~h}$. Then PBN ( $N$-tert-butyl-alpha-Phenylnitrone) (5 equiv.) was added into the reaction system. After stirring 2 minutes, the mixture was immediately transferred into the EPR 
tube for EPR measurement. This EPR result showed a small radical signal, which is not stable for longer time even after trapping with PBN and might be attributed to one of the possible thiols containing radical species. ${ }^{[239]}$
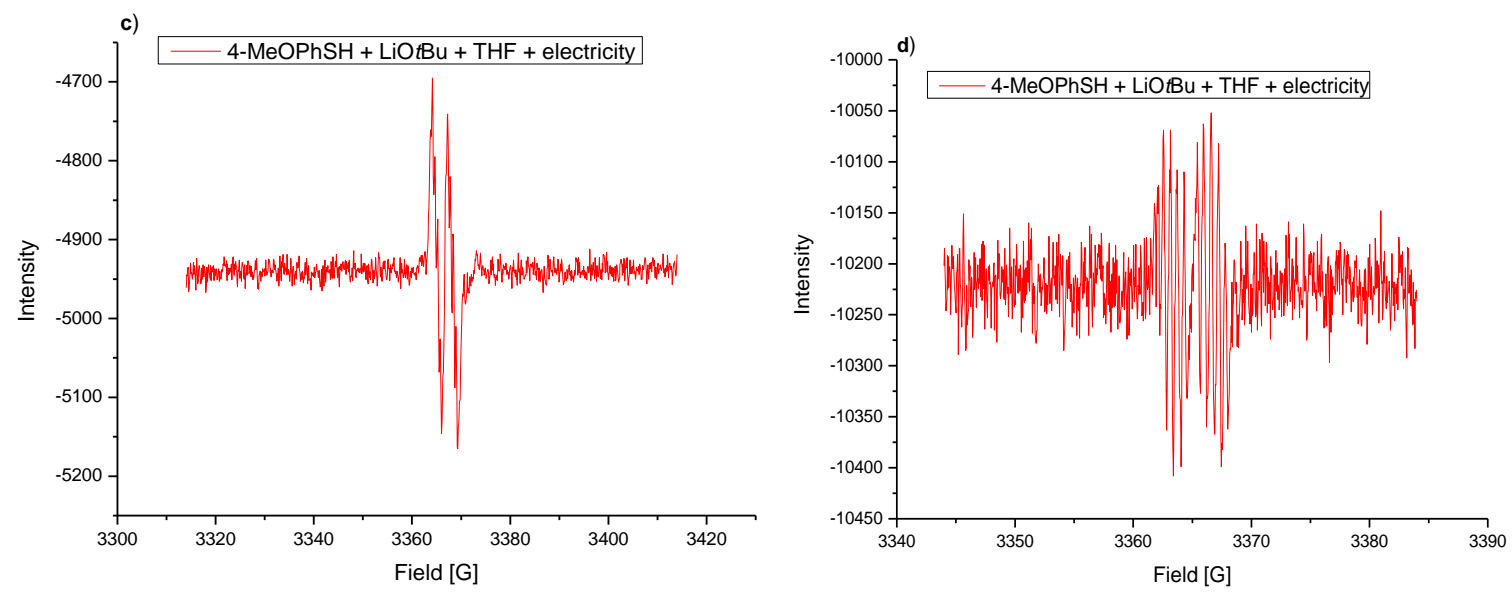

The electrocatalysis was carried out in an undivided cell under air, with a graphite felt (GF) anode $(10 \mathrm{~mm} \times 15 \mathrm{~mm} \times 6 \mathrm{~mm})$ and a platinum cathode $(10 \mathrm{~mm} \times 15 \mathrm{~mm} \times 0.25 \mathrm{~mm}) .0-$ carborane 160a $(0.10 \mathrm{mmol})$ and LiOtBu $(0.2 \mathrm{mmol})$ were dissolved in THF $(3.0 \mathrm{~mL})$. Electrocatalysis was performed at room temperature with a constant current of $2.0 \mathrm{~mA}$ maintained for $2 \mathrm{~h}$. Then PBN ( $N$-tert-butyl-alpha-Phenylnitrone) (5 equiv.) was added into the reaction system. After stirring 2 minutes, the mixture was immediately transferred into the EPR tube for EPR measurement.
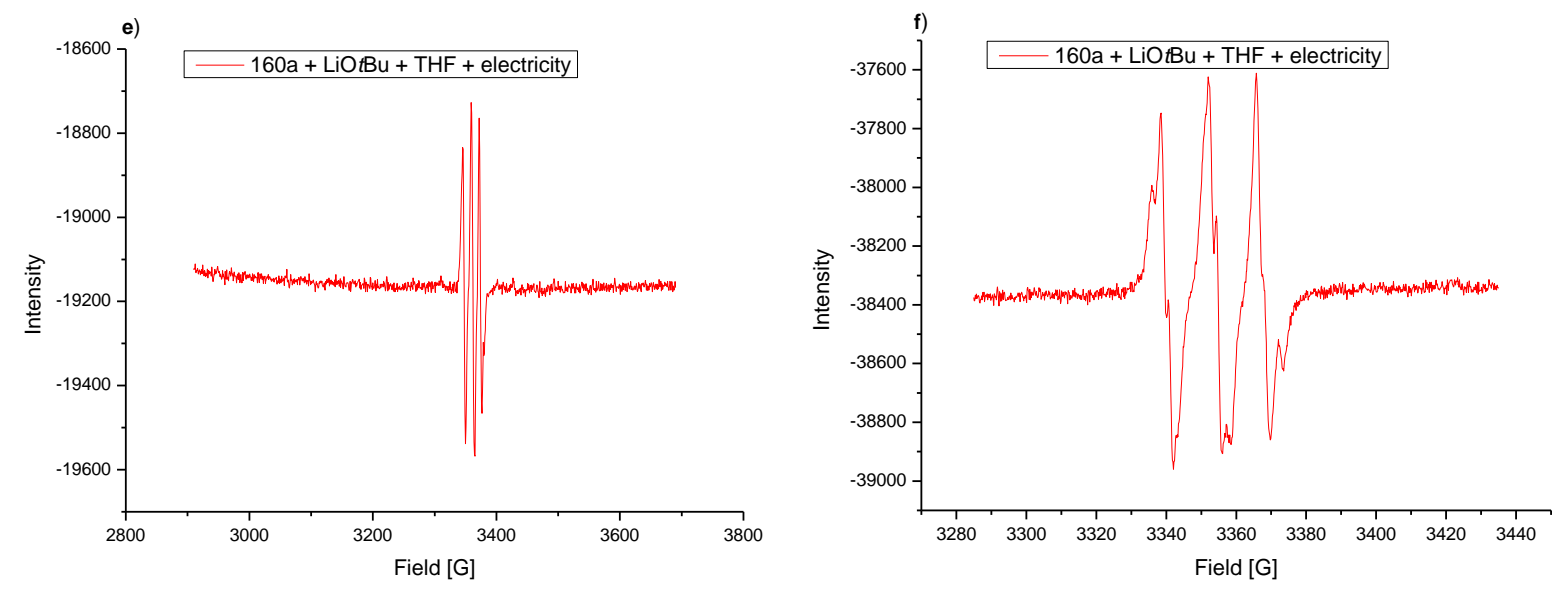


\section{Reference}

[1] a) J. Xie, H. Jin, A. S. K. Hashmi, Chem. Soc. Rev. 2017, 46, 5193-5203; b) C. C. Johansson Seechurn, M. O. Kitching, T. J. Colacot, V. Snieckus, Angew. Chem. Int. Ed. 2012, 51, 5062-5085.

[2] a) Q. Wang, Y. Su, L. Li, H. Huang, Chem. Soc. Rev. 2016, 45, 1257-1272; b) C. Shen, P. Zhang, Q. Sun, S. Bai, T. S. Hor, X. Liu, Chem. Soc. Rev. 2015, 44, 291-314.

[3] a) J. Börgel, T. Ritter, Chem 2020, 6, 1877-1887; b) W. Wang, M. M. Lorion, J. Shah, A. R. Kapdi, L. Ackermann, Angew. Chem. Int. Ed. 2018, 57, 14700-14717; c) D. J. Schipper, K. Fagnou, Chem. Mater. 2011, 23, 1594-1600.

[4] S. A. Matlin, G. Mehta, H. Hopf, A. Krief, Nat. Chem. 2016, 8, 393-398.

[5] a) P. T. Anastas, J. C. Warner, Green Chemistry: Theory and Practice, Oxford Universal Press, Oxford, 1998; b) P. T. Anastas, T. C. Williamson, Green Chemistry: Designing Chemistry for the Environment, ACS Publications, Washington, D.C., 1996.

[6] C. Glaser, Ber. Dtsch. Chem. Ges. 1869, 2, 422-424.

[7] a) P. E. Fanta, Synthesis 1974, 1974, 9-21; b) F. Ullmann, J. Bielecki, Ber. Dtsch. Chem. Ges. 1901, 34, 2174-2185.

[8] a) N. Miyaura, A. Suzuki, Chem. Rev. 1995, 95, 2457-2483; b) N. Miyaura, K. Yamada, A. Suzuki, Tetrahedron Lett. 1979, 20, 3437-3440.

[9] a) J. K. Stille, Angew. Chem. Int. Ed. 1986, 25, 508-524; b) D. Milstein, J. K. Stille, J. Am. Chem. Soc. 1978, 100, 3636-3638; c) M. Kosugi, Y. Shimizu, T. Migita, Chem. Lett. 1977, 6, 1423-1424.

[10] a) T. Hiyama, in Metal-Catalyzed Cross-Coupling Reactions (Eds.: A. de Meijere, F. Diederich), Wiley-VCH, Weinheim, 1998; b) M. Fujita, T. Hiyama, J. Org. Chem. 1988, 53, 5415-5421; c) T. Hiyama, M. Obayashi, I. Mori, H. Nozaki, J. Org. Chem. 1983, 48, 912-914.

[11] K. Tamao, Y. Kiso, K. Sumitani, M. Kumada, J. Am. Chem. Soc. 1972, 94, 9268-9269.

[12] a) E.-I. Negishi, Acc. Chem. Res. 1982, 15, 340-348; b) E.-I. Negishi, A. O. King, N. Okukado, J. Org. Chem. 1977, 42, 1821-1823; c) S. Baba, E.-I. Negishi, J. Am. Chem. Soc. 1976, 98, 6729-6731.

[13] a) J. F. Hartwig, Nature 2008, 455, 314-322; b) A. R. Muci, S. L. Buchwald, Top. Curr. Chem. 2002, 219, 131-209; c) J. F. Hartwig, Angew. Chem. Int. Ed. 1998, 37, 2046-2067.

[14] a) H. Lin, D. Sun, Org. Prep. Proced. Int. 2013, 45, 341-394; b) F. Monnier, M. Taillefer, Angew. Chem. Int. Ed. 2009, 48, 6954-6971.

[15] J. X. Qiao, P. Y. S. Lam, Synthesis 2011, 829-856.

[16] The nobel prize in chemistry 2010 - press release: https://www.nobelprize.org/nobel_prizes/chemistry/laureates/2010/press.html (accessed on 07.02.2021).

[17] L. Ackermann, Modern Arylation Methods, Wiley-VCH: Weinheim, 2009.

[18] a) T. Rogge, N. Kaplaneris, N. Chatani, J. Kim, S. Chang, B. Punji, L. L. Schafer, D. G. Musaev, J. Wencel-Delord, C. A. Roberts, R. Sarpong, Z. E. Wilson, M. A. Brimble, M. J. Johansson, L. Ackermann, Nat. Rev. Methods Primers 2021, 1, 43; b) L. Guillemard, N. Kaplaneris, L. Ackermann, M. J. Johansson, Nat. Rev. Chem. 2021, 5, 522-545; c) S. Rej, Y. Ano, N. Chatani, Chem. Rev. 2020, 120, 1788-1887; d) F. Colobert, J. Wencel-Delord, C-H Activation for Asymmetric Synthesis, Wiley-VCH, Weinheim, 2019; e) L. Ackermann, T. B. Gunnoe, L. G. Habgood, Catalytic Hydroarylation of Carbon-Carbon Multiple Bonds, Wiley-VCH, Weinheim, 2017; f) P. H. Dixneuf, H. Doucet, $\mathrm{C}-\mathrm{H}$ Bond Activation and Catalytic Functionalization II, Springer International Publishing, Switzerland, 2016; g) P. H. Dixneuf, H. Doucet, $\mathrm{C}-\mathrm{H}$ Bond Activation and Catalytic Functionalization I, Springer International Publishing, Switzerland, 2016; h) J. J. Li, C-H Bond Activation in Organic Synthesis, CRC Press, Taylor \& Francis Group, LLC, 2015; i) X. Ribas, C-H and $C-X$ Bond Functionalization: Transition Metal Mediation, Royal Society of Chemistry, Thomas Graham House, Cambridge, 2013; j) J.-Q. Yu, Z. Shi, C-H Activation, Springer-Verlag Berlin, 
Heidelberg, 2010.

[19] a) R. C. Samanta, T. H. Meyer, I. Siewert, L. Ackermann, Chem. Sci. 2020, 11, 8657-8670; b) P. Gandeepan, L. H. Finger, T. H. Meyer, L. Ackermann, Chem. Soc. Rev. 2020, 49, 4254-4272; c) L. Ackermann, S.-L. You, M. Oestreich, S. Meng, D. MacFarlane, Y. Yin, Trends Chem. 2020, 2, 275277; d) T. H. Meyer, L. H. Finger, P. Gandeepan, L. Ackermann, Trends Chem. 2019, 1, 63-76.

[20] a) S. A. Girard, T. Knauber, C.-J. Li, Angew. Chem. Int. Ed. 2014, 53, 74-100; b) C. S. Yeung, V. M. Dong, Chem. Rev. 2011, 111, 1215-1292; c) C. J. Scheuermann, Chem. Asian J. 2010, 5, 436-451; d) C.-J. Li, Z. Li, Pure Appl. Chem. 2006, 78, 935-945.

[21] a) D. L. Davies, S. A. Macgregor, C. L. McMullin, Chem. Rev. 2017, 117, 8649-8709; b) L. Ackermann, Chem. Rev. 2011, 111, 1315-1345; c) D. Balcells, E. Clot, O. Eisenstein, Chem. Rev. 2010, 110, 749-823.

[22] H. Yi, G. Zhang, H. Wang, Z. Huang, J. Wang, A. K. Singh, A. Lei, Chem. Rev. 2017, 117, 9016-9085.

[23] a) J. R. Webb, S. A. Burgess, T. R. Cundari, T. B. Gunnoe, Dalton Trans. 2013, 42, 16646-16665; b) T. G. P. Harper, P. J. Desrosiers, T. C. Flood, Organometallics 1990, 9, 2523-2528.

[24] J. Kua, X. Xu, R. A. Periana, W. A. Goddard, Organometallics 2002, 21, 511-525.

[25] Z. Lin, Coord. Chem. Rev. 2007, 251, 2280-2291.

[26] a) T. R. Cundari, T. R. Klinckman, P. T. Wolczanski, J. Am. Chem. Soc. 2002, 124, 1481-1487; b) J. L. Bennett, P. T. Wolczanski, J. Am. Chem. Soc. 1997, 119, 10696-10719; c) C. C. Cummins, S. M. Baxter, P. T. Wolczanski, J. Am. Chem. Soc. 1988, 110, 8731-8733; d) P. J. Walsh, F. J. Hollander, R. G. Bergman, J. Am. Chem. Soc. 1988, 110, 8729-8731.

[27] J. M. Duff, B. L. Shaw, J. Chem. Soc., Dalton Trans. 1972, 2219-2225.

[28] S. I. Gorelsky, D. Lapointe, K. Fagnou, J. Am. Chem. Soc. 2008, 130, 10848-10849.

[29] a) Y. Boutadla, D. L. Davies, S. A. Macgregor, A. I. Poblador-Bahamonde, Dalton Trans. 2009, 5887-5893; b) D. L. Davies, S. M. A. Donald, S. A. Macgregor, J. Am. Chem. Soc. 2005, 127, 13754-13755.

[30] a) D. Zell, M. Bursch, V. Müller, S. Grimme, L. Ackermann, Angew. Chem. Int. Ed. 2017, 56, 1037810382; b) W. Ma, R. Mei, G. Tenti, L. Ackermann, Chem. Eur. J. 2014, 20, 15248-15251.

[31] T. Rogge, J. C. A. Oliveira, R. Kuniyil, L. Hu, L. Ackermann, ACS Catal. 2020, 10, 10551-10558.

[32] J. M. Brown, S. Murai, H. Alper, A. Furstner, P. Dixneuf, R. Gossage, S. Murai, V. Grushin, L. Hegedus, M. Hidai, Activation of Unreactive Bonds and Organic Synthesis, Springer-Verlag Berlin, Heidelberg, 1999.

[33] a) K. Shen, Y. Fu, J.-N. Li, L. Liu, Q.-X. Guo, Tetrahedron 2007, 63, 1568-1576; b) L. Ackermann, in Directed Metallation (Ed.: N. Chatani), Springer Berlin Heidelberg, Berlin, Heidelberg, 2007, pp. 35-60.

[34] a) G. Cera, L. Ackermann, Top. Curr. Chem. 2016, 374, 191-224; b) L. Ackermann, J. Li, Nat. Chem. 2015, 7, 686-687; c) L. Ackermann, R. Vicente, Top. Curr. Chem. 2010, 292, 211-229; d) L. Ackermann, R. Vicente, A. R. Kapdi, Angew. Chem. Int. Ed. 2009, 48, 9792-9826.

[35] a) L. Ackermann, K. Korvorapun, R. C. Samanta, T. Rogge, Synthesis 2021, 53, 2911-2946; b) P. Gandeepan, L. Ackermann, Chem 2018, 4, 199-222; c) J. Li, S. De Sarkar, L. Ackermann, Top. Organomet. Chem. 2016, 55, 217-257.

[36] J. A. Leitch, C. G. Frost, Chem. Soc. Rev. 2017, 46, 7145-7153.

[37] a) M. Font, J. M. Quibell, G. J. P. Perry, I. Larrosa, Chem. Commun. 2017, 53, 5584-5597; b) N. Y. P. Kumar, A. Bechtoldt, K. Raghuvanshi, L. Ackermann, Angew. Chem. Int. Ed. 2016, 55, 6929-6932.

[38] a) J. Wang, G. Dong, Chem. Rev. 2019, 119, 7478-7528; b) M. Catellani, F. Frignani, A. Rangoni, Angew. Chem. Int. Ed. 1997, 36, 119-122.

[39] J. Chatt, J. M. Davidson, J. Chem. Soc. 1965, 843-855.

[40] L. N. Lewis, J. F. Smith, J. Am. Chem. Soc. 1986, 108, 2728-2735.

[41] S. Murai, F. Kakiuchi, S. Sekine, Y. Tanaka, A. Kamatani, M. Sonoda, N. Chatani, Nature 1993, 366, 529-531. 
[42] H. Weissman, X. Song, D. Milstein, J. Am. Chem. Soc. 2001, 123, 337-338.

[43] a) S. Oi, E. Aizawa, Y. Ogino, Y. Inoue, J. Org. Chem. 2005, 70, 3113-3119; b) S. Oi, S. Fukita, N. Hirata, N. Watanuki, S. Miyano, Y. Inoue, Org. Lett. 2001, 3, 2579-2581.

[44] S. G. Ouellet, A. Roy, C. Molinaro, R. Angelaud, J.-F. Marcoux, P. D. O'Shea, I. W. Davies, J. Org. Chem. 2011, 76, 1436-1439.

[45] L. Ackermann, Org. Lett. 2005, 7, 3123-3125.

[46] a) L. Ackermann, Org. Process Res. Dev. 2015, 19, 260-269; b) L. Ackermann, Acc. Chem. Res. 2014, 47, 281-295.

[47] L. Ackermann, R. Vicente, A. Althammer, Org. Lett. 2008, 10, 2299-2302.

[48] a) M. Schinkel, I. Marek, L. Ackermann, Angew. Chem. Int. Ed. 2013, 52, 3977-3980; b) L. Ackermann, Chem. Commun. 2010, 46, 4866-4877; c) L. Ackermann, P. Novák, R. Vicente, N. Hofmann, Angew. Chem. Int. Ed. 2009, 48, 6045-6048.

[49] a) X. Yang, Y. Sun, Z. Chen, Y. Rao, Adv. Syn. Catal. 2014, 356, 1625-1630; b) F. Yang, K. Rauch, K. Kettelhoit, L. Ackermann, Angew. Chem. Int. Ed. 2014, 53, 11285-11288; c) V. S. Thirunavukkarasu, S. I. Kozhushkov, L. Ackermann, Chem. Commun. 2014, 50, 29-39.

[50] L. Wang, L. Ackermann, Chem. Commun. 2014, 50, 1083-1085.

[51] W. Liu, L. Ackermann, Chem. Commun. 2014, 50, 1878-1881.

[52] a) L. Wang, L. Ackermann, Org. Lett. 2013, 15, 176-179; b) W. Ma, K. Graczyk, L. Ackermann, Org. Lett. 2012, 14, 6318-6321; c) B. Li, H. Feng, N. Wang, J. Ma, H. Song, S. Xu, B. Wang, Chem. Eur. J. 2012, 18, 12873-12879; d) L. Ackermann, L. Wang, A. V. Lygin, Chem. Sci. 2012, 3, 177-180; e) L. Ackermann, A. V. Lygin, Org. Lett. 2012, 14, 764-767; f) L. Ackermann, A. V. Lygin, N. Hofmann, Org. Lett. 2011, 13, 3278-3281; g) L. Ackermann, A. V. Lygin, N. Hofmann, Angew. Chem. Int. Ed. 2011, 50, 6379-6382.

[53] a) M. Deponti, S. I. Kozhushkov, D. S. Yufit, L. Ackermann, Org. Biomol. Chem. 2013, 11, 142-148; b) V. S. Thirunavukkarasu, M. Donati, L. Ackermann, Org. Lett. 2012, 14, 3416-3419; c) R. K. Chinnagolla, M. Jeganmohan, Chem. Commun. 2012, 48, 2030-2032; d) L. Ackermann, J. Pospech, K. Graczyk, K. Rauch, Org. Lett. 2012, 14, 930-933.

[54] L. Ackermann, Acc. Chem. Res. 2014, 47, 281-295.

[55] T. Ueyama, S. Mochida, T. Fukutani, K. Hirano, T. Satoh, M. Miura, Org. Lett. 2011, 13, 706-708.

[56] a) C. Tirler, L. Ackermann, Tetrahedron 2015, 71, 4543-4551; b) B. Li, K. Devaraj, C. Darcel, P. H. Dixneuf, Green Chem. 2012, 14, 2706-2709; c) H. Yuto, U. Takumi, F. Tatsuya, H. Koji, S. Tetsuya, M. Masahiro, Chem. Lett. 2011, 40, 1165-1166; d) P. B. Arockiam, C. Fischmeister, C. Bruneau, P. H. Dixneuf, Green Chem. 2011, 13, 3075-3078.

[57] a) K. Padala, M. Jeganmohan, Org. Lett. 2012, 14, 1134-1137; b) K. Padala, M. Jeganmohan, Org. Lett. 2011, 13, 6144-6147.

[58] a) K. Padala, S. Pimparkar, P. Madasamy, M. Jeganmohan, Chem. Commun. 2012, 48, 7140-7142; b) K. Graczyk, W. Ma, L. Ackermann, Org. Lett. 2012, 14, 4110-4113.

[59] a) M. C. Reddy, M. Jeganmohan, Eur. J. Org. Chem. 2013, 1150-1157; b) J. Li, C. Kornhaaß, L. Ackermann, Chem. Commun. 2012, 48, 11343-11345.

[60] W. Ma, L. Ackermann, Chem. Eur. J. 2013, 19, 13925-13928.

[61] a) L.-Q. Zhang, S. Yang, X. Huang, J. You, F. Song, Chem. Commun. 2013, 49, 8830-8832; b) B. Li, J. Ma, W. Xie, H. Song, S. Xu, B. Wang, J. Org. Chem. 2013, 78, 9345-9353.

[62] a) J. Zhang, T.-P. Loh, Chem. Commun. 2012, 48, 11232-11234; b) Y. Hashimoto, T. Ortloff, K. Hirano, T. Satoh, C. Bolm, M. Miura, Chem. Lett. 2012, 41, 151-153; c) L. Ackermann, L. Wang, R. Wolfram, A. V. Lygin, Org. Lett. 2012, 14, 728-731.

[63] a) F. Yang, L. Ackermann, J. Org. Chem. 2014, 79, 12070-12082; b) C. Kornhaaß, J. Li, L. Ackermann, J. Org. Chem. 2012, 77, 9190-9198; c) R. K. Chinnagolla, S. Pimparkar, M. Jeganmohan, Org. Lett. 2012, 14, 3032-3035; d) B. Li, H. Feng, S. Xu, B. Wang, Chem. Eur. J. 2011, 17, 12573-12577; e) L. Ackermann, S. Fenner, Org. Lett. 2011, 13, 6548-6551. 
[64] B. Li, J. Ma, N. Wang, H. Feng, S. Xu, B. Wang, Org. Lett. 2012, 14, 736-739.

[65] Z. Zhou, G. Liu, Y. Shen, X. Lu, Org. Chem. Front. 2014, 1, 1161-1165.

[66] J. Li, S. De Sarkar, L. Ackermann, Top. Organomet. Chem. 2016, 55, 217-257.

[67] G. R. Clark, C. E. L. Headford, W. R. Roper, L. J. Wright, V. P. D. Yap, Inorg. Chim. Acta 1994, 220, 261-272.

[68] J.-P. Sutter, D. M. Grove, M. Beley, J.-P. Collin, N. Veldman, A. L. Spek, J.-P. Sauvage, G. van Koten, Angew. Chem. Int. Ed. 1994, 33, 1282-1285.

[69] C. Coudret, S. Fraysse, Chem. Commun. 1998, 663-664.

[70] A. M. Clark, C. E. F. Rickard, W. R. Roper, L. J. Wright, Organometallics 1999, 18, 2813-2820.

[71] L. Ackermann, N. Hofmann, R. Vicente, Org. Lett. 2011, 13, 1875-1877.

[72] a) K. Korvorapun, N. Kaplaneris, T. Rogge, S. Warratz, A. C. Stückl, L. Ackermann, ACS Catal. 2018, 8, 886-892; b) Z. Ruan, S. K. Zhang, C. Zhu, P. N. Ruth, D. Stalke, L. Ackermann, Angew. Chem. Int. Ed. 2017, 56, 2045-2049; c) J. Li, K. Korvorapun, S. De Sarkar, T. Rogge, D. J. Burns, S. Warratz, L. Ackermann, Nat. Commun. 2017, 8, 1-8; d) J. Li, S. Warratz, D. Zell, S. De Sarkar, E. E. Ishikawa, L. Ackermann, J. Am. Chem. Soc. 2015, 137, 13894-13901; e) N. Hofmann, L. Ackermann, J. Am. Chem. Soc. 2013, 135, 5877-5884.

[73] a) X.-G. Wang, Y. Li, H.-C. Liu, B.-S. Zhang, X.-Y. Gou, Q. Wang, J.-W. Ma, Y.-M. Liang, J. Am. Chem. Soc. 2019, 141, 13914-13922; b) A. J. Paterson, C. J. Heron, C. L. McMullin, M. F. Mahon, N. J. Press, C. G. Frost, Org. Biomol. Chem. 2017, 15, 5993-6000; c) G. Li, P. Gao, X. Lv, C. Qu, Q. Yan, Y. Wang, S. Yang, J. Wang, Org. Lett. 2017, 19, 2682-2685; d) Z. Y. Li, L. Li, Q. L. Li, K. Jing, H. Xu, G. W. Wang, Chem. Eur. J. 2017, 23, 3285-3290; e) A. J. Paterson, S. St John-Campbell, M. F. Mahon, N. J. Press, C. G. Frost, Chem. Commun. 2015, 51, 12807-12810.

[74] a) I. Choi, V. Müller, Y. Wang, K. Xue, R. Kuniyil, L. B. Andreas, V. Karius, J. G. Alauzun, L. Ackermann, Chem. Eur. J. 2020, 26, 15290-15297; b) K. Korvorapun, M. Moselage, J. Struwe, T. Rogge, A. M. Messinis, L. Ackermann, Angew. Chem. Int. Ed. 2020, 59, 18795-18803; c) P. Gandeepan, J. Koeller, K. Korvorapun, J. Mohr, L. Ackermann, Angew. Chem. Int. Ed. 2019, 58, 9820-9825; d) M. Moselage, J. Li, F. Kramm, L. Ackermann, Angew. Chem. Int. Ed. 2017, 56, 5341-5344.

[75] O. Saidi, J. Marafie, A. E. W. Ledger, P. M. Liu, M. F. Mahon, G. Kociok-Köhn, M. K. Whittlesey, C. G. Frost, J. Am. Chem. Soc. 2011, 133, 19298-19301.

[76] K. Korvorapun, R. Kuniyil, L. Ackermann, ACS Catal. 2019, 10, 435-440.

[77] H. L. Barlow, C. J. Teskey, M. F. Greaney, Org. Lett. 2017, 19, 6662-6665.

[78] C. Jia, N. Wu, X. Cai, G. Li, L. Zhong, L. Zou, X. Cui, J. Org. Chem. 2020, 85, 4536-4542.

[79] K. Jing, Z.-Y. Li, G.-W. Wang, ACS Catal. 2018, 8, 11875-11881.

[80] a) G. M. Reddy, N. S. Rao, H. Maheswaran, Org. Chem. Front. 2018, 5, 1118-1123; b) S. Warratz, D. J. Burns, C. Zhu, K. Korvorapun, T. Rogge, J. Scholz, C. Jooss, D. Gelman, L. Ackermann, Angew. Chem. Int. Ed. 2017, 56, 1557-1560; c) C. J. Teskey, A. Y. W. Lui, M. F. Greaney, Angew. Chem. Int. Ed. 2015, 54, 11677-11680; d) Q. Yu, L. a. Hu, Y. Wang, S. Zheng, J. Huang, Angew. Chem. Int. Ed. 2015, 54, 15284-15288.

[81] Z. Fan, J. Ni, A. Zhang, J. Am. Chem. Soc. 2016, 138, 8470-8475.

[82] W. Liu, L. Ackermann, Org. Lett. 2013, 15, 3484-3486.

[83] J. A. Leitch, C. L. McMullin, A. J. Paterson, M. F. Mahon, Y. Bhonoah, C. G. Frost, Angew. Chem. Int. Ed. 2017, 56, 15131-15135.

[84] a) C. Yuan, L. Zhu, C. Chen, X. Chen, Y. Yang, Y. Lan, Y. Zhao, Nat. Commun. 2018, 9, 1189; b) C. Yuan, L. Zhu, R. Zeng, Y. Lan, Y. Zhao, Angew. Chem. Int. Ed. 2018, 57, 1277-1281.

[85] A. Volta, Philos. Trans. R. Soc. London 1800, 90, 403-431.

[86] a) H. Kolbe, Liebigs Ann. Chem. 1849, 69, 257-294; b) H. Kolbe, Liebigs Ann. Chem. 1848, 64, 339-341.

[87] M. Faraday, Philos. Trans. R. Soc. London 1825, 440-466. 
[88] a) L. Zeng, H. Li, J. Hu, D. Zhang, J. Hu, P. Peng, S. Wang, R. Shi, J. Peng, C.-W. Pao, J.-L. Chen, J.-F. Lee, H. Zhang, Y.-H. Chen, A. Lei, Nat. Catal. 2020, 3, 438-445; b) J. C. Siu, N. Fu, S. Lin, Acc. Chem. Res. 2020, 53, 547-560; c) P. Xiong, H.-C. Xu, Acc. Chem. Res. 2019, 52, 3339-3350; d) A. Wiebe, T. Gieshoff, S. Möhle, E. Rodrigo, M. Zirbes, S. R. Waldvogel, Angew. Chem. Int. Ed. 2018, 57, 55945619; e) Y. Jiang, K. Xu, C. Zeng, Chem. Rev. 2018, 118, 4485-4540; f) M. Yan, Y. Kawamata, P. S. Baran, Chem. Rev. 2017, 117, 13230-13319; g) R. Feng, J. A. Smith, K. D. Moeller, Acc. Chem. Res. 2017, 50, 2346-2352; h) E. J. Horn, B. R. Rosen, P. S. Baran, ACS Cent. Sci. 2016, 2, 302-308; i) R. Francke, R. D. Little, Chem. Soc. Rev. 2014, 43, 2492-2521; j) J.-i. Yoshida, K. Kataoka, R. Horcajada, A. Nagaki, Chem. Rev. 2008, 108, 2265-2299; k) A. Jutand, Chem. Rev. 2008, 108, 2300-2347; I) E. Duñach, D. Franco, S. Olivero, Eur. J. Org. Chem. 2003, 1605-1622.

[89] T. H. Meyer, L. H. Finger, P. Gandeepan, L. Ackermann, Trends Chem. 2019, 1, 63-76.

[90] a) L. Ackermann, Acc. Chem. Res. 2020, 53, 84-104; b) Y. Qiu, J. Struwe, L. Ackermann, Synlett 2019, 30, 1164-1173; c) Q.-L. Yang, P. Fang, T.-S. Mei, Chin. J. Chem. 2018, 36, 338-352; d) S. Tang, Y. Liu, A. Lei, Chem 2018, 4, 27-45; e) C. Ma, P. Fang, T.-S. Mei, ACS Catal. 2018, 8, 7179-7189; f) N. Sauermann, T. H. Meyer, Y. Qiu, L. Ackermann, ACS Catal. 2018, 8, 7086-7103; g) N. Sauermann, T. H. Meyer, L. Ackermann, Chem. Eur. J. 2018, 24, 16209-16217.

[91] C. Amatore, C. Cammoun, A. Jutand, Adv. Synth. Catal. 2007, 349, 292-296.

[92] a) Y. Fujiwara, I. Moritani, S. Danno, R. Asano, S. Teranishi, J. Am. Chem. Soc. 1969, 91, 7166-7169; b) Y. Fujiwara, I. Moritani, M. Matsuda, S. Teranishi, Tetrahedron Lett. 1968, 9, 633-636; c) I. Moritanl, Y. Fujiwara, Tetrahedron Lett. 1967, 8, 1119-1122.

[93] a) H. Aiso, T. Kochi, H. Mutsutani, T. Tanabe, S. Nishiyama, F. Kakiuchi, J. Org. Chem. 2012, 77, 7718-7724; b) F. Kakiuchi, T. Kochi, H. Mutsutani, N. Kobayashi, S. Urano, M. Sato, S. Nishiyama, T. Tanabe, J. Am. Chem. Soc. 2009, 131, 11310-11311.

[94] M. Konishi, K. Tsuchida, K. Sano, T. Kochi, F. Kakiuchi, J. Org. Chem. 2017, 82, 8716-8724.

[95] F. Saito, H. Aiso, T. Kochi, F. Kakiuchi, Organometallics 2014, 33, 6704-6707.

[96] K.-J. Jiao, Y.-K. Xing, Q.-L. Yang, H. Qiu, T.-S. Mei, Acc. Chem. Res. 2020, 53, 300-310.

[97] Q.-L. Yang, Y.-Q. Li, C. Ma, P. Fang, X.-J. Zhang, T.-S. Mei, J. Am. Chem. Soc. 2017, 139, 3293-3298.

[98] C. Ma, C.-Q. Zhao, Y.-Q. Li, L.-P. Zhang, X.-T. Xu, K. Zhang, T.-S. Mei, Chem. Commun. 2017, 53, 12189-12192.

[99] Y.-Q. Li, Q.-L. Yang, P. Fang, T.-S. Mei, D. Zhang, Org. Lett. 2017, 19, 2905-2908.

[100] a) X.-Y. W. Q.-L. Yang, X.-J. Weng, X. Yang, X.-T. Xu, X., P. F. Tong, X.-Y. Wu, T.-S. Mei, Acta Chim. Sinica 2019, 77, 866-873; b) Q.-L. Yang, X.-Y. Wang, T.-L. Wang, X. Yang, D. Liu, X. Tong, X.-Y. Wu, T.S. Mei, Org. Lett. 2019, 21, 2645-2649.

[101] Q.-L. Yang, C.-Z. Li, L.-W. Zhang, Y.-Y. Li, X. Tong, X.-Y. Wu, T.-S. Mei, Organometallics 2019, 38, 1208-1212.

[102] A. Shrestha, M. Lee, A. L. Dunn, M. S. Sanford, Org. Lett. 2018, 20, 204-207.

[103] T. V. Grayaznova, Y. B. Dudkina, D. R. Islamov, O. N. Kataeva, O. G. Sinyashin, D. A. Vicic, Y. H. Budnikova, J. Organomet. Chem. 2015, 785, 68-71.

[104] Z. Duan, L. Zhang, W. Zhang, L. Lu, L. Zeng, R. Shi, A. Lei, ACS Catal. 2020, 10, 3828-3831.

[105] U. Dhawa, C. Tian, T. Wdowik, J. C. A. Oliveira, J. Hao, L. Ackermann, Angew. Chem. Int. Ed. 2020, 59, 13451-13457.

[106] Y. Qiu, W.-J. Kong, J. Struwe, N. Sauermann, T. Rogge, A. Scheremetjew, L. Ackermann, Angew. Chem. Int. Ed. 2018, 57, 5828-5832.

[107] Y. Zhang, J. Struwe, L. Ackermann, Angew. Chem. Int. Ed. 2020, 59, 15076-15080.

[108] Y. Qiu, A. Scheremetjew, L. Ackermann, J. Am. Chem. Soc. 2019, 141, 2731-2738.

[109] W.-J. Kong, L. H. Finger, J. C. A. Oliveira, L. Ackermann, Angew. Chem. Int. Ed. 2019, 58, 63426346.

[110] W.-J. Kong, Z. Shen, L. H. Finger, L. Ackermann, Angew. Chem. Int. Ed. 2020, 59, 5551-5556.

[111] W.-J. Kong, L. H. Finger, A. M. Messinis, R. Kuniyil, J. C. A. Oliveira, L. Ackermann, J. Am. Chem. Soc. 
2019, 141, 17198-17206.

[112] a) Y. Wang, J. C. A. Oliveira, Z. Lin, L. Ackermann, Angew. Chem. Int. Ed. 2021, 60, 6419-6424; b) Y.-K. Xing, X.-R. Chen, Q.-L. Yang, S.-Q. Zhang, H.-M. Guo, X. Hong, T.-S. Mei, Nat. Commun. 2021, $12,930$.

[113] Z. Shen, I. Maksso, R. Kuniyil, T. Rogge, L. Ackermann, Chem. Commun. 2021, 57, 3668-3671.

[114] X. Tan, L. Massignan, X. Hou, J. Frey, J. C. A. Oliveira, M. N. Hussain, L. Ackermann, Angew. Chem. Int. Ed. 2021, 60, 13264-13270.

[115] Z.-J. Wu, F. Su, W. Lin, J. Song, T.-B. Wen, H.-J. Zhang, H.-C. Xu, Angew. Chem. Int. Ed. 2019, 58, 16770-16774.

[116] a) F. Xu, Y.-J. Li, C. Huang, H.-C. Xu, ACS Catal. 2018, 8, 3820-3824; b) Y. Qiu, C. Tian, L. Massignan, T. Rogge, L. Ackermann, Angew. Chem. Int. Ed. 2018, 57, 5818-5822.

[117] a) X. Tan, X. Hou, T. Rogge, L. Ackermann, Angew. Chem. Int. Ed. 2021, 60, 4619-4624; b) L. Yang, R. Steinbock, A. Scheremetjew, R. Kuniyil, L. H. Finger, A. M. Messinis, L. Ackermann, Angew. Chem. Int. Ed. 2020, 59, 11130-11135; c) M.-J. Luo, M. Hu, R.-J. Song, D.-L. He, J.-H. Li, Chem. Commun. 2019, 55, 1124-1127; d) M.-J. Luo, T.-T. Zhang, F.-J. Cai, J.-H. Li, D.-L. He, Chem. Commun. 2019, 55, 7251-7254; e) Z.-Q. Wang, C. Hou, Y.-F. Zhong, Y.-X. Lu, Z.-Y. Mo, Y.-M. Pan, H.-T. Tang, Org. Lett. 2019, 21, 9841-9845; f) R. Mei, J. Koeller, L. Ackermann, Chem. Commun. 2018, 54, 12879-12882.

[118] L. Massignan, X. Tan, T. H. Meyer, R. Kuniyil, A. M. Messinis, L. Ackermann, Angew. Chem. Int. Ed. 2020, 59, 3184-3189.

[119] a) K. Shin, Y. Park, M.-H. Baik, S. Chang, Nat. Chem. 2018, 10, 218-224; b) G. Tan, Q. You, J. Lan, J. You, Angew. Chem. Int. Ed. 2018, 57, 6309-6313; c) S. Y. Hong, Y. Park, Y. Hwang, Y. B. Kim, M.-H. Baik, S. Chang, Science 2018, 359, 1016-1021; d) B. A. Arndtsen, R. G. Bergman, Science 1995, 270, 1970.

[120] Y. Qiu, M. Stangier, T. H. Meyer, J. C. A. Oliveira, L. Ackermann, Angew. Chem. Int. Ed. 2018, 57, 14179-14183.

[121] Q.-L. Yang, H.-W. Jia, Y. Liu, Y.-K. Xing, R.-C. Ma, M.-M. Wang, G.-R. Qu, T.-S. Mei, H.-M. Guo, Org. Lett. 2021, 23, 1209-1215.

[122] Q.-L. Yang, Y.-K. Xing, X.-Y. Wang, H.-X. Ma, X.-J. Weng, X. Yang, H.-M. Guo, T.-S. Mei, J. Am. Chem. Soc. 2019, 141, 18970-18976.

[123] X. Ye, C. Wang, S. Zhang, J. Wei, C. Shan, L. Wojtas, Y. Xie, X. Shi, ACS Catal. 2020, 10, 1169311699.

[124] N. Sauermann, T. H. Meyer, C. Tian, L. Ackermann, J. Am. Chem. Soc. 2017, 139, 18452-18455.

[125] T. H. Meyer, J. C. A. Oliveira, D. Ghorai, L. Ackermann, Angew. Chem. Int. Ed. 2020, 59, 1095510960.

[126] a) N. Sauermann, R. Mei, L. Ackermann, Angew. Chem. Int. Ed. 2018, 57, 5090-5094; b) X. Gao, P. Wang, L. Zeng, S. Tang, A. Lei, J. Am. Chem. Soc. 2018, 140, 4195-4199.

[127] C. Tian, U. Dhawa, J. Struwe, L. Ackermann, Chin. J. Chem. 2019, 37, 552-556.

[128] a) R. Mei, W. Ma, Y. Zhang, X. Guo, L. Ackermann, Org. Lett. 2019, 21, 6534-6538; b) C. Tian, L. Massignan, T. H. Meyer, L. Ackermann, Angew. Chem. Int. Ed. 2018, 57, 2383-2387; c) R. Mei, N. Sauermann, J. C. A. Oliveira, L. Ackermann, J. Am. Chem. Soc. 2018, 140, 7913-7921.

[129] S. Tang, D. Wang, Y. Liu, L. Zeng, A. Lei, Nat. Commun. 2018, 9, 798.

[130] a) R. Mei, X. Fang, L. He, J. Sun, L. Zou, W. Ma, L. Ackermann, Chem. Commun. 2020, 56, 13931396; b) T. H. Meyer, J. C. A. Oliveira, S. C. Sau, N. W. J. Ang, L. Ackermann, ACS Catal. 2018, 8, 9140-9147.

[131] a) S. C. Sau, R. Mei, J. Struwe, L. Ackermann, ChemSusChem 2019, 12, 3023-3027; b) L. Zeng, H. Li, S. Tang, X. Gao, Y. Deng, G. Zhang, C.-W. Pao, J.-L. Chen, J.-F. Lee, A. Lei, ACS Catal. 2018, 8, 54485453.

[132] U. Dhawa, C. Tian, W. Li, L. Ackermann, ACS Catal. 2020, 10, 6457-6462. 
[133] P. Gandeepan, T. Müller, D. Zell, G. Cera, S. Warratz, L. Ackermann, Chem. Rev. 2019, 119, 21922452.

[134] S.-K. Zhang, R. C. Samanta, N. Sauermann, L. Ackermann, Chem. Eur. J. 2018, 24, 19166-19170.

[135] S.-K. Zhang, J. Struwe, L. Hu, L. Ackermann, Angew. Chem. Int. Ed. 2020, 59, 3178-3183.

[136] S.-K. Zhang, A. Del Vecchio, R. Kuniyil, A. M. Messinis, Z. Lin, L. Ackermann, Chem 2021, 7, 13791392.

[137] a) A. E. Wendlandt, A. M. Suess, S. S. Stahl, Angew. Chem. Int. Ed. 2011, 50, 11062-11087; b) O. Daugulis, H.-Q. Do, D. Shabashov, Acc. Chem. Res. 2009, 42, 1074-1086; c) L. Ackermann, H. K. Potukuchi, D. Landsberg, R. Vicente, Org. Lett. 2008, 10, 3081-3084.

[138] Q.-L. Yang, X.-Y. Wang, J.-Y. Lu, L.-P. Zhang, P. Fang, T.-S. Mei, J. Am. Chem. Soc. 2018, 140, 1148711494.

[139] S. Kathiravan, S. Suriyanarayanan, I. A. Nicholls, Org. Lett. 2019, 21, 1968-1972.

[140] C. Tian, U. Dhawa, A. Scheremetjew, L. Ackermann, ACS Catal. 2019, 9, 7690-7696.

[141] a) R. Shang, L. Ilies, E. Nakamura, Chem. Rev. 2017, 117, 9086-9139; b) G. Cera, L. Ackermann, Top. Curr. Chem. 2016, 374, 191-224.

[142] C. Zhu, M. Stangier, J. C. A. Oliveira, L. Massignan, L. Ackermann, Chem. Eur. J. 2019, 25, 1638216389.

[143] T. E. Boddie, S. H. Carpenter, T. M. Baker, J. C. DeMuth, G. Cera, W. W. Brennessel, L. Ackermann, M. L. Neidig, J. Am. Chem. Soc. 2019, 141, 12338-12345.

[144] a) R. N. Grimes, Dalton Trans. 2015, 44, 5939-5956; b) C. Douvris, J. Michl, Chem. Rev. 2013, 113, PR179-PR233.

[145] a) T. Heying, J. Ager Jr, S. Clark, D. Mangold, H. Goldstein, M. Hillman, R. Polak, J. Szymanski, Inorg. Chem. 1963, 2, 1089-1092; b) M. M. Fein, J. Bobinski, N. Mayes, N. Schwartz, M. S. Cohen, Inorg. Chem. 1963, 2, 1111-1115.

[146] a) J. Poater, M. Solà, C. Viñas, F. Teixidor, Chem. Eur. J. 2016, 7437-7443; b) J. Poater, M. Solà, C. Viñas, F. Teixidor, Angew. Chem. Int. Ed. 2014, 53, 12191-12195.

[147] a) A. Saha, E. Oleshkevich, C. Vinas, F. Teixidor, Adv. Mater. 2017, 29, 1704238; b) E. A. Qian, A. I. Wixtrom, J. C. Axtell, A. Saebi, D. Jung, P. Rehak, Y. Han, E. H. Moully, D. Mosallaei, S. Chow, M. S. Messina, J. Y. Wang, A. T. Royappa, A. L. Rheingold, H. D. Maynard, P. Kral, A. M. Spokoyny, Nat. Chem. 2017, 9, 333-340; c) C. J. Villagómez, T. Sasaki, J. M. Tour, L. Grill, J. Am. Chem. Soc. 2010, 132, 16848-16854; d) M. Koshino, T. Tanaka, N. Solin, K. Suenaga, H. Isobe, E. Nakamura, Science 2007, 316, 853-853.

[148] a) F. Issa, M. Kassiou, L. M. Rendina, Chem. Rev. 2011, 111, 5701-5722; b) M. Scholz, E. HeyHawkins, Chem. Rev. 2011, 111, 7035-7062.

[149] a) X. Zhang, H. Yan, Coord. Chem. Rev. 2019, 378, 466-482; b) W.-B. Yu, P.-F. Cui, W.-X. Gao, G.-X. Jin, Coord. Chem. Rev. 2017, 350, 300-319; c) Z.-J. Yao, G.-X. Jin, Coord. Chem. Rev. 2013, 257, 2522-2535.

[150] a) V. Bregadze, Z. Xie, Eur. J. Inorg. Chem. 2017, 2017, 4344; b) R. N. Grimes, Carboranes, Academic Press, 2016; c) Z. Xie, G.-X. Jin, Dalton Trans. 2014, 43, 4924-4924.

[151] a) Y. K. Au, Z. Xie, Bull. Chem. Soc. Jpn. 2021, 94, 879-899; b) Y. Quan, Z. Xie, Chem. Soc. Rev. 2019, 48, 3660-3673.

[152] F. Teixidor, G. Barberà, A. Vaca, R. Kivekäs, R. Sillanpää, J. Oliva, C. Viñas, J. Am. Chem. Soc. 2005, 127, 10158-10159.

[153] Y. Quan, Z. Qiu, Z. Xie, Chem. Eur. J. 2018, 24, 2795-2805.

[154] E. L. Hoel, M. Talebinasab-Savari, M. Hawthorne, J. Am. Chem. Soc. 1977, 99, 4356-4367.

[155] M. G. Mirabelli, L. G. Sneddon, J. Am. Chem. Soc. 1988, 110, 449-453.

[156] R. Cheng, Z. Qiu, Z. Xie, Nat. Commun. 2017, 8, 14827.

[157] C. X. Li, H. Y. Zhang, T. Y. Wong, H. J. Cao, H. Yan, C. S. Lu, Org. Lett. 2017, 19, 5178-5181.

[158] C.-X. Cui, J. Zhang, Z. Qiu, Z. Xie, Dalton Trans. 2020, 49, 1380-1383. 
[159] T.-T. Xu, K. Cao, C.-Y. Zhang, J. Wu, L.-F. Ding, J. Yang, Org. Lett. 2019, 21, 9276-9279.

[160] Z. Y. Zhang, X. Zhang, J. Yuan, C. D. Yue, S. Meng, J. Chen, G. A. Yu, C. M. Che, Chem. Eur. J. 2020, 26, 5037-5050.

[161] R. Cheng, Z. Qiu, Z. Xie, Chem. Eur. J. 2020, 26, 7212-7218.

[162] R. Cheng, Z. Qiu, Z. Xie, Chin. J. Chem. 2020, 38, 1575-1578.

[163] Y. Quan, Z. Xie, J. Am. Chem. Soc. 2014, 136, 15513-15516.

[164] H. Lyu, Y. Quan, Z. Xie, Angew. Chem. Int. Ed. 2015, 54, 10623-10626.

[165] C. Zhang, Q. Wang, S. Tian, J. Zhang, J. Li, L. Zhou, J. Lu, Org. Bio. Chem. 2020, 18, 4723-4727.

[166] Y. K. Au, Y. Quan, Z. Xie, Chem. Asian J. 2020, 15, 2170-2173.

[167] Y. Chen, Y. K. Au, Y. Quan, Z. Xie, Sci. China Chem. 2018, 62, 74-79.

[168] Y. Quan, Z. Xie, Angew. Chem. Int. Ed. 2016, 55, 1295-1298.

[169] a) X. Zhang, H. Yan, Chem. Sci. 2018, 9, 3964-3969; b) X. Zhang, H. Zheng, J. Li, F. Xu, J. Zhao, H. Yan, J. Am. Chem. Soc. 2017, 139, 14511-14517.

[170] T. T. Xu, K. Cao, C. Y. Zhang, J. Wu, L. Jiang, J. Yang, Chem. Commun. 2018, 54, 13603-13606.

[171] R. Cheng, B. Li, J. Wu, J. Zhang, Z. Qiu, W. Tang, S.-L. You, Y. Tang, Z. Xie, J. Am. Chem. Soc. 2018, 140, 4508-4511.

[172] Y. Quan, H. Lyu, Z. Xie, Chem. Commun. 2017, 53, 4818-4821.

[173] Y. Chen, Y. Quan, Z. Xie, Chem. Commun. 2020, 56, 7001-7004.

[174] Y. Quan, C. Tang, Z. Xie, Chem. Sci. 2016, 7, 5838-5845.

[175] Q. Wang, S. Tian, C. Zhang, J. Li, Z. Wang, Y. Du, L. Zhou, J. Lu, Org. Lett. 2019, 21, 8018-8021.

[176] K. Cao, C.-Y. Zhang, T.-T. Xu, J. Wu, L.-F. Ding, L. Jiang, J. Yang, J. Organomet. Chem. 2019, 902, 120956.

[177] H. Lyu, Y. Quan, Z. Xie, Angew. Chem. Int. Ed. 2016, 55, 11840-11844.

[178] H. Lyu, Y. Quan, Z. Xie, J. Am. Chem. Soc. 2016, 138, 12727-12730.

[179] a) Y. Baek, S. Kim, J.-Y. Son, K. Lee, D. Kim, P. H. Lee, ACS Catal. 2019, 10418-10425; b) H. Li, F. Bai, H. Yan, C. Lu, V. I. Bregadze, Eur. J. Org. Chem. 2017, 2017, 1343-1352.

[180] H. Lyu, Y. Quan, Z. Xie, Chem. Eur. J. 2017, 23, 14866-14871.

[181] a) J. Wu, K. Cao, C. Y. Zhang, T. T. Xu, X. Y. Wen, B. Li, J. Yang, Inorg. Chem. 2020, 59, 17340-17346; b) J. Wu, K. Cao, C.-Y. Zhang, T.-T. Xu, L.-F. Ding, B. Li, J. Yang, Org. Lett. 2019, 21, 5986-5989.

[182] Y. Chen, Y. Quan, Z. Xie, Chem. Commun. 2020, 56, 12997-13000.

[183] H. Lyu, Y. Quan, Z. Xie, Chem. Sci. 2018, 9, 6390-6394.

[184] a) Y. K. Au, H. Lyu, Y. Quan, Z. Xie, Chin. J. Chem. 2020, 38, 383-388; b) Y. K. Au, H. Lyu, Y. Quan, Z. Xie, J. Am. Chem. Soc. 2019, 141, 12855-12862.

[185] Y. Baek, K. Cheong, G. H. Ko, G. U. Han, S. H. Han, D. Kim, K. Lee, P. H. Lee, J. Am. Chem. Soc. 2020, 142, 9890-9895.

[186] Z. Qiu, Y. Quan, Z. Xie, J. Am. Chem. Soc. 2013, 135, 12192-12195.

[187] a) T.-T. Xu, K. Cao, J. Wu, C.-Y. Zhang, J. Yang, Inorg. Chem. 2018, 57, 2925-2932; b) K. Cao, T.-T. Xu, J. Wu, L. Jiang, J. Yang, Chem. Commun. 2016, 52, 11446-11449.

[188] T. T. Xu, C. Y. Zhang, K. Cao, J. Wu, L. Jiang, J. Li, B. Li, J. Yang, ChemistrySelect 2017, 2, 3396-3399.

[189] J. Wu, K. Cao, T.-T. Xu, X.-J. Zhang, L. Jiang, J. Yang, Y. Huang, RSC Adv. 2015, 5, 91683-91685.

[190] K. Cao, Y. Huang, J. Yang, J. Wu, Chem. Commun. 2015, 51, 7257-7260.

[191] H. Lyu, J. Zhang, J. Yang, Y. Quan, Z. Xie, J. Am. Chem. Soc. 2019, 141, 4219-4224.

[192] P. Gandeepan, L. H. Finger, T. H. Meyer, L. Ackermann, Chem. Soc. Rev. 2020, 49, 4254-4272.

[193] a) D. A. Rudakov, V. I. Potkin, I. V. Lantsova, Russ. J. Electrochem. 2009, 45, 813-817; b) D. Rudakov, V. Shirokii, V. Potkin, N. Maier, V. Bragin, P. Petrovskii, I. Sivaev, V. Bregadze, A. Kisin, Russ. Chem. Bull. 2005, 54, 1599-1602.

[194] Y. K. Au, H. Lyu, Y. Quan, Z. Xie, J. Am. Chem. Soc. 2020, 142, 6940-6945.

[195] a) B. M. Trost, Angew. Chem. Int. Ed. 1995, 34, 259-281; b) B. Trost, Science 1991, 254, 14711477. 
[196] a) P. A. Wender, B. L. Miller, Nature 2009, 460, 197-201; b) P. A. Wender, M. P. Croatt, B. Witulski, Tetrahedron 2006, 62, 7505-7511.

[197] a) S. I. Kozhushkov, L. Ackermann, Chem. Sci. 2013, 4, 886-896; b) P. B. Arockiam, C. Bruneau, P. H. Dixneuf, Chem. Rev. 2012, 112, 5879-5918; c) L. Ackermann, R. Vicente, in C-H Activation (Eds.: J.-Q. Yu, Z. Shi), Springer Berlin Heidelberg, Berlin, Heidelberg, 2010, pp. 211-229; d)

[198] a) J. C. Chu, T. Rovis, Angew. Chem. Int. Ed. 2018, 57, 62-101; b) P. Gandeepan, L. Ackermann, Chem 2018, 4, 199-222; c) G. Rouquet, N. Chatani, Angew. Chem. Int. Ed. 2013, 52, 11726-11743; d) L. Ackermann, R. Vicente, A. R. Kapdi, Angew. Chem. Int. Ed. 2009, 48, 9792-9826.

[199] P. B. Arockiam, C. Bruneau, P. H. Dixneuf, Chem. Rev. 2012, 112, 5879-5918.

[200] a) M. Seki, Org. Process Res. Dev. 2016, 20, 867-877; b) L. Ackermann, Org. Process Res. Dev. 2015, 19, 260-269.

[201] J. Hubrich, T. Himmler, L. Rodefeld, L. Ackermann, ACS Catal. 2015, 5, 4089-4093.

[202] S. Vasquez-Cespedes, X. Wang, F. Glorius, ACS Catal. 2018, 8, 242-257.

[203] Y. Park, J. Heo, M.-H. Baik, S. Chang, J. Am. Chem. Soc. 2016, 138, 14020-14029.

[204] a) M. Simonetti, D. M. Cannas, X. Just-Baringo, I. J. Vitorica-Yrezabal, I. Larrosa, Nat. Chem. 2018, 10, 724-731; b) L. Ackermann, R. Born, P. Álvarez-Bercedo, Angew. Chem. Int. Ed. 2007, 46, 63646367; c) L. Ackermann, A. Althammer, R. Born, Synlett 2007, 2833-2836; d) L. Ackermann, A. Althammer, R. Born, Angew. Chem. Int. Ed. 2006, 45, 2619-2622.

[205] D. G. Farnum, G. Mehta, G. G. I. Moore, F. P. Siegal, Tetrahedron Lett. 1974, 15, 2549-2552.

[206] a) C. Zhao, Y. Guo, Y. Zhang, N. Yan, S. You, W. Li, J. Mater. Chem. A 2019, 7, 10174-10199; b) Y. Patil, R. Misra, Chem. Asian J. 2018, 13, 220-229; c) W. Li, K. H. Hendriks, M. M. Wienk, R. A. J. Janssen, Acc. Chem. Res. 2016, 49, 78-85; d) M. J. Robb, S.-Y. Ku, F. G. Brunetti, C. J. Hawker, J. Polym. Sci., Part A: Polym. Chem. 2013, 51, 1263-1271; e) Y. Wu, W. Zhu, Chem. Soc. Rev. 2013, 42, 2039-2058; f) Y. Li, P. Sonar, L. Murphy, W. Hong, Energy Environ. Sci. 2013, 6, 1684-1710; g) B. Tieke, A. R. Rabindranath, K. Zhang, Y. Zhu, Beilstein J. Org. Chem. 2010, 6, 830-845.

[207] M. Kaur, D. H. Choi, Chem. Soc. Rev. 2015, 44, 58-77.

[208] a) Z. Ni, H. Wang, H. Dong, Y. Dang, Q. Zhao, X. Zhang, W. Hu, Nat. Chem. 2019, 11, 271-277; b) D. Feng, G. Barton, C. N. Scott, Org. Lett. 2019, 21, 1973-1978; c) S.-Y. Liu, D.-G. Wang, A.-G. Zhong, H.-R. Wen, Org. Chem. Front. 2018, 5, 653-661; d) W. Masayuki, O. Fumiyuki, Asian J. Org. Chem 2018, 7, 1206-1216; e) S. Yu, F. Liu, J. Yu, S. Zhang, C. Cabanetos, Y. Gao, W. Huang, J. Mater. Chem. C 2017, 5, 29-40.

[209] K.-J. Jiao, Y.-K. Xing, Q.-L. Yang, H. Qiu, T.-S. Mei, Acc. Chem. Res. 2020, 53, 300-310.

[210] a) Z.-J. Wu, F. Su, W. Lin, J. Song, T.-B. Wen, H.-J. Zhang, H.-C. Xu, Angew. Chem. Int. Ed. 2019, 58, 16770-16774; b) W.-J. Kong, L. H. Finger, J. C. A. Oliveira, L. Ackermann, Angew. Chem. Int. Ed. 2019, 58, 6342-6346.

[211] a) T. O. Olusanya, G. Calabrese, D. G. Fatouros, J. Tsibouklis, J. R. Smith, Biophys. Chem. 2019, 247, 25-33; b) I. V. Korolkov, A. L. Kozlovskiy, Y. G. Gorin, A. V. Kazantsev, D. I. Shlimas, M. V. Zdorovets, N. K. Ualieva, V. S. Rusakov, J. Nanopart. Res. 2018, 20, 1-11.

[212] a) H. Shen, Z. Xie, J. Am. Chem. Soc. 2010, 132, 11473-11480; b) Z. Xie, Coord. Chem. Rev. 2006, 250, 259-272; c) N. S. Hosmane, J. A. Maguire, Eur. J. Inorg. Chem. 2003, 2003, 3989-3999.

[213] a) A. Shmal'ko, S. Anufriev, A. Anisimov, M. Y. Stogniy, I. Sivaev, V. Bregadze, Russ. Chem. Bull. 2019, 68, 1239-1247; b) M. Y. Stogniy, S. A. Erokhina, K. Y. Suponitsky, A. A. Anisimov, I. B. Sivaev, V. I. Bregadze, New J. Chem. 2018, 42, 17958-17967; c) S. A. Anufriev, I. B. Sivaev, K. Y. Suponitsky, I. A. Godovikov, V. I. Bregadze, Eur. J. Inorg. Chem. 2017, 2017, 4436-4443. M. Chen, D. Zhao, J. Xu, C. Li, C. Lu, H. Yan, Angew. Chem. Int. Ed. 2021, 60, 7838-7844. a) A. Gangjee, Y. Zeng, T. Talreja, J. J. McGuire, R. L. Kisliuk, S. F. Queener, J. Med. Chem. 2007, 50, 3046-3053; b) Z.-Y. Sun, E. Botros, A.-D. Su, Y. Kim, E. Wang, N. Z. Baturay, C.-H. Kwon, J. Med. Chem. 2000, 43, 4160-4168.

[216] a) V. Hirschbeck, P. H. Gehrtz, I. Fleischer, Chem. Eur. J. 2018, 24, 7092-7107; b) I. P. Beletskaya, V. 
P. Ananikov, Chem. Rev. 2011, 111, 1596-1636; c) M. Mellah, A. Voituriez, E. Schulz, Chem. Rev. 2007, 107, 5133-5209.

[217] F. Lin, J.-L. Yu, Y. Shen, S.-Q. Zhang, B. Spingler, J. Liu, X. Hong, S. Duttwyler, J. Am. Chem. Soc. 2018, 140, 13798-13807.

[218] Y. F. Liang, L. Yang, T. Rogge, L. Ackermann, Chem. Eur. J. 2018, 24, 16548-16552.

[219] E. Gońka, L. Yang, R. Steinbock, F. Pesciaioli, R. Kuniyil, L. Ackermann, Chem. Eur. J. 2019, 25, 16246-16250.

[220] M. Grzybowski, E. Glodkowska-Mrowka, T. Stoklosa, D. T. Gryko, Org. Lett. 2012, 14, 2670-2673.

[221] L. Yang, R. Steinbock, A. Scheremetjew, R. Kuniyil, L. H. Finger, A. M. Messinis, L. Ackermann, Angew. Chem. Int. Ed. 2020, 59, 11130-11135.

[222] Y.-F. Liang, L. Yang, B. B. Jei, R. Kuniyil, L. Ackermann, Chemi. Sci. 2020, 11, 10764-10769.

[223] L. Yang, B. Bongsuiru Jei, A. Scheremetjew, R. Kuniyil, L. Ackermann, Angew. Chem. Int. Ed. 2021, $60,1482-1487$.

[224] a) H. Mayr, A. R. Ofial, Acc. Chem. Res. 2016, 49, 952-965; b) M. Baidya, F. Brotzel, H. Mayr, Org. Bio. Chem. 2010, 8, 1929-1935; c) F. Brotzel, B. Kempf, T. Singer, H. Zipse, H. Mayr, Chem. Eur. J. 2007, 13, 336-345.

[225] Z. Yang, W. Zhao, W. Liu, X. Wei, M. Chen, X. Zhang, X. Zhang, Y. Liang, C. Lu, H. Yan, Angew. Chem. Int. Ed. 2019, 58, 11886-11892.

[226] a) K.-R. Wee, W.-S. Han, D. W. Cho, S. Kwon, C. Pac, S. O. Kang, Angew. Chem. Int. Ed. 2012, 51, 2677-2680; b) K.-R. Wee, Y.-J. Cho, S. Jeong, S. Kwon, J.-D. Lee, I.-H. Suh, S. O. Kang, J. Am. Chem. Soc. 2012, 134, 17982-17990.

[227] F. Wang, S. S. Stahl, Angew. Chem. Int. Ed. 2019, 58, 6385-6390.

[228] Y. Xu, X. Yang, X. Zhou, L. Kong, X. Li, Org. Lett. 2017, 19, 4307-4310.

[229] M. Grzybowski, E. Glodkowska-Mrowka, T. Stoklosa, D. T. Gryko, Org. Lett. 2012, 14, 2670-2673.

[230] M. J. Mio, L. C. Kopel, J. B. Braun, T. L. Gadzikwa, K. L. Hull, R. G. Brisbois, C. J. Markworth, P. A. Grieco, Org. Lett. 2002, 4, 3199-3202.

[231] K. S. Halskov, H. S. Roth, J. A. Ellman, Angew. Chem. Int. Ed. 2017, 56, 9183-9187.

[232] J. M. Villar, J. Suárez, J. s. A. Varela, C. Saá, Org. Lett. 2017, 19, 1702-1705.

[233] A. Toppino, A. R. Genady, M. E. El-Zaria, J. Reeve, F. Mostofian, J. Kent, J. F. Valliant, Inorg. Chem. 2013, 52, 8743-8749.

[234] K. Nozawa, M. Yamada, Y. Tsuda, K. Kawai, S. Nakajima, Chem. Pharm. Bull. 1981, 29, 2491-2495.

[235] M. Uchiyama, H. Ozawa, K. Takuma, Y. Matsumoto, M. Yonehara, K. Hiroya, T. Sakamoto, Org. Lett. 2006, 8, 5517-5520.

[236] S. A. Shahzad, C. Venin, T. Wirth, Eur. J. Org. Chem. 2010, 3465-3472.

[237] P. K. Dutta, S. Sen, Chem. Eur. J. 2018, 2018, 5512-5519.

[238] A. Obata, A. Sasagawa, K. Yamazaki, Y. Ano, N. Chatani, Chem. Sci. 2019, 10, 3242-3248.

[239] O. Ito, M. Matsuda, Bull. Chem. Soc. Jpn. 1984, 57, 1745-1749. 


\section{NMR Spectra}

\subsection{Ruthenium(II/IV)-Catalyzed Annulation}
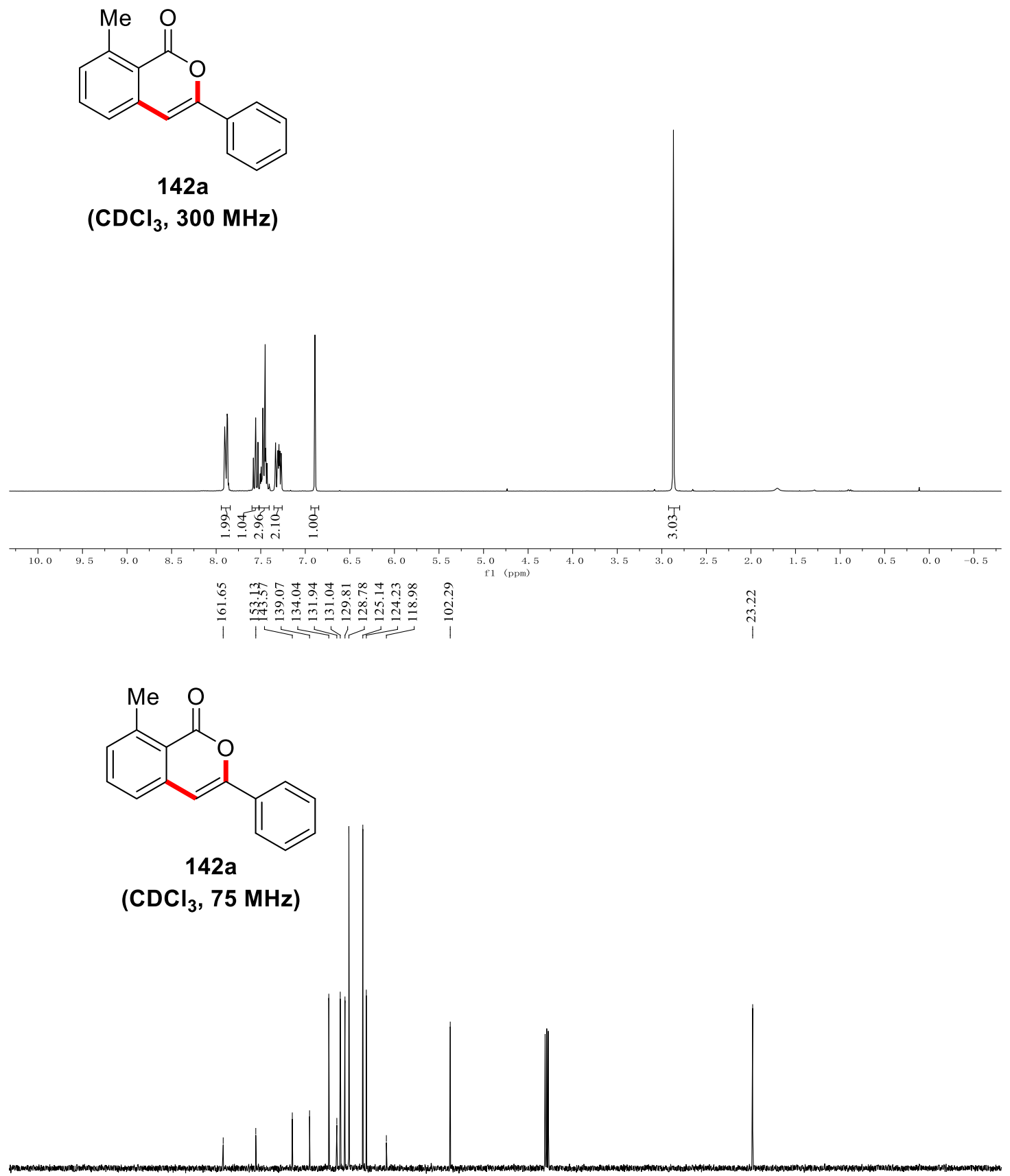


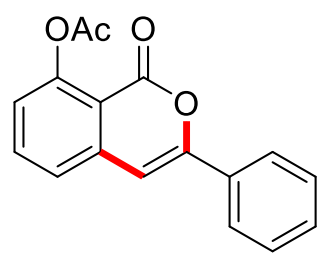

$142 b$

$\left(\mathrm{CDCl}_{3}, 300 \mathrm{MHz}\right)$

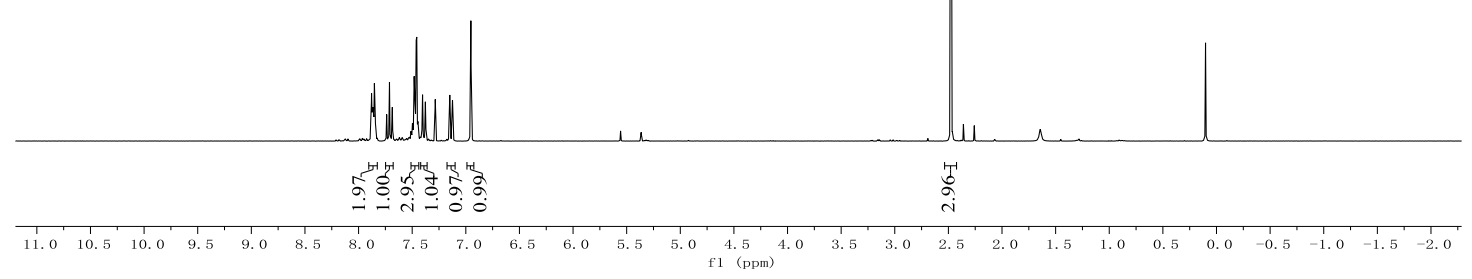

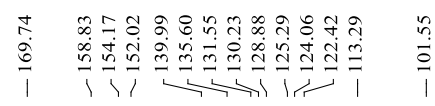

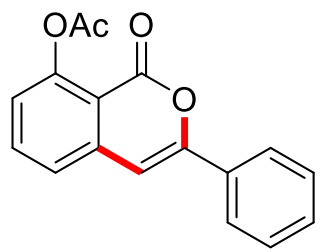

142b

$\left(\mathrm{CDCl}_{3}, 75 \mathrm{MHz}\right)$

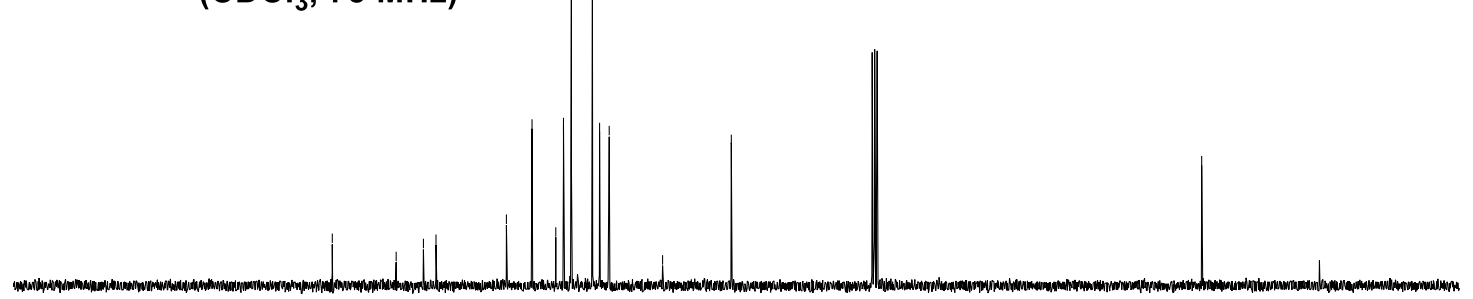

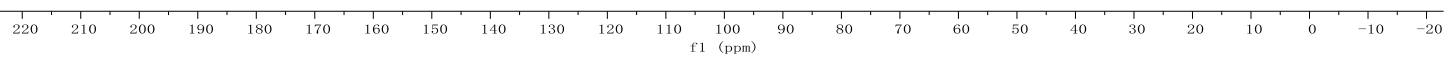




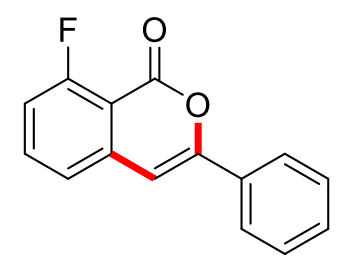

142c

$\left(\mathrm{CDCl}_{3}, 300 \mathrm{MHz}\right)$

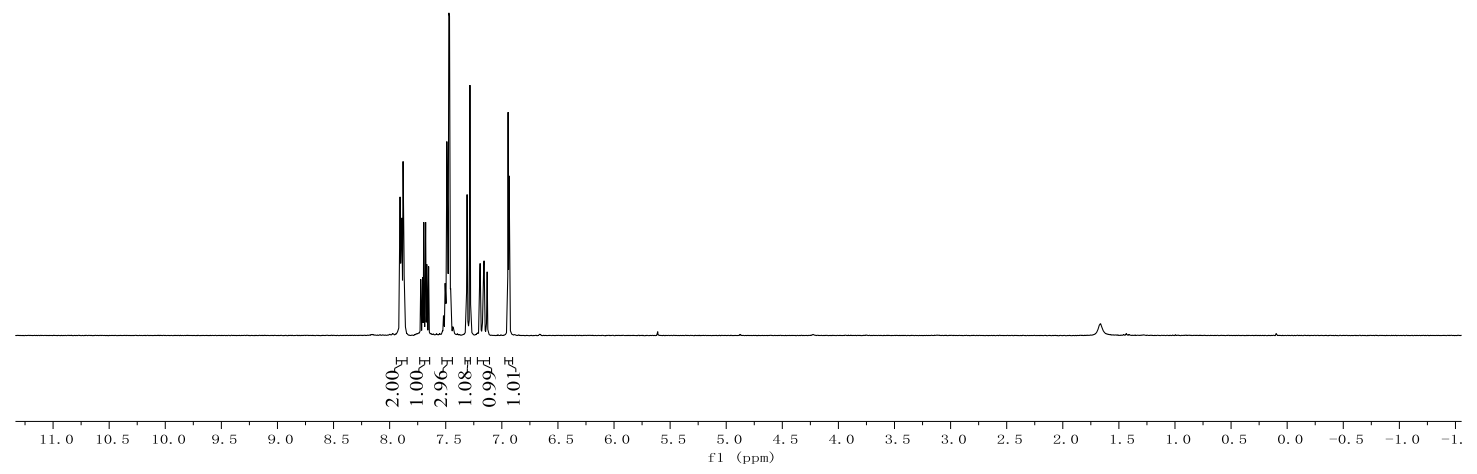

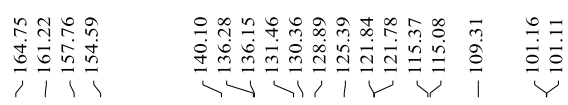<smiles>O=c1oc(-c2ccccc2)cc2cccc(F)c12</smiles>

142c

$\left(\mathrm{CDCl}_{3}, 75 \mathrm{MHz}\right)$
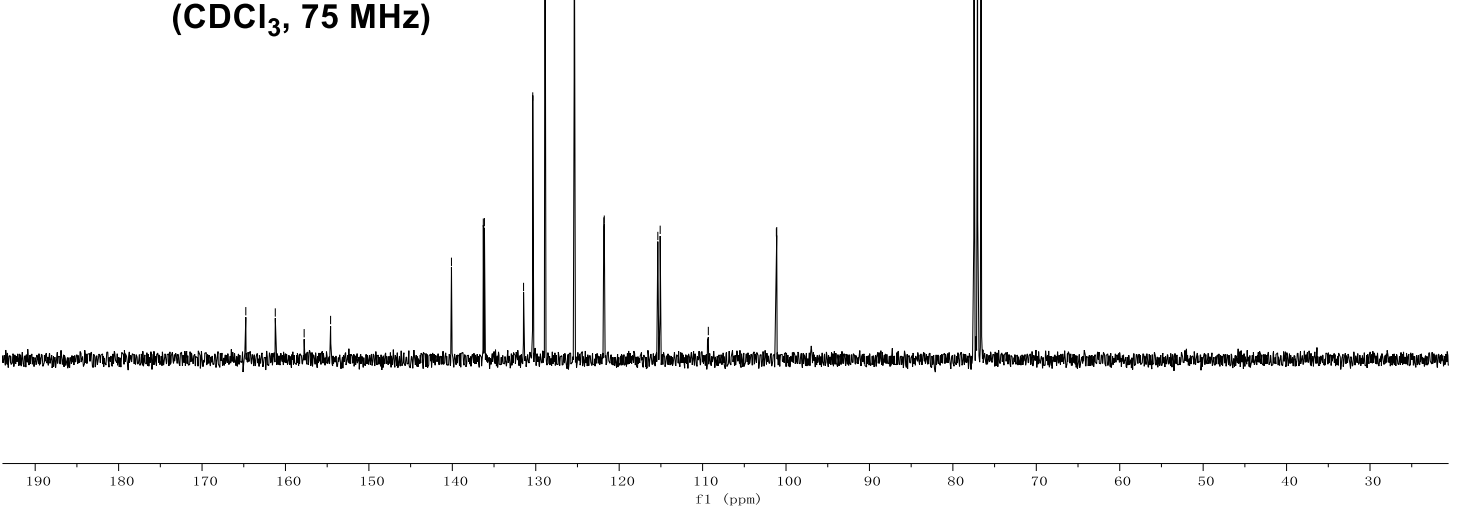
<smiles>O=c1oc(-c2ccccc2)cc2cccc(F)c12</smiles>
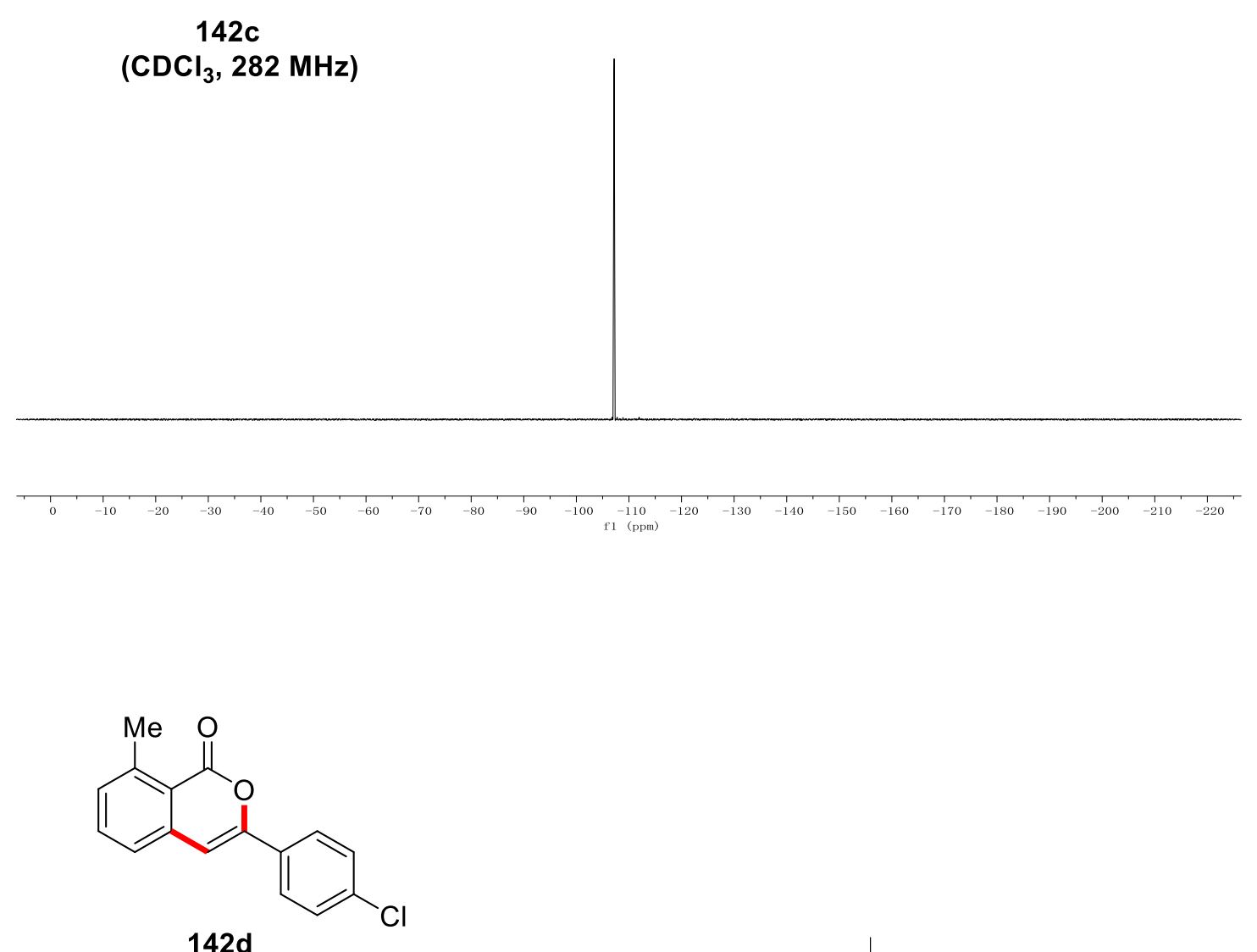

$\left(\mathrm{CDCl}_{3}, 300 \mathrm{MHz}\right)$

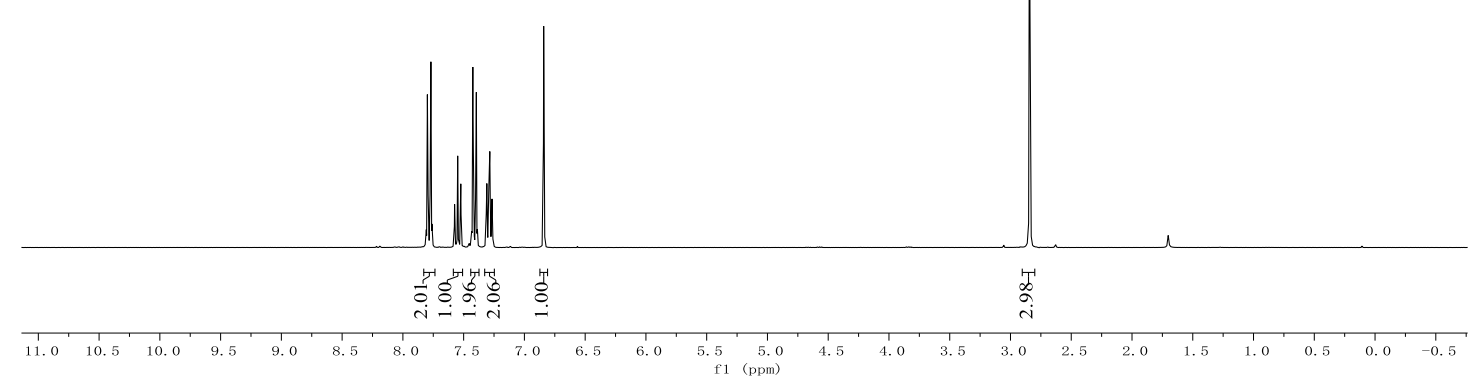




\section{NMR Spectra}
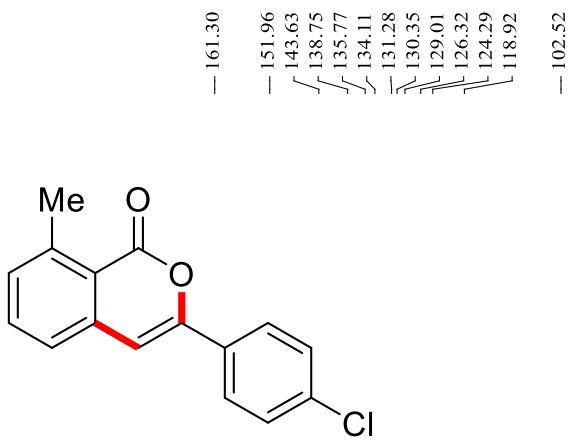

142d

$\left(\mathrm{CDCl}_{3}, 75 \mathrm{MHz}\right)$
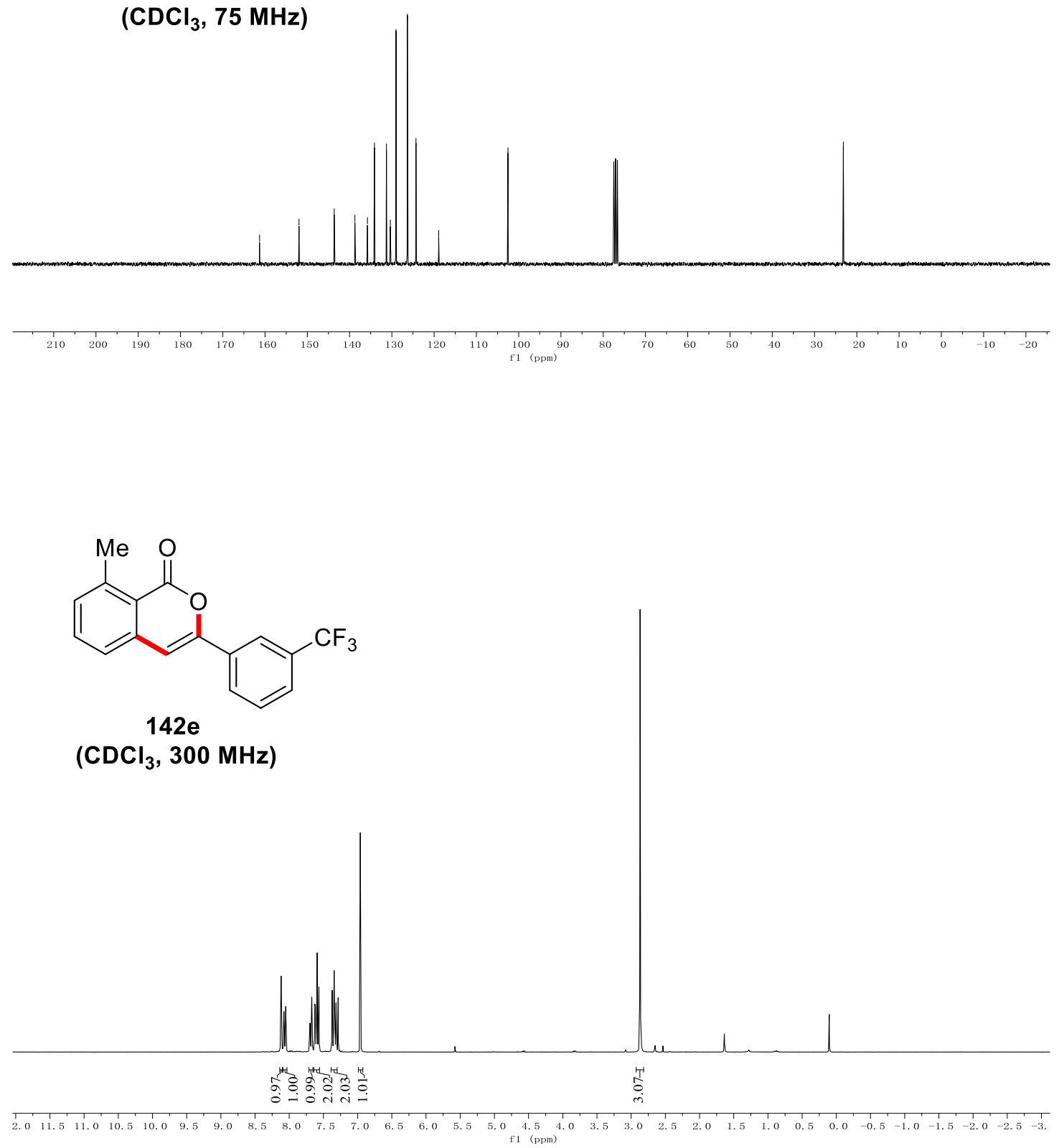
<smiles>Cc1cccc2cc(-c3cccc(C(F)(F)F)c3)oc(=O)c12</smiles>

$142 \mathrm{e}$

$\left(\mathrm{CDCl}_{3}, 75 \mathrm{MHz}\right)$

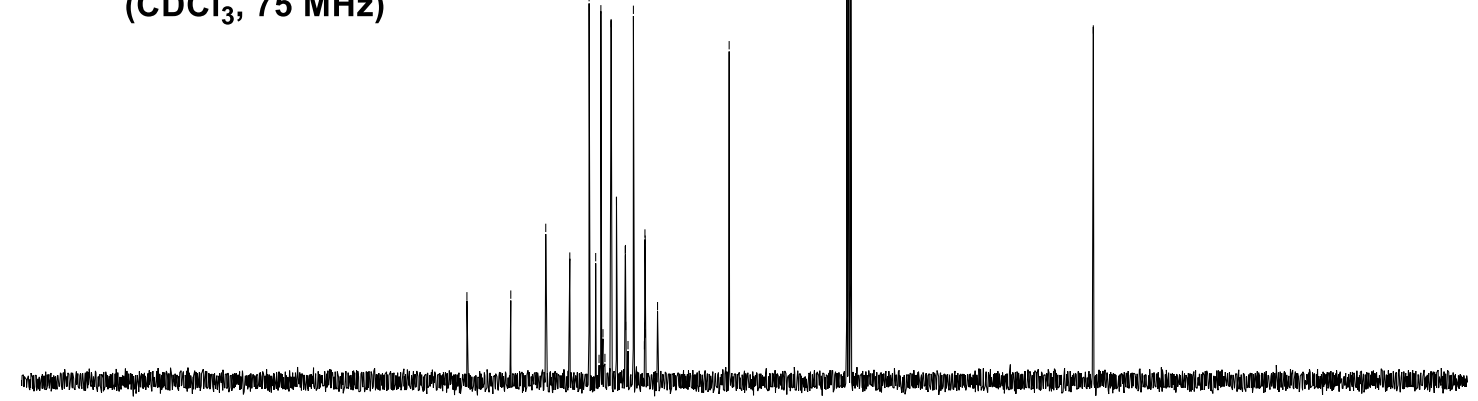

\begin{tabular}{rlllllllllllllllllllllllllllllllllllll}
\hline & 1 \\
250 & 240 & 230 & 220 & 210 & 200 & 190 & 180 & 170 & 160 & 150 & 140 & 130 & 120 & 110 & 100 & 90 & 80 & 70 & 60 & 50 & 40 & 30 & 20 & 10 & 0 & -10 & -20 & -30 & -40 & -50
\end{tabular}<smiles>Cc1cccc2cc(-c3cccc(C(F)(F)F)c3)oc(=O)c12</smiles>

$142 e$

$\left(\mathrm{CDCl}_{3}, 282 \mathrm{MHz}\right)$

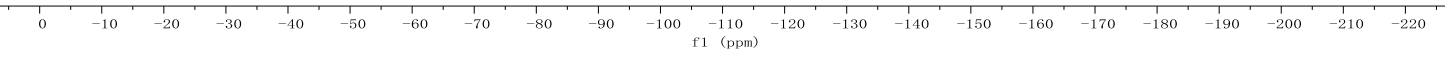



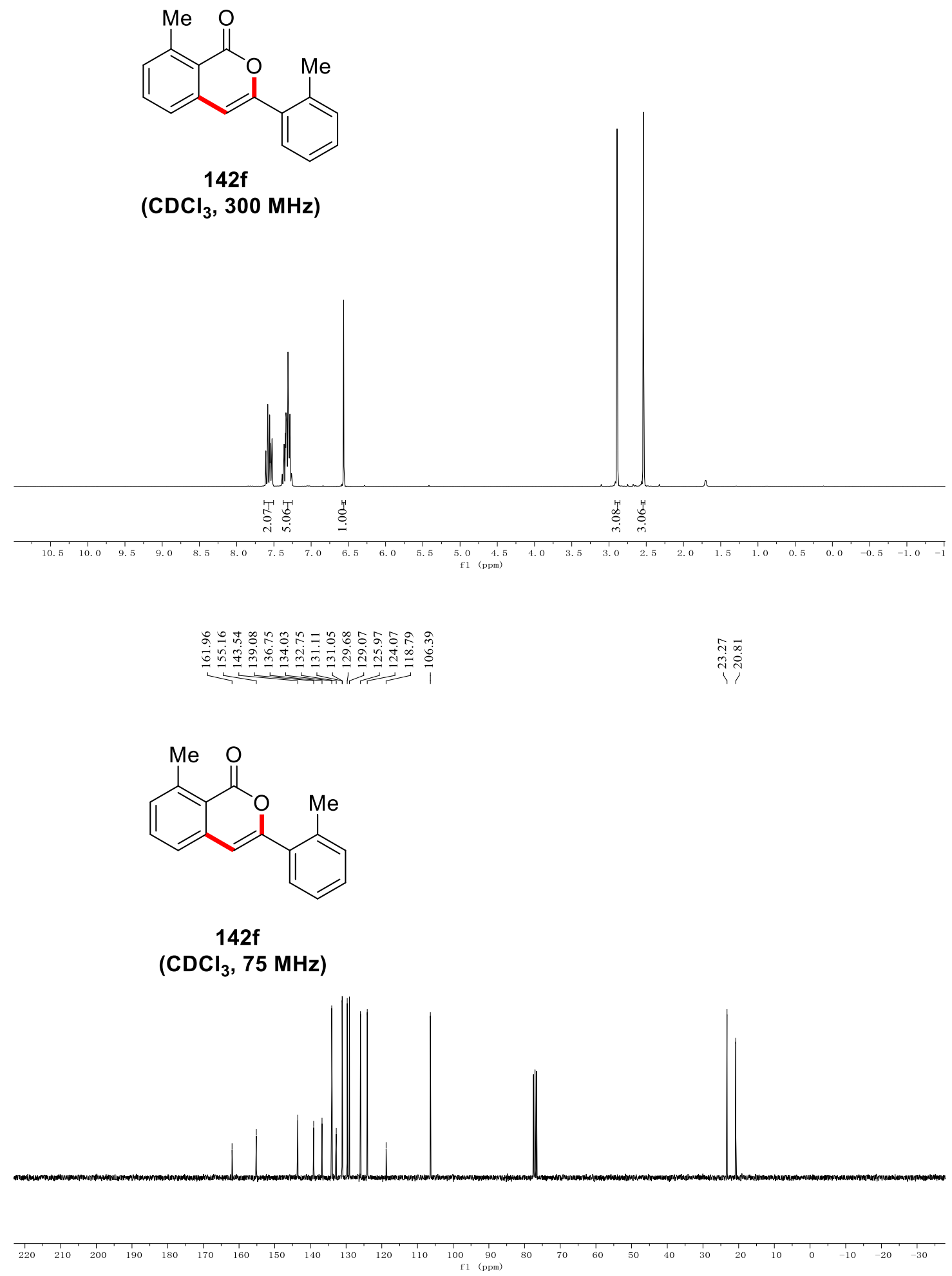


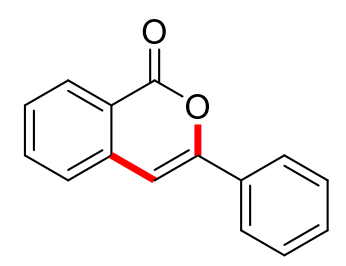

$142 \mathrm{~g}$

( $\mathrm{CDCl}_{3}, 300 \mathrm{MHz}$ )

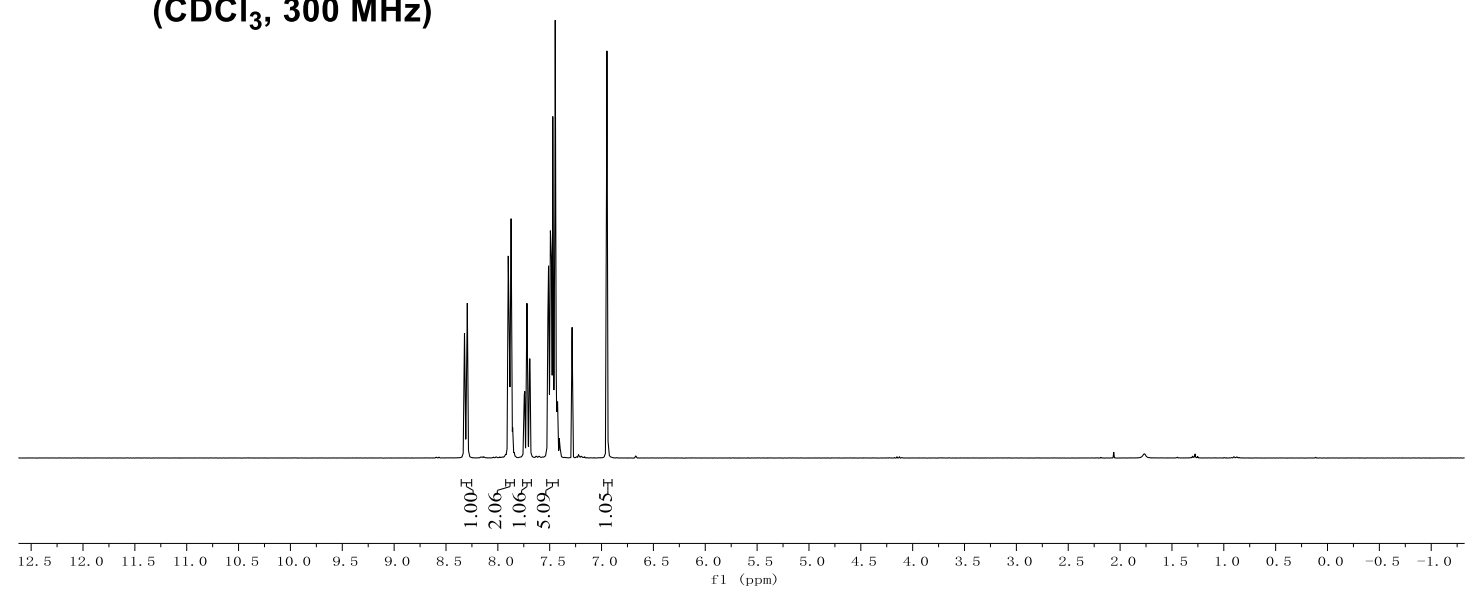

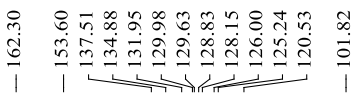<smiles>O=c1oc(-c2ccccc2)cc2ccccc12</smiles>

$142 \mathrm{~g}$

$\left(\mathrm{CDCl}_{3}, 75 \mathrm{MHz}\right)$

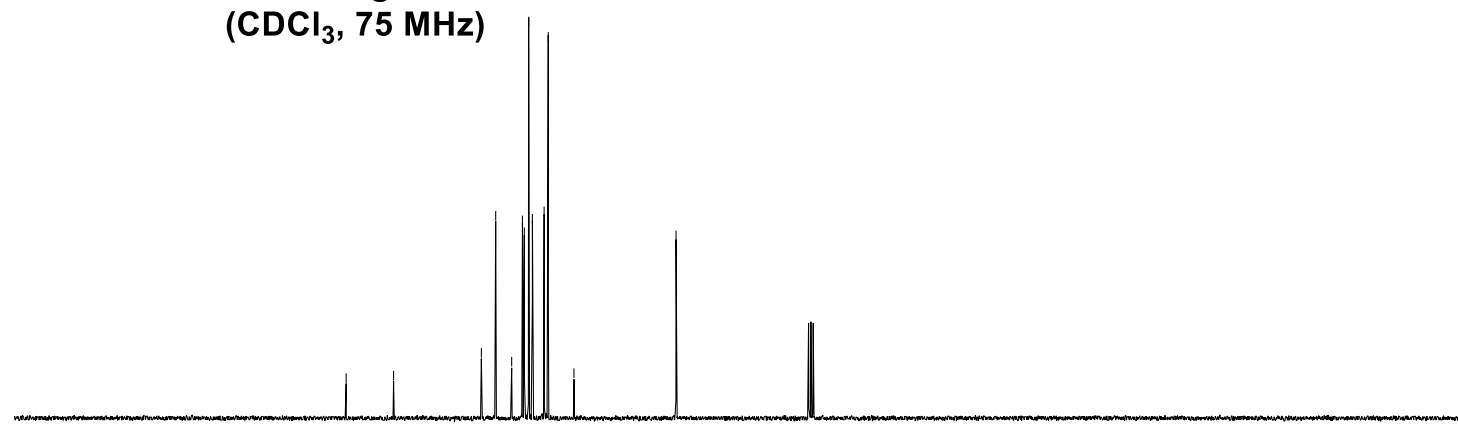

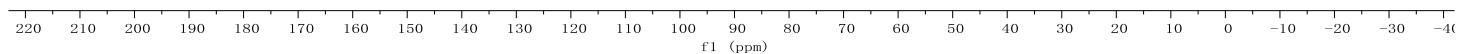



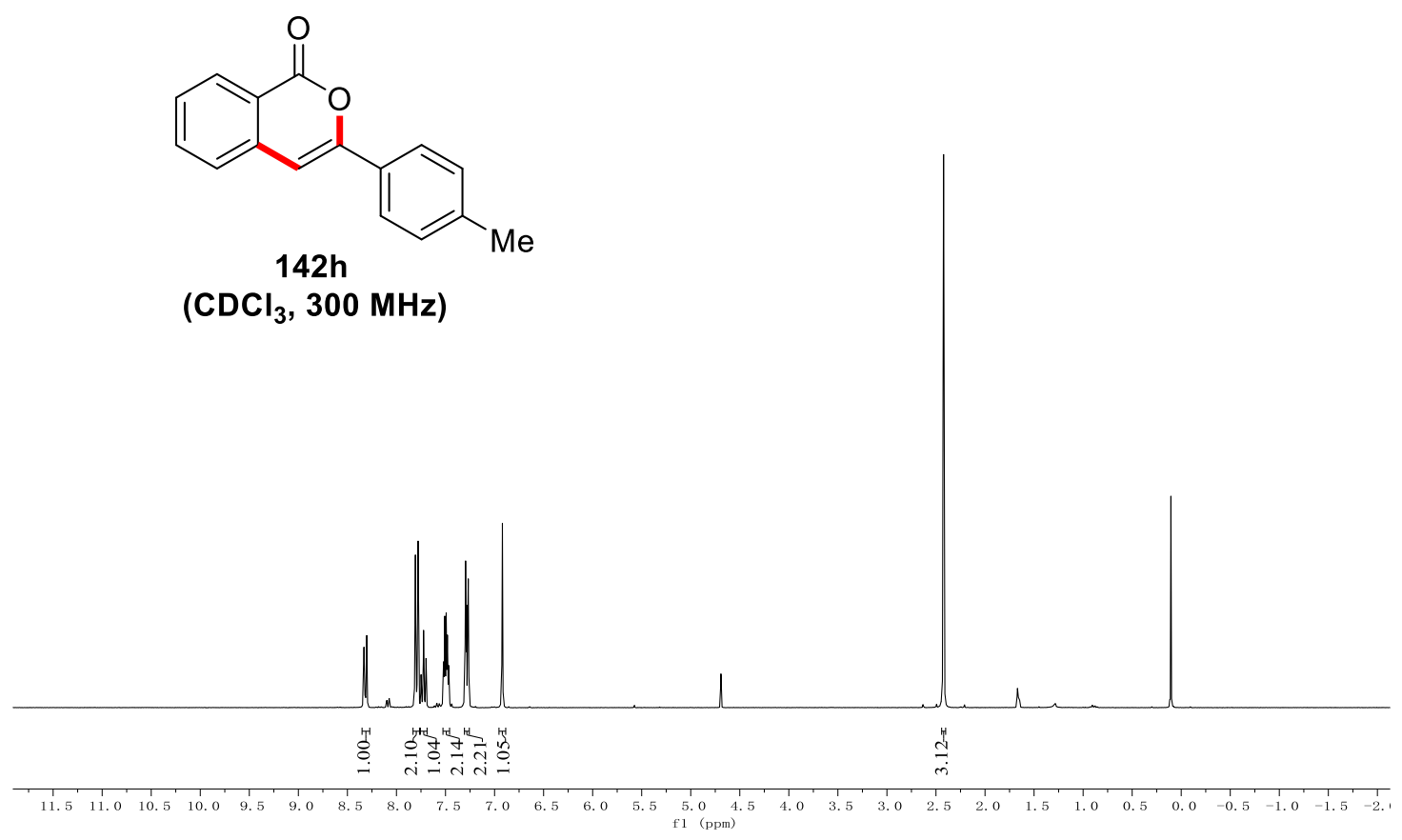

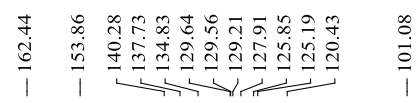

$\frac{\text { i }}{\text { i }}$

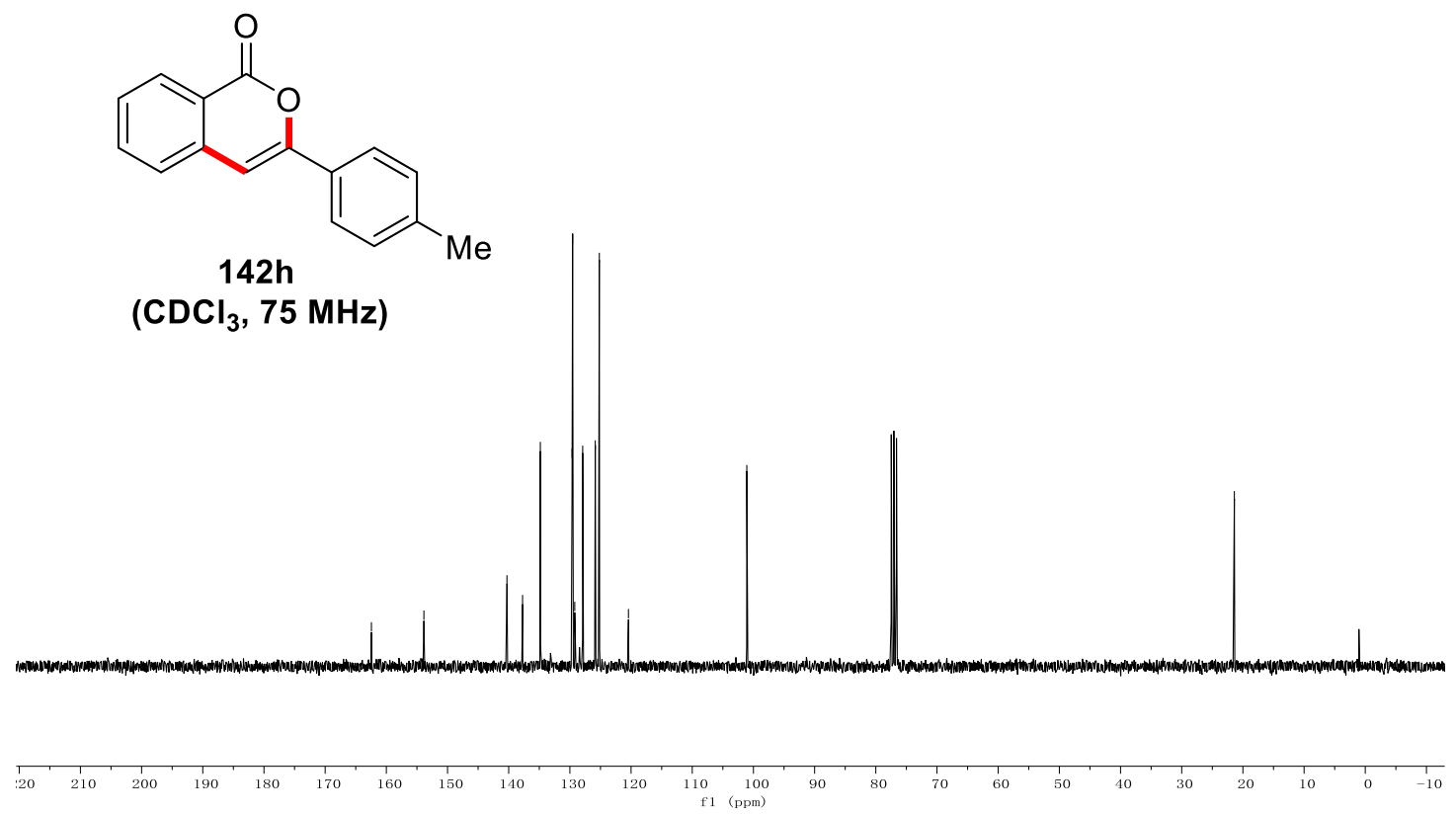



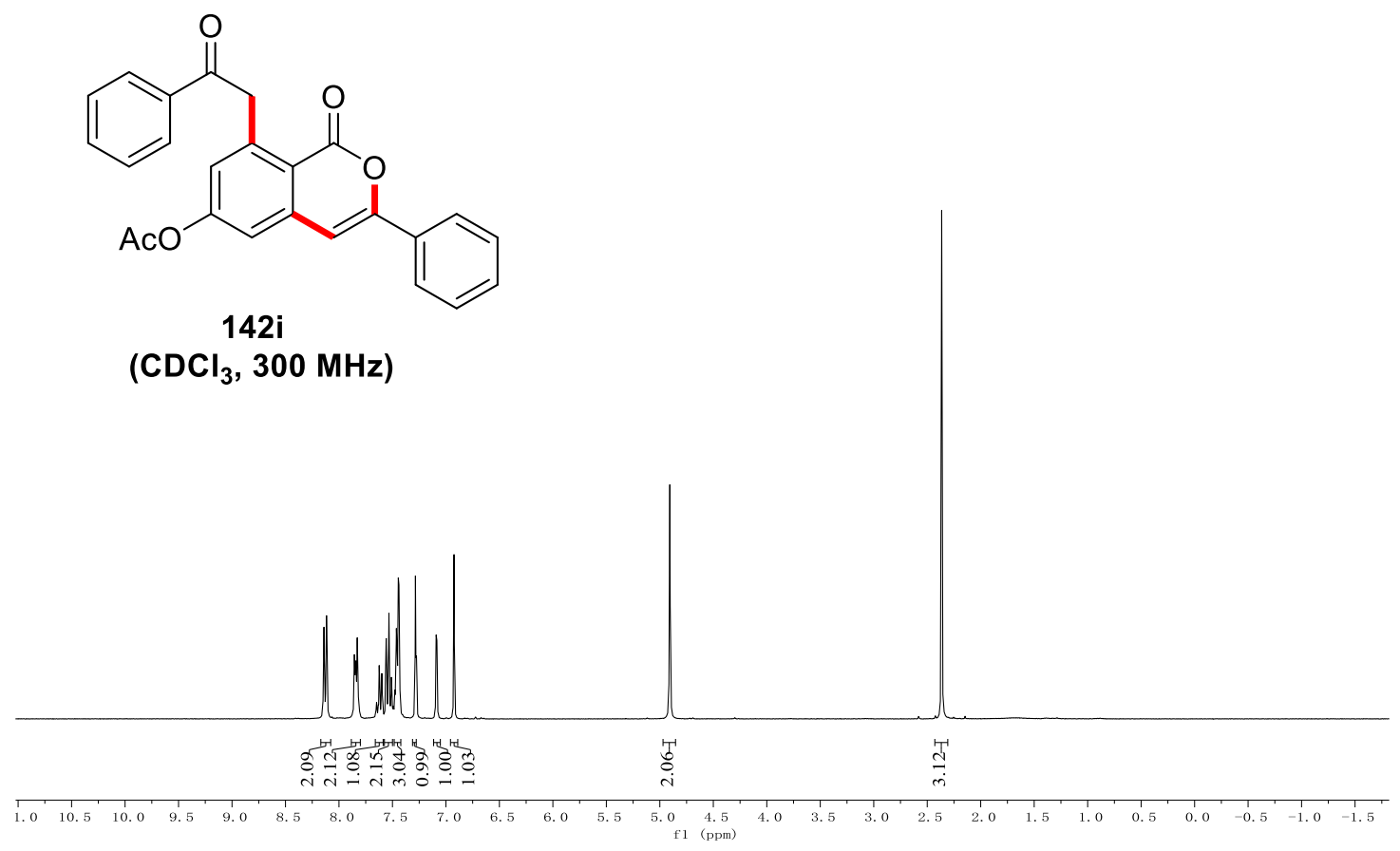

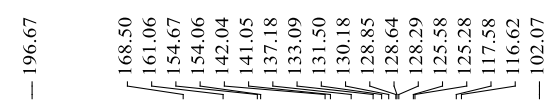

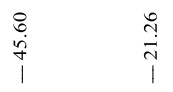

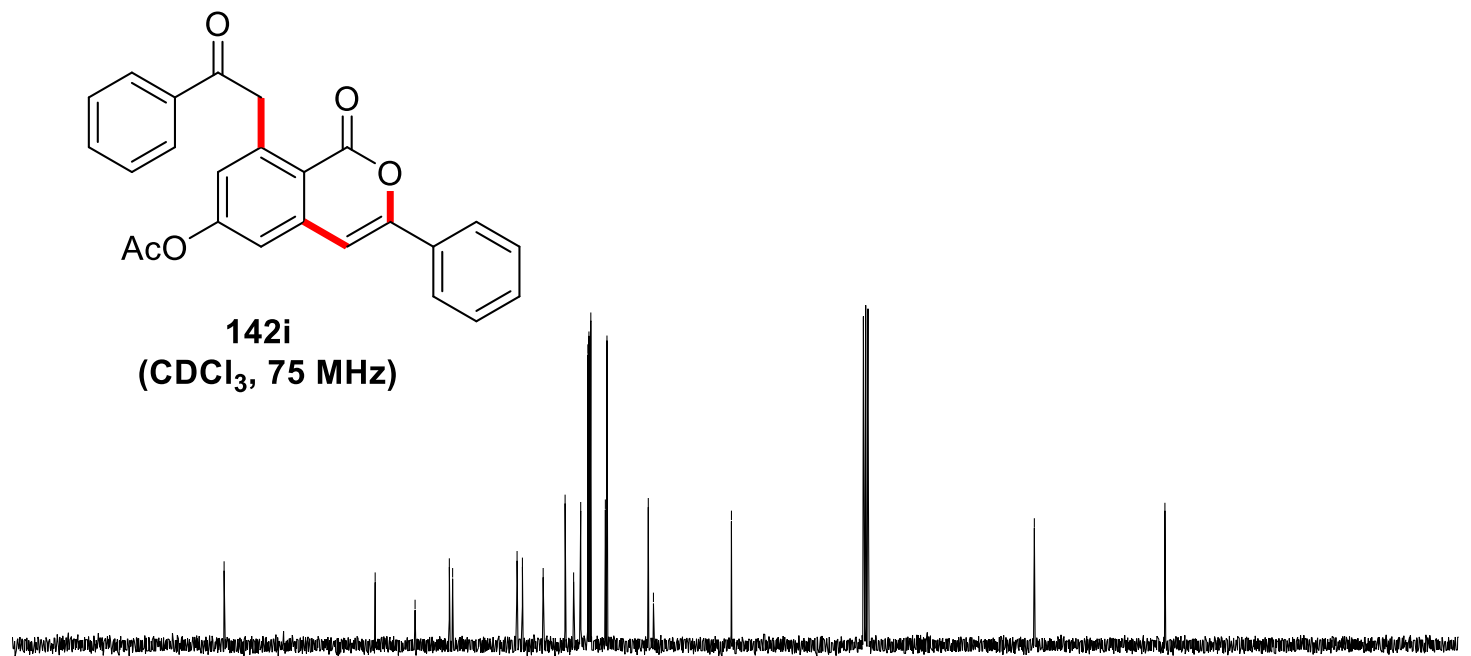




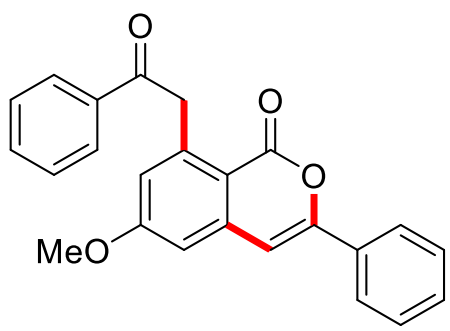

142j

$\left(\mathrm{CDCl}_{3}, 300 \mathrm{MHz}\right)$

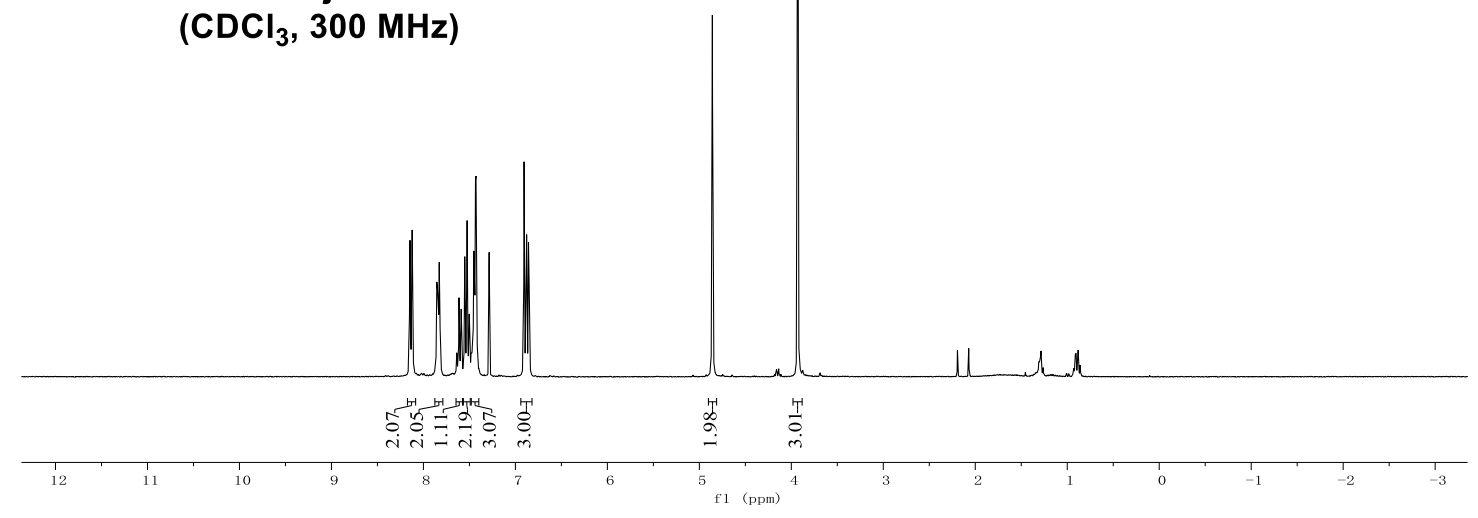

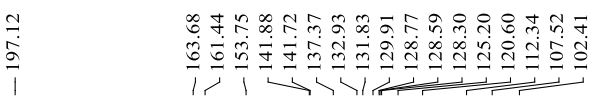

$\begin{array}{ll}n & \text { in } \\ \text { in } & \text { i } \\ 1 & 1\end{array}$

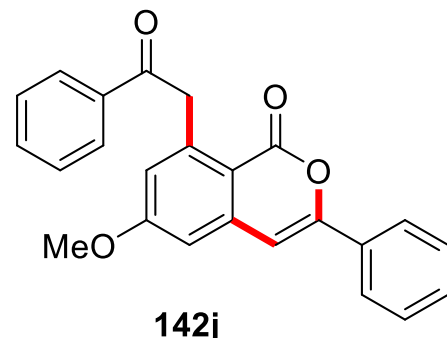

$142 \mathrm{j}$

$\left(\mathrm{CDCl}_{3}, 75 \mathrm{MHz}\right)$
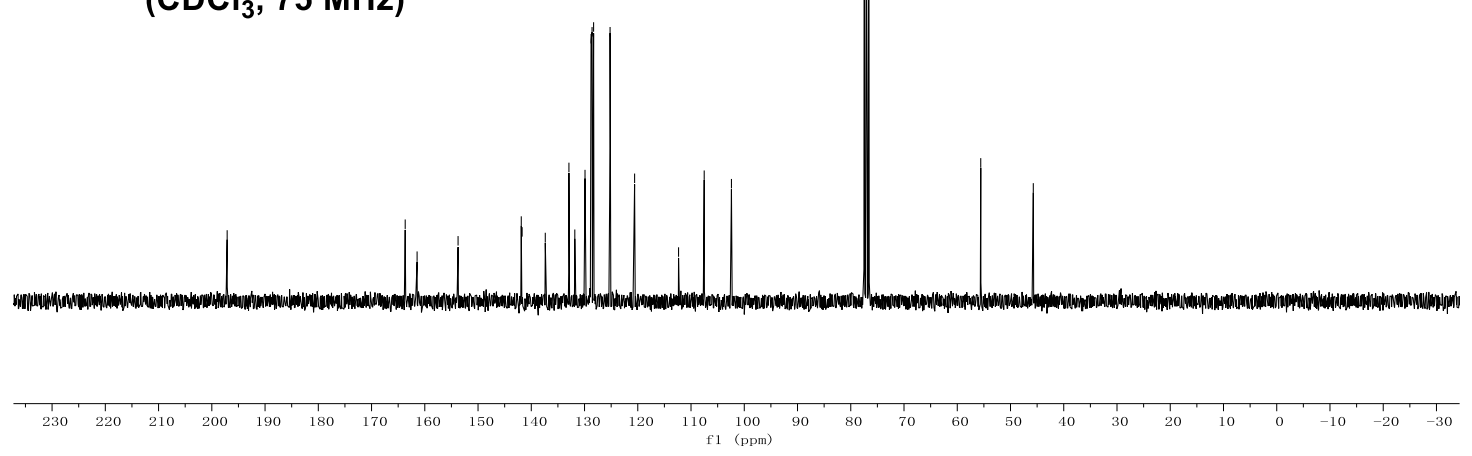
<smiles>CC(C)(C)c1cc(CC(=O)c2ccccc2)c2c(=O)oc(-c3ccccc3)cc2c1</smiles>

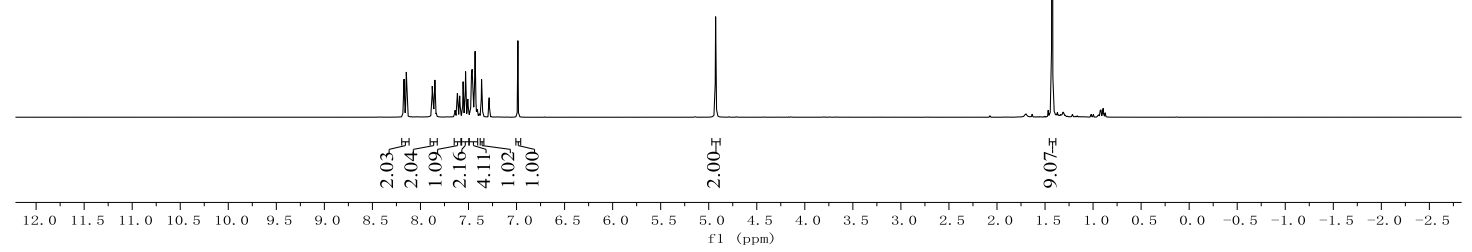

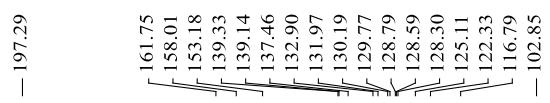
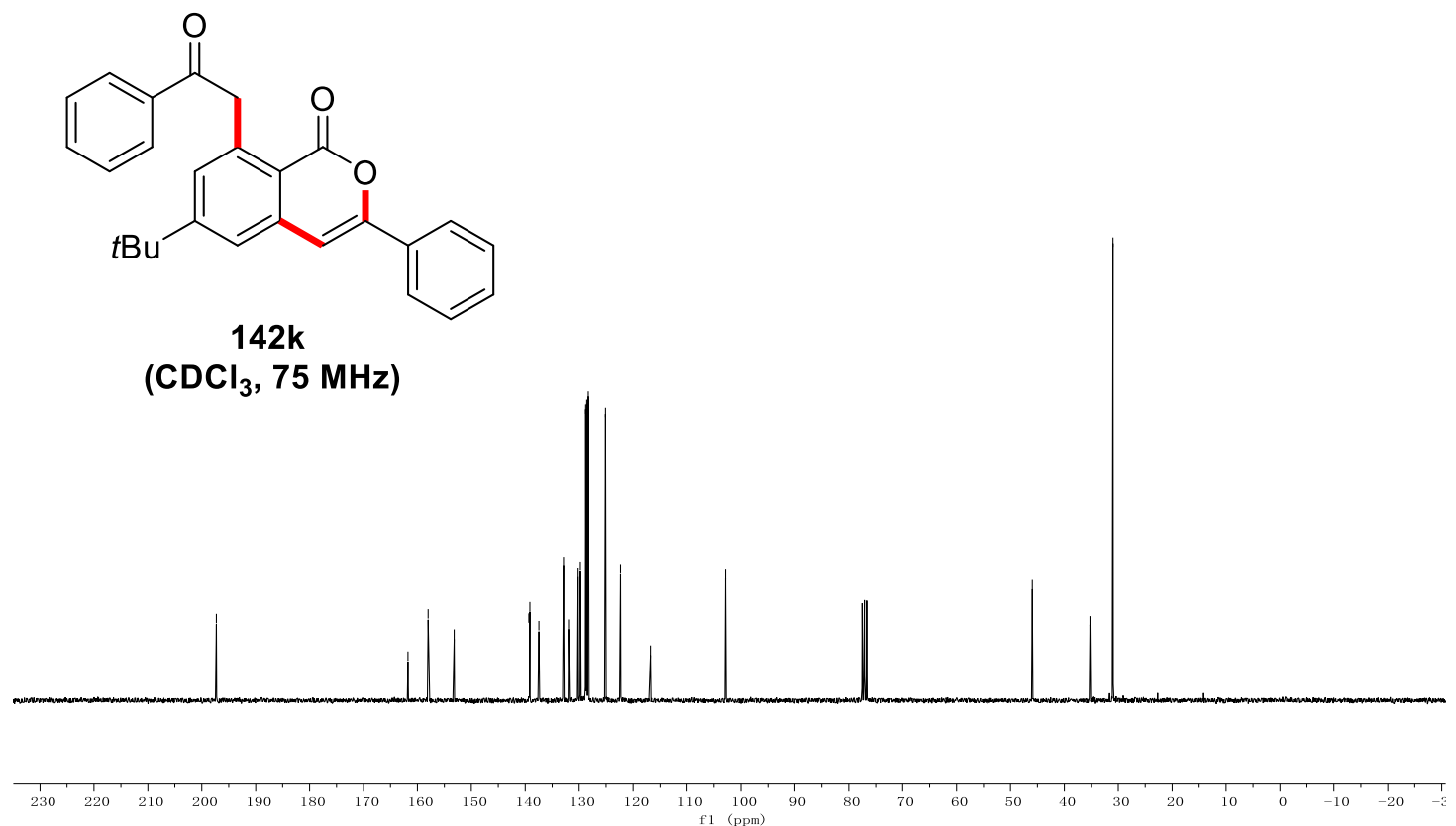

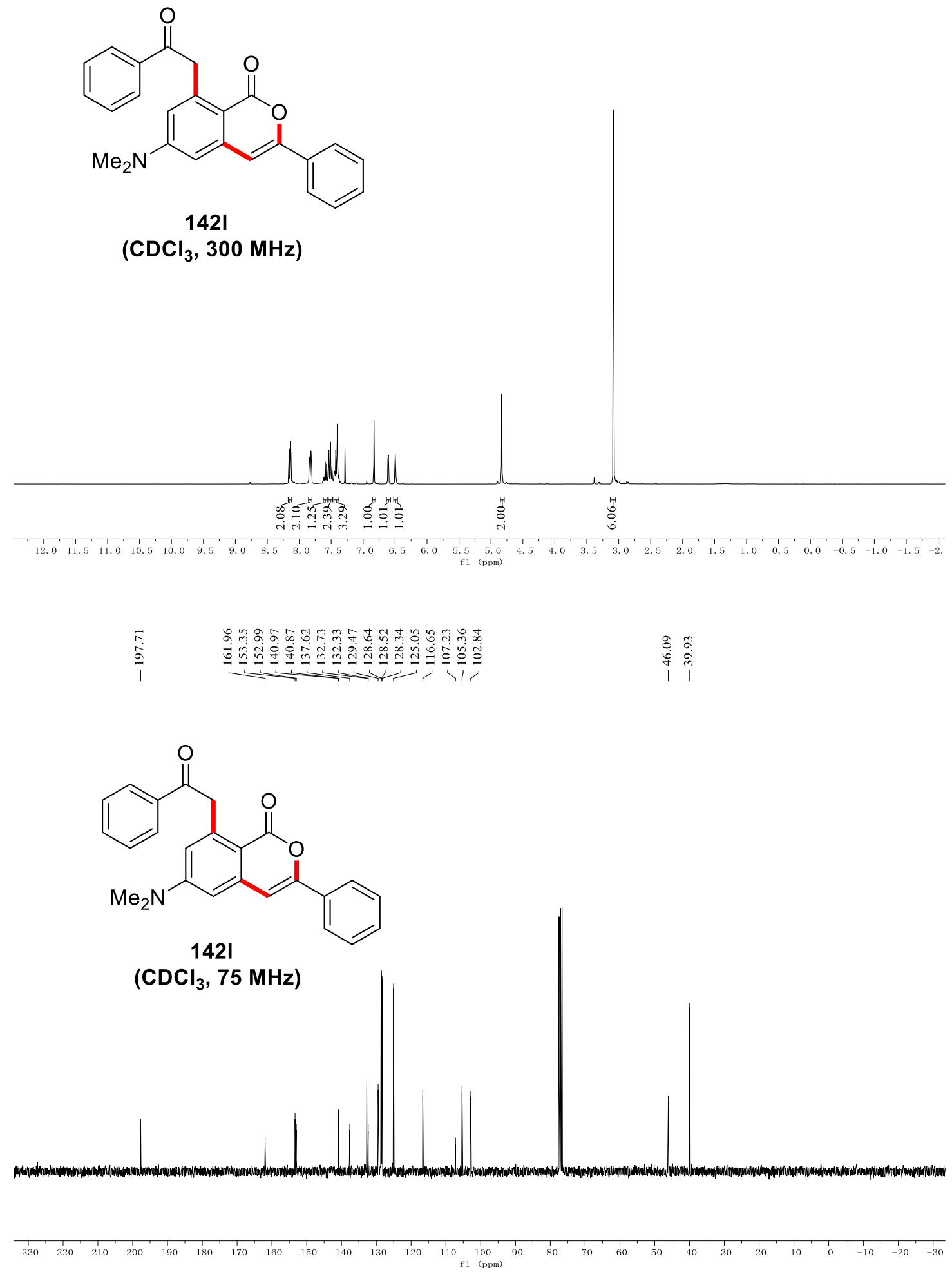

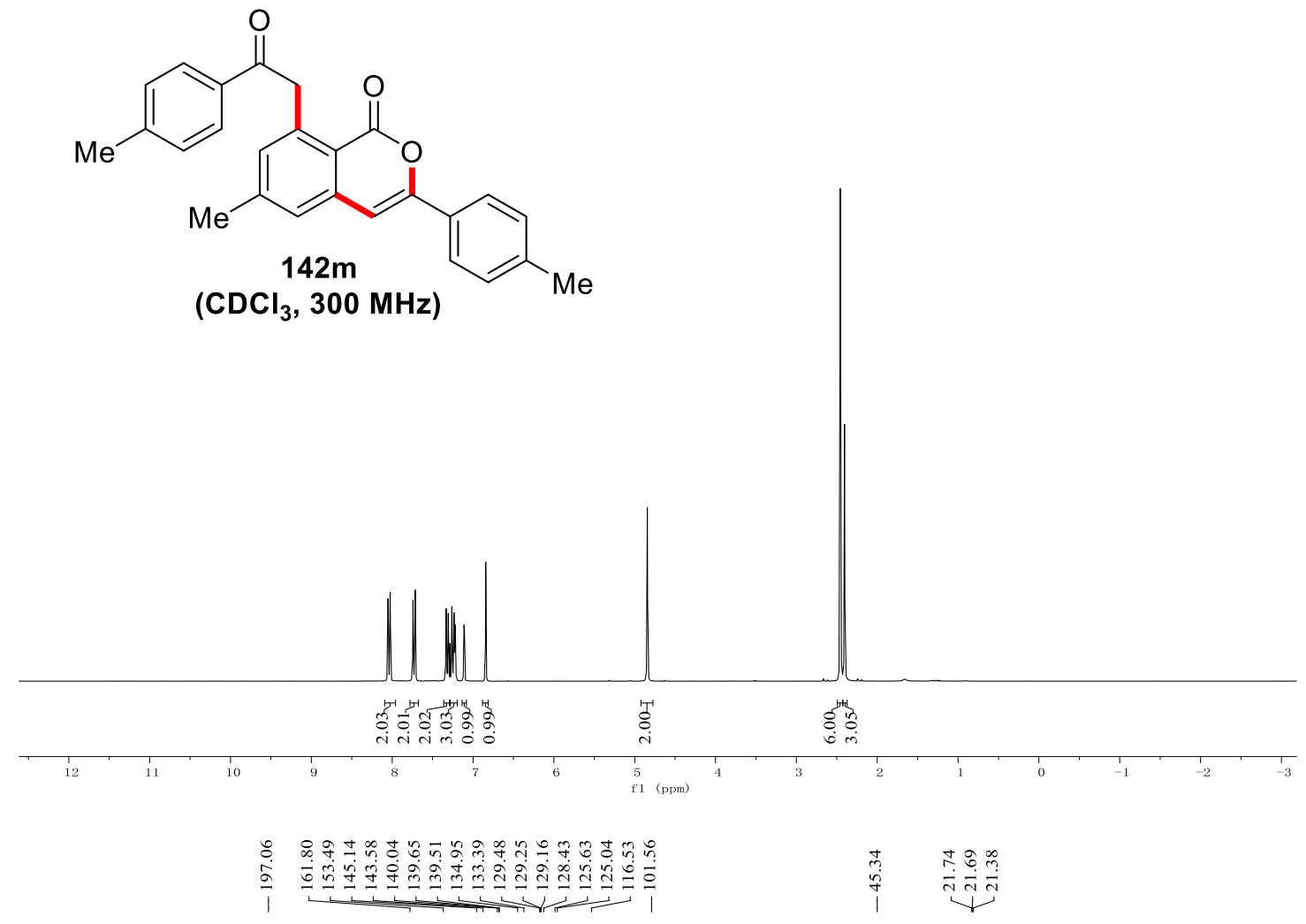<smiles>Cc1ccc(C(=O)Cc2cc(C)cc3c(=O)oc(-c4ccc(C)cc4)cc23)cc1</smiles>

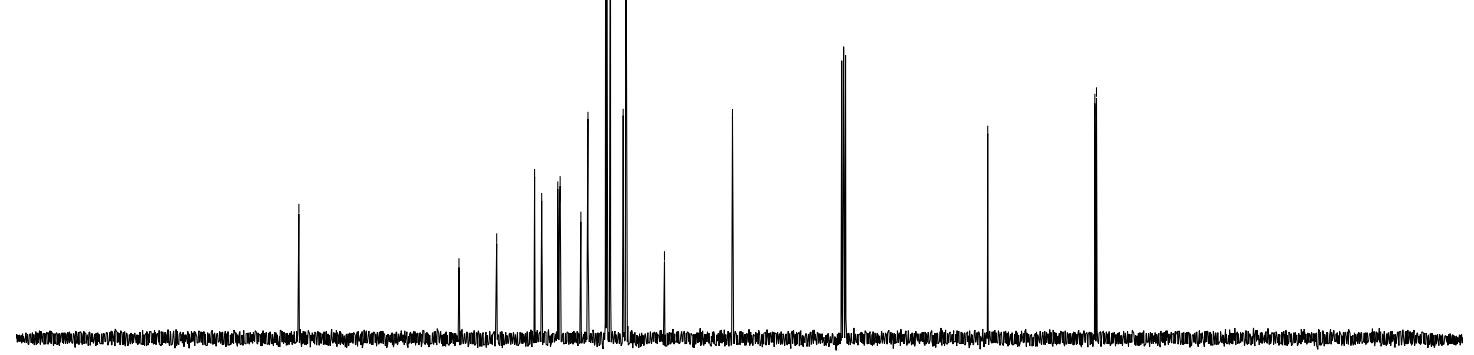

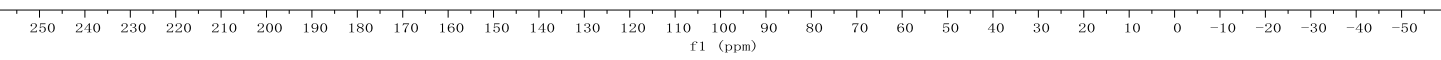


<smiles>Cc1cc(CC(=O)c2ccc(Cl)cc2)c2c(=O)oc(-c3ccc(Cl)cc3)cc2c1</smiles>

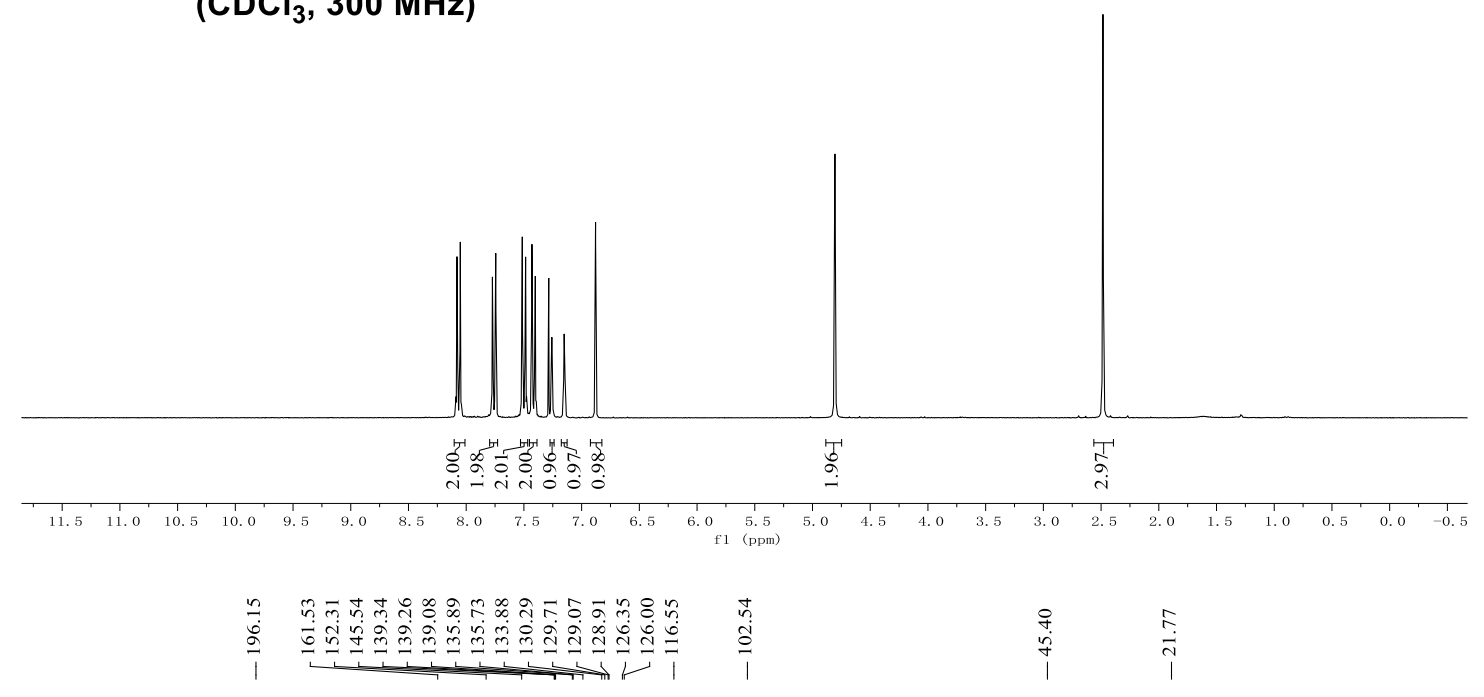<smiles>Cc1cc(CC(=O)c2ccc(Cl)cc2)c2c(=O)oc(-c3ccc(Cl)cc3)cc2c1</smiles>

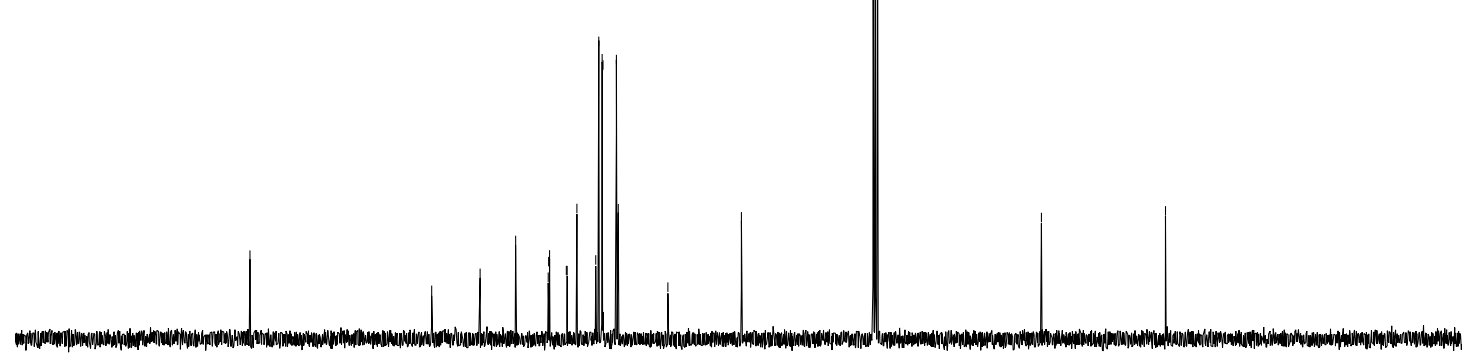

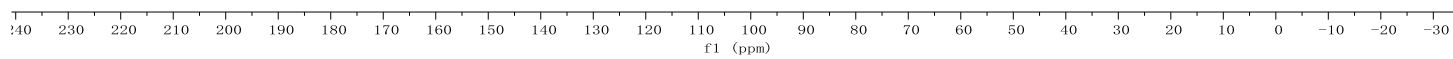


<smiles>Cc1cc(CC(=O)c2cccc(C(F)(F)F)c2)c2c(=O)oc(-c3cccc(C(F)(F)F)c3)cc2c1</smiles>

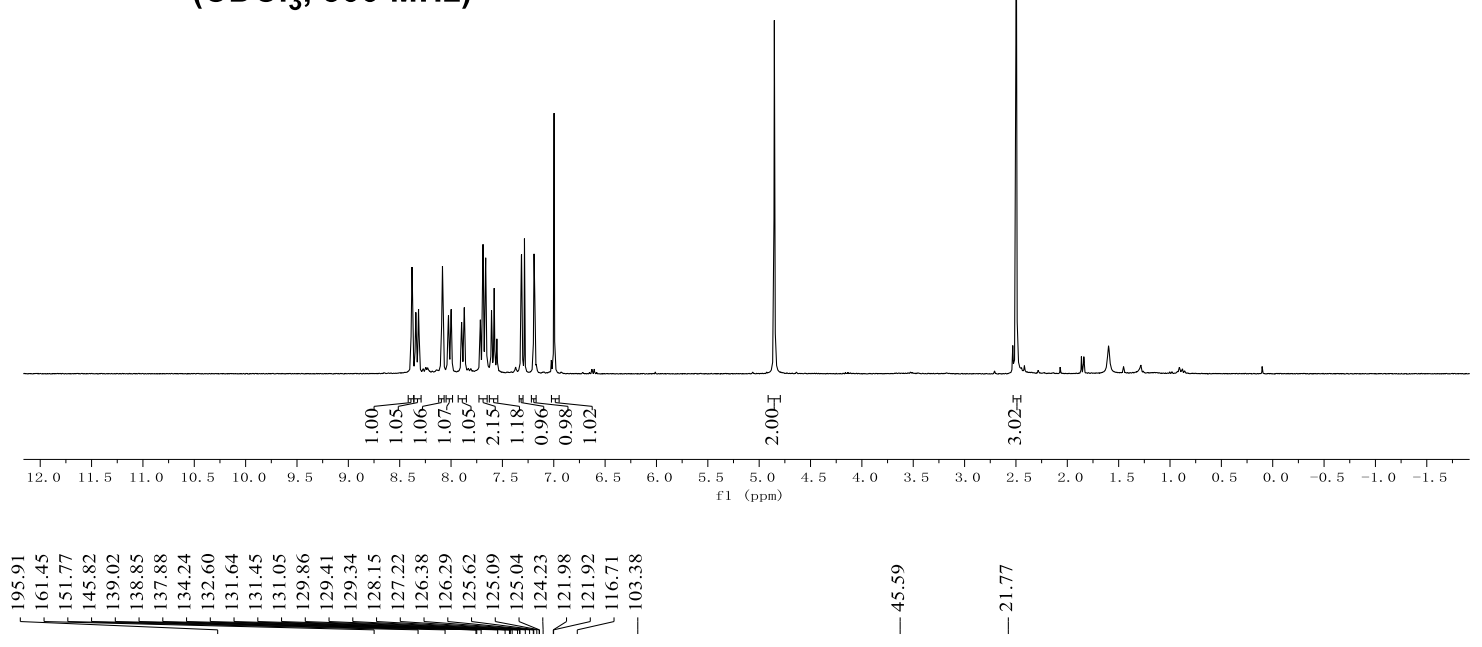<smiles>Cc1cc(CC(=O)c2cccc(C(F)(F)F)c2)c2c(=O)oc(-c3cccc(C(F)(F)F)c3)cc2c1</smiles>

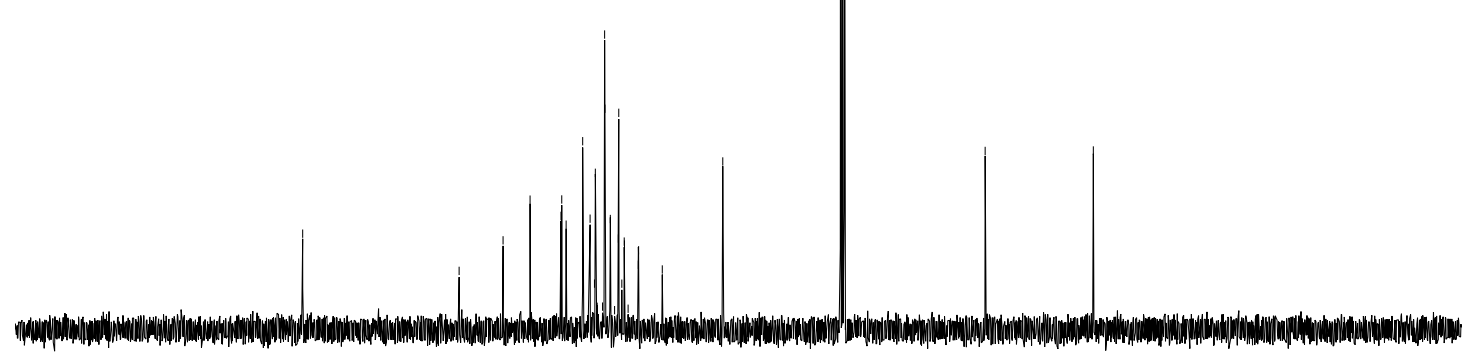



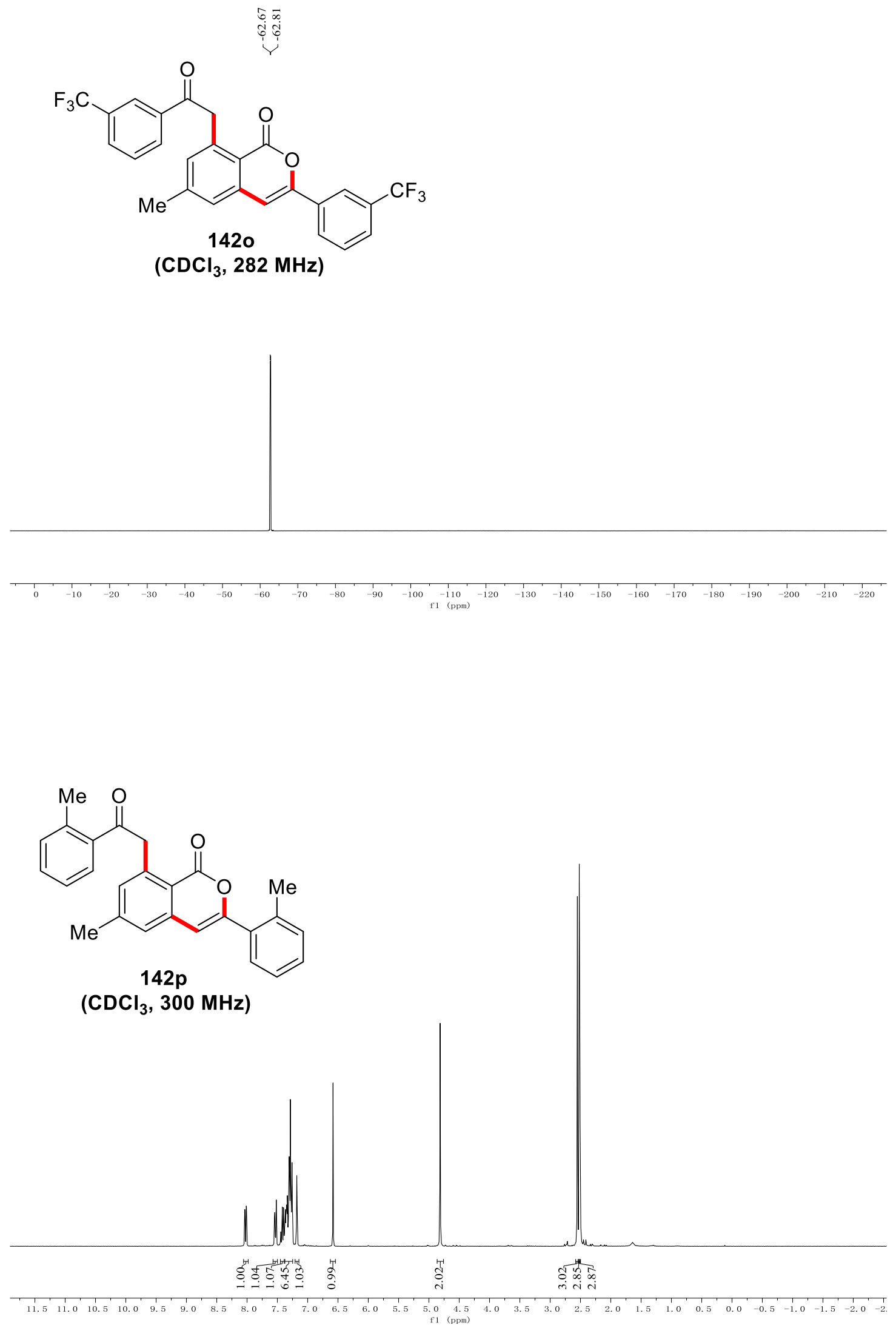


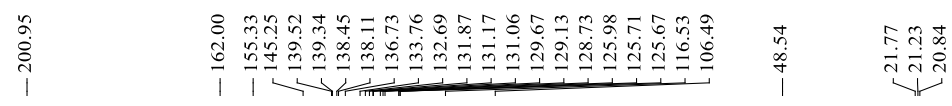

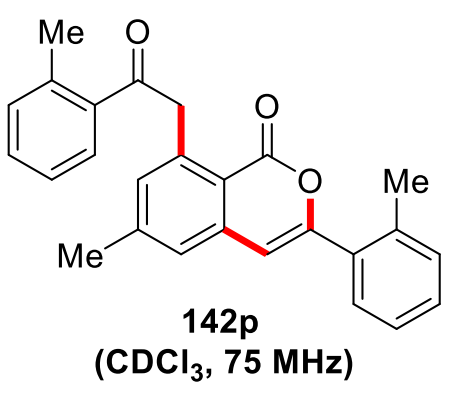
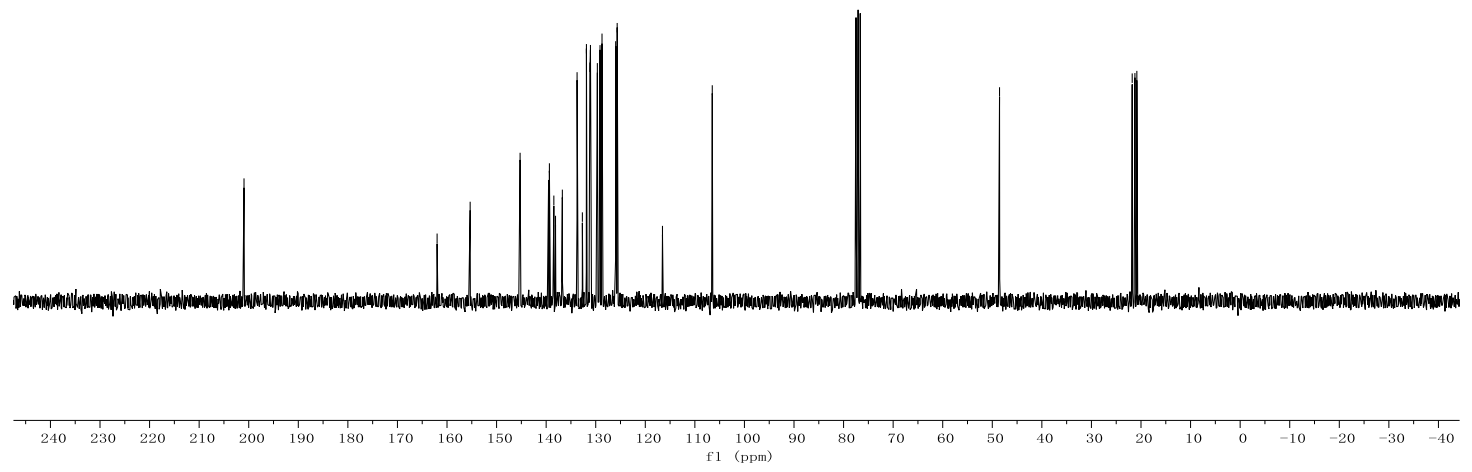<smiles>Cc1ccc(C(=O)Cc2cccc3cc(-c4ccc(C)cc4)oc(=O)c23)cc1</smiles>

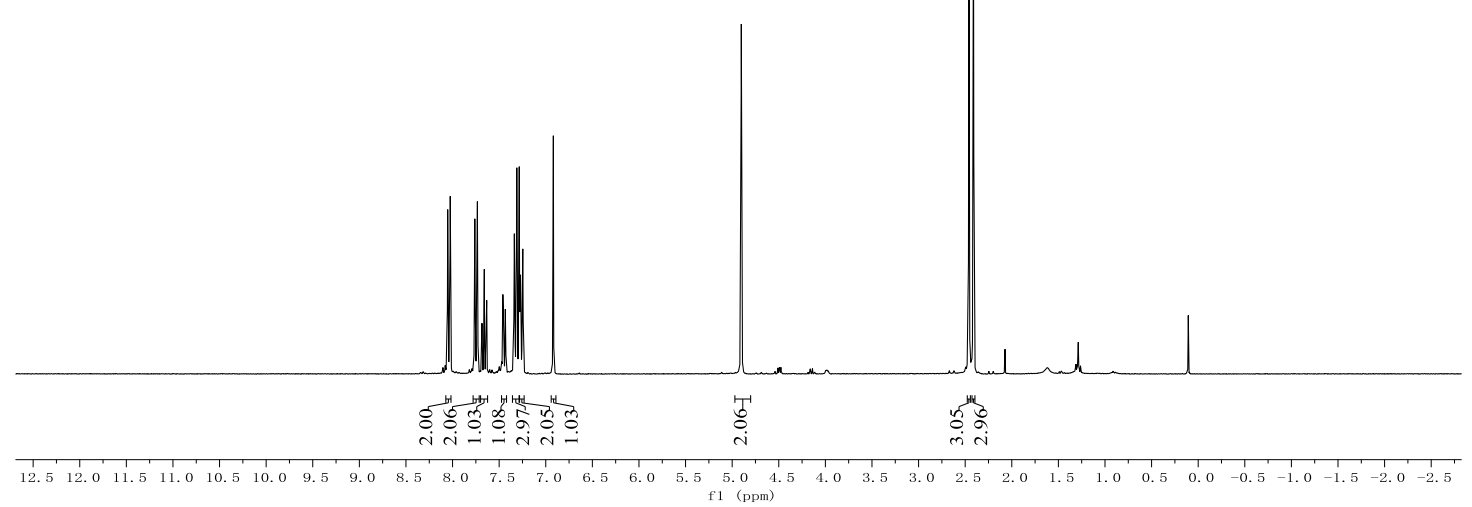




\section{NMR Spectra}

$\begin{array}{ll}n & \\ \infty & 0 \\ 0 & 0\end{array}$

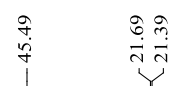<smiles>Cc1ccc(C(=O)Cc2cccc3cc(C4CCCCC4)oc(=O)c23)cc1</smiles>

$\left(\mathrm{CDCl}_{3}, 75 \mathrm{MHz}\right)$

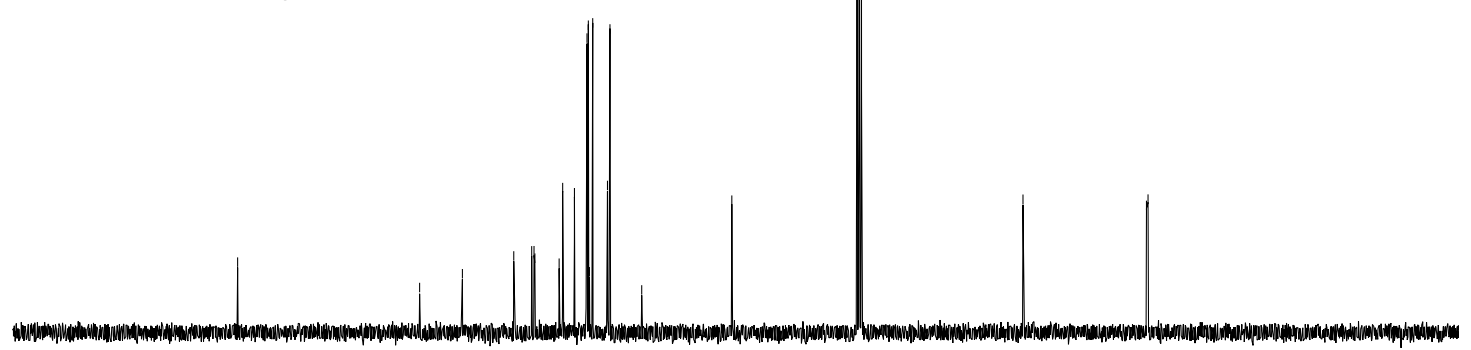

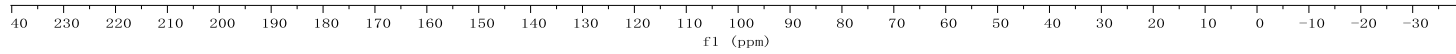

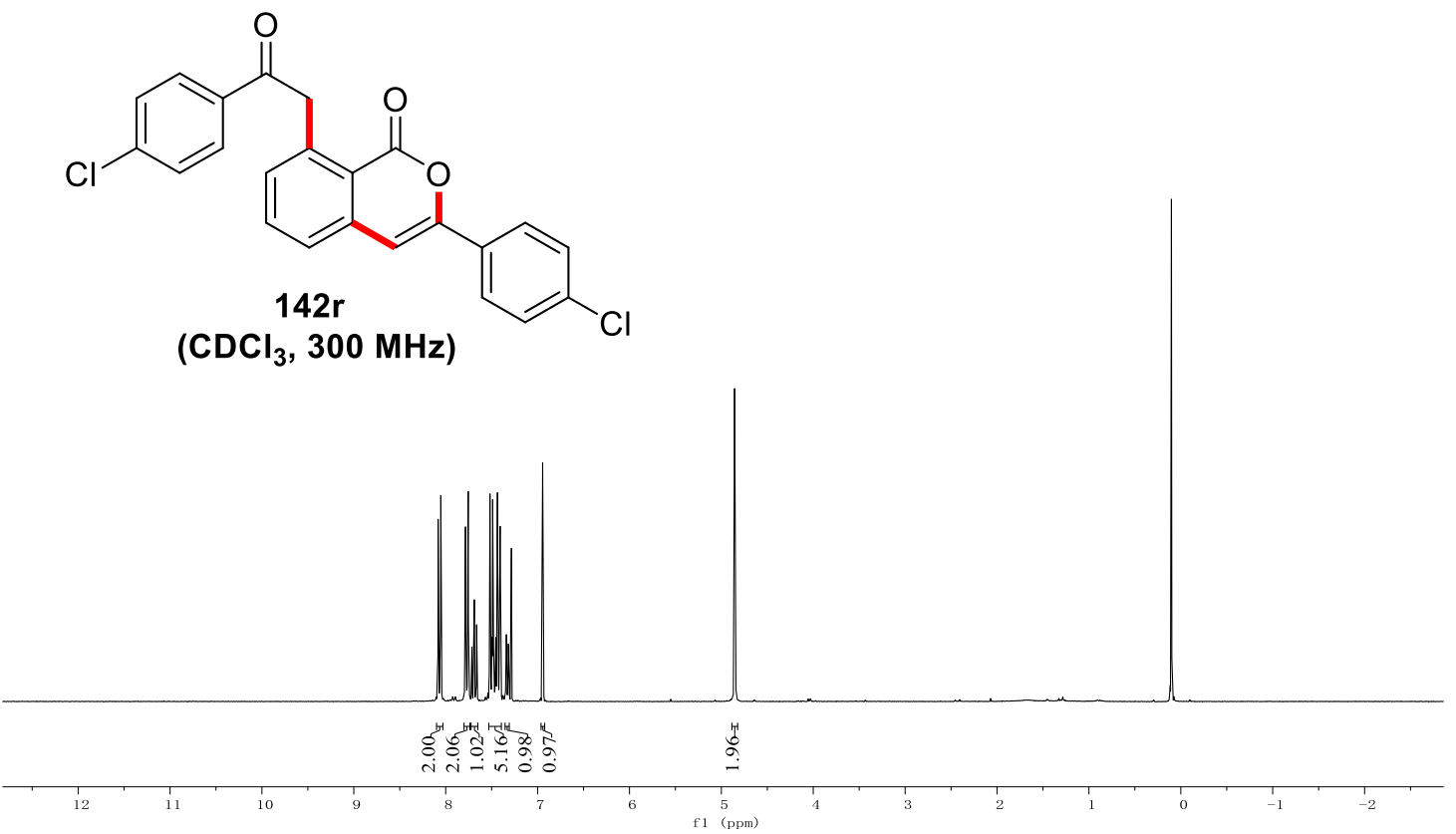




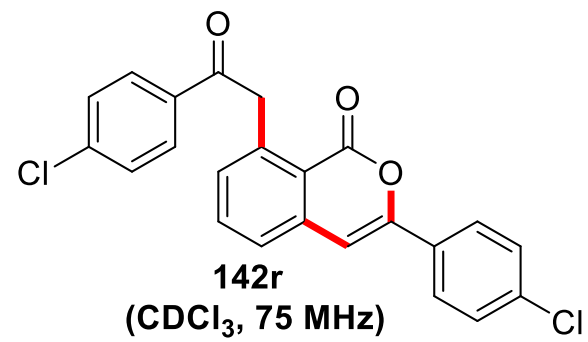
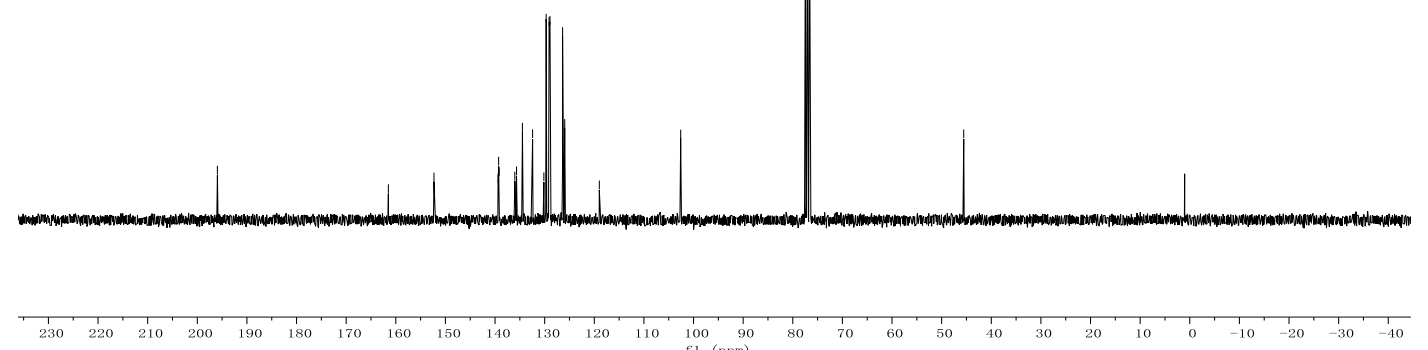

\subsection{Ruthenium(II)-Catalyzed DPP Annulation}

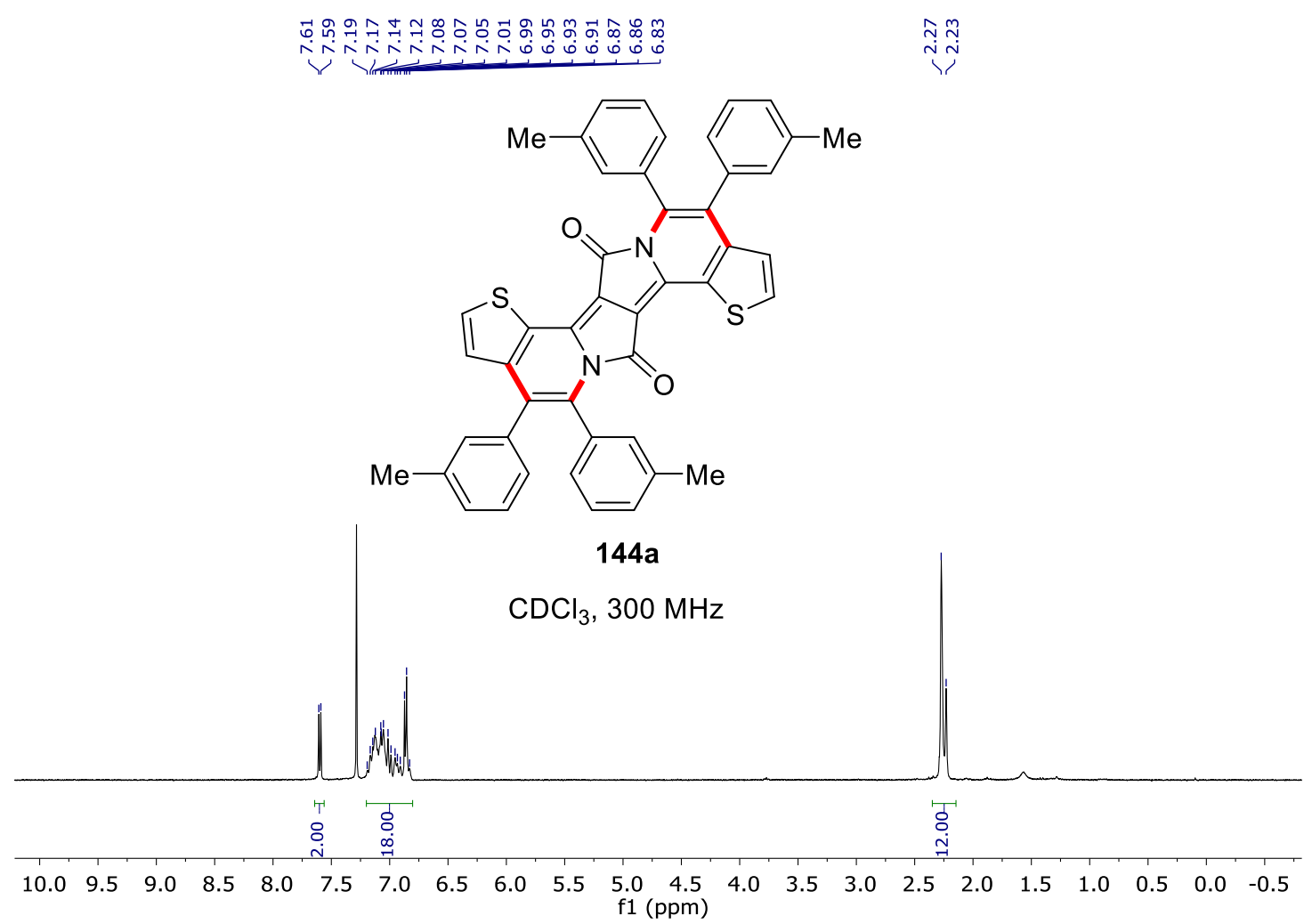



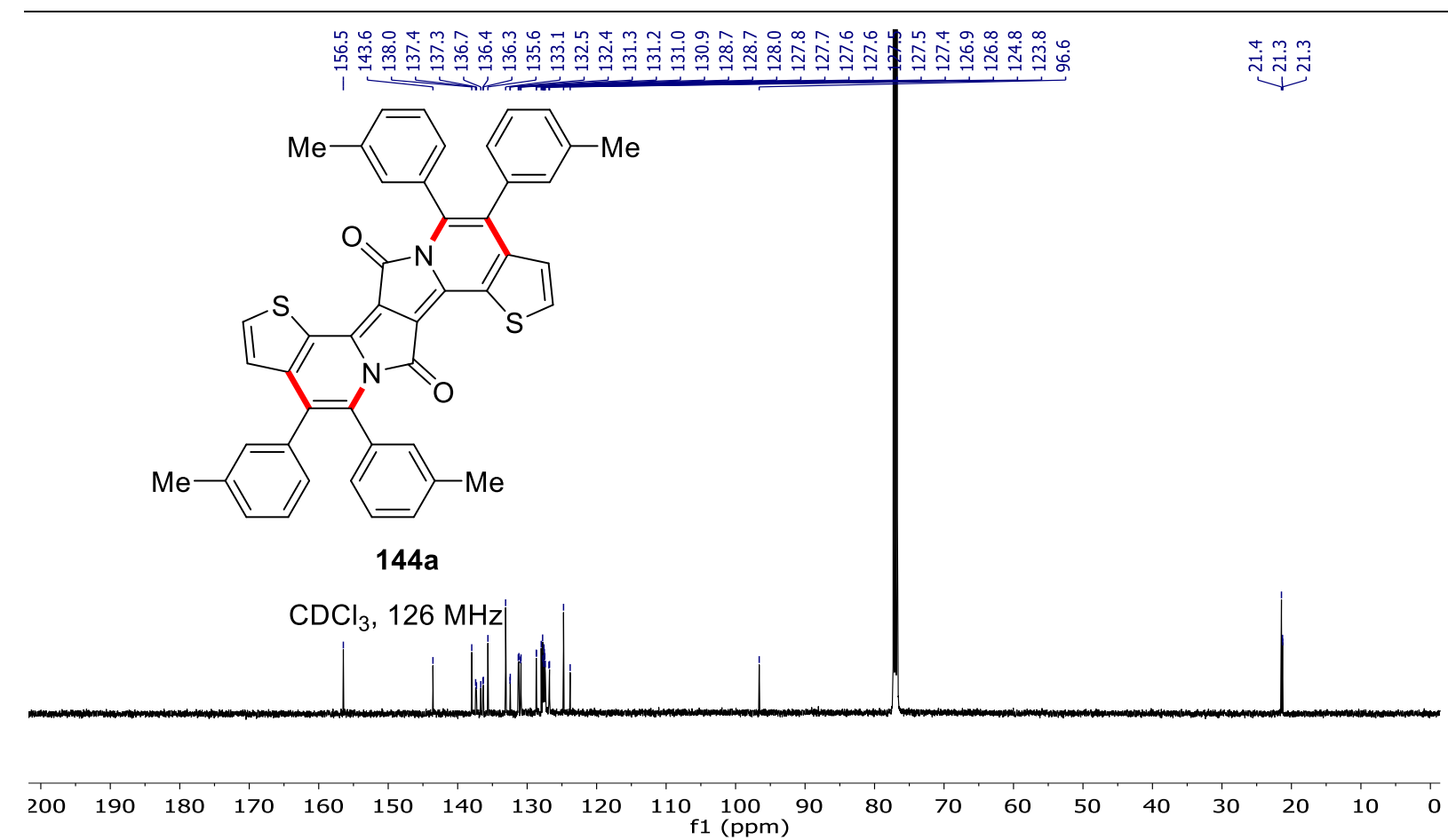

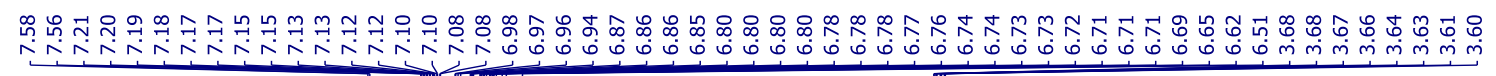

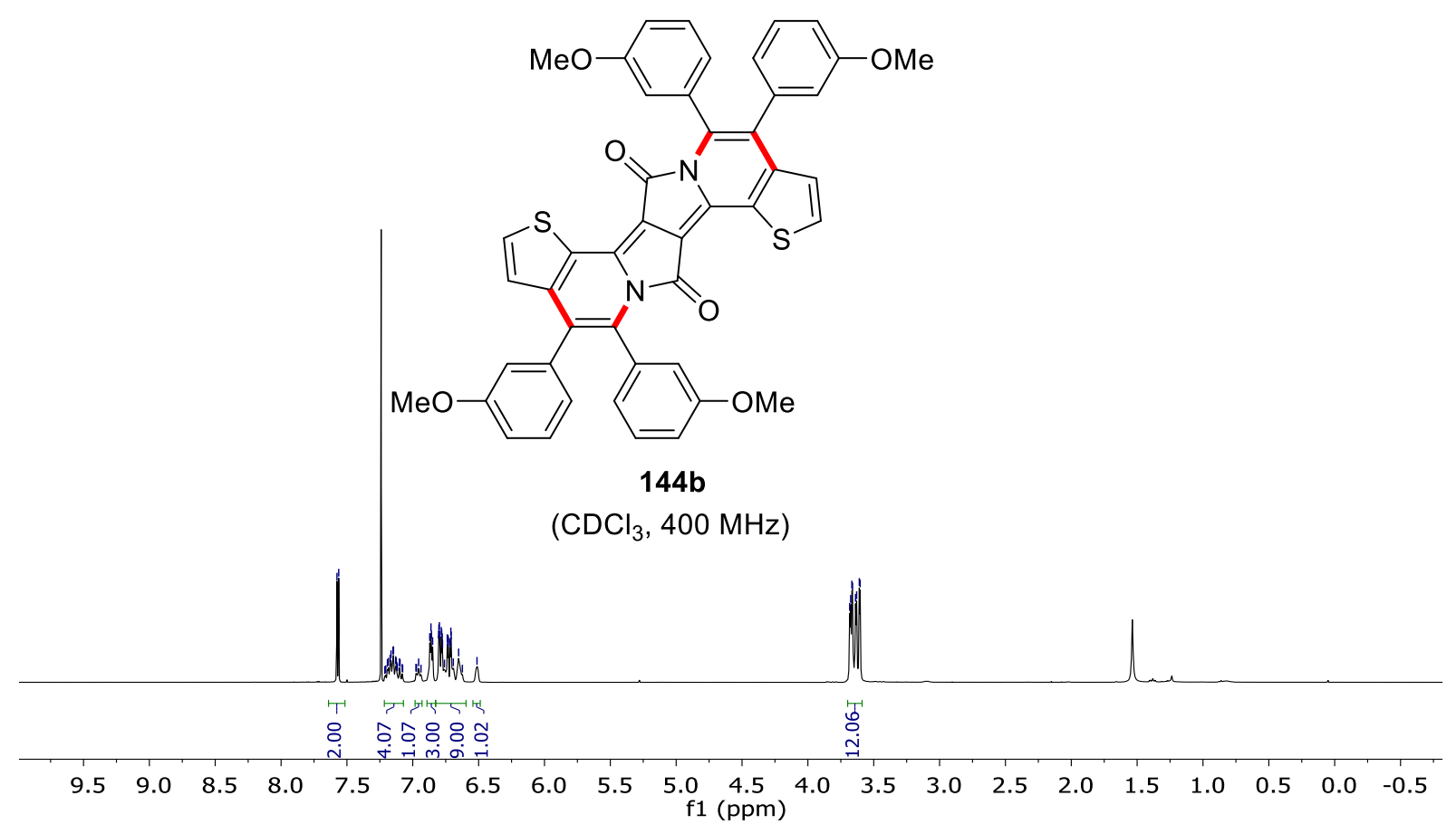




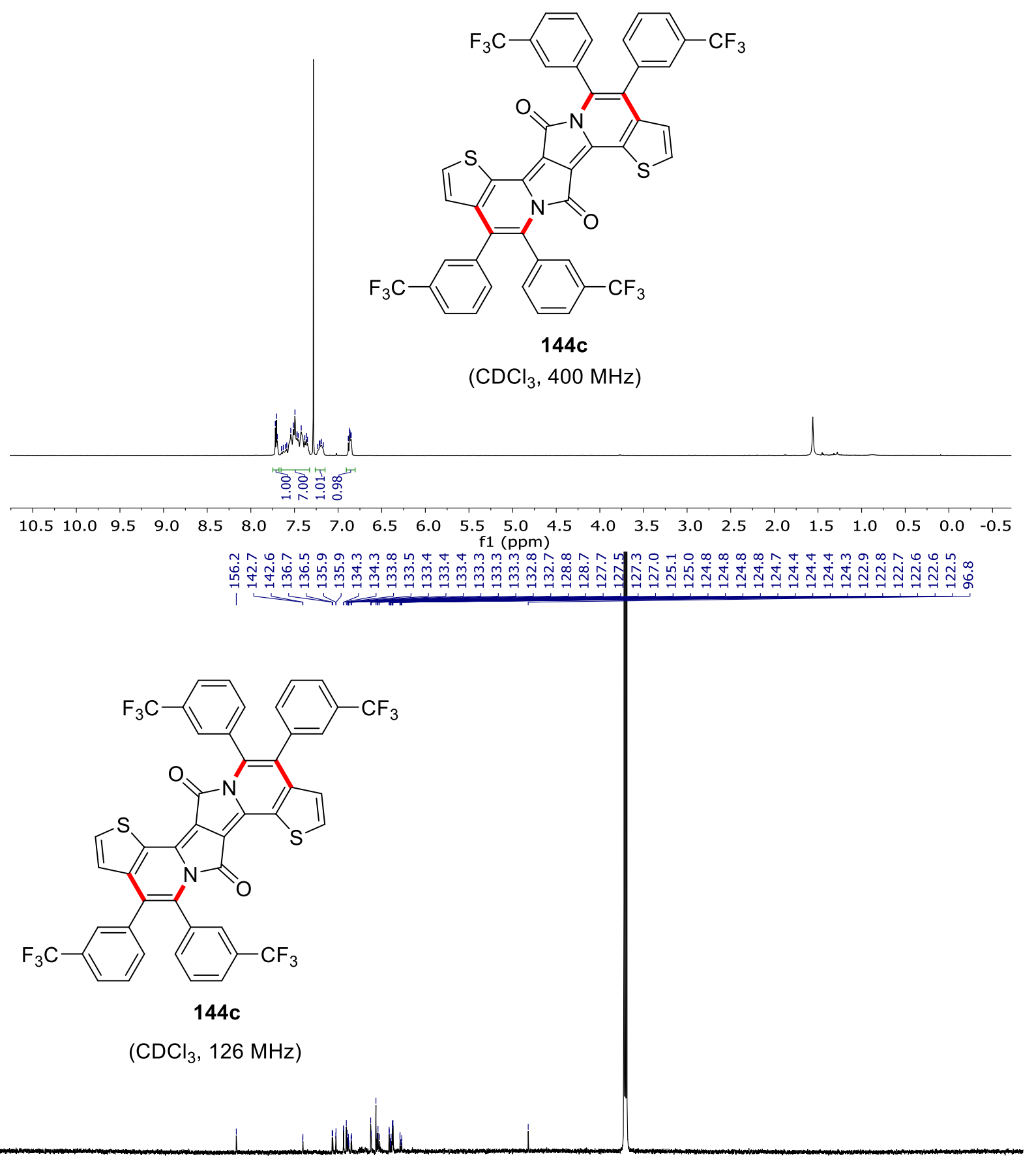

$\begin{array}{lllllllllllllllllllll}1 & 190 & 180 & 170 & 160 & 150 & 140 & 130 & 120 & \begin{array}{c}110 \\ \mathrm{f} 1(\mathrm{ppm})\end{array} & 100 & 90 & 70 & 60 & 50 & 40 & 30 & 20 & 10 & 0\end{array}$




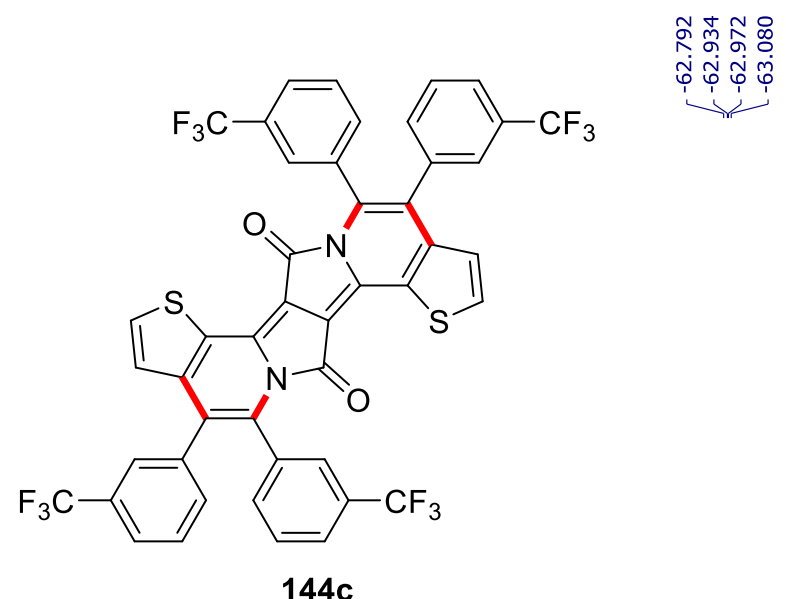

$\left(\mathrm{CDCl}_{3}, 477 \mathrm{MHz}\right)$

\begin{tabular}{|c|c|c|c|c|c|c|c|c|c|c|c|}
\hline 30 & -35 & -40 & -45 & -50 & -55 & $\begin{array}{l}-60 \\
\mathrm{f} 1\end{array}$ & -65 & -70 & -75 & -80 & -85 \\
\hline
\end{tabular}

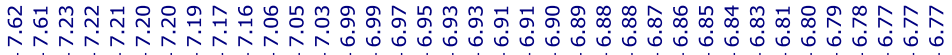

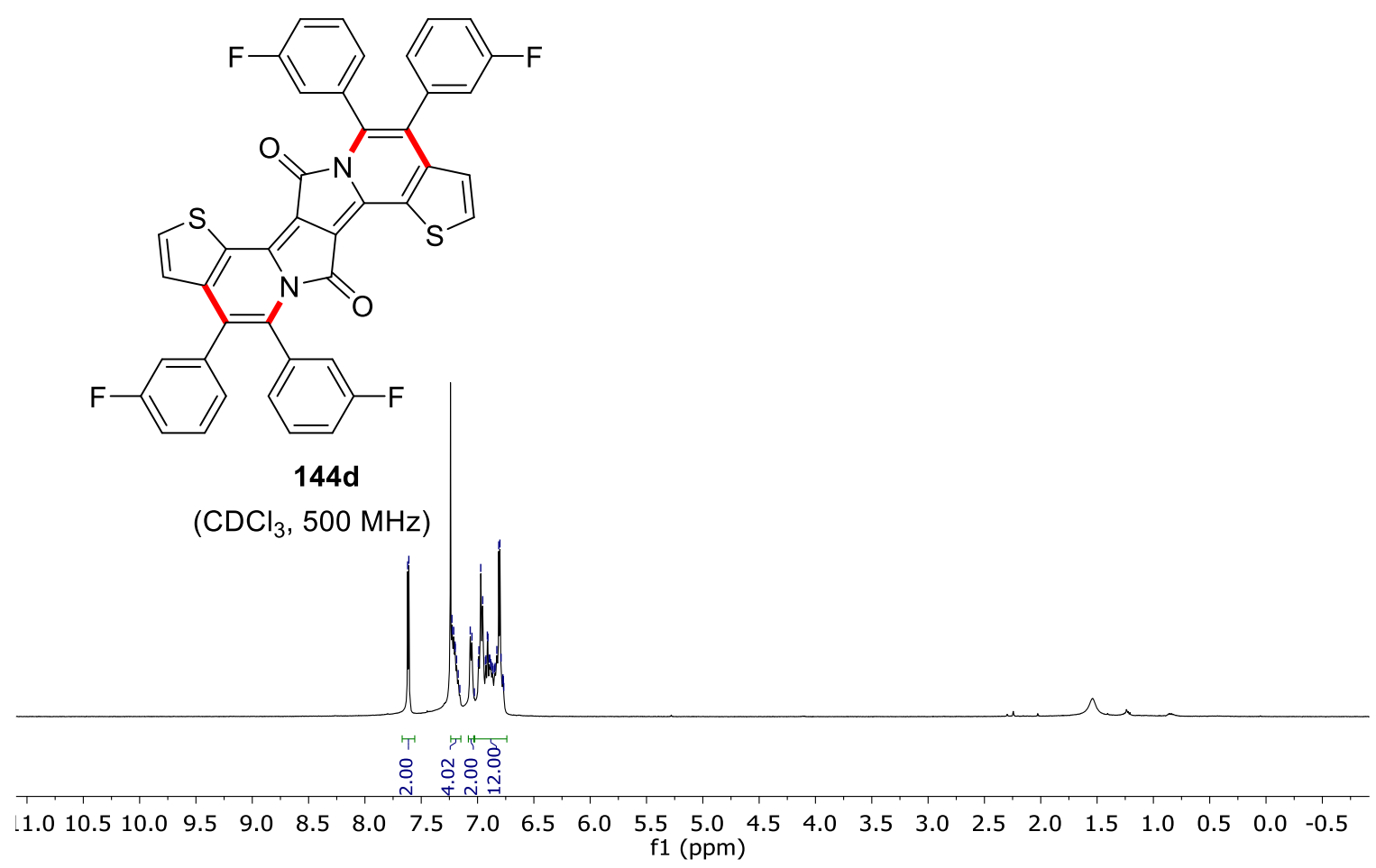




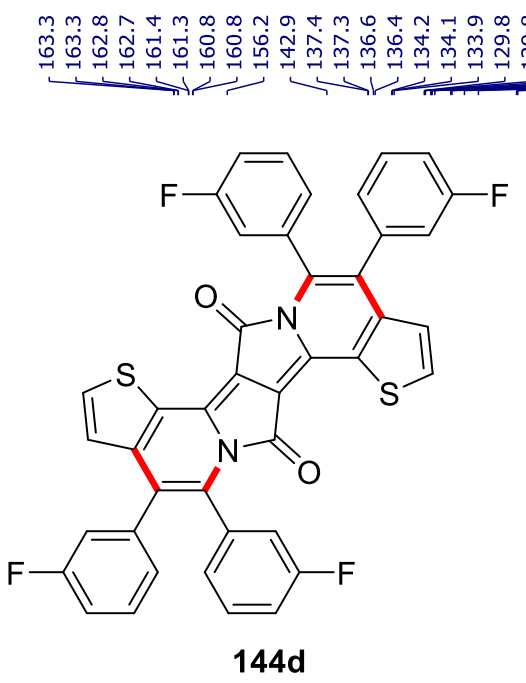

$\left(\mathrm{CDCl}_{3}, 126 \mathrm{MHz}\right)$
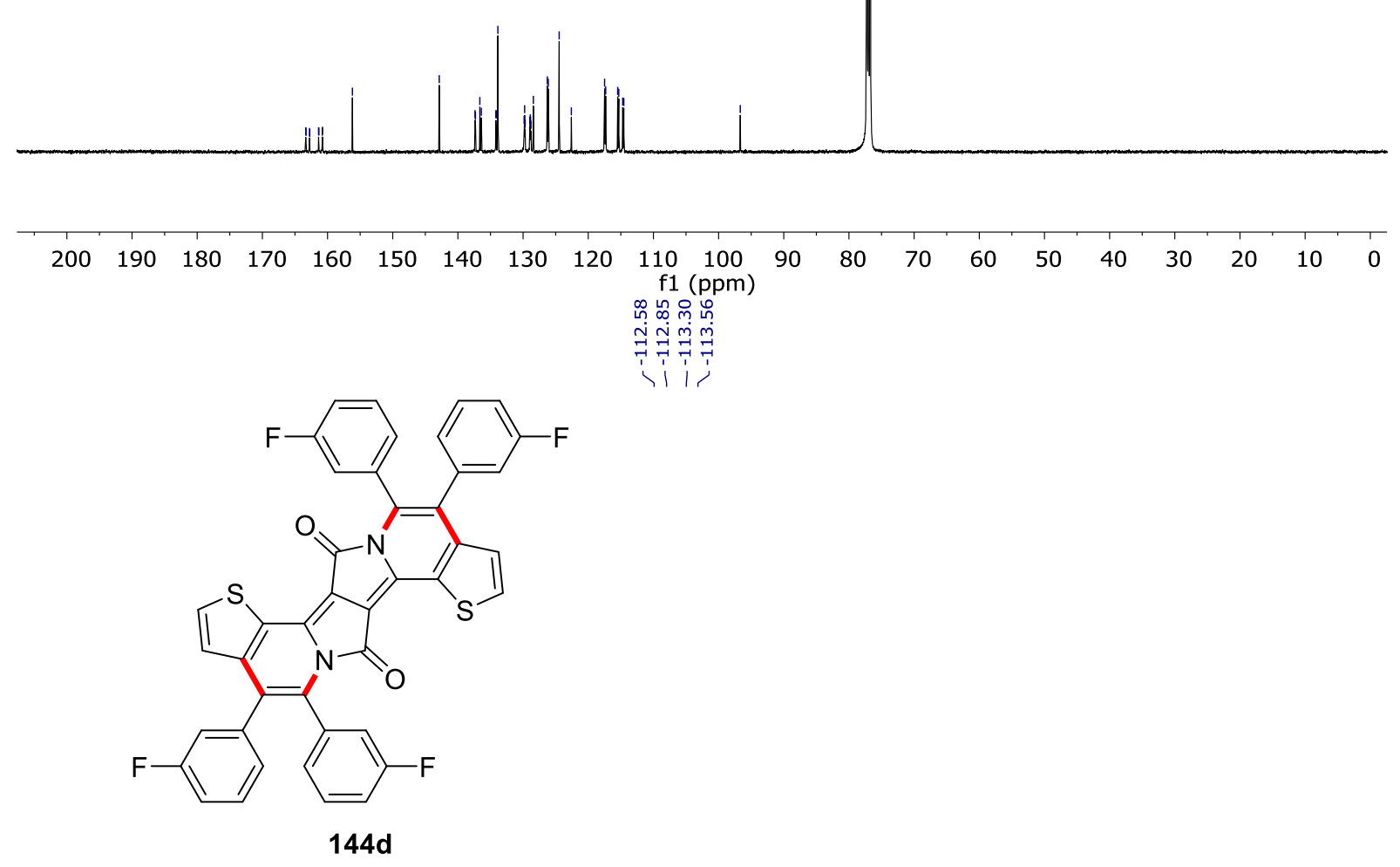

$\left(\mathrm{CDCl}_{3}, 471 \mathrm{MHz}\right)$

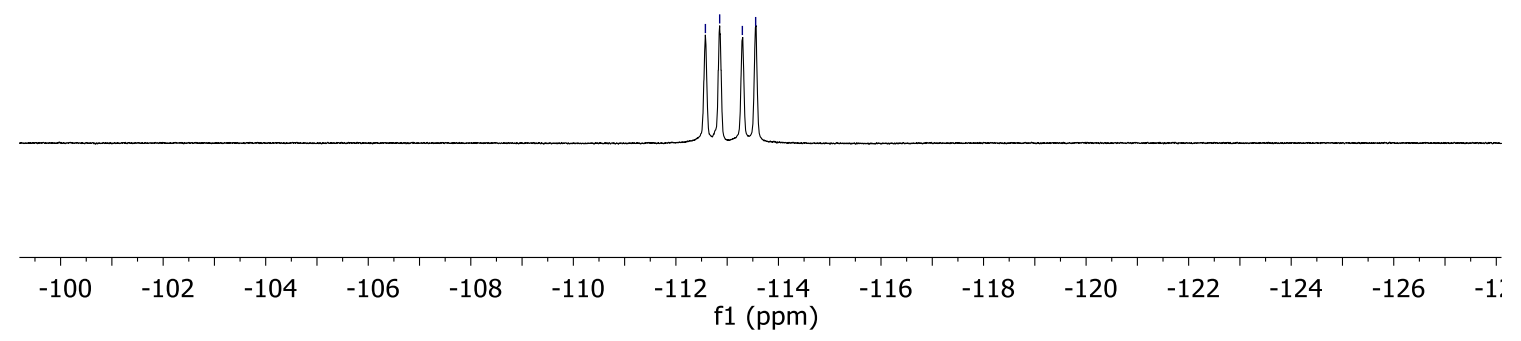




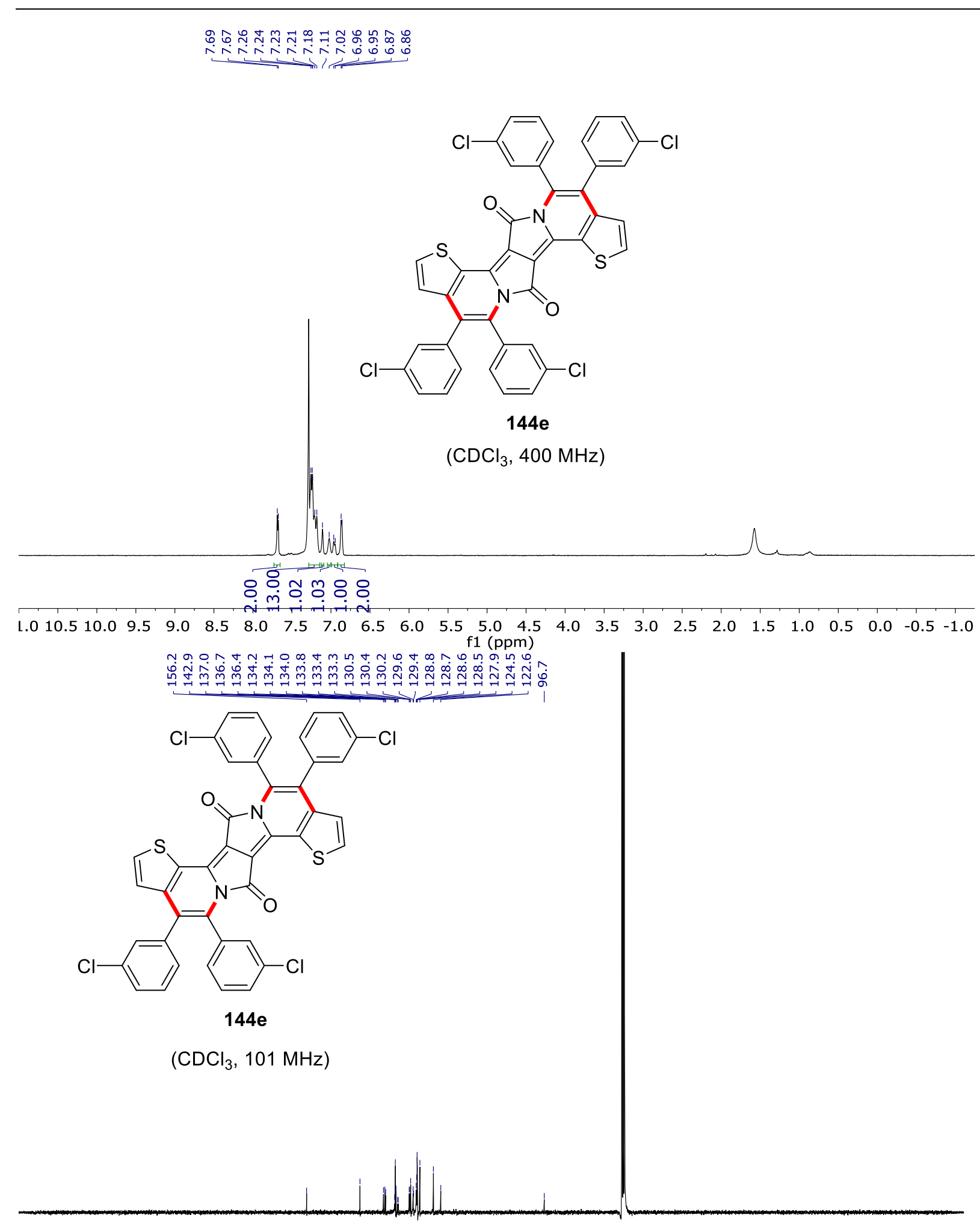

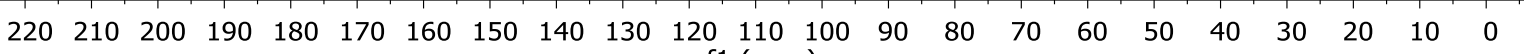
f1 (ppm) 


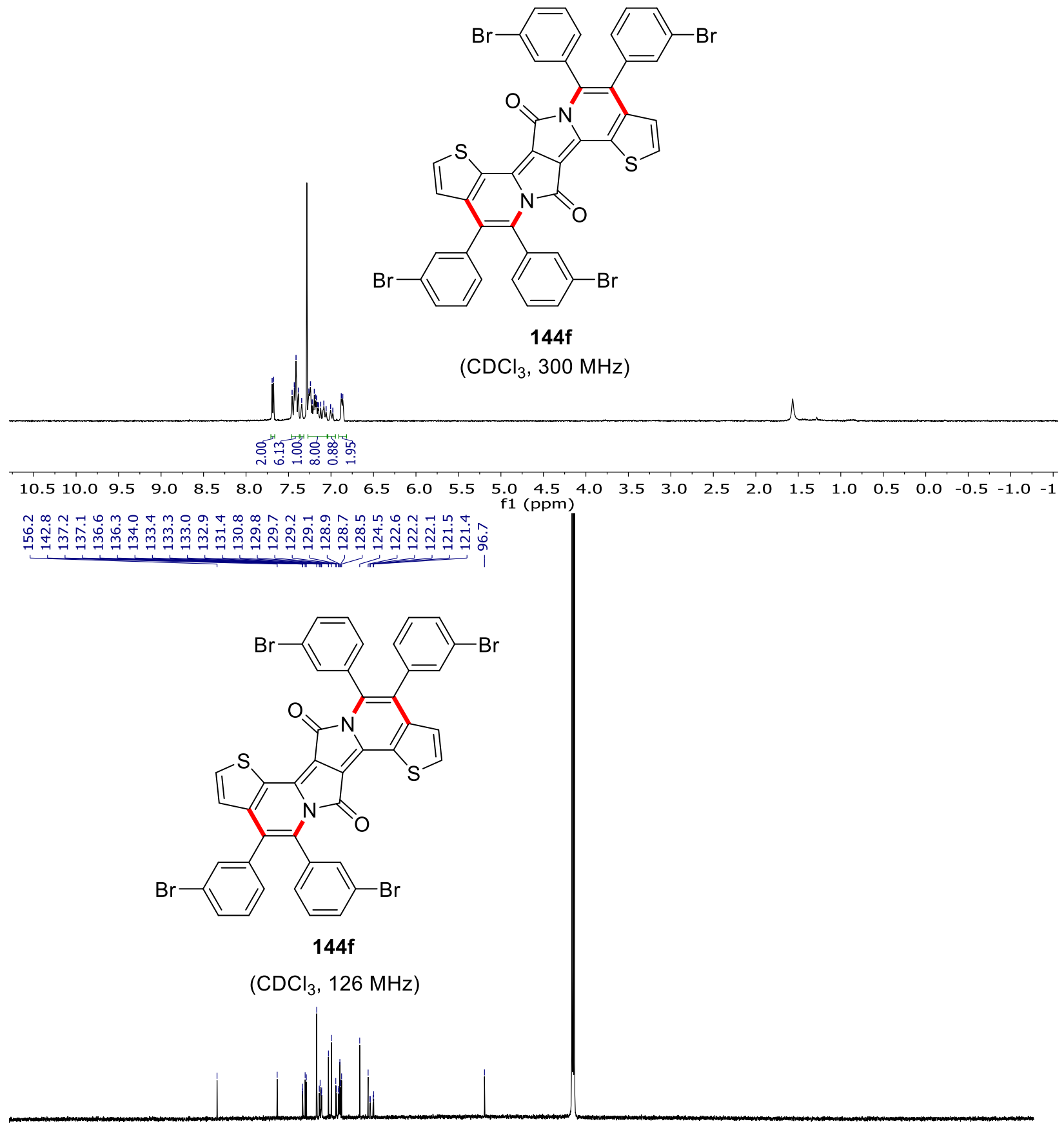

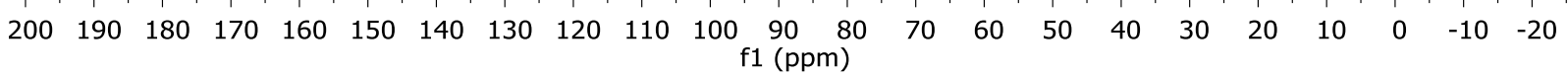


NMR Spectra

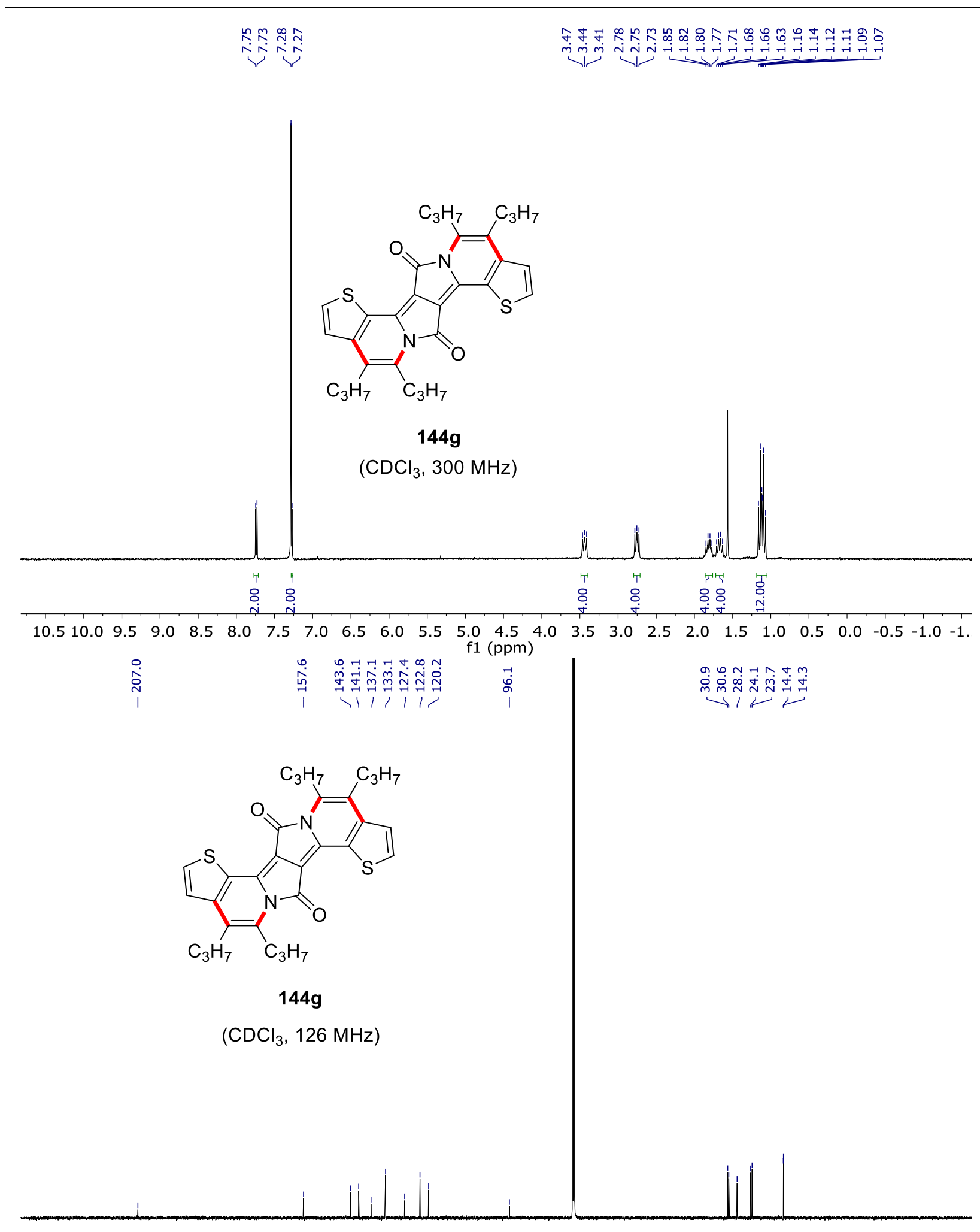

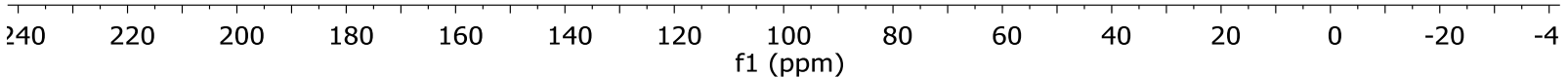


NMR Spectra

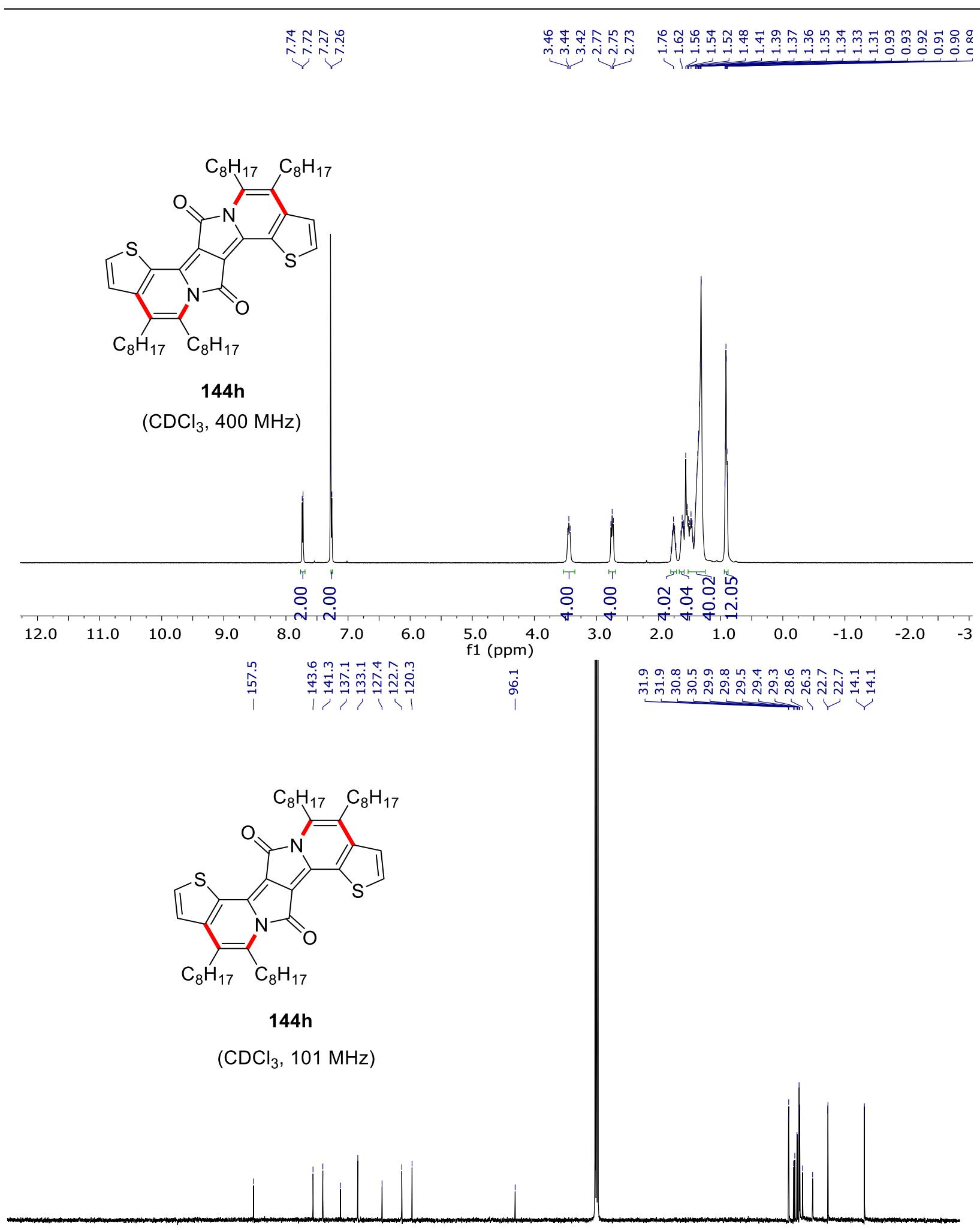

$\begin{array}{llllllllllllllllllllll}210 & 200 & 190 & 180 & 170 & 160 & 150 & 140 & 130 & 120 & 110 & 100 & 90 & 80 & 70 & 60 & 50 & 40 & 30 & 20 & 10 & 0\end{array}$ 


\subsection{Ruthenaelectro(II/III/I)-Catalyzed Annulation}

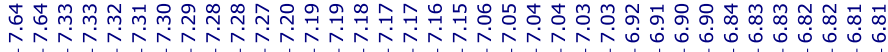

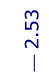<smiles>Cc1c(-c2ccccc2)c(-c2ccccc2)c(-c2ccccc2)n2ccnc12</smiles>

$146 a$

(300 MHz, $\mathrm{CDCl}_{3}$ )

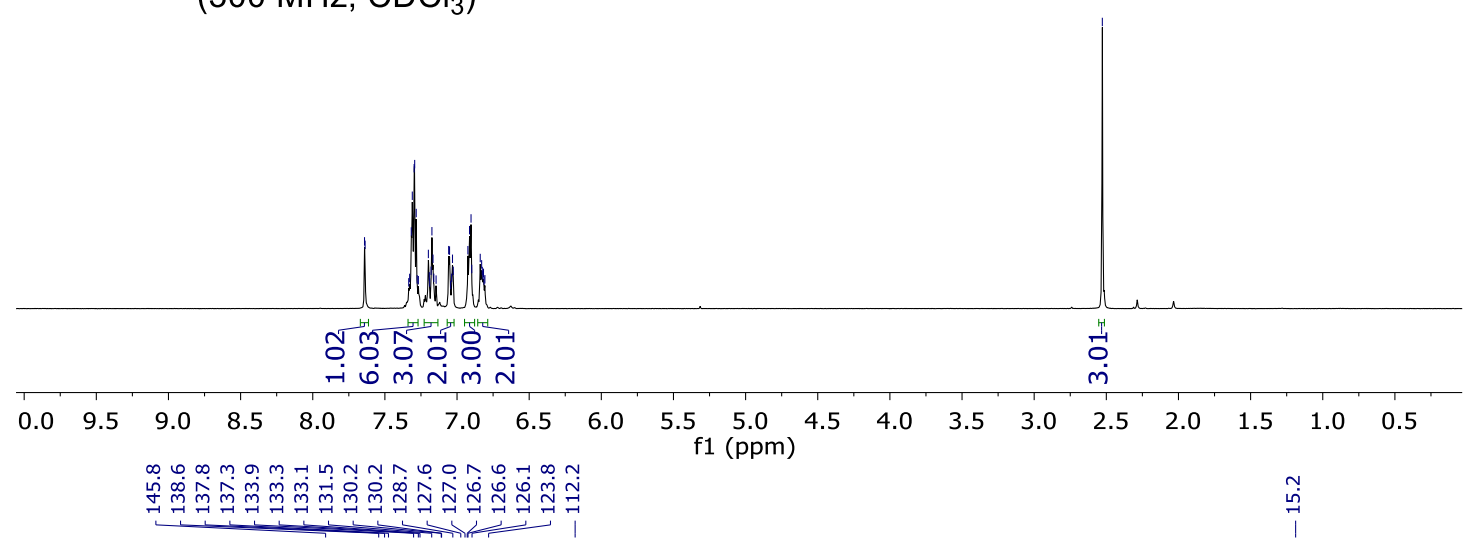<smiles>Cc1c(-c2ccccc2)c(-c2ccccc2)c(-c2ccccc2)n2ccnc12</smiles>

146

(101 $\mathrm{MHz}, \mathrm{CDCl}_{3}$ )

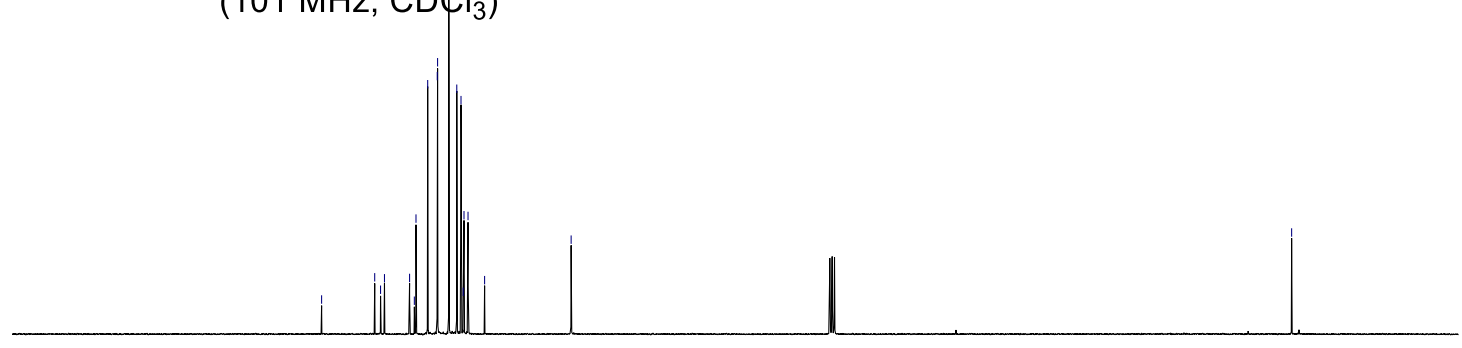

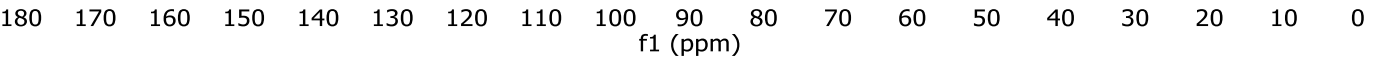




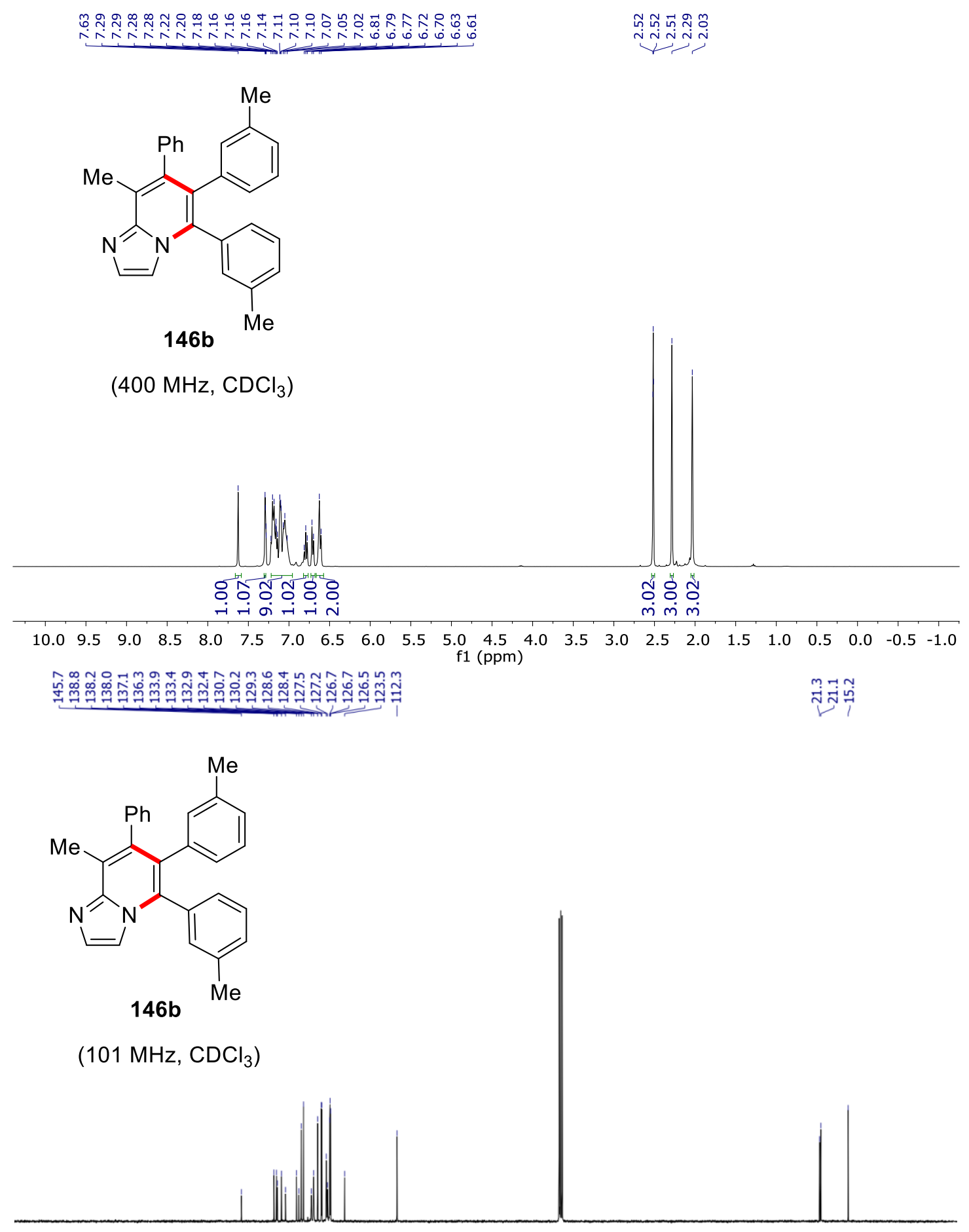

$\begin{array}{lllllllllllllllllll}190 & 180 & 170 & 160 & 150 & 140 & 130 & 120 & 110 & \underset{f 1}{100} \underset{(\mathrm{ppm})}{90} & 80 & 70 & 60 & 50 & 40 & 30 & 20 & 10 & 0\end{array}$ 

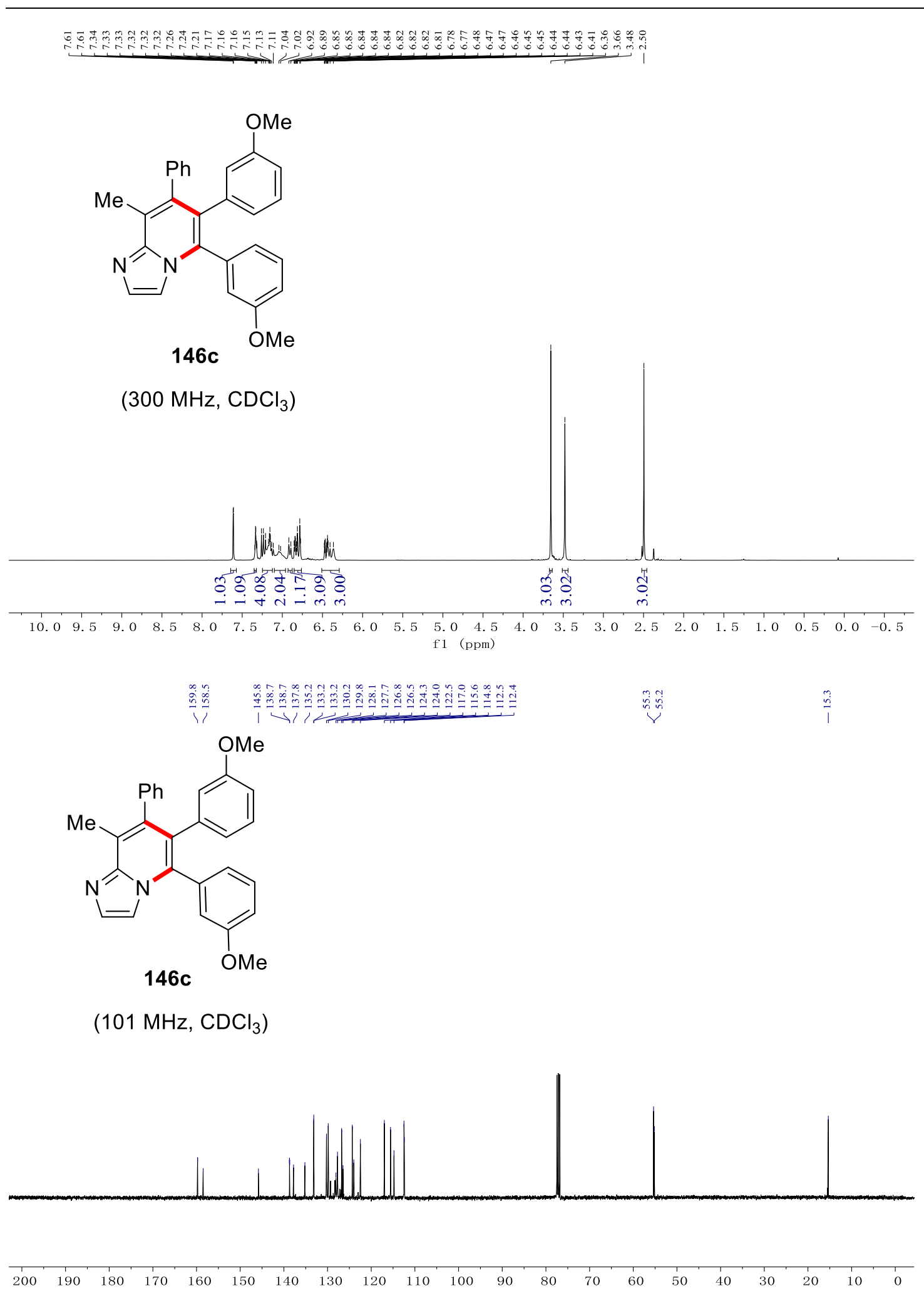
<smiles>Cc1c(-c2ccccc2)c(-c2cccc(C(F)(F)F)c2)c(-c2cccc(C(C)(C)C)c2)n2ccnc12</smiles>

(400 MHz, $\mathrm{CDCl}_{3}$ )

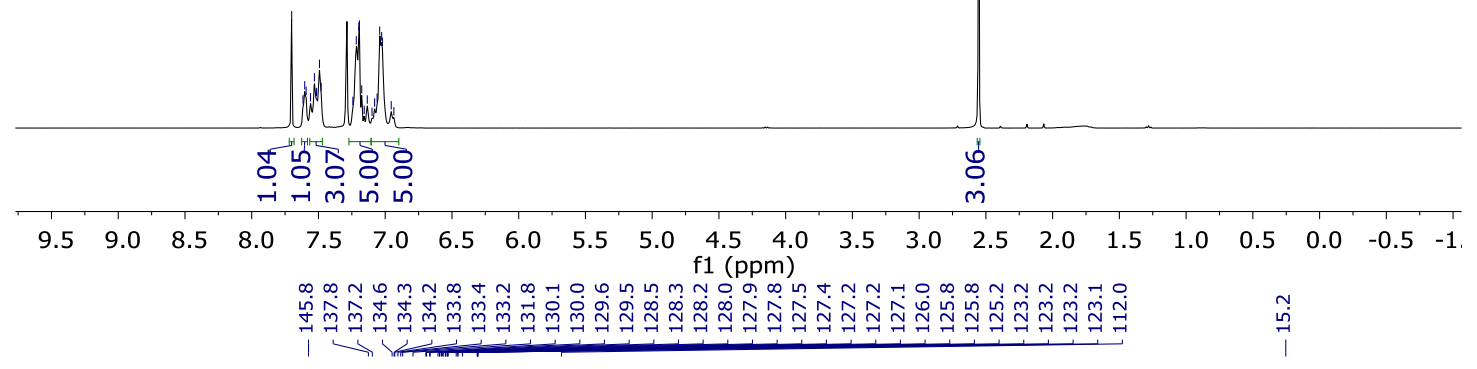<smiles>Cc1c(-c2ccccc2)c(-c2cccc(C(F)(F)F)c2)c(-c2cccc(C(C)(C)C)c2)n2ccnc12</smiles>

(101 MHz, $\mathrm{CDCl}_{3}$ )

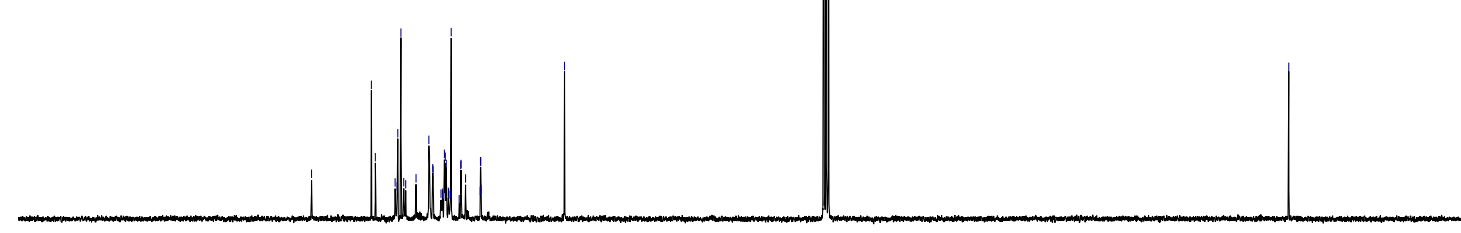

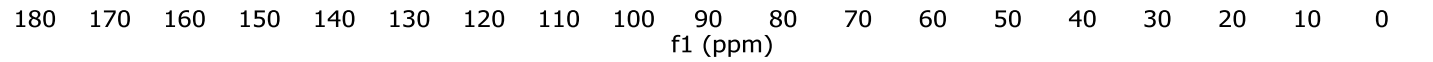




\section{NMR Spectra}

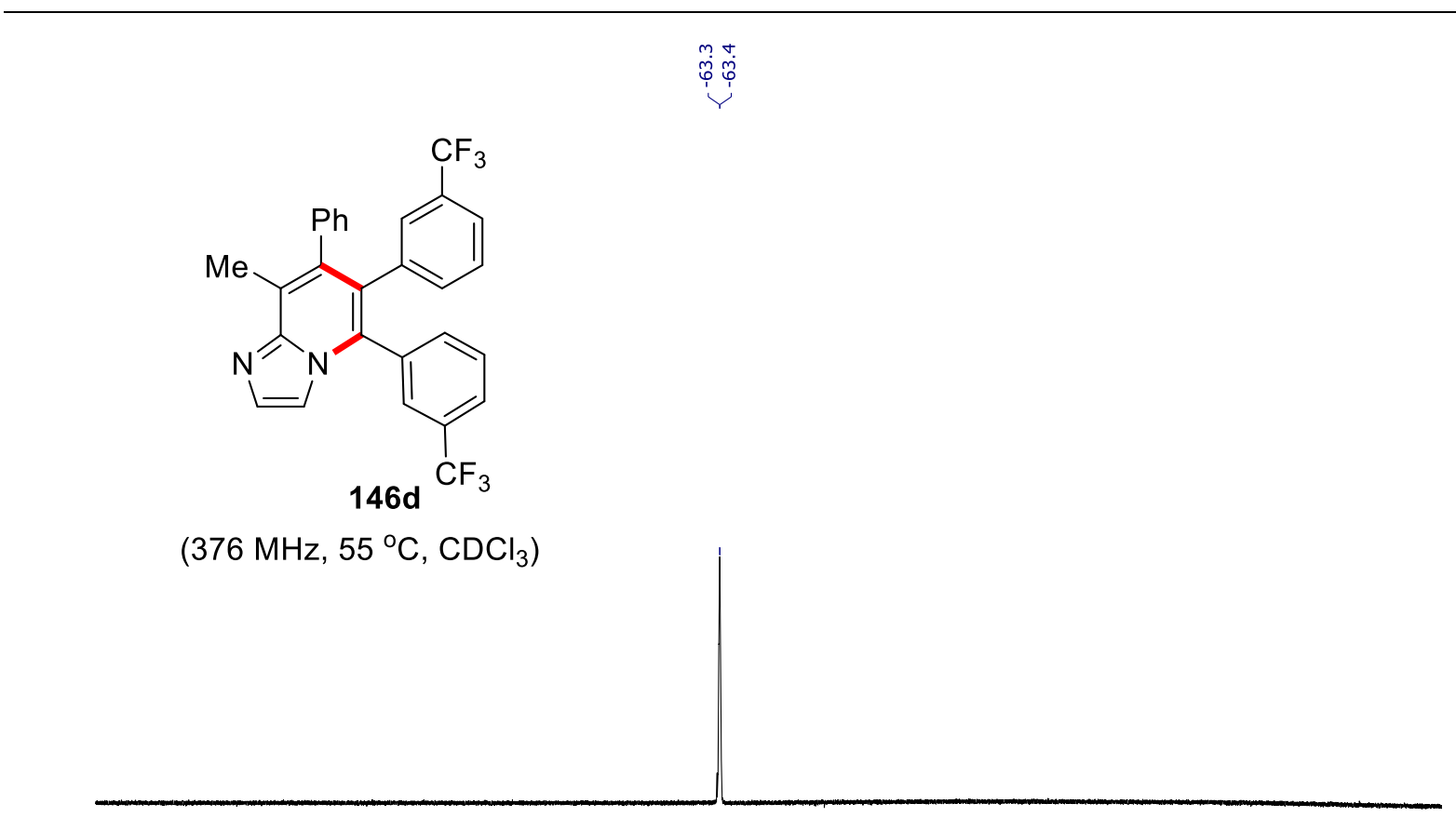

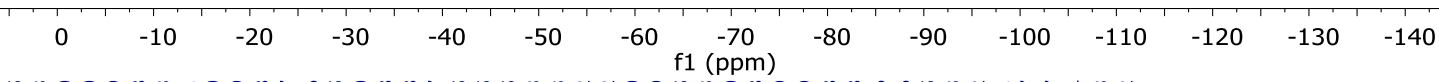

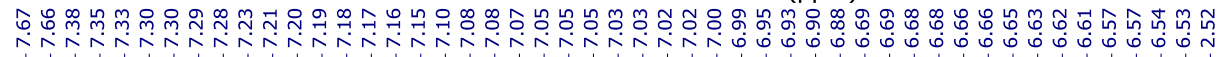<smiles>Cc1c(-c2ccccc2)c(-c2cccc(F)c2)c(-c2cccc(F)c2)n2ccnc12</smiles>

(300 MHz, $\mathrm{CDCl}_{3}$ )

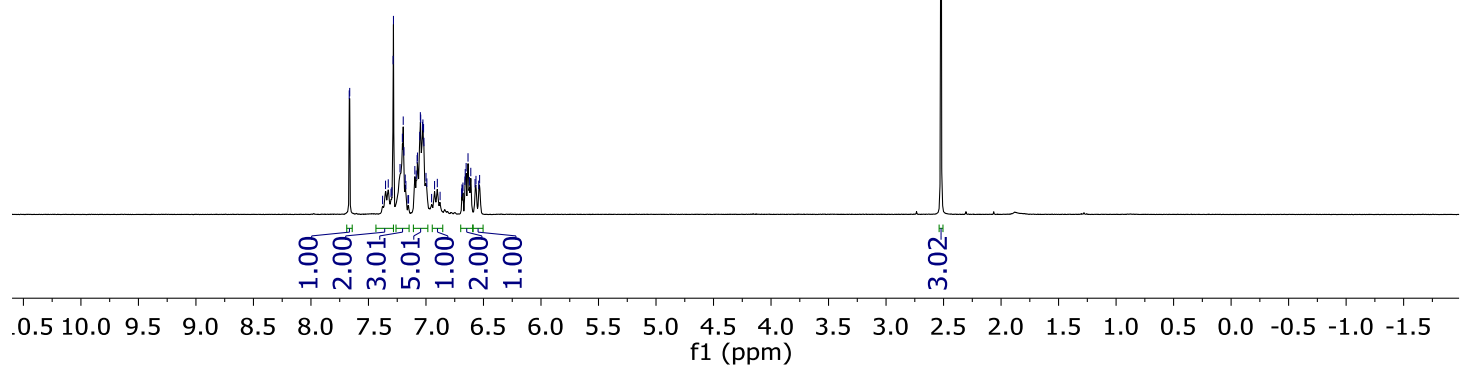



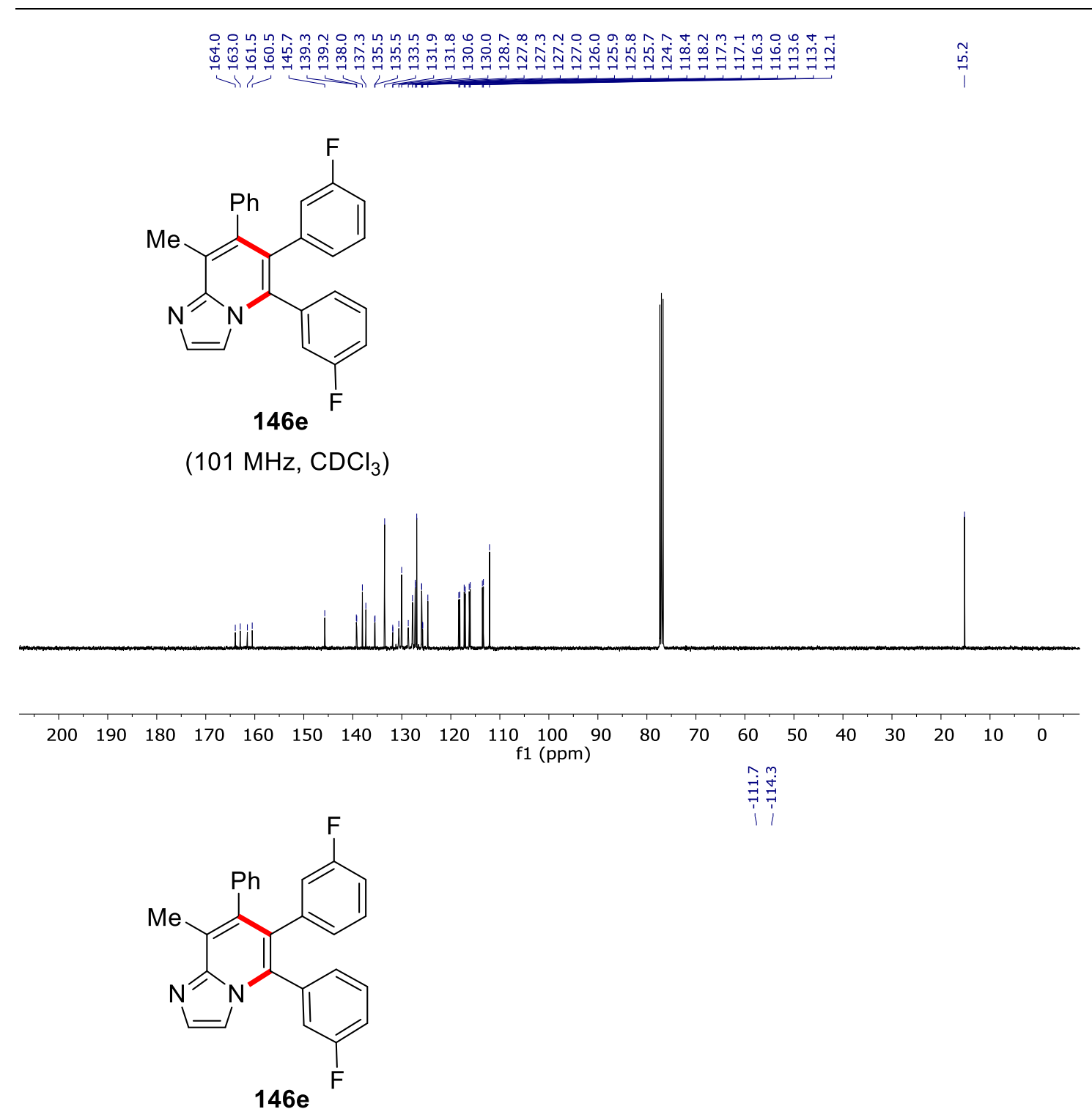

(376 MHz, $55^{\circ} \mathrm{C}, \mathrm{CDCl}_{3}$ )

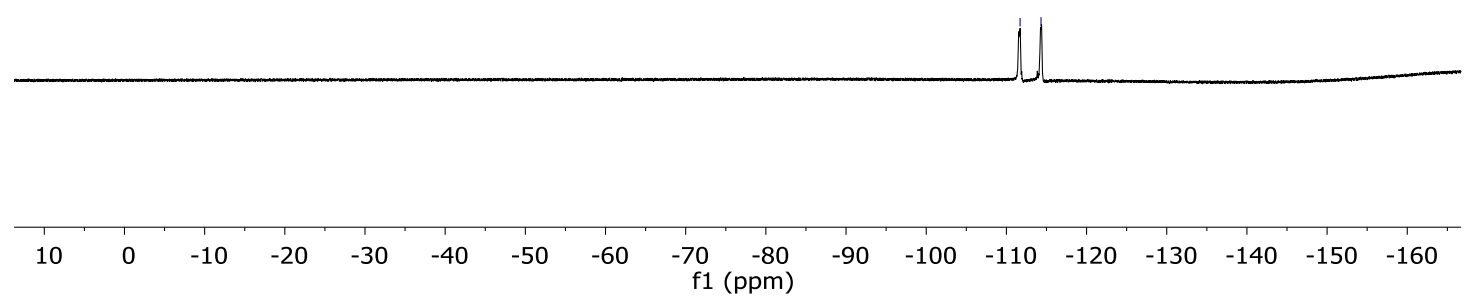




\section{NMR Spectra}

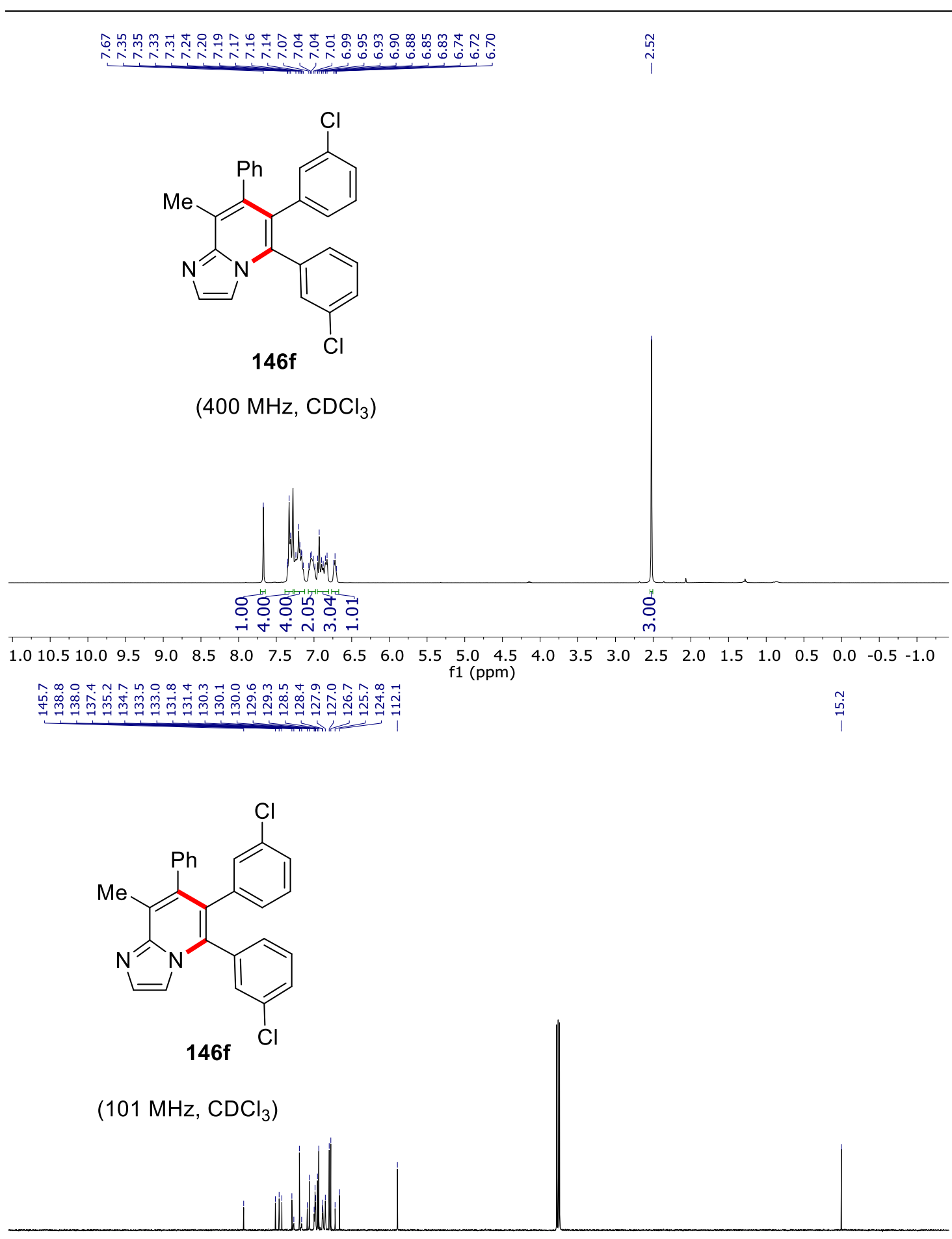

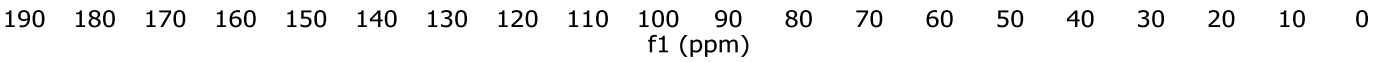




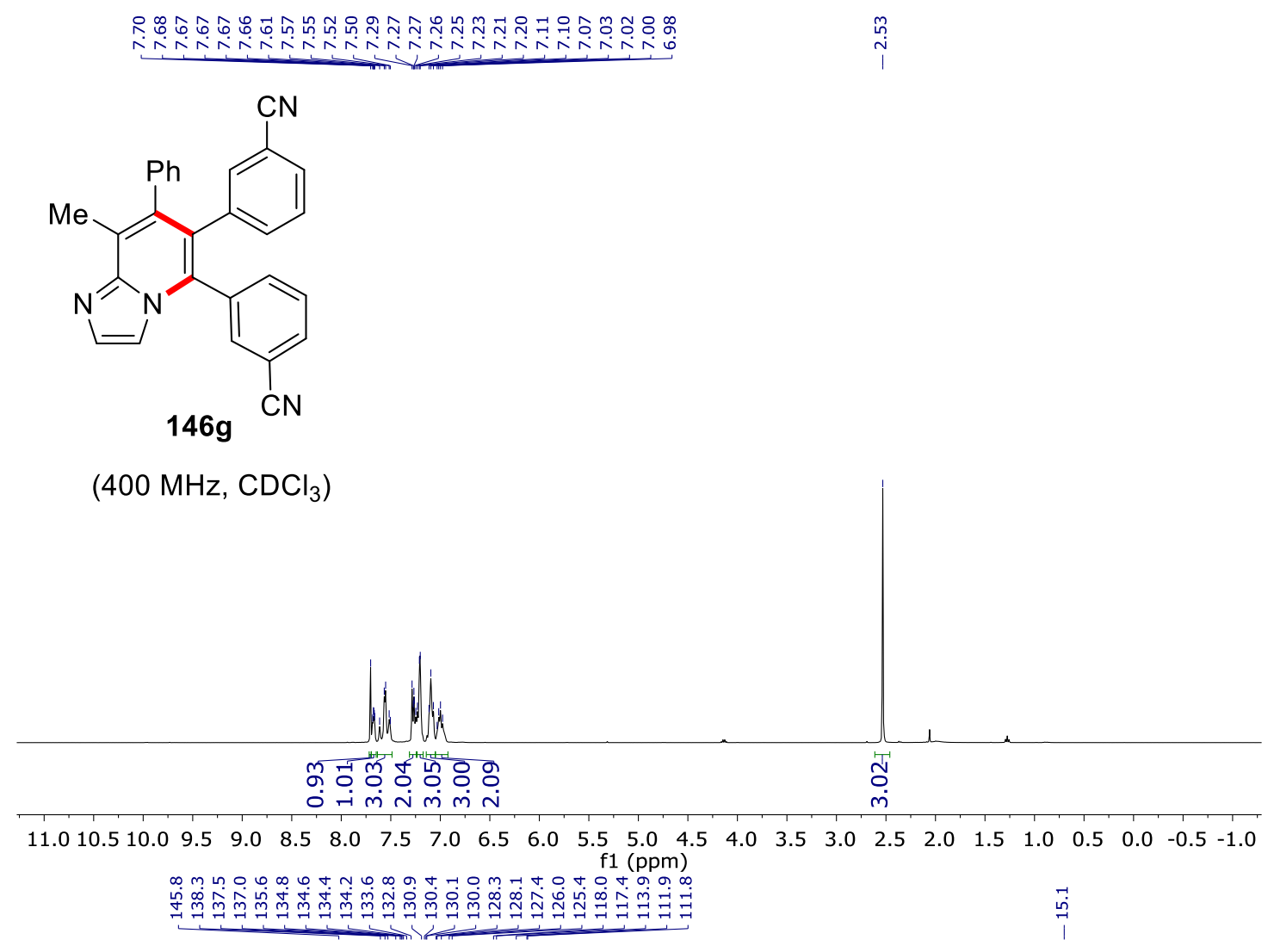<smiles>Cc1c(-c2cccc(C(C)(C)C)c2)c(-c2cccc(C#N)c2)c(-c2ccccc2)n2ccnc12</smiles>

$\left(101 \mathrm{MHz}, \mathrm{CDCl}_{3}, 55^{\circ} \mathrm{C}\right)$

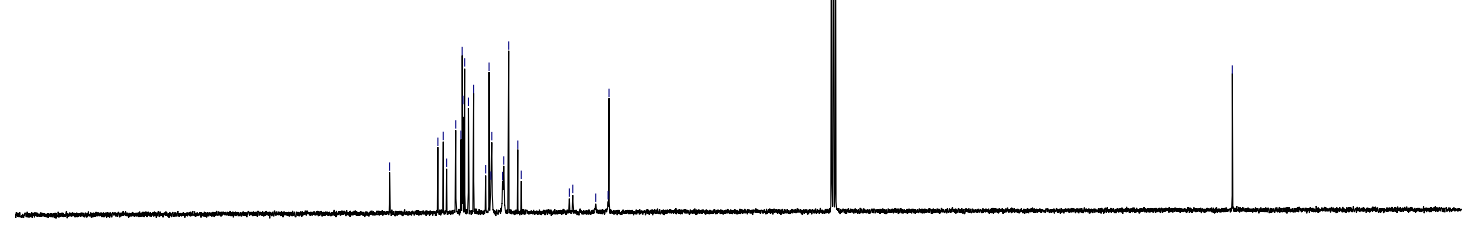

$\begin{array}{lllllllllllllllllllllll}200 & 190 & 180 & 170 & 160 & 150 & 140 & 130 & 120 & 110 & 100 & \begin{array}{c}90 \\ \mathrm{f} 1\end{array}(\mathrm{ppm}) & 80 & 70 & 60 & 50 & 40 & 30 & 20 & 10 & 0 & -10 & -\bar{z}\end{array}$ 


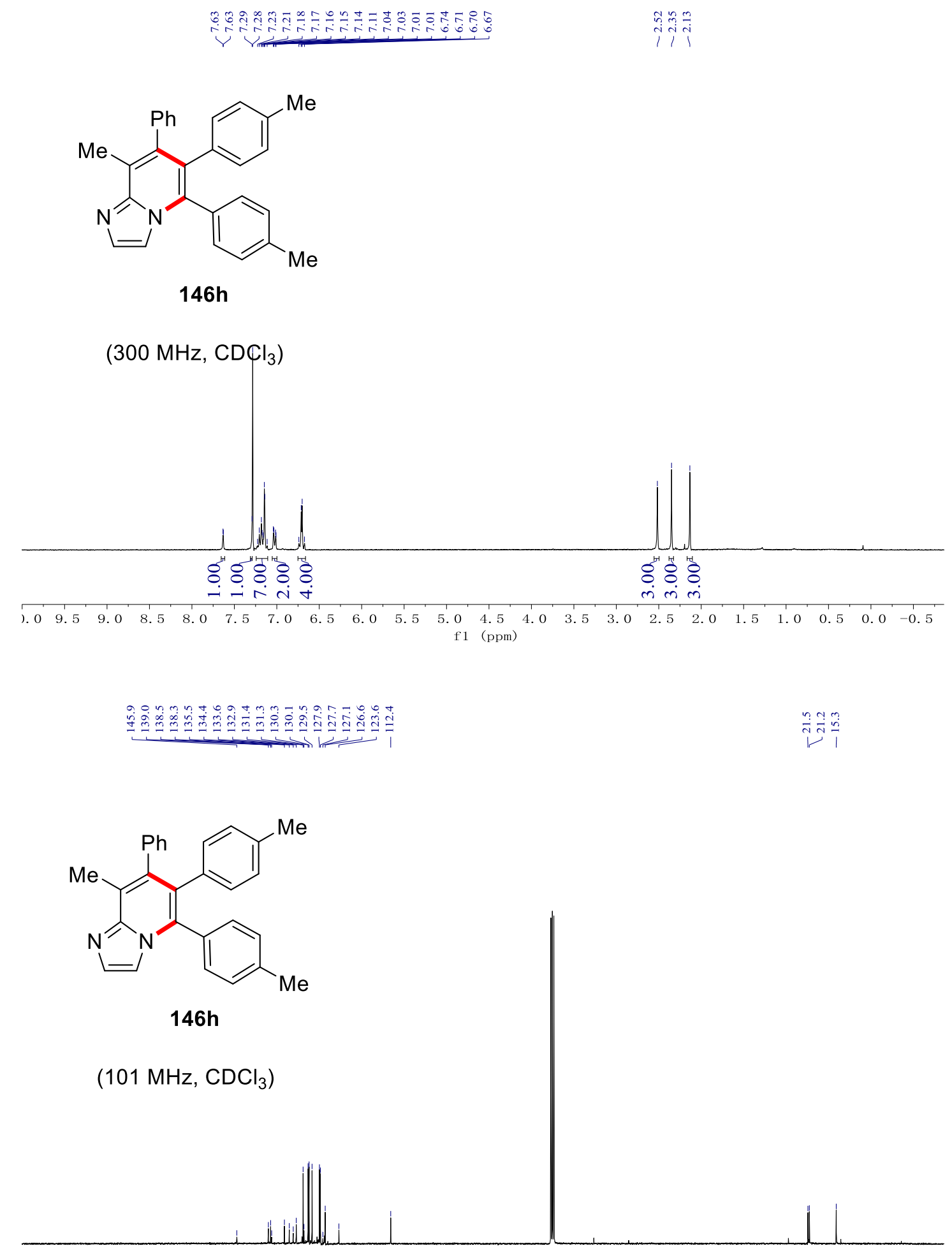

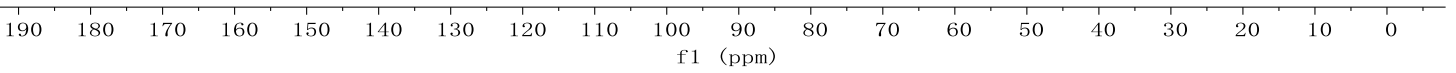


<smiles>COc1ccc(-c2c(-c3ccccc3)c(C)c3nccn3c2-c2ccccc2)cc1</smiles>

$146 i$

$\left(400 \mathrm{MHz}, \mathrm{CDCl}_{3}\right)$

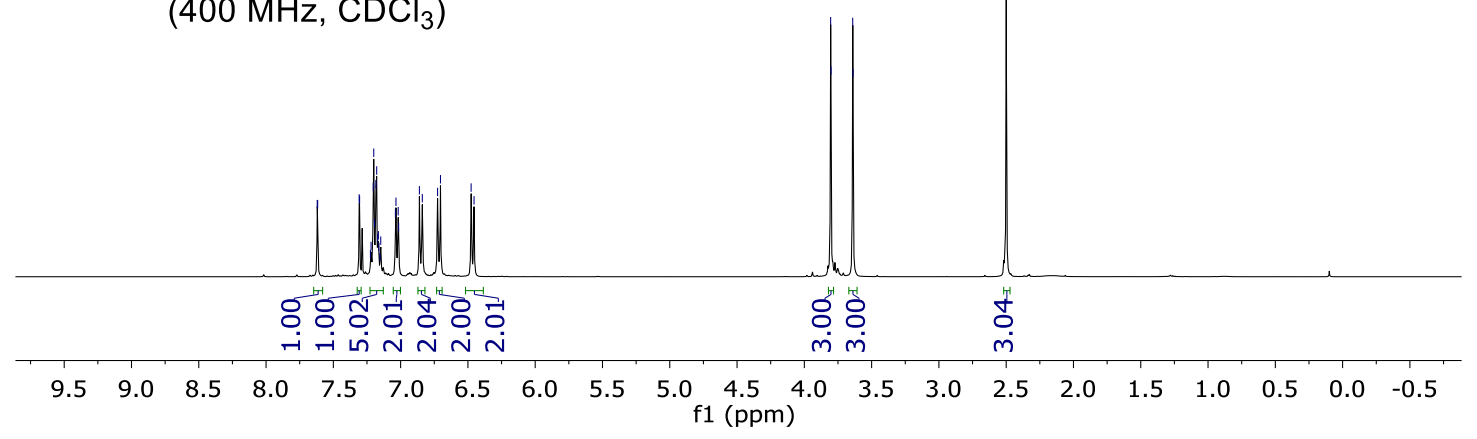

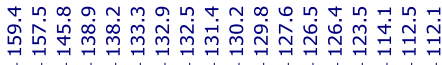

ֻุ<smiles>COc1ccc(-c2c(-c3ccccc3)c(C)c3nccn3c2-c2ccccc2)cc1</smiles>

$146 i$

$\left(101 \mathrm{MHz}, \mathrm{CDCl}_{3}\right)$

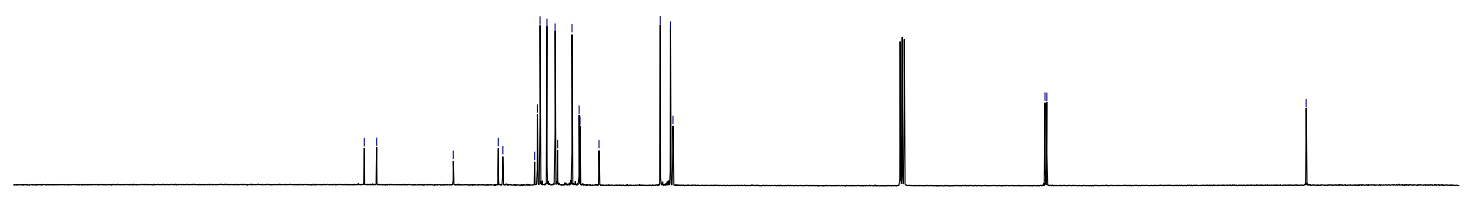

$\begin{array}{llllllllllllllllllllll}210 & 200 & 190 & 180 & 170 & 160 & 150 & 140 & 130 & 120 & 110 & 100 & 90 & 80 & 70 & 60 & 50 & 40 & 30 & 20 & 10 & 0\end{array}$ 
<smiles>Cc1c(-c2ccccc2)c(-c2ccc(C(F)(F)F)cc2)c(-c2ccc(C(F)(F)F)cc2)n2ccnc12</smiles>

146j

$\left(300 \mathrm{MHz}, \mathrm{CDCl}_{3}\right)$

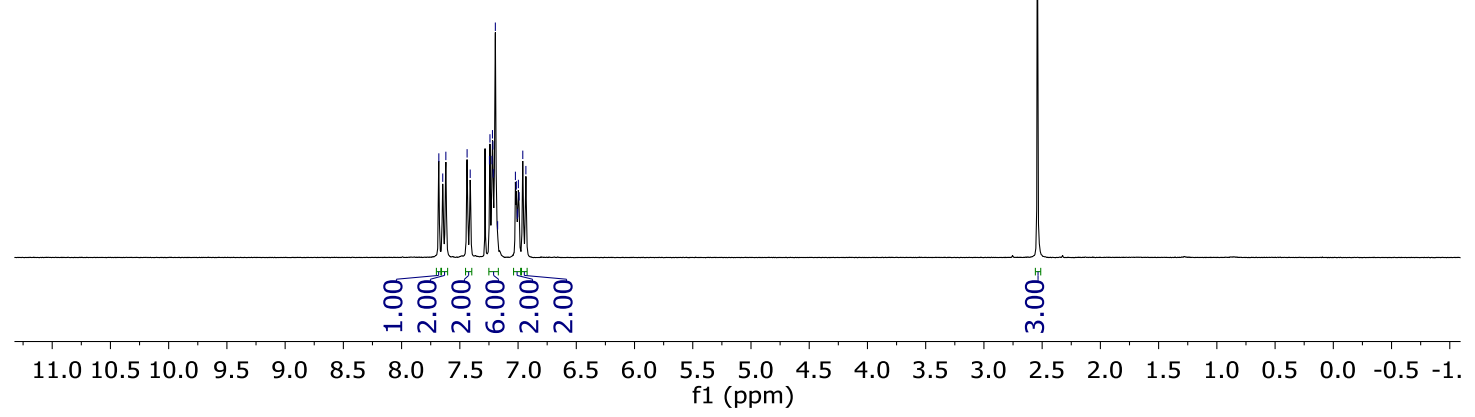

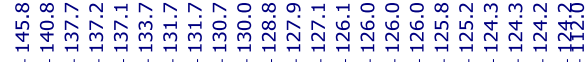<smiles>Cc1c(-c2ccccc2)c(-c2ccc(C(F)(F)F)cc2)c(-c2ccc(C(F)(F)F)cc2)n2ccnc12</smiles>

146j

$\left(101 \mathrm{MHz}, \mathrm{CDCl}_{3}\right)$

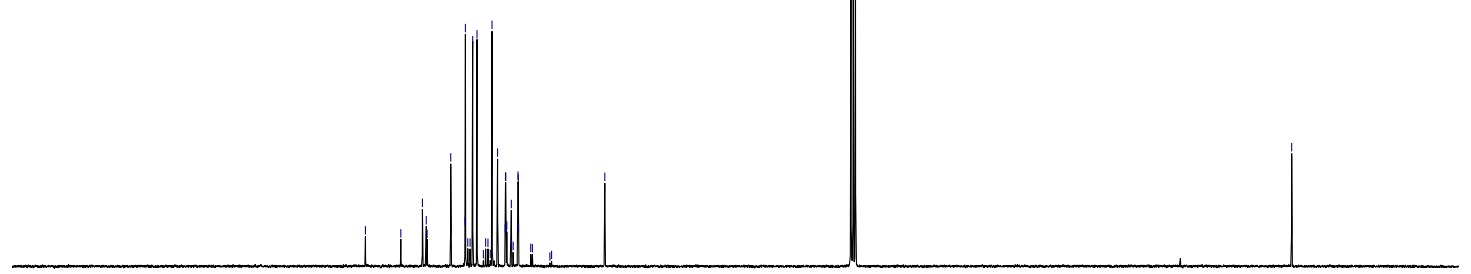




\section{NMR Spectra}

\section{ஸิ}<smiles>Cc1c(-c2ccccc2)c(-c2ccc(C(F)(F)F)cc2)c(-c2ccc(C(F)(F)F)cc2)n2ccnc12</smiles>

146j

(282 $\left.\mathrm{MHz}, \mathrm{CDCl}_{3}\right)$

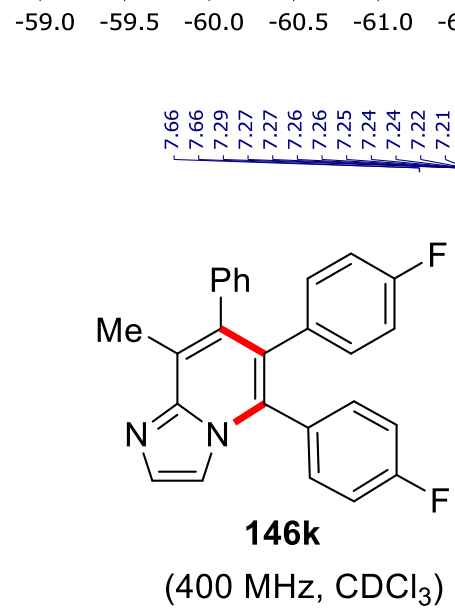
$\left(400 \mathrm{MHz}, \mathrm{CDCl}_{3}\right)$ f1 (ppm)

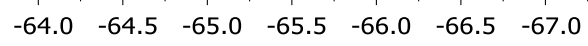

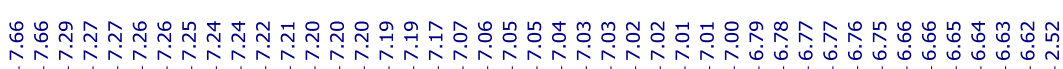

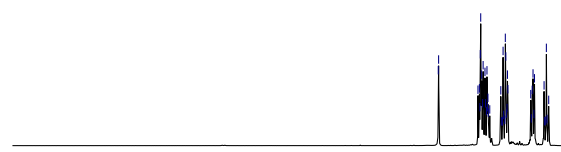

\begin{tabular}{|c|c|c|c|c|c|c|c|c|c|c|c|c|c|}
\hline & & & & 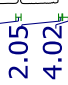 & 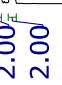 & & & & ஜे & & & & \\
\hline 11.5 & 10.5 & 9.5 & 8.5 & 7.5 & 6.5 & 5.5 & $\begin{array}{r}4.5 \\
\mathrm{pm})\end{array}$ & 3.5 & 2.5 & 1.5 & 0.5 & -0.5 & -1.5 \\
\hline
\end{tabular}




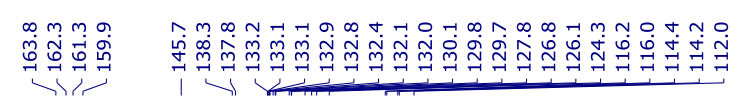<smiles>Cc1c(-c2ccccc2)c(-c2ccc(F)cc2)c(-c2ccc(F)cc2)n2ccnc12</smiles>

(101 MHz, $\mathrm{CDCl}_{3}$ )
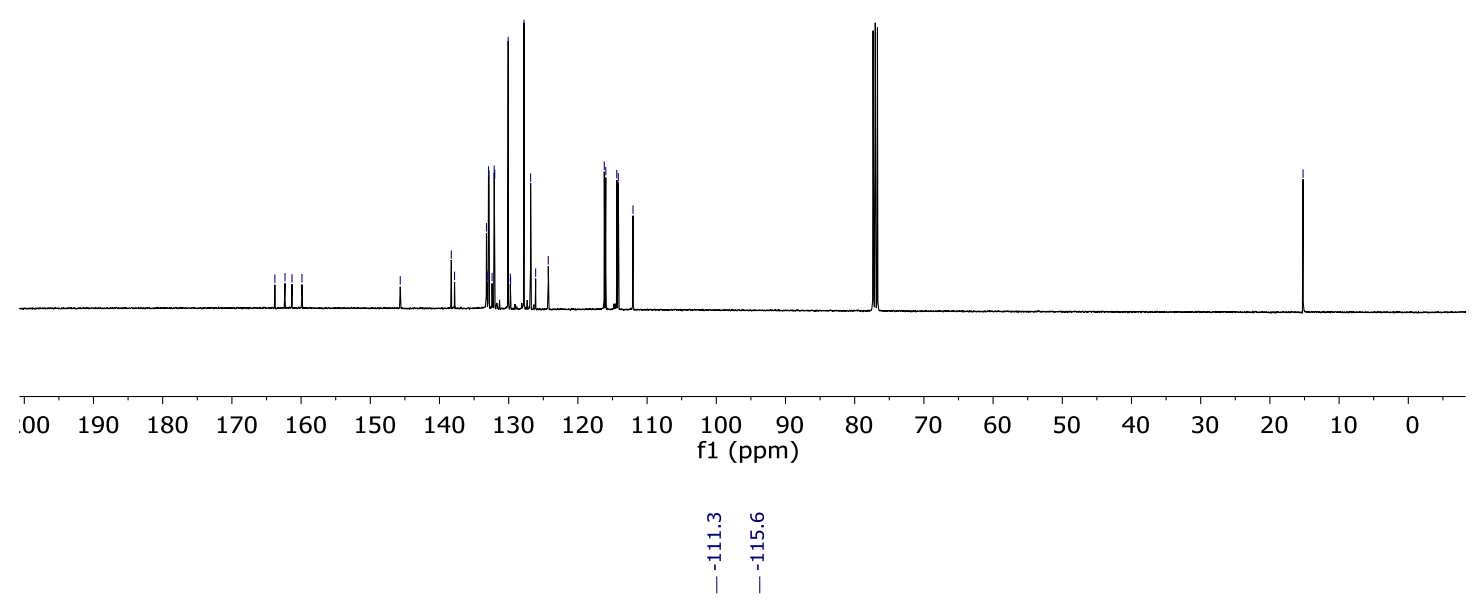<smiles>Cc1c(-c2ccccc2)c(-c2ccc(F)cc2)c(-c2ccc(F)cc2)n2ccnc12</smiles>

(377 MHz, $\mathrm{CDCl}_{3}$ )

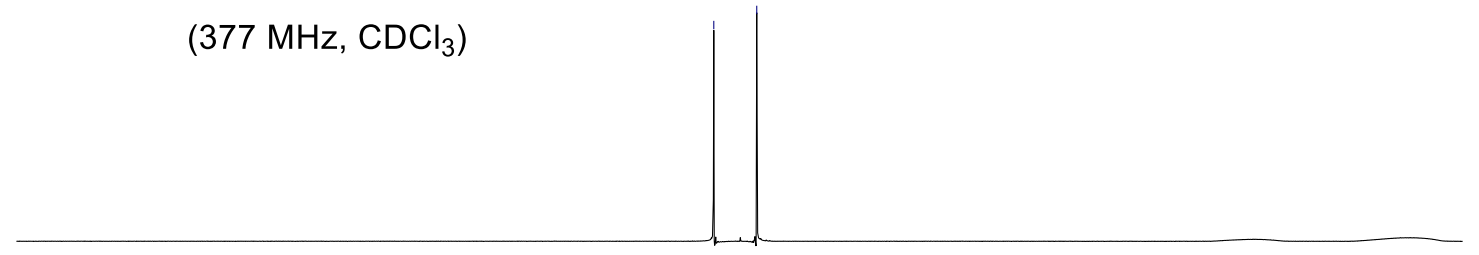

\begin{tabular}{|c|c|c|c|c|c|c|c|c|c|c|c|c|c|c|}
\hline-45 & -55 & -65 & -75 & -85 & -95 & -105 & f1 $\begin{array}{c}-115 \\
(\mathrm{ppm})\end{array}$ & -125 & -135 & -145 & -155 & -165 & -175 & $-1 \varepsilon$ \\
\hline
\end{tabular}


<smiles>Cc1c(-c2ccccc2)c(-c2ccc(Br)cc2)c(-c2ccc(Br)cc2)n2ccnc12</smiles>

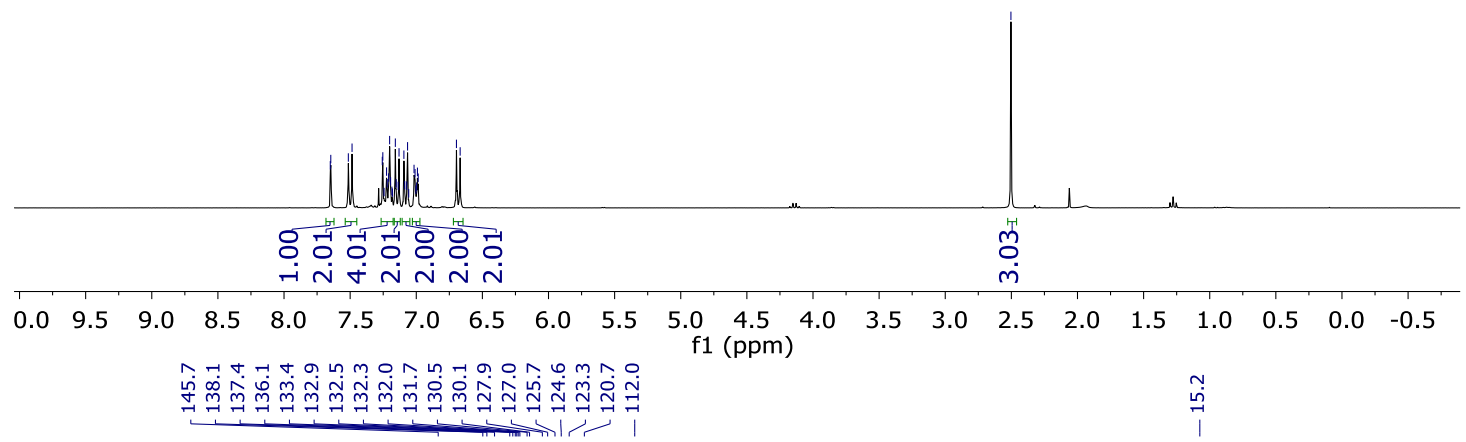<smiles>Cc1c(-c2ccccc2)c(-c2ccc(Br)cc2)c(-c2ccc(Br)cc2)n2ccnc12</smiles>

(75 MHz, $\mathrm{CDCl}_{3}$ )

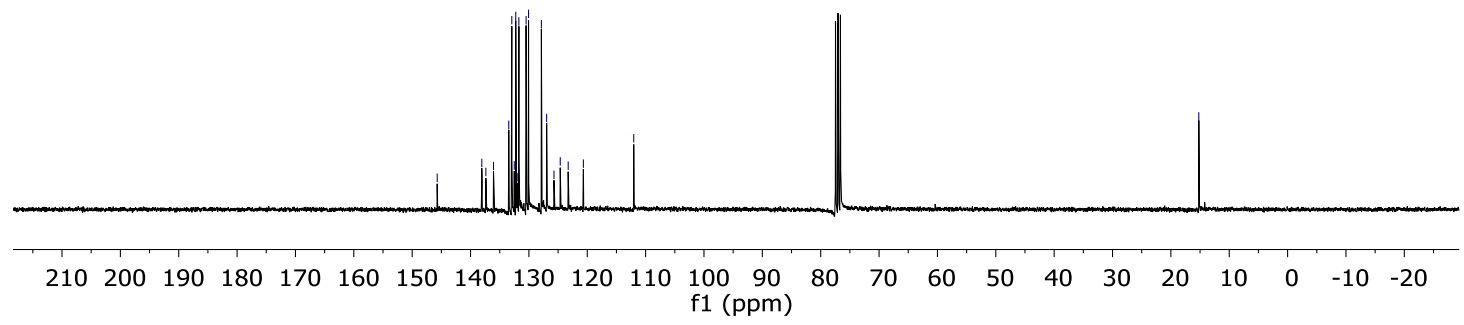




\section{NMR Spectra}<smiles>Cc1cc(-c2ccccc2)c(-c2ccccc2)n2ccnc12</smiles>

$146 \mathrm{~m}$

(300 MHz, $\mathrm{CDCl}_{3}$ )

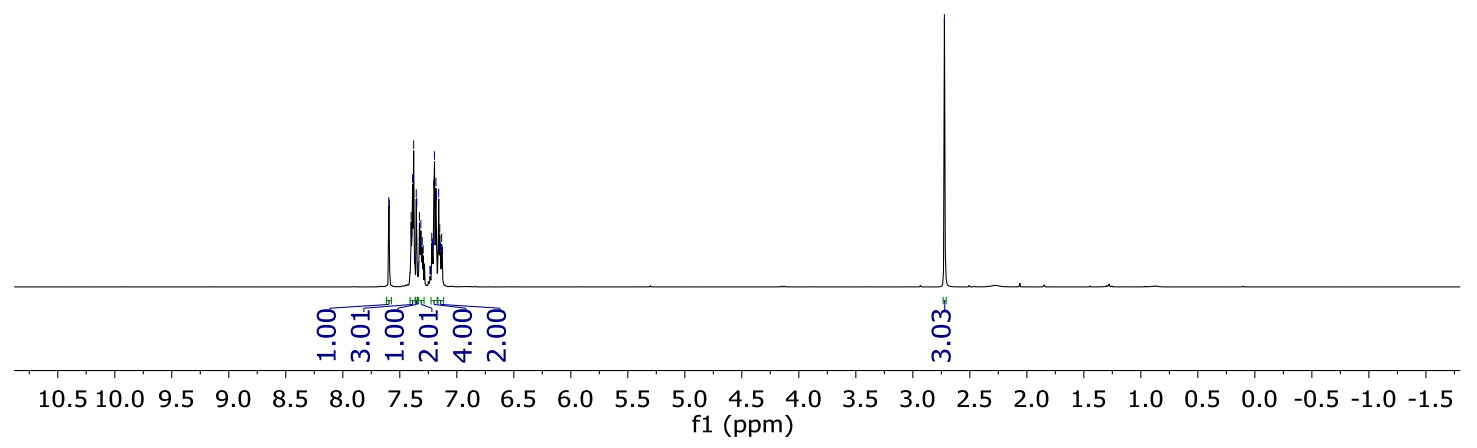

人

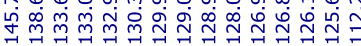<smiles>Cc1cc(-c2ccccc2)c(-c2ccccc2)n2ccnc12</smiles>

$146 \mathrm{~m}$

(75 MHz, $\mathrm{CDCl}_{3}$ )

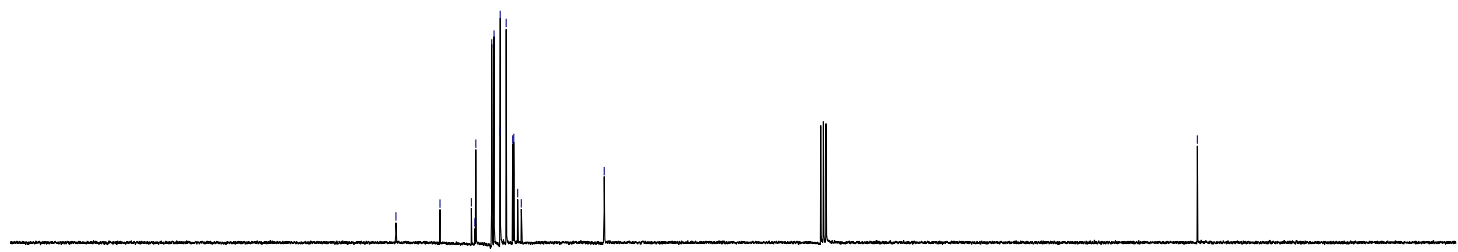

$\begin{array}{lllllllllllllllllllllll}200 & 190 & 180 & 170 & 160 & 150 & 140 & 130 & 120 & 110 & 100 & \mathrm{f} 1(\mathrm{ppm}) & 80 & 70 & 60 & 50 & 40 & 30 & 20 & 10 & 0 & -10 & -20\end{array}$ 

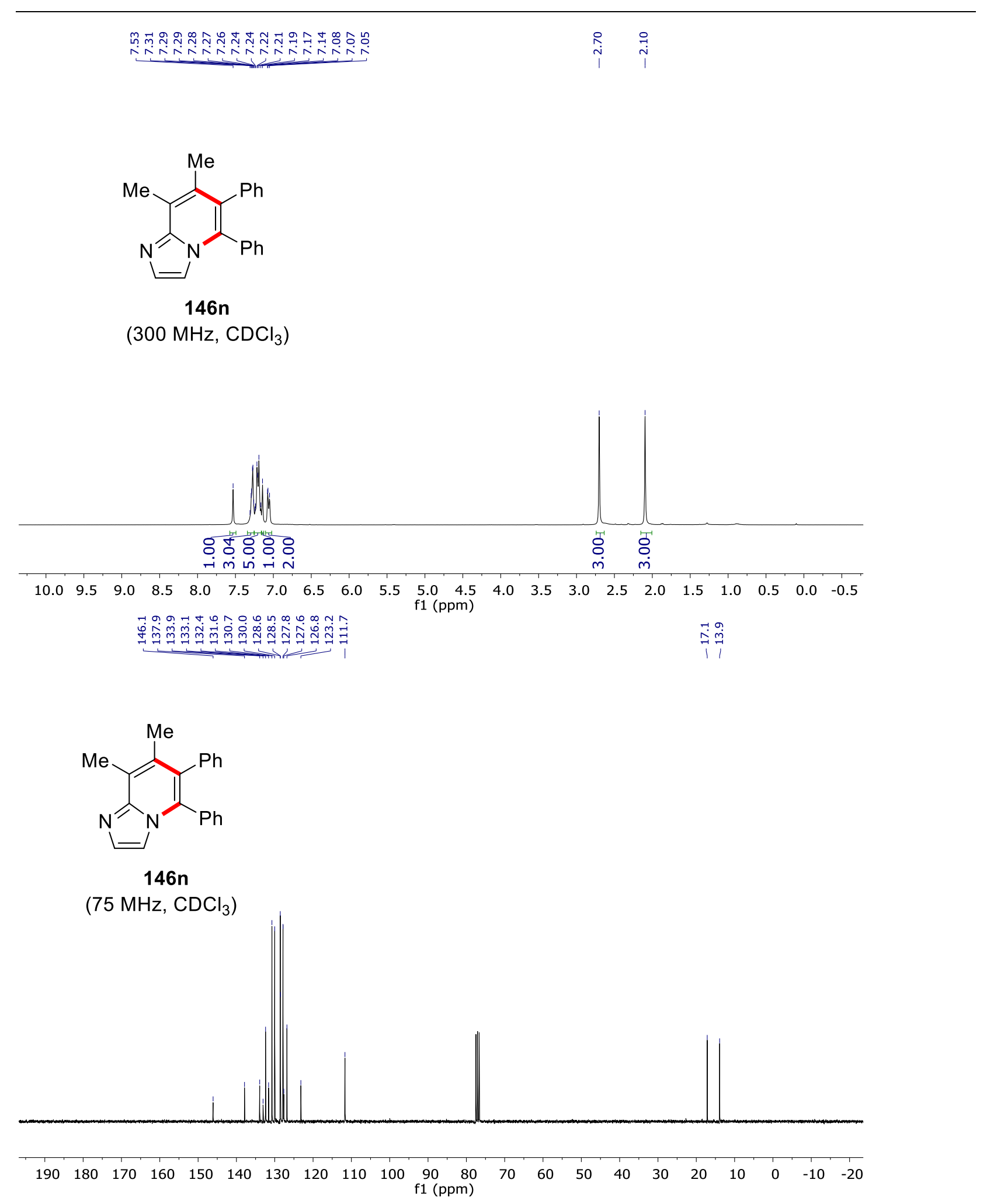


\section{NMR Spectra}

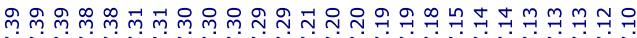

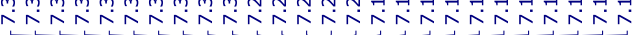

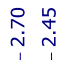<smiles>Cc1cn2c(-c3ccccc3)c(-c3ccccc3)cc(C)c2n1</smiles>

$\left(400 \mathrm{MHz}, \mathrm{CDCl}_{3}\right)$
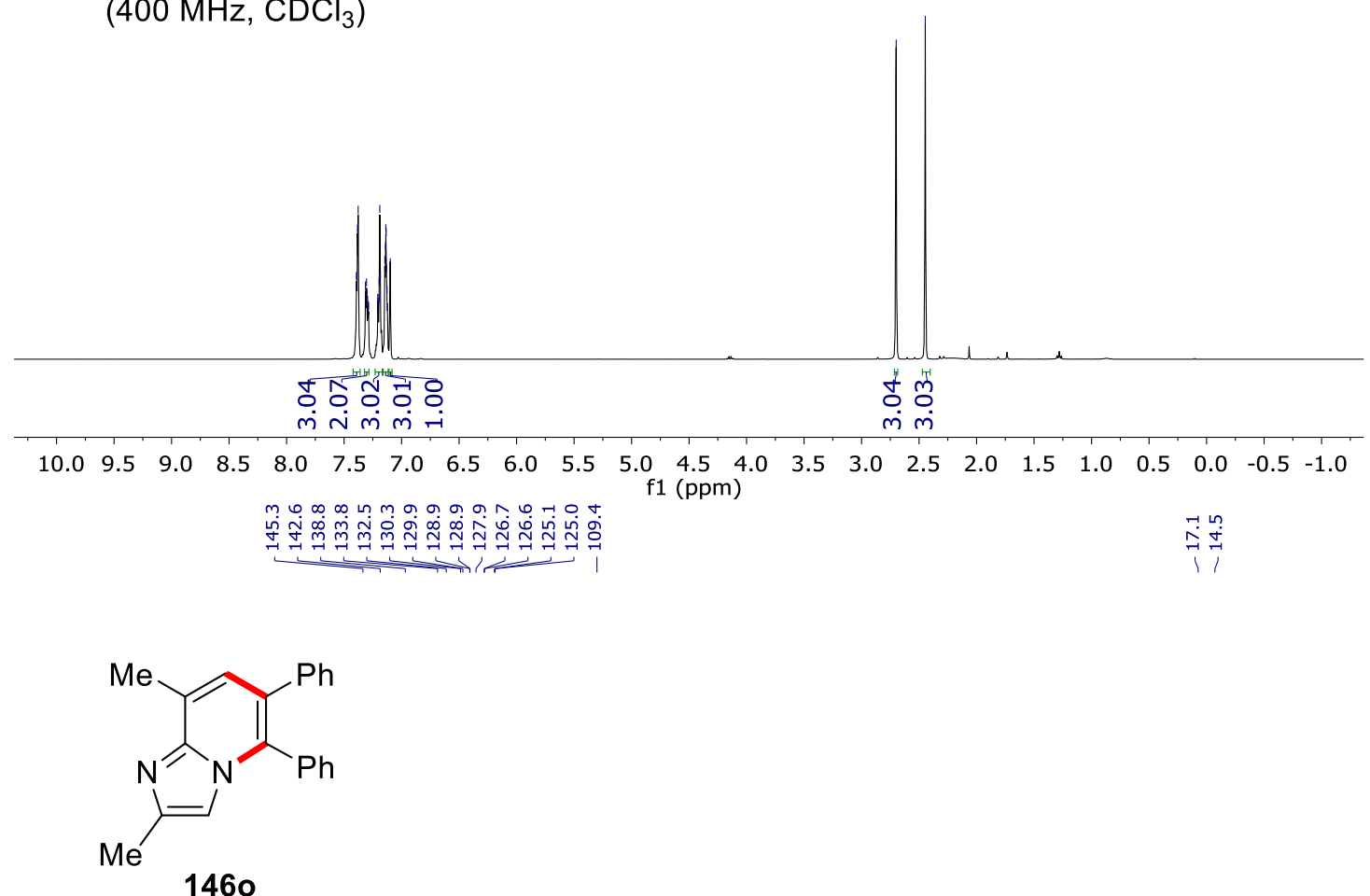

(101 MHz, $\mathrm{CDCl}_{3}$ )

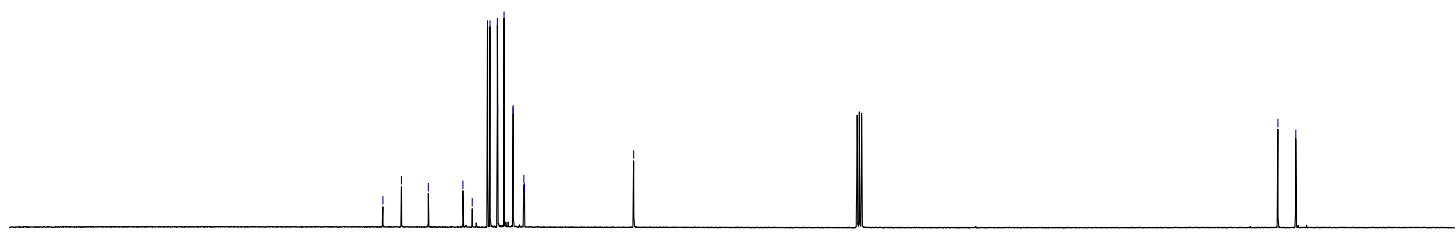

$\begin{array}{llllllllllllllllllll}190 & 180 & 170 & 160 & 150 & 140 & 130 & 120 & 110 & \begin{array}{l}100 \\ \mathrm{f} 1(\mathrm{ppm})\end{array} & 80 & 70 & 60 & 50 & 40 & 30 & 20 & 10 & 0\end{array}$ 


\section{NMR Spectra}

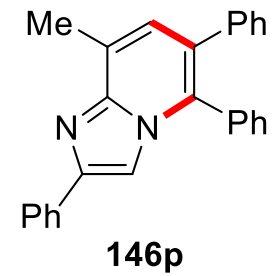

(300 MHz, $\mathrm{CDCl}_{3}$ )
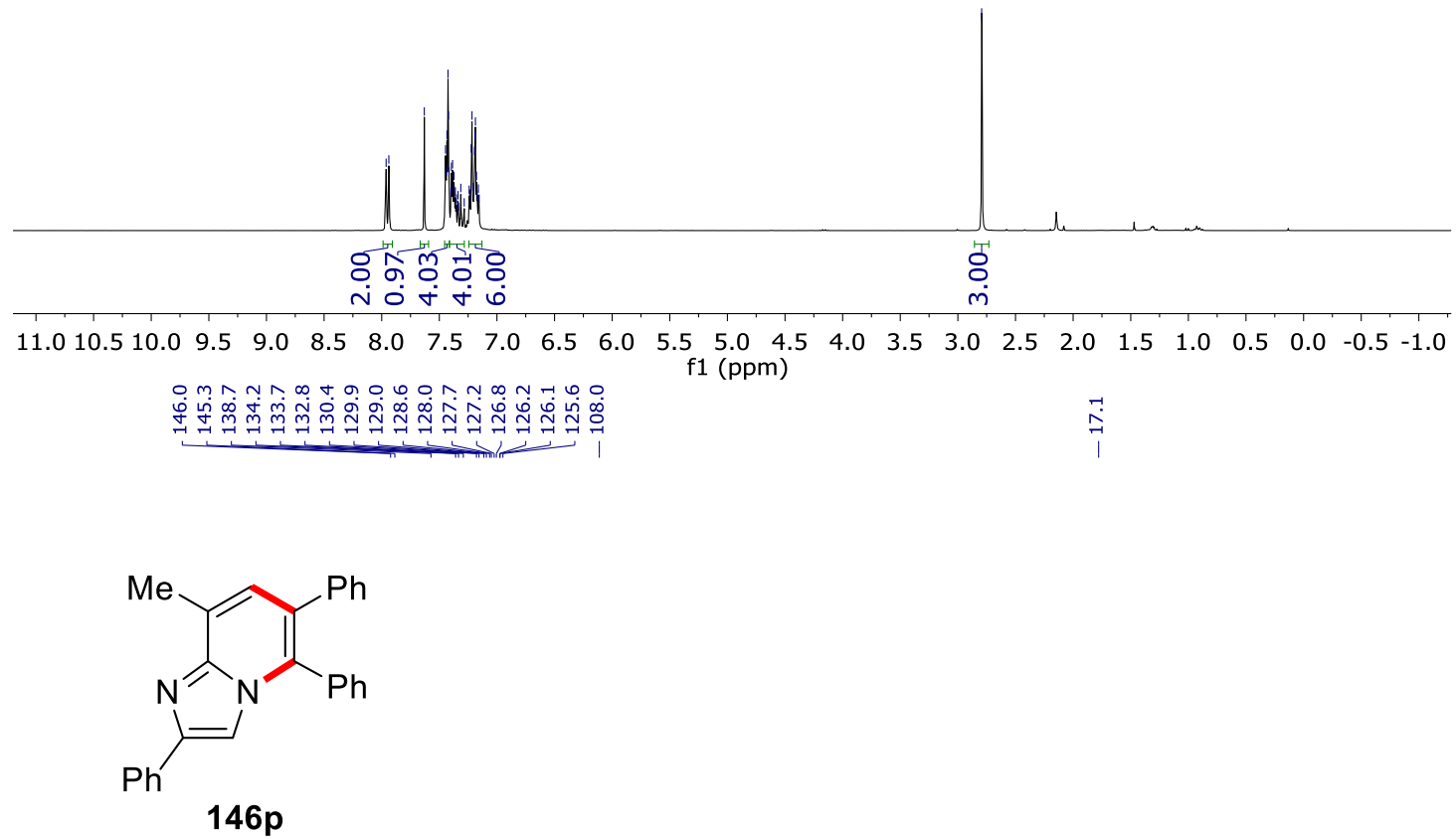

$\left(75 \mathrm{MHz}, \mathrm{CDCl}_{3}\right.$ )

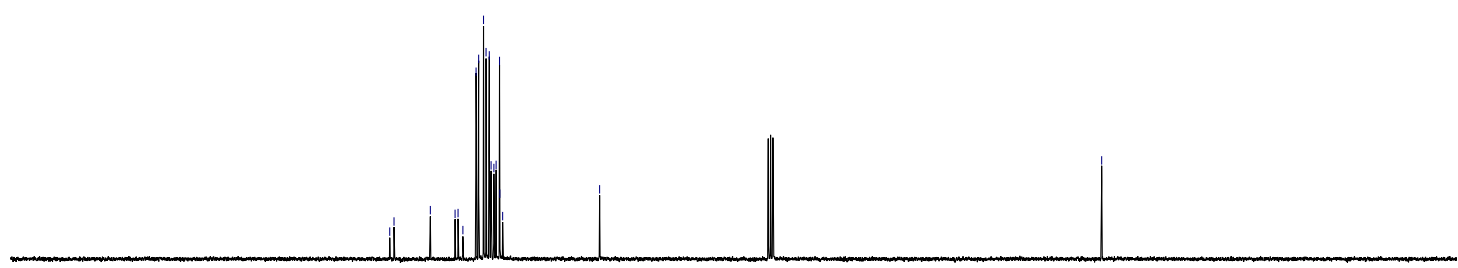

$\begin{array}{lllllllllllllllllllllllll}210 & 200 & 190 & 180 & 170 & 160 & 150 & 140 & 130 & 120 & 110 & 100 & \begin{array}{c}90 \\ \mathrm{f} 1(\mathrm{ppm})\end{array} & 80 & 60 & 50 & 40 & 30 & 20 & 10 & 0 & -10 & -20 & -30 & -40\end{array}$ 


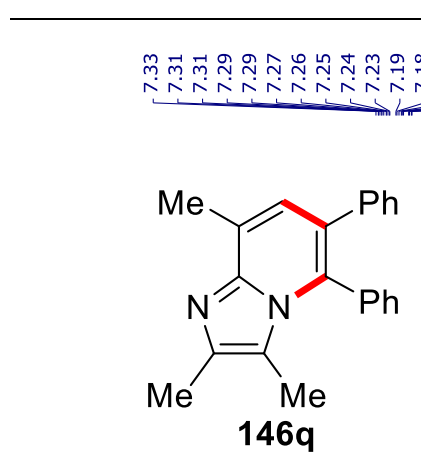

$\left(400 \mathrm{MHz}, \mathrm{CDCl}_{3}\right)$
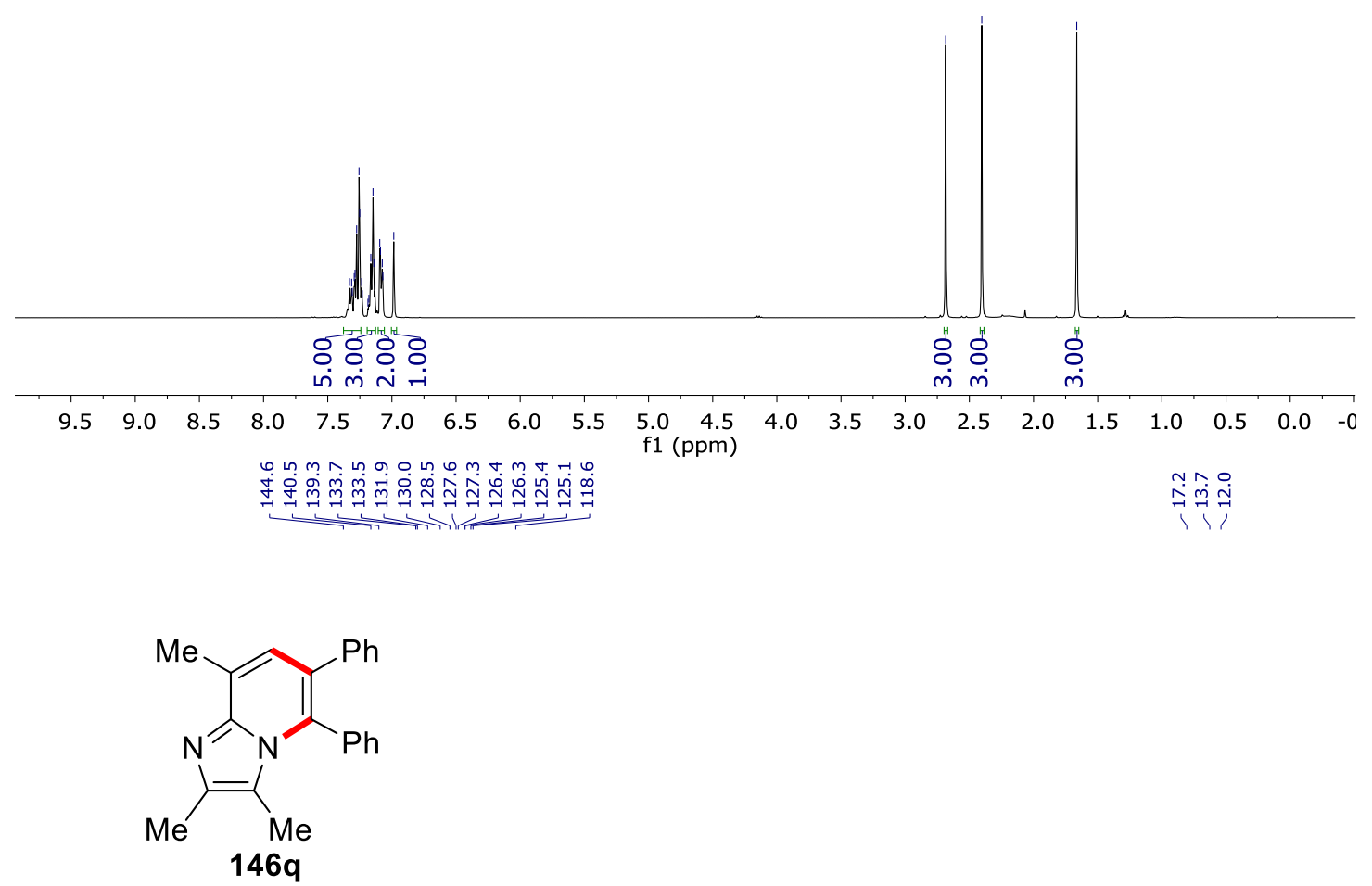

$\left(101 \mathrm{MHz}, \mathrm{CDCl}_{3}\right.$ )

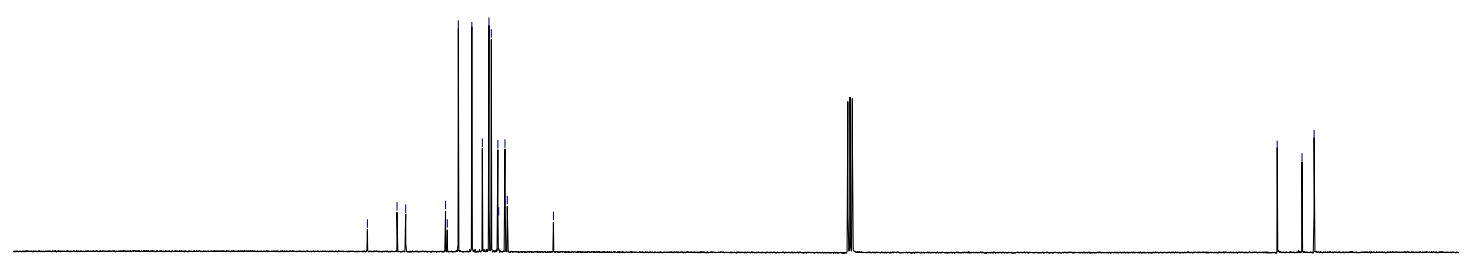

$\begin{array}{llllllllllllllllllll}190 & 180 & 170 & 160 & 150 & 140 & 130 & 120 & 110 & \begin{array}{c}100 \\ \mathrm{f} 1(\mathrm{ppm})\end{array} & 80 & 70 & 60 & 50 & 40 & 30 & 20 & 10 & 0\end{array}$ 


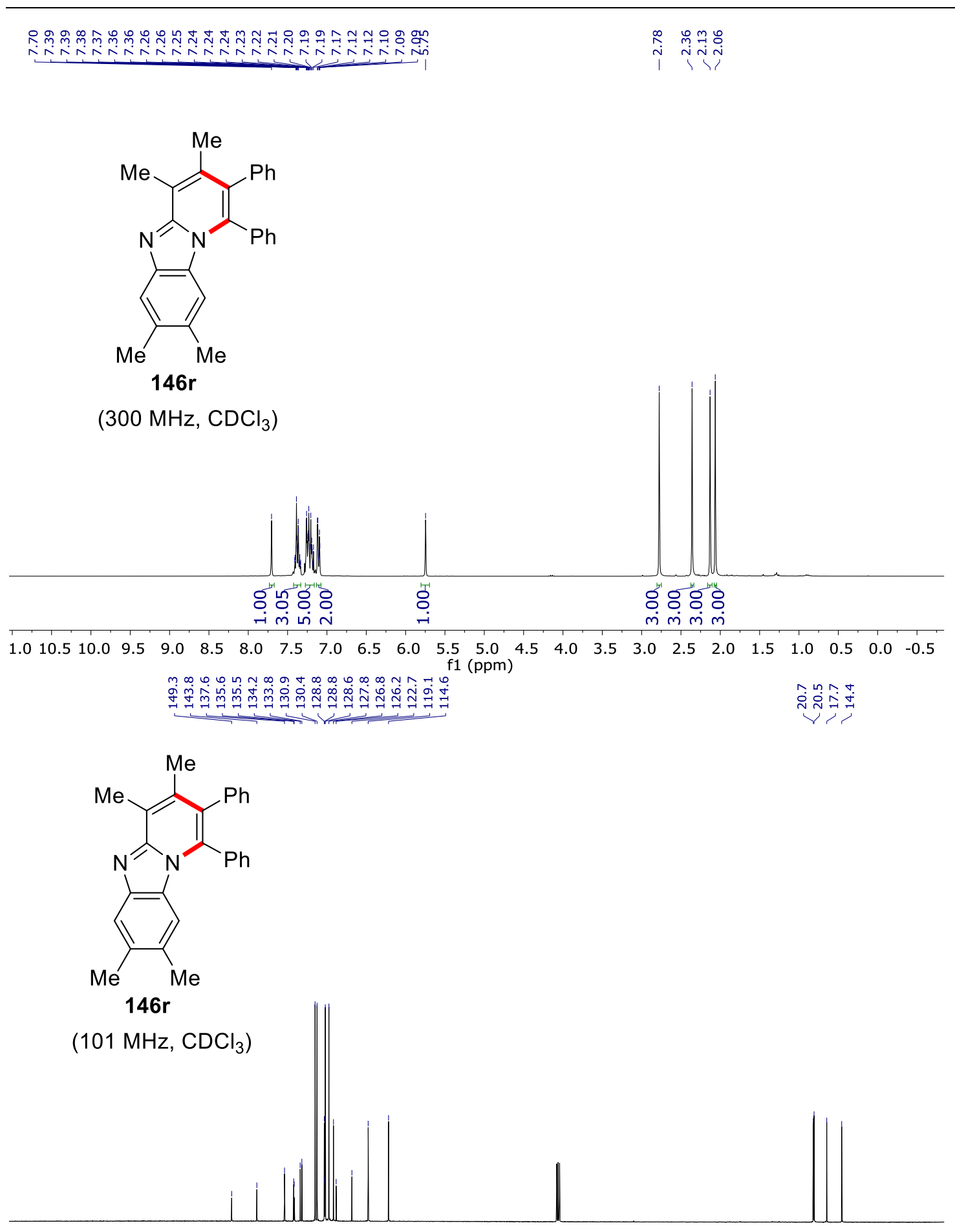

$\begin{array}{llllllllllllllllllll}190 & 180 & 170 & 160 & 150 & 140 & 130 & 120 & 110 & \begin{array}{l}100 \\ \mathrm{f} 1(\mathrm{ppm})\end{array} & 80 & 70 & 60 & 50 & 40 & 30 & 20 & 10 & 0\end{array}$ 


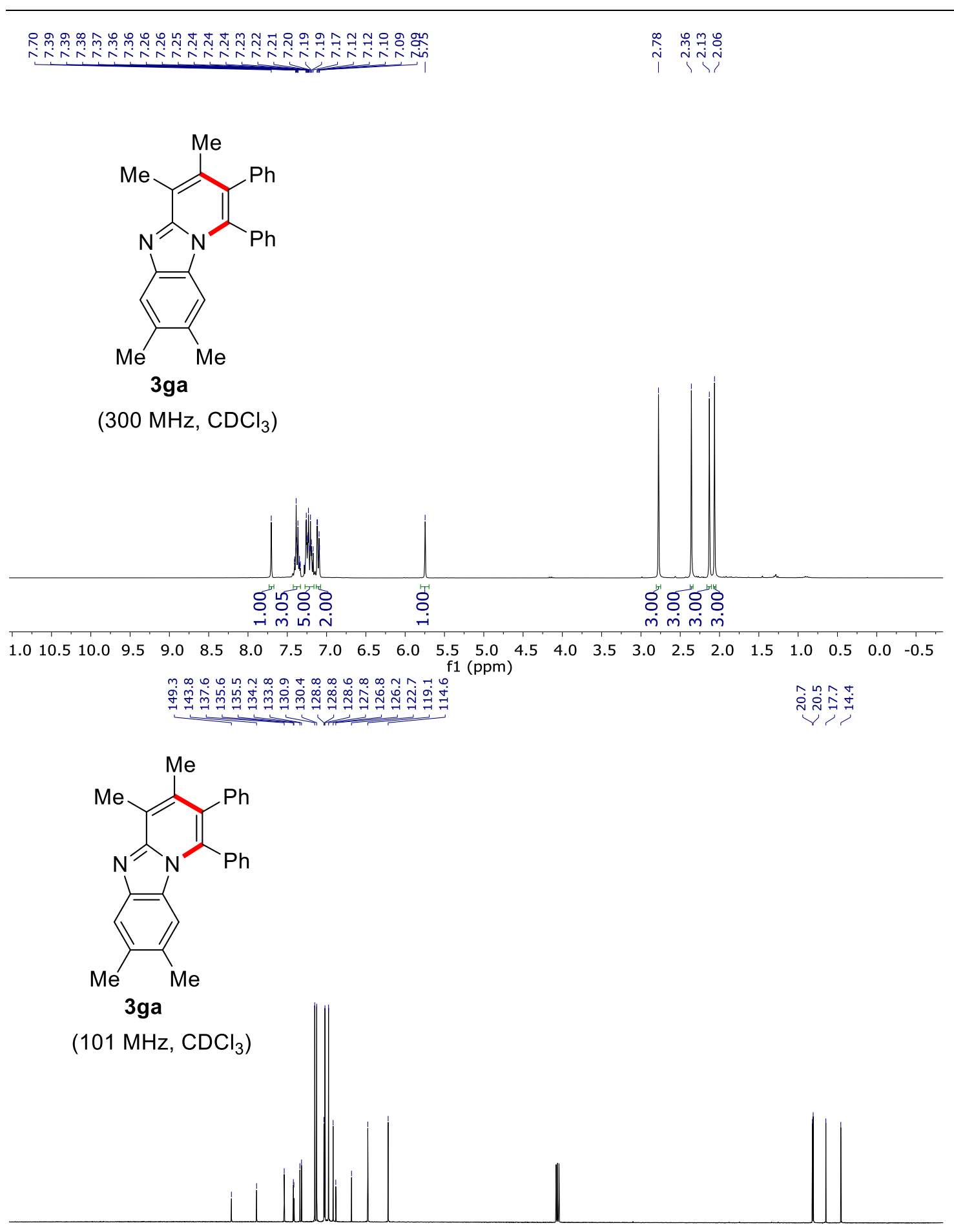

$\begin{array}{llllllllllllllllllll}190 & 180 & 170 & 160 & 150 & 140 & 130 & 120 & 110 & \begin{array}{l}100 \\ \mathrm{f} 1(\mathrm{ppm})\end{array} & 80 & 70 & 60 & 50 & 40 & 30 & 20 & 10 & 0\end{array}$ 
<smiles>Cc1cc(-c2ccccc2)c(-c2ccccc2)n2c1nc1ccccc12</smiles>

$146 s$

$\left(300 \mathrm{MHz}, \mathrm{CDCl}_{3}\right)$

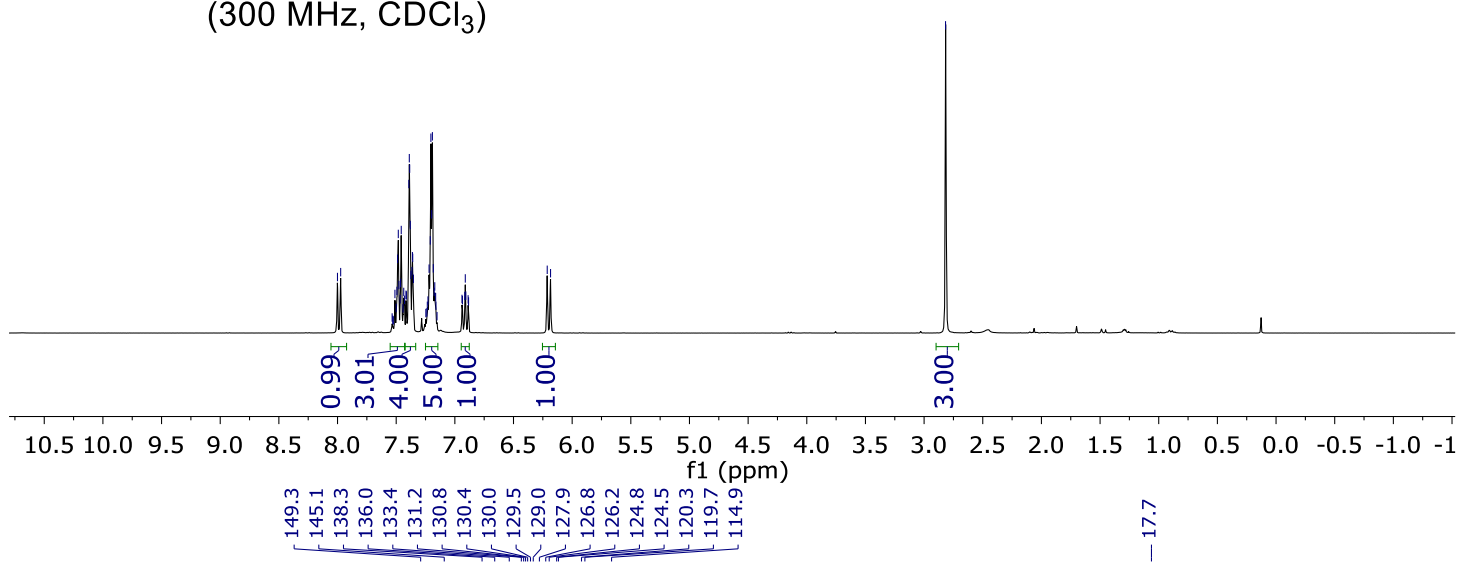<smiles>Cc1cc(-c2ccccc2)c(-c2ccccc2)n2c1nc1ccccc12</smiles>

$146 s$

(75 $\mathrm{MHz}, \mathrm{CDCl}_{3}$ )

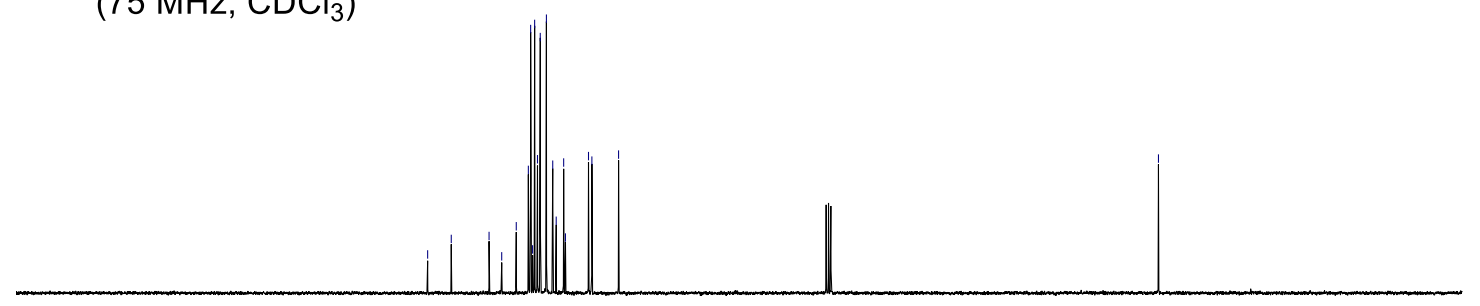

$220210200190180170160150140130120110 \begin{gathered}100 \quad 90 \\ f 1(\mathrm{ppm})\end{gathered}$ 
<smiles>c1ccc(-c2c(-c3ccccc3)n3c4ccccc4nc3c3sccc23)cc1</smiles>

$146 t$

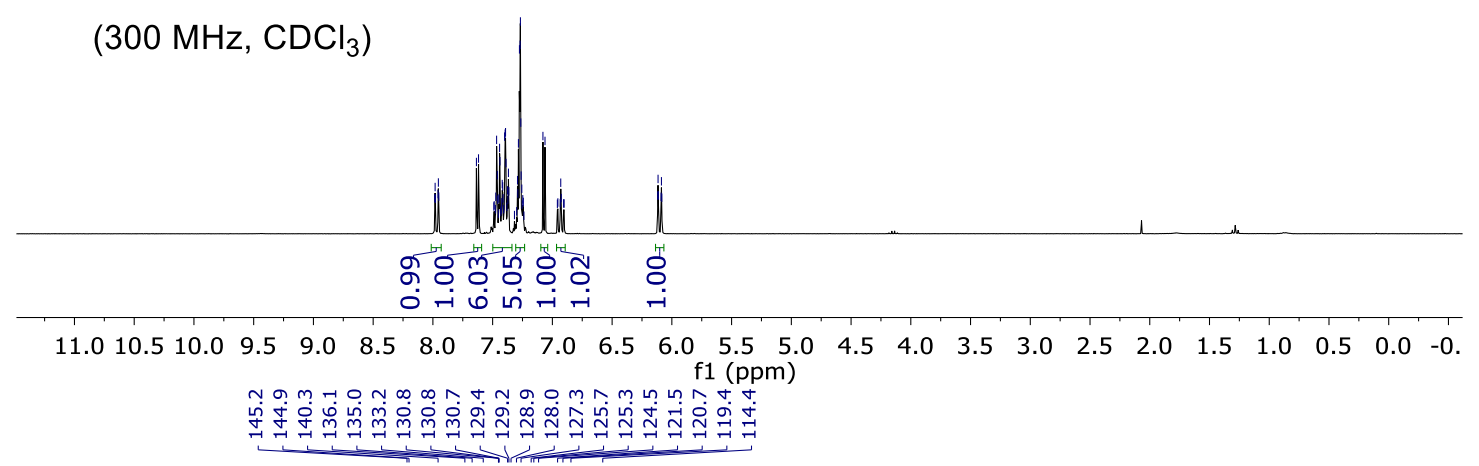<smiles></smiles>

$146 t$

(75 $\mathrm{MHz} \mathrm{CDCl}_{3}$ )

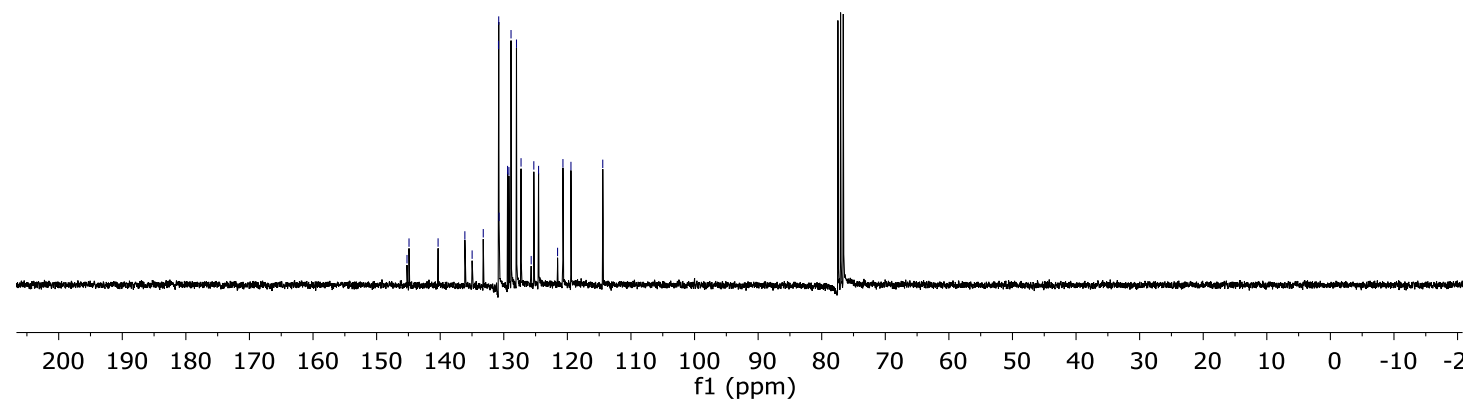




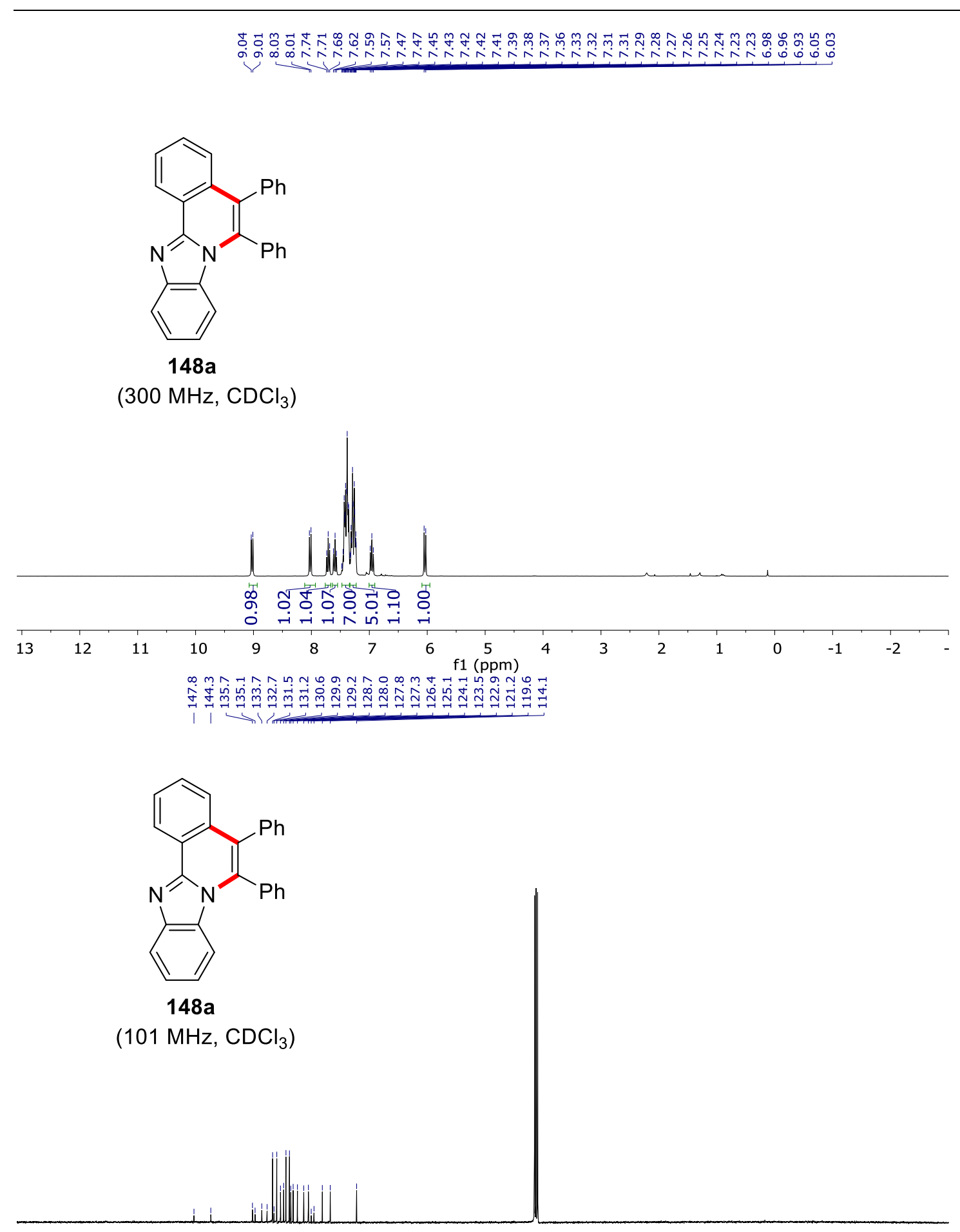

$\begin{array}{lllllllllllllllllll}180 & 170 & 160 & 150 & 140 & 130 & 120 & 110 & 100 \underset{\mathrm{f} 1(\mathrm{ppm})}{90} \mathbf{8 0} & 70 & 60 & 50 & 40 & 30 & 20 & 10 & 0\end{array}$ 
<smiles>Cc1ccc2c(c1)c(-c1ccccc1)c(-c1ccccc1)n1c3ccccc3nc21</smiles>

$148 b$

(300 MHz, $\mathrm{CDCl}_{3}$ )

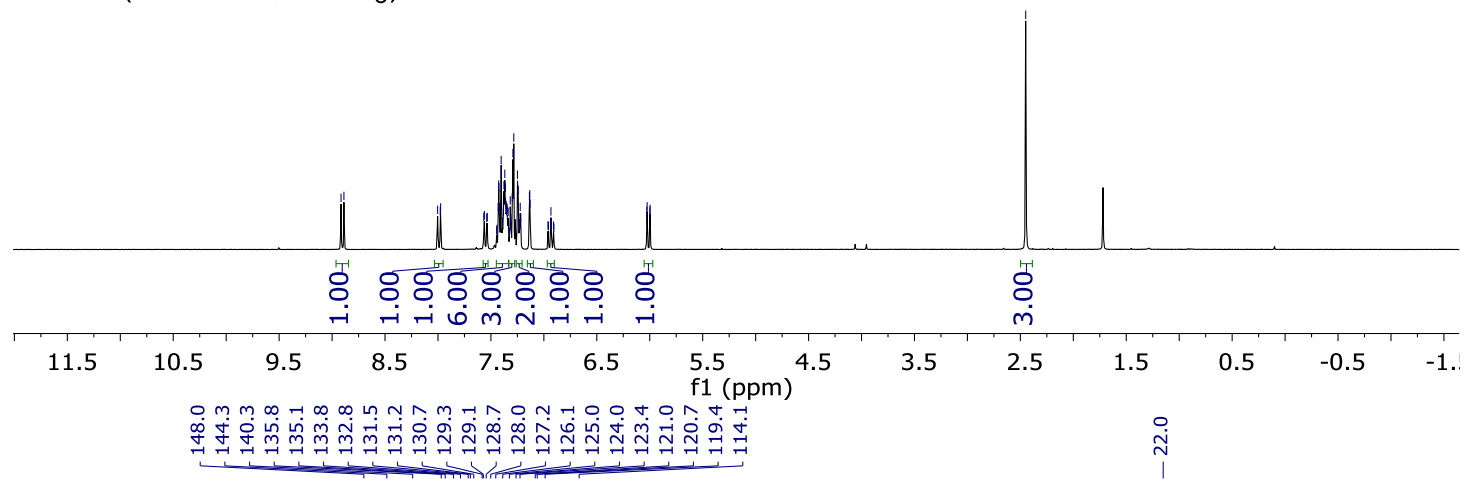<smiles>Cc1ccc2c(c1)c(-c1ccccc1)c(-c1ccccc1)n1c3ccccc3nc21</smiles>

$148 b$

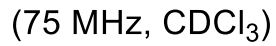

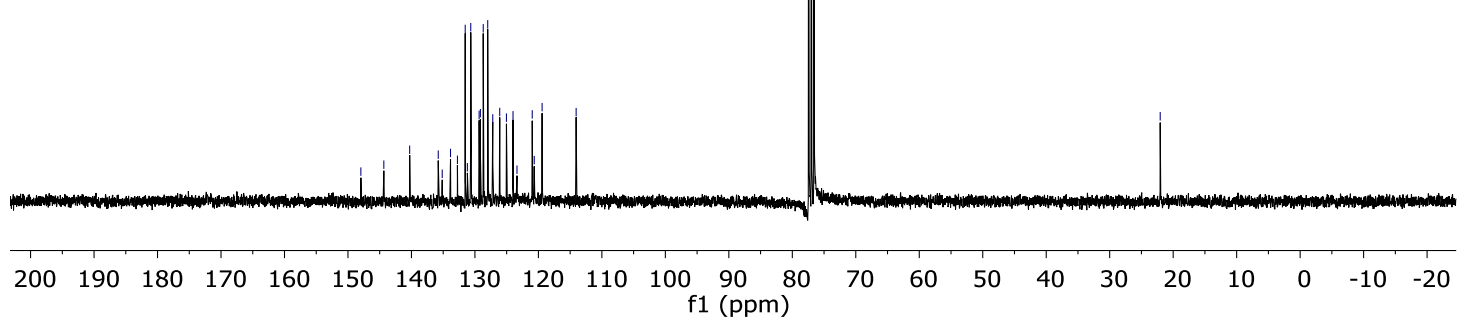



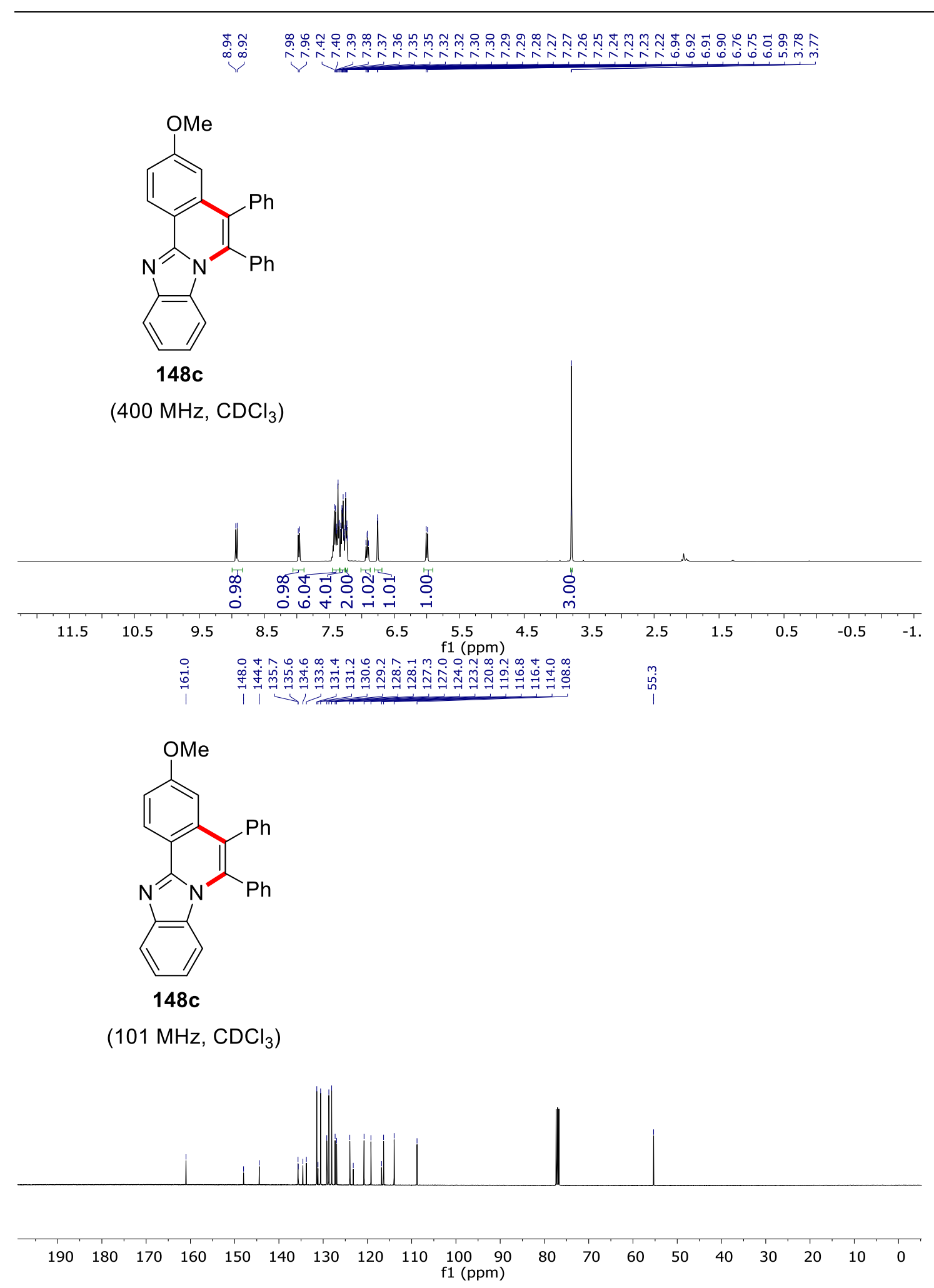
<smiles>FC(F)(F)c1ccc2c(c1)c(-c1ccccc1)c(-c1ccccc1)n1c3ccccc3nc21</smiles>

148d

$\left(400 \mathrm{MHz}, \mathrm{CDCl}_{3}\right)$

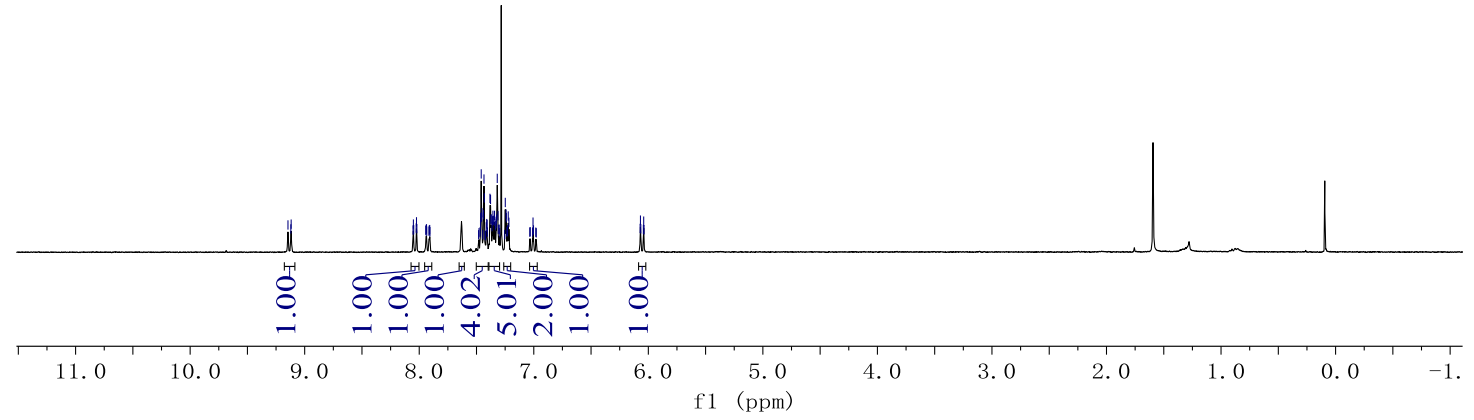

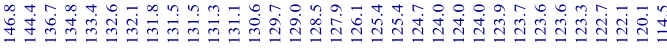<smiles>FC(F)(F)c1ccc2c(c1)c(-c1ccccc1)c(-c1ccccc1)n1c3ccccc3nc21</smiles>

148d

$\left(101 \mathrm{MHz} \mathrm{CDCl}_{3}\right)$

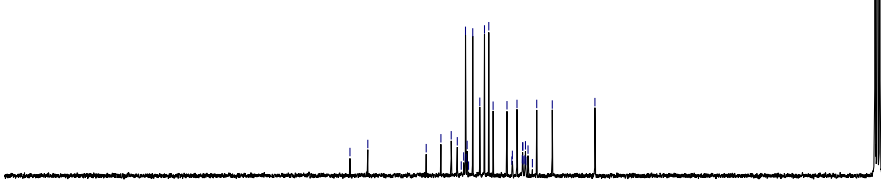

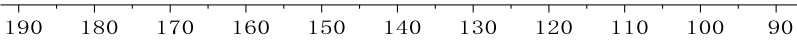

f1 (ppm) 


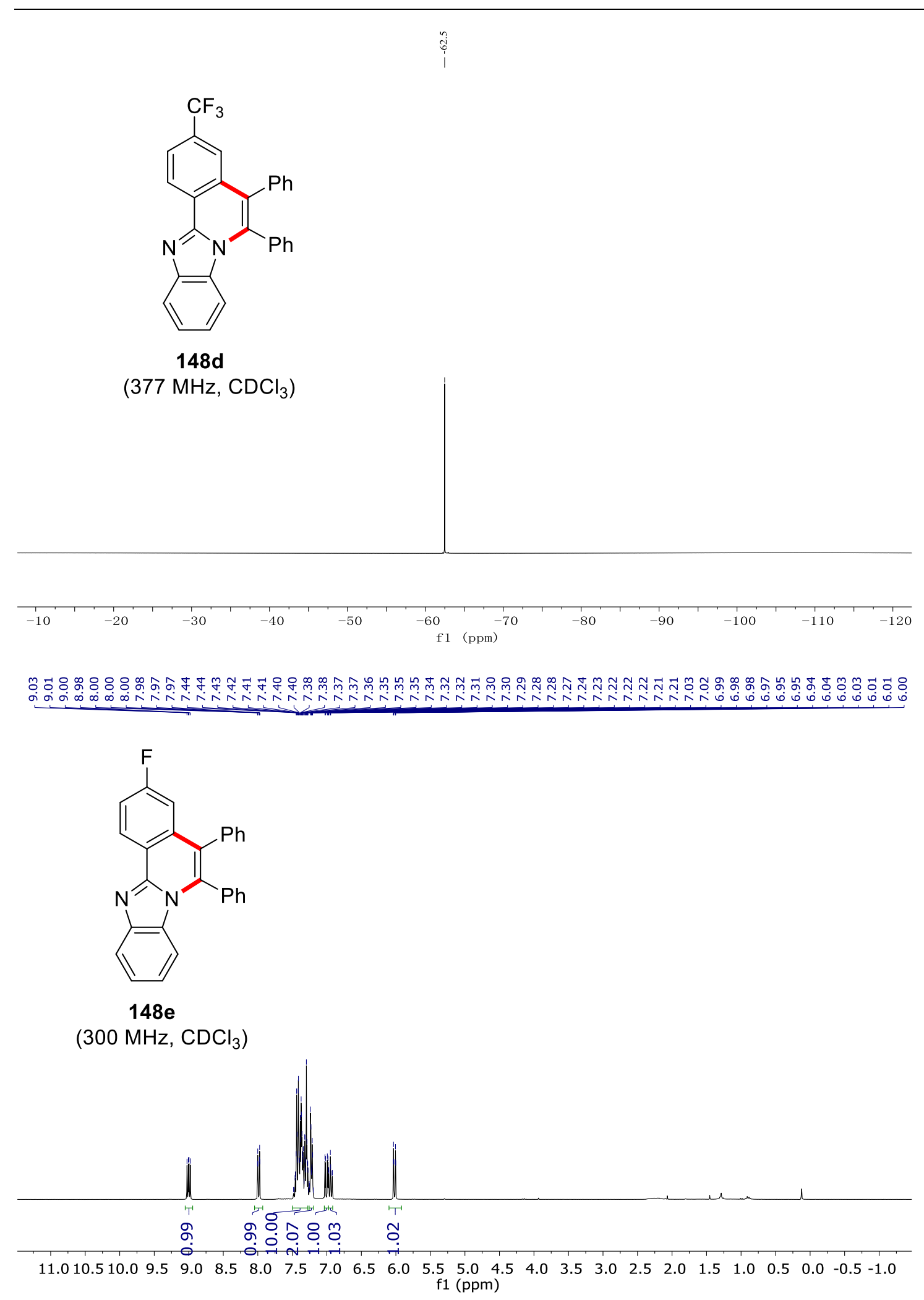



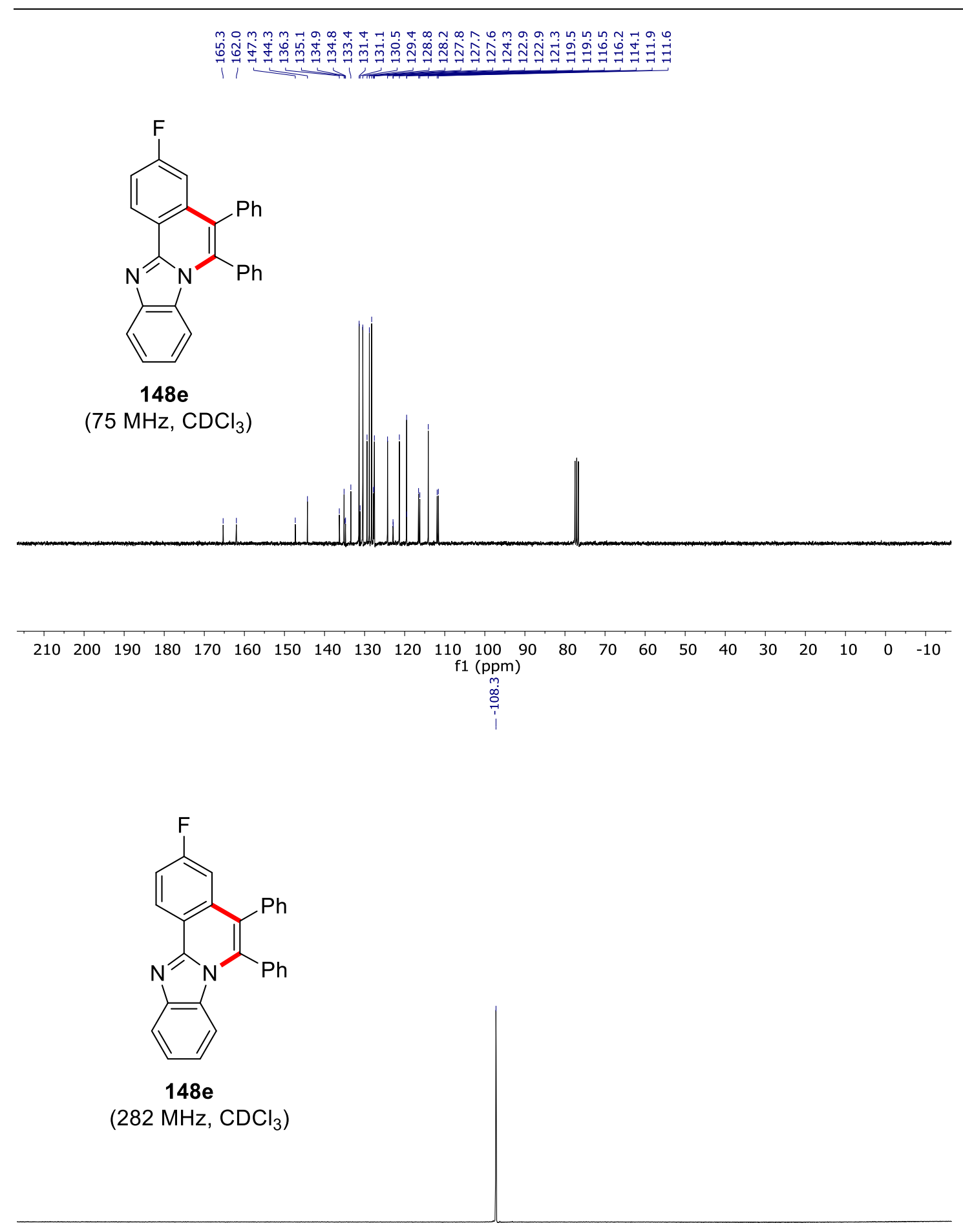

\begin{tabular}{|c|c|c|c|c|c|c|c|c|c|c|c|c|}
\hline-45 & -55 & -65 & -75 & -85 & -95 & $\begin{array}{l}-105 \\
\mathrm{f} 1(\mathrm{ppm})\end{array}$ & -115 & -125 & -135 & -145 & -155 & -165 \\
\hline
\end{tabular}




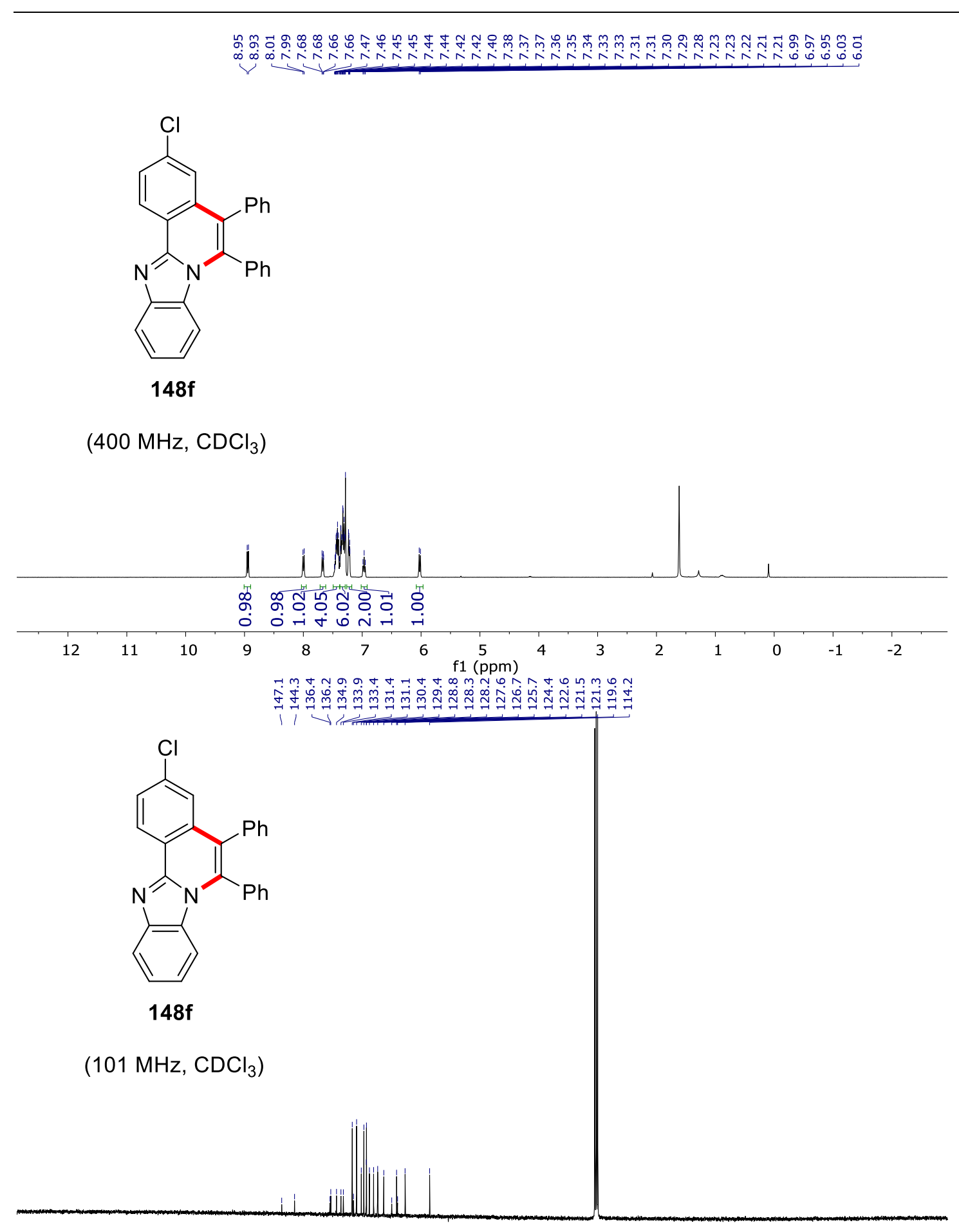

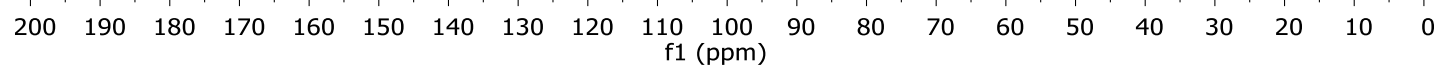


<smiles>Brc1ccc2c(c1)c(-c1ccccc1)c(-c1ccccc1)n1c3ccccc3nc21</smiles>

$148 \mathrm{~g}$

$\left(400 \mathrm{MHz}, \mathrm{CDCl}_{3}\right)$

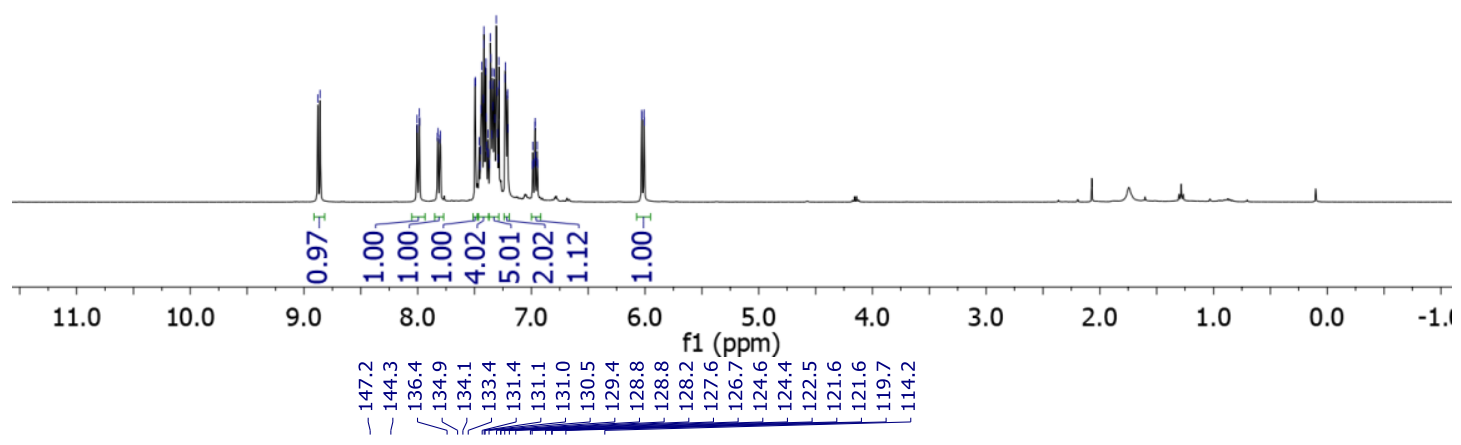<smiles>Brc1ccc2c(c1)c(-c1ccccc1)c(-c1ccccc1)n1c3ccccc3nc21</smiles>

$148 \mathrm{~g}$

$\left(101 \mathrm{MHz} \mathrm{CDCl}_{3}\right)$

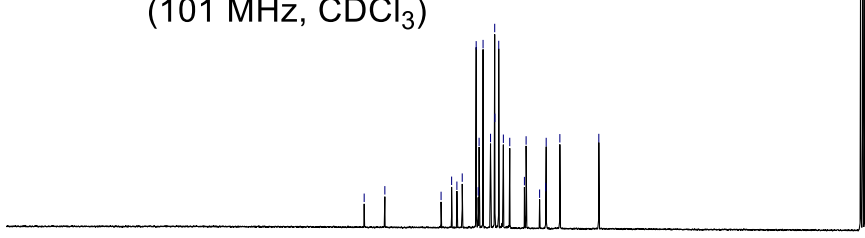




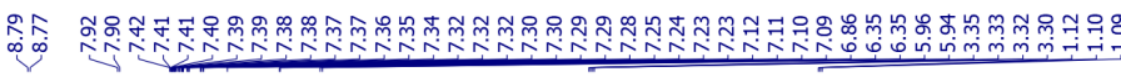<smiles>CCNc1ccc2c(c1)c(-c1ccccc1)c(-c1ccccc1)n1c3ccccc3nc21</smiles>

$148 h$

$\left(400 \mathrm{MHz}, \mathrm{CDCl}_{3}\right)$

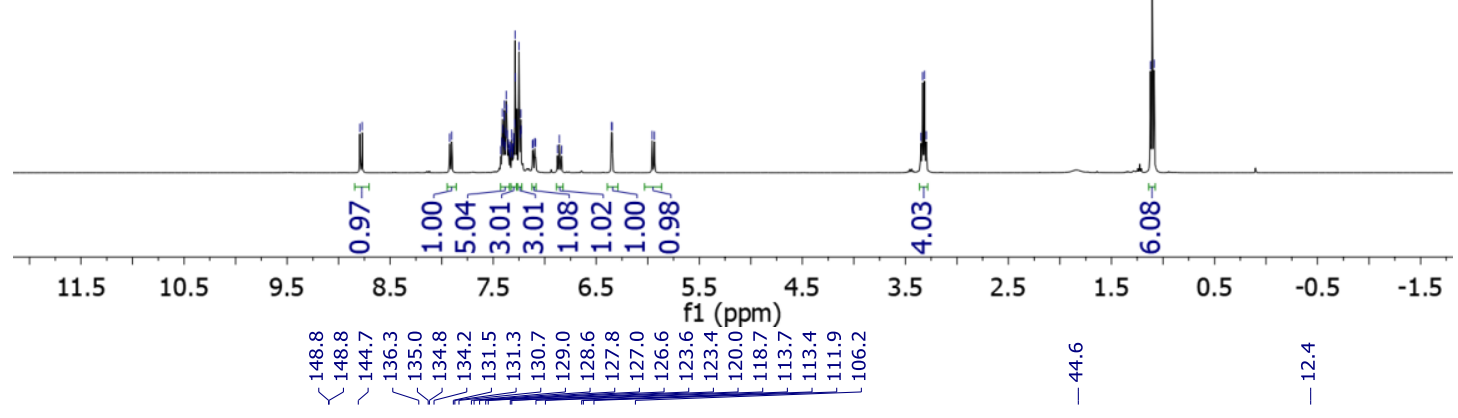<smiles>CCN(CC)c1ccc2c(c1)c(-c1ccccc1)c(-c1ccccc1)n1c3ccccc3nc21</smiles>

$148 \mathrm{~h}$

(101 MHz, $\mathrm{CDCl}_{3}$ )

190180

$170 \quad 160$

150

$140 \quad 130 \quad 120$

110 $100 \underset{f 1(\mathrm{ppm})}{90} 80$ 
然<smiles>FC(F)(F)c1ccc2c(-c3ccccc3)c(-c3ccccc3)n3c4ccccc4nc3c2c1</smiles>

148i

$\left(400 \mathrm{MHz} \mathrm{CDCl}_{3}\right)$

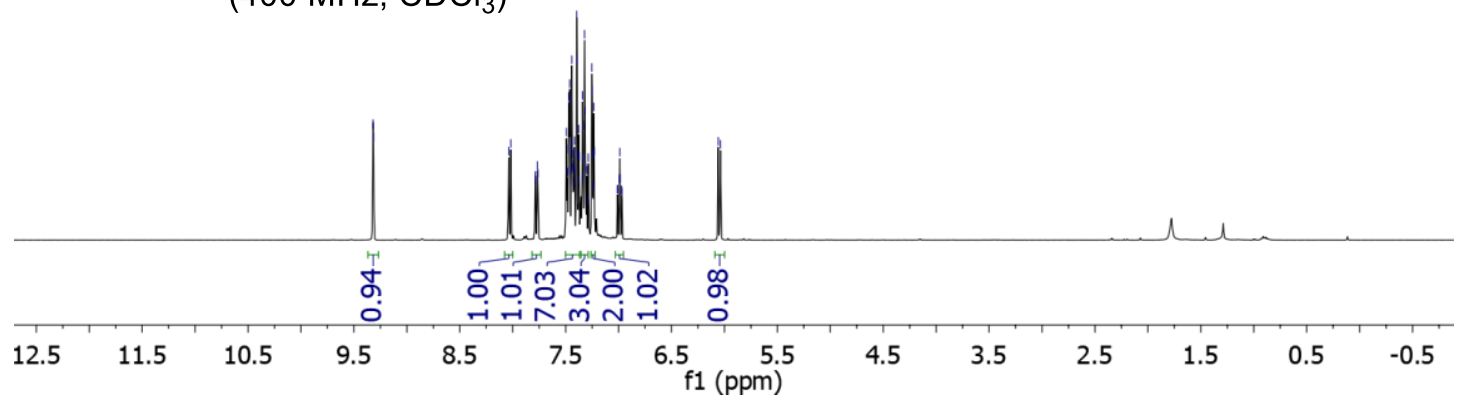

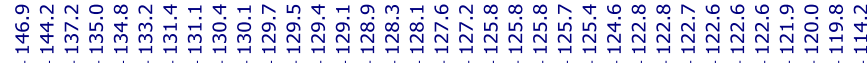<smiles>FC(F)(F)c1ccc2c(-c3ccccc3)c(-c3ccccc3)n3c4ccccc4nc3c2c1</smiles>

148i

$\left(101 \mathrm{MHz}^{\mathrm{CDCl}}{ }_{3}\right)$

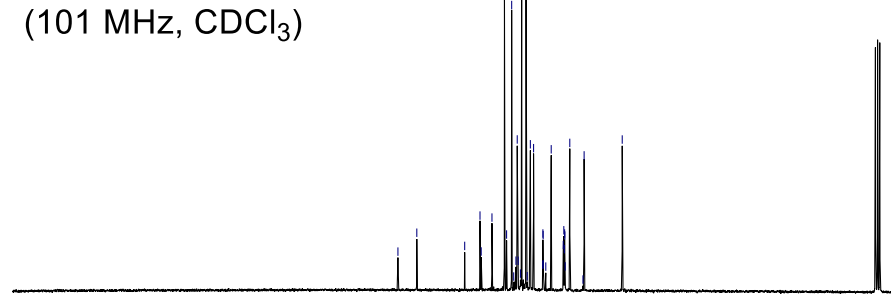

$\begin{array}{lllllllllllllllllllll}200 & 190 & 180 & 170 & 160 & 150 & 140 & 130 & 120 & 110 & 100 & 90 & 80 & 70 & 60 & 50 & 40 & 30 & 20 & 10 & 0\end{array}$ 


\section{NMR Spectra}

\section{$\stackrel{\substack{i \\ i}}{i}$}<smiles>FC(F)(F)c1ccc2c(-c3ccccc3)c(-c3ccccc3)n3c4ccccc4nc3c2c1</smiles>

$148 \mathrm{i}$

(377 MHz, $\mathrm{CDCl}_{3}$ )

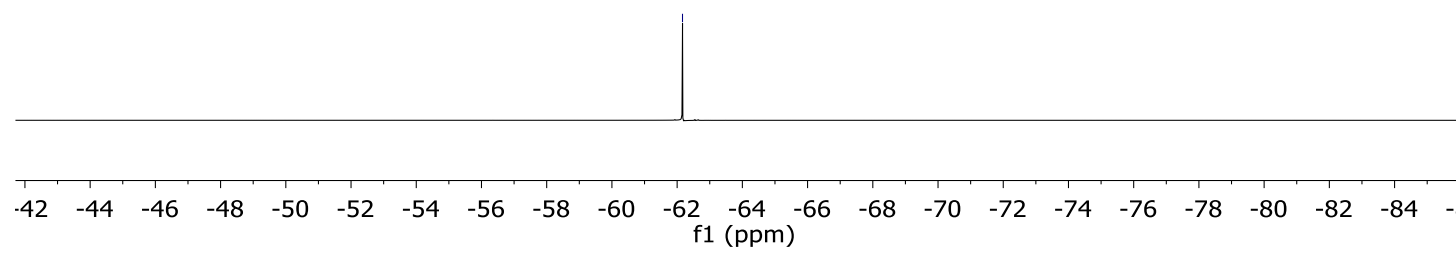

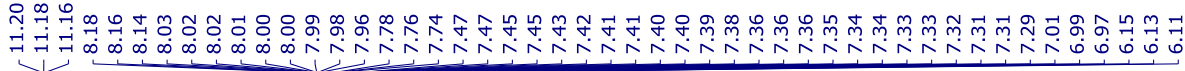<smiles>c1ccc(-c2c(-c3ccccc3)c3ccc4ccccc4n3c2-c2ccccc2)cc1</smiles>

148j

$\left(400 \mathrm{MHz}, \mathrm{CDCl}_{3}\right)$

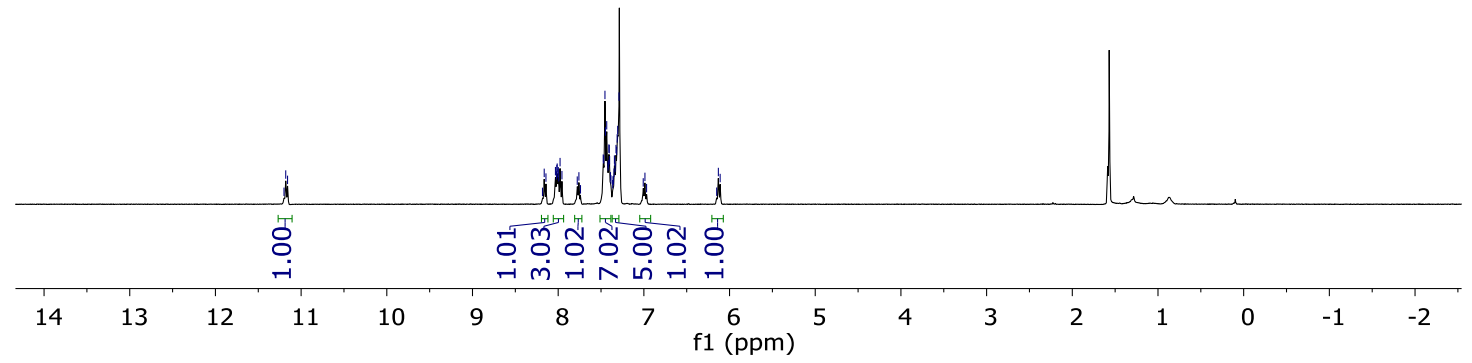




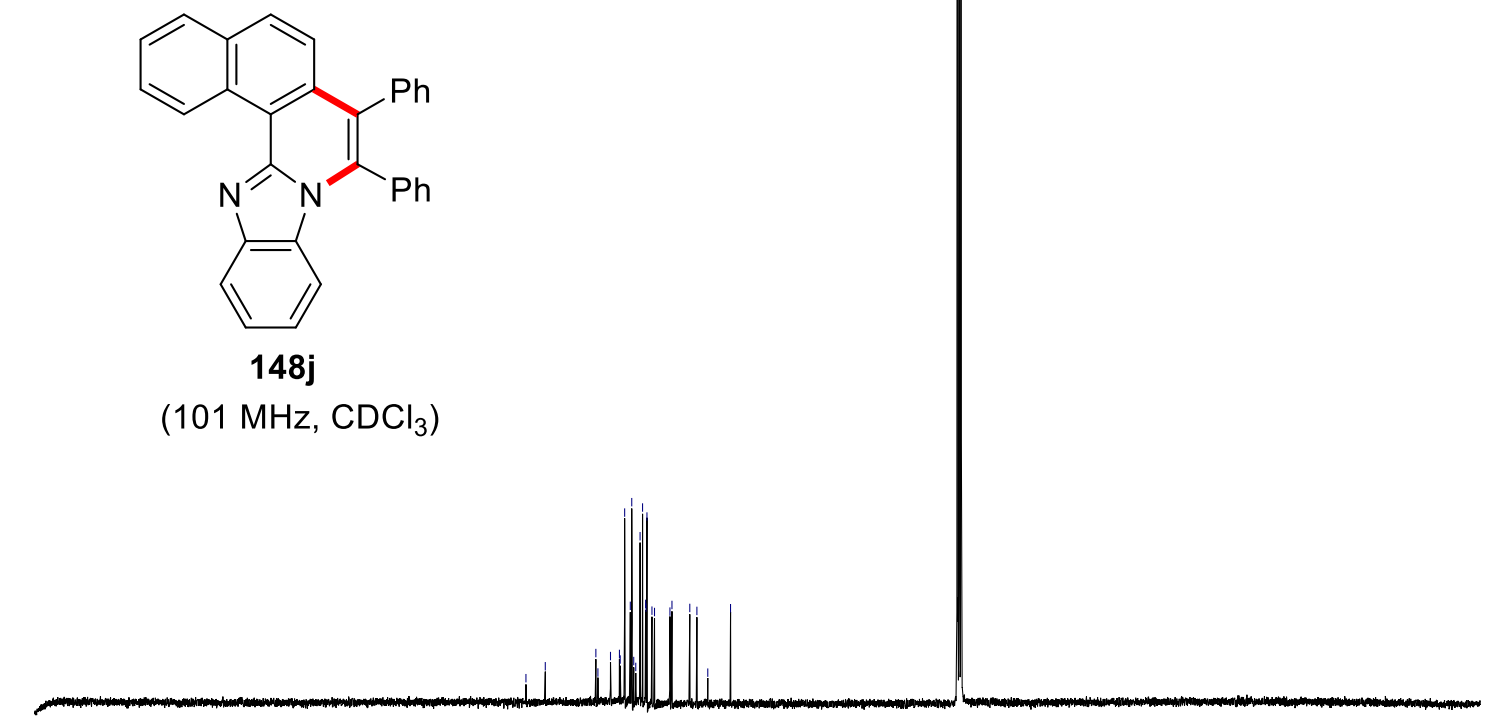

148j

$\left(101 \mathrm{MHz}, \mathrm{CDCl}_{3}\right)$
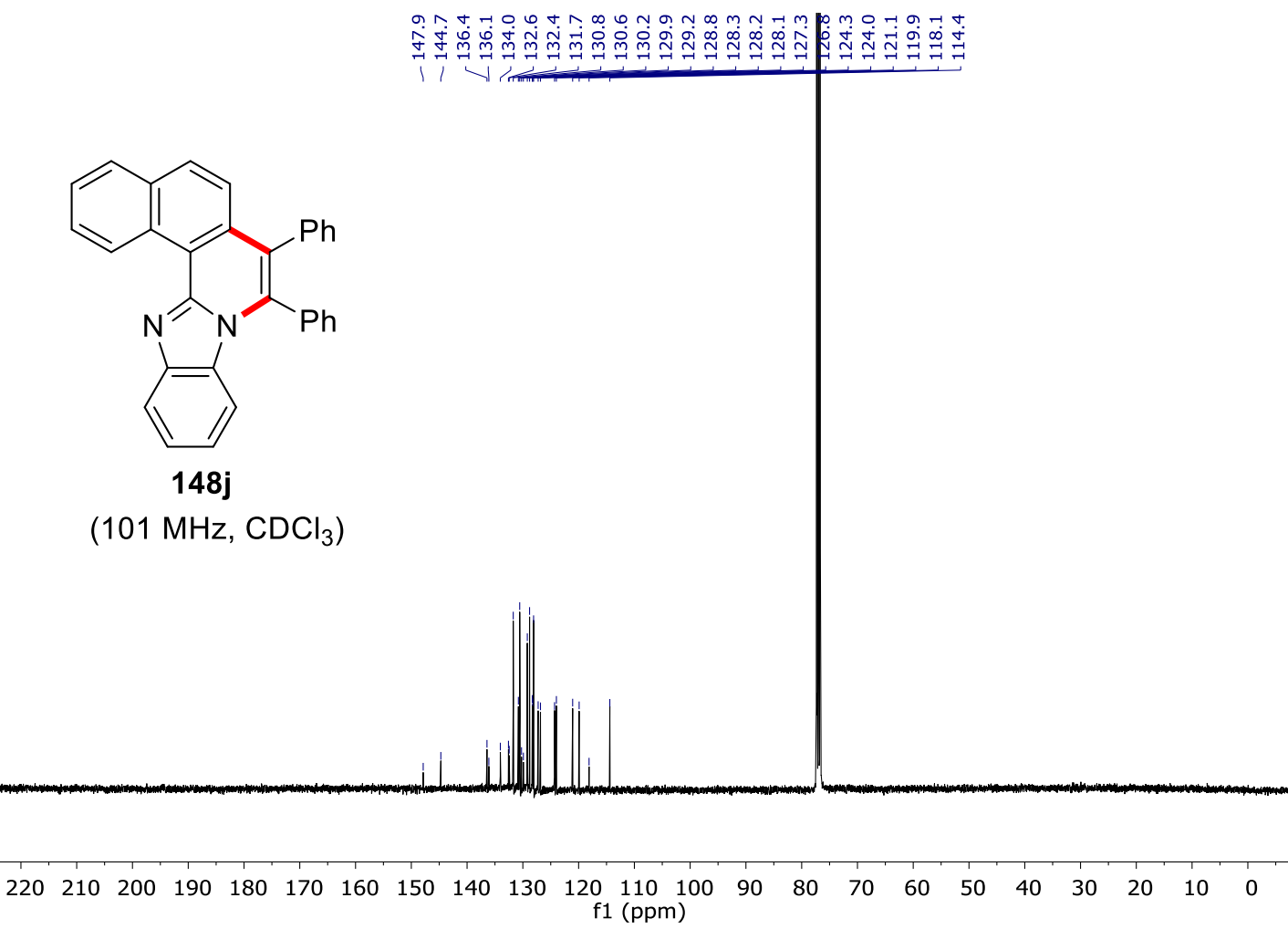

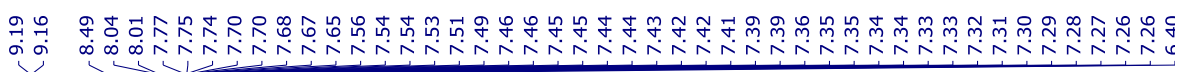<smiles>c1ccc(-c2c(-c3ccccc3)n3c4cc5ccccc5cc4nc3c3ccccc23)cc1</smiles>

148k

$\left(300 \mathrm{MHz}, \mathrm{CDCl}_{3}\right)$

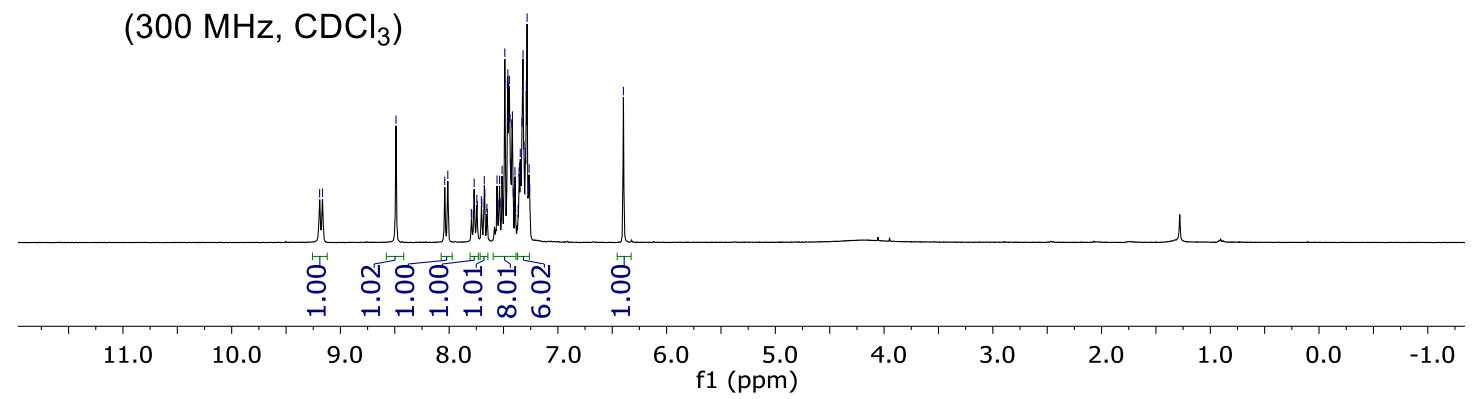




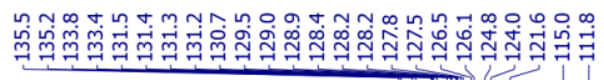<smiles></smiles>

148k

$\left(75 \mathrm{MHz}, \mathrm{CDCl}_{3}\right)$

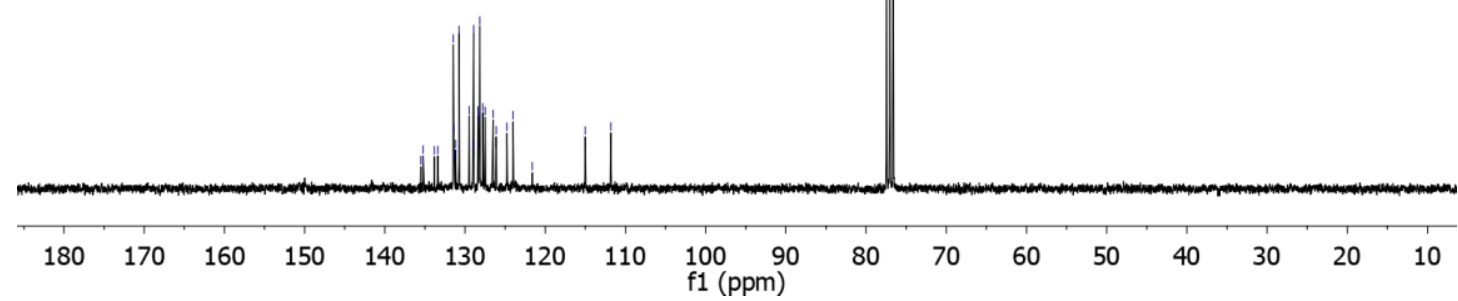

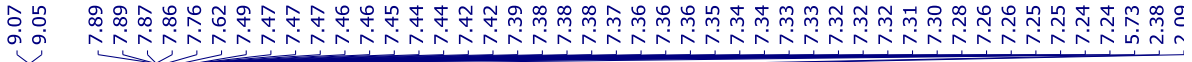<smiles>Cc1cc2nc3c4ccc(C(F)(F)F)cc4c(-c4ccccc4)c(-c4ccccc4)n3c2cc1C</smiles>

$\left(400 \mathrm{MHz}, \mathrm{CDCl}_{3}\right)$

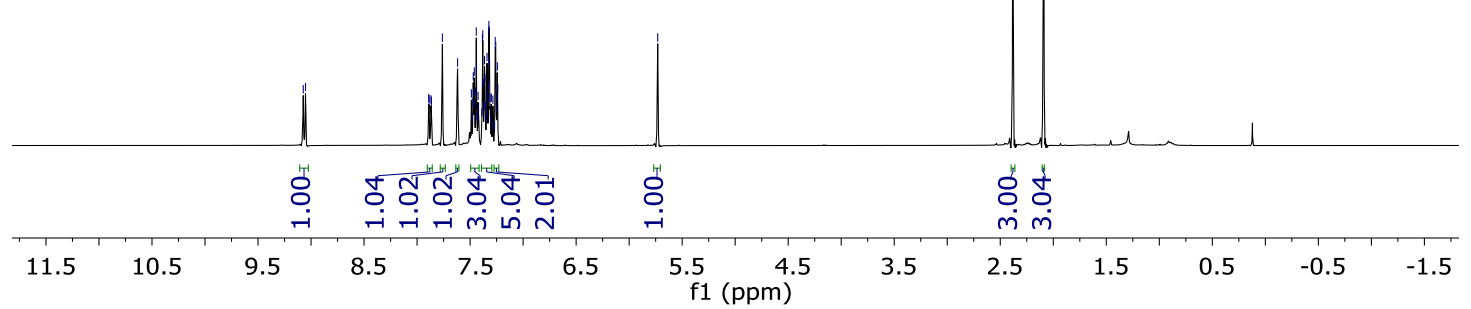



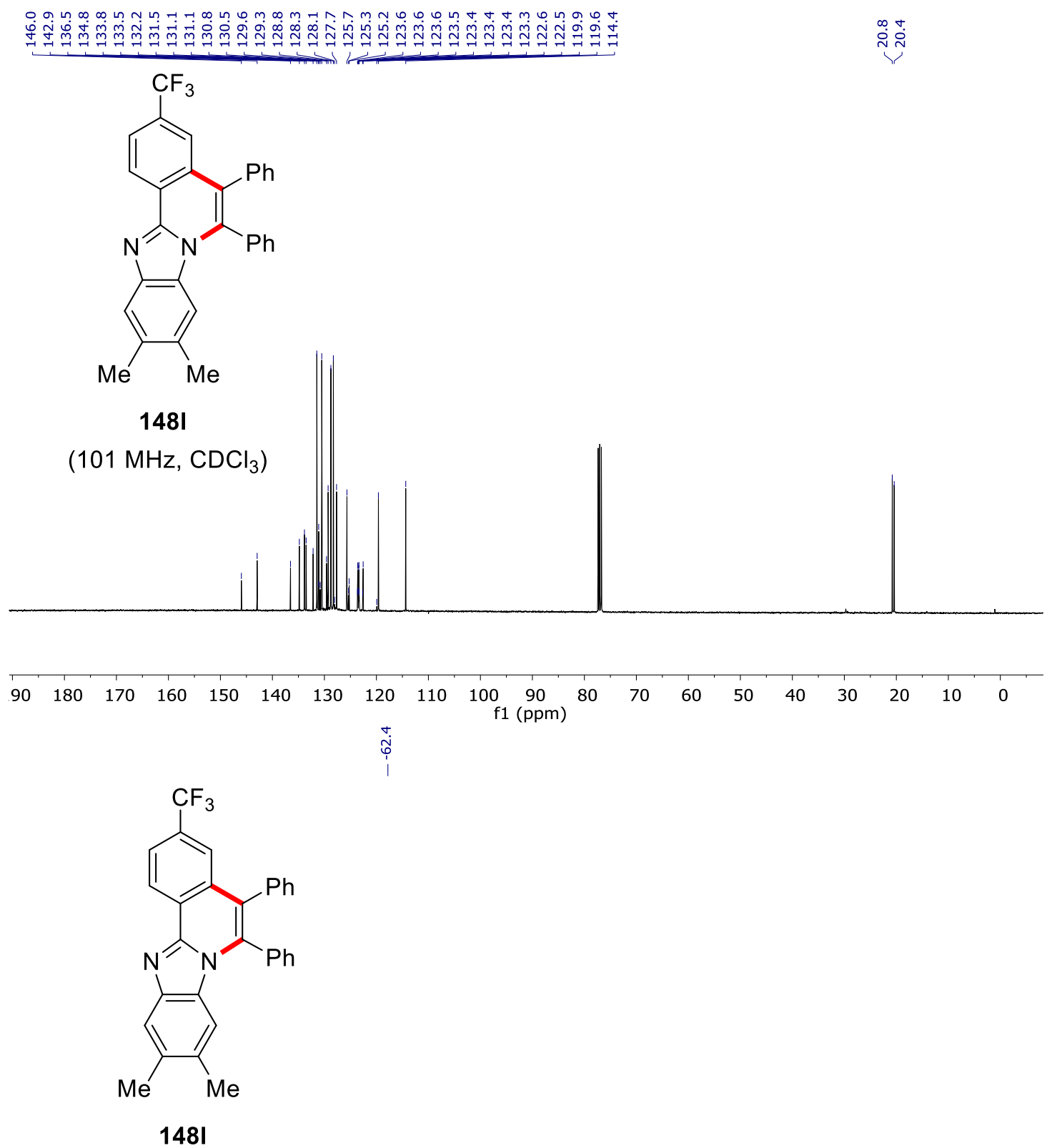

(377 MHz, $\mathrm{CDCl}_{3}$ )

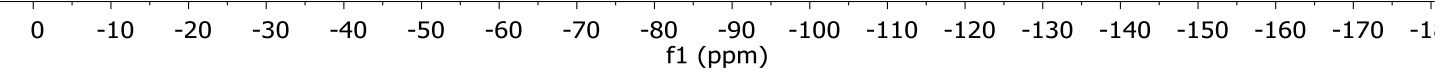


<smiles>Cc1cc2nc3c4ccc(Br)cc4c(-c4ccccc4)c(-c4ccccc4)n3c2cc1C</smiles>

$148 \mathrm{~m}$

$\left(400 \mathrm{MHz}, \mathrm{CDCl}_{3}\right)$
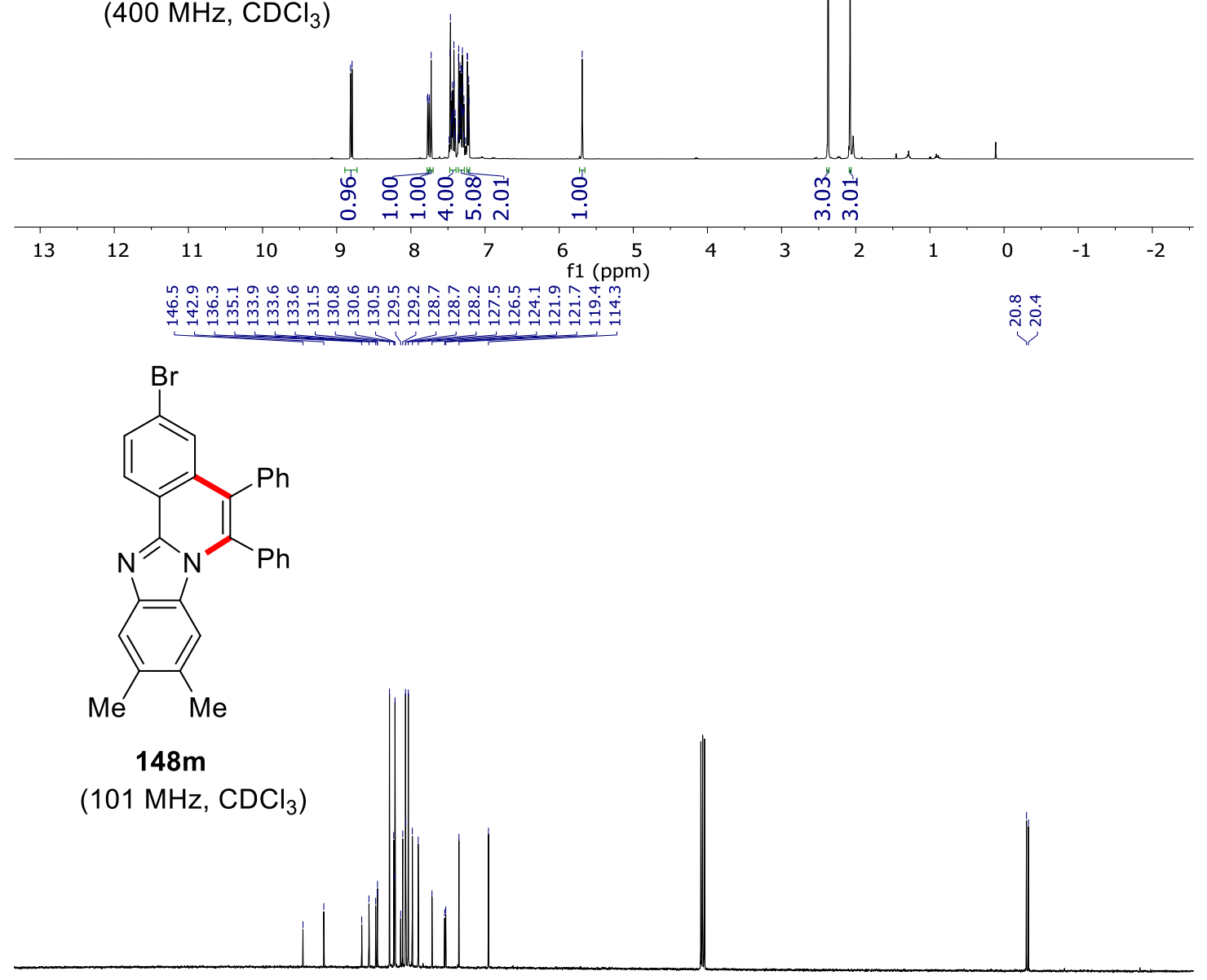

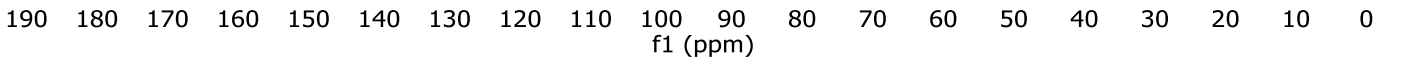


<smiles>Cc1c(-c2ccccc2)n2c3ccccc3nc2c2ccccc12</smiles>

148n

$\left(300 \mathrm{MHz}, \mathrm{CDCl}_{3}\right.$ )

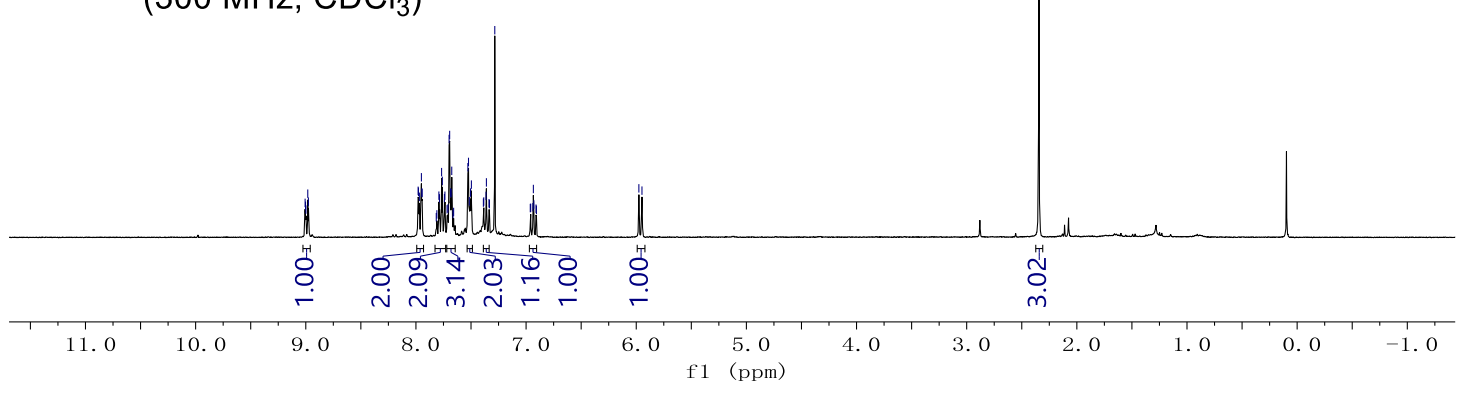

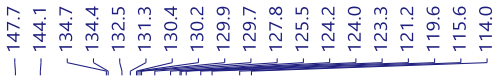

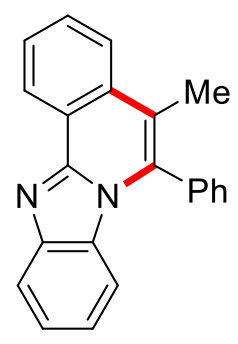

148n

$\left(101 \mathrm{MHz}, \mathrm{CDCl}_{3}\right.$ )
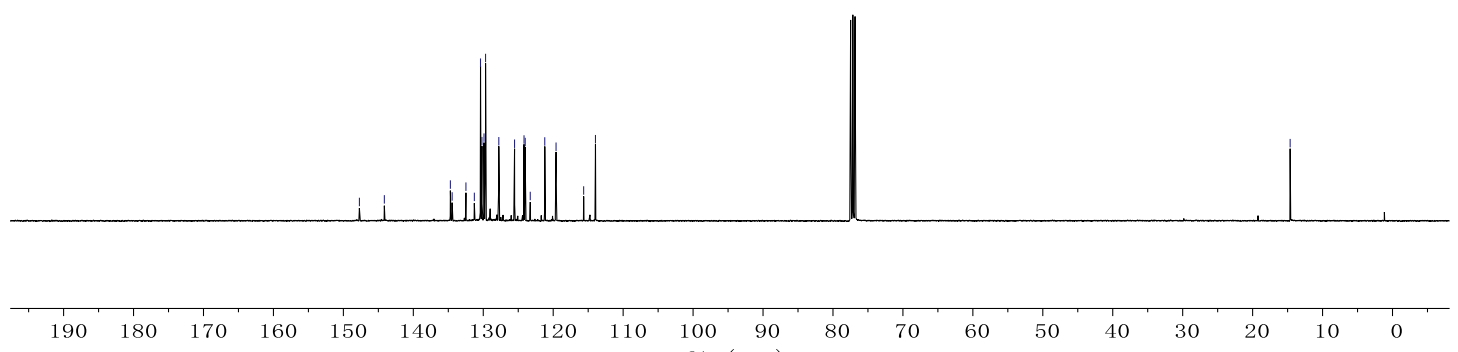

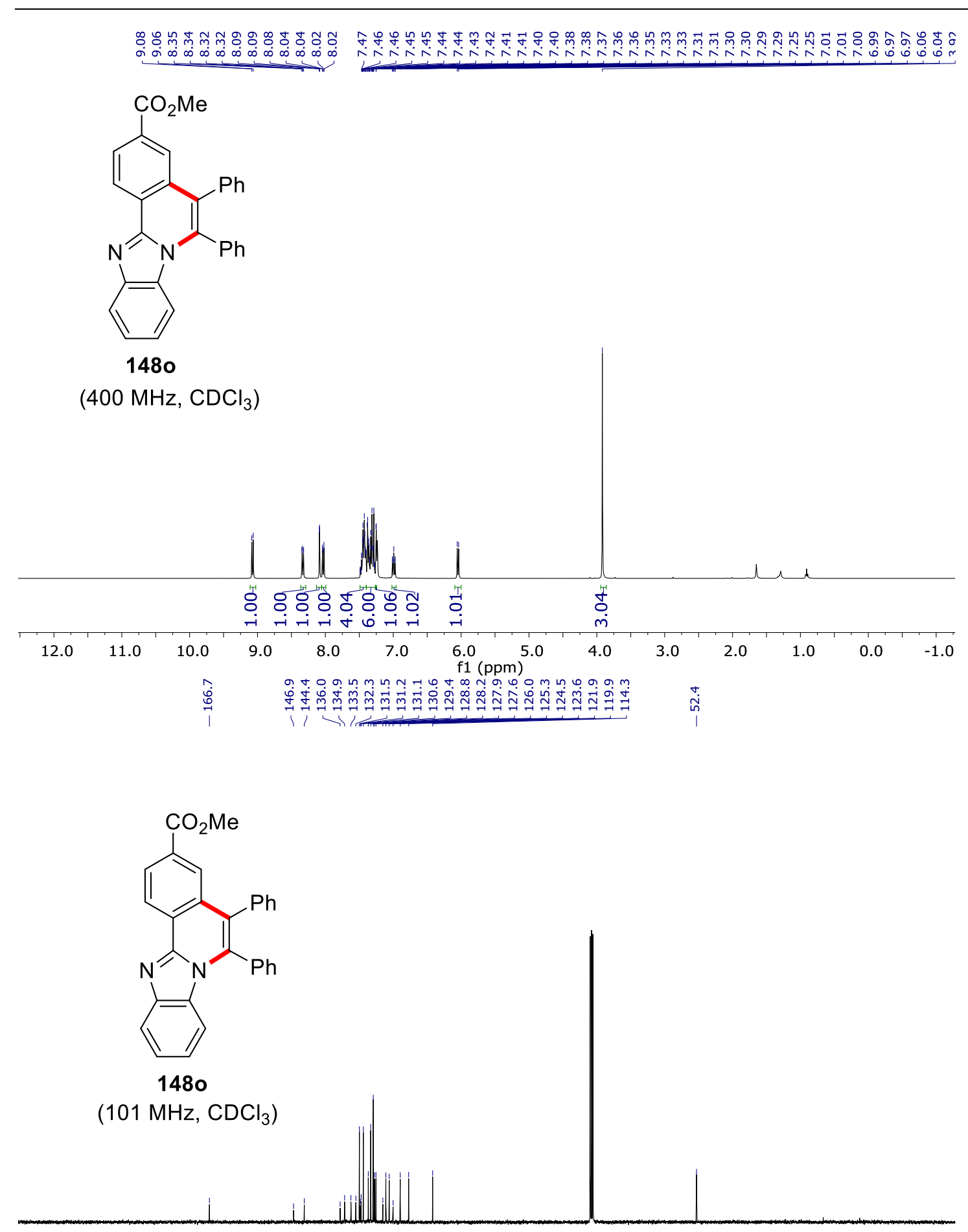

$\begin{array}{llllllllllllllllllllll}210 & 200 & 190 & 180 & 170 & 160 & 150 & 140 & 130 & 120 & 110 & 100 & 90 & 80 & 70 & 60 & 50 & 40 & 30 & 20 & 10 & 0\end{array}$ 


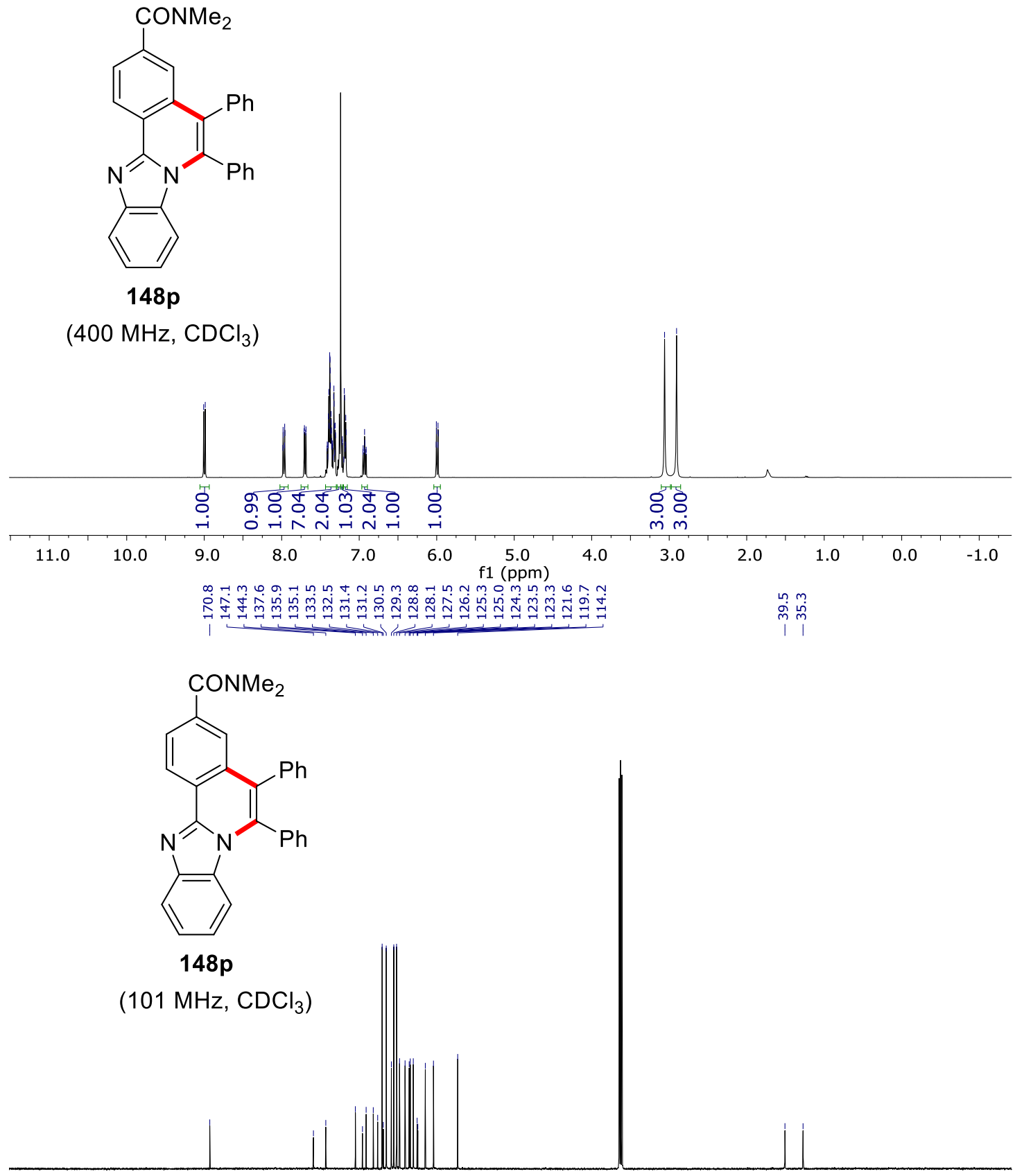

$\begin{array}{lllllllllllllllllllllll}210 & 200 & 190 & 180 & 170 & 160 & 150 & 140 & 130 & 120 & \begin{array}{c}110 \\ \mathrm{f} 1(\mathrm{ppm})\end{array}\end{array}$ 


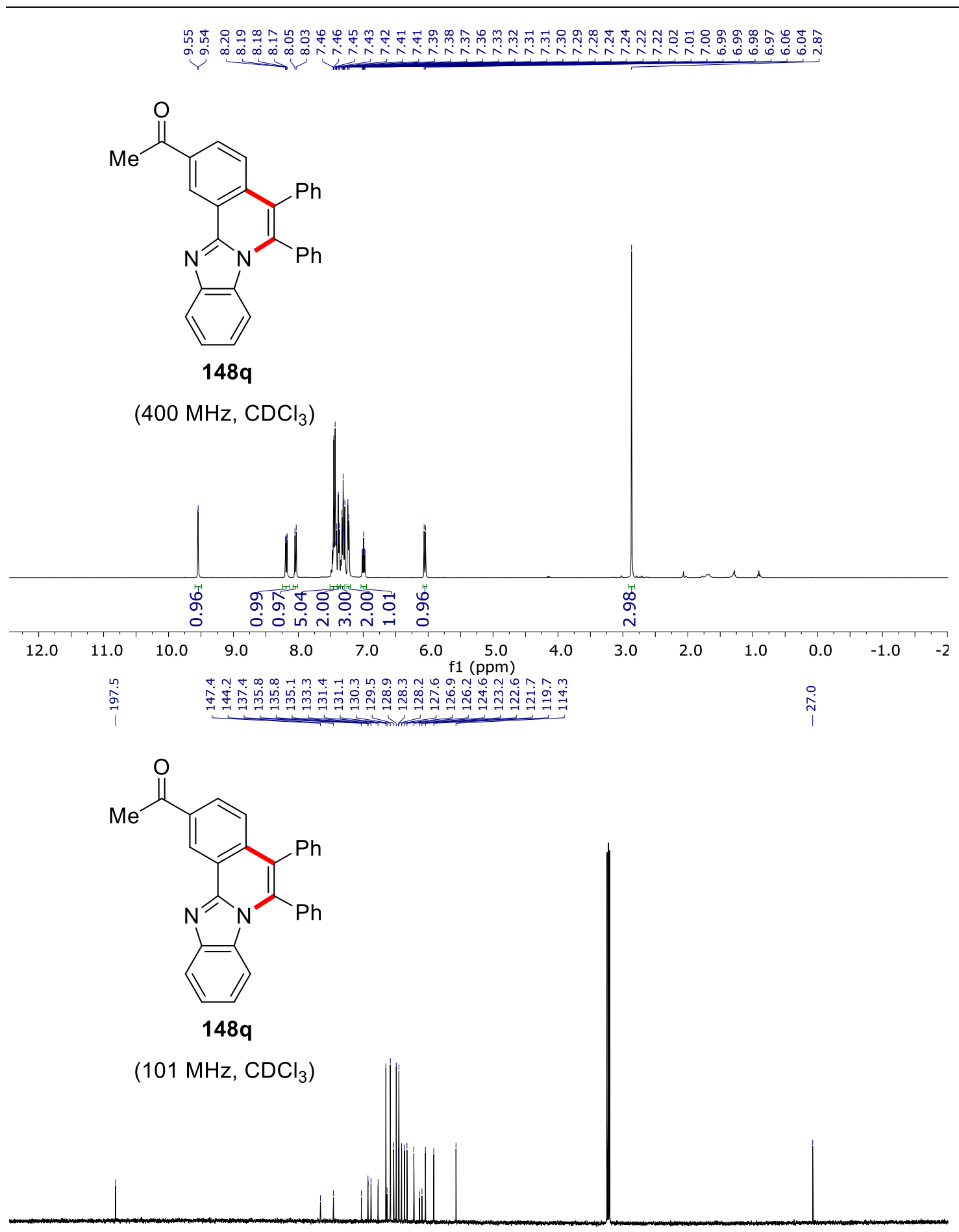

$\begin{array}{lllllllllllllllllllllll}220 & 210 & 200 & 190 & 180 & 170 & 160 & 150 & 140 & 130 & \begin{array}{c}120 \\ \mathrm{f} 1(\mathrm{ppm})\end{array} & 110 & 100 & 90 & 80 & 70 & 60 & 50 & 40 & 30 & 20 & 10 & 0\end{array}$ 


\section{NMR Spectra}

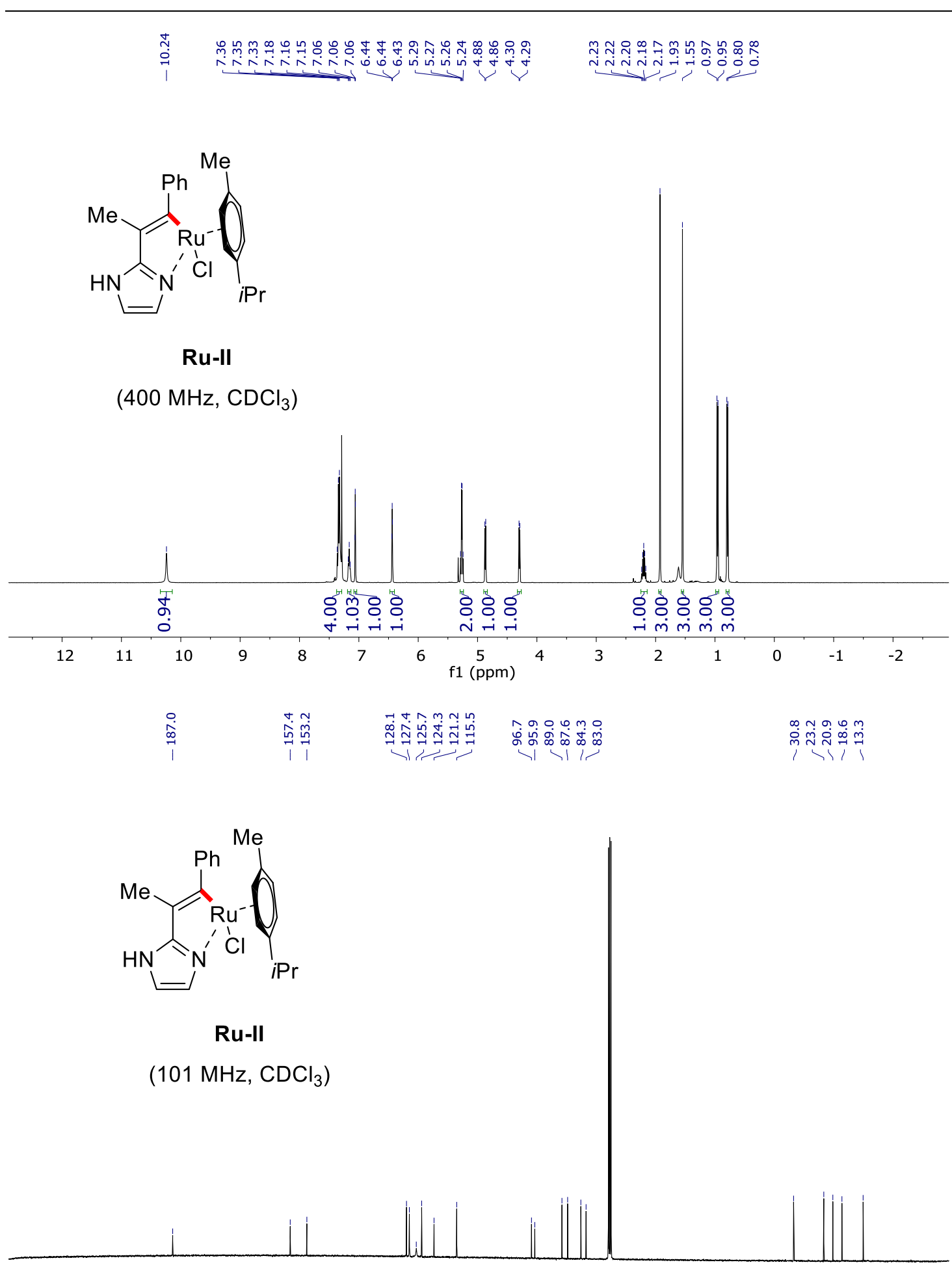

$\begin{array}{lllllllllllllllllllllll}220 & 210 & 200 & 190 & 180 & 170 & 160 & 150 & 140 & 130 & \begin{array}{c}120 \\ \mathrm{f} 1\end{array} \begin{array}{l}110 \\ (\mathrm{ppm})\end{array} & 100 & 90 & 80 & 70 & 60 & 50 & 40 & 30 & 20 & 10 & 0\end{array}$ 


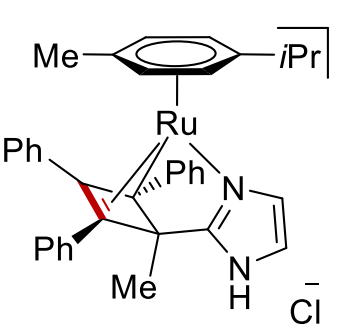

Ru-IVa

$\left(400 \mathrm{MHz}, \mathrm{CDCl}_{3}\right)$
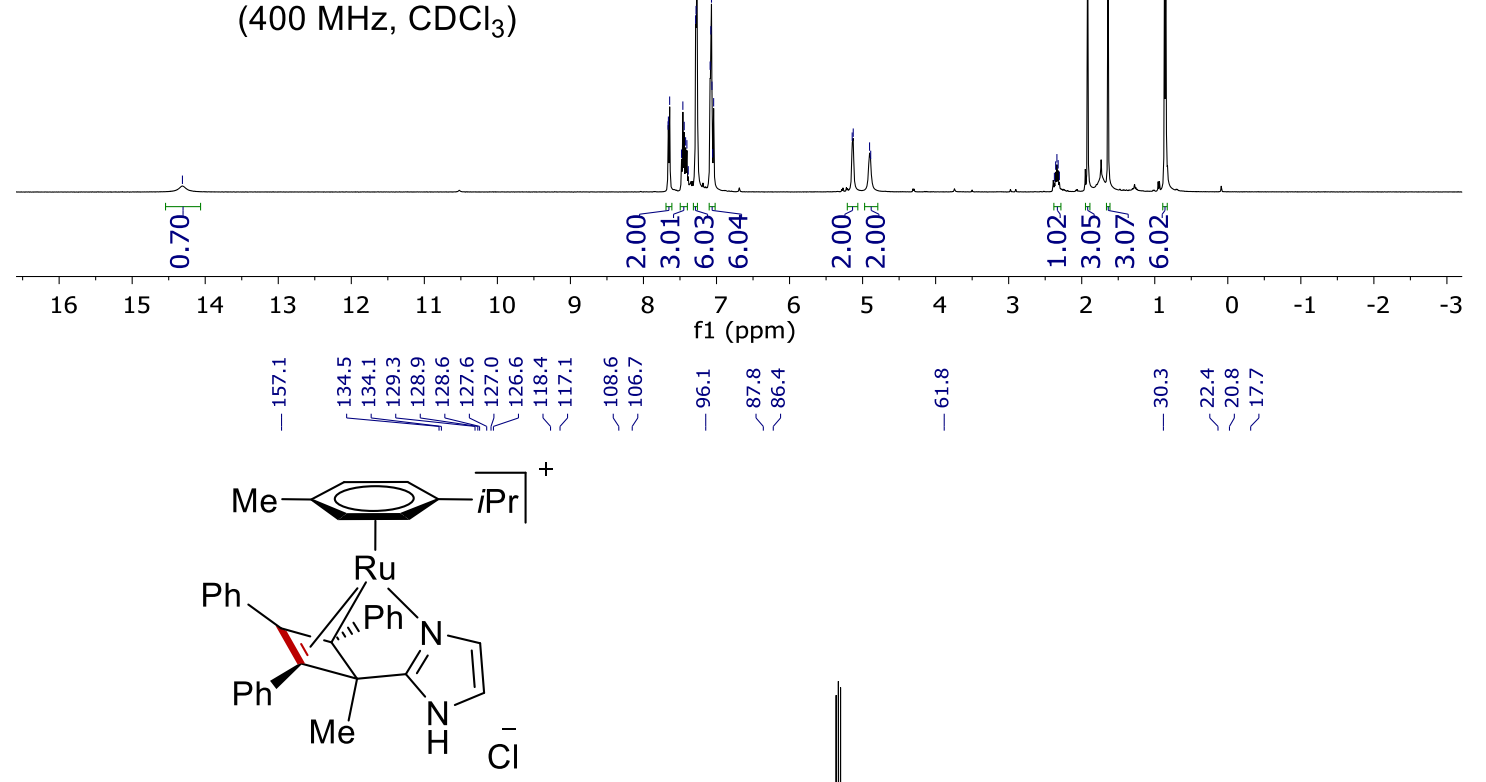

Ru-IVa

$\left(101 \mathrm{MHz}, \mathrm{CDCl}_{3}\right)$

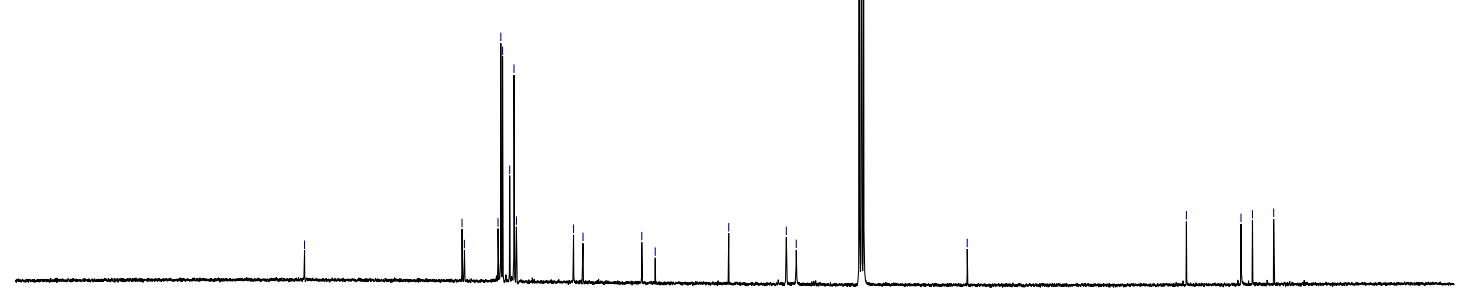

$\begin{array}{llllllllllllllllllllll}190 & 180 & 170 & 160 & 150 & 140 & 130 & 120 & 110 & \begin{array}{l}100 \\ \mathrm{f} 1(\mathrm{ppm})\end{array} & 90 & 70 & 60 & 50 & 40 & 30 & 20 & 10 & 0\end{array}$ 


\section{NMR Spectra}

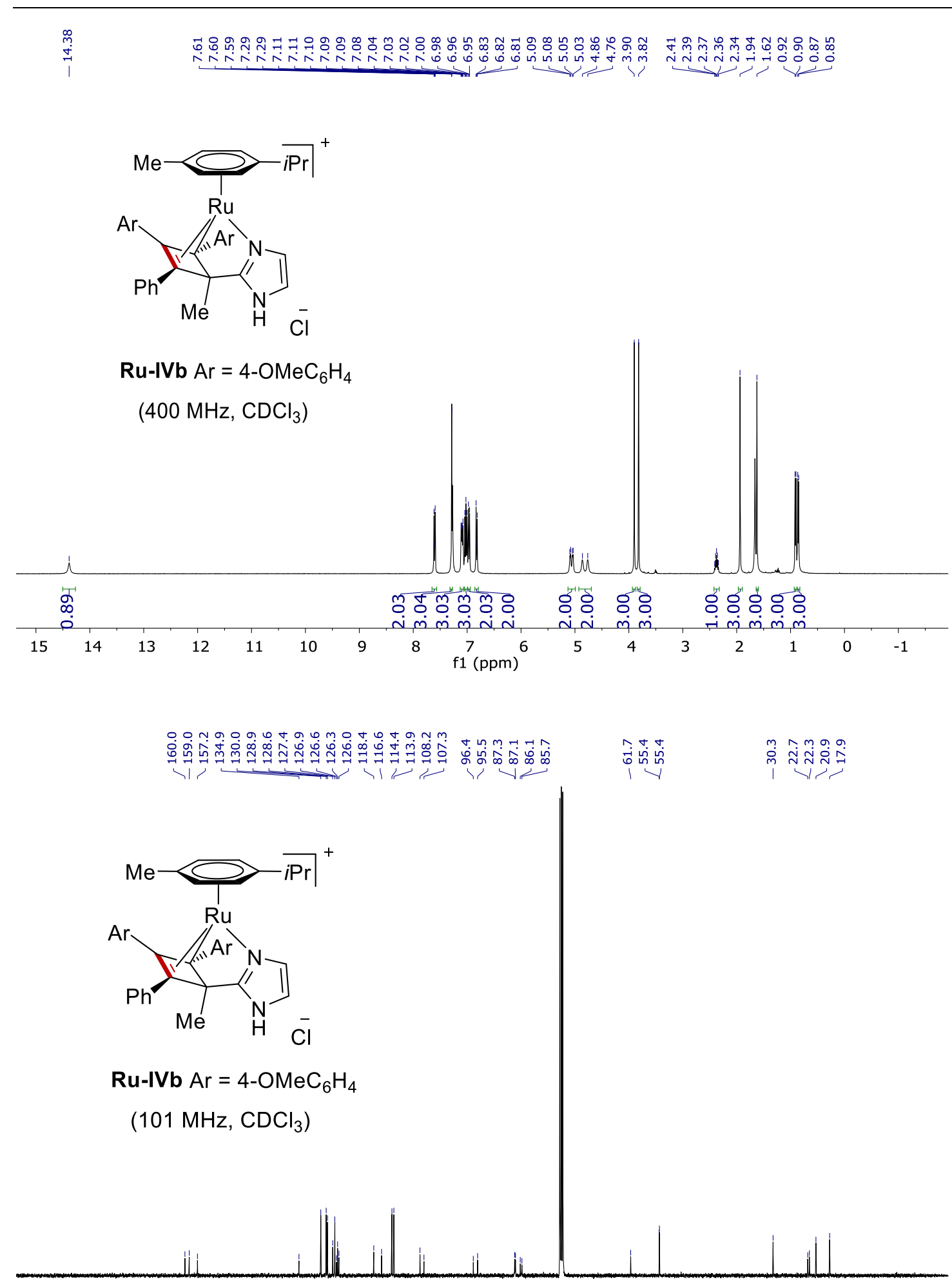

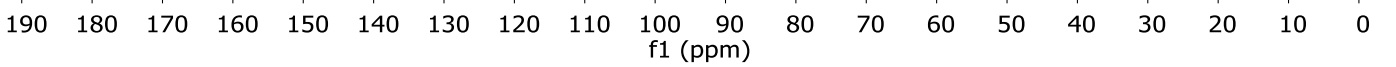




\subsection{Palladium(II)-Catalyzed B(3,4)-Arylation of o-Carboranes}
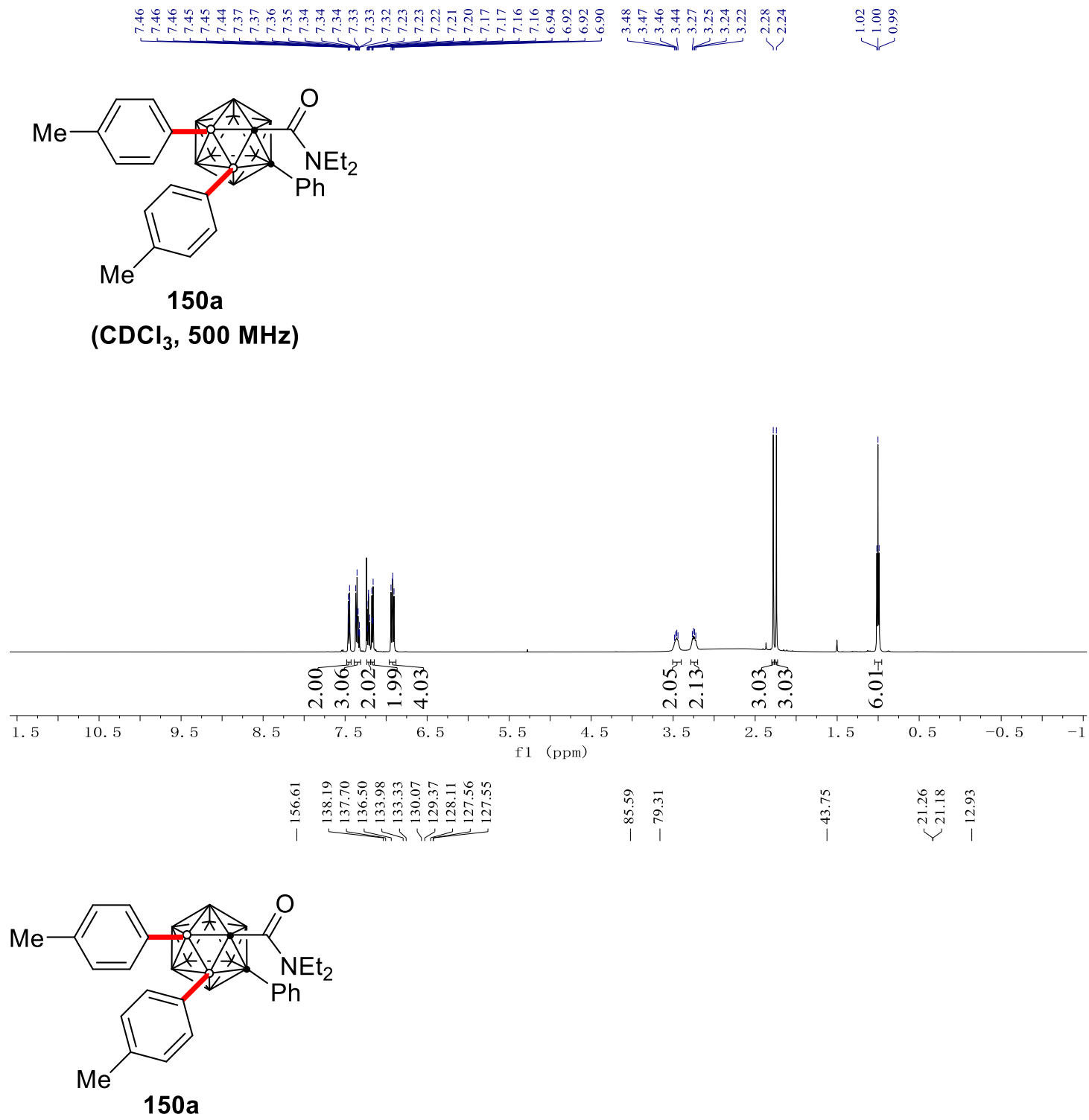

$\left(\mathrm{CDCl}_{3}, 125 \mathrm{MHz}\right)$

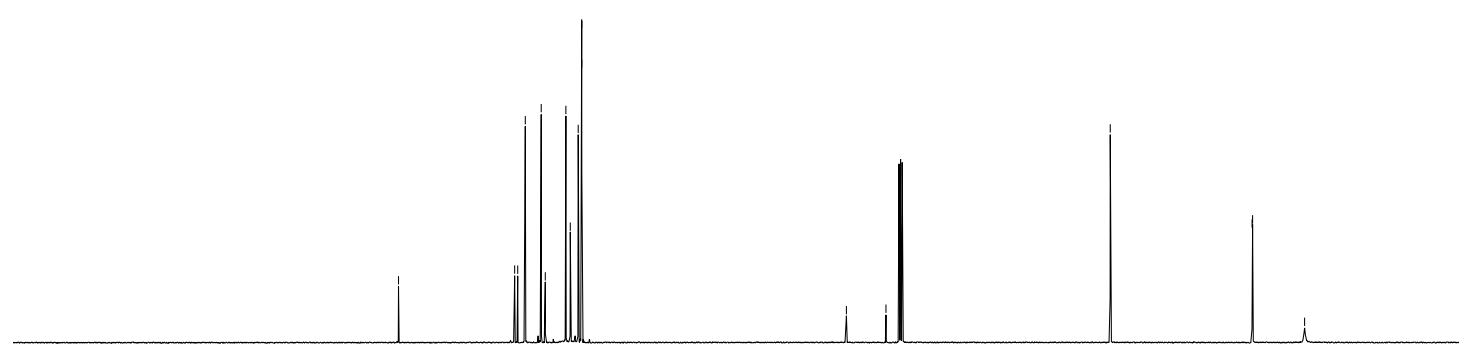




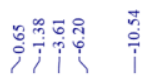
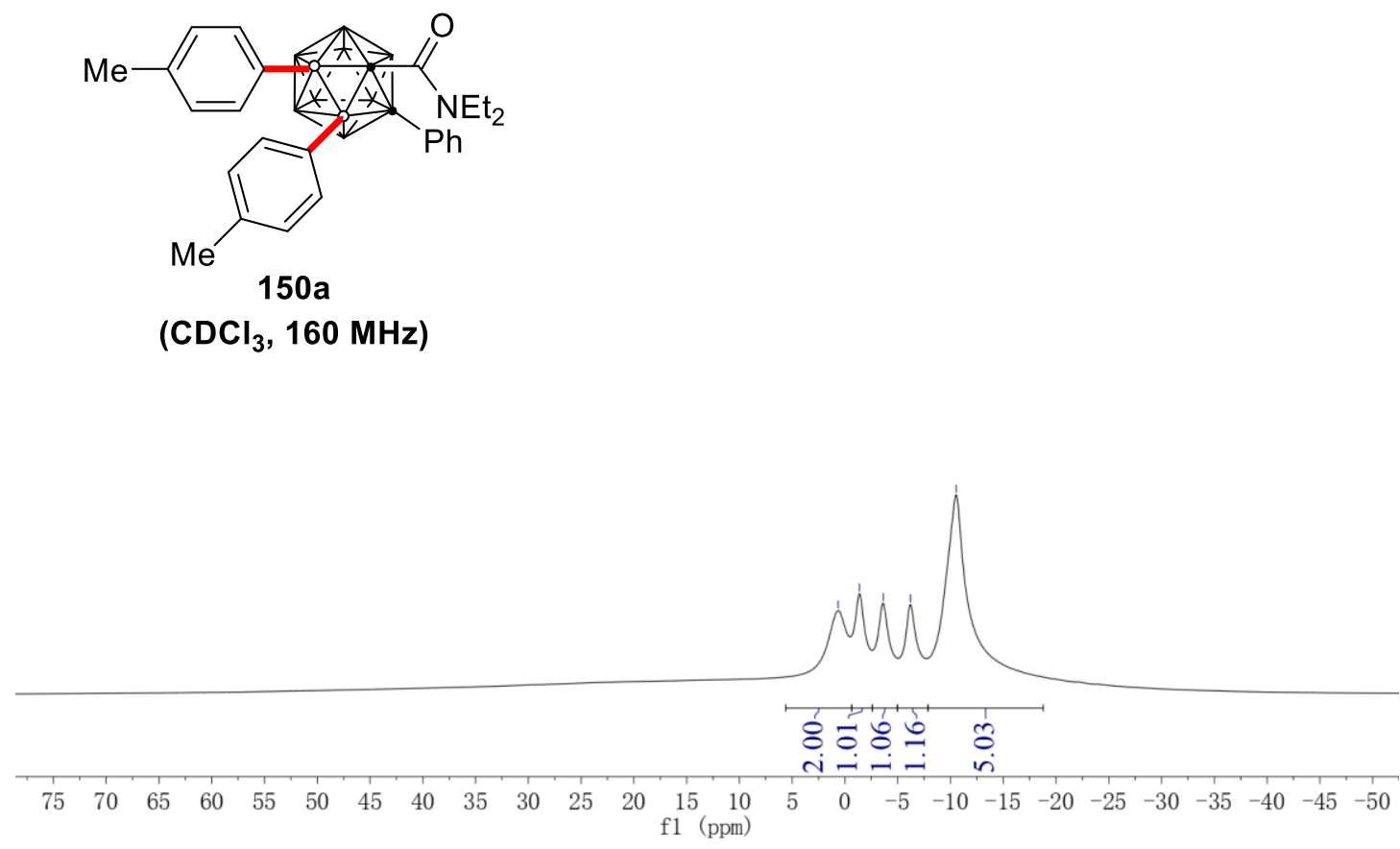

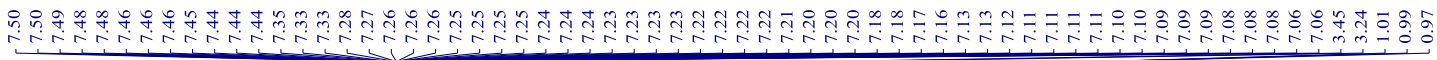

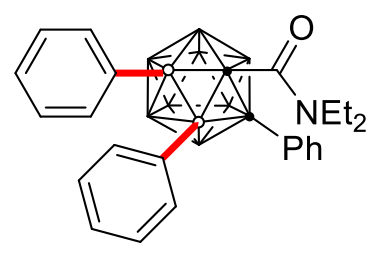

$150 \mathrm{~b}$

$\left(\mathrm{CDCl}_{3}, 400 \mathrm{MHz}\right)$

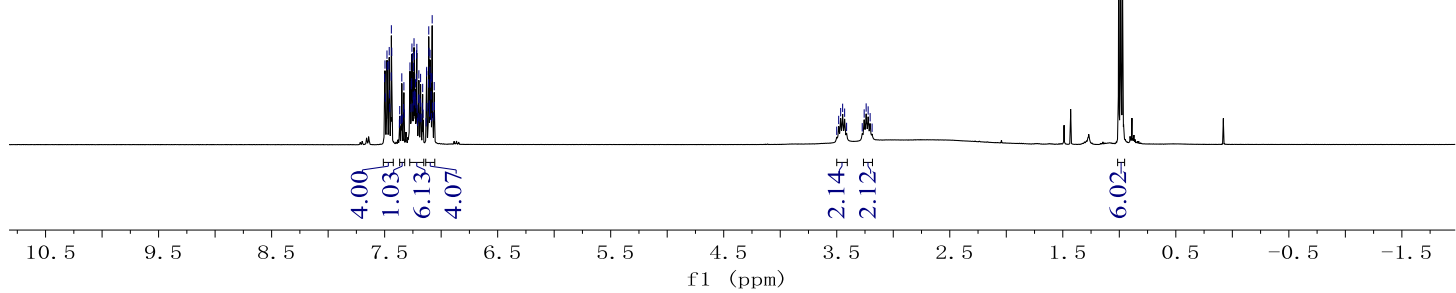


NMR Spectra
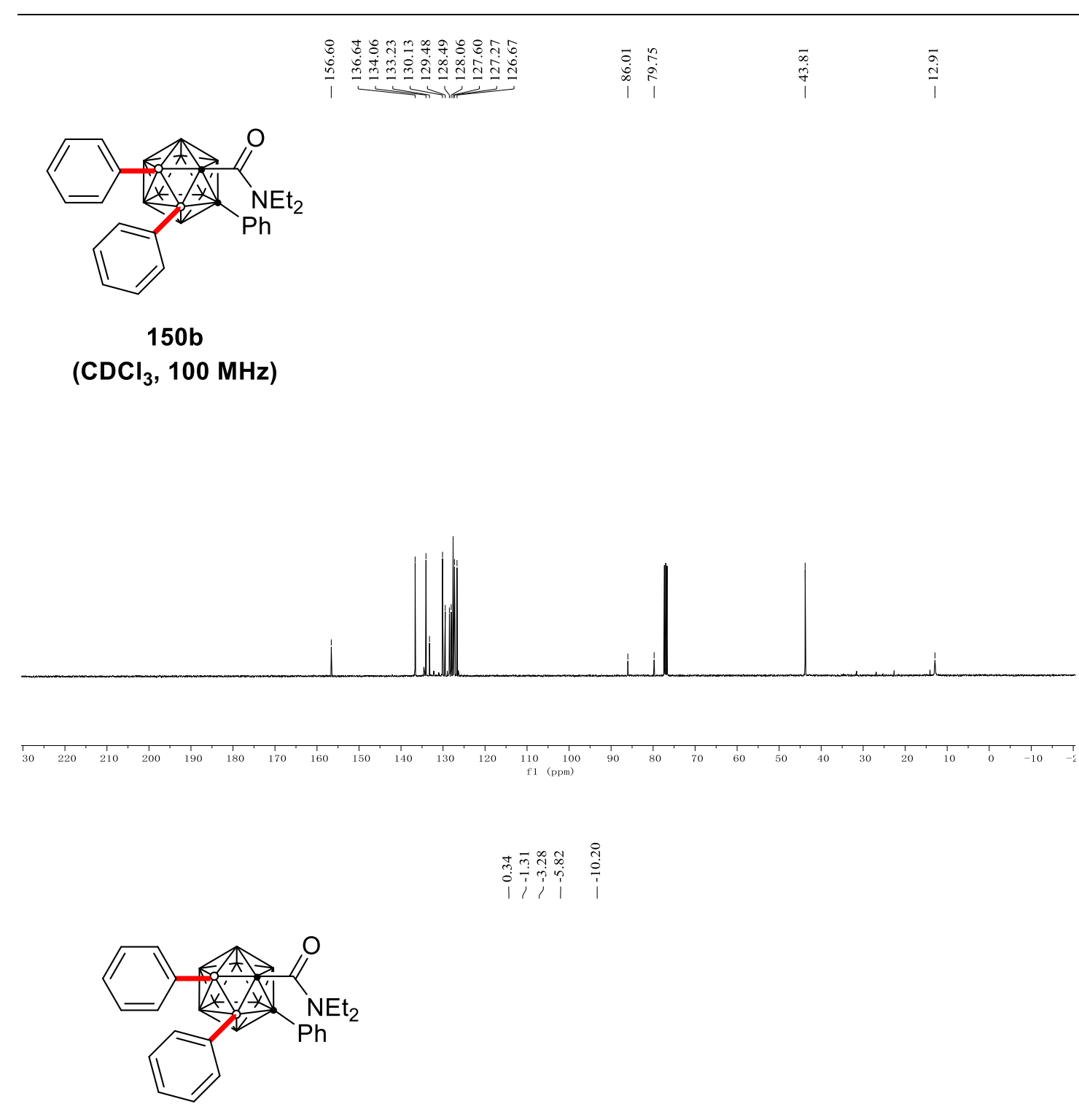

$150 \mathrm{~b}$

$\left(\mathrm{CDCl}_{3}, 128 \mathrm{MHz}\right)$

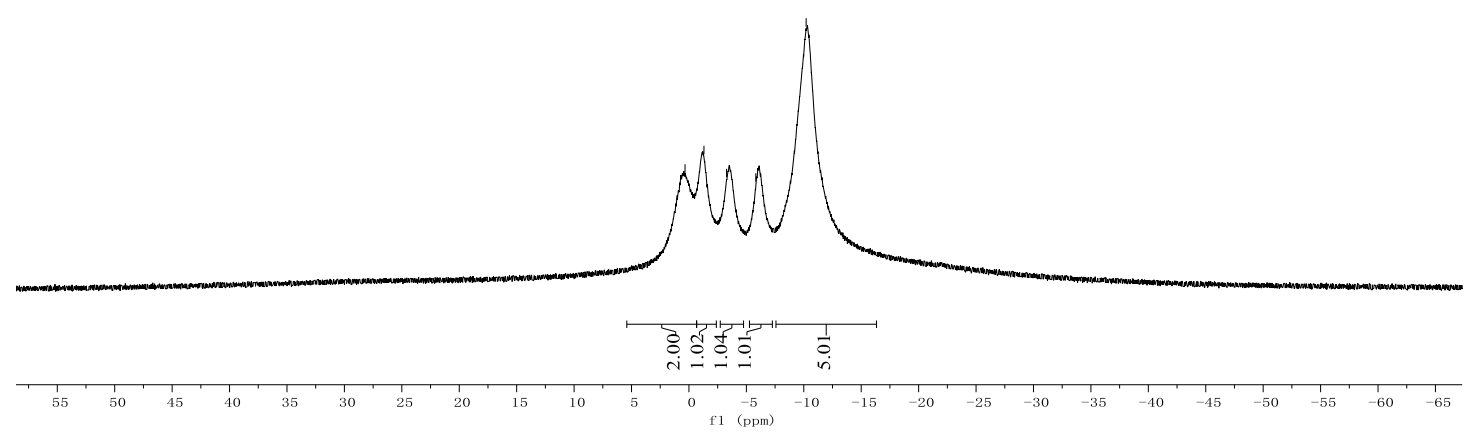




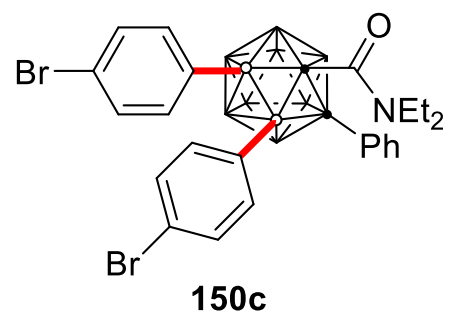

$\left(\mathrm{CDCl}_{3}, 300 \mathrm{MHz}\right)$
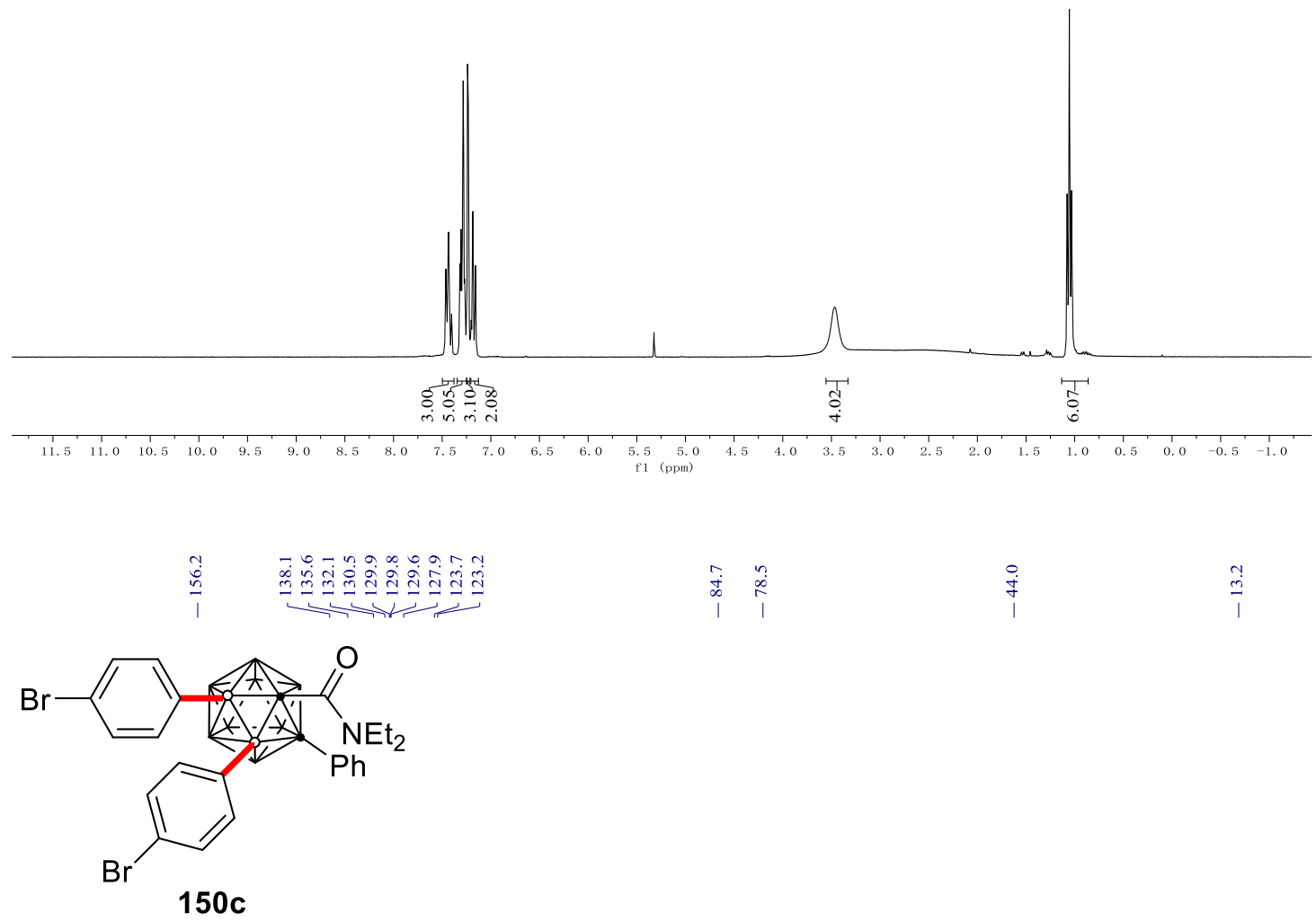

$\left(\mathrm{CDCl}_{3}, 75 \mathrm{MHz}\right)$

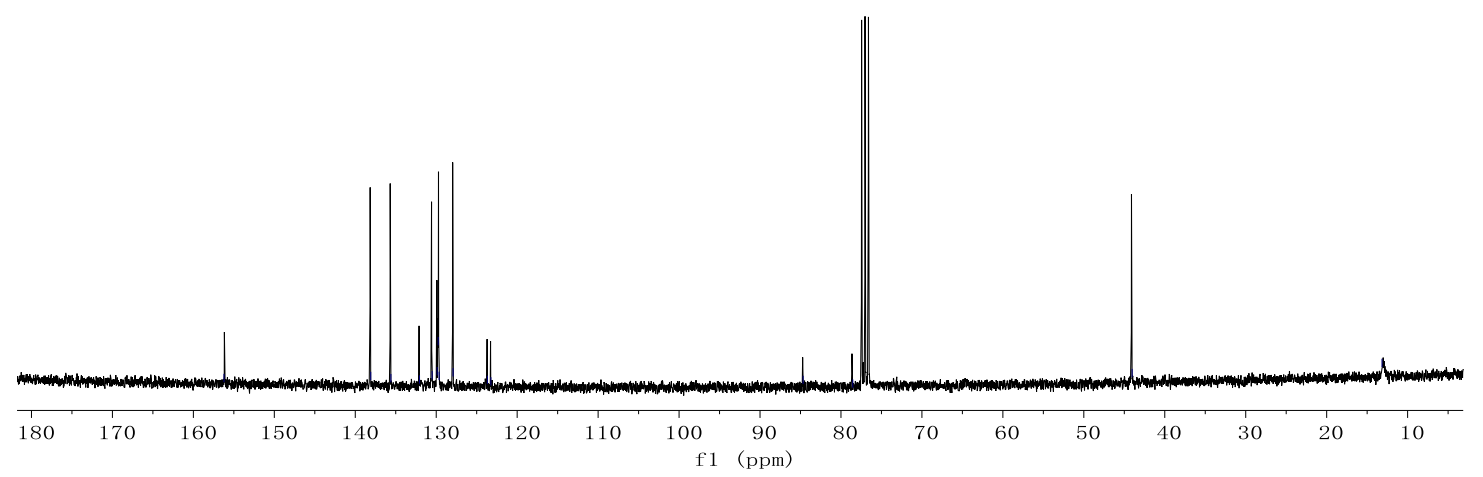




\section{NMR Spectra}
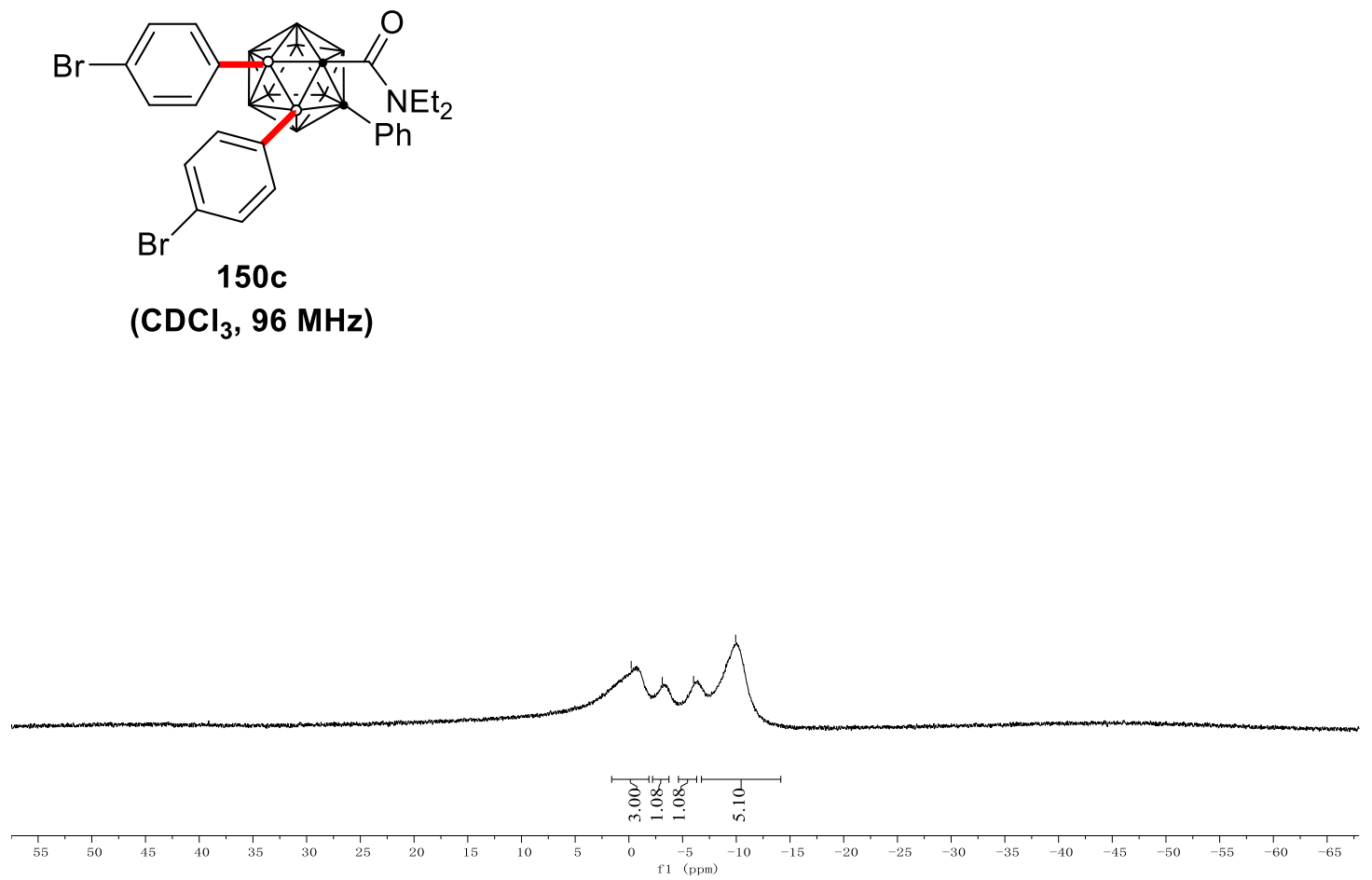

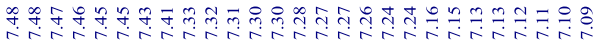
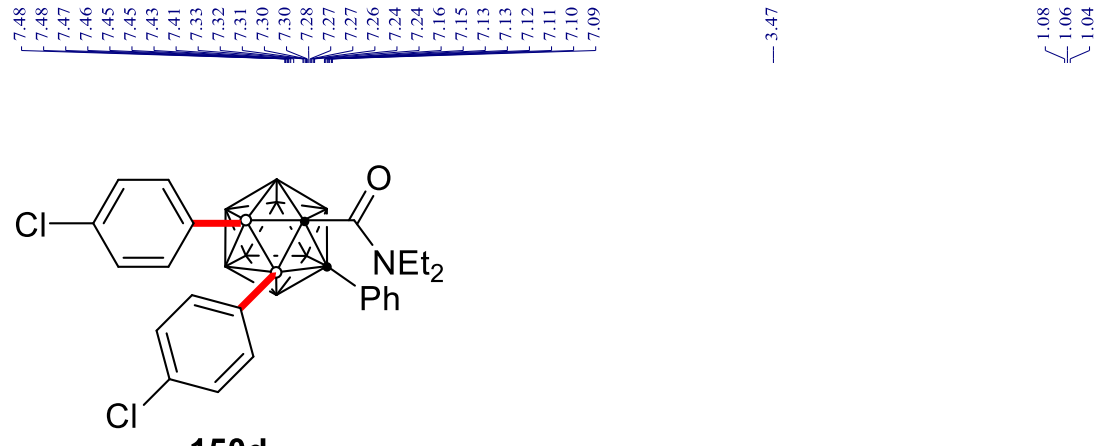

$150 d$

$\left(\mathrm{CDCl}_{3}, 300 \mathrm{MHz}\right)$

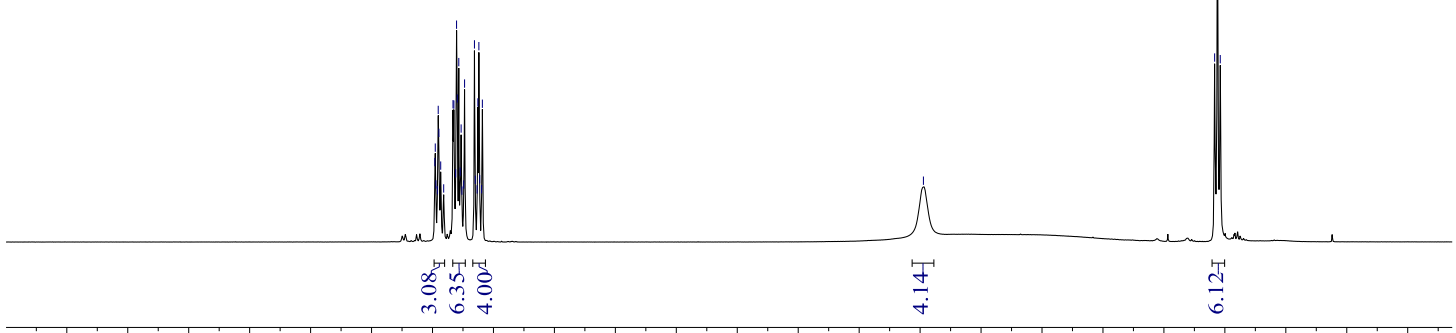

$\begin{array}{lllllllllllllllllllllllllllll}10.5 & 10.0 & 9.5 & 9.0 & 8.5 & 8.0 & 7.5 & 7.0 & 6.5 & 6.0 & 5.5 & 5.0 & 4.5 & 4.0 & 3.5 & 3.0 & 2.5 & 2.0 & 1.5 & 1.0 & 0.5 & 0.0 & -0.5\end{array}$ 


\section{NMR Spectra}
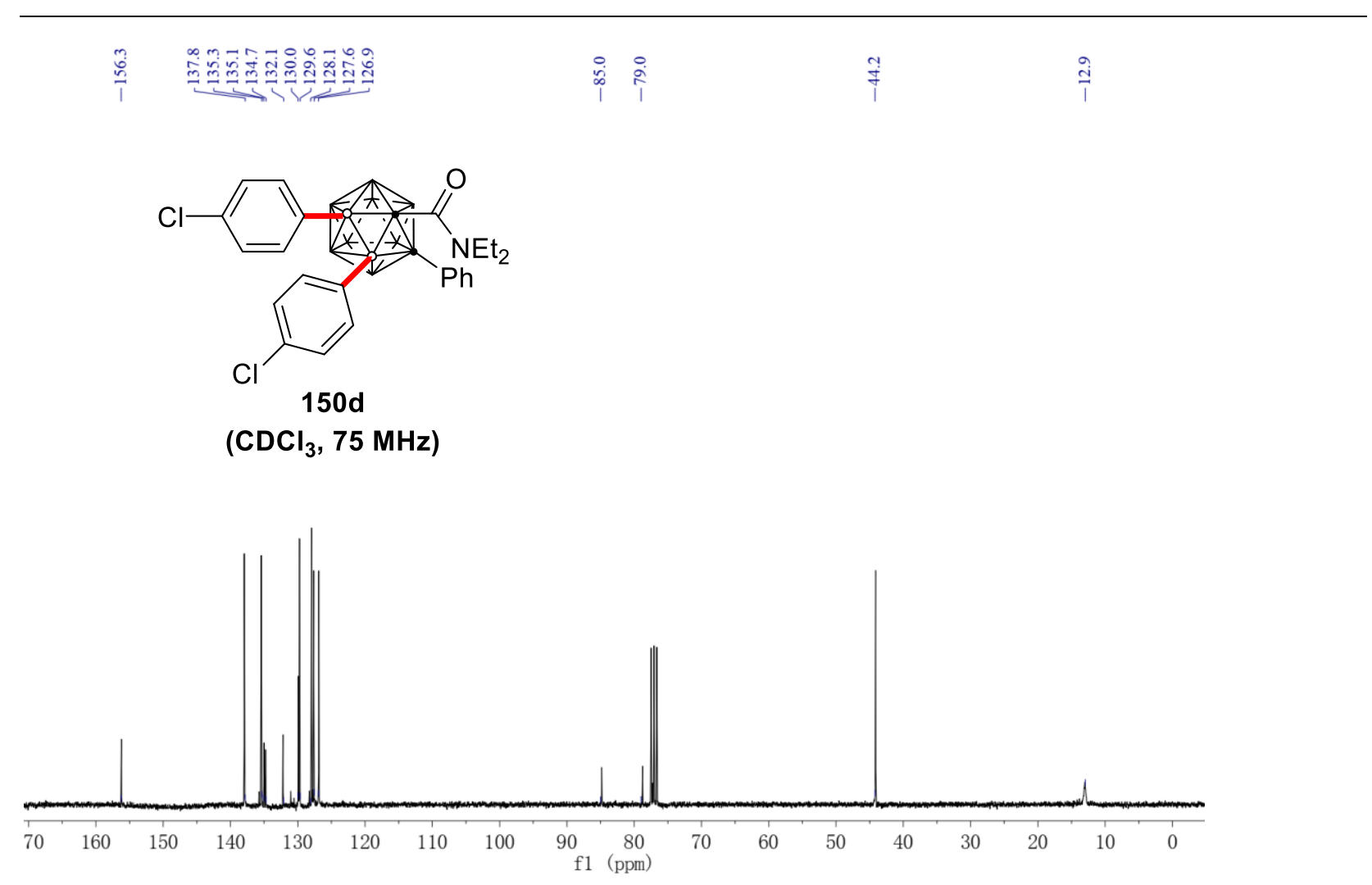

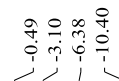
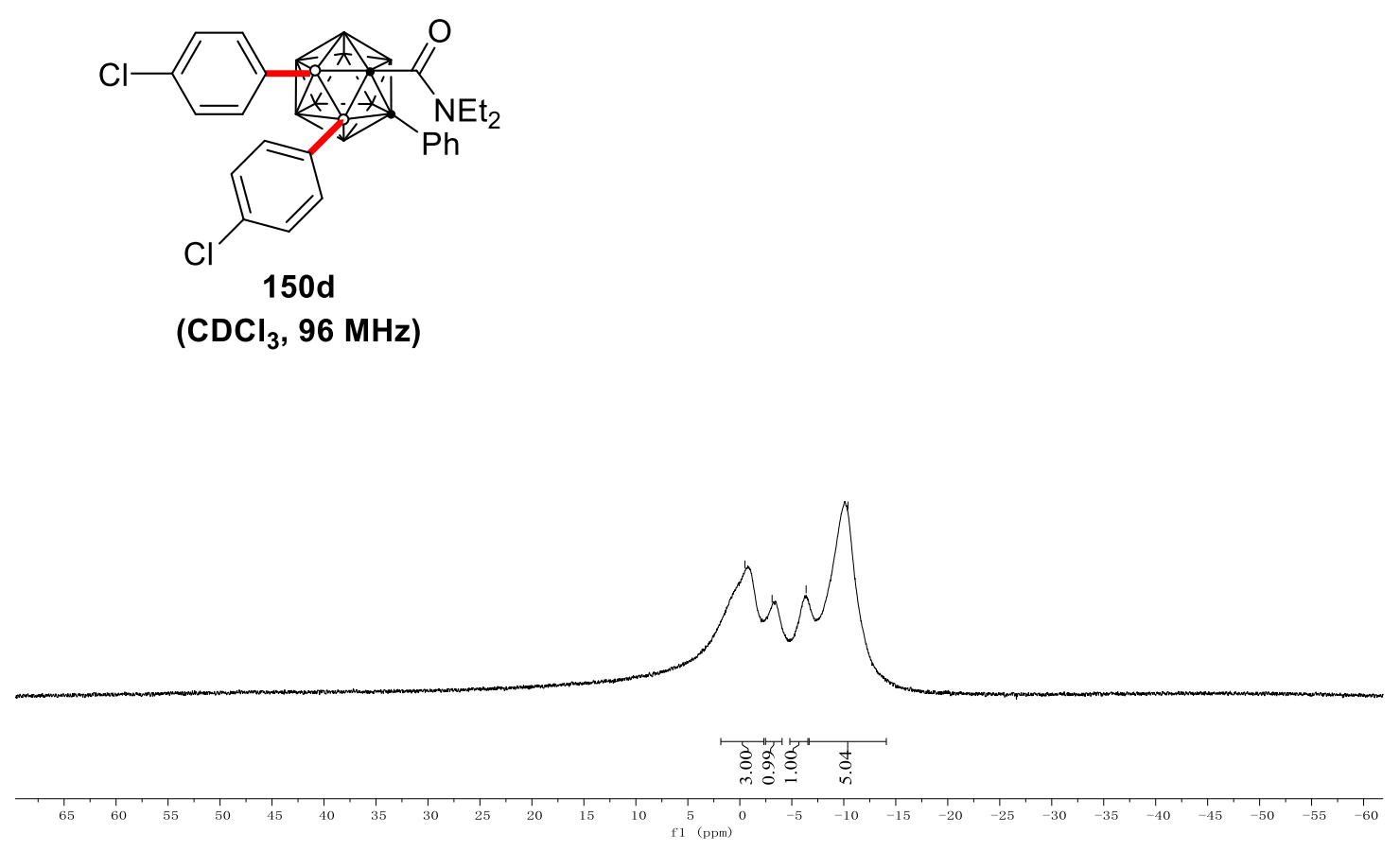

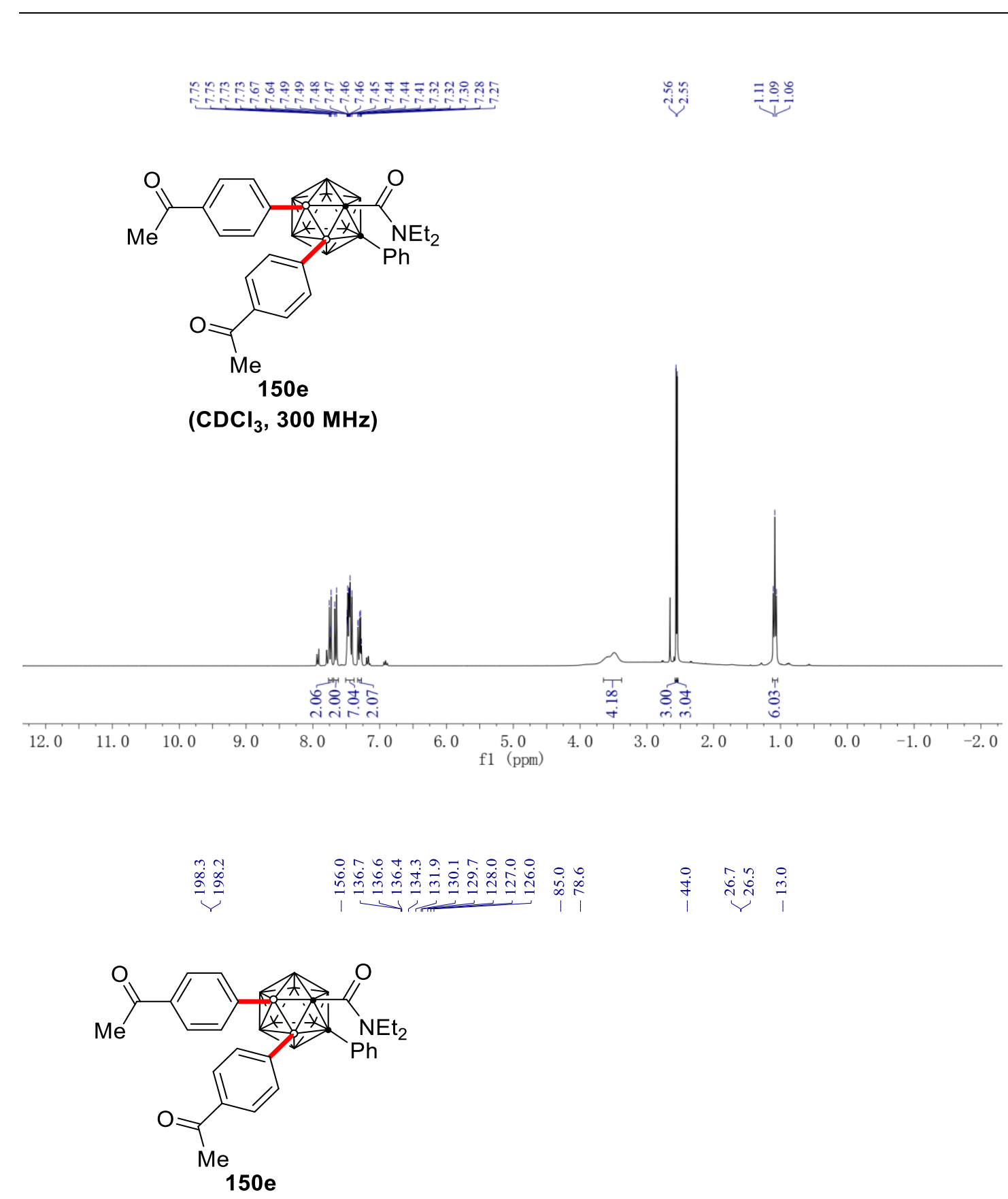

$\left(\mathrm{CDCl}_{3}, 75 \mathrm{MHz}\right)$

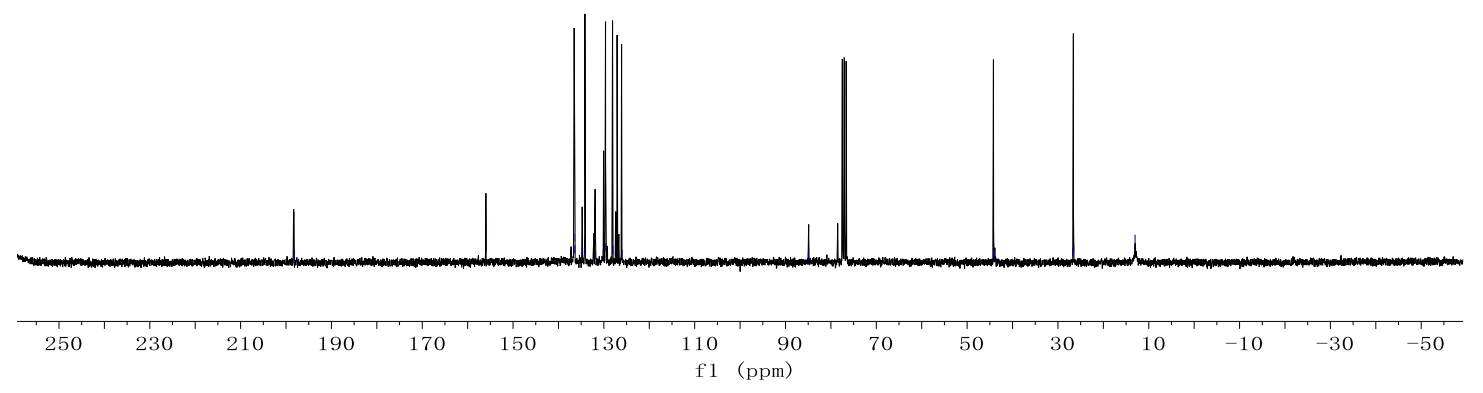



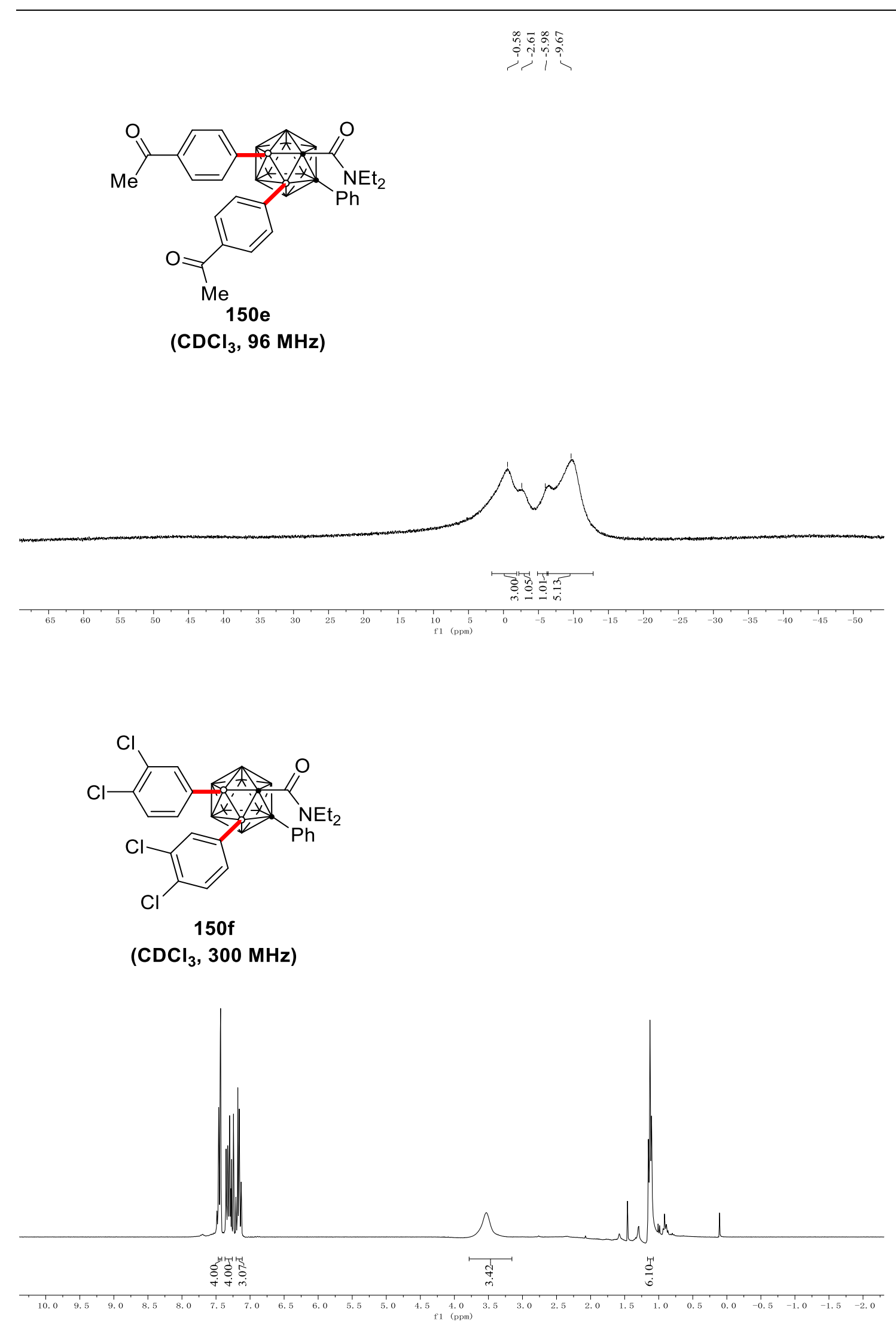
NMR Spectra
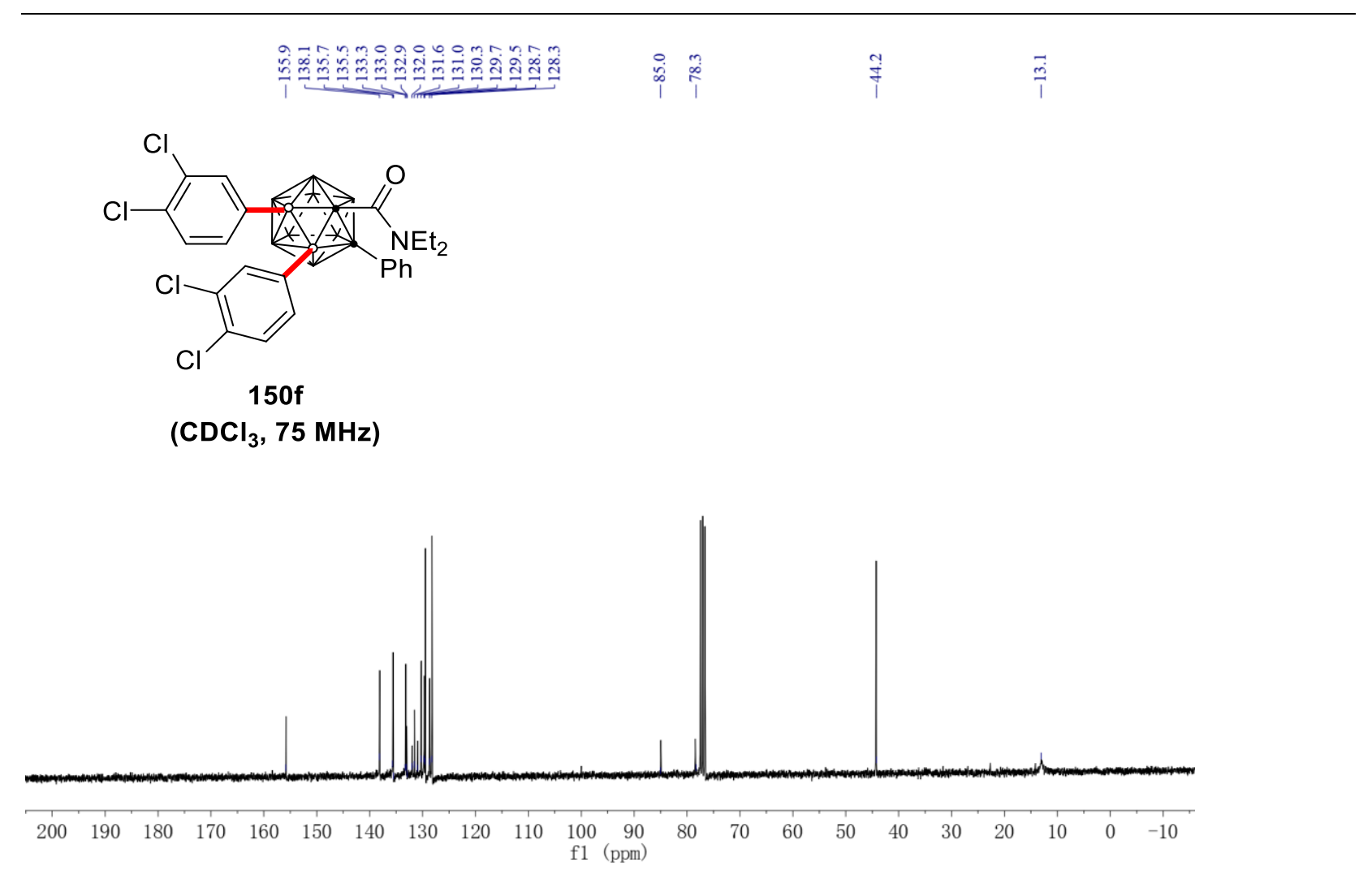

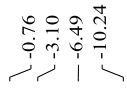

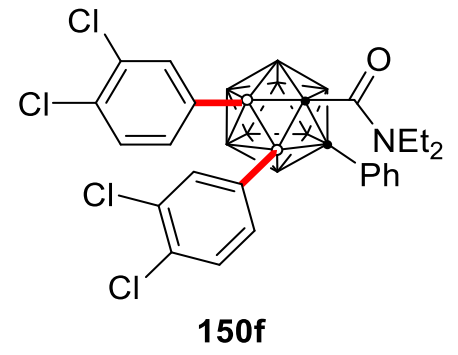

$\left(\mathrm{CDCl}_{3}, 96 \mathrm{MHz}\right)$

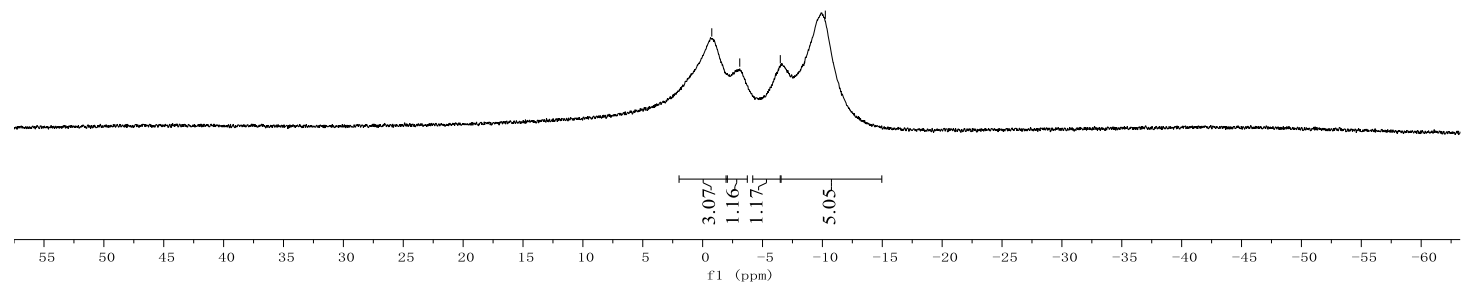




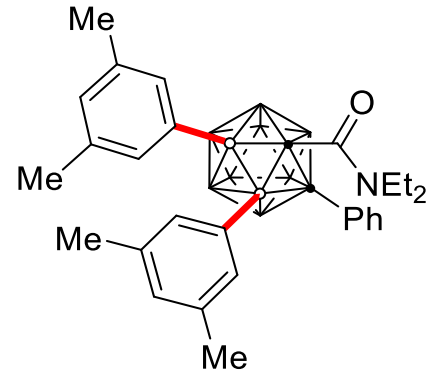

$150 \mathrm{~g}$

$\left(\mathrm{CDCl}_{3}, 300 \mathrm{MHz}\right)$
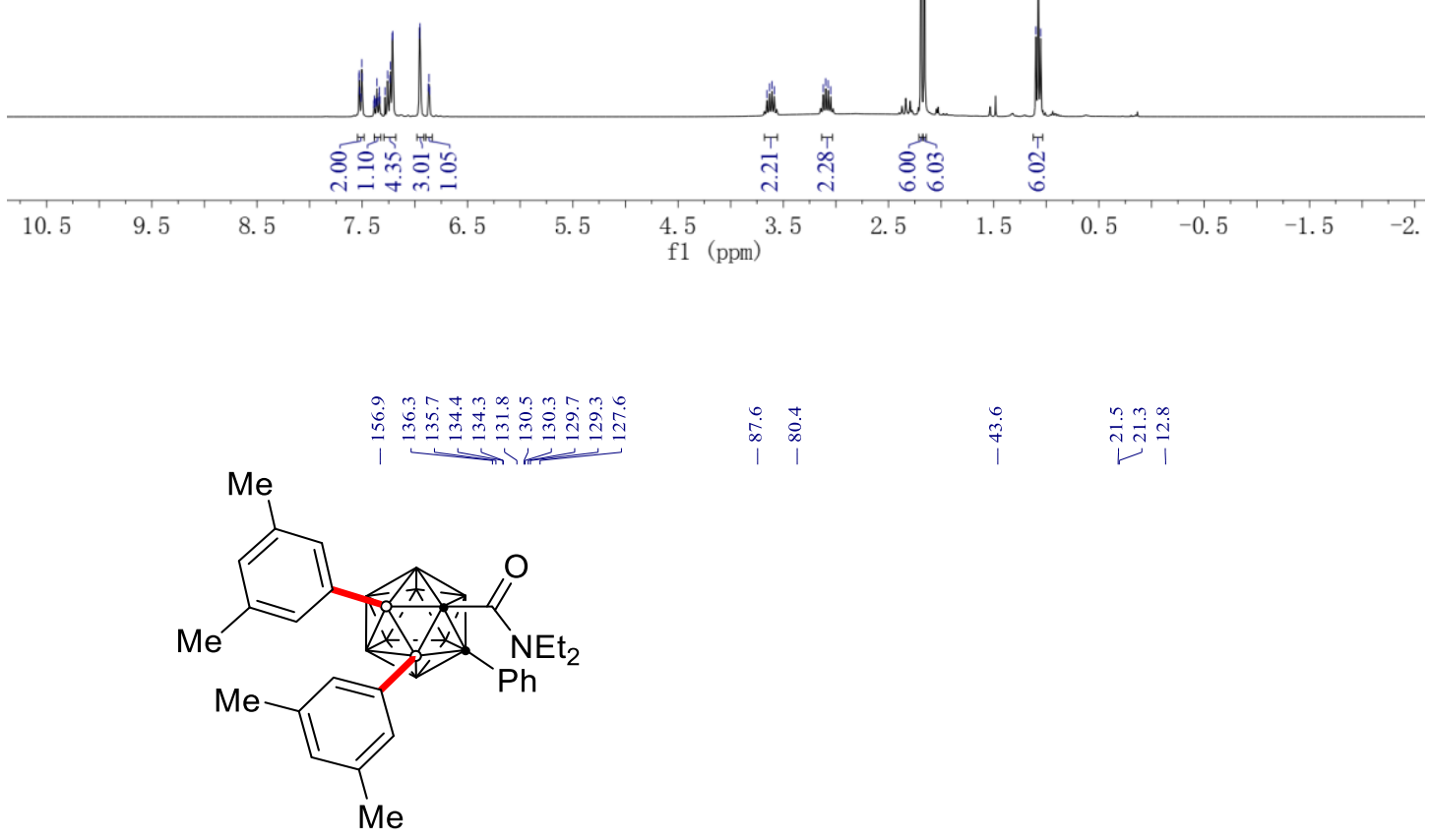

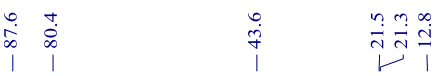

$150 \mathrm{~g}$

$\left(\mathrm{CDCl}_{3}, 75 \mathrm{MHz}\right)$

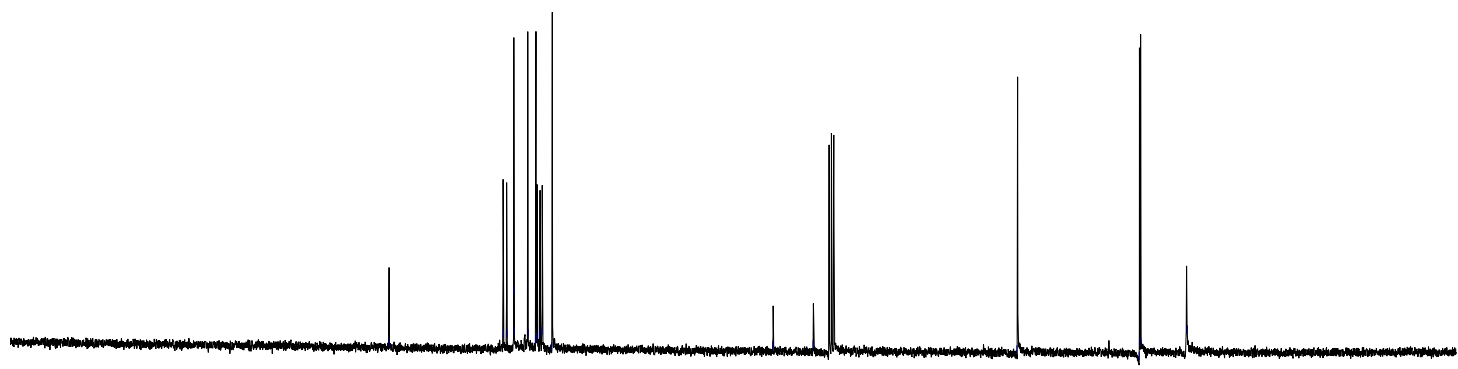

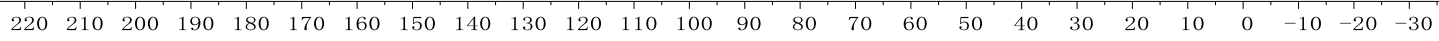
f1 (ppm) 


\section{NMR Spectra}

\section{$\begin{array}{llll}0 & =0 & 0 & 0 \\ 0 & 0 & 0 \\ 0 & 1 & n & 1\end{array}$}

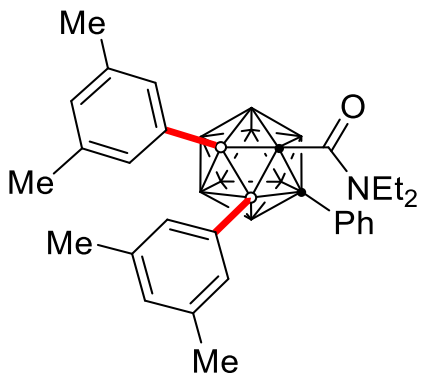

$150 \mathrm{~g}$

$\left(\mathrm{CDCl}_{3}, 96 \mathrm{MHz}\right)$
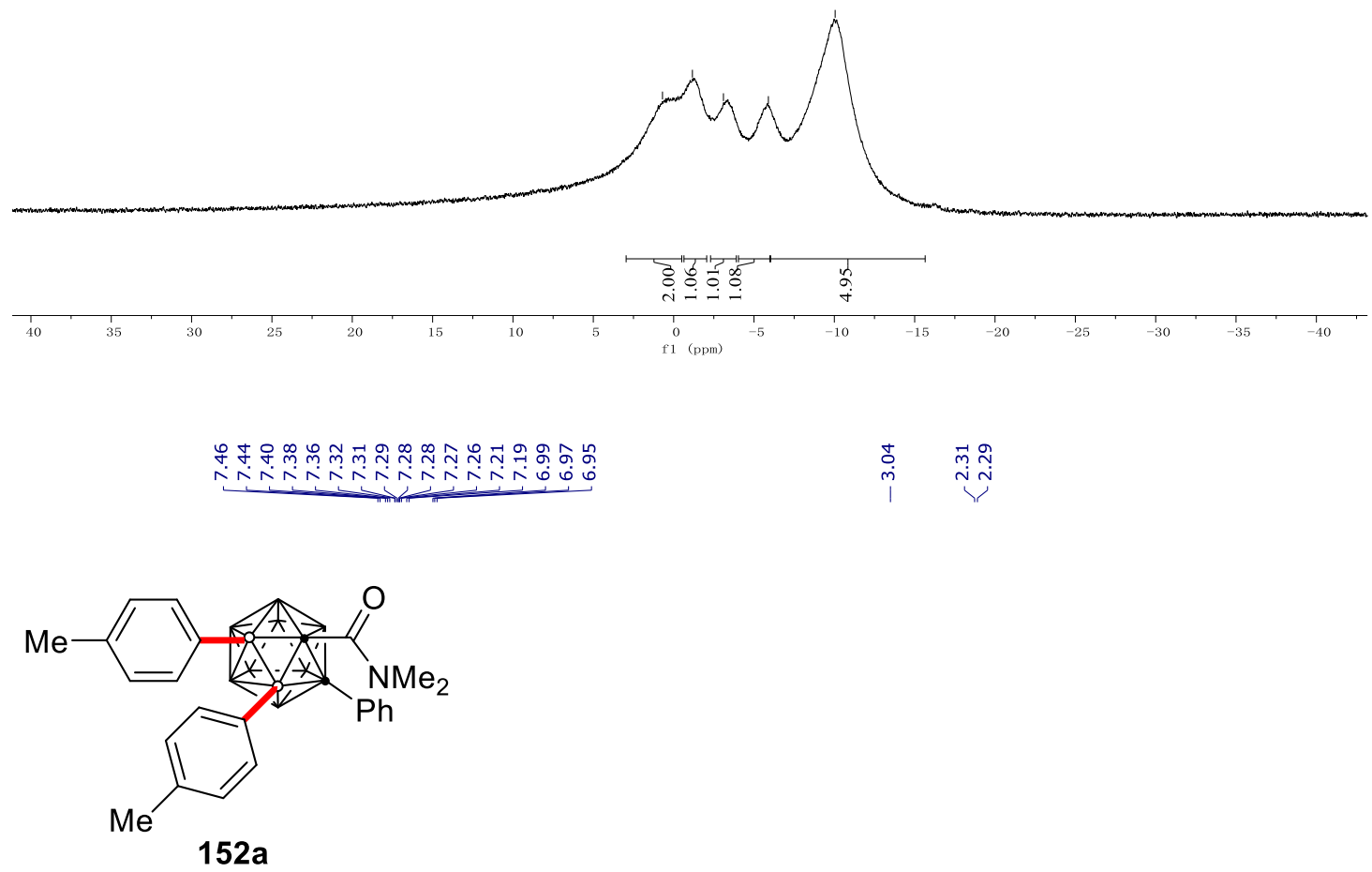

$\left(\mathrm{CDCl}_{3}, 400 \mathrm{MHz}\right)$

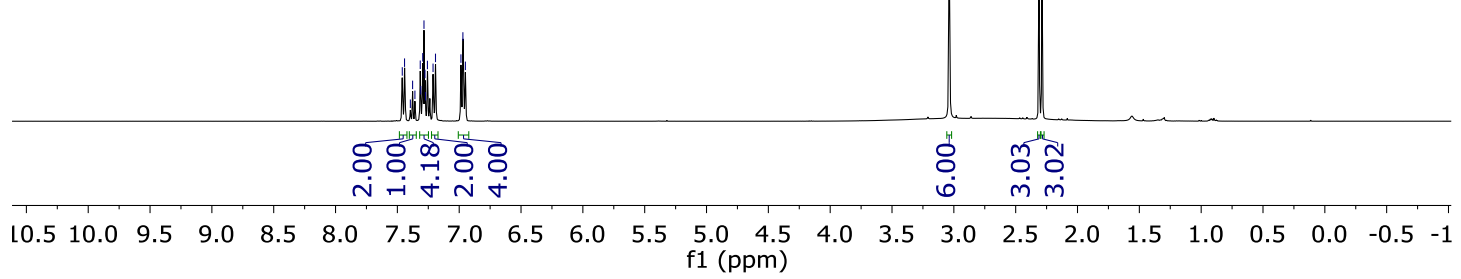


NMR Spectra

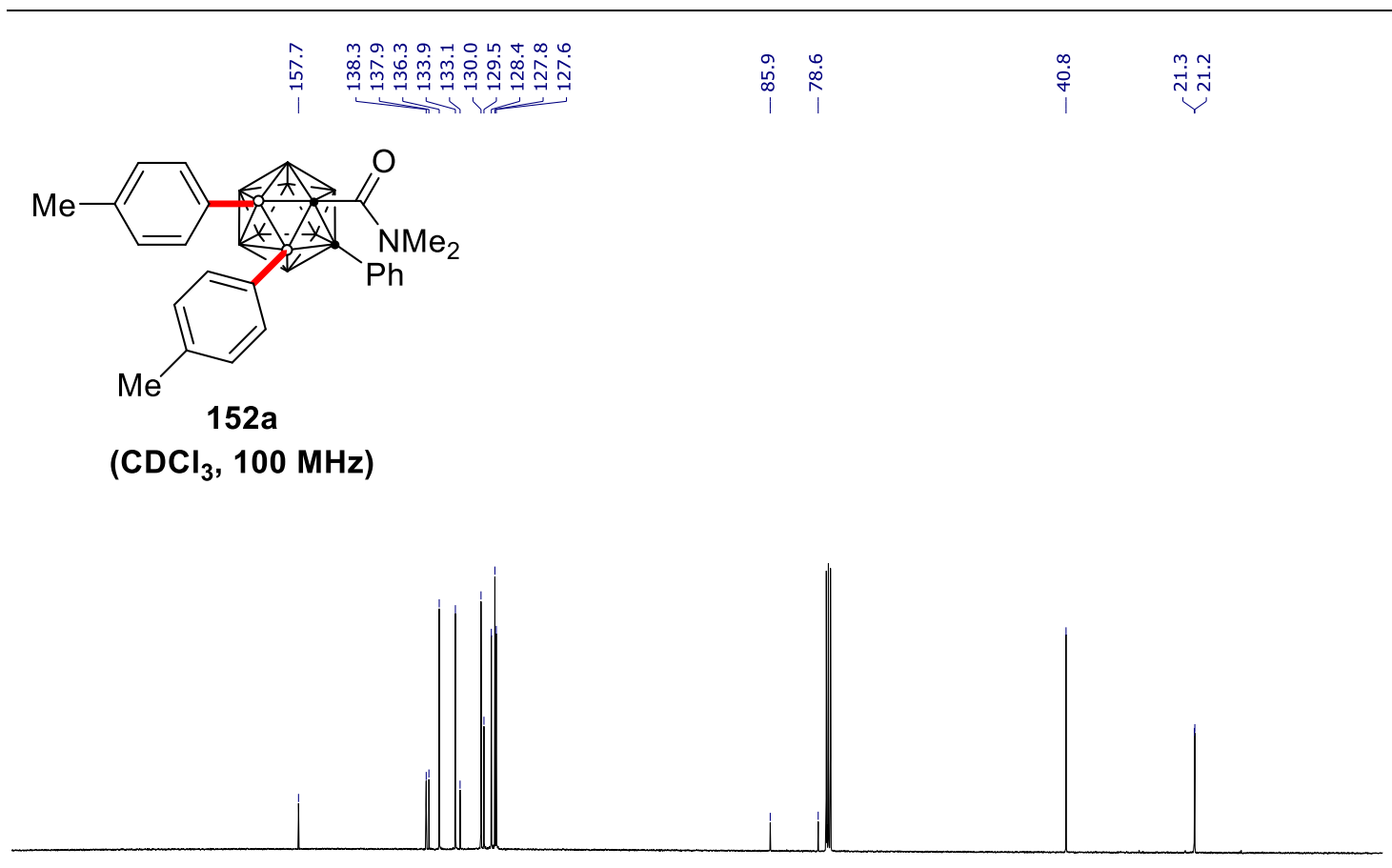

$\begin{array}{lllllllllllllllllllllllll}200 & 190 & 180 & 170 & 160 & 150 & 140 & 130 & 120 & 110 & \begin{array}{c}100 \\ \mathrm{f} 1(\mathrm{ppm})\end{array} & 90 & 70 & 60 & 50 & 40 & 30 & 20 & 10 & 0\end{array}$

$$
\text { lin }
$$
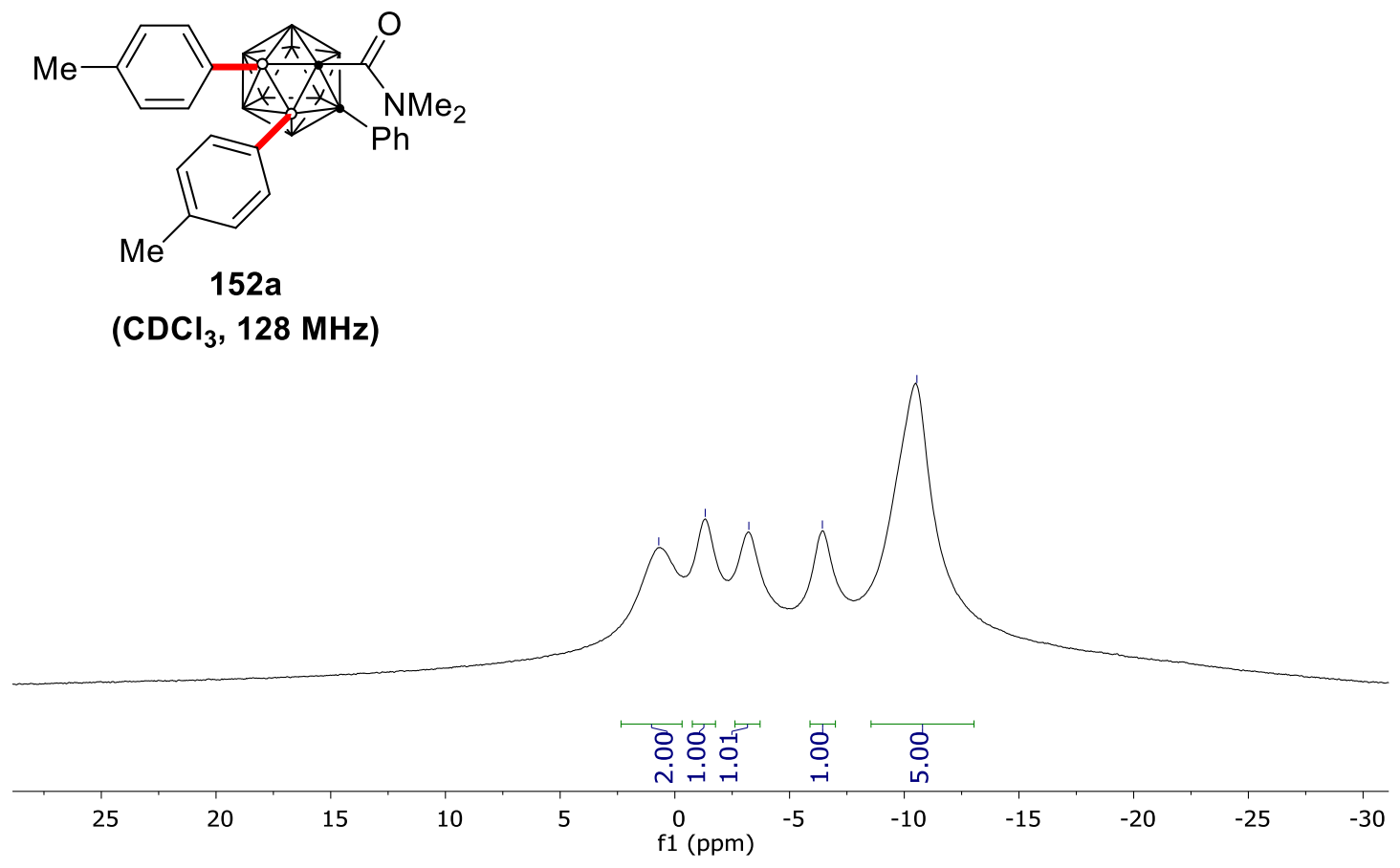


\section{NMR Spectra}

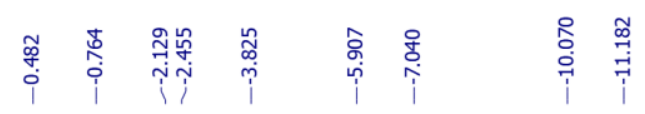

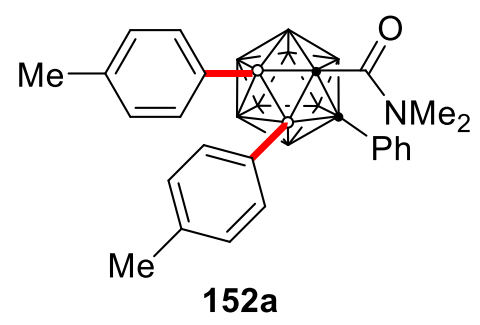

$\left(\mathrm{CDCl}_{3}, 128 \mathrm{MHz}\right)$

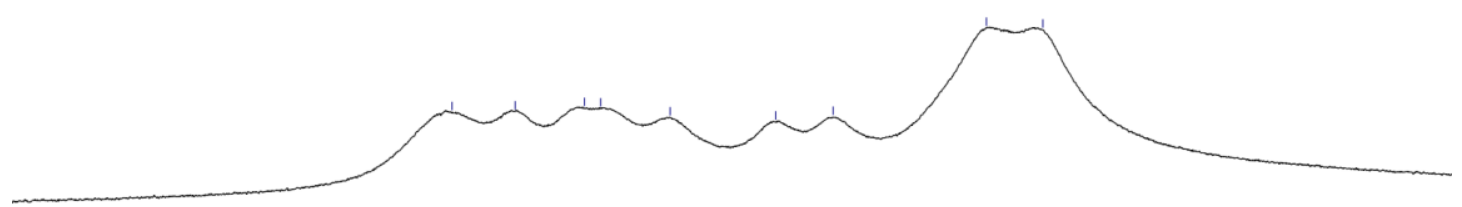

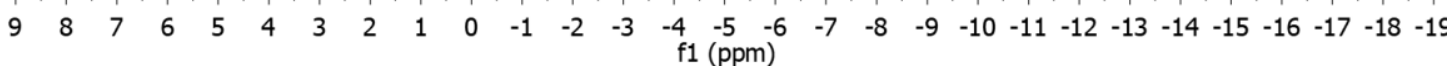

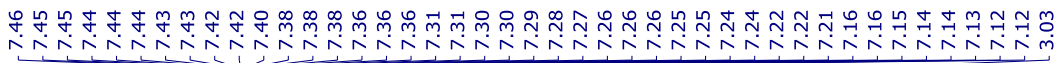

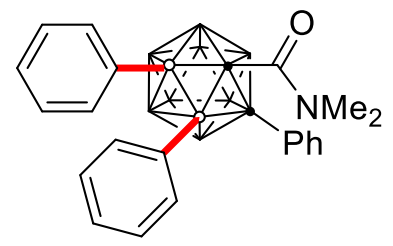

$152 b$

$\left(\mathrm{CDCl}_{3}, 400 \mathrm{MHz}\right)$

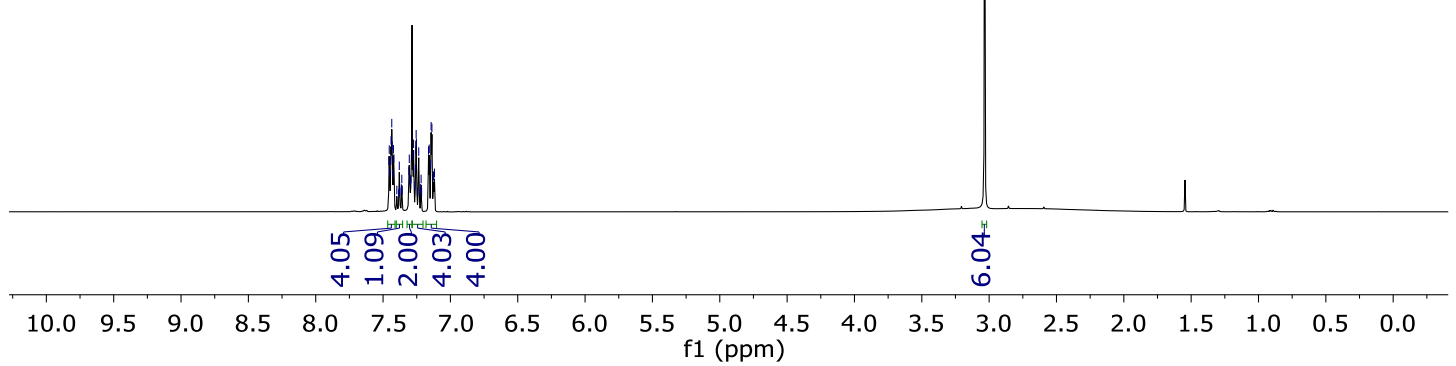




\section{NMR Spectra}
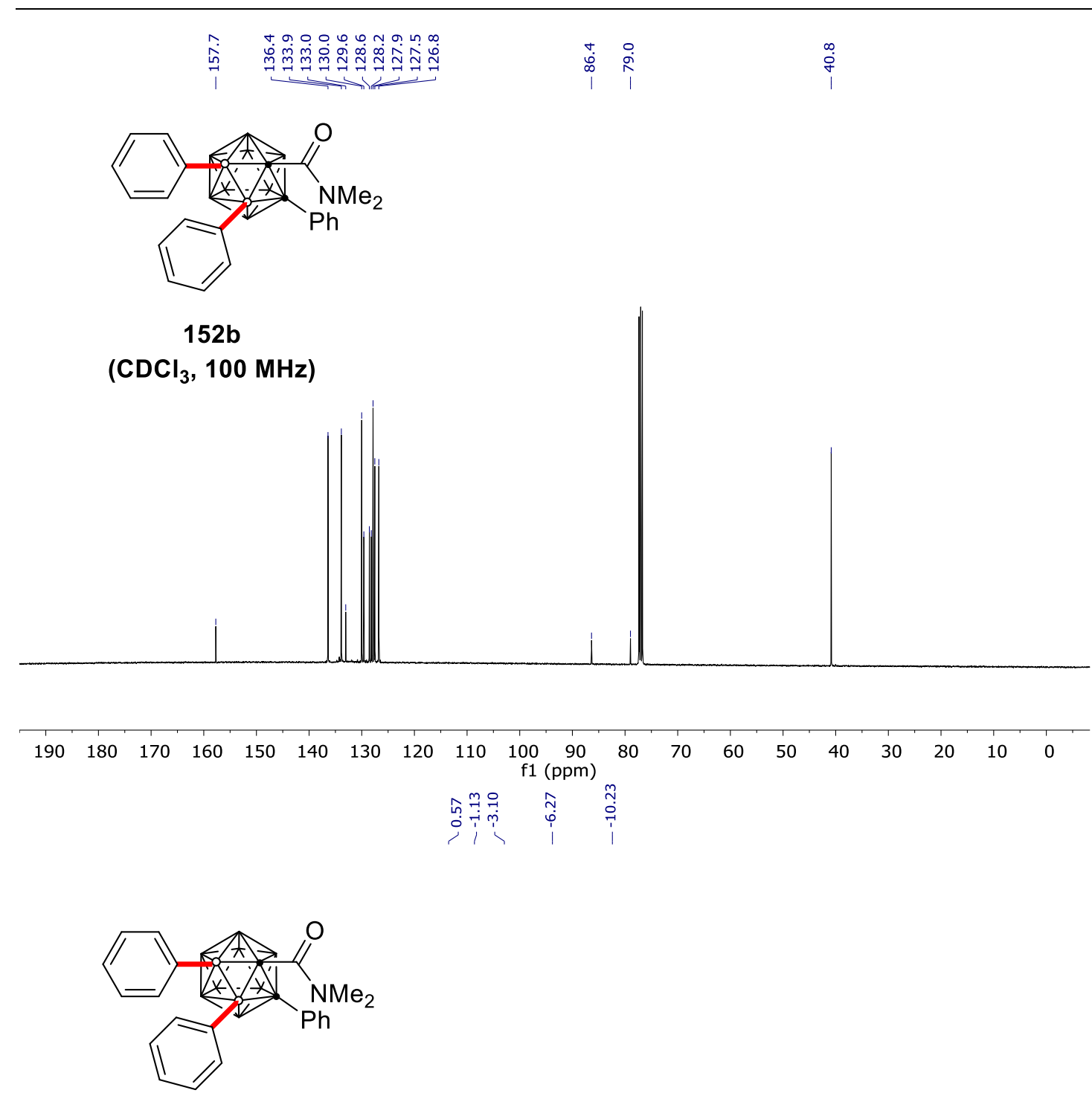

$152 b$

$\left(\mathrm{CDCl}_{3}, 128 \mathrm{MHz}\right)$

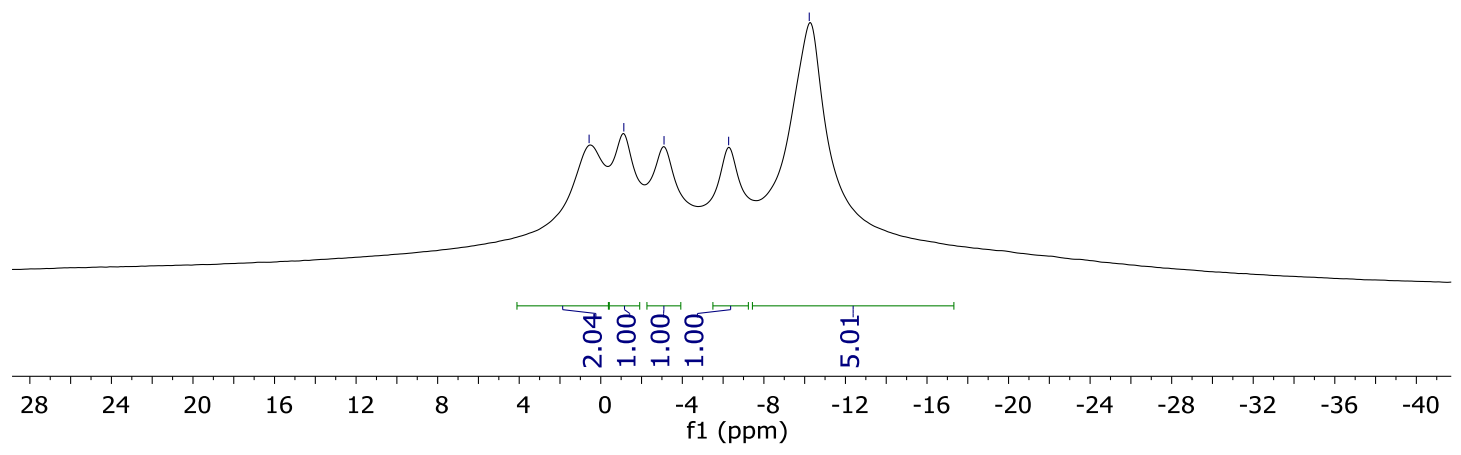




\section{NMR Spectra}
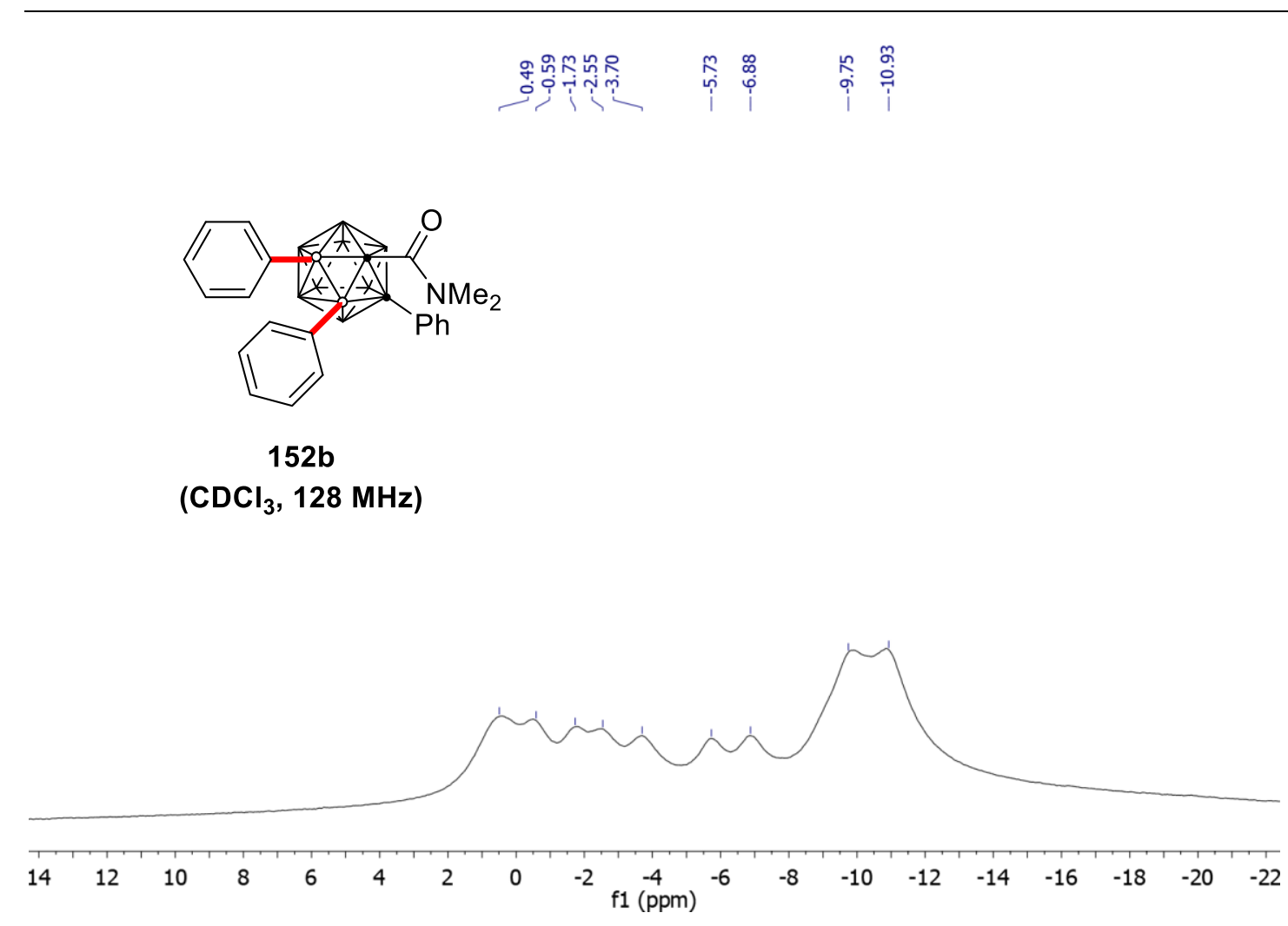

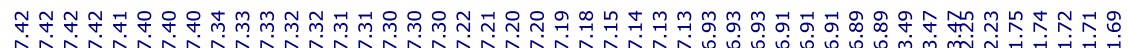

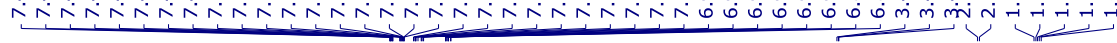

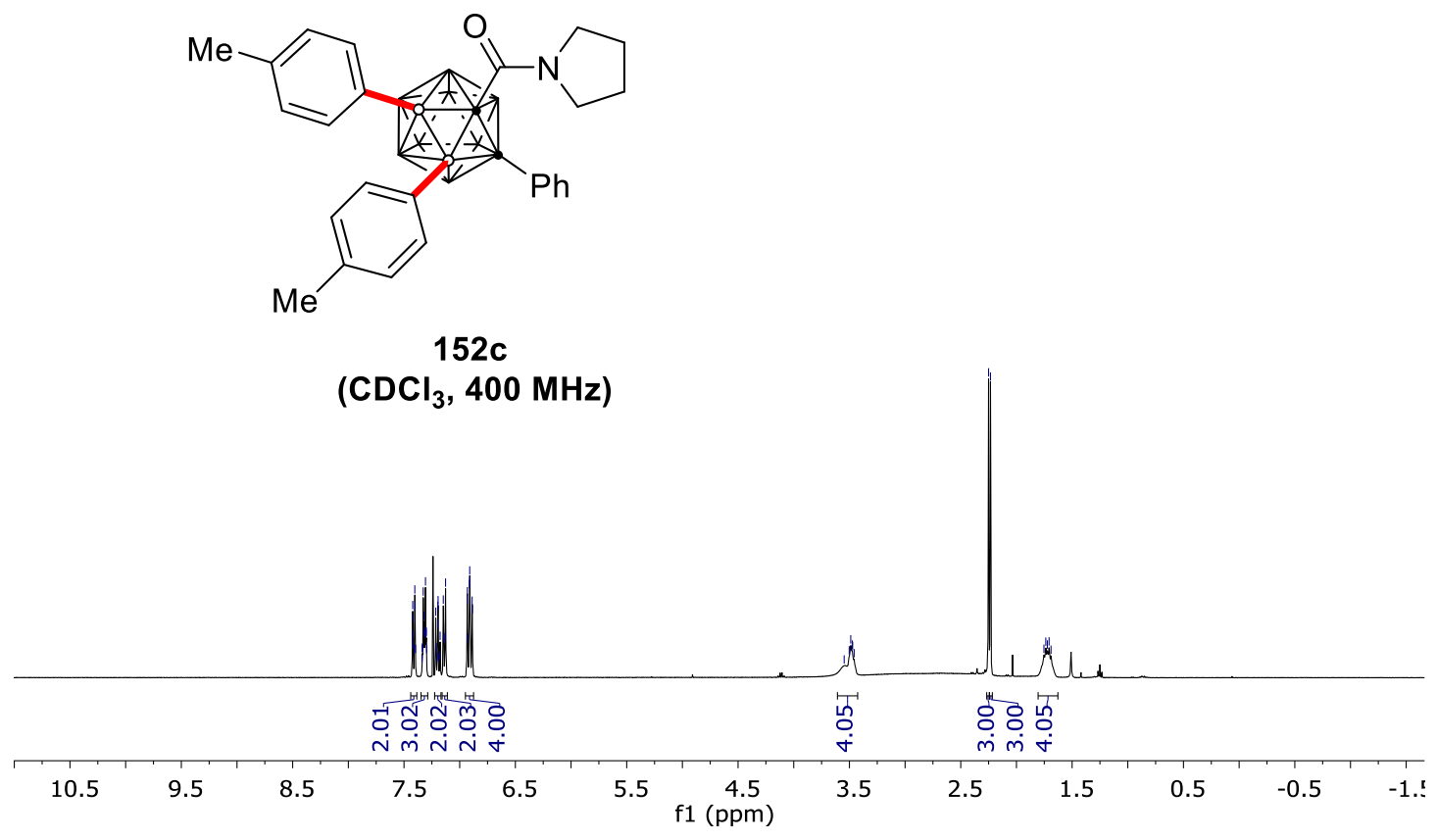




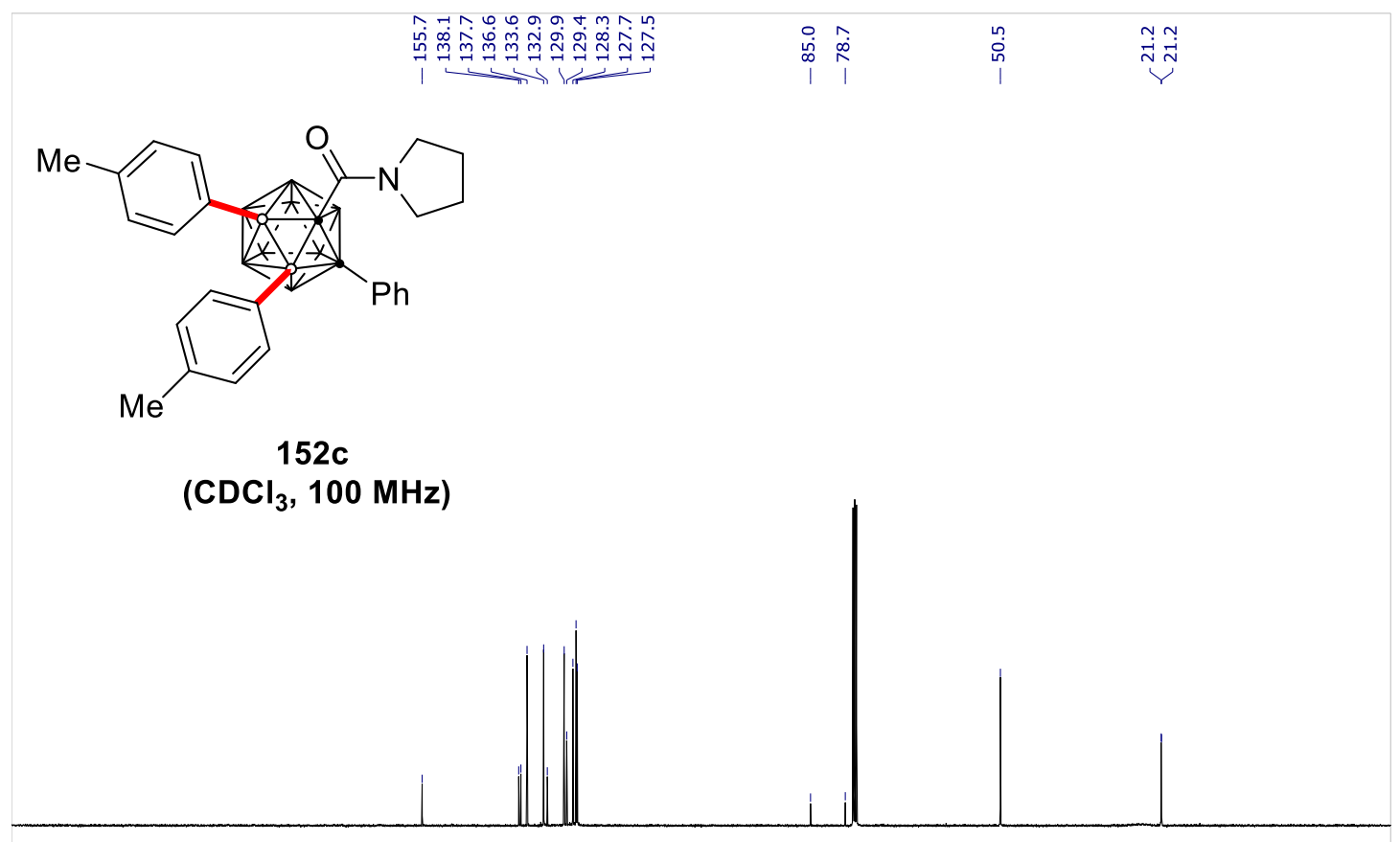

$\begin{array}{rllllllllllllllllllllllllllllllllll}30 & 220 & 210 & 200 & 190 & 180 & 170 & 160 & 150 & 140 & 130 & 120 & 110 & 100 & 90 & 80 & 70 & 60 & 50 & 40 & 30 & 20 & 10 & 0 & -10 & -\bar{z}\end{array}$

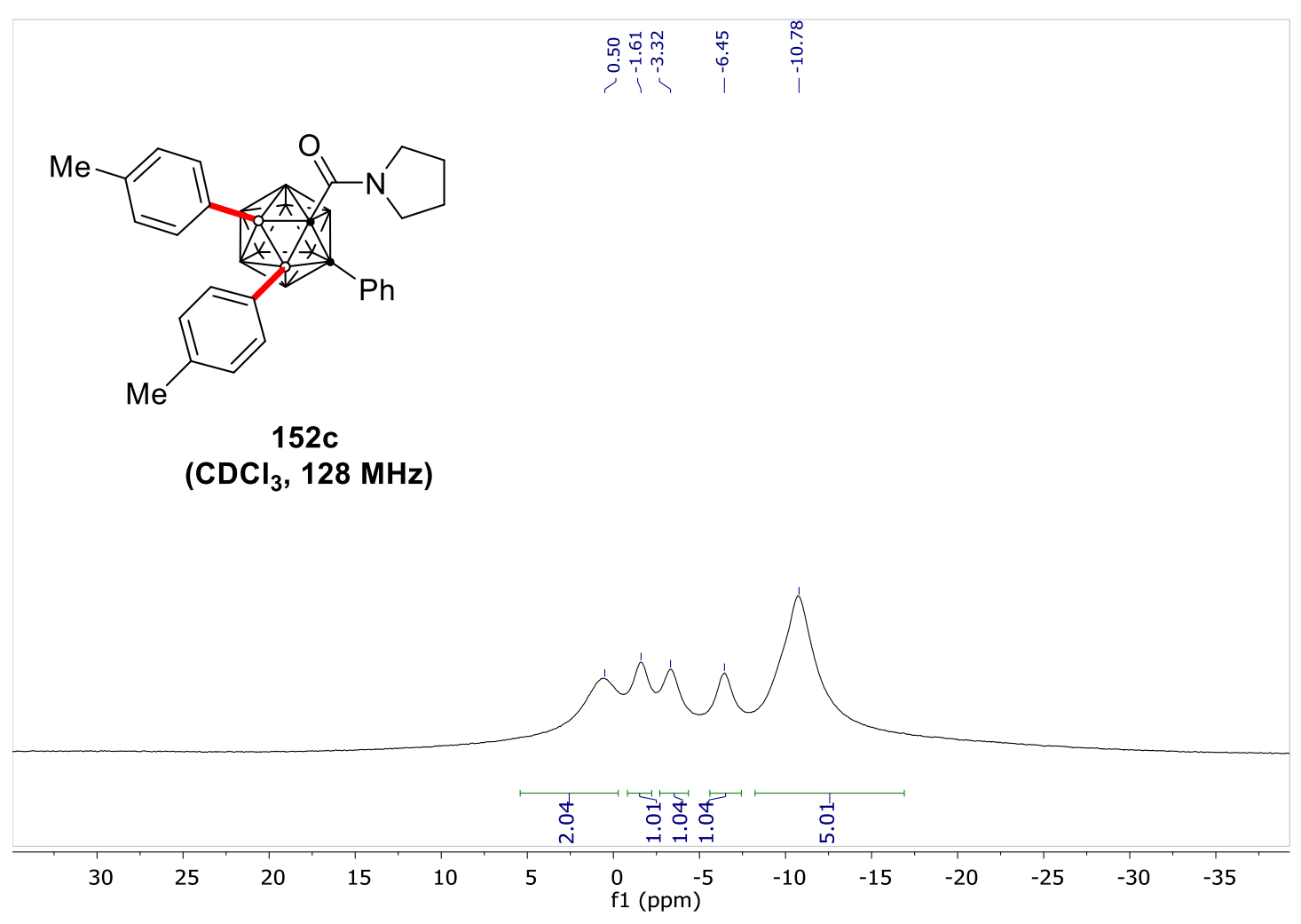




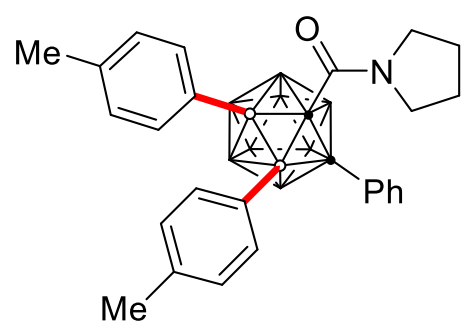

$152 \mathrm{c}$

$\left(\mathrm{CDCl}_{3}, 128 \mathrm{MHz}\right)$
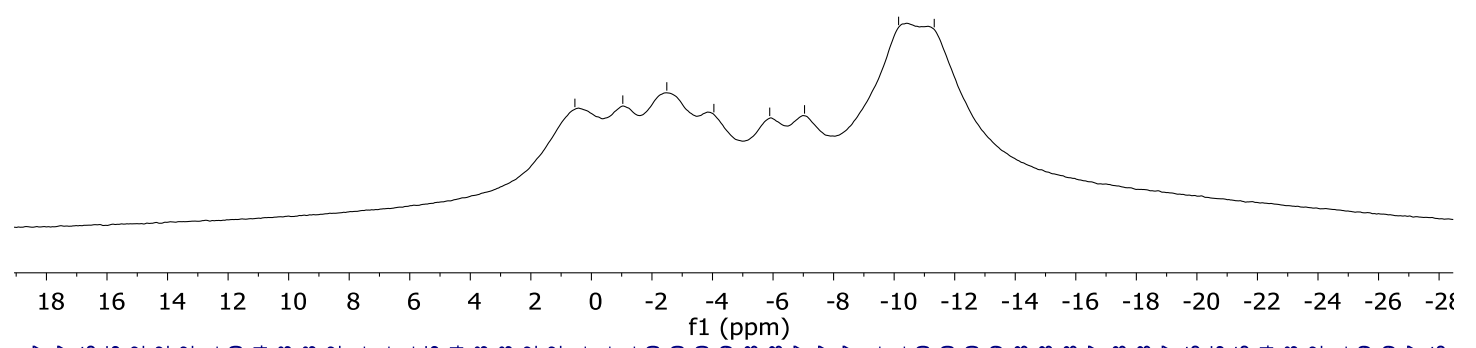

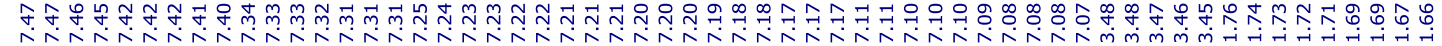

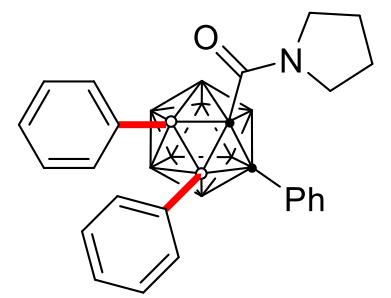

152d

$\left(500 \mathrm{HMz}, \mathrm{CDCl}_{3}\right)$

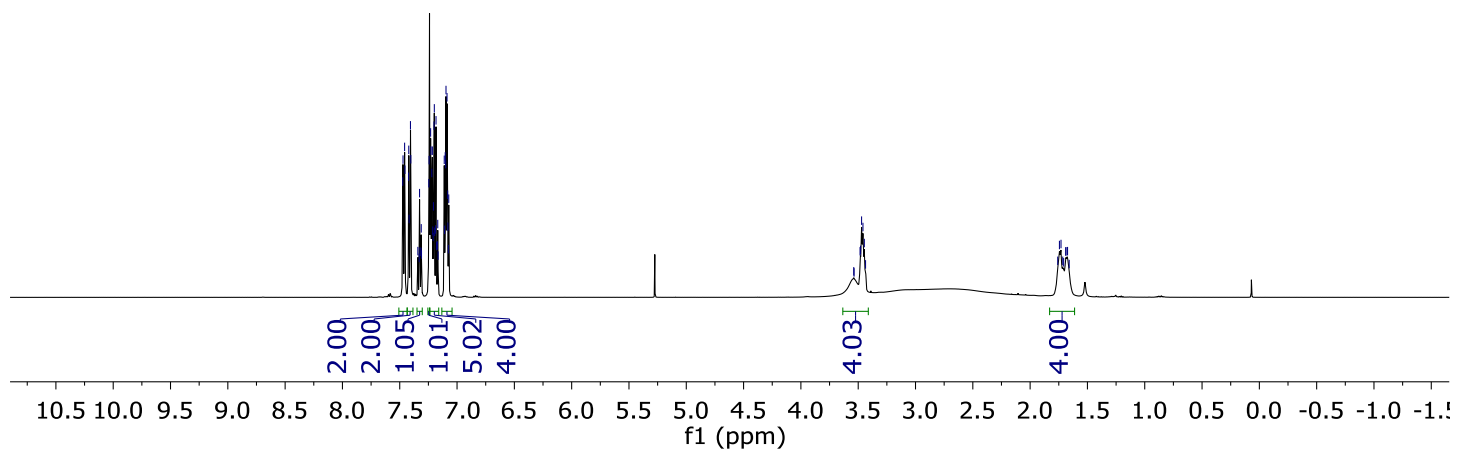




\section{NMR Spectra}
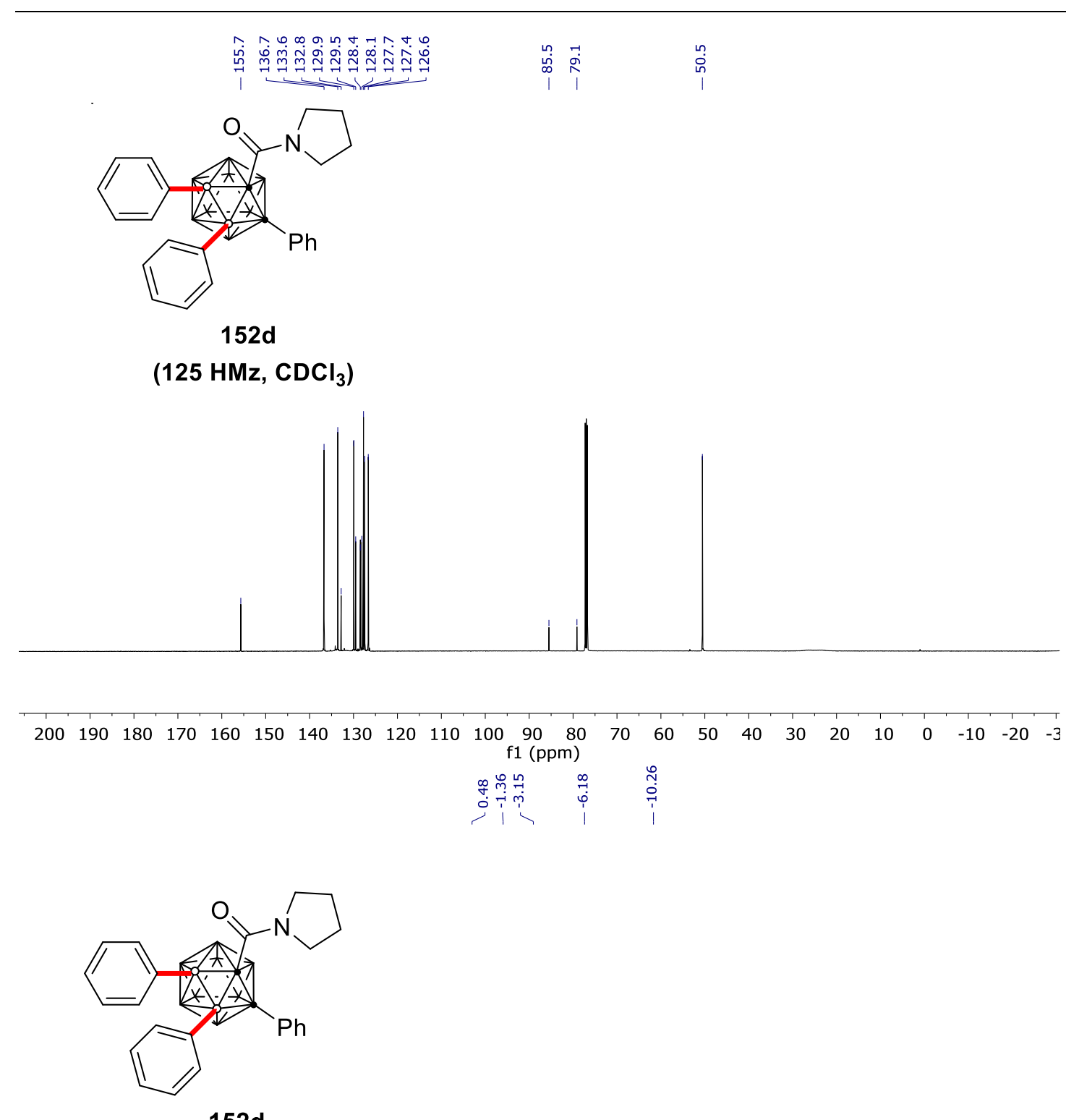

152d

(96 HMz, $\mathrm{CDCl}_{3}$ )

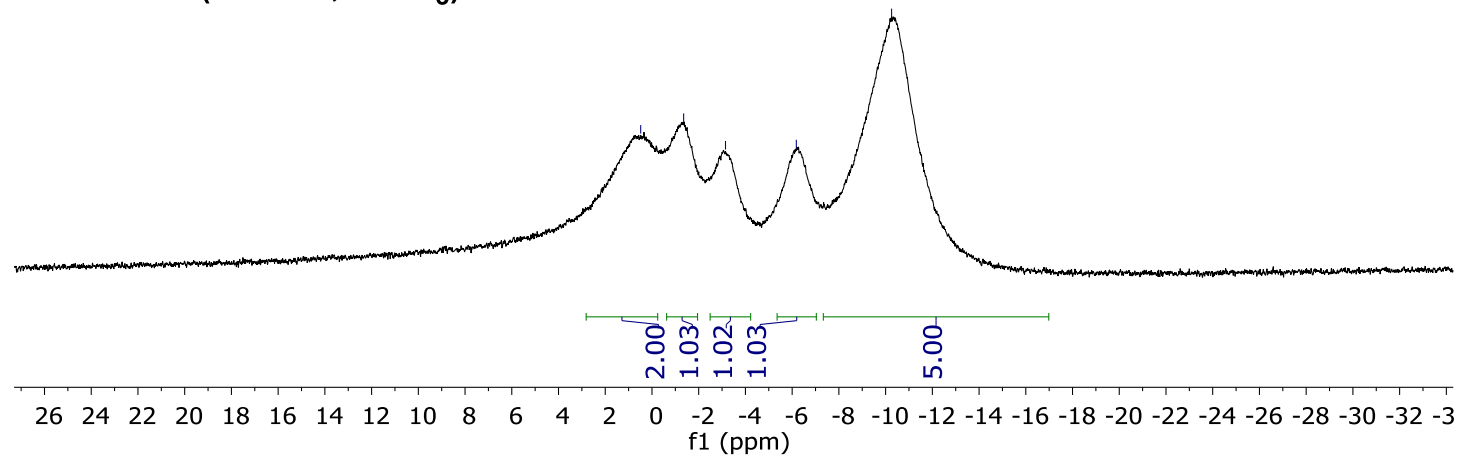




\section{NMR Spectra}
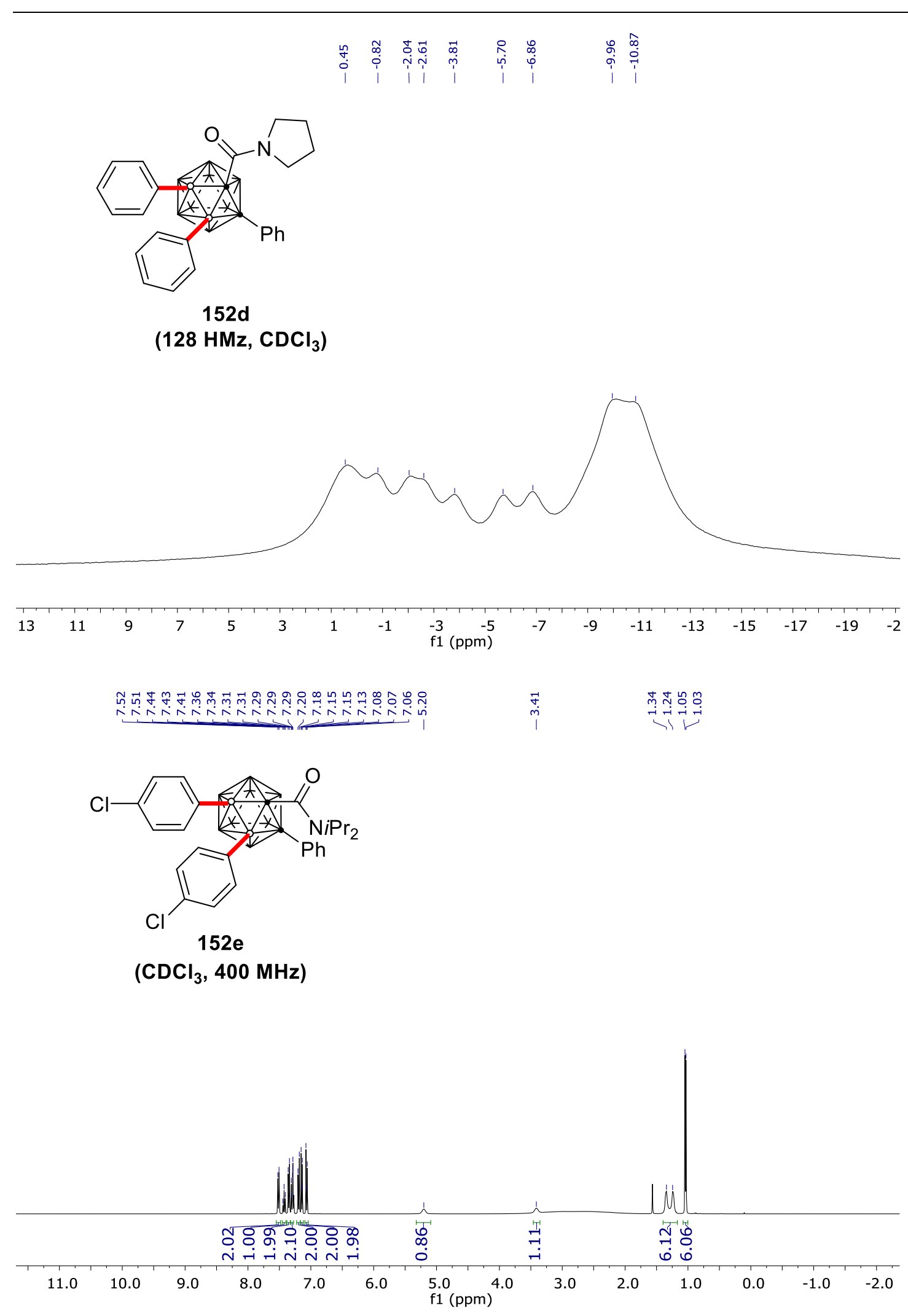
NMR Spectra

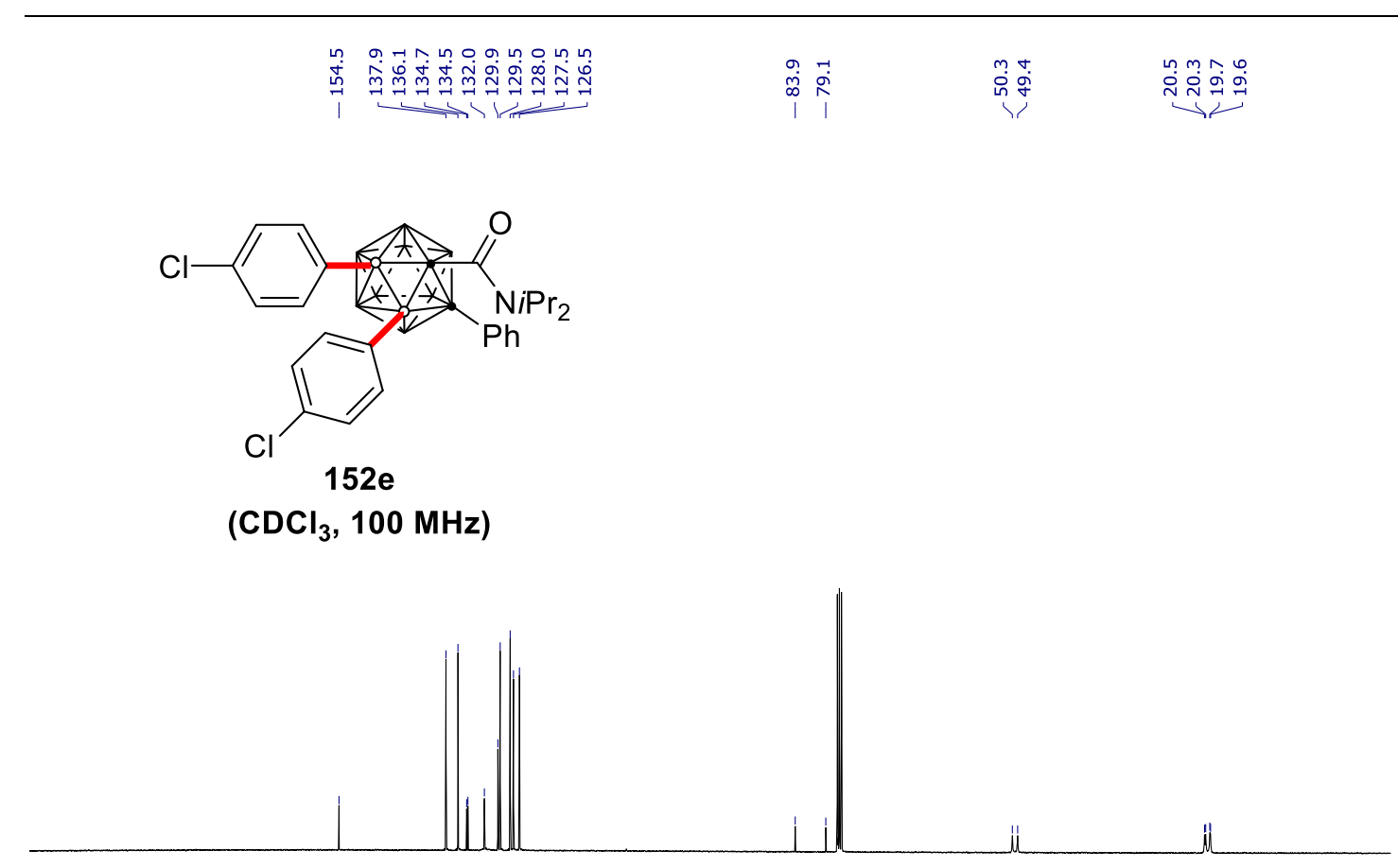

$\begin{array}{llllllllllllllllllll}200 & 190 & 180 & 170 & 160 & 150 & 140 & 130 & 120 & 110 & \begin{array}{c}100 \\ \mathrm{f} 1(\mathrm{ppm})\end{array} & 80 & 70 & 60 & 50 & 40 & 30 & 20 & 10 & 0\end{array}$

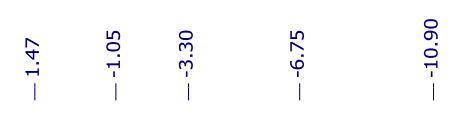
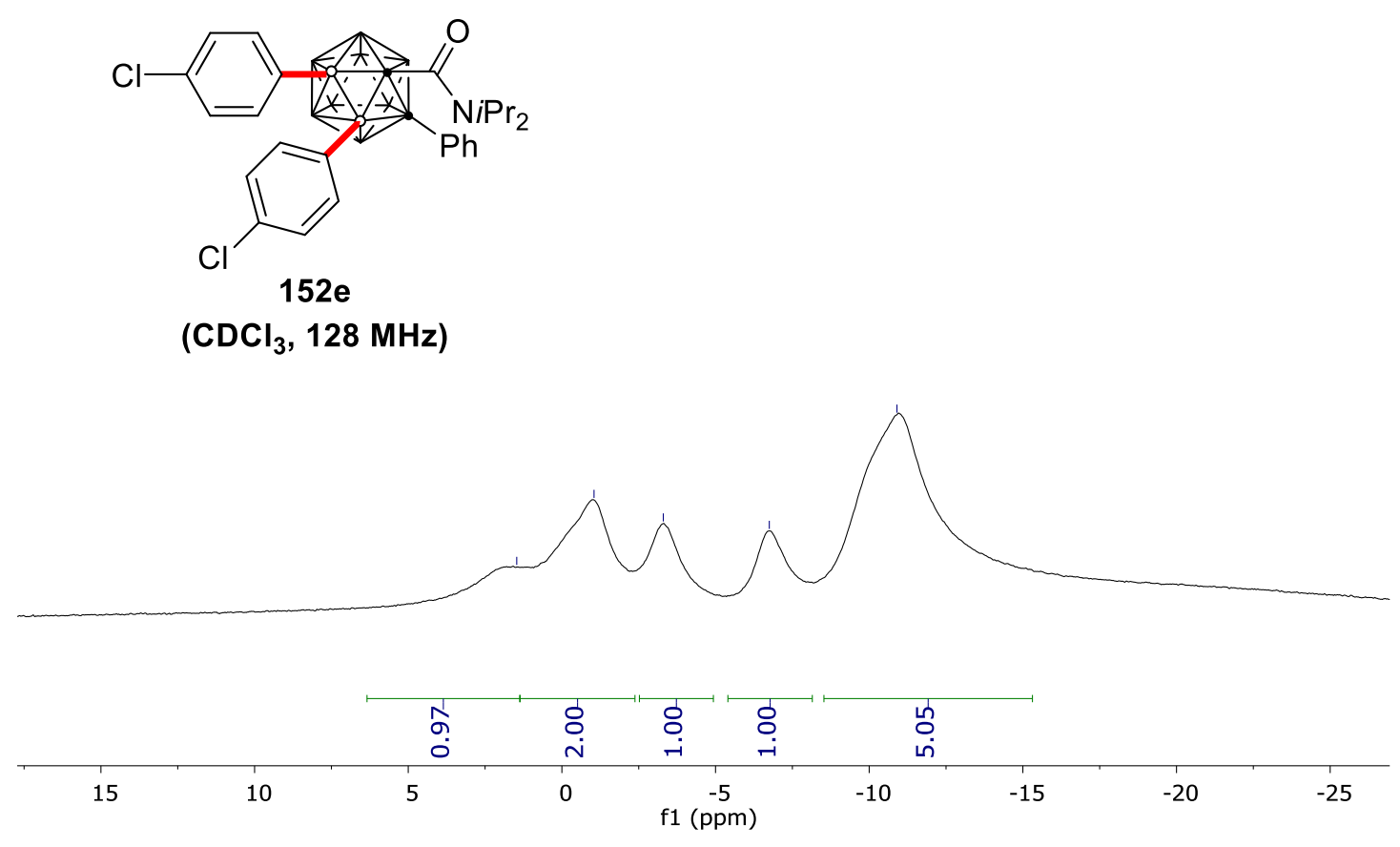


\section{NMR Spectra}

$$
\text { in }
$$

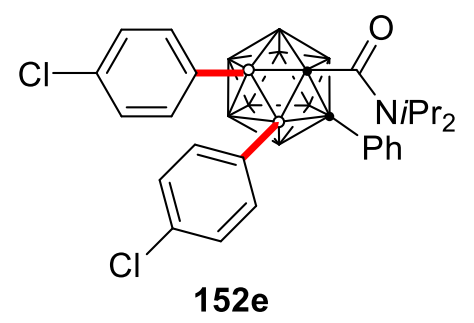

$\left(\mathrm{CDCl}_{3}, 128 \mathrm{MHz}\right)$

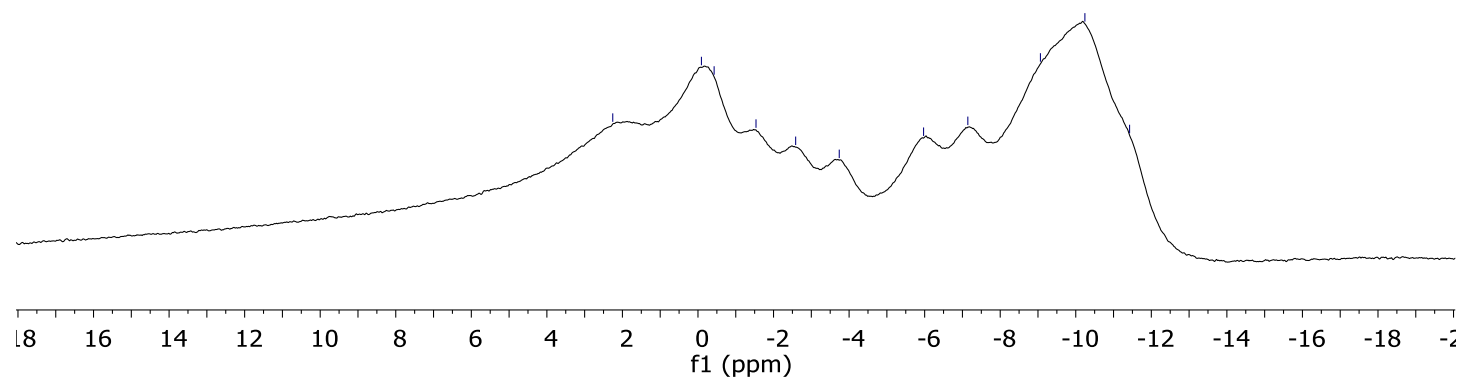

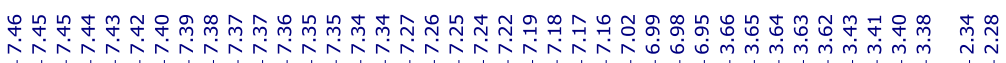

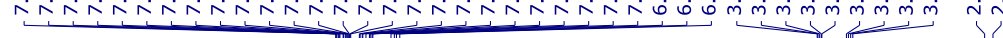
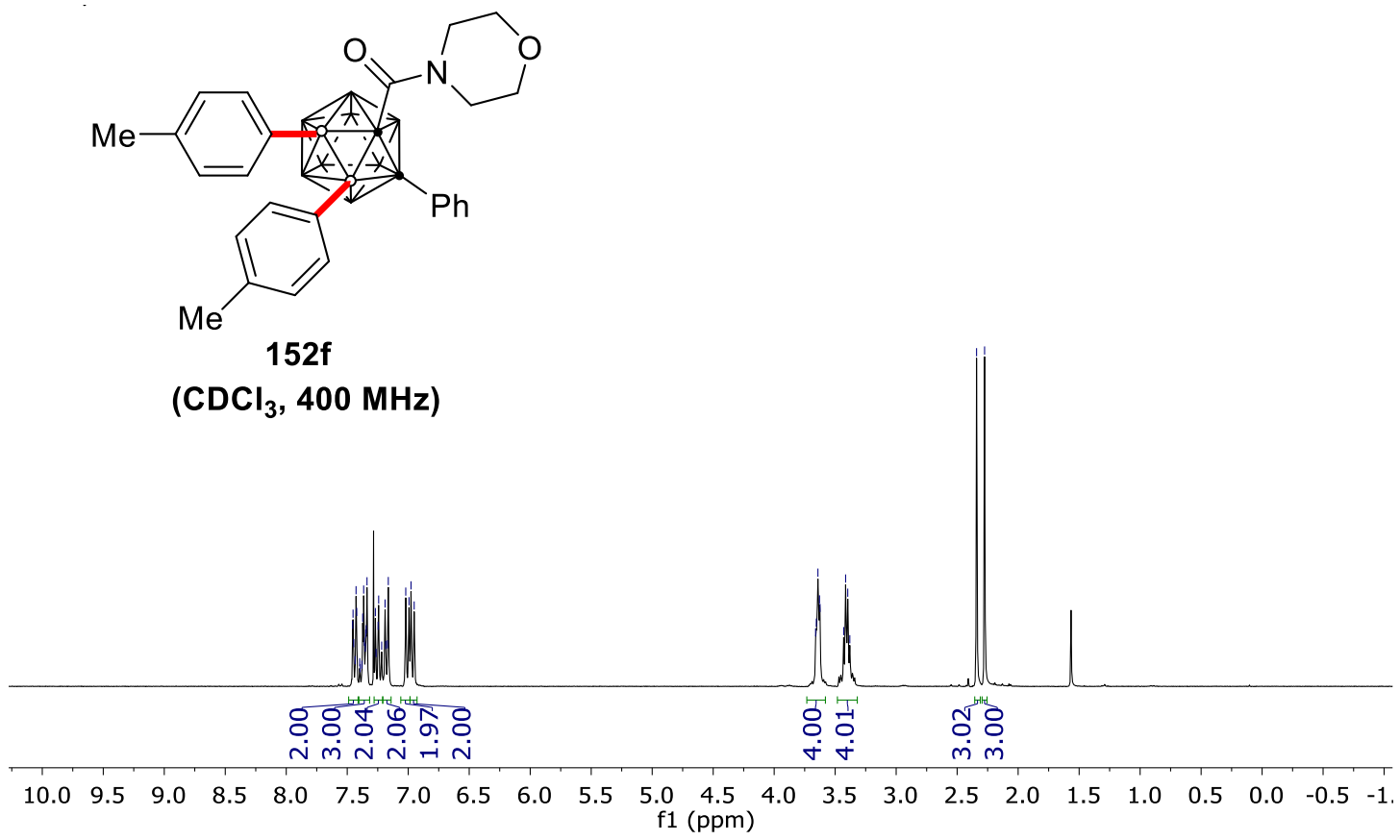
NMR Spectra
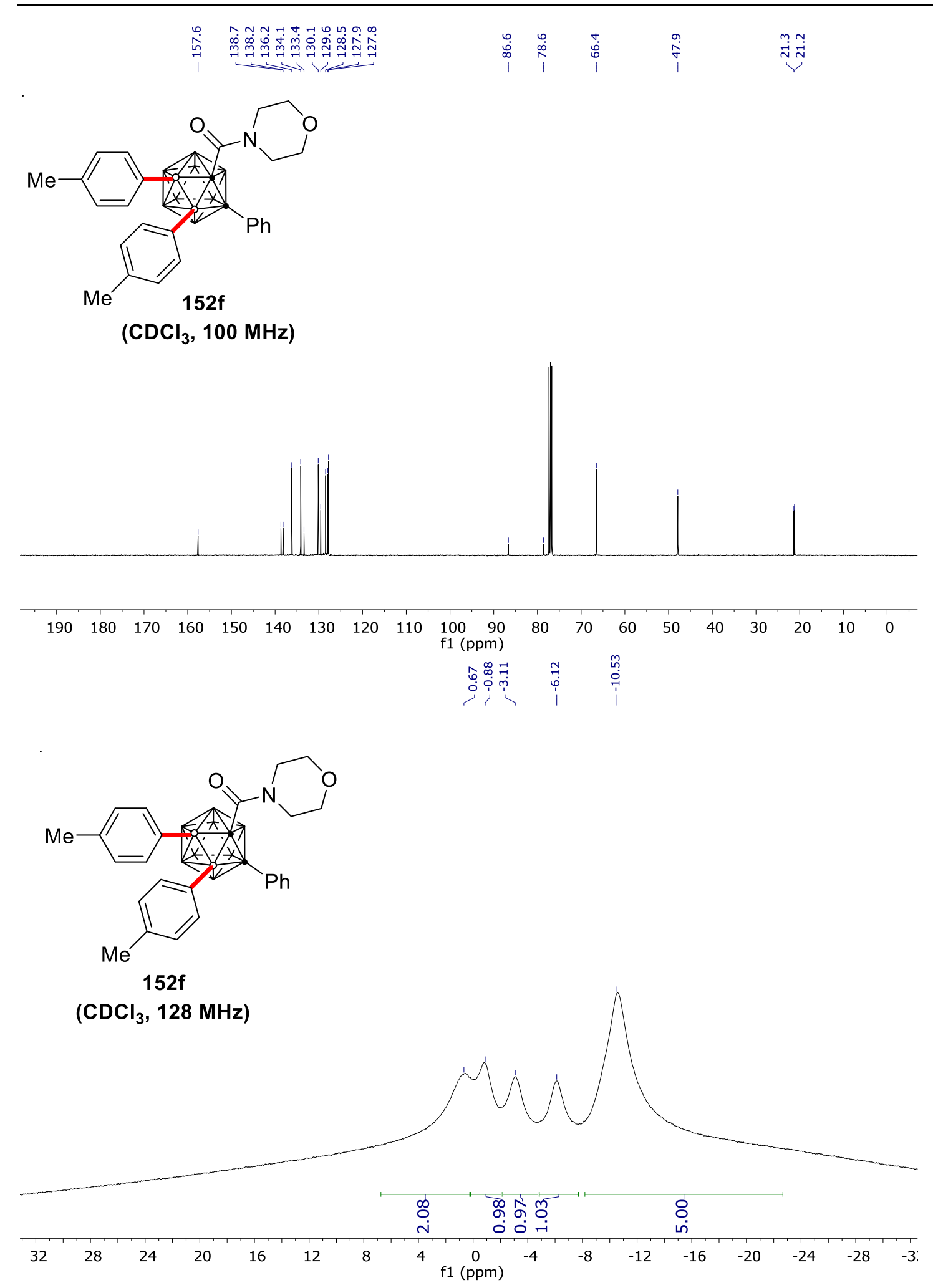


\section{NMR Spectra}
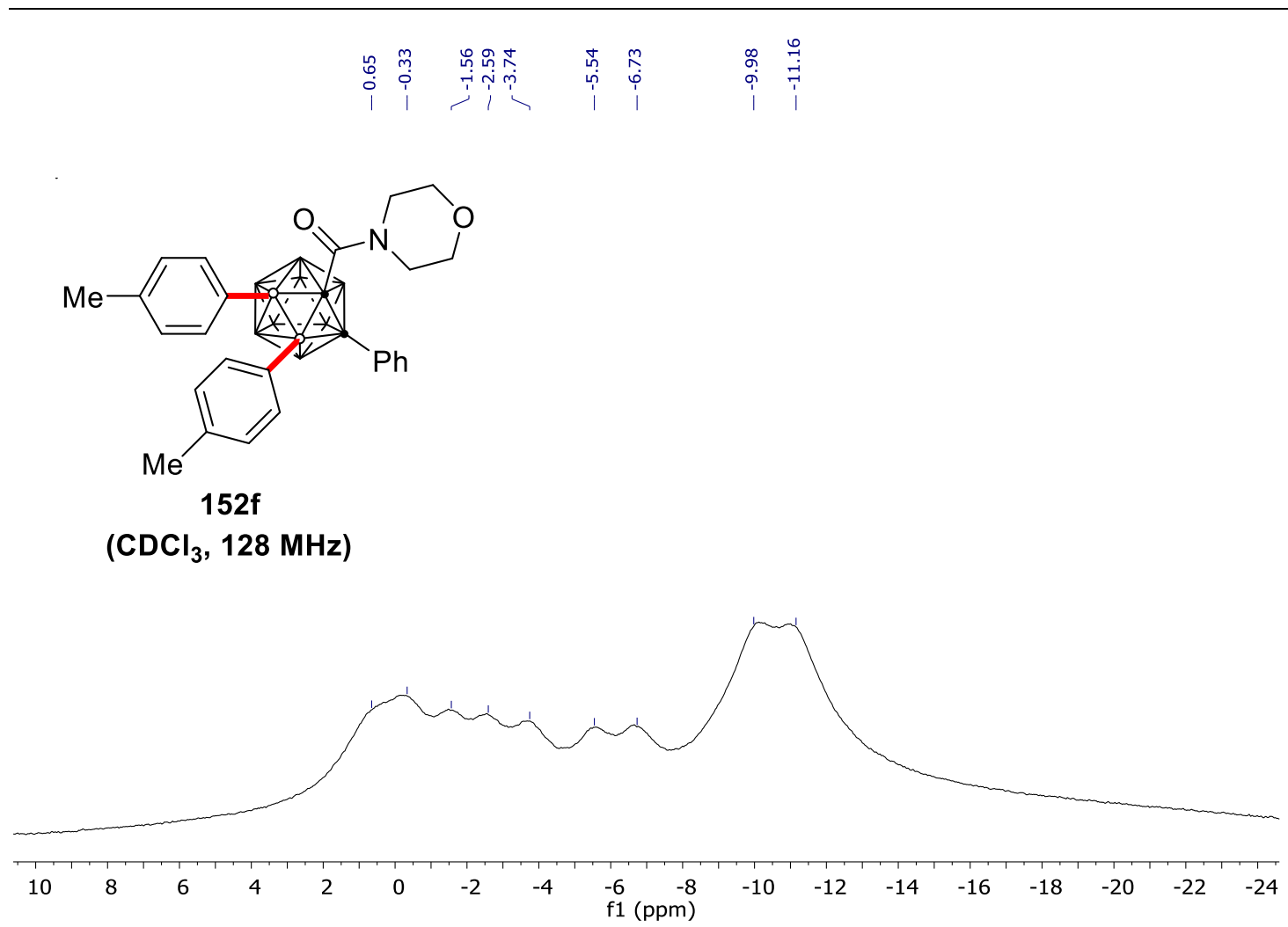

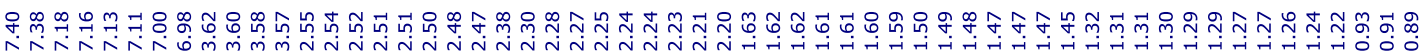
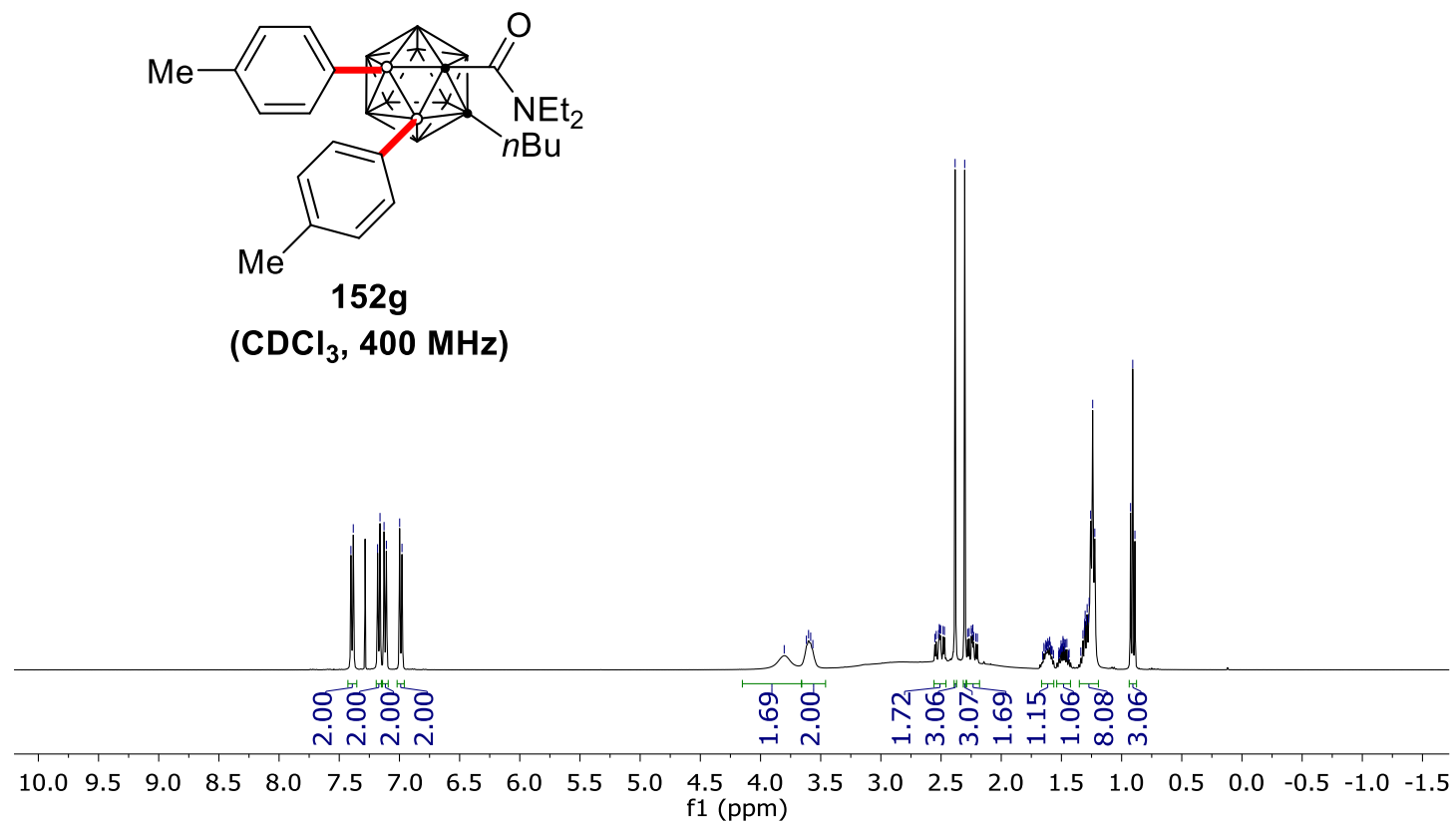
NMR Spectra
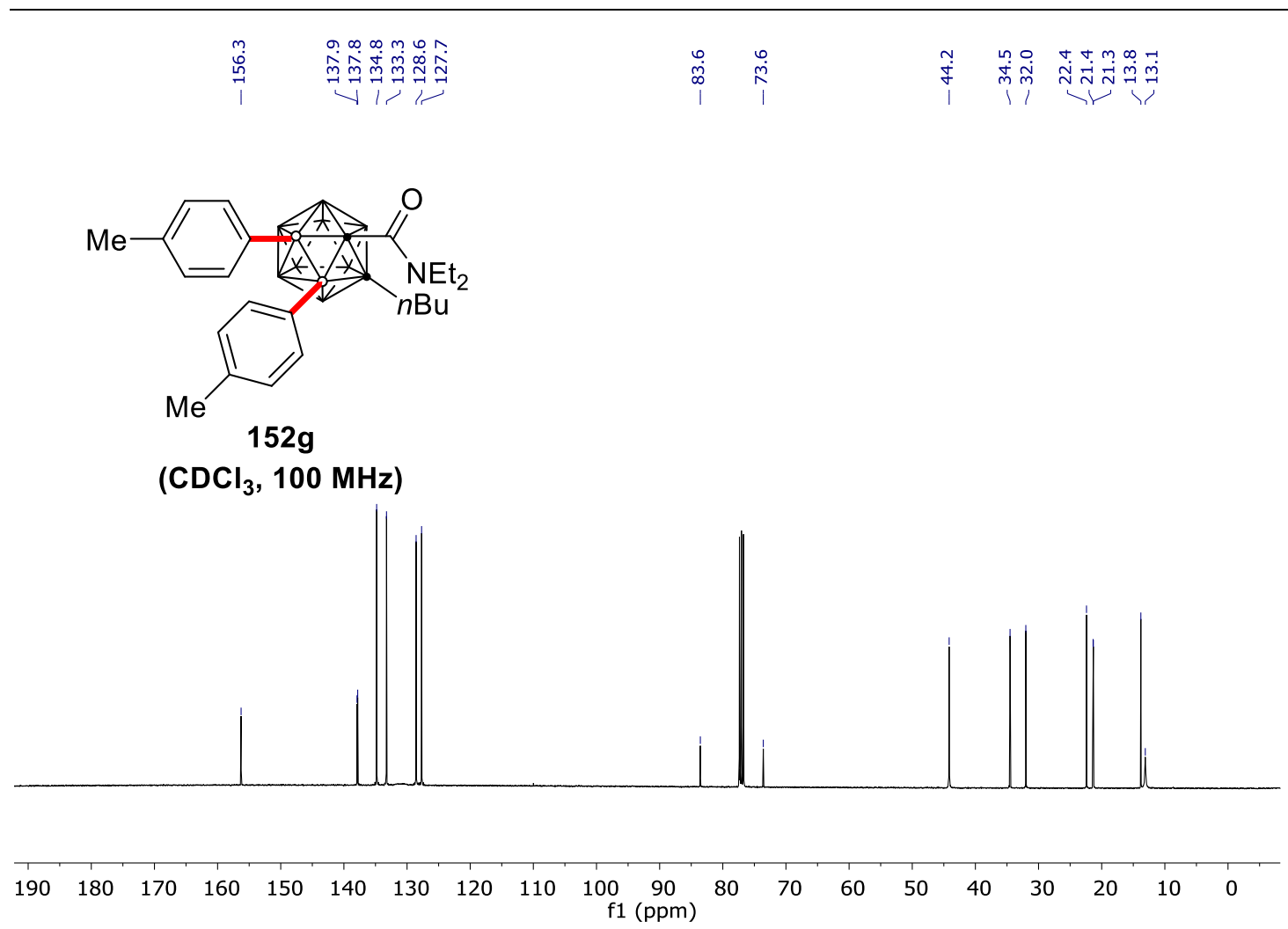

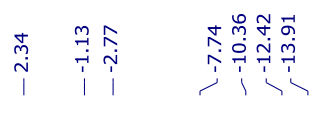
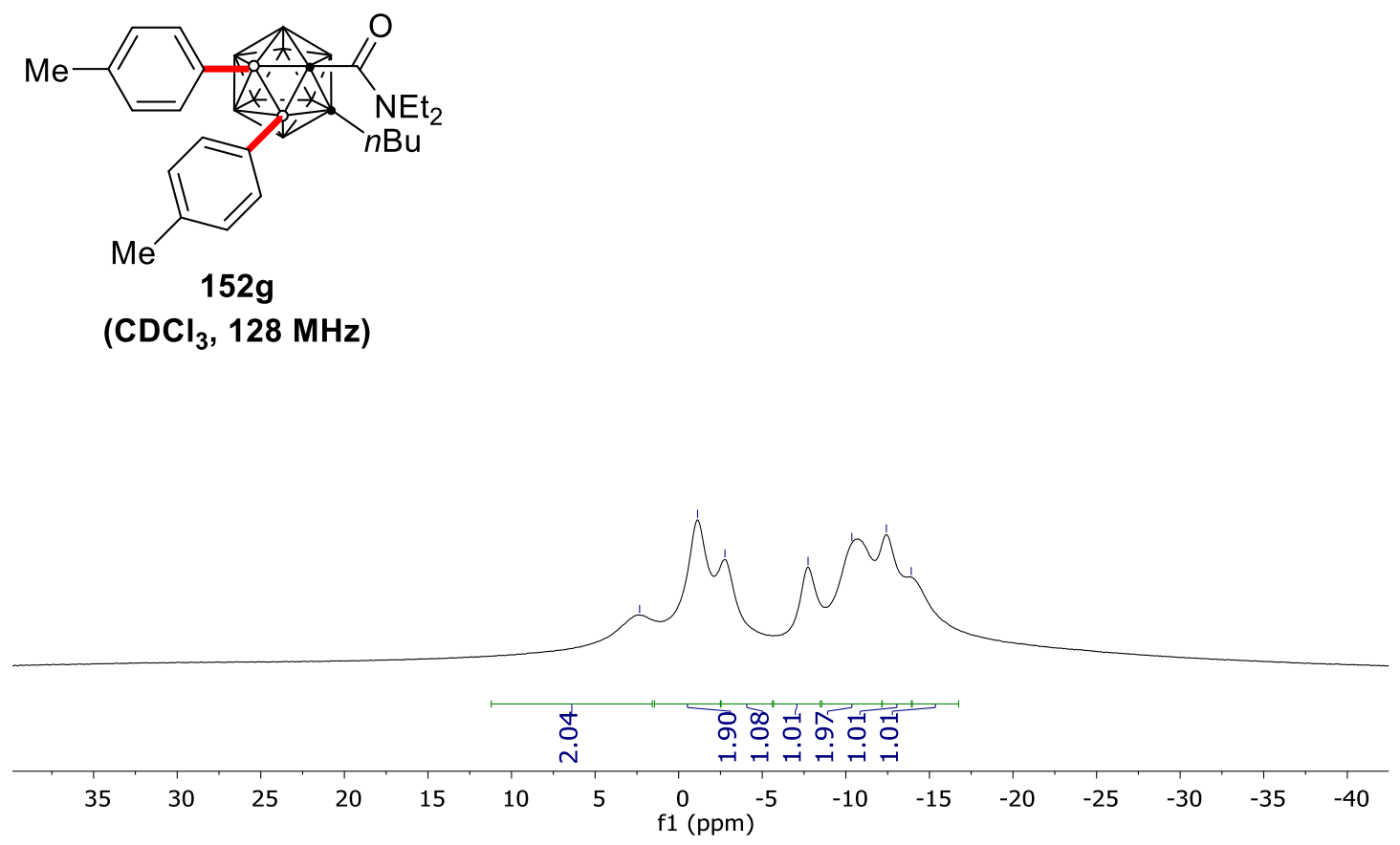


\section{NMR Spectra}

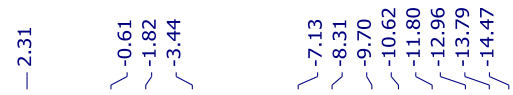
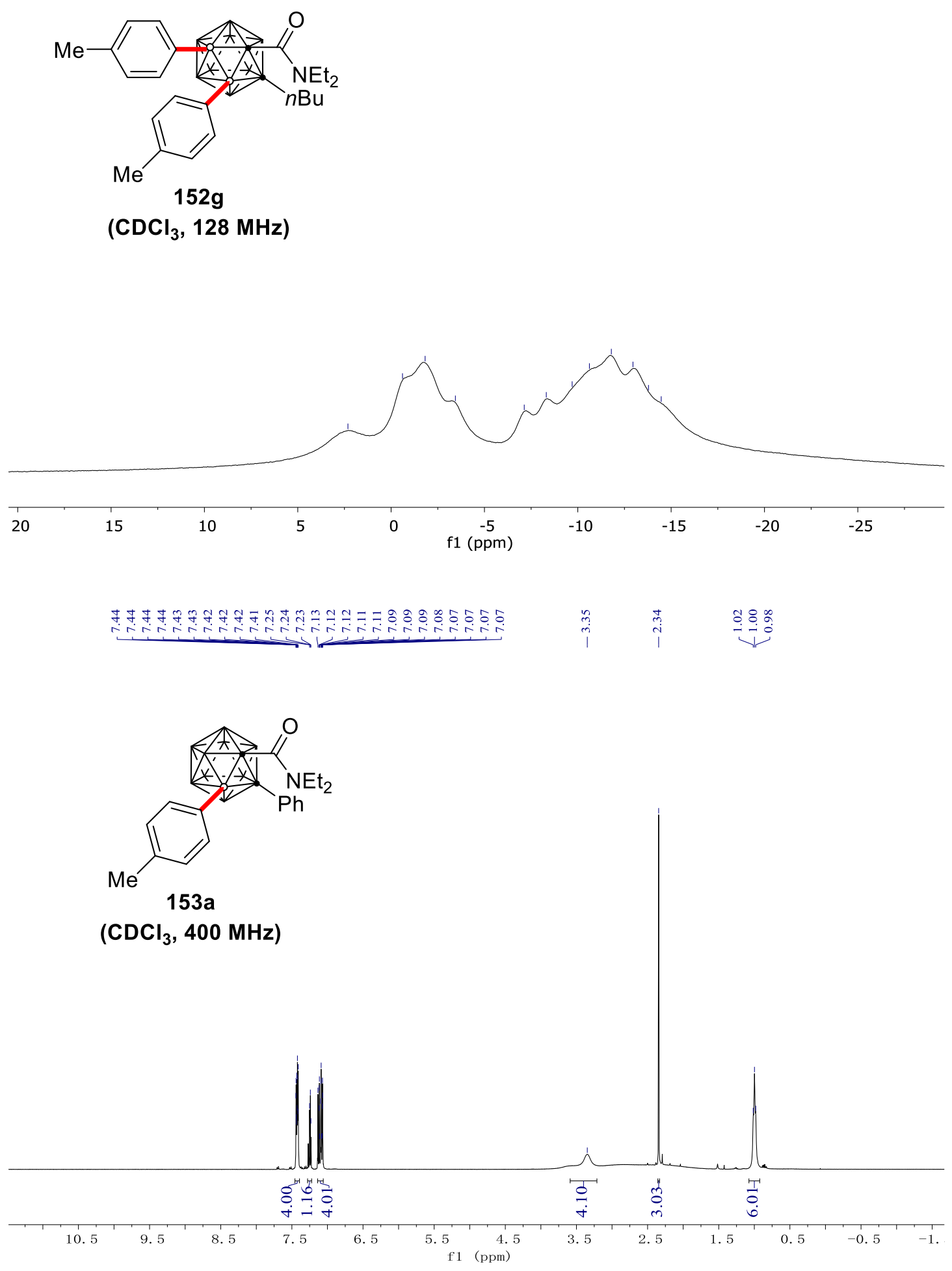
NMR Spectra
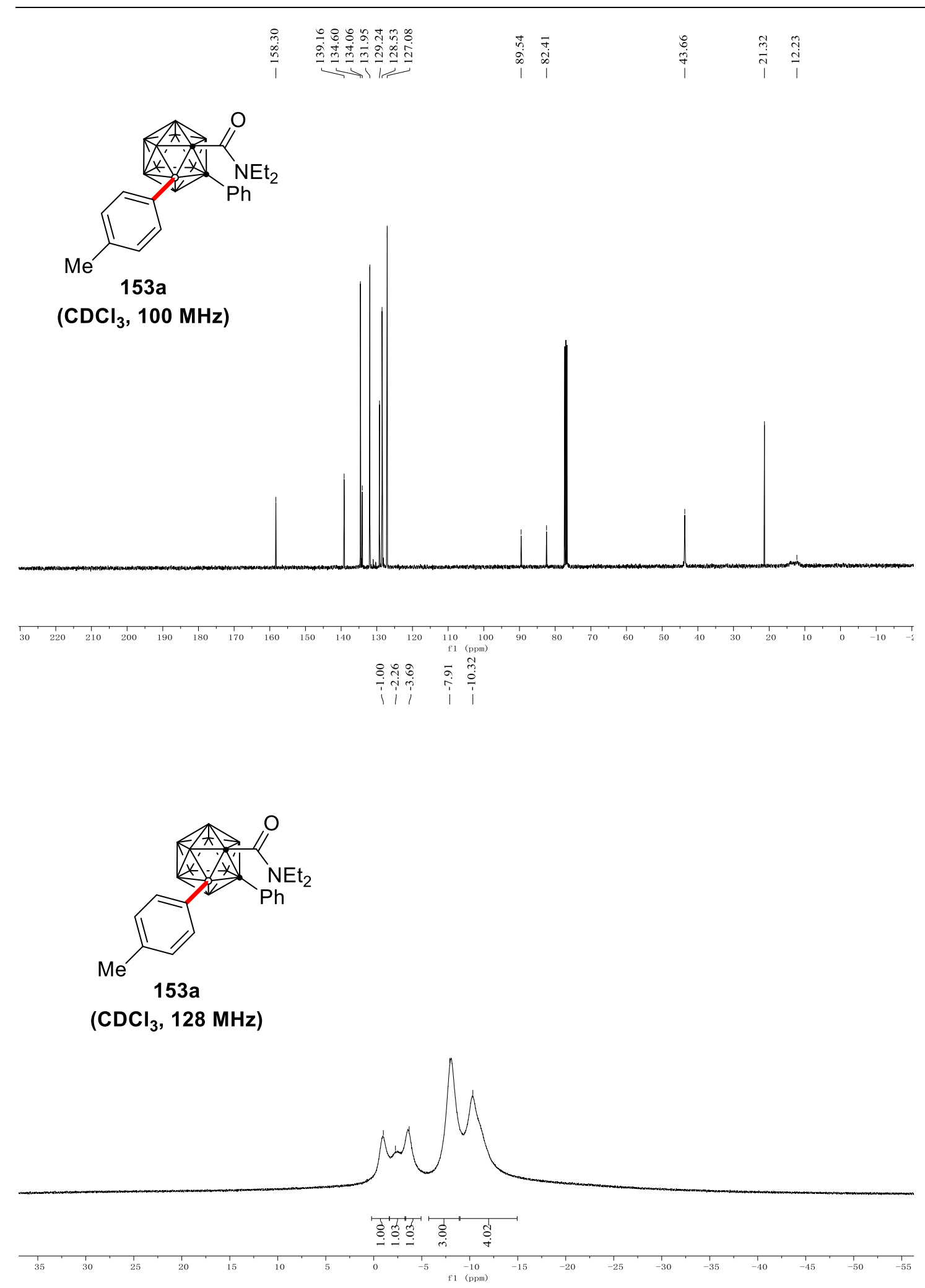


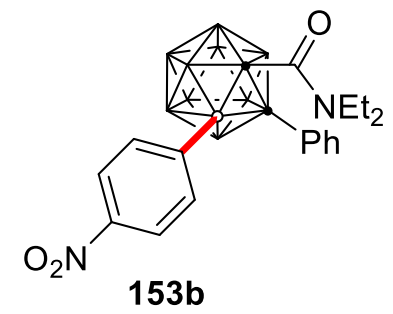

$\left(\mathrm{CDCl}_{3}, 300 \mathrm{MHz}\right)$
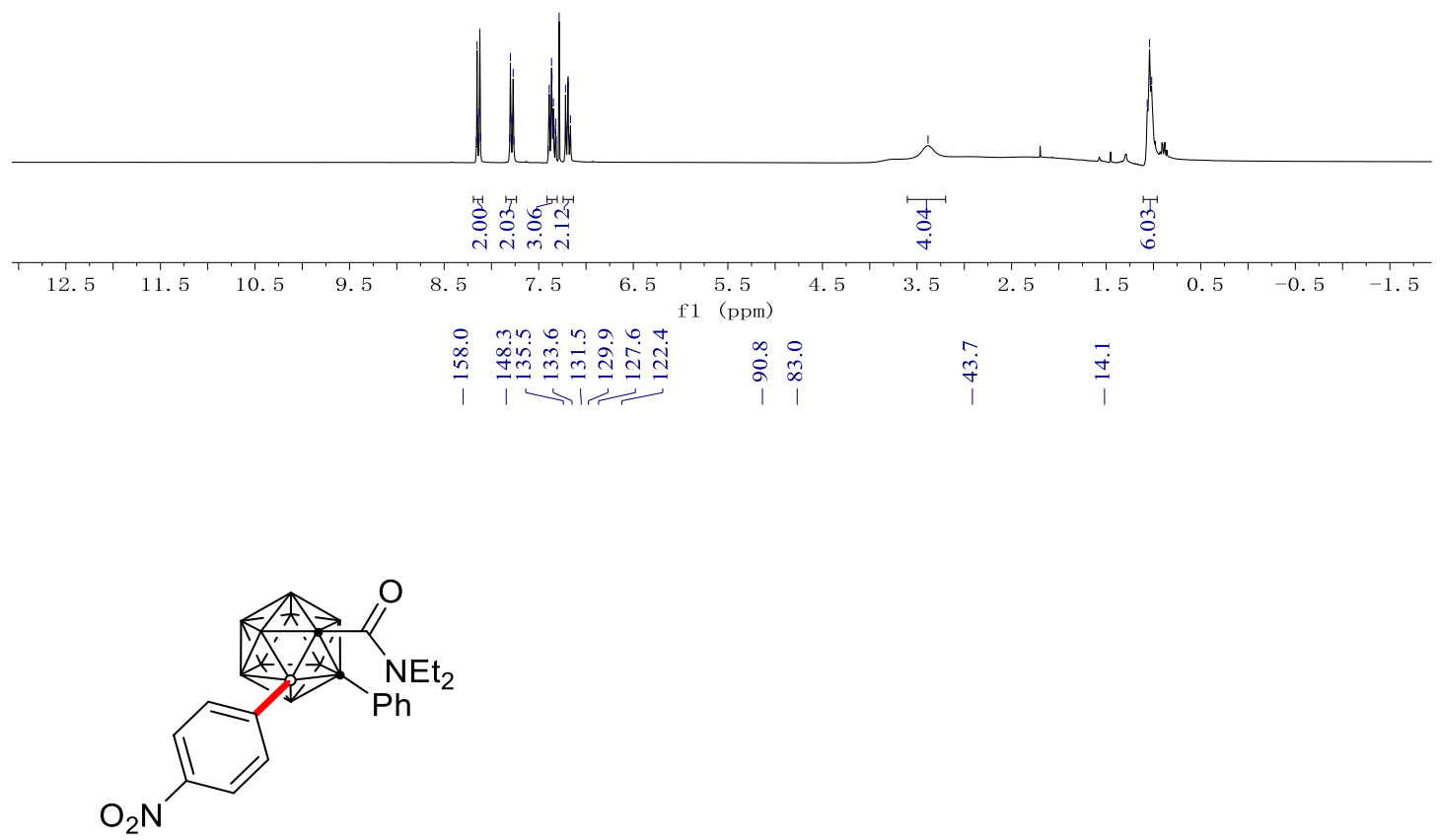

153b

$\left(\mathrm{CDCl}_{3}, 75 \mathrm{MHz}\right)$

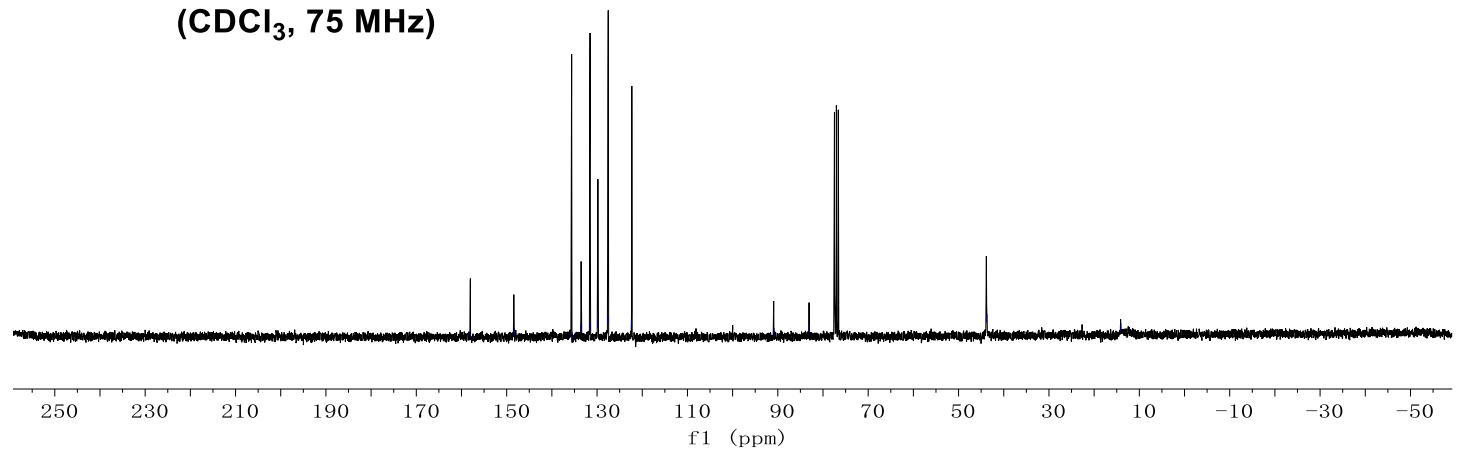




\section{NMR Spectra}

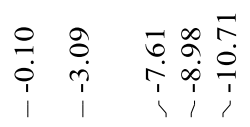
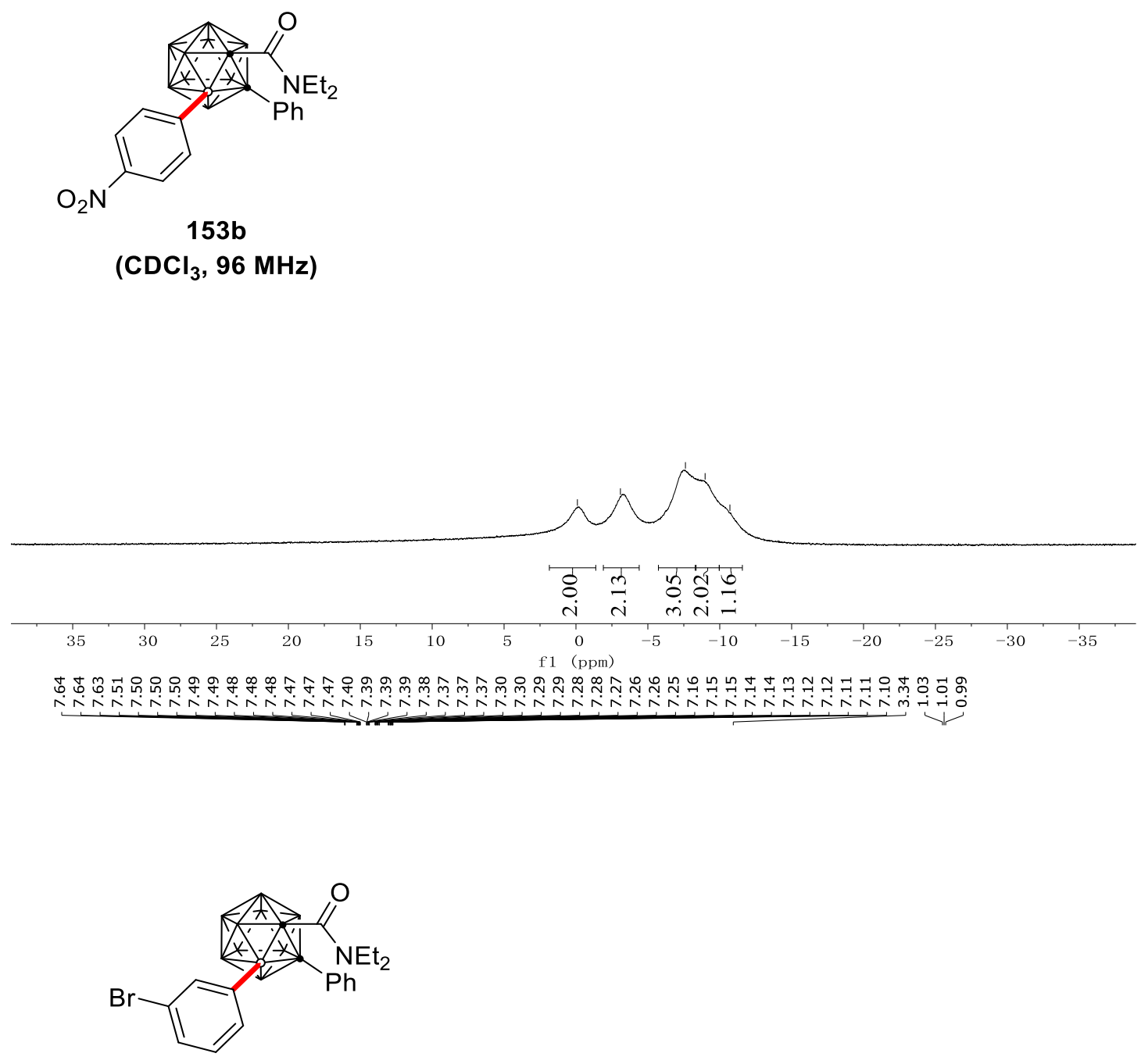

$153 \mathrm{c}$

$\left(\mathrm{CDCl}_{3}, 400 \mathrm{MHz}\right)$

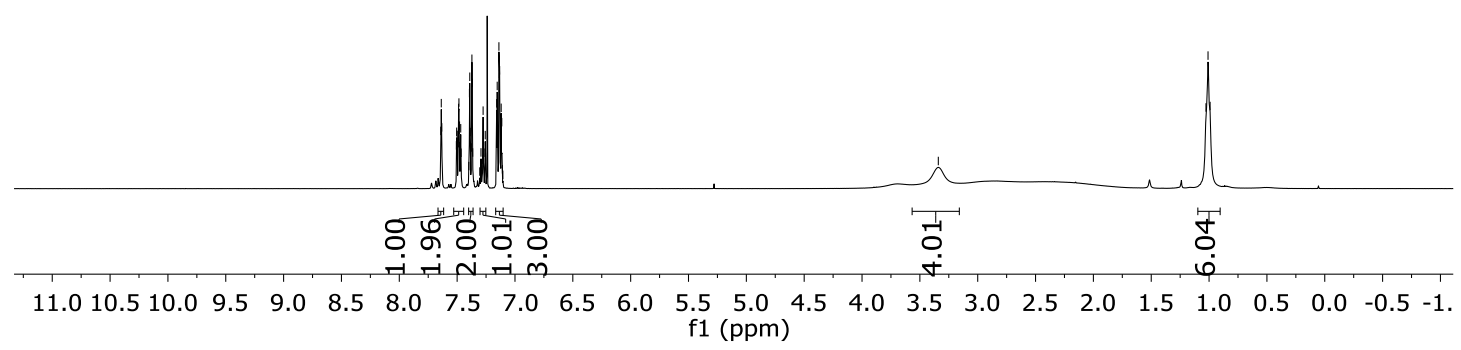




\section{NMR Spectra}

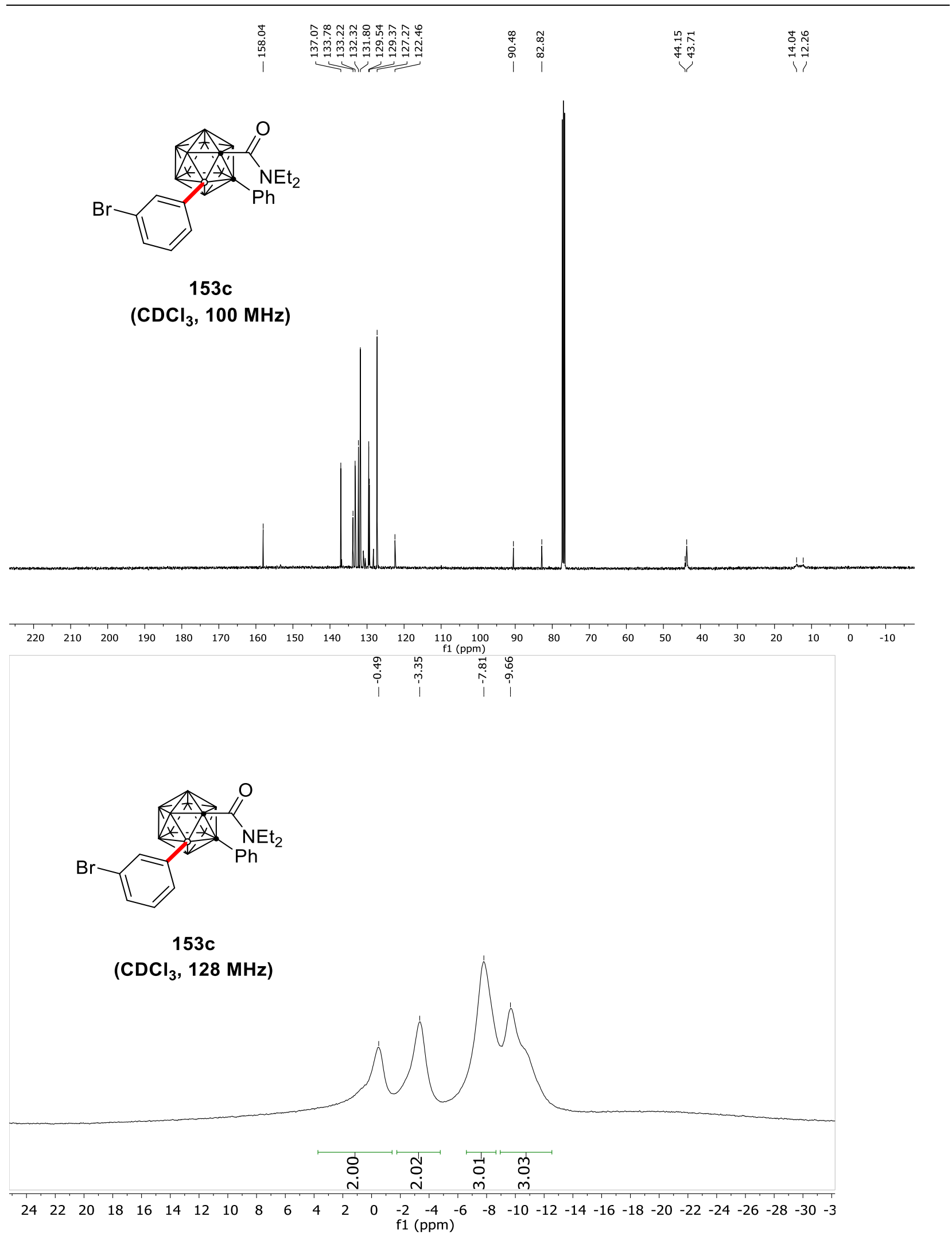



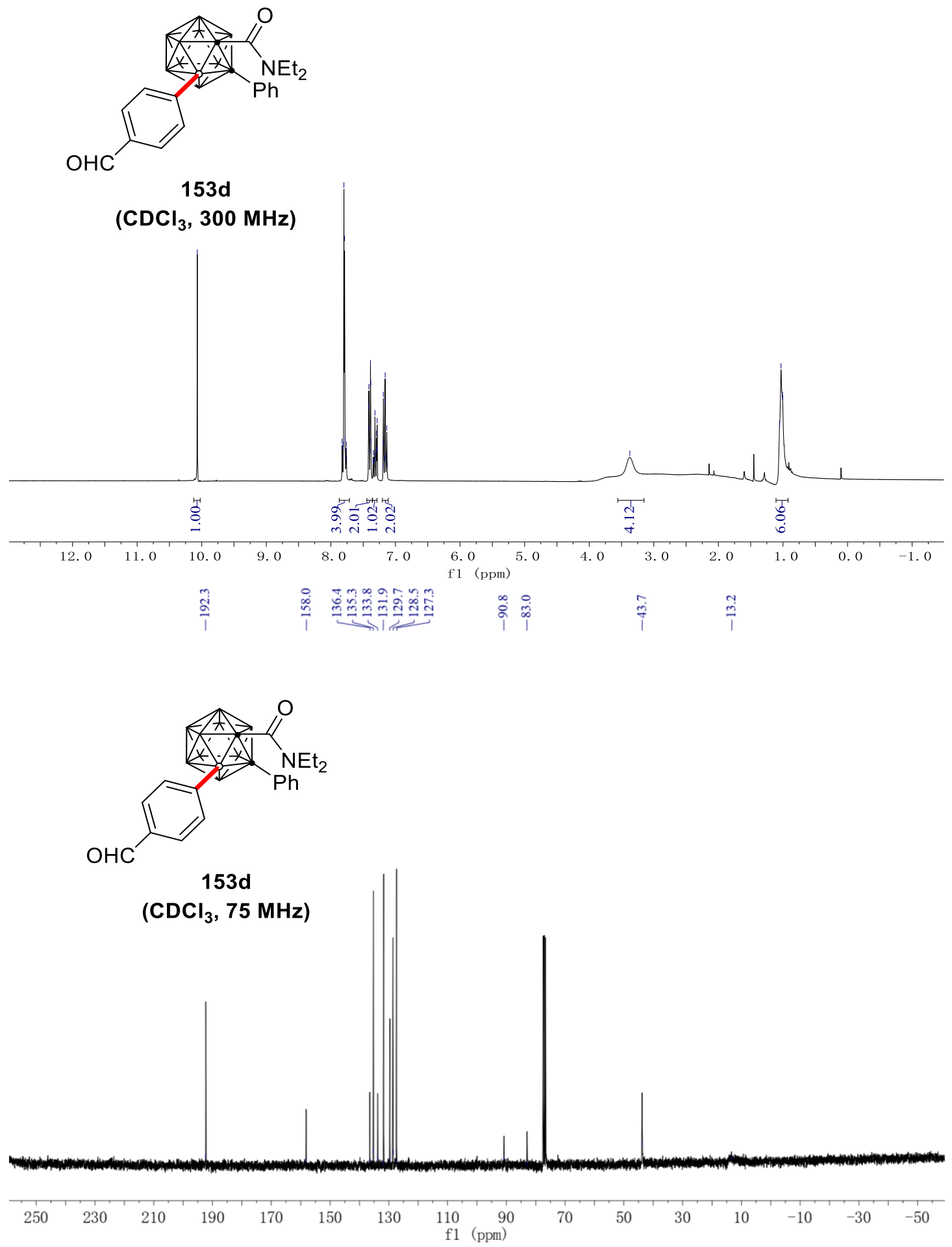


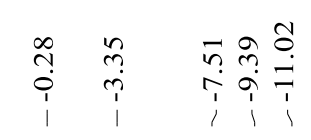
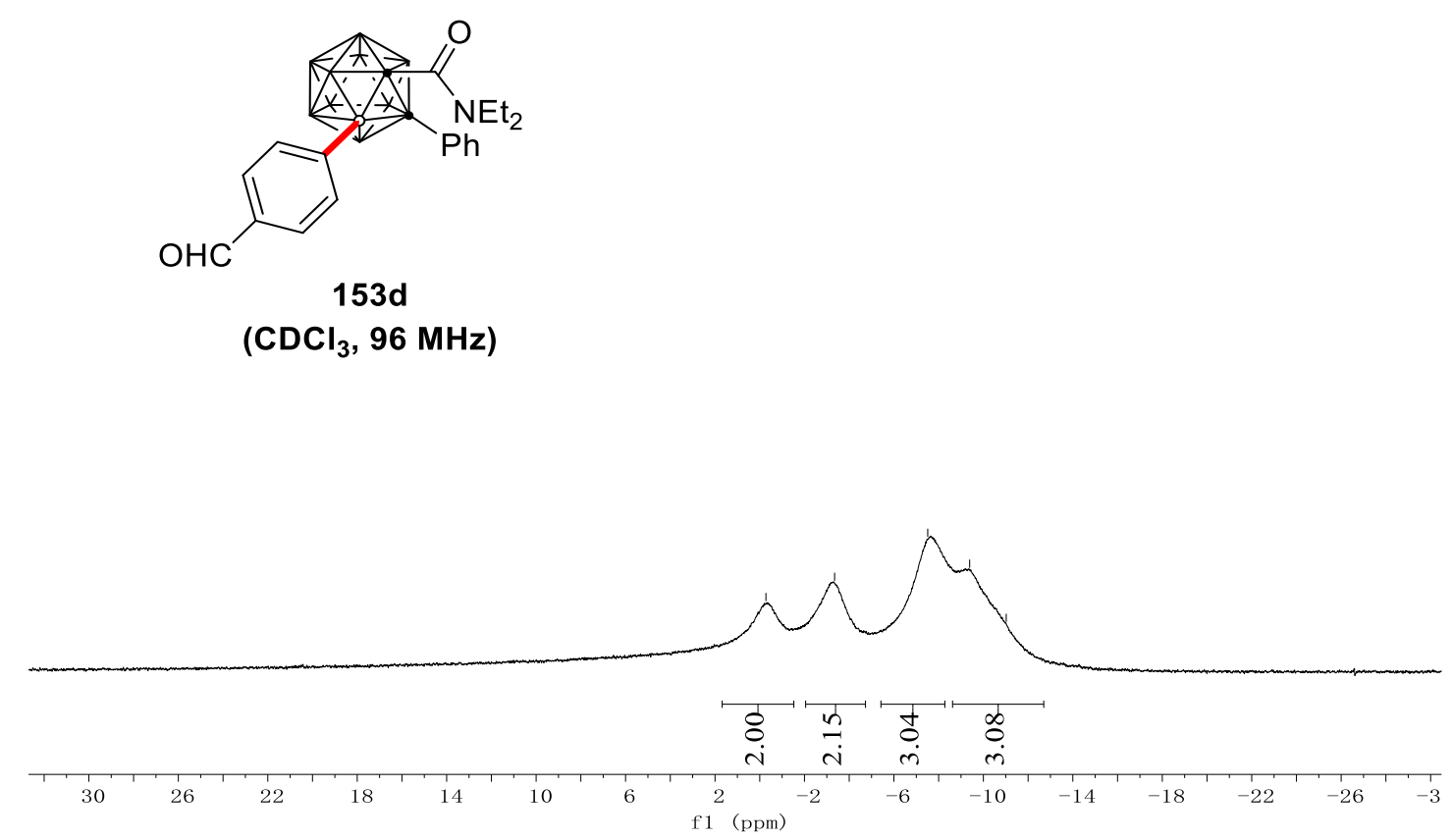

\subsection{Electrochemical B-H Nitrogenation of nido-Carboranes}

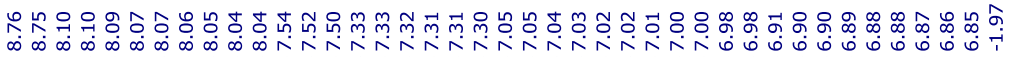

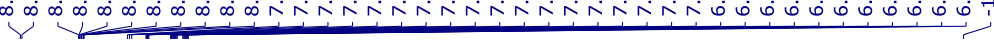

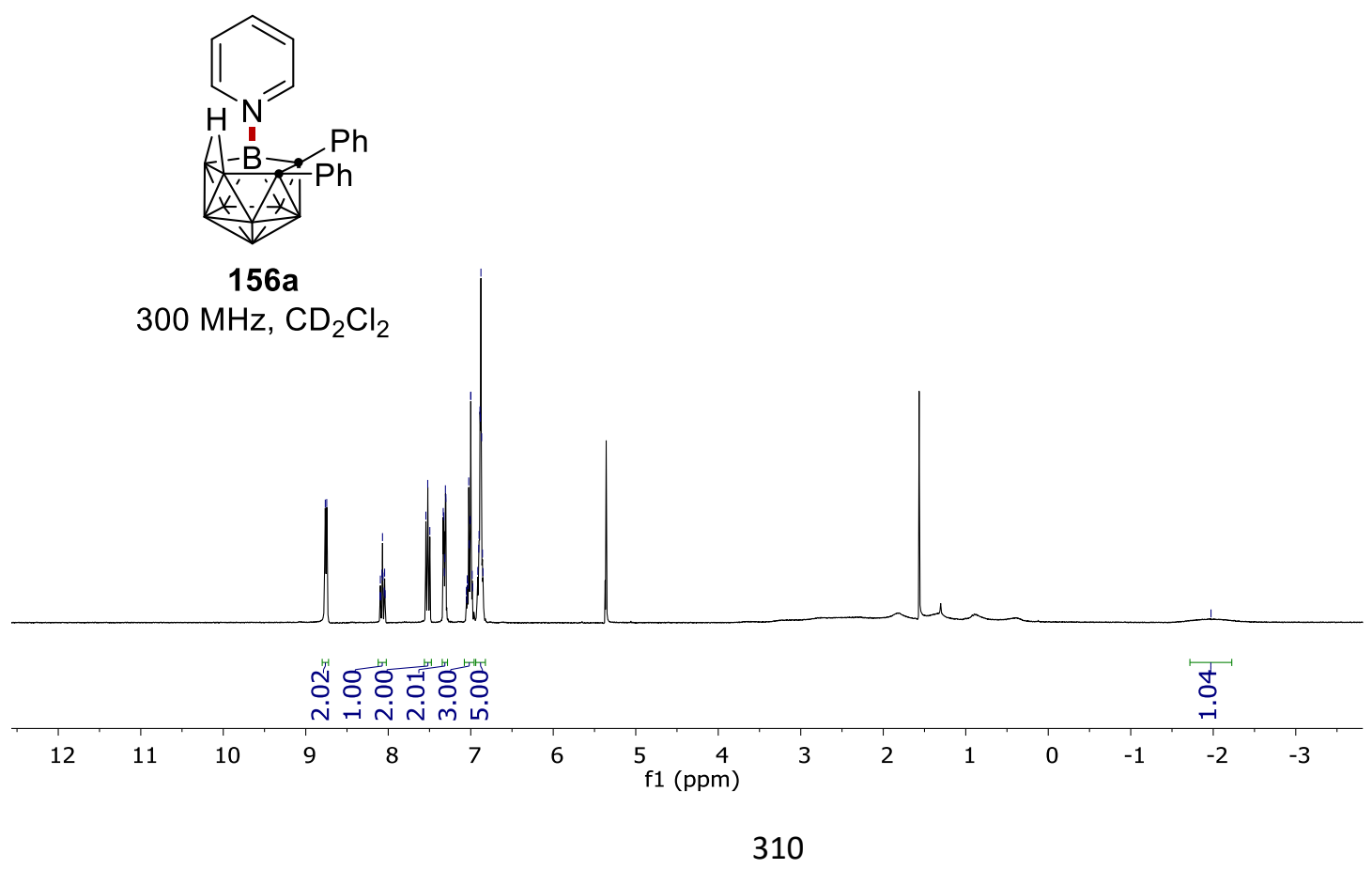




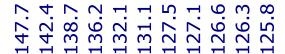

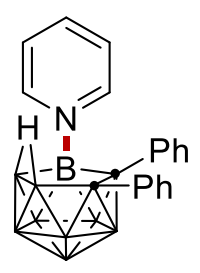

$156 a$

$101 \mathrm{MHz}, \mathrm{CD}_{2} \mathrm{Cl}_{2}$

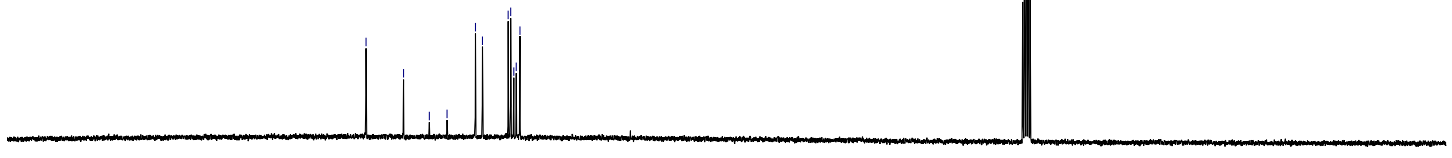

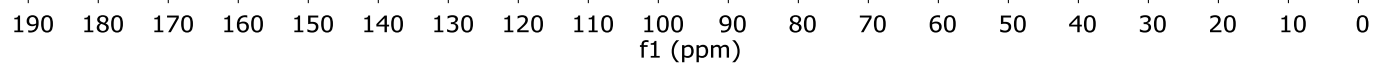

\begin{tabular}{|c|c|c|c|c|c|c|}
\hline$\approx$ & $\begin{array}{l}\infty \\
\stackrel{1}{1} \\
1 \\
\mid\end{array}$ & 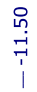 & $\begin{array}{l}\stackrel{m}{\wedge} \\
\stackrel{n}{n} \\
\dot{1} \\
\mid\end{array}$ & 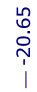 & 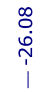 & $\begin{array}{l}\hat{a} \\
0 \\
\dot{m} \\
1\end{array}$ \\
\hline
\end{tabular}

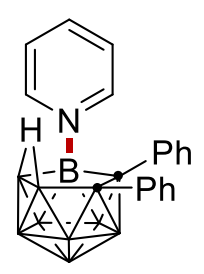

$156 a$

$96 \mathrm{MHz}, \mathrm{CD}_{2} \mathrm{Cl}_{2}$

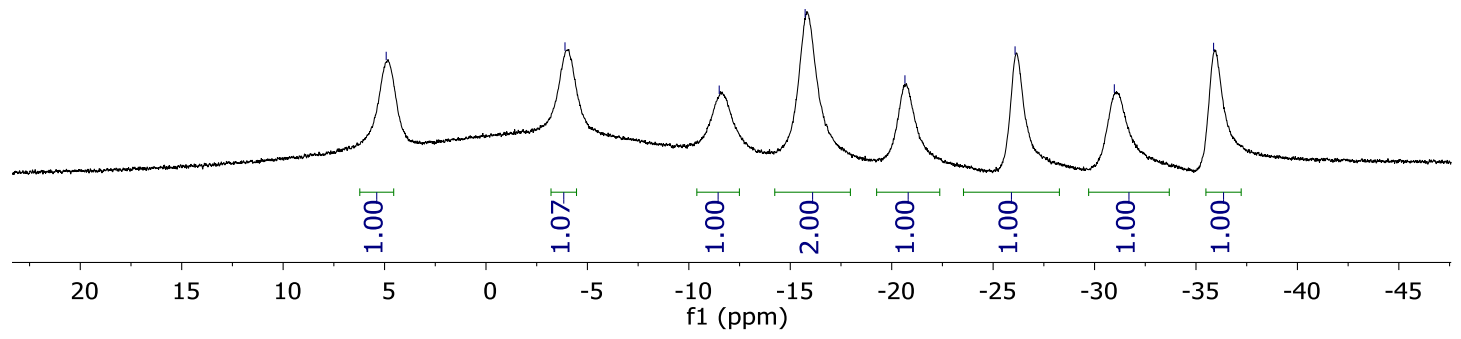




\section{NMR Spectra}
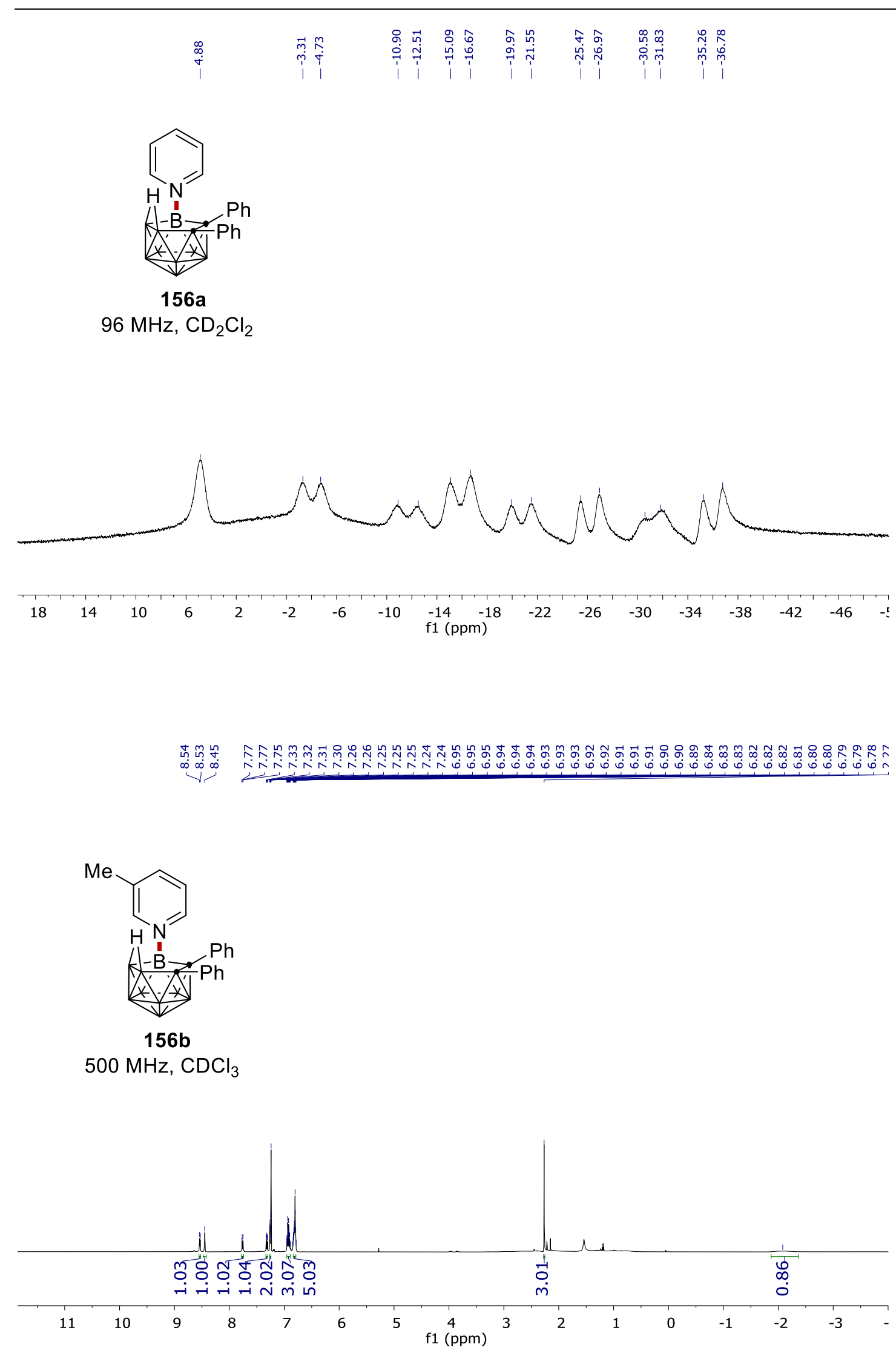


\section{NMR Spectra}

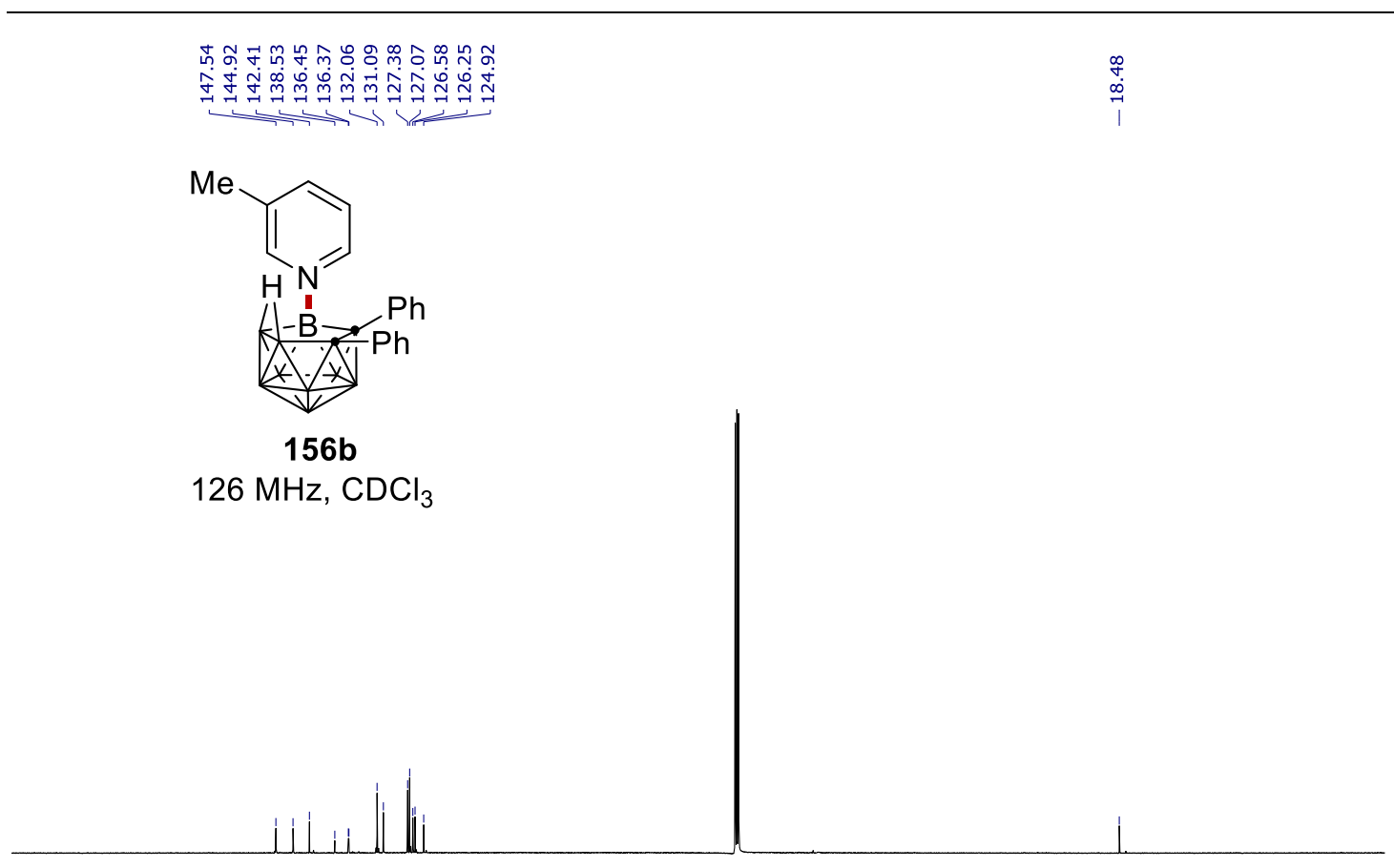

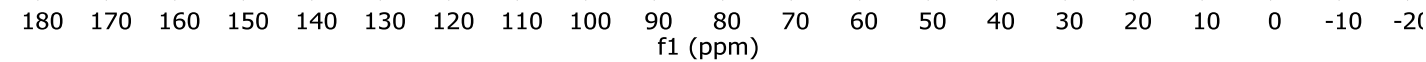

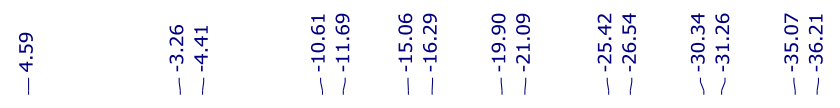

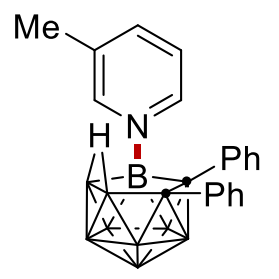

156b

$128 \mathrm{MHz}, \mathrm{CDCl}_{3}$

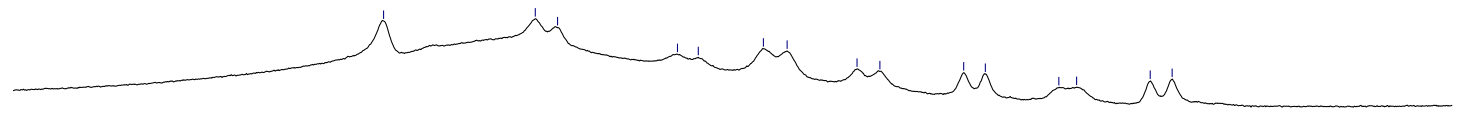

\begin{tabular}{|c|c|c|c|c|c|c|c|c|c|c|c|c|c|}
\hline 20 & 15 & 10 & 5 & 0 & -5 & $\begin{array}{rr}-10 & -15 \\
& f 1(p p m)\end{array}$ & -20 & -25 & -30 & -35 & -40 & -45 & -51 \\
\hline
\end{tabular}




\section{NMR Spectra}

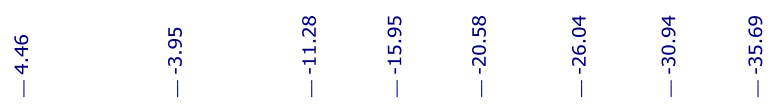

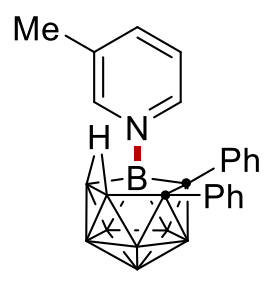

156b

$128 \mathrm{MHz}, \mathrm{CDCl}_{3}$
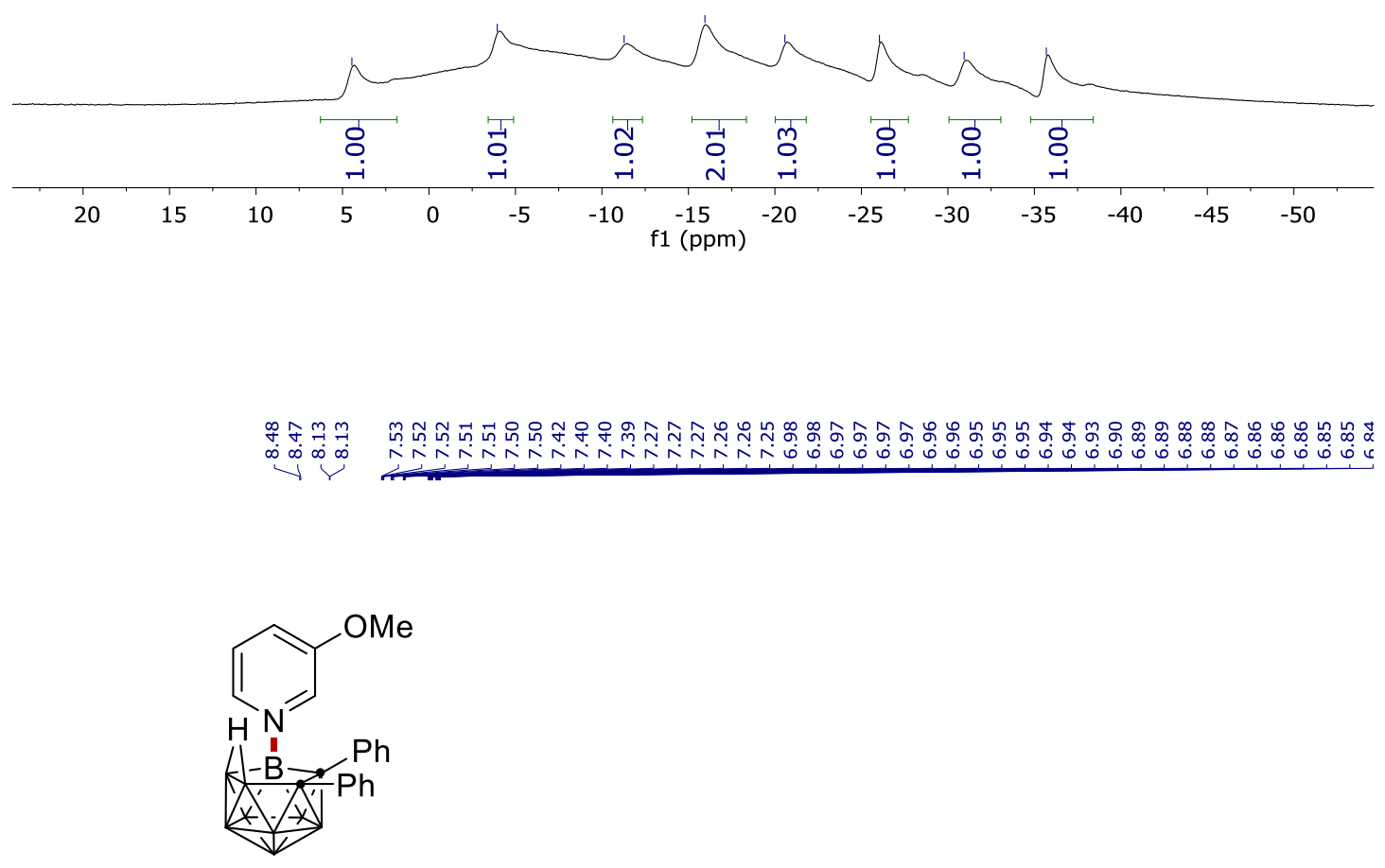

156c

$500 \mathrm{MHz}, \mathrm{CD}_{2} \mathrm{Cl}_{2}$

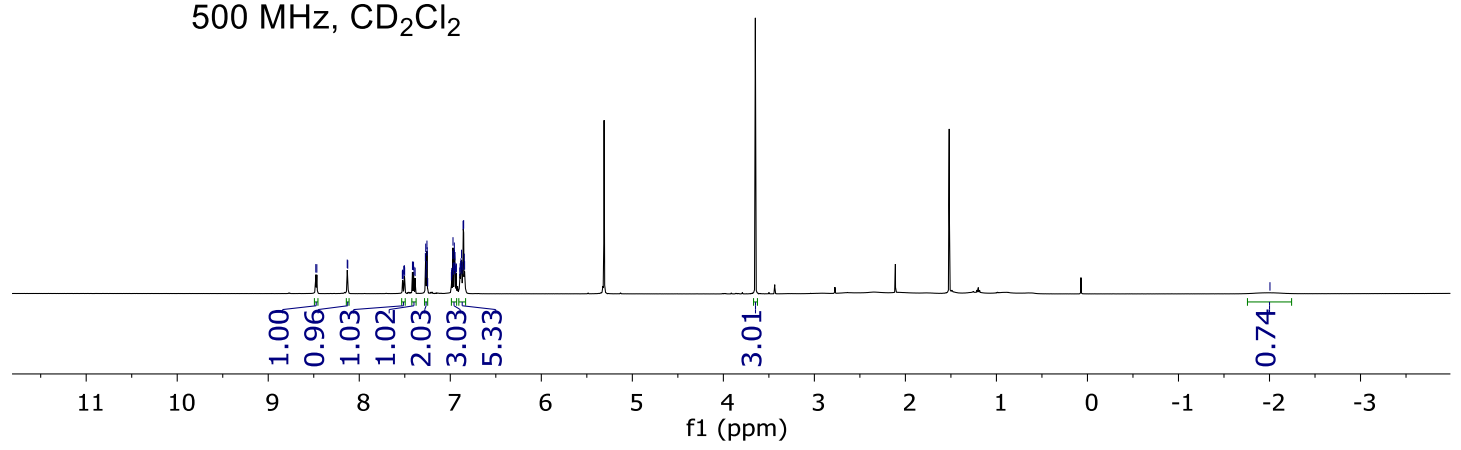




\section{NMR Spectra}
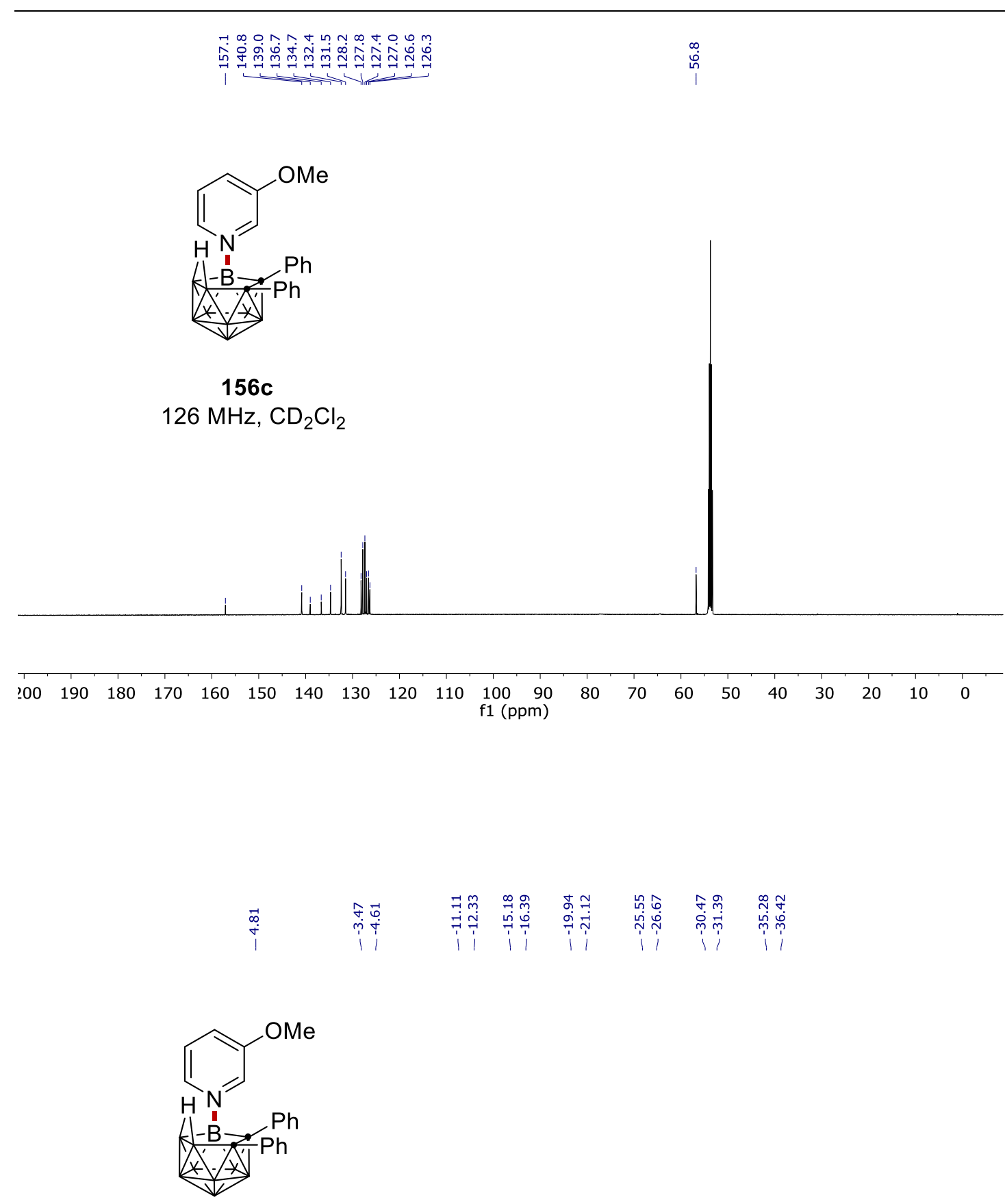

$156 \mathrm{c}$

$128 \mathrm{MHz}, \mathrm{CD}_{2} \mathrm{Cl}_{2}$

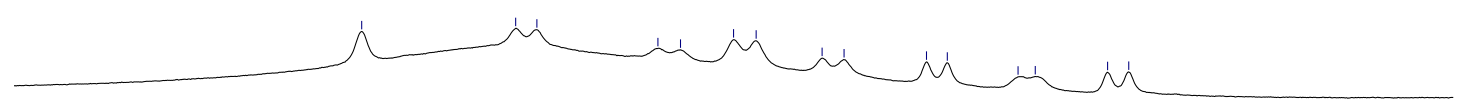

$\begin{array}{lllllllllllllll}20 & 15 & 10 & 5 & 0 & -5 & -10 & -15 & -20 & -25 & -30 & -35 & -40 & -45 & -50\end{array}$




\section{NMR Spectra}
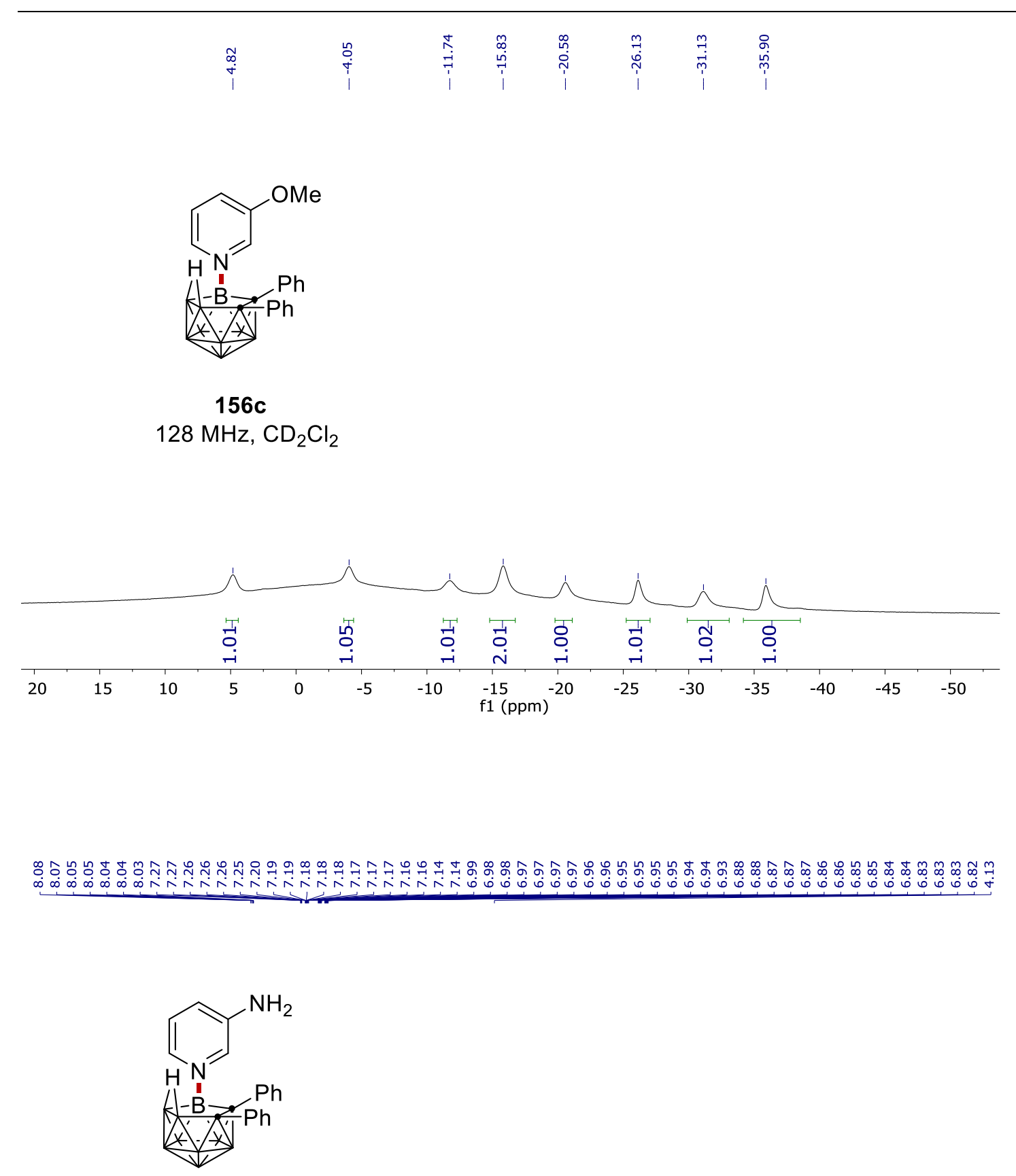

156d $500 \mathrm{MHz}, \mathrm{CD}_{2} \mathrm{Cl}_{2}$

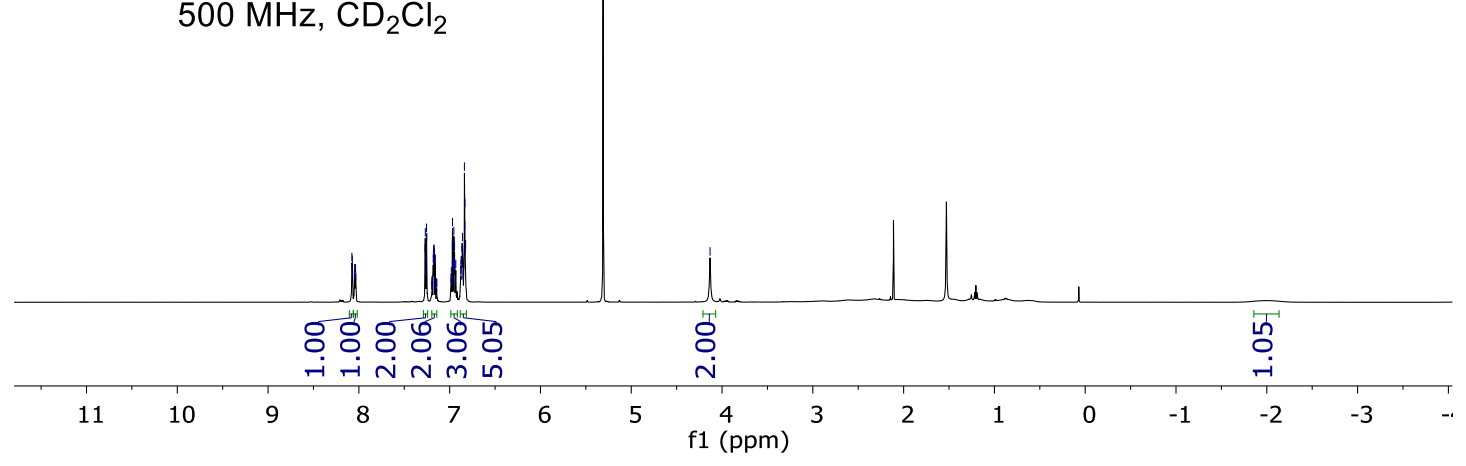



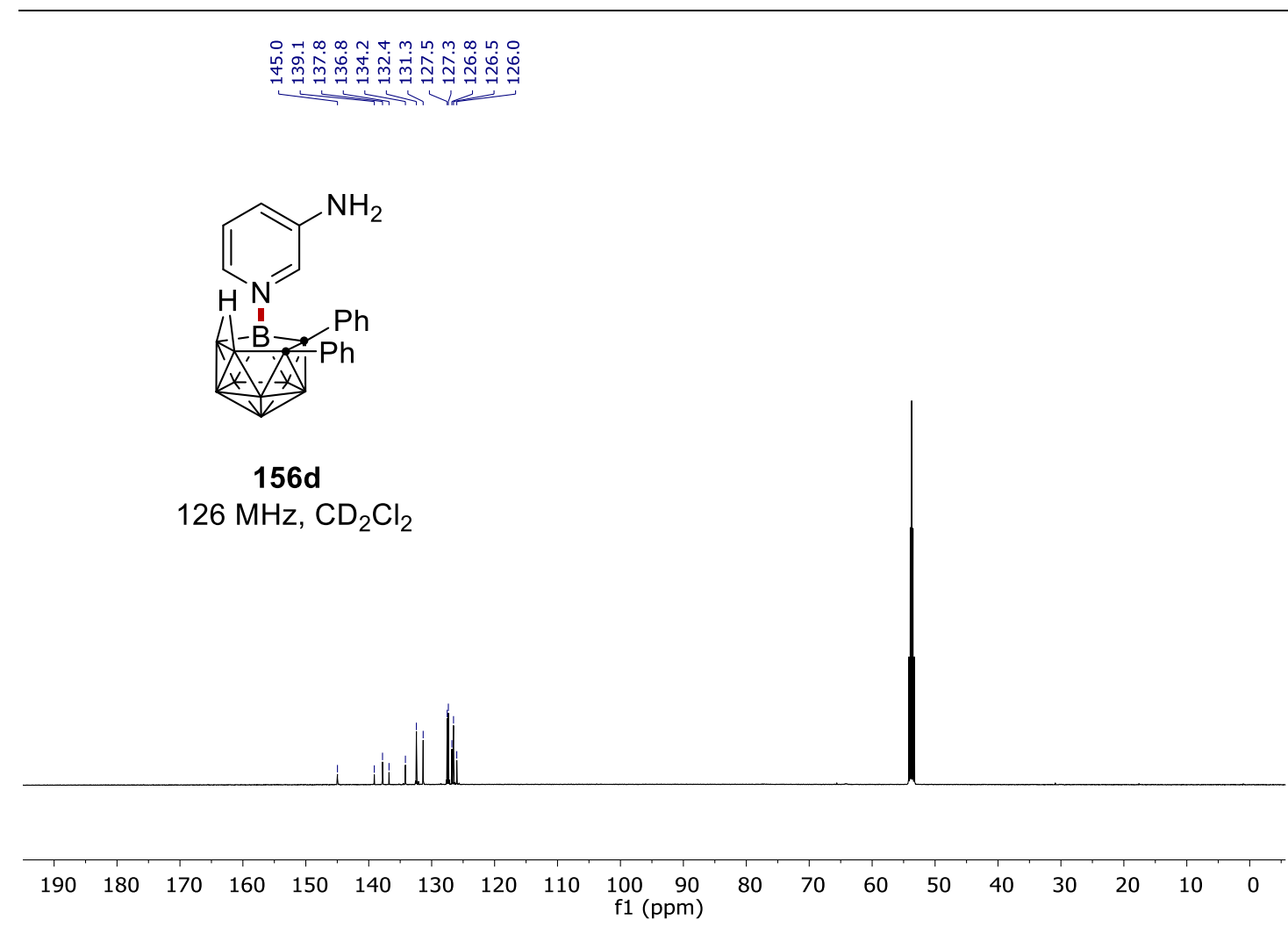

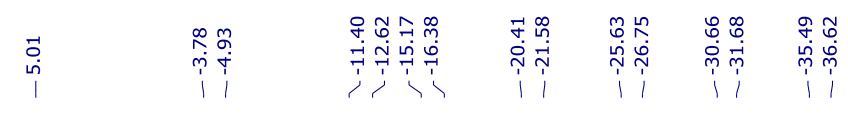

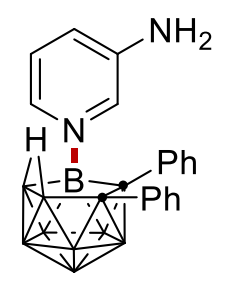

156d

$128 \mathrm{MHz}, \mathrm{CD}_{2} \mathrm{Cl}_{2}$

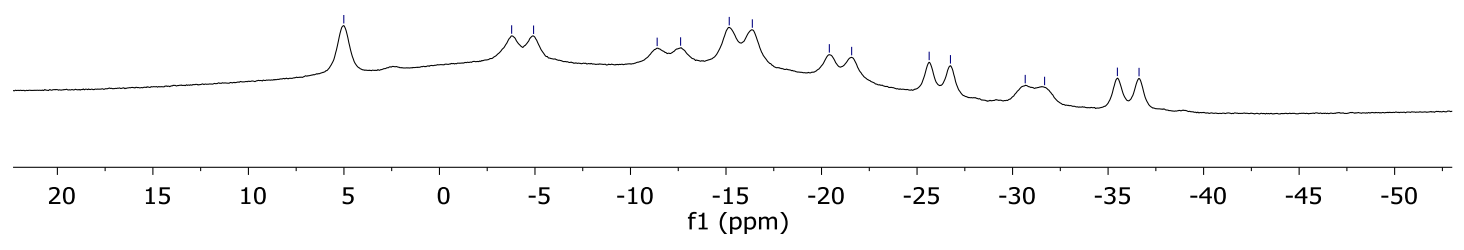




\section{NMR Spectra}
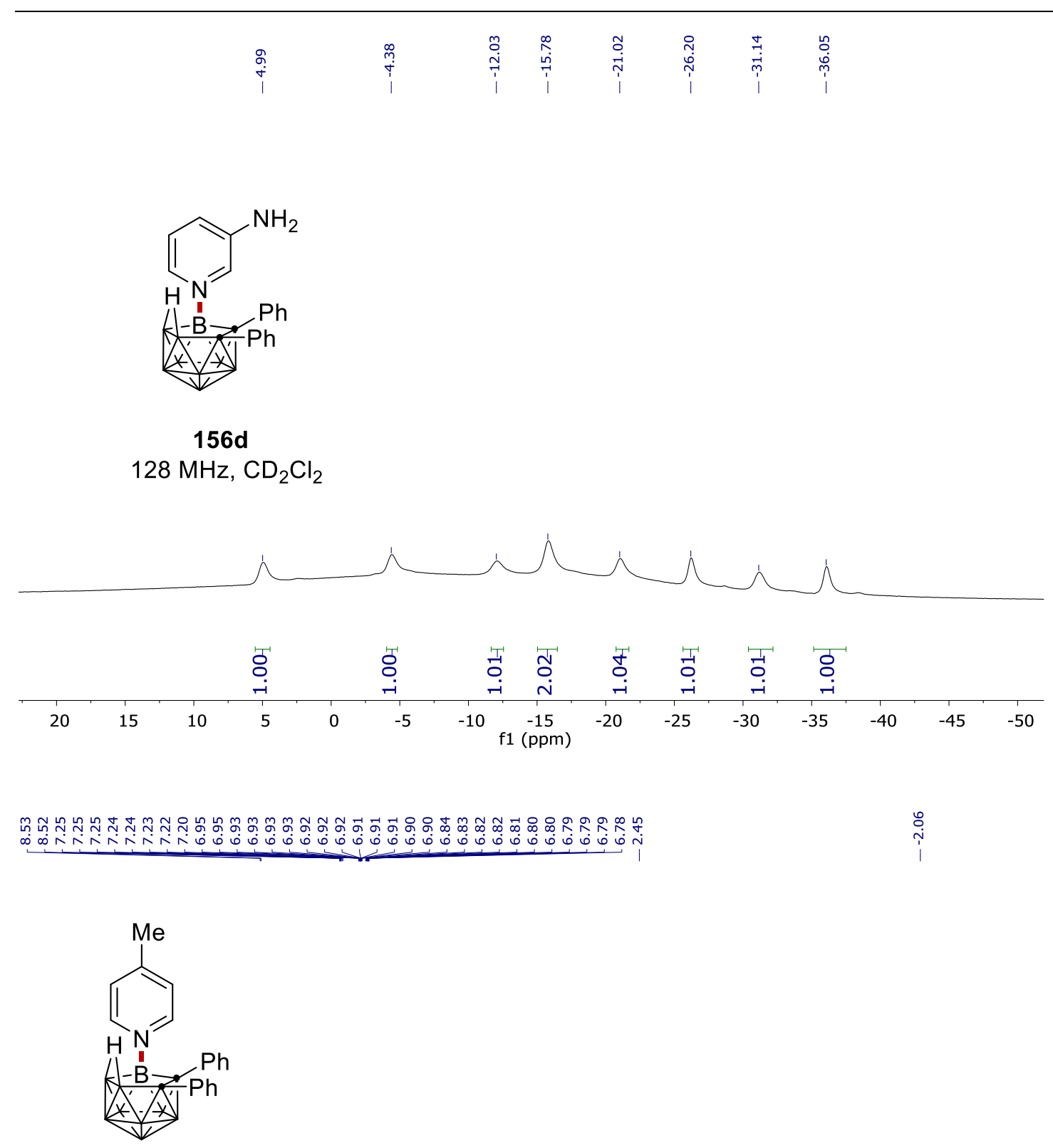

$156 \mathrm{e}$

$500 \mathrm{MHz}, \mathrm{CDCl}_{3}$

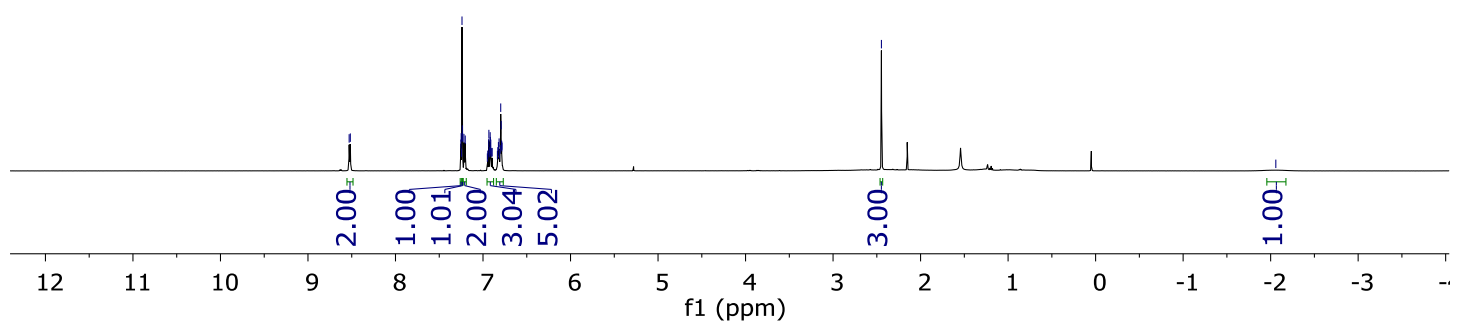



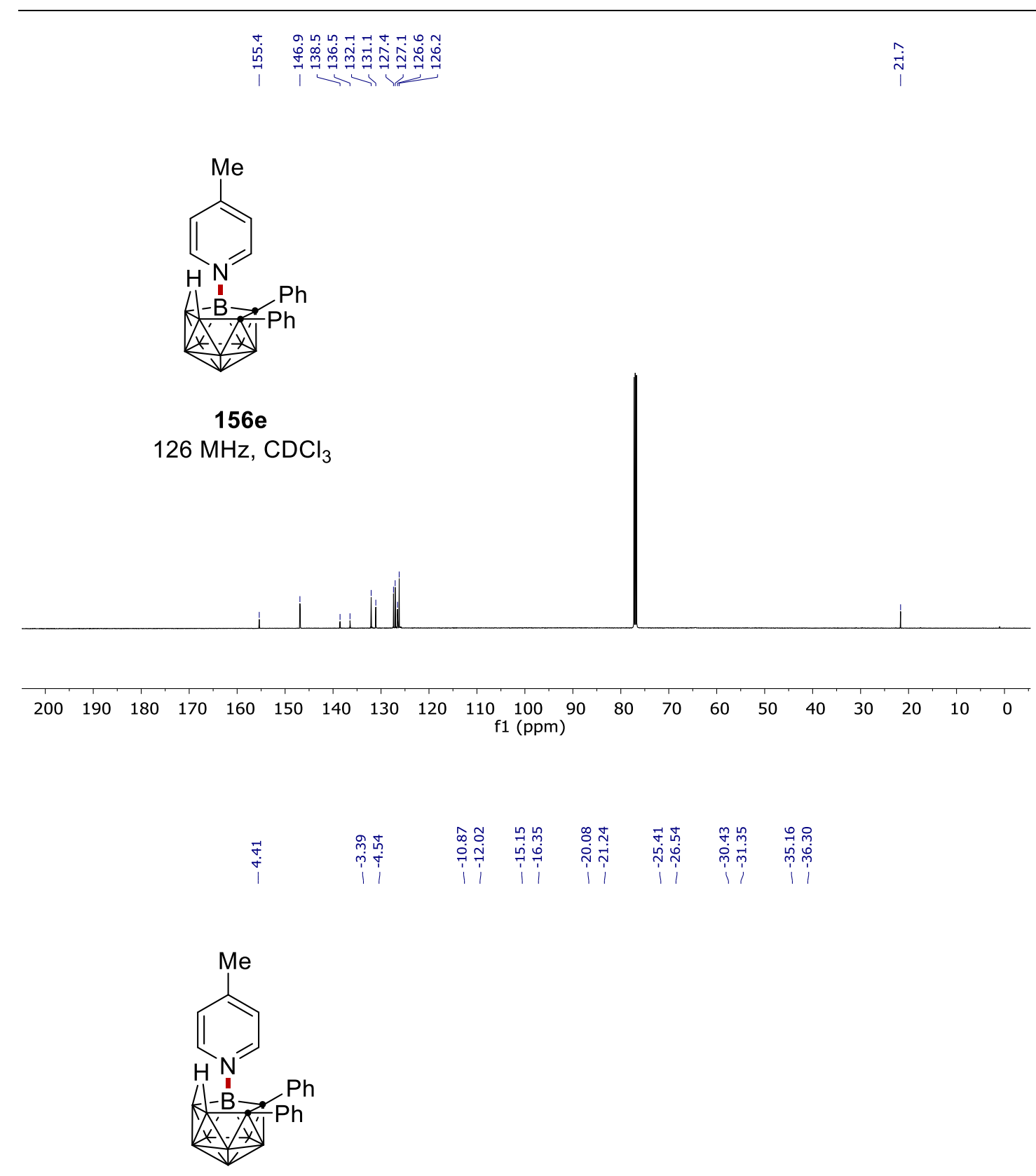

$156 \mathrm{e}$

$128 \mathrm{MHz}, \mathrm{CDCl}_{3}$

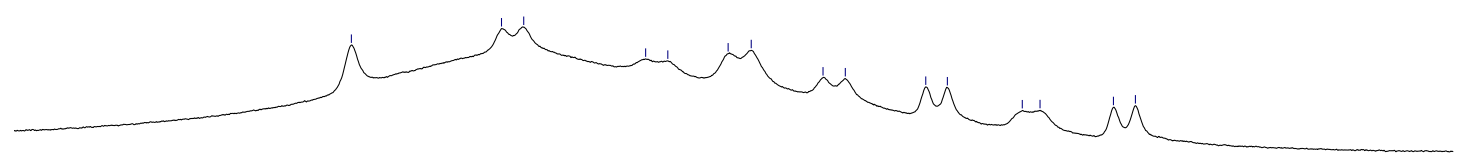

\begin{tabular}{|c|c|c|c|c|c|c|c|c|c|c|c|c|c|c|}
\hline 20 & 15 & 10 & 5 & 0 & -5 & -10 & $\begin{array}{c}-15 \\
\mathrm{f} 1 \text { (ppm) }\end{array}$ & -20 & -25 & -30 & -35 & -40 & -45 & -50 \\
\hline
\end{tabular}




\section{NMR Spectra}
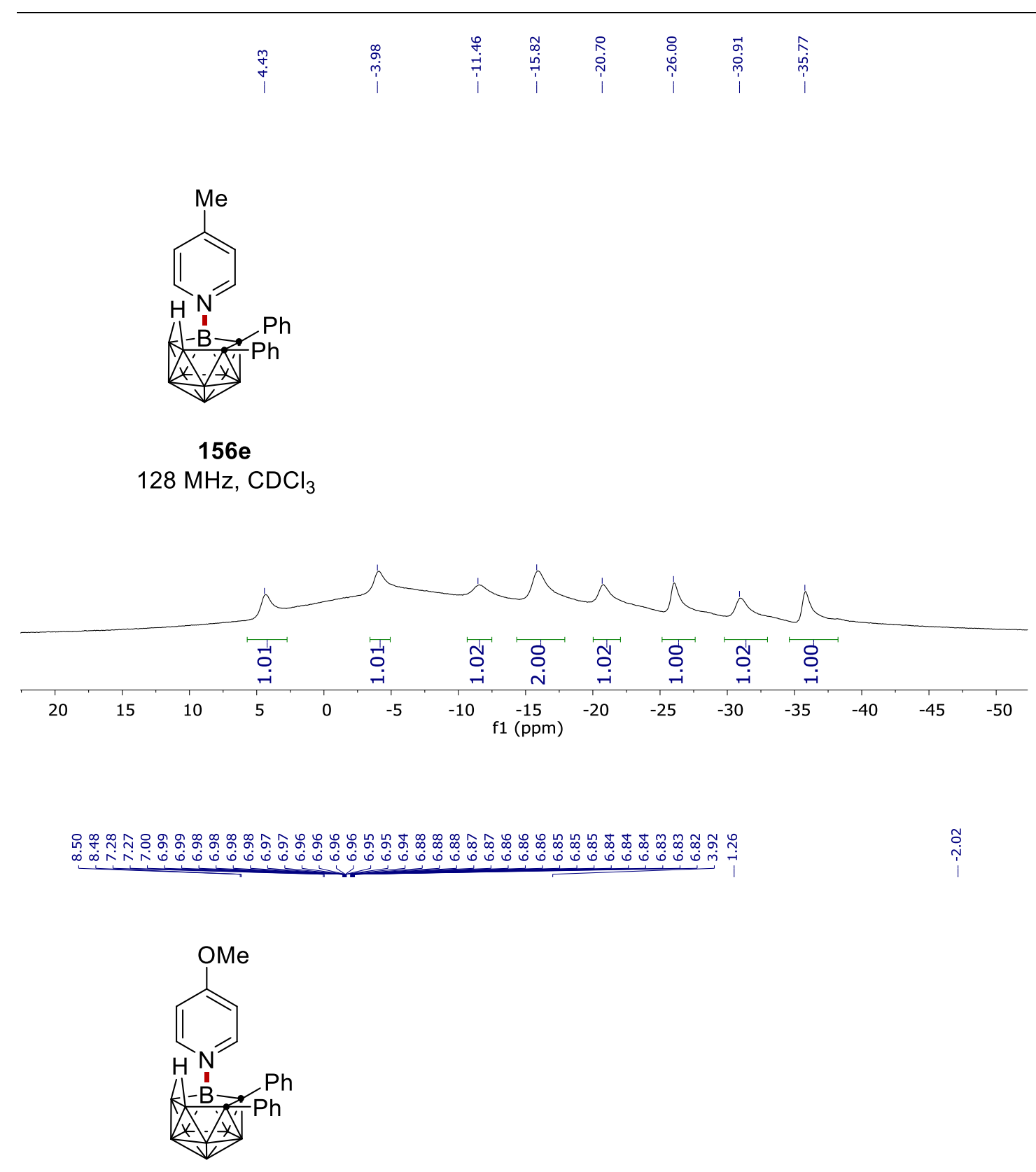

$156 f$

$500 \mathrm{MHz}, \mathrm{CD}_{2} \mathrm{Cl}_{2}$

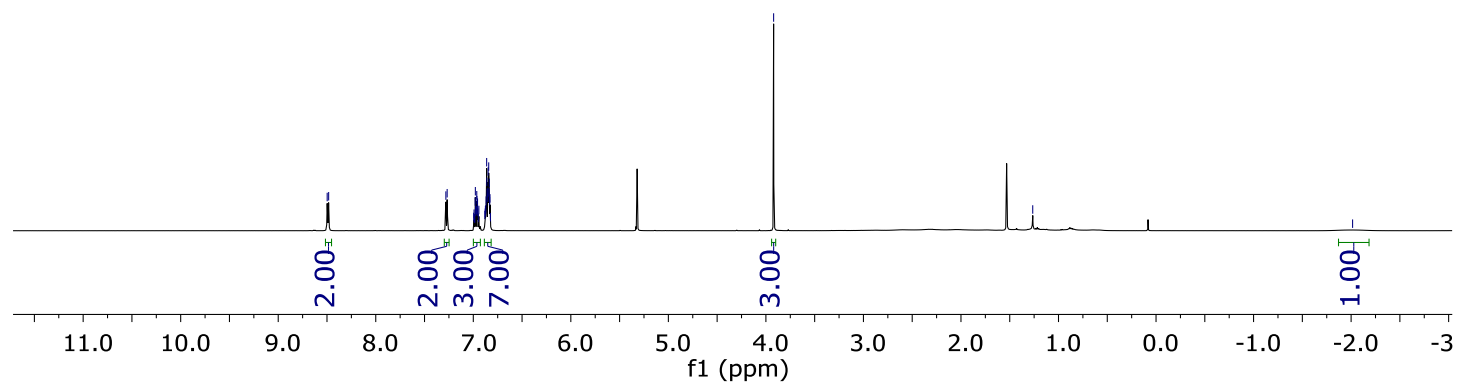




\section{NMR Spectra}

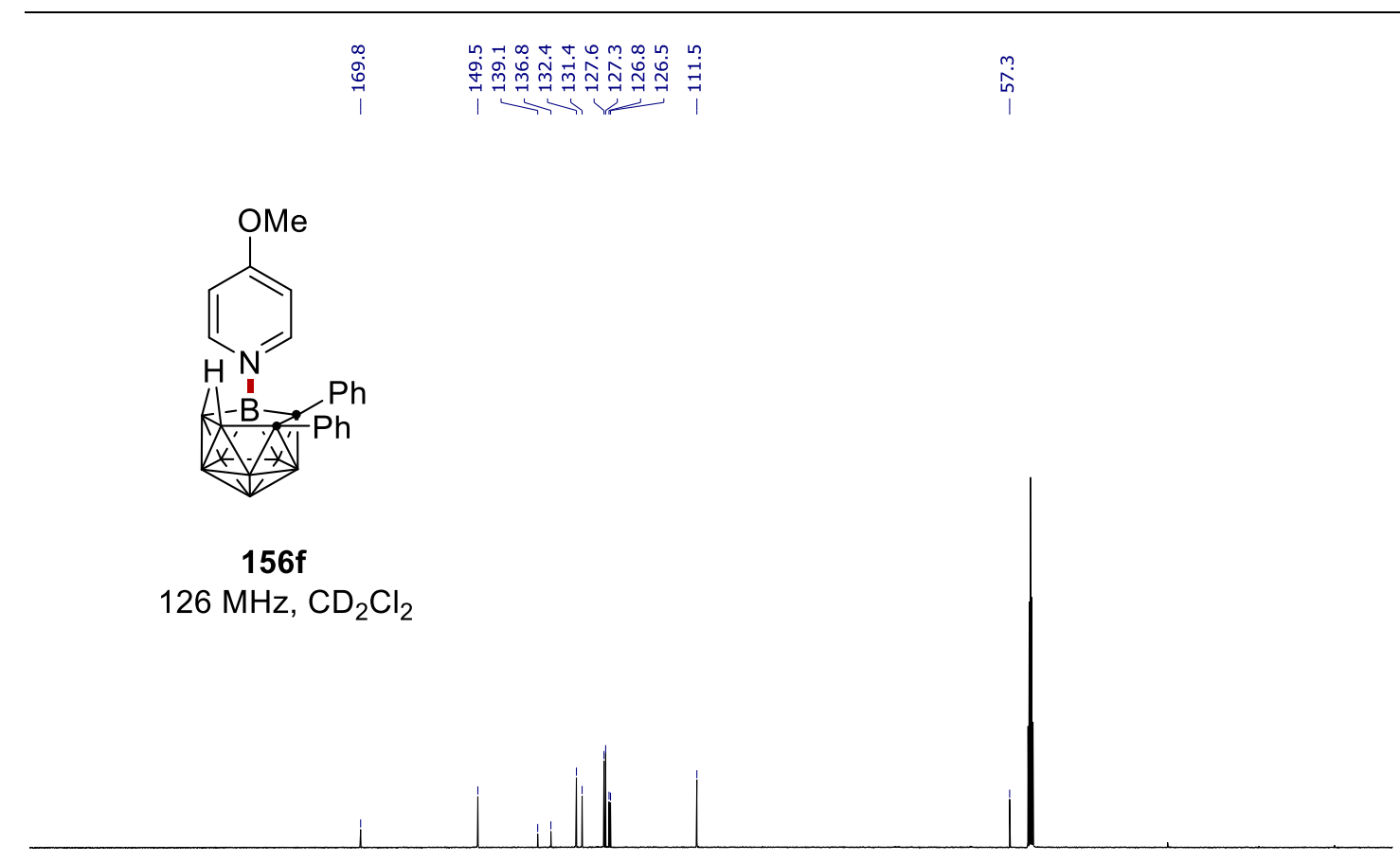

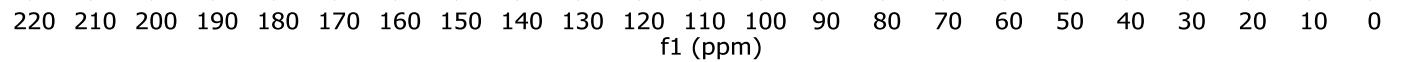

\begin{tabular}{|c|c|c|c|c|c|}
\hline 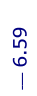 & 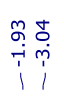 & 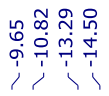 & $\begin{array}{ll}0 & \infty \\
0 & \infty \\
\infty & 0 \\
0 & 0 \\
1 & 1 \\
1 & 1\end{array}$ & 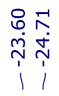 & 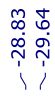 \\
\hline
\end{tabular}

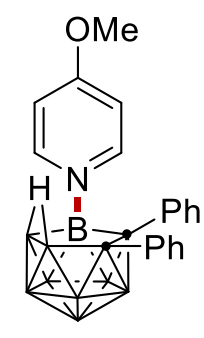

$156 f$

$128 \mathrm{MHz}, \mathrm{CD}_{2} \mathrm{Cl}_{2}$

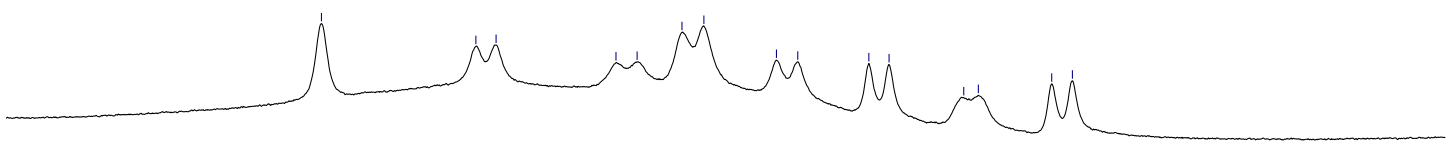

\begin{tabular}{|c|c|c|c|c|c|c|c|c|c|c|c|c|c|c|c|}
\hline 20 & 15 & 10 & 5 & 0 & -5 & -10 & $\begin{array}{l}-15 \\
\mathrm{f} 1 \text { (ppm }\end{array}$ & -20 & -25 & -30 & -35 & -40 & -45 & -50 & -5 \\
\hline
\end{tabular}




\section{NMR Spectra}

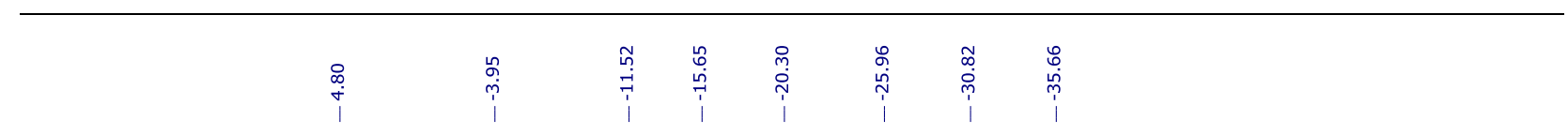

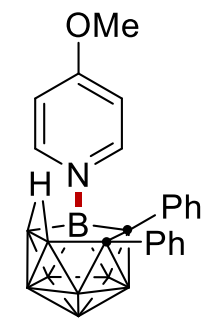

$156 f$

$128 \mathrm{MHz}, \mathrm{CD}_{2} \mathrm{Cl}_{2}$

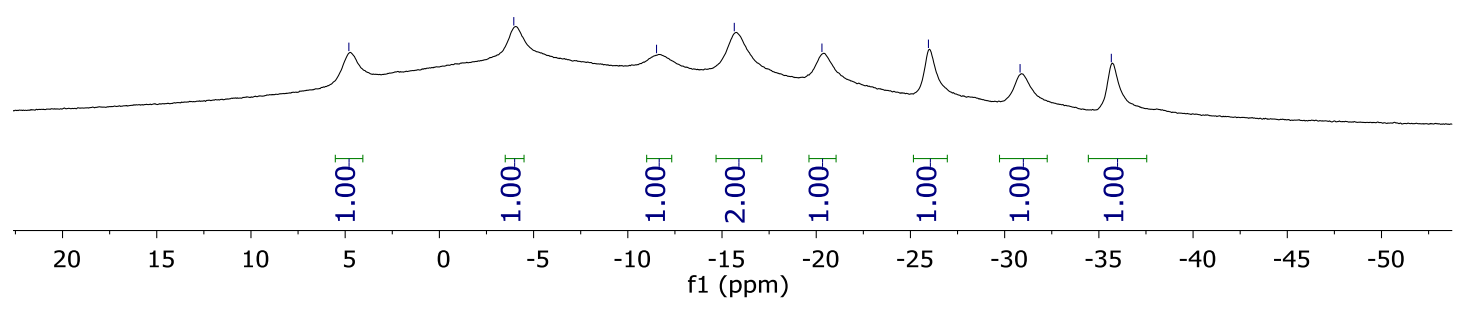

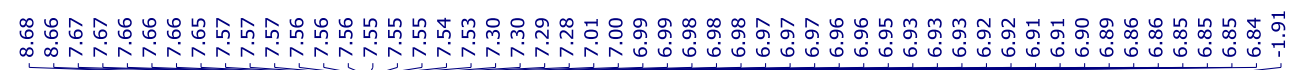

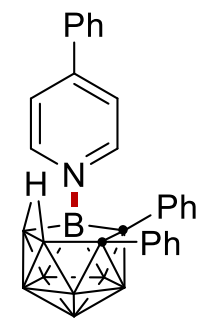

$156 \mathrm{~g}$

$500 \mathrm{MHz}, \mathrm{CD}_{2} \mathrm{Cl}_{2}$

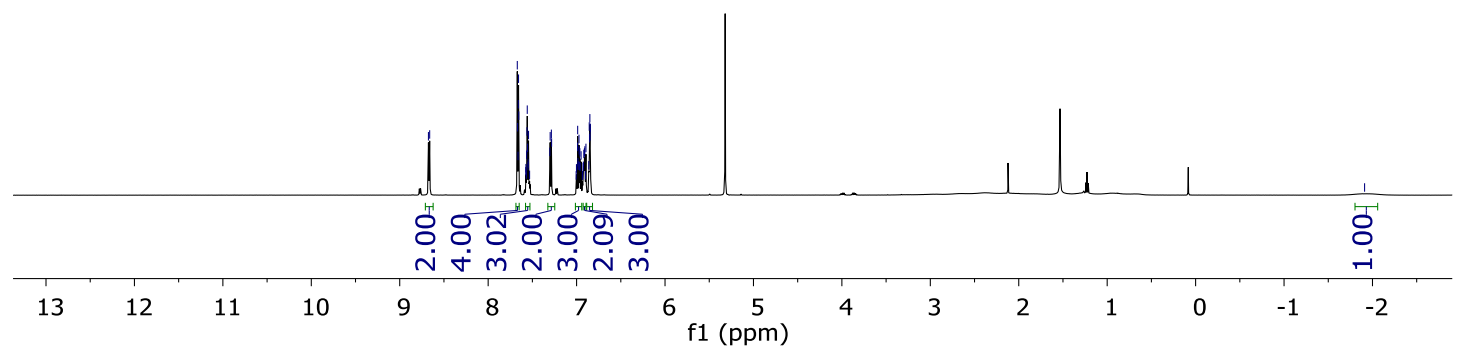




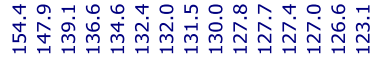

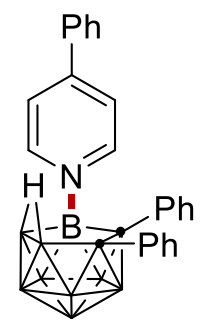

$156 \mathrm{~g}$

$126 \mathrm{MHz}, \mathrm{CD}_{2} \mathrm{Cl}_{2}$

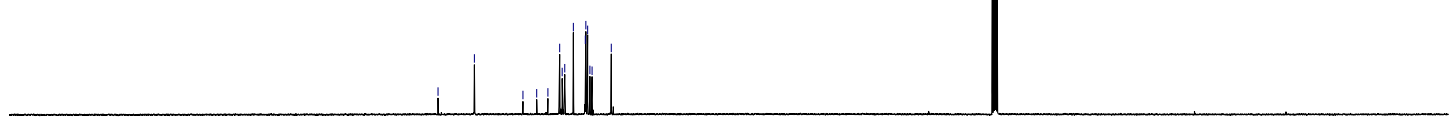

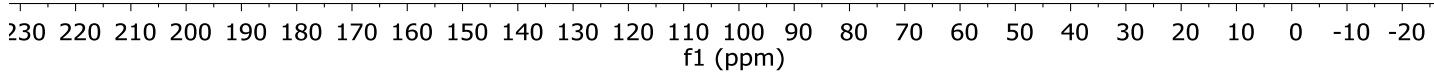

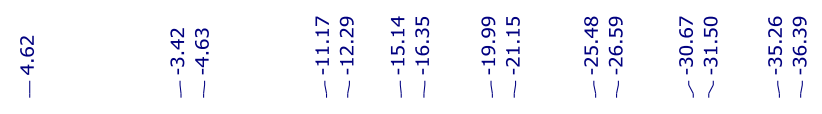

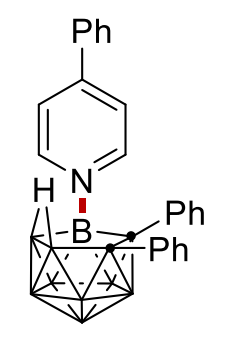

$156 \mathrm{~g}$

$128 \mathrm{MHz}, \mathrm{CD}_{2} \mathrm{Cl}_{2}$

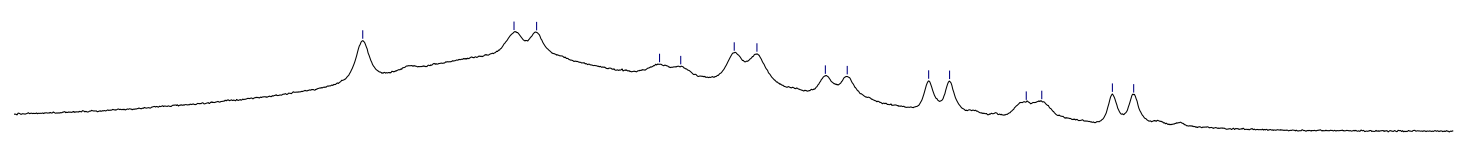

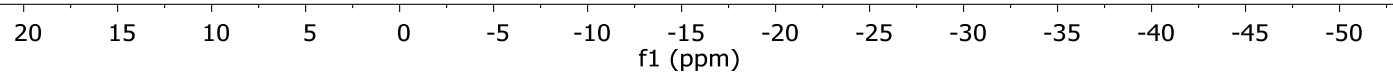




\section{NMR Spectra}

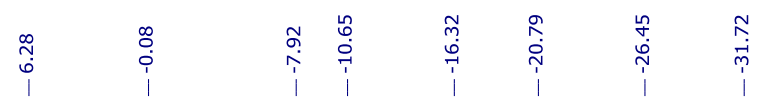

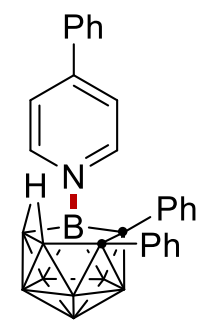

$156 \mathrm{~g}$

$128 \mathrm{MHz}, \mathrm{CD}_{2} \mathrm{Cl}_{2}$
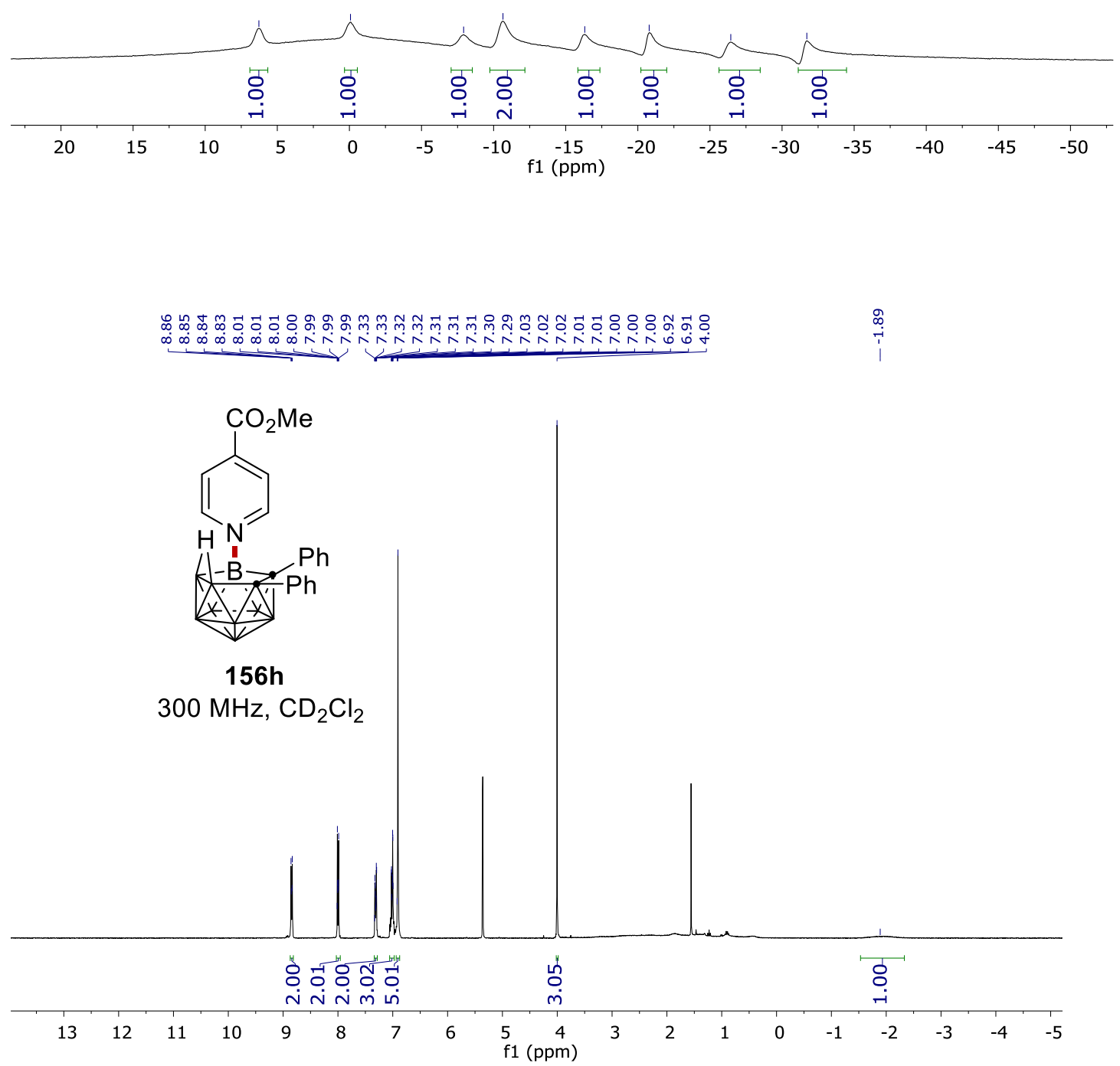

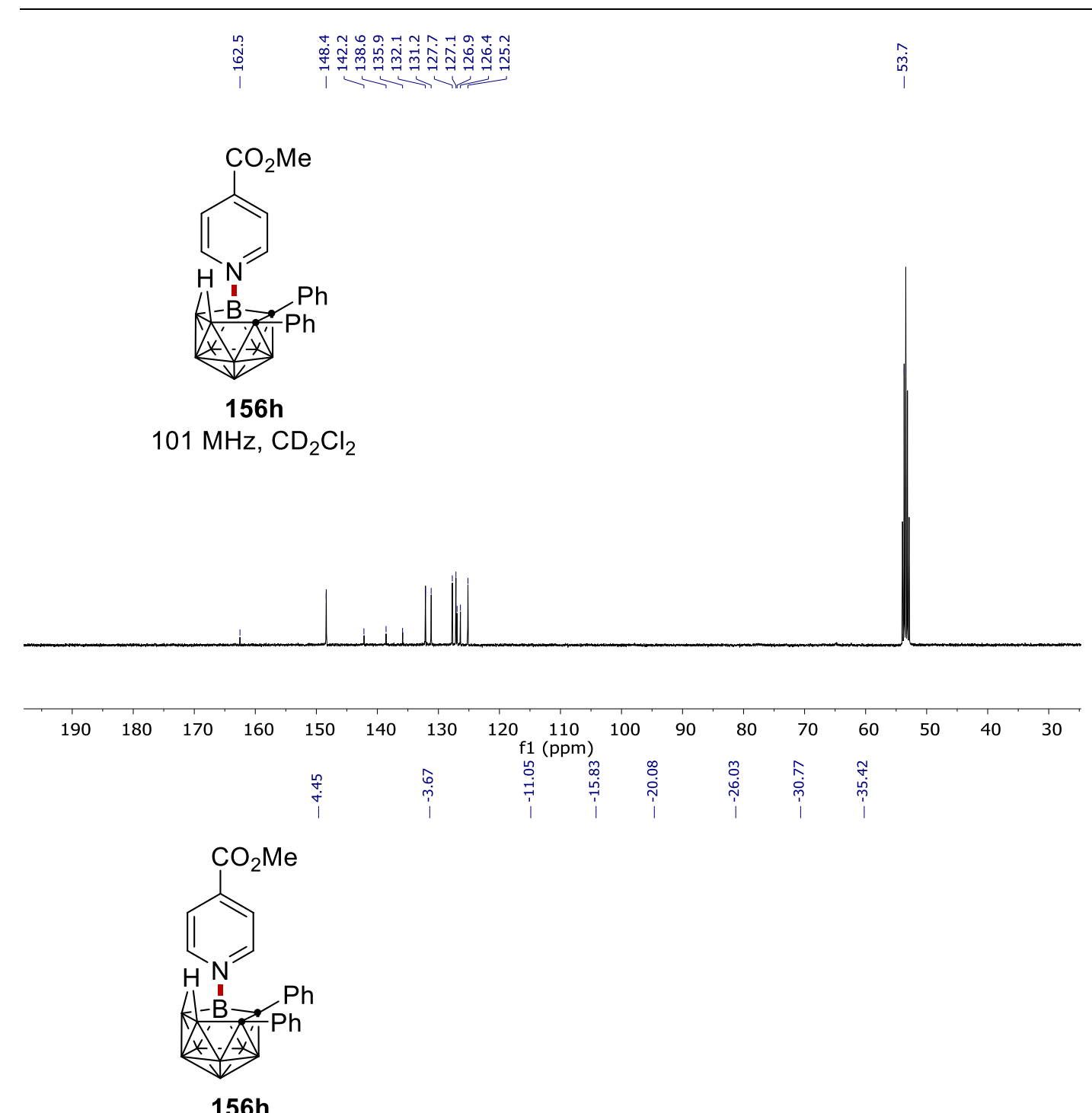

$128 \mathrm{MHz}, \mathrm{CD}_{2} \mathrm{Cl}_{2}$

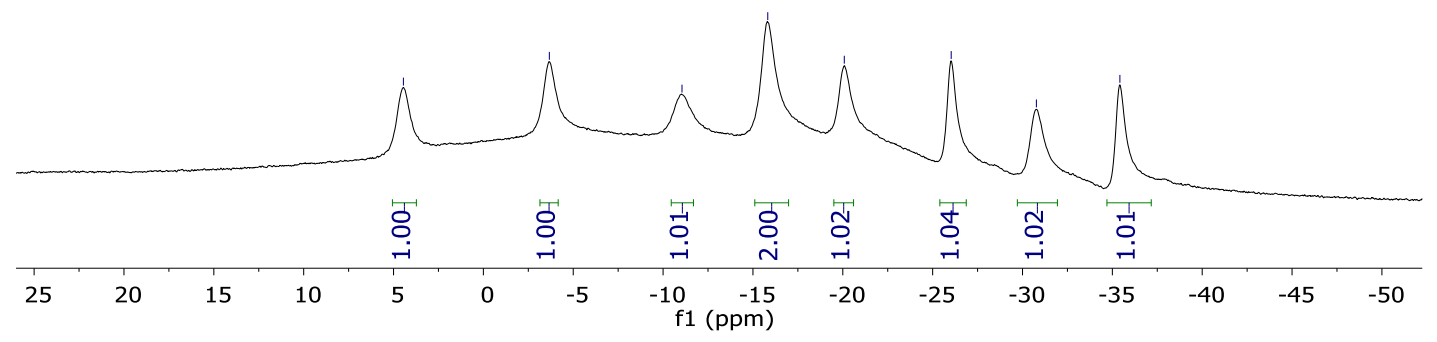




\section{NMR Spectra}

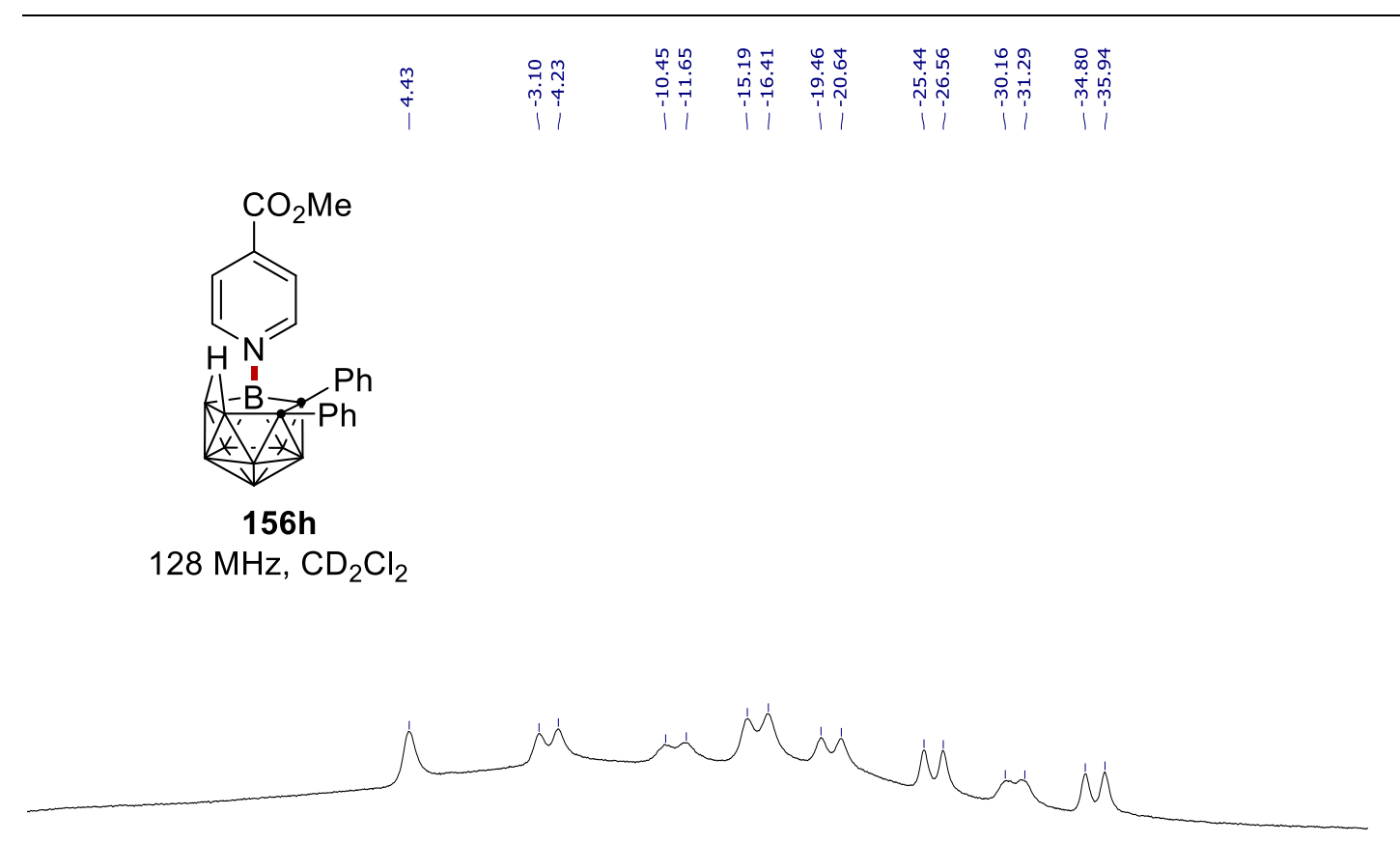

\begin{tabular}{|c|c|c|c|c|c|c|c|c|c|c|c|c|c|c|c|}
\hline 25 & 20 & 15 & 10 & 5 & 0 & -5 & $\begin{array}{l}-10 \\
\text { f1 }\end{array}$ & m) & -20 & -25 & -30 & -35 & -40 & -45 & -50 \\
\hline
\end{tabular}

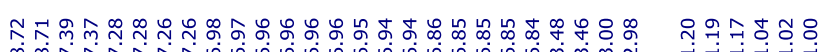

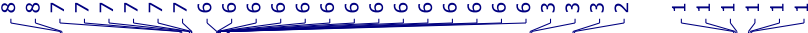

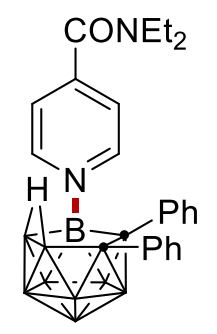

$156 i$

$400 \mathrm{MHz}, \mathrm{CD}_{2} \mathrm{Cl}_{2}$

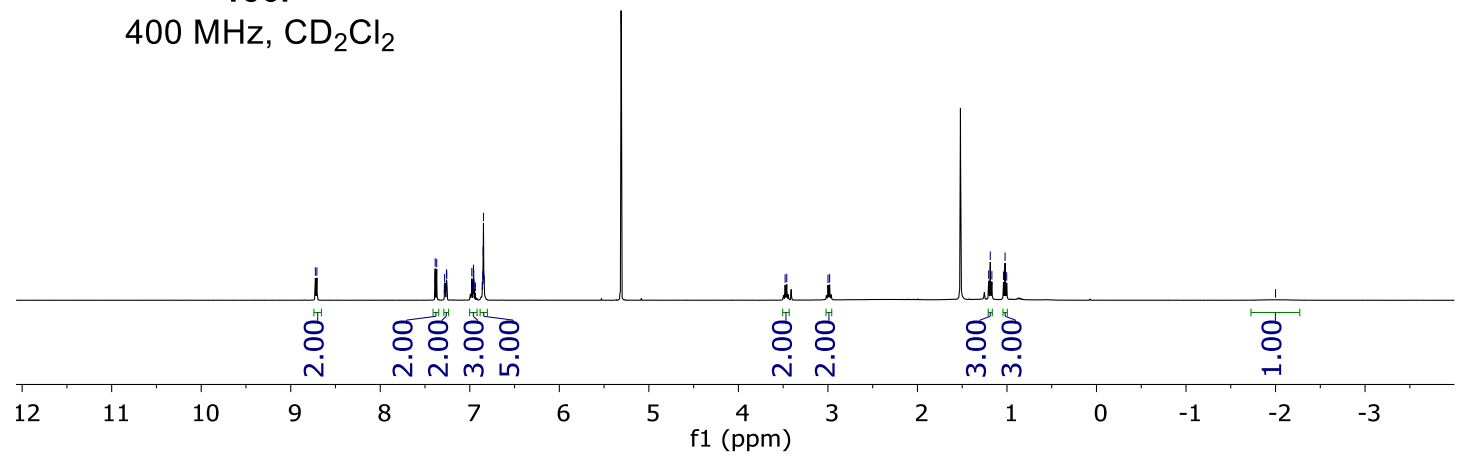


NMR Spectra

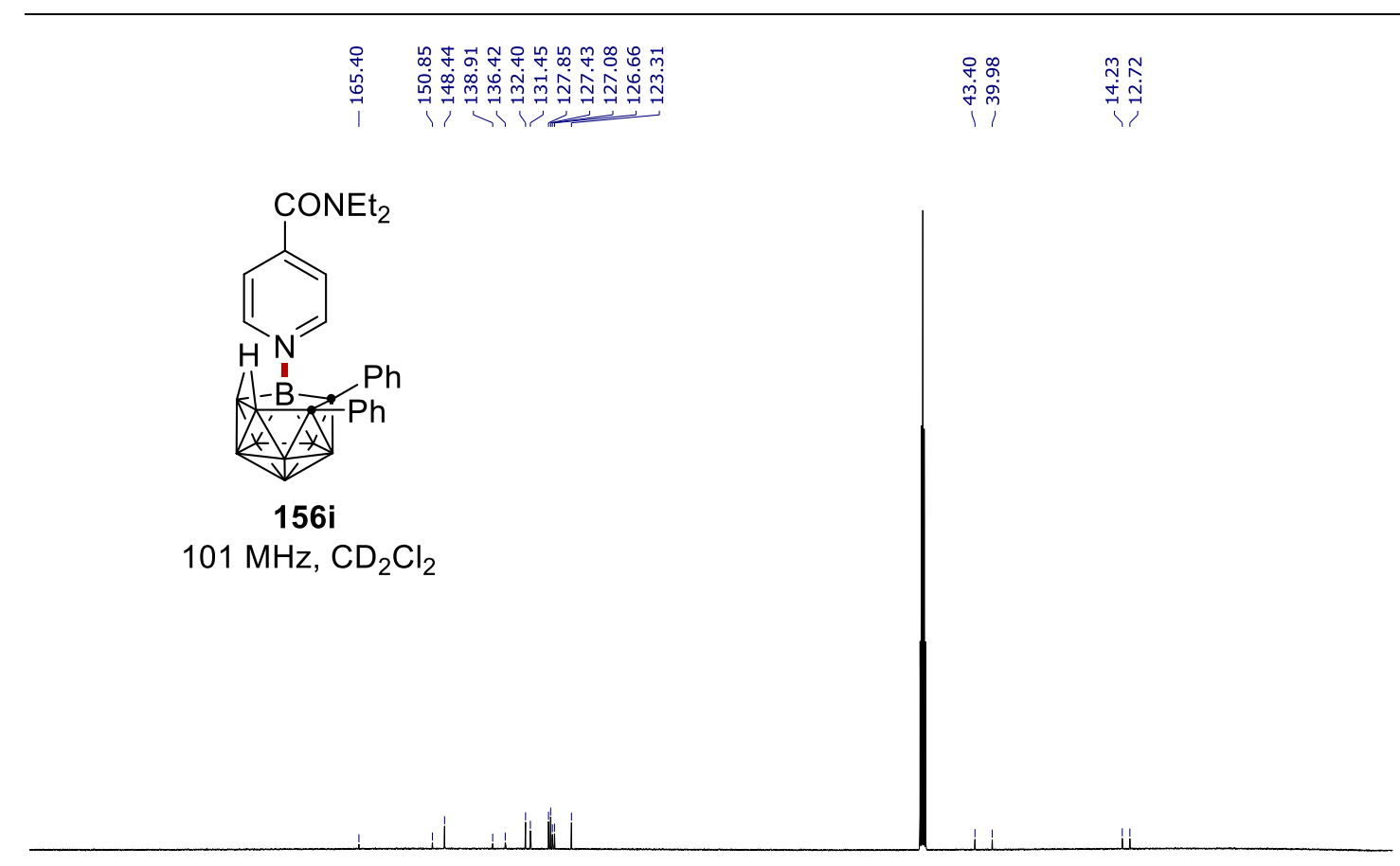

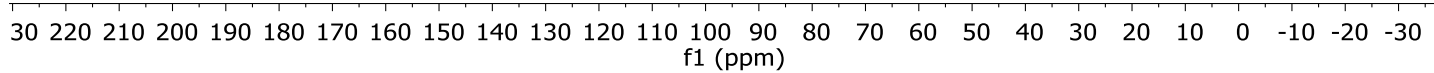

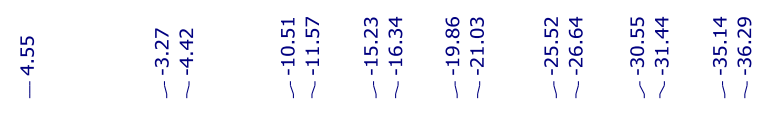

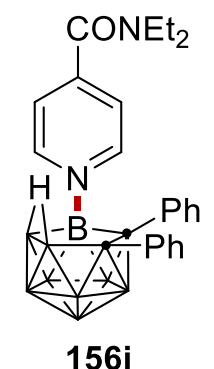

$128 \mathrm{MHz}, \mathrm{CD}_{2} \mathrm{Cl}_{2}$

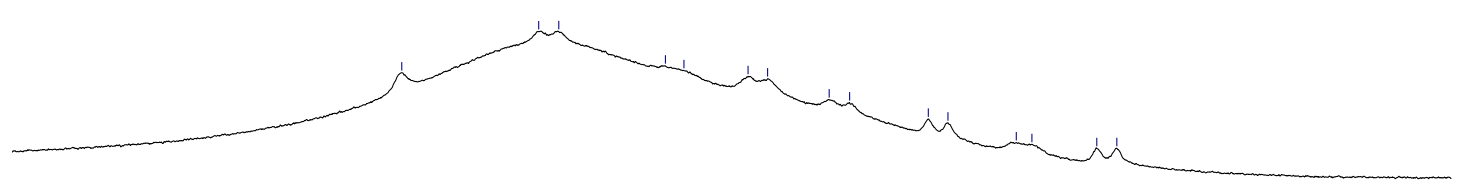

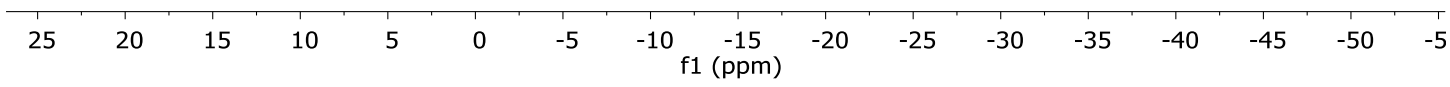




\section{NMR Spectra}

\begin{tabular}{|c|c|c|c|c|}
\hline ợ & $\begin{array}{l}\dot{\Phi} \\
\stackrel{\oplus}{i} \\
i\end{array}$ & ָ̦ & $\begin{array}{c}\infty \\
\stackrel{\infty}{2} \\
\stackrel{2}{1} \\
i\end{array}$ & ? \\
\hline
\end{tabular}

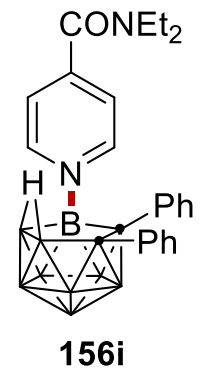

$128 \mathrm{MHz}, \mathrm{CD}_{2} \mathrm{Cl}_{2}$

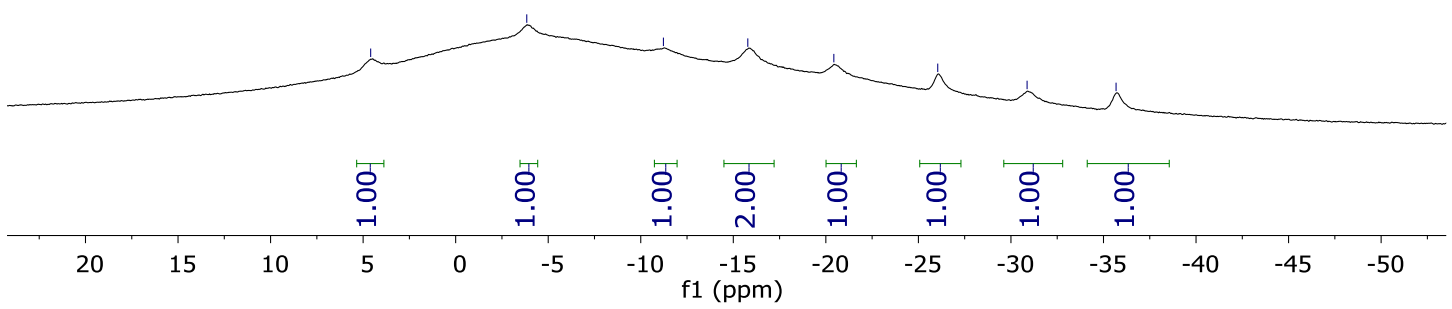

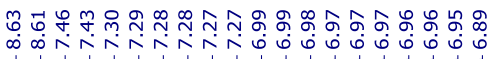

o

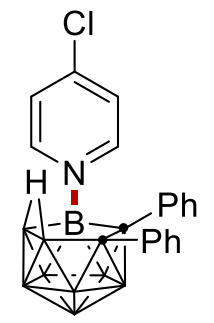

156j

$300 \mathrm{MHz}, \mathrm{CDCl}_{3}$

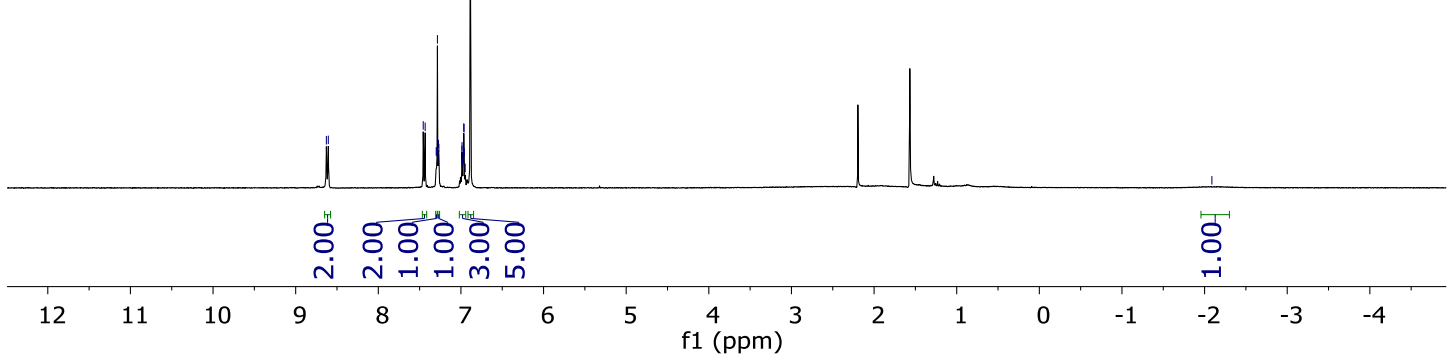




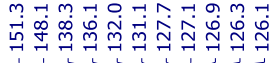

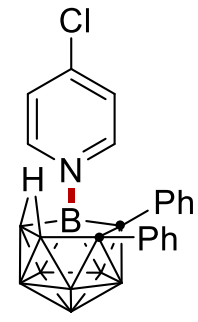

156j

$101 \mathrm{MHz}, \mathrm{CDCl}_{3}$
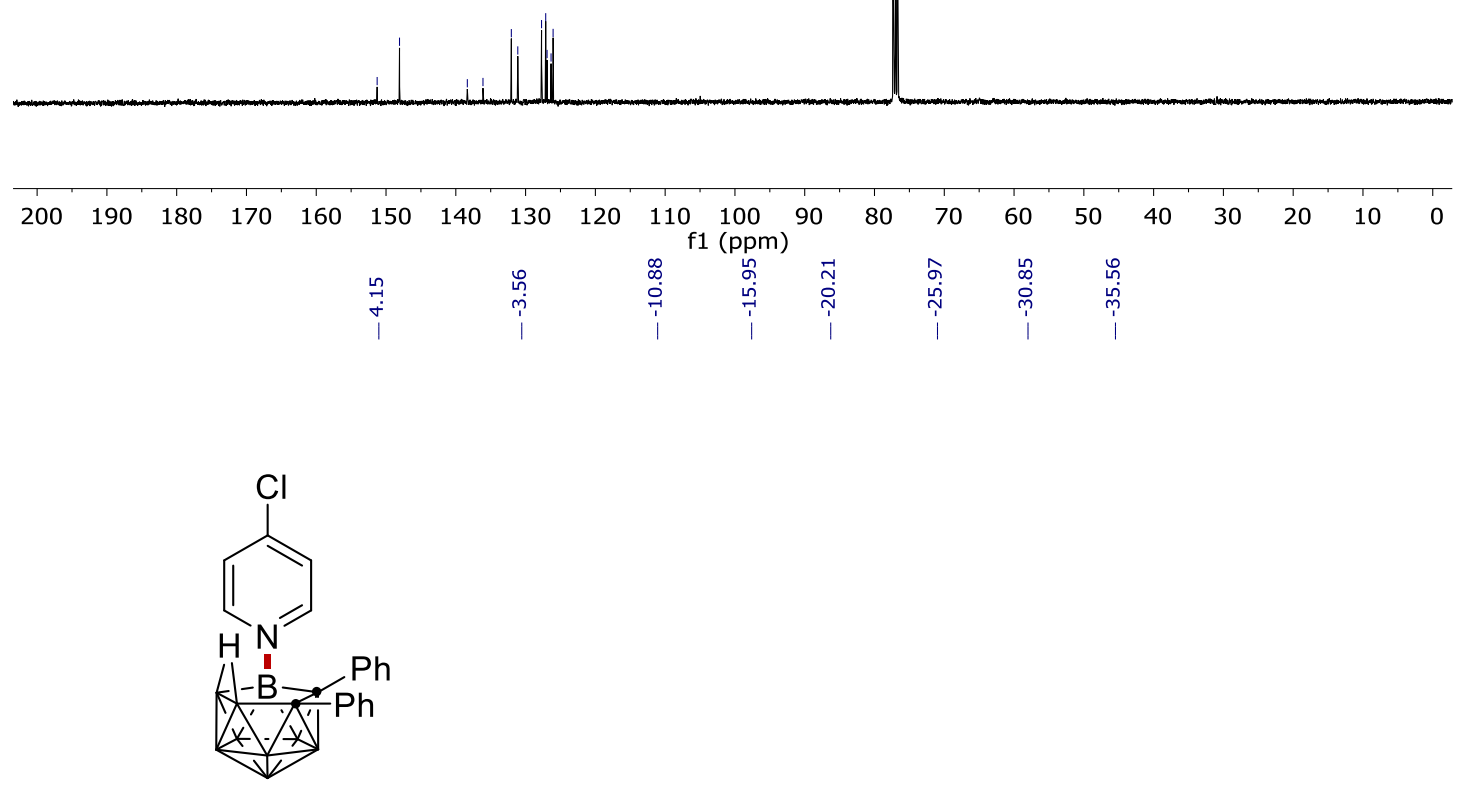

156j

$128 \mathrm{MHz}, \mathrm{CDCl}_{3}$

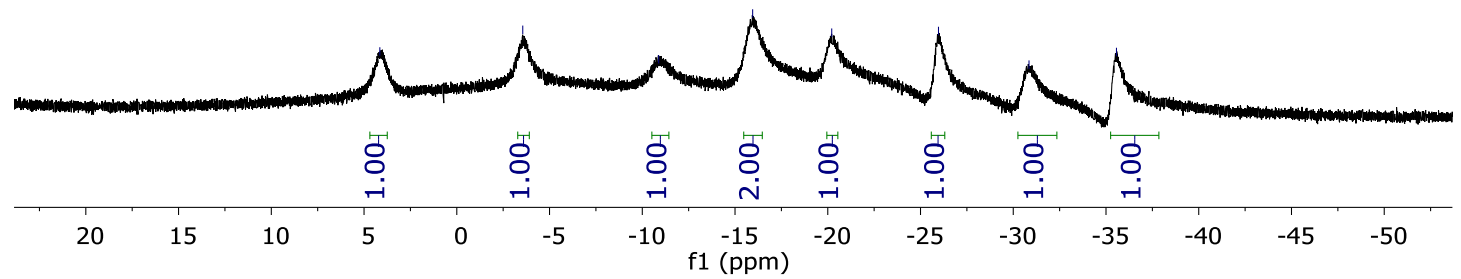




\section{NMR Spectra}
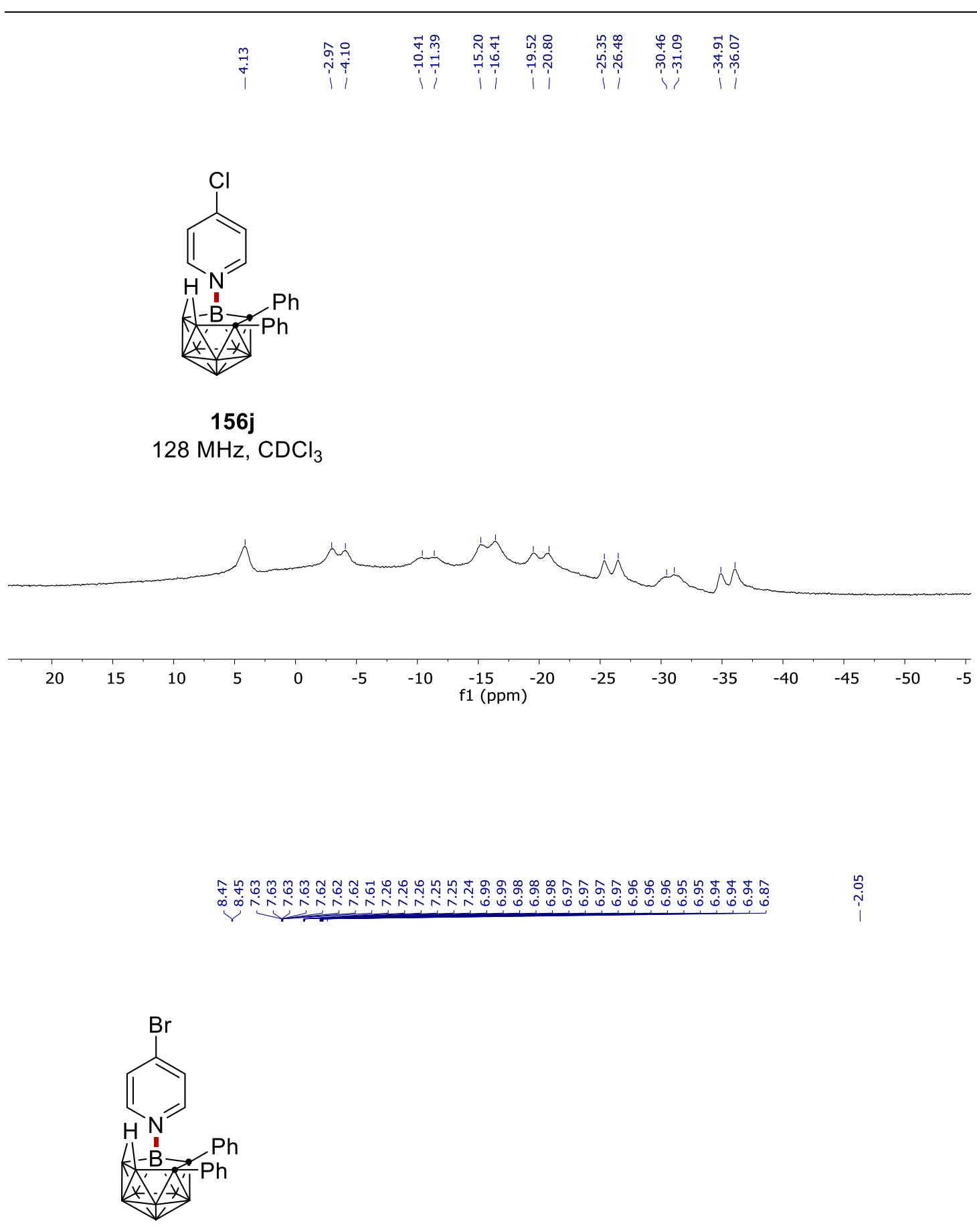

$156 \mathrm{k}$

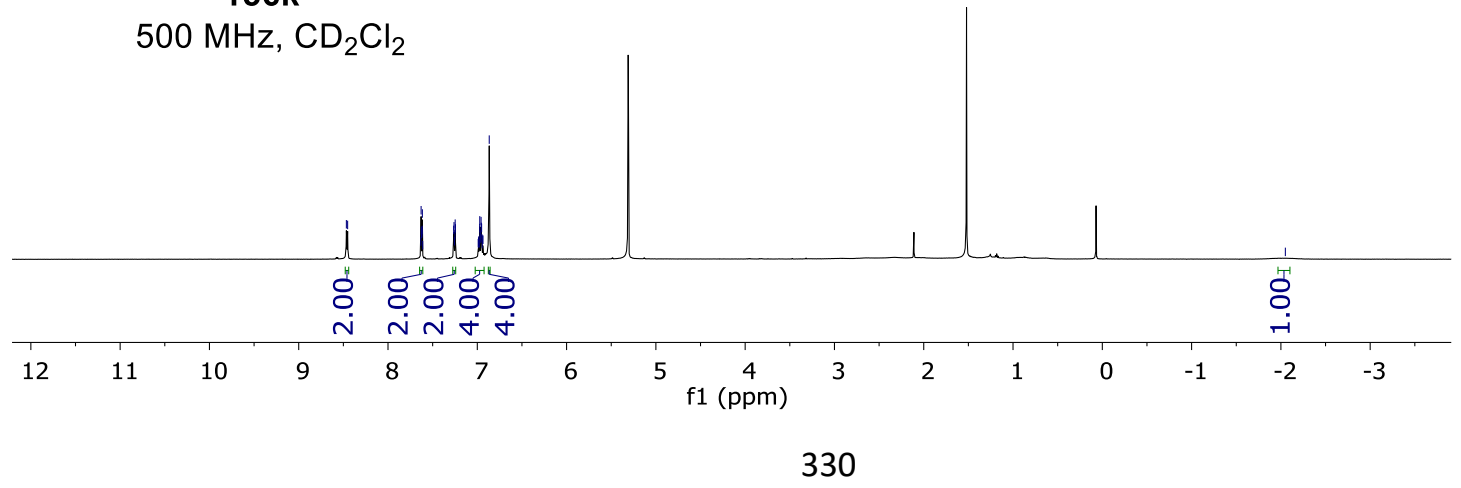



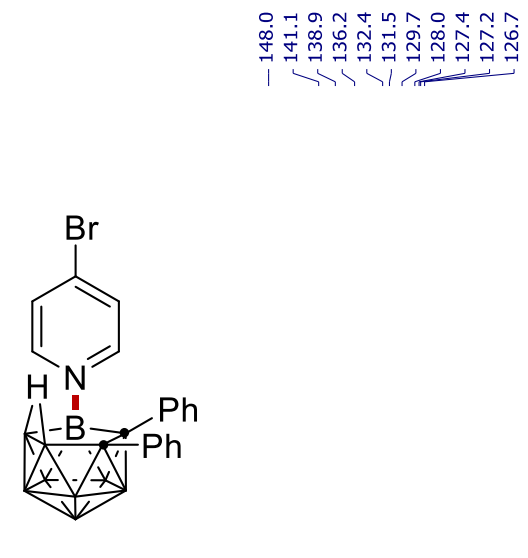

$156 \mathrm{k}$

$126 \mathrm{MHz}, \mathrm{CD}_{2} \mathrm{Cl}_{2}$
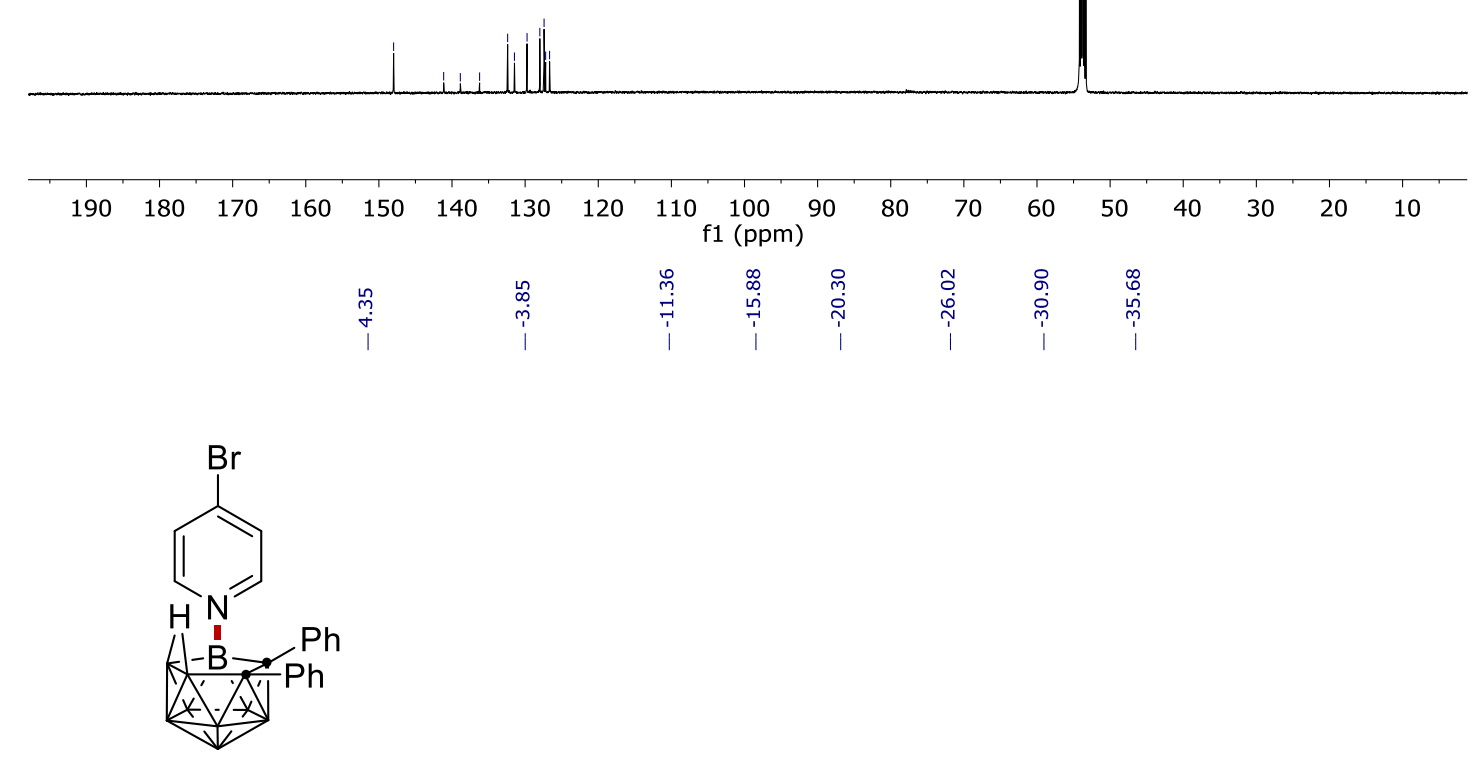

156k

$128 \mathrm{MHz}, \mathrm{CD}_{2} \mathrm{Cl}_{2}$

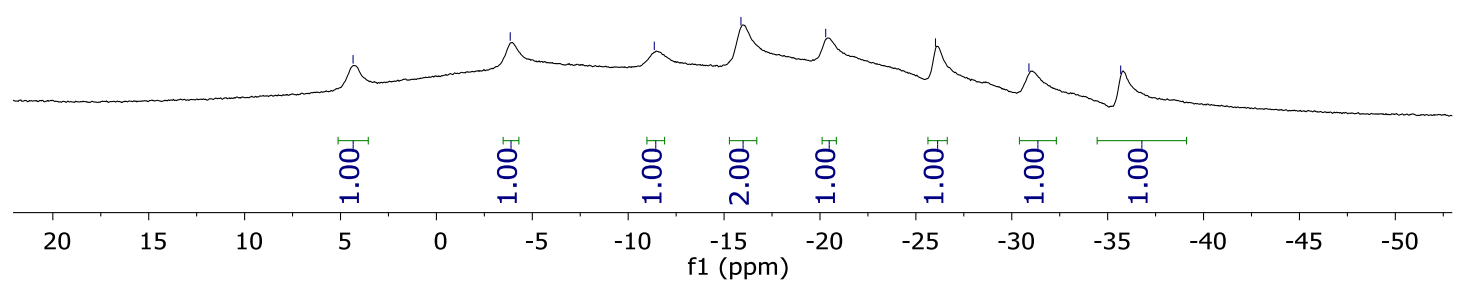




\section{NMR Spectra}
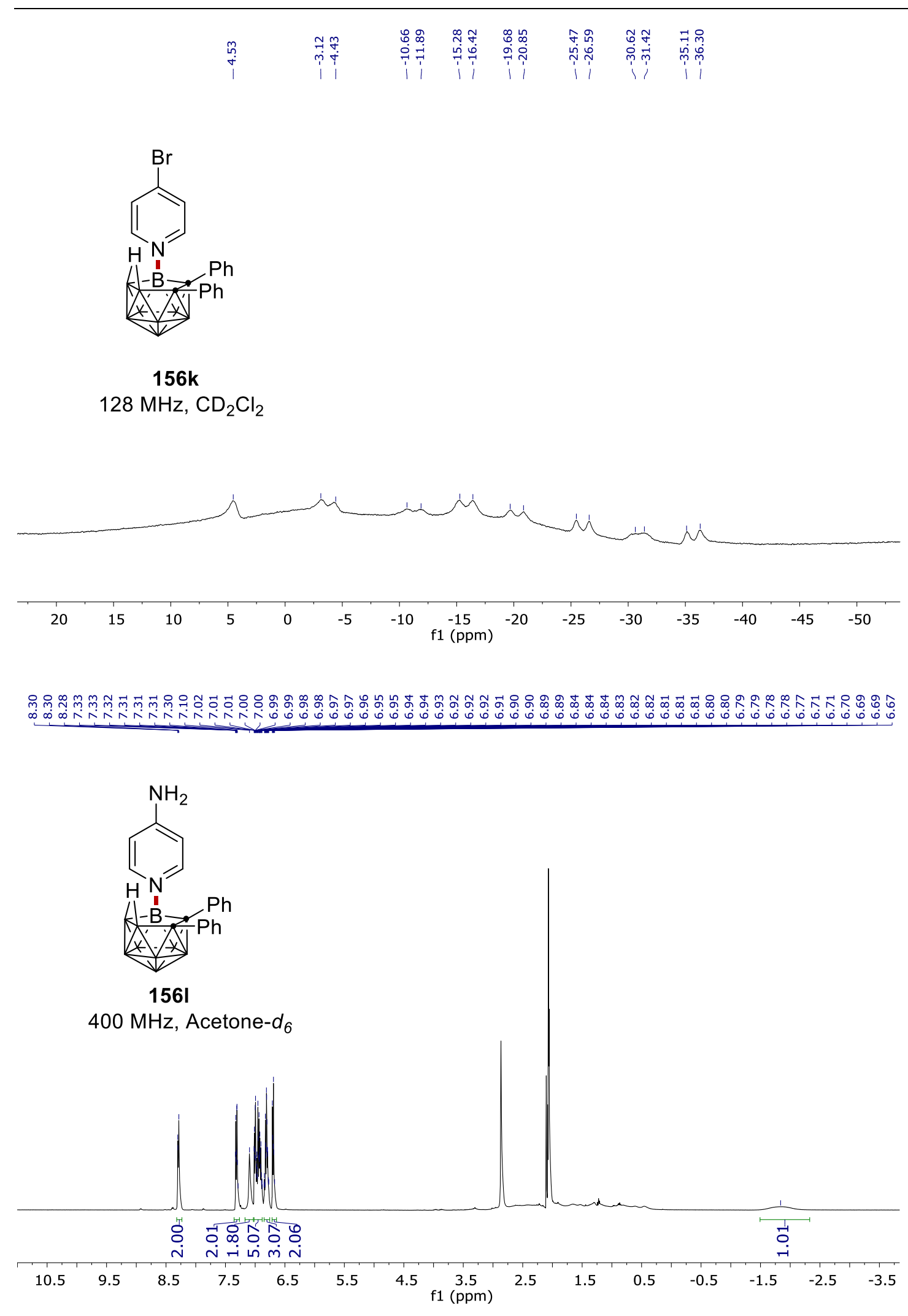

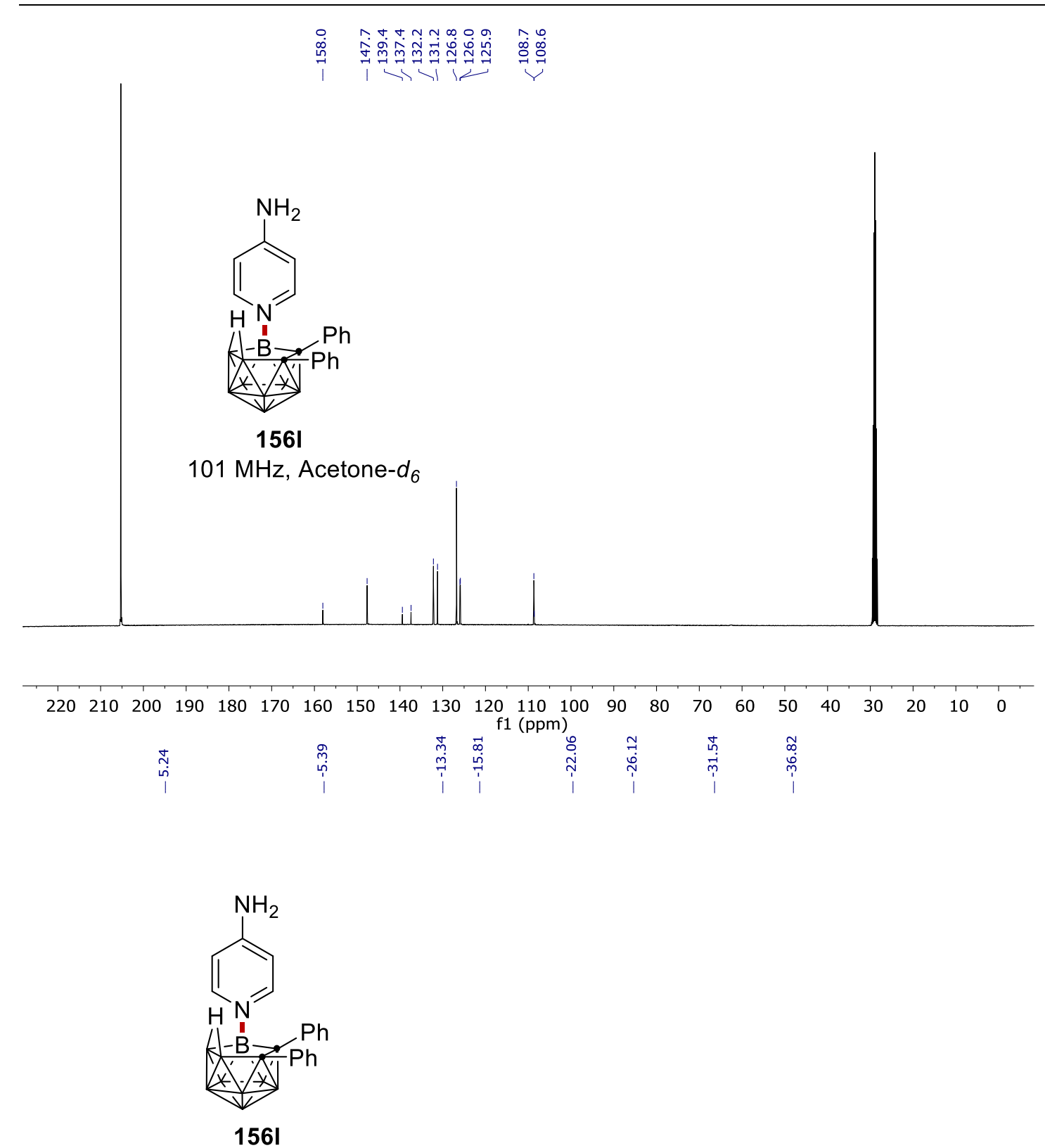

$96 \mathrm{MHz}$, Acetone- $d_{6}$

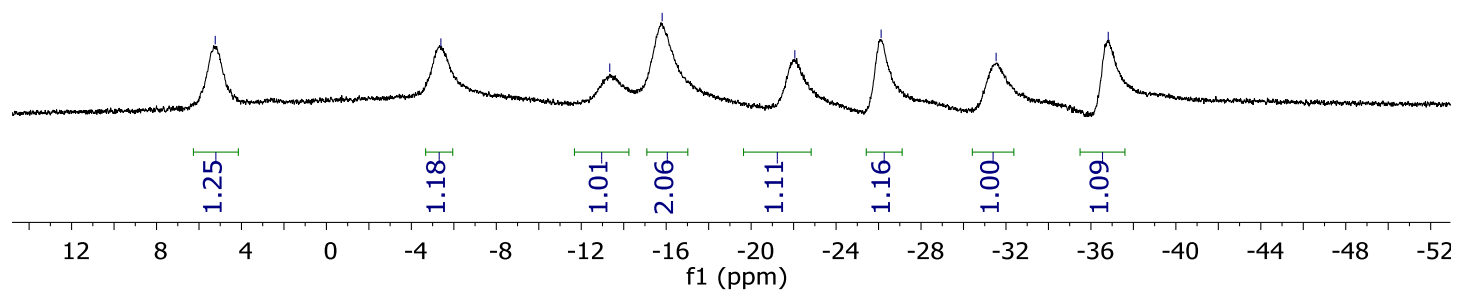




\section{NMR Spectra}

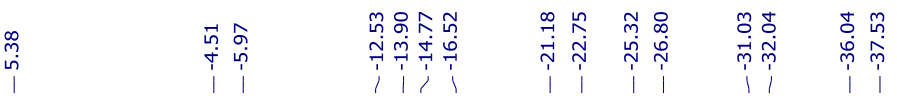

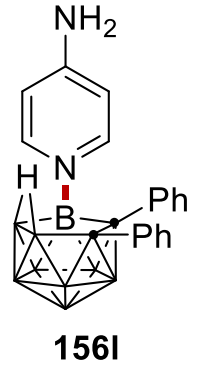

$96 \mathrm{MHz}$, Acetone- $d_{6}$

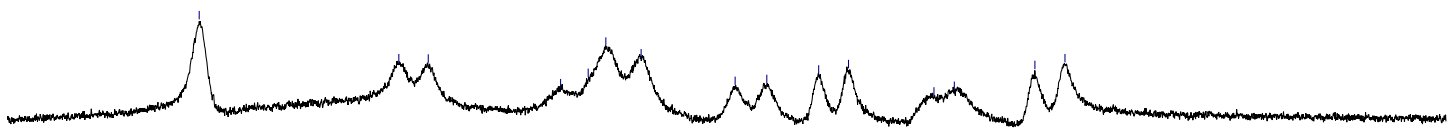

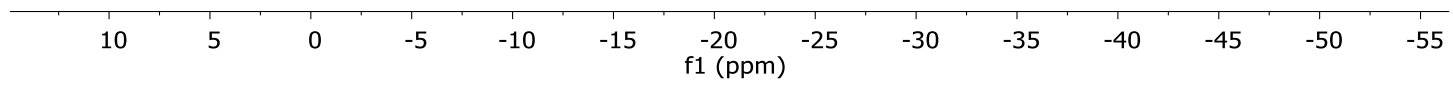

\section{mo}

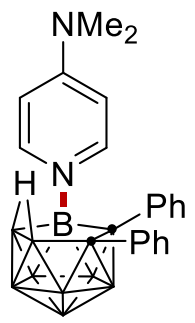

$156 \mathrm{~m}$

$300 \mathrm{MHz}, \mathrm{DMSO}-d_{6}$

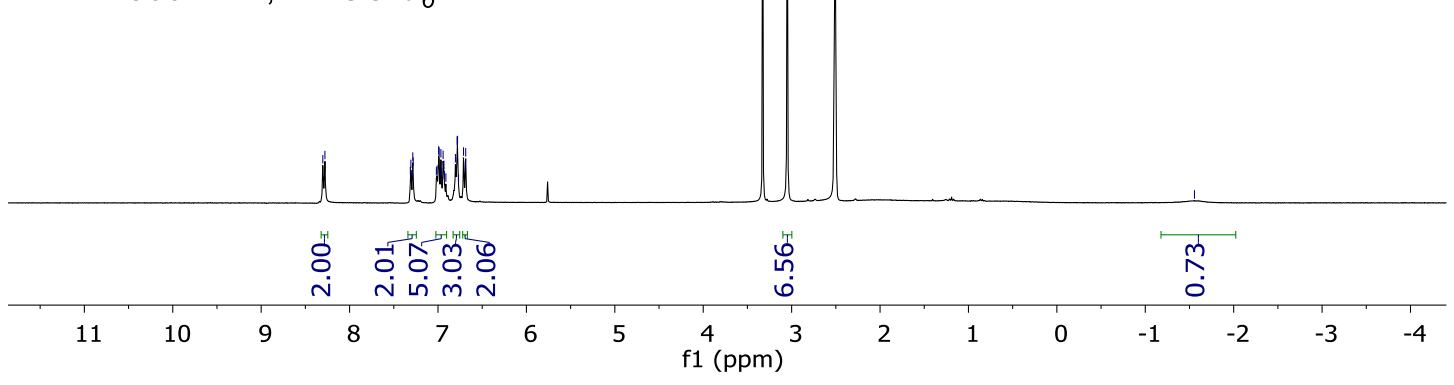



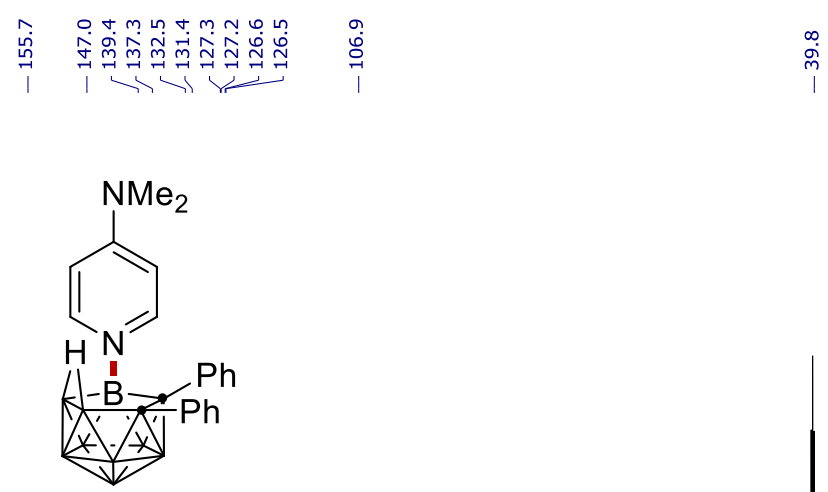

$156 \mathrm{~m}$

$101 \mathrm{MHz}, \mathrm{DMSO}-d_{6}$

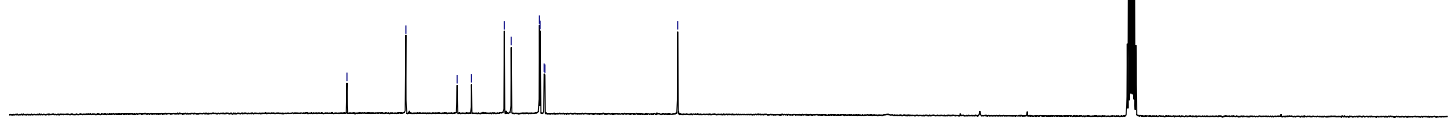

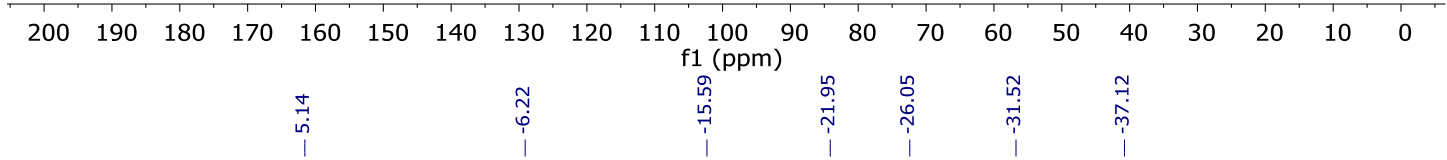

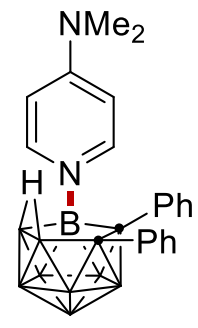

$156 \mathrm{~m}$

$128 \mathrm{MHz}, \mathrm{DMSO}^{-d_{6}}$

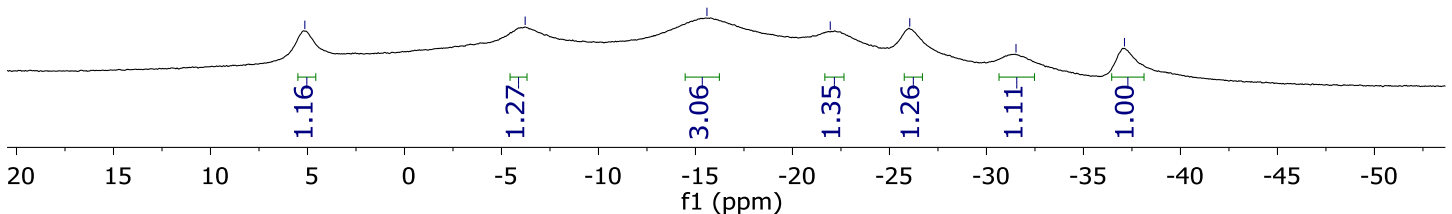




\section{NMR Spectra}

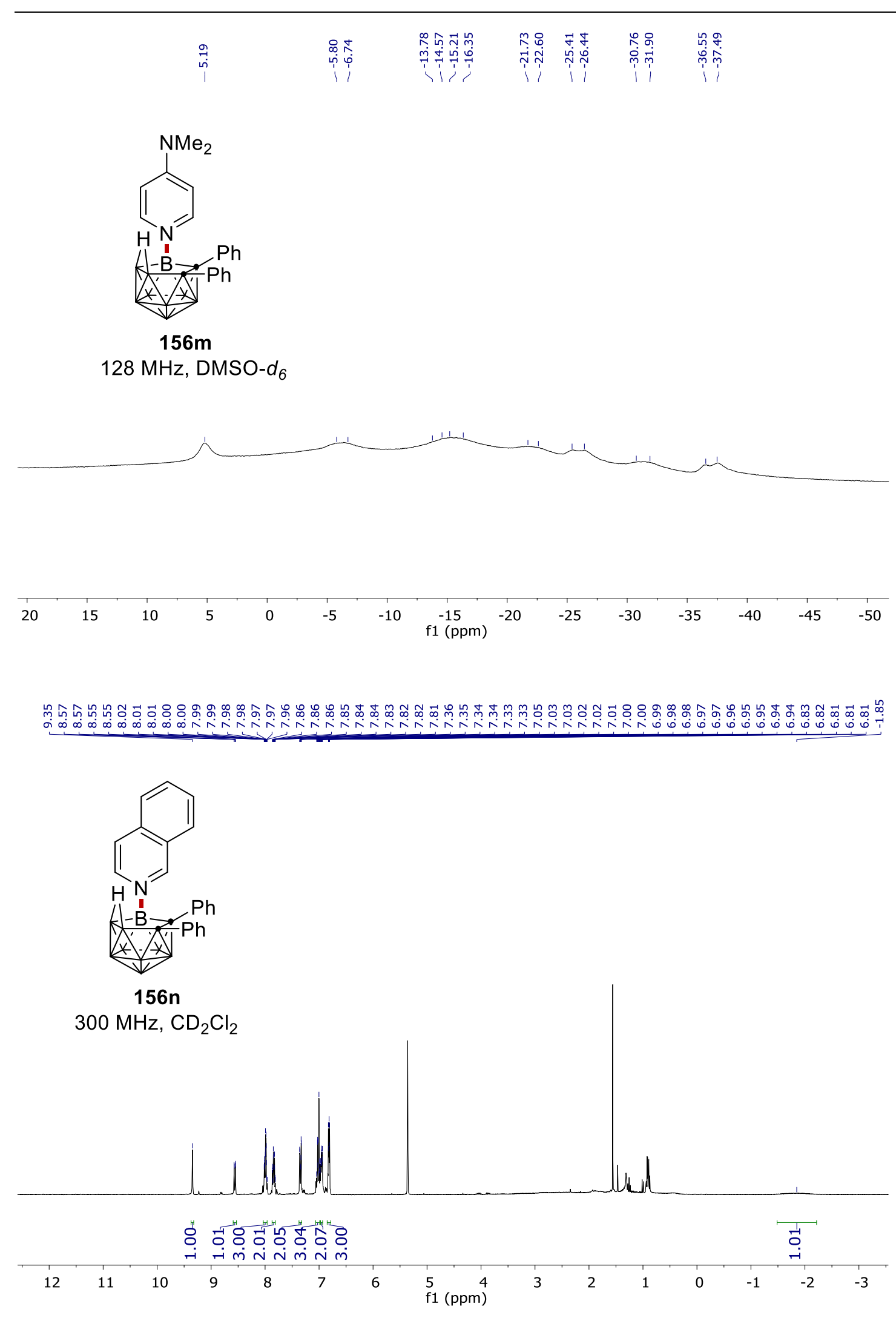




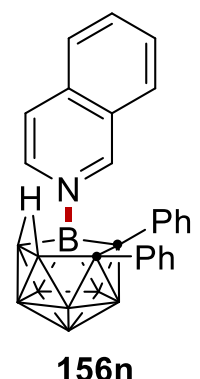

$101 \mathrm{MHz}, \mathrm{CD}_{2} \mathrm{Cl}_{2}$

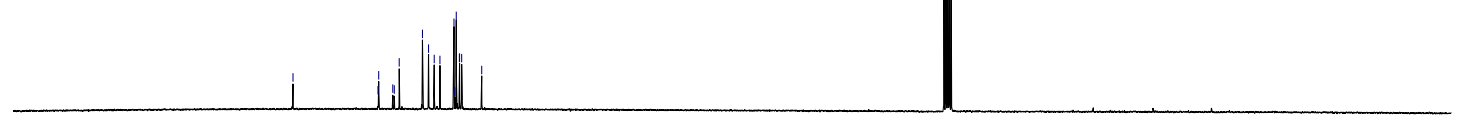

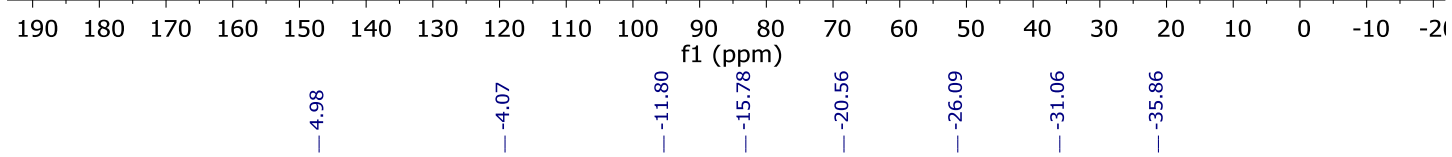

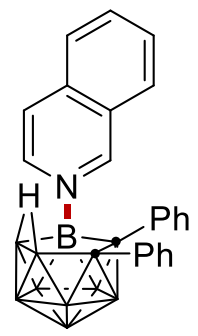

156n

$128 \mathrm{MHz}, \mathrm{CD}_{2} \mathrm{Cl}_{2}$

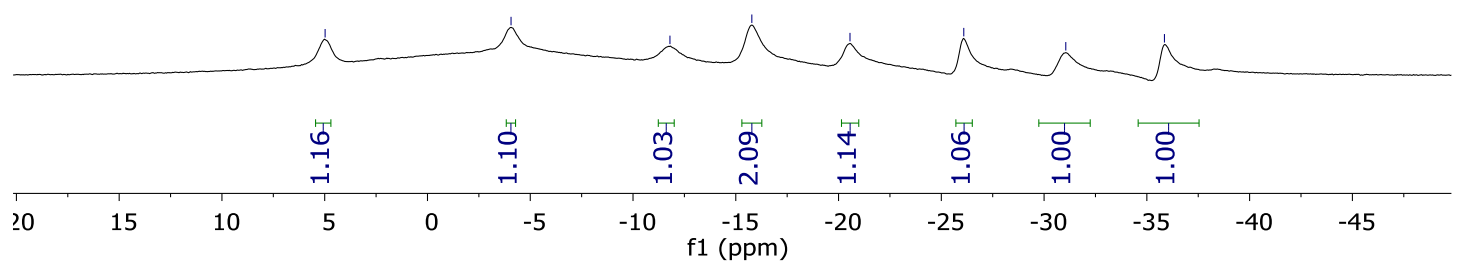




\section{NMR Spectra}

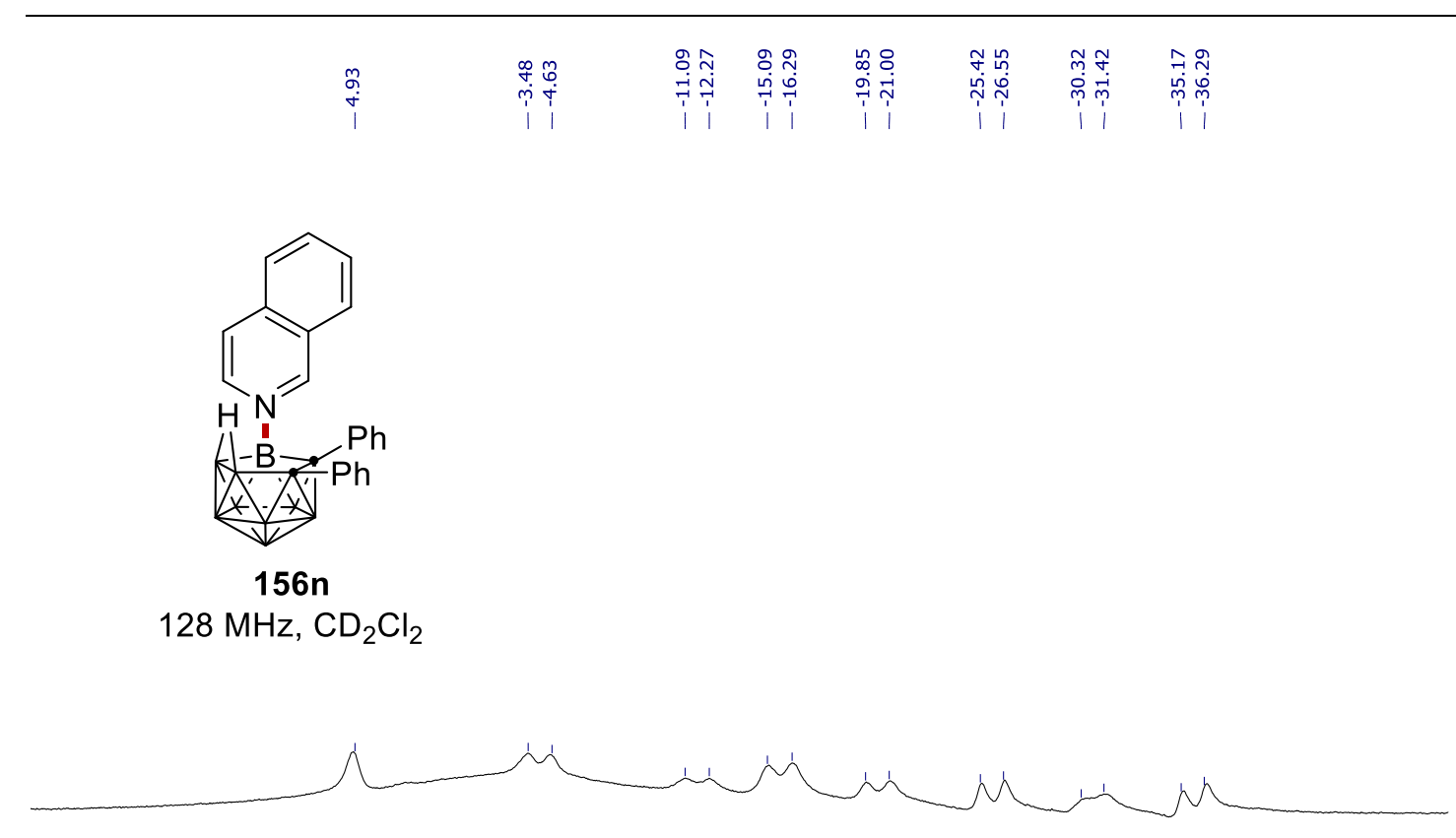

$\begin{array}{llllllllllllllllll}20 & 16 & 12 & 8 & 4 & 0 & -4 & -8 & -12 & -16 & -20 & -24 & -28 & -32 & -36 & -40 & -44 & -4\end{array}$

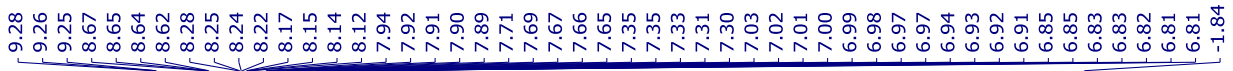

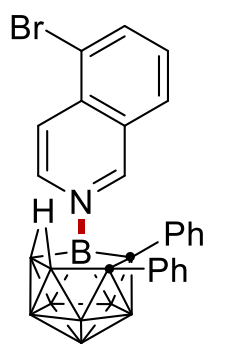

1560

$400 \mathrm{MHz}, \mathrm{CD}_{2} \mathrm{Cl}_{2}$

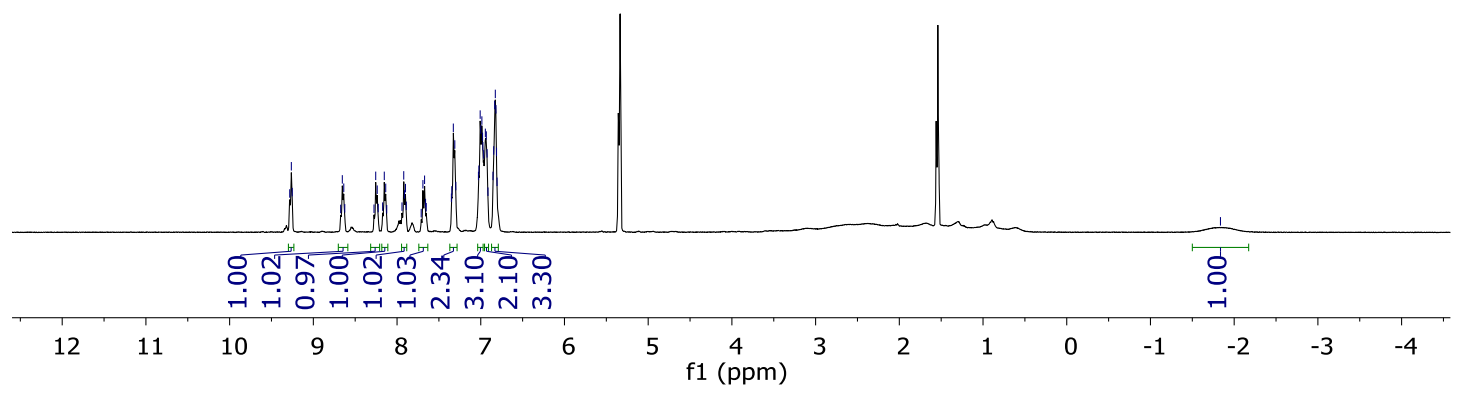




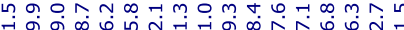

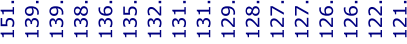 \\ $1 \mathrm{M}$}

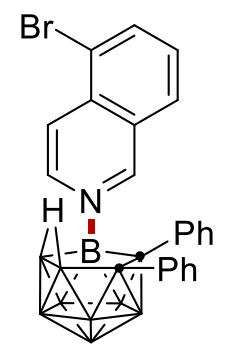

1560

$101 \mathrm{MHz}, \mathrm{CD}_{2} \mathrm{Cl}_{2}$
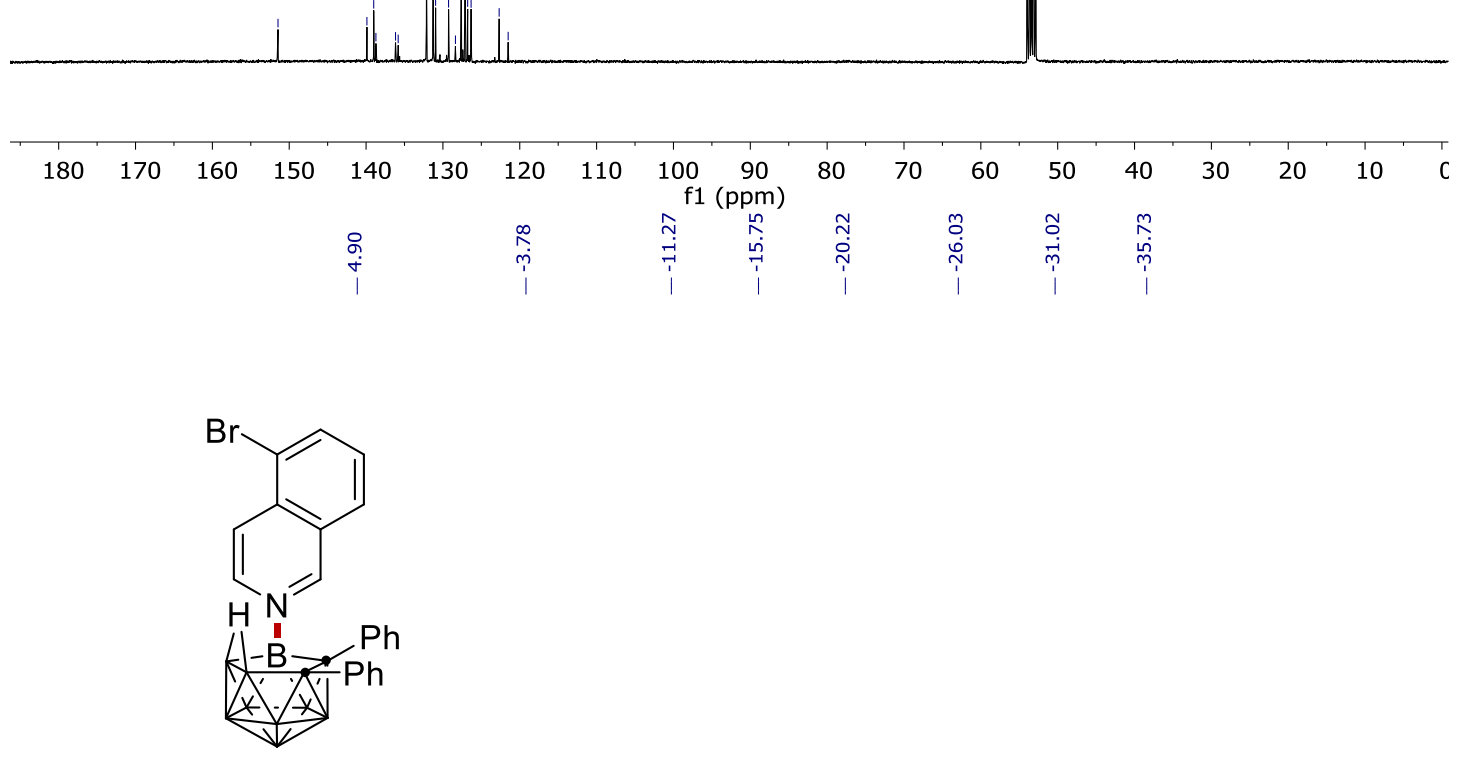

156o

$96 \mathrm{MHz}, \mathrm{CD}_{2} \mathrm{Cl}_{2}$

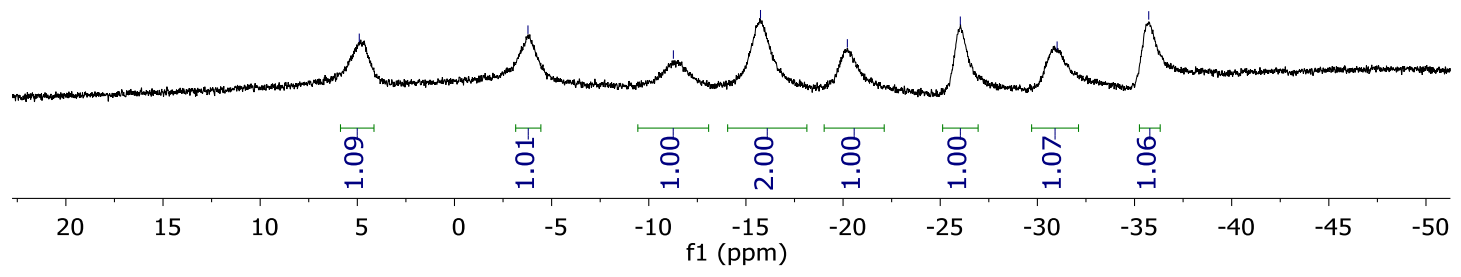




\section{NMR Spectra}
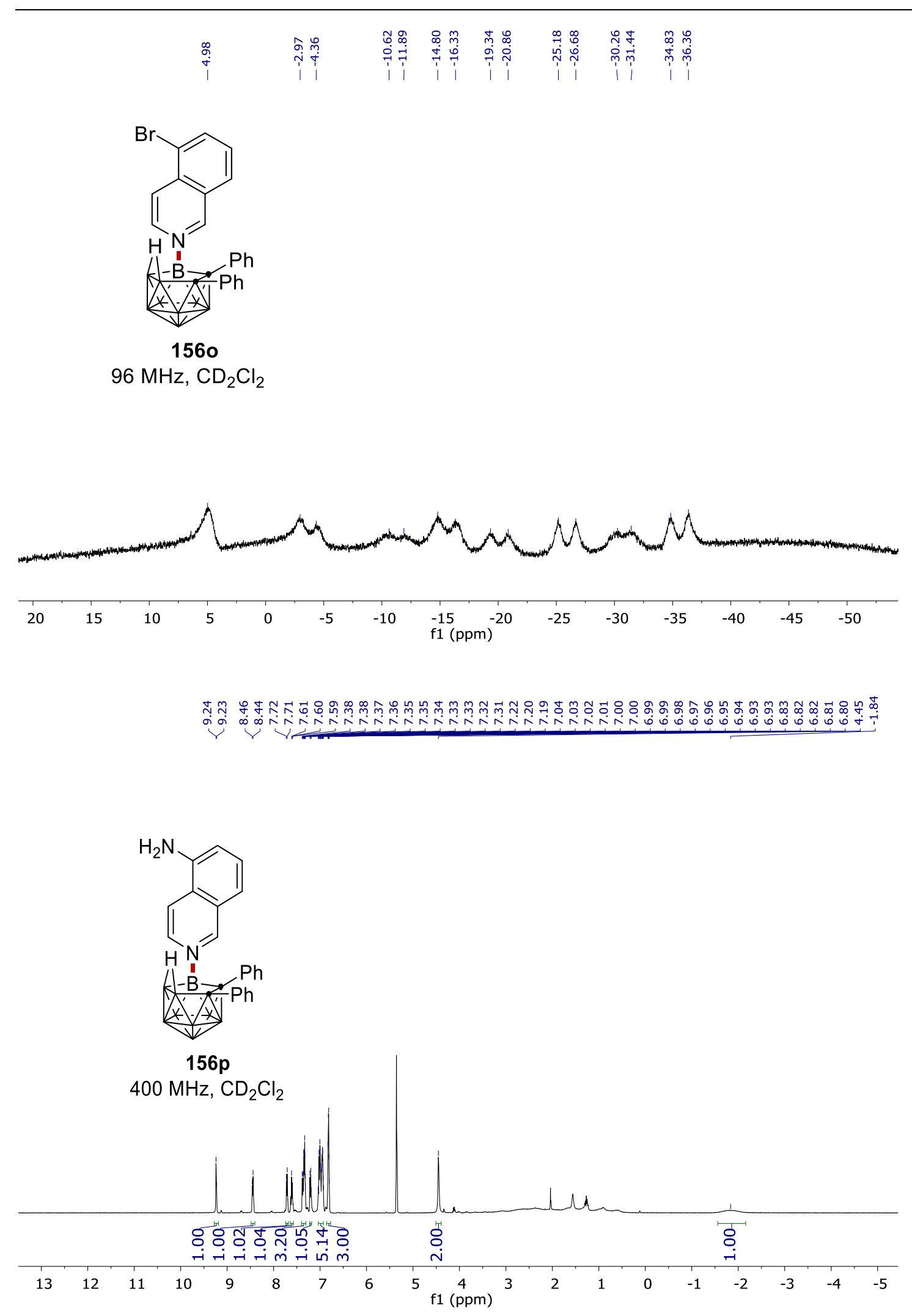

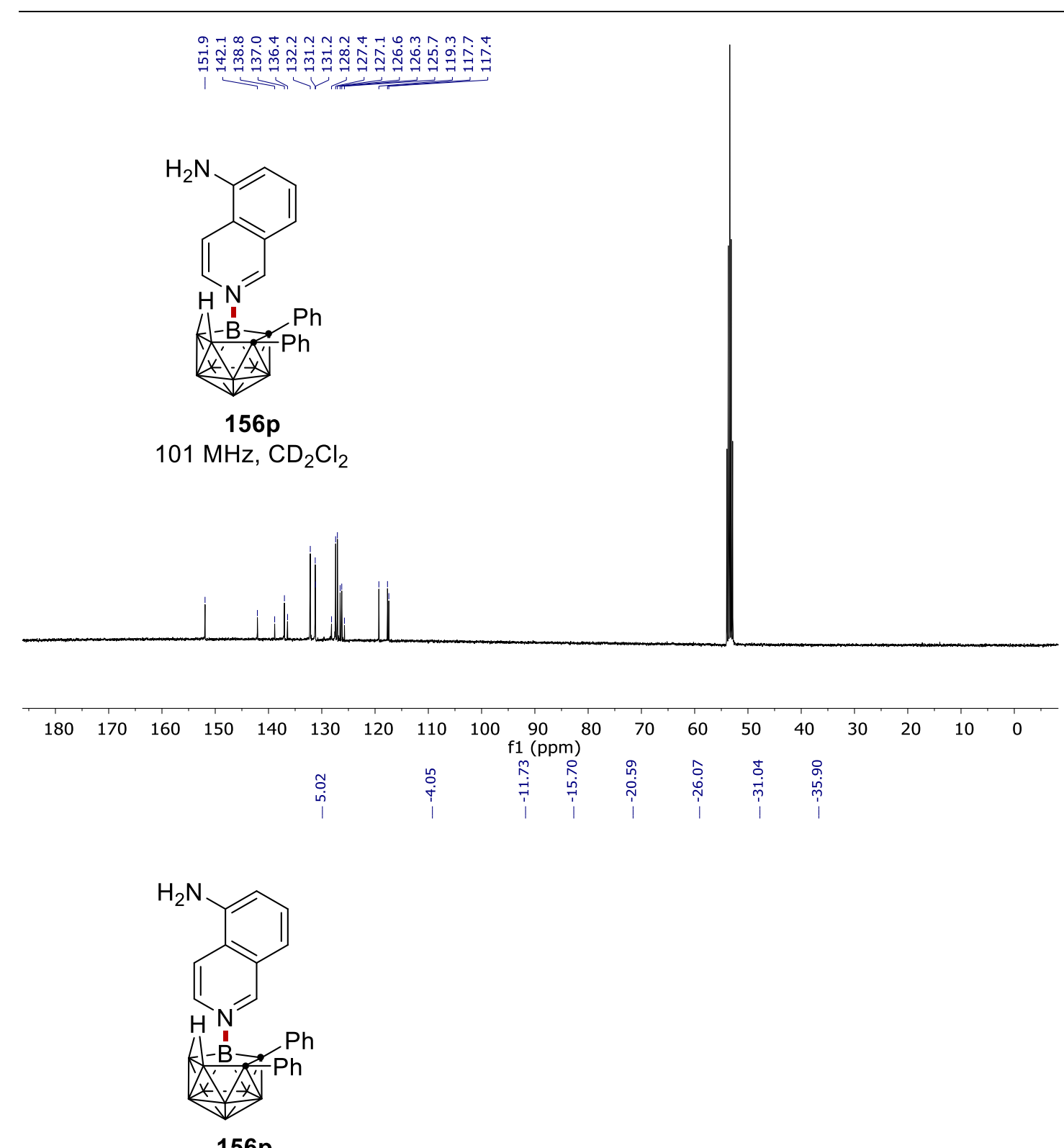

$96 \mathrm{MHz}, \mathrm{CD}_{2} \mathrm{Cl}_{2}$

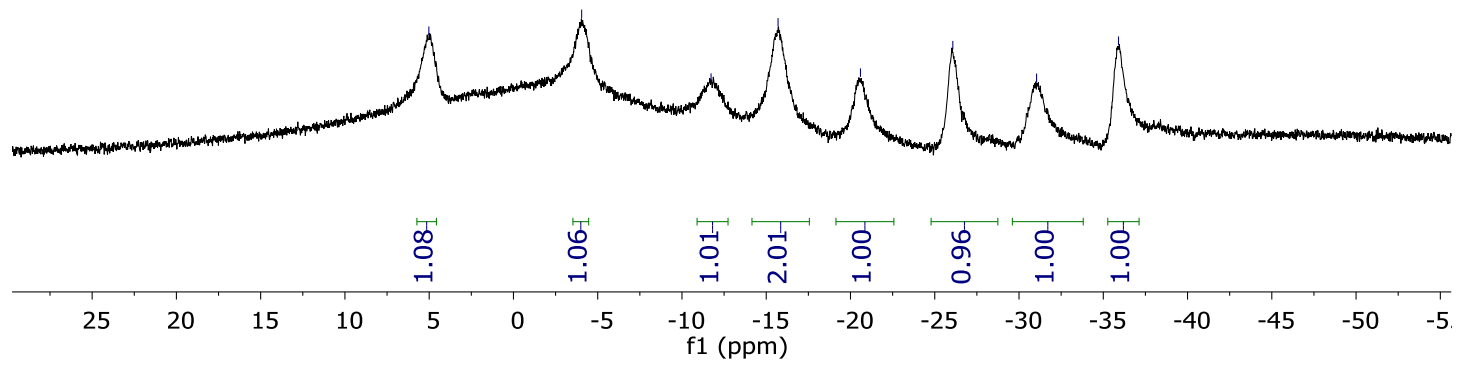




\section{NMR Spectra}

\begin{tabular}{|c|c|c|c|c|c|c|}
\hline $\begin{array}{c}\dot{0} \\
\text { in } \\
1\end{array}$ & 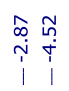 & 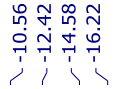 & 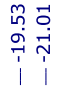 & 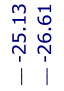 & 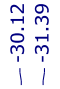 & 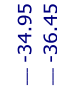 \\
\hline
\end{tabular}

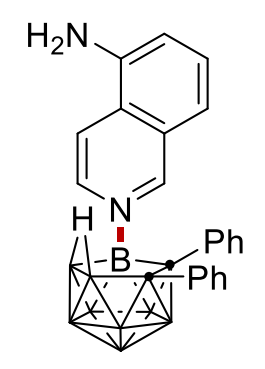

156p

$96 \mathrm{MHz}, \mathrm{CD}_{2} \mathrm{Cl}_{2}$

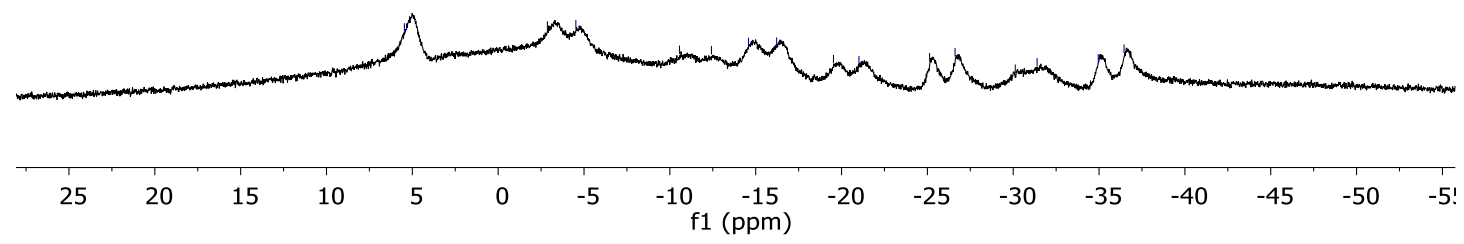

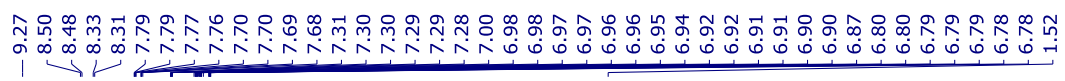

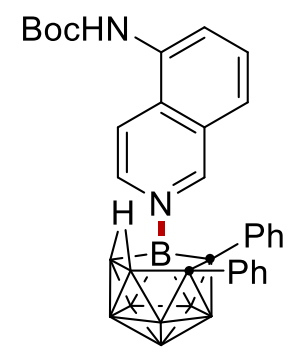

$156 q$

$400 \mathrm{~Hz}, \mathrm{CD}_{2} \mathrm{Cl}_{2}$

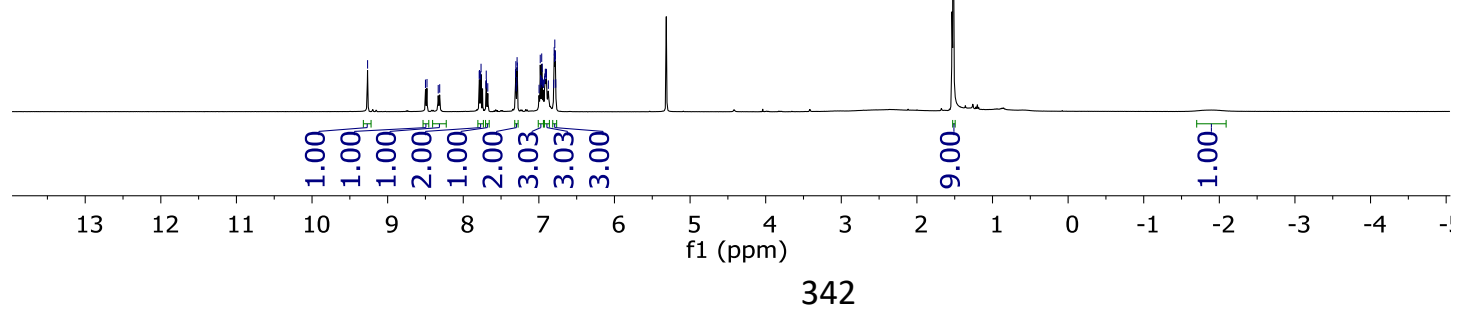


NMR Spectra
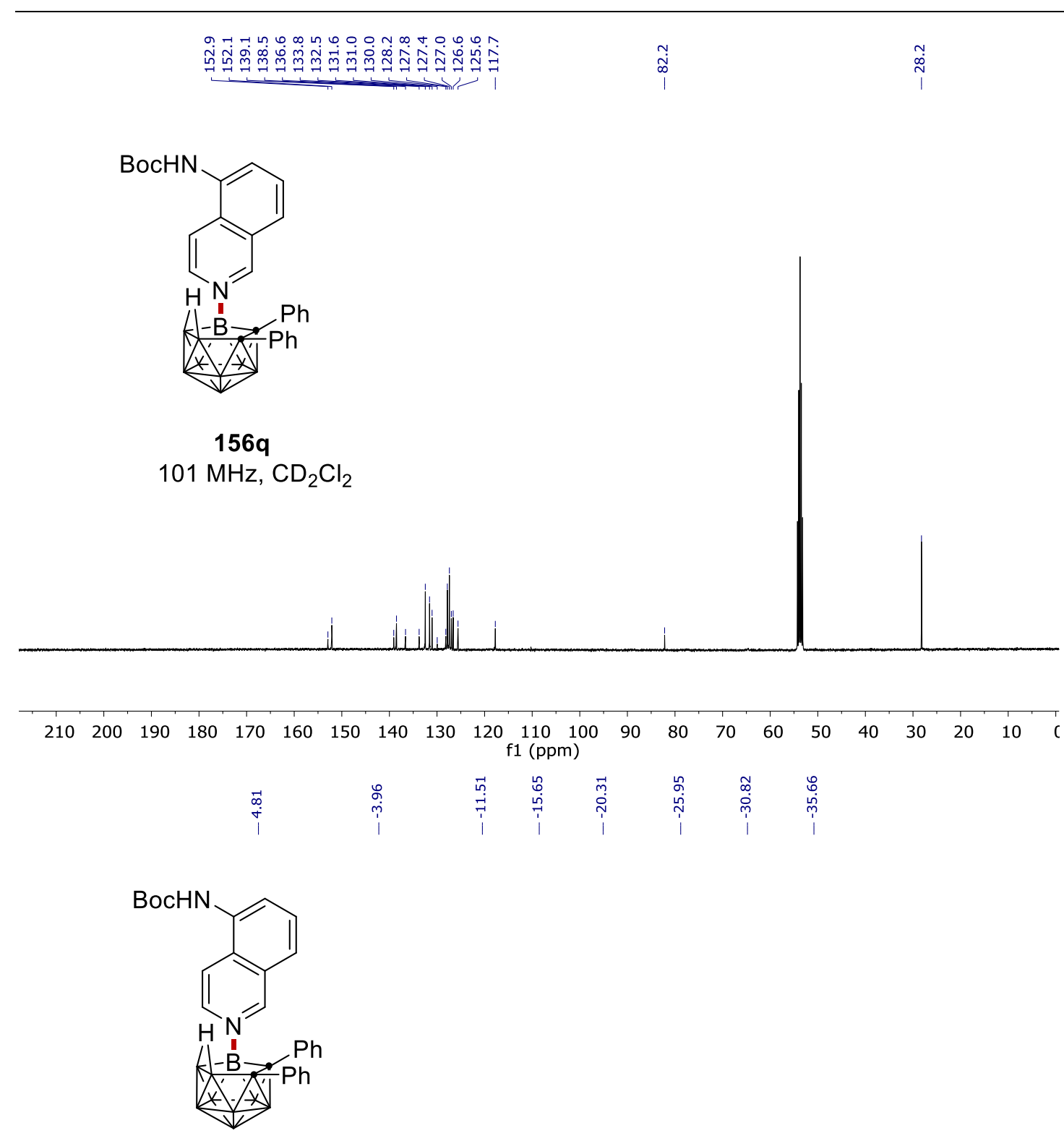

$156 q$

$128 \mathrm{MHz}, \mathrm{CD}_{2} \mathrm{Cl}_{2}$

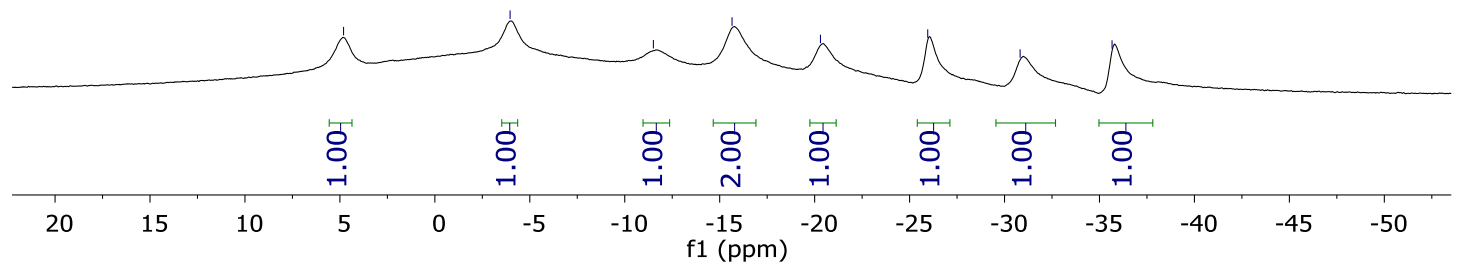




\section{NMR Spectra}

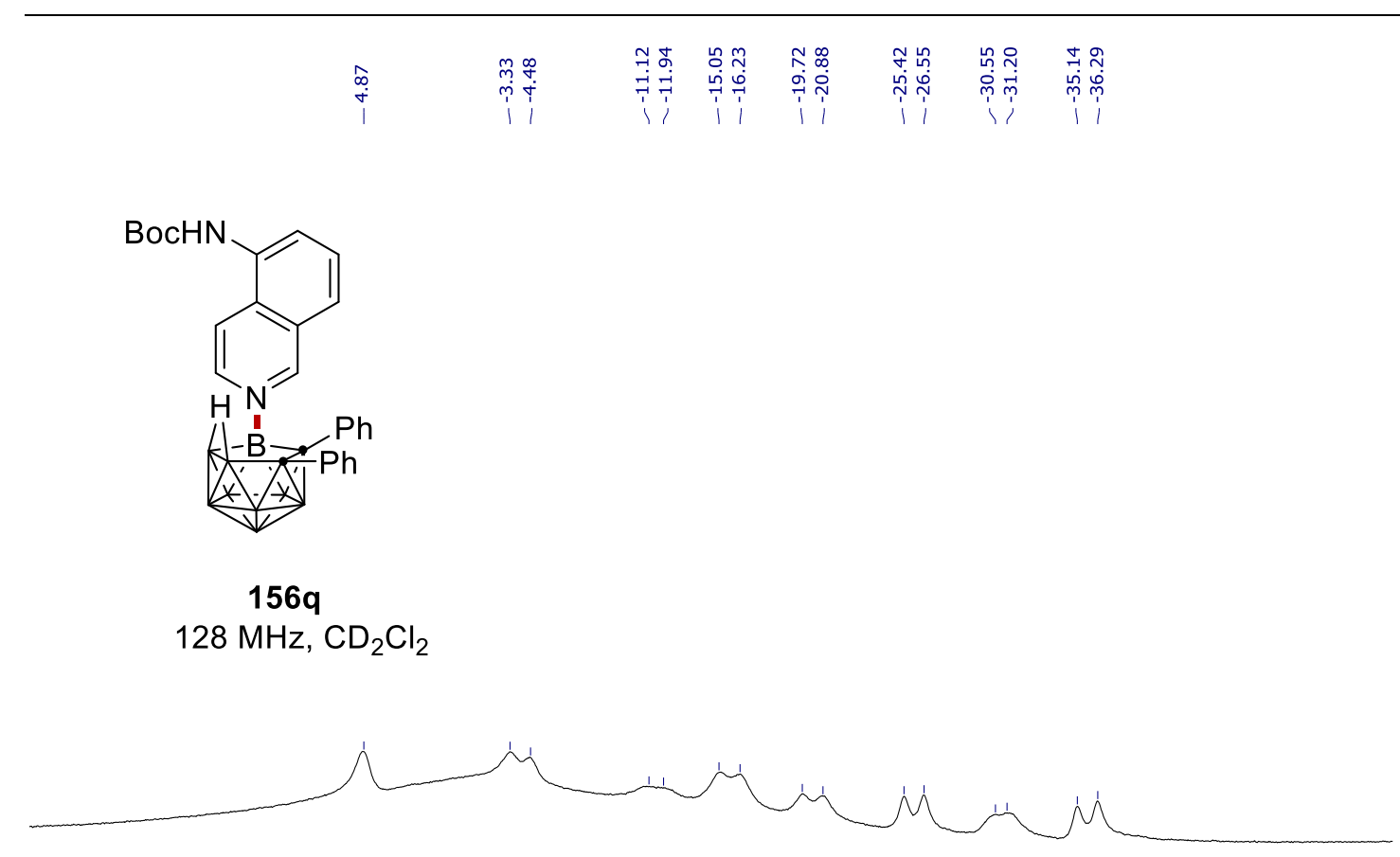

\begin{tabular}{lllllllllllllll}
\hline & 15 & 10 & 5 & 0 & -5 & -10 & -15 & -20 & -25 & -30 & -35 & -40 & -45 & -50
\end{tabular}

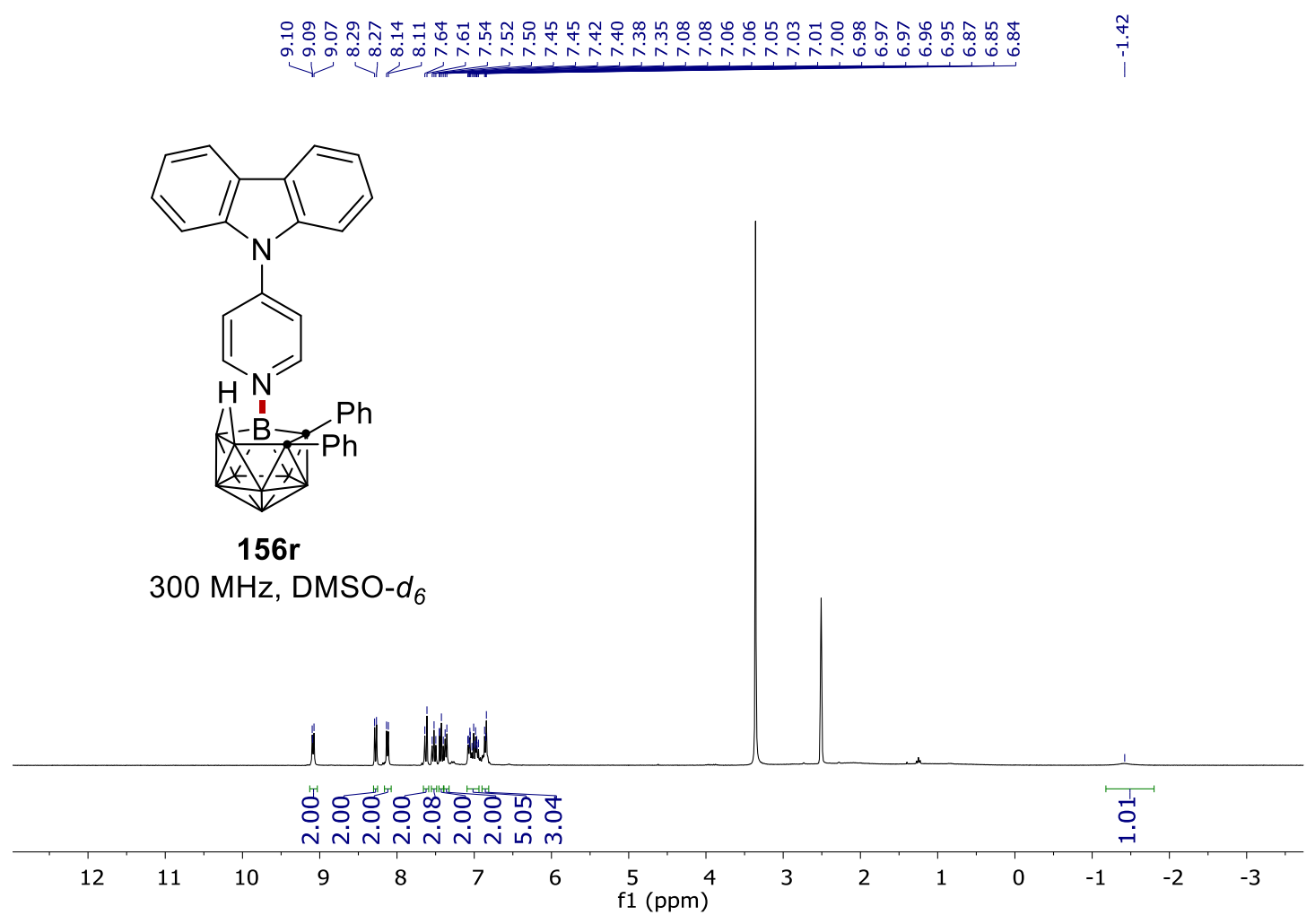




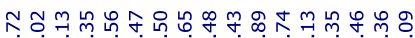

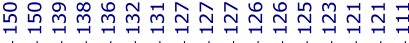

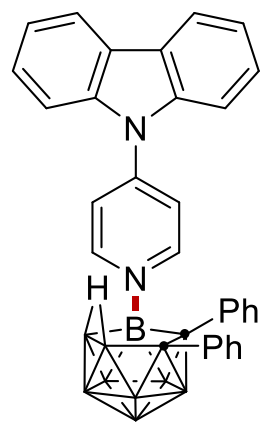

$156 r$

$101 \mathrm{MHz}, \mathrm{DMSO}-d_{6}$

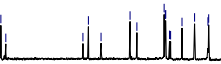

$\begin{array}{llllllllllllllllllll}190 & 180 & 170 & 160 & 150 & 140 & 130 & 120 & 110 & \begin{array}{c}100 \\ \mathrm{f} 1(\mathrm{ppm})\end{array} & 80 & 70 & 60 & 50 & 40 & 30 & 20 & 10 & 0\end{array}$

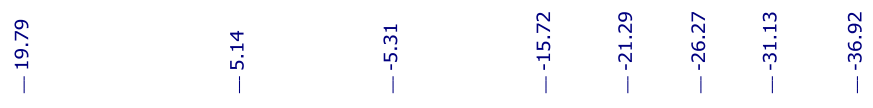

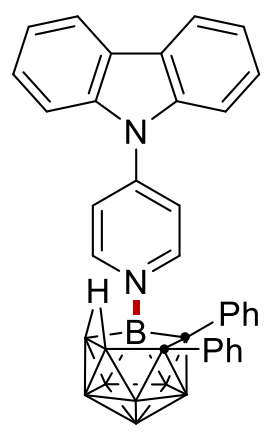

$156 r$

$161 \mathrm{MHz}, \mathrm{DMSO}-d_{6}$

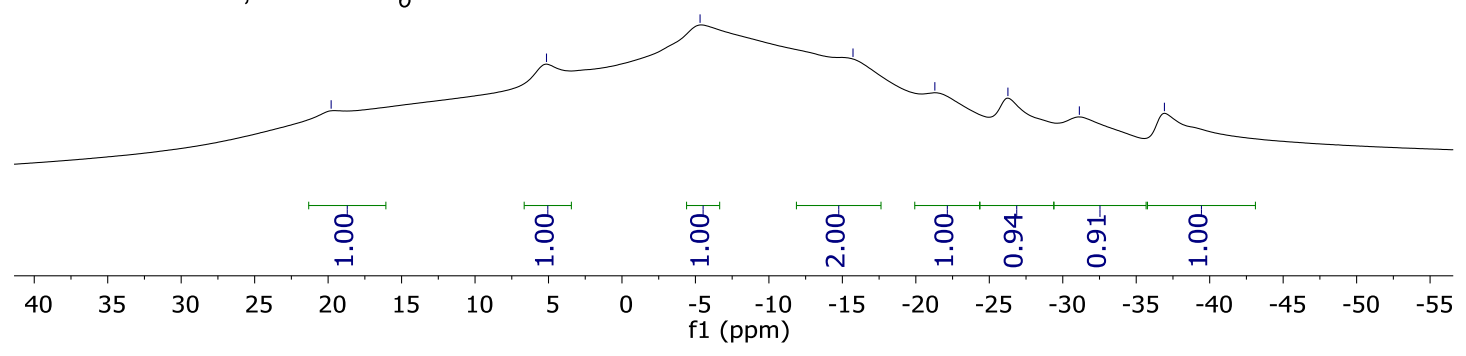




\section{NMR Spectra}
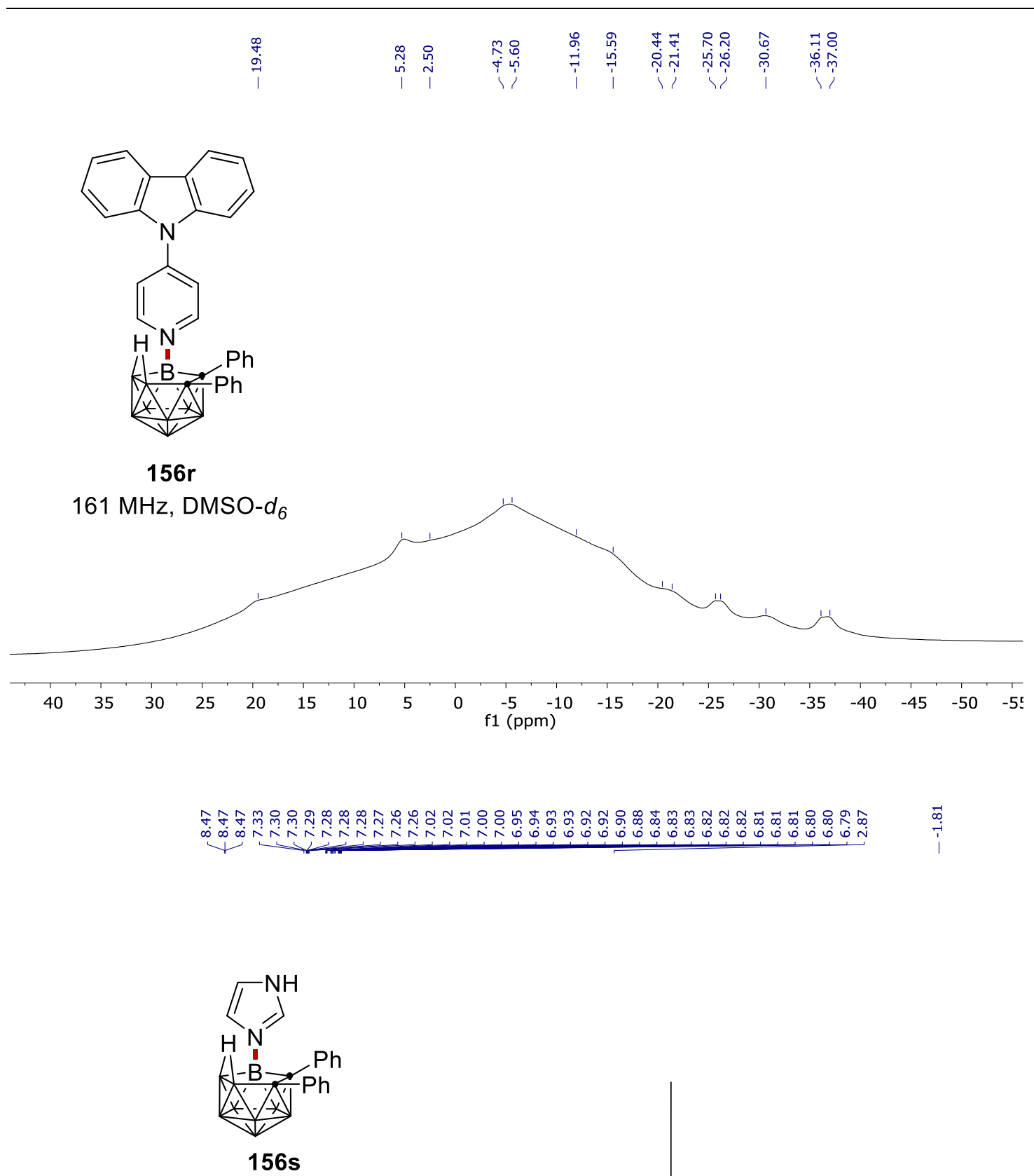

$500 \mathrm{MHz}$, Acetone- $d_{6}$

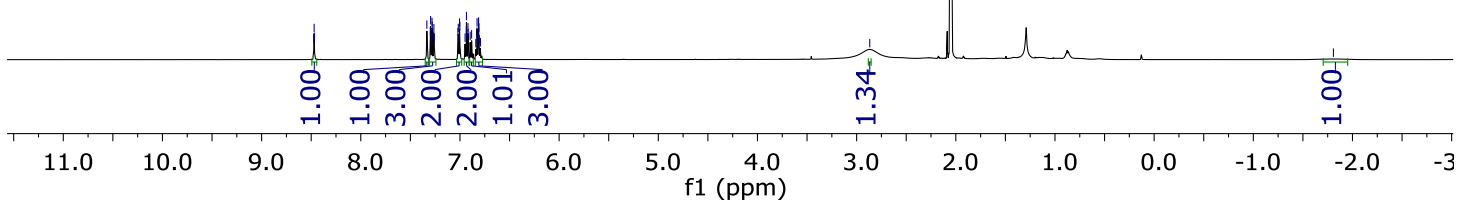




\section{NMR Spectra}

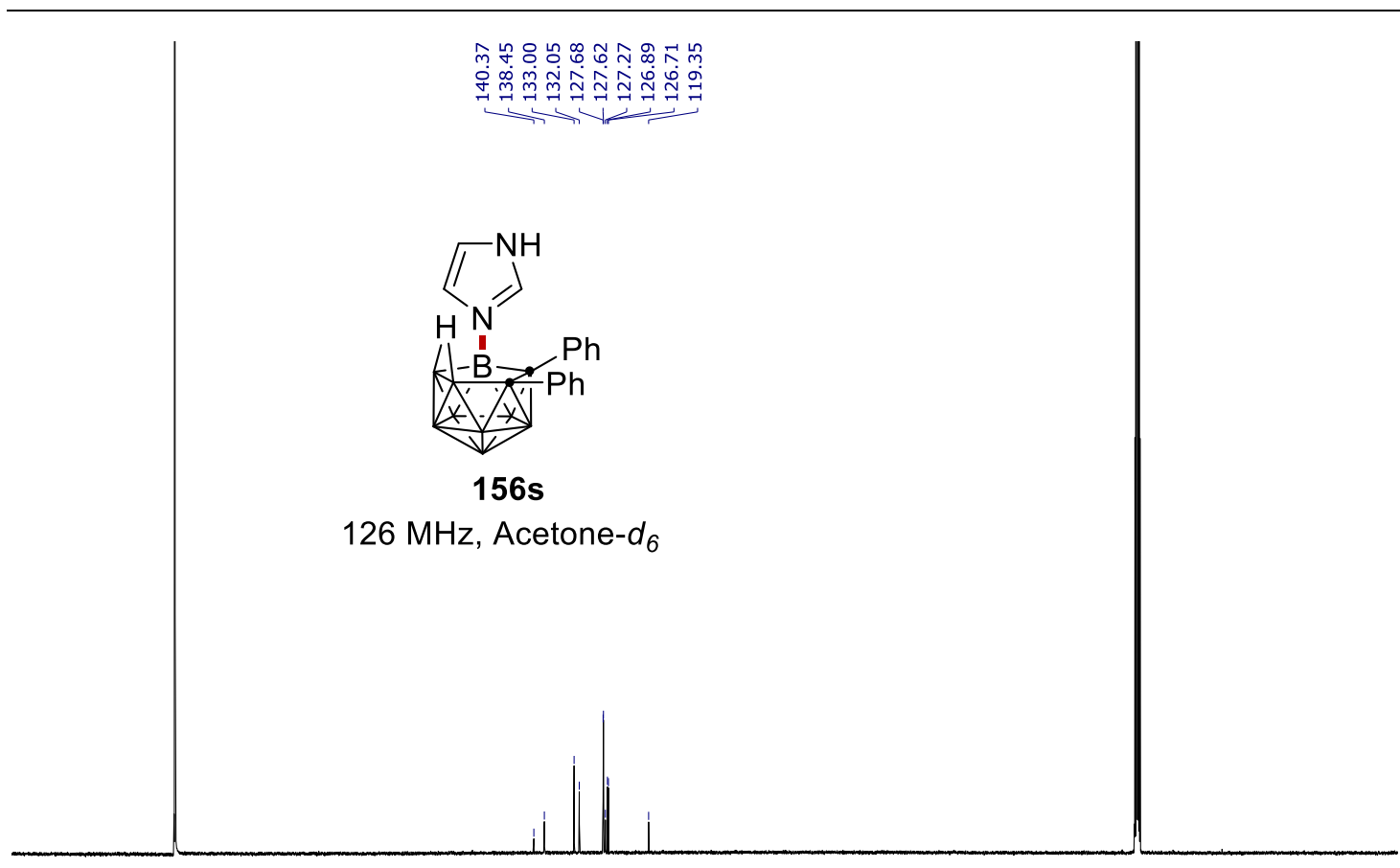

$\begin{array}{lllllllllllllllllllllllll}230 & 220 & 210 & 200 & 190 & 180 & 170 & 160 & 150 & 140 & 130 & 120 & 110 & 100 & 90 & 80 & 70 & 60 & 50 & 40 & 30 & 20 & 10 & 0 & -10\end{array}$ f1 (ppm)

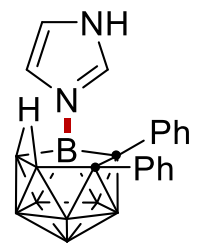

$156 s$

$128 \mathrm{MHz}$, Acetone- $d_{6}$

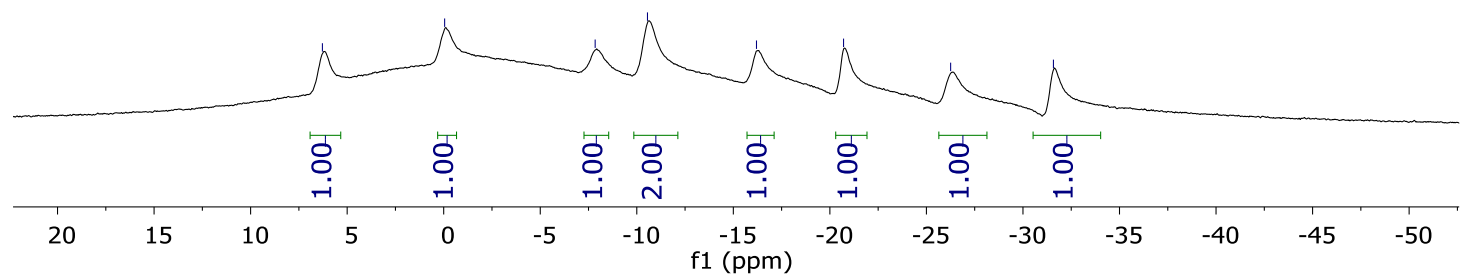




\section{NMR Spectra}

\begin{tabular}{|c|c|c|c|c|c|}
\hline $\begin{array}{l}\tilde{m} \\
\dot{\omega} \\
1\end{array}$ & $\begin{array}{ll}n & 0 \\
\text { n̊n } \\
0 \\
0 \\
1 & 1\end{array}$ & 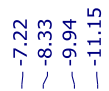 & 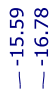 & 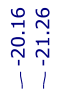 & 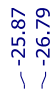 \\
\hline
\end{tabular}

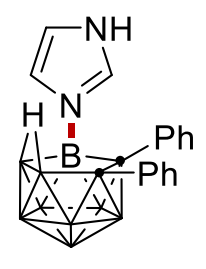

156s

$128 \mathrm{MHz}$, Acetone- $d_{6}$

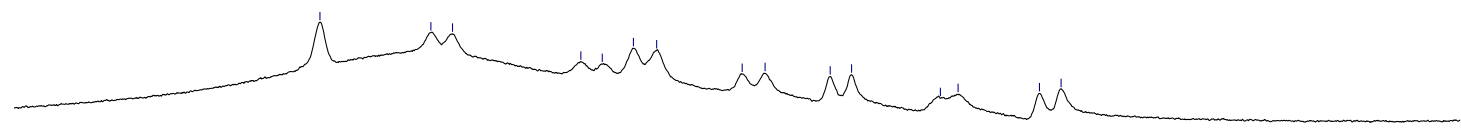

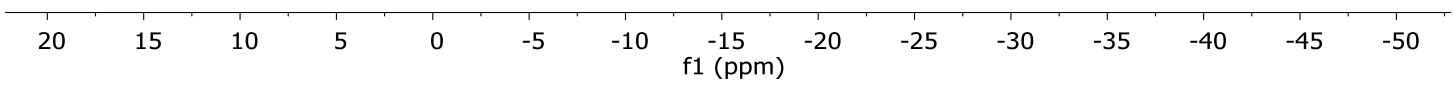

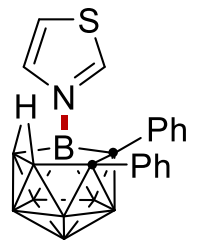

$156 t$

$500 \mathrm{MHz}$, Acetone- $d_{6}$

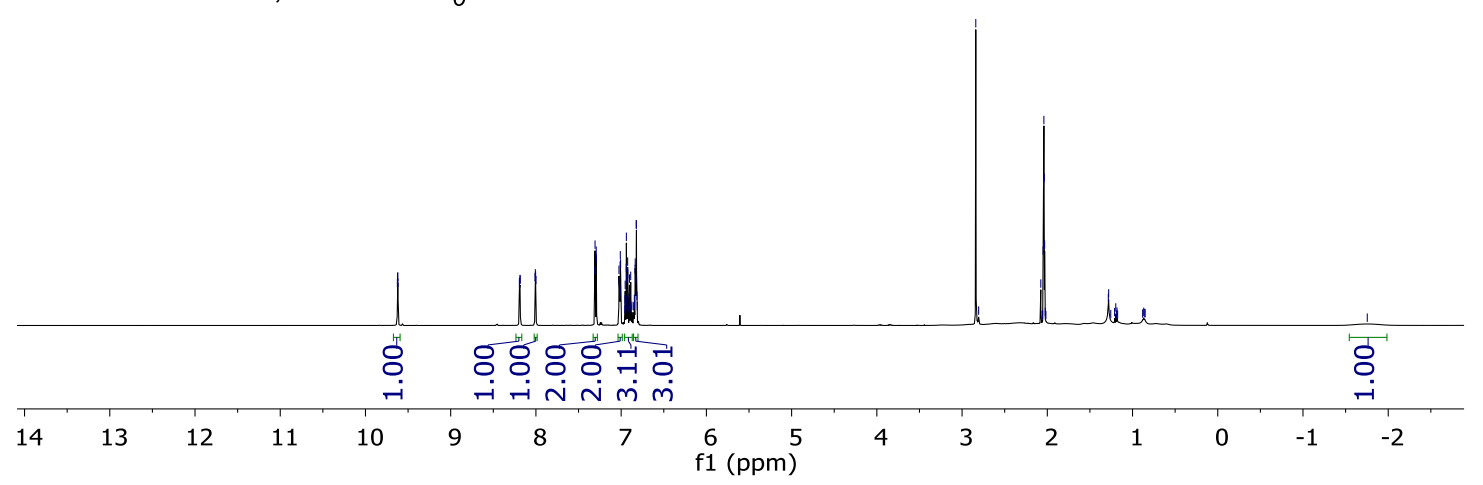




\section{NMR Spectra}
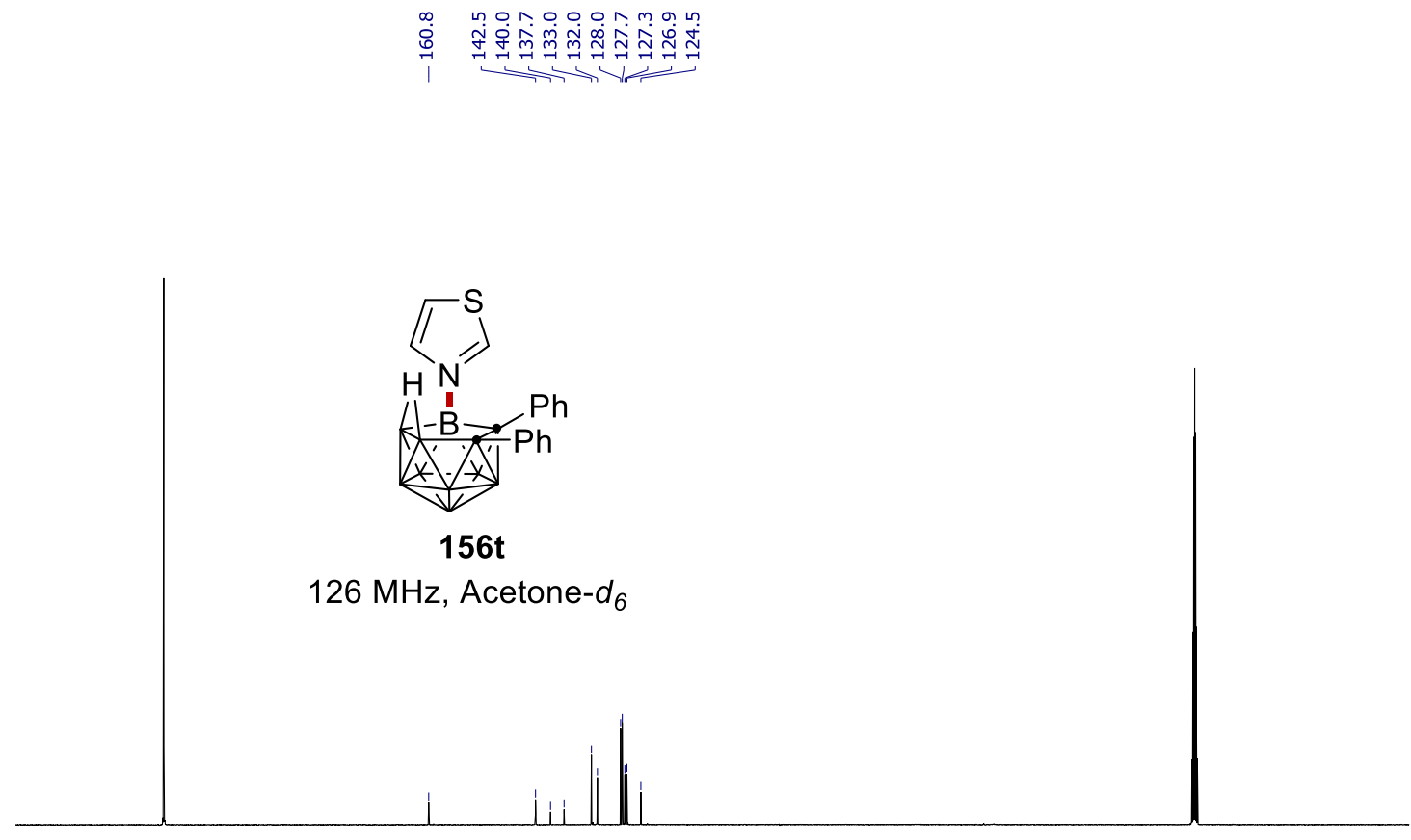

$\begin{array}{lllllllllllllllllllllllll}3 & 220 & 210 & 200 & 190 & 180 & 170 & 160 & 150 & 140 & 130 & 120 & 110 & 100 & 90 & 80 & 70 & 60 & 50 & 40 & 30 & 20 & 10 & 0\end{array}$ f1 (ppm)

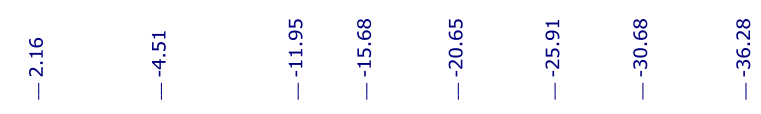

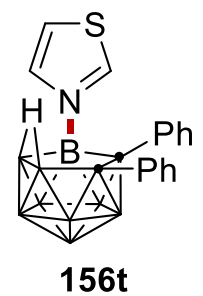

$128 \mathrm{MHz}$, Acetone- $d_{6}$

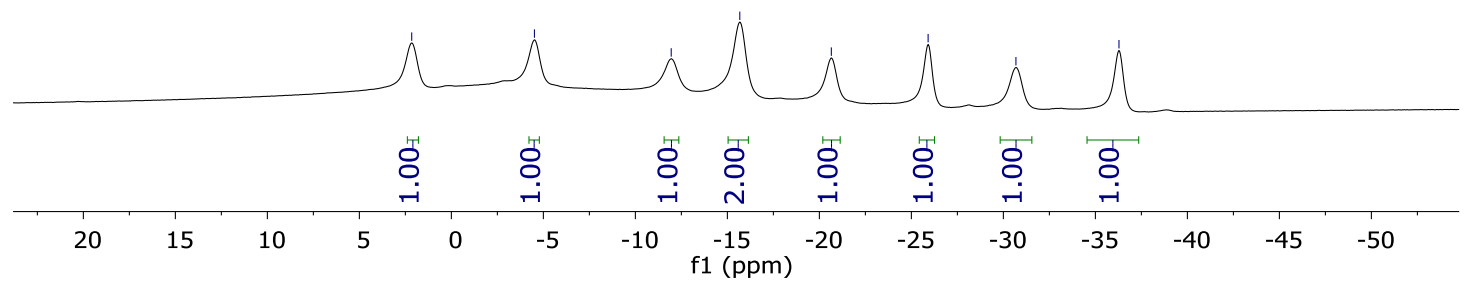




\section{NMR Spectra}
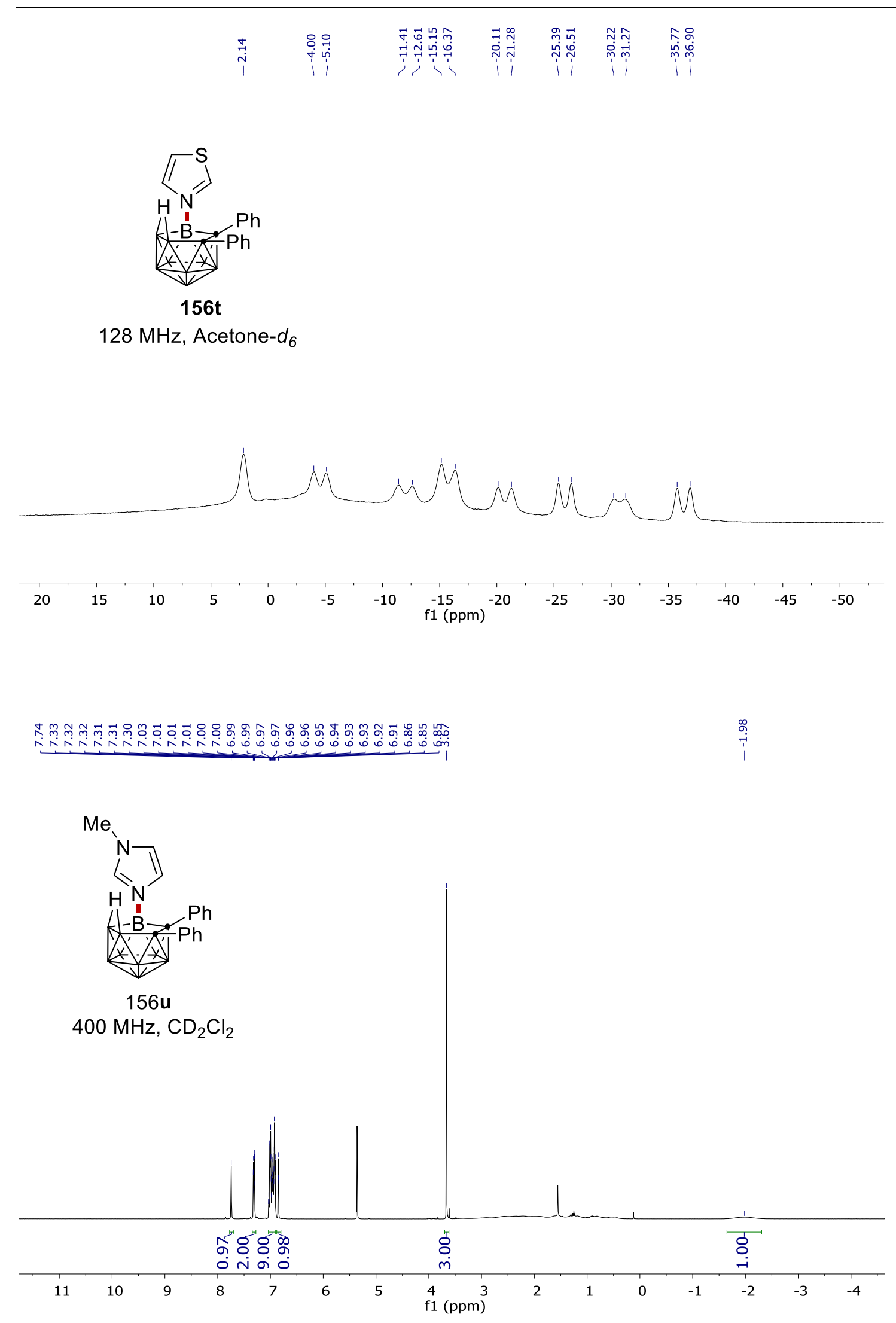


\section{NMR Spectra}
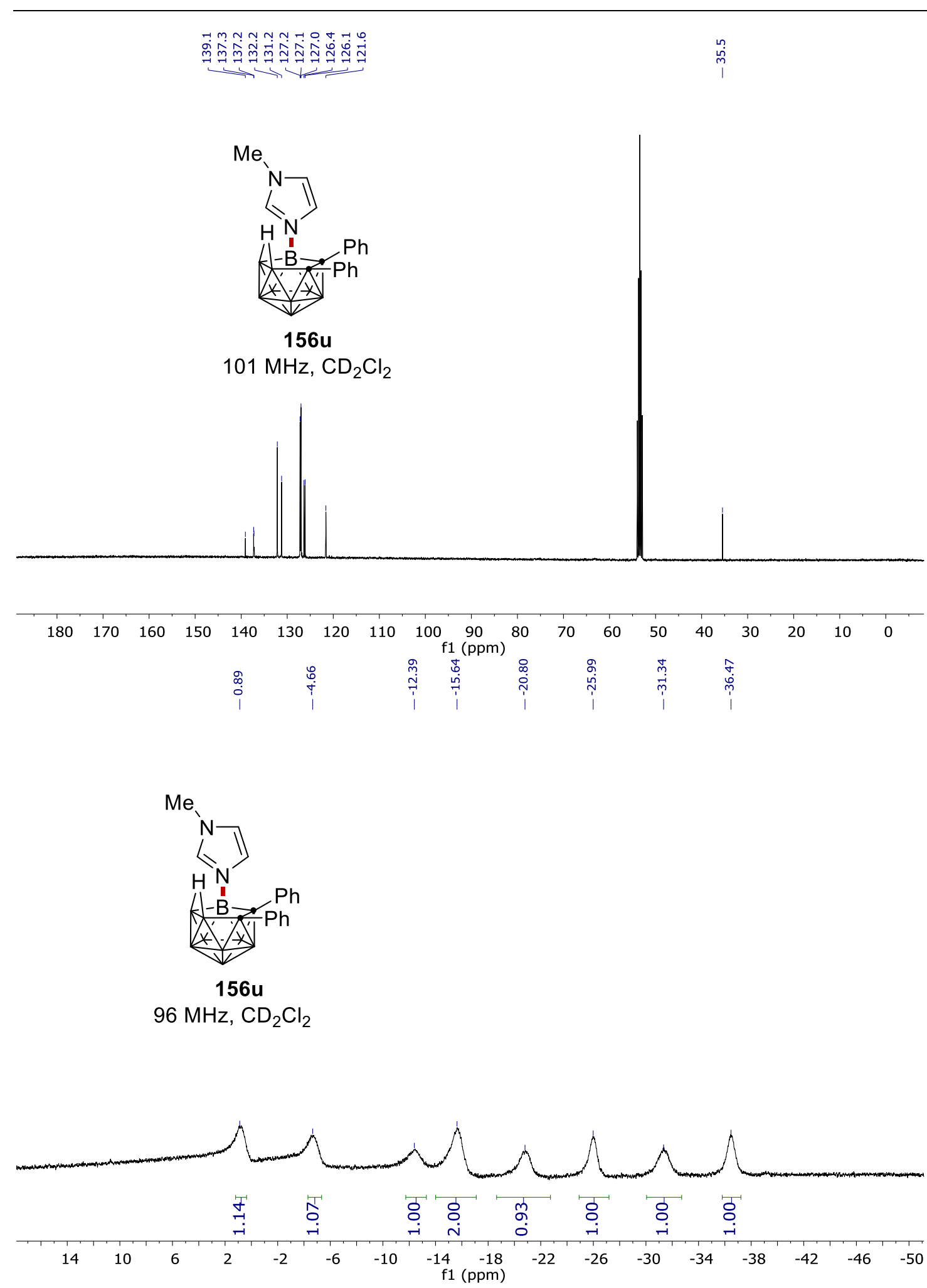


\section{NMR Spectra}

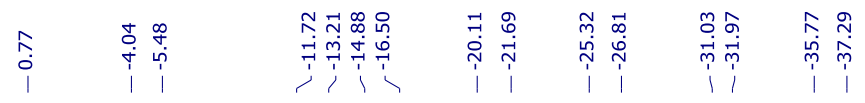

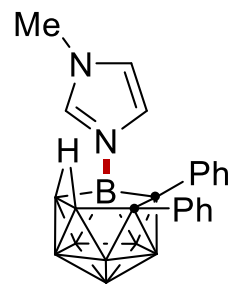

156u

$96 \mathrm{MHz}, \mathrm{CD}_{2} \mathrm{Cl}_{2}$
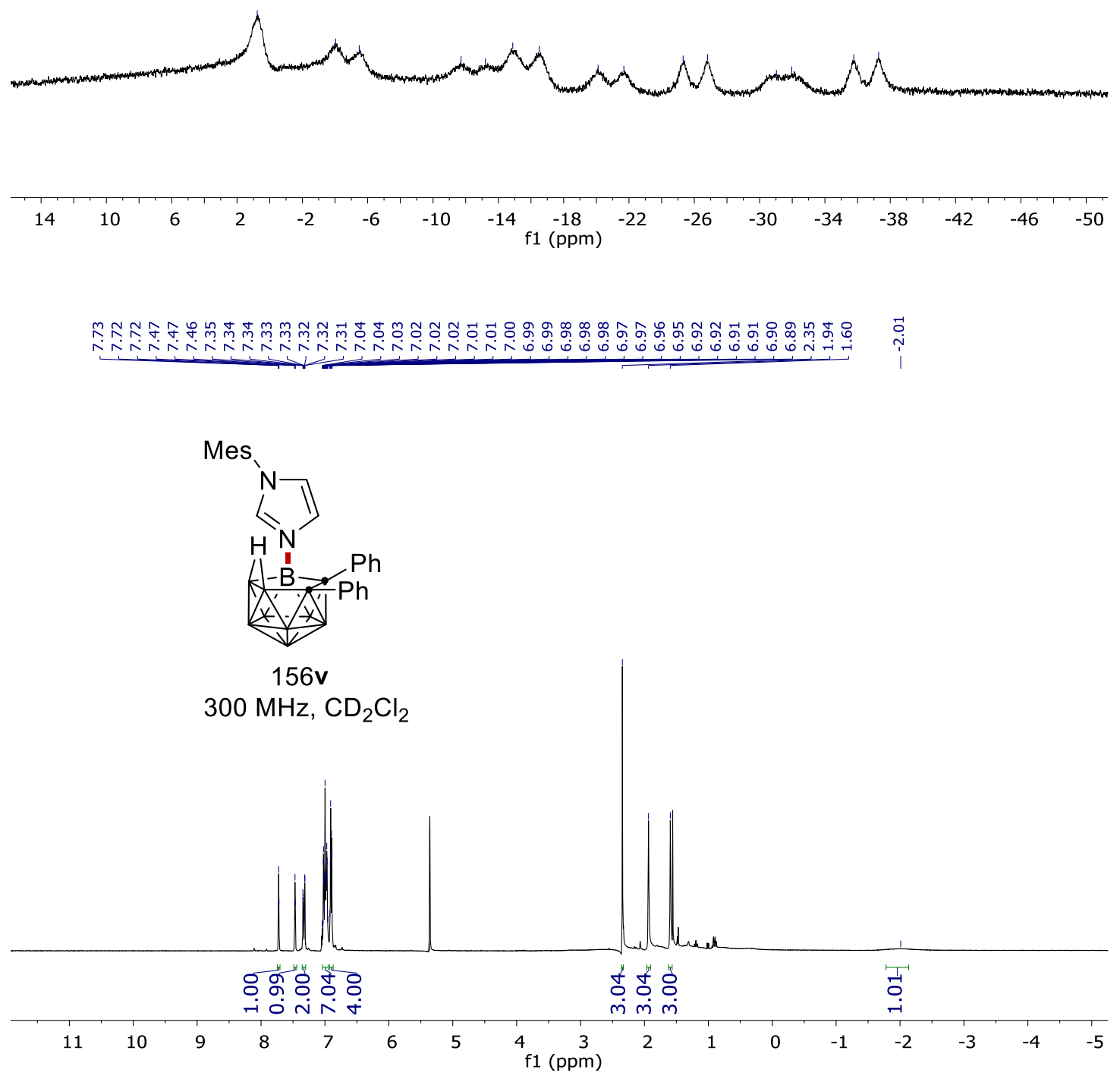
Mes<smiles></smiles>

$101 \mathrm{MHz}, \mathrm{CD}_{2} \mathrm{Cl}_{2}$
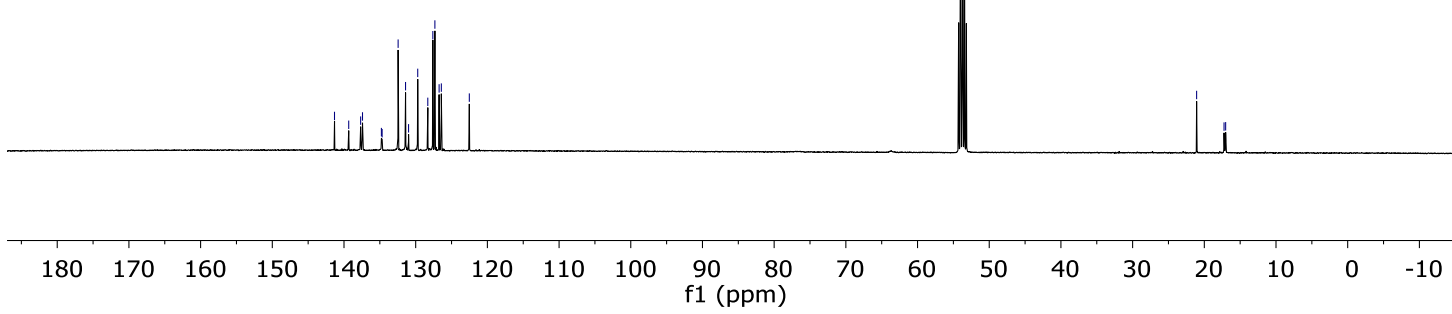

\begin{tabular}{|c|c|c|c|c|c|c|}
\hline & 요 & f & के & ণ্ & ஜ & $\stackrel{\infty}{\stackrel{\infty}{~}}$ \\
\hline 0 & $\stackrel{\widehat{\gamma}}{\dot{\gamma}}$ & $\stackrel{2}{\rightarrow}$ & $\stackrel{\text { nn }}{\rightarrow}$ & $\vec{\dagger}$ & 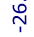 & $\dot{m}$ \\
\hline I & 1 & I & I & I & 1 & I \\
\hline
\end{tabular}

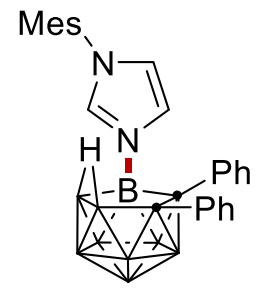

156v

$128 \mathrm{MHz}, \mathrm{CD}_{2} \mathrm{Cl}_{2}$

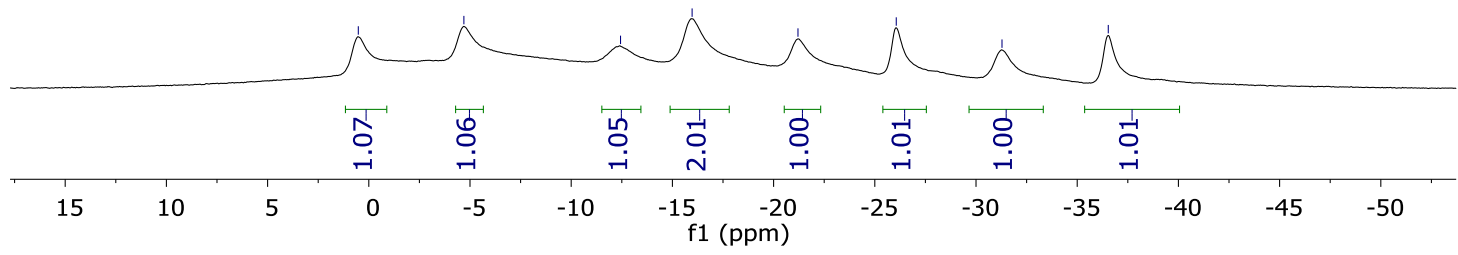


NMR Spectra

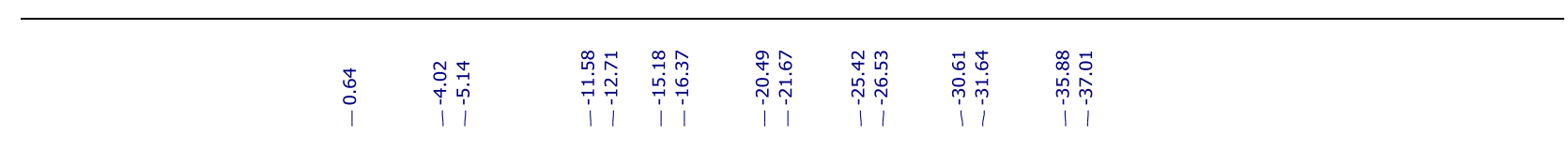
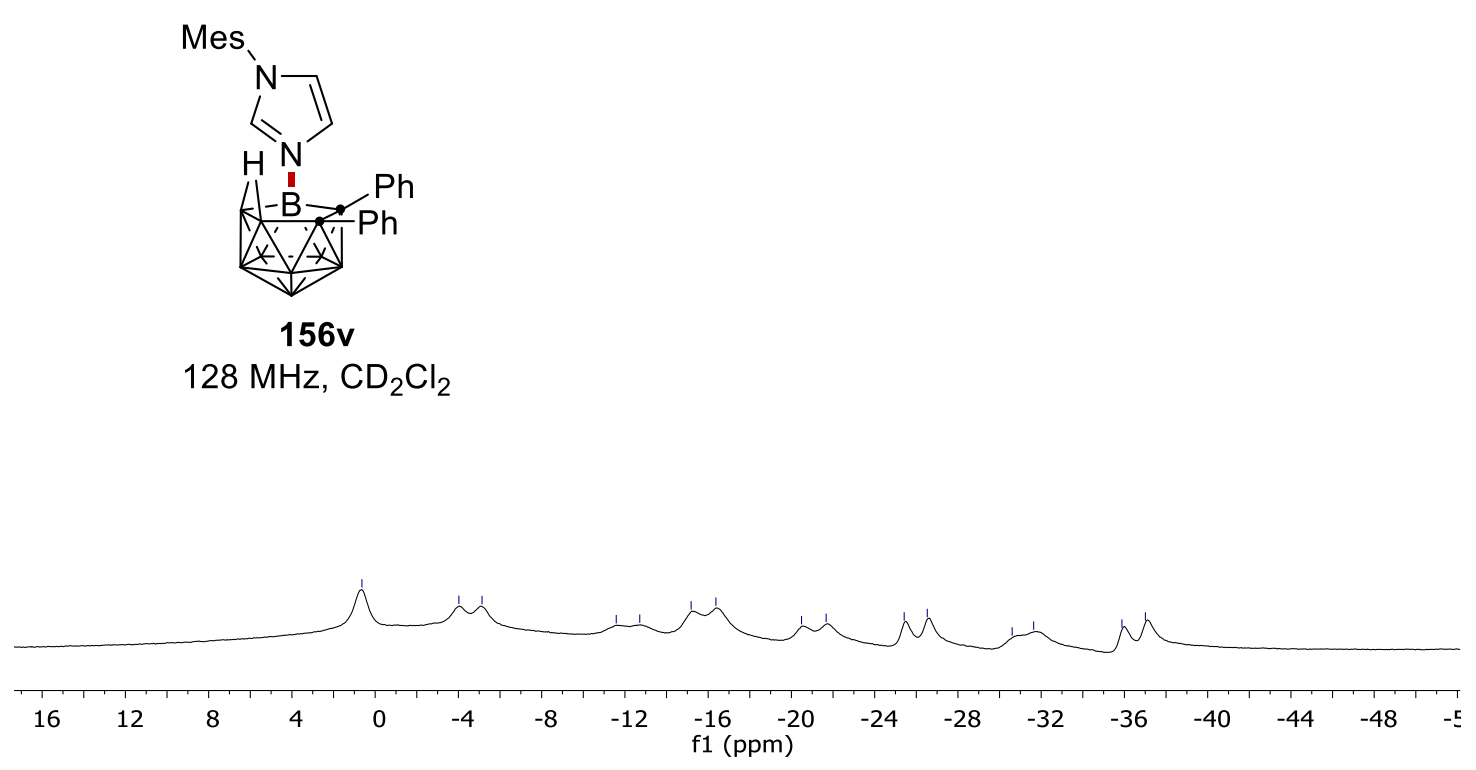

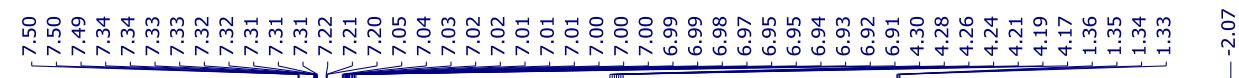

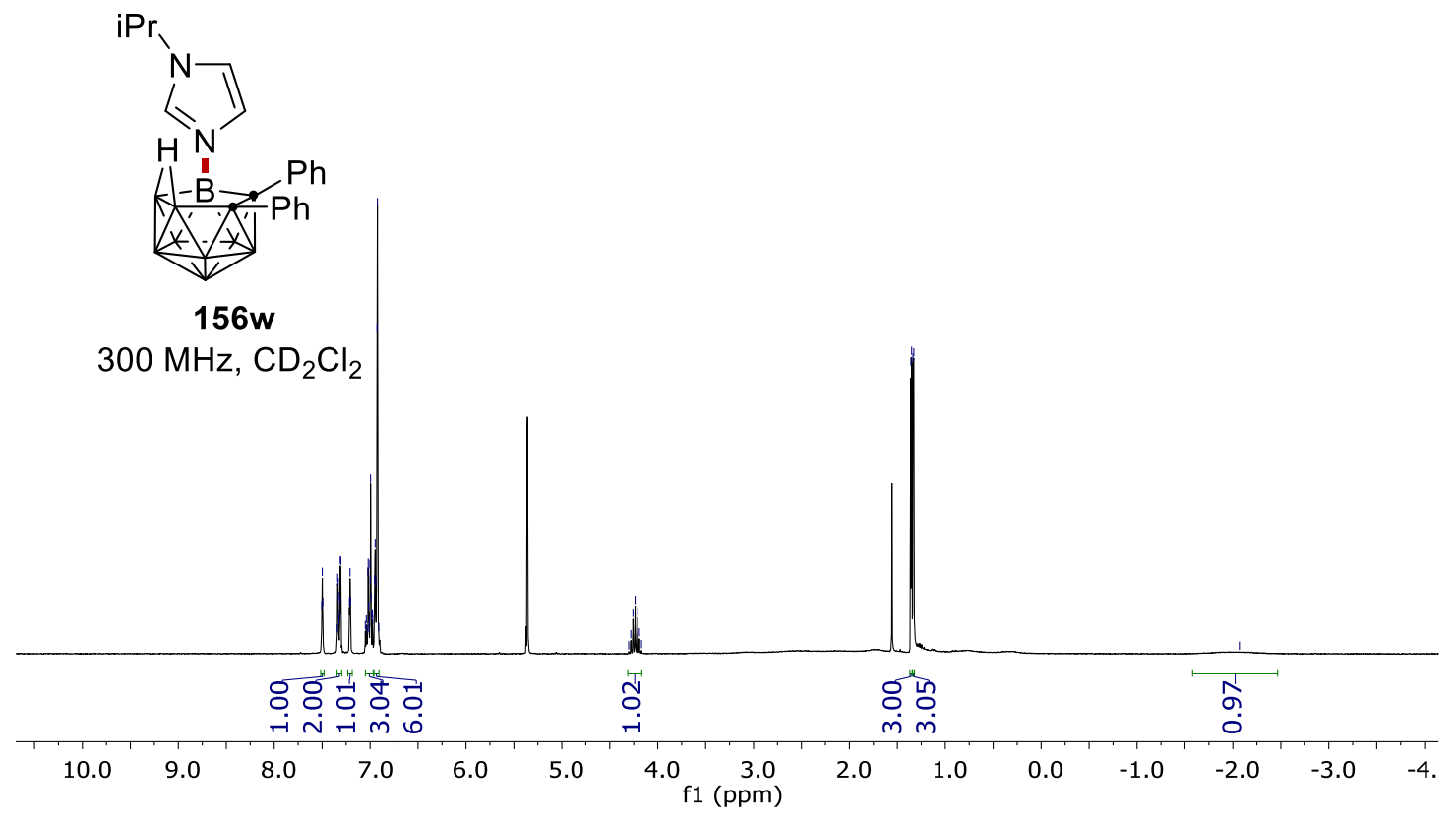



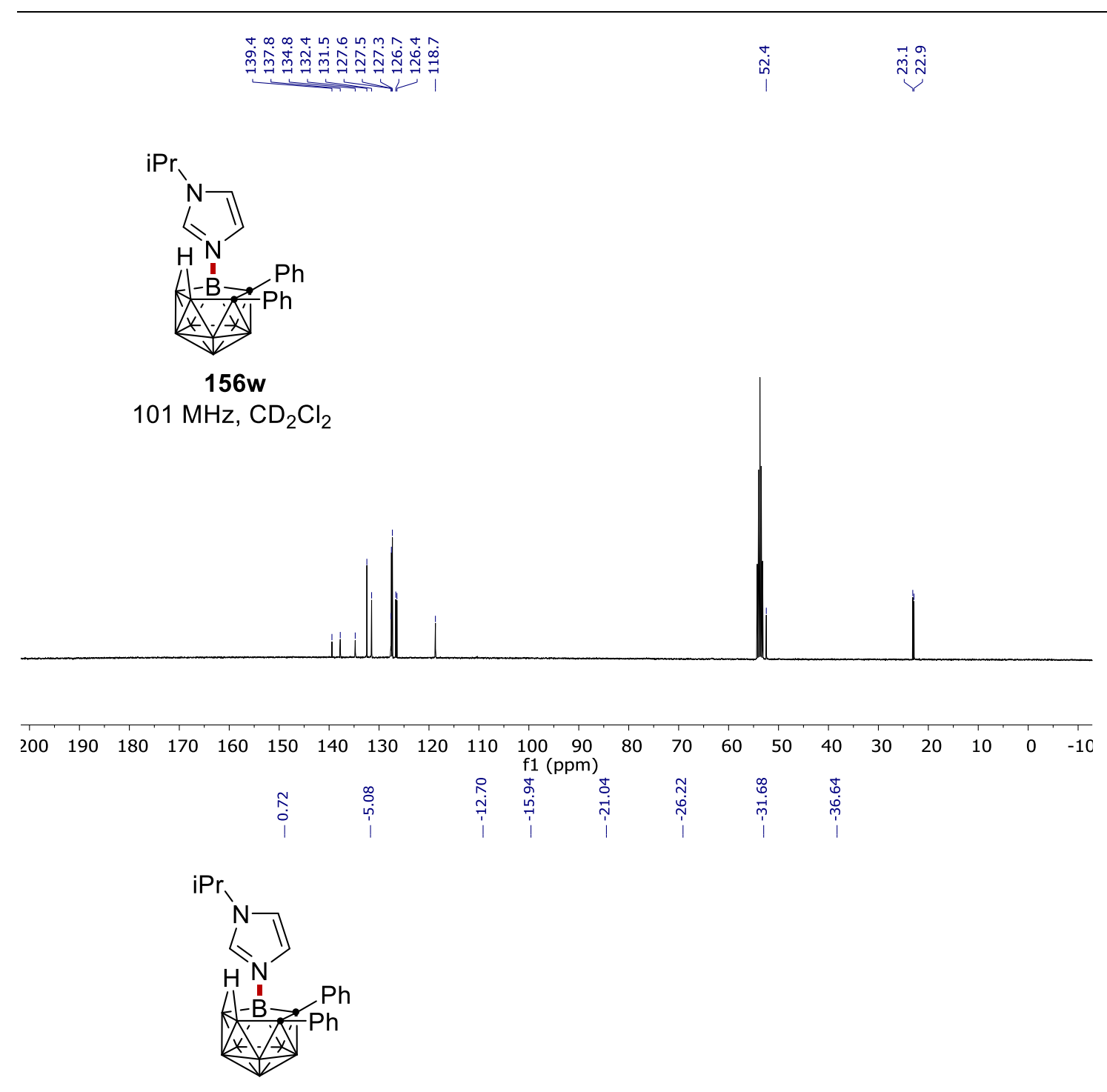

$156 \mathrm{w}$

$128 \mathrm{MHz}, \mathrm{CD}_{2} \mathrm{Cl}_{2}$

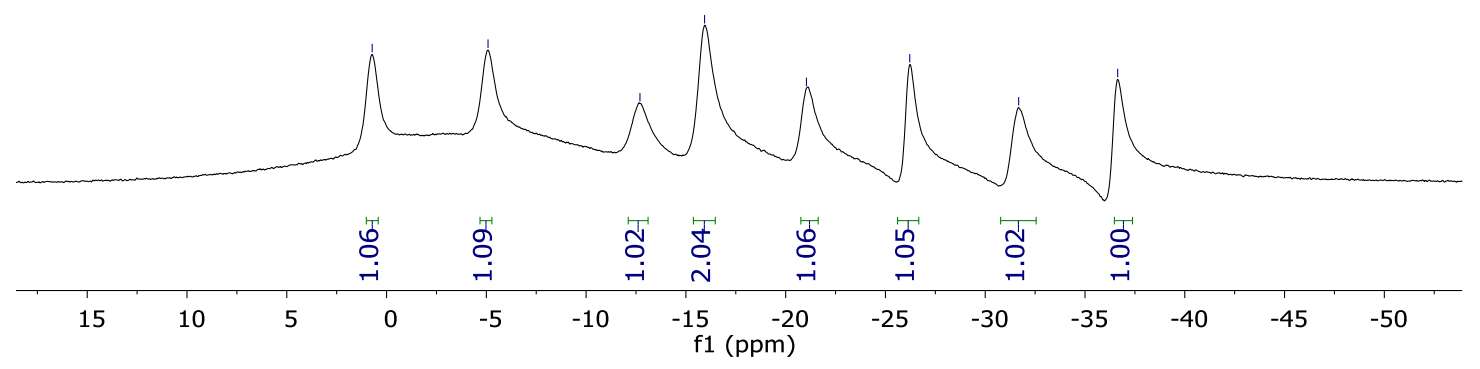




\section{NMR Spectra}
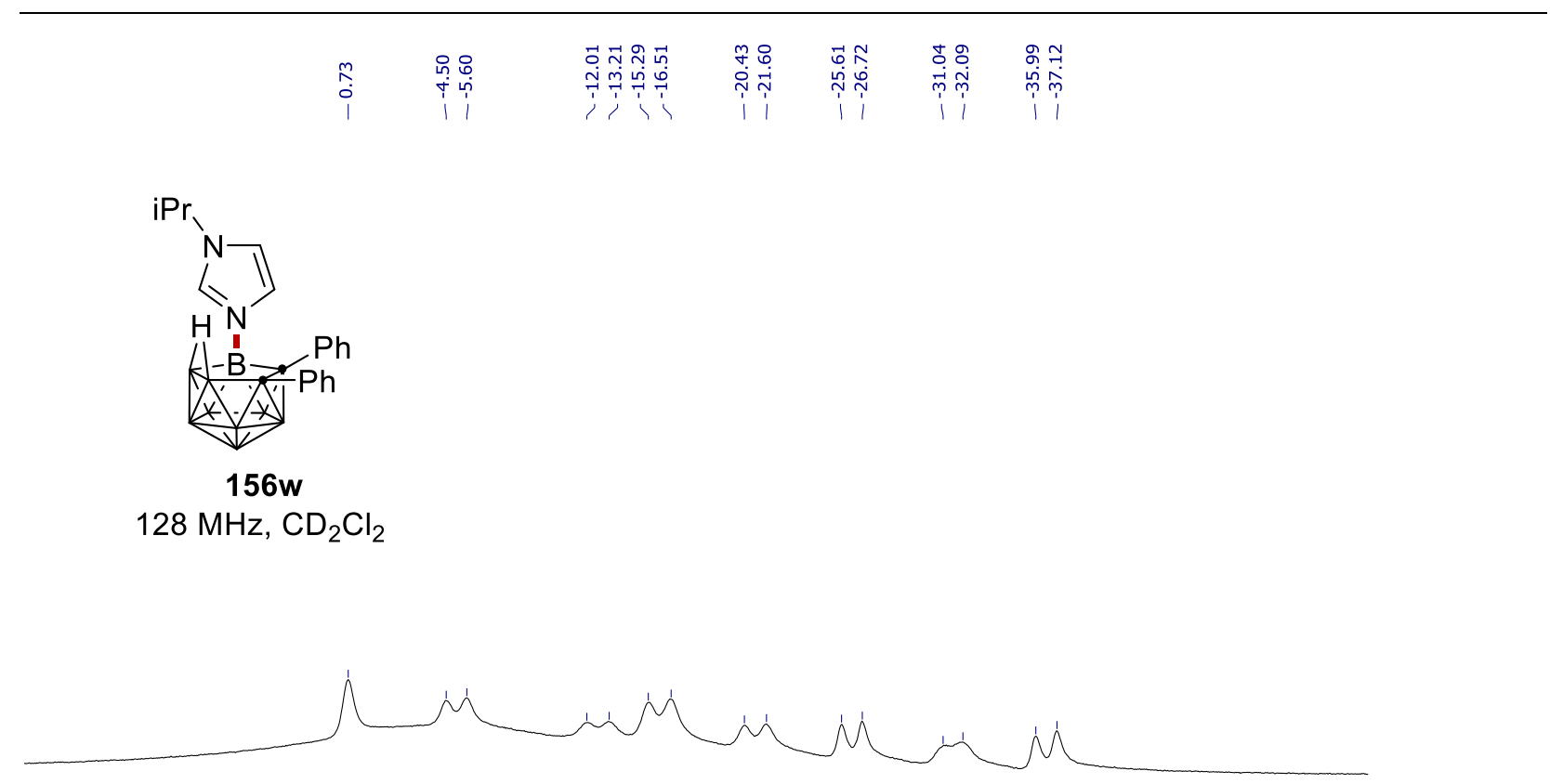

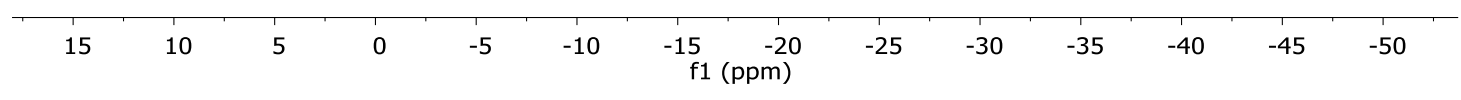

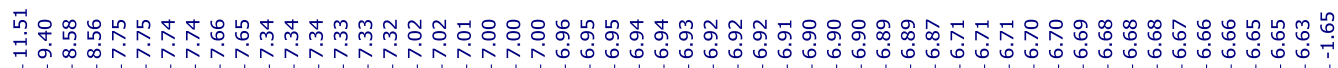

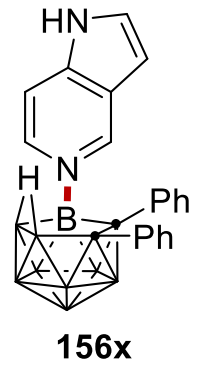

$500 \mathrm{MHz}$, Acetone- $d_{6}$

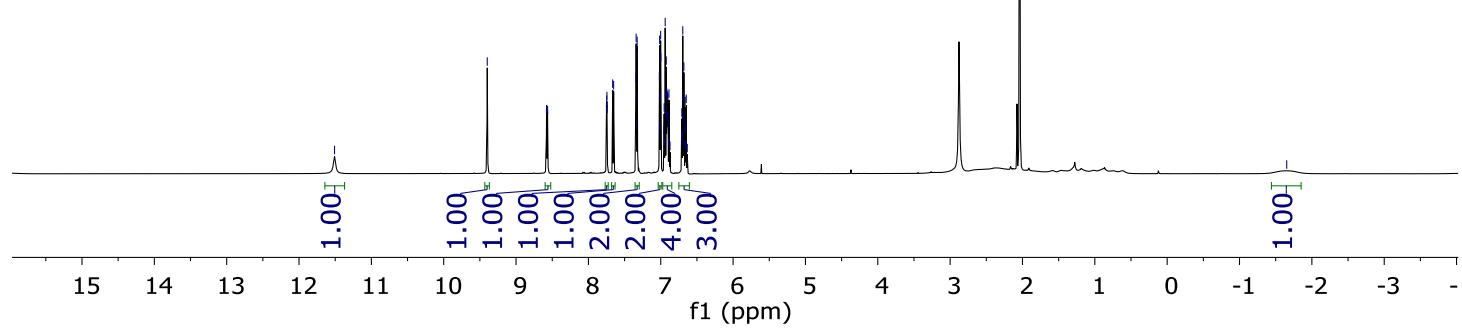




\section{NMR Spectra}

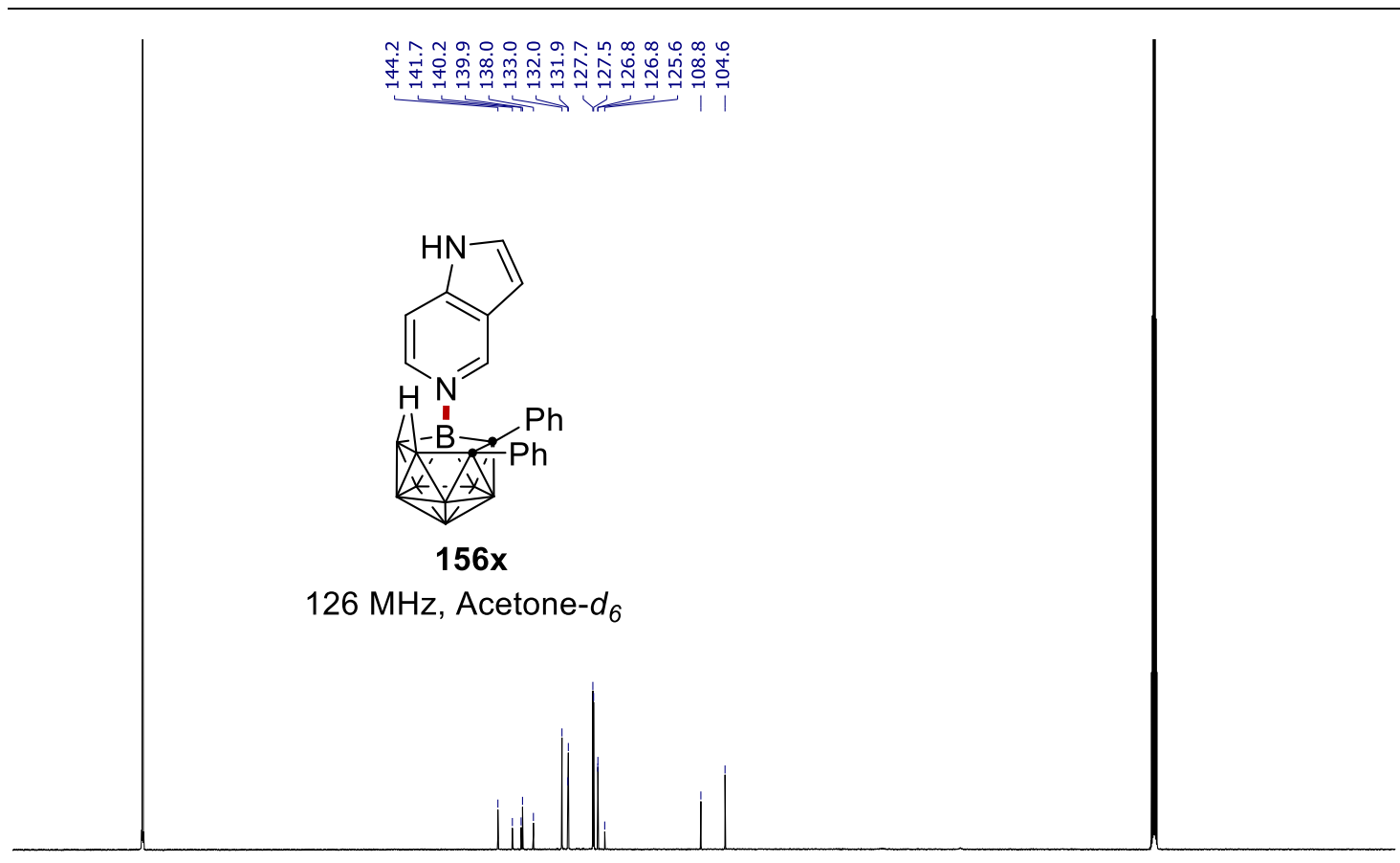

$\begin{array}{lllllllllllllllllllllllll}220 & 210 & 200 & 190 & 180 & 170 & 160 & 150 & 140 & 130 & 120 & 110 & 100 & 90 & 80 & 70 & 60 & 50 & 40 & 30 & 20 & 10 & 0 & -11\end{array}$ $\mathrm{f1}(\mathrm{ppm})$

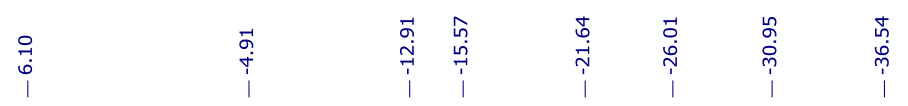

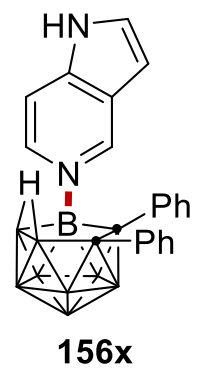

$128 \mathrm{MHz}$, Acetone- $d_{6}$

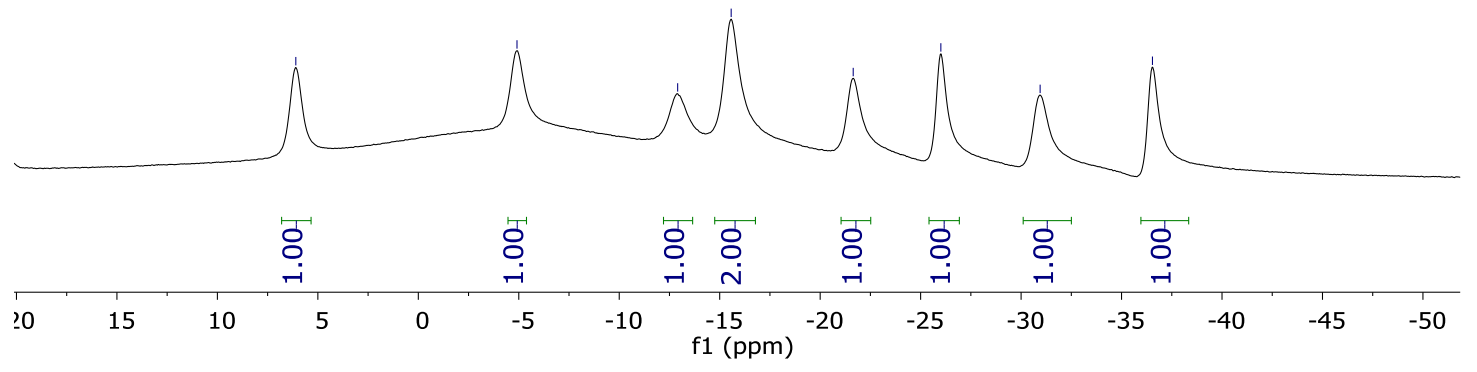




\section{NMR Spectra}

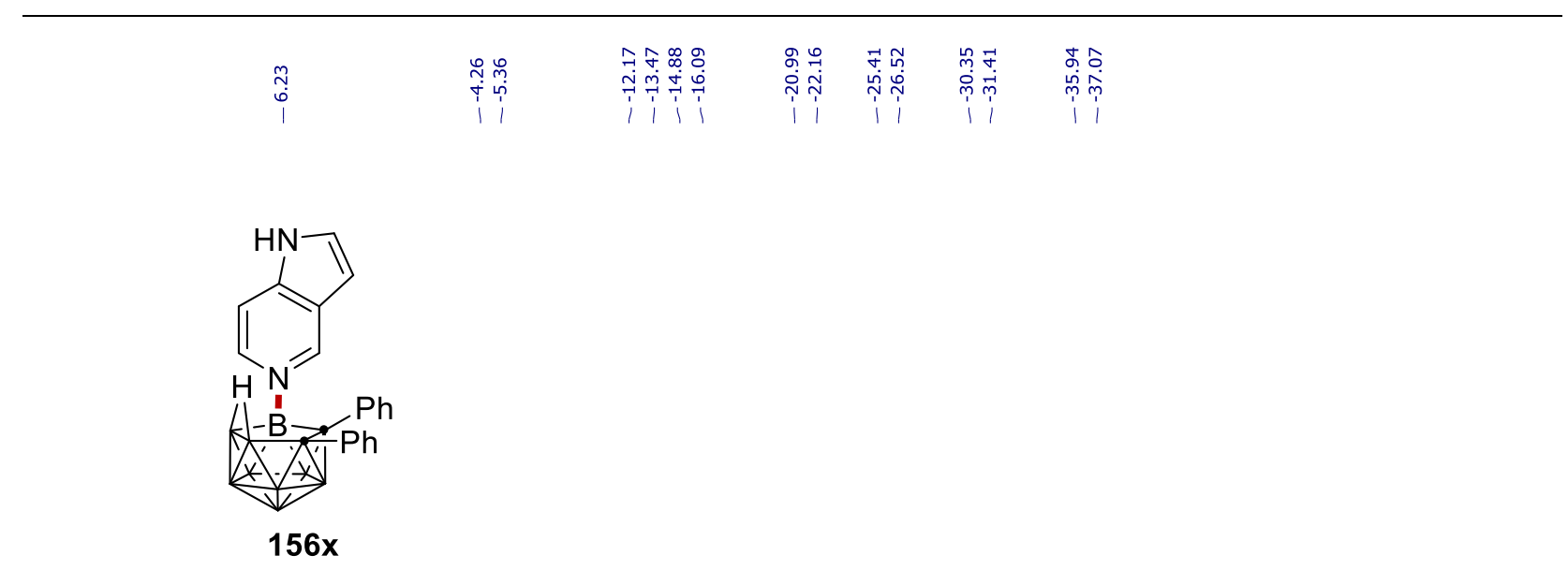

$128 \mathrm{MHz}$, Acetone- $d_{6}$

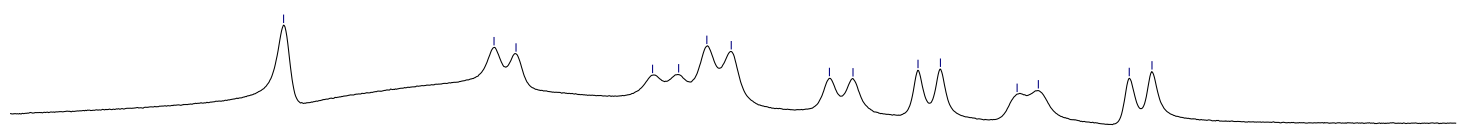

\begin{tabular}{|c|c|c|c|c|c|c|c|c|c|c|c|c|c|}
\hline 15 & 10 & 5 & 0 & -5 & -10 & $\begin{array}{l}-15 \\
\mathrm{f} 1(\mathrm{ppm}\end{array}$ & -20 & -25 & -30 & -35 & -40 & -45 & -50 \\
\hline
\end{tabular}
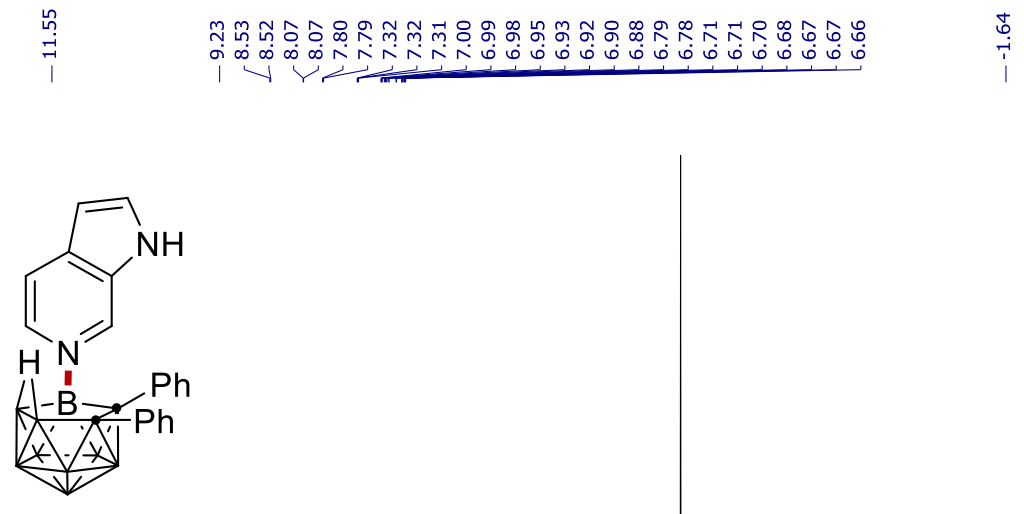

156y

$500 \mathrm{MHz}$, Acetone- $d_{6}$

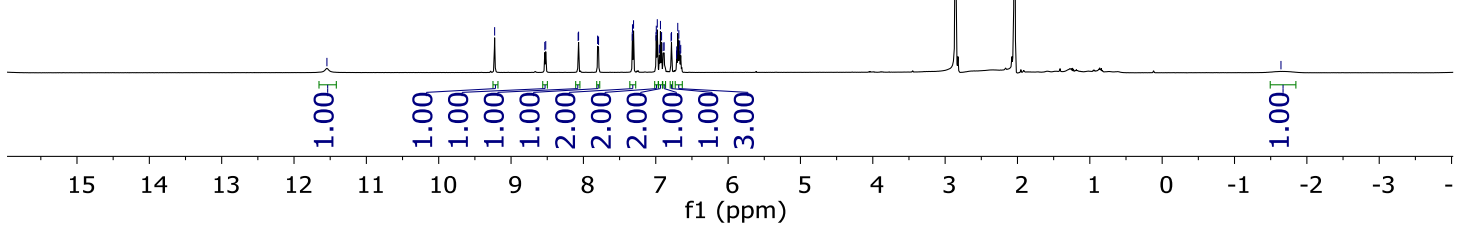




\section{NMR Spectra}

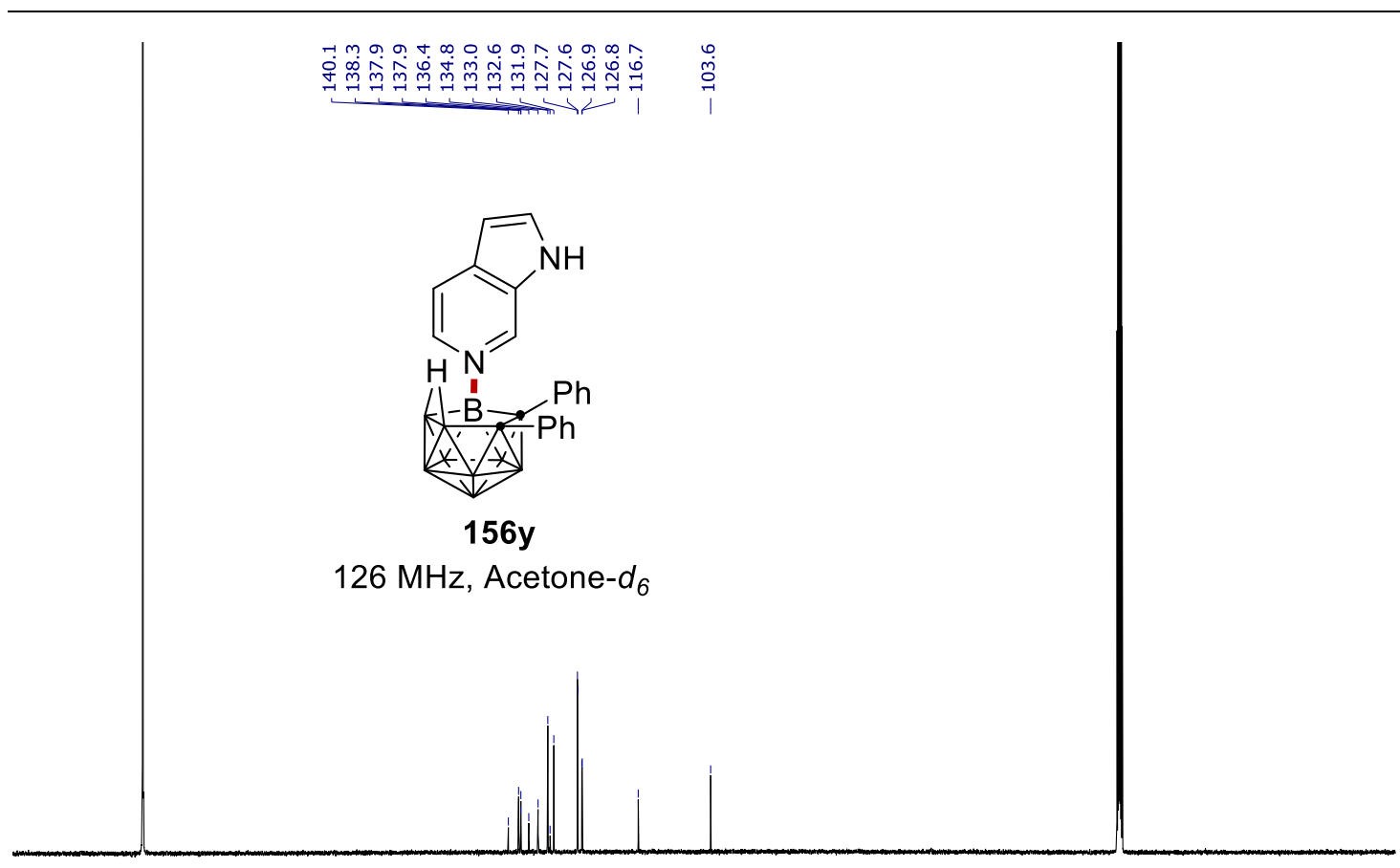

$\begin{array}{lllllllllllllllllllllllll}220 & 210 & 200 & 190 & 180 & 170 & 160 & 150 & 140 & 130 & 120 & 110 & 100 & 90 & 80 & 70 & 60 & 50 & 40 & 30 & 20 & 10 & 0 & -10 & -:\end{array}$ f1 (ppm)

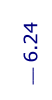

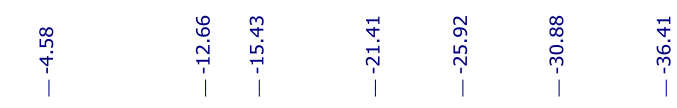

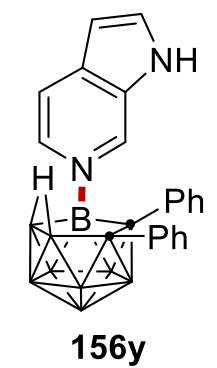

$128 \mathrm{MHz}$, Acetone- $d_{6}$
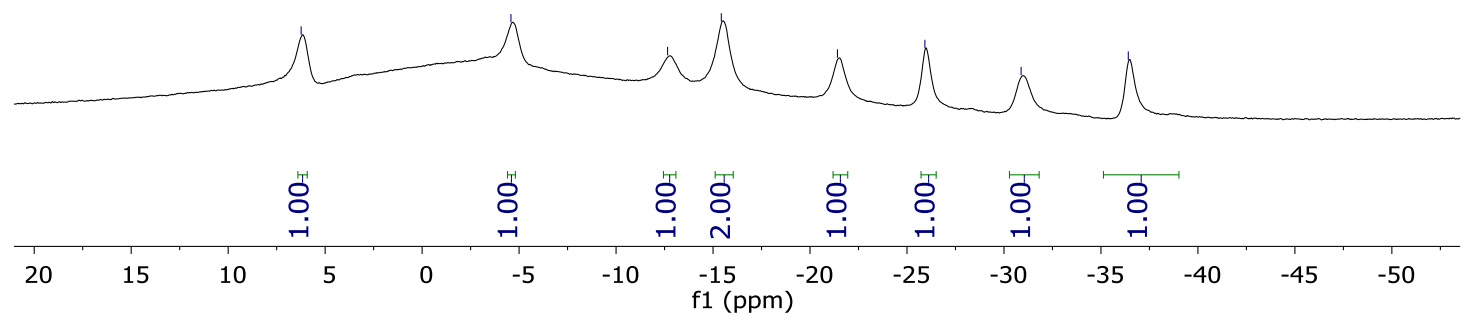


\section{NMR Spectra}

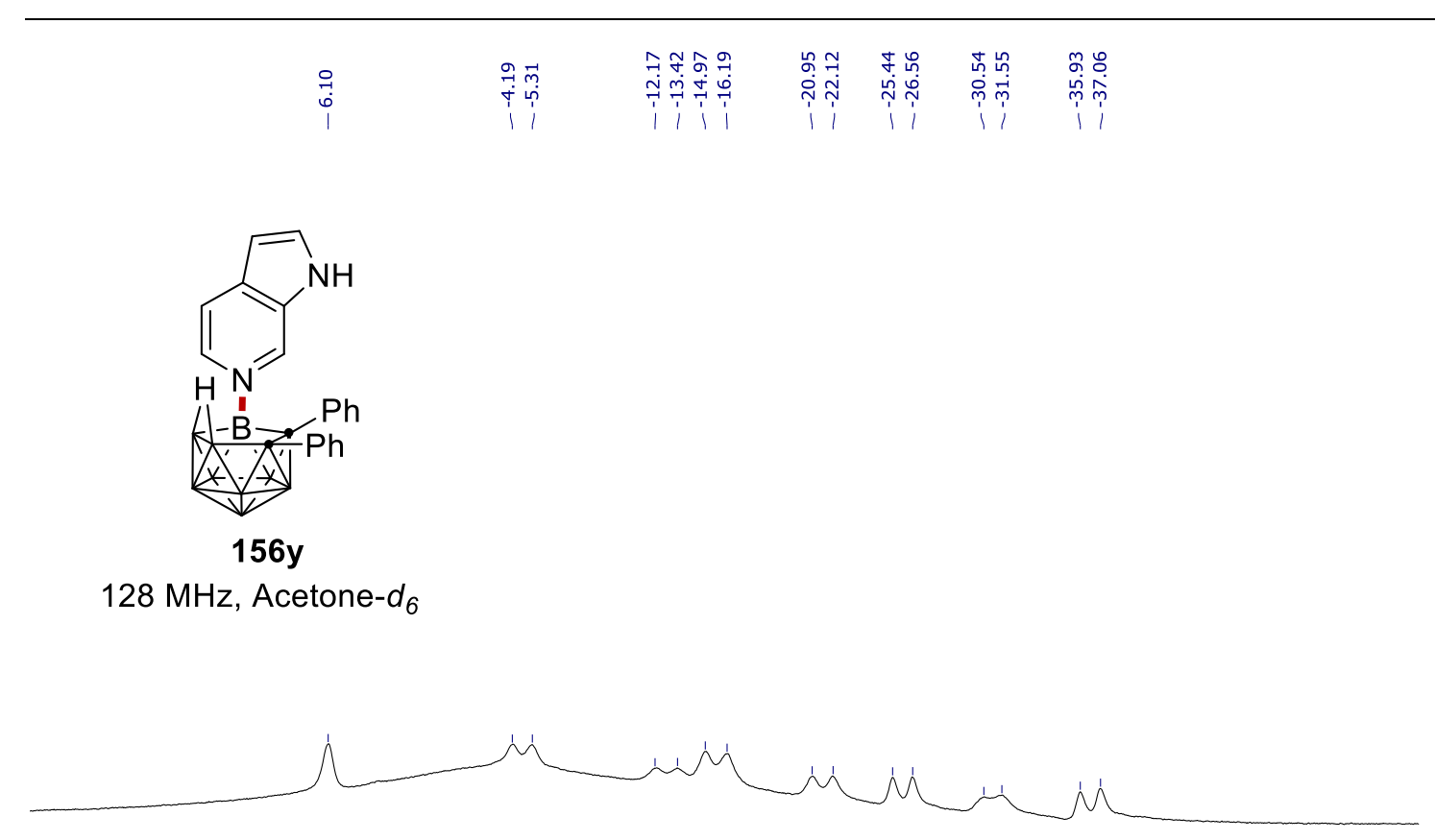

\begin{tabular}{|c|c|c|c|c|c|c|c|c|c|c|c|c|c|c|}
\hline 20 & 15 & 10 & 5 & 0 & -5 & -10 & $\begin{array}{c}-15 \\
\mathrm{f} 1(\mathrm{ppm})\end{array}$ & -20 & -25 & -30 & -35 & -40 & -45 & -50 \\
\hline
\end{tabular}

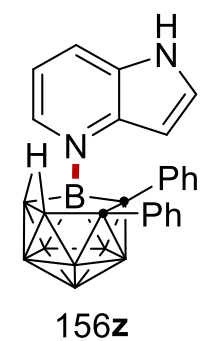

$500 \mathrm{MHz}$, Acetone- $d_{6}$

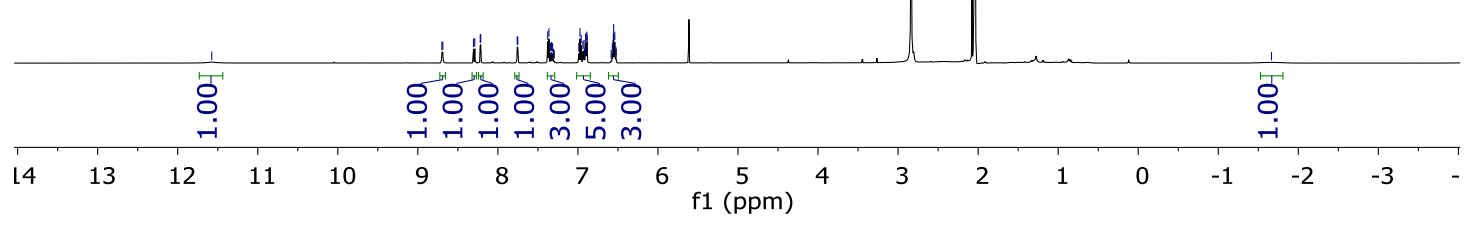




\section{NMR Spectra}

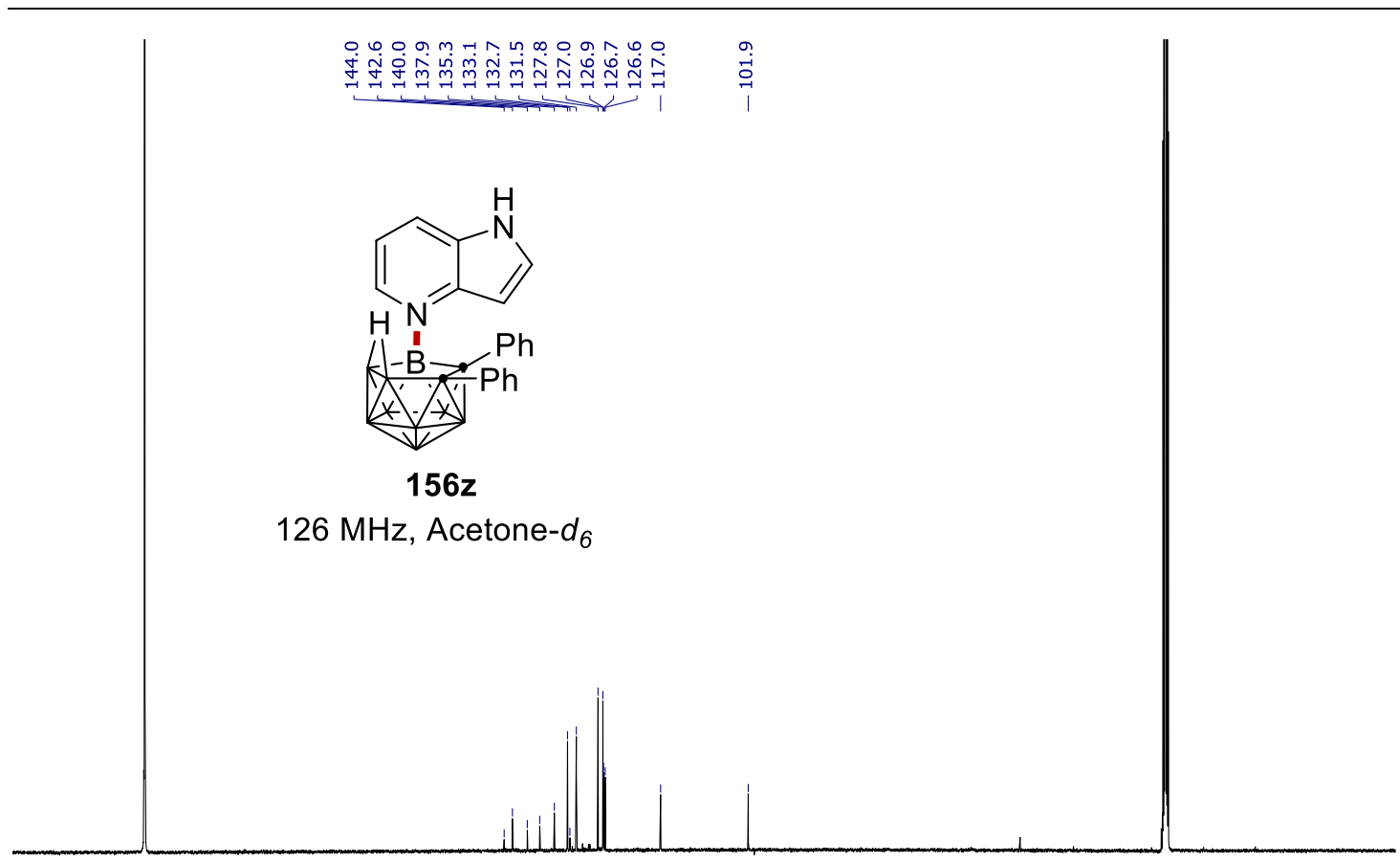

$\begin{array}{lllllllllllllllllllllll}220 & 210 & 200 & 190 & 180 & 170 & 160 & 150 & 140 & 130 & 120 & 110 & 100 & 90 & 80 & 70 & 60 & 50 & 40 & 30 & 20 & 10 & 0\end{array}$ f1 (ppm)

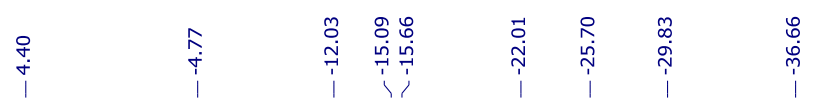

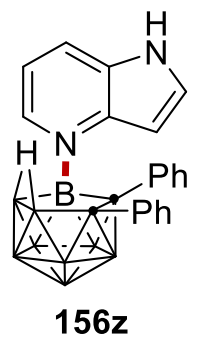

$128 \mathrm{MHz}$, Acetone- $d_{6}$

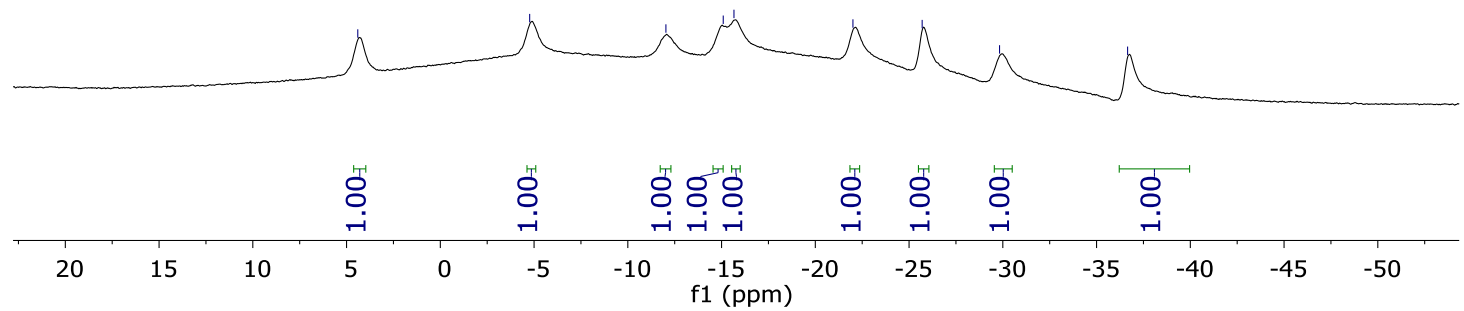




\section{NMR Spectra}

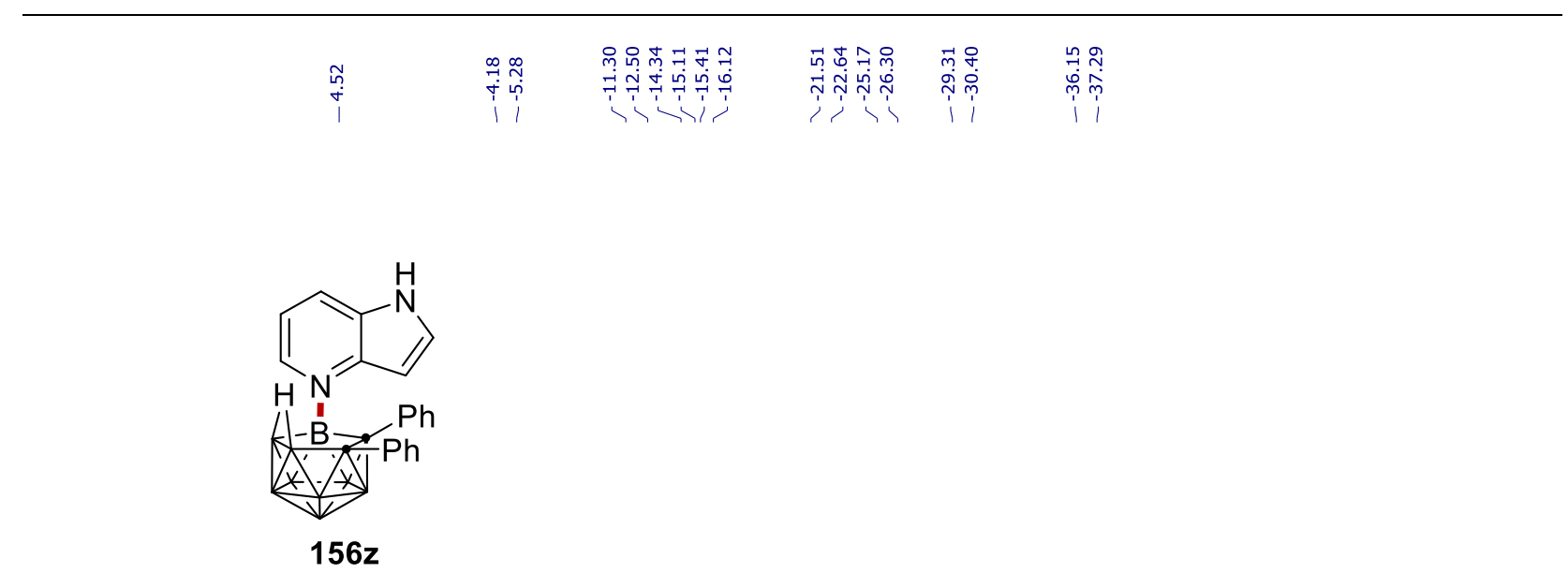

$128 \mathrm{MHz}$, Acetone- $d_{6}$

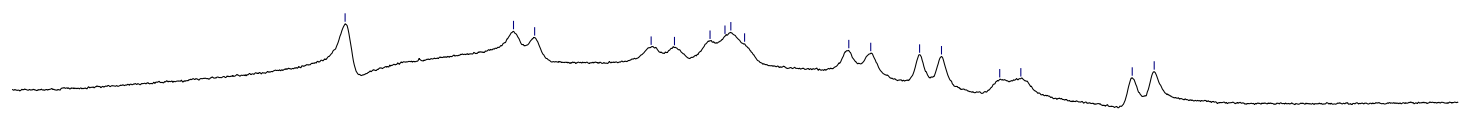

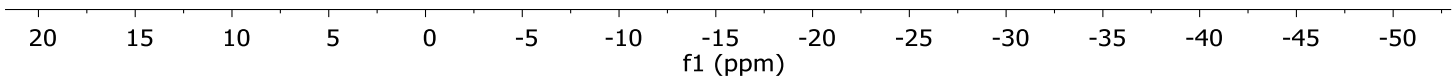

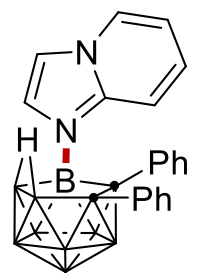

156aa

$500 \mathrm{MHz}, \mathrm{CD}_{2} \mathrm{Cl}_{2}$

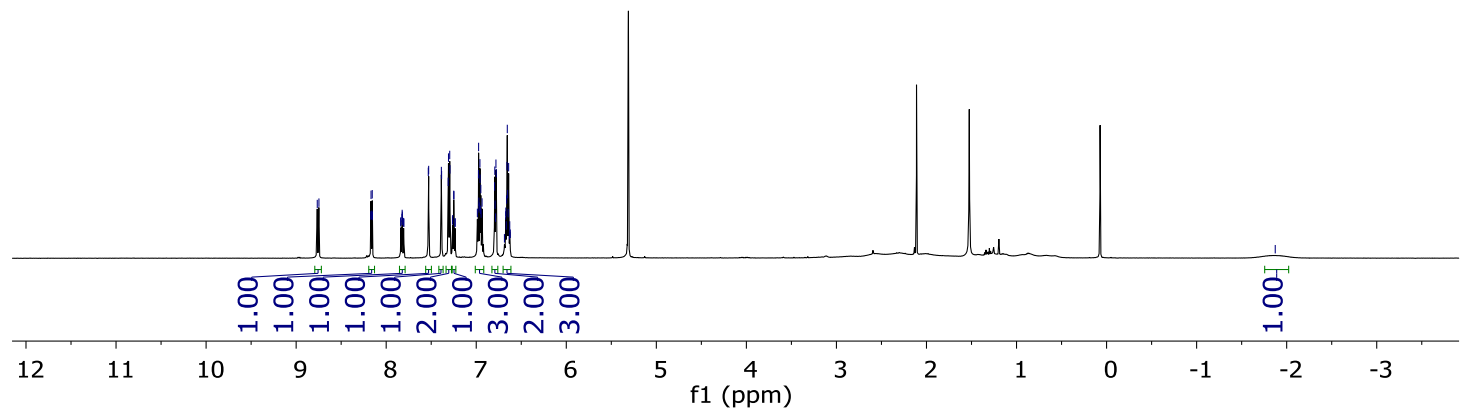




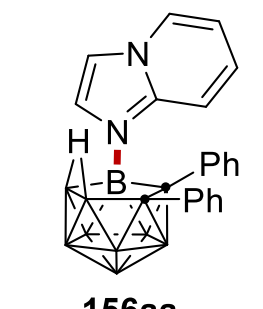

$126 \mathrm{MHz}, \mathrm{CD}_{2} \mathrm{Cl}_{2}$
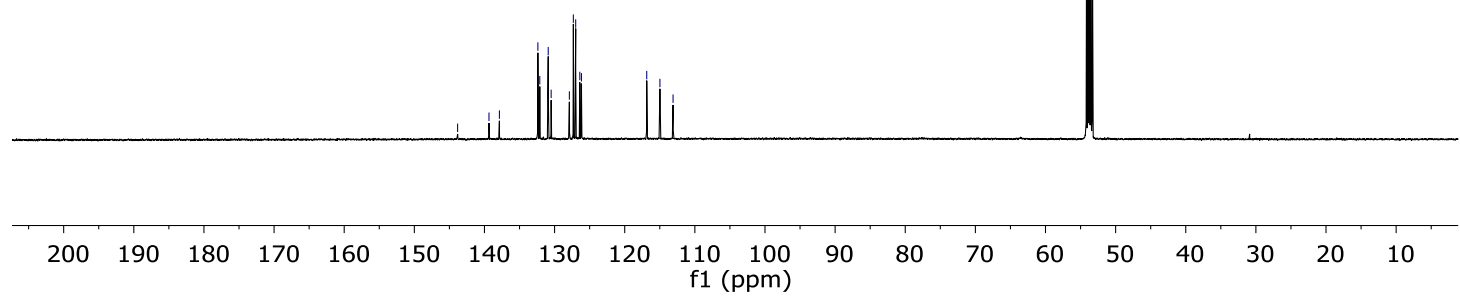

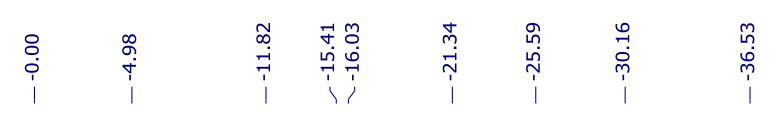

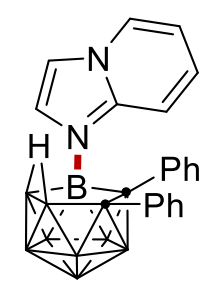

$156 a a$

$128 \mathrm{MHz}, \mathrm{CD}_{2} \mathrm{Cl}_{2}$

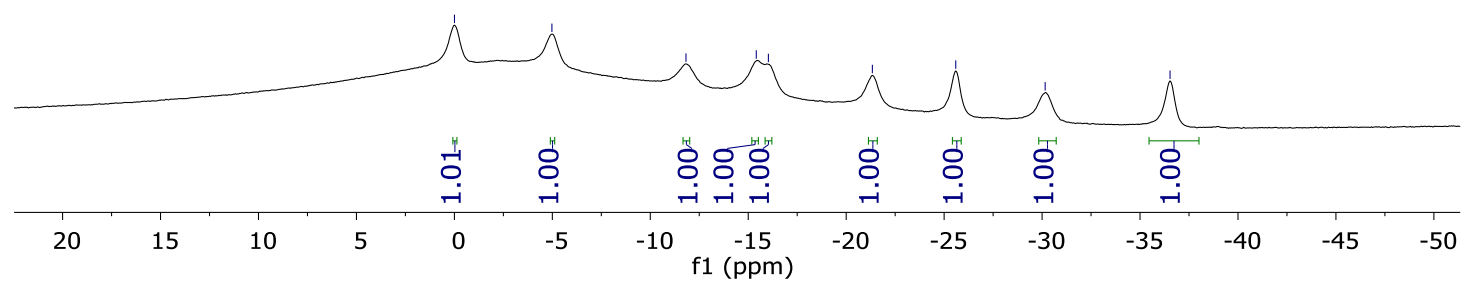




\section{NMR Spectra}

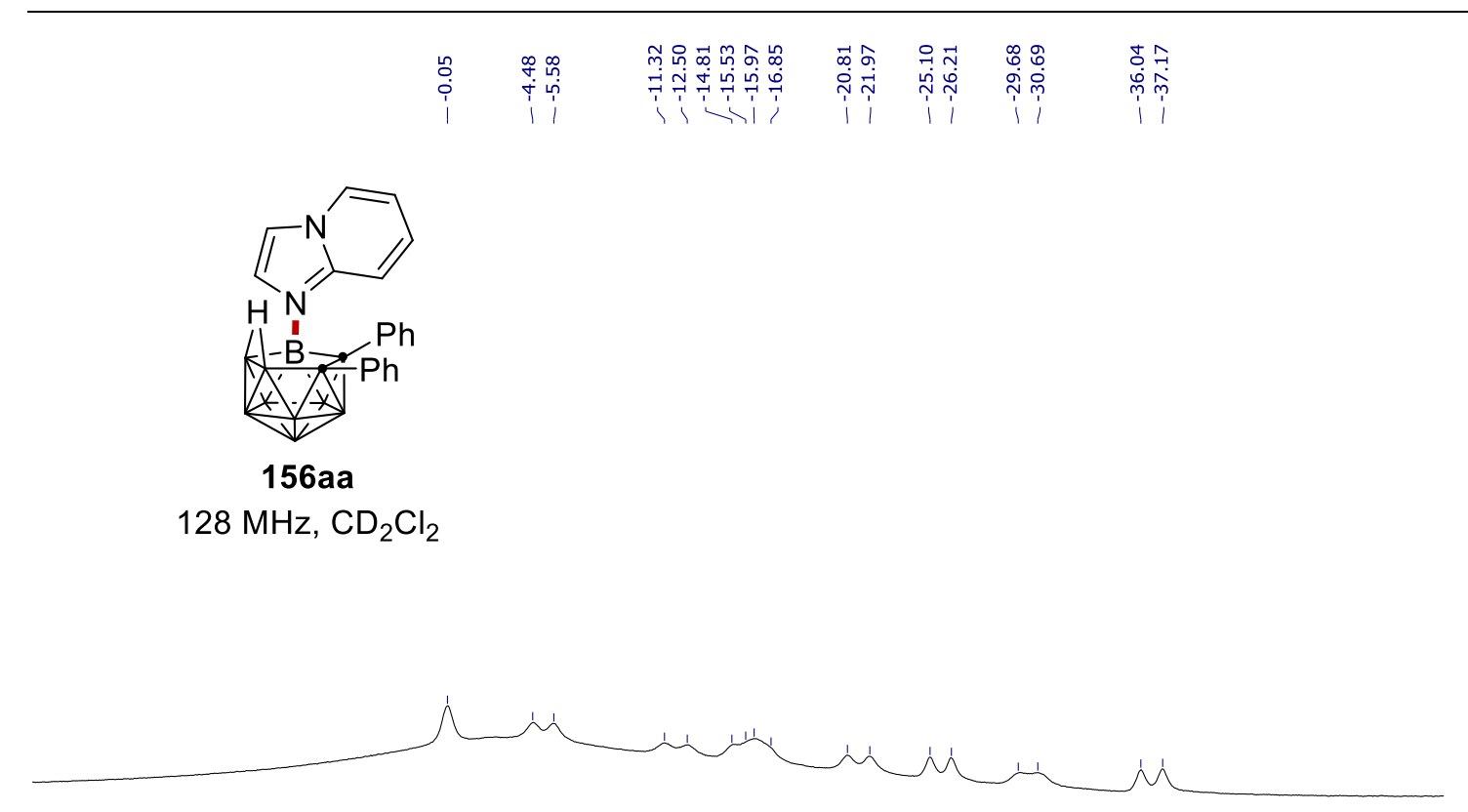

\begin{tabular}{|c|c|c|c|c|c|c|c|c|c|c|c|c|c|c|}
\hline 20 & 15 & 10 & 5 & 0 & -5 & -10 & $\begin{array}{c}-15 \\
\mathrm{f} 1(\mathrm{ppm})\end{array}$ & -20 & -25 & -30 & -35 & -40 & -45 & -50 \\
\hline
\end{tabular}

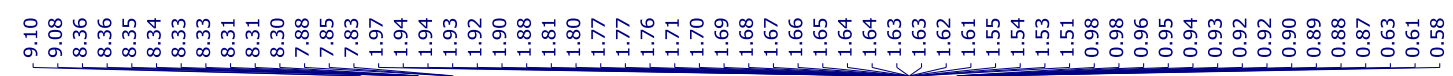

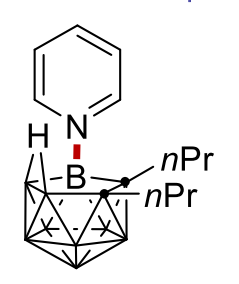

$156 \mathrm{bb}$ $300 \mathrm{MHz}, \mathrm{CD}_{2} \mathrm{Cl}_{2}$

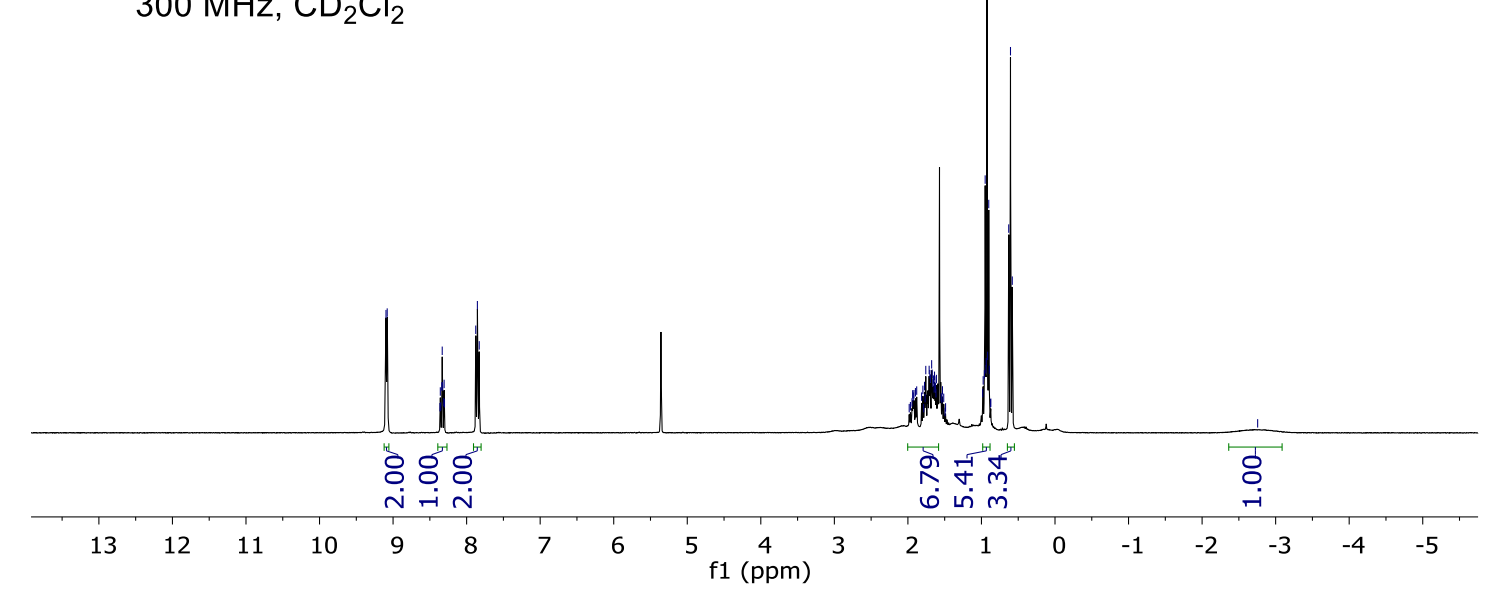




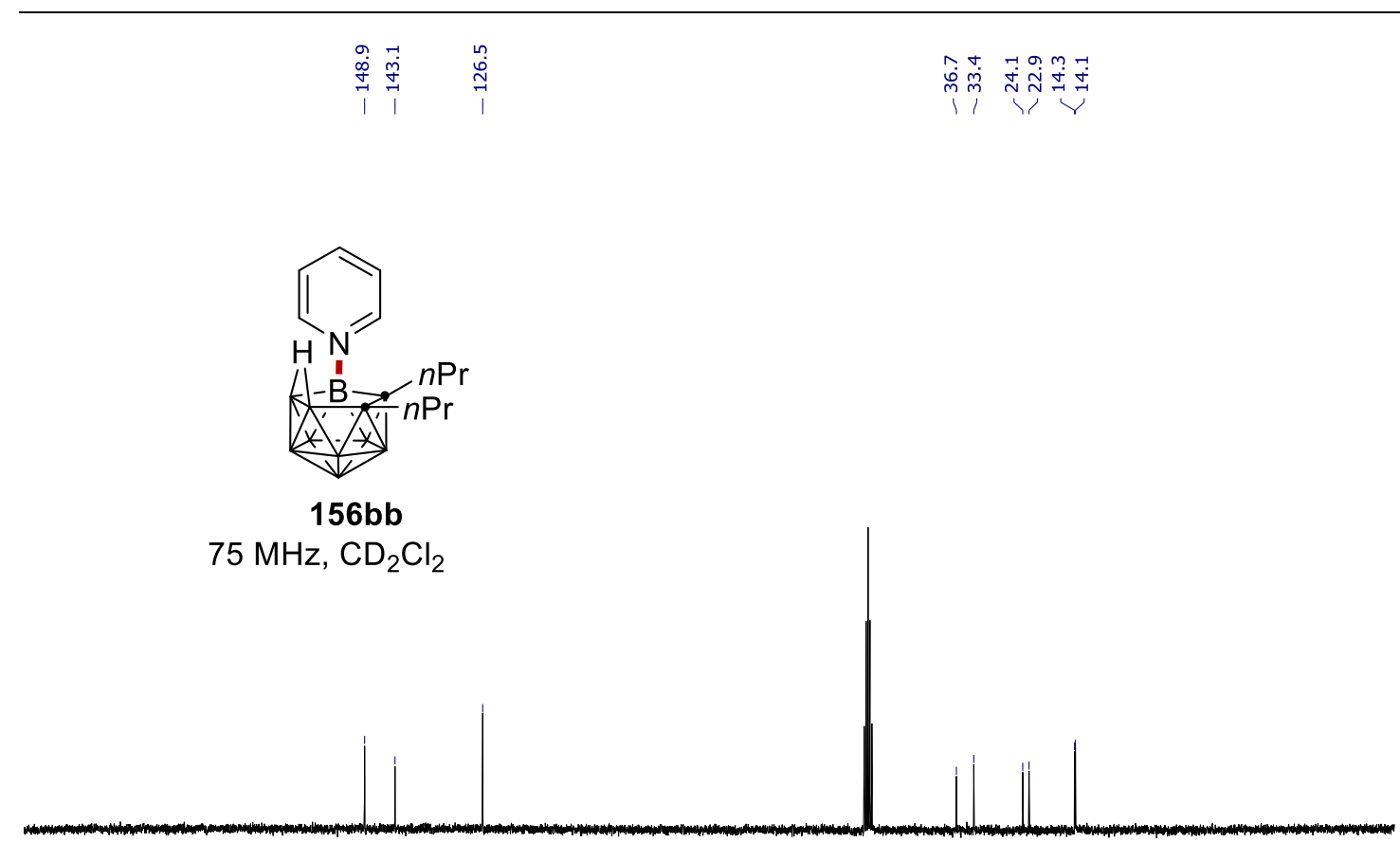

$\begin{array}{lllllllllllllllllllllllll}210 & 200 & 190 & 180 & 170 & 160 & 150 & 140 & 130 & 120 & 110 & 100 & \begin{array}{l}90 \\ \mathrm{f} 1(\mathrm{ppm})\end{array} & 70 & 60 & 50 & 40 & 30 & 20 & 10 & 0 & -10 & -20 & -30 & -40\end{array}$

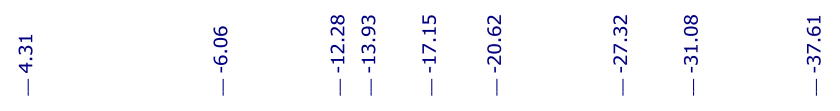

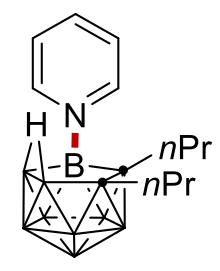

$156 \mathrm{bb}$

$96 \mathrm{MHz}, \mathrm{CD}_{2} \mathrm{Cl}_{2}$

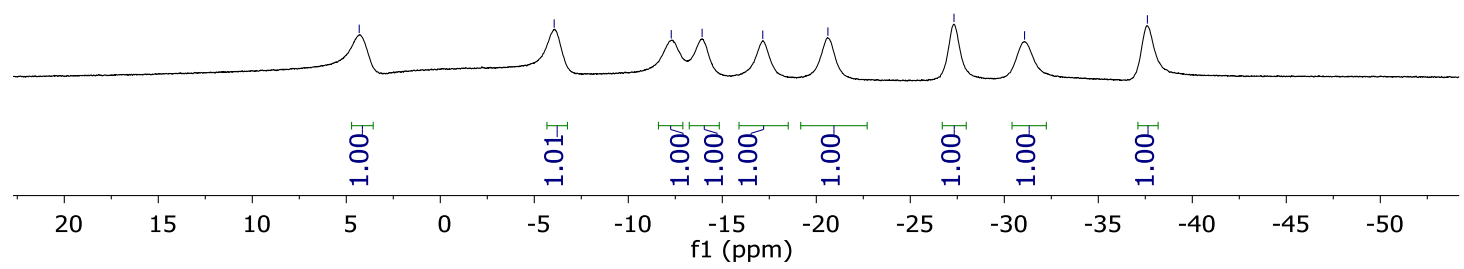




\section{NMR Spectra}

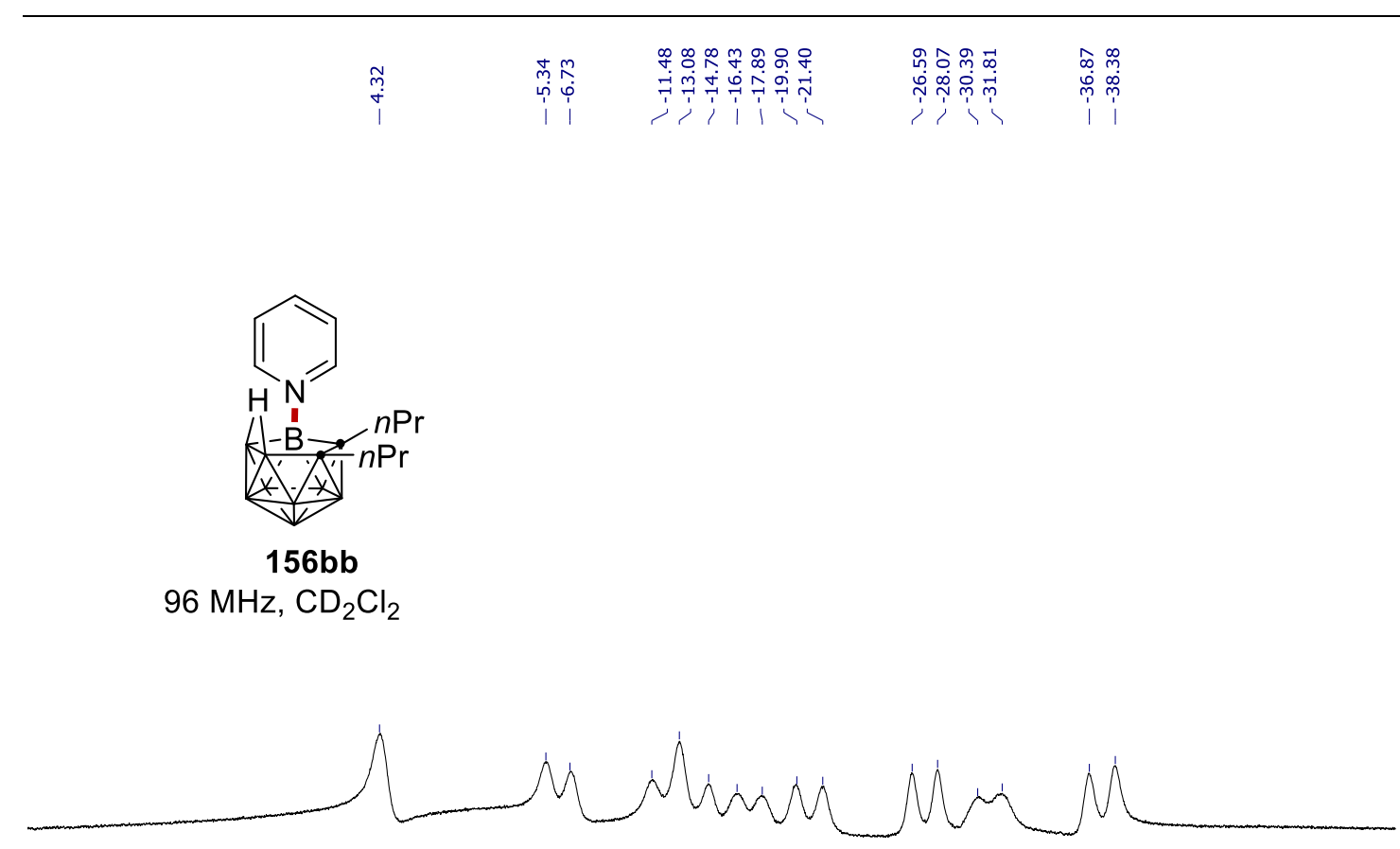

\begin{tabular}{|c|c|c|c|c|c|c|c|c|c|c|c|c|c|c|}
\hline & 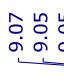 & $\begin{array}{ll}m & - \\
0 & 0 \\
\infty & \infty \\
1 & \\
\end{array}$ & $\Rightarrow$ & I & 敨 & ن & 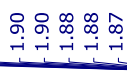 & $\begin{array}{r}n \\
\infty \\
\infty \\
i \\
i \\
\end{array}$ & 吾 & 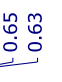 & & $\underset{\substack{N \\
i \\
i}}{i}$ & & \\
\hline
\end{tabular}

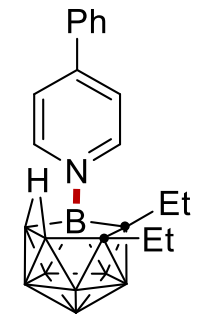

$156 \mathrm{cc}$

$300 \mathrm{MHz}, \mathrm{CD}_{2} \mathrm{Cl}_{2}$

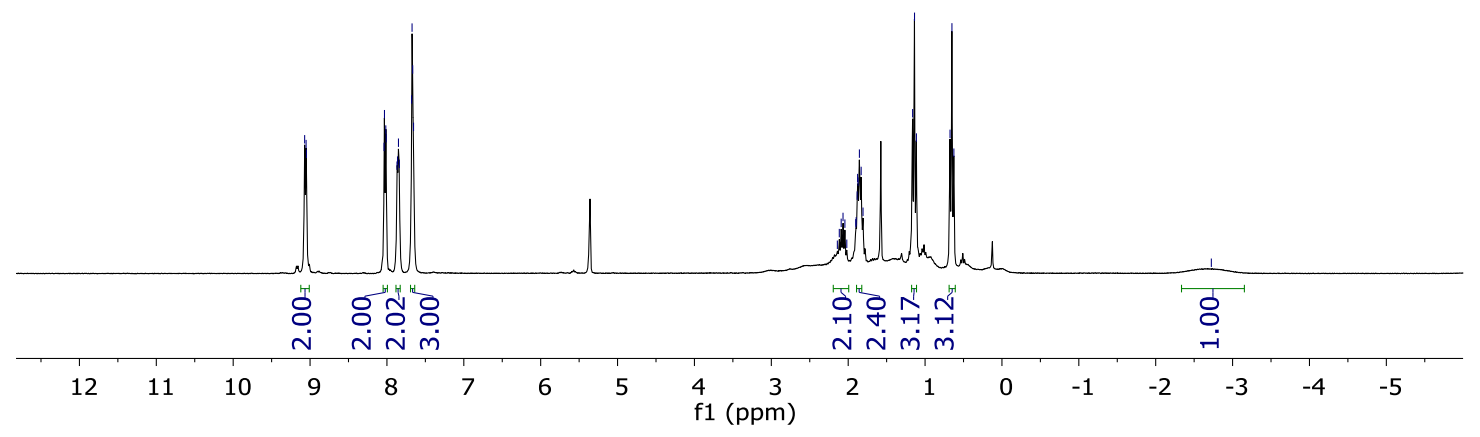




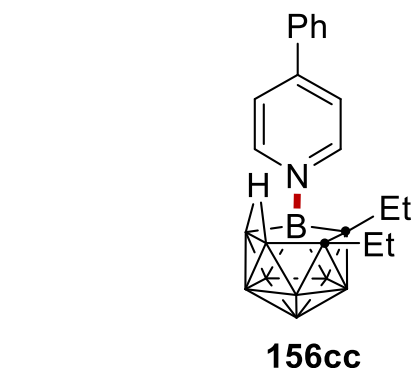

$75 \mathrm{MHz}, \mathrm{CD}_{2} \mathrm{Cl}_{2}$
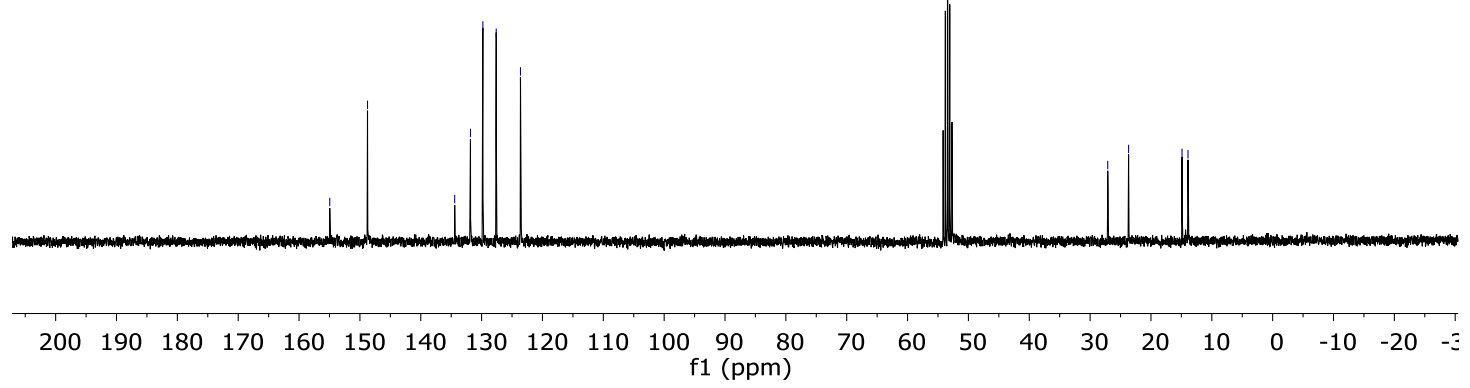

\begin{tabular}{|c|c|c|c|c|c|c|}
\hline 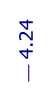 & 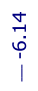 & 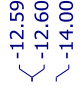 & $\stackrel{\substack{n \\
7}}{7}$ & $\begin{array}{l}\text { शे } \\
\text { iे } \\
i \\
i\end{array}$ & 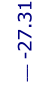 & $\begin{array}{c}\stackrel{ \pm}{t} \\
\stackrel{-1}{1} \\
1\end{array}$ \\
\hline
\end{tabular}

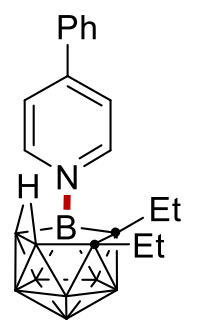

$156 \mathrm{cc}$

$96 \mathrm{MHz}, \mathrm{CD}_{2} \mathrm{Cl}_{2}$

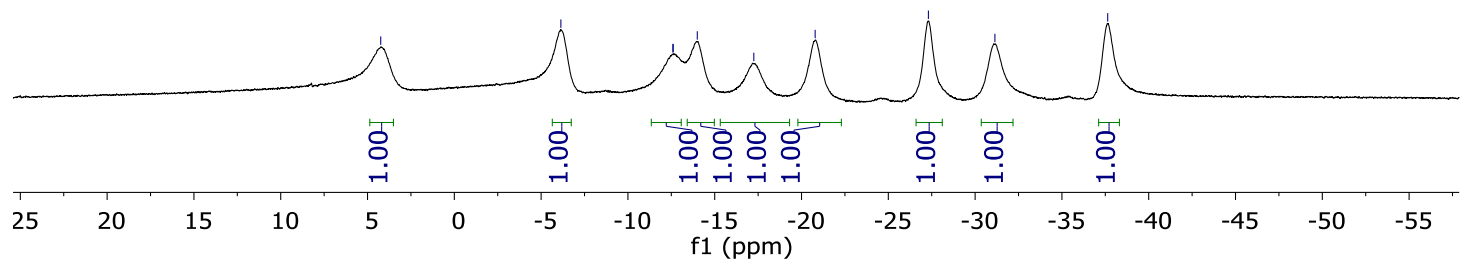




\section{NMR Spectra}

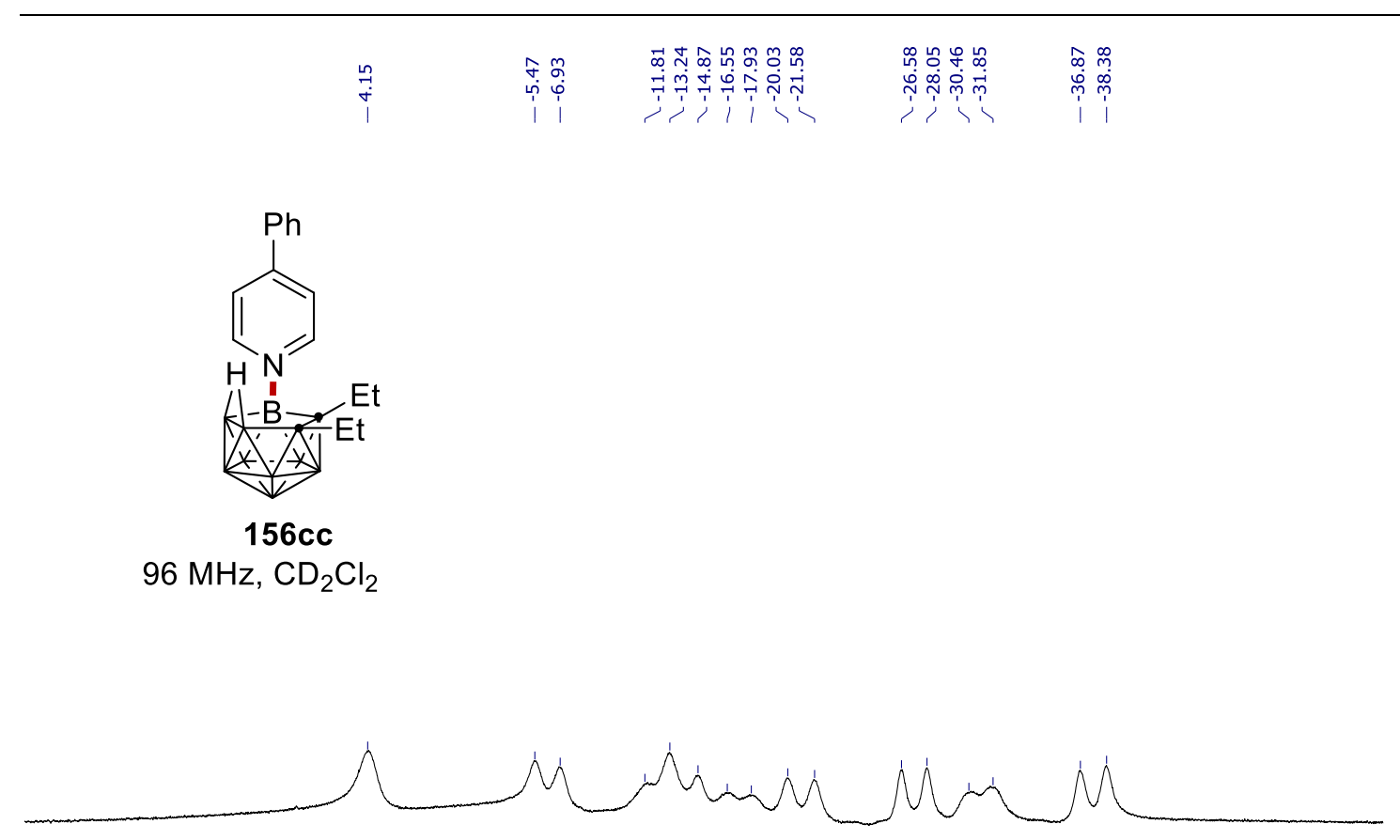

\begin{tabular}{|c|c|c|c|c|c|c|c|c|c|c|c|c|c|c|}
\hline 20 & 15 & 10 & 5 & 0 & -5 & -10 & $\begin{array}{c}-15 \\
\mathrm{f} 1(\mathrm{ppm})\end{array}$ & -20 & -25 & -30 & -35 & -40 & -45 & -50 \\
\hline
\end{tabular}
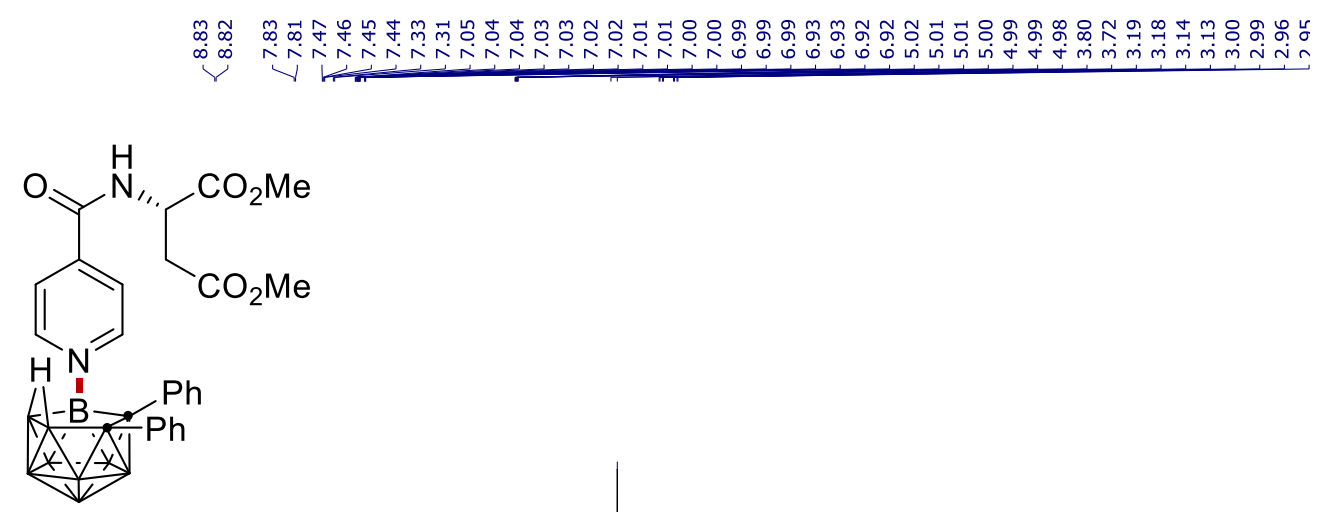

157a

$400 \mathrm{MHz}, \mathrm{CD}_{2} \mathrm{Cl}_{2}$

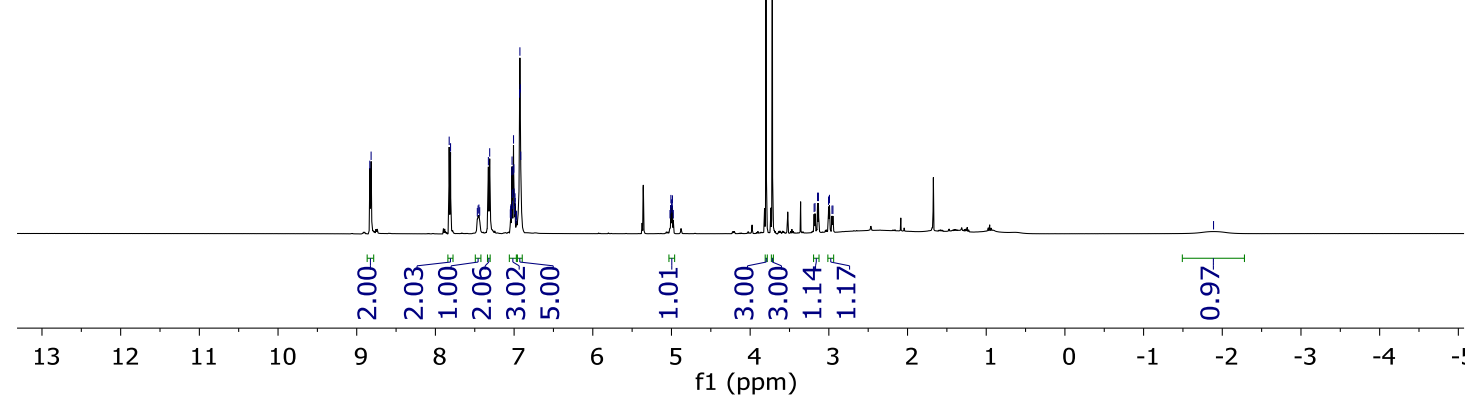



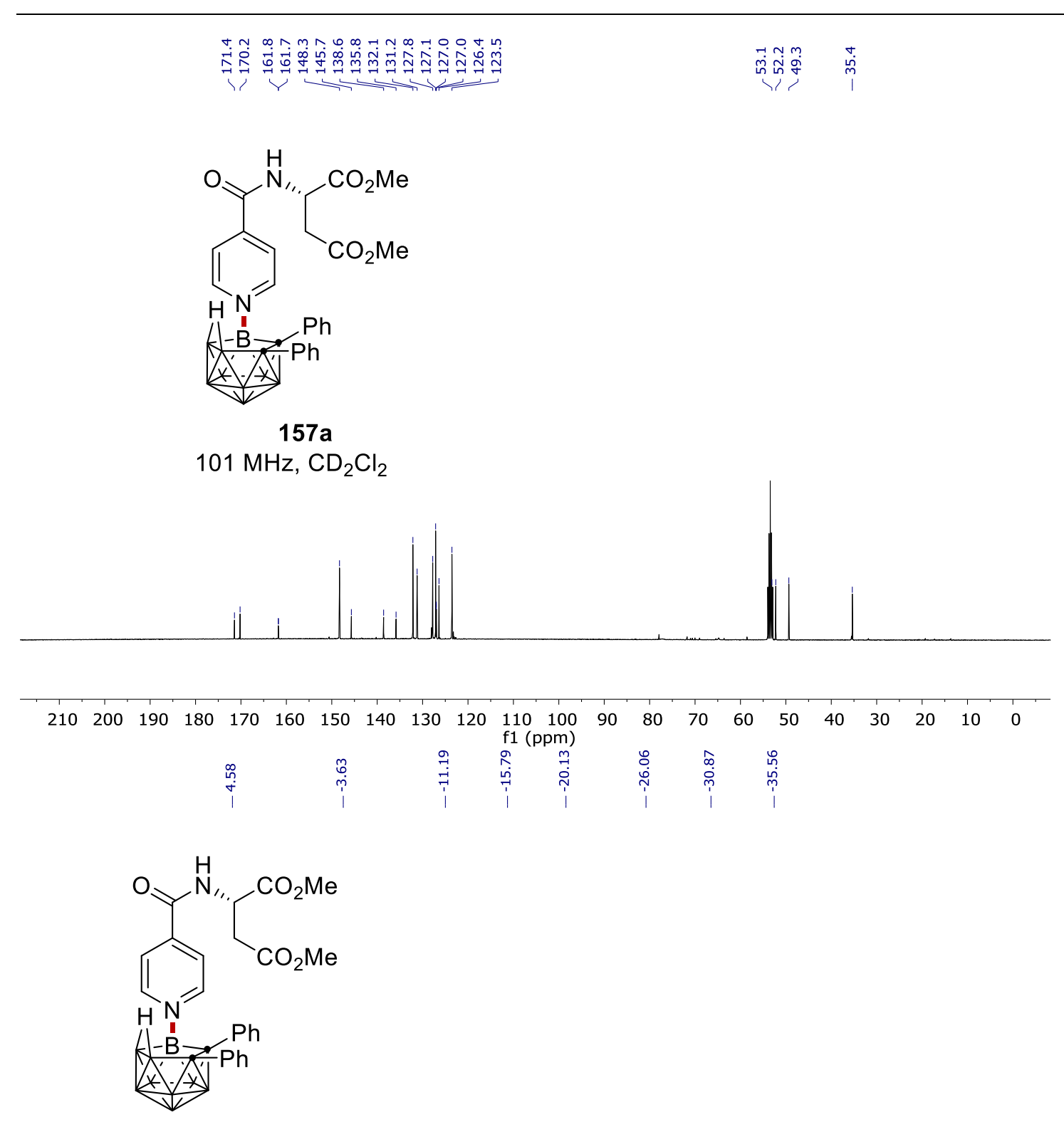

\section{7a}

$96 \mathrm{MHz}, \mathrm{CD}_{2} \mathrm{Cl}_{2}$

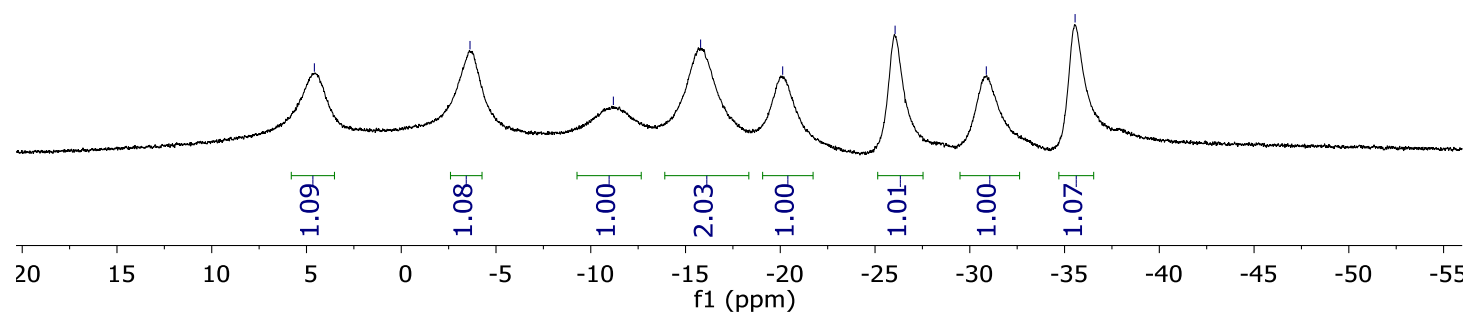




\section{NMR Spectra}

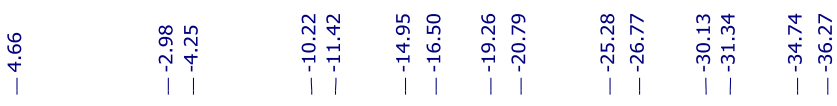

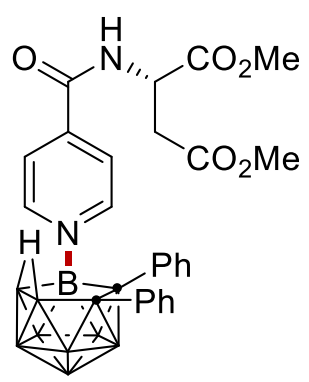

$157 a$

$96 \mathrm{MHz}, \mathrm{CD}_{2} \mathrm{Cl}_{2}$
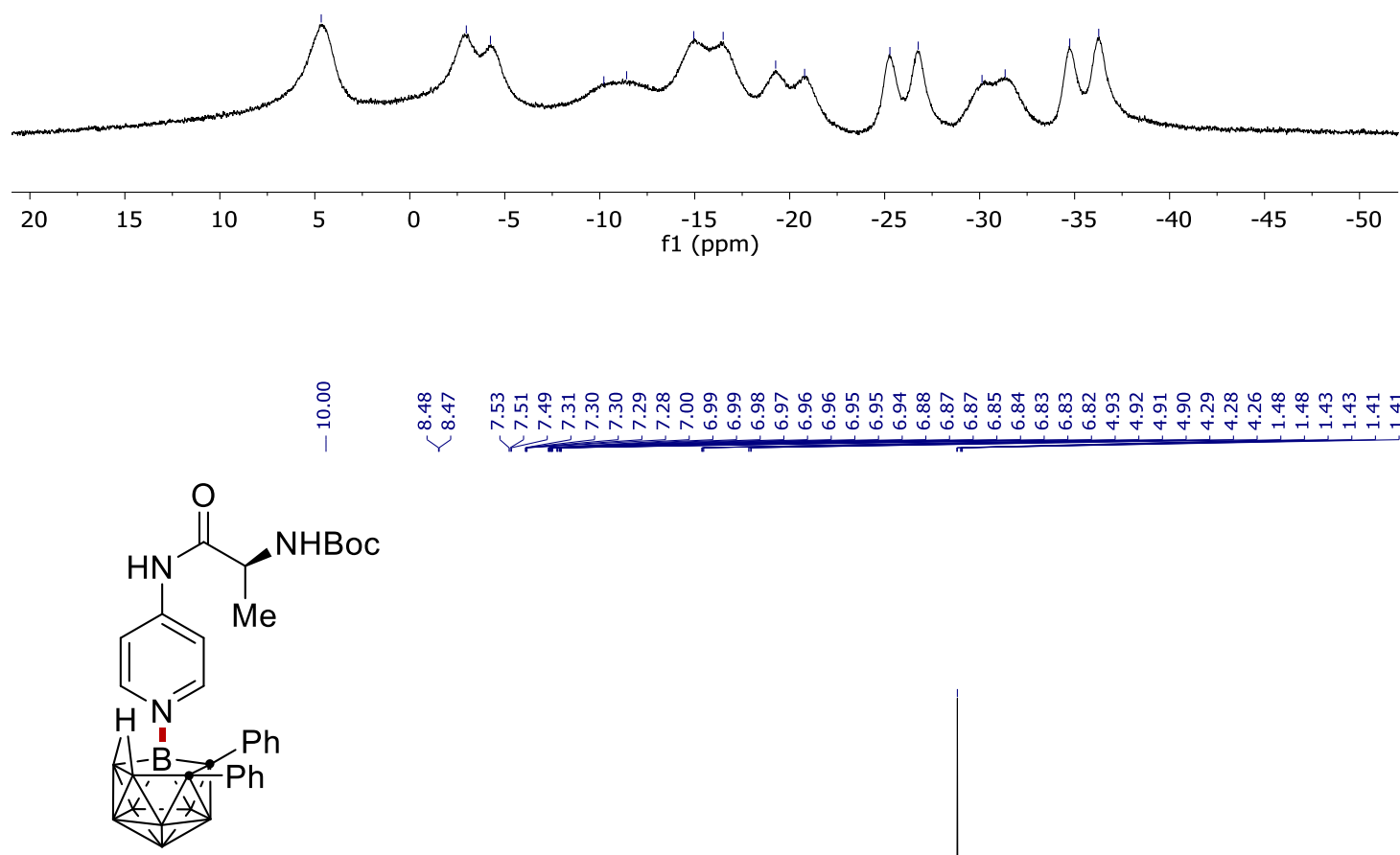

157b

$400 \mathrm{MHz}, \mathrm{CDCl}_{3}$

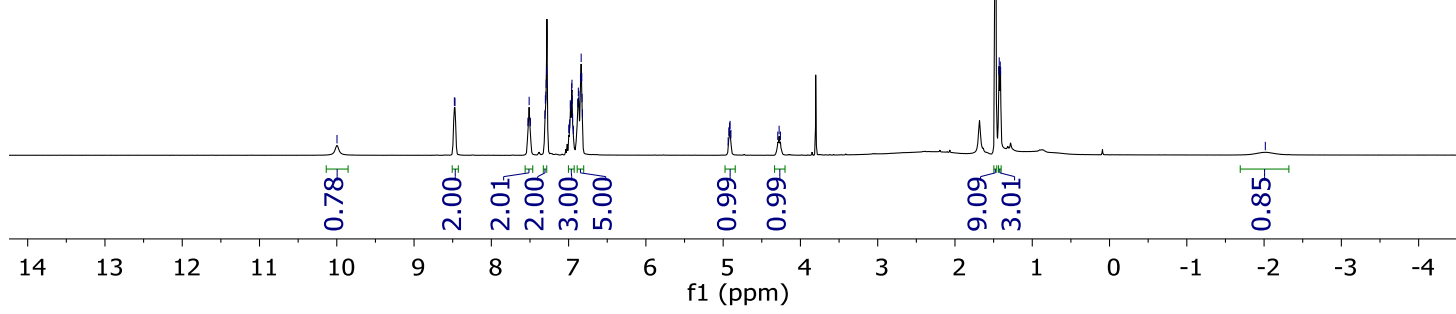



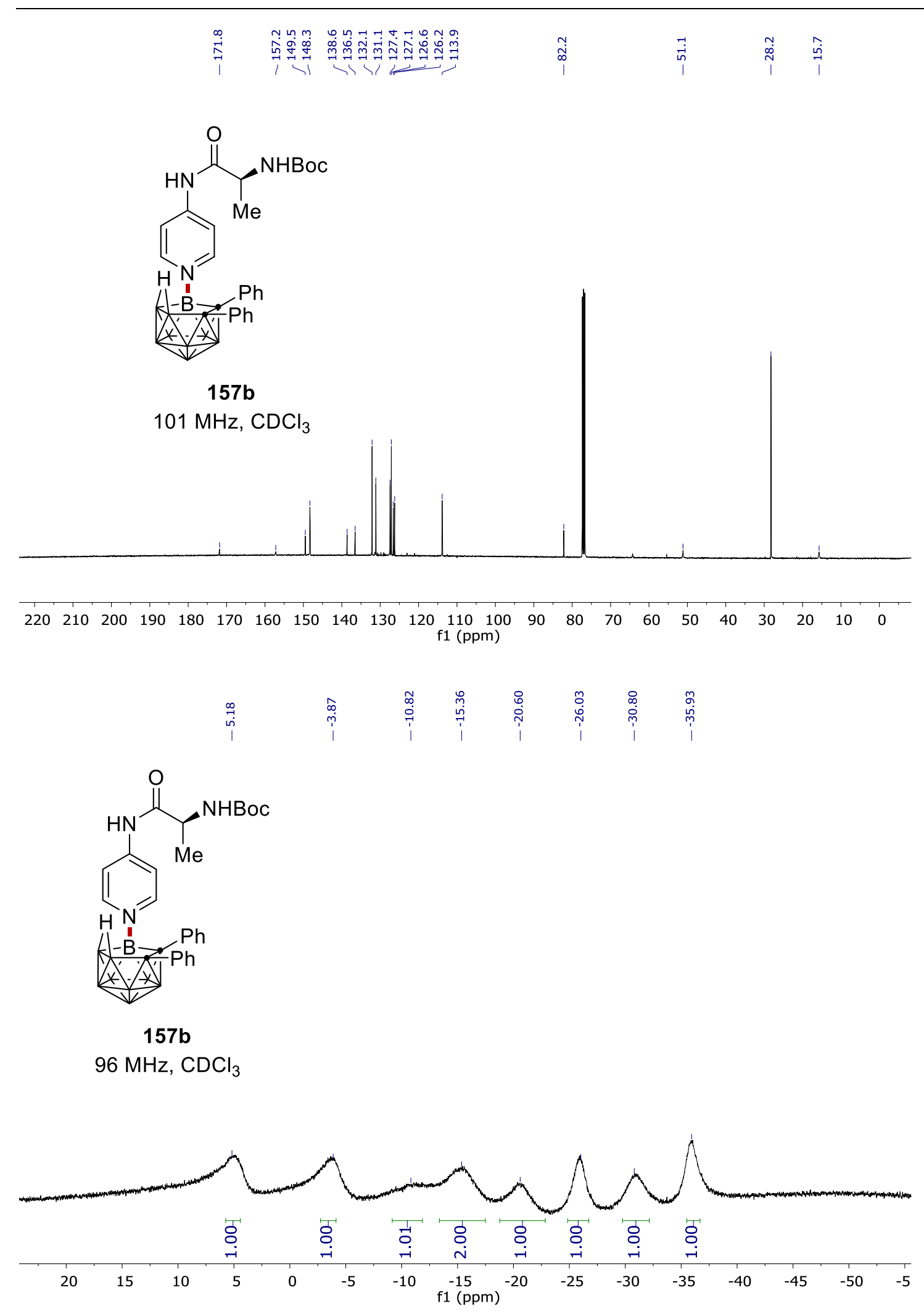


\section{NMR Spectra}
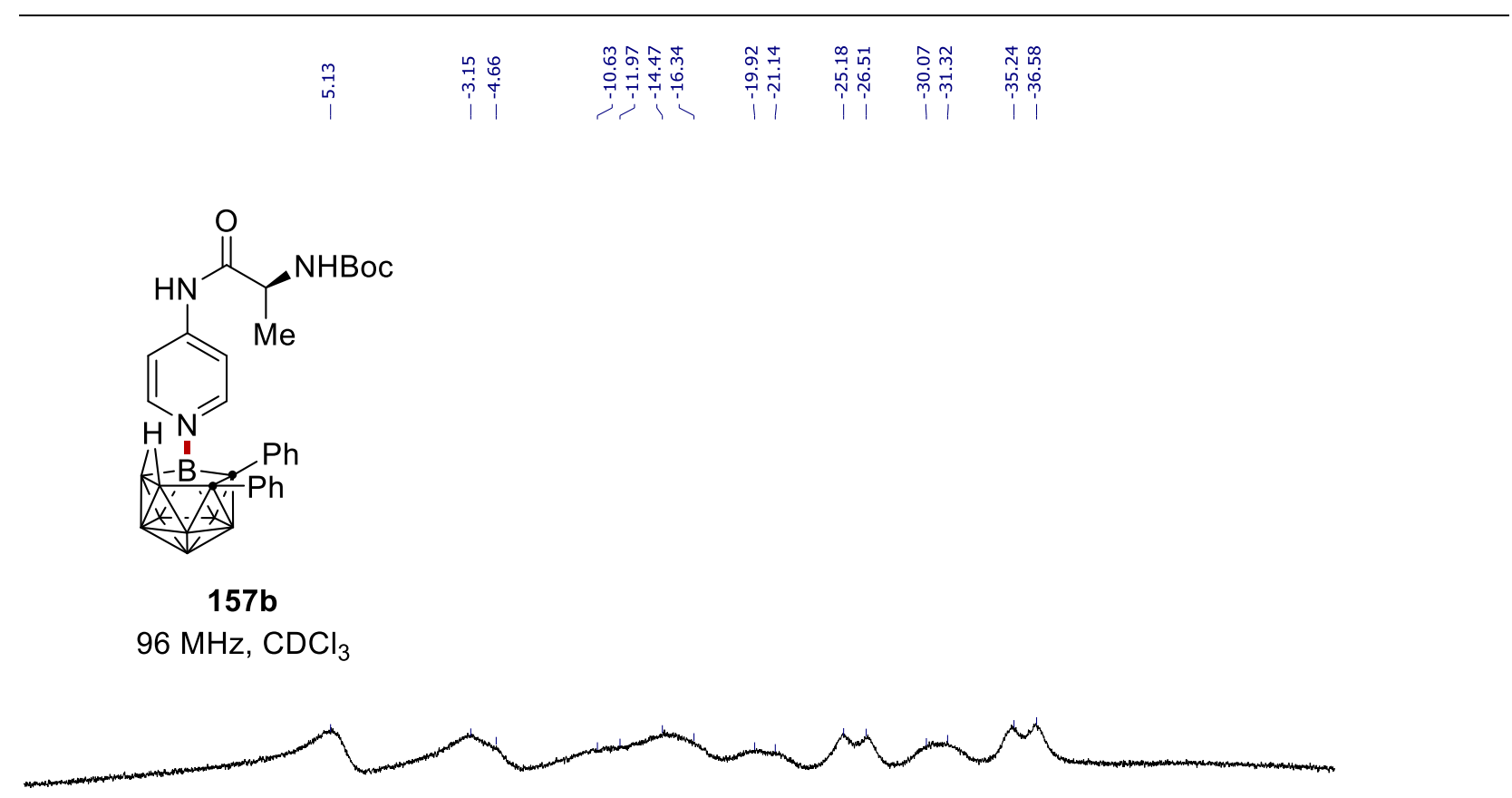

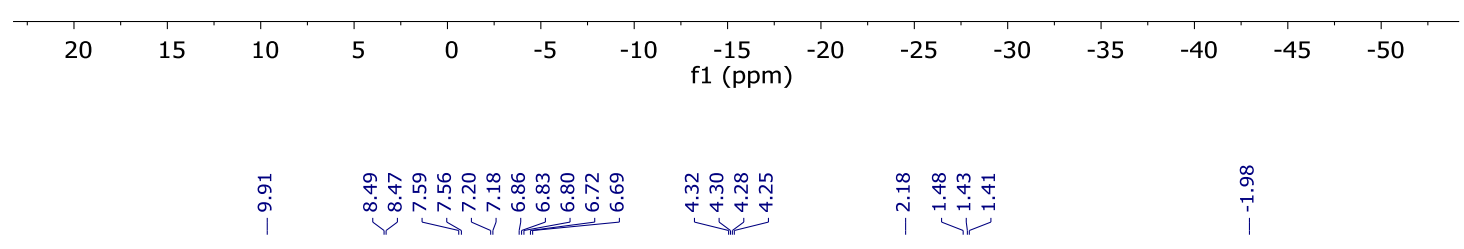

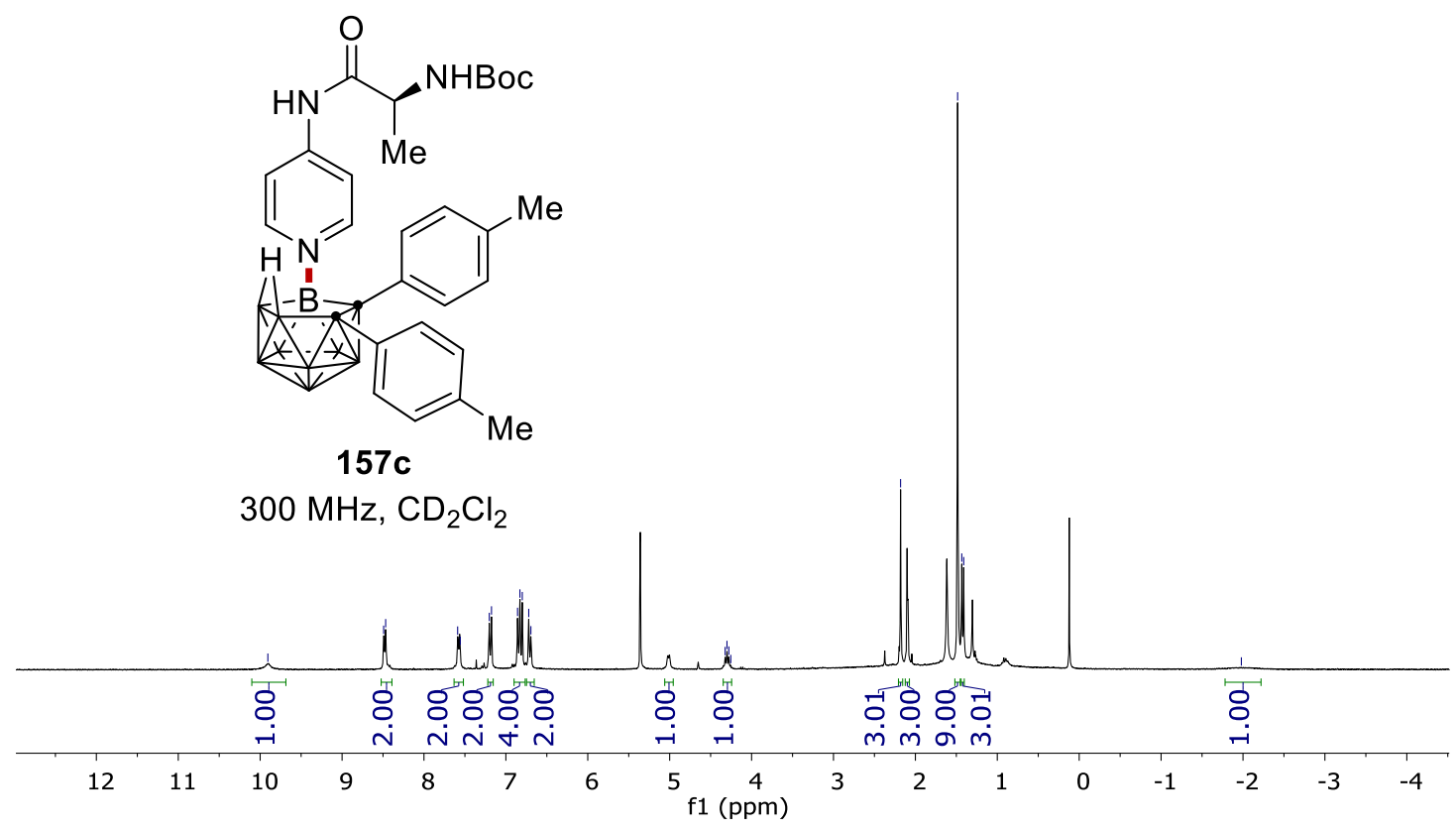



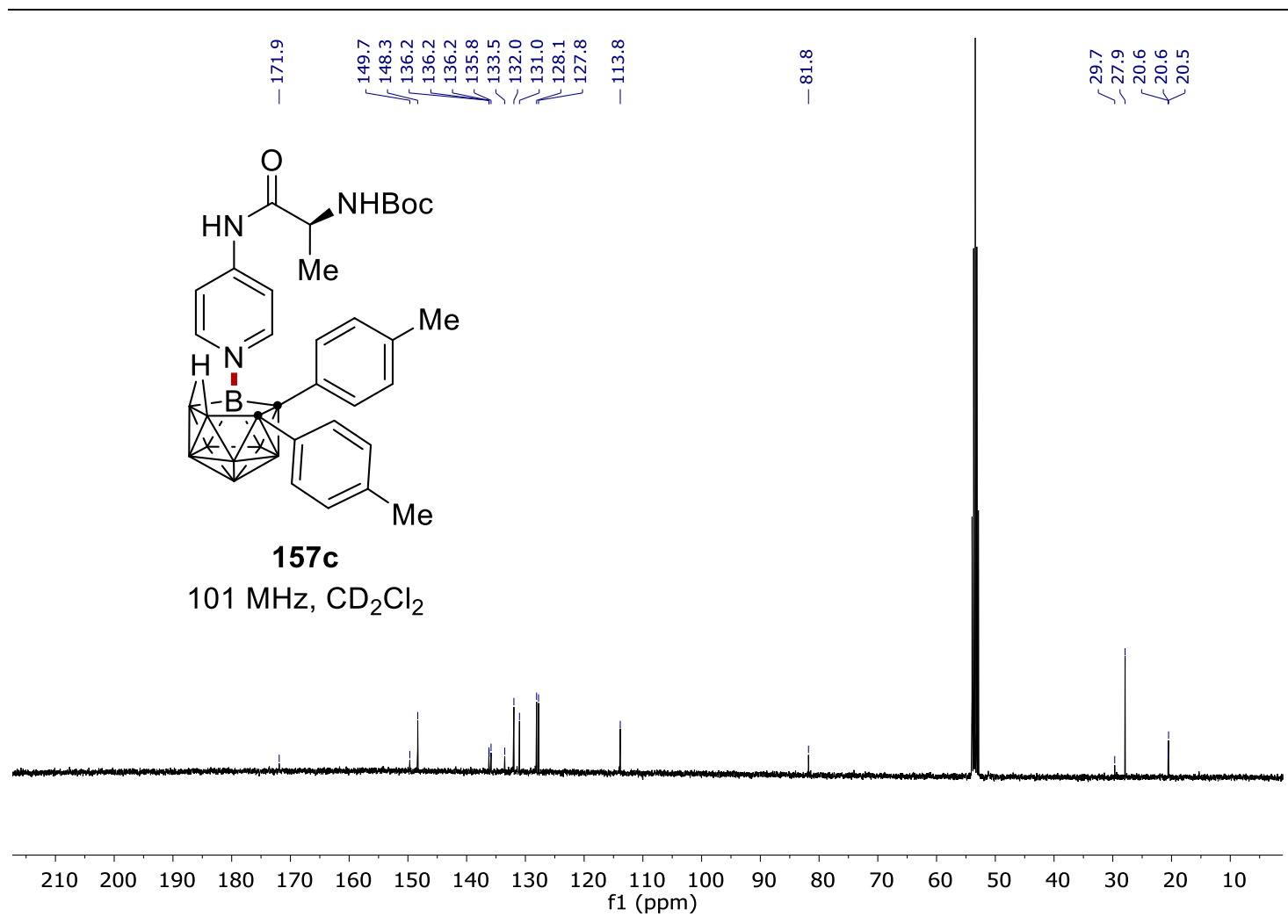

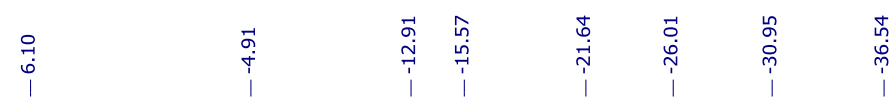

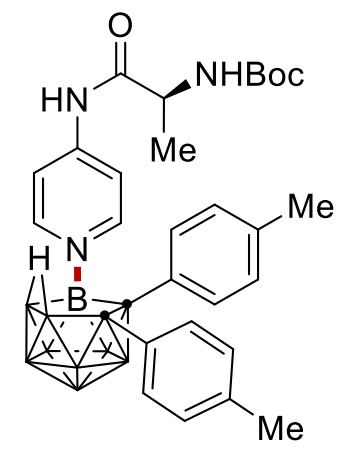

$157 \mathrm{c}$

$128 \mathrm{MHz}, \mathrm{CD}_{2} \mathrm{Cl}_{2}$

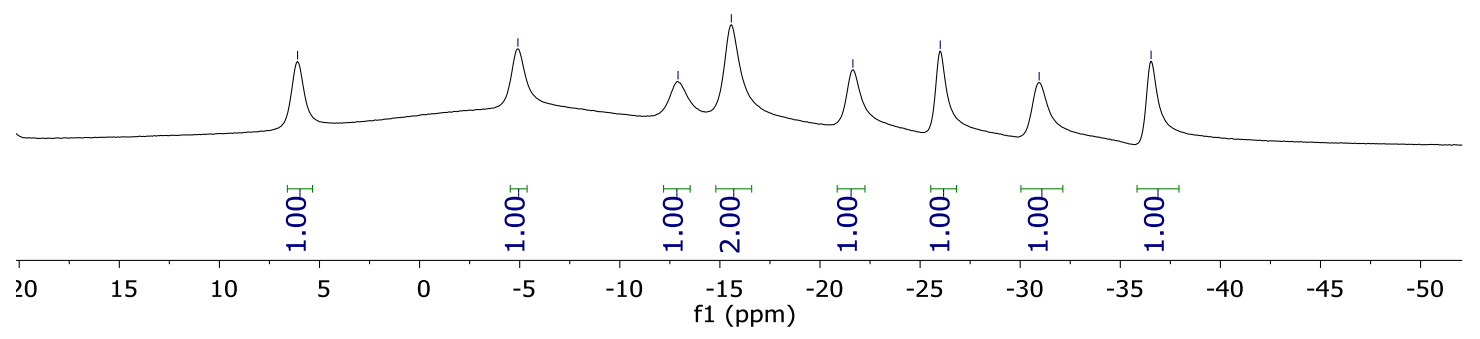




\section{NMR Spectra}

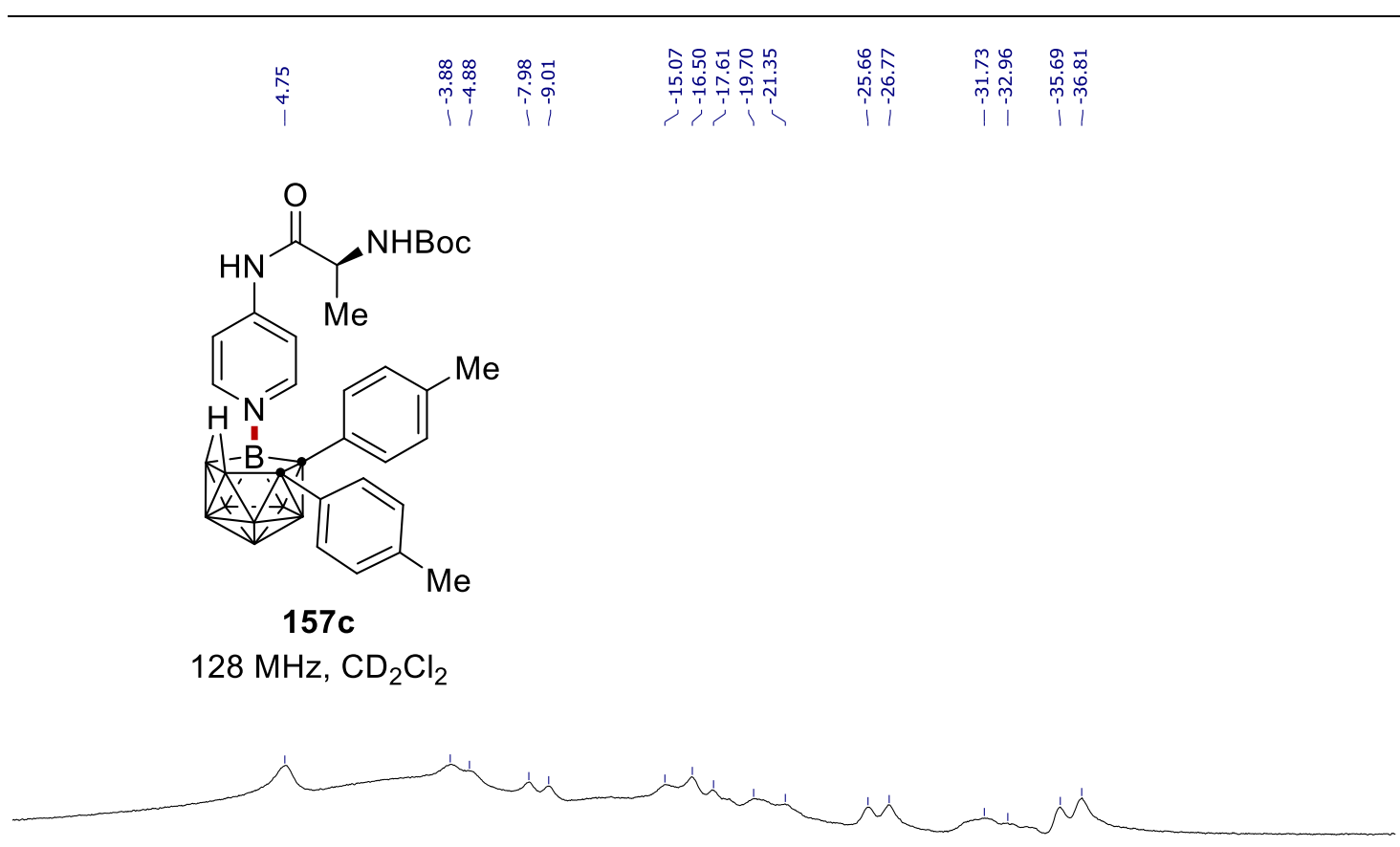

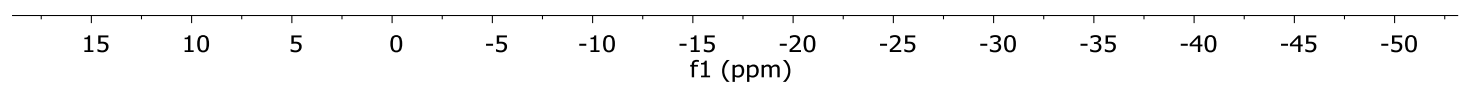

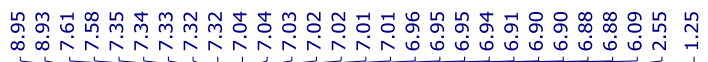

$\stackrel{\text { ڤ̆ }}{i}$

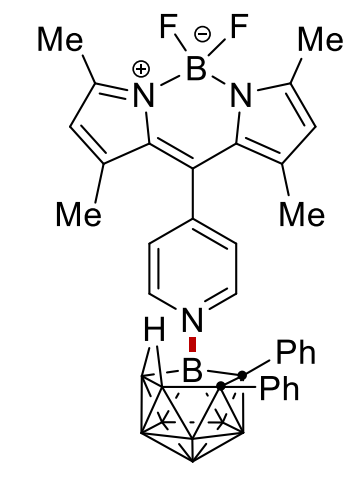

157d

$300 \mathrm{MHz}, \mathrm{CD}_{2} \mathrm{Cl}_{2}$

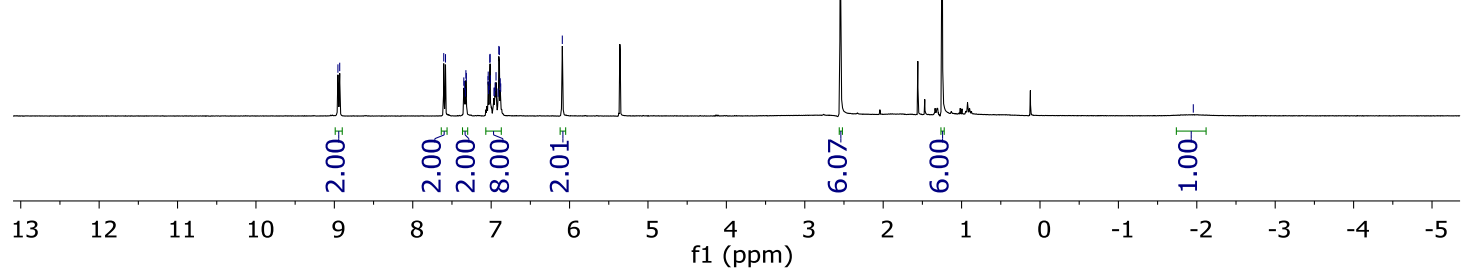



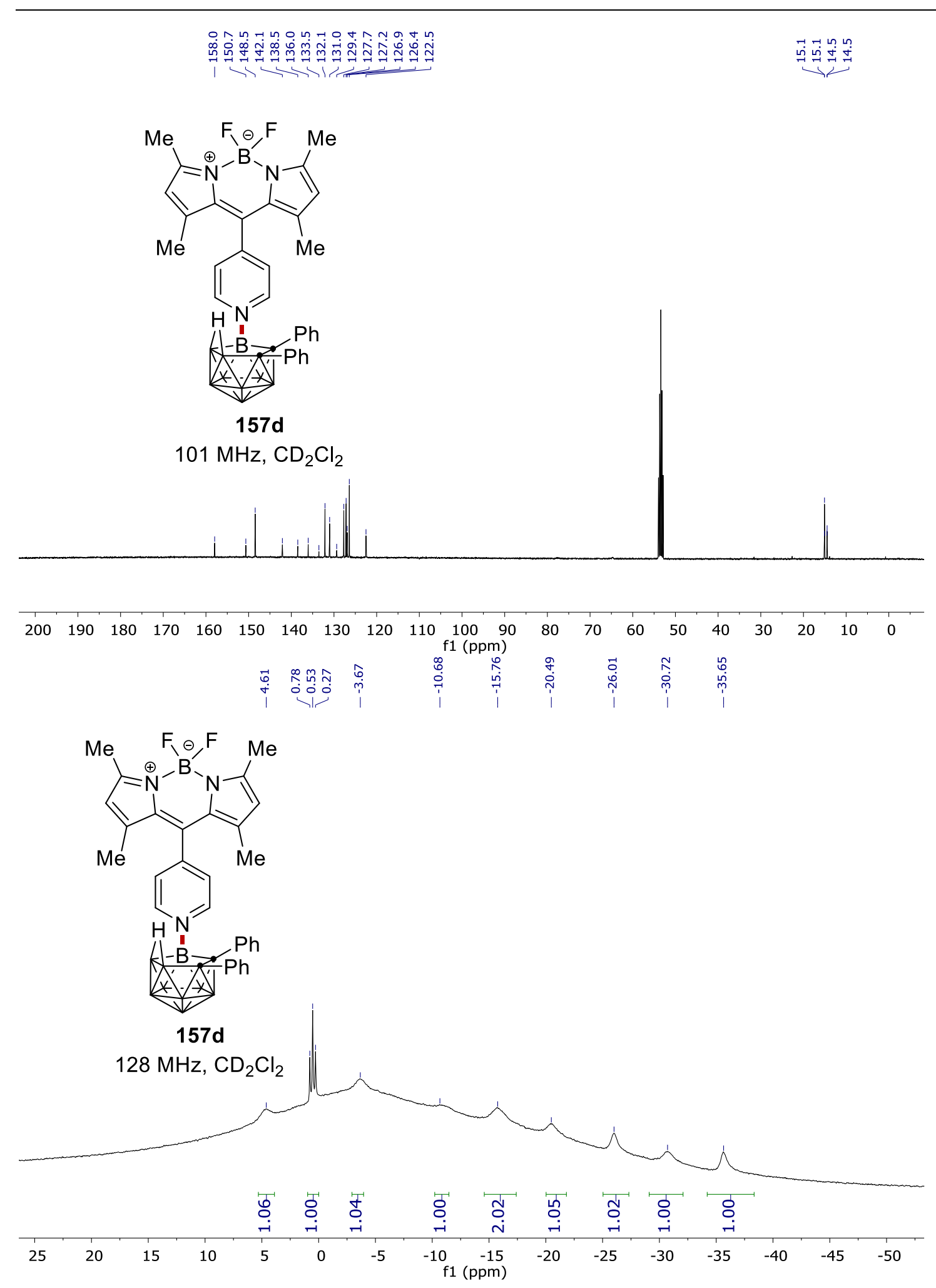


\section{NMR Spectra}
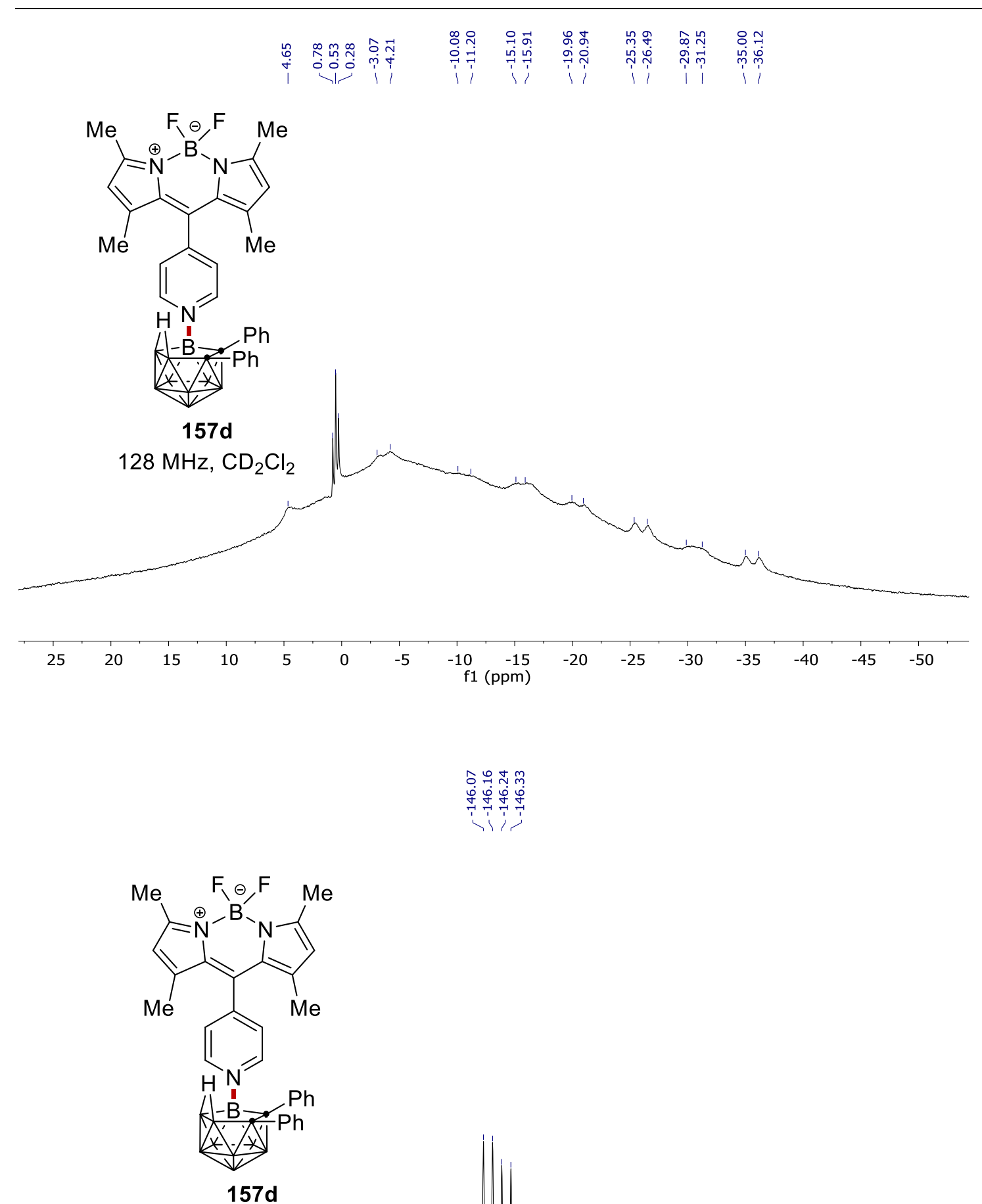

$377 \mathrm{MHz}, \mathrm{CD}_{2} \mathrm{Cl}_{2}$

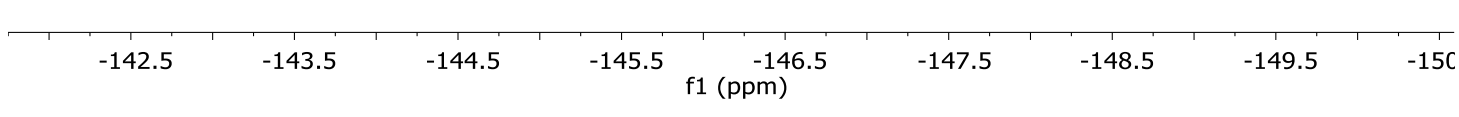




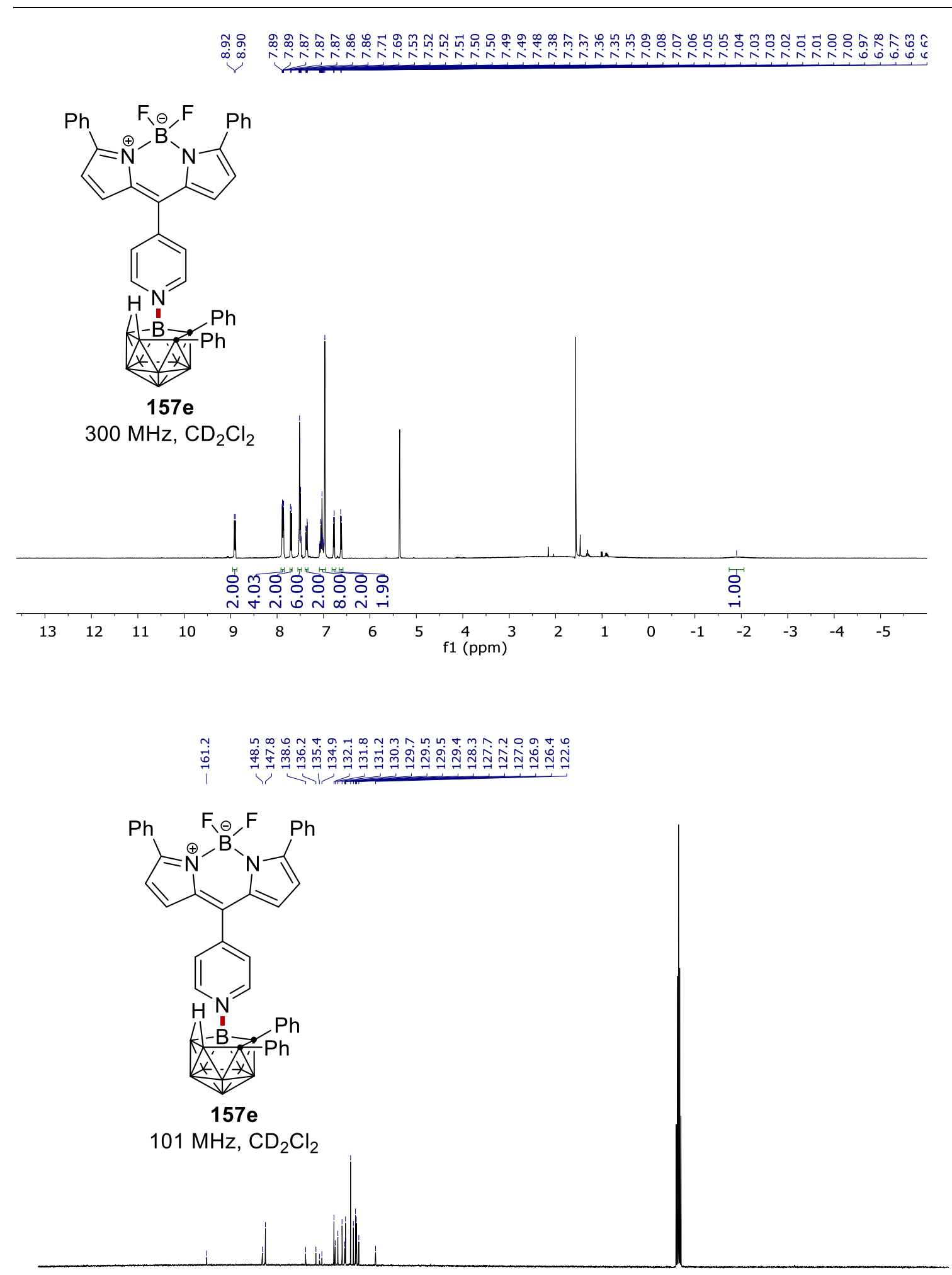

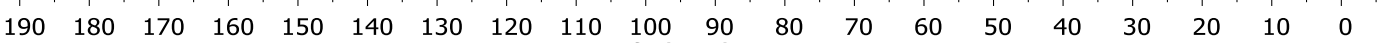




\section{NMR Spectra}
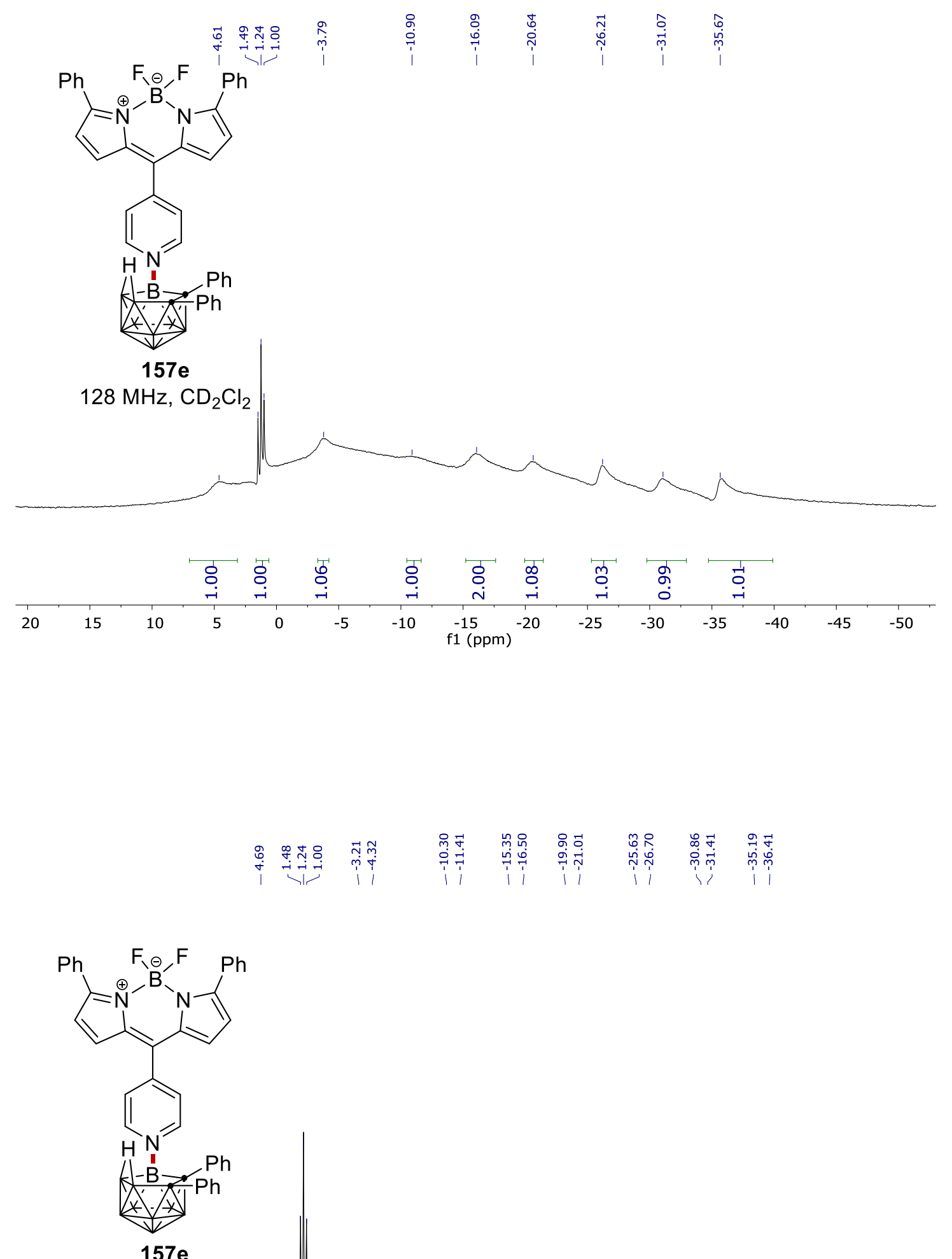

$128 \mathrm{MHz}, \mathrm{CD}_{2} \mathrm{Cl}_{2}$

\begin{tabular}{|c|c|c|c|c|c|c|c|c|c|c|c|c|c|c|}
\hline 20 & 15 & 10 & 5 & 0 & -5 & -10 & $\begin{array}{c}-15 \\
(\mathrm{ppm})\end{array}$ & -20 & -25 & -30 & -35 & -40 & -45 & -50 \\
\hline
\end{tabular}




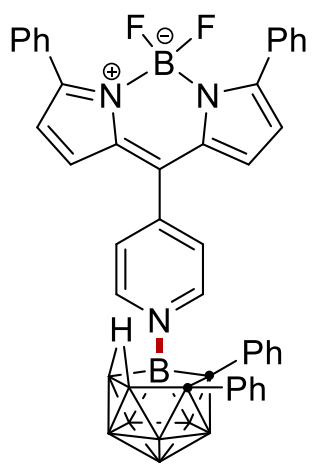

157e

$377 \mathrm{MHz}, \mathrm{CD}_{2} \mathrm{Cl}_{2}$

$\begin{array}{lllllllllllllllllllll}22 & -123 & -124 & -125 & -126 & -127 & -128 & -129 & -130 & -131 & -132 & -133 & -134 & -135 & -136 & -137 & -138 & -139 & -140 & -141 & -142\end{array}$ f1 (ppm)

mై

r

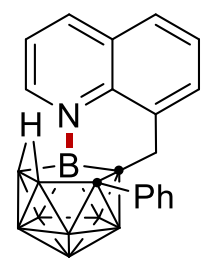

$159 a$

$300 \mathrm{MHz}, \mathrm{CD}_{2} \mathrm{Cl}_{2}$

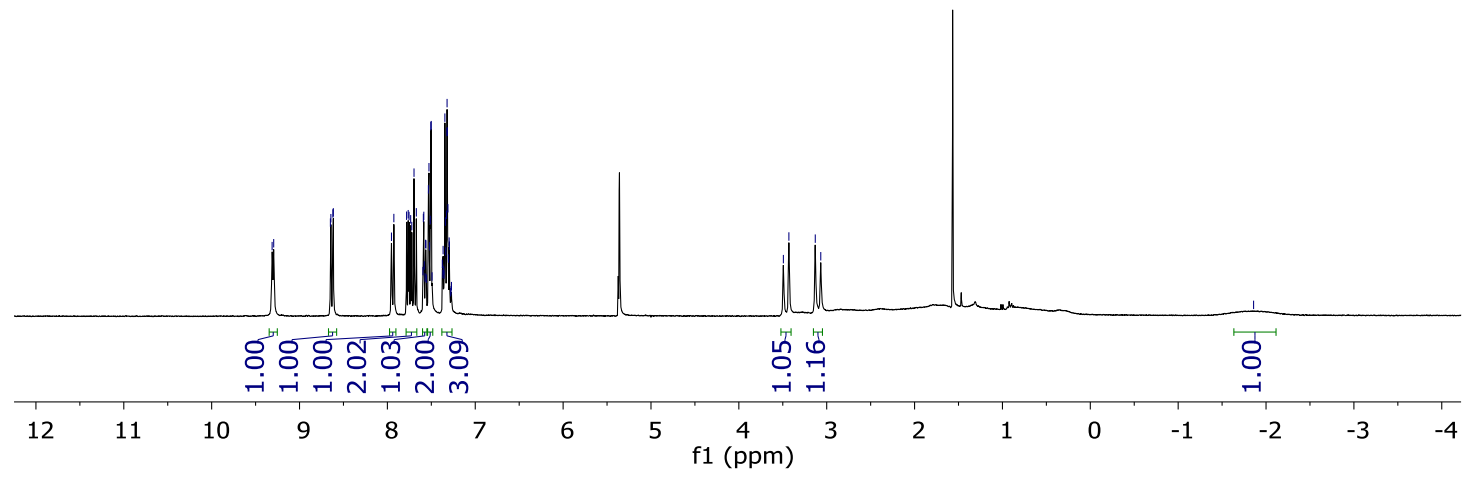




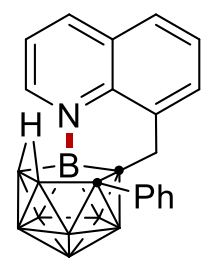

159a

$101 \mathrm{MHz}, \mathrm{CD}_{2} \mathrm{Cl}_{2}$

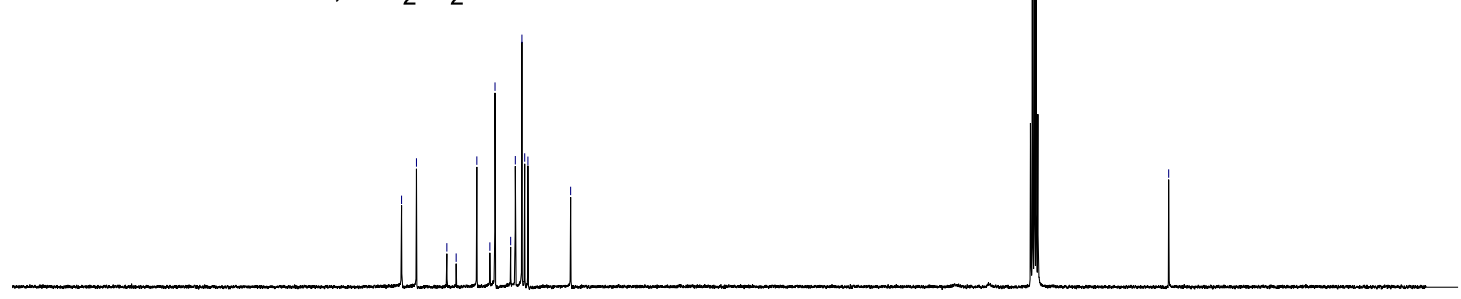

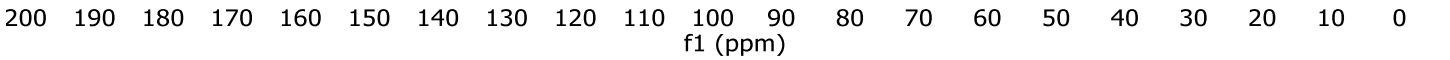

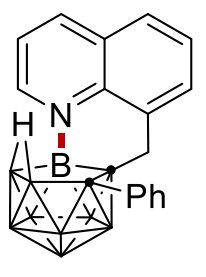

159a

$96 \mathrm{MHz}, \mathrm{CD}_{2} \mathrm{Cl}_{2}$

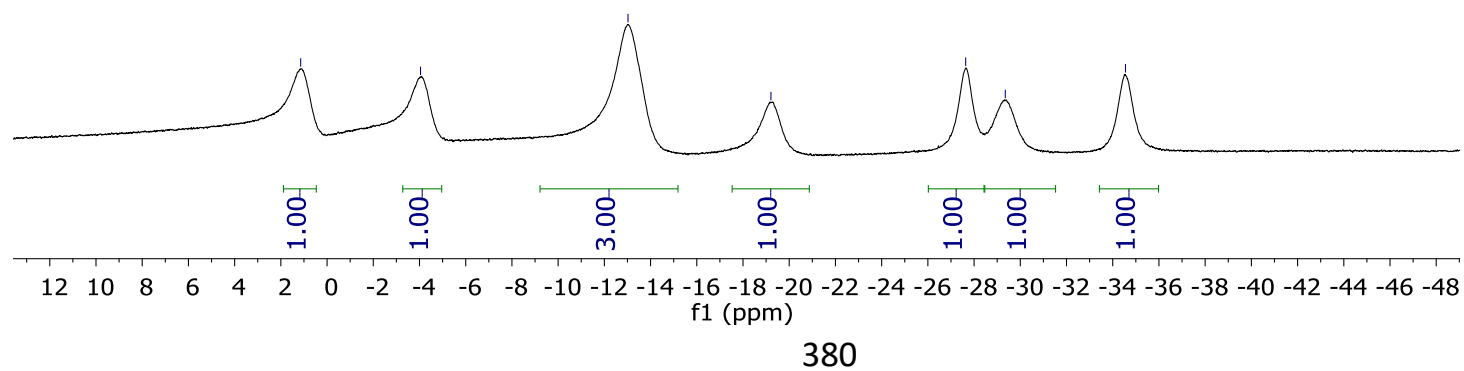




\section{NMR Spectra}

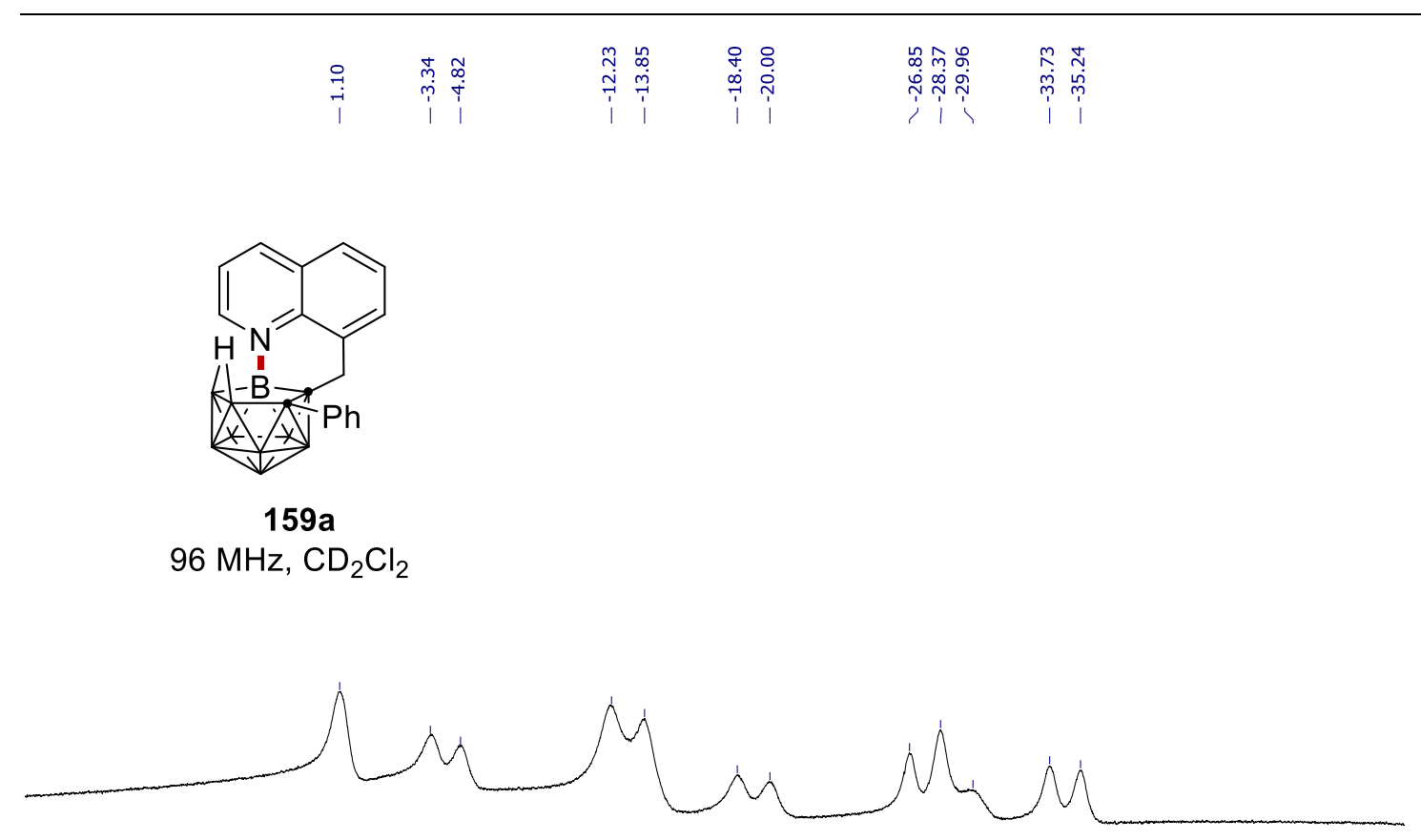

\begin{tabular}{|c|c|c|c|c|c|c|c|c|c|c|c|c|c|c|c|c|c|}
\hline 14 & 10 & 6 & 2 & -2 & & -6 & -10 & -14 & $\begin{array}{c}-18 \\
(\mathrm{ppm})\end{array}$ & -22 & -26 & -30 & -34 & -38 & -42 & -46 & -50 \\
\hline
\end{tabular}

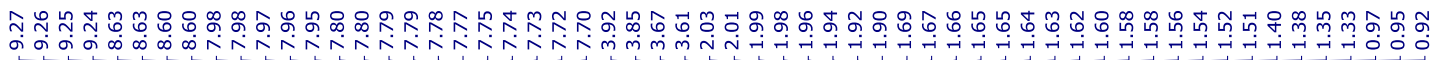

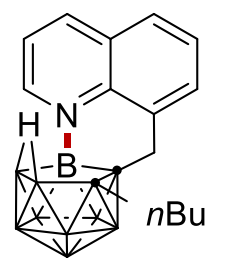

$159 b$

$300 \mathrm{MHz}, \mathrm{CD}_{2} \mathrm{Cl}_{2}$

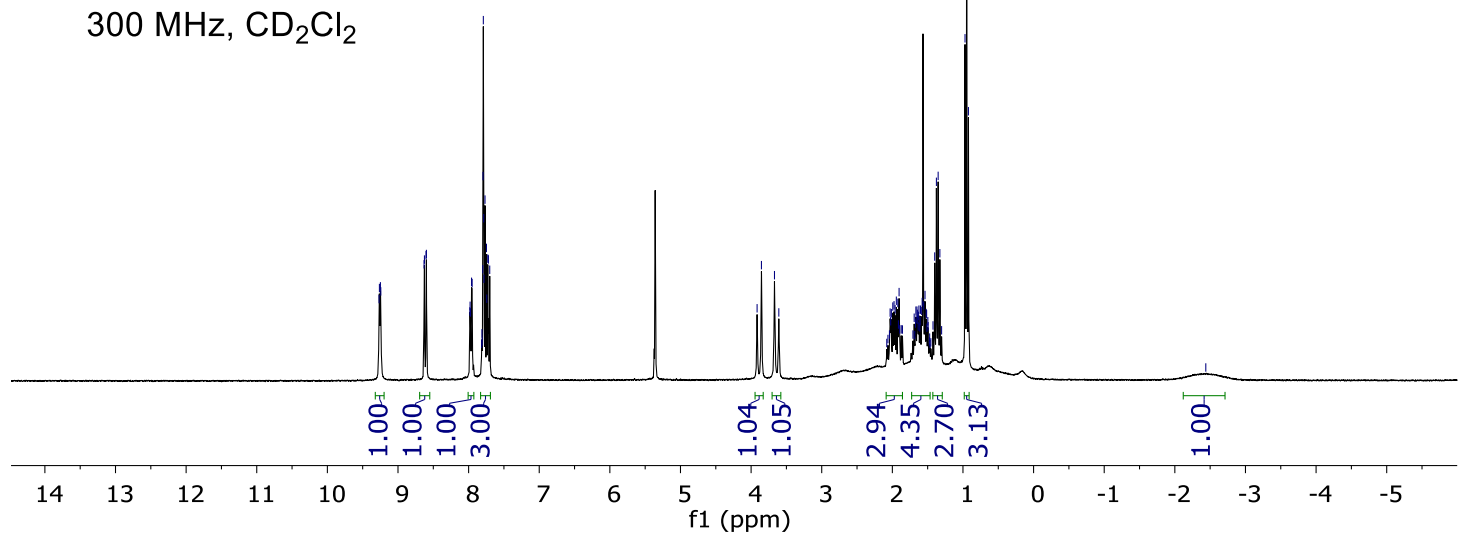



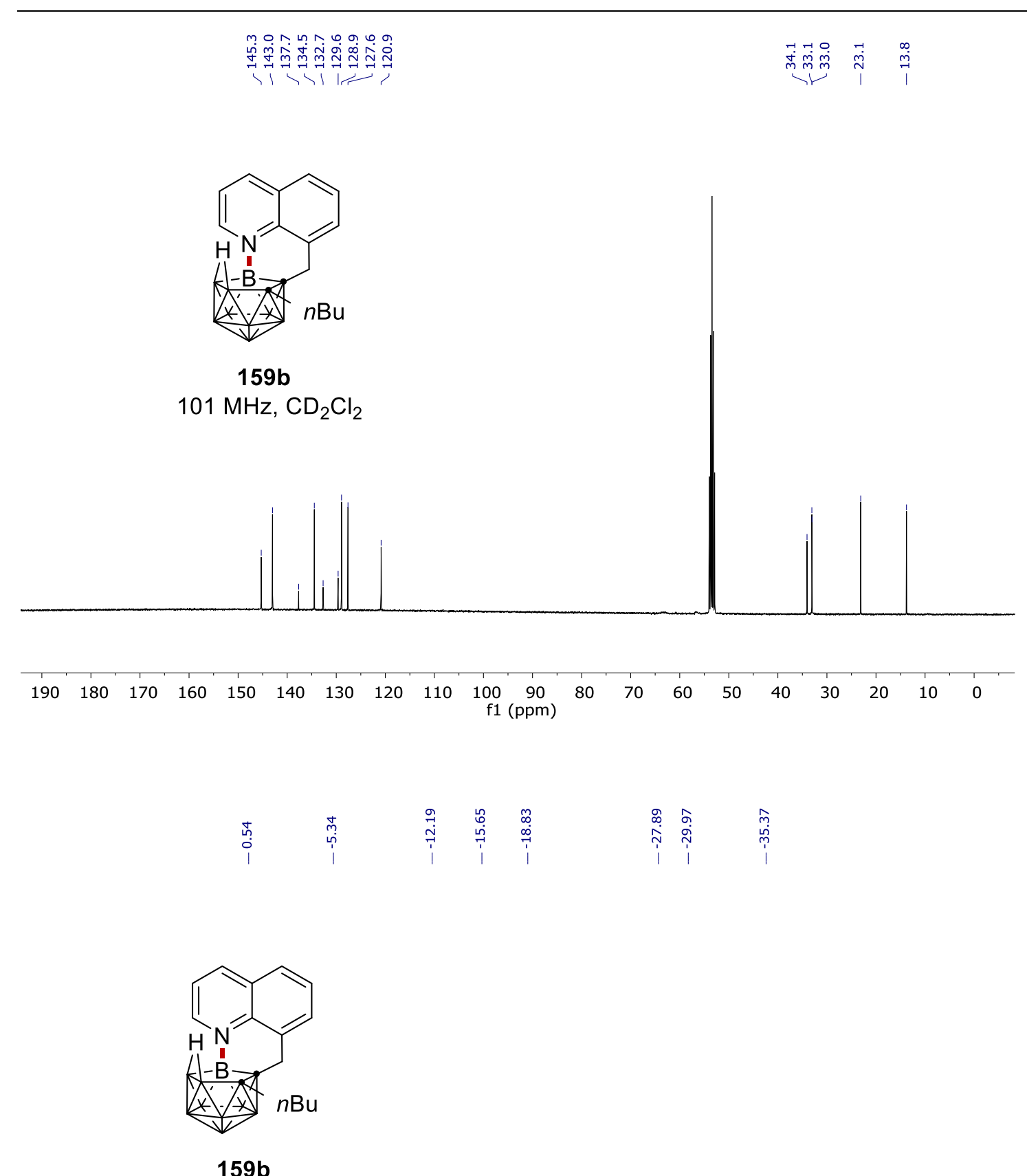

$96 \mathrm{MHz}, \mathrm{CD}_{2} \mathrm{Cl}_{2}$

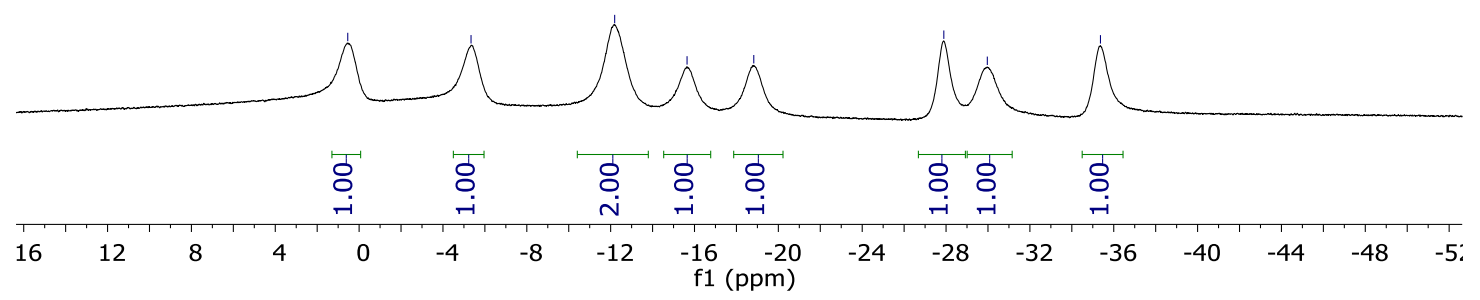




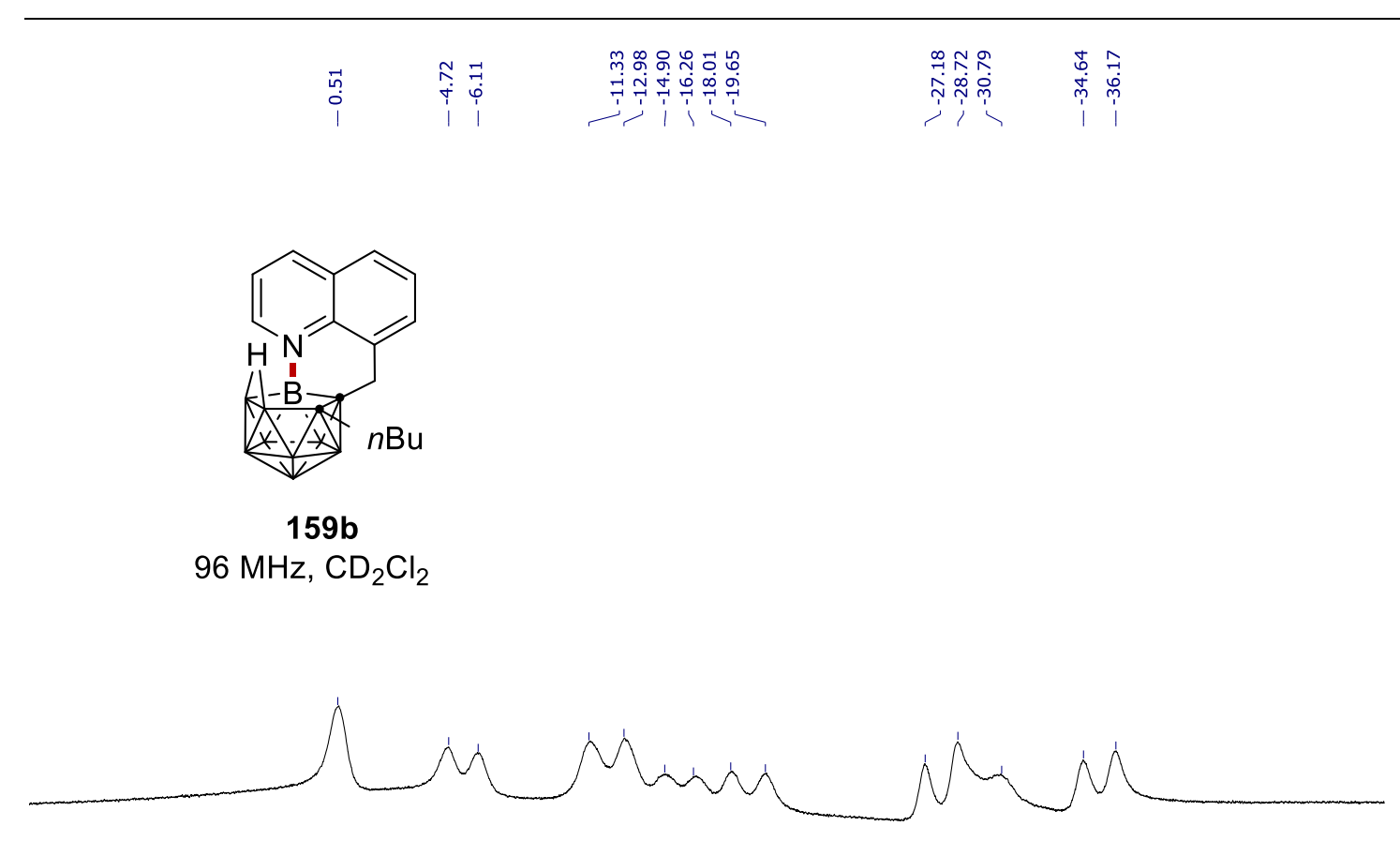

\begin{tabular}{|c|c|c|c|c|c|c|c|c|c|c|c|c|c|c|c|}
\hline 12 & 8 & 4 & 0 & -4 & -8 & -12 & $\begin{array}{c}-16 \\
\mathrm{f} 1(\mathrm{ppm})\end{array}$ & )$^{-20}$ & -24 & -28 & -32 & -36 & -40 & -44 & $-4 \varepsilon$ \\
\hline
\end{tabular}

\subsection{Cupraelectro-Oxidative Chalcogenation of $o$-Carboranes}

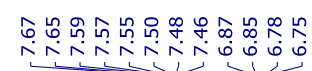

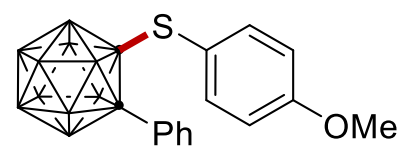

$162 a$

$400 \mathrm{MHz}, \mathrm{CDCl}_{3}$

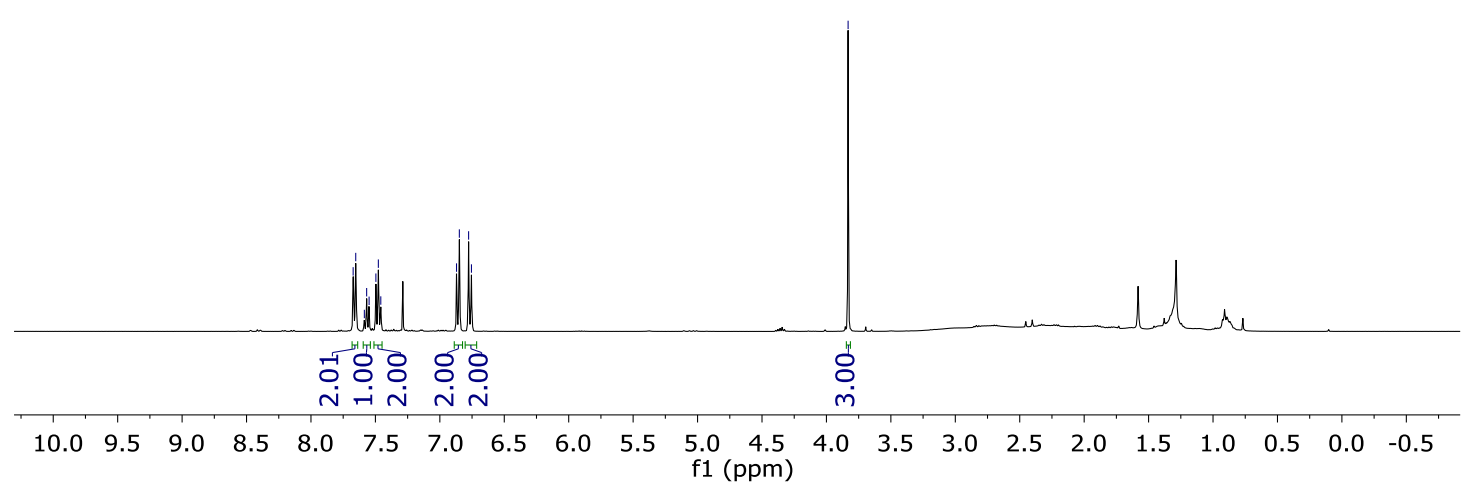




\section{NMR Spectra}
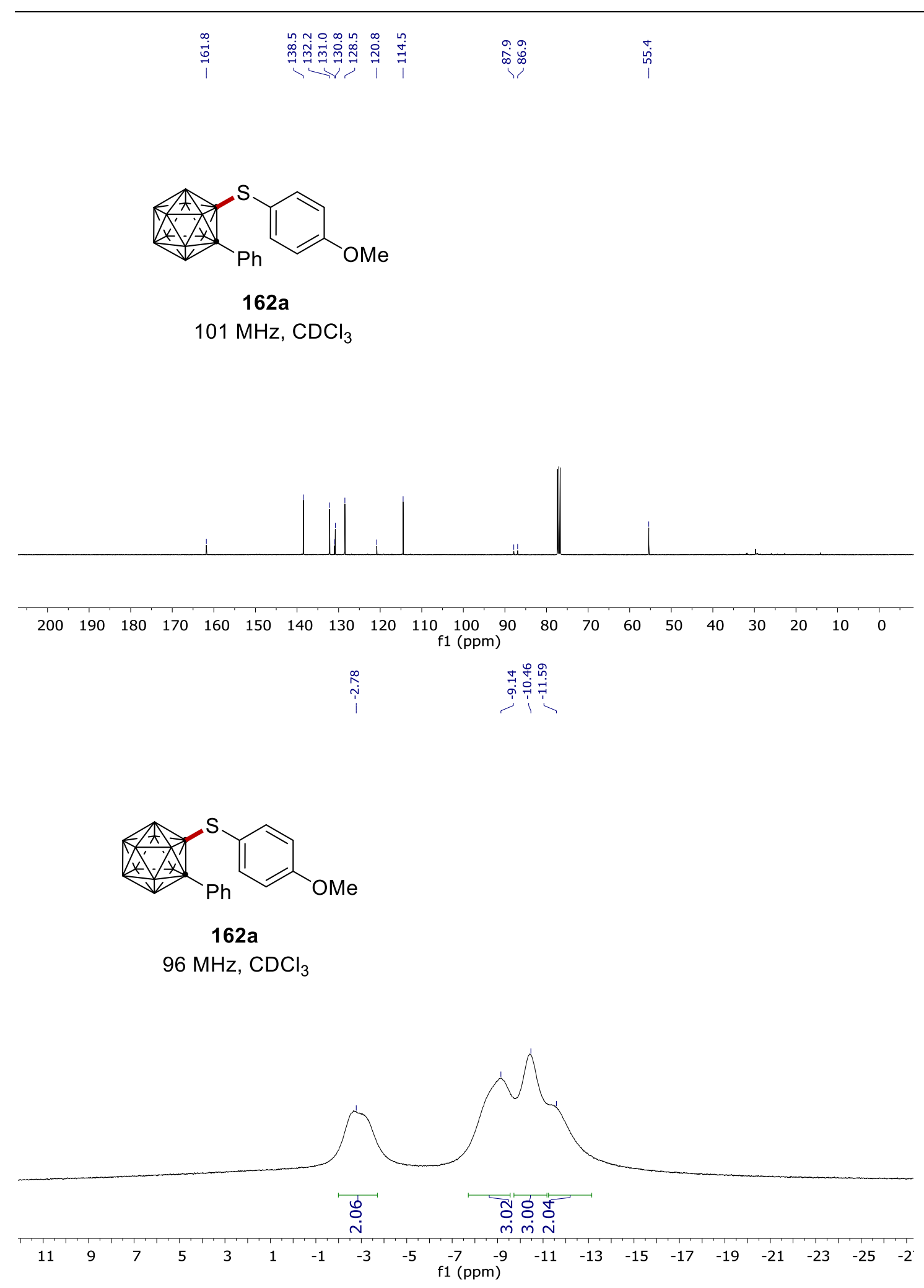


\section{NMR Spectra}

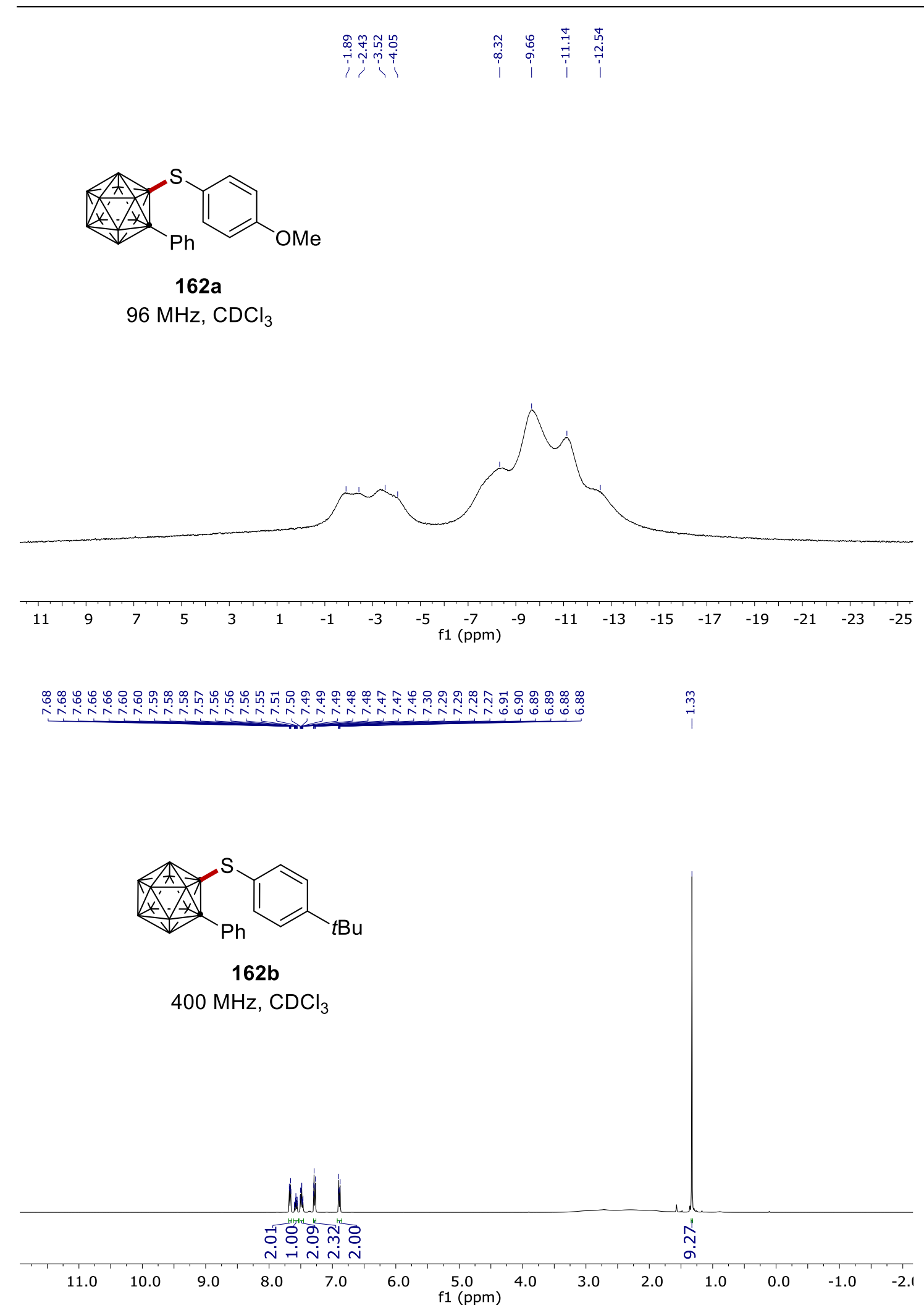




\section{NMR Spectra}
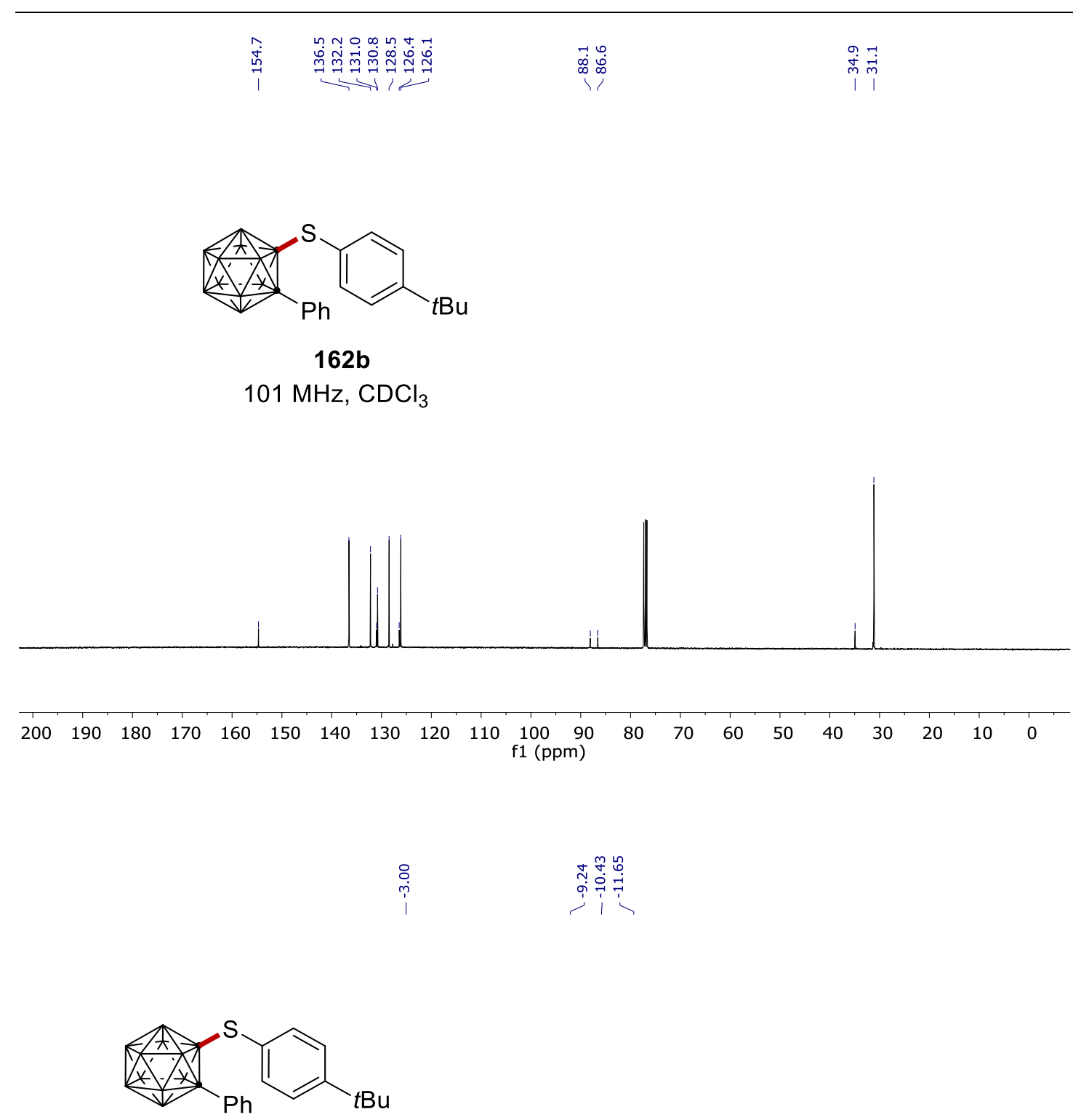

162b

$96 \mathrm{MHz}, \mathrm{CDCl}_{3}$

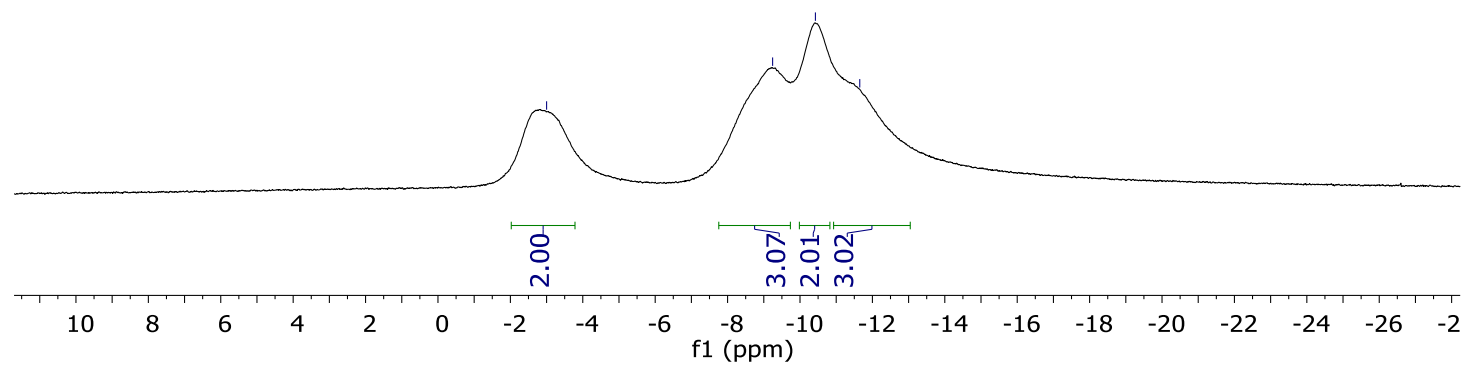




\section{NMR Spectra}
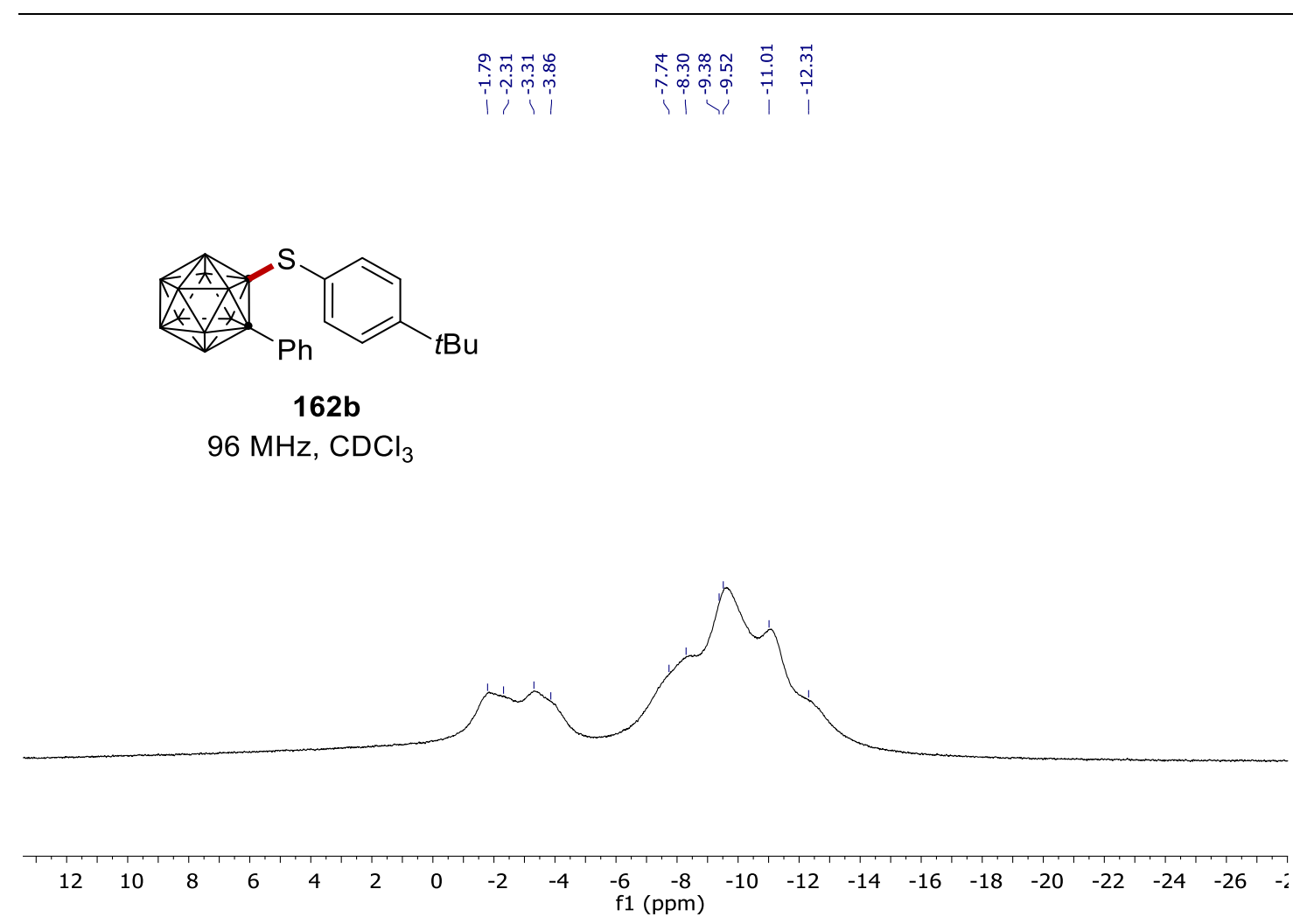

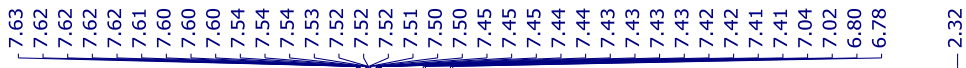

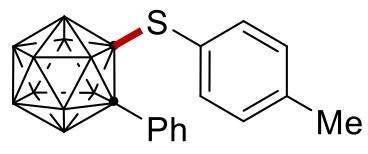

162c

$400 \mathrm{MHz}, \mathrm{CDCl}_{3}$

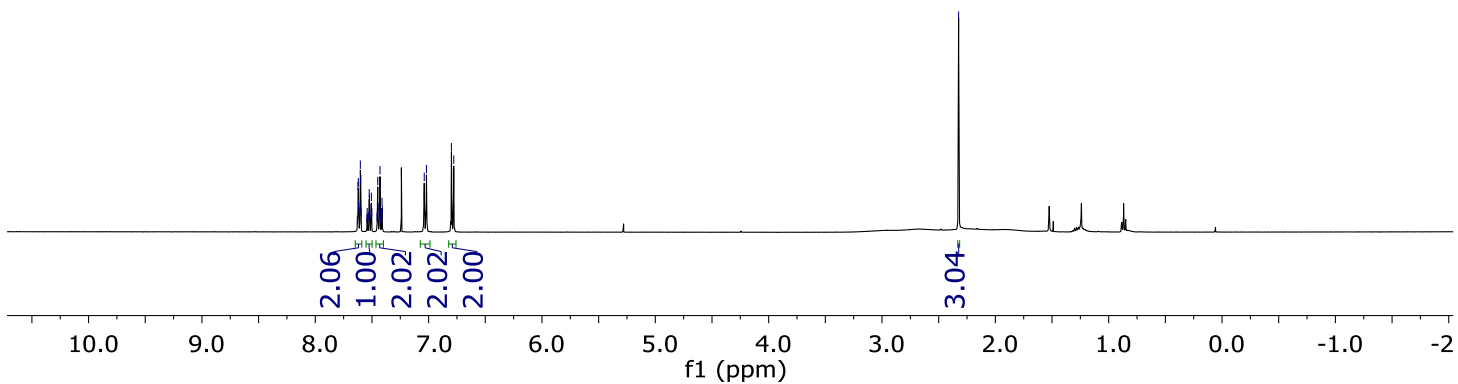




\section{NMR Spectra}
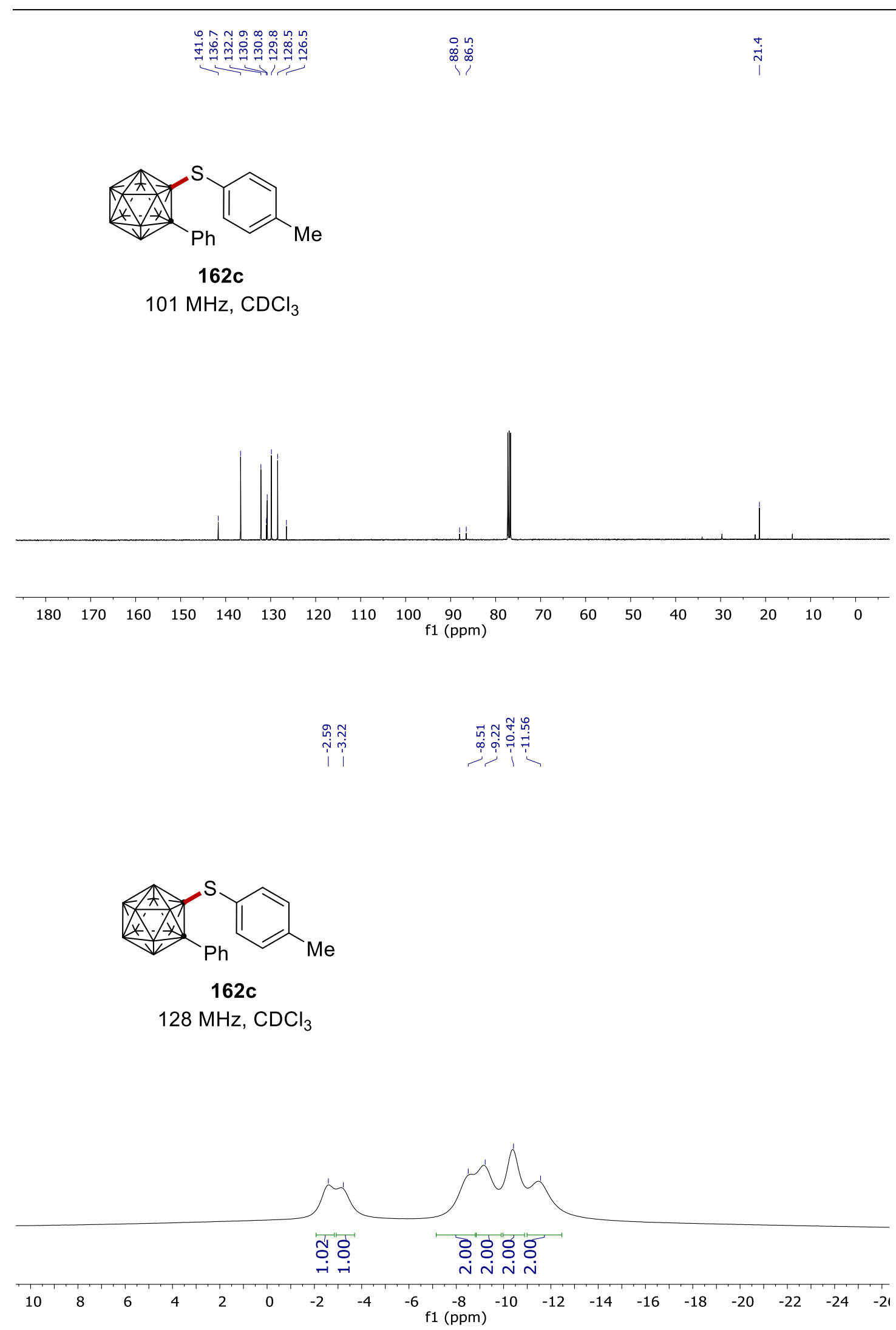


\section{NMR Spectra}
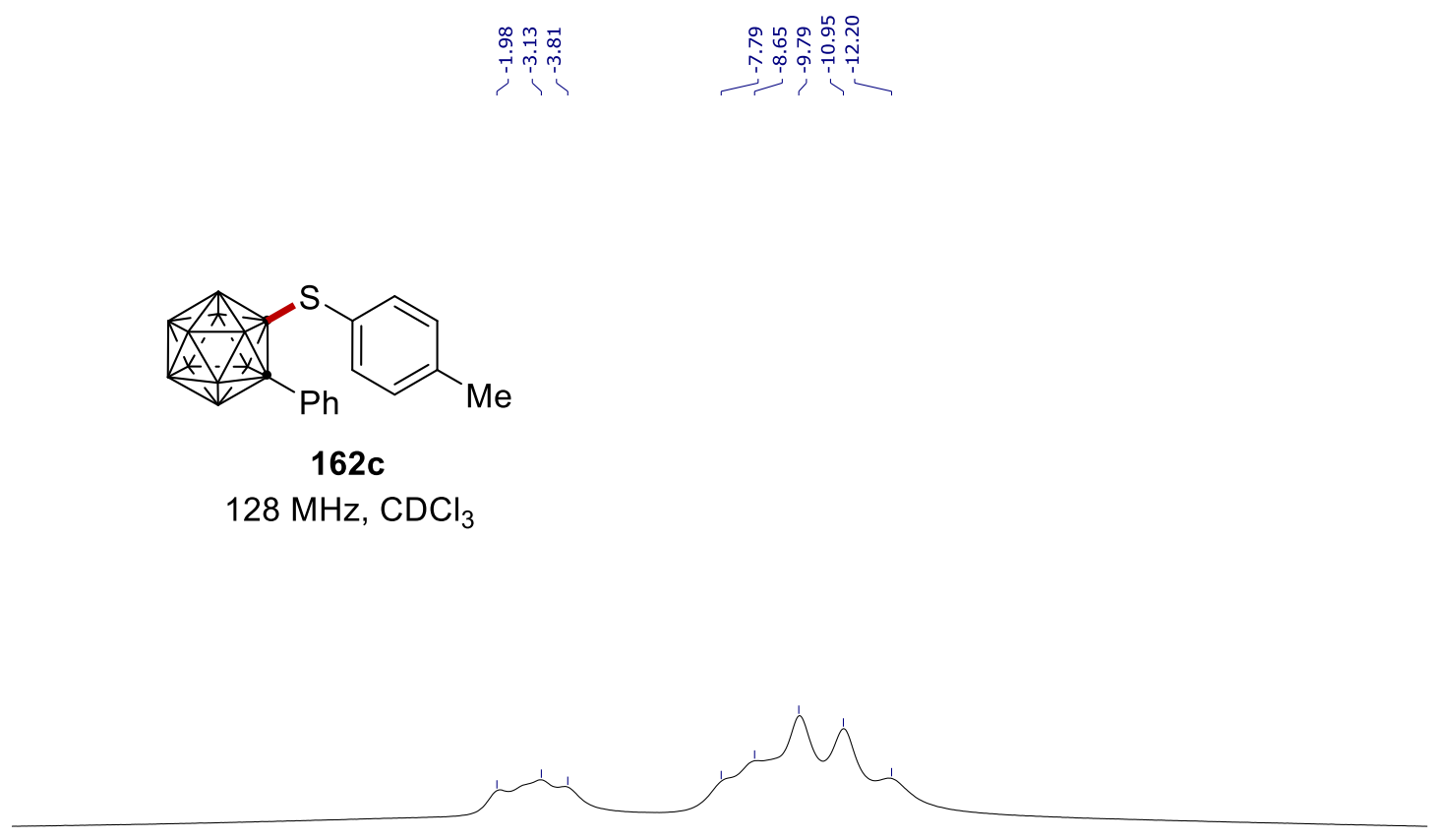

$\begin{array}{lllllllllllllllllllll}10 & 8 & 6 & 4 & 2 & 0 & -2 & -4 & -6 & -8 & -10 & -12 & -14 & -16 & -18 & -20 & -22 & -24 & -2\end{array}$

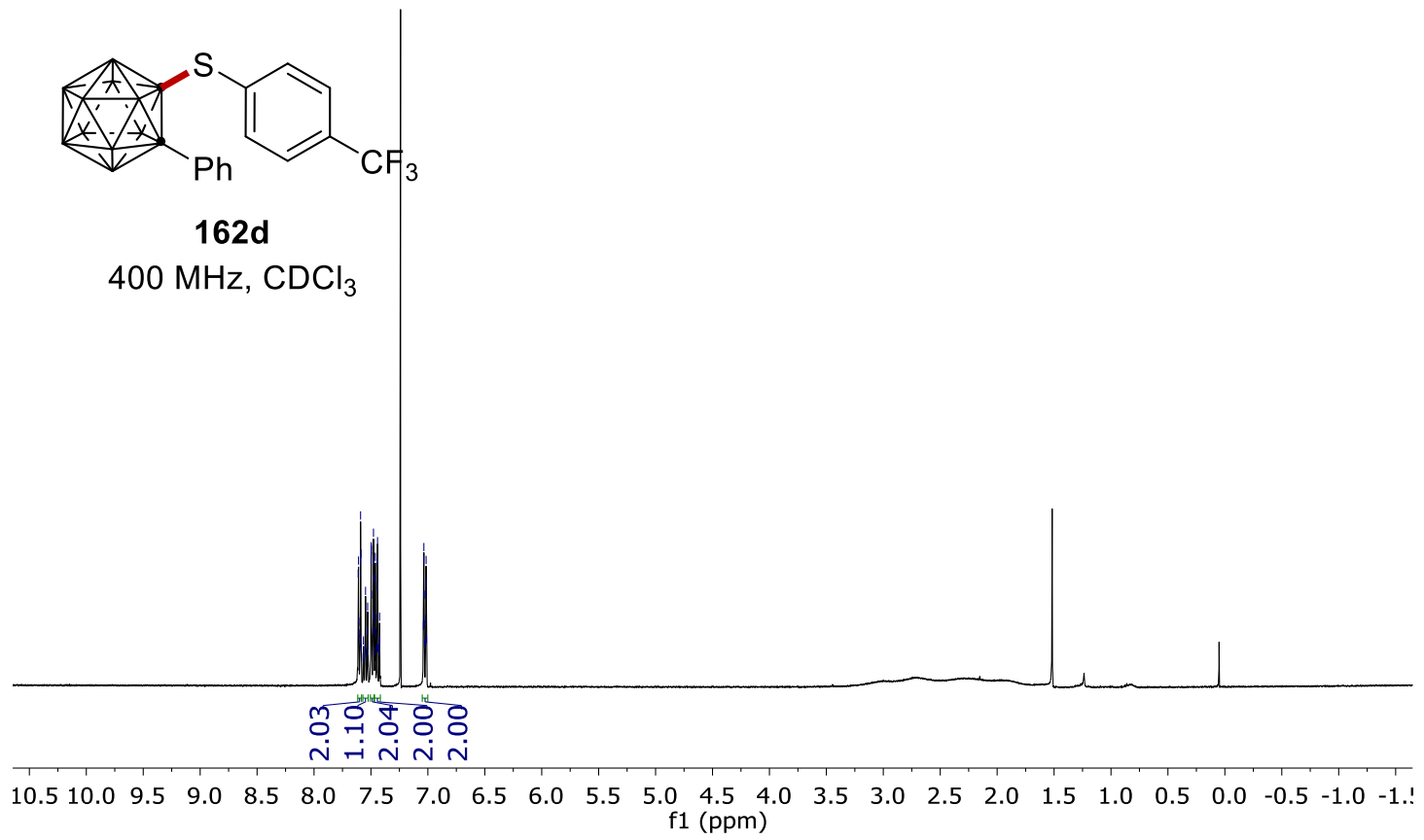




\section{NMR Spectra}

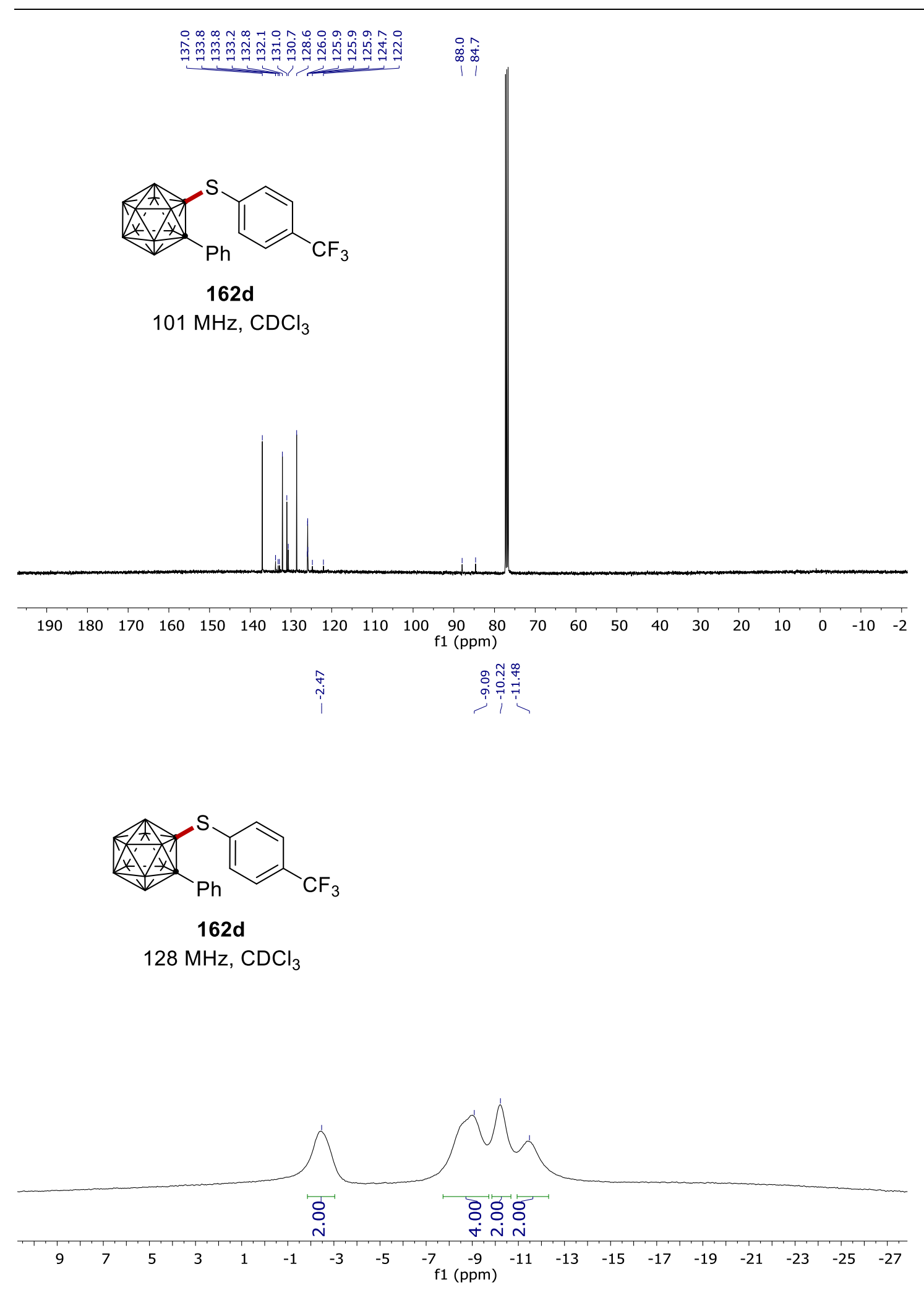




\section{NMR Spectra}
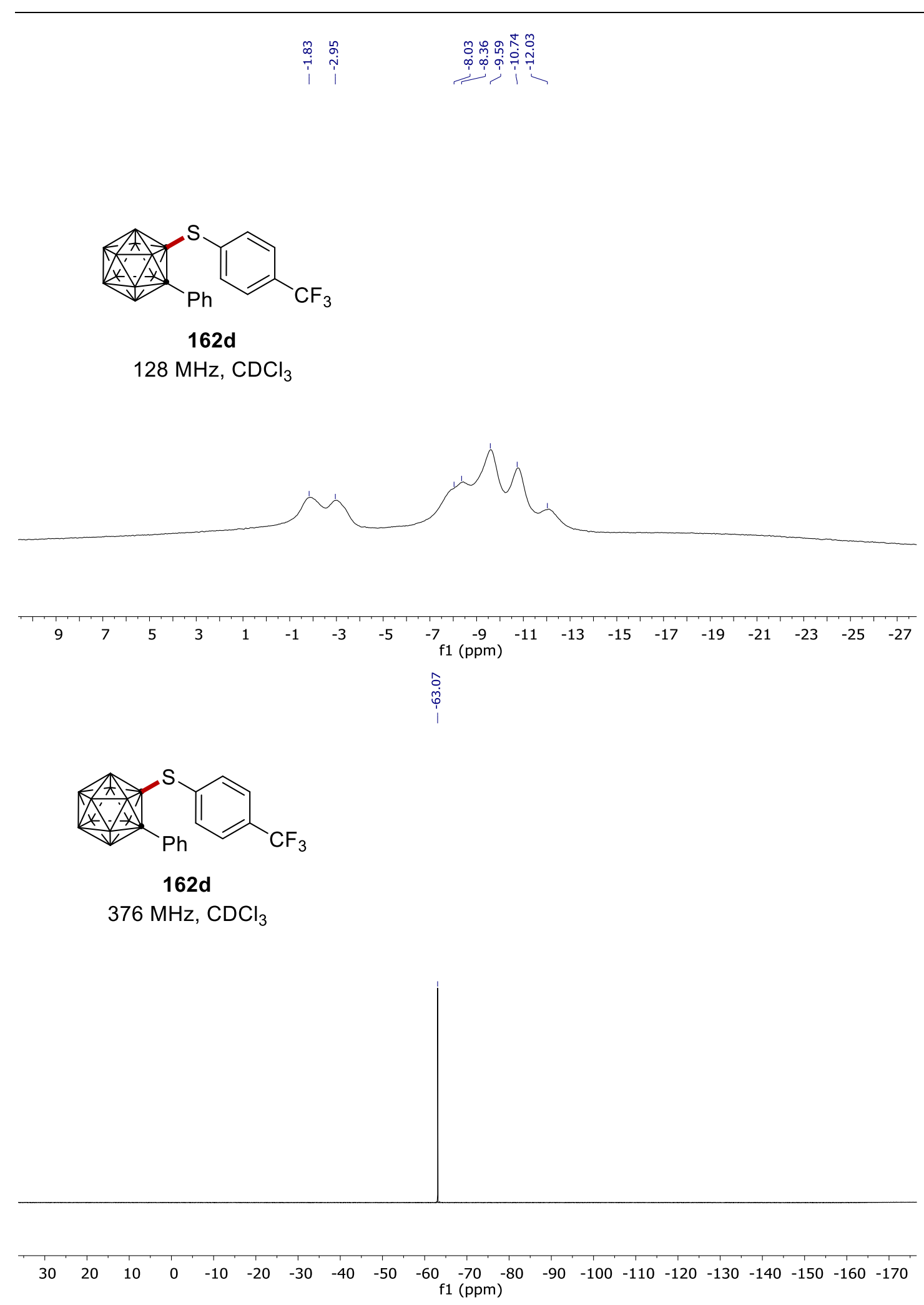


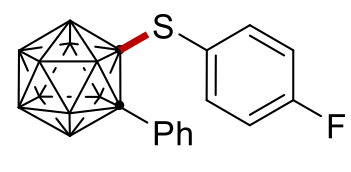

$162 \mathrm{e}$

$400 \mathrm{MHz}, \mathrm{CDCl}_{3}$
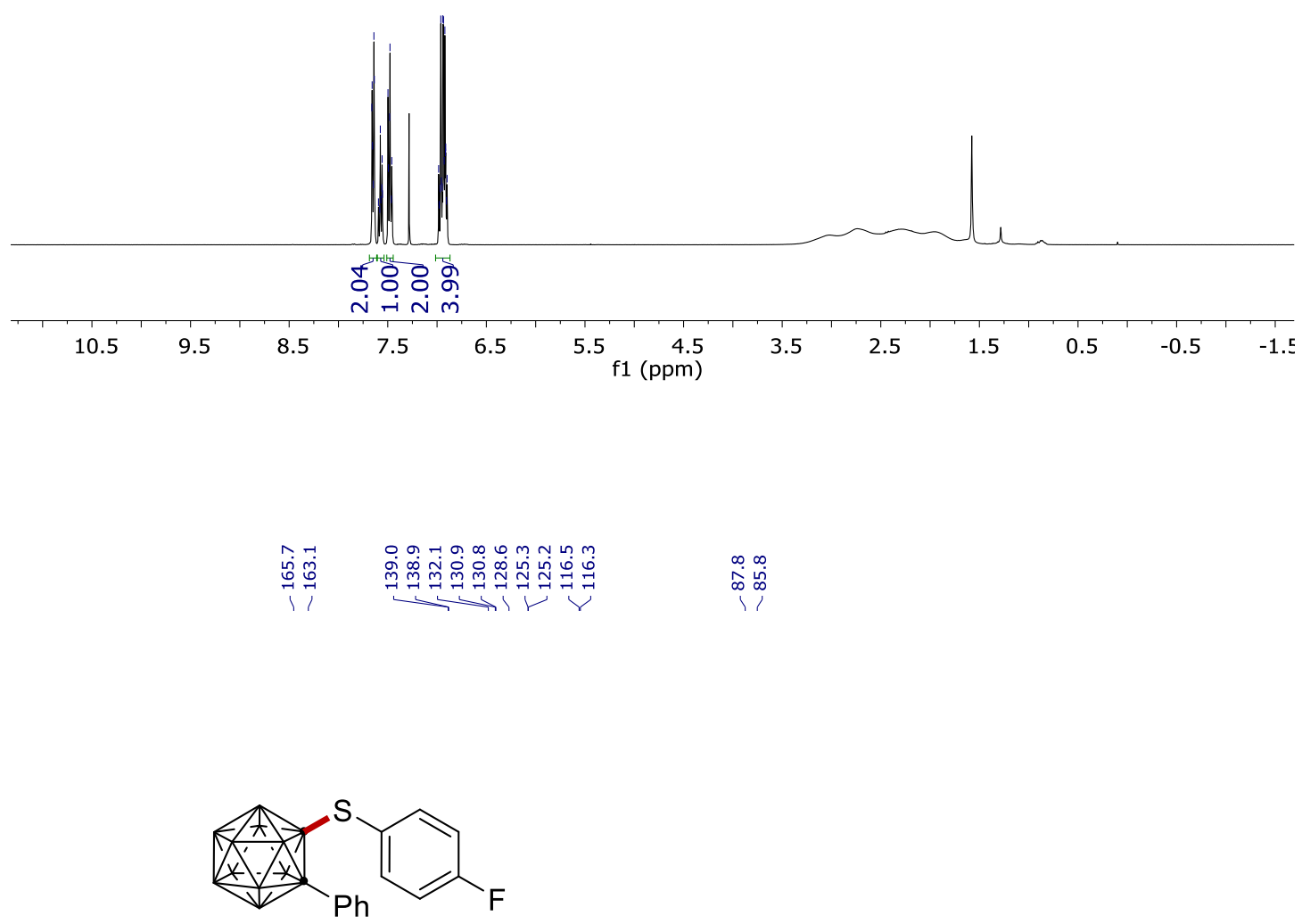

$162 \mathrm{e}$

$101 \mathrm{MHz}^{\mathrm{CDCl}_{3}}$

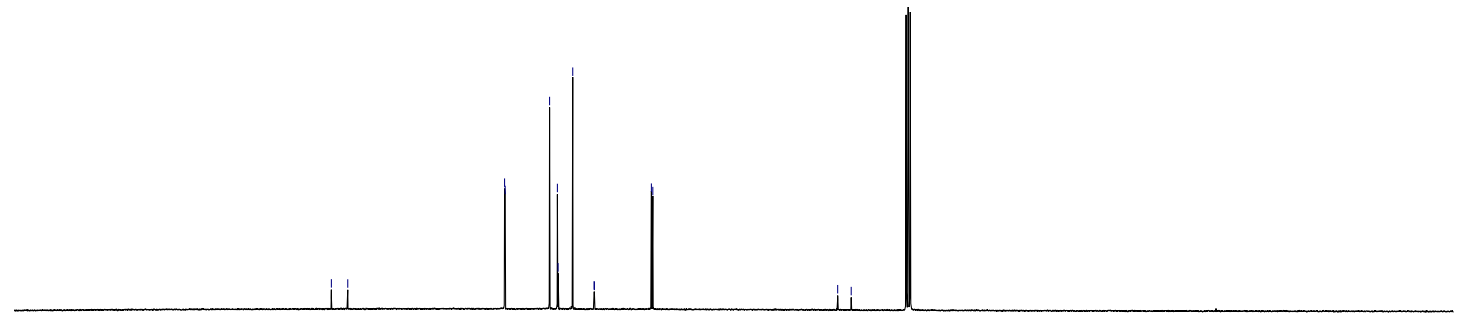

$210 \quad 200 \quad 190 \quad 180$

150140

120

$$
\begin{array}{cc}
110 & 100 \\
\mathrm{f} 1(\mathrm{ppm})
\end{array}
$$




\section{NMR Spectra}
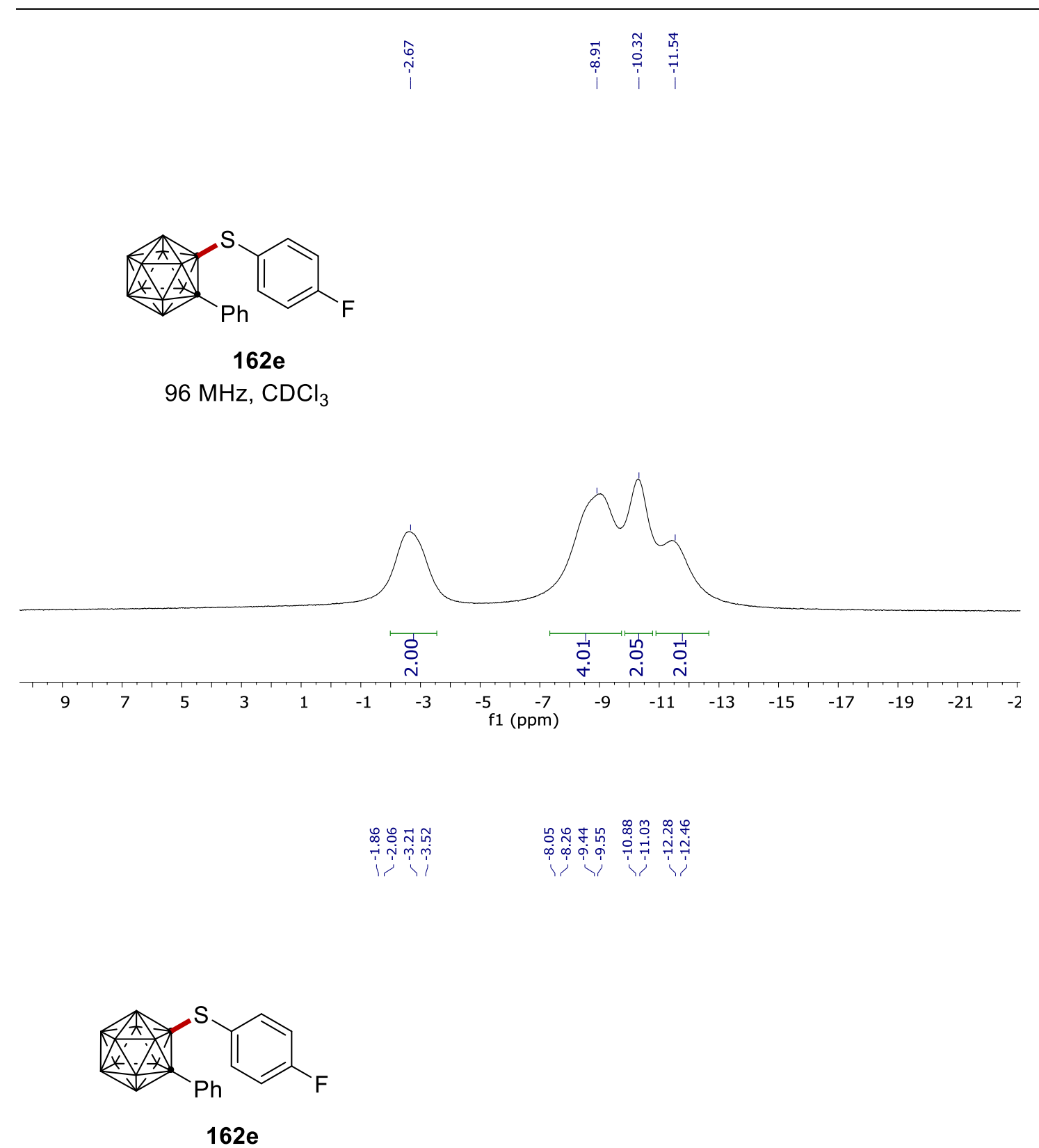

$96 \mathrm{MHz}, \mathrm{CDCl}_{3}$

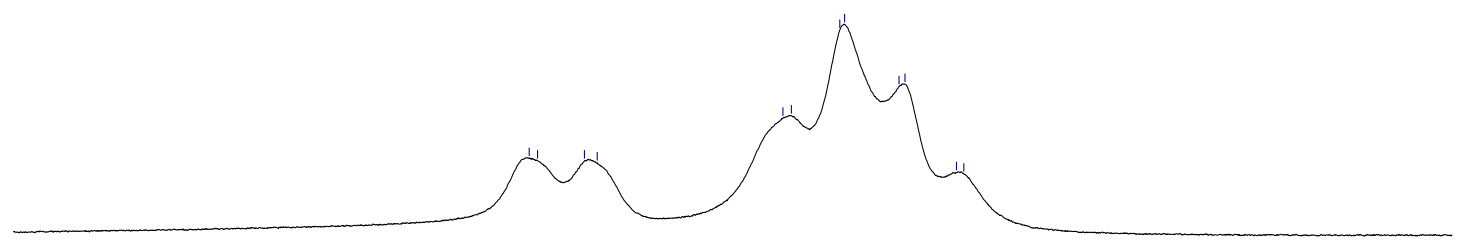

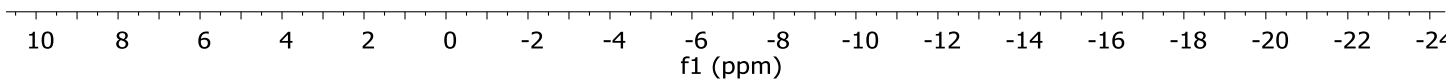




\section{NMR Spectra}

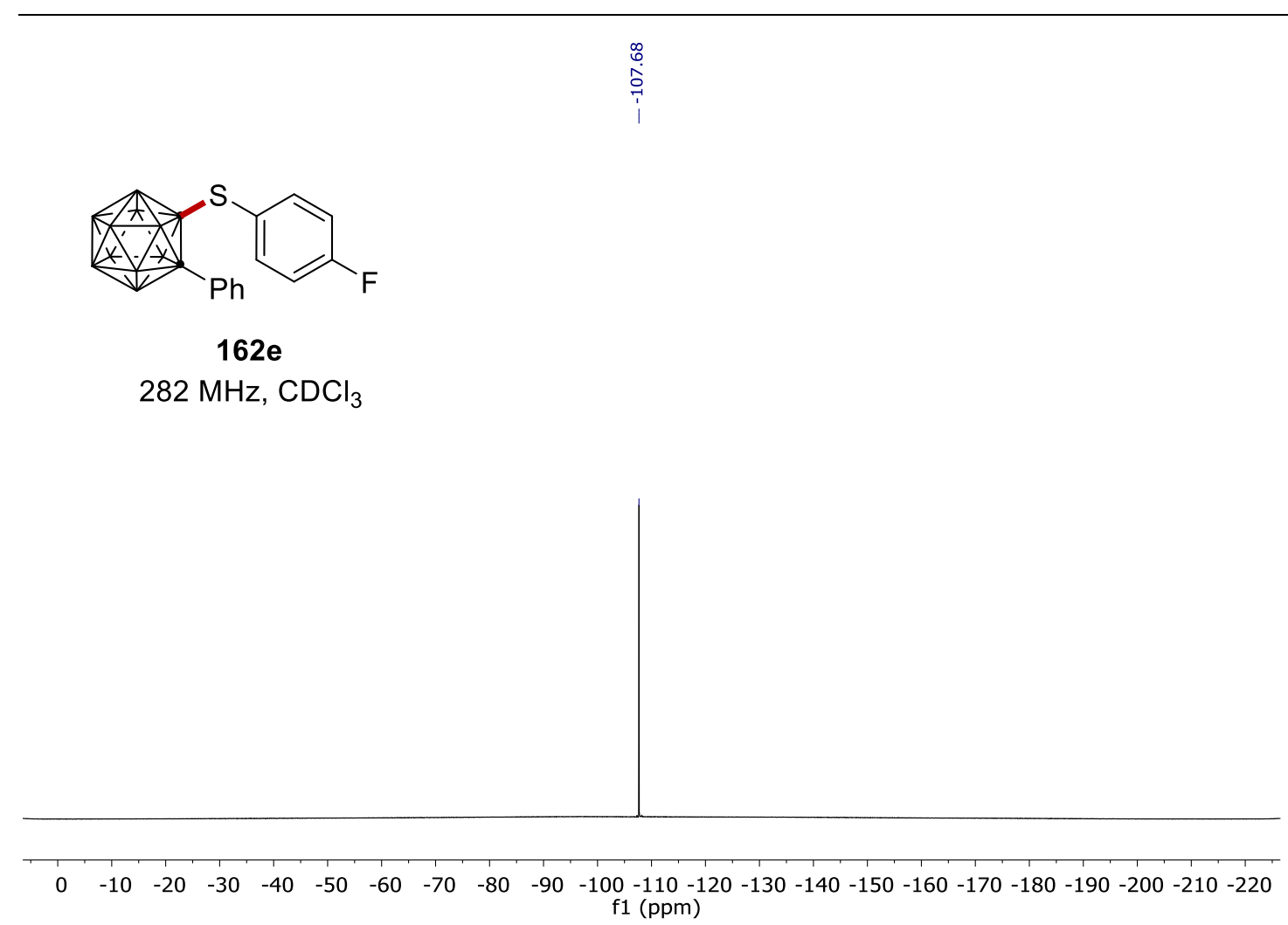

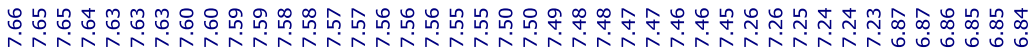
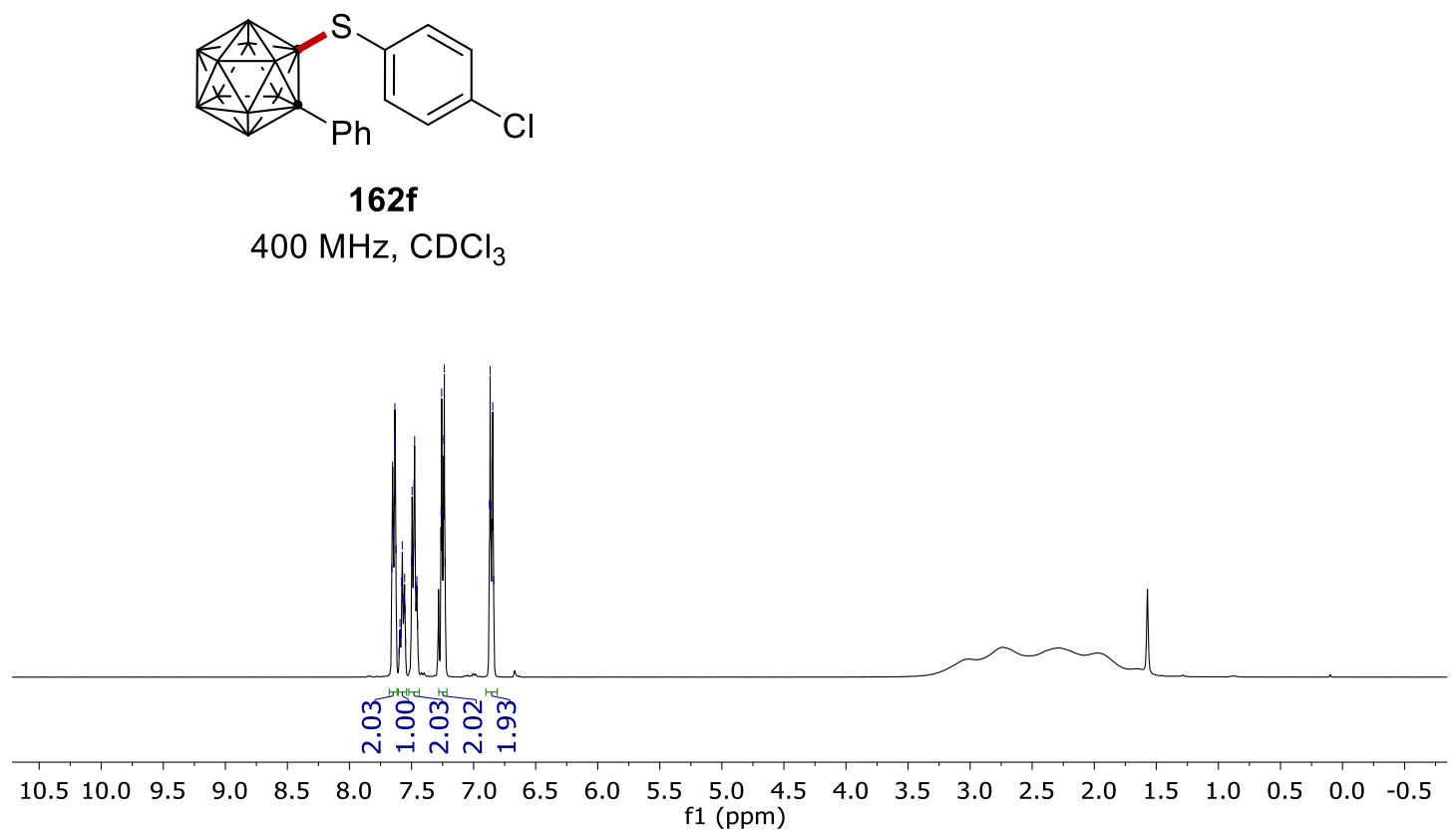


\section{NMR Spectra}

金品

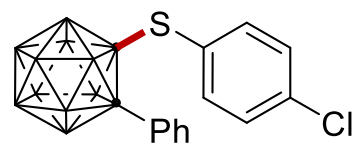

$162 f$

$101 \mathrm{MHz}, \mathrm{CDCl}_{3}$
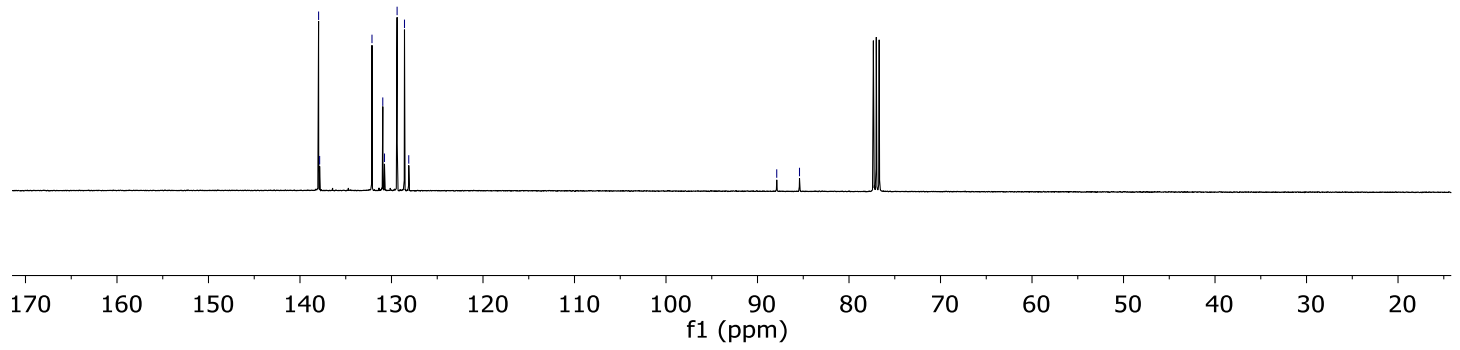

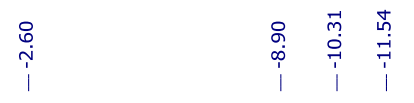

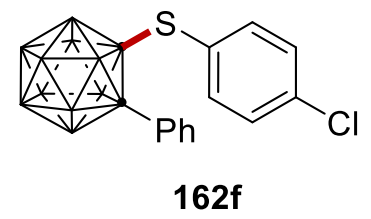

$96 \mathrm{MHz}, \mathrm{CDCl}_{3}$

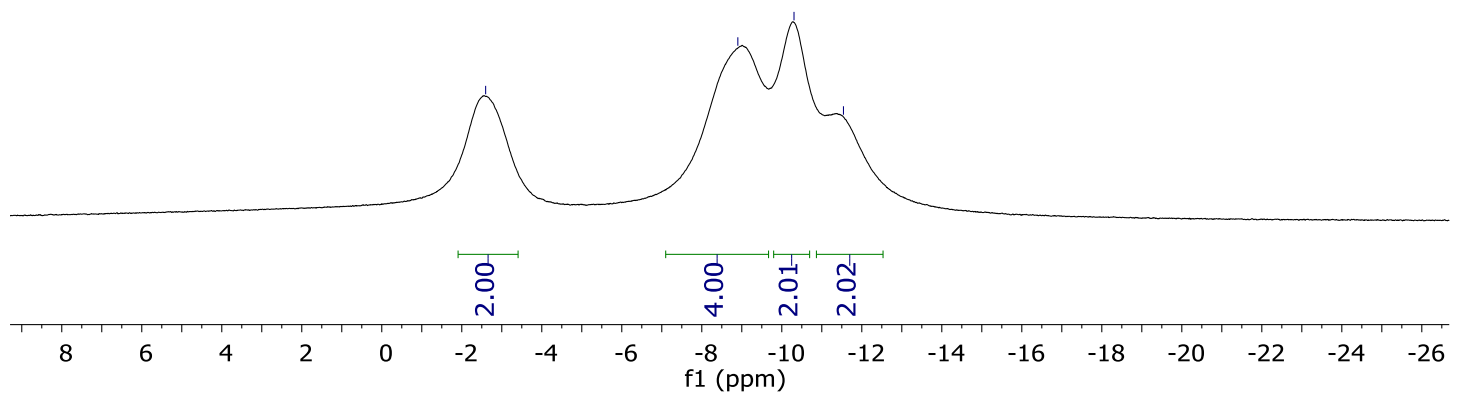




\section{NMR Spectra}
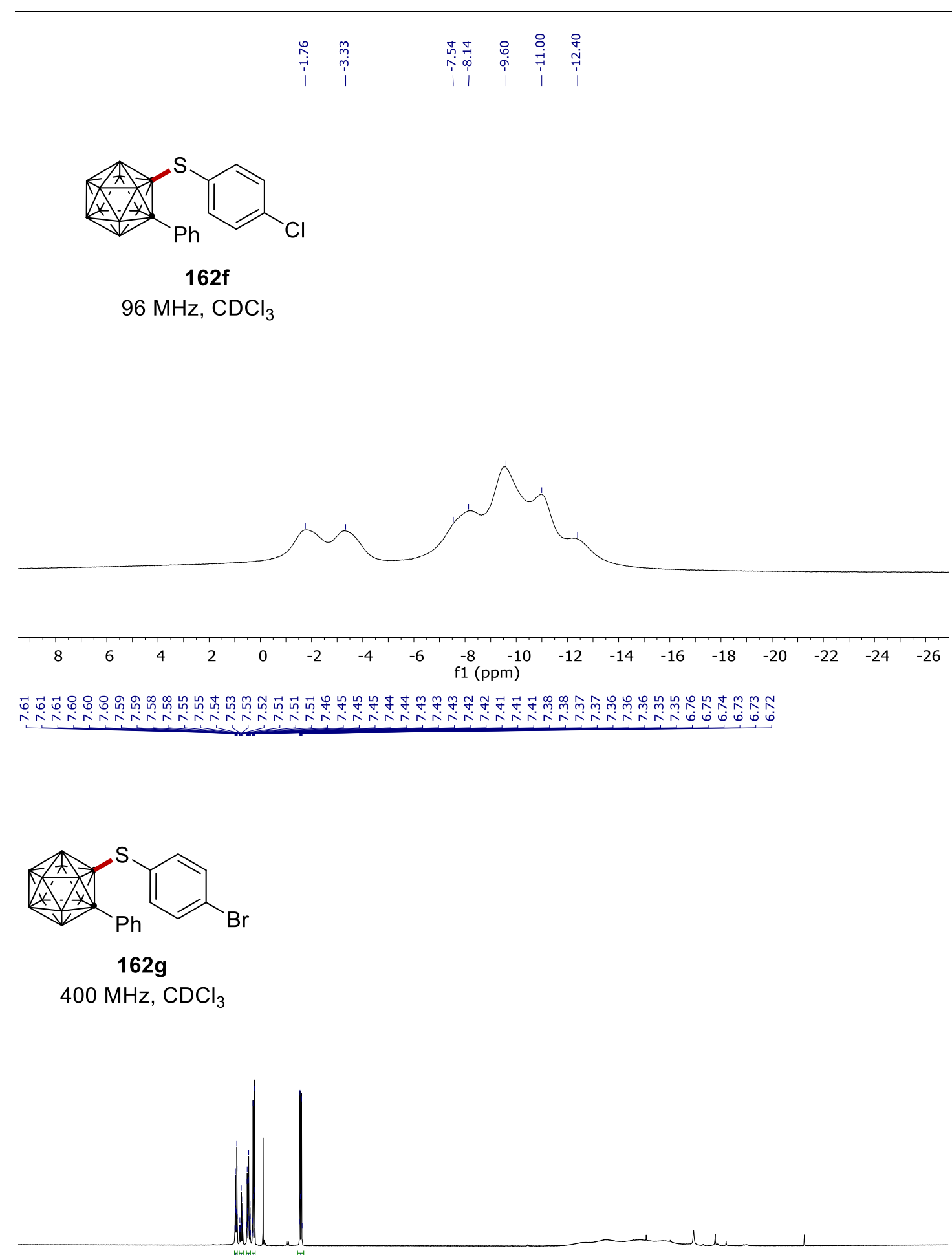

웅 에을

i

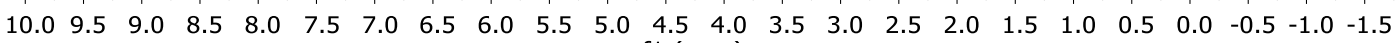
f1 (ppm) 


\section{NMR Spectra}

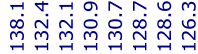

â

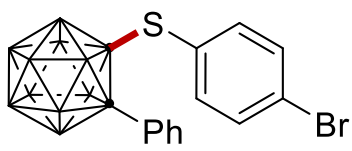

$162 g$

$101 \mathrm{MHz}, \mathrm{CDCl}_{3}$
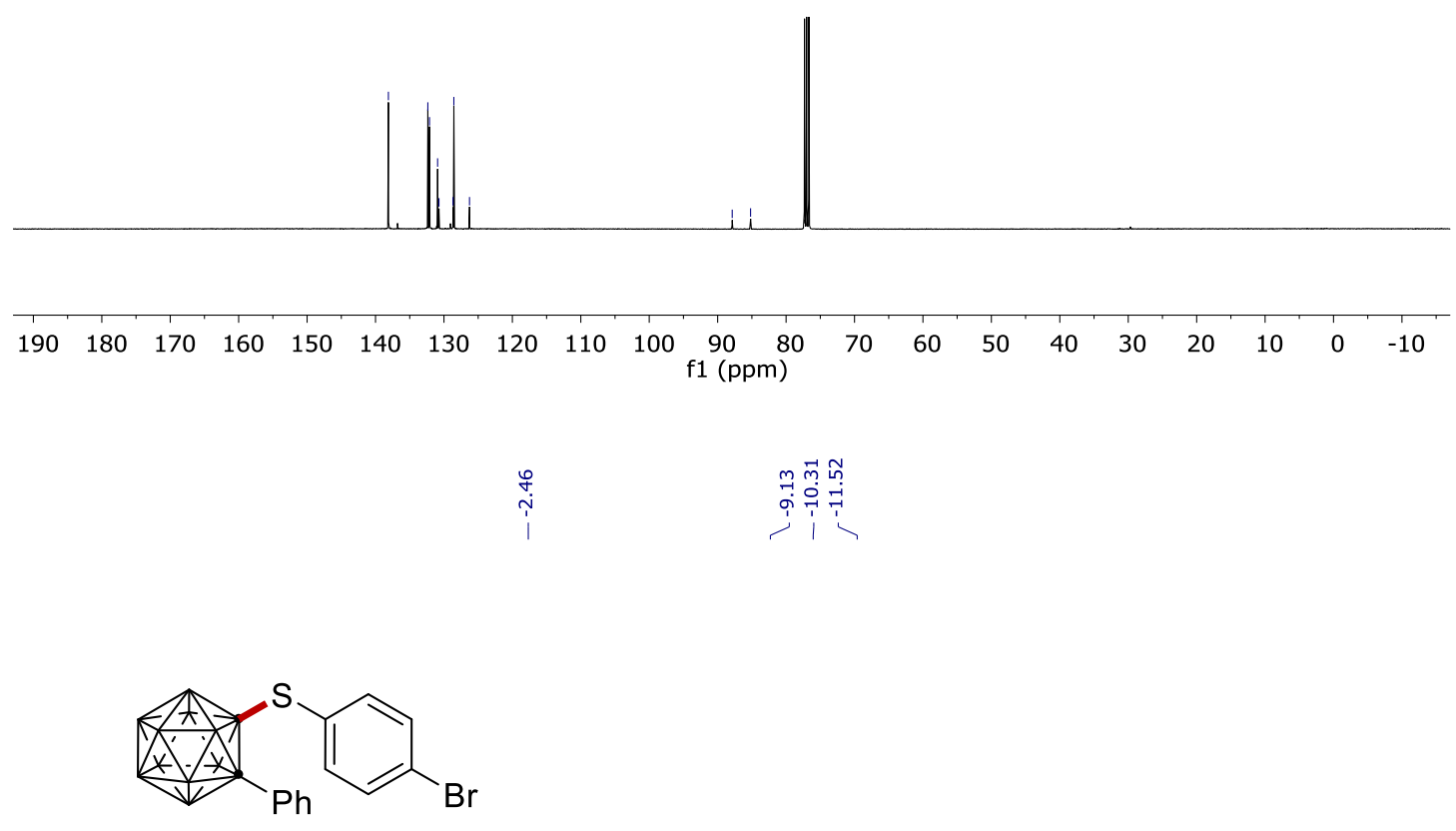

162g

$128 \mathrm{MHz}, \mathrm{CDCl}_{3}$

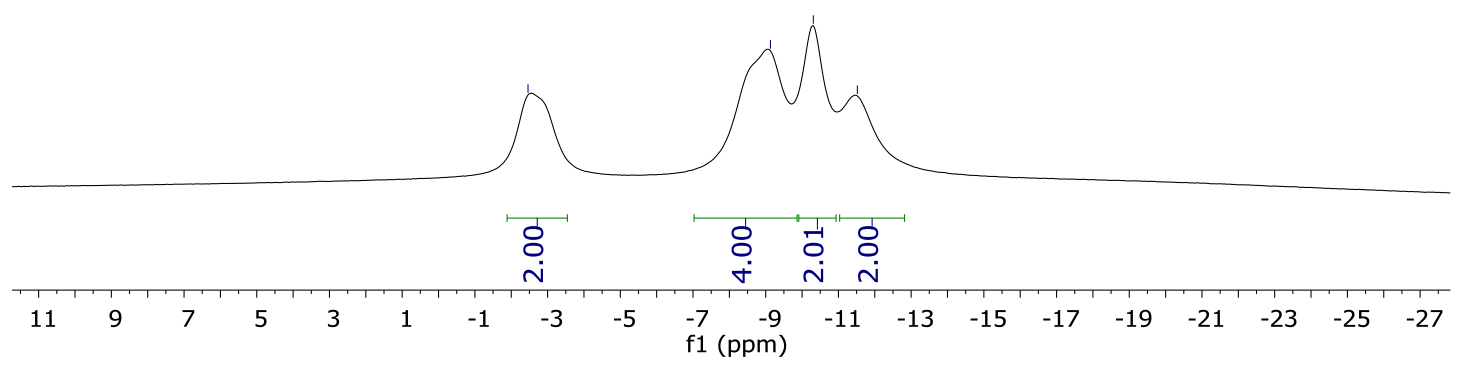




\section{NMR Spectra}

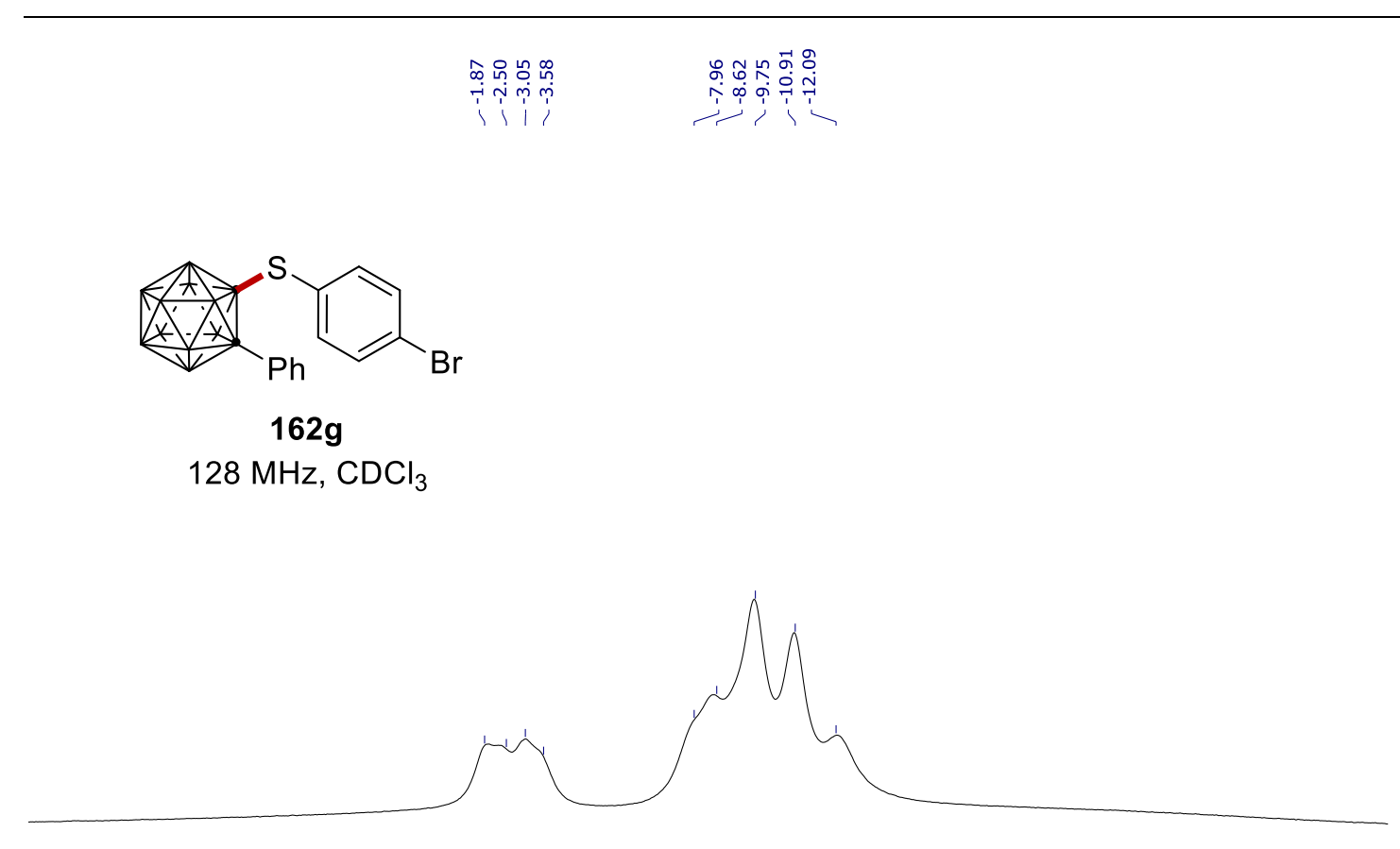

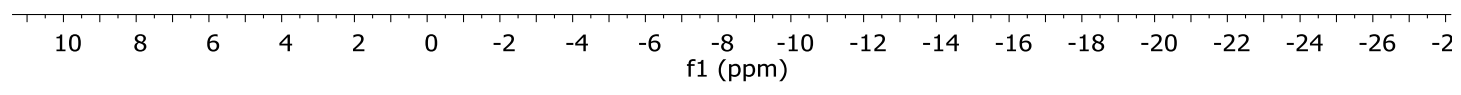

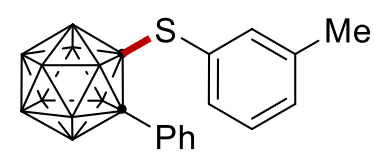

$162 \mathrm{~h}$

$400 \mathrm{MHz}^{\mathrm{CDCl}} 3$

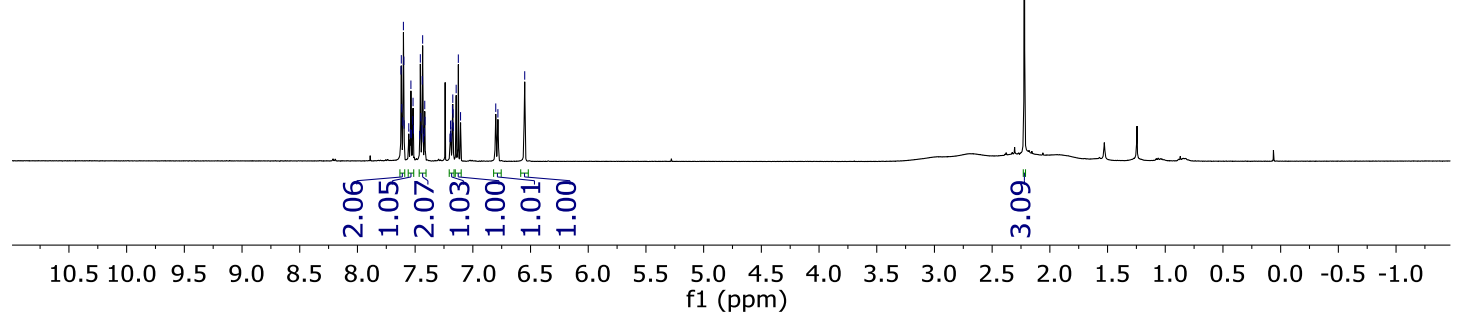




\section{NMR Spectra}

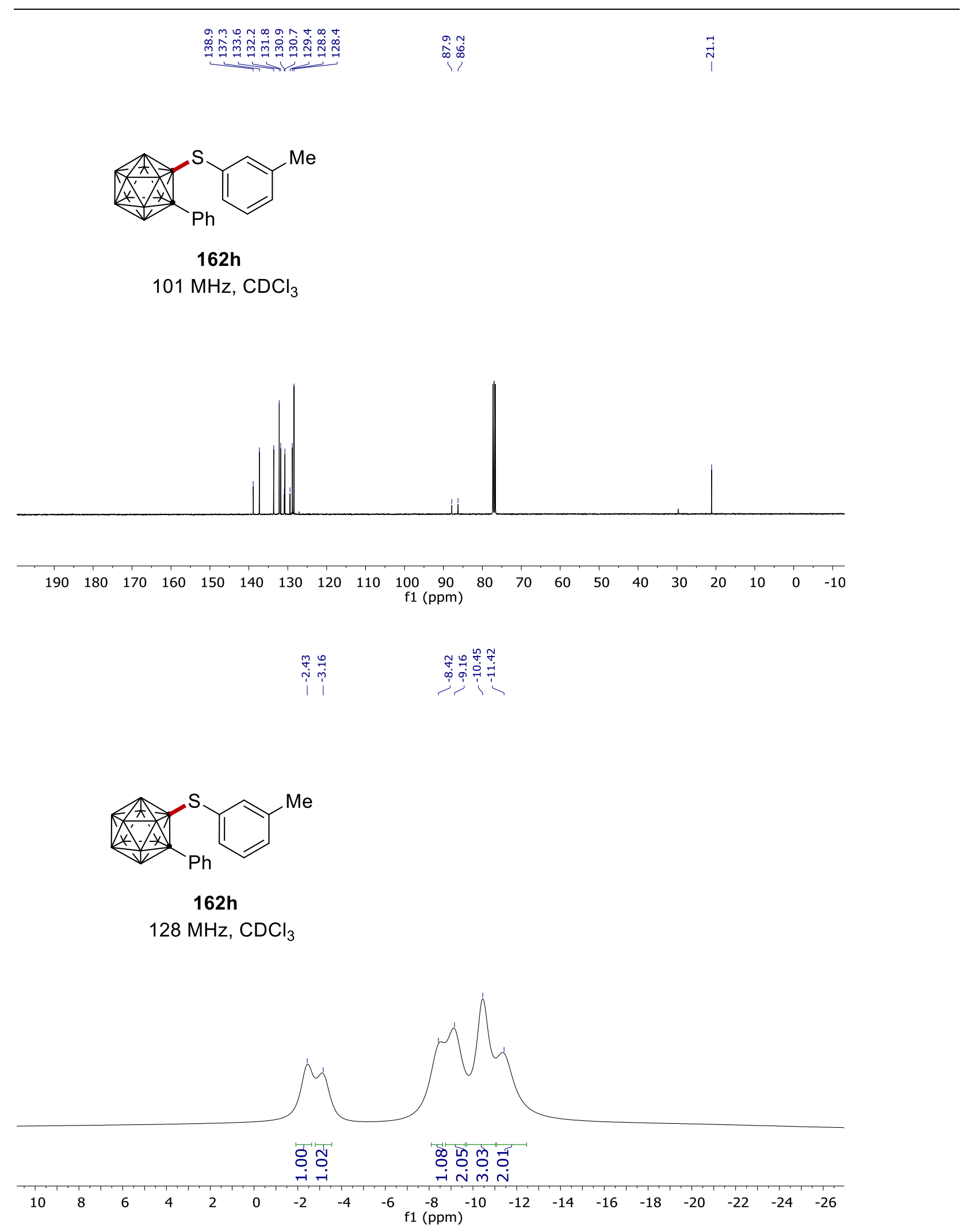




\section{NMR Spectra}
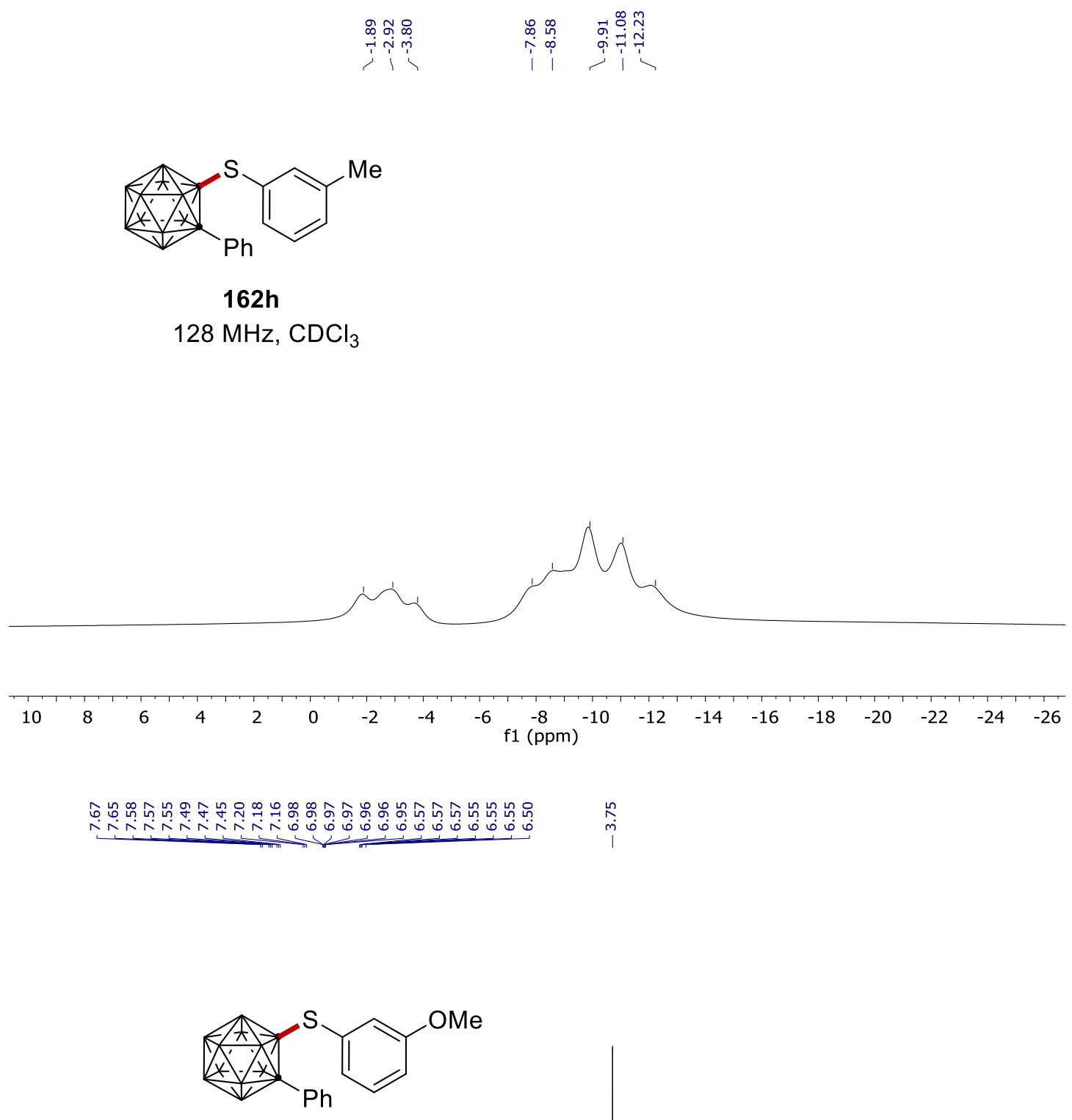

$162 i$

$400 \mathrm{MHz}, \mathrm{CDCl}_{3}$

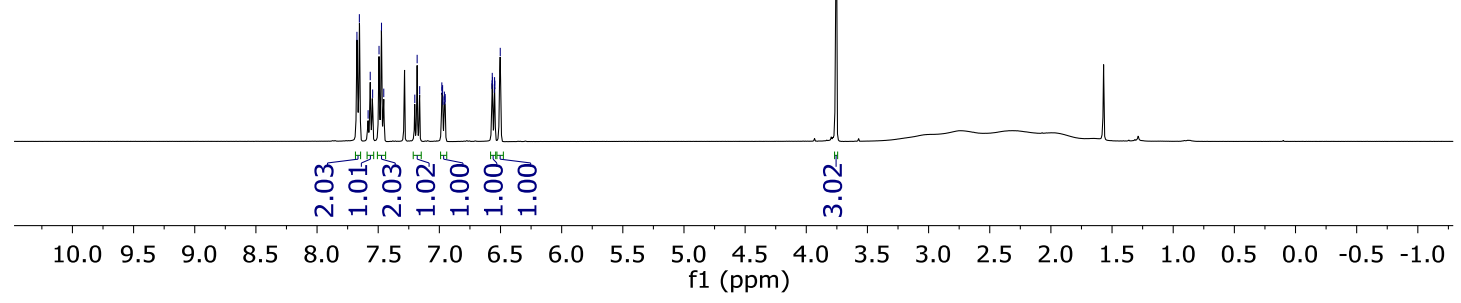




\section{NMR Spectra}
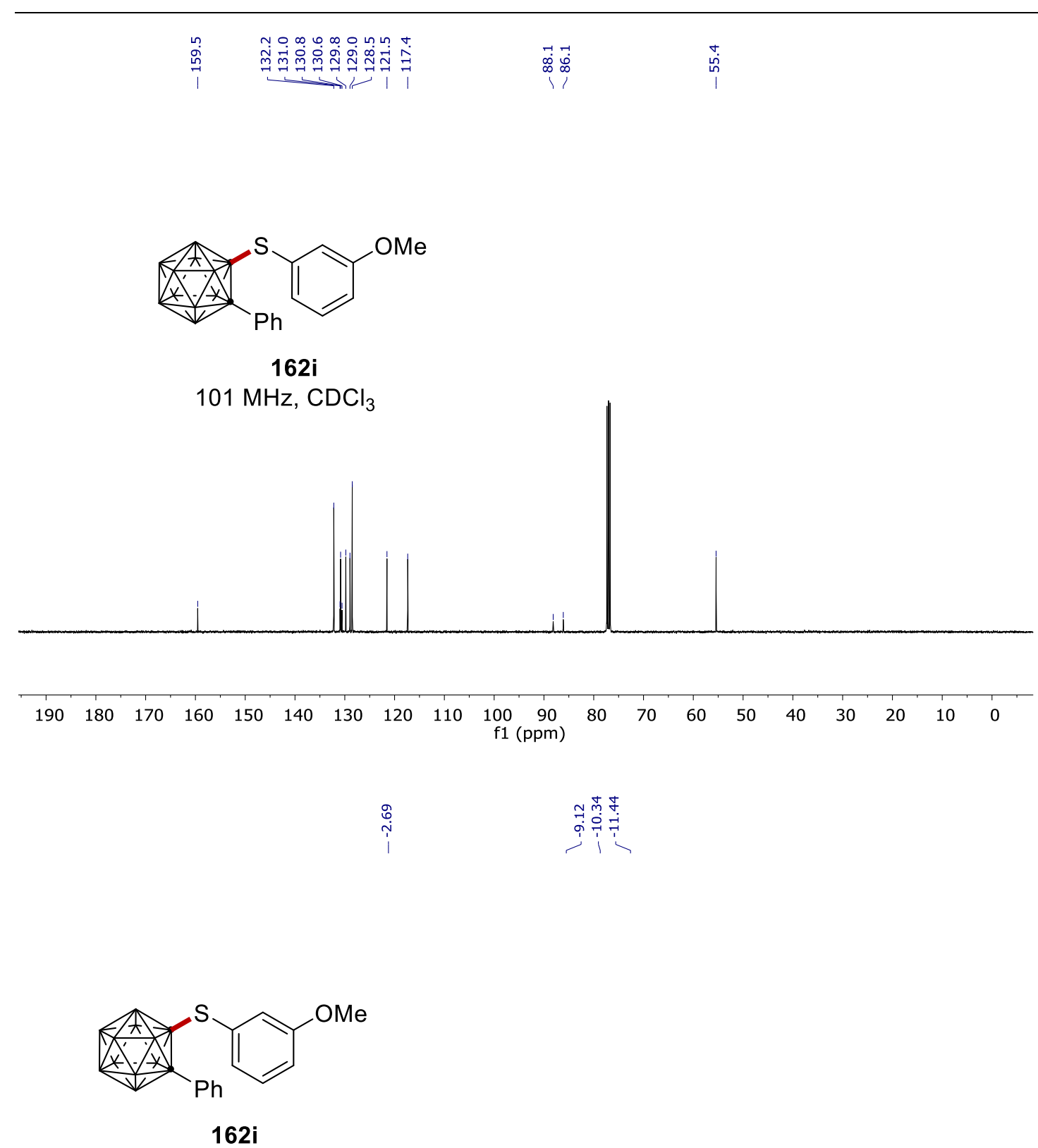

$96 \mathrm{MHz}, \mathrm{CDCl}_{3}$

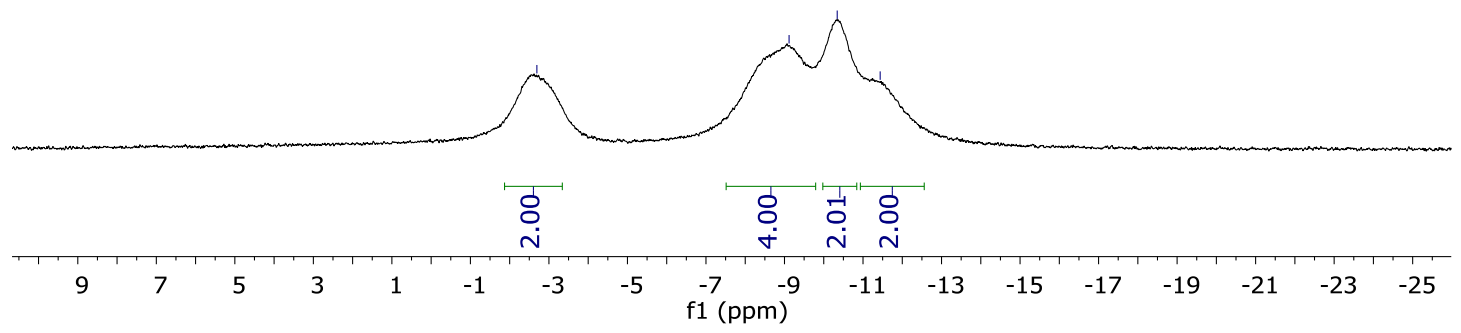




\section{NMR Spectra}

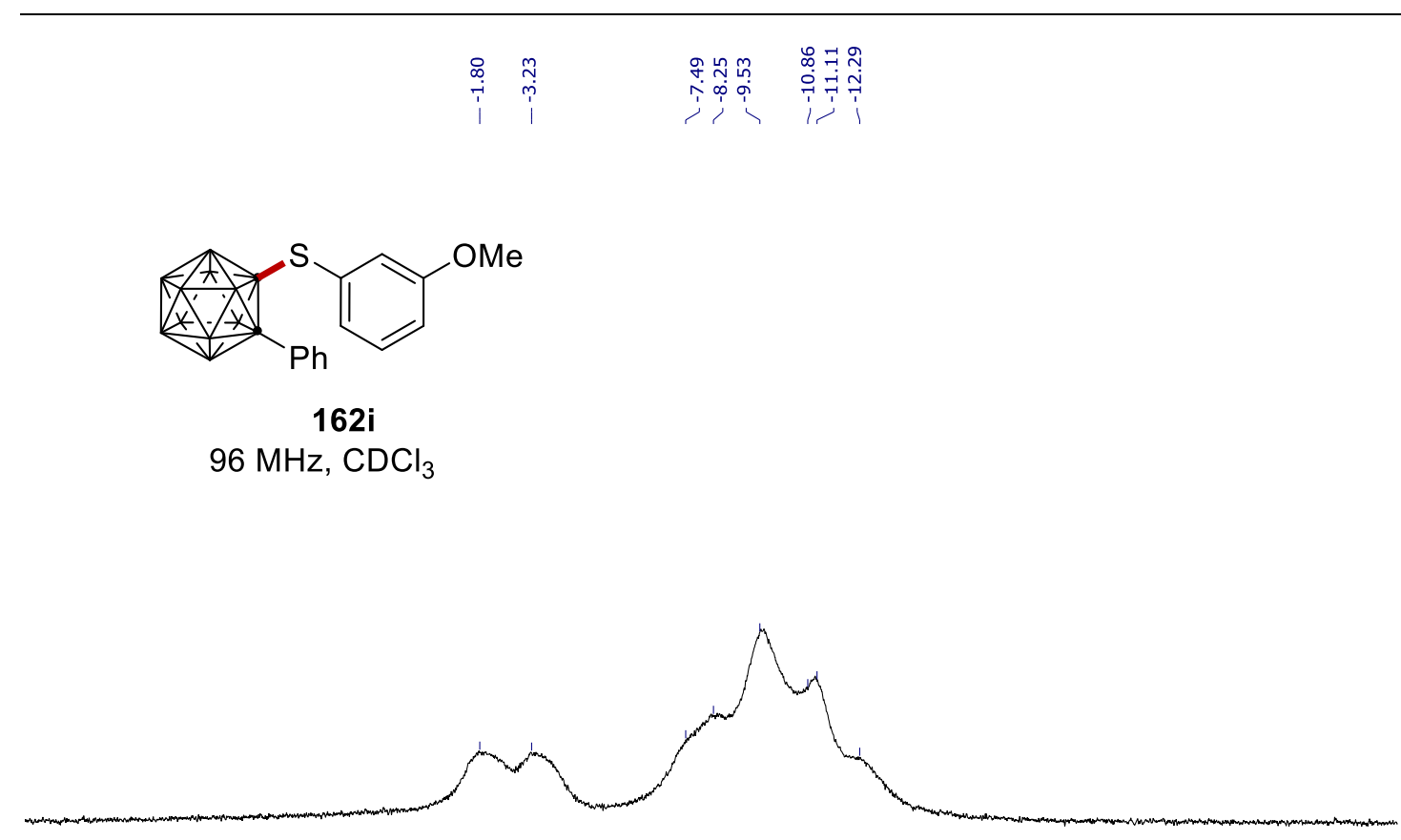

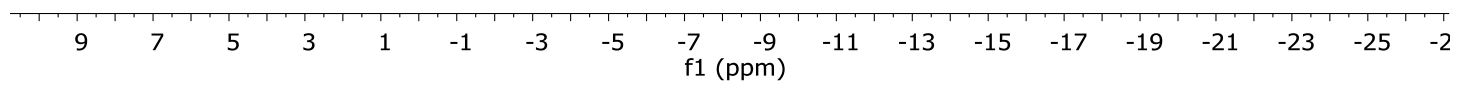

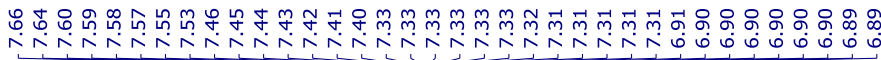

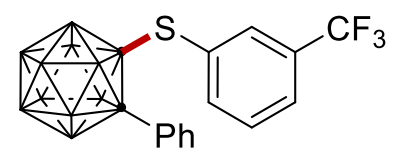

162j

$400 \mathrm{MHz}, \mathrm{CDCl}_{3}$

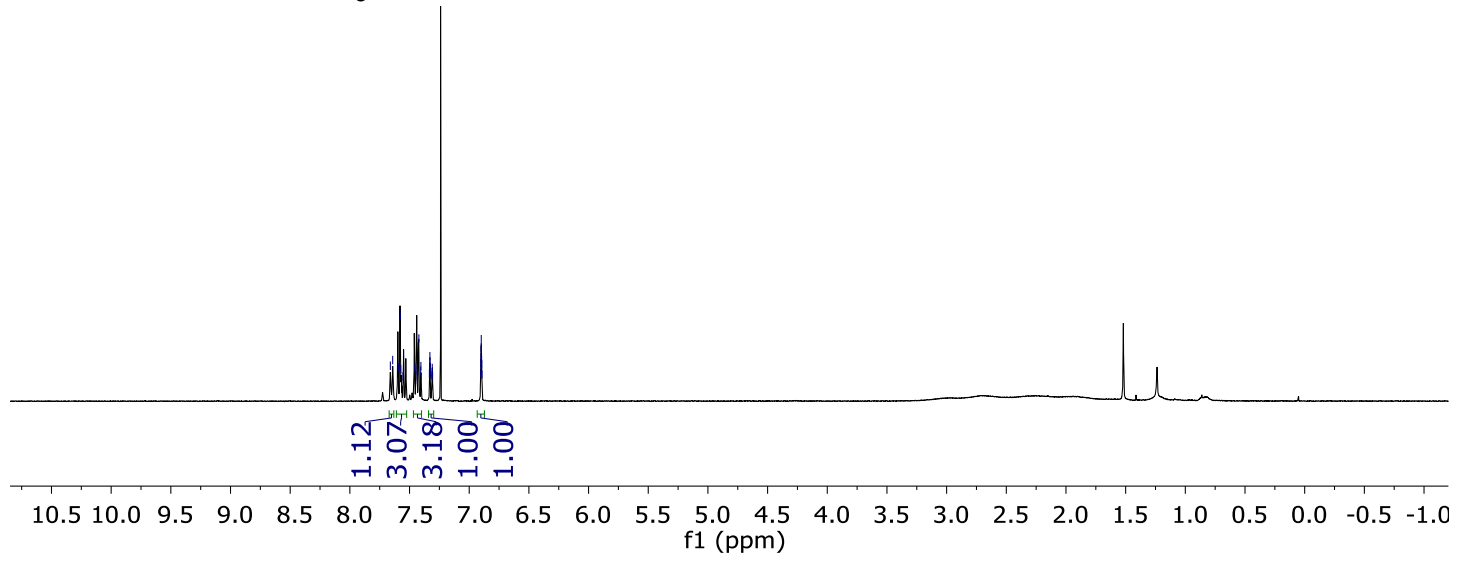




\section{NMR Spectra}

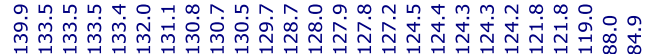

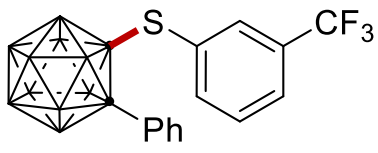

162j

$101 \mathrm{MHz}, \mathrm{CDCl}_{3}$

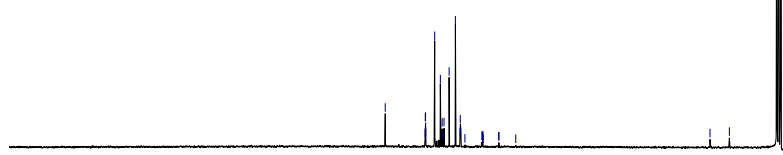

$\begin{array}{lllllllllllllllllllllll}00 & 190 & 180 & 170 & 160 & 150 & 140 & 130 & 120 & 110 & 100 & \begin{array}{c}90 \\ \mathrm{f} 1(\mathrm{ppm})\end{array} & 70 & 60 & 50 & 40 & 30 & 20 & 10 & 0 & -10 & -20 & -\end{array}$
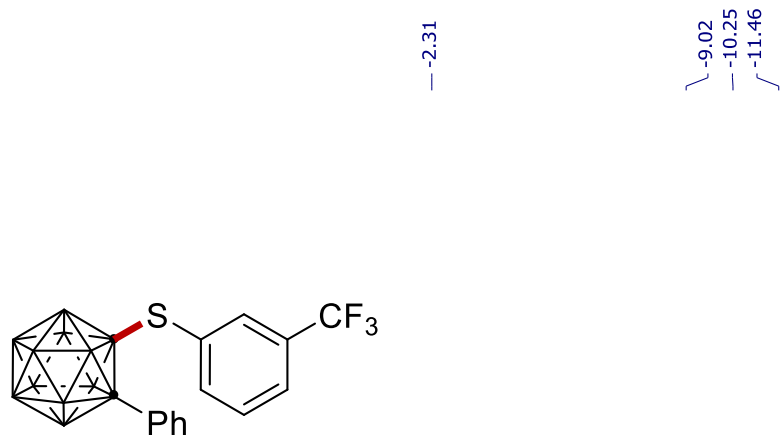

162j

$128 \mathrm{MHz}, \mathrm{CDCl}_{3}$

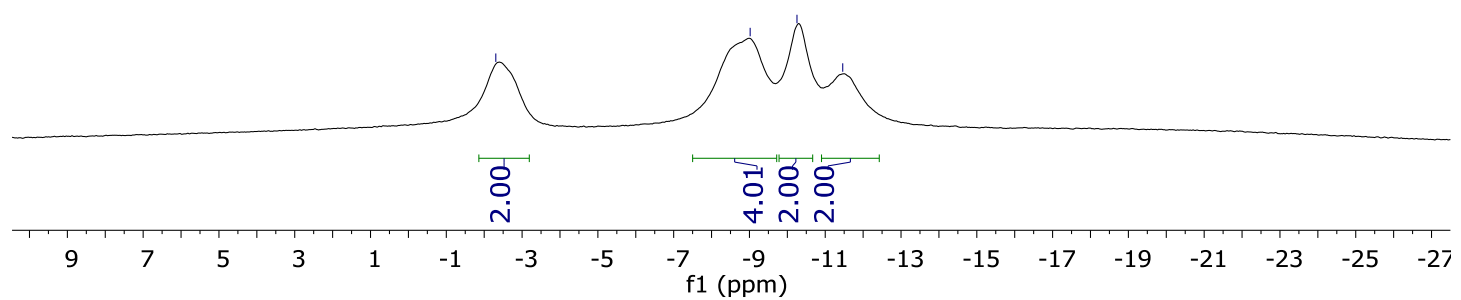




\section{NMR Spectra}
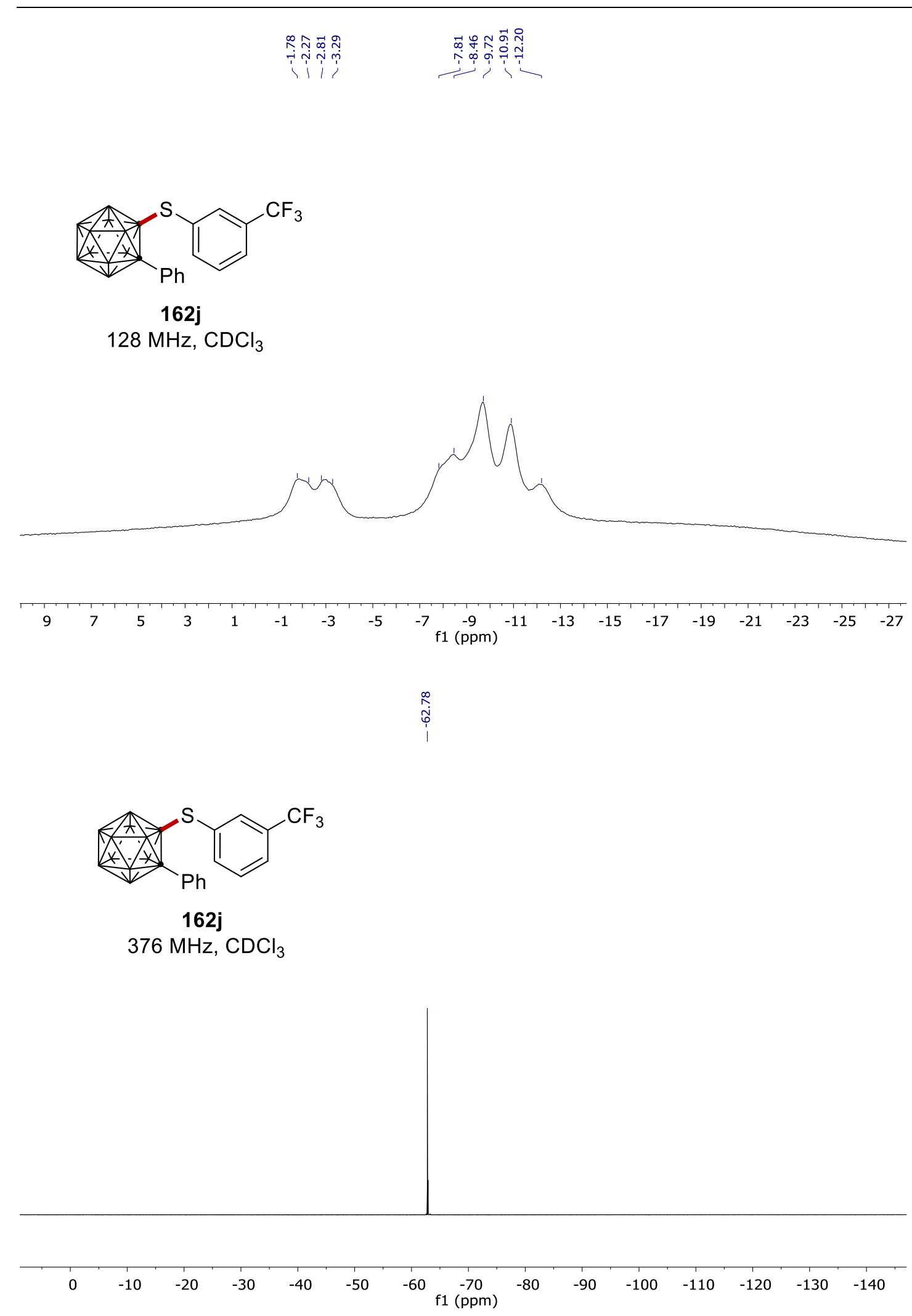


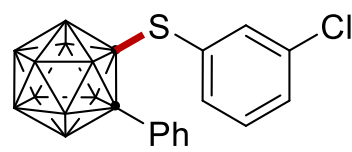

$162 k$

$400 \mathrm{MHz}, \mathrm{CDCl}_{3}$

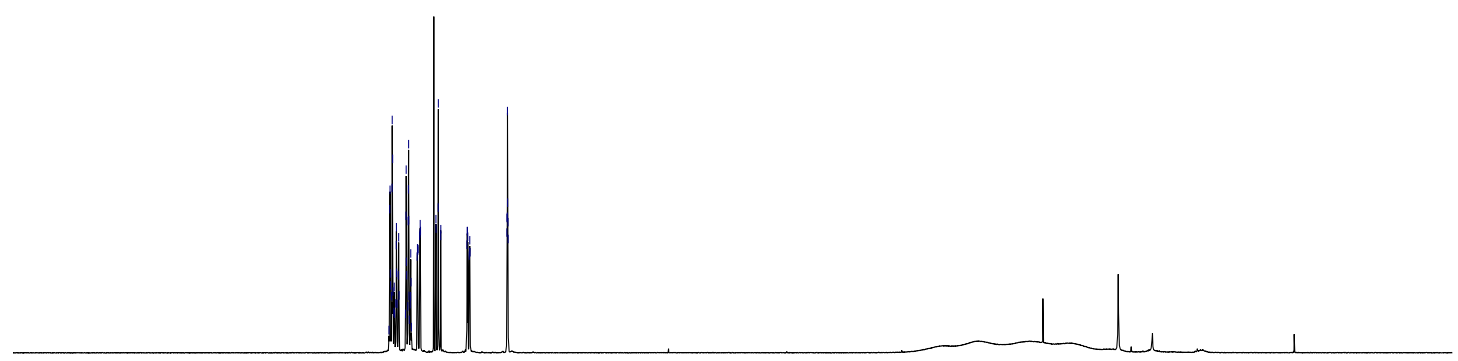

तथ

$\begin{array}{rllllllllllllllllllllllllll}10.5 & 10.0 & 9.5 & 9.0 & 8.5 & 8.0 & 7.5 & 7.0 & 6.5 & 6.0 & 5.5 & \begin{array}{l}5.0 \\ \mathrm{f} 1(\mathrm{ppm})\end{array} & 4.0 & 3.5 & 3.0 & 2.5 & 2.0 & 1.5 & 1.0 & 0.5 & 0.0 & -0.5 & -1.0\end{array}$

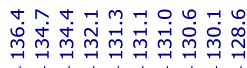

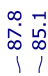

$\underbrace{A}_{P h}$

$162 \mathrm{k}$

$101 \mathrm{MHz}, \mathrm{CDCl}_{3}$

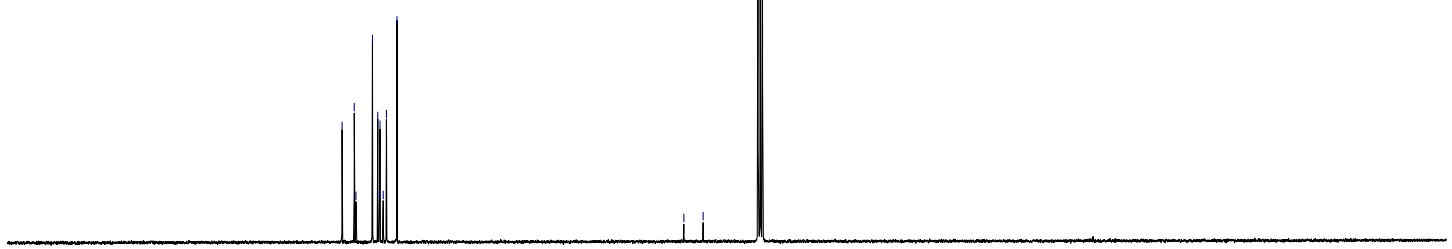

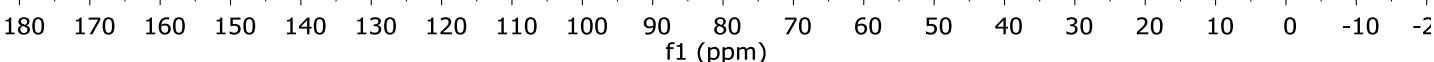




\section{NMR Spectra}

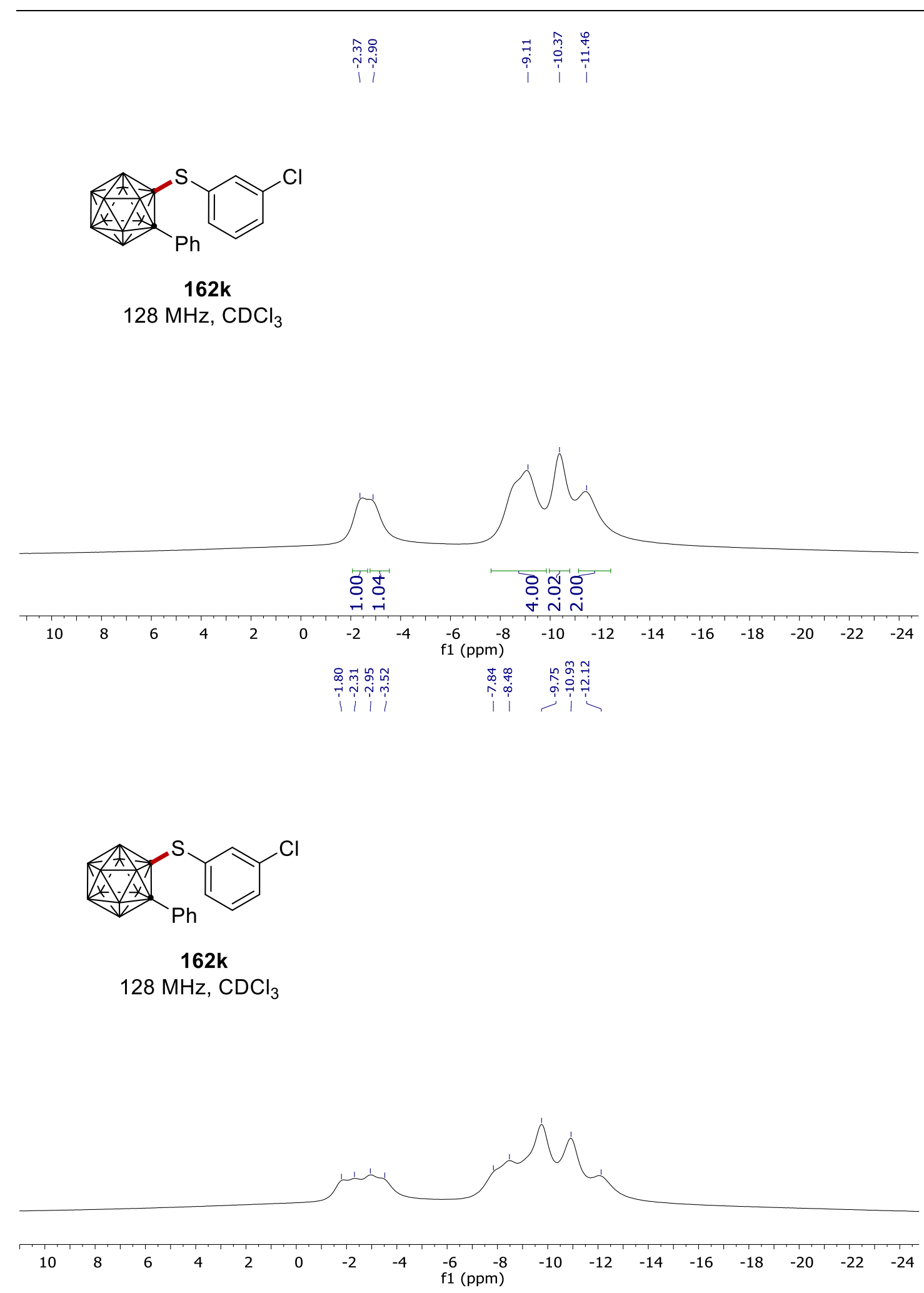




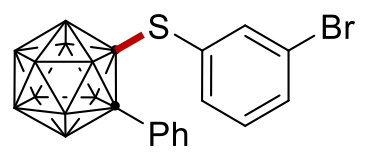

162I

$400 \mathrm{MHz}, \mathrm{CDCl}_{3}$
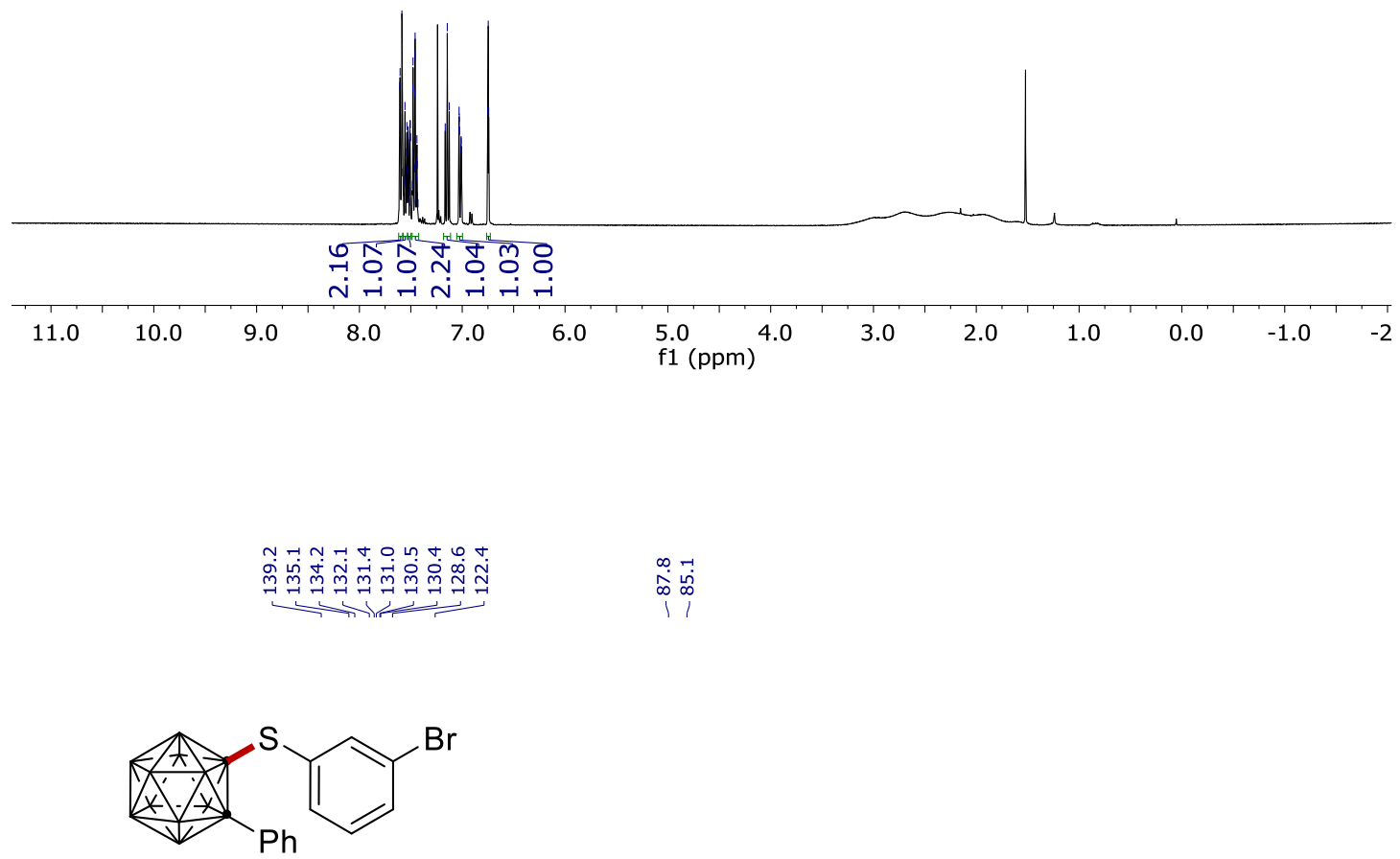

162I

$101 \mathrm{MHz}, \mathrm{CDCl}_{3}$

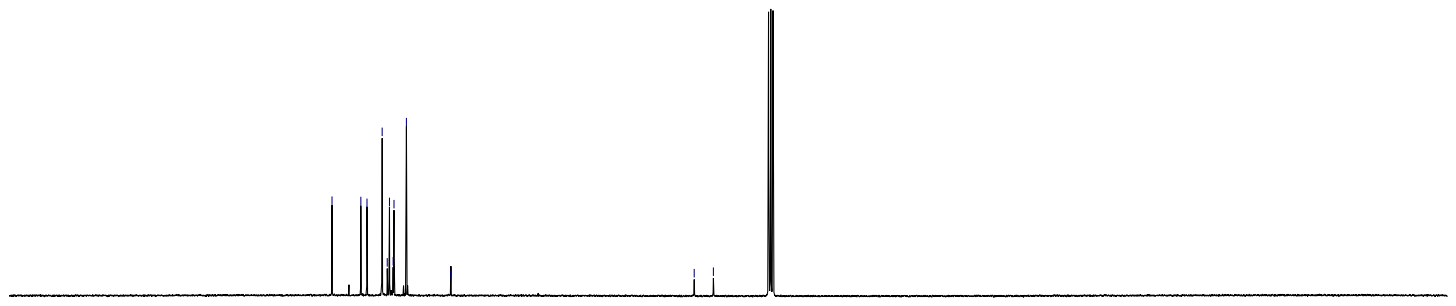

$\begin{array}{llllllllllllllllllll}180 & 170 & 160 & 150 & 140 & 130 & 120 & 110 & 100 & \begin{array}{c}90 \\ \mathrm{f} 1(\mathrm{ppm})\end{array} & 70 & 60 & 50 & 40 & 30 & 20 & 10 & 0 & -10\end{array}$ 


\section{NMR Spectra}
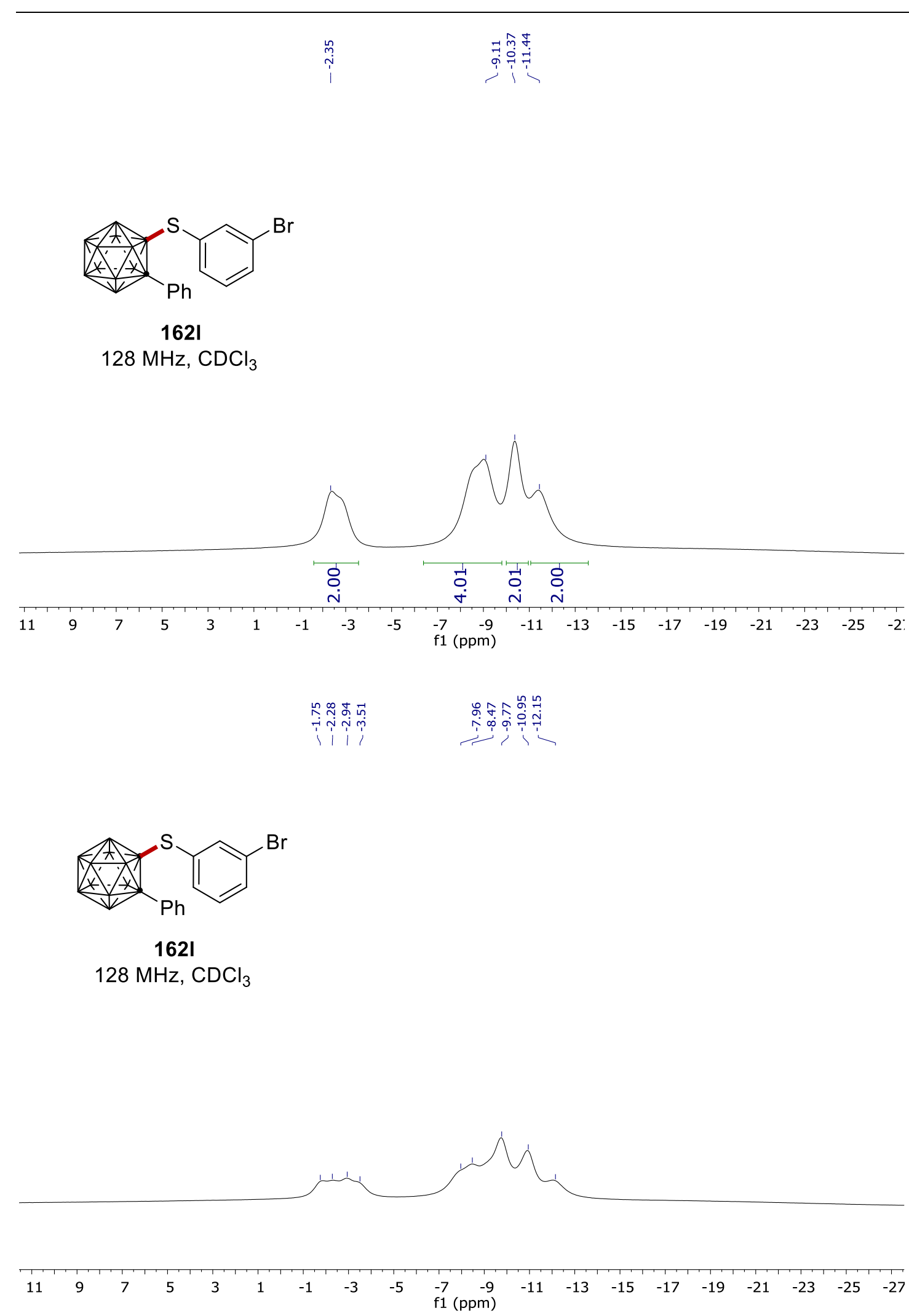
<smiles>Fc1ccccc1SC12c3ccccc3C34C5=CC=CC=C3C1C1C5C4C12</smiles>

$162 \mathrm{~m}$
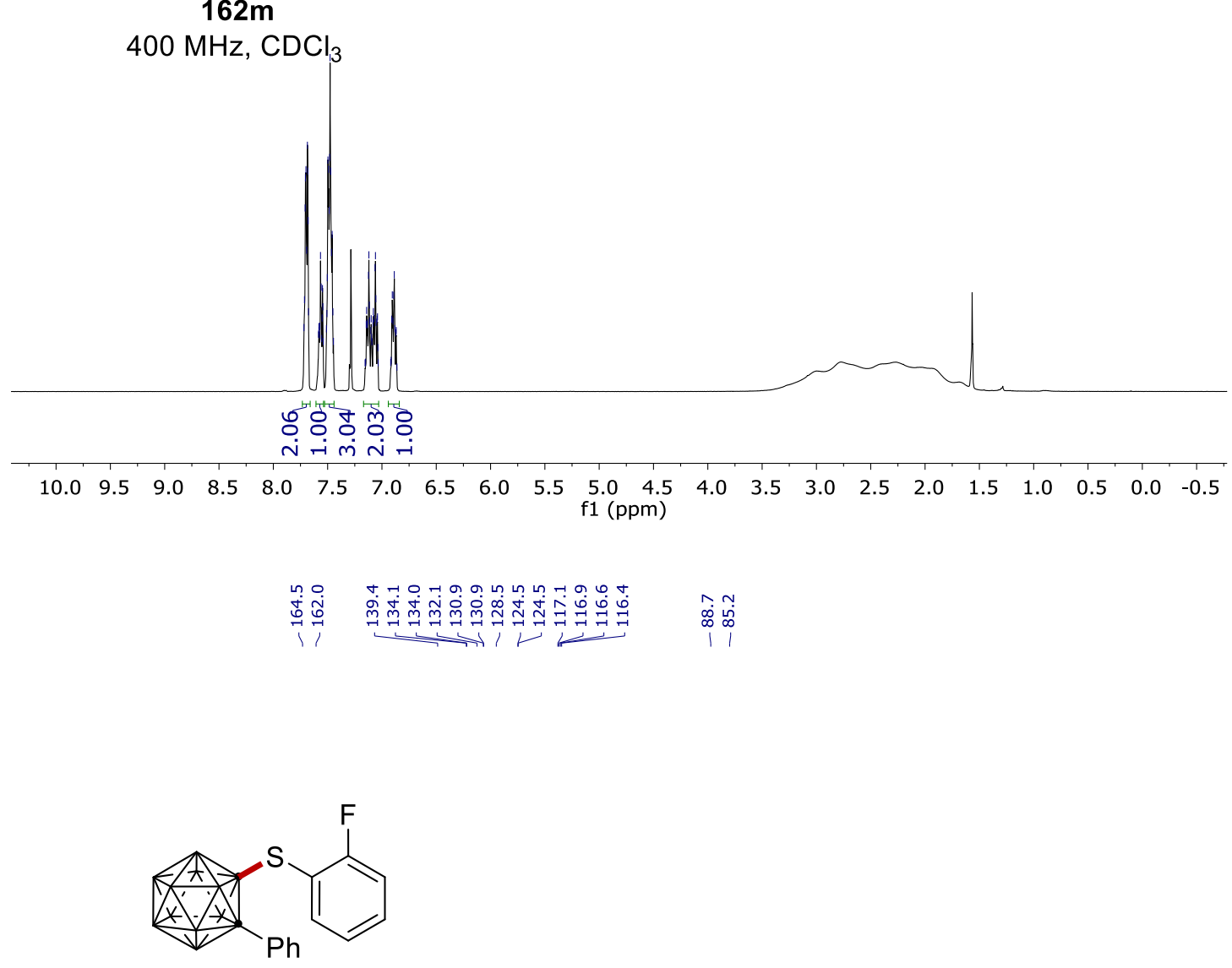

$162 \mathrm{~m}$

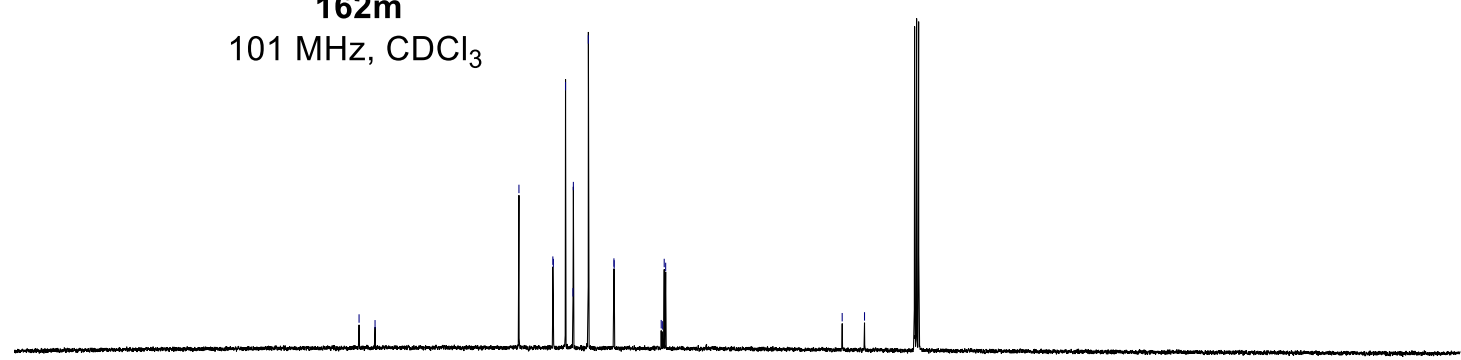

$\begin{array}{llllllllllllllllllllll}210 & 200 & 190 & 180 & 170 & 160 & 150 & 140 & 130 & 120 & 110 & 100 & 90 & 80 & 70 & 60 & 50 & 40 & 30 & 20 & 10 & 0\end{array}$ 


\section{NMR Spectra}

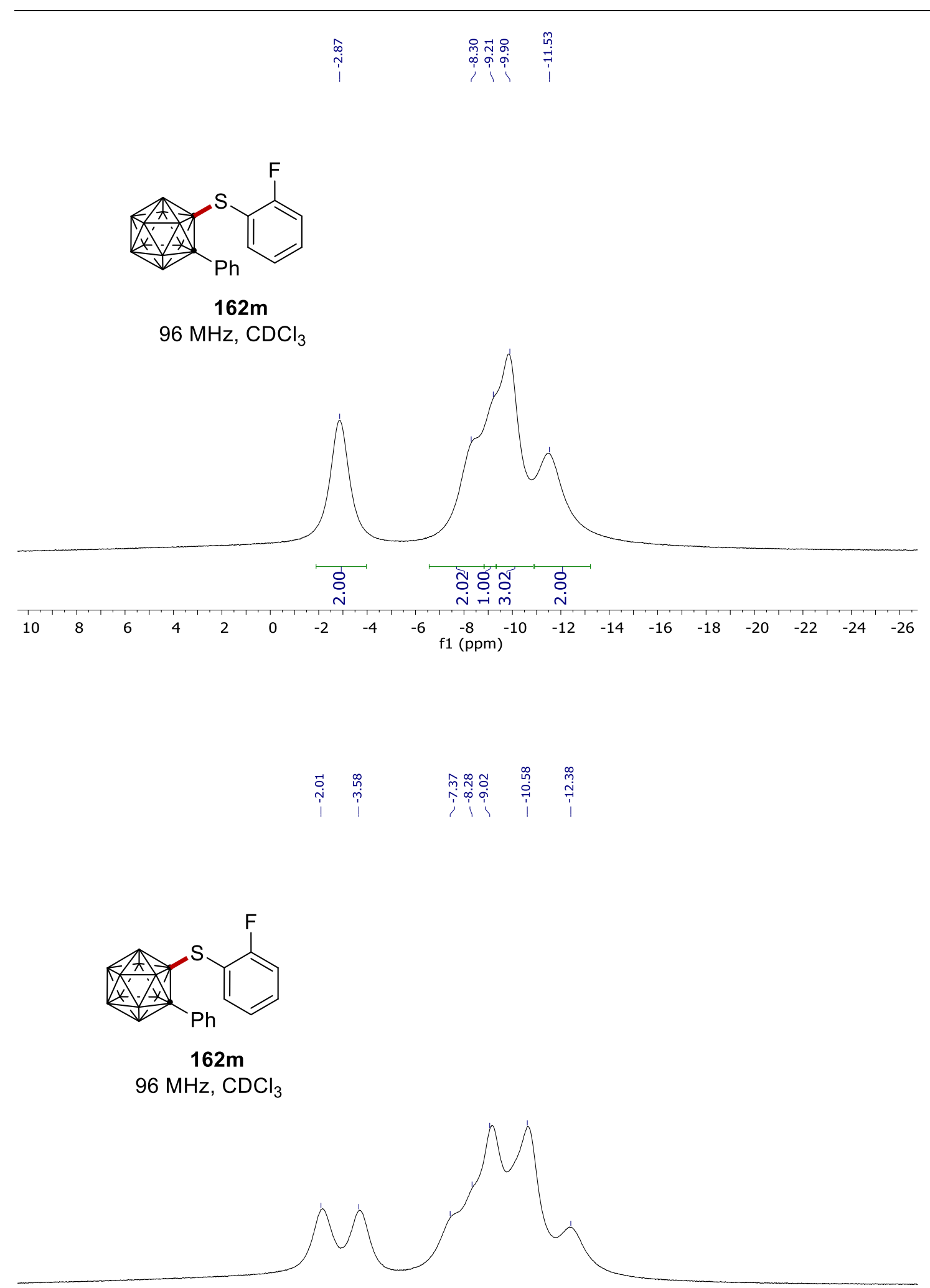

$\begin{array}{lllllllllllllllllllllll}10 & 8 & 6 & 4 & 2 & 0 & -2 & -4 & -6 & -8 & -10 & -12 & -14 & -16 & -18 & -20 & -22 & -24 & -26\end{array}$




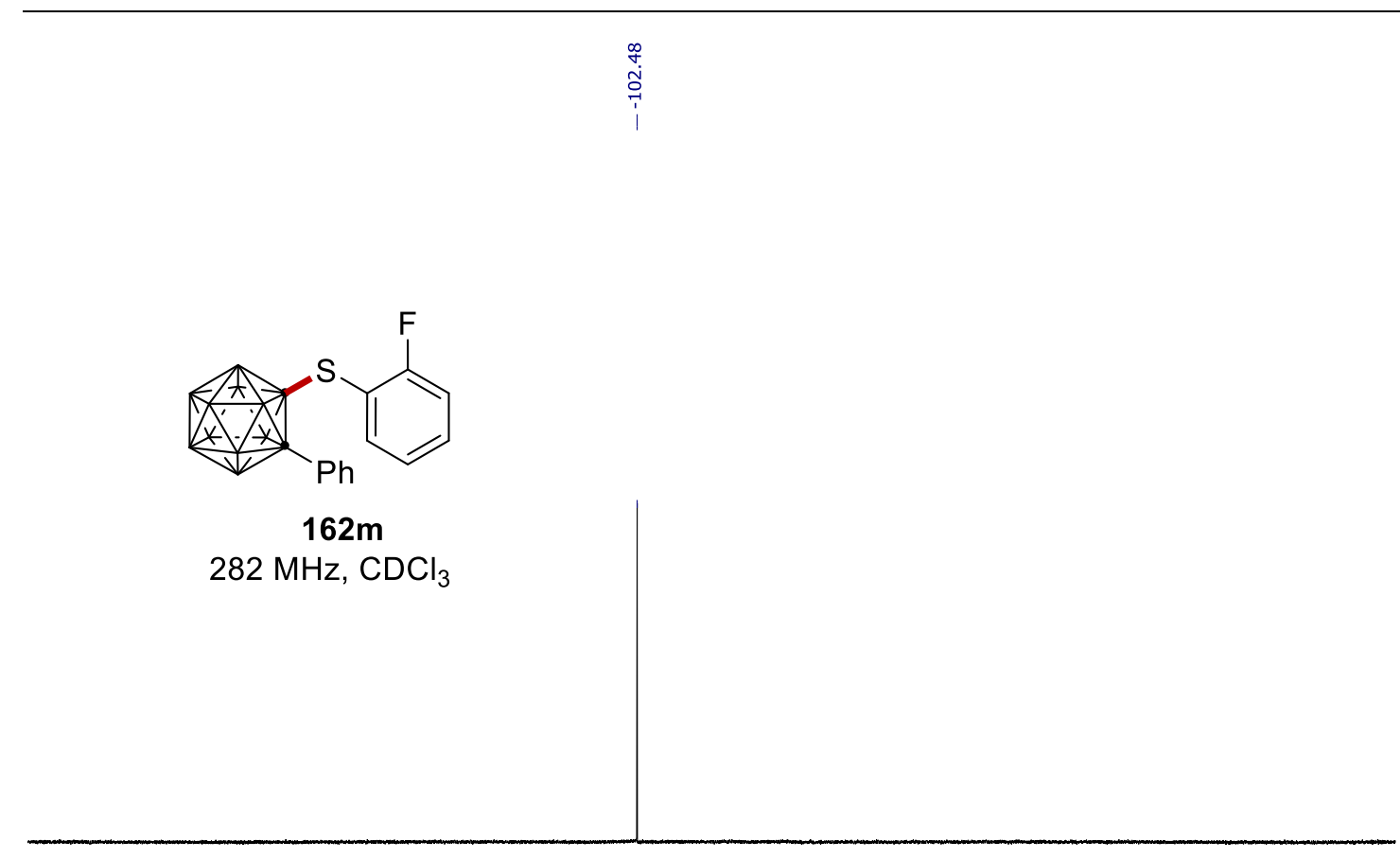

\begin{tabular}{|c|c|c|c|c|c|c|c|c|c|c|c|c|c|}
\hline-45 & -55 & -65 & -75 & -85 & -95 & $\begin{array}{r}-105 \\
\quad \text { 1 }\end{array}$ & $\mathrm{pm}^{-115}$ & -125 & -135 & -145 & -155 & -165 & -17 \\
\hline
\end{tabular}

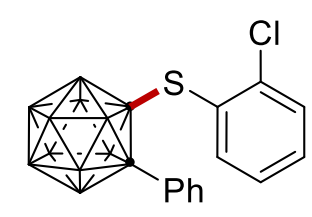

162n

$400 \mathrm{MHz}, \mathrm{CDCl}_{3}$

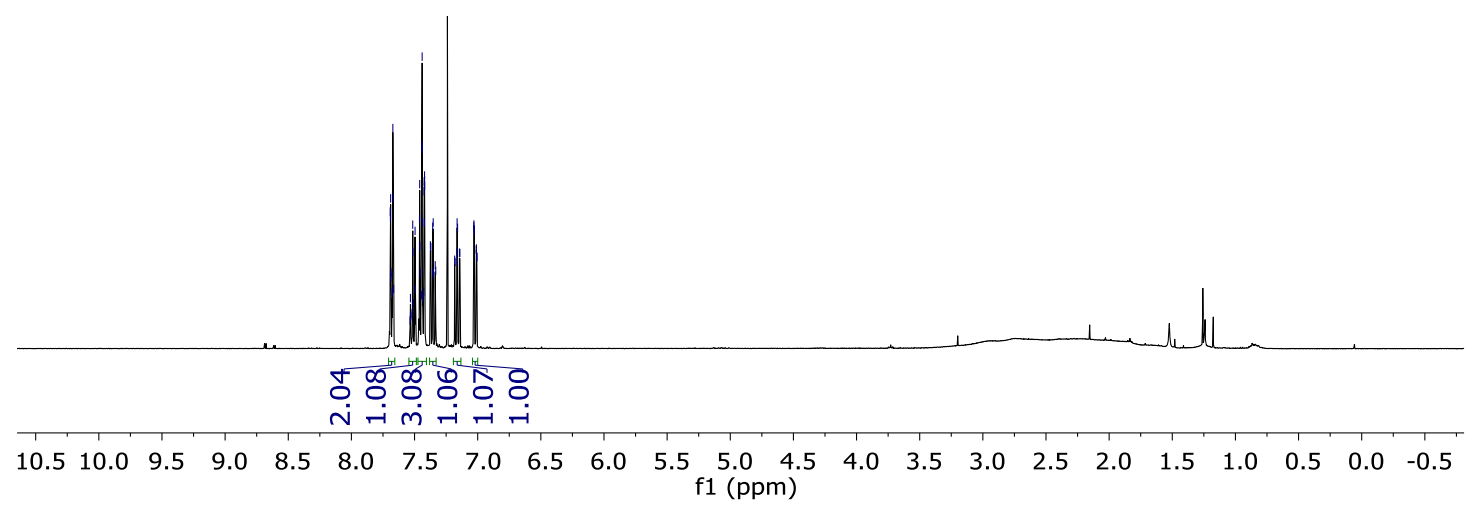




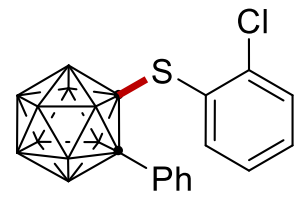

162n

$101 \mathrm{MHz}, \mathrm{CDCl}_{3}$
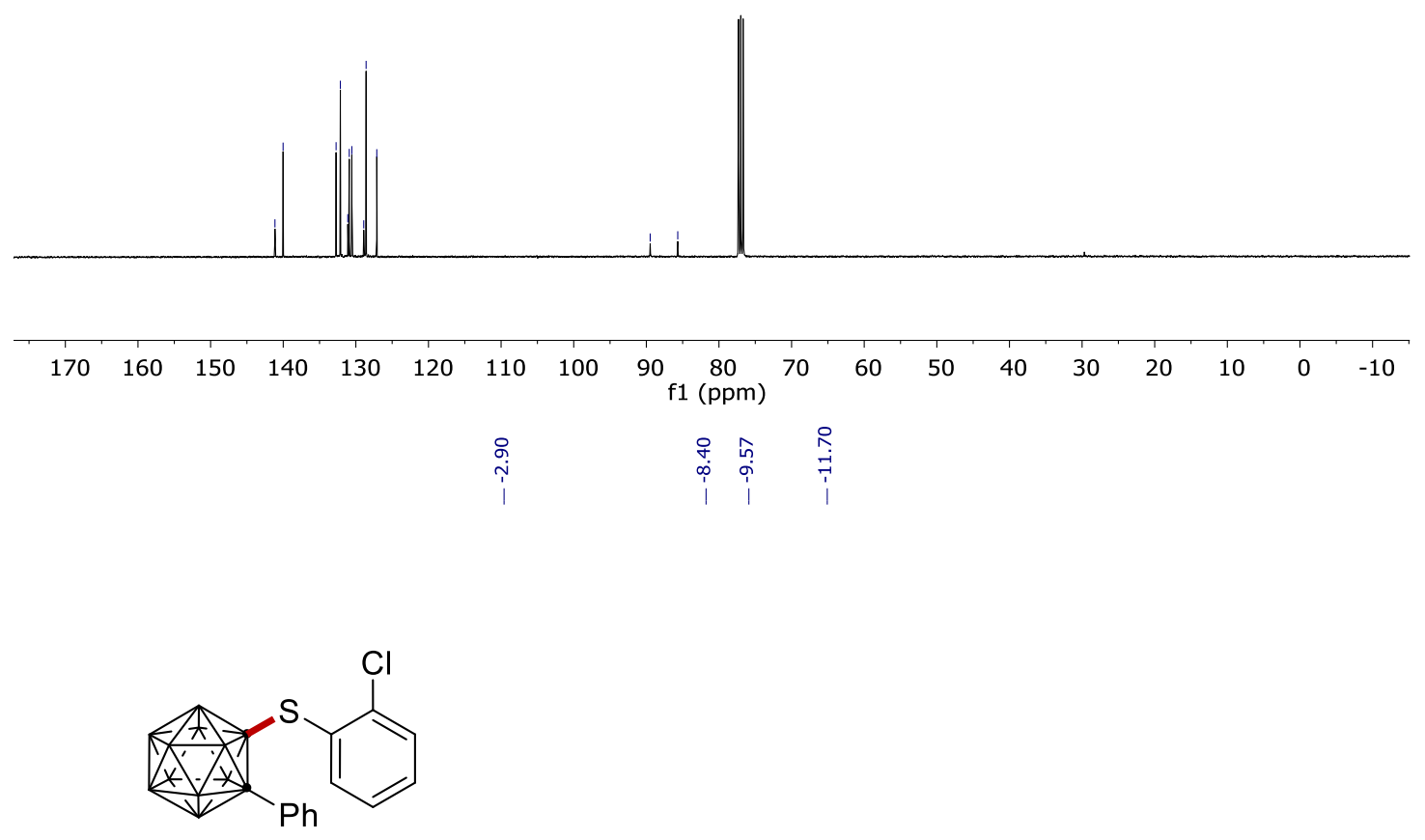

162n

$128 \mathrm{MHz} \mathrm{CDCl}_{3}$

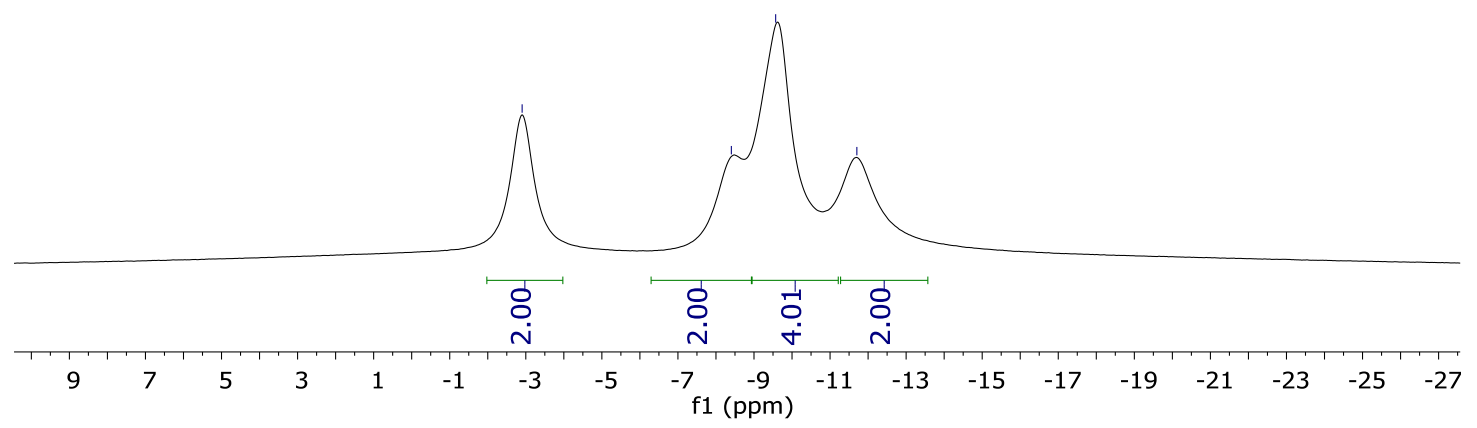




\section{NMR Spectra}

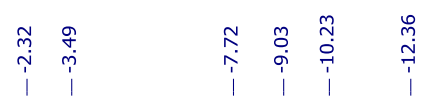

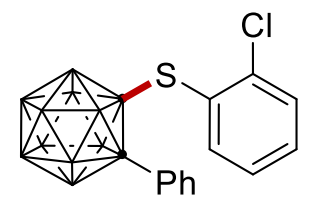

162n

$128 \mathrm{MHz}, \mathrm{CDCl}_{3}$
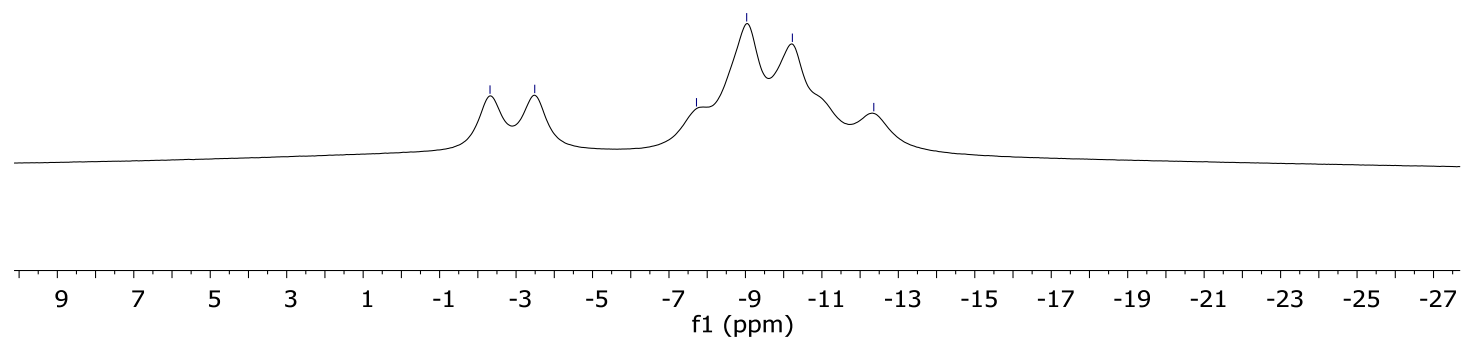

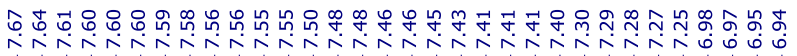

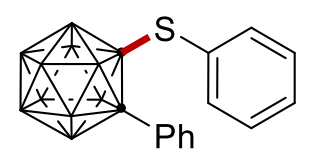

1620

$300 \mathrm{MHz}, \mathrm{CDCl}_{3}$

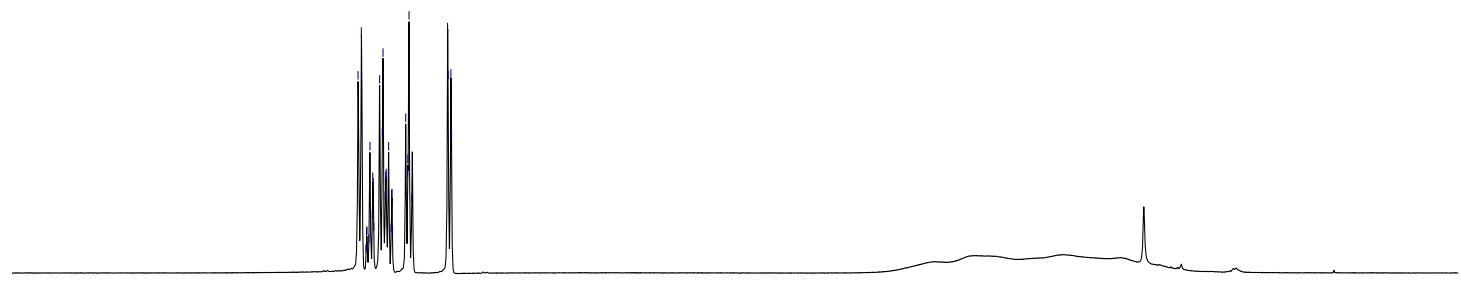

moth

$\dot{N}-\dot{m} \dot{N} \dot{n}$

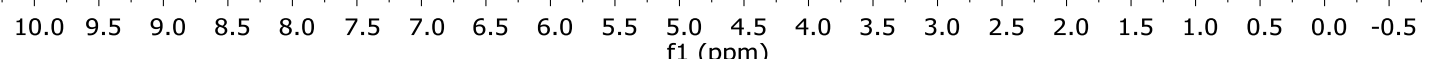




\section{NMR Spectra}

$\infty$
0
0
$\dot{p}$

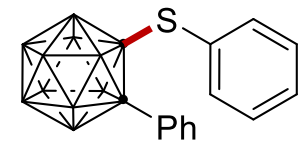

1620

$75 \mathrm{MHz}, \mathrm{CDCl}_{3}$
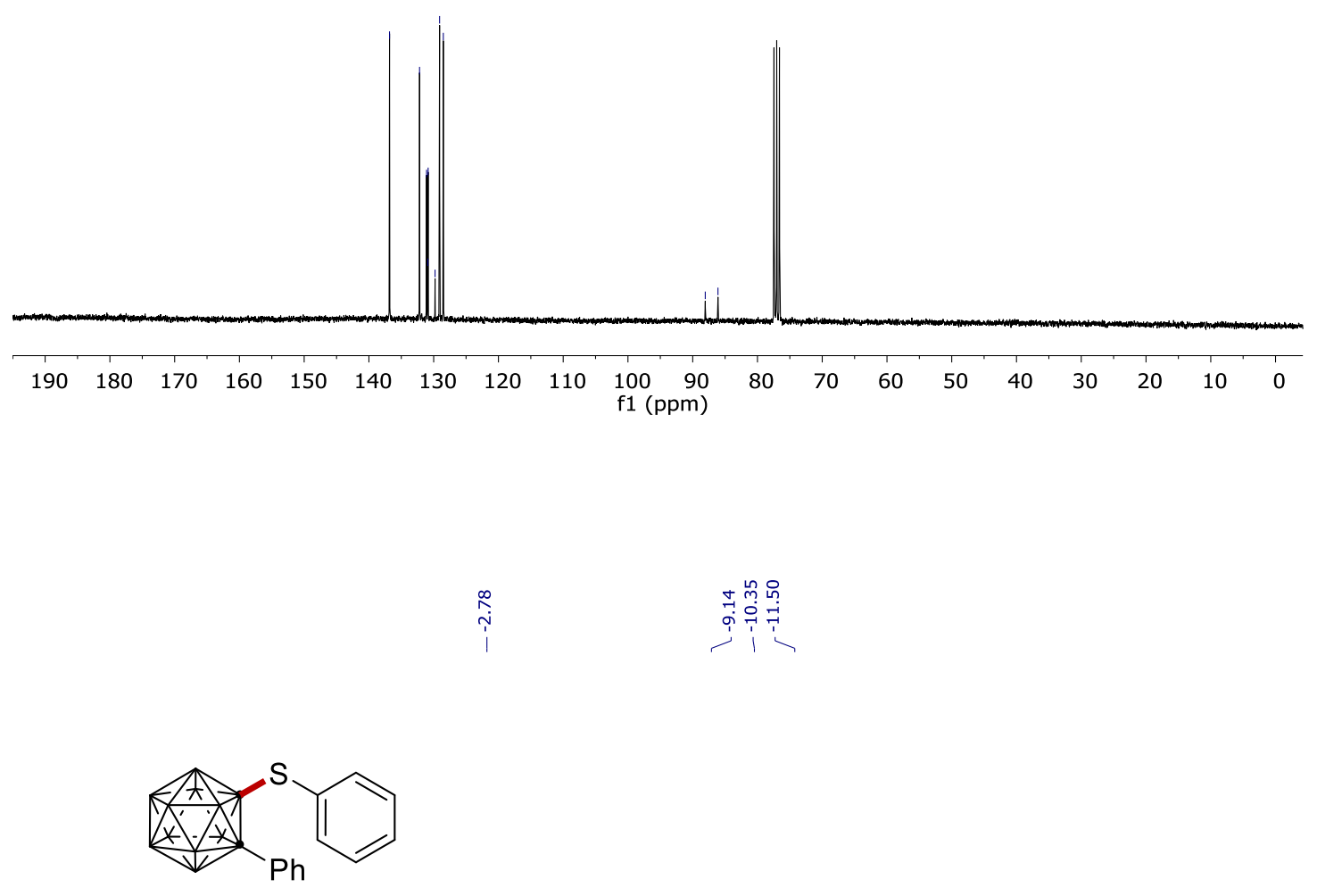

1620

$96 \mathrm{MHz}, \mathrm{CDCl}_{3}$

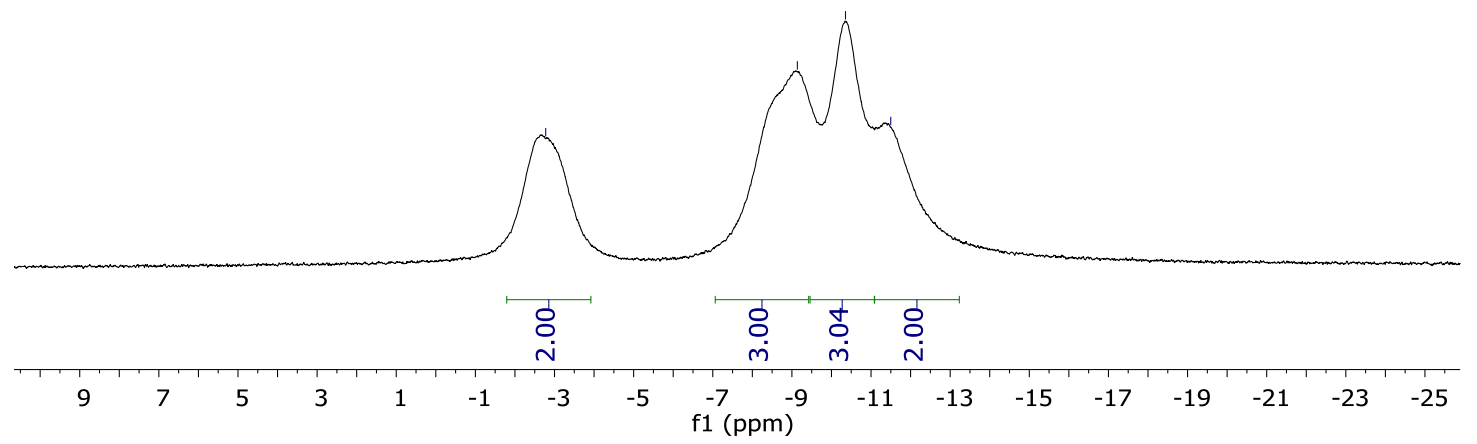




\section{NMR Spectra}

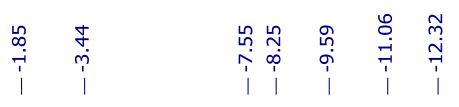

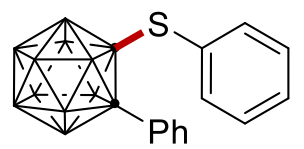

1620

$96 \mathrm{MHz}, \mathrm{CDCl}_{3}$

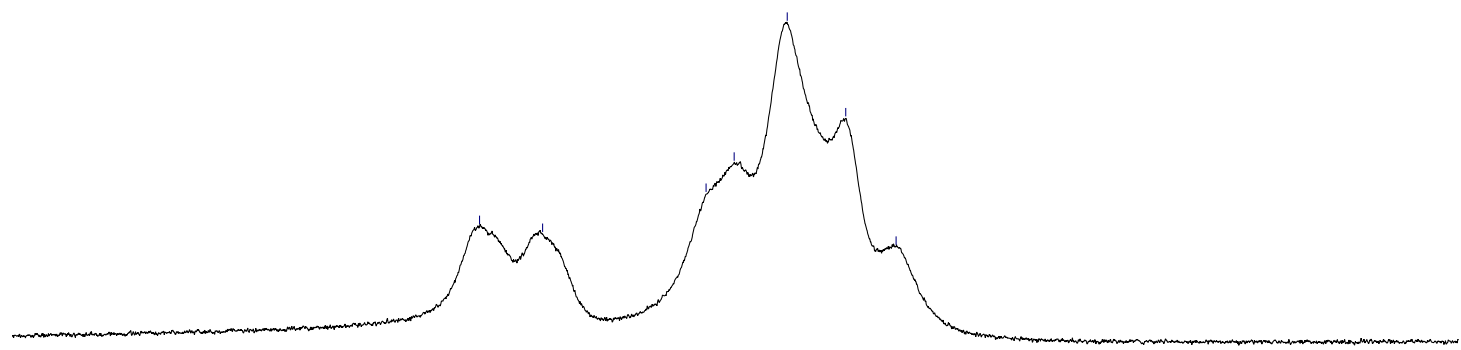

\begin{tabular}{|c|c|c|c|c|c|c|c|c|c|c|c|c|c|c|c|c|c|}
\hline 8 & 6 & 4 & 2 & 0 & -2 & -4 & -6 & $\stackrel{-8}{\mathrm{f} 1}(\mathrm{ppm})$ & )$^{-10}$ & -12 & -14 & -16 & -18 & -20 & -22 & -24 & $-2 \epsilon$ \\
\hline
\end{tabular}

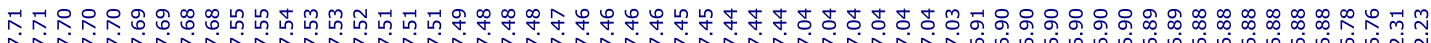

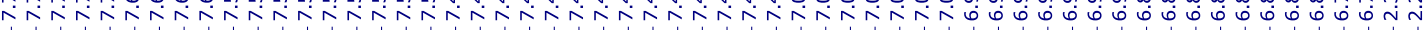

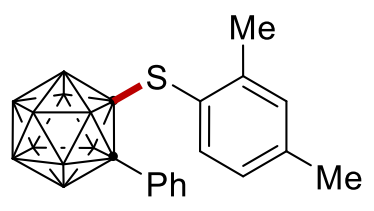

$162 p$

$400 \mathrm{MHz}, \mathrm{CDCl}_{3}$

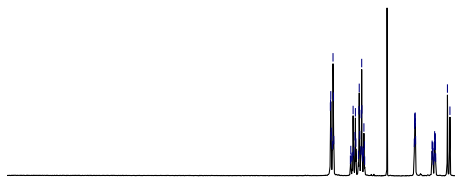

นn

i n i i i

$\begin{array}{lllllllllllllllllllllllllllll}10.0 & 9.5 & 9.0 & 8.5 & 8.0 & 7.5 & 7.0 & 6.5 & 6.0 & 5.5 & 5.0 & 4.5 & 4.0 & 3.5 & 3.0 & 2.5 & 2.0 & 1.5 & 1.0 & 0.5 & 0.0 & -0.5 & -1.6\end{array}$ 


\section{NMR Spectra}

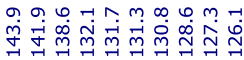

ஸุ่

ํํำ

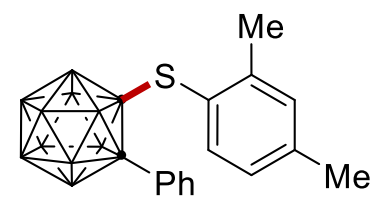

$162 p$

$101 \mathrm{MHz}, \mathrm{CDCl}_{3}$
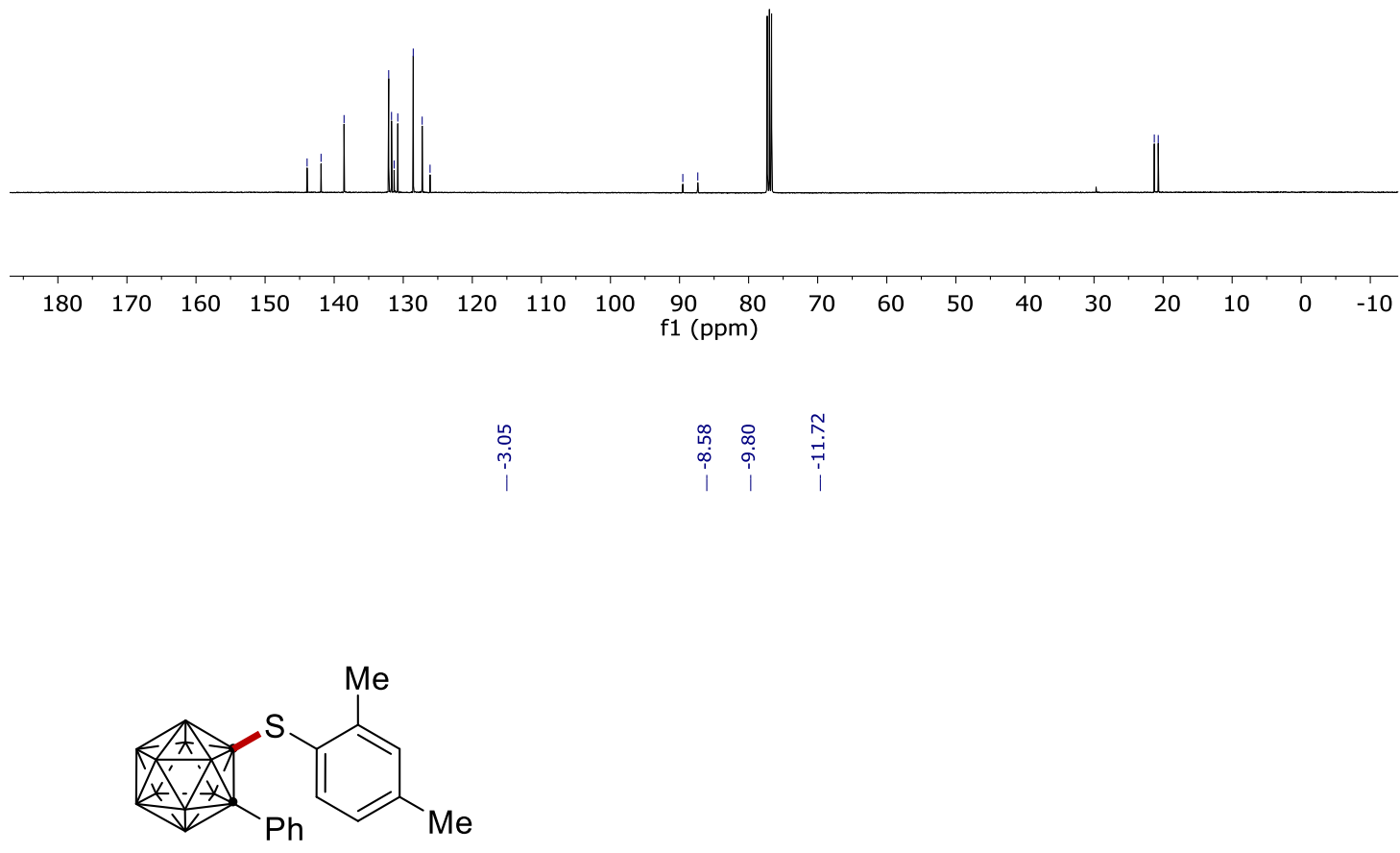

$162 p$

$128 \mathrm{MHz}, \mathrm{CDCl}_{3}$

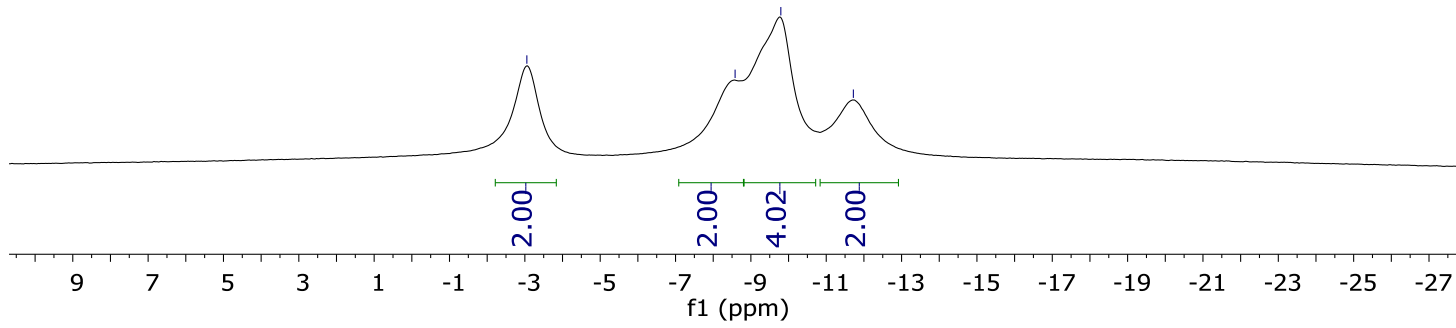




\section{NMR Spectra}

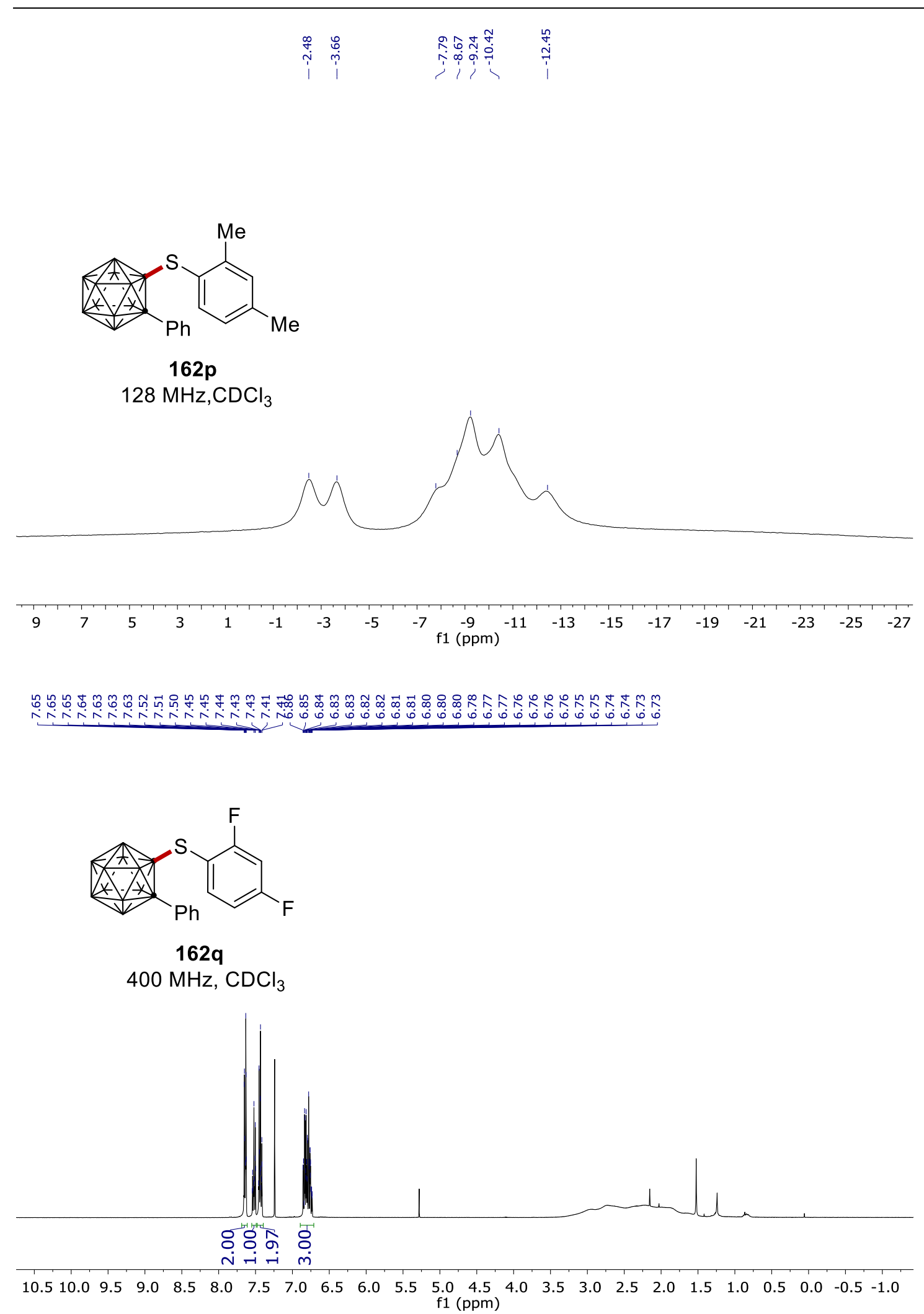




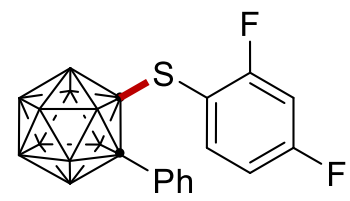

$162 q$

$101 \mathrm{MHz}, \mathrm{CDCl}_{3}$

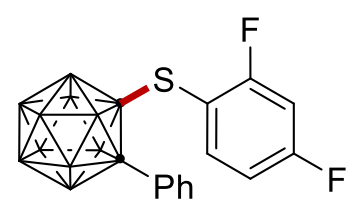

$162 q$

$128 \mathrm{MHz} \mathrm{CDCl}_{3}$

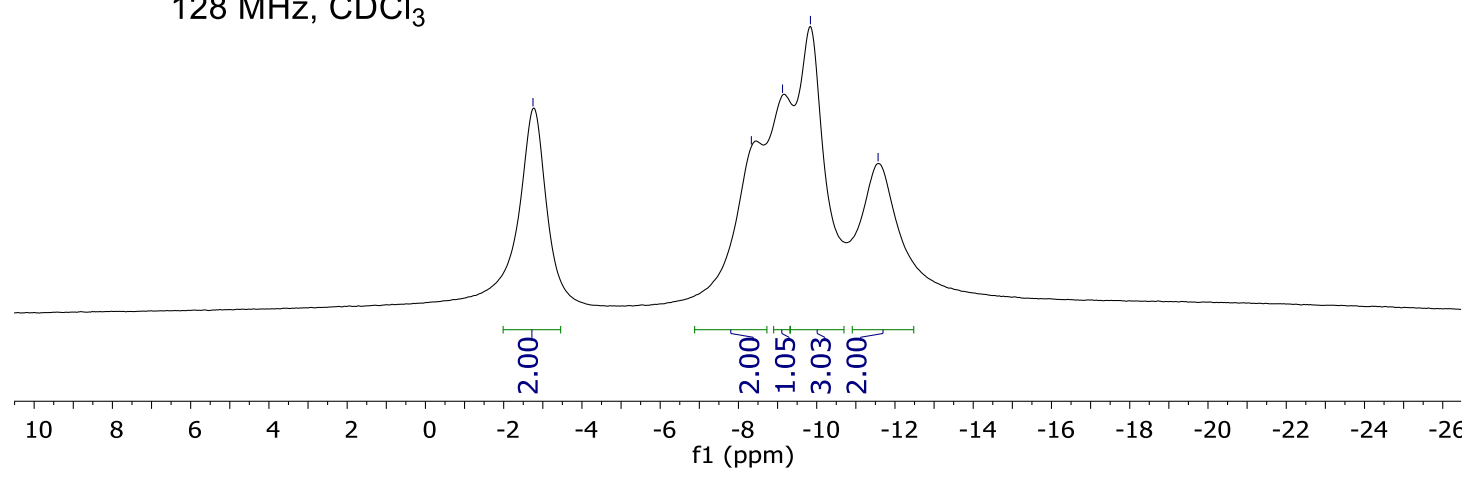




\section{NMR Spectra}

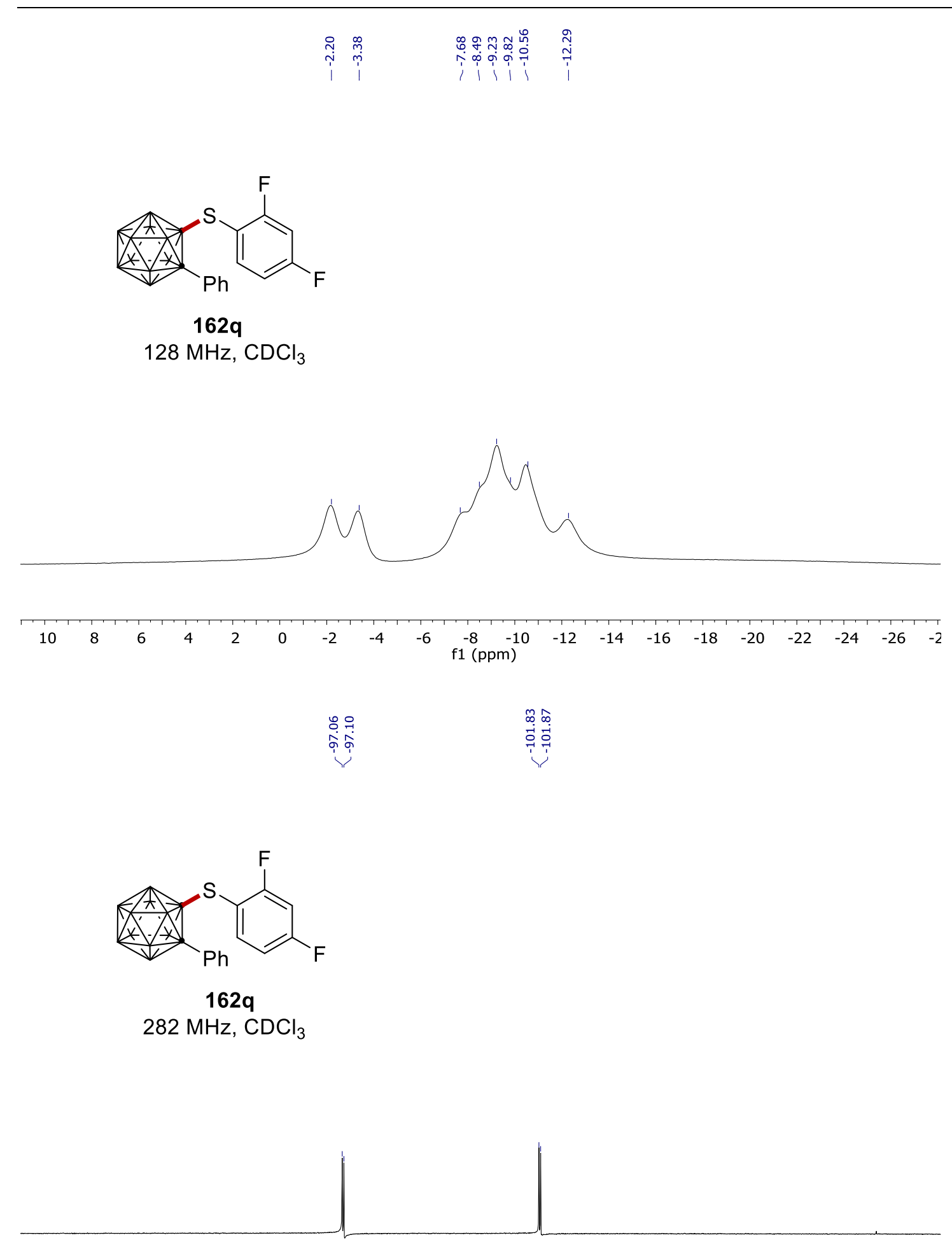

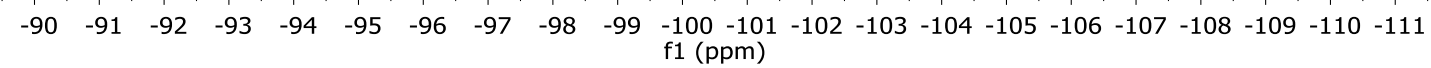




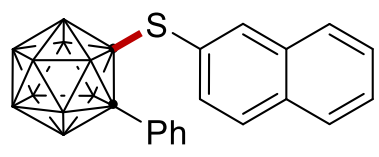

$162 r$

$400 \mathrm{MHz}, \mathrm{CDCl}_{3}$

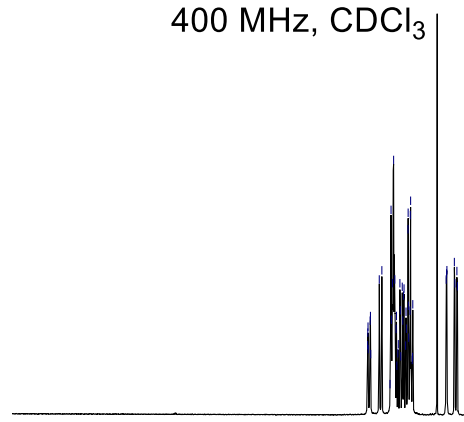

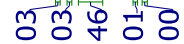

-

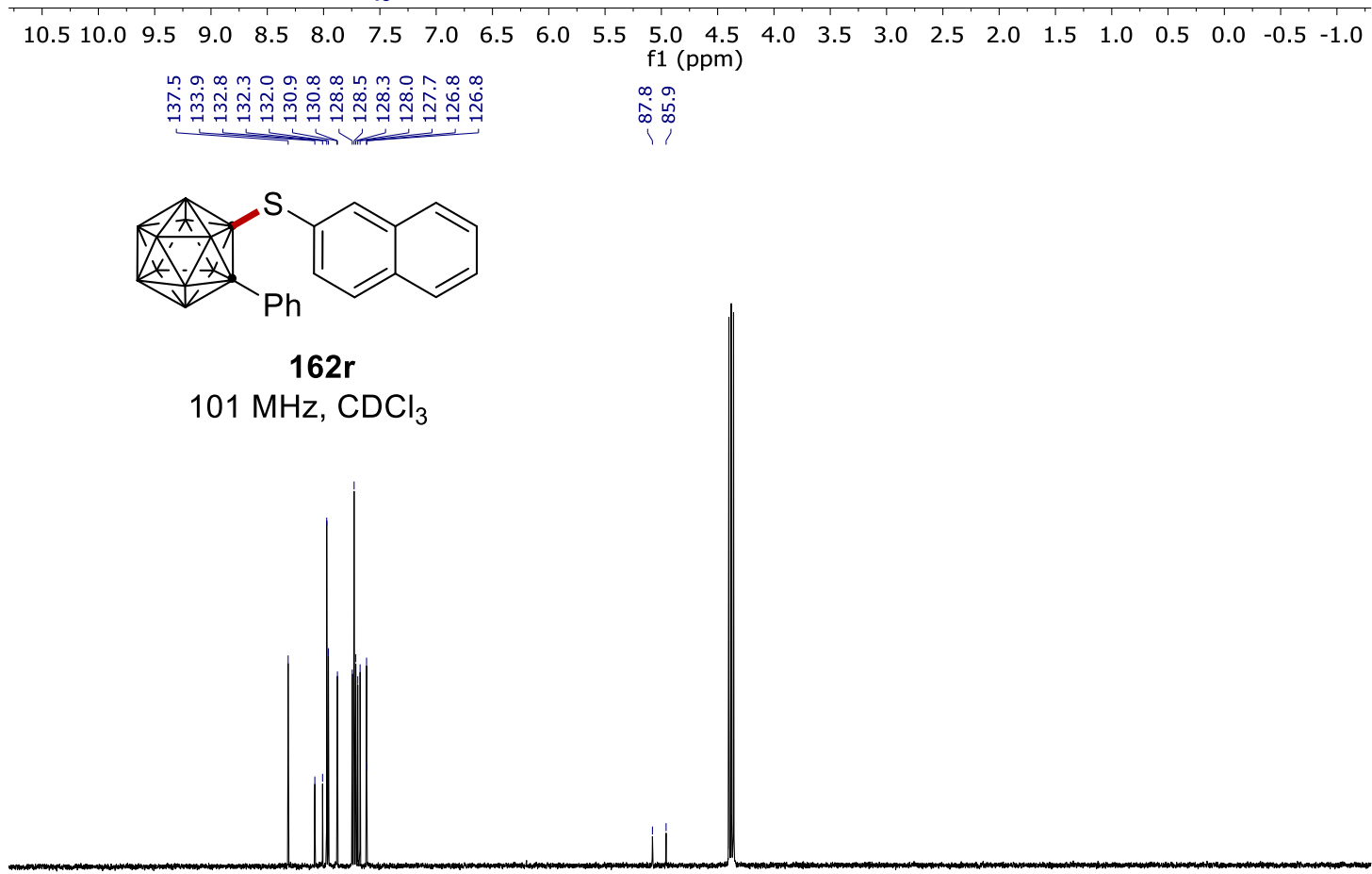

$\begin{array}{lllllllllllllllllll}170 & 160 & 150 & 140 & 130 & 120 & 110 & 100 & 90 \underset{\mathrm{f} 1(\mathrm{ppm})}{80} & 70 & 60 & 50 & 40 & 30 & 20 & 10 & 0 & -1\end{array}$ 


\section{NMR Spectra}

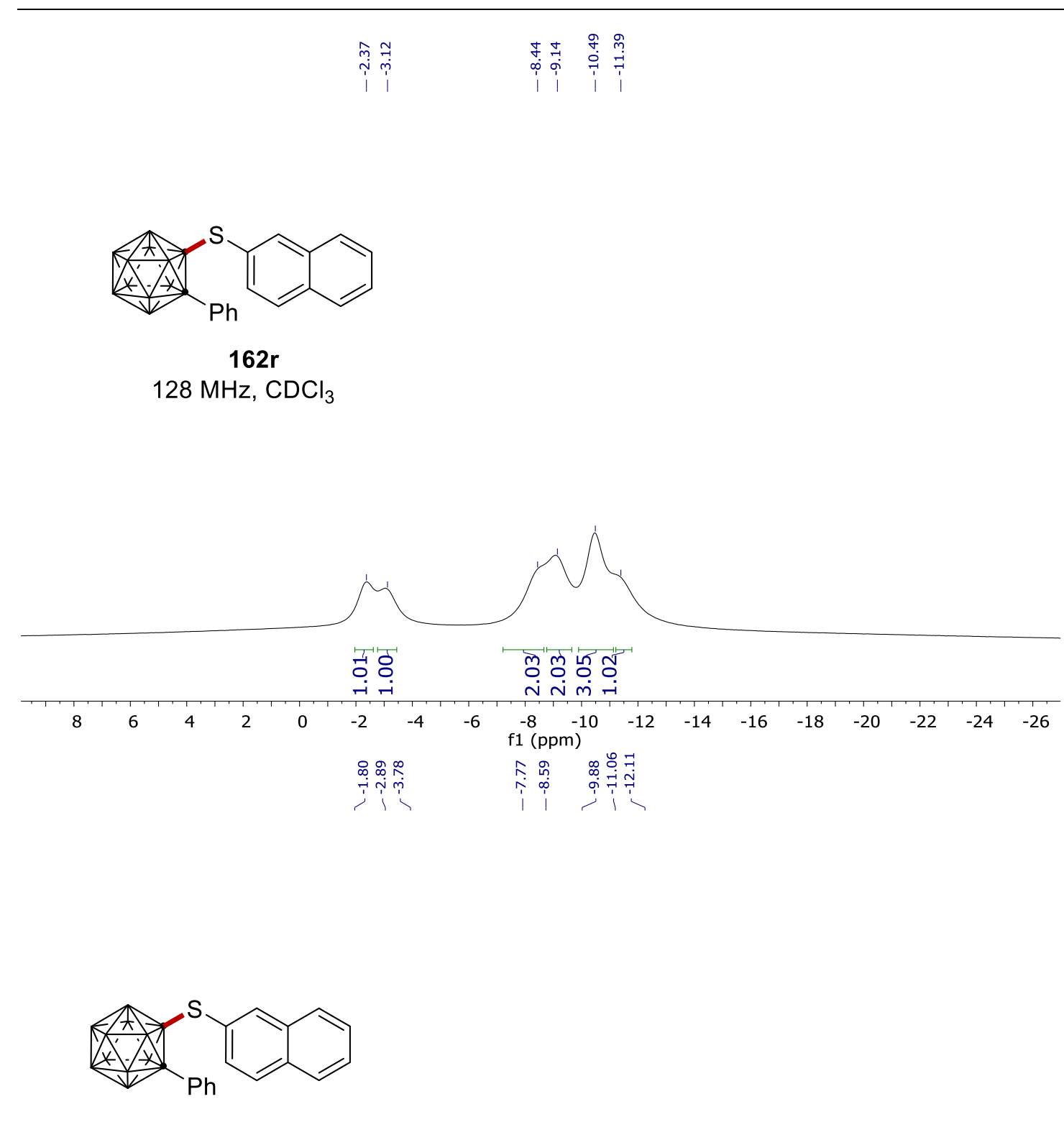

$162 r$

$128 \mathrm{MHz}, \mathrm{CDCl}_{3}$

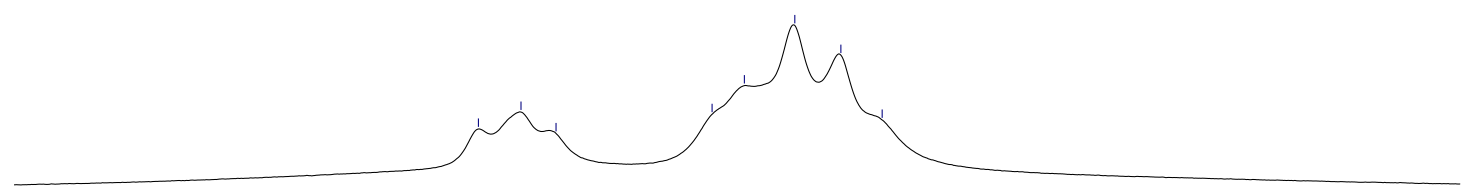

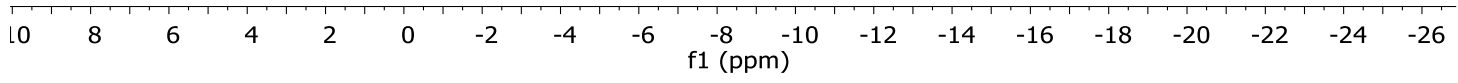




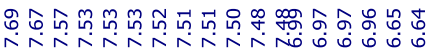

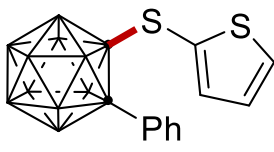

162s

$300 \mathrm{MHz}, \mathrm{CDCl}_{3}$

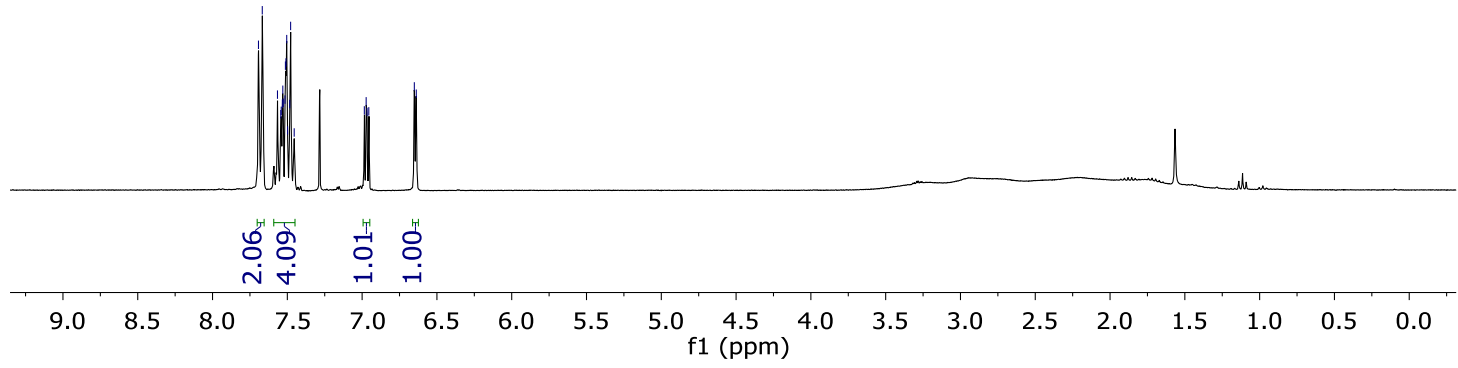

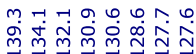

穴.

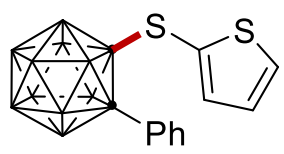

162s

$75 \mathrm{MHz}^{\mathrm{CDCl}} \mathrm{CD}_{3}$

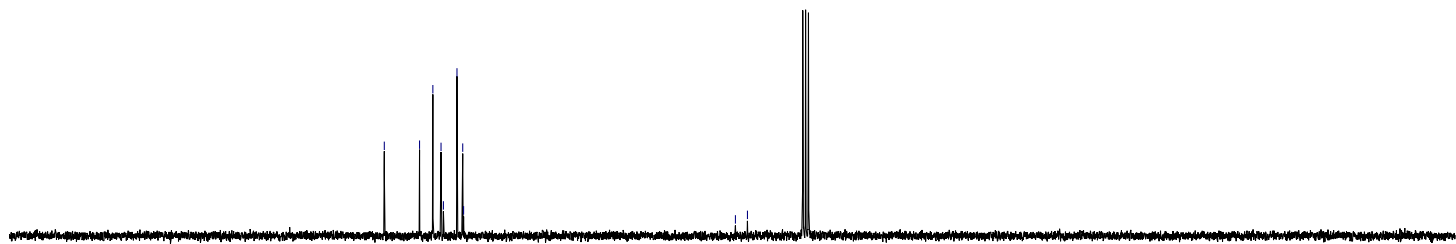

$\begin{array}{lllllllllllllllllllll}190 & 180 & 170 & 160 & 150 & 140 & 130 & 120 & 110 & 100 & \begin{array}{c}90 \\ \mathrm{f} 1(\mathrm{ppm})\end{array} & 70 & 60 & 50 & 40 & 30 & 20 & 10 & 0 & -10\end{array}$ 


\section{NMR Spectra}

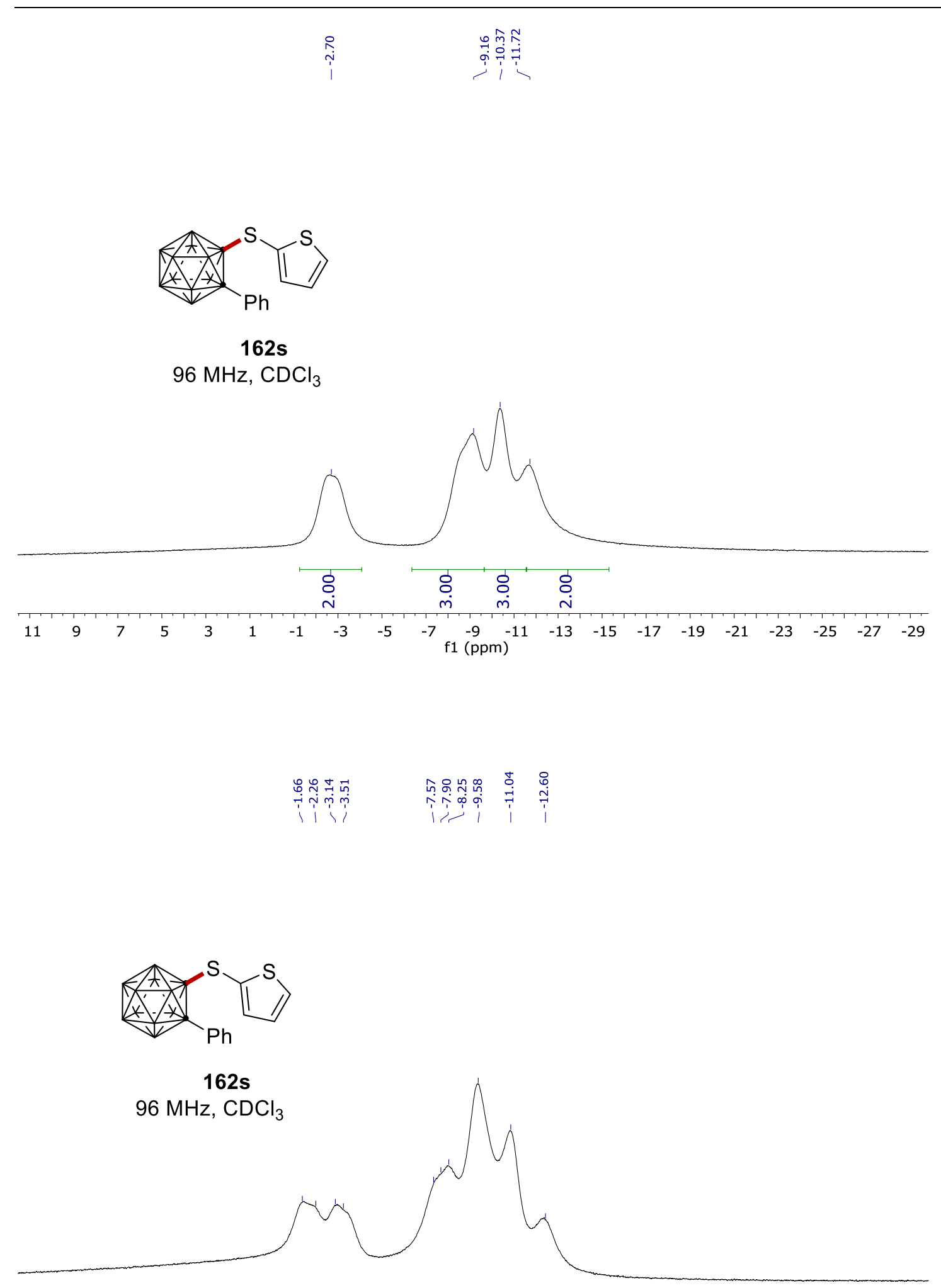

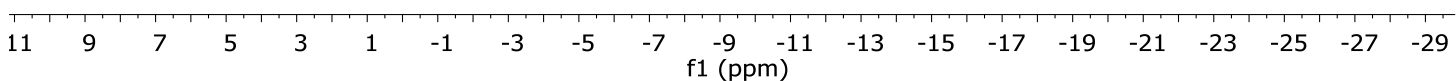




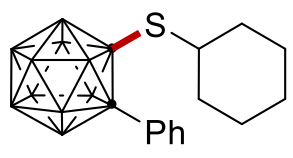

3at

$400 \mathrm{MHz}, \mathrm{CDCl}_{3}$
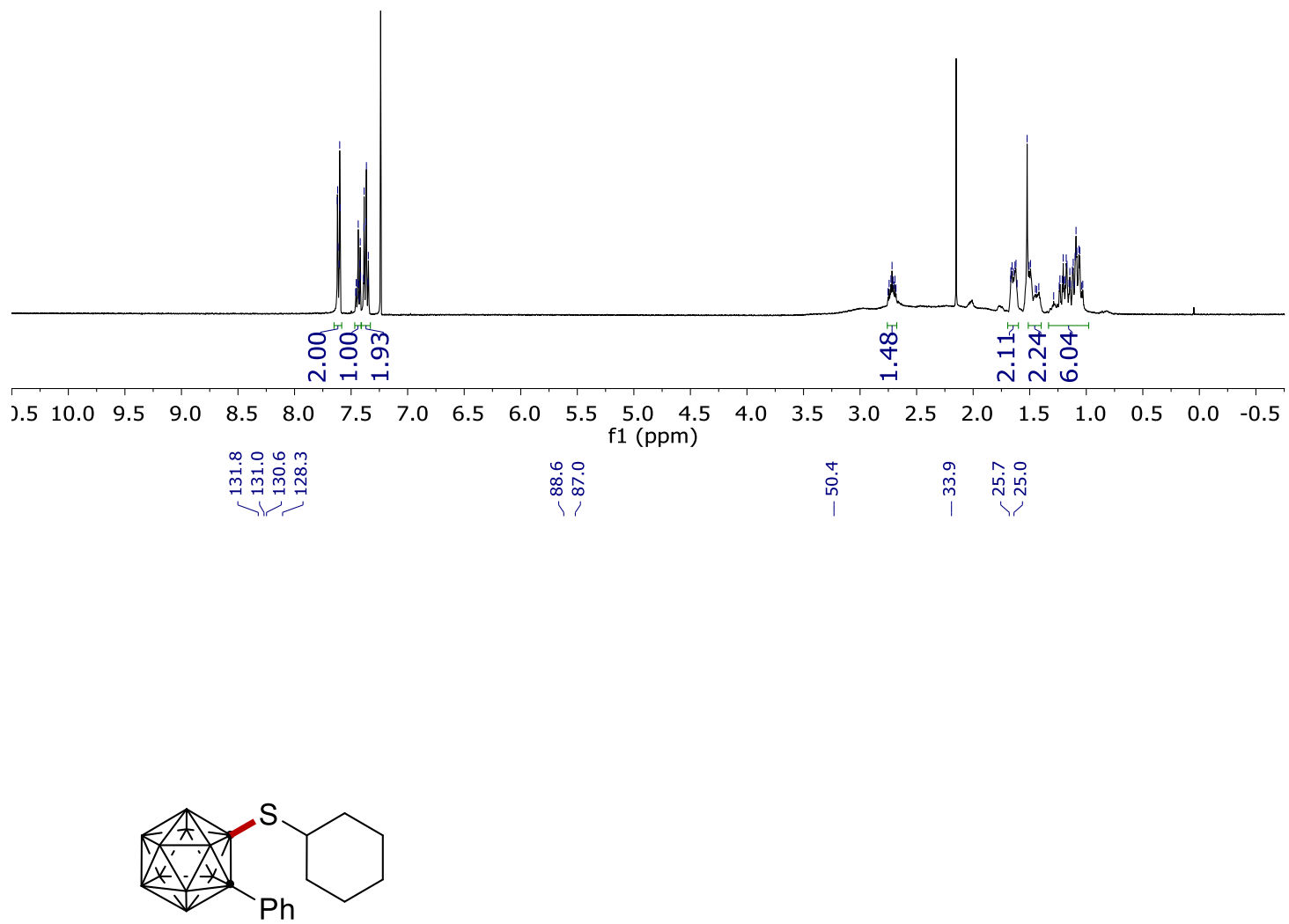

$162 t$

$101 \mathrm{MHz}, \mathrm{CDCl}_{3}$

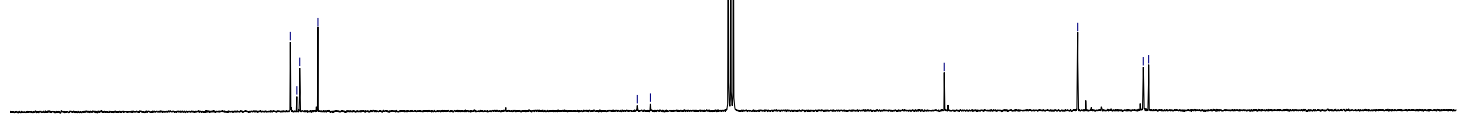

$\begin{array}{llllllllllllllllll}160 & 150 & 140 & 130 & 120 & 110 & 100 & 90 & \begin{array}{c}80 \\ \mathrm{f} 1(\mathrm{ppm})\end{array} & 60 & 50 & 40 & 30 & 20 & 10 & 0 & -10\end{array}$ 


\section{NMR Spectra}

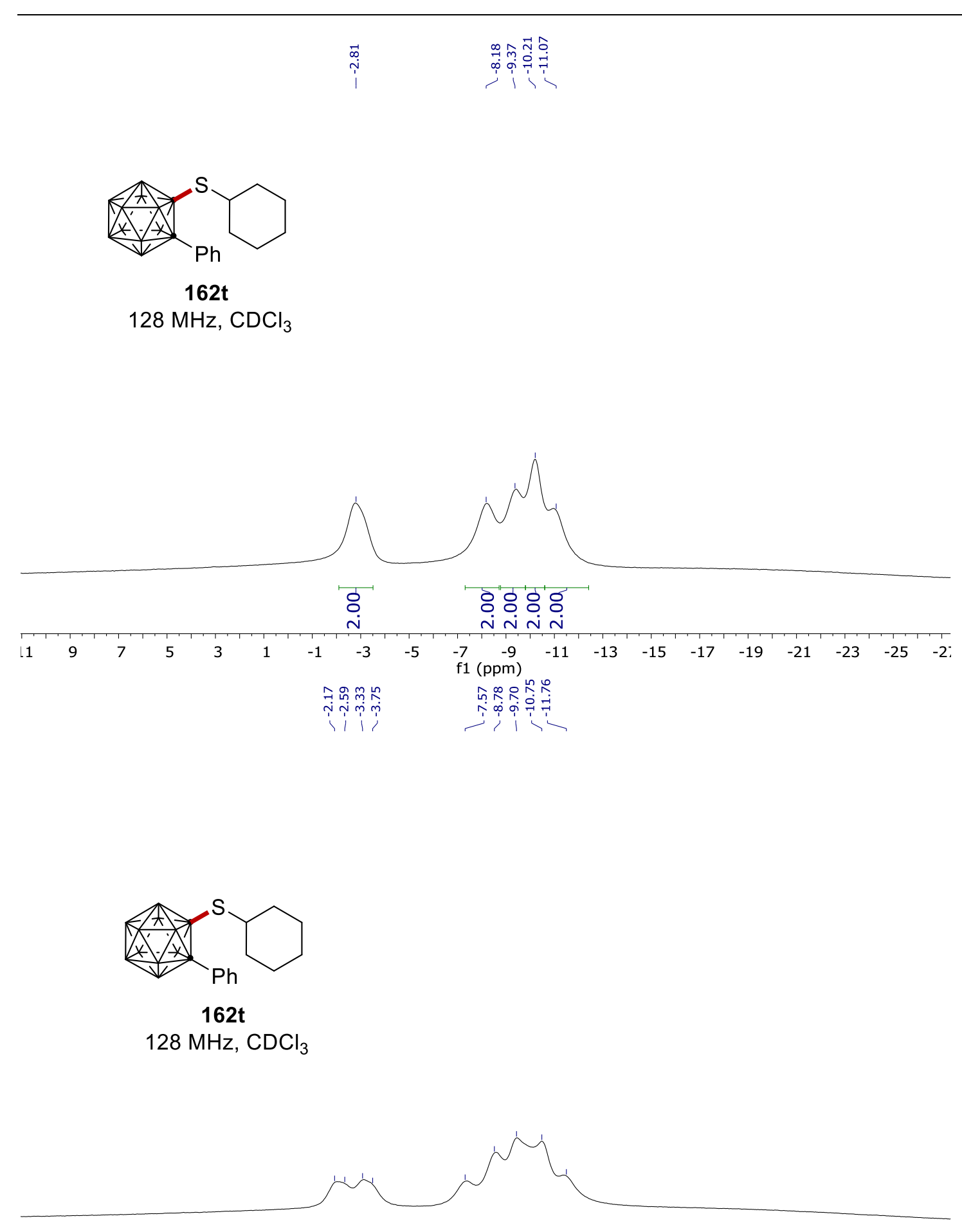

\begin{tabular}{|c|c|c|c|c|c|c|c|c|c|c|c|c|c|c|c|c|c|c|c|}
\hline 9 & 7 & 5 & 3 & 1 & -1 & -3 & -5 & $\begin{array}{r}-7 \\
\mathrm{f} 1\end{array}$ & $\begin{array}{c}-9 \\
\text { ppm) }\end{array}$ & -11 & -1 & & 15 & -17 & -19 & -21 & -23 & -25 & -27 \\
\hline
\end{tabular}


NMR Spectra
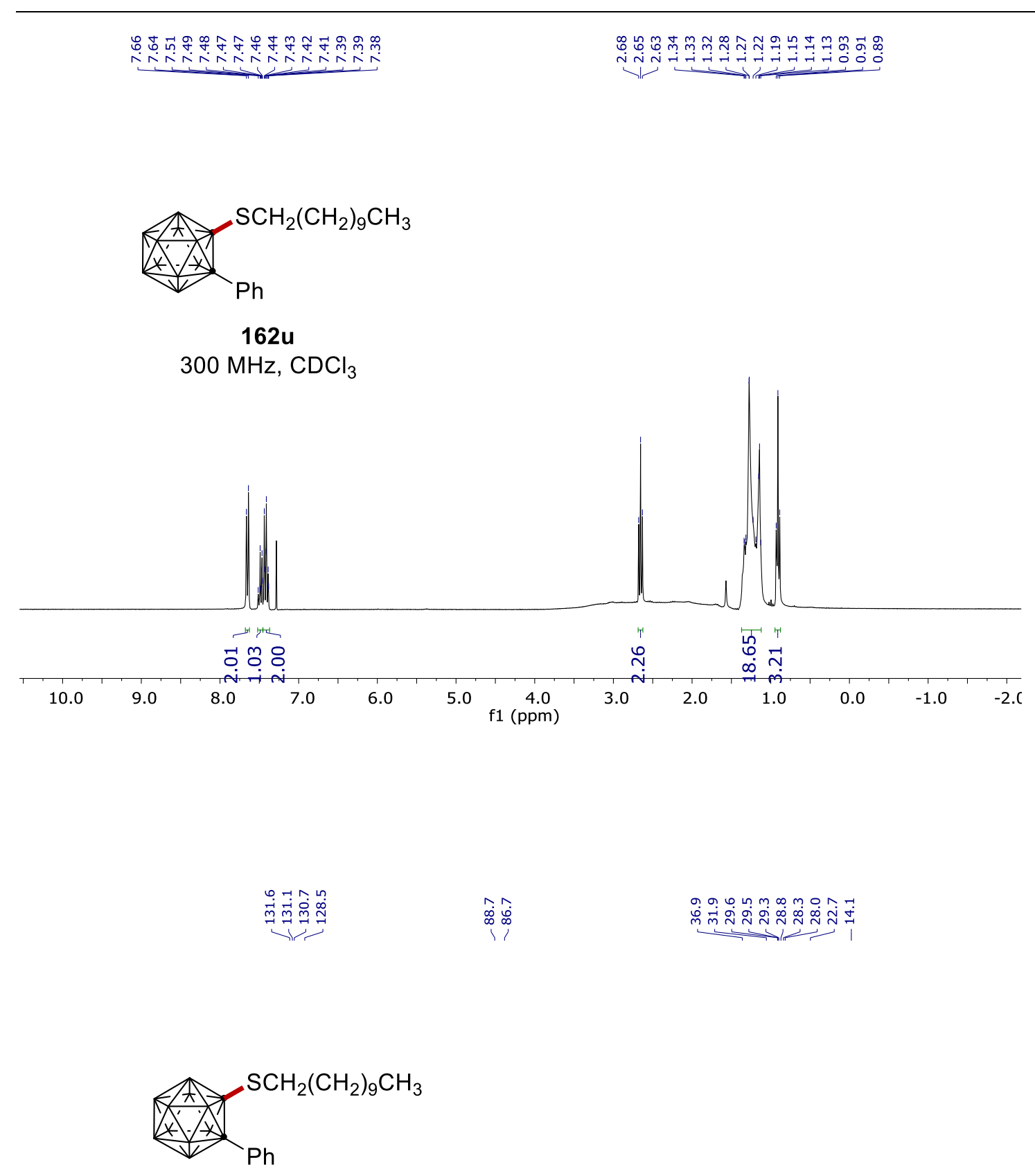

$162 u$

$75 \mathrm{MHz}, \mathrm{CDCl}_{3}$

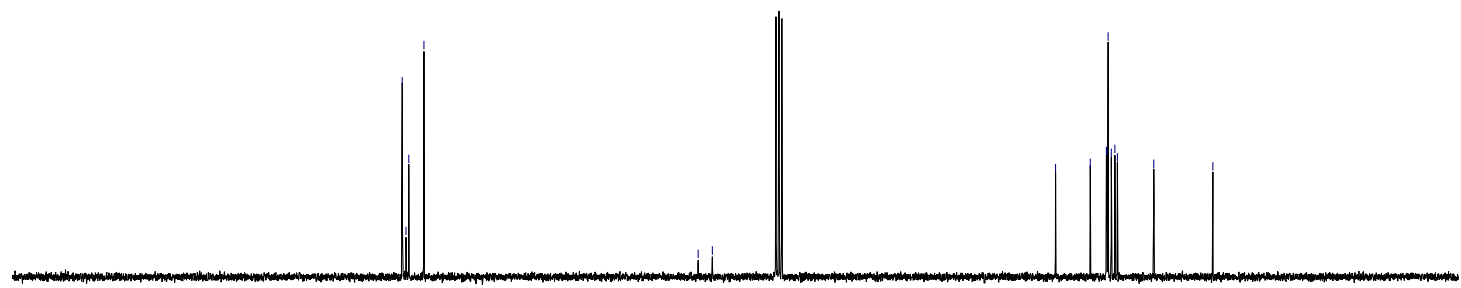

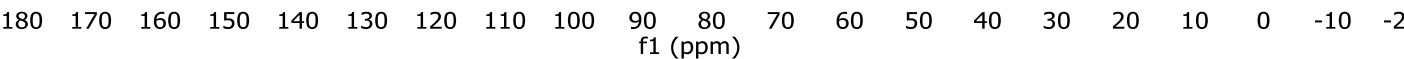




\section{NMR Spectra}
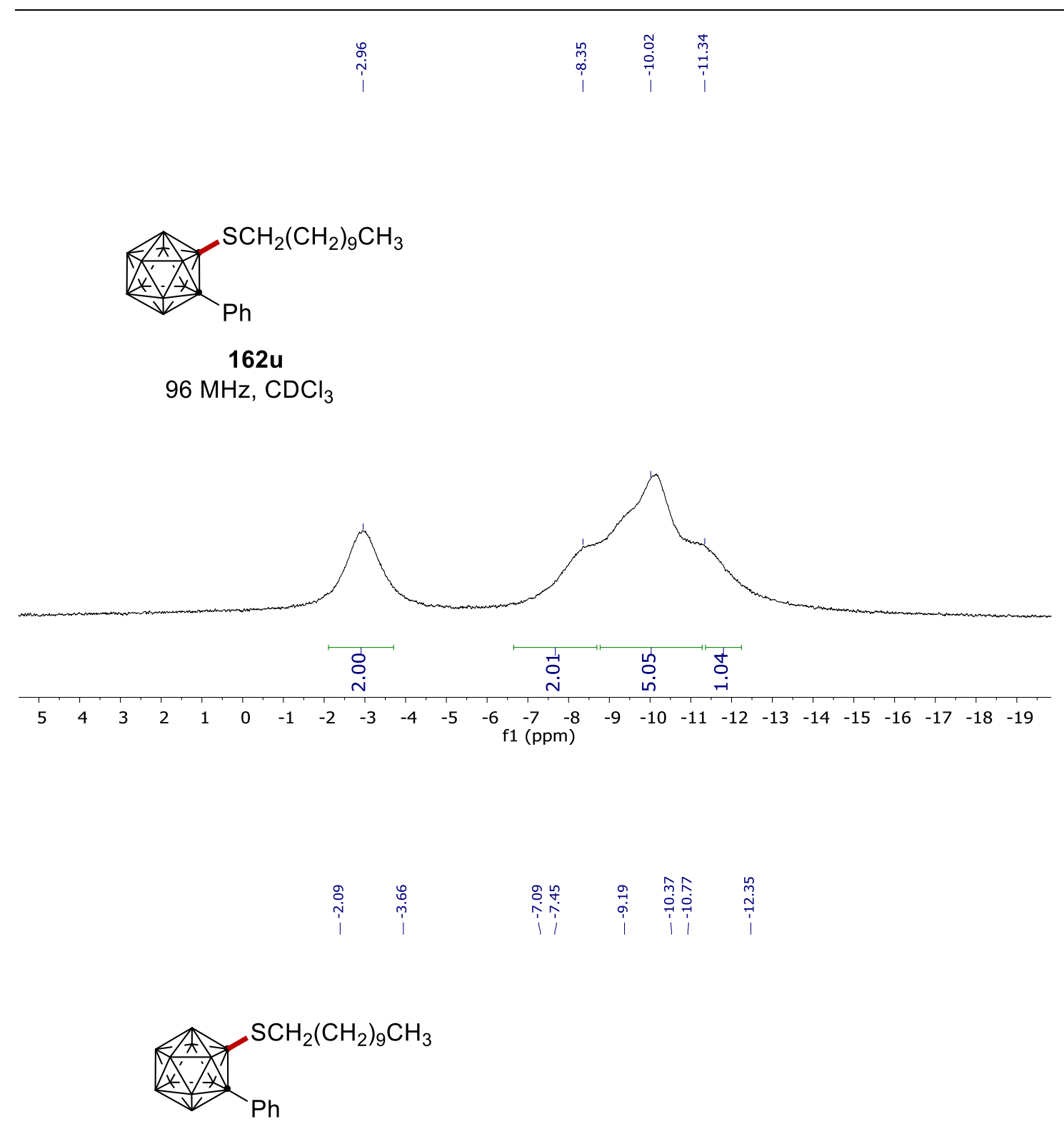

$162 u$

$96 \mathrm{MHz}, \mathrm{CDCl}_{3}$

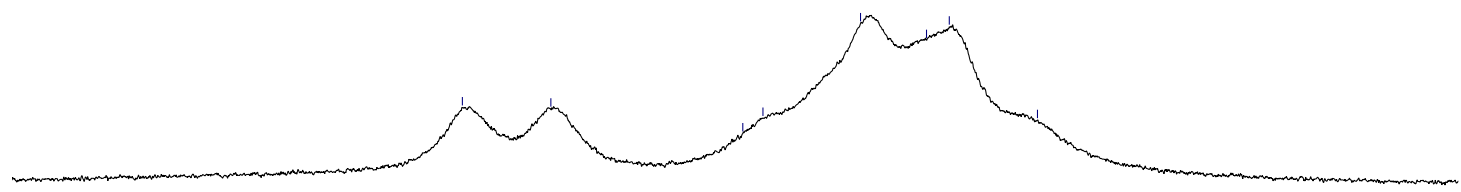




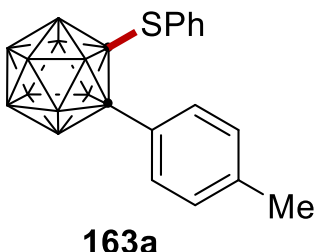

$400 \mathrm{MHz}, \mathrm{CDCl}_{3}$
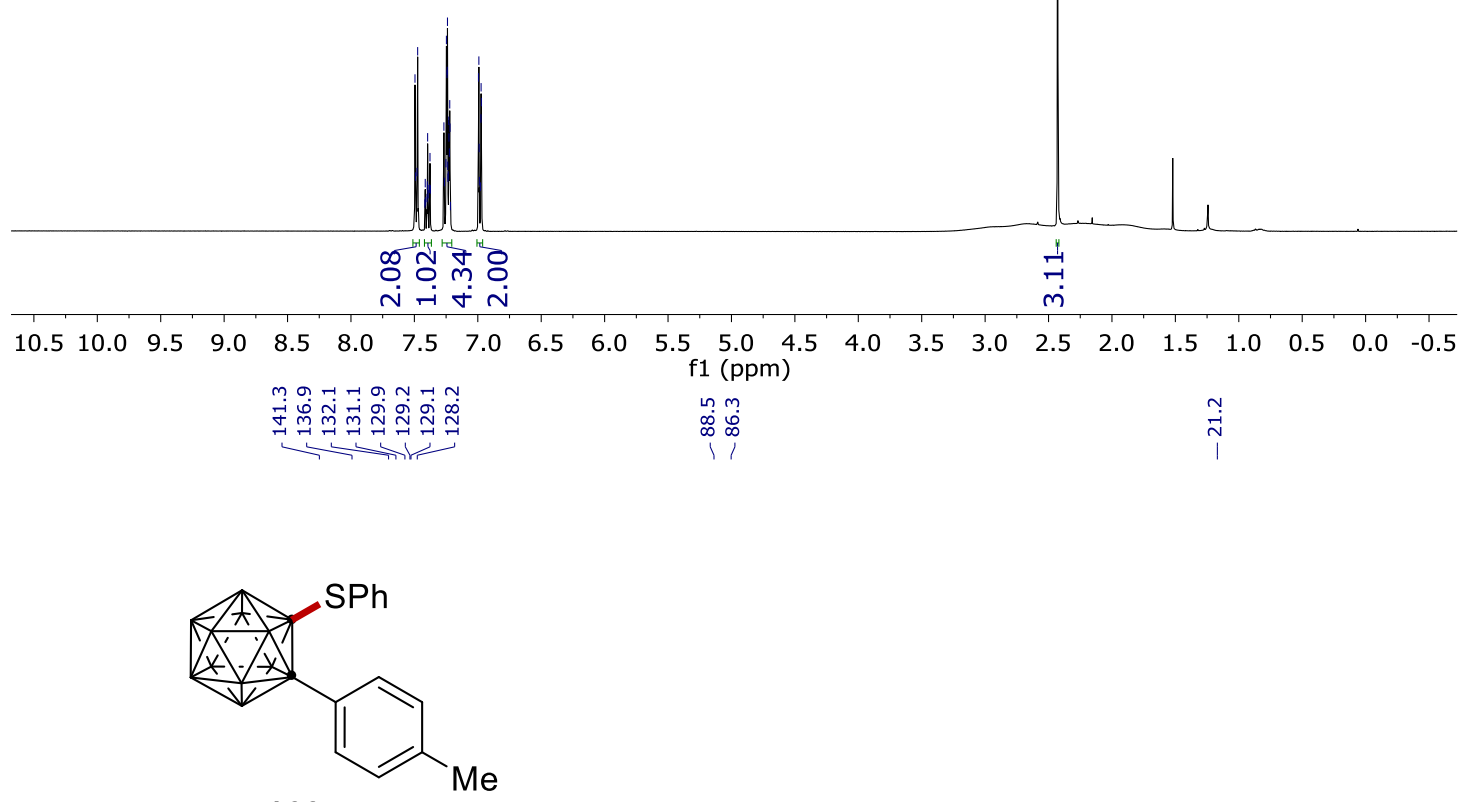

$163 a$

$101 \mathrm{MHz}^{\mathrm{CDCl}} \mathrm{CD}_{3}$

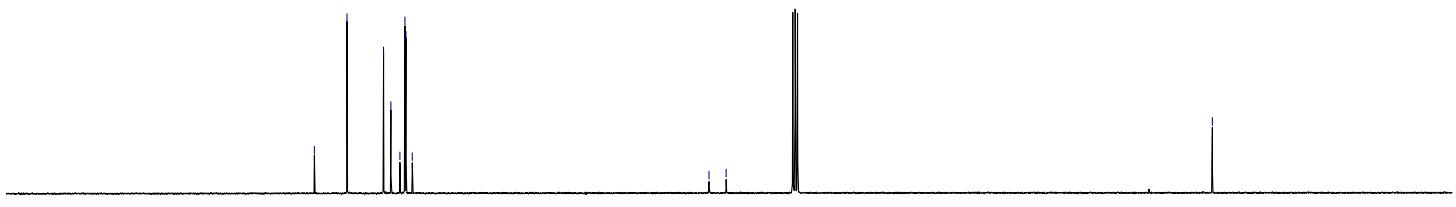

$\begin{array}{llllllllllllllllllll}180 & 170 & 160 & 150 & 140 & 130 & 120 & 110 & 100 & \begin{array}{c}90 \\ \mathrm{f} 1(\mathrm{ppm})\end{array} & 70 & 60 & 50 & 40 & 30 & 20 & 10 & 0 & -1\end{array}$ 


\section{NMR Spectra}
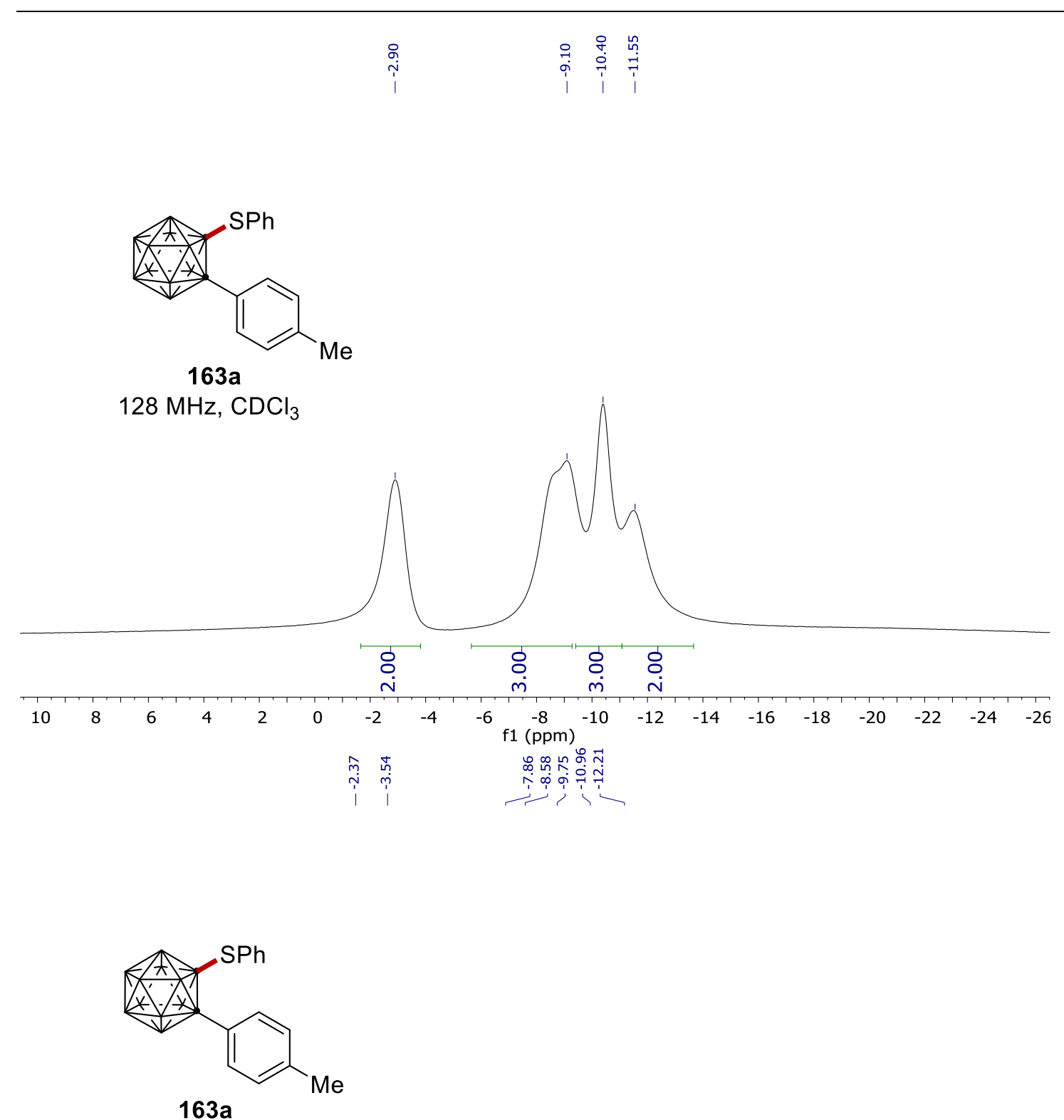

$128 \mathrm{MHz}, \mathrm{CDCl}_{3}$

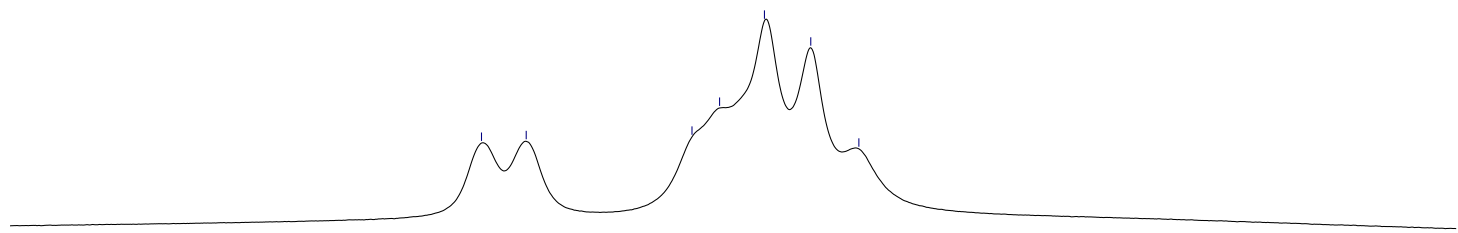

$\begin{array}{lllllllllllllllllllll}9 & 7 & 5 & 3 & 1 & -1 & -3 & -5 & -7 & -9 & -11 & -13 & -15 & -17 & -19 & -21 & -23 & -25 & -27\end{array}$




\section{NMR Spectra}
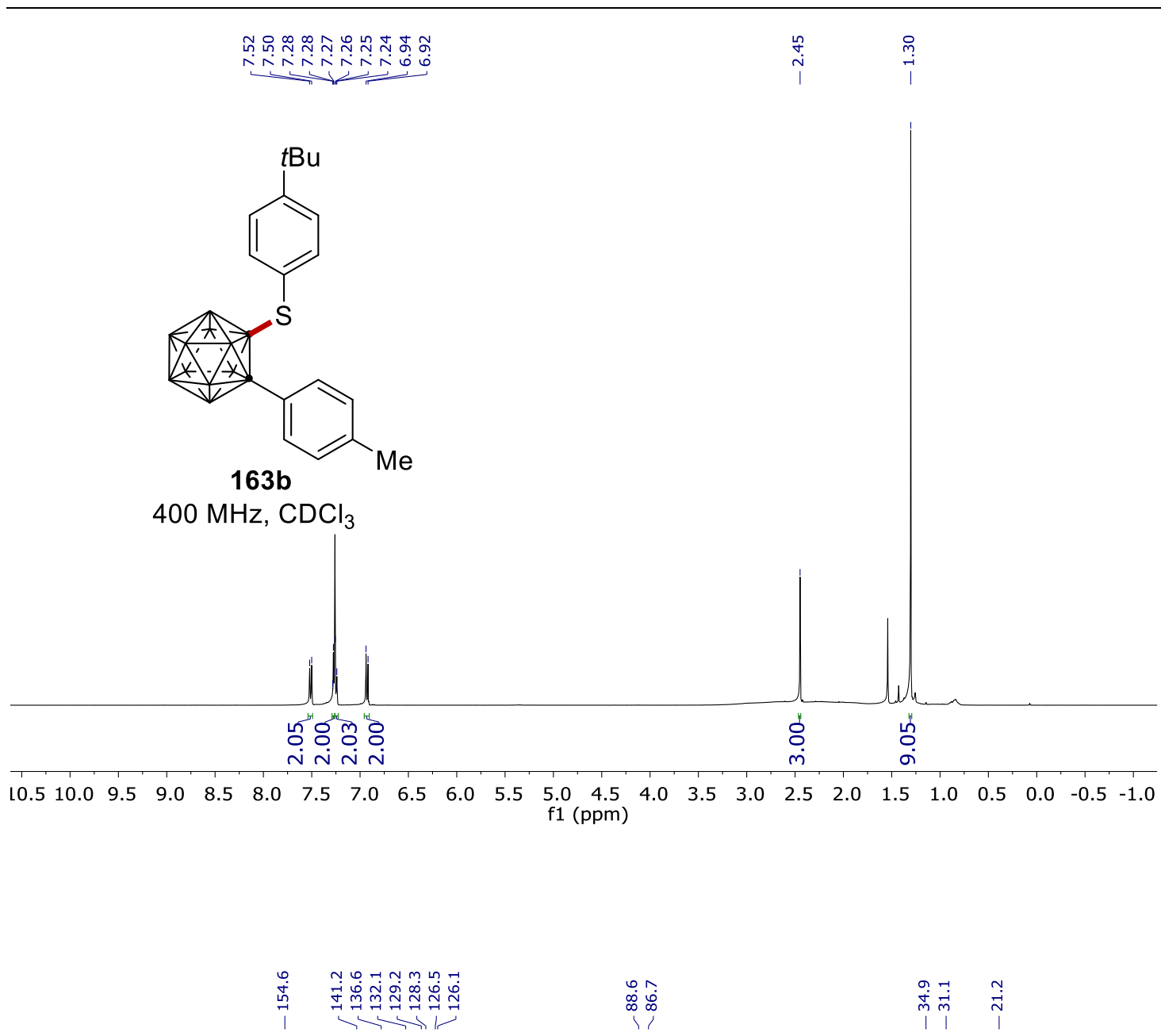

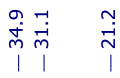
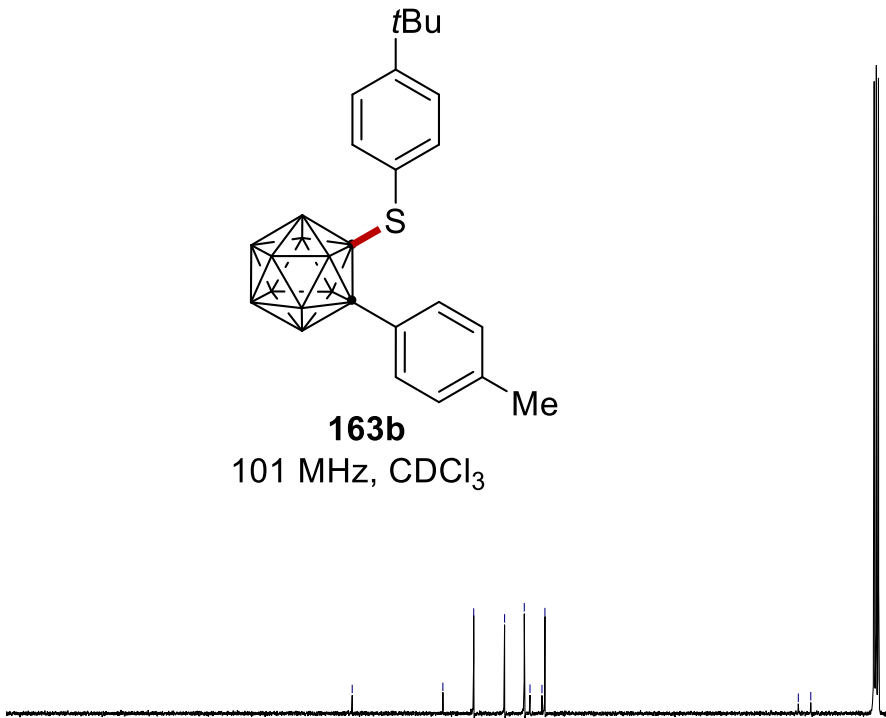

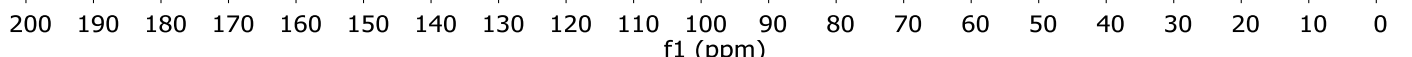




\section{NMR Spectra}
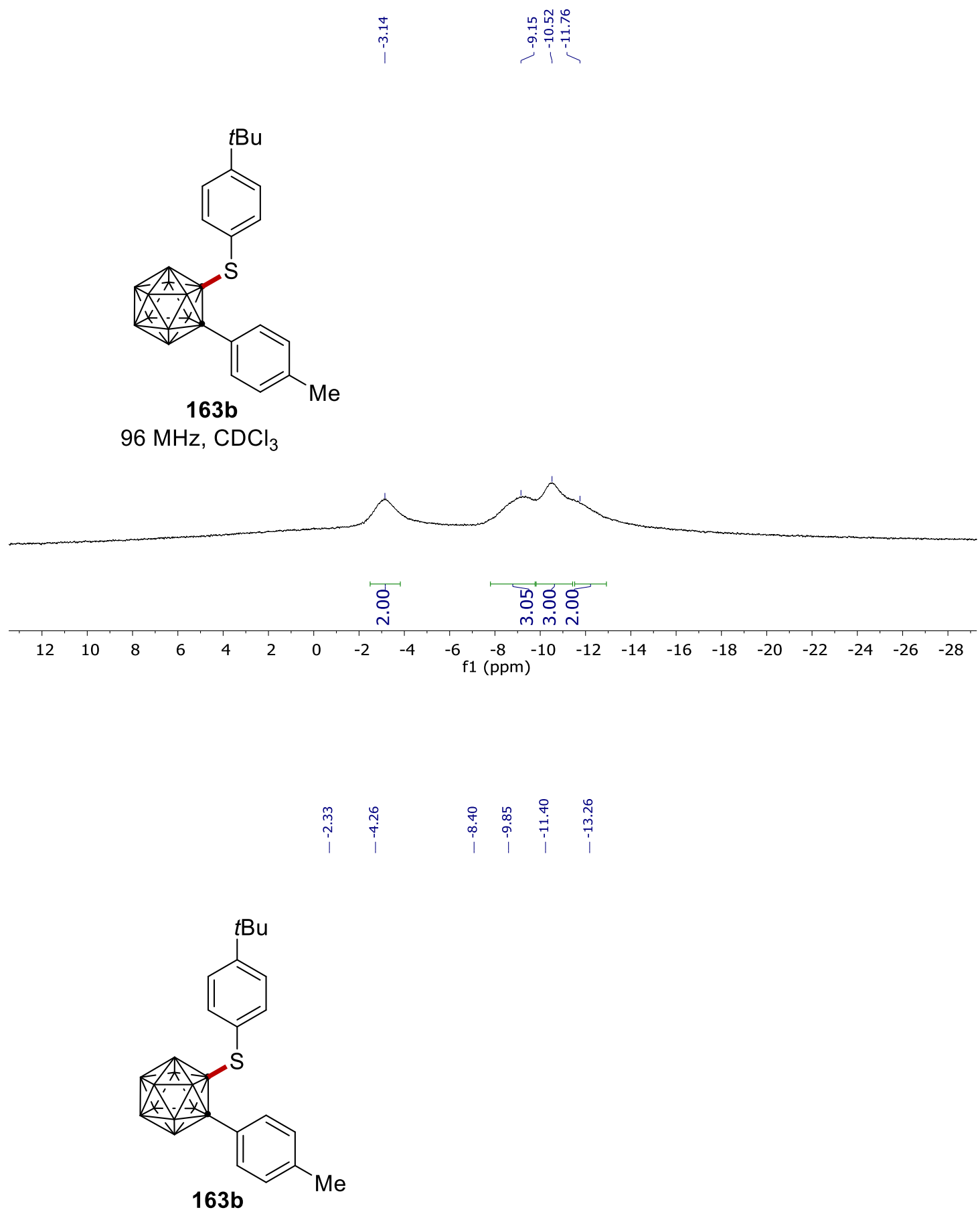

$96 \mathrm{MHz}, \mathrm{CDCl}_{3}$

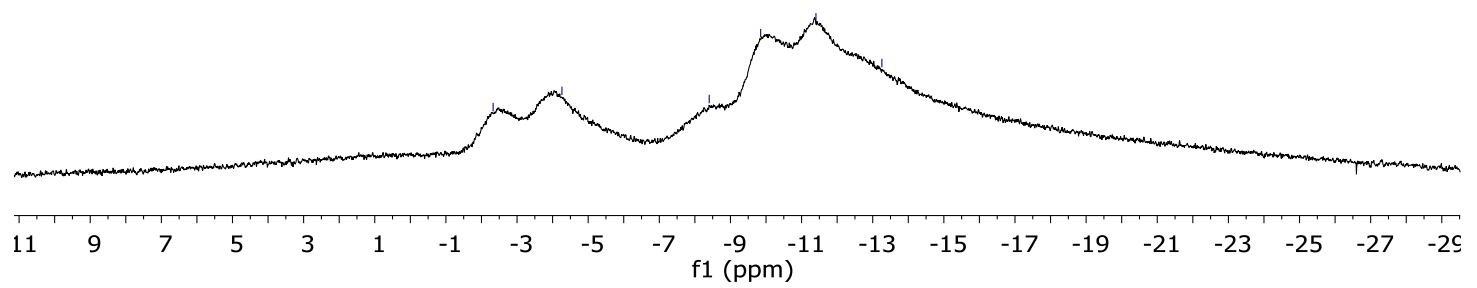




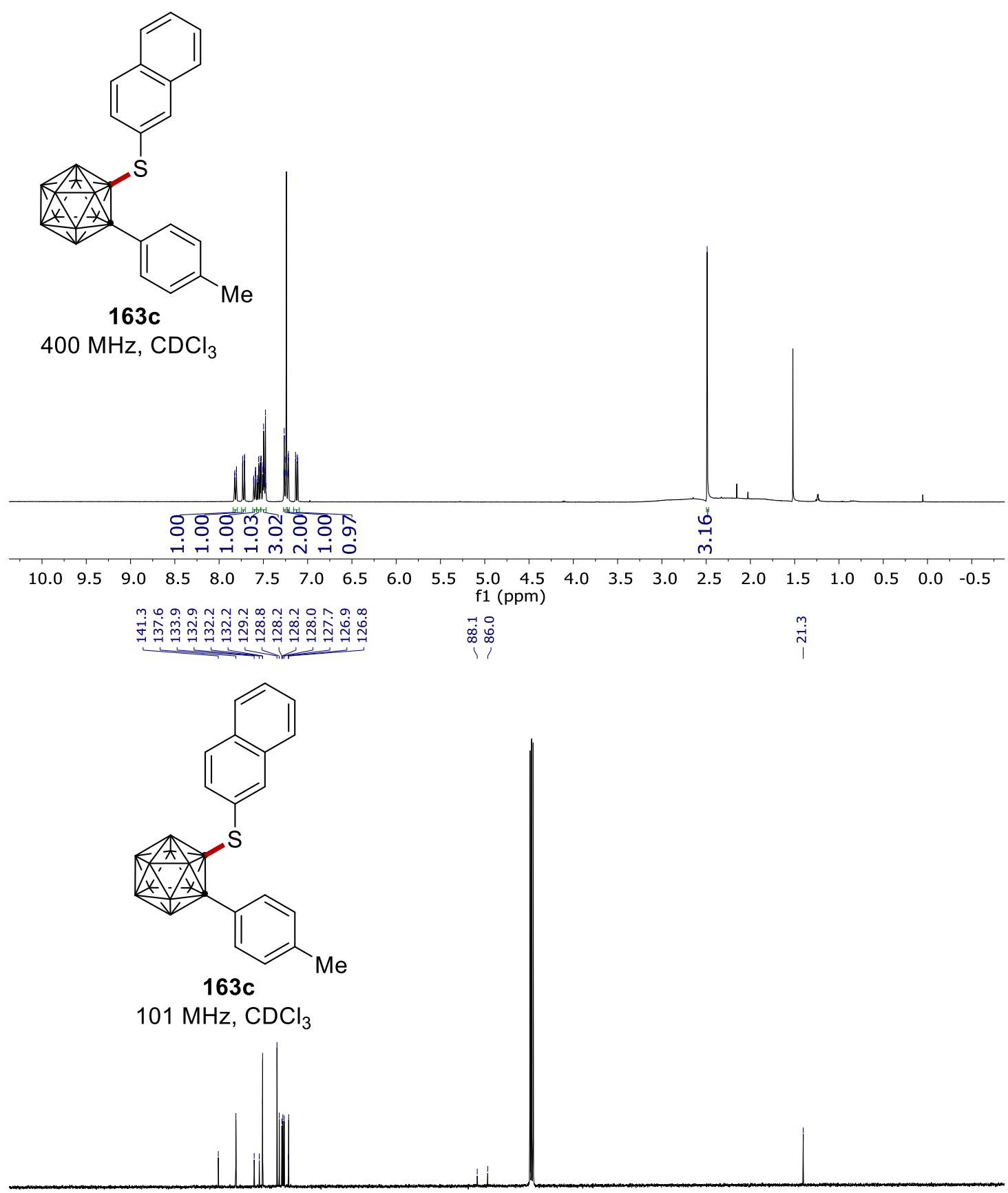

$\begin{array}{lllllllllllllllllllll}180 & 170 & 160 & 150 & 140 & 130 & 120 & 110 & 100 & 90 \underset{\mathrm{f} 1(\mathrm{ppm})}{80} & 70 & 60 & 50 & 40 & 30 & 20 & 10 & 0 & -10 & -:\end{array}$ 


\section{NMR Spectra}
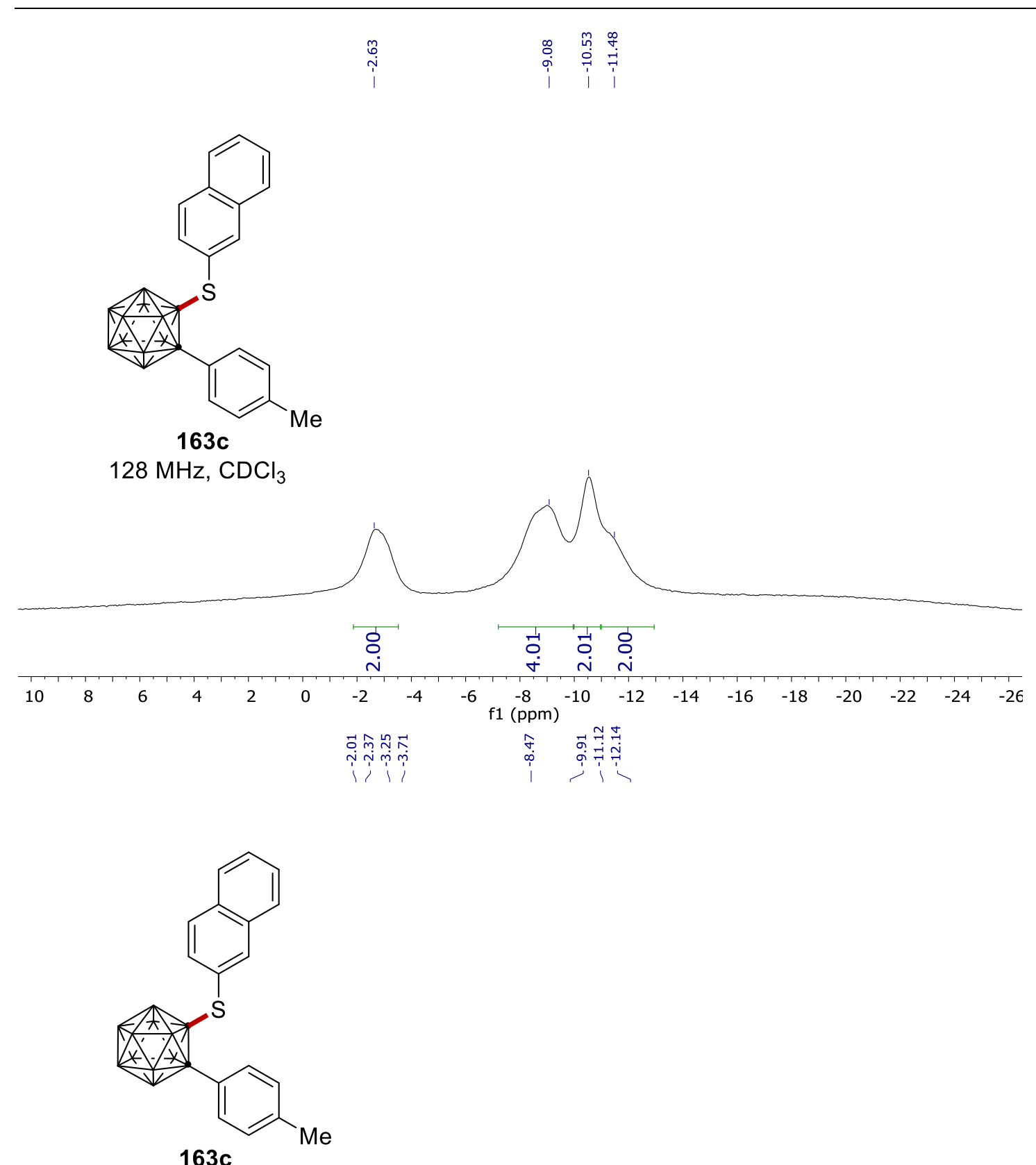

$128 \mathrm{MHz}, \mathrm{CDCl}_{3}$

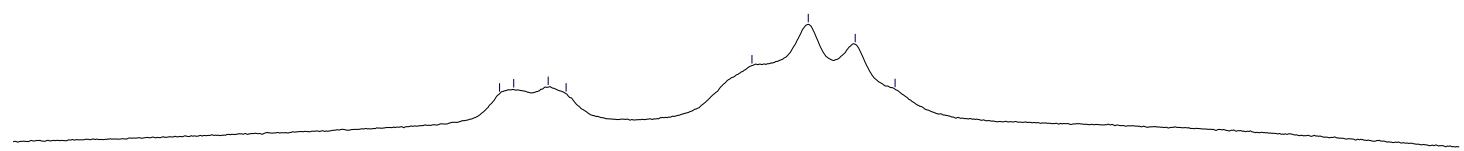

$\begin{array}{lllllllllllllllllllll}10 & 8 & 6 & 4 & 2 & 0 & -2 & -4 & -6 & -8 & -10 & -12 & -14 & -16 & -18 & -20 & -22 & -24 & -26\end{array}$




\section{NMR Spectra}

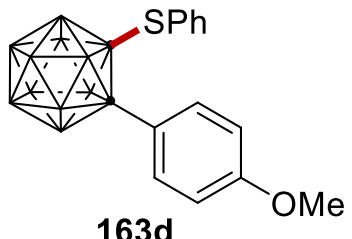

$400 \mathrm{MHz}, \mathrm{CDCl}_{3}$
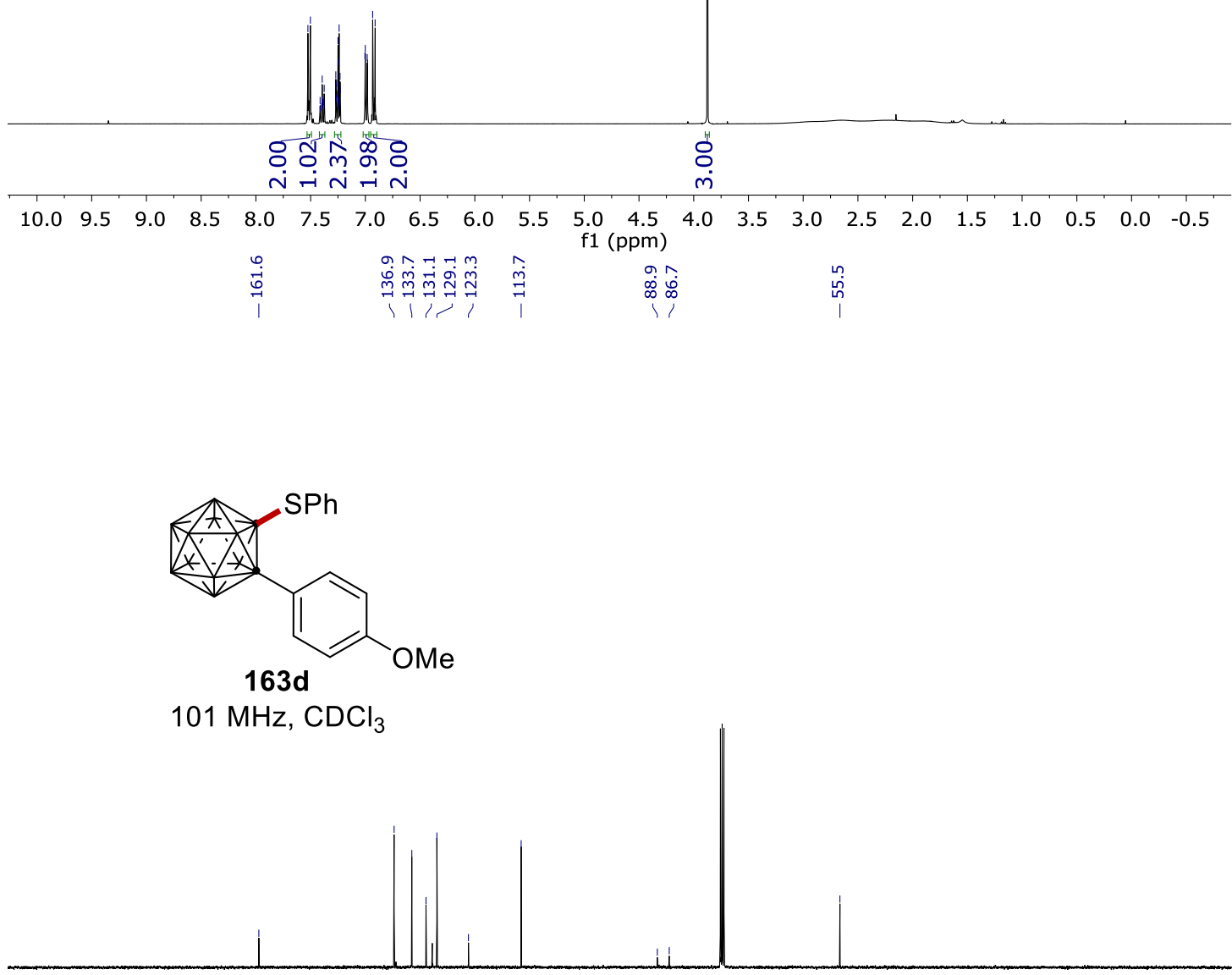

$\begin{array}{lllllllllllllllllllll}200 & 190 & 180 & 170 & 160 & 150 & 140 & 130 & 120 & 110 & \begin{array}{l}100 \\ \mathrm{f} 1(\mathrm{ppm})\end{array} & 80 & 70 & 60 & 50 & 40 & 30 & 20 & 10 & 0 & -10\end{array}$ 


\section{NMR Spectra}
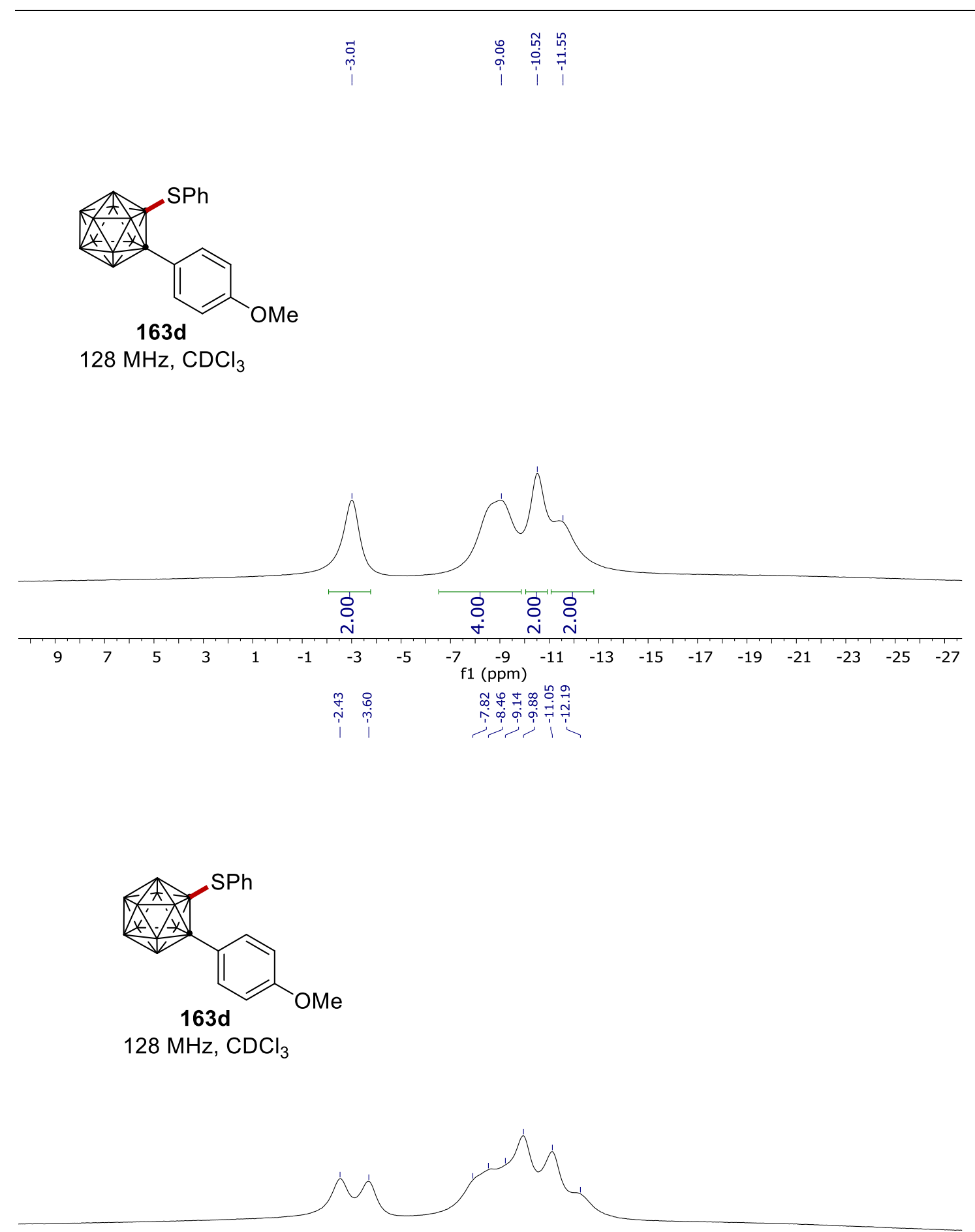

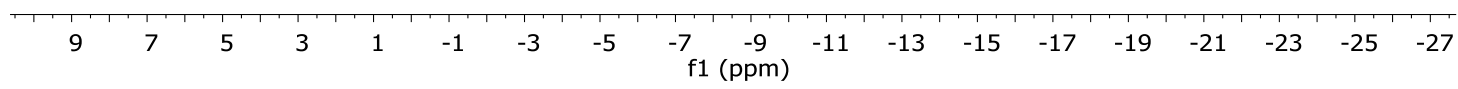




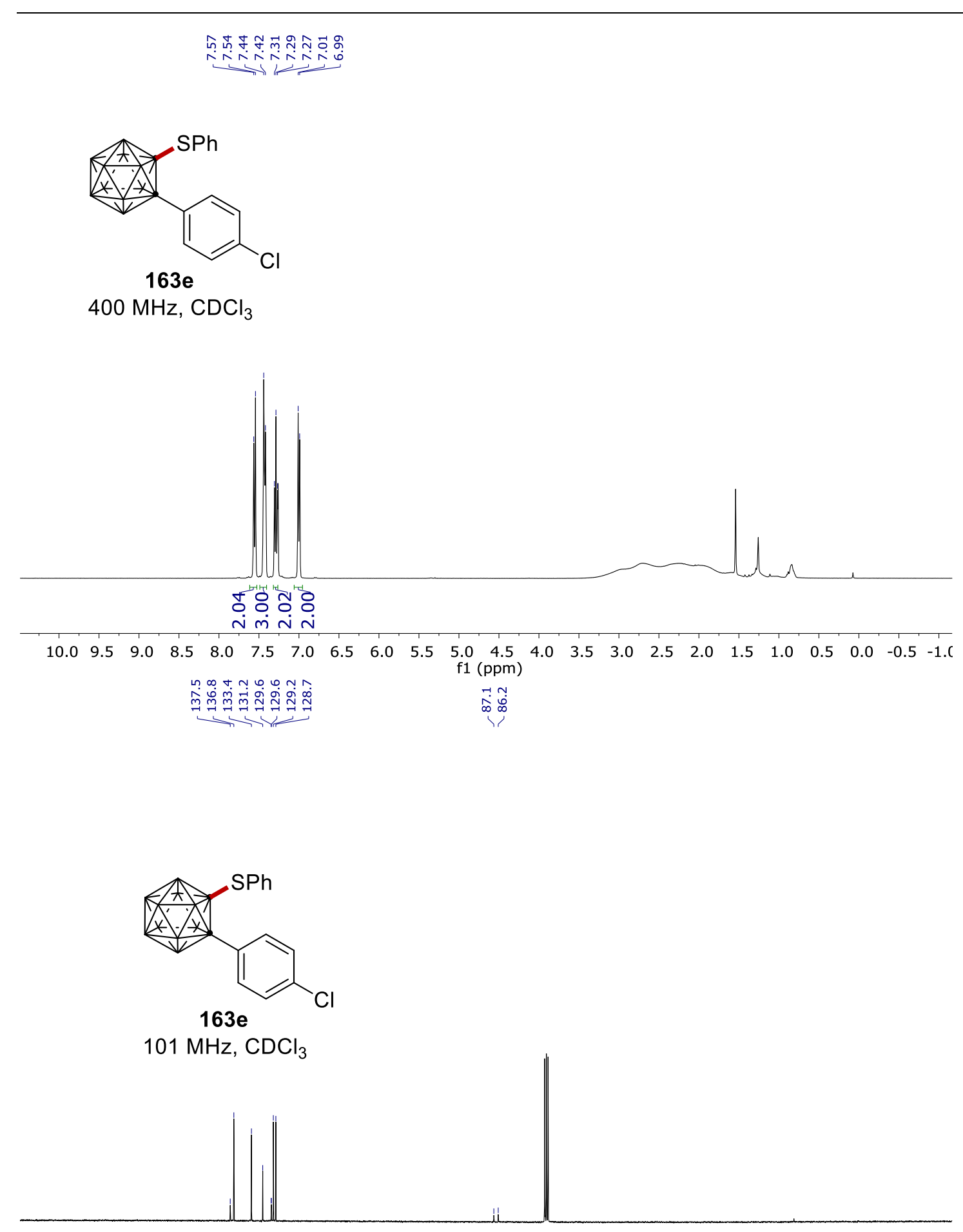

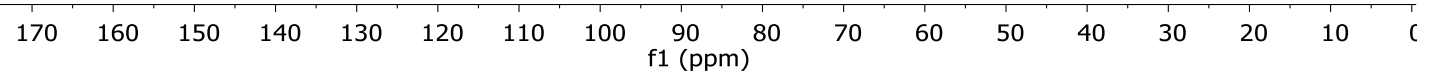




\section{NMR Spectra}
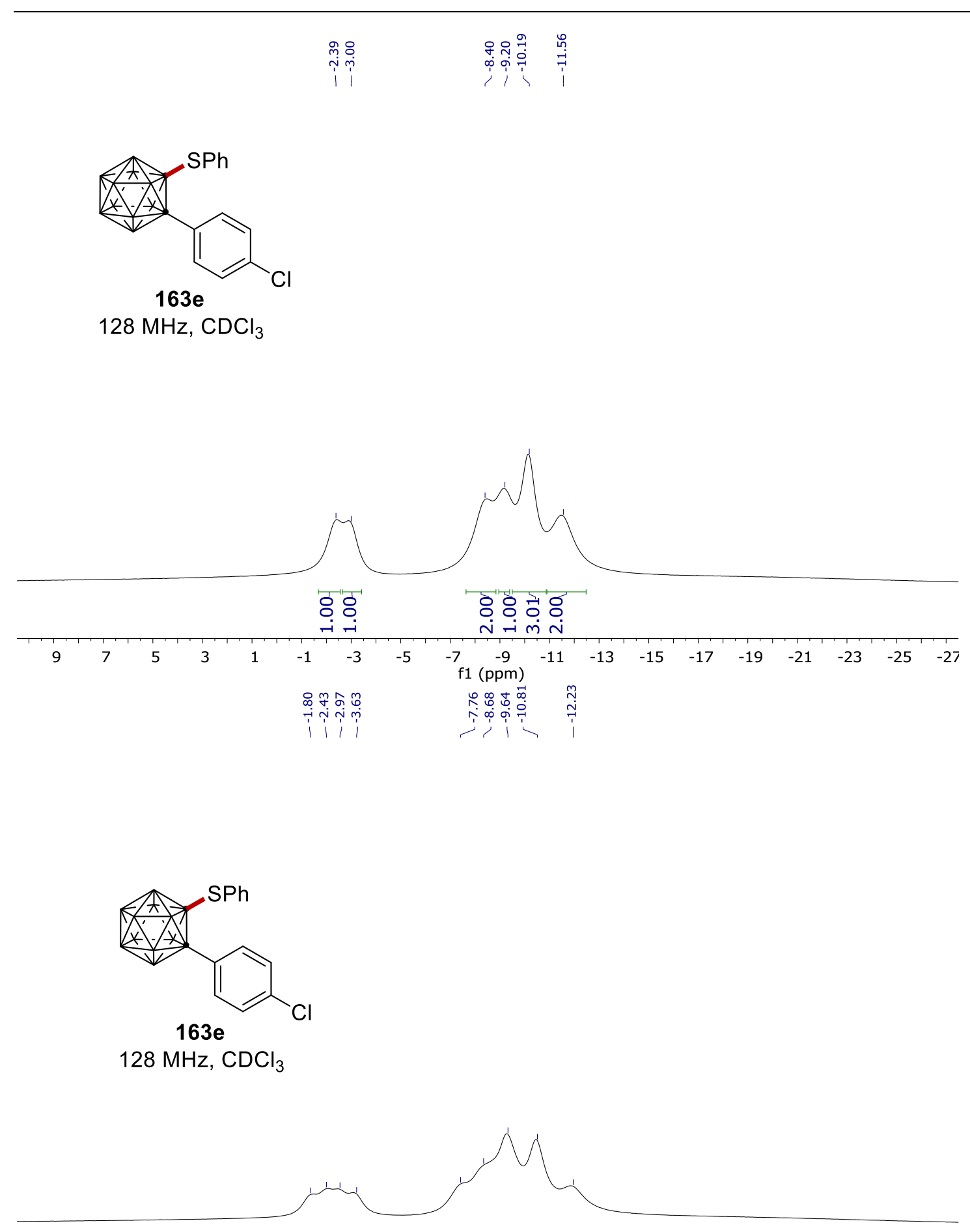

$\begin{array}{llllllllllllllllllllll}9 & 7 & 5 & 3 & 1 & -1 & -3 & -5 & -7 & -9 & -11 & -13 & -15 & -17 & -19 & -21 & -23 & -25 & -27\end{array}$



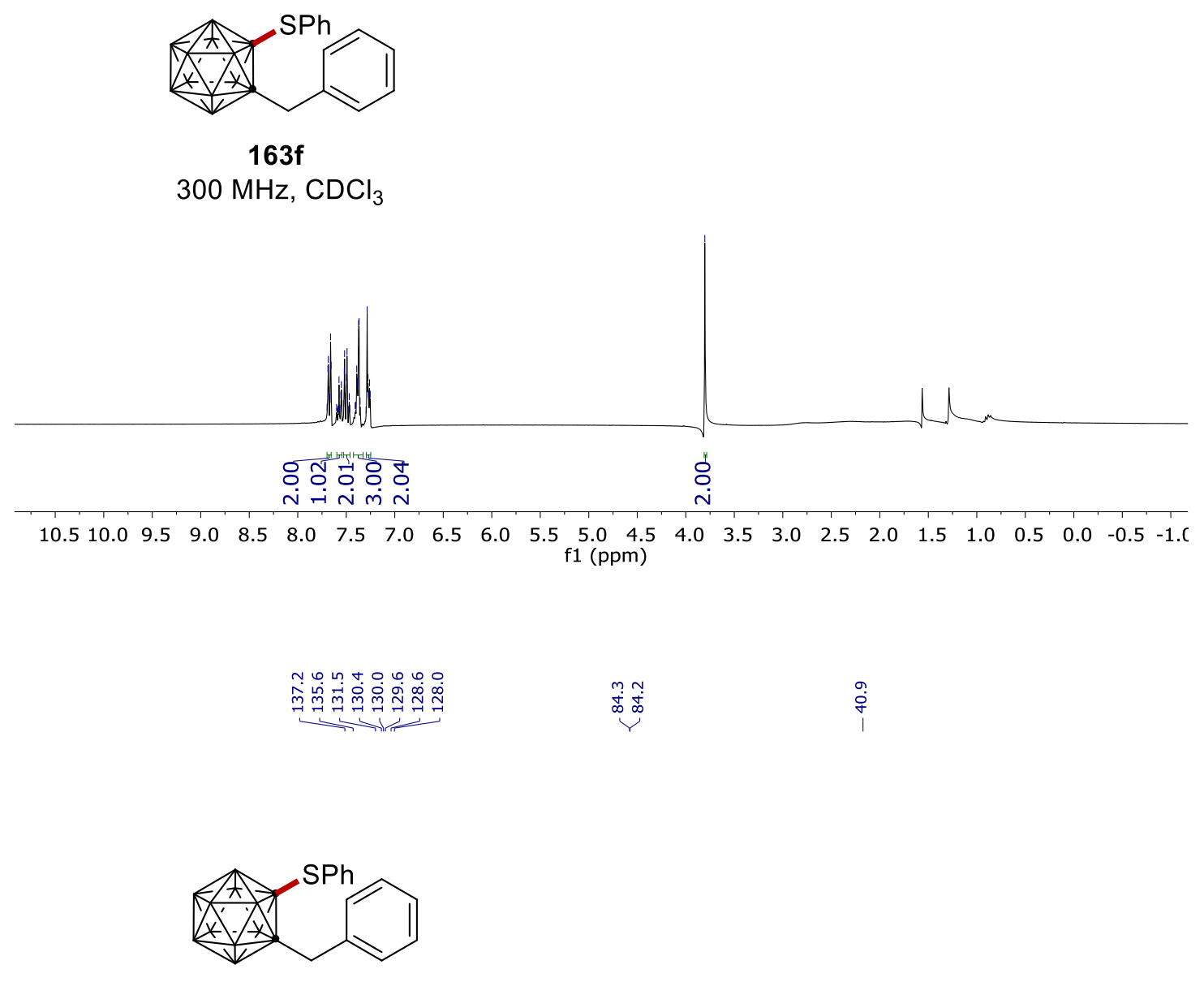

$163 f$

$75 \mathrm{MHz}, \mathrm{CDCl}_{3}$

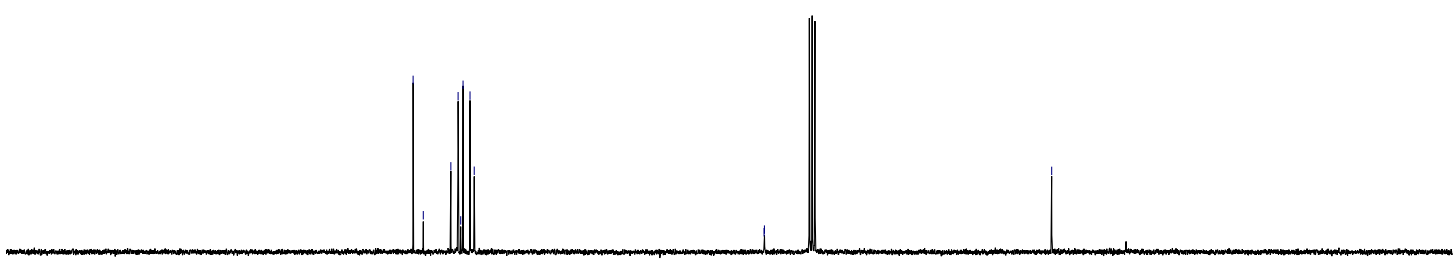

$\begin{array}{llllllllllllllllllll}190 & 180 & 170 & 160 & 150 & 140 & 130 & 120 & 110 & 100 \underset{\mathrm{f} 1}{(\mathrm{ppm})} & \begin{array}{c}90 \\ (\mathrm{ppm}\end{array} & 70 & 60 & 50 & 40 & 30 & 20 & 10 & 0 & -10\end{array}$ 


\section{NMR Spectra}
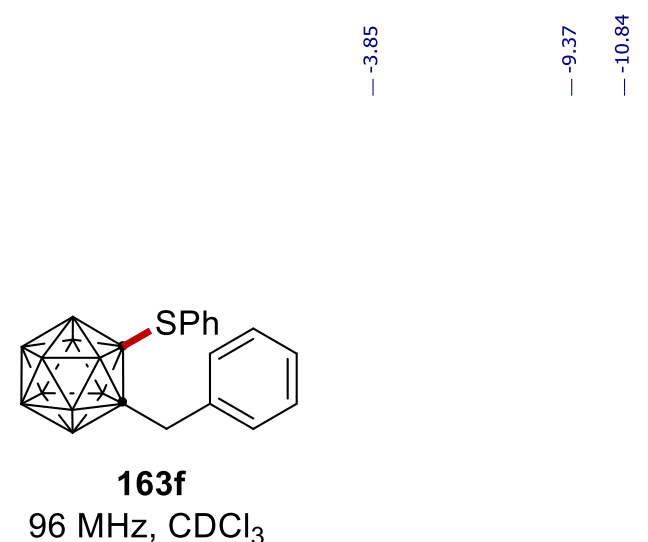

$96 \mathrm{MHz}, \mathrm{CDCl}_{3}$

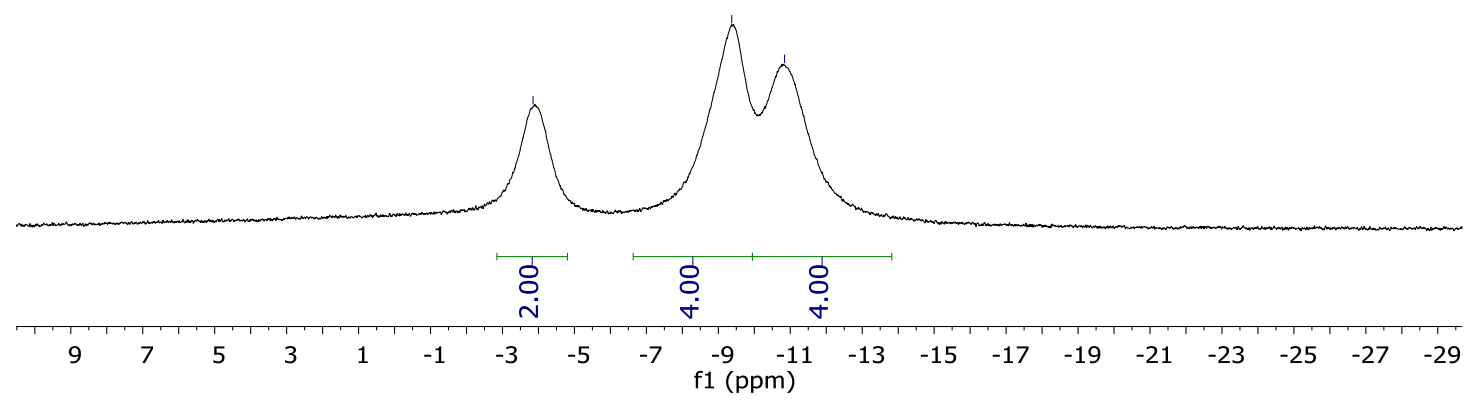

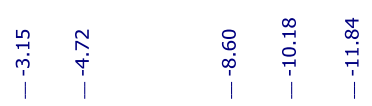

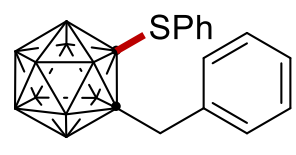

$163 f$

$96 \mathrm{MHz}, \mathrm{CDCl}_{3}$
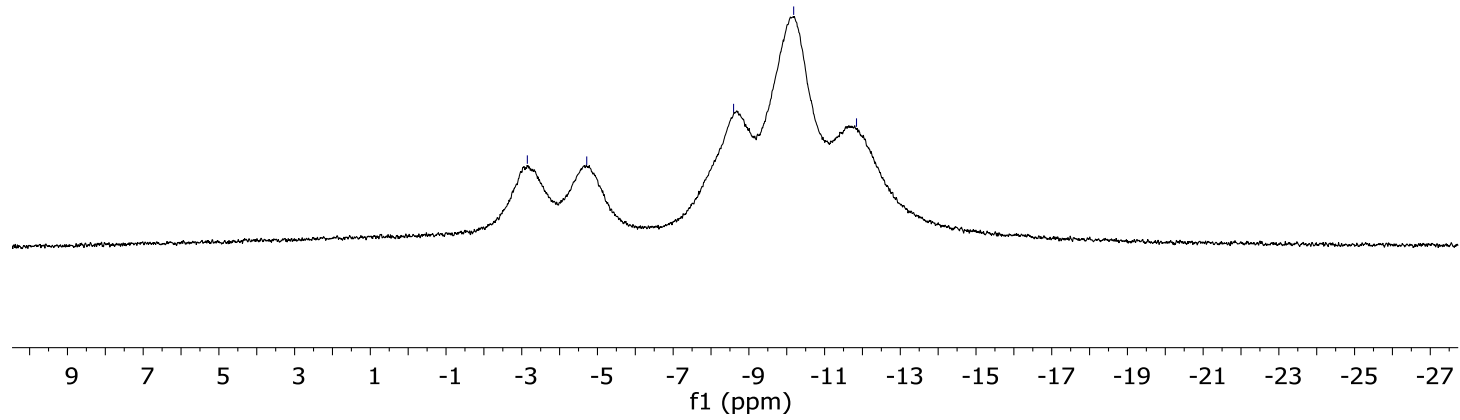

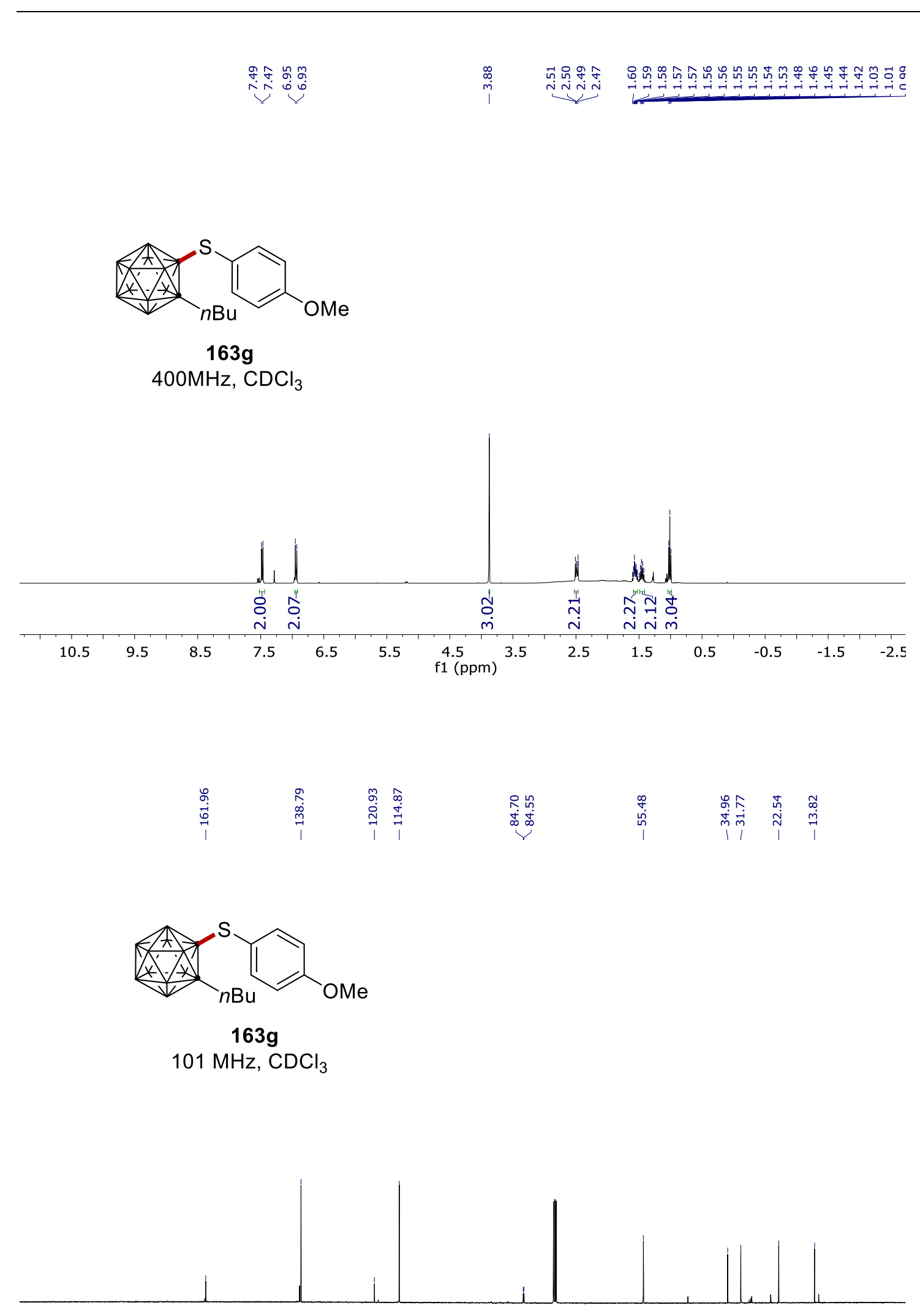

$\begin{array}{lllllllllllllllllllll}200 & 190 & 180 & 170 & 160 & 150 & 140 & 130 & 120 & 110 & 100 & 100 & 80 & 70 & 60 & 50 & 40 & 30 & 20 & 10 & 0\end{array}$ 


\section{NMR Spectra}

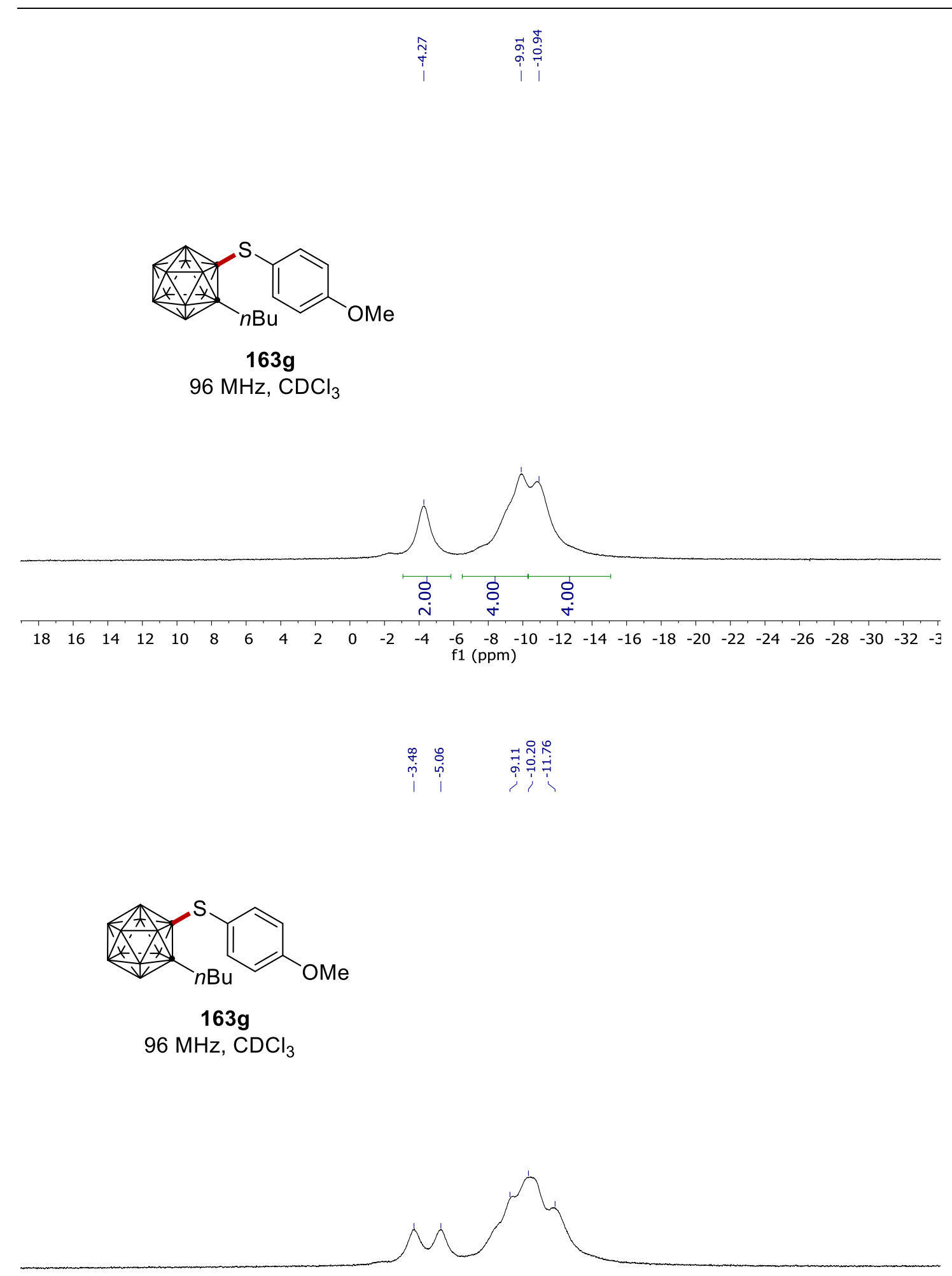

$\begin{array}{lllllllllllllllllllllllllllllllllllllll}18 & 16 & 14 & 12 & 10 & 8 & 6 & 4 & 2 & 0 & -2 & -4 & -6 & -8 & -10 & -12 & -14 & -16 & -18 & -20 & -22 & -24 & -26 & -28 & -30 & -32 & -3\end{array}$ 


\section{NMR Spectra}
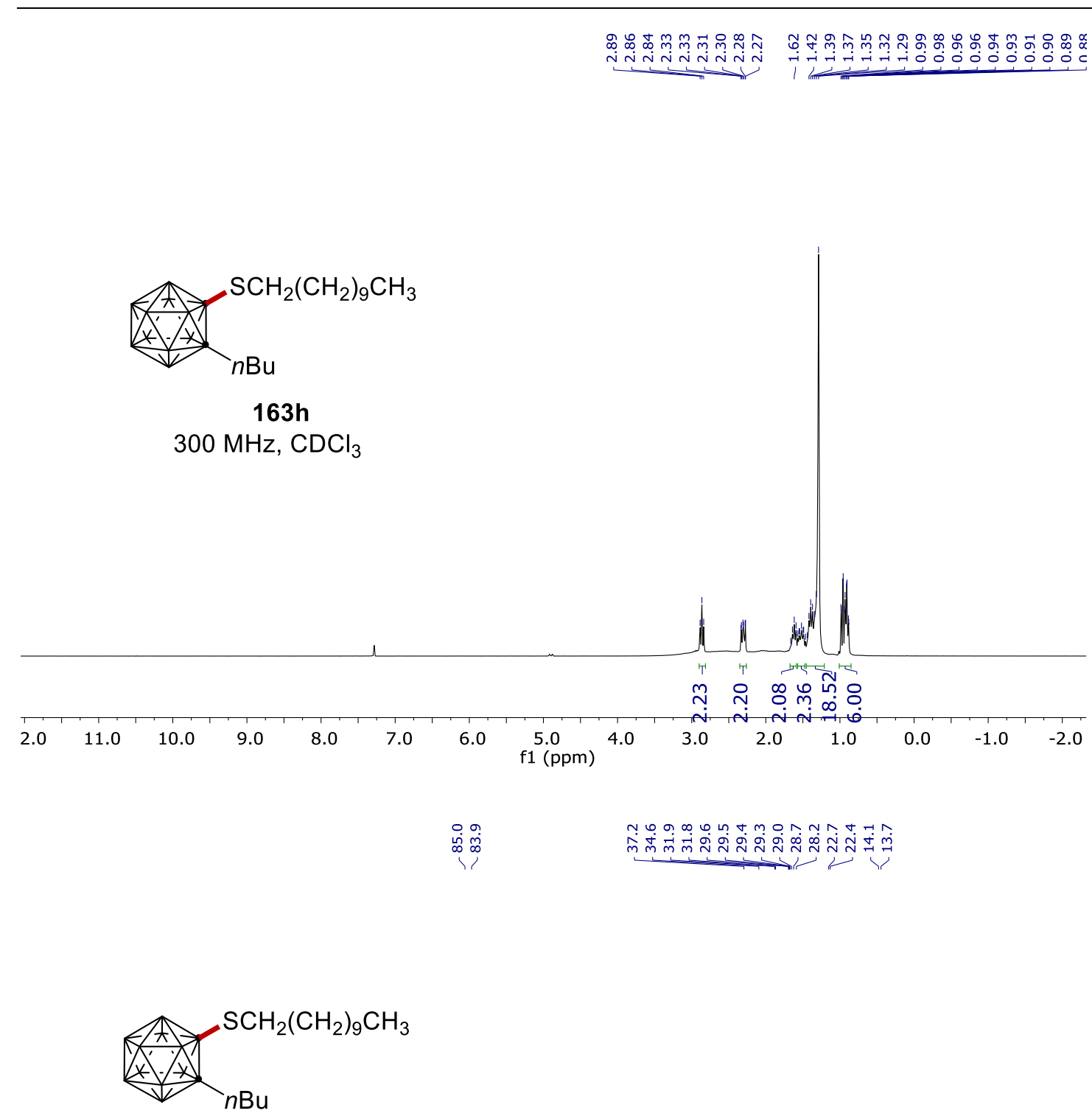

$163 \mathrm{~h}$

$75 \mathrm{MHz}, \mathrm{CDCl}_{3}$

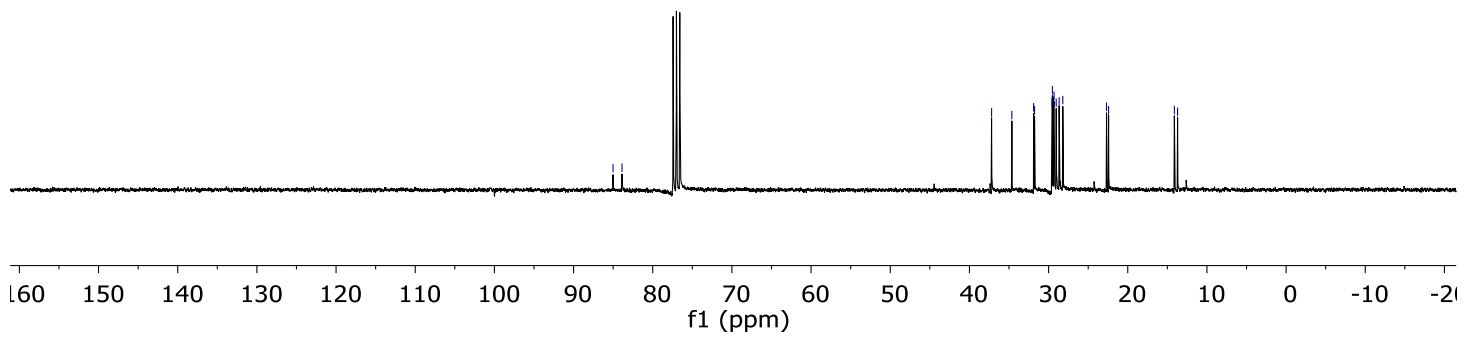




\section{NMR Spectra}
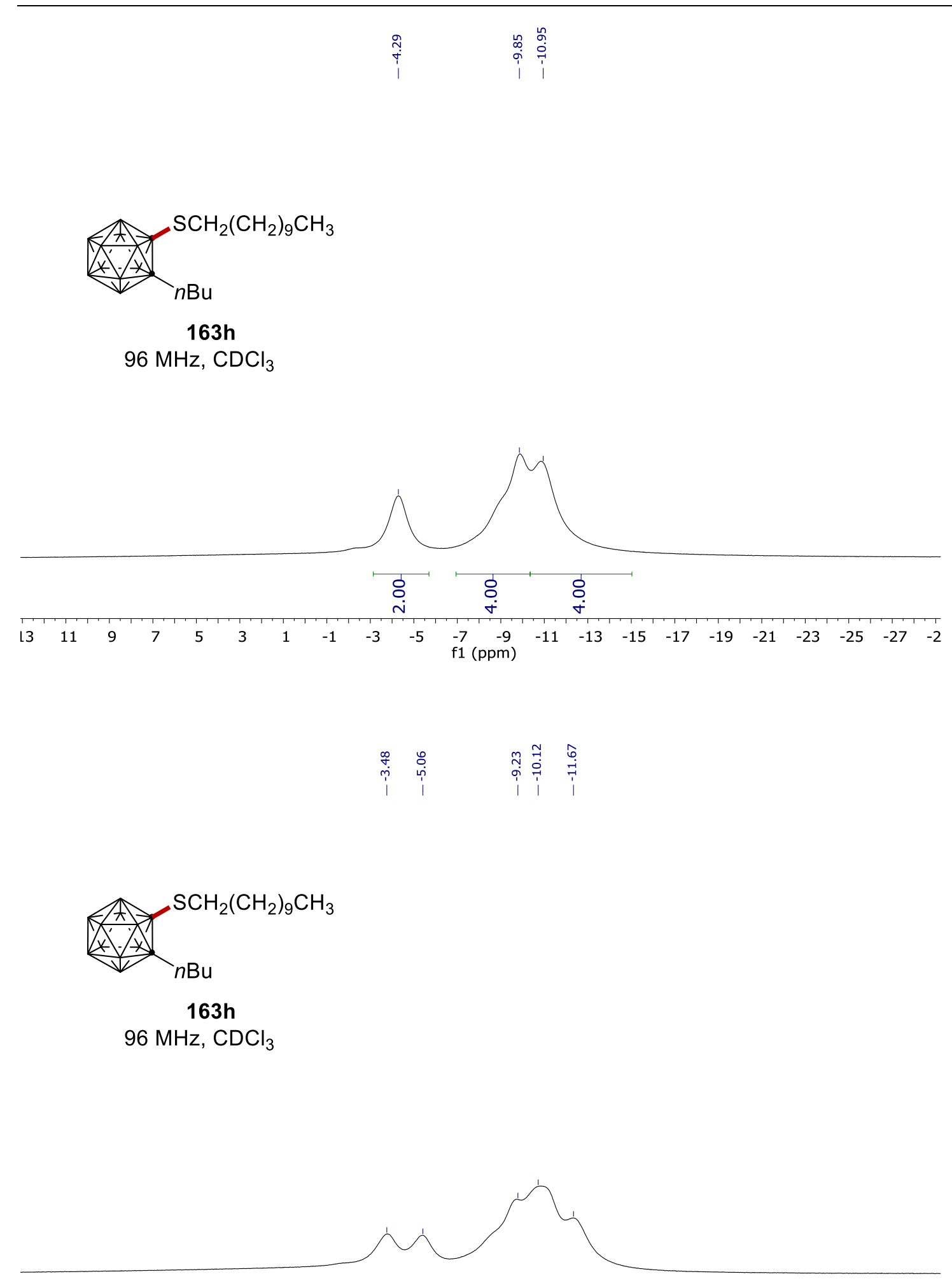

$\begin{array}{llllllllllllllllllll}11 & 9 & 7 & 5 & 3 & 1 & -1 & -3 & -5 & -7 & -9 & -11 & -13 & -15 & -17 & -19 & -21 & -23 & -25 & -27\end{array}$




\section{NMR Spectra}

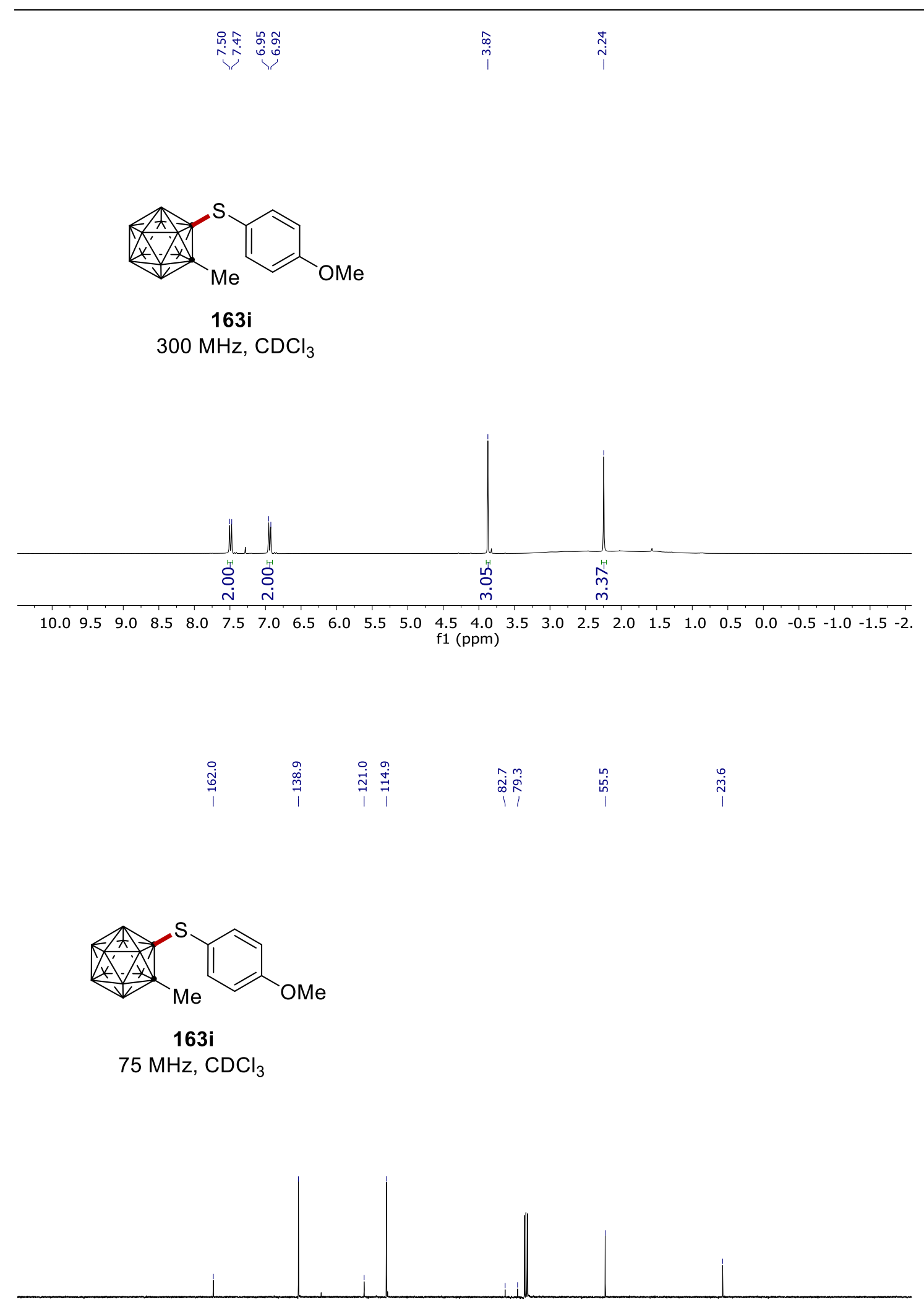

$\begin{array}{lllllllllllllllllllllllllllllllllll}210 & 200 & 190 & 180 & 170 & 160 & 150 & 140 & 130 & 120 & 110 & 100 & 90 & 80 & 70 & 60 & 50 & 40 & 30 & 20 & 10 & 0 & -10 & -20\end{array}$ 


\section{NMR Spectra}
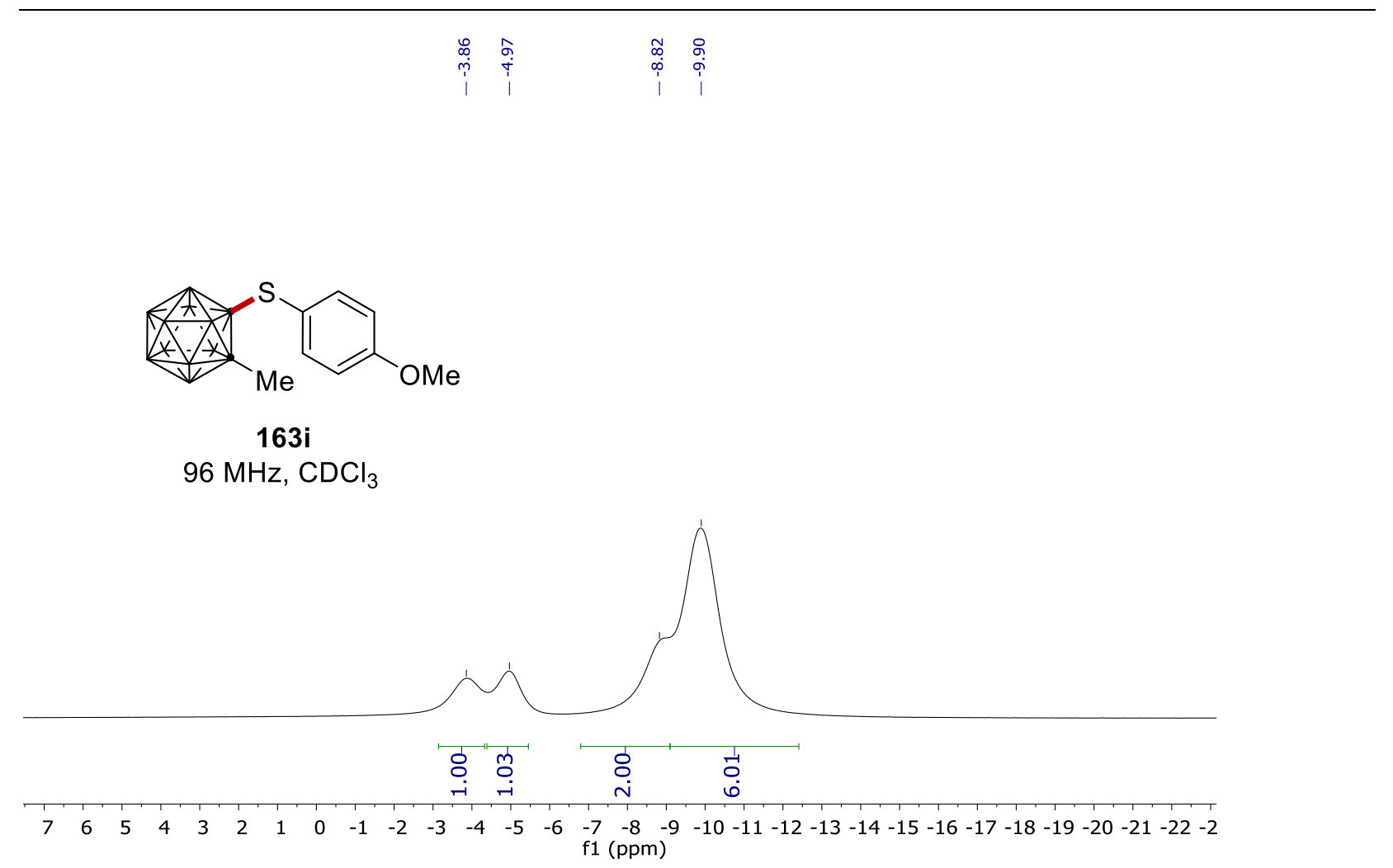

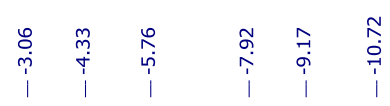

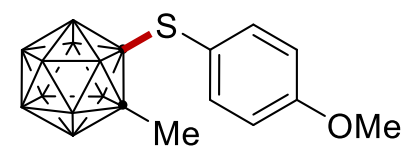

163i

$96 \mathrm{MHz}, \mathrm{CDCl}_{3}$

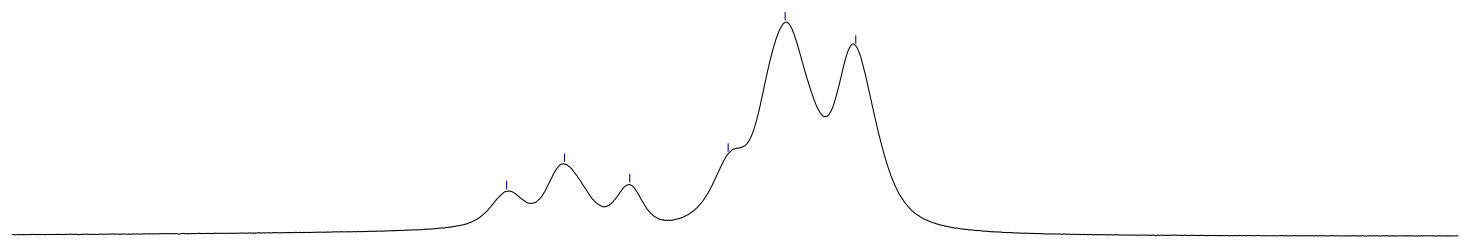

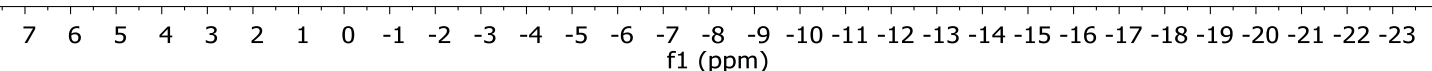




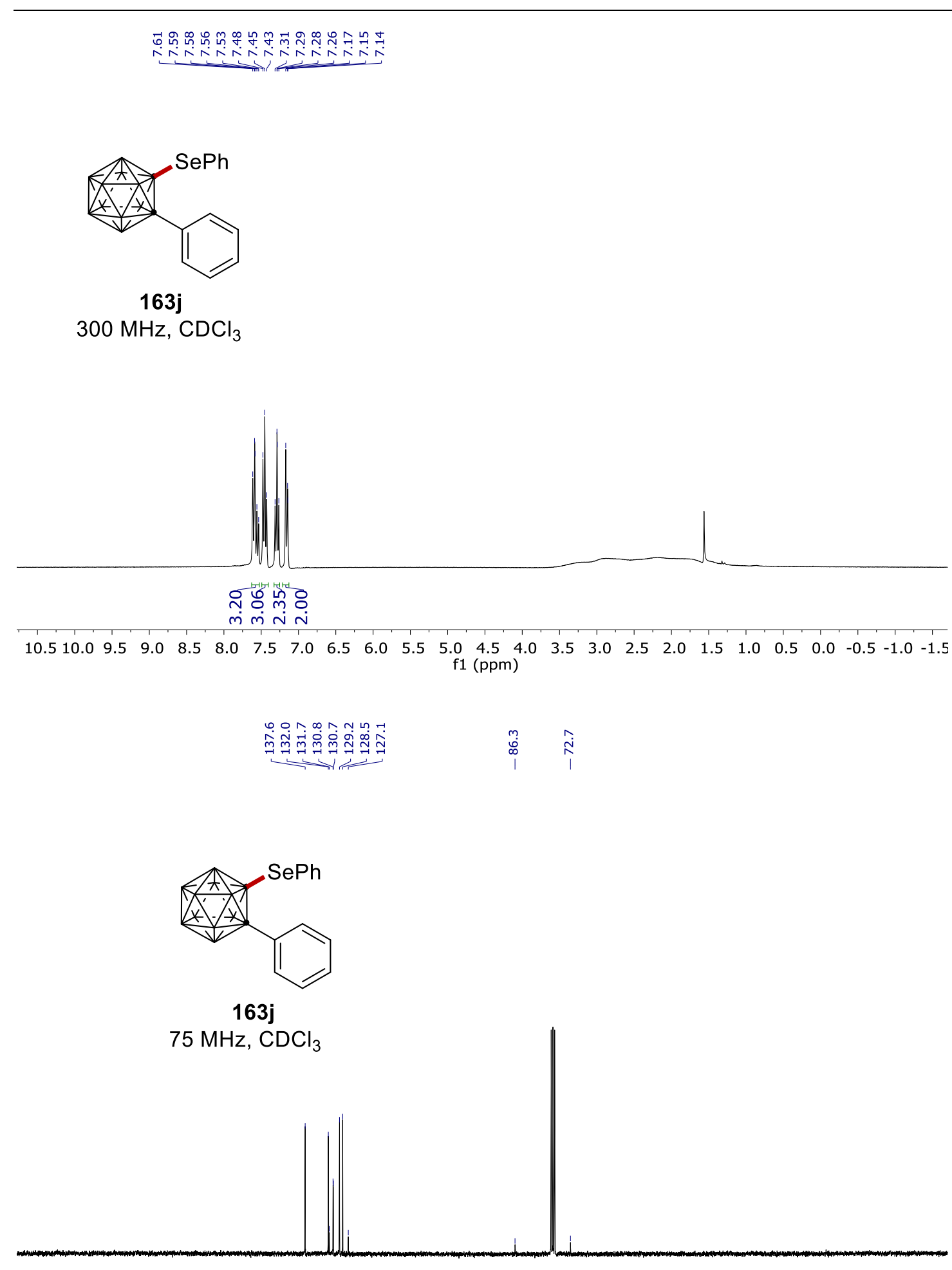

$\begin{array}{lllllllllllllllllllll}200 & 190 & 180 & 170 & 160 & 150 & 140 & 130 & 120 & 110 & \begin{array}{c}100 \\ \mathrm{f} 1(\mathrm{ppm})\end{array} & 80 & 70 & 60 & 50 & 40 & 30 & 20 & 10 & 0 & -10\end{array}$ 


\section{NMR Spectra}

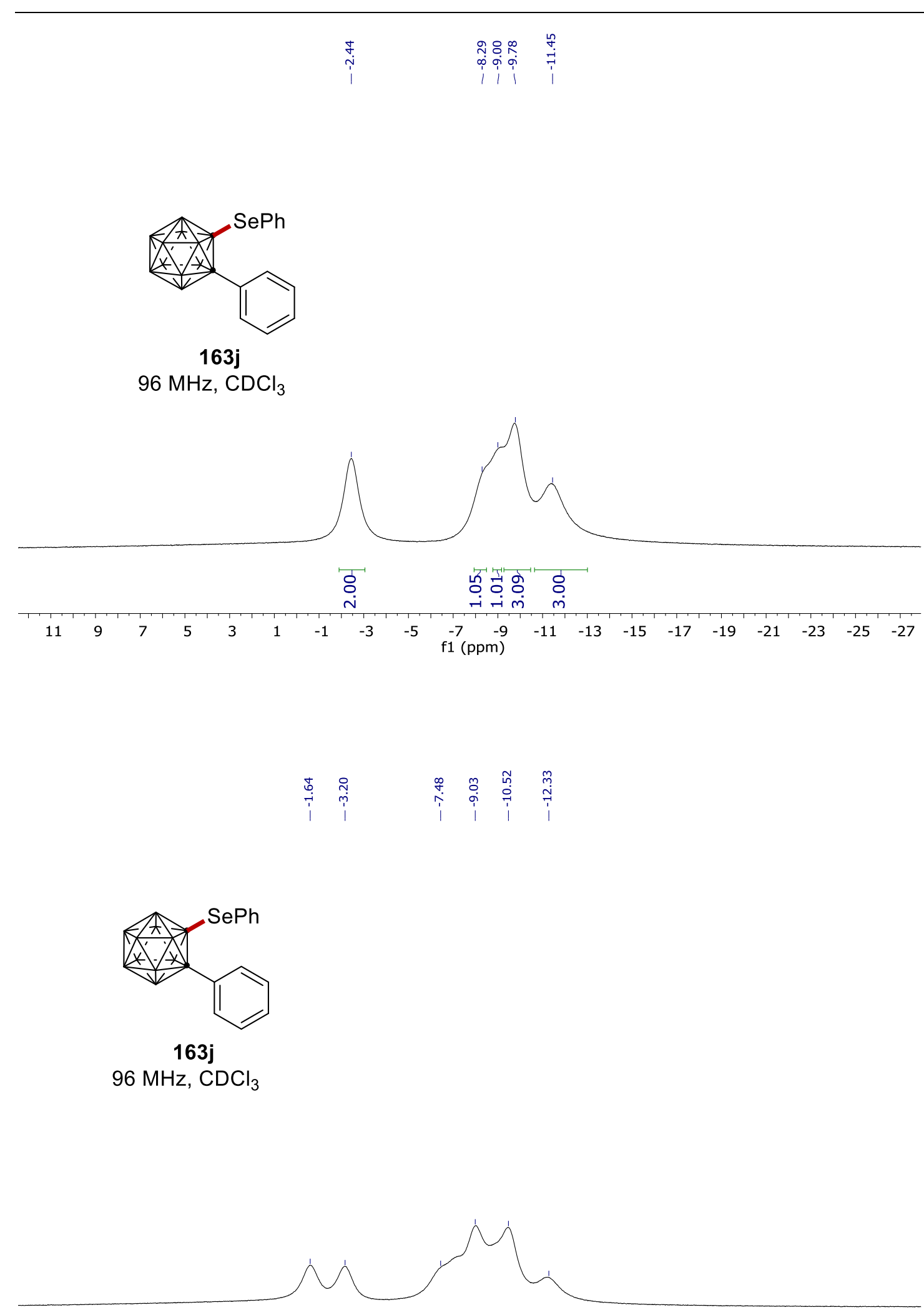

$\begin{array}{lllllllllllllllllllllll} & 11 & 9 & 7 & 5 & 3 & 1 & -1 & -3 & -5 & -7 & -9 & -11 & -13 & -15 & -17 & -19 & -21 & -23 & -25 & -27 & -2\end{array}$ 


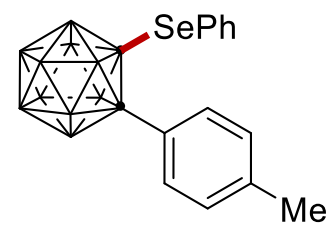

163k

$300 \mathrm{MHz}, \mathrm{CDCl}_{3}$
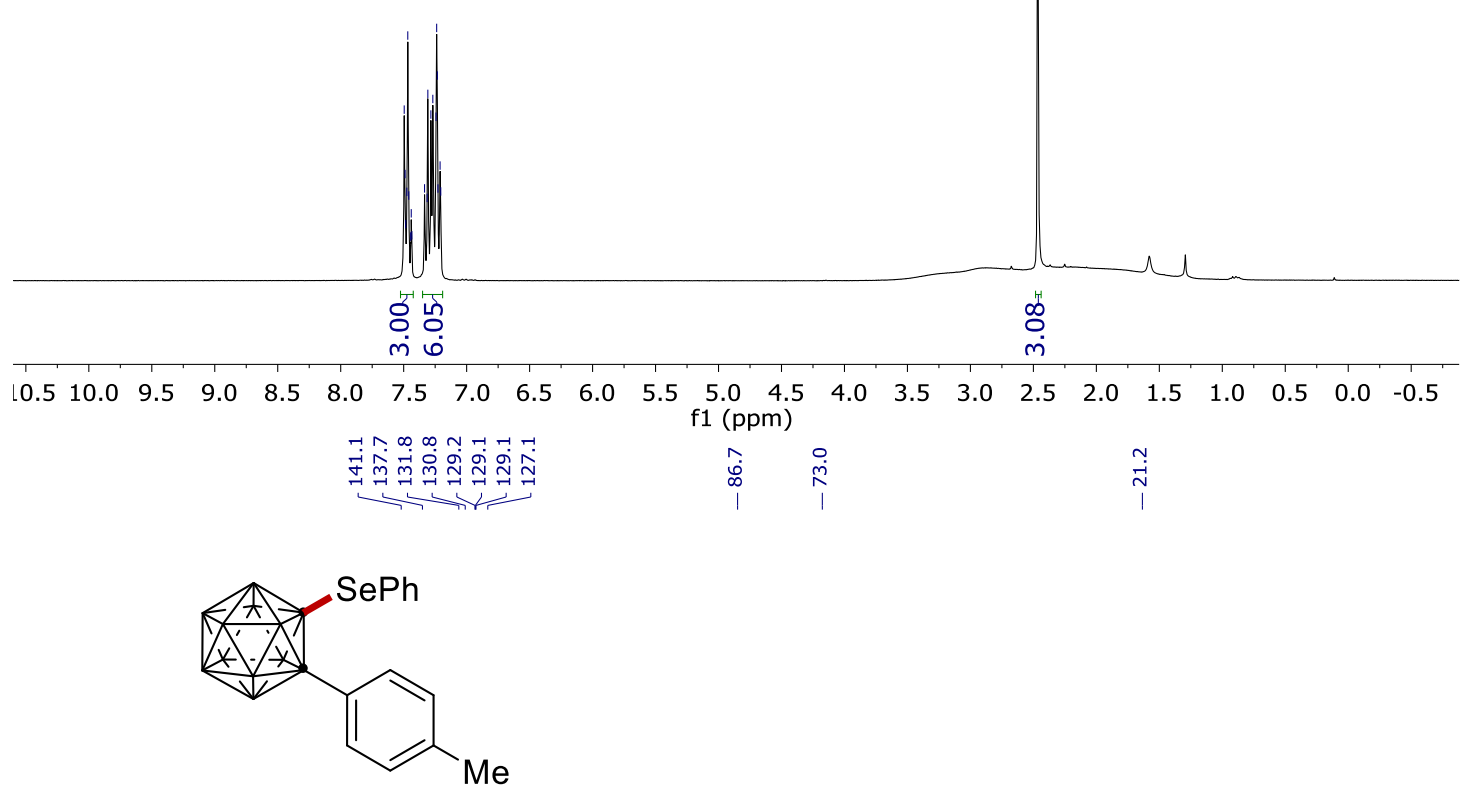

163k

$75 \mathrm{MHz}, \mathrm{CDCl}_{3}$

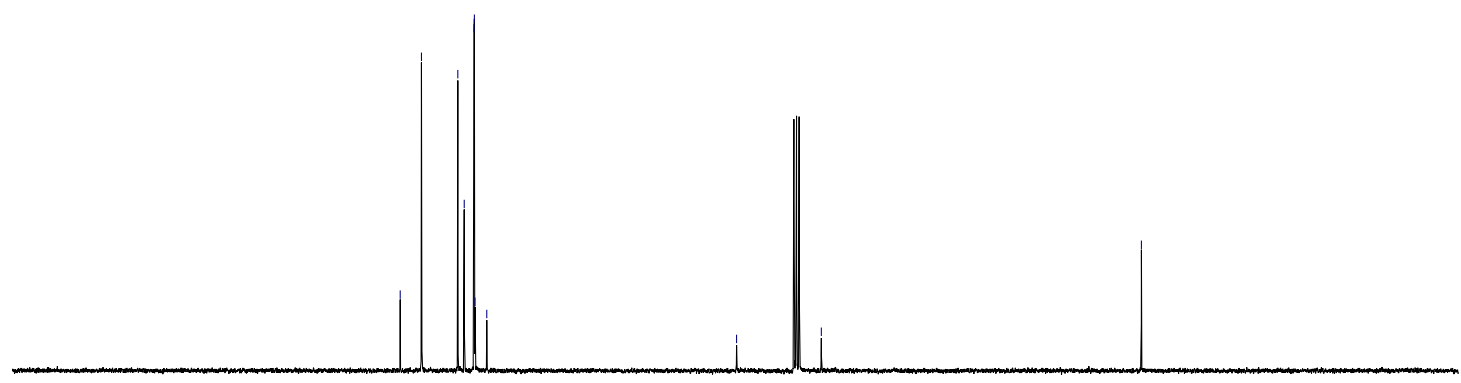

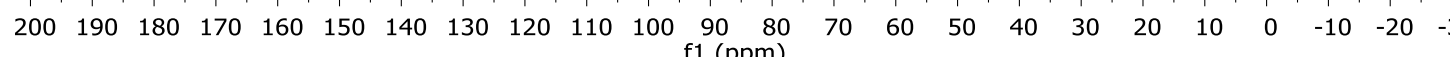




\section{NMR Spectra}

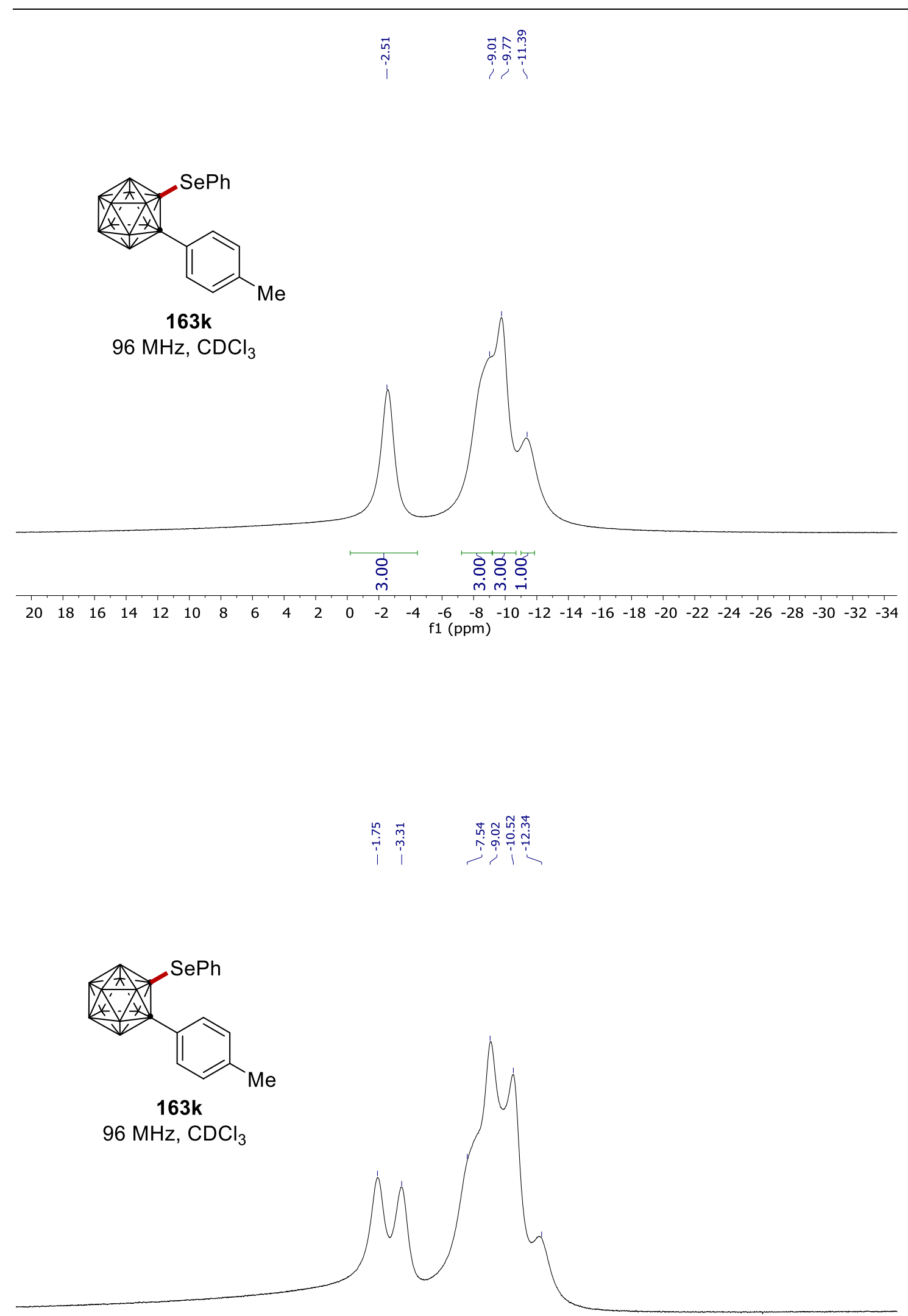

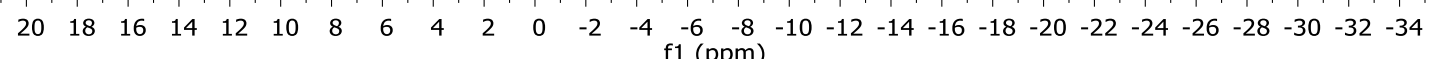
449 


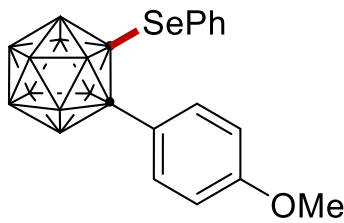

163I

$300 \mathrm{MHz}, \mathrm{CDCl}_{3}$

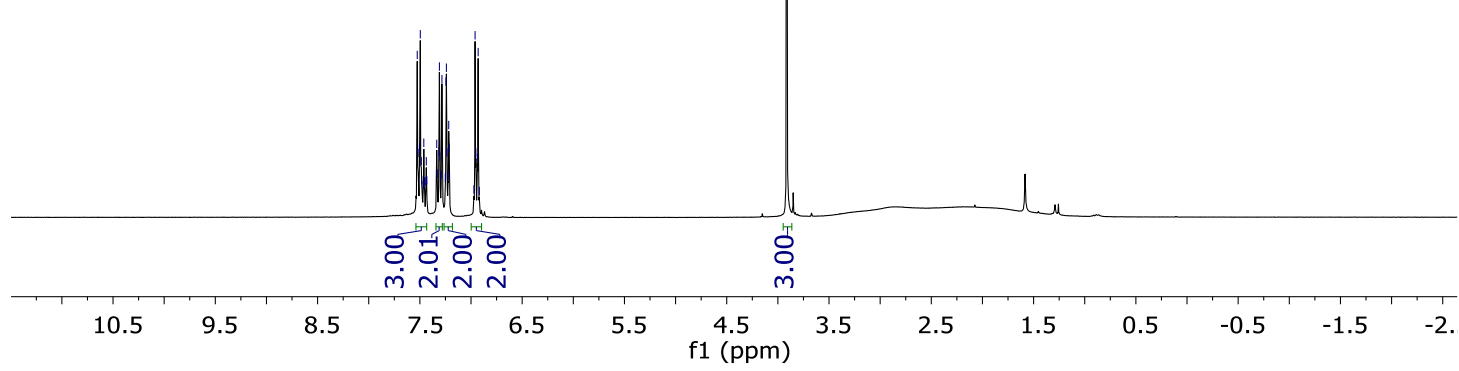

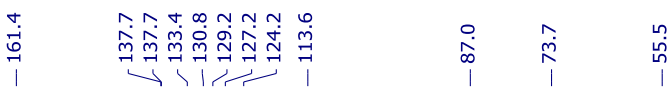

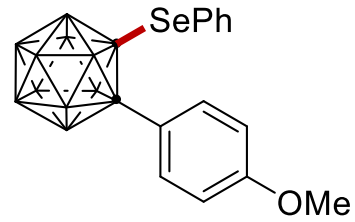

1631

$75 \mathrm{MHz}, \mathrm{CDCl}_{3}$

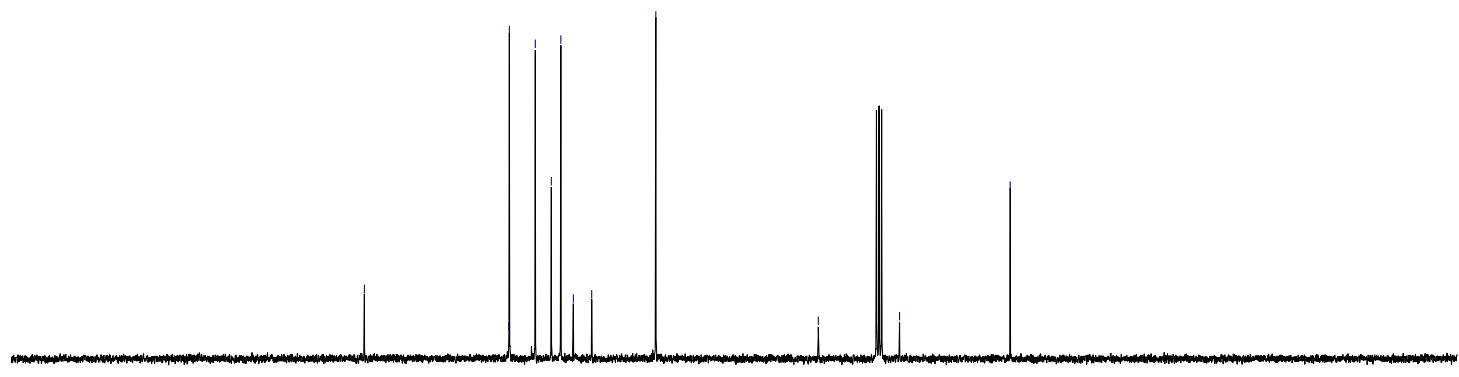

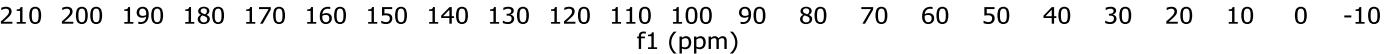




\section{NMR Spectra}

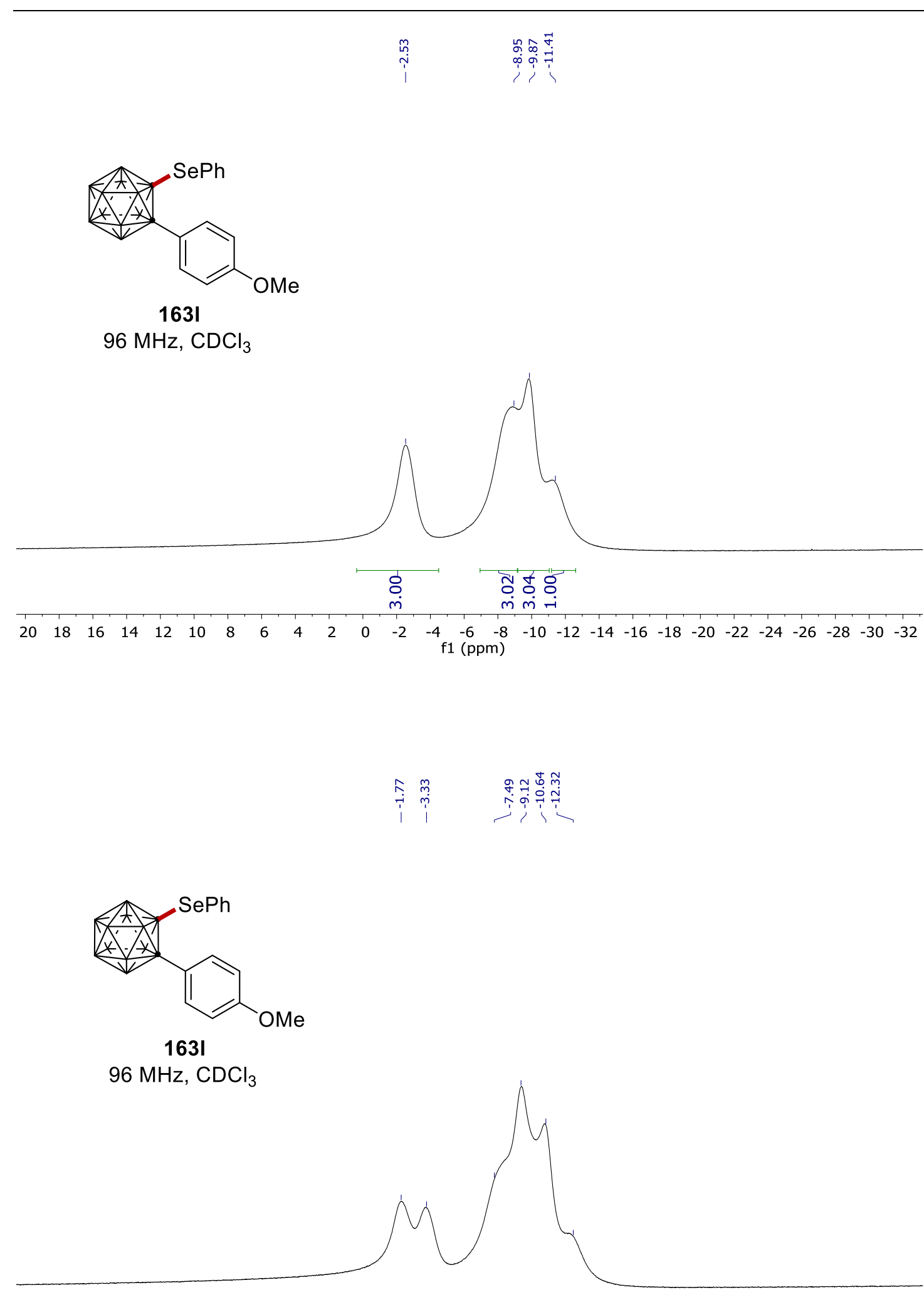

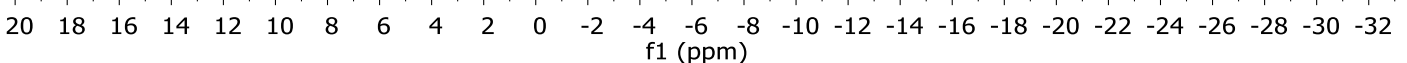




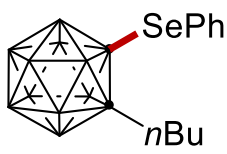

$163 \mathrm{~m}$

$300 \mathrm{MHz}, \mathrm{CDCl}_{3}$

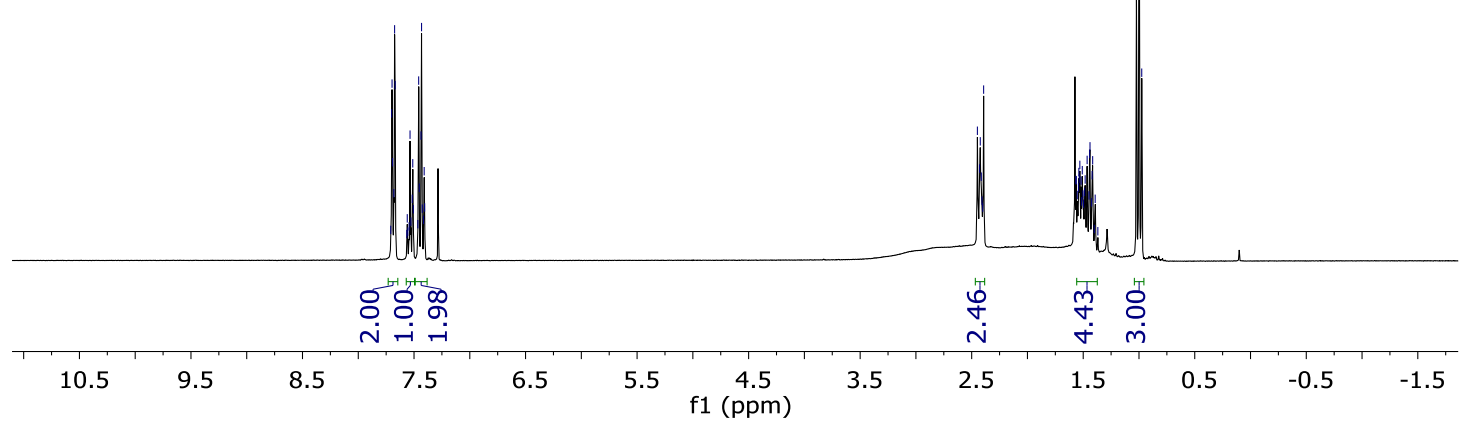

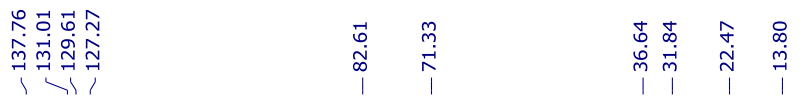

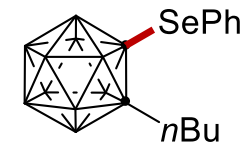

$163 \mathrm{~m}$

$75 \mathrm{MHz}^{\mathrm{CDCl}} 3$

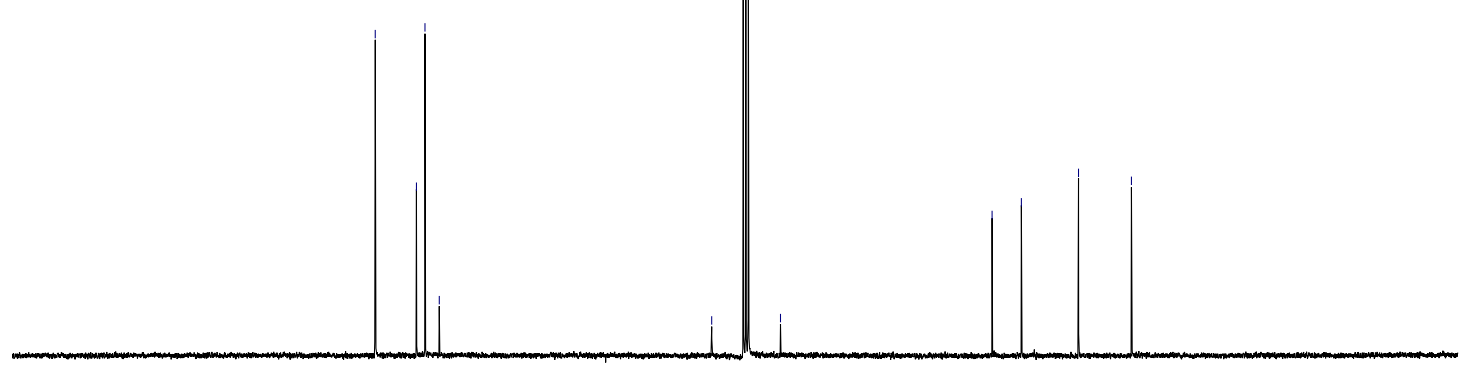

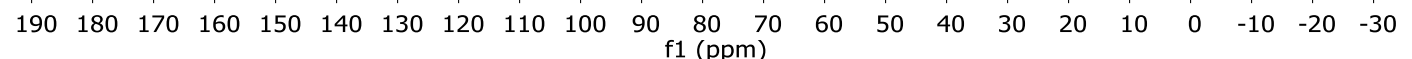




\section{NMR Spectra}
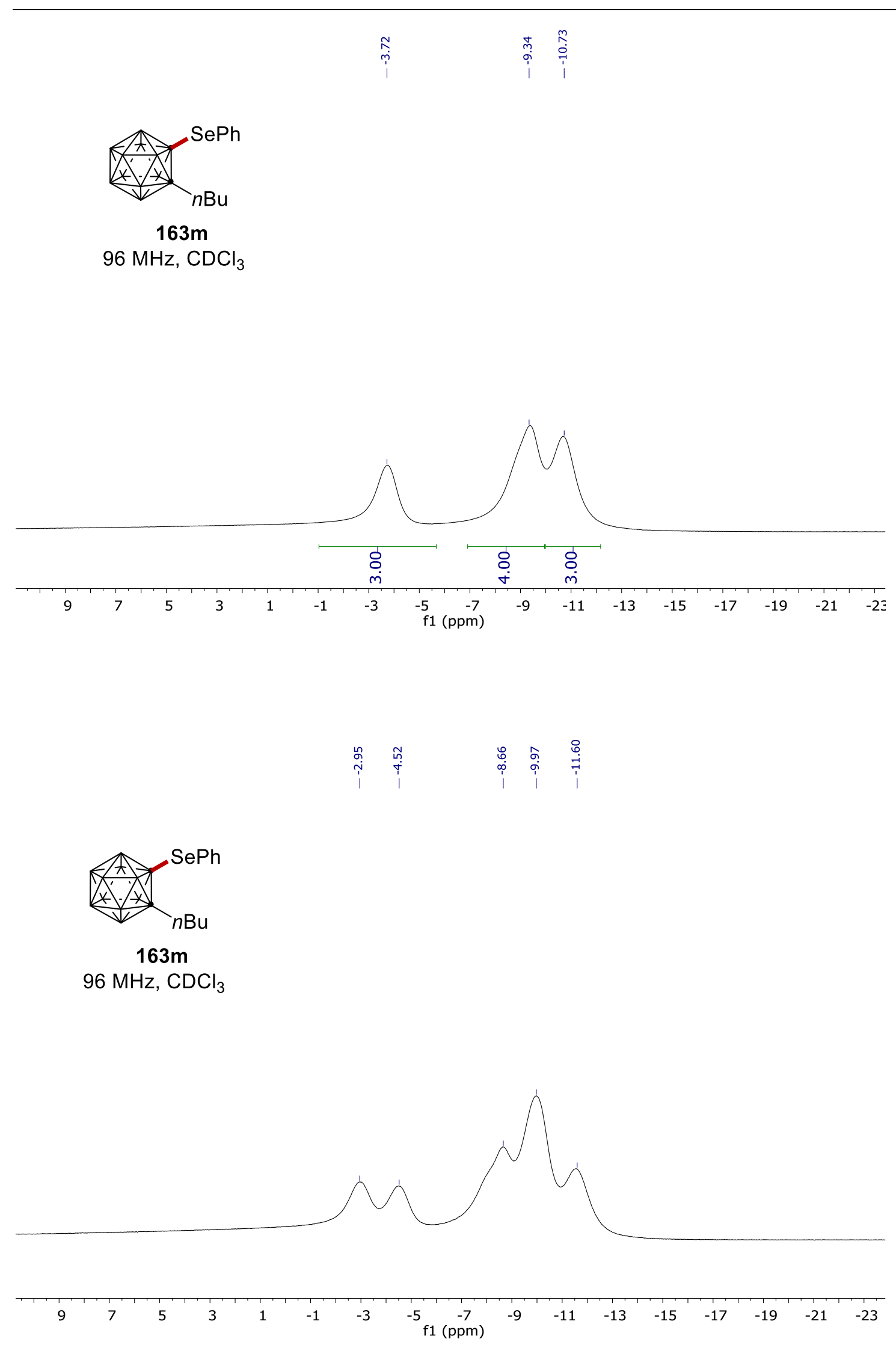

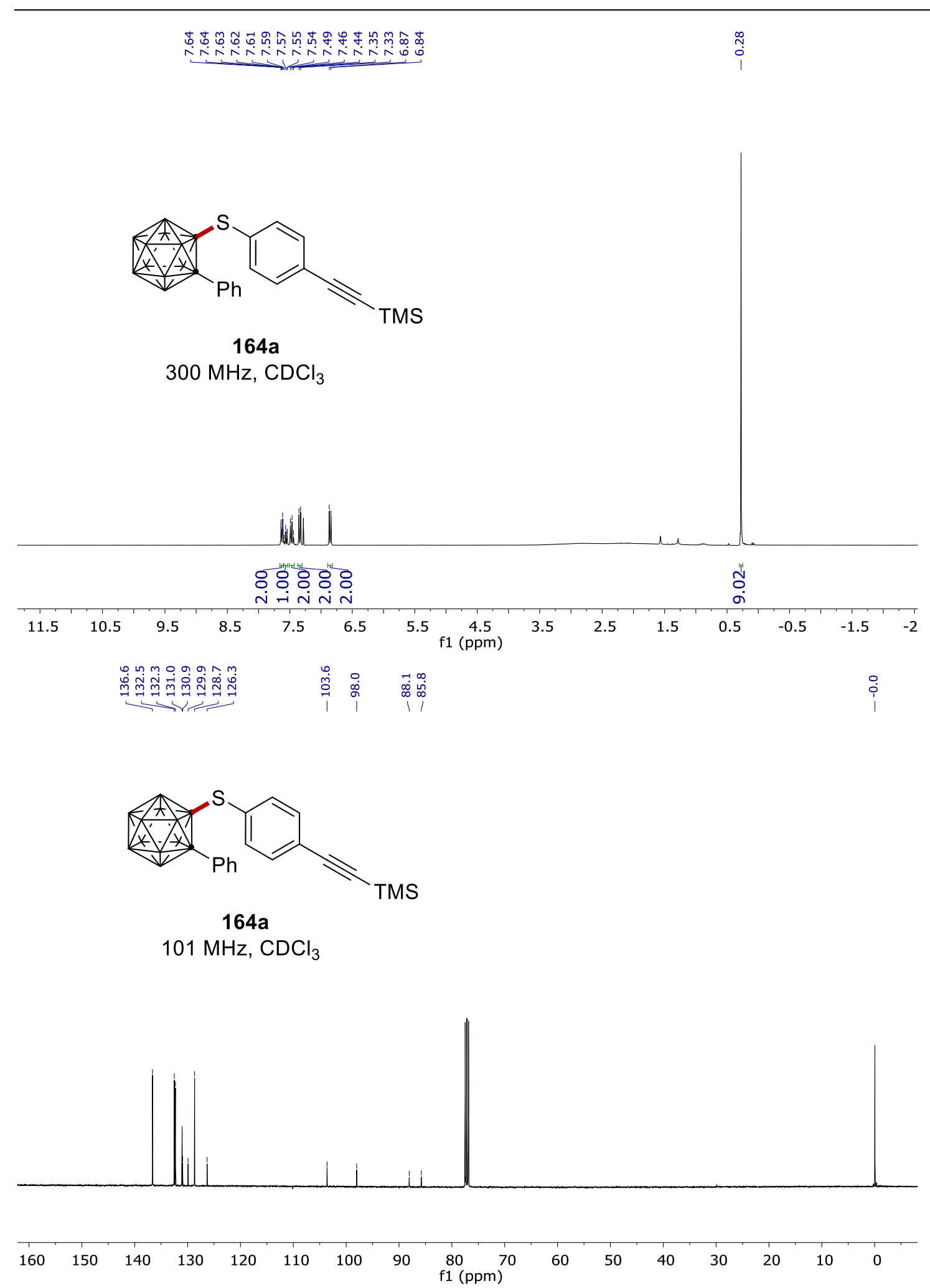


\section{NMR Spectra}

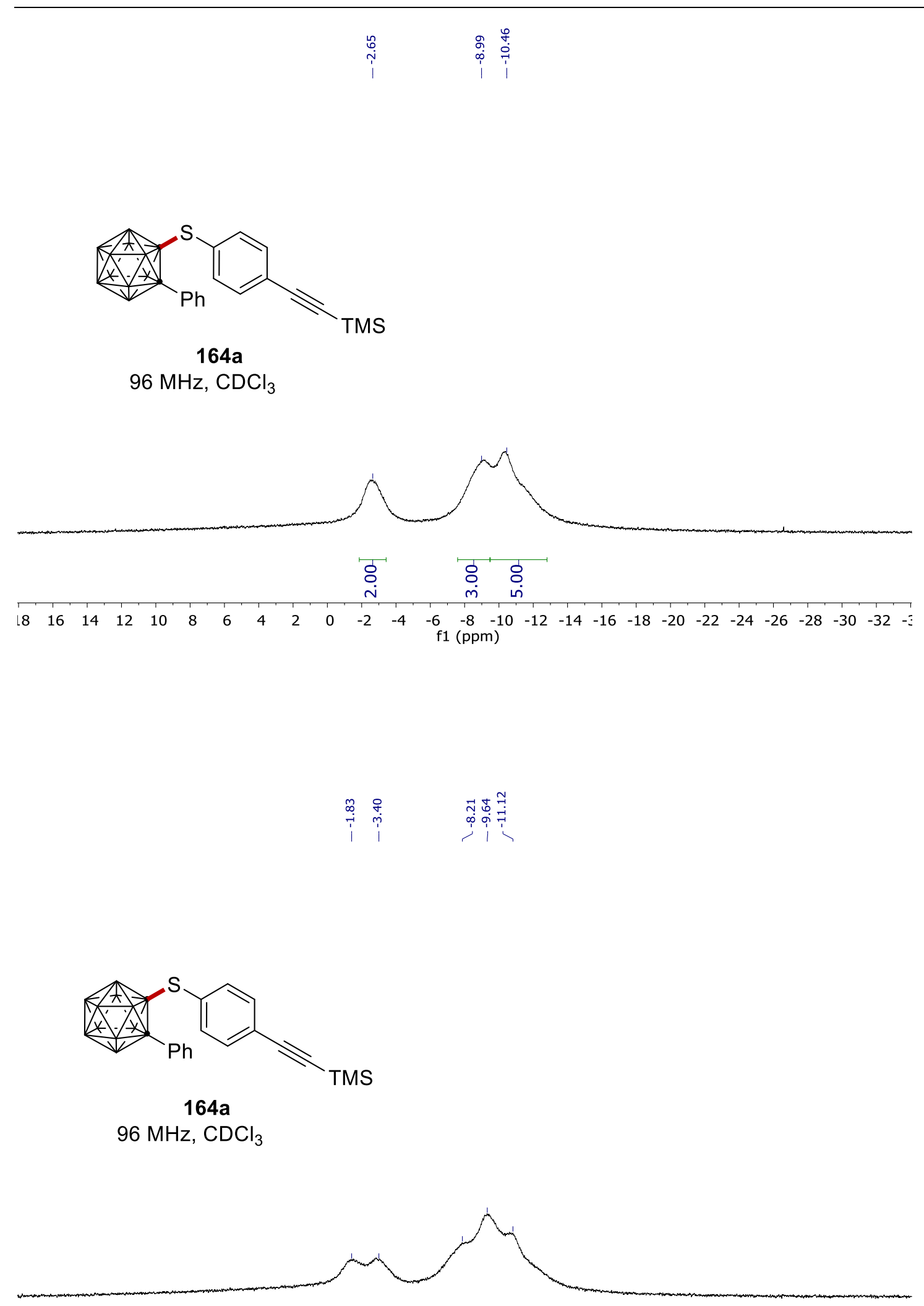

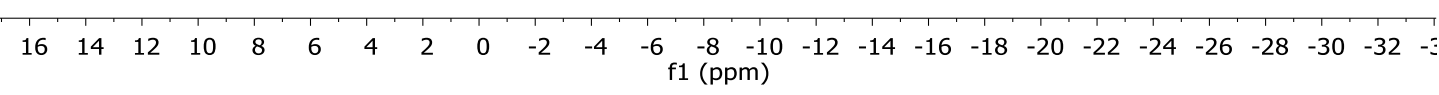



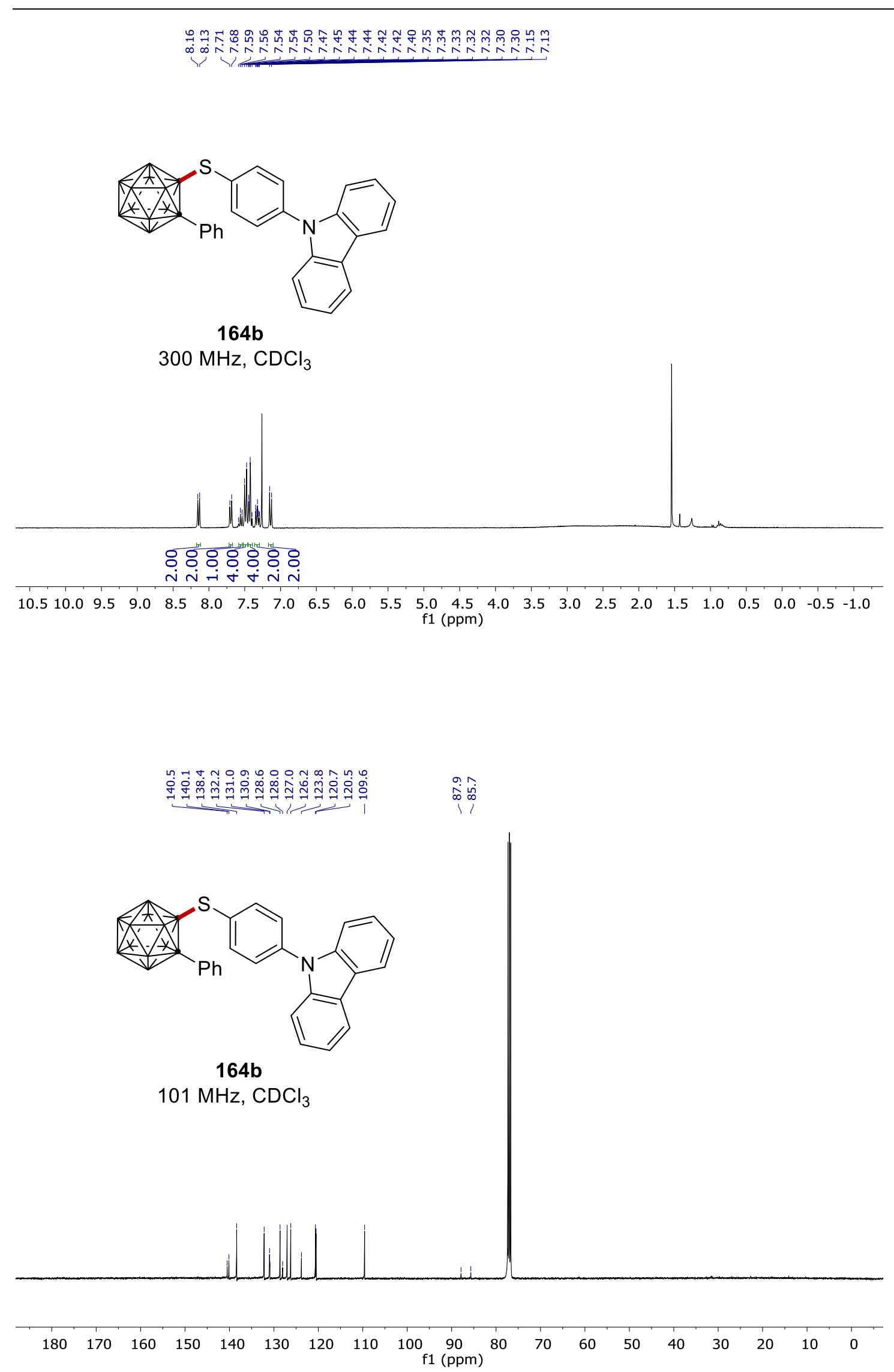


\section{NMR Spectra}

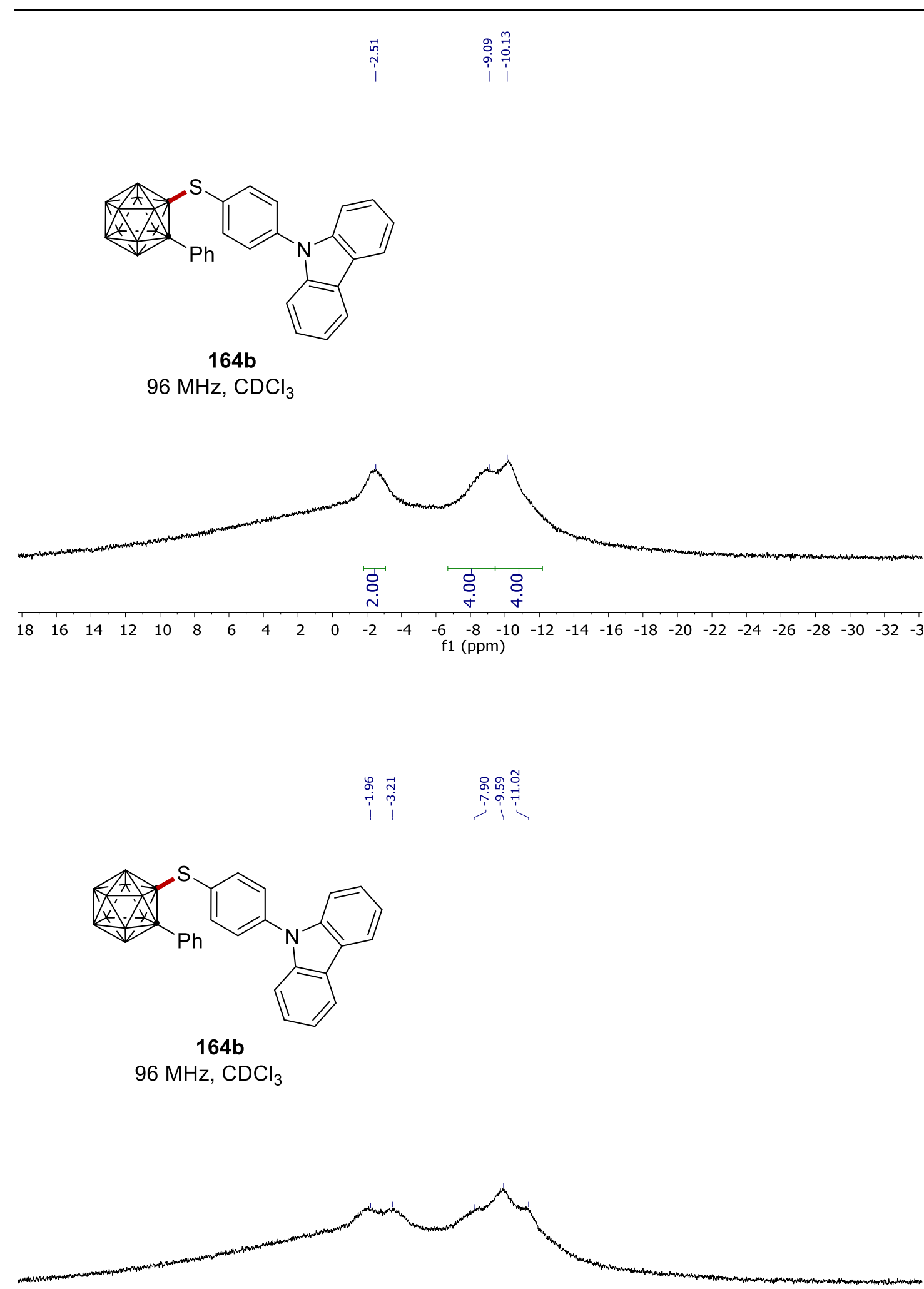

$\begin{array}{lllllllllllllllllllllllllllllll}18 & 16 & 14 & 12 & 10 & 8 & 6 & 4 & 2 & 0 & -2 & -4 & -6 & -8 & -10 & -12 & -14 & -16 & -18 & -20 & -22 & -24 & -26 & -28 & -30 & -32\end{array}$ 


\section{Acknowledgement}

Herein, I would like to extend my sincere gratitude to my doctoral supervisor Prof. Dr. Lutz Ackermann for giving me this fascinating opportunity to carry out my $\mathrm{PhD}$ study here at University of Göttingen and sharing all those creative ideas, enlightening suggestions and helpful discussions with me throughout my research.

I am very grateful to Prof. Dr. Shoubhik Das for his kindly accepting to be the second supervisor. I also thank the other members of the examination committee, Prof. Dr. Dietmar Stalke, Jun.Prof. Dr. Johannes C. L. Walker, Dr. Michael John, and Dr. Daniel Janßen-Müller.

I gratefully acknowledge China Scholarship Council (CSC) for the financial support during my research stay in Germany.

I thank Dr. Yu-Feng, Liang, Dr. Elżbieta Gońka, Dr. Fabio Pescaioli, Dr. Rositha Kuniyil, Dr. Torben Rogge, Dr. Lars H. Finger, Dr. Antonis M. Messinis, Dr. Johanna Frey, Dr. A. Claudia Stückl, Becky Bongsuiru Jei, Ralf Steinbock, Alexej Scheremetjew, Dr. Yiyi Weng and Binbin Yuan, very much for their great contributions to my PhD projects. And many thanks to the people who helped me correct the doctoral thesis: Dr. Ramesh C. Samanta, Dr. Robert Connon, Dr. Bartlomiej Sadowski, Dr. Shou-Kun Zhang, Dr. Yulei Wang, Dr. Yanjun Li, Isaac Choi, Julia Struwe, Jun Wu and Becky Bongsuiru Jei.

I deeply appreciate Ms. Gabriele Keil-Knepel and Bianca Spitalieri for their kind assistance in the laboratory as well as in my daily life. I thank Mr. Stefan Beußhausen for the technical assistance with the instruments, and Mr. Karsten Rauch for his suggestions on the lab work and safety. I also want to thank all the members of the analytical departments of IOBC for their kind support in chemistry. I appreciate the help form Dr. Christopher Golz for the X-ray analysis.

I sincerely would also like to thank all the people who helped me to correct manuscripts and supporting information: Dr. Torben Rogge, Dr. Rositha Kuniyil, Dr. João C. A. de Oliveira, Dr. Lars H. Finger, Dr. Robert Connon, Dr. Tomasz Wdowik, Dr. Johanna Frey, Ralf Steinbock, Alexj Scheremetjew, Maximilian Stangier, Dr. Nikolaos Kaplaneris and Dr. Uttam Dhawa. I thank all the group members in Ackermann Group, particularly the past and current members in Lab 309, Dr. Fabio Pesciaioli, Dr. Yu-Feng Liang, Dr. Debasish Ghorai, Dr. Tomasz Wdowik, Dr. Robert Connon, Dr. Cong Tian, Dr. Elżbieta Gońka, Dr. Uttam Dhawa, Dr. Valentin Müller, Ralf 
Steinbock, Becky Bongsuiru Jei, Weizhao Li, Rongxin Yin.

I really enjoyed the football and basketball games with Alexj Scheremetjew, Dr. Tjark Meyer, Maximilian Stangier, Dr. Ramesh C. Samanta, Dr. Youai Qiu, Leonardo Massignan, Dr. Wei-Jun Kong, Dr. Shou-Kun Zhang, Jun Wu, Dr. Thomas Müller, Dr. Antonis M. Messinis, Dr. Yan Zhang, Dr. João C. A. de Oliveira, Dr. Wei Wang, Dr. Zhigao Shen, Ralf Steinbock, Zhipeng Lin, Shan Chen, Dr. Yulei Wang, Dr. Yanjun Li, Hendrik Simon, Isaac Maksso, Takuya Michiyuki, Tsuyoshi Ohyama.

Last but not the least, I would like to express my deepest gratitude to my wife, my son and my parents. Their endless love, unconditional support and encouragement made it possible to come this far. 


\title{
Curriculum Vitae
}

\section{Personal Information}

Name: Long Yang

Date of birth: February 14, 1991

Place of birth: Ganzhou, Jiangxi, P. R. China

Nationality: Chinese

Address: Tammannstrasse 2, 37077, Göttingen, Germany

Email: ylong@gwdg.de

\section{Academic Education}

\author{
10.2017-present Ph.D. Candidate in Organic Chemistry \\ Georg-August-Universität Göttingen \\ Supervisor: Prof. Dr. Lutz Ackermann \\ Thesis: Selective C-H Activation: Ruthenaelectro-Catalysis \\ and Carborane Cage Activation \\ 09.2014-06.2017 M.Sc. in Organic Chemistry \\ Fuzhou University \\ Supervisor: Prof. Dr. Gang Li \\ Thesis: Palladium-Catalyzed ortho-C-H Bond Activation of Benzoic Acids \\ and meta-C-H Bond Activation of Anilines \\ 09.2010-06.2014 B.Sc. in Chemical Engineering and Technology \\ Jinggangshan University
}

\section{Attended Symposiums}

$1^{\text {st }}$ Summer School on Organic Catalysis for Energy Conversion, Göttingen, Germany, September 24-29, 2017.

$5^{\text {th }}$ International Symposium on C-H Activation. Georg-August-Universität Göttingen, Germany, July 27-30, 2020.

ONLINE SYMPOSIUM: Earth-Abundant 3d Metal Catalysis BEILSTEIN ORGANIC CHEMISTRY SYMPOSIUM 2020, Germany, September 22-23, 2020

Visual Summer School organized within C-H•AIR project, Göttingen, Germany, June 22-24, 2021. 


\section{Publications}

1. L. Yang, ${ }^{+}$B. B. Jei, ${ }^{+}$A. Scheremetjew, B. Yuan, A. C. Stückl and L. Ackermann, ${ }^{*}$ "Electrooxidative o-Carborane Chalcogenations Without Directing Groups: Cage Activation by Copper Catalysis at Room Temperature" Chem.Sci. 2021, Accepted.

2. L. Yang, ${ }^{+}$B. B. Jei, ${ }^{+}$A. Scheremetjew, R. Kuniyil, L. Ackermann, ${ }^{*}$ "Electrochemical B-H Nitrogenation: Access to Amino Acid and BODIPY-Labeled nido-Carboranes" Angew. Chem. Int. Ed. 2021, 60, 1482-1487.

3. L. Yang, R. Steinbock, A. Scheremetjew, R. Kuniyil, L. H. Finger, A. M. Messinis, L. Ackermann," "Azaruthena(II)-Bicyclo-[3.2.0]-Heptadiene: Key Intermediate for Ruthenaelectro(II/III/I)-Catalyzed Alkyne Annulations" Angew. Chem. Int. Ed. 2020, 59, 11130-11135.

4. L. Yang, J. Frey, L. Ackermann," "Nickela-electrocatalyzed sulfide and phosphine oxygenations with water" Sci. China Chem. 2021, 64, 873-874.

5. Y.-F. Liang, ${ }^{+}$L. Yang, ${ }^{+}$B. B. Jei, R. Kuniyil, L. Ackermann, ${ }^{*}$ Regioselective $B(3,4)-H$ Arylation of 0 -Carboranes by Weak Amide Coordination at Room Temperature" Chem. Sci. 2020, 11, 10764-10769.

6. E. Gońka, ${ }^{+}$L. Yang, ${ }^{+}$R. Steinbock, F. Pescaioli, R. Kuniyil, L. Ackermann, " "т-Extended Polyaromatic Hydrocarbons by Sustainable Alkyne Annulations through Double $\mathrm{C}-\mathrm{H} / \mathrm{N}-\mathrm{H}$ Activation" Chem. Eur. J. 2019, 25, 16246-16250.

7. Y.-F. Liang, ${ }^{+}$L. Yang, ${ }^{+}$T. Rogge, ${ }^{+}$L. Ackermann, ${ }^{*}$ "Ruthenium(IV) Intermediates in $\mathrm{C}-\mathrm{H}$ Activation/Annulation by Weak O-Coordination" Chem. Eur. J. 2018, 24, 16548-16552.

8. L. Yang, S. Li, L. Cai, Y. Ding, L. Fu, Z. Cai, H. Ji, G. Li," "Palladium-Catalyzed C-H Trifluoroethoxylation of N-Sulfonylbenzamides" Org. Lett. 2017, 19, 2746-2749.

9. L. Yang, ${ }^{+}$L. Fu, ${ }^{+}$G. Li, ${ }^{*}$ "Incorporation of Carbon Dioxide into Carbamate Directing Groups: Palladium-Catalyzed meta-C-H Olefination and Acetoxylation of Aniline Derivatives" Adv. Synth. Catal. 2017, 359, 2235-2240.

10. Y.-F. Liang, R. Steinbock, L. Yang, L. Ackermann, "Continuous Visible Light-Photo-Flow Approach for Manganese-Catalyzed (Het)Arene $\mathrm{C}-\mathrm{H}$ Arylation" Angew. Chem. Int. Ed. 2018, 57, 10625-10629.

11. S. Li, L. Cai, H. Ji, L. Yang, G. Li, " $\mathrm{Pd}(\mathrm{II})$-catalysed meta-C-H functionalizations of benzoic acid derivatives" Nat. Commun. 2016, 7, 10443.

12. Y. Weng, H. Chen, N. Li, L. Yang, L. Ackermann, * "Electrooxidative Metal-Free Cyclization of 4-Arylaminocoumarins Employing DMF as C1-Source" Adv. Synth. Catal. 2021, 363, 2773-2777. ( ${ }^{+}$Equal contribution) 